\title{
Electrical Resistivity Correlation to Vadose Zone Sediment and Pore- Water Composition for the BC Cribs and Trenches Area
}

\author{
RJ Serne \\ DF Rucker ${ }^{1}$ \\ AL Ward \\ DC Lanigan \\ W Um \\ MW Benecke ${ }^{2}$ \\ BN Bjornstad \\ 1 HydroGEOPHYSICS, Inc., Tucson, AZ \\ 2 CH2M-HILL Plateau Remediation Contractor, Richland, WA
}

June 2009

Pacific Northwest

NATIONAL LABORATORY

Proudly Operated by Battelle Since 1965 


\title{
DISCLAIMER
}

This report was prepared as an account of work sponsored by an agency of the United States Government. Neither the United States Government nor any agency thereof, nor Battelle Memorial Institute, nor any of their employees, makes any warranty, express or implied, or assumes any legal liability or responsibility for the accuracy, completeness, or usefulness of any information, apparatus, product, or process disclosed, or represents that its use would not infringe privately owned rights. Reference herein to any specific commercial product, process, or service by trade name, trademark, manufacturer, or otherwise does not necessarily constitute or imply its endorsement, recommendation, or favoring by the United States Government or any agency thereof, or Battelle Memorial Institute. The views and opinions of authors expressed herein do not necessarily state or reflect those of the United States Government or any agency thereof.

\author{
PACIFIC NORTHWEST NATIONAL LABORATORY \\ operated by \\ BATTELLE \\ for the \\ UNITED STATES DEPARTMENT OF ENERGY \\ under Contract DE-AC05-76RL01830
}

Printed in the United States of America

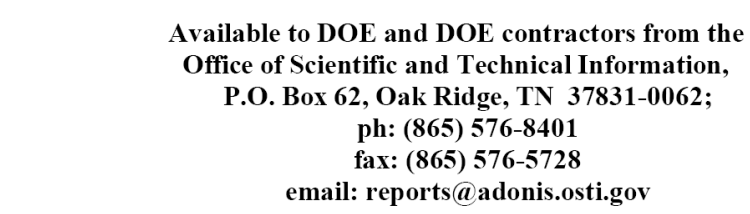

Available to the public from the National Technical Information Service, U.S. Department of Commerce, 5285 Port Royal Rd., Springfield, VA 22161 ph: (800) 553-6847 fax: (703) 605-6900 email: orders@ntis.fedworld.gov online ordering: http://www.ntis.gov/ordering.htm This document was printed on recycled paper. $(9 / 2003)$ 


\title{
Electrical Resistivity Correlation to Vadose Zone Sediment and Pore- Water Composition for the BC Cribs and Trenches Area
}

\author{
RJ Serne \\ DF Rucker ${ }^{1}$ \\ AL Ward \\ DC Lanigan \\ W Um \\ MW Benecke ${ }^{2}$ \\ BN Bjornstad \\ 1 HydroGEOPHYSICS, Inc., Tucson, AZ \\ 2 CH2M-HILL Central Plateau Remediation Contractor, Richland, WA
}

June 2009

Prepared for

the U.S. Department of Energy

under Contract DE-AC05-76RL01830

Pacific Northwest National Laboratory

Richland, Washington 99352 



\section{Acknowledgments}

We wish to acknowledge the following persons for their cited contributions. Mitzi Miller and Tom DiFebbo from EQM, Inc. led the preparation of the Sampling and Analysis Plan (DOE/RL-2007-13, Rev. 0, Sampling and Analysis Plan for Electrical Resistivity Correlation for the BC Cribs and Trenches Area Waste Site). Their efforts and diligence on pointing out important depth zones that warranted emphasis significantly improved the conduct of the sample collection field work and the laboratory work. The staff in Pacific Northwest National Laboratory’s (PNNL’s) Environmental Sciences Analytical Laboratory performed all the sediment sample tests and geochemical parameter analyses. Steven Baum operated the inductively coupled plasma emission spectrometer used to measure cations and trace metals in both water and acid extracts, Eric Clayton operated the inductively coupled plasma-mass spectrometer used to measure uranium, technetium-99, and most Resource Conservation and Recovery Act metals in the extracts. Christian Iovin operated the ion chromatograph used to measure anions in the water extracts. Dennese Smith operated the alkalinity titrator and performed the $\mathrm{pH}$ and electrical conductivity measurements on the water extracts. Igor Kutynakov operated the total carbon analyzer, gamma energy analysis system, and liquid scintillation counter used to measure the calcium carbonate and radionuclide contents of the sediments. Michelle Valenta, Dennese Smith, Ben Williams, and Kevin Miller performed the various sediment extracts. Ray Clayton, Chris Strickland, and Kate Draper performed the MiniSting soil electrical conductivity measurements and particle-size analyses on the cores from borehole A (C5923). Michelle Valenta, Mike Lindberg, Chris Brown, and Keith Geiszler managed the laboratory work and conducted the quality control/quality assurance checks on the analytical facilities and reviewed the data before final transmittal as electronic data packages to the client. Without all of their efforts the large amount of data and quality checks would not have met the expedited schedule required to finish the draft report in a timely fashion. Tao Fu generated the model simulations of field resistivity profiles from the lab-measured soil resistivity on sediments from borehole A (C5923).

This technical report was reviewed by the following technical experts. Mike Thompson and Steve Miller (both geophysics experts under subcontract to Fluor Hanford Company), Susan Narbutovski (geophysicist with CH2M-Hill Plateau Remediation Company), Dave Myer (Hanford geologist and field deployer of electrical resistivity techniques for tank farms; with Washington River Protection Solutions Company), and Cliff Narquis (Fluor Federal Services). Technical and programmatic reviews were also performed by Mark Freshley (PNNL client relationship manager), Kevin Leary (Office of River Protection) and Greg Sinton (U.S. Department of Energy [DOE]-Richland). Each of the reviewers provided comments that led to significant additions and improvements to this final report. The technical report was edited and produced by Wayne Cosby (PNNL). Wayne also coordinated the PNNL word processing staff, Barbara Wilson and Stacy Larson, who generated the draft and final document promptly to meet short deadlines. The authors are greatly indebted to their efforts.

Finally, we would like to acknowledge the supplemental funding provided by the DOE Environmental Management Office of Engineering and Technology, EM-22 (Mark Gilbertson and Skip Chamberlain), that allowed us to analyze many more sediment samples from boreholes A (C5923) and B (C5924) for the various geochemical parameters that constitute the pore-water ionic strength and for the laboratory soil-resistivity measurements to improve the electrical resistivity groundtruthing exercise. The additional funds from EM-22 are also being used to perform other detailed characterization of these sediments that will allow more fundamental pedotransfer functions to be generated that explore the relationships between readily measured parameters, such as particle size, with more difficult and costly 
PNNL-17821

measurements, such as sediment hydraulic conductivity, as function of moisture content. Wayne Martin and Dawn Wellman (at PNNL) are our liaisons and advocates with EM-22 to keep the collaborative efforts active. Their efforts are greatly appreciated. 


\section{Abstract}

This technical report documents the results of comparing electrical-resistivity characterization (ERC) to geochemical measurement on sediment obtained from four boreholes (C4191, C5923, C5924, and C5925) drilled in the BC Cribs and Trench area. The geochemical characterization was conducted to determine the efficacy of ERC methodology for use at the Hanford Site and was focused on addressing three data quality objectives specified in Sampling and Analysis Plan DOE/RL-2007-13. As a whole, the ERC data do correlate with the presence of high-concentration sodium nitrate salt plumes as determined by extensive sediment sampling. The surface-based ERC data were sufficient to indicate the lateral, and to some extent, vertical, distribution of mobile contaminants. The surface-based geophysical survey data seemed to suffer from a sort of "myopia," where looking down from the ground surface, the maximum pore-water salt concentration depths were difficult to resolve. Further, ERC measures bulk resistivity, which is related to dissolved electrolyte content and not individual chemical species. Further, because technetium-99 has transport attributes that are very similar to nitrate, the ERC measurements correlate to technetium-99 in the vadose zone fortuitously. The concentrations of elevated technetium-99 range from 90 to $146 \mathrm{pCi} / \mathrm{g}$ sediment (C5923), 34 to $51 \mathrm{pCi} / \mathrm{g}$ sediment (C5924), and 64 to $107 \mathrm{pCi} / \mathrm{g}$ sediment (C4191). Again we stress that ERC cannot directly distinguish individual chemical or radionuclide species themselves.

One specific outcome of the BC Cribs and Trenches area ground-truthing exercise was confirmation that separate contaminant plumes exist for the cribs and nearby trenches. Finally, because ERC data were used to select the borehole locations for three of the new boreholes outside the footprints of BC Cribs and Trenches, and contaminants were found (or not found) as expected, ERC is a very useful guide for selecting vadose zone sampling locations, particularly when the targeted subsurface plumes exhibit high ionic strength.

Laboratory-scale resistivity measurements conducted on grab and core samples from Well C5923 (A) directly verify the presence of anomalously low-resistivity zones observed by the surface-based resistivity survey. Based on this correlation alone, the surface-based ERC approach can map the probable lateral extent of high-ionic-strength subsurface plumes and thus is applicable at Hanford as long as the sites are not significantly impacted by sub-surface low-resistivity infrastructure (e.g., metallic tanks and pipelines). The leading edge of the salt plume at three boreholes (C5924, C4191, and C5923) reached depths of 130, 160, and $260 \mathrm{ft}$, respectively. Borehole C5925 showed no significant indications of any contamination. The leading edge of each salt plume is shallower than the regional water table, which is present at 340 to $350 \mathrm{ft}$ bgs. The fact that the salt plumes at each borehole did not reach the water table despite millions of liters being disposed of is likely because of the thin, fine-grained lenses in the Hanford $\mathrm{H} 2$ unit, which provide several capillary breaks that promote horizontal spreading in the upper portion of the Hanford formation.

A second goal of the sediment characterization was to measure the total and water-leachable concentrations of key contaminants of concern as a function of depth and distance from the footprints of inactive disposal facilities. The total and water-leachable concentrations of key contaminants will be used to update contaminant-distribution conceptual models and to provide more data for improving baseline risk predictions and remedial alternative selections. None of the borehole sediments show significantly elevated acid-extractable Resource Conservation and Recovery Act (RCRA) metals. As expected, based 
on their known immobility, no detectable amount of mercury, strontium-90 or nickel-63 was found in the sediments obtained from boreholes C5923, C5924, or C5925. Thus, outside the facility footprints, the vadose zone sediments do not appear to contain concentrations of RCRA metals significantly different from natural background. Elevated acid-extractable (likely precipitated) uranium appears to exist only right at the bottoms of the inactive cribs and trenches as was found at borehole C4191 (drilled right through the 216-B-26 trench footprint). In conclusion, outside the facility footprints and also deep below (e.g., more than 20 meters) the facility footprints, the vadose zone sediments do not appear to contain chemical or radionuclide contaminants, except sodium, nitrate, sulfate, and technetium-99, at concentrations significantly above natural background levels. 


\section{Executive Summary}

This technical report documents the results of comparing electrical resistivity characterization (ERC) to geochemical measurement on sediment obtained from four boreholes (C4191, C5923, C5924, and C5925) drilled in the BC Cribs and Trench area. The data used in this study were derived from 1) subsurface electrical-resistivity models constructed from surface-based resistivity surveys, 2) geochemical measurements of water extracts of sediments from the four boreholes, and 3) laboratoryscale resistivity measurements conducted on vadose sediment grab and core samples from borehole C5923. Vadose zone sediment samples were obtained at a frequency of about every $2.5 \mathrm{ft}$ from approximately $5 \mathrm{ft}$ bgs to borehole total depth. In total, 505 grab samples and thirty-nine 6-in.-long cores were obtained for characterization. This sediment suite represents the largest data set ever collected at the Hanford site for correlating with surface-based soil electrical-resistivity field measurements.

The geochemical characterization was conducted to determine the efficacy of ERC methodology for use at the Hanford Site and focused on addressing three data quality objectives (DQOs) specified in Sampling and Analysis Plan DOE/RL-2007-13.

The DQO process led to the following three key questions that needed to be answered:

\#1 Do ERC data gener ally correlate with vadose zone contaminant of concern (COC) plumes that are established by analyzing borehole sediment samples?

\#2 Is the correlation of ERC and laboratory analytical data sufficient to use ERC to assist in updating the existing conceptual site models (CSMs) and evaluating remedial alternatives?

\#3 Is ERC data interpretation useful for guiding vadose zone sediment sampling for targeted COCs?

As a whole, the ERC data do correlate with the presence of high-concentration ( $>0.3 \mathrm{M}$ ) sodium nitrate salt plumes as determined by extensive sediment sampling (DQO \#1). For the BC Cribs and Trenches area waste sites, the surface-based ERC data were sufficient to indicate the extent of contamination, particularly on a lateral scale. This groundtruthing exercise has improved our ability to interpret field electrical resistivity surveys in a more quantitative fashion and has provided valuable data on determining the capability of surface-based ERC to delineate the bounds of lateral and vertical distances so that the technique can identify low resistivity (high electrical conductivity) sub-surface plumes. However, ERC techniques measure bulk resistivity (or its reciprocal electrical conductivity, which is related to dissolved electrolyte content) and not individual chemical species. At the BC Cribs and Trenches area (and at most Hanford sites surrounding inactive disposal units), the dominant electrolytes in the vadose zone pore water are nitrate and sodium. The ERC measurements correlate to the total electrolyte concentrations and because nitrate and sodium dominate the electrolyte composition, correlations with these two individual species are good. Further, because technetium-99 has transport attributes that are very similar to nitrate, the ERC measurements correlate to technetium-99 in the vadose zone fortuitously. ERC cannot distinguish individual chemical or radionuclide species themselves, especially contaminants that are present at low mass concentrations in the subsurface. The ERC technique can aid in delineating the lateral and, to some extent, vertical distribution of mobile contaminants that have transport attributes similar to the nitrate and thus can aid in improving mobile CSMs. One specific outcome of the BC Cribs and Trench area ground-truthing exercise was confirmation that separate contaminant plumes exist for the cribs and nearby trenches (DQO \#2). Finally, because 
ERC data were used to select the borehole locations for the three new boreholes outside the foot prints of BC Cribs and Trenches, and contaminants were found (or not found) as expected, ERC is a very useful guide to selecting vadose zone sampling locations, particularly when the targeted subsurface plumes exhibit high ionic strength (DQO \#3).

Laboratory-scale resistivity measurements conducted on grab and core samples from Well C5923 (A) directly verify the presence of anomalously low-resistivity zones observed by the surface resistivity survey. In this case, sedimentary intervals with relatively high ionic-strength pore-water have a corresponding laboratory-measured soil-resistivity that is well below natural variations in uncontaminated sediments. Based on this correlation alone, a target-based approach using surface-based electricalresistivity to map the probable lateral extent of high-ionic-strength subsurface plumes or zones is applicable at the Hanford Site as long as the sites are not significantly impacted by the presence of subsurface low resistivity infrastructure (e.g., metallic tanks and pipelines). The infrastructure complications can be mitigated by using other complementary geophysical measurements and historical knowledge (used judiciously). The lower limit of pore-water ionic strength that is necessary to yield definitive detection of low-resistivity sub-surface zones was not quantitatively determined, but pore-water ionic strength above $0.3 \mathrm{M}$ appears to yield adequate low-resistivity signals that are readily detected.

The pore-water chemical composition data, laboratory-scale soil resistivity, and other ancillary physical and hydrologic measurements and analyses described in this report are designed to provide a crucial link between direct measurements on sediments and the surface-based electrical-resistivity information obtained via field surveys. A second goal of the sediment characterization was to measure the total and water-leachable concentrations of key contaminants of concern as a function of depth and distance from the footprints of inactive disposal facilities. The total and water-leachable concentrations of key contaminants will be used to update contaminant-distribution conceptual models and to provide more data for improving baseline risk predictions and remedial alternative selections.

The ERC ground-truthing exercise for the individual boreholes, as quantified by regression analysis of soil resistivity values versus vadose zone pore-water constituent concentrations, showed mixed results. The regression correlations, as quantified by the $\mathrm{R}^{2}$ coefficient, varied between 0.01 and 0.73 , dependent on borehole and whether the correlation was based on a linear or logarithm relationship with a pore-water parameter. In general, the best correlations were for a logarithm relationship. These correlation coefficients are not as high as might be desired; the low-correlation results from the different scales of investigations between the coarser-scale surface-based resistivity data and the finer-scale borehole sediment based data. Despite the differences in measurement scales, high concentrations of dissolved salts in the pore waters of sediments from C5923, C5924, and C4191 generally produced a low-resistivity "target" in the processed resistivity field surveys, and variability could be seen in the resistivity data that relates to the variability in pore-water concentrations.

In all boreholes except C5925 (C), where the geochemical characterization was conducted at a much lower rate (because it was discovered early that there was little or no contamination present), the inverted (processed) ERC profiles, which were based on a much coarser volume (scale), were not capable of producing high correlation coefficients with the smaller-scale pore-water measurements. The resolution of the ERC surveys is less than the scale at which the geochemical sampling was conducted. The large variation in pore-water composition in the thin, fine-grained sediments in comparison to the composition of the bulk sand sediments is impossible for the surfaced-based geophysics to replicate, and the geophysical measurements act as a low-pass filter. That is, high-frequency components are not observed 
in the raw apparent-resistivity (field survey) measurements. Then during inversion, the same smooth apparent-resistivity data used as input to the inversion model produce a smooth estimate of the true soil resistivity. The inversion cannot recreate the high-frequency components (highly varying pore-water chemistry over small depth increments) that were removed during the original field measurements. That being said, the best correlation was at borehole C4191 where the fine-scale variability in pore-water chemistry as a function of depth showed two nearly equally concentrated salt plumes separated by only a few 10s of feet. The correlation coefficients for the inverted (processed) field geophysical profiles with the actual pore-water major chemical constituents ranged from 0.4 to 0.7 where a value of 1 is perfect correlation.

The surface-based geophysical survey data also seemed to suffer from a sort of "myopia," where looking down from the ground surface, the target’s (e.g., each of the maximum pore-water salt concentration) depths were difficult to resolve. This was certainly the case with the ERC comparison made with Borehole C5923 (A), which exhibited at least a tri-modal depth distribution in pore-water salt concentrations. Some improvement in correlating the field-resistivity profile with the pore-water profiles was shown by shifting the geophysical response either downwards for the $2 \mathrm{D}$ inversion or upwards for the 3D inversion. The required shift was slight (3 to $5 \mathrm{~m}$, dependent on borehole) and was on the order of the thickness of an individual layer used in the finite difference numerical model used to process the field survey data. The apparent depth shift in the geophysics is likely a consequence of the smoothing constraints and stabilization function implemented in the commercial inversion codes used to perform the modeling. To combat this problem, academic and industry researchers are currently studying methods to sharpen images and form more realistic geologic interpretations of geophysical data. It will be some time, however, before these new methods are routinely applied.

The best correlations between the field electrical-resistivity surveys and borehole pore-water data sets were obtained when focusing on the areal extent of the salt plume. Lateral resolution of the geophysical field data is best conducted by comparing an aggregated set of geophysical data on all boreholes together. When assembling the pore-water data for all four boreholes in an areal view, the surface-based field ERC data in the author's judgment produced a reasonable distribution (physically plausible) of low-resistivity values that were indicative of the high-concentration salt plumes that exist below the BC Cribs and Trenches area. To estimate the lateral extent of contamination from historical disposal in the BC Cribs and Trenches area, the resistivity data were converted to ionic strength using the least squares regression formula obtained using inversion results from the 3D resistivity. The 3D inverted results were chosen for this exercise based on their reasonable reconciliation of the resistivity in the northeast corner between the cribs and trenches (near borehole $\mathrm{C}$ ). The lateral extent of the subsurface salt plume from this exercise is shown in Figure S.1. The 3D inversion results were composed of four individual models that encompass overlapping domains. Figure S.1 was created by merging the results of the four models. The figure shows the areal rendering (plan view) of calculated ionic strength equal to or above $0.3 \mathrm{M}$. The 0.3-M isopleth covers the area of the footprints of the individual liquid disposal trenches as well as the area between each of the trenches, suggesting that liquids from each trench mixed in the sediments below each trench and coalesced into one larger plume in each north-south row of trenches. In the middle of the trenches near the location of borehole B (C5924), the 0.3-M isopleth is continuous between the two westernmost rows of trenches. The total volume of waste and total mass of salt disposed of into each of the five cribs closest to this region with continuous salt plume (216-B-33, 216-B-34, 216-B-52, 216-B23, and 216-B-24) averages over 5-million liters and 1.5-million kg of nitrate. Another trench region with lateral continuity of the salt plume is between the northern diagonal trenches (216-B-22, 216-B-21, and 


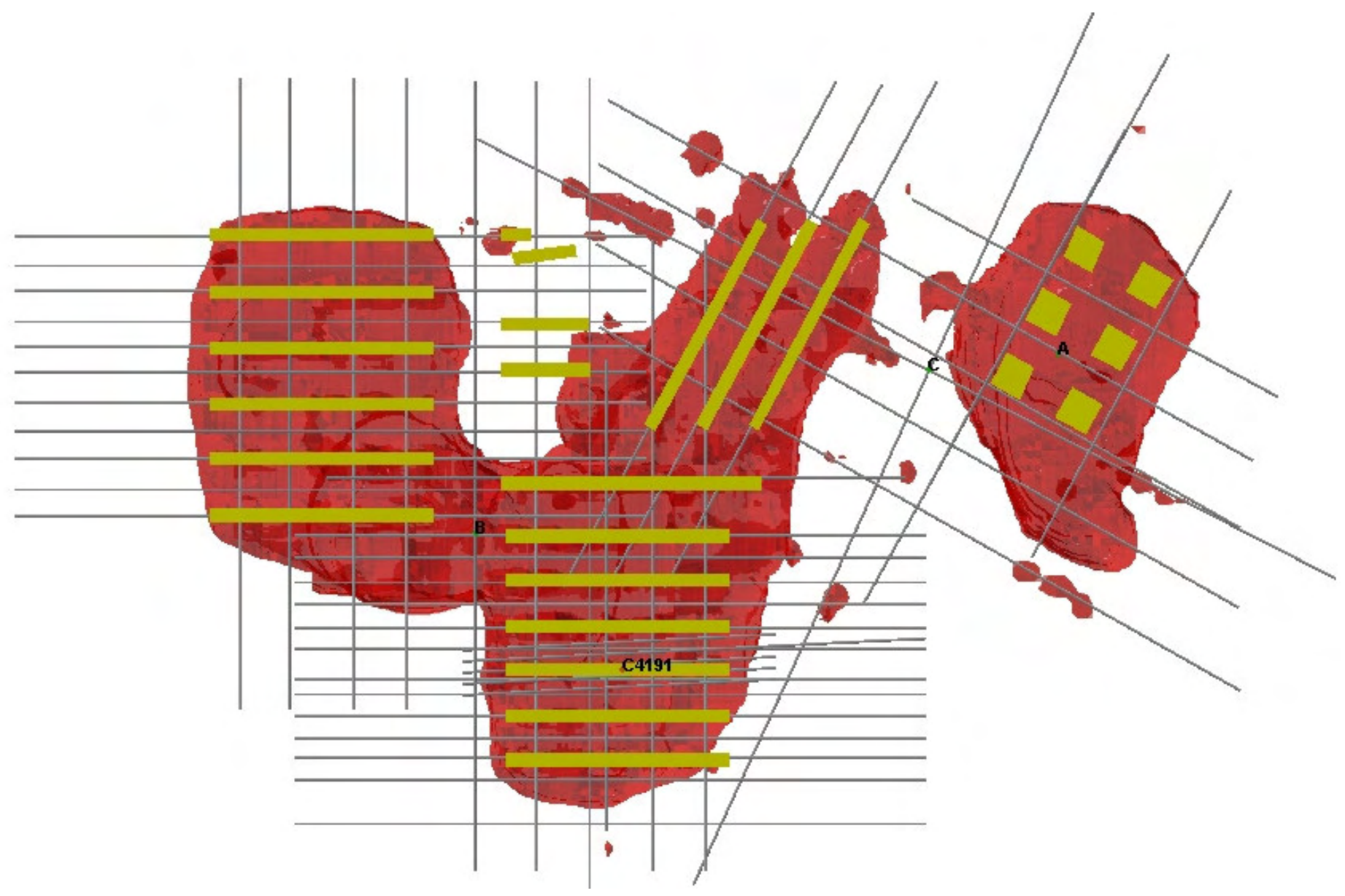

Figure S.1. Field Survey Estimate of the Lateral Extent of the Subsurface Salt Plume at BC Cribs and Trenches Area (0.3-M pore-water ionic strength calculated from 3D inverted soil resistivity data)

216-B-20) and 216-B-52. The total area that encompasses the 0.3-M isopleths in the region of the BC trenches is 11.3 hectares.

In the northeast corner of the BC Cribs and Trenches area, where the six cribs are located, the subsurface salt plume is continuous and much larger than the footprint of the individual cribs. The 0.3-M ionic strength isopleths extend approximately $90 \mathrm{~m}$ south of crib B-18 (southeastern corner of BC Crib complex). The total area encompassed by the 0.3-M isopleths in the $\mathrm{BC}$ cribs region is 2.7 hectares. The lateral extent of the salt plumes analysis shown in Figure S.1 predicts that at the location of borehole C (C5925), there is no contamination with salt at or above $0.3 \mathrm{M}$. This is corroborated by the actual sediment analyses (see Section 8) that shows pore-water ionic strengths throughout the depth profile (20 to $203 \mathrm{ft}$ bgs) range from 0.02 to $0.12 \mathrm{M}$. We conclude that the surface-based ERC survey at the BC Cribs and Trenches area provides a good estimate of the lateral extent of sub-surface contamination where the pore-water ionic strength is near to or above $0.3 \mathrm{M}$.

Future work that relies on more laboratory soil resistivity and the incorporation of other types of field data (spectral gamma, neutron moisture, and soil density logs) and physical and hydraulic measurements 
could be used to develop a more detailed petrophysical model of the sediments below the BC Cribs and Trenches. This more detailed petrophysical model can be used as a more realistic "earth model" in the inversion process to better manipulate the raw field survey data. It is also recommended that one more borehole be drilled after a thorough vetting of the current data with geophysics experts and other Hanford stakeholders to optimize where to place the borehole, what electrical and other geophysical surveys should be conducted, where to take sediment samples, and what parameters should be measured on the sediments to attempt one more "ground-truthing" exercise. The rest of this executive summary describes 1) details of the borehole sediment characterization activities and 2) findings on the second objective of determining the distribution of potential contaminants of concern.

As part of the vadose zone sediment characterization, experienced geologists examined the samples and all available geophysical logging data for the new boreholes and then generated very detailed information on the local stratigraphy in the BC Cribs and Trenches area. The geologic framework of the vadose zone sediments controls the migration of the liquid waste and dissolved contaminants as they travel towards the unconfined aquifer. A key geological finding is the presence of several (5 to 7) thin ( $<1$-m thick), finer-grained relatively wet lenses within the upper $130 \mathrm{ft}$ of Hanford formation $\mathrm{H} 2 \mathrm{unit}$ at all four boreholes. These thin, relatively moist sediments can act as horizontal spreading zones for slowly percolating liquid wastes or natural recharge waters.

The most important geochemical parameters that were measured to "ground truth" the surface-based field-resistivity surveys at the BC Cribs and Trenches region were major dissolved salts in the vadose zone pore waters. Pore-water electrical conductivity (EC), and the major ions sodium and nitrate are especially relevant. Theoretically, the pore-water parameter having the highest correlation with electrical response should be total ionic strength, which accounts for the total electrical conductivity of the pore water.

As part of the second objective, gamma energy analysis, de-ionized water, and strong acid extractions were performed on selected grab samples to identify the distribution of key contaminants. Contaminants of potential concern included Resource Conservation and Recovery Act (RCRA) metals and radionuclides, with an emphasis on mercury and chromium and technetium-99, uranium, strontium-90, nickel-63, and gamma-emitting fission products, respectively. Gross-beta and gross-alpha analyses of the acid extracts were used to assess whether we had overlooked any radionuclides of potential concern. The gross-alpha and beta results for the acid extracts did not show any signs of unaccounted radioactivity beyond that found in the specific analyses.

The vadose zone sediments at three of the boreholes (C5923, C5924, and C4191) contained high concentrations $(>0.3 \mathrm{M}$ ) of dissolved salts (mainly sodium nitrate) with either bi- or tri-modal distributions with depth. The vertical distribution of the salt plume at C5923 was the most irregular and tri-modal and extended at least $246 \mathrm{ft}$ below ground surface. The highest pore-water EC at C5923 was $293 \mathrm{mS} / \mathrm{cm}$. The vertical distribution of the salt plume at boreholes C5924 and C4191 were bi-modal with the shallower lobe being slightly more concentrated than the deeper lobe. At C4191, the highest pore-water EC was $176 \mathrm{mS} / \mathrm{cm}$ and at C5924 was $92.7 \mathrm{mS} / \mathrm{cm}$. The two maxima (bi-modal) salt concentrations in both of these boreholes occurred at about the similar depths ( $\sim 70$ and $123 \mathrm{ft}$ bgs) and ( $\sim 90$ and $133 \mathrm{ft}$ bgs), respectively. The pore-water-corrected EC data for C5925 ranged from 1.2 to 8.8 $\mathrm{mS} / \mathrm{cm}$, which in comparison to the other three boreholes are very low, which is consistent with the hypothesis that no waste percolated through these sediments. The total ionic strengths of the pore waters in the borehole's maximum salt plume regions ranged as follows: 2.4 to $3.5 \mathrm{M}$ (C5923), 0.7 to $1.3 \mathrm{M}$ 
(C5924), and 0.4 to $2.3 \mathrm{M}$ (C4191). The total ionic strength distribution in C5925 pore waters ranges from 0.019 to $0.12 \mathrm{M}$, which is within the range of uncontaminated Hanford formation pore-water values.

The leading edge of the salt plume at two boreholes (C5924 and C4191) near to or within trenches reached depths of 130 and $160 \mathrm{ft}$, respectively. The leading edge of each salt plume is shallower than the regional water table, which is present at 340 to $350 \mathrm{ft}$ bgs. The fact that the salt plumes at each borehole did not reach the water table despite millions of liters being disposed of is likely because of the thin, finegrained lenses in the Hanford $\mathrm{H} 2$ unit, which provide several capillary breaks (contrasts between fine sand and coarse sand) that promote horizontal spreading in the upper portion of the Hanford formation. On an areal basis, the BC cribs received much larger volumes of liquid waste than the BC trenches so that the deeper penetration of the salt plume at C5923 makes sense. Further, the sediments underlying C5923 appear to exhibit fewer (5 vs 7) finer-grained lenses that promote horizontal spreading of wastes.

The vadose zone $\mathrm{pH}$ profiles in C5923 and C4191 show elevated values (maximum >9.2), indicative of caustic waste in the depth region of 8 to $18 \mathrm{ft}$ bgs and 17.5 to $37.5 \mathrm{ft} \mathrm{bgs}$, respectively. At C5924, the highest $\mathrm{pH}$ observed was 8.8, and two zones appeared to show weak signs of caustic waste interaction (18 to 35 and 53 to $57 \mathrm{ft}$ bgs). At borehole C5925, there was no elevated $\mathrm{pH}$ in the water extracts and no other chemical signatures indicating the presence of waste. For the three boreholes where elevated $\mathrm{pH}$ was found in the shallow sediments, a few of the major elements (Al, Fe, and $\mathrm{Mn}$ ) show elevated acidextractable concentrations. This suggests that the sediments interact with the caustic-waste fluids through dissolution and precipitation/neutralization reactions that likely form more leachable amorphous solid phases and metal hydroxides/oxides in contrast with more stable alumino-silicate and crystalline metal oxides. The shallow sediments at these three boreholes also show signs of elevated acidextractable phosphorous indicative of phosphate precipitates from the waste interacting with native sediments. None of the borehole sediments show significantly elevated acid-extractable RCRA metals, and only borehole C4191 shows signs of elevated acid-extractable uranium ( $>5 \mu \mathrm{g} / \mathrm{g}$ ).

The water-extractable concentrations of major cations in the C5923 vadose zone sediments do not show depletions in the divalent cations in the shallowest ion exchange front (which also is the thickest lobe and highest concentration of pore-water sodium). This may indicate that waste fluids migrated horizontally into the sediments in the shallow portion of borehole C5923 as opposed to vertically. At boreholes C5924 and C4191, two ion exchange fronts (where the monovalent cation concentrations are low and divalent cation concentrations are high relative to each other) were found at the depths where the bi-modal salt peaks reside, suggesting a significant vertical flow pattern for disposed waste liquids. The two ion exchange fronts at borehole C5924 and C4191 are readily discernable in contrast to the waterextract cation distribution at borehole C5923 that does not show distinct separation between the monoand divalent cations in the borehole profile with depth. Thus, the vertical distribution of waterextractable cations observed at borehole C5923 is not easily interpreted as being caused by one or a few separate ion exchange fronts.

The water-extract data for technetium-99 in boreholes C5923, C5924, and C4191 show elevated technetium-99 concentrations occurring at the same locations as elevated nitrate and EC. The deepest penetration of significant technetium-99 contamination also occurs at the same place as the significantly elevated nitrate because they are mobile contaminants and distribute in the vadose zone in a similar pattern. The concentrations of elevated technetium-99 at these three boreholes range from 90 to $146 \mathrm{pCi} / \mathrm{g}$ sediment (C5923), 34 to $51 \mathrm{pCi} / \mathrm{g}$ sediment (C5924), and 64 to $107 \mathrm{pCi} / \mathrm{g}$ sediment (C4191). 
In contrast to the shallow sediments at borehole C4191, which was emplaced directly through the footprint of the 216-B-26 trench, no detectable strontium-90 or nickel-63 was found in the sediments obtained from boreholes C5923 or C5924. Because these radionuclides are quite immobile in the geochemical environment in Hanford's subsurface, given the nature of the waste stream disposed of at BC Cribs and Trenches, and the fact that the boreholes are several 10s of feet from facility footprints, finding no detectable nickel-63 or strontium-90 was expected. The sediment samples from C5923, C5924, and C5925 also did not contain detectable concentrations of mercury, and the concentrations of other RCRA metals were low and within the range of natural background. Thus, outside the facility footprints, the vadose zone sediments do not appear to contain concentrations of RCRA metals significantly different from natural background. Elevated acid-extractable (likely precipitated) uranium appears to exist only right at the bottoms of the inactive cribs and trenches as was found at borehole C4191 (drilled right through the 216-B-26 trench footprint).

The sediment from borehole C4191 contains some manmade gamma radioactivity in some of the shallow grab samples. Essentially, the only significant gamma activity observed was in C4191 where cesium-137 was detected in the first few samples from 13 and $27.5 \mathrm{ft}$ bgs. The samples at 13 to $14 \mathrm{ft}$ bgs contain between $5 \times 10^{+5}$ to $1 \times 10^{+6} \mathrm{pCi} / \mathrm{g}$ cesium-137, and sediments deeper down to $27.5 \mathrm{ft}$ bgs contain about $10 \mathrm{pCi} / \mathrm{g}$ or less. In addition, a few pCi/g of shorter-lived antimony-125 and europium-155 were detected in isolated samples. Sub-pCi/g activities of cobalt-60 were also detected in a few samples with no consistent depth profile. At the three boreholes outside facility footprints, manmade gamma activities (cesium-137) were at most a few tenths $\mathrm{pCi} / \mathrm{g}$ in the shallow sediments. In conclusion, outside the facility footprints and also deep below (e.g., more than 20 meters) the facility footprints, the vadose zone sediments do not appear to contain chemical or radionuclide contaminants, except sodium, nitrate, sulfate, and technetium-99 at concentrations significantly above natural background levels.

Based on historical groundwater monitoring records and the highly elevated deep vadose zone nitrate concentrations at C5923 (A), we hypothesize that low concentrations of nitrate exist, and perhaps other mobile contaminants from the mid 1950s disposal of scavenged bismuth phosphate waste, in the groundwater below the BC cribs. The groundwater concentration of nitrate (10 to $20 \mathrm{mg} / \mathrm{L}$ ) currently is below the drinking water standard of $45 \mathrm{mg} / \mathrm{L}$. There was no detectable technetium-99 in the groundwater at the bottom of borehole C5923 (A). Based on groundwater results at borehole C4191, the vadose zone sediment distribution of nitrate and technetium-99 (deepest descent found more that $180 \mathrm{ft}$ above the water table) and the historical records reviewed in Appendix C, we hypothesize that groundwater below most of the $\mathrm{BC}$ trenches is not contaminated with residual scavenged bismuth phosphate wastes today nor was the groundwater below the BC trenches contaminated significantly in the past during and within a decade after the active disposal in the mid 1950s. 



\section{Acronyms and Abbreviations}

\begin{tabular}{|c|c|}
\hline $\begin{array}{l}\text { BET } \\
\text { bgs }\end{array}$ & $\begin{array}{l}\text { Brunauer-Emmett-Teller-method used to measure specific surface area of solid } \\
\text { below ground surface }\end{array}$ \\
\hline CCU & Cold Creek Unit \\
\hline CEC & Cation Exchange Capacity \\
\hline $\mathrm{COC}$ & contaminant(s) of concern \\
\hline CSM & Conceptual Site Model \\
\hline DETW & $\begin{array}{l}\text { Deep electrode to well electrode configuration of field electrical resistivity } \\
\text { electrodes }\end{array}$ \\
\hline DIC & depth of investigation characteristics \\
\hline DOE & U.S. Department of Energy \\
\hline DQO & Data Quality Objectives \\
\hline $\mathrm{EC}$ & electrical conductivity—measure of salt content in fluid \\
\hline EPA & Environmental Protection Agency \\
\hline EM & electromagnetic induction \\
\hline ERC & Electrical Resistivity Characterization \\
\hline ERDF & Environmental Restoration Disposal Facility \\
\hline ESL & Environmental Sciences Laboratory \\
\hline FFS & focused feasibility studies \\
\hline FHI & Fluor Hanford, Inc. \\
\hline GD & gravel-dominated \\
\hline GEA & Gamma Energy Analysis \\
\hline GPS & global positioning survey \\
\hline GW & groundwater \\
\hline HASQARD & $\begin{array}{l}\text { Hanford Analytical Services Quality Assurance Requirements Document } \\
\text { (DOE/RL-96-68) }\end{array}$ \\
\hline HEIS & Hanford Environmental Information System \\
\hline HGI & HydroGEOPHYSICS, Inc. \\
\hline HRR & High Resolution Resistivity \\
\hline IC & Ion Chromatograph—used to measure anions concentrations \\
\hline IC & inorganic carbon \\
\hline ICP-MS & Inductively Coupled Plasma Mass Spectroscopy \\
\hline ICP-OES & Inductively Coupled Plasma Optical Emission Spectroscopy \\
\hline ID & identification \\
\hline IDF & Integrated Disposal Facility \\
\hline IP & induced polarization \\
\hline ISSD & Interbedded sand- and silt-dominated \\
\hline
\end{tabular}


PNNL-17821

$\begin{array}{ll}\text { LDS } & \text { Laser Diffraction Spectrometry } \\ \text { NIST } & \text { National Institute of Standards and Technology } \\ \text { NM } & \text { neutron moisture } \\ \text { PNNL } & \text { Pacific Northwest National Laboratory } \\ \text { PSD } & \text { Particle size distribution } \\ \text { RL } & \text { (DOE’s) Richland Operations Office } \\ \text { RTK } & \text { real-time kinematic } \\ \text { SD } & \text { sand-dominated } \\ \text { SG } & \text { spectral gamma } \\ \text { SGE } & \text { Surface Geophysical Exploration } \\ \text { SSA } & \text { specific surface area } \\ \text { STW } & \text { Ground surface to well electrode configuration of field electrical resistivity } \\ \text { TDR } & \text { electrodes } \\ \text { TG } & \text { time domain reflectrometry } \\ \text { UFA } & \text { Total gamma } \\ \text { USGS } & \text { Unsaturated Flow Apparatus - used to extract pore fluids out of moist sediments } \\ \text { WSCF } & \text { United States Geological Society } \\ \text { WTDE } & \text { Waste Sampling and Characterization Facility } \\ \text { WTS } & \text { Well to deep electrode configuration of field electrical resistivity electrodes } \\ \text { WTW } & \text { Well to ground surface configuration of field electrical resistivity electrodes } \\ & \text { Well to well configuration of field electrical resistivity electrodes } \\ \end{array}$




\section{Contents}

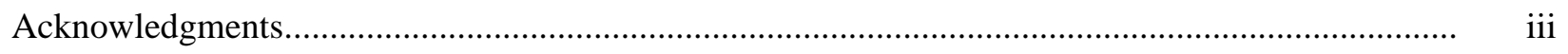

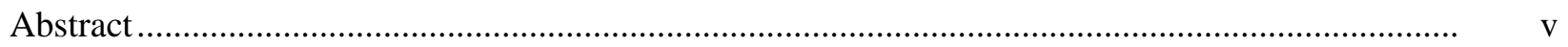

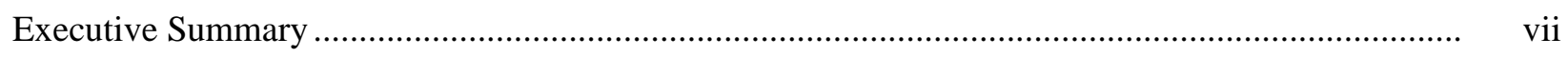

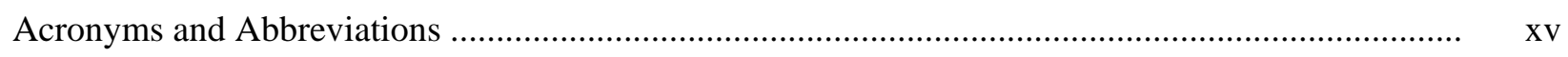

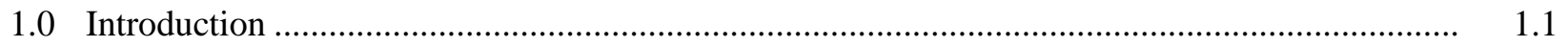

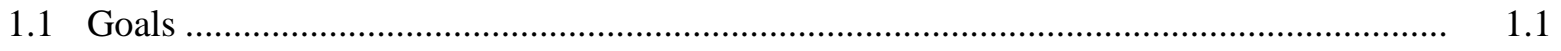

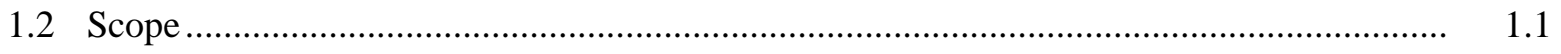

1.3 Report Organization ................................................................................................. 1.1

1.4 BC Cribs and Trenches Field Electrical Resisitivity Characterization (ERC) “Ground

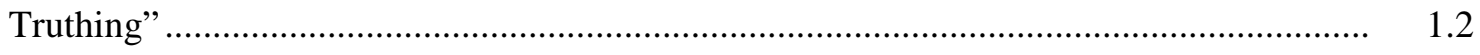

1.5 Early Efforts to "Ground Truth" the ERC Method ....................................................... 1.4

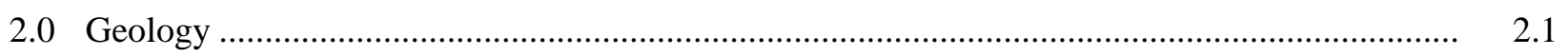

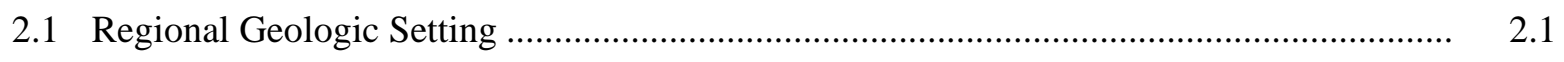

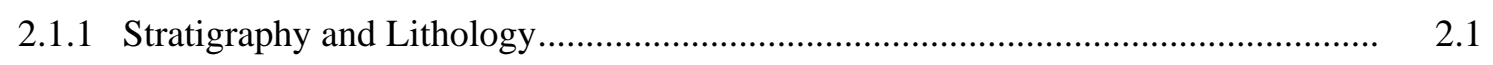

2.1.1.1 Columbia River Basalt Group ................................................................. 2.1

2.1.1.2 Ringold Formation.............................................................................. 2.2

2.1.1.3 Cold Creek Unit (CCU) ....................................................................... 2.2

2.1.1.4 Hanford Formation ................................................................................ 2.3

2.1.1.5 Recent Deposits ................................................................................ 2.5

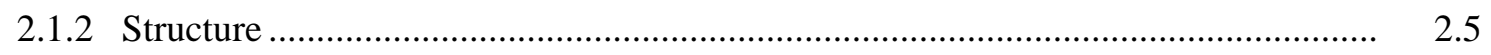

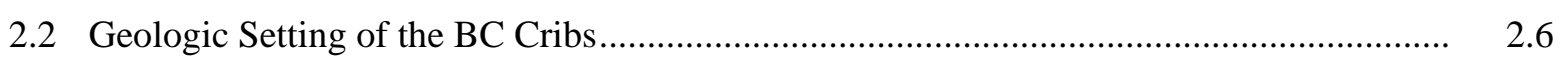

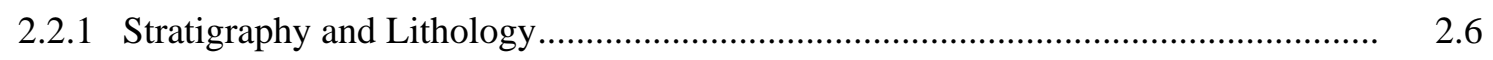

2.2.1.1 Columbia River Basalt Group …….......................................................... 2.11

2.2.1.2 Ringold Formation............................................................................. 2.11

2.2.1.3 Hanford Formation/Cold Creek Unit (Undifferentiated)........................... 2.12

2.2.1.4 Hanford Formation ............................................................................. 2.14

2.2.1.5 Recent Deposits ................................................................................ 2.19

2.3 Summary of Recent Characterization Activities at BC Cribs and Trenches Area .............. 2. 2.19

2.3.1 Borehole C4191..................................................................................... 2.20

2.3.2 Borehole C5923 (299-E13-62) ....................................................................... 2.25

2.3.3 Borehole C5924 (299-E13-63) ......................................................................... 2.32

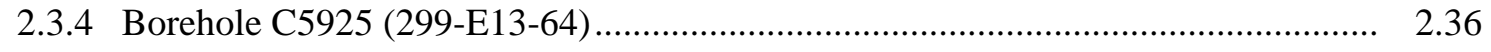

2.4 Historical Water Levels .................................................................................................... 2.40 


\section{Contents}

3.0 Geochemical/Geohydrological Methods and Materials ..................................................

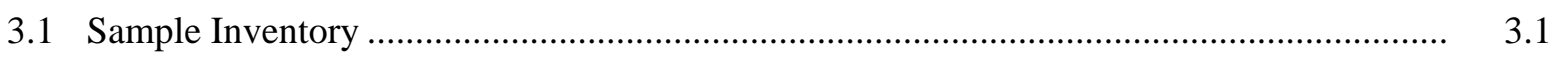

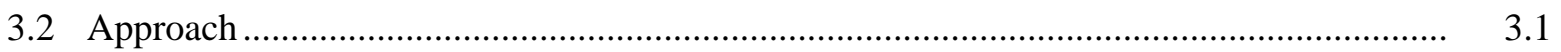

3.3 Materials and Methods ............................................................................................ 3.2

3.3.1 Moisture Content................................................................................................ 3.2

3.3.2 1:1 Sediment: Water Extracts........................................................................... 3.2

3.3.2.1 pH and Conductivity .......................................................................... 3.3

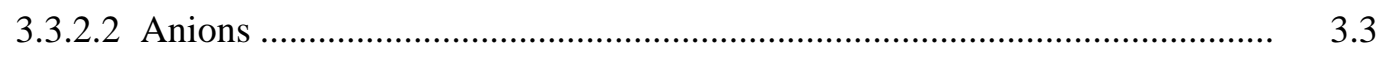

3.3.2.3 Cations and Trace Metals ........................................................................ 3.3

3.3.2.4 Alkalinity ......................................................................................... 3.3

3.3.3 8 M Nitric Acid Extracts and Elemental Analysis .............................................. 3.3

3.3.4 Radioanalytical Analysis................................................................................. 3.4

3.3.5 Unsaturated Flow Apparatus (UFA) Analysis ...................................................... 3.5

3.3.6 Pore Water Composition Analysis ....................................................................... 3.5

3.3.7 Carbon Content on Sediment ......................................................................... 3.6

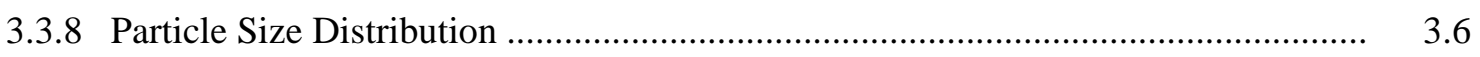

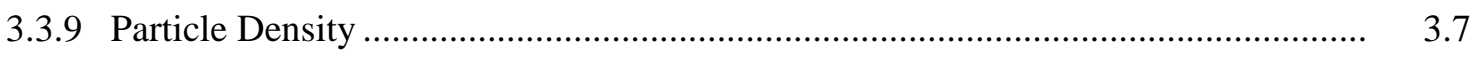

3.3.10 Porosity and Bulk Density................................................................................... 3.8

3.3.11 Specific Surface Area ............................................................................................ 3.8

3.3.12 Cation Exchange Capacity .............................................................................. 3.9

3.3.13 Saturated Hydraulic Conductivity ..................................................................... 3.9

3.3.14 Air Permeability ……..................................................................................... 3.11

4.0 Field Geophysical Methods and Materials ...................................................................

4.1 Electrical-Resistivity Field Acquisition …..................................................................... 4.2

4.1.1 Method of Acquisition ................................................................................ 4.2

4.1.2 HRR Processing (ERC Processing).................................................................. 4.6

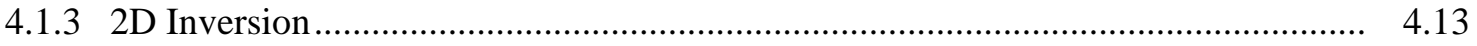

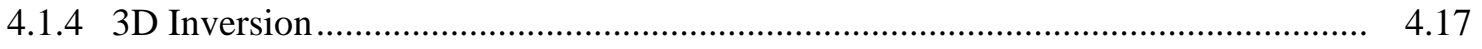

4.2 Electrical-Resistivity Laboratory Acquisition............................................................... 4.19

4.2.1 Sample Preparation ....................................................................................... 4.20

4.2.2 Electrical-Resistivity Measurements …............................................................... 4.21

5.0 Borehole A (C5923) Results and Discussion .................................................................. 5.1

5.1 Geochemical Results from Borehole A (C5923) ............................................................. 5.1

5.1.1 Moisture Content............................................................................................ 5.1 


\section{Contents}

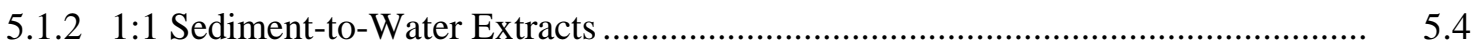

5.1.3 Water Extract Composition of the 1:1 Sediment to Water Extracts for C5923 ........ 5.8

5.1.4 8 M Nitric Acid Extractable Amounts of Selected Elements................................... 5.23

5.1.5 Radionuclide Content in Vadose Zone Sediment from C5923 ............................... 5.25

5.1.6 Groundwater Analysis of Sample Obtained Prior to Decommissioning Borehole

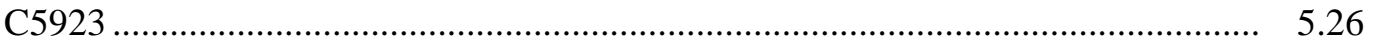

5.2 Field Electrical-Resistivity Results at Borehole C5923 (A)........................................... 5.28

5.2.1 HRR at Borehole C5923 (A) ............................................................................. 5.28

5.2.2 2D Inversion at Borehole C5923 (A) ............................................................... 5.33

5.2.3 3D Inversion at Borehole C5923 (A) ................................................................ 5.36

5.3 Laboratory Geophysical Results at Borehole A (C5923)............................................... 5.41

5.3.1 Laboratory Measured Geo-Hydrological Parameters........................................... 5.41

5.3.1.1 Particle Size Distribution of Sediments in Borehole C5923 (A) ................. 5.41

5.3.1.2 Particle-Size Distribution of Sediments in Borehole C5924 (B) ................. 5.45

5.3.1.3 Porosity and Bulk Density of Intact Cores from Borehole C5923 (A)........ 5.47

5.3.1.4 Specific Surface Area of Vadose Sediments from Borehole C5923 (A)..... 5.48

5.3.1.5 Cation Exchange Capacity of Vadose Zone Sediments from Borehole

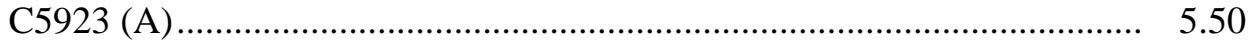

5.3.1.6 Saturated Hydraulic Conductivity ……..................................................... 5.51

5.3.1.7 Air Permeability ............................................................................... 5.55

5.3.2 Laboratory Electrical Results for Borehole C5923 (A)...................................... 5.58

5.3.2.1 Profile of Laboratory-Measured Soil Electrical Resistivity ....................... 5.63

5.3.2.2 Relationship Between Apparent Bulk Resistivity and Pore-water Chemistry ..................................................................................... 5.66

5.3.2.3 The Relationship Between Laboratory-Measured and Field Resistivity ..... 5.69

5.3.2.4 Resolution of Electrical-Resistivity Measurements from the Surface.......... 5.71

5.3.2.5 The Relationship between the Soil Electrical Resistivity Profile and Borehole Logs ...................................................................................... 5.78

5.3.2.6 The Relationship Between the Laboratory Measured Soil Electrical Resistivity Profile and Laboratory Measured PSD, SA, and CEC .............. 5.82

6.0 Borehole B (C5924) Results and Discussion....................................................................

6.1 Geochemical Results from Borehole B (C5924) .......................................................... 6.1

6.1.1 Moisture Content ............................................................................................ 6.1

6.1.2 1:1 Sediment: Water Extracts of Sediments from Borehole C5924 (B).................. 6.1

6.1.3 Composition of the 1:1 Sediment:Water Extracts from Borehole C5924 (B).......... 6.8 


\section{Contents}

6.1.4 8 M Nitric Acid Extractable Amounts of Selected Elements.................................. 6.20

6.1.5 Radionuclide Content in Vadose Zone Sediment from Borehole C5924 (B) .......... 6.22

6.2 Field Electrical-Resistivity Results at Borehole B (C5924)............................................ 6.23

6.2.1 HRR at Borehole C5924 (B) .......................................................................... 6.23

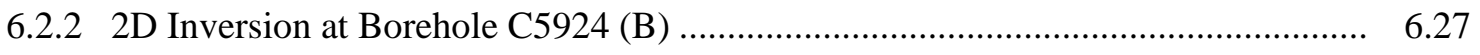

6.2.3 3D Inversion at Borehole C5924 (B) ............................................................ 6.31

7.0 Borehole C (C5925) Results and Discussion.................................................................

7.1 Geochemical Results from Borehole C (C5925)...........................................................

7.1.1 Moisture Content.......................................................................................

7.1.2 1:1 Sediment: Water Extracts of Sediments from Borehole C (C5925)................... 7.3

7.1.3 Composition of the 1:1 Sediment:Water Extracts from Borehole C5925 (C).......... 7.5

7.1.4 8 M Nitric Acid Extractable Amounts of Selected Elements .................................. 7.10

7.1.5 Radionuclide Content in Vadose Zone Sediment from Borehole C5925 (C) ........... 7.13

7.2 Field Resistivity Results at Borehole C (C5925) …....................................................... 7.14

7.2.1 HRR at Borehole C5925 (C) .......................................................................... 7.14

7.2.2 2D Inversion at Borehole C5925 (C) .............................................................. 7.16

7.2.3 3D Inversion at Borehole C5925 (C) ............................................................... 7.17

8.0 Borehole C4191 Results and Discussion..........................................................................

8.1 Geochemical Results from Borehole C4191 …............................................................ 8.1

8.1.1 Moisture Content........................................................................................... 8.1

8.1.2 1:1 Sediment-to-Water Extracts for Borehole C4191 …........................................ 8.3

8.1.3 Water Extract Composition of the 1:1 Sediment to Water Extracts for C4191 ........ 8.5

8.1.4 8 M Nitric Acid Extractable Amounts of Selected Elements .................................. 8.19

8.1.5 Radionuclide Content in Vadose Zone Sediment from C4191 .............................. 8.26

8.1.6 Total Carbon, Calcium Carbonate, and Organic Carbon Content of Vadose Zone Sediment from Borehole C4191 ....................................................................... 8.33

8.1.7 Groundwater Analysis of Sample Obtained Prior to Decommissioning Borehole

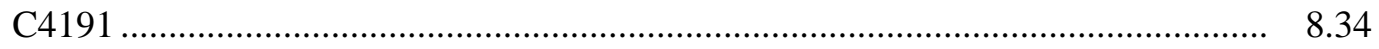

8.2 Field Resistivity Results at Borehole C4191 ................................................................. 8.35

8.2.1 HRR at Borehole C4191 .................................................................................. 8.35

8.2.2 2D Inversion at Borehole C4191 ..................................................................... 8.39

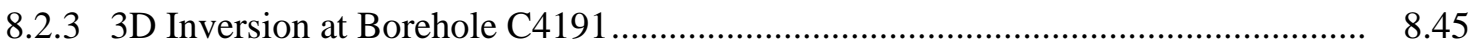

9.0 Summary and Conclusions ........................................................................................... 9.1

9.1 Drilling and Sampling Summary at the BC Cribs and Trenches...................................... 9.1 


\section{Contents}

9.1.1 C5923 Geochemical Results ................................................................... 9.2

9.1.2 C5924 Geochemical Results ........................................................................ 9.4

9.1.3 C5925 Geochemical Results .................................................................... 9.6

9.1.4 C4191 Geochemical Results ........................................................................ 9.7

9.1 .5 Groundwater Analyses .................................................................................. 9.8

9.2 Summary of Field Geophysical Acquisition at the BC Cribs and Trenches ..................... 9.9

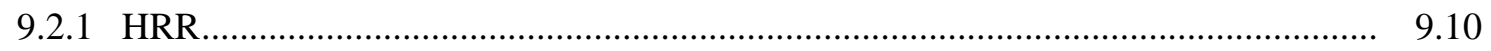

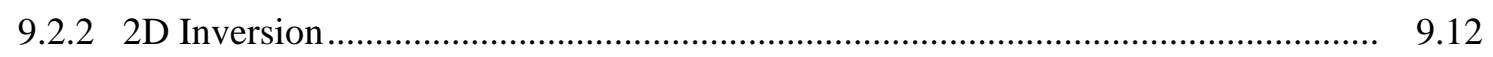

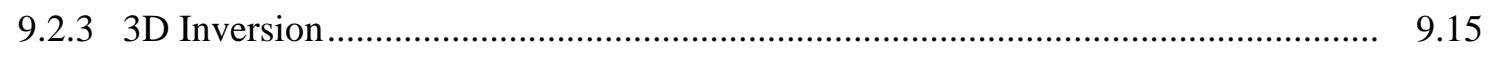

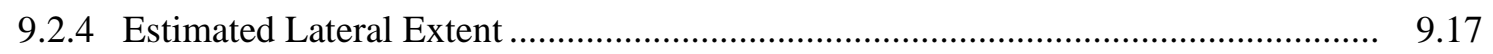

9.3 Summary of Laboratory Geophysical Results at Borehole A (C5923) ............................. 9.19

9.4 Discussion of How Findings in this Report Relate to DQO Decision Statements .............. 9.22

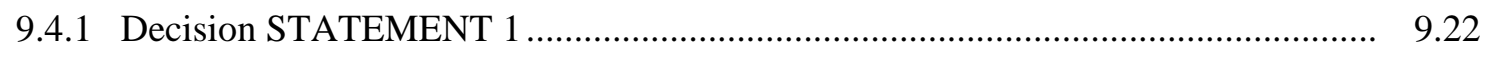

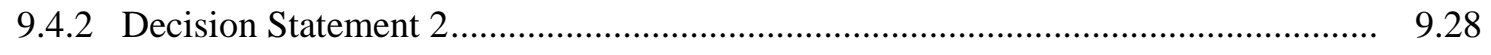

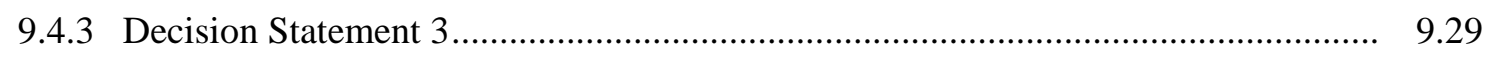

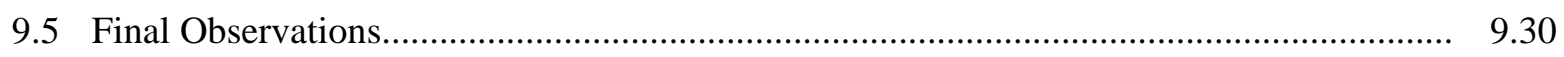

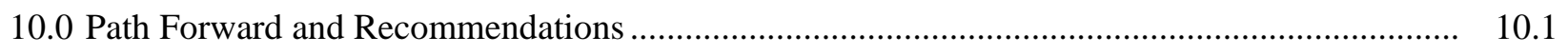

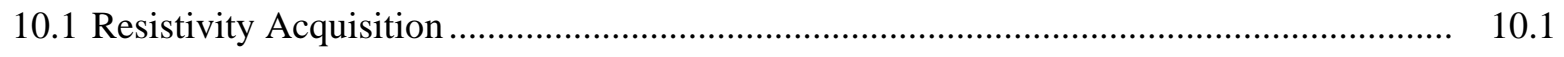

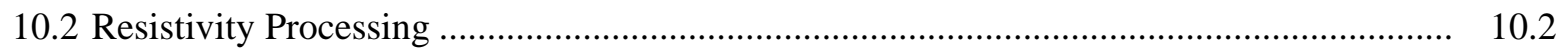

10.3 Resistivity and Geochemistry Comparisons................................................................... 10.3

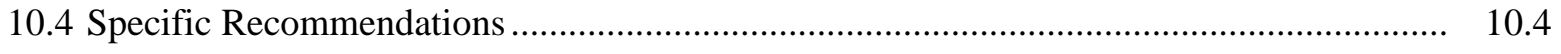

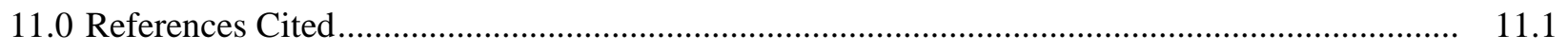

Appendix A: Geologist Logs for Samples Opened in the Lab From Boreholes in the BC Cribs

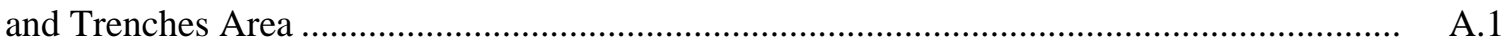

Appendix B: Photographs of Sediment Samples Opened in the Lab from Boreholes in the BC Cribs and Trenches Area........................................................................................ B. B.

Appendix C: Review of Historical Groundwater Monitoring Documents and Tabulation of Pertinent Groundwater Data from HEIS ......................................................................... C.1 


\section{Figures}

1.1. Location of the Boreholes Either Drilled in 2003 and 2007-2008 or Proposed for Future Years.

2.1. North-South Geologic Cross Section Across the Western Hanford Site

2.2. BC Cribs and Trenches Area in Relation to Ice Age Flood Features Within the Central Pasco Basin.

2.3. Location of Hydrogeologic Cross Sections .

2.4. Hydrogeologic Cross Section A-A'......

2.5. Hydrogeologic Cross Section B-B'. See 2.6 for location.

2.6. BC Cribs and Trenches Area Location Map

2.7. Silty Sandy Gravel of the Ringold Formation Unit E in borehole C4191, $321 \mathrm{ft}$ Depth.

2.8. Gravelly Sand of the Hanford Formation/Cold Creek Unit (Undifferentiated) Sequence from Borehole C5923, $303 \mathrm{ft}$ Depth.

2.9. Moderately Sorted, Medium- to Coarse-Grained Sand of the Hanford Formation/CCU (Undifferentiated) from Borehole C4191, $266 \mathrm{ft}$ Depth

2.10. Nearby Excavations and Analog Sites for the Hanford Formation Near the BC Cribs and Trenches.

2.11. Close-up of Heterogeneous, Anisotropic Sedimentary Strata Typical of the Hanford Formation H2 Unit at $\sim 50 \mathrm{ft}$ Depth in the ERDF Excavation

2.12. Hanford Formation H2 Unit Exposed in the IDF Excavation

2.13. U.S. Ecology Excavation, Located Just West of BC Trenches and Cribs

2.14. Hanford Formation (H2 Unit) from Borehole C5923, $13 \mathrm{ft}$ Depth

2.15. Gravelly, Basaltic Sand from the Hanford Formation (H2 Unit) in Borehole C5925, $78 \mathrm{ft}$ Depth

2.16. Hanford Formation (H2 Unit) from Borehole C4191, 86 ft Depth

2.17. Hanford Formation (H2 Unit) from Borehole C5923, $103 \mathrm{ft}$ Depth

2.18. Composite Summary Log for Borehole C4191

2.19. Composite Summary Log for Borehole C5923

2.20. Composite Summary Log for Borehole C5924

2.21. Composite Summary Log for Borehole C5925

2.22. Hydrograph for Well 299-E13-14. Y-axis is elevation (ft).

3.1. Schematic of Falling Head Apparatus to Measure Saturated Hydraulic Conductivity

3.2. Stages of Core Preparation for Falling Head Conductivity Measurements, (a) Soil Core Just After Removal of End Caps, (b) Core After Attachment of the Collar Needed to Connect End Caps, (c) Fully Assembled Core with Collars and End Caps, and (d) Soaking Tank with Fixed Overflow Used for Containing the Core During Falling 


\section{Figures}

Head Tests

3.12

4.1. Electrical-Resistivity Line Layout over the BC Cribs and Trenches Site ................................

4.2. Geometry Factor for the Four Electrode Array ..................................................................

4.3. Example Error Values for FY05-Line 4 ........................................................................ 4.6

4.4. Example Data Removal Procedure ................................................................................... 4.7

4.5. Linear Pseudosection Plotting of Apparent Resistivity Data ................................................. 4.8

4.6. Depth Plotting of Apparent Resistivity Data Using the HRR Algorithm and Linear Pseudosection

4.7. HRR plotting of data at BC Cribs.....

4.8. Numerical Simulation and HRR Plotting of a Low-Resistivity Anomaly in a Homogeneous Soil.

4.9. HRR Apparent-Resistivity Processing of a Water Table (100 ohm-m) in a Background Soil (1000 ohm-m)

4.10. Forward Modeling of a Low-Resistivity (10 ohm-m target zone) And Water Table (100 ohm-m) in a Background Soil (1000 ohm-m)

4.11. Flowchart of the Resistivity Inversion Process

4.12. Inversion Results for the Resistivity Data Presented in 4.7

4.13. Results of the $3 \mathrm{D}$ inversion at BC Cribs - Slice at 30m bgs

4.14. Stages of Core Preparation for Electrical Measurements, (a) Soil Core Just After Removal of End Caps, (b) Core After Attachment of the Collar Needed to Connect End Caps, (c) Porous Stainless Steel Electrode in End Cap, and (d) Fully Assembled Core with Collars and End Caps with Electrodes.

4.15. A Schematic of a Conventional Four-Electrode Array Used to Measure Subsurface Resistivity.

5.1. Moisture Content of Grab Samples from C5923 Compared to Field Neutron Moisture Log ....

5.2. Pore-Water EC, Ionic Strength and Major Ions in Borehole C5923

5.3. Water-Extractable Nitrate, Sodium, Technetium-99, and Uranium in Sediments from Borehole C5923.

5.4. Distribution of Water Extractable Mono- and Di-valent Cations in Borehole C5923 Sediments

5.5. Pore Water Electrical Conductivity, Calculated Ionic Strength, and Reciprocal of Inverted Field Soil Resistivity Data for C5923 Borehole.

5.6. HRR Results of FY05-Line 4

5.7. Vertical Profiles of HRR, 2D Inverted, and 3D Inverted Resistivity Data at the Location of Borehole C5923 (A)

5.8. Profile and Scatter Plots for HRR and Pore-Water EC at Borehole C5923 (A). 


\section{Figures}

5.9. Profile and Scatter Plots for HRR and Ionic Strength at Borehole C5923 (A) ....................... 5.32

5.10. Profile and Scatter Plots for HRR and Nitrate Concentration at Borehole C5923 (A)............. 5.32

5.11. Profile and Scatter Plots for HRR and Technetium-99 Concentration at Borehole C5923 (A)

5.12. 2D Inversion Results of FY05-Line 4 5.33

5.13. Profile and Scatter Plots for 2D Inversion and Pore-Water EC at Borehole C5923 (A). 5.34

5.14. Profile and Scatter Plots for 2D Inversion and Pore-Water EC at Borehole C5923 (A), with Inversion Elevations Shifted by $3.4 \mathrm{~m}$

5.15. Profile and Scatter Plots of Geochemistry Data and 2D Inversion Results for Borehole C5923 (A), Including Ionic Strength, Nitrate Concentration, and Technetium-99 Concentration

5.16. 3D Inversion Results of Model Domain 3 of the BC Cribs Site 5.38

5.17. Profile and Scatter Plots for 3D Inversion and Pore-Water EC at Borehole C5923 (A) 5.39

5.18. Profile and Scatter Plots of Geochemistry Data and 3D Inversion Results for Borehole C5923 (A), Including Ionic Strength, Nitrate Concentration, and Technetium-99 Concentration

5.19. PSD Curves from Borehole C5923 (A) Showing Range of Textures

5.20. The Dependence of Effective Particle Diameter on Textural Components, (a) Clay Content, (b) Silt Content, (c) Sand Content, and (d) Mud Content.

5.21. Grain-Size Frequency Histograms for Sediments from Borehole 5924 (B), Analyzed by Dry Sieving and Laser Granulometery

5.22. Measured (left axis) and Caculated (right axis) SSA as a Function of Texture for Borehole C5923 (A) Sediment

5.23. Measured CEC as a Function of Soil Textural Parameters for Borehole C5923 (A) Sediments

5.24. Plots of Discharge Versus Hydraulic Head for Borehole C5923 (A) Core Samples, (a) Core B1TJ4-2, and (b) B1TJ8-2, (c) B1TJ6-2, and (d) B1TK2-2.

5.25. Plots of Saturated Hydraulic Conductivity for Borehole C5923 (A) Core Samples, (a) $\mathrm{K}_{\mathrm{s}}$ Compared to Effective Diameter from PSDs, (b) $\mathrm{K}_{\mathrm{s}}$ Compared to Mud (silt plus clay) Mass Fraction

5.26. Plots of Air Conductivity at the Antecedent Moisture Content and Saturated Hydraulic Conductivity for Borehole C5923 (A) Core Samples.

5.27. Semi-Log Plot of Vertical Resistivity Profile at the Location of Borehole C5923 (A), (a) Resistivity on all Samples, and (b) Resistivity Separated by Sample Type

5.28. Semi-Log Plot of Vertical Resistivity Profile at the Location of Borehole C5923 (A), (a) Resistivity and (b) Pore Water Nitrate Concentration Extracted from Grab Samples

5.29. Semi-Log Plot of Vertical Resistivity Profile at the Location of Borehole C5923 (A), 


\section{Figures}

(a) Apparent Resistivity, and (b) Pore Water Technetium-99 Concentration Extracted from Grab Samples.

5.30. Semi-Log Plot of Vertical Resistivity Profile at the Location of Borehole C5923 (A),

(a) Apparent Resistivity, and (b) Mean Ionic Strength Measured on Water Extracts from Grab Samples.

5.31. Profiles of Resistivity for Borehole C5923 (A), (a) Obtained from D.C. Resistivity Measurements on Borehole C5923 (A) Grab and Core Samples, (b) HRR, 2D Inverted, and 3D Inverted....

5.32. Example Pole-Pole Filter for Determining Apparent-Resistivity Values of a Layered Earth Using Digital Filter Theory

5.33. Reanalysis of MiniSting Data from Borehole 5923(A), (a) Data Averaged by Discretizing Layers Along Logical Breaks in Continuity and Calculating the Resulting Resistivity Values Within the Layer Using a Parallel Resistor Model and (b) D Filtering of Averaged MiniSting Data

5.34. Comparison of Resistivity Profile and Sounding Curves from Borehole C5923 (A) (a) Resistivity Normalized Between 0.0 and 1.0 over the Depth Interval and a Walsh LowPass Representation of the Resistivity Profile Showing the Calculated Boundaries Between Resistivity Zones, (b) Resistivity Soundings from HRR, 2D Inverted, and 3D Inverted.

5.35. The Apparent-Resistivity Pseudosection (a rectangular prism) from a Simulated 2D Wenner Imaging Survey over the C5923 Borehole.

5.36. Comparison of Resistivity Profile and Sounding Curves from Borehole C5923 (A) (a) Resistivity Normalized Between 0.0 and 1.0 over the Depth Interval and a Walsh Low-Pass Representation of the Resistivity Profile Showing the Calculated Boundaries Between Resistivity Zones, (b) Resistivity Profiles from HRR, 2D Inversion of Field Data, and 3D Inversion of Field Data Compared to a Profile Derived from the Inversion of a Simulated Survey Using the Laboratory-Measured Profile as the Starting Mode

5.38. The Relationship Between Resistivity and SG Logs at Borehole C5923 (A), (a) Resistivity Based on Laboratory Measurements and (b) Electrical Conductivity Calculated from Resistivity, and (c) Normalized Total Gamma.

5.39. The Relationship Between Resistivity and SG Potassium-40 Logs at Borehole C5923 (A), (a) Apparent Resistivity Based on Laboratory Measurements and (b) Total Potassium Distribution Versus Depth from ${ }^{40} \mathrm{~K}$ log.....

5.40. Relationship Between (a) Laboratory-Measured Resistivity and (b) Grain Size Distribution Indicators, Including the Geometric Mean Diameter and the Sorting Index....

5.41. The Variation in CEC and SA with Depth at Borehole C5923 (A), (a) CEC, and (b) SSA Results are Further Separated by Pre-Wash Ionic Strength....

5.42. The Variation in CEC and SSA with Depth at Borehole C5923 (A) and the Relation to Water Content (a) CEC, and (b) SSA.

5.43. The Relationship Between Water content and (a) CEC, (b) SSA Based on Measurements on Borehole C5923 (A) 


\section{Figures}

5.44. The Relationship Between CEC and Soil Textural Parameters (s) Sand Mass Fraction, (b) Silt Mass Fraction, (c) Mud, and (d) the Fredle index, Calculated as the Ratio of the Mean Diameter to the Sorting Index

5.45. The Relationship Between SSA and Soil Textural Parameters (s) Sand Mass Fraction,

(b) Silt Mass Fraction, (c) Mud, and (d) the Fredle index, Calculated as the Ratio of the Mean Diameter to the Sorting Index

5.46. The Relationship Between SSA and CEC for Borehole C5923 (A).

5.47. Relationship Between Electrical Properties, CEC, and SA for Borehole C5923 (A), (a) Resistivity vs. CEC, (b) Resistivity vs, SA, (c) Bulk Eletrical Conductivity vs CEC and (d) Bulk Electrical Conductivity Versus SA.

6.1. Laboratory and Field Measured Moisture Contents (wt\%) for Borehole C5924 (B)

6.2. Pore Water EC, Calculated Ionic Strength, and Concentrations of Nitrate, Sulfate, Sodium, and Calcium for Borehole C5924 (B)

6.3. Measured Nitrate, Sodium, Technetium-99 and Uranium for Borehole C5924 (B) Sediments

6.4. Water Leachable Mono-Valent and Divalent Cations for Borehole C5924 (B) Sediments

6.5. Pore-water EC, Ionic Strength, And Field Measured Reciprocal Inverted Resistivity (2D) for Borehole C5924 (B)

6.6. HRR Results of FY05-Line 30 and FY05-Line 25.

6.7. Profiles of HRR at the Location of Borehole C5924 (B)

6.8. Profile and Scatterplots for HRR and Pore-Water EC at Borehole C5924 (B) with Coefficients from Rucker and Fink (2007) and Optimized Coefficients Using Data from Borehole C5924 (B) as Calibration

6.9. Profile and Scatter Plots of Geochemistry Data and HRR Results for Borehole C5924 (B), Including Ionic Strength, Nitrate Concentration, and Technetium-99 Concentration.

6.10. 2D Inversion Results of FY05-Line 30 and FY05-Line 25.

6.11. Profiles of 2D Inversion at the Location of Borehole C5924 (B)

6.12. Profile and Scatter Plots for 2D Inversion. (top) Pore-Water EC (bottom) Ionic Strength at Borehole C5924 (B)

6.13. Profile and Scatter Plots for 2D Inversion and Pore-Water EC at Borehole C5924 (B) .

6.14. 3D Inversion Results of Model Domain 1 of the BC Cribs Site

6.15. Profile and Scatter Plots for 3D Inversion with Pore-Water EC and Ionic Strength at Borehole C5924 (B)

6.16. Profile and Scatter Plots for 3D Inversion for Nitrate Concentration and Technetium99 Concentration at Borehole C5924 (B).

7.1. Laboratory and Field Measured Moisture Contents (wt\%) for Borehole C5925 (C)......

7.2. Pore water EC, Calculated Ionic Strength, and Concentrations of Nitrate, Sulfate, Sodium, 


\section{Figures}

and Calcium for Borehole C5925 (C).

7.3. Measured Nitrate, Sodium, Tc and U for Borehole C5925 (C) Sediments .............................

7.4. Water-Leachable Mono-Valent and Divalent Cations for Borehole C5925 (C) Sediments....... 7.9

7.5. Pore water EC, Ionic Strength, and Field Measured Reciprocal Inverted Resistivity (2D) for

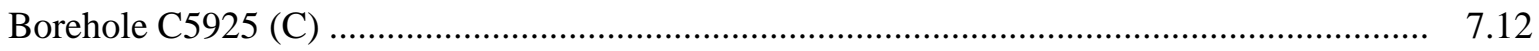

7.6. $\quad$ HRR Results of FY06-Line 1 and FY06-Line 2 2...............................................................

7.7. Profiles of HRR at the Location of Borehole C5925 (C) ...................................................... 7.16

7.8. Profile and Scatter Plots for HRR with Pore-Water EC and Ionic Strength at Borehole

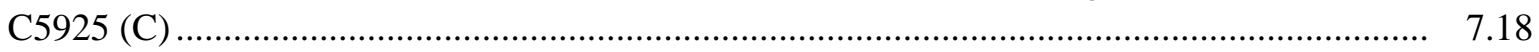

7.9. Profile and Scatter Plots for HRR with Nitrate Concentrations at Borehole C5925 (C)........... 7.19

7.10. 2D Inversion Results of FY06-Line 1 and FY06-Line 2 …................................................. 7.19

7.11. Profiles of 2D Inversion at the Location of Borehole C5925 (C).......................................... 7.20

7.12. Profile and Scatter Plots for 2D Inversion with Pore-Water EC and Ionic Strength at

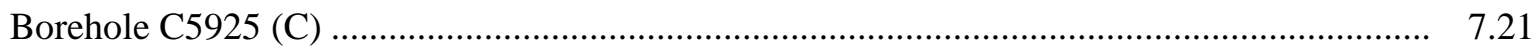

7.13. Profile and Scatter Plots for 2D Inversion with Nitrate Concentration at Borehole

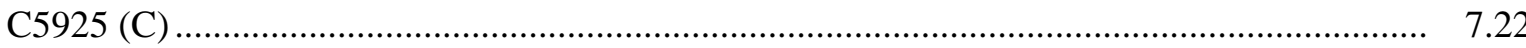

7.14. 3D Inversion Results of Model Domain 3 of the BC Cribs Site ............................................. 7.22

7.15. Profile and Scatter Plots for 3D Inversion with Porewater EC and Ionic Strength at

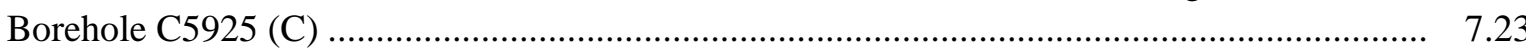

7.16. Profile and Scatter Plots for 3D Inversion for Nitrate Concentrations at Borehole C5925 (C)

8.1. Pore water Tc and U, Gravimetric Moisture Content, $\mathrm{pH}$ and Electrical Conductivity for Borehole C4191 Samples .................................................................................................. 8.6

8.2. Major Anions (in 1:1 sediment-to-water extracts) from Borehole C4191............................... 8.12

8.3. Calculated C4191 Pore Water Concentrations of Major Anions............................................ 8.13

8.4. Cations in 1:1 Sediment-to-Water Extracts and Acid Extracts for Borehole C4191................. 8.17

8.5. Calculated Cations Concentrations in Borehole C4191 Pore Water ......................................... 8.18

8.6. Calculated Technetium-99 and Uranium Pore-Water Concentrations in C4191 Sediments vs Depth.

8.7. Water- and Acid-Extractable Concentrations of Key Contaminants in Borehole C4191 Sediment.

8.8. Acid-Extractable Concentrations of Selected Metals C4191 Sediments.................................. 8.28

8.9. Concentration of Aluminum, Iron, Manganese, Vanadium, and Barium Acid and Water Extracts from Borehole C4191 Sediment

8.10. Profiles of HRR at the location of Borehole C4191 _......................................................... 8.36

8.11. Profile and Scatter Plots for HRR with Pore-Water EC and Ionic Strength at Borehole 


\section{Figures}

C4191

8.12. Profile and Scatter Plots for HRR With Nitrate and the Logarithm of Nitrate Concentrations at Borehole C4191

8.13. Profile and Scatter Plots for HRR with Technetium-99 and the Logarithm of Technetium-99 Concentrations at Borehole C4191

8.14. Profiles of 2D Inversion at the Location of Borehole C4191.

8.15. Profile and Scatter Plots for 2D Inversion with Pore-Water EC at Borehole C4191 for Shifted And Unshifted Data

8.16. Profile and Scatter Plots for 2D Inversion with Ionic Strength at Borehole C4191.....

8.17. Profile and Scatter Plots for 2D Inversion with the Nitrate and Logarithm of Nitrate Concentrations at Borehole C4191

8.18. Profile and Scatter Plots for 2D Inversion with the Technetium-99 and Logarithm of Technetium-99 Concentrations at Borehole C4191

8.19. 3D Inversion Results of Model Domain 1 of the BC Cribs Site.

8.20. Profile and Scatter Plots for 3D Inversion with Pore-Water EC and Ionic Strength at Borehole C4191

8.21. Profile and Scatter Plots for 3D Inversion with the Logarithm of Nitrate and Technetium-99 Concentration at Borehole C4191...

9.1. Scatter Plot of Pore-Water EC and HRR Apparent Resistivity for All Boreholes

9.2. Scatter Plot of Ionic Strength and HRR Apparent Resistivity for All Boreholes

9.3. Scatter Plot of Nitrate Concentration and HRR Apparent Resistivity for All Boreholes.

9.4. Scatter Plot of Technetium-99 Concentration and HRR Apparent Resistivity for All Boreholes....

9.5. Scatter Plot of Pore-Water EC and 2D Inverted Resistivity for All Boreholes.

9.6. Scatter Plot of Ionic Strength and 2D Inverted Resistivity for All Boreholes...... 9.14

9.7. Scatter Plot of Nitrate Concentration and 2D Inverted Resistivity for All Boreholes. 9.14

9.8. Scatter Plot of Technetium-99 Concentration and 2D Inverted Resistivity for All Boreholes .. 9.15

9.9. Scatter Plot of Pore-Water EC and 3D Inverted Resistivity for All Boreholes 9.15

9.10. Scatter Plot of Pore-Water Ionic Strength and 3D Inverted Resistivity for All Boreholes 9.16

9.11. Scatter Plot of Pore-Water Nitrate Concentration and 3D Inverted Resistivity for All Boreholes.

9.12. Scatter Plot of Pore-Water Technetium-99 Concentration and 3D Inverted Resistivity for All Boreholes. 


\section{Tables}

1.1. Summary of BC Cribs and Trenches Drilling Information .....................................................

2.1. Lithofacies of the Cold Creek Unit (after DOE 2002) ......................................................... 2.3

2.2. Boreholes in Vicinity of BC Cribs and Trenches Area Used in Hydrogeologic Cross

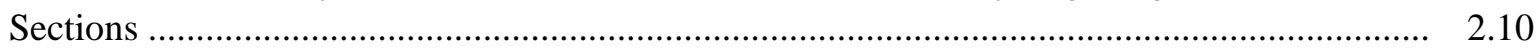

2.3. Grab Samples Collected, Described, and Photographed from Borehole C4191 ..................... 2.21

2.4. Vadose Zone Samples Collected, Described, and Photographed from Borehole C5923 .......... 2.25

2.5. Grab Samples Collected, Described, and Photographed from Borehole C5924 ...................... 2.32

2.6. Grab Samples Collected, Described, and Photographed from Borehole C5925 ...................... 2.36

4.1. Resistivity Data and 2D Inversion Statistics ...................................................................... 4.17

4.2. Resistivity Data and 3D Inversion Statistics ...................................................................... 4.18

5.1. Gravimetric Moisture Content of Grab Samples Obtained from Borehole C5923 .................. 5.3

5.2. Core Liners Obtained from Borehole C5923 .................................................................... 5.5

5.3. $\mathrm{pH}$ and EC Values for 1:1 Sediment to Water Extracts from C5923 .................................... 5.6

5.4. Anion Composition of Water Extracts of C5923 (units $\mu \mathrm{g} / \mathrm{g}$ dry sediment) ............................ 5.9

5.5. Water-ExtracAnions Converted to Pore Water Concentrations for C5923 Borehole Samples

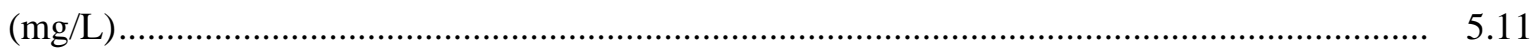

5.6. Water ExtracCations in Borehole C5923 Sediments ( $\mu \mathrm{g} / \mathrm{g}$ dry soil)..................................... 5.17

5.7. Water-ExtracCations as Pore Water Concentrations in Borehole C5923 Sediments (mg/L).... 5.19

5.8. Water-ExtracRadionuclides and Pore Water Total Ionic Strength........................................ 5.22

5.9. Acid-ExtracLight Elements in Borehole C5923 Sediments ( $\mu \mathrm{g} / \mathrm{g}$ dry sediment) .................... 5.24

5.10. Acid-ExtracHeavy Elements in Borehole C5923 Sediments ( $\mu \mathrm{g} / \mathrm{g}$ dry sediment)................... 5.24

5.11. Acid ExtracContent for RCRA Metals and Radionuclides in Borehole C5923 Sediments

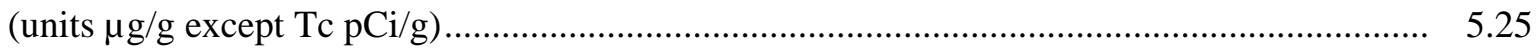

5.12. Man-Made Fission Product GEA Data (pCi/g sediment) for Grab Samples from C5923 ......... 5.26

5.13. Other Radionuclides Present in the C5923 Sediments .......................................................... 5.27

5.14. Groundwater Composition at Water at C5923 in July 2008................................................ 5.27

5.15. Textural Composition and Particle-Size Statistics for Borehole C5923 (A) Samples............... 5.43

5.16. Grain Size Frequency for Borehole C5924 (B) Analyzed by Sieving and Laser Diffraction

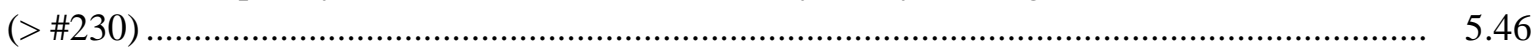

5.17. Summary of Hydro-Physical Properties for Core Samples from Borehole C5923 (A)............ 5.47

5.18. SSA and CEC for Borehole C5923 (A) Vadose Zone Sediments .......................................... 5.49

5.19. Saturated Hydraulic Conductivity for Borehole C5923 (A) Sediment Cores .......................... 5.53

5.20. Air Permeability at Antecedent Soil Water Content for Borehole C5923 (A) Samples............ 5.56

5.21. Summary of Laboratory MiniSting Resistivity Measurements on Borehole C5923 (A) 


\section{Tables}

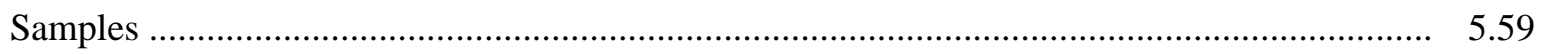

6.1. Gravimetric Moisture Content of Samples Retrieved from Borehole B (C5924) .................... 6.2

6.2. $\mathrm{pH}$ for 1:1 Sediment: Water Extracts and Electrical Conductivity (EC) Values from

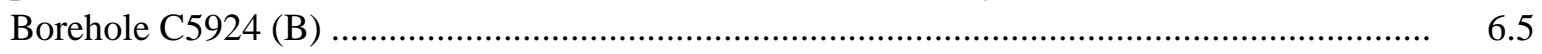

6.3. Water-ExtracAnions Converted to Pore Water Concentrations for Borehole C5924 (B) Sediments (mg/L)

6.4. Anion Composition of Water Extracts of Borehole C5924 (B) Sediment ( $\mu \mathrm{g} / \mathrm{g}$ dry sediment) .

6.5. Water ExtracCations in Borehole C5924 (B) Sediments ( $\mu \mathrm{g} / \mathrm{g}$ dry soil) .

6.6. Water-ExtracCations as Pore Water Concentrations in Borehole C5924 (B) Sediments $(\mathrm{mg} / \mathrm{L})$.

6.7. Water-ExtracRadionuclides and Pore Water Total Ionic Strength for Borehole C5924 (B)......

6.8. Acid-ExtracLight Elements in Borehole C5924 (B) Sediments ( $\mu \mathrm{g} / \mathrm{g}$ dry sediment). 6.21

6.9. Acid-ExtracHeavy Elements in Borehole C5924 (B) Sediments ( $\mu \mathrm{g} / \mathrm{g}$ dry sediment) 6.21

6.10. Acid ExtracContent for RCRA Metals and Radionuclides in Borehole C5924 (B) (units $\mu \mathrm{g} / \mathrm{g}$ except Tc pCi/g).

6.11. Man-Made Fission Product Data (pCi/g sed) for Grab Samples from Borehole C5924 (B)......

7.1. Gravimetric Moisture Content of Samples Retrieved from Borehole C (C5925)

7.2. $\mathrm{pH}$ for 1:1 Sediment: Water Extracts and Electrical Conductivity (EC) Values from Borehole C5925 (C)

7.3. Water-ExtracAnions Converted to Pore Water Concentrations for Borehole C5925 (C) Sediments (mg/L)

7.4. Anion Composition of Water Extracts of Borehole C5925 (C) Sediment ( $\mu \mathrm{g} / \mathrm{g}$ dry sediment)

7.5. Water-ExtracCations in Borehole C5925 (C) Sediments ( $\mu$ g/g dry soil)

7.6. Water-ExtracCations as Pore Water Concentrations in Borehole C5925 (C) Sediments (mg/L).

7.7. Water-ExtracRadionuclides and Pore Water Total Ionic Strength for Borehole C5925 (C)......

7.8. Acid-ExtracLight Elements in Borehole C5925 (C) Sediments ( $\mu \mathrm{g} / \mathrm{g}$ dry sediment).....

7.9. Acid-ExtracHeavy Elements in Borehole C5925 (C) Sediments ( $\mu \mathrm{g} / \mathrm{g}$ dry sediment) .....

7.10. Acid ExtracContent for RCRA Metals and Uranium in Borehole C5925 (C) (units $\mu \mathrm{g} / \mathrm{g}$ ).................

7.11. Man-Made Fission Product GEA Data (pCi/g sed) for Grab Samples from Borehole C5925 (C).

7.12. Fission Product Data (pCi/g sed) for Grab Samples from Borehole C5925 (C)

8.1. Gravimetric Moisture Content of Grab Samples Obtained from Borehole C4191 .................. 8.1

8.2. $\mathrm{pH}$ and EC Values for 1:1 Sediment to Water Extracts from C4191 ...................................... 8.4 


\section{Tables}

8.3. Anion Composition of Water Extracts of C4191 Sediment (units $\mu \mathrm{g} / \mathrm{g}$ dry sediment).............. 8.7

8.4. Water-ExtracAnions Converted to Pore-Water Concentrations for C4191 Borehole Samples

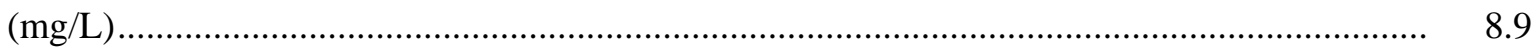

8.5. Water ExtracCations in Borehole C4191 Sediments ( $\mu \mathrm{g} / \mathrm{g}$ dry soil) .................................... 8.14

8.6. Water-ExtracCations as Pore Water Concentrations in Borehole C4191 Sediments (mg/L).... 8.15

8.7. Water-ExtracRadionuclides and Pore Water Total Ionic Strength for Borehole C4191 ............ 8.20

8.8. Acid-ExtracLight Elements in Borehole C4191 Sediments ( $\mu \mathrm{g} / \mathrm{g}$ dry sediment) ..................... 8.23

8.9. Acid-ExtracHeavy Elements in Borehole C4191 Sediments ( $\mu \mathrm{g} / \mathrm{g}$ dry sediment)................... 8.24

8.10. Acid ExtracContent for RCRA Metals and Radionuclides in Borehole C4191 Sediments

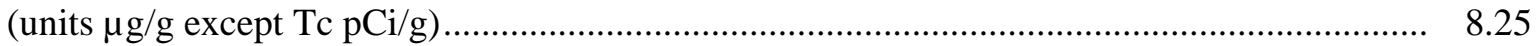

8.11. Man-Made Fission Product GEA Data (pCi/g sed) for Grab Samples from C4191 ................. 8.30

8.12. Gamma Energy Analysis Results for C4191 Core Samples.................................................... 8.32

8.13. Other Radionuclides Present in the C4191 Core Samples Obtained by FHI........................... 8.33

8.14. Total, Inorganic and Organic Carbon Content of Vadose Zone Sediments from Borehole

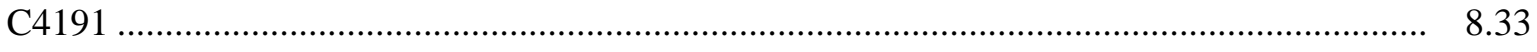

8.15. Groundwater Composition at Water in C4191 in Jan. 2004................................................. 8.35

9.1. Targeted Parameters for Electrical Resistivity Evaluation ................................................... 9.23

9.2. Range of Groundwater Concentrations of Selected Constituents in M (moles/L) ................... 9.25

9.3. Composition of the Three Waste Types Disposed to BC Cribs and Trenches ......................... 9.27 



\subsection{Introduction}

\subsection{Goals}

The overall goal of this report is to provide data and analyses to quantify the resolution limits of surface-based, electrical-resistivity surveys conducted at the BC-Cribs and Trenches area in terms of the capability to accurately image the subsurface electrical distribution and detect geo-electrical effects resulting from past liquid waste discharges. The data and analyses described in this report are designed to provide a crucial link between direct measurements of geochemical, hydraulic, and soil resistivity of subsurface material and the surface-based electrical-resistivity information obtained via field surveys. This borehole sediment-to-surface-based linkage is otherwise known as "ground truthing" and is accomplished by directly measuring resistivity and other hydraulic properties of sediment samples taken from boreholes placed in the region of study. Water extracts should also be taken from the sediments with subsequent measurement of pore-water composition. Pore-water parameters measured include specific electrical conductivity (EC), common cation and anion concentrations, $\mathrm{pH}$, and alkalinity. From all these laboratory measurements on sediments and water extracts, pore water ionic strength and petrophysics relationships are generated that can be compared with the field (or laboratory) electrical resistivity data, both directly and after the field data are processed using petrophysics-based algorithms.

Secondary goals of the work described in this report are to measure the total and/or water-leachable concentrations of key contaminants of concern (COCs) in the sediments as a function of depth and distance from inactive disposal facilities in a region called the BC Cribs and Trenches area. All the data collected on the sediments from the boreholes are used to generate conceptual models of the contaminants' distribution in the subsurface and future potential mobility. From these conceptual models and the available sediment characterization, data baseline risk assessments and guidance on choosing remedial-action alternatives are possible. Finally, the newly acquired data and analyses can aid in the future decisions that must be made by the U.S. Department of Energy (DOE) regarding the near-term operations, future waste site remediation, and final closure activities for the inactive disposal facilities.

\subsection{Scope}

Specifically, this report contains all the geologic, geochemical, hydrological, geophysical, and selected physical characterization data collected on vadose zone sediment recovered from four boreholes placed within the BC Crib and trenches area [C4191, C5923, C5924, and C5925]. Also provided is interpretation of the data in the context of determining the appropriate lithologic model, the vertical extent of contamination, the migration potential of the contaminants that still reside in the vadose zone, and the correspondence of the contaminant distribution in the borehole sediment to groundwater plumes in the unconfined aquifer proximate and downgradient from the BC Cribs and Trenches area.

\subsection{Report Organization}

This report covers the recently acquired data for the noted four boreholes; up to two additional boreholes may be emplaced in the future to allow more "ground truthing" of the field electrical resistivity data. If additional boreholes are emplaced, the results would be documented in a revision of this technical report. Additional hydraulic characterization testing (e.g., hydraulic conductivity both saturated and 
unsaturated) is also being collected on intact cores from borehole C5923 to augment information on vadose zone water transport and allow correlation between sediment hydraulic, physical, electrical, and geochemical parameters. The correlation exercises relate to a new concept called pedotransfer functions wherein one develops correlations between more readily measured (i.e., less expensive or less time consuming) and more difficult-to-measure parameters. These additional studies and pedotransfer functions derived from adding the new data to existing Hanford data will likely be documented in a separate report.

This document describes the laboratory characterization data collected by Pacific Northwest National Laboratory (PNNL) and field data collected by hydroGEOPHYSICS, Inc [HGI] located in Tucson, AZ. Data were interpreted in concert by both organizations and were ably reviewed by Fluor Hanford, Inc. (FHI) staff, their consultants, and U.S. Department of Energy Richland Operations (DOE-RL).

This report is divided into sections that describe the geology, geochemical characterization methods, field and laboratory geophysical methods and materials, and geochemical and geophysical results by borehole, as well as summary and conclusions, references, and Appendices A and B with additional details including borehole driller's logs and sediment grab-sample photographs.

\subsection{BC Cribs and Trenches Field Electrical Resisitivity Characterization (ERC) "Ground Truthing"}

A diverse group of Hanford stakeholders agreed upon activities required to ground truth the field electrical resistivity data with the Data Quality Objectives (DQO) process. A consensus document (Benecke 2008), entitled "Data Quality Objectives Summary Report for the BC Cribs and Trenches Area - High-Resolution Resistivity (HRR) Correlation (DQO)” was prepared after several meetings of a diverse group of Hanford stakeholders and technical experts. Other details such as sampling and parameter analysis requirements were documented in DOE/RL-2007-13, Rev. 0, Sampling and Analysis Plan for Electrical Resistivity Correlation for the BC Cribs and Trenches Area Waste Site.

The DQO process led to the following three key questions that needed to be answered:

\section{Do ERC data generally correlate with vadose zone COC plumes that are established by} analyses of borehole sediment samples?

2. Is the correlation of ERC and laboratory analytical data sufficient to use ERC to assist in updating the existing conceptual site models [CSM] and evaluating remedial alternatives?

3. Is ERC data interpretation useful for guiding vadose zone sediment sampling for targeted COCs?

To answer these three questions, the following actions were needed:

1. Estimate the degree of correlation between ERC data and the distribution (i.e., concentration and location) of targeted COCs in the vadose zone.

2. Determine whether ERC and analytical data correlate sufficiently to use ERC data to assist in updating the existing CSM and evaluating remedial alternatives.

3. Determine whether ERC data interpretations are useful for guiding vadose zone sediment sampling for targeted COCs. 
Tables 3-1 and 3-4 in the DQO document list the information required to resolve the decision statements identified above. Table 3-1 lists the important physical and geochemical data that could be collected on the sediment samples obtained from the proposed boreholes. Table 3-4 lists the key COCs at the BC Cribs and Trenches that should be measured in the sediment samples obtained from the boreholes. Additional physical and geochemical data are listed in Table 3-2 of the DQO document for parameters that are not required for ERC evaluation, but are useful for updating and further developing the conceptual site model (CSM). Table 3-3 in the DQO indicates whether the data already exist, and when they do exist, source references are provided for data that already exist. In general, Table 3-3 in the DQO shows that for many parameters, there are no data or only data of low quality and quantity. Thus, they are insufficient to resolve the associated decision statements.

Therefore, a drilling and sampling program was developed with a potential for five new boreholes in the vadose zone of the BC Cribs and Trenches Area. Accommodations were also made to collect additional data on key contaminants of potential concern (COPCs) and sediment hydraulic properties to augment future focused feasibility studies (FFSs) of remedial alternatives. Furthermore, the boreholes could be deepened and converted to groundwater monitoring wells if necessary to collect saturated zone data, or the boreholes could be converted into vadose zone injection wells wherein dry air is pumped in to desiccate the sediments to lower the transport of contaminants through the vadose zone.

The key focus of the ERC ground-truthing efforts were 1) to gather and characterize vadose zone sediment samples from the boreholes that were strategically located where apparent resistivity anomalies of varying intensity were found with the ERC ground-surface geophysical surveys and 2) to measure the concentrations of COCs and develop the distribution of mobile risk-based COCs in sediment samples from the boreholes. The DQO document explains the process for evaluating ERC geophysical interpretations by comparing the vertical and lateral extent of the ERC anomalies to the vadose zone porewater concentrations of major cations and anions and mobile COCs in the vadose zone of the BC Cribs and Trenches Area. Analyses of sediment samples from outside the ERC anomaly are intended to assess the potential for ERC data interpretations to produce a "false negative."

Sediment analytical data from the new boreholes were compared to corresponding ERC data. The proposed new borehole locations are shown in Figure 1.1. The purpose of each borehole is described below. The planned total depth of each borehole depends on its location, but no borehole was planned to extend beyond the water table. For boreholes that are not planned to intercept the water table, drilling was continued below the ERC anomaly until field-screening and/or "quick turnaround” laboratory analyses indicated that sediment electrical conductivity, and water-extractable nitrate and technetium-99 has returned to background values.

Borehole A (C5923) is located between the cribs and trenches near an area where FY06 ERC data were interpreted as a "pantleg effect” (i.e., a "false positive" image showing diagonally downwarded target's edges) at a depth of approximately 70 meters below ground surface (bgs). Drilling for Borehole

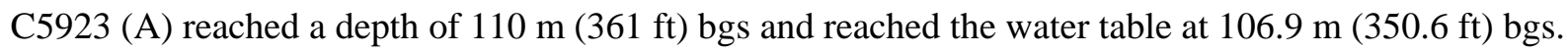
One groundwater sample was taken before the deeper portion of the borehole was decommissioned. Borehole B (C5924) and proposed borehole D (C5926) are located where ERC data indicate lower or no COC concentrations in the deeper vadose zone. The total depth for Borehole C5924 (B) was $248 \mathrm{ft}$ bgs (75.6 m bgs), which is approximately 10 meters (32.8 ft.) deeper than the base of the ERC apparent resistivity anomaly at that location. Borehole D (C5926) (if drilled) would be located east of Trenches 216-B-25 and 216-B-26, outside the lateral perimeter of the ERC apparent resistivity anomaly. The total 
required depth for ERC evaluation in Borehole D is approximately $196.9 \mathrm{ft}$. (60 meters) bgs because the nearby ERC apparent resistivity anomaly extends to approximately 50 meters bgs. Borehole C (C5925) and Borehole E (C5927) if it is drilled are located where ERC data indicate relatively higher COC concentrations at deeper depths in the vadose zone. The total depth for Borehole $\mathrm{C}$ was approximately 62.2 meters (204 ft) bgs. Drilling at Borehole E might be continued until the water table is encountered should a decision be made to drill this borehole. However, in fiscal year (FY) 2008, only three wells (C5923, C5924, and C5925) were drilled, and subsequent sediments samples were collected. The first

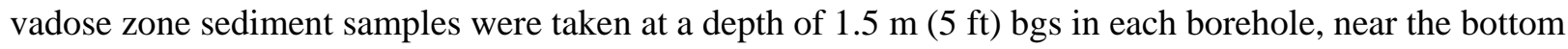
of the shallower waste sites in the BC Cribs and Trenches Area. Subsequent sediment samples were taken at depth intervals of 0.76 meters $(2.5 \mathrm{ft}$ ) until the total depth of each borehole was reached. Selected sediment samples were analyzed for ERC evaluation and/or CSM updating. Other sediment samples were archived. Groundwater samples were collected from the two boreholes that encountered the water table (C5923 and C4191). Summary information on all four boreholes is given in Table 1.1.

\subsection{Early Efforts to "Ground Truth" the ERC Method}

In late 2003, vadose zone sediment samples were collected at 0.76-meter (2.5-foot) intervals from Borehole C4191 that was drilled in the approximate center of Trench 216-B-26 (see Figure 1.1 for the location). The EC of pore-water extracts from 39 of the sediment samples from depths of 5.3 to 104 meters (17.3 to $341 \mathrm{ft}$ ) bgs was compared to concentrations of technetium-99, uranium-238, sodium, calcium, potassium, magnesium, fluoride, chloride, nitrate, and sulfate. The comparison was based on waste inventory data in DOE (1996). After borehole C4191 was drilled, HGI was subcontracted to perform a surface-based soil resistivity survey of the BC Cribs and Trenches area so that this ERC technique could be compared with the laboratory data obtained from the sediment samples from C4191. The details on the surface-based ERC are found in several internal contractor reports and nicely summarized in Rucker and Benecke (2006). HGI compared their apparent soil resistivity (HRR) field data with the laboratory-calculated pore-water concentrations of individual constituents using linear regression and found correlation coefficients of 0.85 to 0.89 for technetium-99, sodium, calcium, magnesium, chloride, and nitrate. Correlation coefficients for potassium and sulfate were positive, but less than 0.65. Negative correlation coefficients of -0.12 and -0.24 were calculated for uranium-238 and fluoride, respectively. A correlation coefficient of 0.9 was calculated between EC and the total ionic strength. HGI indicated that nitrate and sodium provided most of the total ionic strength of pore water. The ERC correlation results for Borehole C4191 represent a comparison in a single relatively high concentration area directly under a waste disposal site. A key conclusion of this early analysis was that the correlation of ERC and sediment analytical data should be further evaluated in other portions of the vadose zone in the BC Cribs and Trenches Area. Thus, the activities documented in the DQO and additional tasks described in this report were performed. Additional details on the preliminary correlation of ERC data with sediment pore water from borehole C4191 can be found in Rucker and Benecke (2006). 


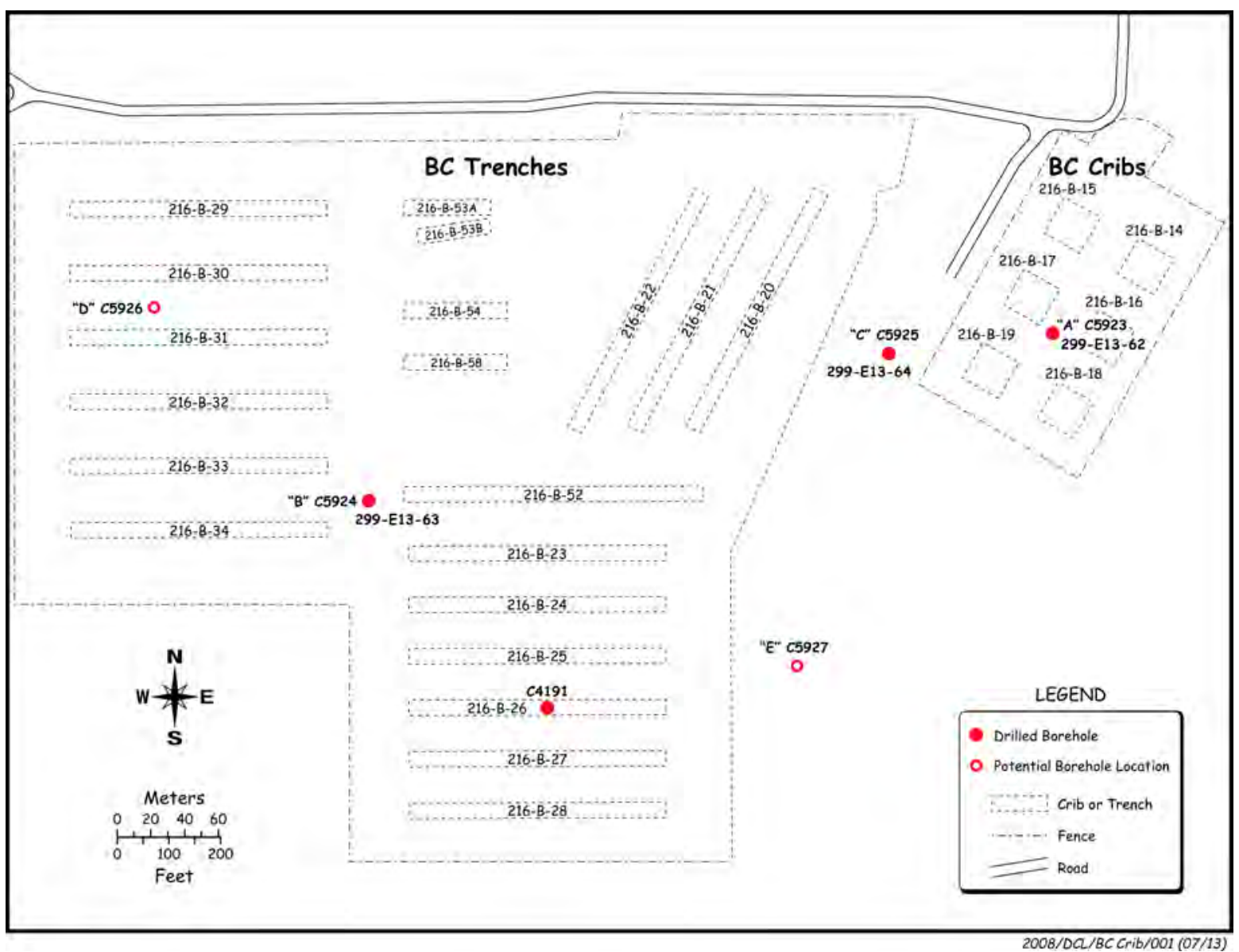

Figure 1.1. Location of the Boreholes Either Drilled in 2003 and 2007-2008 or Proposed for Future Years

Table 1.1. Summary of BC Cribs and Trenches Drilling Information

\begin{tabular}{|c|c|c|c|c|c|c|c|}
\hline $\begin{array}{l}\text { Borehole and } \\
\text { Well ID }\end{array}$ & $\begin{array}{l}\text { Start } \\
\text { Date }\end{array}$ & $\begin{array}{l}\text { Finish } \\
\text { Date for } \\
\text { Drilling }\end{array}$ & $\begin{array}{l}\text { Northing } \\
\text { (m) }\end{array}$ & $\begin{array}{l}\text { Easting } \\
\text { (m) }\end{array}$ & $\begin{array}{l}\text { Ground } \\
\text { Surface } \\
\text { (m) }\end{array}$ & $\begin{array}{l}\text { Total Drill } \\
\text { Depth } \\
\text { (m) }\end{array}$ & Comments \\
\hline $\begin{array}{c}\text { A (C5923) } \\
299-E 13-62\end{array}$ & 2/19/08 & $7 / 2 / 08$ & $134,361.44$ & $573,588.14$ & 227.43 & 107.29 & $\begin{array}{l}\text { Tagged water table at } 350.6 \\
\mathrm{ft} \text { bgs \& sampled } \\
\text { groundwater at } 359.9 \mathrm{ft} \text { bgs. }\end{array}$ \\
\hline $\begin{array}{c}\text { В (C5924) } \\
\text { 299-E13-63 }\end{array}$ & $1 / 30 / 08$ & 2/21/08 & $134,69.53$ & $573,192.36$ & 226.20 & 75.59 & \\
\hline $\begin{array}{l}\text { C (C5925) } \\
\text { 299-E13-64 }\end{array}$ & $2 / 28 / 08$ & 3/13/08 & $134,350.79$ & $573,500.38$ & 226.91 & 62.03 & \\
\hline $\begin{array}{c}\text { C4191 } \\
\text { No well \# } \\
\text { assigned }\end{array}$ & $12 / 9 / 03$ & $1 / 13 / 04$ & $134,146.02$ & $573,286.84$ & 224.11 & 104.02 & $\begin{array}{l}\text { Tagged water table at } 337.8 \\
\mathrm{ft} \text { bgs \& sampled at } 338 \text { to } \\
340 \mathrm{ft} \text { bgs. }\end{array}$ \\
\hline
\end{tabular}

All locations are Washington State Plane Coordinates (South Zone) using NAD83(91) Horizontal Datum and NAVD88 Vertical Datum. 



\subsection{Geology}

\subsection{Regional Geologic Setting}

\subsubsection{Stratigraphy and Lithology}

Strata within the Pasco Basin and Hanford Site can be divided into five stratigraphic units: 1) Recent deposits, 2) Hanford formation, 3) Cold Creek unit, 4) Ringold Formation, and 5) Columbia River Basalt Group. More detailed descriptions on the regional geology are provided in a number of other reports (Tallman et al. 1979; DOE 1988, 2002; Lindsey et al. 1992; Lindsey 1995; Reidel et al. 1994; Williams et al. 2000, Reidel and Chamness 2007). A regional geologic cross section showing the general stratigraphic relationships of the suprabasalt sediments within the vadose zone is presented in Figure 2.1.

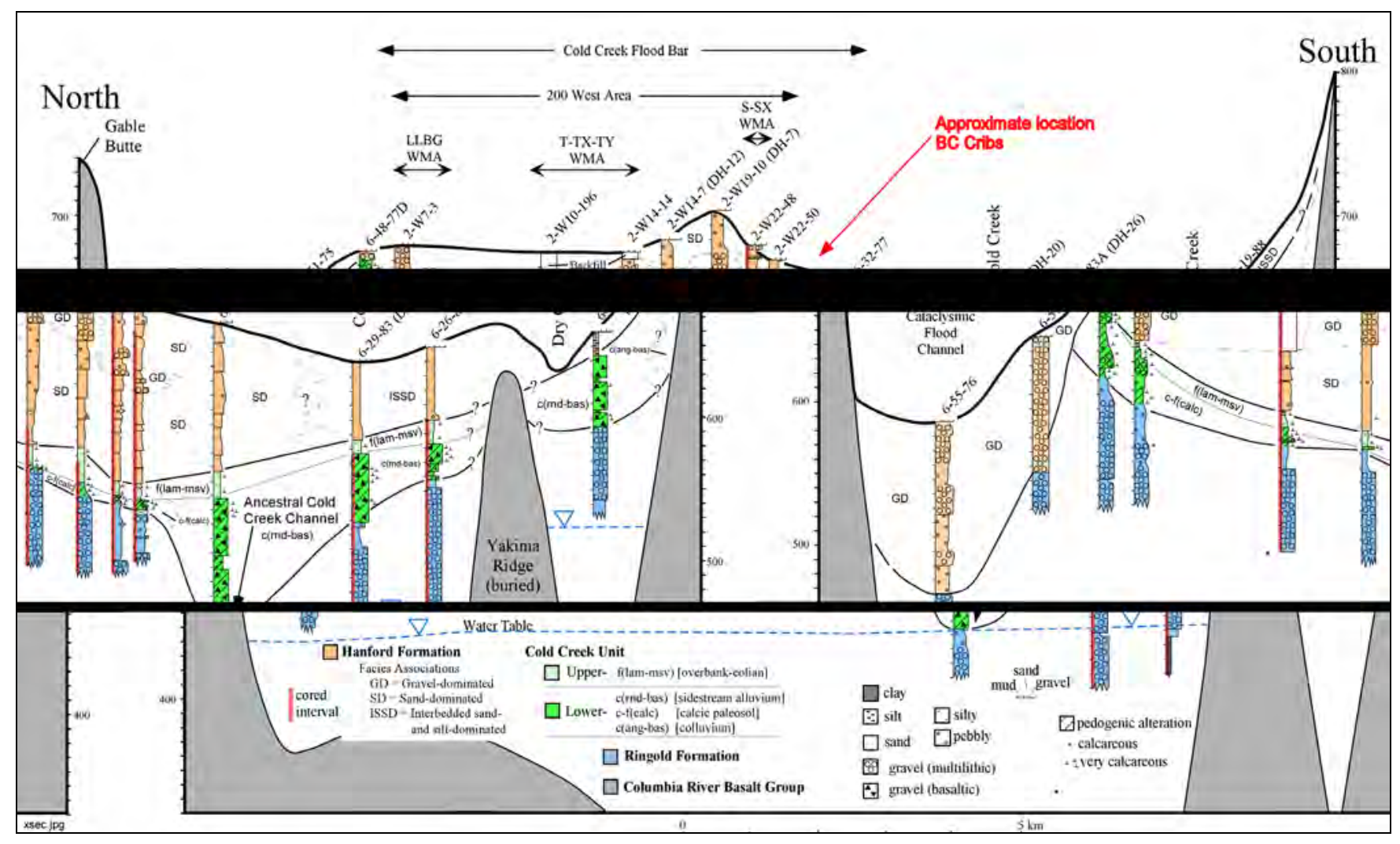

Figure 2.1. North-South Geologic Cross Section Across the Western Hanford Site (after DOE 2002). See Figure 2.2 for location. Strata at BC Cribs are comparable to those illustrated about midway and $\sim 4$ miles out of line with this cross section.

\subsubsection{Columbia River Basalt Group}

Miocene Columbia River basalt forms the basement rock over most of eastern Washington, derived from north-south trending volcanic vents in southeast Washington, northeast Oregon, and west-central Idaho (DOE 1988; Reidel and Hooper 1989). Up to 300 separate basaltic lava flows accumulated to 
15,000 ft thick within the Pasco Basin. The earliest flows of Columbia River basalt reached the Pasco Basin about 17 million years ago and the last about 8.5 million years ago. During and since their eruption, flows of Columbia River basalt have been folded into a series of east-west trending anticlines and synclines, referred to as the Yakima Fold Belt.

\subsubsection{Ringold Formation}

The Ringold Formation blankets Columbia River basalt over most of the Pasco Basin. The Ringold Formation records fluvial-lacustrine deposition associated with the ancestral Columbia River drainage system, following the last eruption of basalt at the Hanford Site about 8.5 m.y. ago (DOE 1988, Lindsey 1995). Deformation of the Yakima folds, which began in the middle Miocene Epoch, concurrent with the Columbia River basalt volcanism, continued into Ringold time so the centers of down-warped basins received more sediments than the margins. The Ringold Formation is up to $600 \mathrm{ft}$ (185 m) thick in the center of the basin and pinches out against the basin-bounding basalt ridges.

The Ringold Formation consists of semi-indurated clay, silt, fine- to coarse-grained sand, and variably cemented granule to cobble gravel. Ringold Formation sediments have been classified into five sediment facies associations: 1) fluvial gravel, 2) fluvial sand, 3) overbank deposits, 4) lacustrine deposits, and 5) alluvial fan deposits. More detailed descriptions of these facies are presented in Lindsey (1995). Most of the unconfined aquifer in the Pasco Basin lies within the member of Wooded Island (Unit E) of the Ringold Formation.

\subsubsection{Cold Creek Unit (CCU)}

The Cold Creek unit represents deposits that accumulated within the central Pasco Basin from about 2 to 3 million years ago, which brackets two significant geologic events. The older event is a regional baselevel drop and subsequent incision of the Ringold Formation (DOE 1988). The younger event is the initiation of Ice Age cataclysmic flooding, which began at the beginning of the Pleistocene, about 1.5 to 2.5 million years ago (Bjornstad et al. 2001; Bjornstad 2006).

The accumulation of the Ringold Formation ceased abruptly beginning about 3.4 million years ago, during a period of rapid downcutting and incision by the ancestral Columbia-Snake River system (Fecht et al. 1987; DOE 1988; Reidel et al. 1994). Incision resulted in the removal of up to $600 \mathrm{ft}$ of Ringold Formation sediments from the central portion of the Pasco Basin. Following incision, a new local base level was established at approximately the 100-m (300-ft) elevation at Wallula Gap. At this point, significant fluvial erosion and incision of the Ringold Formation ceased, once again permitting aggradation and backfilling to occur locally on the post-Ringold Formation landscape.

After this period of post-Ringold incision, the eroded surface of the Ringold Formation was locally weathered and/or covered with accretionary deposits of the CCU. These deposits consist of fluvial, eolian, and/or colluvial sediment, often pedogenically altered (DOE 2002). The CCU includes those deposits formerly referred to as the "Plio-Pleistocene unit" and "pre-Missoula Gravels," as well as the "early Palouse soil” and "caliche layer" within the 200 West Area. The new name, Cold Creek unit, was given to these deposits because more-recent studies suggest this unit is mostly or all of late Pliocene age (DOE 2002). 
Five CCU lithofacies can be differentiated on the basis of grain size, sedimentary structure, sorting, roundness, fabric, and mineralogic composition. The five facies, along with interpreted depositional environment, are listed in Table 2.1.

Table 2.1. Lithofacies of the Cold Creek Unit (after DOE 2002)

\begin{tabular}{lll}
\hline Lithofacies & Symbol & Environment of Deposition \\
\hline $\begin{array}{l}\text { Fine-grained, laminated to } \\
\text { massive }\end{array}$ & CCUf(lam-msv) & Fluvial-overbank and/or eolian \\
$\begin{array}{l}\text { Fine- to coarse-grained, calcium- } \\
\text { carbonate cemented }\end{array}$ & CCUf-c(calc) & Calcic paleosol \\
$\begin{array}{l}\text { Coarse-grained, multilithic } \\
\text { Coarse-grained, angular, basaltic }\end{array}$ & CCUc(mL) & Mainstream alluvium \\
Coarse-grained, rounded, basaltic & CCUc(rnd-bas) & $\begin{array}{l}\text { Colluvium } \\
\text { Sidestream alluvium }\end{array}$ \\
\hline
\end{tabular}

Some Cold Creek unit deposits appear to be present beneath most of the central Pasco Basin, except where it was locally stripped away during subsequent Pleistocene cataclysmic flooding. Ice Age flooding locally removed older sediments and scoured into basalt bedrock, particularly through the central Pasco Basin where the floodwaters were the most active. Around the margins of the basin, however, little or no erosion of the Cold Creek unit occurred during flooding.

\subsubsection{Hanford Formation}

The Hanford formation is an informal name assigned to Pleistocene cataclysmic flood deposits within the Pasco Basin (Tallman et al. 1979; DOE 1988, 2002). Ice-Age floods originated from periodic outbursts from glacial Lake Missoula and other Pleistocene water bodies (Bjornstad 2006). The Hanford formation consists predominantly of unconsolidated sediments that cover a wide range in grain size and sorting, from poorly sorted boulder-size gravel to better-sorted sand, silty sand, and silt. The sorting ranges from poorly sorted for coarse-grained to well sorted for fine-grained flood deposits. In general, the Hanford formation is subdivided into three principal facies: 1) gravel-dominated (GD), 2) sand-dominated (SD), and 3) interbedded sand- and silt-dominated (ISSD). These facies may grade into one another, both laterally as well as vertically.

GD flood deposits formed toward the center of the basin where currents and energy were the strongest. Here smaller particles were kept in suspension by the fast moving, highly turbulent flood waters. As flood energy decreased toward the margins of the basin, flood deposits transitioned laterally to the SD and ISSD facies (Figure 2.1). Because of the widely different and complex flow dynamics during Ice Age flooding, Hanford formation strata are extremely heterogeneous and anisotropic (DOE 2002; Bjornstad 2006). The bulk of the vadose zone within the Pasco Basin and the Hanford Site lies within sediments of the Hanford formation.

During Ice Age flooding, sediments accumulated onto the huge Cold Creek Bar (Figure 2.2), which makes up the 200 Area Plateau. Cold Creek Bar is a major floods' landform, up to 12 miles long and several miles wide, that grew during repeated Ice Age floods that expanded into the basin and dropped their sedimentary load. Cold Creek Bar grew as sediments were episodically laid down in series of 
perhaps hundreds of floods spanning a million years or more (Pluhar et al. 2006). The north edge of the bar received mostly coarse-grained gravel and sand (GD facies) while the central and southern portions of the bar received thick blankets of sand intercalated with thin beds of silt (SD facies). Further to the south, ISSD facies were deposited in areas of increased slack-water sedimentation (Figure 2.1).

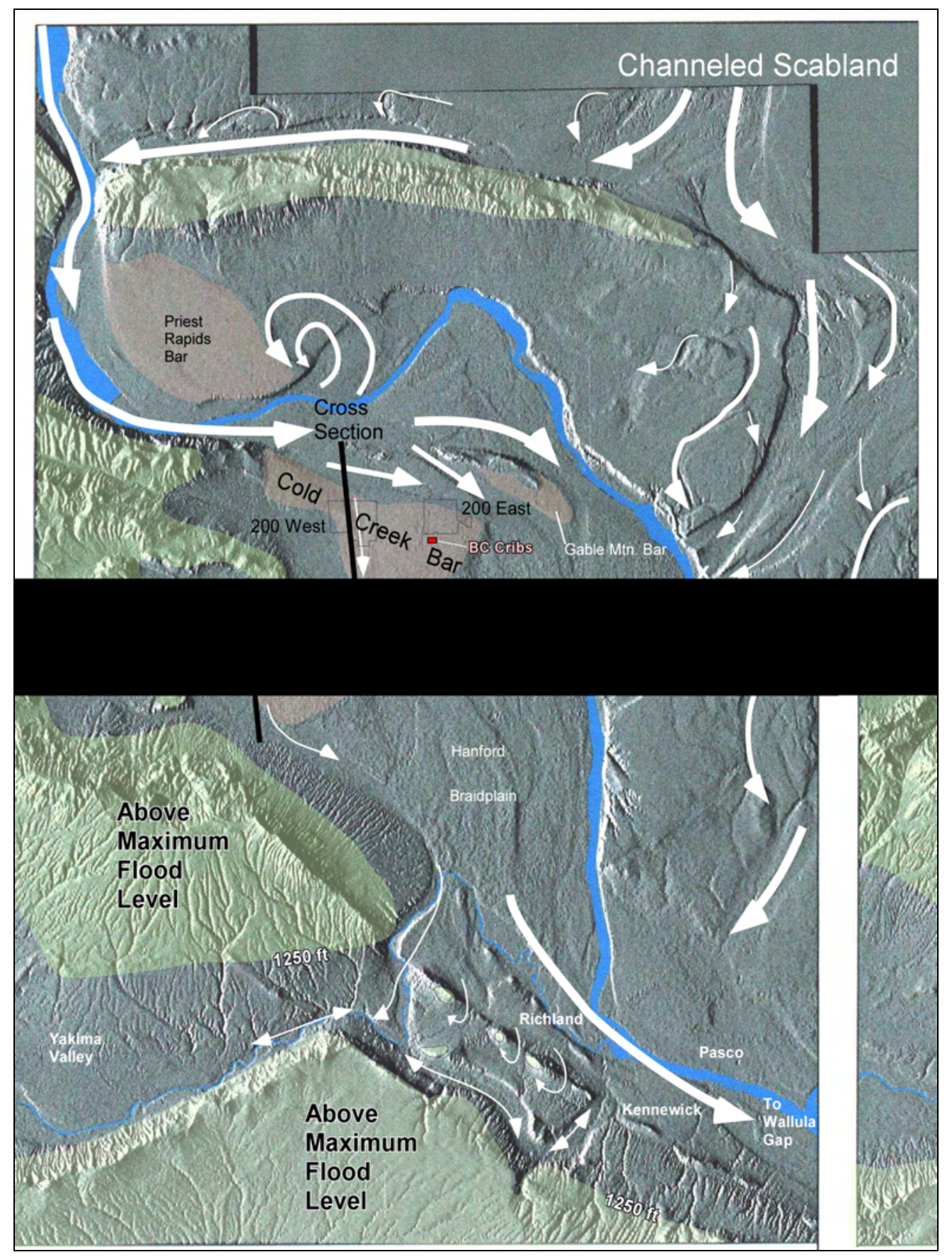

Figure 2.2. $\quad$ BC Cribs and Trenches Area in Relation to Ice Age Flood Features Within the Central Pasco Basin. The BC Cribs and Trenches Area lies atop the 12-mile-long and 300-ft-thick Cold Creek flood bar. See Figure 2.1 for a geologic profile across the bar. 
Along the northern 200 Area Plateau, two sequence of coarser, GD facies are separated by SD facies. In some studies (e.g., Reidel and Chamness 2007) the SD facies has been assigned the Hanford formation $\mathrm{H} 2$ unit, while the upper and lower GD facies are designated H1 and H3, respectively. However, along the southern margin of the 200 Area Plateau, the GD facies grade laterally into a single thick sequence of SD facies, like that at BC Cribs.

Unlike other stratigraphic units, the stratigraphy of the Hanford formation is extremely complex. This is primarily due a dynamic, constantly changing environment of deposition and erosion that took place with each Ice Age flood. With evidence for up to hundreds of separate Ice Age flood events, and the variable sedimentation that occurred during each flood, the variability is understandable. The end result is a diverse assemblage of layered, heterogeneous strata, especially within the SD and ISSD facies of the Hanford formation, which behave anisotropically with respect to movement of vadose-zone moisture and contaminants.

\subsubsection{Recent Deposits}

Recent deposits within the Pasco Basin include Holocene-age eolian deposits of sand and loess (windblown sand and silt), alluvium, and mass-wastage deposits (i.e., slopewash and talus). Other recent deposits are anthropogenic (e.g., backfill) deposits laid down on the surface over waste-management areas.

\subsubsection{Structure}

The Pasco Basin is defined by uplifted basalt ridges (Rattlesnake Mountain and Saddle Mountains) of the Yakima Fold Belt. The Yakima Fold belt is characterized by a series of segmented, narrow, asymmetric east-west trending anticlines. The northern limbs of these anticlines generally dip steeply to the north and are vertical or even overturned; thrust or high-angle reverse faults with fault planes that generally parallel fold axial trends occur on the north sides of these anticlines. The southern limbs of Yakima folds dip gently to the south. The anticlinal ridges are separated by broad synclines or basins that, in many cases, contain thick accumulations of Neogene- to Quaternary-age sediments.

Clastic dikes are vertical to subvertical sedimentary structures that crosscut normal sedimentary layering that are common to ice-age flood deposits, especially in the SD and ISSD facies of the Hanford formation (Fecht et al. 1999). Clastic dikes are much less common in the GD facies of the Hanford formation.

Where clastic dikes intersect the ground surface and are not covered with younger deposits, a feature known as patterned ground can be observed (Fecht et al. 1999). Clastic dikes occur in swarms with 4- to 8-sided polygons that range from $3 \mathrm{~cm}$ to $1 \mathrm{~m}$ in width, from $2 \mathrm{~m}$ to greater than $20 \mathrm{~m}$ in depth, and from 1.5 to $100 \mathrm{~m}$ along strike. Smaller dikelets, sills, and small-scale faults and shears are commonly associated with master dikes that form the polygons.

In general, a clastic dike has an outer skin of clay with coarser infilling material. Clay linings are commonly $0.03 \mathrm{~mm}$ to $1.0 \mathrm{~mm}$ in thickness, but linings up to about $10 \mathrm{~mm}$ are known. The width of individual infilling layers ranges from as little as $0.01 \mathrm{~mm}$ to more than $30 \mathrm{~cm}$, and their length can vary from about $0.2 \mathrm{~m}$ to more than $20 \mathrm{~m}$. Infilling sediments are typically poor- to well-sorted sand, but may contain clay, silt, and gravel. 


\subsection{Geologic Setting of the BC Cribs}

\subsubsection{Stratigraphy and Lithology}

The stratigraphy and lithology in the vicinity of the BC Cribs and Trenches is illustrated in two hydrogeologic cross sections (Figure 2.3). Cross section A-A' (Figure 2.4) is a north-south profile over a larger area, compared to cross section B-B' (Figure 2.5), an east-west profile in the immediate vicinity of the BC Cribs and Trenches. A more detailed location map for BC Cribs and Trenches and cross section B-B' is presented in Figure 2.6. Background information on the boreholes used to construct these cross sections is presented in Table 2.2.

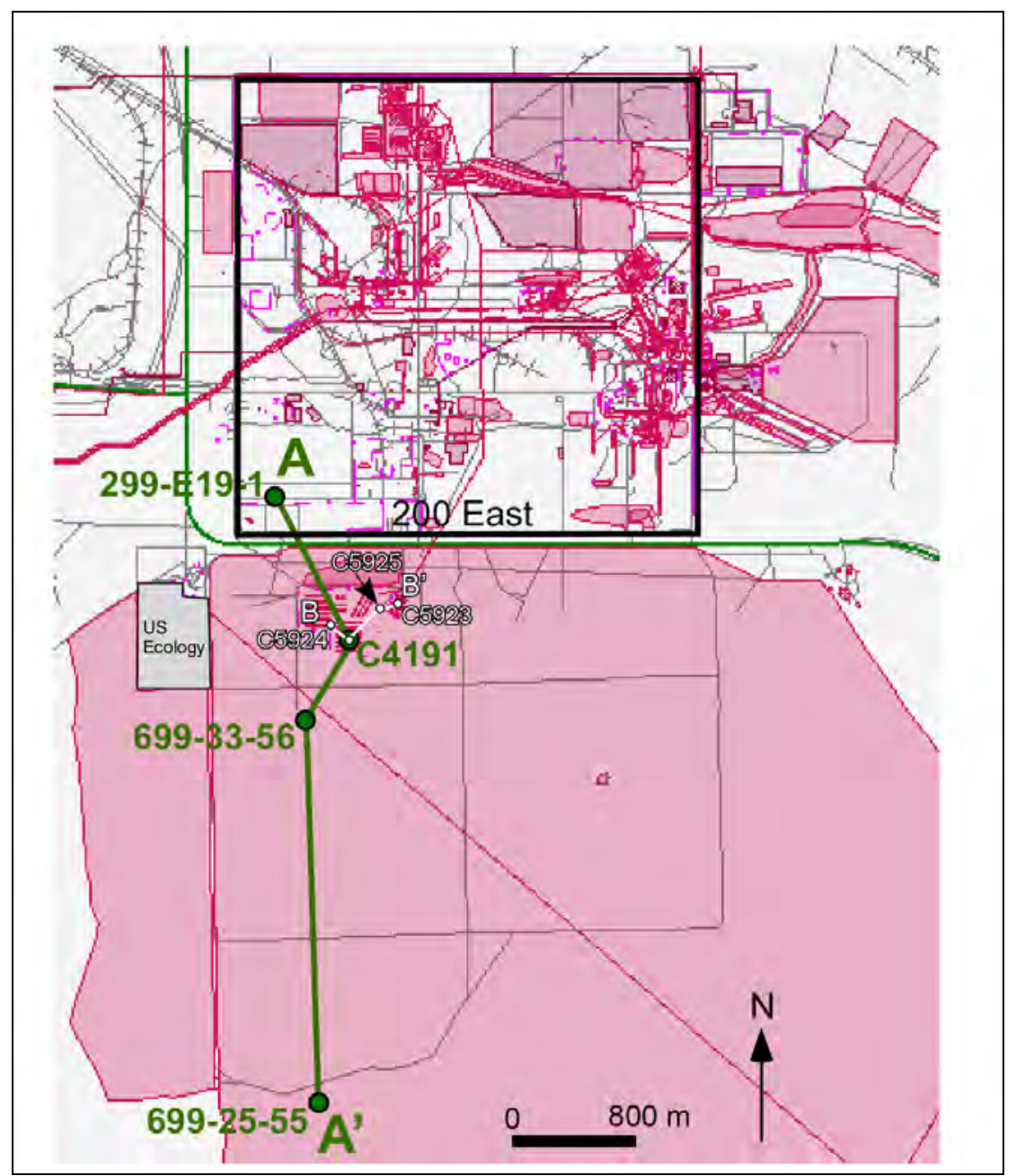

Figure 2.3. Location of Hydrogeologic Cross Sections. See Figure 2.6 for more detailed location of cross section B-B'. 


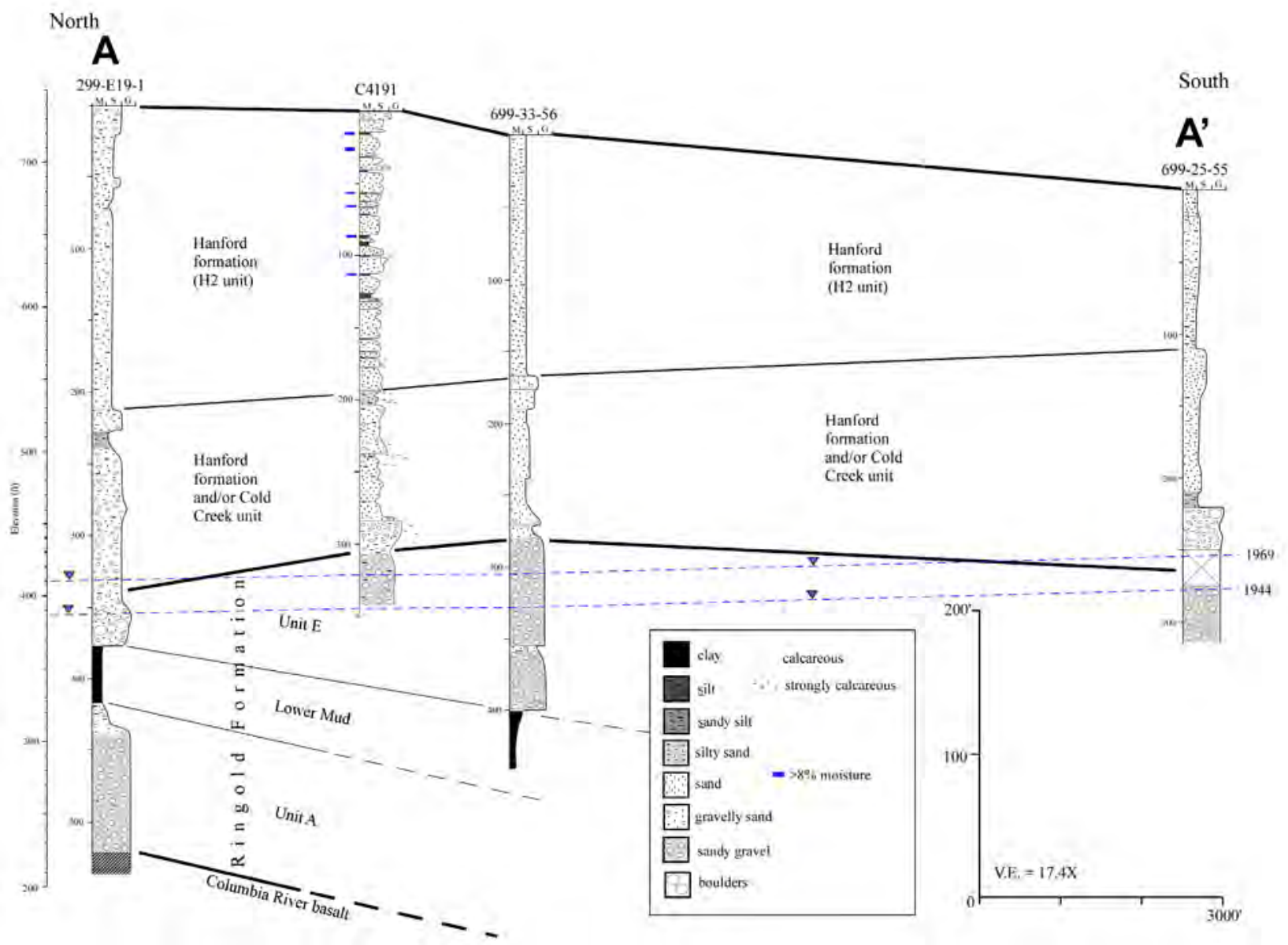

Figure 2.4. Hydrogeologic Cross Section A-A' 


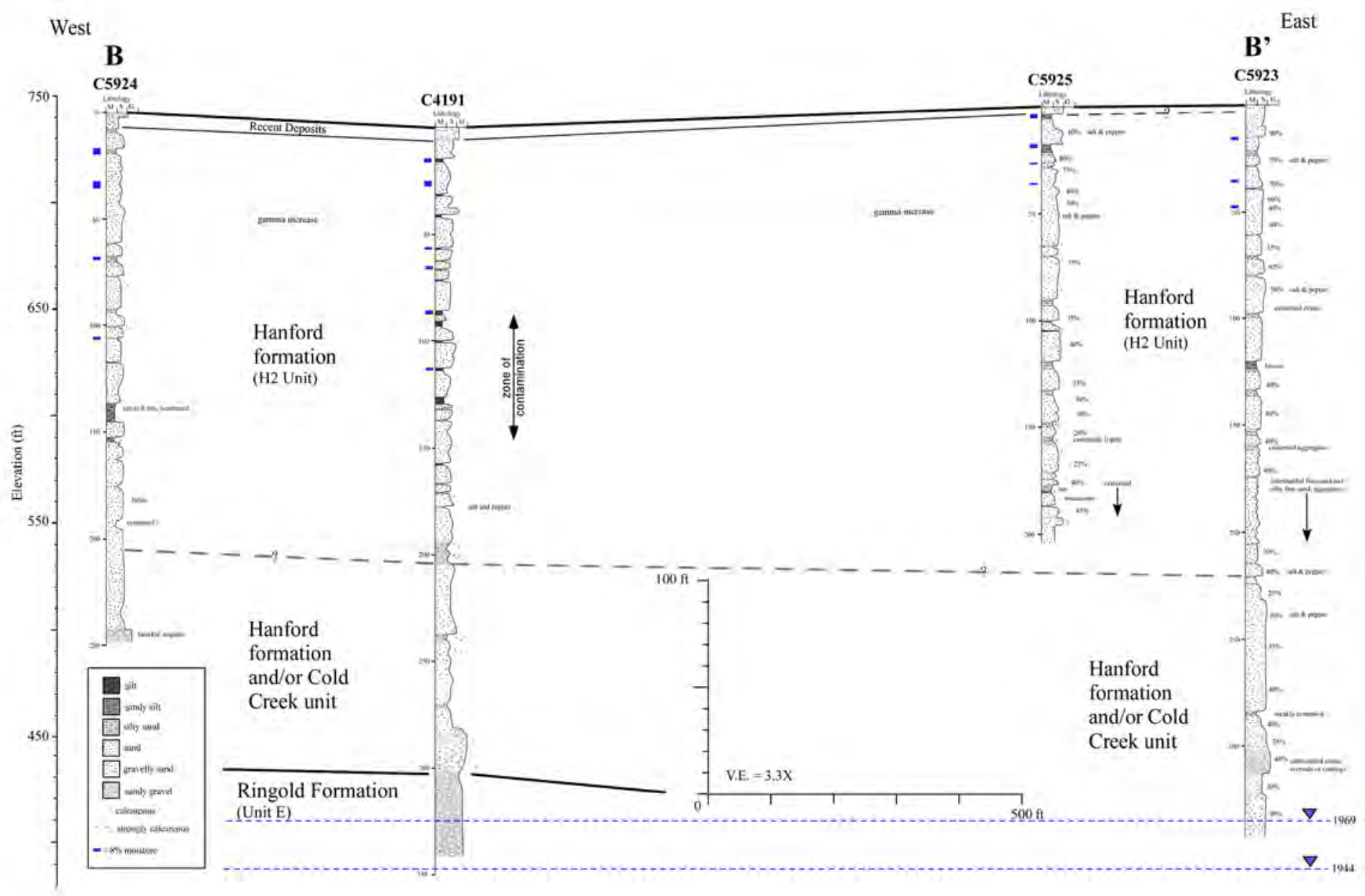

Figure 2.5. Hydrogeologic Cross Section B-B'. See Figure 2.6 for location. 


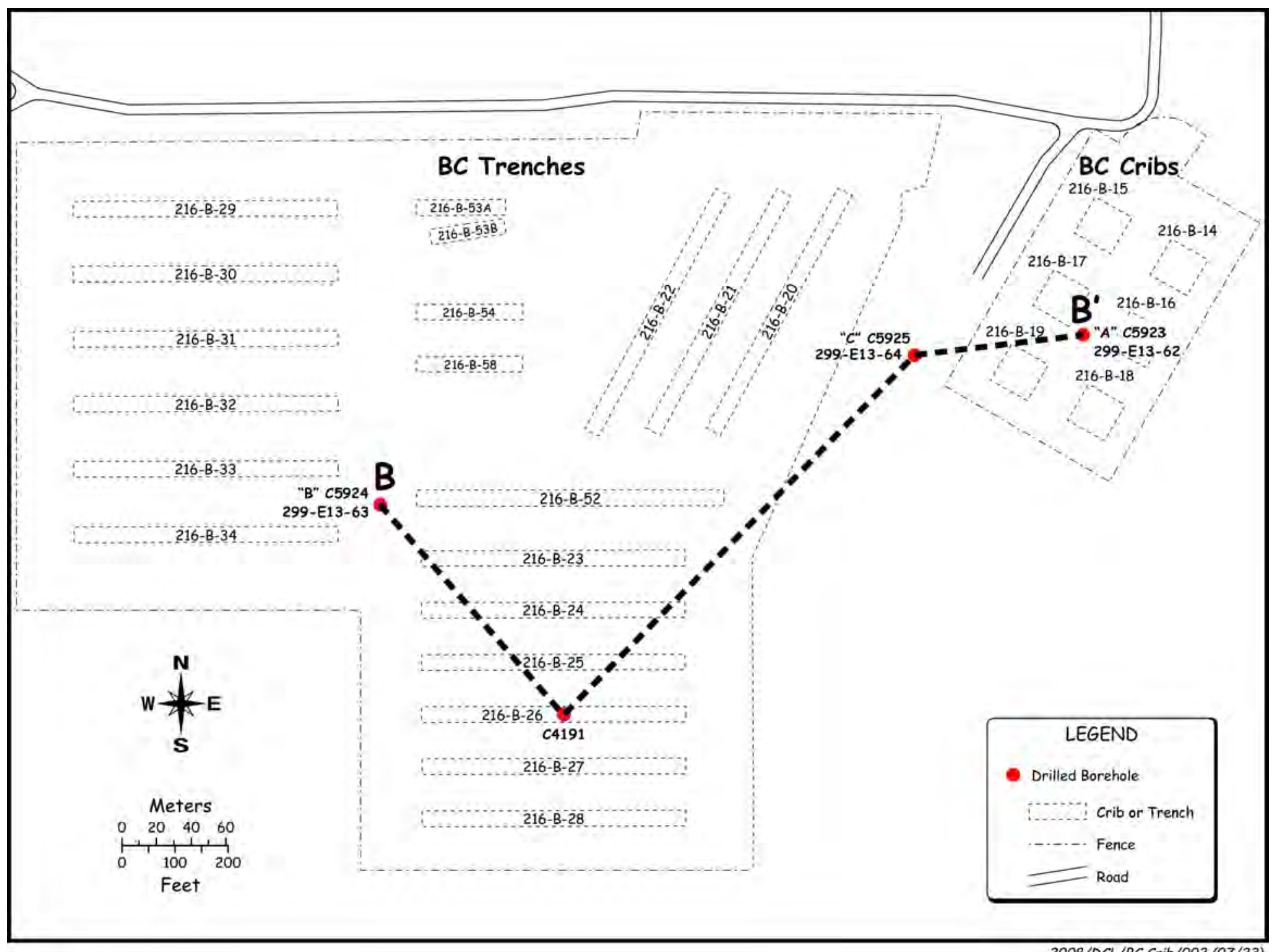

Figure 2.6. BC Cribs and Trenches Area Location Map. Heavy dashed line is location for cross section B-B' (Figure 2.5). 
PNNL-17821

Table 2.2. Boreholes in Vicinity of BC Cribs and Trenches Area Used in Hydrogeologic Cross Sections

\begin{tabular}{|c|c|c|c|c|c|c|c|c|c|}
\hline & $\begin{array}{l}\text { Borehole } \\
\text { ID }\end{array}$ & $\begin{array}{l}\text { Borehole } \\
\text { Name }\end{array}$ & $\begin{array}{l}\text { Cross } \\
\text { Section }\end{array}$ & $\begin{array}{l}\text { Drilling } \\
\text { completed }\end{array}$ & $\begin{array}{l}\text { Surface } \\
\text { Elevation }\end{array}$ & $\begin{array}{l}\text { Total } \\
\text { Depth (ft) }\end{array}$ & $\begin{array}{l}\text { Drill } \\
\text { Method }\end{array}$ & $\begin{array}{l}\text { Geophysical } \\
\text { Logs }^{(a)}\end{array}$ & Comments \\
\hline & C4191 & & A, B & $1 / 04$ & 735 & 341 & Cable tool & TG, SG, NM & $\begin{array}{l}\text { Groundwater sample taken before } \\
\text { Decommissioning; } 14 \text { split spoon samples }\end{array}$ \\
\hline$\cong$ & C5923 & 299-E13-62 & B & $7 / 08$ & 746 & 352 & Cable tool & TG, SG, NM & $\begin{array}{l}\text { Groundwater sample taken ; } 19 \text { split-spoon cores } \\
\text { that yielded } 39 \text { “intact” liner samples }\end{array}$ \\
\hline 3 & C5924 & 299-E13-63 & B & $2 / 08$ & 742 & 248 & Cable tool & TG, SG, NM & \\
\hline 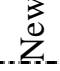 & C5925 & 299-E13-64 & B & $3 / 08$ & 744.5 & 203.5 & Cable tool & TG, SG, NM & \\
\hline$\frac{n}{\bar{z}}$ & A5889 & 299-E19-1 & A & $12 / 57$ & 739 & $368 / 536$ & $\begin{array}{l}\text { Cable tool/ } \\
\text { diamond } \\
\text { rotary core }\end{array}$ & & Core from 368-536 ft in 1977 \\
\hline 3 & A5133 & $699-33-56$ & A & $10 / 58$ & 720 & 440 & Cable tool & & \\
\hline$\frac{\tilde{0}}{0}$ & A5098 & $699-25-55$ & A & $7 / 48$ & 680 & 315 & Cable tool & & \\
\hline
\end{tabular}


The strata beneath the BC Cribs and Trenches Area are divided into five units: 1) Recent deposits, 2) Hanford formation, 3) Hanford formation/Cold Creek unit (undifferentiated), 4) Ringold formation, and 5) Columbia River basalt. The following is a description of these strata, from oldest to youngest.

\subsubsection{Columbia River Basalt Group}

Bedrock beneath the BC Cribs and Trenches area consists of black, volcanic rock belonging to the Miocene-age Columbia River Basalt Group. The youngest basalt flow beneath the BC Cribs and Trenches area belongs to the Elephant Mountain Member, dated at 10.5 million years before present. None of the new borings were drilled deep enough to reach basalt; however, the depth and attitude of the basalt is generally known from deep wells drilled to the north within the 200 East Area (see cross section A-A' in Figure 2.4).

\subsubsection{Ringold Formation}

Only one of the four new boreholes (C4191) at the BC Cribs and Trenches area penetrated deep enough to intersect the Ringold Formation. Older, nearby boreholes (Figure 2.4), on the other hand, penetrate deeper into the Ringold Formation. These wells show that the top of basalt and the Ringold Formation dip southward toward the axis of the Cold Creek Syncline. Beneath the BC Cribs and Trenches, two sequences of fluvial Ringold Formation gravel (Unit A and Unit E) are separated by a thick sequence of fluvial-lacustrine silt and clay, known as the Ringold Formation lower mud unit (Lindsey 1995).

Within the BC Trenches, only one of the boreholes (C4191) encountered the Ringold Formation (i.e., sandy gravel facies of the Ringold Formation [Unit E]) at a depth of about $300 \mathrm{ft}$ bgs. One of the grab samples from this unit is shown in Figure 2.7. 


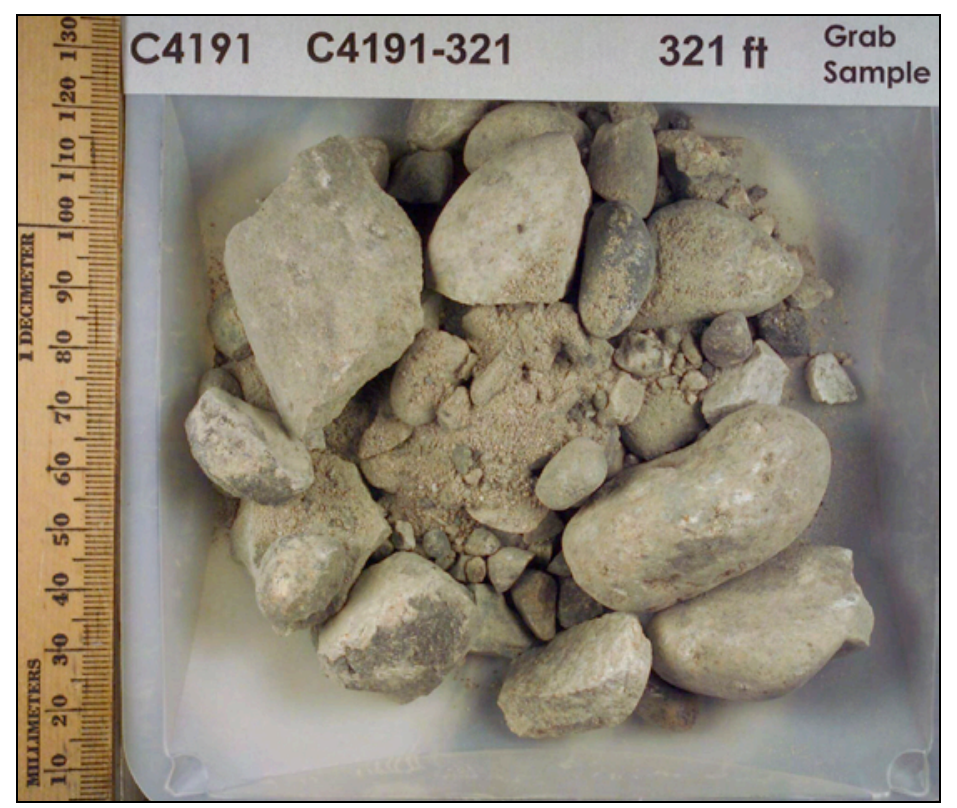

Figure 2.7. Silty Sandy Gravel of the Ringold Formation Unit E in borehole C4191, $321 \mathrm{ft}$ Depth. The combination of unbroken clasts that are well rounded and have low basalt content, overall brown color, and cementation characterize this sediment as Ringold Formation.

Characteristics used to identify the Ringold Formation Unit E are 1) bimodal pebble-cobble gravel in a well-sorted fine- to medium-grained sand matrix, 2) well rounded and polished gravel clasts,

3) weathering rinds and clay skins around gravel clasts, 4) quartzo-feldspathic matrix with normally $<20 \%$ mafic grains, 5) pervasive, rusty orange stain on sand and gravel, and 6) slight-to-moderate consolidation or cementation. Sand grains in fluvial facies of the Ringold Formation are predominantly quartz and feldspar, derived from erosion of older, silicic and felsic basement rocks around the perimeter of the Columbia Plateau.

\subsubsection{Hanford Formation/Cold Creek Unit (Undifferentiated)}

Above the sandy gravel facies of Ringold Formation Unit $\mathrm{E}$ is a sedimentary sequence, up to $33 \mathrm{~m}$ $(100 \mathrm{ft})$ thick, of sand to gravelly sand with occasional layers of fine-grained silty sand. The basalt (i.e., mafic) content of the sand fraction is generally 20 to 40 volume $\%$, which is typically greater than that observed in the Ringold Formation, but less than typical for the Hanford formation. Furthermore, these deposits are overall less weathered and generally lack the pervasive iron-stained coatings, weathering rinds, and clay skins that are typical of the Ringold Formation. There are some calcic zones, especially in C4191, which are atypical of the Ringold Formation. In summary, this sequence is distinctly different from the underlying Ringold Formation and lacks regular graded bedding, which is characteristic of the overlying Hanford formation. Therefore, the coarser gravelly strata are believed to be all or part of the mainstream alluvial facies of the Cold Creek unit (CCUc[mL]), formerly referred to as pre-Missoula gravels (Table 2.2).

The upper portion of this sequence may be all or in part equivalent to a coarser-grained facies of the Hanford formation, deposited early in the history of Ice Age flooding before the Cold Creek flood bar had grown appreciably (Figure 2.8). With the information available, it is unclear where the CCU alluvium 
ends and the Ice Age flood deposits of the Hanford formation begin. Thus this sequence, for the time being, is referred to as Hanford formation/CCU (undifferentiated). A higher basalt content, subrounded

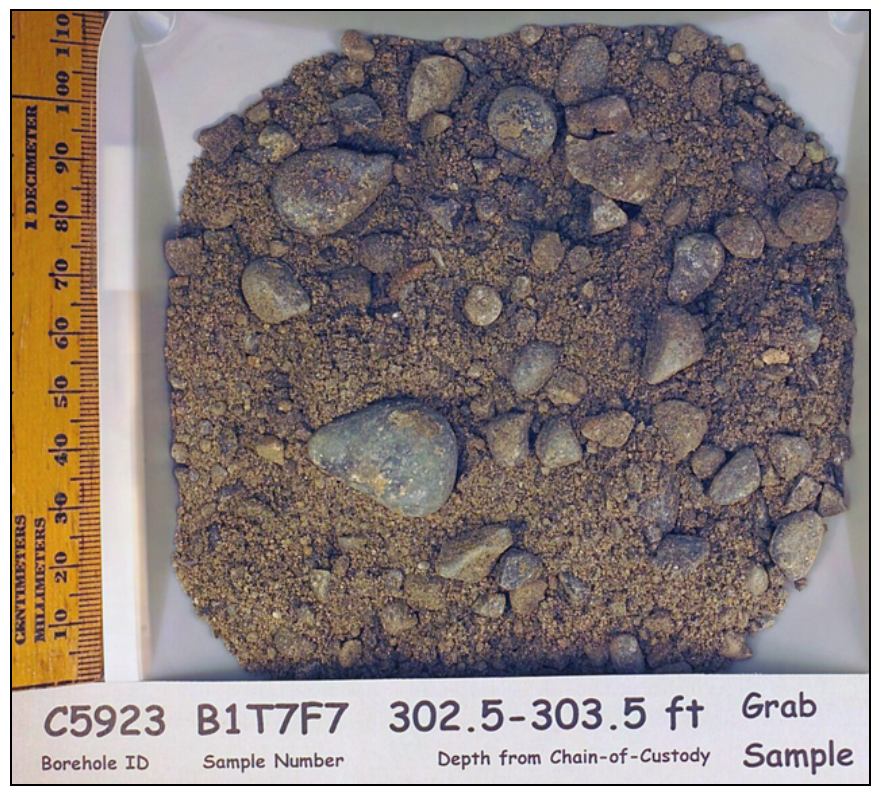

Figure 2.8. Gravelly Sand of the Hanford Formation/Cold Creek Unit (Undifferentiated) Sequence from Borehole C5923, 303 ft Depth

to subangular gravel clasts and less weathering, indicates that these sediments are younger and separate from the Ringold Formation (Figure 2.9).

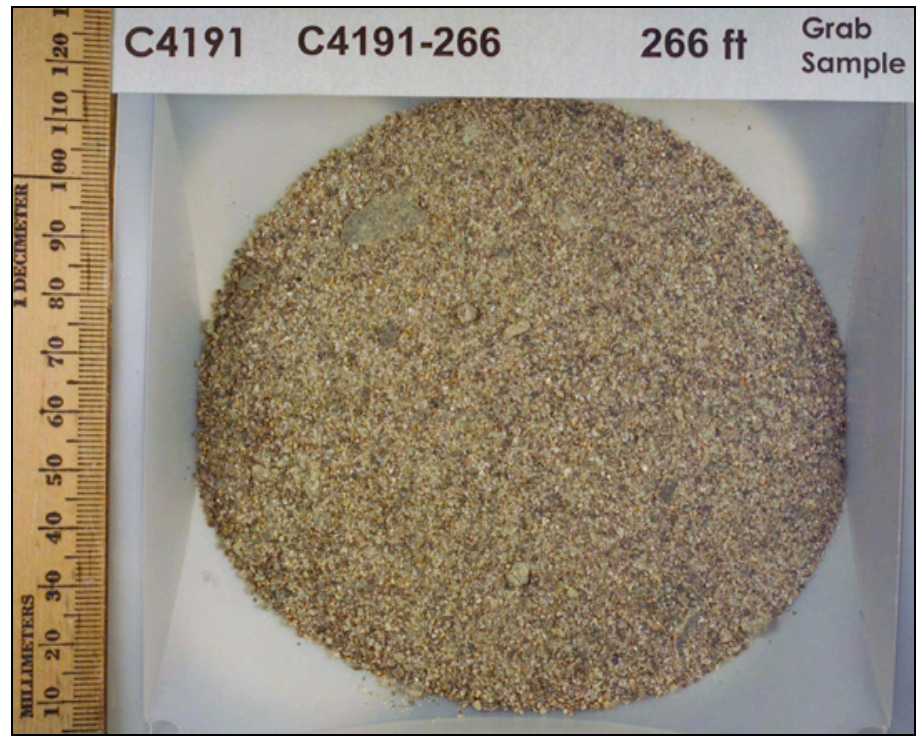

Figure 2.9. Moderately Sorted, Medium- to Coarse-Grained Sand of the Hanford Formation/CCU (Undifferentiated) from Borehole C4191, $266 \mathrm{ft}$ Depth. The moderate number of basalt grains ( 20 volume \%) in this sample distinguishes this from almost pure, light-colored quartzo-feldspathic sand of the Ringold Formation and the more-concentrated basaltic sand of the Hanford formation. 


\subsubsection{Hanford Formation}

Several excavations exposing the Hanford formation are located near the BC Cribs and Trenches (Figure 2.10). These include Hanford's Integrated Disposal Facility (IDF) to the northeast, the U.S. Ecology disposal trenches (Smith 1993) immediately to the west, and the Environmental Restoration Disposal Facility (ERDF) farther to the west. These excavations have produced excellent exposures for evaluating the stratigraphy of the uppermost $50 \mathrm{ft}$ of the Hanford formation. Since these sites all lie near the same elevation along the Cold Creek flood bar (Figure 2.2) and within a similar depositional environment with respect to the Ice Age floods, they should be very similar to the sediments deposited in the uppermost $50 \mathrm{ft}$ at the BC Cribs and Trenches area.

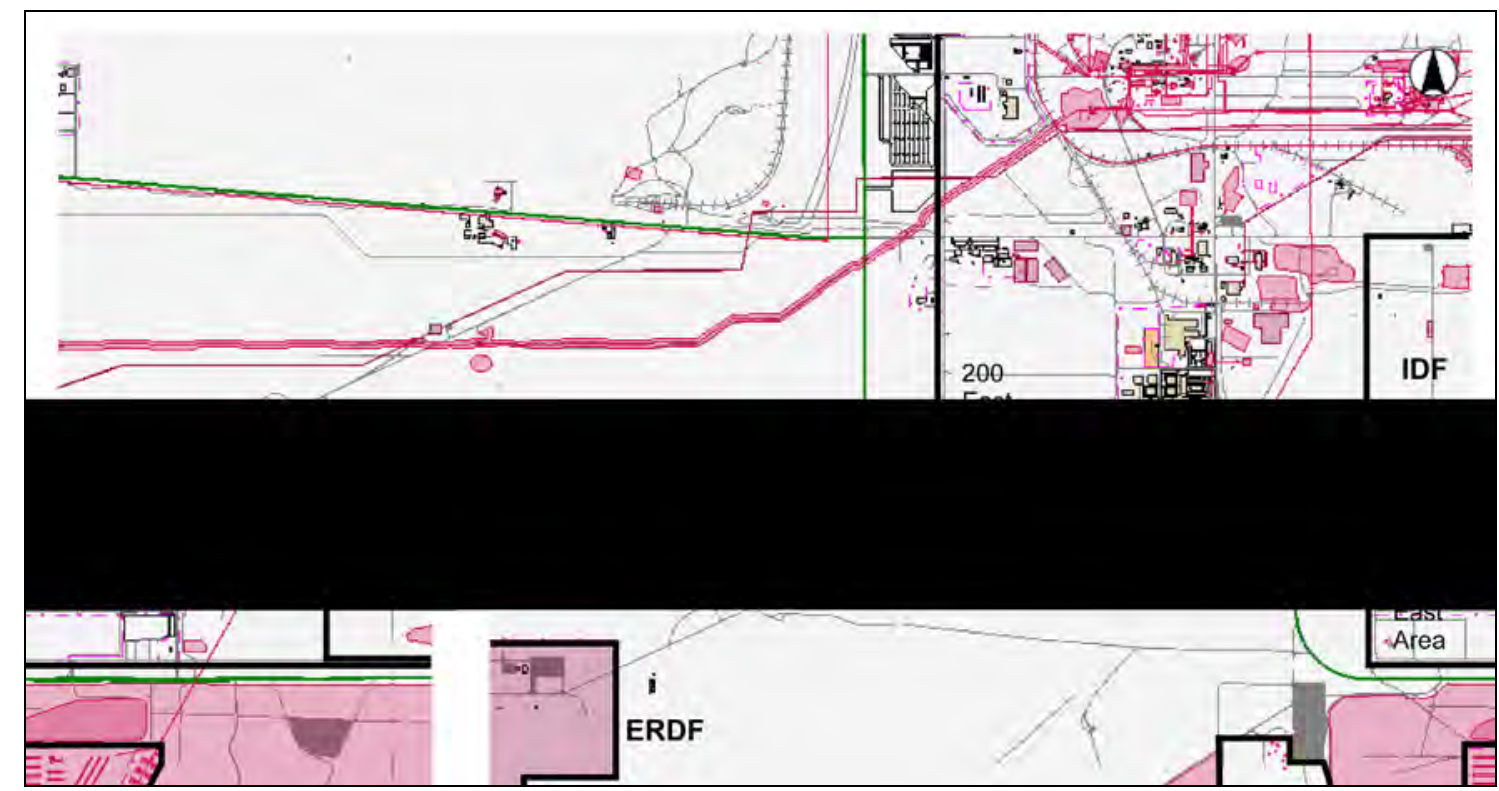

Figure 2.10. Nearby Excavations and Analog Sites for the Hanford Formation Near the BC Cribs and Trenches. ERDF = Environmental Restoration Disposal Facility, IDF = Integrated Disposal Facility

A thick sand-dominated sequence of the Hanford formation (H2 unit), dominates the vadose zone beneath the BC Cribs and Trenches area. Internally, this sequence appears to contain multiple beds of fine- to coarse-grained sand up to several meters thick. Typically, sand-dominated facies average about 50\% mafic (i.e., basalt) and 50\% quartz-feldspar (Tallman et al. 1979). The coarser sands typically have a higher basalt content and are commonly referred to as "salt-and-pepper" sands and are generally shades of gray. This is a direct result of the coarser units being derived from the extensive erosion of the Columbia River basalt, which underlies the Channeled Scabland, by the Ice Age floods. Sand-dominated deposits of the Hanford formation typically display horizontal-to-ripple laminations in outcrops (Figure 2.11). Normal and reverse grading between different sand sizes is common, adding to the heterogeneity and anisotropy of this facies type. Reverse grading is common between strata in the SD facies and may represent pulsations or surges during flooding.

The thick beds of sand may grade back and forth between coarse sand to fine sand multiple times before finally grading up into a silty fine sand to silt textured cap (Figure 2.12 and Figure 2.11). The finer-grained layers typically contain a higher proportion of quartz, feldspar, and mica, resulting in a more brown color (Figure 2.11). Finer-grained materials present in the Hanford formation H2 unit produce 
higher moisture retention (10 to $15 \mathrm{wt} \%$ ) due to naturally higher capillary forces present in these types of sediments. Fine-grained flood deposits, however, are derived principally from reworked quartzofeldspathic deposits of Palouse loess, and/or other older fluvial or glaciofluvial deposits eroded along the flood path. During flooding, these finer-grained materials remained suspended within the floodwaters, some of which settled out of suspension in slack-water environments during the waning stages of flooding.

The texture and thickness of graded beds in the area appear to decrease upward within the Hanford formation $\mathrm{H} 2$ unit. This is apparent in cross section B-B' (Figure 2.5) and clearly visible at the U.S. Ecology excavation (Figure 2.13). The overall fining and thinning of beds is probably related to Ice Age floods that became progressively smaller at the end of the Ice Age (Waitt 1980). This is significant to moisture and contaminant migration since there is an increased likelihood for lateral spreading in the upper Hanford formation $\mathrm{H} 2$ unit. This is due to a higher frequency of fine-grained, silty, slack-water beds in the upper part of the Hanford formation. Flood beds that are thicker and coarser downsection have proportionately less fine-grained beds to cause lateral spreading.

In continuous outcrops, such as that exposed at U.S. Ecology (Figure 2.13), fine-grained facies appear to be laterally continuous and can be traced laterally for hundreds of feet. However, using borehole information, it is difficult to correlate individual beds with confidence from one borehole to another. One exception at the BC Cribs and Trenches area is a relatively thick (up to $15 \mathrm{ft}$ ) of fine silty sand to sandy silt, which lies at a depth of 120 to $130 \mathrm{ft}$ bgs (Figure 2.5) and may be correlative across the site. This thick fine-grained layer lies within the zone of elevated ${ }^{99}$ Tc and electrical conductivity observed in borehole C4191. Another correlative boundary within the Hanford formation is a sudden increase in TG activity at 40 to $50 \mathrm{ft}$. There is no evidence for a distinct lithologic boundary at this depth, but it may conform to a mineralogical change from more to less basaltic sand starting at this depth.

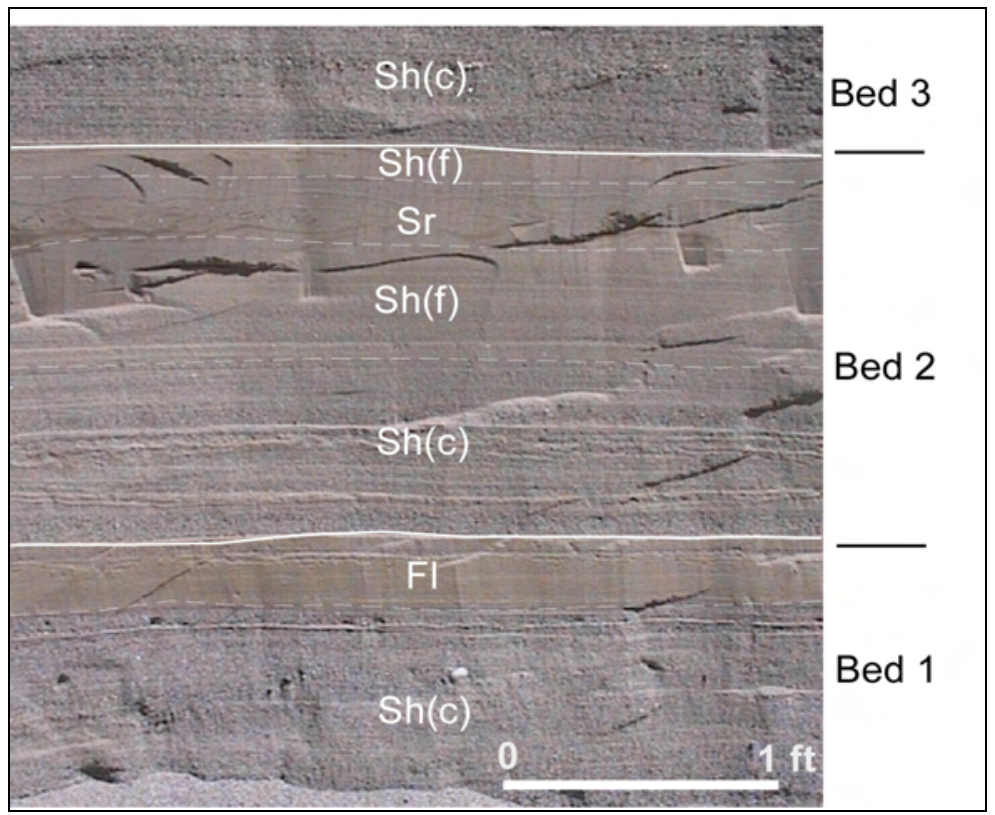

Figure 2.11. Close-up of Heterogeneous, Anisotropic Sedimentary Strata Typical of the Hanford Formation H2 Unit at $~ 50 \mathrm{ft}$ Depth in the ERDF Excavation 
Each of the three graded beds may represent as many separate Ice-Age flood events: Sh(c) = horizontally laminated medium to coarse sand deposited during initial flood pulse followed by, $\mathrm{Sh}(\mathrm{f})=$ horizontally laminated fine to medium sand, $\mathrm{Sr}$ = ripple-laminated fine sand, and/or finally $\mathrm{Fl}$ = laminated fine sand to silt, laid down during final slackwater phase of flooding. Vadosezone moisture tends to concentrate along interfaces between strongly contrasting beds or within finergrained strata, which have an affinity for moisture that may spread laterally.

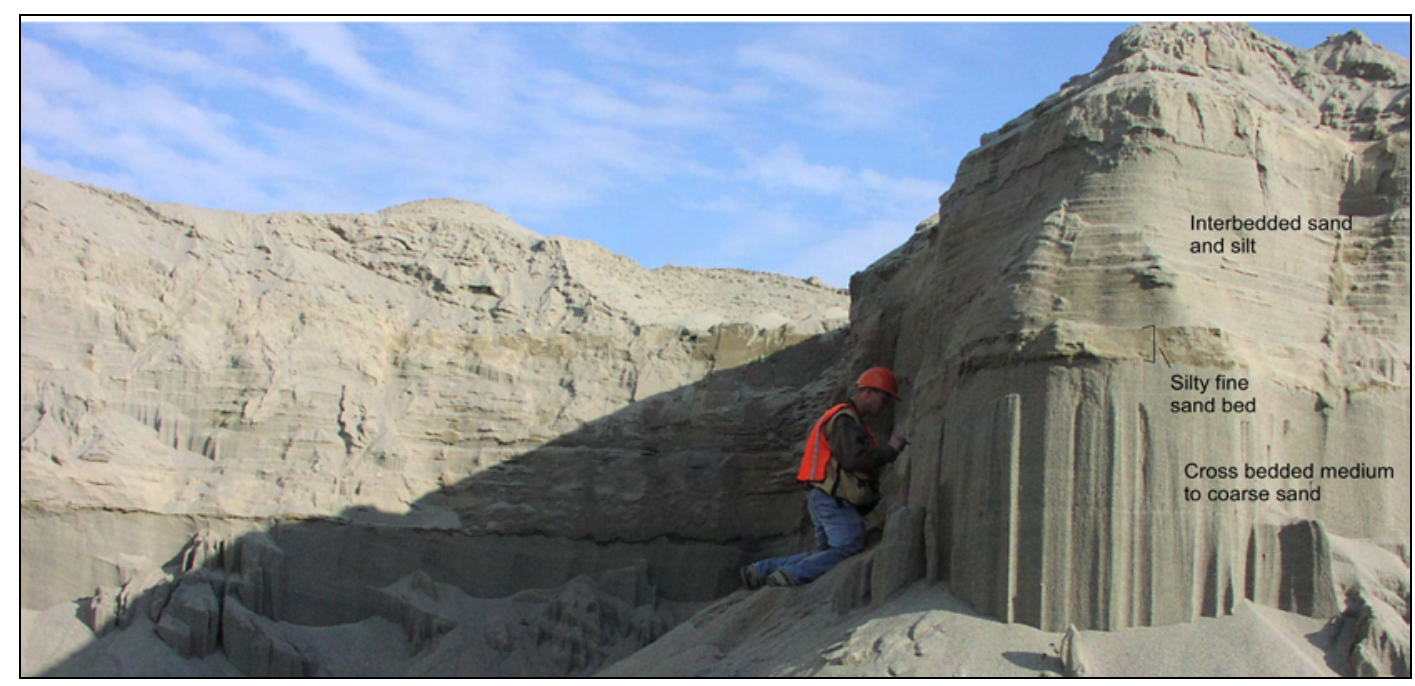

Figure 2.12. Hanford Formation H2 Unit Exposed in the IDF Excavation. Several feet of uniform medium- to coarse-grained sand are capped by a thin bed of slackwater silty fine sand. Above the worker's head are multiple layers of complexly interstratifed sandy and silty beds. These deposits are from about 30 to $40 \mathrm{ft}$ depth in the excavation.

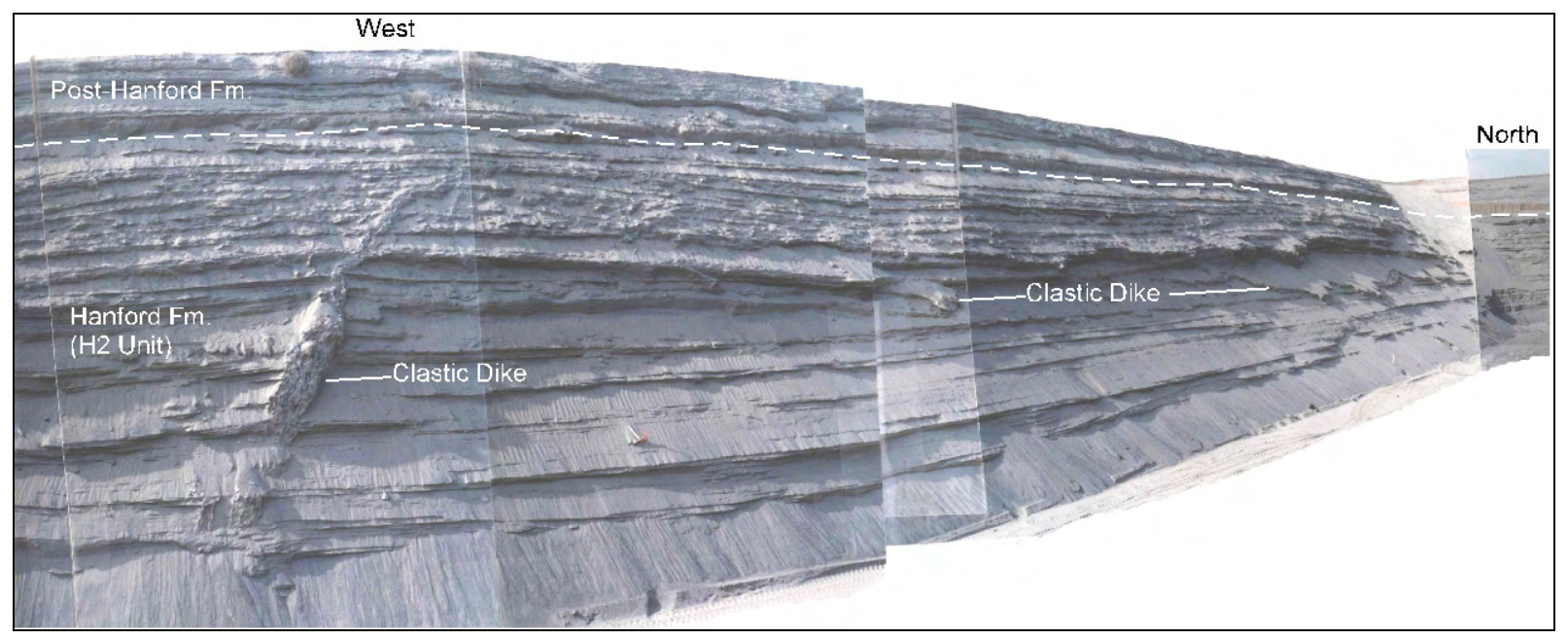

Figure 2.13. U.S. Ecology Excavation, Located Just West of BC Trenches and Cribs. Excavation is about $50 \mathrm{ft}$ deep. Note lateral continuity of finer-grained beds, which are more cohesive and thus stand out with more relief along bluff face. Note that the overall thickness of the rhythmic, graded beds decreases upsection. Discordant clastic dikes cut across the bedding. 
Examples of grab samples collected during drilling of the Hanford formation at BC Cribs and Trenches are shown in the photographs below. Figure 2.14 is from a bed of coarse sand especially concentrated in basalt rock fragments ( 90\%). This highly basaltic layer, located $\sim 12 \mathrm{ft}$ bgs, may correlate with a near-surface layer of highly basaltic sand reported at the IDF excavation (Qb layer of Reidel and Fecht 2005).

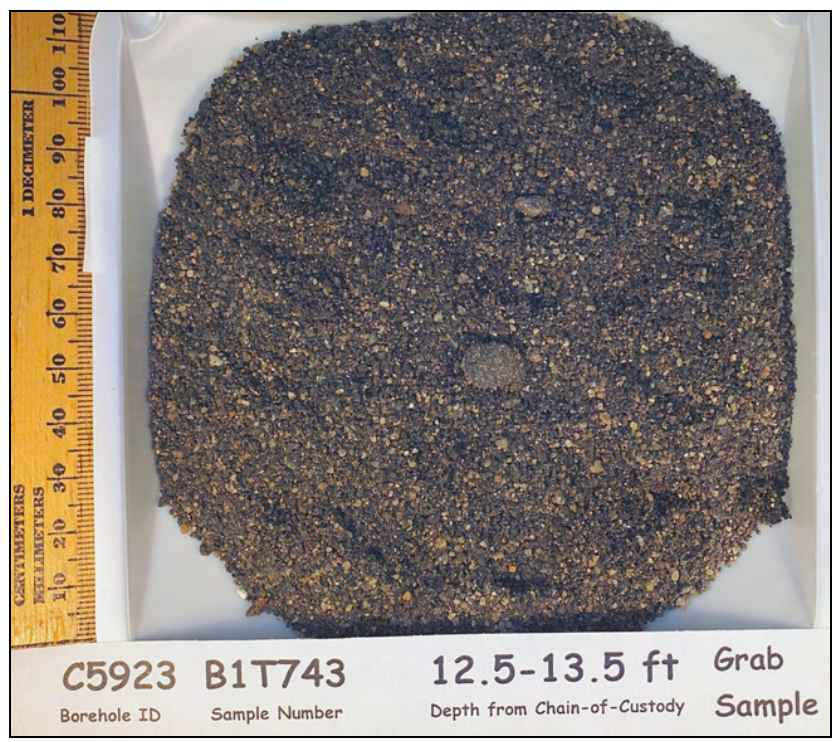

Figure 2.14. Hanford Formation (H2 Unit) from Borehole C5923, $13 \mathrm{ft}$ Depth

This sample consists of predominantly coarse-grained sand, composed of up to $90 \%$ basalt rock fragments.

Figure 2.15 shows a loose, poorly sorted, gravelly, fine-to-coarse-grained sand. About 40 to $50 \%$ of sand grains are basalt rock fragments, more typical of the Hanford formation than that represented in Figure 2.14. 


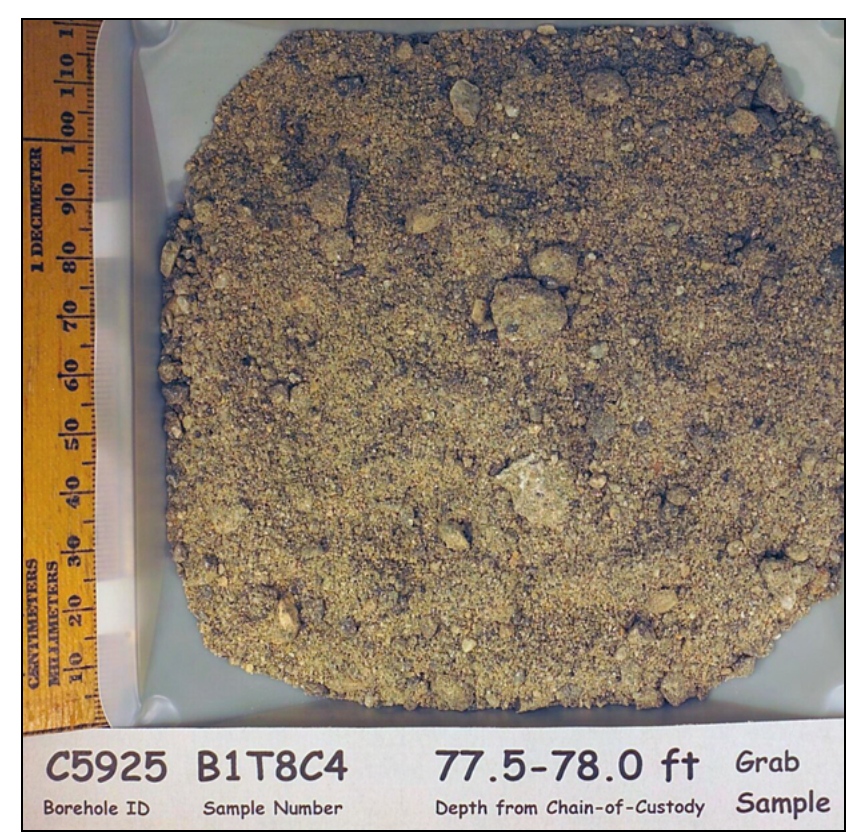

Figure 2.15. Gravelly, Basaltic Sand from the Hanford Formation (H2 Unit) in Borehole C5925, $78 \mathrm{ft}$ Depth

Figure 2.16 shows a poorly sorted, sandy mixture of sand with abundant silty aggregates. Silty sediment is more compact and cohesive and therefore does not totally disaggregate during the process of drilling and sampling. Apparently during the drilling of this sample, multiple beds were sampled, including a layer of loose sand, along with a more cohesive silty bed resulting in the mixture of different sediment types.

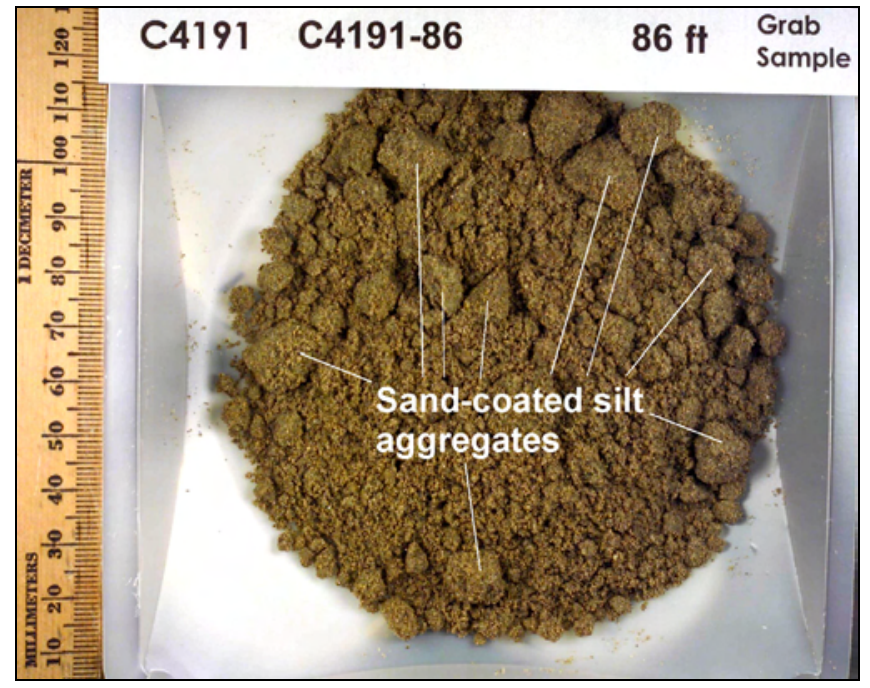

Figure 2.16. Hanford Formation (H2 Unit) from Borehole C4191, $86 \mathrm{ft}$ Depth. This grab sample is a mixture of sand and finer-grained aggregates derived from drilling into a silty interbed.

Figure 2.17 shows characteristic loose, moderately sorted, "salt and pepper" sands, which are the dominant lithofacies beneath the BC Cribs and Trenches area. 


\subsubsection{Recent Deposits}

A few feet of anthropogenic backfill, composed of a mixture of sand and gravel, often blankets the surface of the BC Cribs and Trenches area.

\subsection{Summary of Recent Characterization Activities at BC Cribs and Trenches Area}

Hydrogeologic characterization of the four new boreholes at the BC Cribs and Trenches area (Figure 2.6) included the drilling of over 1,100 ft of hole via the cable-tool drill method. These holes were geologically logged in the field and also logged via down-hole spectral gamma (SG) and neutronmoisture geophysical tools. During drilling, over 480 grab sediment samples were collected in air-tight containers and transported to PNNL's Environmental Sciences Laboratory (ESL) for laboratory analysis. In the laboratory, subsamples were collected for moisture content immediately upon opening the grab samples, and high-resolution, color photographs were obtained of each sample (Appendix B). Next, standard descriptions of grain size, sorting, color, consolidation, visible moisture, mineralogy, and reaction with hydrochloric acid were entered onto geologic logs (Appendix A). Cores were archived in refrigerators until analyses of grab samples were available to guide further laboratory characterization of physical, hydraulic, and chemical properties. A listing of all the samples collected for each of the four holes is presented below.

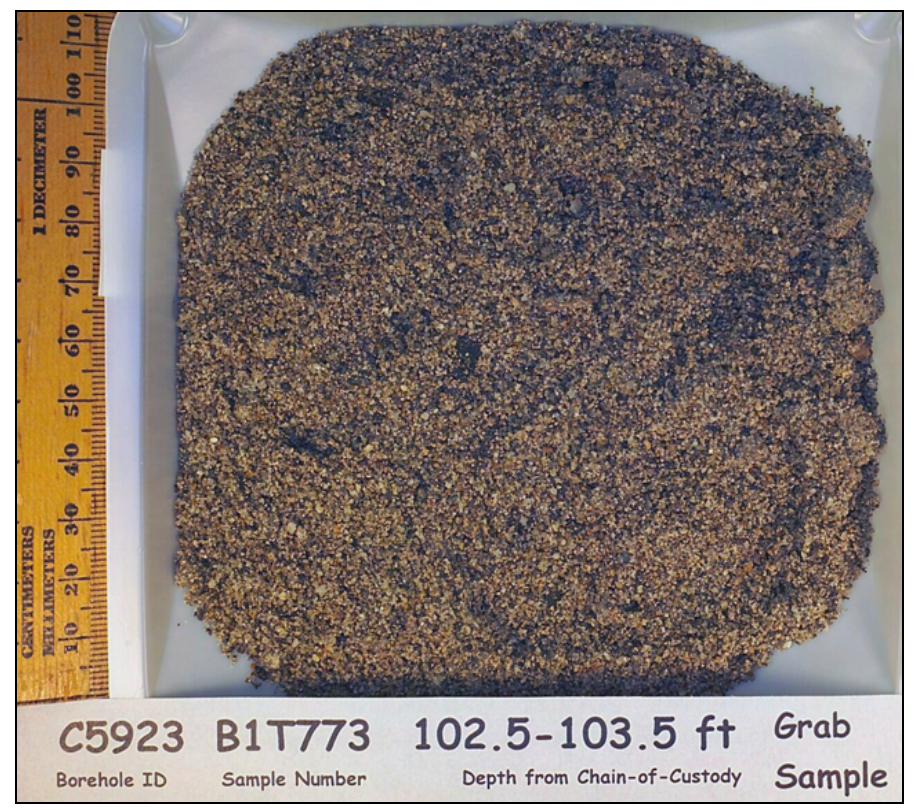

Figure 2.17. Hanford Formation (H2 Unit) from Borehole C5923, 103 ft Depth

Note medium- to coarse-grained, salt-and-pepper sand, composed of about equal amounts of dark basalt rock fragments vs. light-colored quartz, feldspar, and mica.

The composite summary logs (Figure 2.18 to Figure 2.21), compiled from all available field and laboratory data, are also presented for each borehole. The sediment sampling frequency and efforts to examine and describe the sediments from these four boreholes greatly improved the data set for the BC Cribs and Trenches area. Before these four boreholes were drilled, very little detailed information was 
available of the local stratigraphy. These logs show there is a good correlation between fine-grained, silty, slack-water beds and moisture measured both in neutron-moisture geophysical logs and moisture measured in the laboratory on the grab samples. The composite logs also show relatively large volumes of sand-dominated sediment vs. finer-grained silty beds. Even though slack-water beds make up a relatively small volume of the total Hanford formation sequence, they appear to have a large impact on the distribution and lateral movement of moisture within the vadose zone.

\subsubsection{Borehole C4191}

Drilling grab samples collected for physical and chemical characterization from borehole C4191 are listed in Table 2.3.

A summary hydrogeologic log, which shows an integration of all the geologic, geophysical, and moisture data collected for borehole C4191, is presented in Figure 2.18. 
Table 2.3. Grab Samples Collected, Described, and Photographed from Borehole C4191

\begin{tabular}{|c|c|c|c|c|}
\hline Type & Lab \# & Depth & Lithology & Stratigraphic Unit \\
\hline Grab & C4191-13 & 13 & md-crs sand & Hanford fm (H2 unit) \\
\hline Grab & C4191-17.5 & 17.5 & silty fn-crs sand & Hanford fm (H2 unit) \\
\hline Grab & C4191-22.5 & 22.5 & silty fn-crs sand & Hanford fm (H2 unit) \\
\hline Grab & C4191-27.5 & 27.5 & fn sand & Hanford fm (H2 unit) \\
\hline Grab & C4191-37.5 & 37.5 & sl pebbly md-crs sand & Hanford fm (H2 unit) \\
\hline Grab & C4191-41 & 41 & silty fn sand & Hanford fm (H2 unit) \\
\hline Grab & C4191-43.5 & 43.5 & md-crs sand & Hanford fm (H2 unit) \\
\hline Grab & C4191-46 & 46 & md-crs sand & Hanford fm (H2 unit) \\
\hline Grab & C4191-48.5 & 48.5 & md sand & Hanford fm (H2 unit) \\
\hline Grab & C4191-51 & 51 & md sand & Hanford fm (H2 unit) \\
\hline Grab & C4191-53.5 & 53.5 & md-crs sand & Hanford fm (H2 unit) \\
\hline Grab & C4191-56 & 56 & md-crs sand & Hanford fm (H2 unit) \\
\hline Grab & C4191-58.5 & 58.5 & md-crs sand & Hanford fm (H2 unit) \\
\hline Grab & C4191-61 & 61 & fn-md sand & Hanford fm (H2 unit) \\
\hline Grab & C4191-63.5 & 63.5 & fn-crs sand & Hanford fm (H2 unit) \\
\hline Grab & C4191-66 & 66 & md-crs sand & Hanford fm (H2 unit) \\
\hline Grab & C4191-68.5 & 68.5 & fn-md sand & Hanford fm (H2 unit) \\
\hline Grab & C4191-71 & 71 & fn-md sand & Hanford fm (H2 unit) \\
\hline Grab & C4191-73.5 & 73.5 & md-crs sand & Hanford fm (H2 unit) \\
\hline Grab & C4191-76 & 76 & md-crs sand & Hanford fm (H2 unit) \\
\hline Grab & C4191-78.5 & 78.5 & md-crs sand & Hanford fm (H2 unit) \\
\hline Grab & C4191-81 & 81 & fn-md sand & Hanford fm (H2 unit) \\
\hline Grab & C4191-83.5 & 83.5 & md sand & Hanford fm (H2 unit) \\
\hline Grab & C4191-86 & 86 & silty fn-md sand & Hanford fm (H2 unit) \\
\hline Grab & C4191-88.5 & 88.5 & fn-md sand & Hanford fm (H2 unit) \\
\hline Grab & C4191-91 & 91 & silty fn-md sand & Hanford fm (H2 unit) \\
\hline Grab & C4191-93.5 & 93.5 & fn-md sand & Hanford fm (H2 unit) \\
\hline Grab & C4191-96 & 96 & md-crs sand & Hanford fm (H2 unit) \\
\hline Grab & C4191-98.5 & 98.5 & md-crs sand & Hanford fm (H2 unit) \\
\hline Grab & C4191-101 & 101 & md-crs sand & Hanford fm (H2 unit) \\
\hline Grab & C4191-103.5 & 103.5 & md sand & Hanford fm (H2 unit) \\
\hline Grab & C4191-106 & 106 & md-crs sand & Hanford fm (H2 unit) \\
\hline Grab & C4191-108.5 & 108.5 & md-crs sand & Hanford fm (H2 unit) \\
\hline Grab & C4191-111 & 111 & md sand & Hanford fm (H2 unit) \\
\hline Grab & C4191-113.5 & 113.5 & fn-md sand & Hanford fm (H2 unit) \\
\hline Grab & C4191-116 & 116 & md-crs sand & Hanford fm (H2 unit) \\
\hline Grab & C4191-118.5 & 118.5 & md-crs sand & Hanford fm (H2 unit) \\
\hline Grab & C4191-121 & 121 & fn-md sand & Hanford fm (H2 unit) \\
\hline Grab & C4191-123.5 & 123.5 & fn-md sand & Hanford fm (H2 unit) \\
\hline Grab & C4191-126 & 126 & silty fn sand & Hanford fm (H2 unit) \\
\hline Grab & C4191-128.5 & 128.5 & md-crs sand & Hanford fm (H2 unit) \\
\hline Grab & C4191-131 & 131 & md-crs sand & Hanford fm (H2 unit) \\
\hline Grab & C4191-133.5 & 133.5 & fn-md sand & Hanford fm (H2 unit) \\
\hline Grab & C4191-136 & 136 & silty fn sand & Hanford fm (H2 unit) \\
\hline
\end{tabular}


Table 2.3. Grab Samples Collected, Described, and Photographed from Borehole C4191

\begin{tabular}{|c|c|c|c|c|}
\hline Type & Lab \# & Depth & Lithology & Stratigraphic Unit \\
\hline Grab & C4191-138.5 & 138.5 & md-crs sand & Hanford fm (H2 unit) \\
\hline Grab & C4191-141 & 141 & silty fn sand & Hanford fm (H2 unit) \\
\hline Grab & C4191-143.5 & 143.5 & fn-md sand & Hanford fm (H2 unit) \\
\hline Grab & C4191-146 & 146 & md-crs sand & Hanford fm (H2 unit) \\
\hline Grab & C4191-148.5 & 148.5 & md-crs sand & Hanford fm (H2 unit) \\
\hline Grab & C4191-151 & 151 & fn-md sand & Hanford fm (H2 unit) \\
\hline Grab & C4191-153.5 & 153.5 & md sand & Hanford fm (H2 unit) \\
\hline Grab & C4191-156 & 156 & md sand & Hanford fm (H2 unit) \\
\hline Grab & C4191-158.5 & 158.5 & silty fn sand & Hanford fm (H2 unit) \\
\hline Grab & C4191-161 & 161 & md sand & Hanford fm (H2 unit) \\
\hline Grab & C4191-163.5 & 163.5 & md sand & Hanford fm (H2 unit) \\
\hline Grab & C4191-166 & 166 & silty fn-md sand & Hanford fm (H2 unit) \\
\hline Grab & C4191-168.5 & 168.5 & silty fn-md sand & Hanford fm (H2 unit) \\
\hline Grab & C4191-171 & 171 & silty fn-md sand & Hanford fm (H2 unit) \\
\hline Grab & C4191-173.5 & 173.5 & md-crs sand & Hanford fm (H2 unit) \\
\hline Grab & C4191-176 & 176 & md sand & Hanford fm (H2 unit) \\
\hline Grab & C4191-178.5 & 178.5 & fn-md sand & Hanford fm (H2 unit) \\
\hline Grab & C4191-181 & 181 & fn-md sand & Hanford fm (H2 unit) \\
\hline Grab & C4191-183.5 & 183.5 & md sand & Hanford fm (H2 unit) \\
\hline Grab & C4191-186 & 186 & fn-md sand & Hanford fm (H2 unit) \\
\hline Grab & C4191-188.5 & 188.5 & md sand & Hanford fm (H2 unit) \\
\hline Grab & C4191-191 & 191 & fn-md sand & Hanford fm (H2 unit) \\
\hline Grab & C4191-193.5 & 193.5 & fn-md sand & Hanford fm or Cold Creek unit \\
\hline Grab & C4191-196 & 196 & silty fn sand & Hanford fm or Cold Creek unit \\
\hline Grab & C4191-198.5 & 198.5 & fn-md sand & Hanford fm or Cold Creek unit \\
\hline Grab & C4191-201 & 201 & silty fn-md sand & Hanford fm or Cold Creek unit \\
\hline Grab & C4191-203.5 & 203.5 & sandy gravel & Hanford fm or Cold Creek unit \\
\hline Grab & C4191-206 & 206 & silty sandy gravel & Hanford fm or Cold Creek unit \\
\hline Grab & C4191-208.5 & 208.5 & pebbly md-crs sand & Hanford fm or Cold Creek unit \\
\hline Grab & C4191-211 & 211 & sandy gravel & Hanford fm or Cold Creek unit \\
\hline Grab & C4191-213.5 & 213.5 & pebbly fn-crs sand & Hanford fm or Cold Creek unit \\
\hline Grab & C4191-216 & 216 & pebbly fn-crs sand & Hanford fm or Cold Creek unit \\
\hline Grab & C4191-218.5 & 218.5 & pebbly fn-crs sand & Hanford fm or Cold Creek unit \\
\hline Grab & C4191-221 & 221 & fn-crs sand & Hanford fm or Cold Creek unit \\
\hline Grab & C4191-223.5 & 223.5 & sl pebbly sand & Hanford fm or Cold Creek unit \\
\hline Grab & C4191-226 & 226 & sandy gravel & Hanford fm or Cold Creek unit \\
\hline Grab & C4191-228.5 & 228.5 & pebbly fn-crs sand & Hanford fm or Cold Creek unit \\
\hline Grab & C4191-231 & 231 & pebbly fn-crs sand & Hanford fm or Cold Creek unit \\
\hline Grab & C4191-233.5 & 233.5 & pebbly fn-crs sand & Hanford fm or Cold Creek unit \\
\hline Grab & C4191-236 & 236 & pebbly fn-crs sand & Hanford fm or Cold Creek unit \\
\hline Grab & C4191-238.5 & 238.5 & silty fn-md sand & Hanford fm or Cold Creek unit \\
\hline Grab & C4191-241 & 241 & sl pebbly fn-crs sand & Hanford fm or Cold Creek unit \\
\hline Grab & C4191-243.5 & 243.5 & fn-md sand & Hanford fm or Cold Creek unit \\
\hline Grab & C4191-246 & 246 & md-crs sand & Hanford fm or Cold Creek unit \\
\hline
\end{tabular}


PNNL-17821

Table 2.3. Grab Samples Collected, Described, and Photographed from Borehole C4191

\begin{tabular}{|c|c|c|c|c|}
\hline Type & Lab \# & Depth & Lithology & Stratigraphic Unit \\
\hline Grab & C4191-248.5 & 248.5 & fn-crs sand & Hanford fm or Cold Creek unit \\
\hline Grab & C4191-251 & 251 & silty fn-crs sand & Hanford fm or Cold Creek unit \\
\hline Grab & C4191-253.5 & 253.5 & fn-md sand & Hanford fm or Cold Creek unit \\
\hline Grab & C4191-256 & 256 & fn-crs sand & Hanford fm or Cold Creek unit \\
\hline Grab & C4191-258.5 & 258.5 & fn-md sand & Hanford fm or Cold Creek unit \\
\hline Grab & C4191-261 & 261 & fn-md sand & Hanford fm or Cold Creek unit \\
\hline Grab & C4191-263.5 & 263.5 & md sand & Hanford fm or Cold Creek unit \\
\hline Grab & C4191-266 & 266 & md-crs sand & Hanford fm or Cold Creek unit \\
\hline Grab & C4191-268.5 & 268.5 & fn-md sand & Hanford fm or Cold Creek unit \\
\hline Grab & C4191-271 & 271 & fn-md sand & Hanford fm or Cold Creek unit \\
\hline Grab & C4191-273.5 & 273.5 & fn-md sand & Hanford fm or Cold Creek unit \\
\hline Grab & C4191-276 & 276 & fn-md sand & Hanford fm or Cold Creek unit \\
\hline Grab & C4191-278.5 & 278.5 & fn-crs sand & Hanford fm or Cold Creek unit \\
\hline Grab & C4191-281 & 281 & fn-md sand & Hanford fm or Cold Creek unit \\
\hline Grab & C4191-283.5 & 283.5 & pebbly fn-md sand & Hanford fm or Cold Creek unit \\
\hline Grab & C4191-286 & 286 & silty pebbly fn-crs sand & Hanford fm or Cold Creek unit \\
\hline Grab & C4191-288.5 & 288.5 & silty sandy gravel & Hanford fm or Cold Creek unit \\
\hline Grab & C4191-291 & 291 & silty sandy gravel & Hanford fm or Cold Creek unit \\
\hline Grab & C4191-293.5 & 293.5 & silty sandy gravel & Hanford fm or Cold Creek unit \\
\hline Grab & C4191-296 & 296 & sl gravelly sandy silt & Hanford fm or Cold Creek unit \\
\hline Grab & C4191-298.5 & 298.5 & silty fn-crs sand & Hanford fm or Cold Creek unit \\
\hline Grab & C4191-301 & 301 & sandy silty gravel & Ringold Formation (Unit E) \\
\hline Grab & C4191-303.5 & 303.5 & sandy gravelly silt & Ringold Formation (Unit E) \\
\hline Grab & C4191-306 & 306 & sandy gravelly silt & Ringold Formation (Unit E) \\
\hline Grab & C4191-308.5 & 308.5 & sandy gravelly silt & Ringold Formation (Unit E) \\
\hline Grab & C4191-311 & 311 & sandy gravelly silt & Ringold Formation (Unit E) \\
\hline Grab & C4191-313.5 & 313.5 & sandy silty gravel & Ringold Formation (Unit E) \\
\hline Grab & C4191-316 & 316 & sandy gravelly silt & Ringold Formation (Unit E) \\
\hline Grab & C4191-318.5 & 318.5 & sandy gravelly silt & Ringold Formation (Unit E) \\
\hline Grab & C4191-321 & 321 & sl silty sl sandy gravel & Ringold Formation (Unit E) \\
\hline Grab & C4191-323.5 & 323.5 & silty sandy gravel & Ringold Formation (Unit E) \\
\hline Grab & C4191-326 & 326 & sandy gravelly silt & Ringold Formation (Unit E) \\
\hline Grab & C4191-328.5 & 328.5 & sandy silty gravel & Ringold Formation (Unit E) \\
\hline Grab & C4191-331 & 331 & sl sandy sl silty gravel & Ringold Formation (Unit E) \\
\hline Grab & C4191-333.5 & 333.5 & silty gravelly sand & Ringold Formation (Unit E) \\
\hline Grab & C4191-336 & 336 & silty sandy gravel & Ringold Formation (Unit E) \\
\hline Grab & C4191-338.5 & 338.5 & silty gravelly sand & Ringold Formation (Unit E) \\
\hline Grab & C4191-341 & 341 & silty sandy gravel & Ringold Formation (Unit E) \\
\hline
\end{tabular}

Crs = coarse; $\mathrm{fn}$ = fine; md = medium; sl = slightly; v = very 


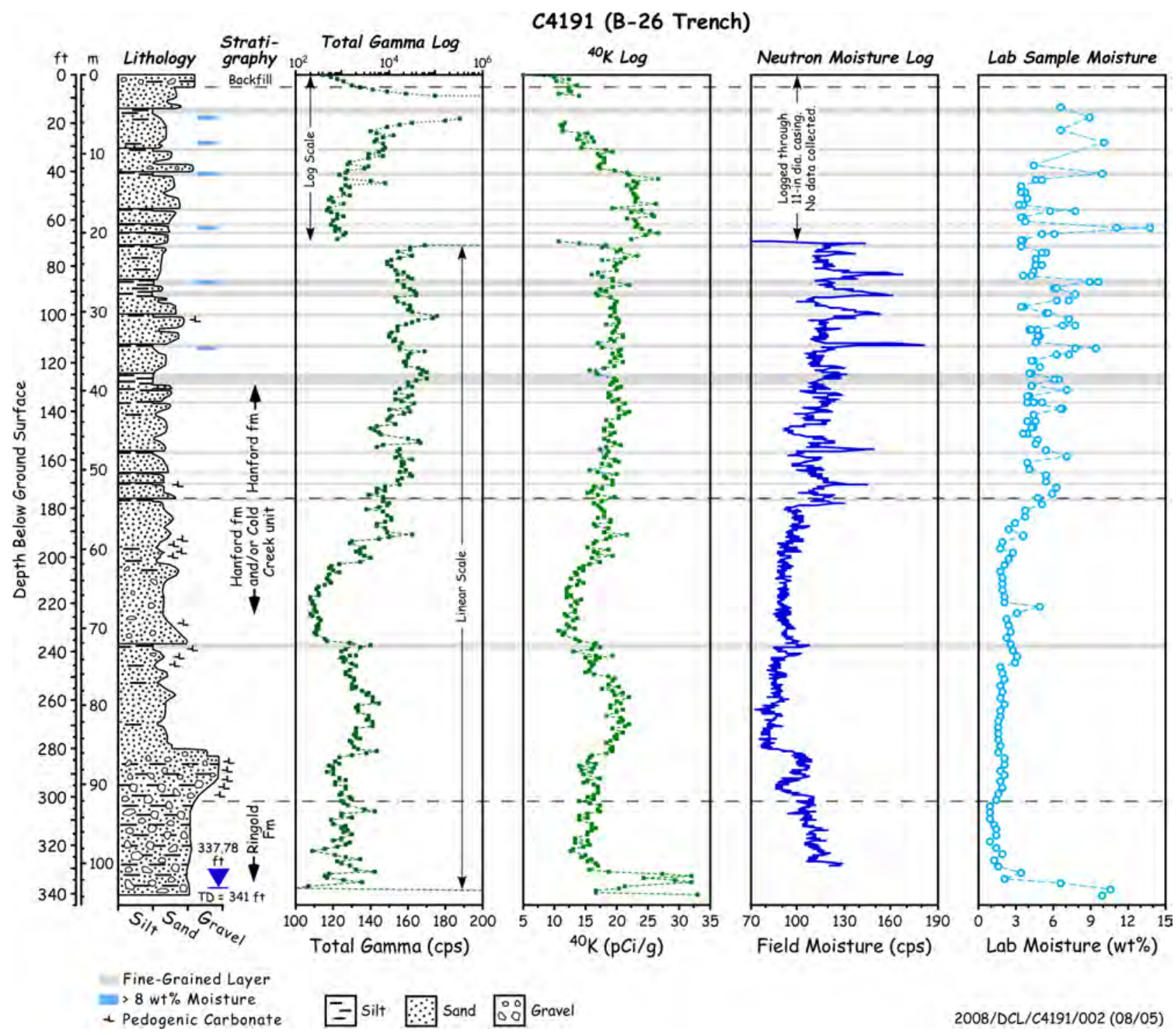

Figure 2.18. Composite Summary Log for Borehole C4191 


\subsubsection{Borehole C5923 (299-E13-62)}

Drilling grab samples collected for physical and chemical characterization from borehole C5923 (BC Crib and Trenches borehole A) are listed in Table 2.4.

Table 2.4. Vadose Zone Samples Collected, Described, and Photographed from Borehole C5923

\begin{tabular}{|c|c|c|c|c|}
\hline Type & HEIS \# & Depth (ft) & Lithology & Stratigraphic Unit \\
\hline Grab & B1T740 & $5-6$ & sl pebbly fn sand & Hanford fm (H2 unit) \\
\hline Grab & B1T741 & 7.5-8.5 & sl pebbly fn-crs sand & Hanford fm (H2 unit) \\
\hline Grab & B1T742 & $10-11$ & sl pebbly crs sand & Hanford fm (H2 unit) \\
\hline Grab & B1T743 & $12.5-13.5$ & sl pebbly crs sand & Hanford fm (H2 unit) \\
\hline Grab & B1T744 & $15-16$ & fn-crs sand & Hanford fm (H2 unit) \\
\hline Grab & B1T745 & 17.5-18.5 & fn-md sand & Hanford fm (H2 unit) \\
\hline Grab & В1T746 & $20-21$ & fn-md sand & Hanford fm (H2 unit) \\
\hline Grab & В1T816 & $20-21$ & fn-md sand & Hanford fm (H2 unit) \\
\hline Grab & B1T747 & $22.5-23.5$ & md sand & Hanford fm (H2 unit) \\
\hline Grab & В1T748 & $25-26$ & md sand & Hanford fm (H2 unit) \\
\hline Grab & B1T749 & 27.5-28.5 & md sand & Hanford fm (H2 unit) \\
\hline Grab & B1T750 & $30-31$ & md sand & Hanford fm (H2 unit) \\
\hline Grab & B1T751 & 32.5-33.5 & md sand & Hanford fm (H2 unit) \\
\hline Grab & В1T825 & $36.5-37.0$ & md sand & Hanford fm (H2 unit) \\
\hline Core & B1T7J4-2 & 38.038 .5 & & Hanford fm (H2 unit) \\
\hline Core & B1T7J3-3 & $38.0-38.5$ & & Hanford fm (H2 unit) \\
\hline Core & B1T7J3-2 & 38.5-39.0 & & Hanford fm (H2 unit) \\
\hline Grab & В1T826 & 39.0-39.5 & md-crs sand & Hanford fm (H2 unit) \\
\hline Core & B1T7J5-3 & $40.5-41.0$ & & Hanford fm (H2 unit) \\
\hline Core & B1T7J5-2 & $41.0-41.5$ & & Hanford fm (H2 unit) \\
\hline Grab & В1Т827 & $41.5-42.0$ & crs sand & Hanford fm (H2 unit) \\
\hline Core & B1T7J6-3 & $43.0-43.5$ & & Hanford fm (H2 unit) \\
\hline Core & B1T7J6-2 & $43.5-44.0$ & & Hanford fm (H2 unit) \\
\hline Grab & В1Т828 & $44.0-44.5$ & sl pebbly crs sand & Hanford fm (H2 unit) \\
\hline Grab & B1T752 & $45-46$ & sl pebbly crs sand & Hanford fm (H2 unit) \\
\hline Grab & B1T753 & $47.5-48.5$ & md-crs sand & Hanford fm (H2 unit) \\
\hline Grab & B1T754 & $50-51$ & md-crs sand & Hanford fm (H2 unit) \\
\hline Grab & B1T755 & $52.5-53.5$ & sl pebbly crs sand & Hanford fm (H2 unit) \\
\hline Grab & B1T756 & $55-56$ & md sand & Hanford fm (H2 unit) \\
\hline Grab & B1T757 & $57.5-58.5$ & md sand & Hanford fm (H2 unit) \\
\hline Grab & B1T758 & $60-61$ & md sand & Hanford fm (H2 unit) \\
\hline
\end{tabular}


Table 2.4 (contd)

\begin{tabular}{|c|c|c|c|c|}
\hline Type & HEIS \# & Depth (ft) & Lithology & Stratigraphic Unit \\
\hline Grab & B1T759 & $62.5-63.5$ & sl pebbly md-crs sand & Hanford fm (H2 unit) \\
\hline Grab & B1T760 & $65-66$ & sl pebbly md sand & Hanford fm (H2 unit) \\
\hline Grab & B1T761 & $67.5-68.5$ & md sand & Hanford fm (H2 unit) \\
\hline Grab & B1T762 & $70-71$ & md-crs sand & Hanford fm (H2 unit) \\
\hline Grab & В1T763 & 72.5-73.5 & crs sand & Hanford fm (H2 unit) \\
\hline Grab & B1T764 & $75-76$ & crs sand & Hanford fm (H2 unit) \\
\hline Grab & B1T765 & 77.5-78.5 & md sand & Hanford fm (H2 unit) \\
\hline Grab & B1T766 & $80-81$ & md-crs sand & Hanford fm (H2 unit) \\
\hline Grab & B1T767 & 82.5-83.5 & sl pebbly md-crs sand & Hanford fm (H2 unit) \\
\hline Field Dup & B1T817 & 82.5-83.5 & sl pebbly md-crs sand & Hanford fm (H2 unit) \\
\hline Core & B1T7J7-3 & $85.5-86.0$ & & Hanford fm (H2 unit) \\
\hline Core & B1T7J7-2 & $86.0-86.5$ & & Hanford fm (H2 unit) \\
\hline Grab & В1Т829 & $86.5-87.0$ & md-v.crs sand & Hanford fm (H2 unit) \\
\hline Core & B1T7J8-3 & $88.0-88.5$ & & Hanford fm (H2 unit) \\
\hline Core & B1T7J8-2 & $88.5-89.0$ & & Hanford fm (H2 unit) \\
\hline Grab & B1T985 & 89.0-89.5 & md sand & Hanford fm (H2 unit) \\
\hline Grab & В1Т768 & $90-91$ & md sand & Hanford fm (H2 unit) \\
\hline Grab & B1T769 & $92.5-93.5$ & md sand & Hanford fm (H2 unit) \\
\hline Grab & В1Т770 & $95-96$ & md sand & Hanford fm (H2 unit) \\
\hline Grab & B1T771 & $97.5-98.5$ & md sand & Hanford fm (H2 unit) \\
\hline Grab & B1T772 & $100-101$ & sl pebbly md-crs sand & Hanford fm (H2 unit) \\
\hline Grab & B1T773 & 102.5-103.5 & sl pebbly md-crs sand & Hanford fm (H2 unit) \\
\hline Core & B1T7J9-3 & 105.5-106.0 & & Hanford fm (H2 unit) \\
\hline Core & B1T7J9-2 & 106.0-106.5 & & Hanford fm (H2 unit) \\
\hline Grab & В1Т9К9 & 106.5-107.0 & md sand & Hanford fm (H2 unit) \\
\hline Core & В1T7K0-3 & 108.0-108.5 & & Hanford fm (H2 unit) \\
\hline Core & B1T7K0-2 & 108.5-109.0 & & Hanford fm (H2 unit) \\
\hline Grab & B1T9L0 & 109.0-109.5 & md sand & Hanford fm (H2 unit) \\
\hline Core & B1T7L3-3 & 113.0-113.5 & & Hanford fm (H2 unit) \\
\hline Core & B1T7L3-2 & 113.5-114.0 & & Hanford fm (H2 unit) \\
\hline Grab & B1T9L1 & 114.0-114.5 & md sand & Hanford fm (H2 unit) \\
\hline Grab & B1T774 & $115-116$ & fn-md sand & Hanford fm (H2 unit) \\
\hline Grab & B1T775 & 117.5-118.5 & fn-md sand & Hanford fm (H2 unit) \\
\hline Grab & B1T776 & $120-121$ & fn-md sand & Hanford fm (H2 unit) \\
\hline Grab & В1Т777 & 122.5-123.5 & fn-md sand & Hanford fm (H2 unit) \\
\hline Field Dup & В1Т818 & 122.5-123.5 & fn-md sand & Hanford fm (H2 unit) \\
\hline Core & B1T7K1-3 & $125.5-126.0$ & & Hanford fm (H2 unit) \\
\hline Core & B1T7K1-2 & 126.0-126.5 & & Hanford fm (H2 unit) \\
\hline Grab & B1T9L2 & 126.5-127.0 & fn-md sand & Hanford fm (H2 unit) \\
\hline
\end{tabular}


Table 2.4 (contd)

\begin{tabular}{|c|c|c|c|c|}
\hline Type & HEIS \# & Depth (ft) & Lithology & Stratigraphic Unit \\
\hline Core & B1T7K2-3 & 128.5-129.0 & & Hanford fm (H2 unit) \\
\hline Core & B1T7K2-2 & 129.0-129.5 & & Hanford fm (H2 unit) \\
\hline Grab & B1T9L3 & 129.0-129.5 & fn-md sand & Hanford fm (H2 unit) \\
\hline Core & В1T7K3-3 & $130.5-131.0$ & & Hanford fm (H2 unit) \\
\hline Core & B1T7K3-2 & 131.0-131.5 & & Hanford fm (H2 unit) \\
\hline Grab & B1T9L4 & $131.5-132.0$ & fn-md sand & Hanford fm (H2 unit) \\
\hline Core & B1T7K4-3 & 133.0-133.5 & & Hanford fm (H2 unit) \\
\hline Core & B1T7K4-2 & $133.5-134.0$ & & Hanford fm (H2 unit) \\
\hline Grab & B1T9L5 & $134.0-134.5$ & silty fn sand & Hanford fm (H2 unit) \\
\hline Grab & B1T778 & $135-136$ & silty fn sand & Hanford fm (H2 unit) \\
\hline Grab & В1T779 & 137.5-138.5 & md sand & Hanford fm (H2 unit) \\
\hline Grab & B1T780 & $140-141$ & md-crs sand & Hanford fm (H2 unit) \\
\hline Grab & B1T781 & $142.5-143.5$ & silty fn-md sand & Hanford fm (H2 unit) \\
\hline Grab & B1T782 & $145-146$ & md sand & Hanford fm (H2 unit) \\
\hline Grab & B1T783 & 147.5-148.5 & md sand & Hanford fm (H2 unit) \\
\hline Grab & B1T784 & $150-151$ & silty md sand & Hanford fm (H2 unit) \\
\hline Grab & B1T785 & $152.5-153.5$ & md-crs sand & Hanford fm (H2 unit) \\
\hline Grab & B1T786 & $155-156$ & md sand & Hanford fm (H2 unit) \\
\hline Grab & B1T787 & 157.5-158.5 & md sand & Hanford fm (H2 unit) \\
\hline Grab & B1T788 & $160-161$ & md sand & Hanford fm (H2 unit) \\
\hline Grab & В1T789 & 162.5-163.5 & md sand & Hanford fm (H2 unit) \\
\hline Grab & B1T790 & 165-166 & silty md sand & Hanford fm (H2 unit) \\
\hline Grab & B1T791 & 167.5-168.5 & md sand & Hanford fm (H2 unit) \\
\hline Grab & B1T792 & $170-171$ & md sand & Hanford fm (H2 unit) \\
\hline Grab & В1T793 & 172.5-173.5 & md sand & Hanford fm (H2 unit) \\
\hline Core & B1T7K5-3 & $175.5-176.0$ & & Hanford fm (H2 unit) \\
\hline Core & B1T7K5-2 & $176.0-176.5$ & & Hanford fm (H2 unit) \\
\hline Grab & B1T9L6 & $176.5-177.0$ & md sand & Hanford fm (H2 unit) \\
\hline Core & B1T7K6-3 & 178.0-178.5 & & Hanford fm (H2 unit) \\
\hline Core & B1T7K6-2 & $178.5-179.0$ & & Hanford fm (H2 unit) \\
\hline Grab & B1T9L7 & 179.0-179.5 & md sand & Hanford fm (H2 unit) \\
\hline Core & B1T7K7-3 & $180.5-181.0$ & & Hanford fm (H2 unit) \\
\hline Core & B1T7K7-2 & 181.0-181.5 & & Hanford fm (H2 unit) \\
\hline Grab & B1T9L8 & $181.5-182.0$ & md sand & Hanford fm (H2 unit) \\
\hline Core & B1T7K8-3 & 183.0-183.5 & & Hanford fm (H2 unit) \\
\hline Core & B1T7K8-2 & $183.5-184.0$ & & Hanford fm (H2 unit) \\
\hline Grab & B1T9L9 & 184.0-184.5 & md sand & Hanford fm (H2 unit) \\
\hline Grab & B1T794 & $185-186$ & md sand & Hanford fm (H2 unit) \\
\hline
\end{tabular}


Table 2.4 (contd)

\begin{tabular}{|c|c|c|c|c|}
\hline Type & HEIS \# & Depth (ft) & Lithology & Stratigraphic Unit \\
\hline$\overline{\text { Grab }}$ & B1T795 & $187.5-188.5$ & md sand & Hanford fm (H2 unit) \\
\hline Grab & B1T796 & 190-191 & md sand & Hanford fm (H2 unit) \\
\hline Grab & В1Т819 & 190-191 & md sand & Hanford fm (H2 unit) \\
\hline Grab & B1T797 & 192.5-193.5 & md sand & Hanford fm (H2 unit) \\
\hline Grab & В1Т798 & 195-196 & sl pebbly md sand & Hanford fm (H2 unit) \\
\hline Grab & В1Т799 & 197.5-198.5 & md sand & Hanford fm (H2 unit) \\
\hline Grab & B1T7B0 & $200-201$ & md sand & Hanford fm (H2 unit) \\
\hline Grab & B1T7B1 & 202.5-203.5 & md sand & Hanford fm (H2 unit) \\
\hline Grab & B1T7B2 & $205-206$ & md-crs sand & Hanford fm (H2 unit) \\
\hline Grab & В1T820 & $205-206$ & md sand & Hanford fm (H2 unit) \\
\hline Grab & B1T7B3 & 207.5-208.5 & md sand & Hanford fm (H2 unit) \\
\hline Grab & B1T7B4 & $210-211$ & md sand & Hanford fm (H2 unit) \\
\hline Grab & B1T7B5 & 212.5-213.5 & md sand & Hanford fm (H2 unit) \\
\hline Grab & B1T7B6 & $215-216$ & fn-md sand & Hanford fm (H2 unit) \\
\hline Grab & B1T7B7 & 217.5-218.5 & md-crs sand & Hanford fm (H2 unit) \\
\hline Grab & B1T7B8 & $220-221$ & fn-md sand & Hanford fm or Cold Creek unit \\
\hline Grab & В1Т7B9 & 222.5-223.5 & fn-md sand & Hanford fm or Cold Creek unit \\
\hline Grab & В1Т821 & 222.5-223.5 & fn-md sand & Hanford fm or Cold Creek unit \\
\hline Grab & B1T7C0 & $225-226$ & fn-md sand & Hanford fm or Cold Creek unit \\
\hline Grab & B1T7C1 & 227.5-228.5 & sl pebbly md sand & Hanford fm or Cold Creek unit \\
\hline Grab & B1T7C2 & $230-231$ & sl pebbly md sand & Hanford fm or Cold Creek unit \\
\hline Grab & B1T7C3 & 232.5-233.5 & sl pebbly md sand & Hanford fm or Cold Creek unit \\
\hline Core & B1T7K9-3 & 235.5-236.0 & & Hanford fm or Cold Creek unit \\
\hline Core & B1T7K9-2 & 236.0-236.5 & & Hanford fm or Cold Creek unit \\
\hline Grab & В1Т9К6 & $236.5-237.0$ & sl pebbly md-crs sand & Hanford fm or Cold Creek unit \\
\hline Core & B1T7L0-3 & 238.0-238.5 & & Hanford fm or Cold Creek unit \\
\hline Core & B1T7L0-2 & 238.5-239.0 & & Hanford fm or Cold Creek unit \\
\hline Grab & В1T9K7 & 239.0-239.5 & sl pebbly md-crs sand & Hanford fm or Cold Creek unit \\
\hline Core & B1T7L1-3 & $240.5-241.0$ & & Hanford fm or Cold Creek unit \\
\hline Core & B1T7L1-2 & 241.0-241.5 & & Hanford fm or Cold Creek unit \\
\hline Grab & В1Т9К8 & $241.5-242.0$ & sl pebbly md-crs sand & Hanford fm or Cold Creek unit \\
\hline Core & B1T7L2-3 & 243.0-243.5 & & Hanford fm or Cold Creek unit \\
\hline Core & B1T7L2-2 & 243.5-244.0 & & Hanford fm or Cold Creek unit \\
\hline Grab & В1Т824 & 244.0-244.5 & gravelly sand & Hanford fm or Cold Creek unit \\
\hline Grab & B1T7C4 & $245-246$ & gravelly sand & Hanford fm or Cold Creek unit \\
\hline Grab & B1T7C5 & 247.5-248.5 & gravelly sand & Hanford fm or Cold Creek unit \\
\hline Grab & B1T7C6 & $250-251$ & gravelly sand & Hanford fm or Cold Creek unit \\
\hline Grab & B1T7C8 & 252.5-253.5 & gravelly sand & Hanford fm or Cold Creek unit \\
\hline Grab & B1T7C7 & 255-256 & md sand & Hanford fm or Cold Creek unit \\
\hline
\end{tabular}


Table 2.4 (contd)

\begin{tabular}{|c|c|c|c|c|}
\hline Type & HEIS \# & Depth (ft) & Lithology & Stratigraphic Unit \\
\hline$\overline{\text { Grab }}$ & B1T7C9 & $257.5-258.5$ & sl pebbly md sand & Hanford fm or Cold Creek unit \\
\hline Grab & B1T7D0 & $260-261$ & sl pebbly md sand & Hanford fm or Cold Creek unit \\
\hline Grab & В1Т822 & $260-261$ & sl pebbly md sand & Hanford fm or Cold Creek unit \\
\hline Grab & B1T7D1 & $262.5-263.5$ & sl pebbly md sand & Hanford fm or Cold Creek unit \\
\hline Grab & B1T7D2 & $265-266$ & sl pebbly md sand & Hanford fm or Cold Creek unit \\
\hline Grab & B1T7D3 & 267.5-268.5 & sl pebbly md sand & Hanford fm or Cold Creek unit \\
\hline Grab & B1T7D4 & $270-271$ & sl pebbly md sand & Hanford fm or Cold Creek unit \\
\hline Grab & B1T7D5 & $272.5-273.5$ & sl pebbly md sand & Hanford fm or Cold Creek unit \\
\hline Grab & B1T7D6 & $275-276$ & gravelly sand & Hanford fm or Cold Creek unit \\
\hline Grab & B1T7D7 & 277.5-278.5 & gravelly sand & Hanford fm or Cold Creek unit \\
\hline Grab & B1T7D8 & $280-281$ & gravelly sand & Hanford fm or Cold Creek unit \\
\hline Grab & B1T7D9 & 282.5-283.5 & sl pebbly md sand & Hanford fm or Cold Creek unit \\
\hline Grab & B1T7F0 & $285-286$ & sl pebbly md sand & Hanford fm or Cold Creek unit \\
\hline Grab & B1T7F1 & 287.5-288.5 & sl pebbly md-crs sand & Hanford fm or Cold Creek unit \\
\hline Grab & B1T7F2 & 290-291 & sl pebbly md sand & Hanford fm or Cold Creek unit \\
\hline Grab & B1T7F3 & 292.5-293.5 & gravelly fn-md san & Hanford fm or Cold Creek unit \\
\hline Grab & B1T7F4 & $295-296$ & silty gravel & Hanford fm or Cold Creek unit \\
\hline Grab & B1T7F5 & 297.5-298.5 & gravelly fn-md sand & Hanford fm or Cold Creek unit \\
\hline Grab & B1T7F6 & $300-301$ & gravelly sandy silt & Hanford fm or Cold Creek unit \\
\hline Grab & B1T7F7 & 302.5-303.5 & silty sandy gravel & Hanford fm or Cold Creek unit \\
\hline Grab & B1T7F8 & $305-306$ & sl silty sl gravelly fn sand & Hanford fm or Cold Creek unit \\
\hline Grab & B1T7F9 & 307.5-308.5 & gravelly sandy silt & Hanford fm or Cold Creek unit \\
\hline Grab & B1T7H0 & $310-311$ & gravelly sandy silt & Hanford fm or Cold Creek unit \\
\hline Grab & B1T7H1 & 312.5-313.5 & sl gravelly fn-md sand & Hanford fm or Cold Creek unit \\
\hline Grab & B1T7H2 & $315-316$ & sl gravelly md sand & Hanford fm or Cold Creek unit \\
\hline Grab & В1Т7H3 & 317.5-318.5 & sl gravelly md sand & Hanford fm or Cold Creek unit \\
\hline Grab & B1T7H4 & $320-321$ & sl gravelly fn-md sand & Hanford fm or Cold Creek unit \\
\hline Grab & B1T7H5 & 322.5-323.5 & gravelly fn sand & Hanford fm or Cold Creek unit \\
\hline Grab & B1T7H6 & $325-326$ & gravelly sandy silt & Hanford fm or Cold Creek unit \\
\hline Grab & B1T7H7 & 327.5-328.5 & gravelly sandy silt & Hanford fm or Cold Creek unit \\
\hline Grab & В1Т7H8 & 330-331 & gravelly sandy silt & Hanford fm or Cold Creek unit \\
\hline Grab & В1Т823 & 330-331 & gravelly sandy silt & Hanford fm or Cold Creek unit \\
\hline Grab & В1T7H9 & 332.5-333.5 & gravelly sandy silt & Hanford fm or Cold Creek unit \\
\hline Grab & B1T7J0 & $335-336$ & silty sandy gravel & Hanford fm or Cold Creek unit \\
\hline Grab & B1T7J1 & 337.5-338.5 & sl gravelly sandy silt & Hanford fm or Cold Creek unit \\
\hline Grab & B1T7J2 & $340-341$ & gravelly sandy silt & Hanford fm or Cold Creek unit \\
\hline Grab & В1Т984 & $341-342$ & gravelly sandy silt & Hanford fm or Cold Creek unit \\
\hline Grab & B1V530 & $343.5-344.5$ & Not processed & Not processed \\
\hline Grab & B1V531 & $346-347$ & Not processed & Not processed \\
\hline
\end{tabular}


PNNL-17821

Table 2.4 (contd)

\begin{tabular}{|c|c|c|c|c|}
\hline Type & HEIS \# & Depth (ft) & Lithology & Stratigraphic Unit \\
\hline Grab & B1V532 & $348.5-349.5$ & Not processed & Not processed \\
\hline Grab & B1V533 & 351-352 & Not processed & Not processed \\
\hline
\end{tabular}

A summary hydrogeologic log, which shows an integration of all the geologic, geophysical, and moisture data collected for borehole C5923, is presented in Figure 2.19. 
299-E13-62 C5923 (BC Cribs)

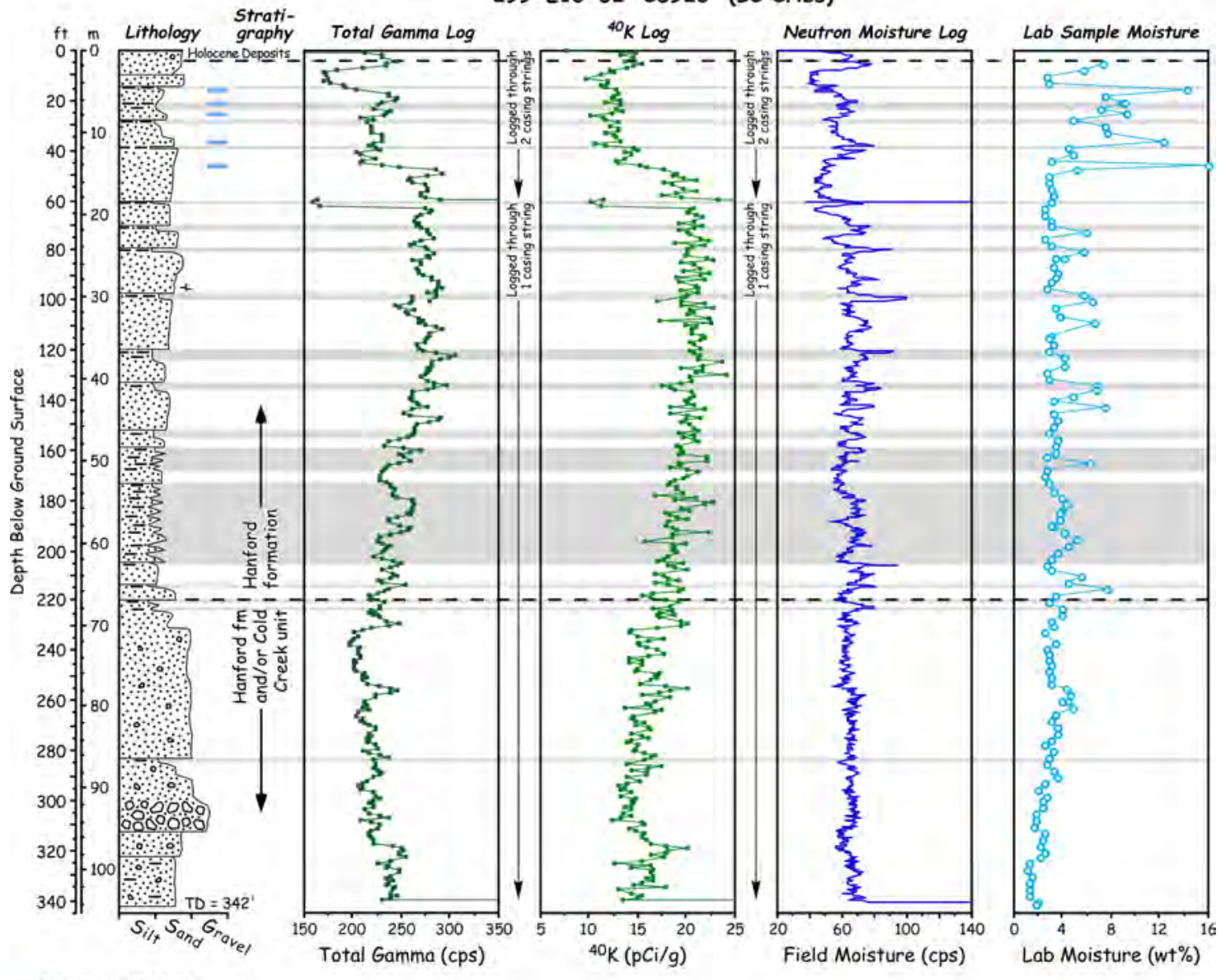

Fine-Grained Layer

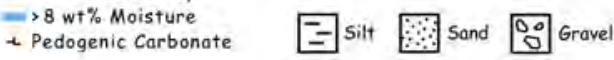

2008/00L/C5923/001(07/23)

Figure 2.19. Composite Summary Log for Borehole C5923 
PNNL-17821

\subsubsection{Borehole C5924 (299-E13-63)}

Grab samples collected for physical and chemical characterization from borehole C5924 (BC Cribs and Trenches area borehole B) are listed in Table 2.5.

Table 2.5. Grab Samples Collected, Described, and Photographed from Borehole C5924

\begin{tabular}{|c|c|c|c|c|}
\hline Sample Type & HEIS \# & Depth (ft) & Lithology & Stratigraphic Unit \\
\hline Grab & B1T677 & $5.0-5.5$ & fn-md sand & Hanford fm (H2 unit) \\
\hline Grab & B1T678 & 7.5-8.0 & sl pebbly fn-crs sand & Hanford fm (H2 unit) \\
\hline Grab & B1T679 & $9.5-10.0$ & sl pebbly fn-crs sand & Hanford fm (H2 unit) \\
\hline Grab & B1T680 & $12.0-12.5$ & md-crs sand & Hanford fm (H2 unit) \\
\hline Grab & B1T681 & $14.5-15.0$ & md sand & Hanford fm (H2 unit) \\
\hline Grab & B1T682 & $17.5-18.0$ & fn sand & Hanford fm (H2 unit) \\
\hline Grab & B1T683 & $19.5-20.0$ & fn sand & Hanford fm (H2 unit) \\
\hline Grab & B1T730 & $19.5-20.0$ & fn sand & Hanford fm (H2 unit) \\
\hline Grab & B1T684 & $22.5-23.0$ & md-crs sand & Hanford fm (H2 unit) \\
\hline Grab & B1T685 & $25.0-25.5$ & md sand & Hanford fm (H2 unit) \\
\hline Grab & B1T686 & $27.0-27.5$ & md-crs sand & Hanford fm (H2 unit) \\
\hline Grab & B1T687 & $29.5-30.0$ & md sand & Hanford fm (H2 unit) \\
\hline Grab & B1T688 & $32.0-32.5$ & fn-md sand & Hanford fm (H2 unit) \\
\hline Grab & B1T689 & $34.5-35.0$ & fn sand & Hanford fm (H2 unit) \\
\hline Grab & B1T690 & $37.0-37.5$ & fn-md sand & Hanford fm (H2 unit) \\
\hline Grab & B1T691 & $40.0-40.5$ & fn-md sand & Hanford fm (H2 unit) \\
\hline Grab & B1T692 & $42.5-43.0$ & fn-md sand & Hanford fm (H2 unit) \\
\hline Grab & B1T693 & $44.5-45.0$ & md-crs sand & Hanford fm (H2 unit) \\
\hline Grab & B1T694 & $47.0-47.5$ & md-crs sand & Hanford fm (H2 unit) \\
\hline Grab & B1T695 & $50.5-51.0$ & fn-md sand & Hanford fm (H2 unit) \\
\hline Grab & B1T696 & $52.5-53.0$ & md sand & Hanford fm (H2 unit) \\
\hline Grab & B1T697 & $54.5-55.0$ & md sand & Hanford fm (H2 unit) \\
\hline Grab & B1T698 & $57.0-57.5$ & md sand & Hanford fm (H2 unit) \\
\hline Grab & В1T699 & $60.0-60.5$ & md sand & Hanford fm (H2 unit) \\
\hline Grab & B1T6B0 & $62.0-62.5$ & fn-md sand & Hanford fm (H2 unit) \\
\hline Grab & B1T6B1 & $65.0-65.5$ & md sand & Hanford fm (H2 unit) \\
\hline Grab & B1T731 & $65.0-65.5$ & md sand & Hanford fm (H2 unit) \\
\hline Grab & B1T6B2 & $67.5-68.0$ & md sand & Hanford fm (H2 unit) \\
\hline Grab & В1T6B3 & $70.0-70.5$ & fn sand & Hanford fm (H2 unit) \\
\hline Grab & B1T6B4 & $72.5-73.0$ & fn-md sand & Hanford fm (H2 unit) \\
\hline Grab & B1T6B5 & $75.0-75.5$ & md-crs sand & Hanford fm (H2 unit) \\
\hline Grab & B1T6B6 & $77.0-77.5$ & fn sand & Hanford fm (H2 unit) \\
\hline Grab & B1T6B7 & $79.5-80.0$ & md sand & Hanford fm (H2 unit) \\
\hline Grab & B1T6B8 & $82.5-83.0$ & md sand & Hanford fm (H2 unit) \\
\hline Grab & В1T6B9 & $85.5-86.0$ & fn-md sand & Hanford fm (H2 unit) \\
\hline Grab & B1T6C0 & $87.5-88.0$ & fn-md sand & Hanford fm (H2 unit) \\
\hline Grab & B1T6C1 & $90.0-90.5$ & fn-md sand & Hanford fm (H2 unit) \\
\hline Grab & B1T6C2 & $92.0-92.5$ & fn-md sand & Hanford fm (H2 unit) \\
\hline Grab & B1T6C3 & $95.0-95.5$ & fn-md sand & Hanford fm (H2 unit) \\
\hline Grab & B1T6C4 & $97.5-98.0$ & md-crs sand & Hanford fm (H2 unit) \\
\hline Grab & B1T6C5 & $100.0-100.5$ & md sand & Hanford fm (H2 unit) \\
\hline
\end{tabular}


Table 2.5 (contd)

\begin{tabular}{|c|c|c|c|c|}
\hline Sample Type & HEIS \# & Depth (ft) & Lithology & Stratigraphic Unit \\
\hline Grab & B1T6C6 & $102.5-103.0$ & md sand & Hanford fm (H2 unit) \\
\hline Grab & B1T6C7 & $105.0-105.5$ & fn-md sand & Hanford fm (H2 unit) \\
\hline Grab & B1T732 & 105.0-105.5 & fn-md sand & Hanford fm (H2 unit) \\
\hline Grab & B1T6C8 & 107.0-107.5 & fn-md sand & Hanford fm (H2 unit) \\
\hline Grab & B1T6C9 & $110.0-110.5$ & fn-md sand & Hanford fm (H2 unit) \\
\hline Grab & B1T6D0 & $112.0-112.5$ & fn-md sand & Hanford fm (H2 unit) \\
\hline Grab & B1T6D1 & 115.0-115.5 & fn-md sand & Hanford fm (H2 unit) \\
\hline Grab & B1T6D2 & $117.5-118.0$ & fn sand & Hanford fm (H2 unit) \\
\hline Grab & B1T6D3 & $120.0-120.5$ & md sand & Hanford fm (H2 unit) \\
\hline Grab & B1T6D4 & $122.5-123.0$ & md sand & Hanford fm (H2 unit) \\
\hline Grab & B1T6D5 & $125.0-125.5$ & md sand & Hanford fm (H2 unit) \\
\hline Grab & B1T6D6 & $127.0-127.5$ & fn-md sand & Hanford fm (H2 unit) \\
\hline Grab & B1T6D7 & 130.0-130.5 & fn sand & Hanford fm (H2 unit) \\
\hline Grab & B1T6D8 & $132.5-133.0$ & fn sand & Hanford fm (H2 unit) \\
\hline Grab & B1T6D9 & 135.0-135.5 & fn-md sand & Hanford fm (H2 unit) \\
\hline Grab & B1T6F0 & $137.5-138.0$ & fn-md sand & Hanford fm (H2 unit) \\
\hline Grab & B1T6F1 & $139.5-140.0$ & fn-md sand & Hanford fm (H2 unit) \\
\hline Grab & B1T6F2 & $142.0-142.5$ & fn sand & Hanford fm (H2 unit) \\
\hline Grab & B1T6F3 & $144.5-145.0$ & fn sand & Hanford fm (H2 unit) \\
\hline Grab & B1T6F4 & $147.0-147.5$ & md sand & Hanford fm (H2 unit) \\
\hline Grab & B1T6F5 & 150.0-150.5 & md sand & Hanford fm (H2 unit) \\
\hline Grab & B1T733 & 150.0-150.5 & md sand & Hanford fm (H2 unit) \\
\hline Grab & B1T6F6 & 153.0-153.5 & fn-md sand & Hanford fm (H2 unit) \\
\hline Grab & B1T6F7 & 155.0-155.5 & fn-md sand & Hanford fm (H2 unit) \\
\hline Grab & B1T6F8 & $157.5-158.0$ & fn-md sand & Hanford fm (H2 unit) \\
\hline Grab & B1T6F9 & $160.0-160.5$ & md sand & Hanford fm (H2 unit) \\
\hline Grab & В1T6H0 & $162.5-163.5$ & fn-md sand & Hanford fm (H2 unit) \\
\hline Grab & B1T6H1 & $165.0-165.5$ & md sand & Hanford fm (H2 unit) \\
\hline Grab & B1T6H2 & $167.5-168.0$ & md sand & Hanford fm (H2 unit) \\
\hline Grab & В1Т6H3 & $170.0-170.5$ & md sand & Hanford fm (H2 unit) \\
\hline Grab & B1T6H4 & $172.5-173.0$ & md sand & Hanford fm (H2 unit) \\
\hline Grab & В1T6H5 & $175.0-175.5$ & fn-md sand & Hanford fm (H2 unit) \\
\hline Grab & B1T6H6 & 178.0-178.5 & fn sand & Hanford fm (H2 unit) \\
\hline Grab & В1T6H7 & 181.0-181.5 & md sand & Hanford fm (H2 unit) \\
\hline Grab & В1T6H8 & $182.5-183.0$ & md sand & Hanford fm (H2 unit) \\
\hline Grab & В1T6H9 & $184.5-185.0$ & md sand & Hanford fm (H2 unit) \\
\hline Grab & B1T6J0 & $187.5-188.0$ & fn sand & Hanford fm (H2 unit) \\
\hline Grab & B1T6J1 & 190.5-191.0 & md sand & Hanford fm (H2 unit) \\
\hline Grab & B1T6J2 & 192.0-192.5 & fn-md sand & Hanford fm (H2 unit) \\
\hline Grab & B1T6J3 & 195.0-195.5 & fn-md sand & Hanford fm (H2 unit) \\
\hline Grab & B1T6J4 & 197.5-198.0 & fn-md sand & Hanford fm (H2 unit) \\
\hline Grab & B1T6J5 & 201.0-201.5 & md-crs sand & Hanford fm (H2 unit) \\
\hline Grab & B1T6J6 & 202.5-203.0 & fn-md sand & Hanford fm (H2 unit) \\
\hline Grab & B1T6J7 & 205.0-205.5 & fn-md sand & Hanford fm (H2 unit) \\
\hline Grab & B1T6J8 & 207.5-208.0 & sl gravelly fn-md sand & Hanford fm or Cold Creek unit \\
\hline Grab & B1T6J9 & $210.5-211.0$ & gravelly md-crs sand & Hanford fm or Cold Creek unit \\
\hline Grab & В1T6K0 & $212.0-212.5$ & sl gravelly md-crs sand & Hanford fm or Cold Creek unit \\
\hline Grab & B1T6K1 & 215.0-215.5 & sl gravelly md-crs sand & Hanford fm or Cold Creek unit \\
\hline
\end{tabular}


PNNL-17821

Table 2.5 (contd)

\begin{tabular}{lllll}
\hline Sample Type & HEIS \# & Depth (ft) & Lithology & Stratigraphic Unit \\
\hline Grab & B1T734 & $215.0-215.5$ & sl gravelly md-crs sand & Hanford fm or Cold Creek unit \\
Grab & B1T6K2 & $217.0-217.5$ & sl gravelly md sand & Hanford fm or Cold Creek unit \\
Grab & B1T6K3 & $220.0-220.5$ & sl gravelly fn sand & Hanford fm or Cold Creek unit \\
Grab & B1T6K4 & $222.5-223.0$ & sl gravelly fn-md sand & Hanford fm or Cold Creek unit \\
Grab & B1T6K5 & $225.0-225.5$ & sl gravelly fn-md sand & Hanford fm or Cold Creek unit \\
Grab & B1T6K6 & $227.0-227.5$ & md sand & Hanford fm or Cold Creek unit \\
Grab & B1T6K7 & $230.0-230.5$ & md sand & Hanford fm or Cold Creek unit \\
Grab & B1T6K8 & $232.5-233.0$ & fn sand & Hanford fm or Cold Creek unit \\
Grab & B1T6K9 & $235.0-235.5$ & fn sand & Hanford fm or Cold Creek unit \\
Grab & B1T6L0 & $237.5-238.0$ & fn sand & Hanford fm or Cold Creek unit \\
Grab & B1T6L1 & $240.0-240.5$ & md-crs sand & Hanford fm or Cold Creek unit \\
Grab & B1T6L2 & $243.0-243.5$ & sl gravelly md-crs sand & Hanford fm or Cold Creek unit \\
Grab & B1T6L3 & $245.0-245.5$ & sl gravelly md-crs sand & Hanford fm or Cold Creek unit \\
Grab & B1T6L4 & $247.5-248.0$ & sl gravelly md-crs sand & Hanford fm or Cold Creek unit \\
\hline \multicolumn{2}{c}{ Crs = coarse; fn fine; md = medium; sl = slightly; v = very } & \\
\hline
\end{tabular}

A summary hydrogeologic log, which shows an integration of all the geologic, geophysical, and moisture data collected for borehole C5924, is presented in Figure 2.20. 


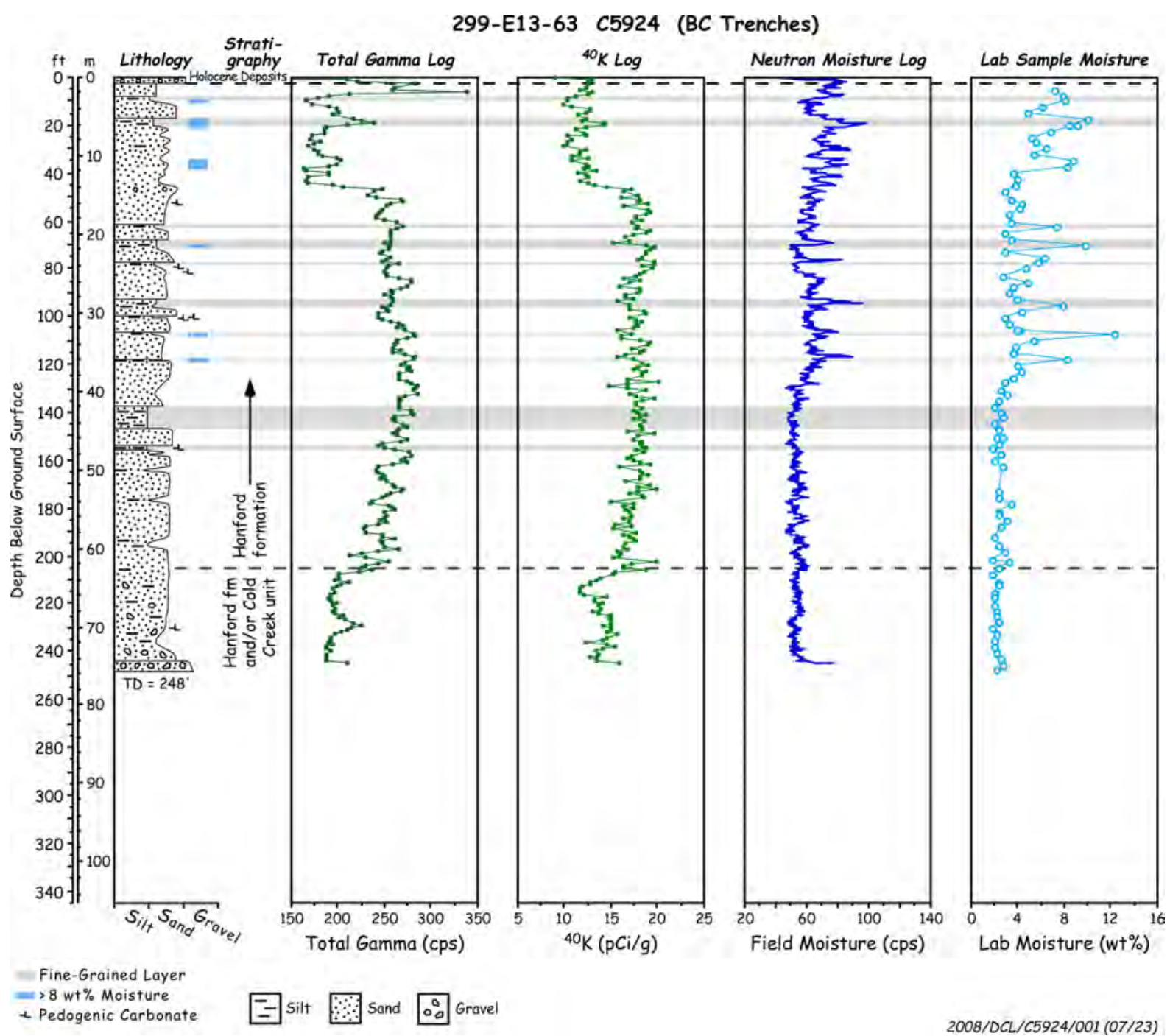

Figure 2.20. Composite Summary Log for Borehole C5924 


\subsubsection{Borehole C5925 (299-E13-64)}

Drilling grab samples collected for physical and chemical characterization from borehole C5925 (BC Cribs and Trenches Area borehole C) are listed in Table 2.6.

Table 2.6. Grab Samples Collected, Described, and Photographed from Borehole C5925

\begin{tabular}{|c|c|c|c|c|}
\hline Type & HEIS \# & Depth (ft) & Lithology & Stratigraphic Unit \\
\hline Grab & B1T884 & $5-5.5$ & fn sand & Hanford fm (H2 unit) \\
\hline Grab & B1T885 & $7.5-8.0$ & fn sand & Hanford fm (H2 unit) \\
\hline Grab & В1T886 & $10-10.5$ & sl gravelly md-crs sand & Hanford fm (H2 unit) \\
\hline Grab & B1T887 & $12.5-13.0$ & sl gravelly md-crs sand & Hanford fm (H2 unit) \\
\hline Grab & В1Т888 & $16-16.5$ & sl gravelly crs sand & Hanford fm (H2 unit) \\
\hline Grab & B1T889 & $18-18.5$ & crs sand & Hanford fm (H2 unit) \\
\hline Grab & В1T890 & $20-20.5$ & sandy silt & Hanford fm (H2 unit) \\
\hline Grab & B1T891 & $23-23.5$ & silty fn-md sand & Hanford fm (H2 unit) \\
\hline Grab & В1Т892 & $24.5-25$ & md sand & Hanford fm (H2 unit) \\
\hline Grab & В1Т893 & $28-28.5$ & sl silty fn sand & Hanford fm (H2 unit) \\
\hline Grab & В1Т894 & $30-30.5$ & sl gravelly crs sand & Hanford fm (H2 unit) \\
\hline Grab & В1T895 & $32.5-33$ & md sand & Hanford fm (H2 unit) \\
\hline Grab & В1T896 & $35-35.5$ & md sand & Hanford fm (H2 unit) \\
\hline Grab & В1Т897 & $37.5-38$ & fn-md sand & Hanford fm (H2 unit) \\
\hline Grab & В1Т898 & $40-40.5$ & crs sand & Hanford fm (H2 unit) \\
\hline Grab & B1T899 & $42.5-43$ & md sand & Hanford fm (H2 unit) \\
\hline Grab & B1T8B0 & $45-45.5$ & md sand & Hanford fm (H2 unit) \\
\hline Grab & B1T8B1 & $47.5-48$ & md-crs sand & Hanford fm (H2 unit) \\
\hline Grab & B1T8B2 & $50-50.5$ & md-crs sand & Hanford fm (H2 unit) \\
\hline Grab & В1T8B3 & $52-53$ & md sand & Hanford fm (H2 unit) \\
\hline Grab & В1T8B4 & $55-55.5$ & md-crs sand & Hanford fm (H2 unit) \\
\hline Grab & B1T8B5 & $57-57.5$ & md-crs sand & Hanford fm (H2 unit) \\
\hline Grab & B1T8B6 & $60-61$ & md-crs sand & Hanford fm (H2 unit) \\
\hline Grab & В1T8B7 & $62.5-63$ & md-crs sand & Hanford fm (H2 unit) \\
\hline Grab & В1T8B8 & $65.5-66$ & sl gravelly md sand & Hanford fm (H2 unit) \\
\hline Grab & В1Т8B9 & $65.5-66$ & sl silty sand & Hanford fm (H2 unit) \\
\hline Grab & B1T8C0 & $67.5-68$ & md sand & Hanford fm (H2 unit) \\
\hline Grab & B1T8C1 & $70-70.5$ & fn-crs sand & Hanford fm (H2 unit) \\
\hline Grab & B1T8C2 & $73-73.5$ & md-crs sand & Hanford fm (H2 unit) \\
\hline Grab & В1T8C3 & $75.5-76$ & md-crs sand & Hanford fm (H2 unit) \\
\hline Grab & B1T8C4 & $77.5-80$ & sl gravelly md-crs sand & Hanford fm (H2 unit) \\
\hline Grab & B1T8C5 & $80-80.5$ & sl gravelly md-crs sand & Hanford fm (H2 unit) \\
\hline Grab & В1T8C6 & $82.5-83$ & md-crs sand & Hanford fm (H2 unit) \\
\hline Grab & B1T8C7 & $85.5-86$ & md sand & Hanford fm (H2 unit) \\
\hline
\end{tabular}


Table 2.6 (contd)

\begin{tabular}{|c|c|c|c|c|}
\hline Type & HEIS \# & Depth (ft) & Lithology & Stratigraphic Unit \\
\hline Grab & B1T8C8 & $87.5-88$ & md sand & Hanford fm (H2 unit) \\
\hline Grab & В1Т8С9 & $90.5-91$ & sl silty md sand & Hanford fm (H2 unit) \\
\hline Grab & B1T8D0 & 93-93.5 & sl silty md sand & Hanford fm (H2 unit) \\
\hline Grab & B1T8D1 & $95-95.5$ & sl silty md sand & Hanford fm (H2 unit) \\
\hline Grab & B1T8D2 & $97.5-98$ & md sand & Hanford fm (H2 unit) \\
\hline Grab & B1T8D3 & $100-100.5$ & silty fn sand & Hanford fm (H2 unit) \\
\hline Grab & B1T8D4 & 102.5-103 & md sand & Hanford fm (H2 unit) \\
\hline Grab & B1T8D5 & $105-105.5$ & md sand & Hanford fm (H2 unit) \\
\hline Grab & B1T8D6 & 108-108.5 & md sand & Hanford fm (H2 unit) \\
\hline Grab & B1T8D7 & $110.5-111$ & md sand & Hanford fm (H2 unit) \\
\hline Grab & B1T8D8 & 110.5-111 & md sand & Hanford fm (H2 unit) \\
\hline Grab & B1T8D9 & 112.5-113 & md-crs sand & Hanford fm (H2 unit) \\
\hline Grab & B1T8F0 & 115-115.5 & md-crs sand & Hanford fm (H2 unit) \\
\hline Grab & B1T8F1 & 117.5-118 & md sand & Hanford fm (H2 unit) \\
\hline Grab & B1T8F2 & 120-120.5 & md sand & Hanford fm (H2 unit) \\
\hline Grab & B1T8F3 & 123-123.5 & md sand & Hanford fm (H2 unit) \\
\hline Grab & B1T8F4 & 125.5-126 & md-crs sand & Hanford fm (H2 unit) \\
\hline Grab & B1T8F5 & $127.5-128$ & md sand & Hanford fm (H2 unit) \\
\hline Grab & B1T8F6 & 130.5-131 & md-crs sand & Hanford fm (H2 unit) \\
\hline Grab & B1T8F7 & $132.5-133$ & silty fn sand & Hanford fm (H2 unit) \\
\hline Grab & B1T8F8 & $135-135.5$ & fn sand & Hanford fm (H2 unit) \\
\hline Grab & B1T8F9 & 137.5-138 & md-crs sand & Hanford fm (H2 unit) \\
\hline Grab & В1T8H0 & $140-140.5$ & md-crs sand & Hanford fm (H2 unit) \\
\hline Grab & В1T8H1 & $142.5-143$ & fn-md sand & Hanford fm (H2 unit) \\
\hline Grab & В1Т8H2 & $145.5-146$ & md sand & Hanford fm (H2 unit) \\
\hline Grab & В1Т8Н3 & $148-148.5$ & fn-md sand & Hanford fm (H2 unit) \\
\hline Grab & В1Т8H4 & $150-150.5$ & md sand & Hanford fm (H2 unit) \\
\hline Grab & В1T8H5 & $153-153.5$ & md sand & Hanford fm (H2 unit) \\
\hline Grab & В1T8H6 & 155-155.5 & fn-md sand & Hanford fm (H2 unit) \\
\hline Grab & В1Т8H7 & 158-158.5 & fn-md sand & Hanford fm (H2 unit) \\
\hline Grab & В1Т8Н8 & $160-160.5$ & md-crs sand & Hanford fm (H2 unit) \\
\hline Grab & В1Т8Н9 & 162.5-163 & md-crs sand & Hanford fm (H2 unit) \\
\hline Grab & B1T8J0 & $162.5-163$ & md-crs sand & Hanford fm (H2 unit) \\
\hline Grab & B1T8J1 & 165.5-166 & md-crs sand & Hanford fm (H2 unit) \\
\hline Grab & B1T8J2 & 167.5-168 & md sand & Hanford fm (H2 unit) \\
\hline Grab & B1T8J3 & $170-170.5$ & md sand & Hanford fm (H2 unit) \\
\hline Grab & B1T8J4 & $172.5-173$ & md sand & Hanford fm (H2 unit) \\
\hline Grab & B1T8J5 & $175-175.5$ & md sand & Hanford fm (H2 unit) \\
\hline Grab & B1T8J6 & $177.5-178$ & fn-md sand & Hanford fm (H2 unit) \\
\hline Grab & B1T8J7 & $180-181$ & md sand & Hanford fm (H2 unit) \\
\hline
\end{tabular}


PNNL-17821

Table 2.6 (contd)

\begin{tabular}{lllll}
\hline Type & HEIS \# & Depth $(\mathrm{ft})$ & Lithology & Stratigraphic Unit \\
\hline Grab & B1T8J8 & $182.5-183$ & md sand & Hanford fm (H2 unit) \\
Grab & B1T8J9 & $185-185.5$ & md sand & Hanford fm (H2 unit) \\
Grab & B1T8K0 & $187.5-188$ & fn-md sand & Hanford fm (H2 unit) \\
Grab & B1T8K1 & $190-190.5$ & md-crs sand & Hanford fm (H2 unit) \\
Grab & B1T8K2 & $192.5-193$ & md sand & Hanford fm (H2 unit) \\
Grab & B1T8K3 & $195-195.5$ & md sand & Hanford fm (H2 unit) \\
Grab & B1T8K4 & $197.5-198$ & md-crs sand & Hanford fm (H2 unit) \\
Grab & B1T8K5 & $200-200.5$ & md sand & Hanford fm (H2 unit) \\
Grab & B1T8K6 & $200-200.5$ & md sand & Hanford fm (H2 unit) \\
Grab & B1T8K7 & 203-203.5 & md sand & Hanford fm (H2 unit) \\
\hline Crs = coarse; fn = fine; md = medium; sl = slightly; v = very & \\
\hline
\end{tabular}

A summary hydrogeologic log, which shows an integration of all the geologic, geophysical, and moisture data collected for borehole C5925, is presented in Figure 2.21. 


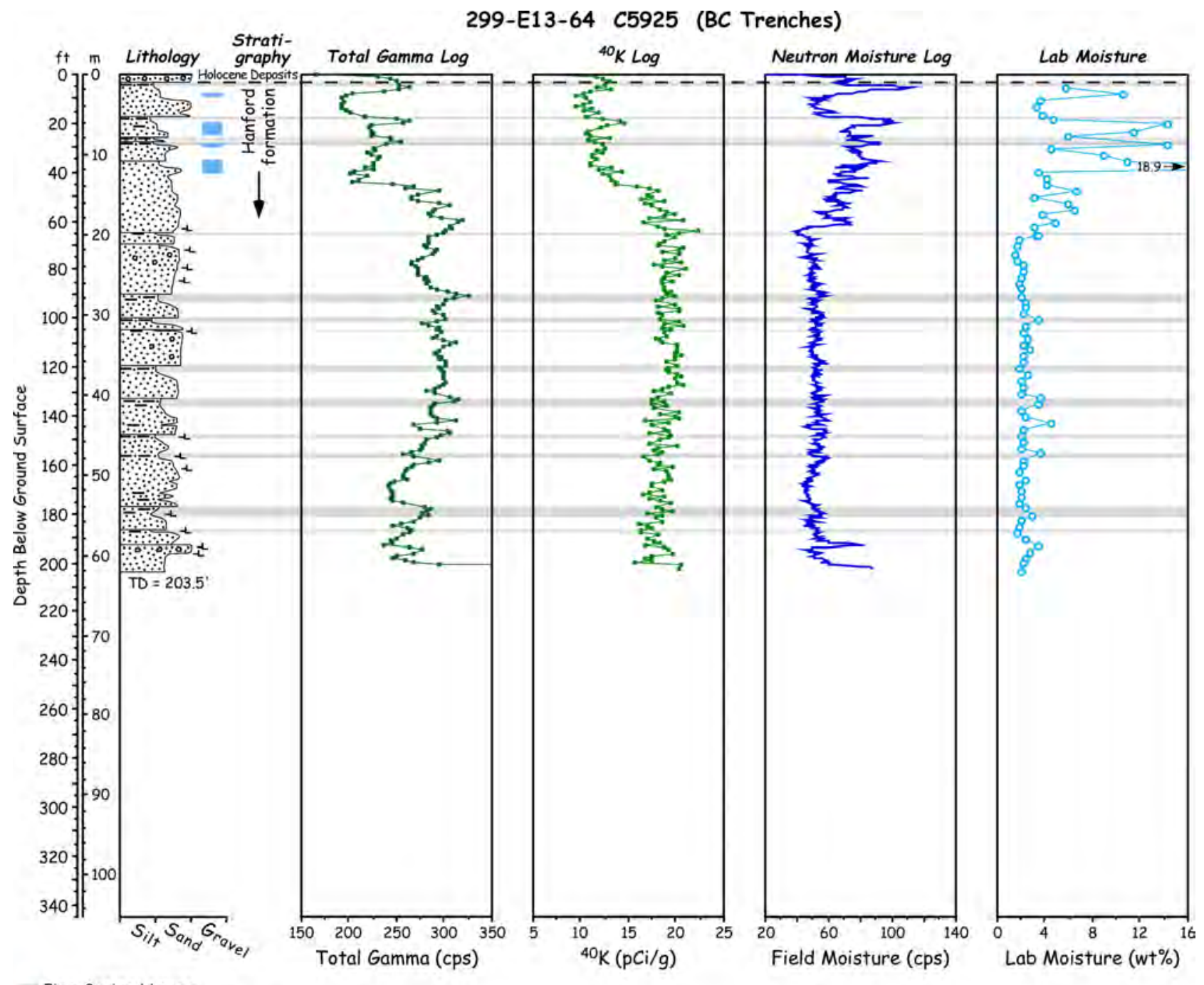

= Fine-Grained Layer

2 wt\% Moisture (Lab)
+ Pedogenic Carbonate

2008/0CL/C5925/001 (07/23)

Figure 2.21. Composite Summary Log for Borehole C5925 


\subsection{Historical Water Levels}

Hydrographs of wells in the BC Cribs and Trenches area show historical changes in groundwater levels going back to 1957. Water levels rose steadily through the 1950s, reaching a peak 1969-1971, and then decreased slowly until 1982. Then the water level increased sharply again, reaching a secondary peak in 1988-1991, which about equaled the 1969 level. Since then the water table has been steadily decreasing as shown in Figure 2.22. These changes in water level appear to be related to fluctuations in artificial recharge at waste-disposal facilities that occurred in the 200 East Area during this time. At the time that C4191 was completed in January 2004, the water table was tagged at $397.49 \mathrm{ft}$ elevation, which is about $3 \mathrm{ft}$ lower than for the hydrograph for well 299-E13-14. In July 2008, the water table was tagged at $395.4 \mathrm{ft}$ elevation for C5923, suggesting that the water table is still declining since 2004.

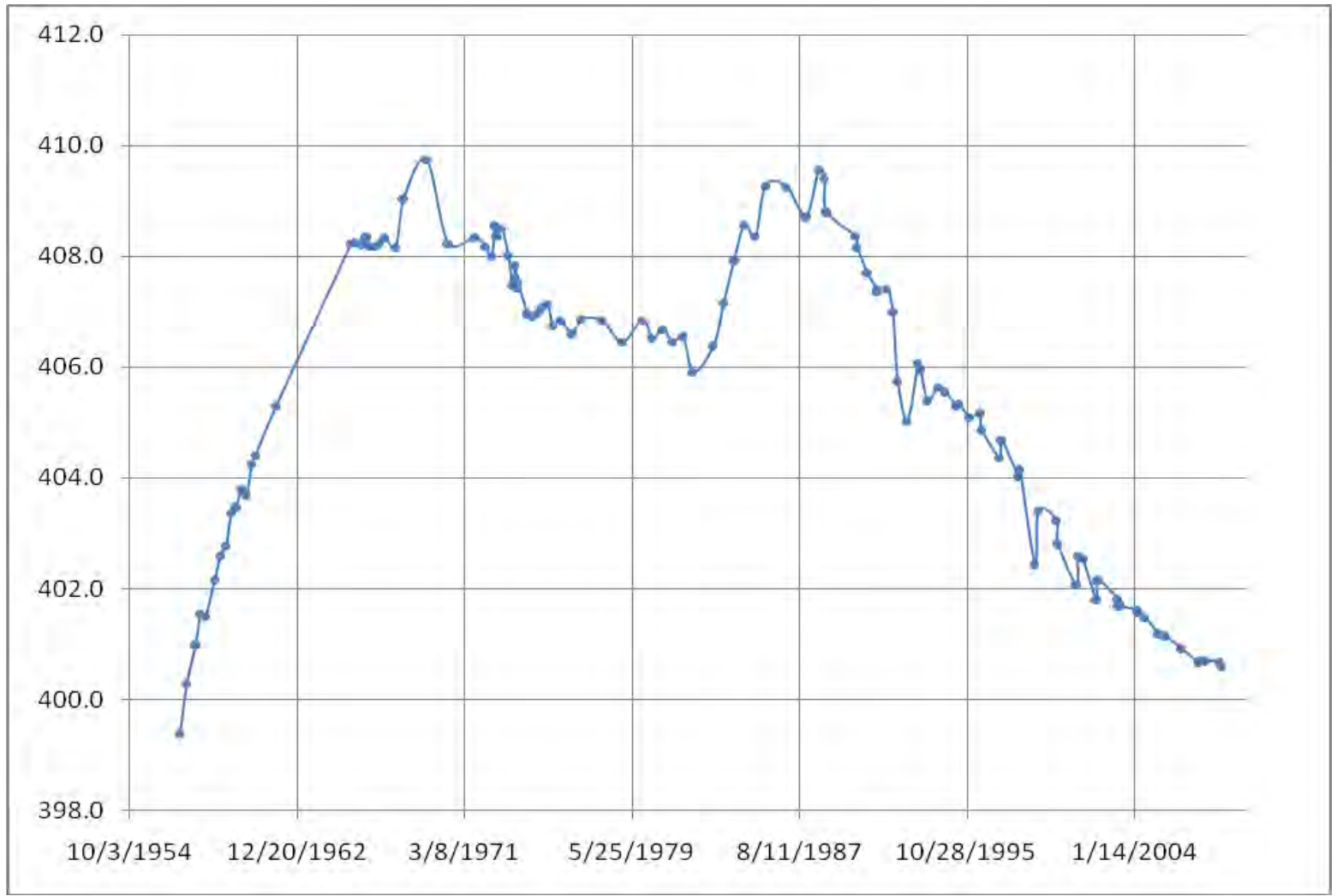

Figure 2.22. Hydrograph for Well 299-E13-14. Y-axis is elevation (ft).

The total difference in water level between 1957 and 2004 has been 10 ft, and by 2008 the water table may have dropped a total of $12 \mathrm{ft}$ since the two highest elevations. However, the pre-Hanford water table in the vicinity of the BC Cribs and Trenches lays at about $388 \mathrm{ft}$ elevation (Gephart et al. 1979). Thus, the total difference in water levels may have ranged $20 \mathrm{ft}$ or more since the beginning of liquidwaste disposal activities on the Hanford Site, suggesting that the water table may drop another $\sim 7.5 \mathrm{ft}$ to return to pre-Hanford conditions. These water-table elevation changes can be used to study whether any sediment samples obtained within these depths show signs of residual water or contaminants from groundwater when it was at its highest elevation. 


\subsection{Geochemical/Geohydrological Methods and Materials}

This chapter discusses the methods and philosophy used to characterize the sediments collected from the BC Cribs and Trenches Area boreholes and the parameters that were measured and analyzed in the laboratory. It also describes the materials and methods used to conduct analyses of the geochemical, radio-analytical, and physical properties of the sediments.

\subsection{Sample Inventory}

Samples were numbered using Hanford Environmental Information System (HEIS)-specific sample names. The core samples from the split-spoon sampling at C5923 were further identified by the numbers 1,2 , 3, or 4 , where the number 1 liner was always in the deeper position closest to the drive shoe. Four 0.5-ft Lexan liners were emplaced within the split-spoon coring device. After discarding liner 4 (top liner) as slough and using liner 1 and the core barrel drive shoe to generate a composite grab sample, liners 2 and 3 were generally sent to the PNNL ESL laboratory in an intact condition. Both core liners (total 39) and grab (total 147 including duplicates) were received from borehole C5923 (A). Additional laboratory duplicate samples were generated during sub-sampling and designated by DUP so that Hanford Analytical Services Quality Assurance Requirements Documents (HASQARD) QA/QC protocols could be met. The PNNL document for implementing HASQARD is Conducting Analytical Work in Support of Regulatory Programs, located at http://etd.pnl.gov/docs/conducting-work/index.stm. Details about the core and grab samples received from borehole A (C5923) are listed in Table 2.4. Only grab samples were received from Borehole C5924 (B) (total 105), C (total 84), and C4191 (total 126). More details and a listing of the grab samples received from boreholes C5924 (B), C5925 (C), and C4191 are found in the previous section (see Table 2.5, Table 2.6, and Table 2.3, respectively).

\subsection{Approach}

From past borehole characterization investigations on Hanford sediments, it was found that changes in sediment type and contaminant concentrations often occurred within a distance of a few inches within a given liner (Serne et al. 2002b). It was concluded that a more methodical scoping approach would be necessary to provide the technical justification for selecting samples for detailed characterization as defined in data quality objectives processes (see, for example, DOE 1999). Subsequently, a method was developed to select samples that considered depth, geology (e.g., lithology, grain-size composition, and carbonate content), individual sediment sample contaminant concentration (e.g., radionuclides, nitrate), moisture content, and overall sample quality. Extraction/leaching procedures were performed and certain key parameters (i.e., moisture content, gamma energy analysis [GEA]) were measured on each sediment sample. During the geologic examination of the grab samples, the sediment contents were sub-sampled for moisture content, gamma-emission radiocounting, 1:1 water extractions (which provide soil $\mathrm{pH}$, alkalinity, [EC, cation and anion data, and ionic strength calculation), cation exchange capacity (CEC), and surface area measurement. Sampling preference was always biased towards the finer-grained and/or wetter material contained in each grab sample. The remaining sediment from each grab sample was then sealed and placed in cold storage. To date, only grab samples from boreholes C5923, C5924, C5925, and C4191 were used for geochemical characterization. Core samples received from borehole C5923 (A) were used solely for laboratory geophysical resistivity and other hydraulic measurements described in sections 4.2 and 3.3-11 to 3.3-15, respectively. 


\subsection{Materials and Methods}

During sub-sampling, every effort was made to minimize moisture loss and prevent cross contamination between samples. Depending on the sample matrix, very coarse pebbles and larger material (i.e., >32 mm) were removed during sub-sampling. Larger substrate was excluded to provide moisture contents representative of GEA and 1:1 sediment: water-extraction samples. Therefore, the results from the sub-sample measurements may contain a possible bias toward higher concentrations for some analytes that would be preferentially associated with the smaller sized sediment fractions.

Procedures ASTM D2488-93 (1993) and PNL-MA-567-DO-1 (PNL 1990) were followed for visual descriptions and geological descriptions of all samples. The sediment classification scheme used for geologic identification of the sediment types (used solely for graphing purposes in this report) was based on the modified Folk/Wentworth classification scheme (Folk 1968 and Wentworth 1922).

This section also describes the laboratory methods used to characterize the geo-hydrologic properties of soil samples collected from Borehole C5923 (A) during the recent drilling campaign. Laboratory measurements were performed on intact cores and grab samples to characterize geo-hydrologic properties. Measured properties included particle-size distribution (PSD), particle density $\left(\rho_{\mathrm{s}}\right)$, specific surface area (SSA), porosity $(\phi)$, hydraulic conductivity $\left(\mathrm{K}_{\mathrm{w}}\right)$, air permeability $\left(\mathrm{K}_{\mathrm{a}}\right)$, and water retention, $\theta(\psi)$, which relates volumetric water content, $\theta$, to the matric potential, $\psi$. A total 20 grab samples from Borehole C5923 (A) and 10 from Borehole C5924 (B) were selected for particle-size analysis and surface area measurements. In addition, 12 samples from Borehole C5923 (A) were selected for analysis of pneumatic and hydraulic properties. In general, samples were selected from fine textured lenses and the first coarse-textured layer occurring beneath each fine layer, i.e., layer sequences that might constitute a capillary break.

\subsubsection{Moisture Content}

Gravimetric water contents of the sediment samples were determined using PNNL procedure PNNLAGG-WC-001 (PNNL 2005). This procedure is based on the American Society for Testing and Materials procedure "Test Method for Laboratory Determination of Water (Moisture) Content of Soil and Rock by Mass” (ASTM D2216-98 [ASTM 1998]). One representative sub-sample of at least 15 to 70 g was used. Sediment aliquots were placed in tared containers, weighed, and dried in an oven at $105^{\circ} \mathrm{C}$ until constant weight was achieved, which took at least 24 hours. The containers were removed from the oven, sealed, cooled, and weighed. At least two weighings, each after a 24-hour heating period, were performed to verify that all moisture was removed. All weighings were performed using a calibrated balance. A calibrated weight set was used to verify balance performance before weighing the samples. The gravimetric water content was computed as the percentage change in soil weight before and after oven drying.

\subsubsection{1:1 Sediment: Water Extracts}

Water-soluble inorganic constituents were determined using a 1:1 sediment:de-ionized-water extract method. The extracts were prepared by adding an exact weight of de-ionized water to approximately 60 to $80 \mathrm{~g}$ of sediment (post air-drying and sieving). The weight of de-ionized water needed was calculated based on the weight of the air-dried samples (residual moisture in the air-dried samples was considered 
negligible). An appropriate amount of de-ionized water was added to screw-cap jars containing the sediment samples. The jars were sealed and briefly shaken by hand and then placed on a mechanical orbital shaker for 1 hour. The samples were allowed to settle overnight until the supernatant liquid was fairly clear. The supernatant was carefully decanted, filtered (passed through $0.45-\mu m$ membranes) and analyzed for conductivity, $\mathrm{pH}$, anions, cations, alkalinity, and radionuclide analyses. More details can be found in Rhoades (1996) and within Methods of Soils Analysis - Part 3 (ASA 1996).

\subsubsection{1 pH and Conductivity}

Two aliquots of approximately 3-mL volume of the 1:1 sediment:water extract supernatants were used for $\mathrm{pH}$ and conductivity measurements. The $\mathrm{pH}$ of the extracts was measured with a solid-state $\mathrm{pH}$ electrode and a pH meter calibrated with buffers 7 and 10. The EC was measured using a Pharmacia Biotech Conductivity Monitor. Approximately 2 to 3 milliliters of filtered sample were measured in the conductivity meter and compared to potassium chloride standards with a range of 0.001 to $1.0 \mathrm{M}$.

\subsubsection{Anions}

The 1:1 sediment:water extracts were analyzed for anions using ion chromatography (IC). Fluoride, chloride, nitrite, bromide, nitrate, phosphate, and sulfate were separated on a Dionex AS17 column with a gradient elution of $1 \mathrm{mM}$ to $35 \mathrm{mM}$ sodium hydroxide and measured using a conductivity detector. This methodology is based on U.S. Environmental Protection Agency (EPA) Method 300.0A (EPA 1984) with the exception of using the gradient elution of sodium hydroxide.

\subsubsection{Cations and Trace Metals}

Major cation analysis was performed using an inductively coupled plasma-optical emission spectroscopy (ICP-OES) unit using high-purity calibration standards to generate calibration curves and verify continuing calibration during the analysis run. Dilutions of $100 \times, 50 \times, 10 \times$, and $5 \times$ were made of each 1:1 water extraction for analysis to investigate and correct for matrix interferences. Details of this method are found in EPA Method 6010B (EPA 2000b). The second instrument used to analyze trace metals, including technetium-99 and uranium-238, was an inductively coupled plasma-mass spectrometer (ICP-MS) using the PNNL-AGG-415 method (PNNL 1998). This method is quite similar to EPA Method 6020 (EPA 2000c).

\subsubsection{Alkalinity}

Alkalinity was measured using a standard titration with acid method. The alkalinity procedure is equivalent to the U.S. Geological survey method in the National Field Manual for the Collection of Water-Quality Data (USGS 2004). Measured alkalinity (mg/L as $\mathrm{CaCO}_{3}$ ) was converted to determine $\mathrm{CO}_{3}{ }^{2-}$ concentration in solution.

\subsection{3 $8 \mathrm{M}$ Nitric Acid Extracts and Elemental Analysis}

Approximately $20 \mathrm{~g}$ of oven-dried sediment was contacted with 8-M nitric acid at a ratio of approximately five parts acid to one part sediment. The slurries were heated to about $80^{\circ} \mathrm{C}$ for several hours, and then the fluid was separated by filtration through $0.2-\mu \mathrm{m}$ membranes. The acid extractions 
were analyzed for major cations and trace metals using ICP-OES and ICP-MS techniques, respectively, to determine the elemental composition of the bulk sediment samples. The acid digestion procedure is based on EPA SW-846 Method 3050B (EPA 2000a).

\subsubsection{Radioanalytical Analysis}

The GEA was performed on selected grab sediments from the four boreholes. All samples for GEA were analyzed using $60 \%$ efficient intrinsic germanium gamma detectors. All germanium counters were efficiency calibrated for distinct geometries using mixed gamma standards traceable to the National Institute of Standards and Technology (NIST). Field-moist samples were placed in $150-\mathrm{cm}^{3}$ counting containers and analyzed for 100 minutes in a fixed geometry. All spectra were background-subtracted. Spectral analysis was conducted using libraries containing most mixed fission products, activation products, and natural decay products. Control samples were run throughout the analysis to verify correct operation of the detectors. The controls contained isotopes with photo peaks spanning the full detector range and were monitored for peak position, counting rate, and full-width half-maximum. Details are found in Gamma Energy Analysis, Operation, and Instrument Verification using Genie2000 ${ }^{\mathrm{TM}}$ Support Software (PNNL 1997).

Aliquots of sediment used for strontium-90 analysis were weighed and spiked with strontium-85. Samples were then leached overnight with concentrated nitric acid after which an aliquot of the leachate was diluted 50\% with de-ionized water. The resulting solutions were passed through SrSpec columns obtained from Eichrom (Darien, IL) with $8 \mathrm{M}$ nitric acid to capture strontium. The resin column was then washed with 10 column volumes of $8 \mathrm{M}$ nitric acid. The strontium was eluted from the SrSpec column using de-ionized water. The de-ionized water eluent was evaporated to dryness in a liquid scintillation vial and was ready for counting after adding the cocktail. The purified strontium samples were analyzed first by gamma spectroscopy to determine chemical yield from the added strontium-85 tracer and to quantify any contamination from other gamma emitters such as cesium-137 that might have been present in the sediment. De-ionized eluents were then analyzed by liquid scintillation counting to determine the amount of strontium-90. A matrix spike, a blank spike, a duplicate, and procedure blanks were run with each batch of samples (generally 20 samples) to determine the efficiency of the separation procedure as well as the purity of reagents. Chemical yields were generally good with some explainable exceptions. Matrix and blank spike yields were good, bias was consistent, and blanks were below detection limits.

The nickel-63 procedure recovers all the nickel (both radioactive and stable) from the BC Cribs and Trench area sediments with very high decontamination of other beta emitters. No yield monitor was used other than the nickel-63 spike used in matrix and blank spikes. An aliquot of the acid extract sample (same acid extract as strontium-90; see above) was placed in a beaker, and $0.1 \mathrm{mg}$ of stable nickel and $2 \mathrm{mg}$ of stable iron (both as 10,000 ppm solutions) were added to the acid extract. Additionally, $200 \mu \mathrm{L}$ of 5000 dpm nickel-63 was used for the blank spike and matrix spike. The treated acid-extract aliquots were evaporated to dryness and then wet-ashed with concentrated nitric acid to eliminate halides, cyanide, organics, and other species that could complex with the nickel. The dry residue was dissolved in dilute nitric acid and then transferred to a centrifuge tube. Strong sodium hydroxide solution was added to precipitate the iron, as $\mathrm{Fe}(\mathrm{OH})_{3}$, which co-precipitates the nickel from solution. This step separates the nickel from the bulk of the treated acid extract. The iron-nickel hydroxide precipitate was dissolved in a small amount of hydrochloric acid, and $5 \mathrm{mg}$ of strontium carrier was added. The solution was made basic with concentrated ammonium hydroxide $\left(\mathrm{NH}_{4} \mathrm{OH}\right)$, and then ammonium carbonate $\left(\mathrm{NH}_{4}\right)_{2} \mathrm{CO}_{3}$ was 
added and reacted for 10 minutes to form $\mathrm{Fe}(\mathrm{OH})_{3}$ and $\mathrm{SrCO}_{3}$ precipitates. During this step, the nickel stayed in solution as an ammonium complex. Most other elements, including strontium, yttrium, the rare earth, and iron, precipitated. The sample slurry then was centrifuged, and the separated supernatant was transferred to a clean container.

The precipitate was dissolved in a small amount of hydrochloric acid as before, and the precipitation was repeated as before to recover the small amount of nickel that might have been entrained in the precipitate. The second supernatant was combined with the first supernatant and evaporated to dryness. The dry residue was dissolved in dilute (1:10) ammonium hydroxide and transferred to a centrifuge tube. Dimethylglyoxime was added to precipitate the nickel as a dimethylglyoxime complex. After the precipitate was completely formed, methylene chloride $(10 \mathrm{~mL})$ was added, and the sample was shaken thoroughly. After centrifugation, the upper layer was washed twice with dilute ammonium hydroxide. Nickel was stripped back out of the methylene chloride solution by shaking it with dilute hydrochloric acid. The hydrochloric acid was evaporated off, and the remaining nickel in solution was counted for nickel-63 by liquid scintillation count (LSC) after adding cocktail solution (15 mL).

\subsubsection{Unsaturated Flow Apparatus (UFA) Analysis}

Several field-moist sediments were packed in drainable cells that were inserted into an UFA. The samples were centrifuged for up to 8 hours at several thousand g's to squeeze the pore water out of the sediment. The pore waters were characterized for $\mathrm{pH}$, EC, cation, trace metals, selected radionuclides, and anions with the same techniques as used for the 1:1 sediment-to-water extracts.

\subsubsection{Pore Water Composition Analysis}

Major cations $\left(\mathrm{Na}^{+}, \mathrm{Ca}^{2+}, \mathrm{K}^{+}, \mathrm{Mg}^{2+}\right.$, and $\left.\mathrm{Ba}^{2+}\right)$ and anions $\left(\mathrm{NO}_{3}{ }^{-}, \mathrm{PO}_{4}{ }^{3-}, \mathrm{CO}_{3}{ }^{2-}, \mathrm{SO}_{4}{ }^{2-}, \mathrm{Cl}^{-}, \mathrm{F}^{-}\right.$, and when present $\mathrm{NO}_{2}{ }^{-}$) concentration measured from both 1:1 water extracts and UFA solution were used to determine the total inorganic salt concentration and the ionic strength (moles/L). The total ionic strength (M) of the pore water was calculated by the molar concentration of each ionic species multiplied by its charge squared:

$$
I=\frac{1}{2} \sum_{i} C_{i} Z_{i}^{2}
$$

where $\mathrm{C}_{i}$ is the molar concentration (mole/L) of each ionic species, and $\mathrm{Z}$ is the charge valence of each ionic species.

Equivalents of both cations and anions were also determined by the measured molar concentration multiplied by its charge valence. Equivalents of total cation and anion species were used to calculate charge balance of measured ionic species in pore water by:

$$
A B S\left[\frac{(\text { cations }- \text { anions })}{(\text { cations }+ \text { anions })}\right]
$$

where ABS is the absolute value; cations and anions are total cation and anion concentrations with respect to equivalents. 


\subsubsection{Carbon Content on Sediment}

The total carbon concentration in aliquots of sediment from the core liners was measured with a Shimadzu TOC-V CSN instrument with a SSM-5000A Total Organic Carbon Analyzer by combustion at approximately $900^{\circ} \mathrm{C}$ based on the ASTM Method, "Standard Test Methods for Analysis of Metal Bearing Ores and Related Materials by Combustion Infrared Absorption Spectrometry” (ASTM 2001). Samples were placed into pre-combusted, tared, ceramic combustion sample holders and weighed on a calibrated balance. After the combustion sample holders were placed into the furnace introduction tube, an approximately 2-minute waiting period was allowed for the ultra-pure oxygen carrier gas to remove any carbon dioxide $\left(\mathrm{CO}_{2}\right)$ introduced to the system from the atmosphere during sample placement. After this sparging process, the sample was moved into the combustion furnace, and the combustion was begun. The carrier gas then delivered the sample combustion products to the cell of a non-dispersive infrared (NDIR) gas analyzer where the $\mathrm{CO}_{2}$ was detected and measured. The amount of $\mathrm{CO}_{2}$ measured is proportional to the total carbon content of the sample. Adequate system performance was confirmed by analyzing known quantities of a calcium carbonate standard.

Sediment/solid samples were analyzed for inorganic carbon content by placing a small aliquot of oven-dry sediment into a ceramic combustion boat. The combustion boat was placed into the sample introduction tube where it was sparged with ultra-pure oxygen for 2 minutes to remove atmospheric $\mathrm{CO}_{2}$. A small amount (usually $0.6 \mathrm{~mL}$ ) of $3 \mathrm{M}$ phosphoric acid was then added to the sample in the combustion boat. The boat was moved into the combustion furnace where it was heated to $200^{\circ} \mathrm{C}$. Samples were completely covered by the acid to allow a full reaction to occur. Ultra-pure oxygen swept the resulting $\mathrm{CO}_{2}$ through a dehumidifier and scrubber into the cell of an NDIR gas analyzer where the $\mathrm{CO}_{2}$ was detected and measured. The amount of $\mathrm{CO}_{2}$ measured is proportional to the inorganic carbon content of the sample.

The organic carbon content was determined by the difference between the inorganic carbon and total carbon concentration.

\subsubsection{Particle Size Distribution}

T he PSD of rocks and soils is important in understanding their hydrogeophysical and geochemical properties. Two methods were used to determine PSD: 1) mechanical analysis by dry sieving, and 2) laser diffraction spectrometry (LDS). Soil samples were separated into four grain-size fractions, namely, gravel, sand, silt, and clay, and sub classes were based on the logarithmic Udden-Wentworth grade scale (Wentworth 1922).

Dry sieving was used to separate the sediments above $62 \mu \mathrm{m}$ into the very coarse, coarse, medium, fine, and very fine subclasses of the gravel and sand fractions. All sieving was performed in a fume hood using a Gilson SS-15 Sieve Shaker with two stacks of 8-in. sieves, one for the gravel fraction and one for the sand fraction. The gravel sieve stack included the $2 \frac{1 / 2}{\mathrm{in}}$., $1 \frac{11 / 4}{\mathrm{in}}$., $5 / 8$ in., and $5 / 16$ in., \# 5 sieves and a pan. The sand sieve stack consisted of the \#10,\#18, \#35, \#60,\#120, and \#230 sieves and a pan. Approximately 500 grams of each sample of interest was placed on a sheet of brown shipping paper laid out on wire racks to air dry over a 48-hr period. Each sample was first sieved through the gravel sieve stack and sieved for about 30 minutes at 3,000 oscillations/min, and the mass of soil was retained on each sieve recorded. The soil collected in the pan was then placed on the sand sieve stack and sieved for 30 minutes, and the mass was retained on each sieve and in the pan recorded. The soil collected in the 
pan consisted of particles with a mean diameter $<63 \mu \mathrm{m}$ ( $<\# 230$ sieve). The percentage of each size fraction was used to determine texture according to the USDA classification. Grain-size statistics were calculated from the grain-size distributions using the methods described by Ward et al. (2006a).

The LDS measurements of PSD were performed with a Mastersizer 2000 (Malvern Instruments, Inc., Southborough, MA). The LDS method requires that the particles be in a dispersed state, either in liquid (suspension) or in air (aerosol). The former is commonly referred to as the "wet" method (LDS-W) while the latter is termed the "dry" method (LDS-D). For these analyses, the LDS-W method was used with a dispersion accessory. The dispersion accessory consists of a 20-mL sample flow cell with a continuous variable and independent pump and ultrasound. The ultrasonic processor is used for particle-size reduction and disintegration of aggregates, a process known as sonication. Both flow and sonication can be controlled and altered. For these measurements, PSD was determined before, during, and after sonication to allow the influence of sonication energy stage on the sample's PSD to be determined. Samples were dispersed in "quartz water" that was free of dispersing agents.

The particle suspensions were placed in a stirred tank and were circulated through the cell, which was placed in the path of the laser beam. A pump speed of 3,000 RPM was used. The laser beam (He-Ne laser, wavelength $633 \mathrm{~nm}$ ) was collimated to $18 \mathrm{~mm}$. The focal length was $1,000 \mathrm{~mm}$, and the cell depth was $14.2 \mathrm{~mm}$. The scattered light was received on a detector consisting of 32 photosensitive rings that detected particle diameters in the range from 19 to 1,880 $\mu \mathrm{m}$. PSDs were measured before and during sonication. For each condition, three successive 12-second measurements of PSD were taken. An average of these measurements was then generated by the analyzer software (Mastersizer 2000 software, Version 5.4). Once measurements were complete, the sonic power for the next condition was set, the sample was given 30 to 60 seconds to equilibrate, and the next set of measurements was taken. Volumetric PSDs were calculated from the distribution of the light energy on the detector using the Fraunhofer diffraction theory for spherical particles (Weiner 1984; Allen 1997). The analysis employed a particle refractive index and absorption of 1.544 and 0 , respectively, and a suspending phase-particle refractive index of 1.33 (for water). Volume PSDs corresponding to coarse (31 to $62.5 \mu \mathrm{m}$ ), medium (16 to $31 \mu \mathrm{m}$ ), fine ( 8 to $16 \mu \mathrm{m}$ ), and very fine ( 4 to $8 \mu \mathrm{m}$ ) silt and to coarse (2 to $4 \mu \mathrm{m}$ ) and fine (1 to $2 \mu \mathrm{m}$ ) clay were determined and scaled to the total mass of sample passing through the \#230 sieve. These data were combined with the dry sieve data to generate a complete PSD curve. Particle-size statistics were calculated from the grain-size distributions using the methods described by Ward et al. (2006a).

\subsubsection{Particle Density}

Particle density, $\rho_{\mathrm{s}}$, is widely used for establishing the density-volume relationship of soil materials. It is used to calculate porosity and estimate optimum moisture in compaction tests. Particle density is defined as the mass of solids in a sample divided by the volume of the solids. Particle density is commonly assumed to be $2.65 \mathrm{Mg} / \mathrm{m}^{3}$, which corresponds to the specific gravity of quartz. However, many silicate and non-silicate minerals, such as feldspars, granites, micas, and kaolinite, exhibit densities from 2.3 to 3.0 whereas the density of iron-containing minerals like hematite and goethite often exceeds 3.3. The mean particle density of a soil therefore depends on the mineral composition and is calculated using a weighted mean. Particle density, $\rho_{\mathrm{s}}$, measurements were performed on three replicates of each size fraction less than $2 \mathrm{~mm}$ using the pycnometer method (Blake and Hartge 1986; ASA 1996). The mean particle density of each sample was then calculated from the $n$ weight fractions, $\mathrm{x}_{1}, \mathrm{x}_{2}, \ldots, \mathrm{x}_{\mathrm{n}}$ and the associated particle densities, $\rho_{s_{1}}, \rho_{s_{2}}, \ldots, \rho_{s_{n}}$, of each fraction as: 


$$
\rho_{s}=\left(\frac{x_{1}}{\rho_{s_{1}}}+\frac{x_{2}}{\rho_{s_{2}}}+\ldots+\frac{x_{n}}{\rho_{s_{n}}}\right)^{-1}
$$

\subsubsection{Porosity and Bulk Density}

Porosities were determined on 12 undisturbed cores from Borehole C5923 (A) by measuring the water content at saturation using time domain electrometric (TDR) techniques. These measurements were made after saturating the cores for saturated hydraulic conductivity measurements. Bulk density was calculated as the ratio of the dry weight of sediment in the packed core to the volume of the core.

\subsubsection{Specific Surface Area}

The SSA is a measure of the exposed surface of a solid sample on the molecular scale and is important for the calculation of sorption properties, surface conductance of the different lithofacies, and description of the retention of water at low saturations. The SSA was measured on 20 grab samples from Borehole C5923 (A) using a Micromeritics ASAP 2020 gas sorption surface-area analyzer. The Monosorb is a direct-reading dynamic-flow surface-area analyzer that uses a single-point BrunauerEmmett-Teller (BET) method to determine the surface area (Brunauer et al. 1938). Standard surface-area reference materials were used to calibrate the instrument over the anticipated range of surface areas. Representative sediment samples from Borehole C5923 (A) were first rinsed three times for short time periods in deionized water to remove the high pore-water salt content. The washed sediments were dried overnight using a heating mantle and then weighed to an accuracy of $0.001 \mathrm{~g}$. The surface analyzer measures the quantity of a gas adsorbed on a solid surface when it is cooled with liquid nitrogen by sensing the change in thermal conductivity of a flowing mixture of an adsorbate (nitrogen) and an inert (helium) carrier gas. With nitrogen and helium, the surface area can be determined down to $0.1 \mathrm{~m}^{2}$. With mixtures of krypton and helium, the limit of detection is extended down to $0.01 \mathrm{~m}^{2}$. The isotherm points are transformed with the BET equation:

$$
\frac{1}{W\left[\left(P_{0} / P\right)-1\right]}=\frac{1}{W_{m} C}+\frac{(C-1)}{W_{m} C} \frac{P}{P_{0}}
$$

where $\quad \mathrm{W}=$ weight of nitrogen adsorbed at a given $\mathrm{P} / \mathrm{P}_{0}$

$\mathrm{P}=$ pressure at each measurement point

$\mathrm{P}_{0}=$ saturation pressure of the gas

$\mathrm{W}_{\mathrm{m}}=$ weight of gas required to give monolayer coverage

C constant related to the heat of adsorption.

A linear relationship between $1 / \mathrm{W}\left[\left(\mathrm{P}_{0} / \mathrm{P}\right)-1\right]$ and $\mathrm{P} / \mathrm{P}_{0}$ is required to obtain the quantity of nitrogen adsorbed. This linear portion of the curve is restricted to a limited portion of the isotherm, generally from 0.05 to $0.30\left(\mathrm{P} / \mathrm{P}_{0}\right)$. The slope and intercept are used to determine the quantity of nitrogen adsorbed in the monolayer and used to calculate the surface area. For the single-point method, the intercept is taken as zero or a small positive value, and the slope from the BET plot is then used to calculate the surface area. The SSA is then calculated by dividing the average of the surface-area measurements obtained by the BET method by the weight of the sample. 


\subsubsection{Cation Exchange Capacity}

The CEC of selected grab samples from borehole C5923 (A) vadose zone sediments was measured by taking $15 \mathrm{~g}$ of distilled water pre-rinsed (three short-duration rinses) air-dried sediment and extracting one time with $1.0 \mathrm{M}$ ammonium acetate (35 mL) to prevent additional dissolution of calcium carbonate. The sediment-ammonium acetate slurries were gently shaken on a linear shaker for 24 hours and then centrifuged. Each supernatant solution was filtered through a 0.2-microm membrane. The exchangeable cations (Ba, $\mathrm{Ca}, \mathrm{K}, \mathrm{Mg}, \mathrm{Na}$, and $\mathrm{Sr}$ ) in the ammonium acetate extract were analyzed by ICP-OES. Cation concentrations were converted to meq and summed to get the total CEC of the composite sediments (in meq/100 g). Our method is quite similar to the ammonium acetate method used to estimate exchangeable cations found in the chapter of ASA (1996) written by Suarez (1996; 583-584).

\subsubsection{Saturated Hydraulic Conductivity}

Hydraulic conductivity is known to vary with saturation and functions describing the saturation dependence are needed to interpret contaminant distributions and to predict flow and transport. The hydraulic conductivity, $K$, as a function of pressure head, $[K=f(h)]$, is the proportionality factor in the Richards' water-flow equation that relates the flux density to a unit potential gradient at a specific water content. Mathematical functions are commonly used to calculate the unsaturated conductivity from the water-retention function, $\theta(h)$, with knowledge of the saturated hydraulic conductivity, $\mathrm{K}_{\mathrm{s}}$. Several functions are available, but the Mualem conductivity function is most commonly used (in conjunction with the van Genuchten retention function). The unsaturated hydraulic conductivity is defined as:

$$
K(h)=K_{s} \frac{\left[1-(\alpha h)^{m n}\left(1+(\alpha h)^{n}\right)^{-m}\right]^{2}}{\left[1+(\alpha h)^{n}\right]^{2 m}}
$$

where $\mathrm{K}_{\mathrm{s}}=$ saturated hydraulic conductivity, the proportionality constant in the Darcy equation that relates the flux density to a unit potential gradient

$\mathrm{m}=1-1 / \mathrm{n}$

$\alpha=$ inverse of the air entry pressure

$l=$ pore-connectivity parameter, estimated to be about 0.5 as an average for many soils (Mualem 1976).

However, more recent studies (e.g., Schuh and Cline 1990; Schaap and Leij 1998; Zhang et al. 2004; Ward et al. 2006b) suggest that values of $\ell$ (rather than 0.5) may represent the hydraulic behavior of many soils equally well or better. In layered soils, saturation-dependent anisotropy, which can lead to increased lateral flow in some layers, is best described by a pore connectivity tensor (Zhang et al. 2003; Raats et al. 2004; Ward et al. 2006b).

Saturated hydraulic conductivity measurements were made on 12 undisturbed core liners from Borehole C5923 (A) using the falling-head method (see Figure 3.1). A major advantage of the fallinghead method over constant head and other methods is that it can be used for both fine-grained and coarsegrained soils, both of which are present at the BC Cribs site. For hydraulic measurements, including falling-head tests, each core liner was fitted with two machined plexiglas ${ }^{\circledR}$ collars, one at each end, to allow attachment of end plates. The end plates were attached, the core saturated and weighed, and a small-diameter reservoir attached to the bottom end of the core. 
PNNL-17821

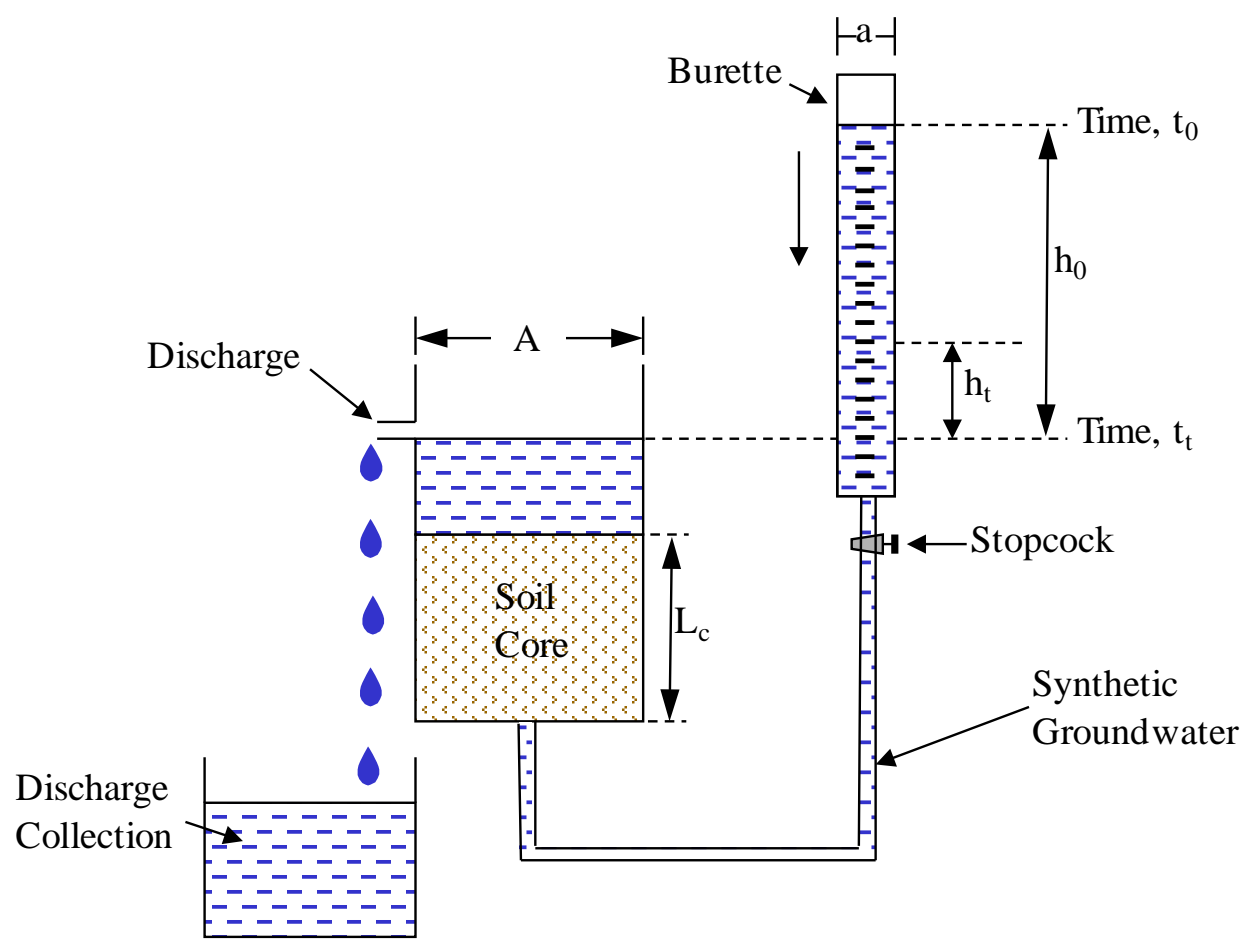

Figure 3.1. Schematic of Falling Head Apparatus to Measure Saturated Hydraulic Conductivity

For these tests, a burette was used as the small-diameter reservoir. The burette was filled with water, and the height at time zero, $\mathrm{h}_{0}$, was recorded. The measurement was started by opening the burette stopcock, and the rate of decline of the water level in the burette was recorded over time. The hydraulic head at the upgradient end of the sample was allowed to decline from $h_{0}$, at time $0\left(t_{0}\right), t_{t} h_{t}$ at some time $t\left(t_{t}\right)$. The calculation of $\mathrm{K}_{\mathrm{s}}$ is based on Darcy's Law, with $\mathrm{K}_{\mathrm{s}}$ being defined as:

$$
K_{s}=\left[\frac{a L_{c}}{A\left(t_{t}-t_{0}\right)}\right] \cdot \log \left(\frac{h_{0}}{h_{t}}\right)
$$

In Eq. (3.9), $a$ is the cross-sectional area of the small reservoir, A is the cross-sectional area of the soil core, and $\mathrm{L}_{\mathrm{c}}$ is the length of the soil core. Equation (3.9) can be simplified to give $\mathrm{K}_{\mathrm{s}}$ in terms of the ratio of the reservoir and core diameters, the elapsed time and head ratios, i.e.,

$$
K_{s}=\left(\frac{d_{r}}{d_{c}}\right)^{2} \cdot\left[\frac{L_{c}}{t_{t}-t_{0}}\right] \cdot \log \left(\frac{h_{0}}{h_{t}}\right)
$$

where $d_{r}$ is the diameter of the reservoir, $L_{c}$ is the length of the core sample, and $d_{c}$ is the diameter of the core. The head at the up-gradient end of the core is simply the height of the water level in the burette, above the datum (the level of the discharge tube), whereas the head at the down-gradient end of the core 
is the height of the discharge point above the datum. Each measurement was repeated three times using different initial hydraulic gradients. A mean value of $\mathrm{K}_{\mathrm{s}}$ was then calculated for head gradient as the average of the three replicates. The photographs in Figure 3.2 show different stages of column preparation for saturated hydraulic conductivity measurements and the soaking tank with fixed overflow used for containing the permeability cell during falling head tests. Owing to the nature and levels of contaminants in the cores, all work conducted on the cores was performed in a radiation control area.

\subsubsection{Air Permeability}

Air permeability is important to gas-transport studies and at the BC Cribs is needed for remediation techniques that may involve the injection of gas-phase reactants and heated dehumidified air for desiccation. Air permeability is relatively easy to measure and can be used as an indicator of soil hydraulic conductivity.

Air-permeability measurements were made on 36 undisturbed core liners from Borehole C5923 (A) using an automated gas mini-permeameter (Tidwell and Wilson 1997). The mini-permeameter consists of four electronic mass-flow meters ( 0 to 50, 0 to 500, 0 to 2000, and 0 to 20,000 $\mathrm{cm}^{3} / \mathrm{min}$. at standard conditions), a pressure transducer ( 0 to $100 \mathrm{kPa}$ gauge), a barometer, and a gas temperature sensor that are all connected to a regulated source of air, generated by an automated piston. Measurements were made by pressing a molded silicone rubber tip seal against the soil surface (core end) while injecting gas at a constant pressure. We used a tip seal with an inner radius of $0.31 \mathrm{~cm}$ and an outer radius measuring twice the inner diameter. An inner spring-driven guide and an immobile outer guide maintained a consistent seal geometry under compressed conditions. The ring-shaped seal imposed a strongly divergent flow field resulting in a roughly hemispherical sample support (i.e., sample volume). Gas flow was directed into the soil via the tip seal affixed to a rigid brass housing (Tidwell and Wilson 1997; 1999). 
(a)

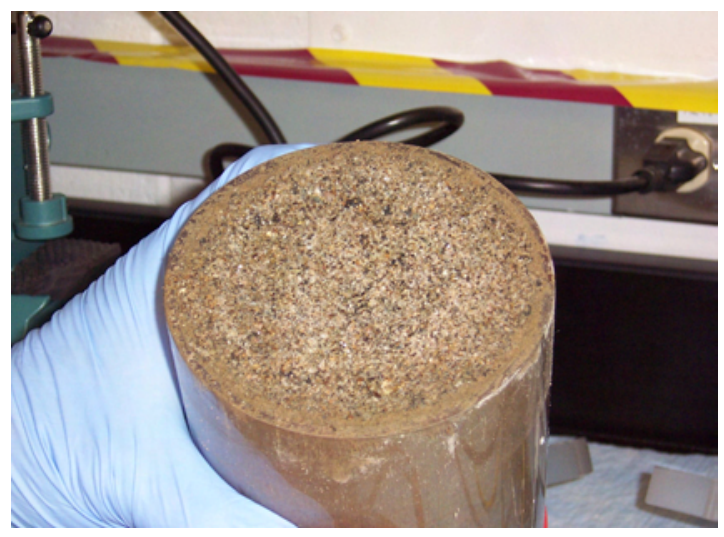

(c)

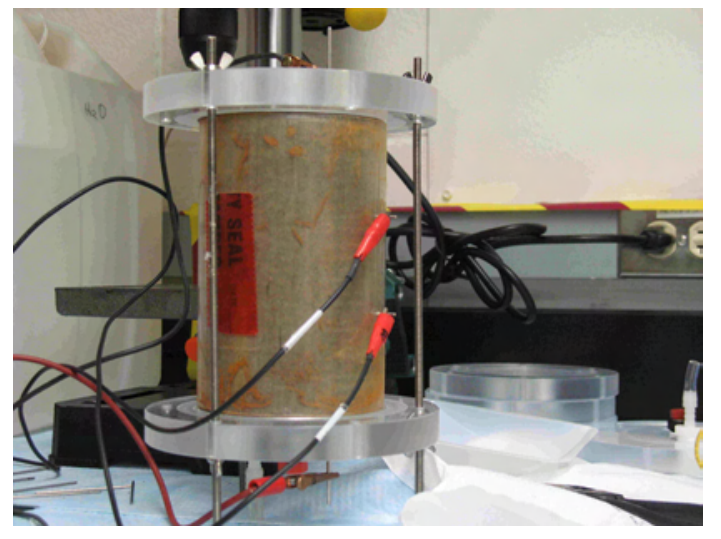

(b)

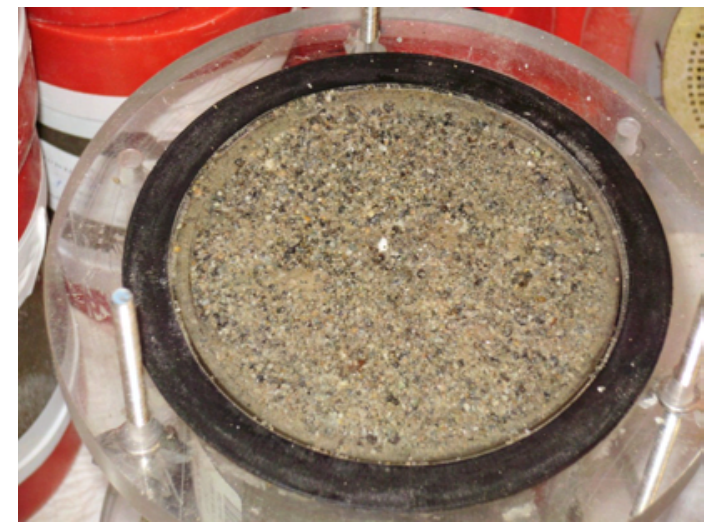

(d)

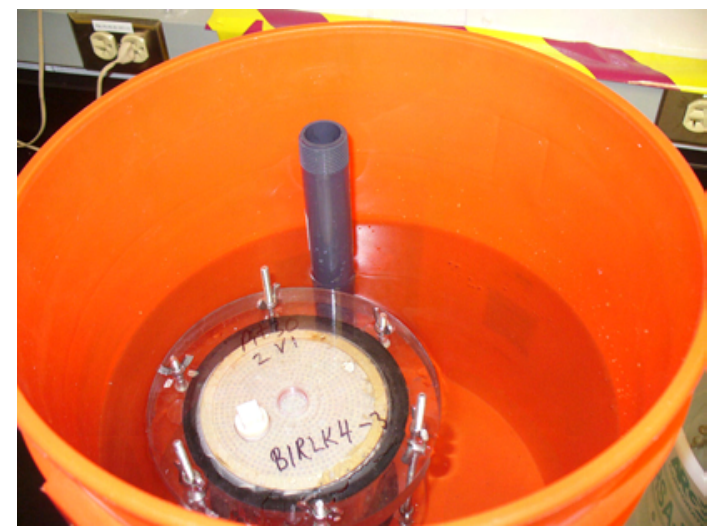

Figure 3.2. Stages of Core Preparation for Falling Head Conductivity Measurements, (a) Soil Core Just After Removal of End Caps, (b) Core After Attachment of the Collar Needed to Connect End Caps, (c) Fully Assembled Core with Collars and End Caps, and (d) Soaking Tank with Fixed Overflow Used for Containing the Core During Falling Head Tests

Using information on the seal geometry, gas flow rate, gas injection pressure, and barometric pressure, the permeability was calculated using a modified form of Darcy's Law (Goggin et al. 1988):

$$
k_{a}=\frac{Q_{1} P_{1} \mu_{a}(T)}{0.5 r_{i} G_{0}\left(\frac{r_{0}}{r_{i}}\right)\left[P_{1}^{2}-P_{0}^{2}\right]}
$$


PNNL-17821

where

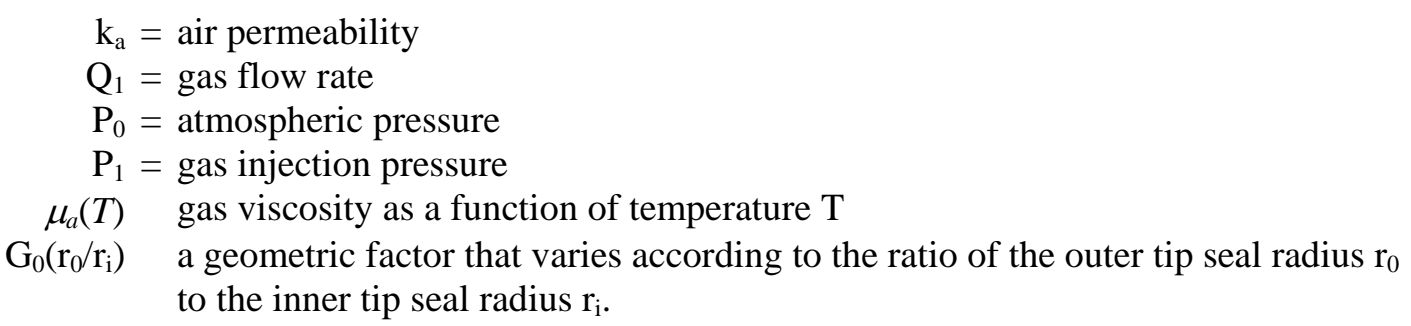

For the permeameter used for these measurements, $\mathrm{G}_{0}\left(\mathrm{r}_{0} / \mathrm{r}_{\mathrm{i}}\right)=\mathrm{G}_{0}(2)=5.03$. Vertical $\mathrm{k}_{\mathrm{a}}$ measurements were made on three randomly selected locations on each end of the intact sediment core, and the results were averaged to compute the mean vertical air permeability for each sample. 



\subsection{Field Geophysical Methods and Materials}

Geophysics is a science of measuring intrinsic physical properties of the earth (or subsurface) and associating observed changes in the measured properties with geologically, hydrologically, and/or anthropologically significant features. Geophysics, for example, can be used to map changes in hydrogeological properties, to locate buried utilities, and to extend borehole-derived information laterally away from the well point. Geophysical surveys are often used as a first-order target recognition tool or as a tool to map stratigraphic sequences. In the target recognition mode, the physical properties of the feature of interest must be sufficiently different from background conditions to distinguish the entirety of the target and confirm the extent of its edges. A target will not be identified if the variations in properties of the background material are similar in contrast and scale to those associated with the target. Assuming the target can be identified, the next order of interpretation is the relative degree of target size and intensity, referred to as the resolution limit and sensitivity, respectively.

Electrical-resistivity surveys have been conducted at the BC-Cribs and Trenches area (Rucker and Benecke 2006) in an attempt to identify anomalous regions (targets) that are likely associated with past liquid waste discharges. The working hypothesis is that the introduction of liquid waste (primarily of high sodium and nitrate concentrations) has locally altered the electrical properties within the subsurface to a degree measureable (and interpretable) using surface-based soil-resistivity surveys. Thus, the performance of these electrical-resistivity surveys is examined in this report, and the discussion that follows focuses on this technique.

Low electrical-resistivity regions may have discernable features that identify relative concentrations of salt and moisture within the target. If data are of exceptionally high quality, i.e., the data are free from significant noise and have been acquired properly, they may be correlated to specific observed phenomena to develop relationships that convert directly geophysical data to hydrogeological (i.e., moisture content or texture) or geochemical data (i.e., total dissolved solids or ionic strength) . This scenario requires that empirical models be developed from observed, co-located geophysical and geochemical data. The empirical models are then used to translate and extrapolate the geophysical data to obtain geochemical values over the site.

Electrical-resistivity surveys have been completed over the entire BC Cribs and Trenches area and documented in Rucker and Benecke (2006). The field-data acquisition campaign included 55 pole-pole resistivity transects separately collected along parallel and orthogonal lines (two-dimensional [2D] acquisition methodology as compared with true three-dimensional [3D] acquisition, where data are collected simultaneously over a surface areal grid). The resulting data sets were compiled for 3D analysis by 1 ) compositing 2D profile models into a 3D volume and 2) true 3D inversion. A few of the resistivity lines were acquired approximately one kilometer away from the BC Cribs and Trenches site in areas where no historical waste disposal is understood to have occurred to provide a control for understanding the effects of natural variability of soil types and moisture. It is believed that the interpretation of the geophysical data over the BC Cribs and Trenches waste disposal area have gone through sufficient steps to move beyond the simple target recognition and into the development of empirical models for direct comparison with co-located geochemical data from boreholes C5923 (A), C5924 (B), C5925 (C), and C4191. The following sections will help provide justification for the development of empirical models by describing the field-acquisition methods, data quality, and processing methodology. In addition to fieldmeasured electrical resistivity, soil electrical resistivity was measured in the laboratory to supplement the 
field-acquired data and help explain the occurrence of geophysical anomalies at the BC Cribs and Trenches area.

\subsection{Electrical-Resistivity Field Acquisition}

The primary objective of the BC Cribs and Trenches geophysical investigation was to characterize the subsurface beneath the BC Cribs and Trenches site using electrical resistivity to estimate the lateral (and to some degree, vertical) extent of ground surface that would need to be covered with a surface barrier or cap to minimize future water infiltration via natural recharge. The field investigation was performed to help extend the value of the sediment characterization information obtained from borehole C4191 and to help understand the extent to which the electrolytic components of the disposed waste may have migrated. To help augment the electrical-resistivity survey and to map subsurface infrastructure that may interfere with the interpretation of the resistivity, magnetometry and electromagnetic induction (EM) surveys were completed over the area. Interpretations of the magnetic survey identified several ferrous pipelines and suspected ferrous metallic debris. The EM data identified localized areas of conductive soil associated with liquid-waste disposal, pipelines, suspected metallic debris (ferrous and non-ferrous), and areas where disposal and mitigation efforts likely have impacted the soil.

The resistivity surveying was conducted over several field campaigns during the summers of 2004 (FY04), 2005 (FY05), and 2006 (FY06). The details of all field campaigns and results can be found in Rucker and Benecke (2006). In FY04, a 10-line exploratory survey was conducted to test the effectiveness of electrical resistivity as a mapping tool at BC Cribs and Trenches. Five lines were run parallel to trench 216-B-26 with a line spacing of $15 \mathrm{~m}$. Two additional lines were run, with a line over (parallel) trench 216-B-52 and the second perpendicular to trenches 216-B-52 to 216-B-28. The last three lines of the initial campaign were run near the cribs in the northeast corner of the site.

The FY05 campaign included a full-site characterization with 42 lines of acquisition. Two of the lines were run south of BC Cribs in areas of no waste. The remaining 40 lines were distributed orthogonally to the waste sites that received liquid waste, with a focus mainly on the BC trenches. The lines were extended approximately $125 \mathrm{~m}$ off ends of the trenches to sufficiently characterize the background for target identification. For this effort, approximately 20 line kilometers of data were acquired.

The last campaign in FY06 included three additional lines in the cribs area to answer the question about a deep anomaly between the trenches and cribs. The anomaly was identified by both HRR and 2D inversion processing. It was suspected that the anomaly was a false positive, and the three lines were strategically placed over the area to incorporate the data into a 3D inversion model.

Figure 4.1 shows the line layout immediately over the site. For reference, the trenches, cribs, roads, and monitoring wells have been included. In total, approximately 24 line kilometers of pole-pole resistivity data have been acquired at the site.

\subsubsection{Method of Acquisition}

The electrical-resistivity method is based on the capacity of earth materials to conduct electrical current where zones with the lowest electrical-conductance correspond to the most electrically resistive 
zones. Earth resistivity is an intrinsic material property that is a function of soil type, porosity, moisture, and electrical-properties of pore-fluids. The concept behind applying the resistivity method is to detect and map changes or distortions in an imposed electrical field due to heterogeneities in the subsurface.

In the field, the electric current may be generated by battery or motor-generator-driven equipment, depending on the particular application and the amount of power required. Current is introduced into the ground through electrodes (metal rods). Earth-to-electrode coupling is typically enhanced by pouring small volumes water around the electrodes. The electrodes are placed along linear transects and provide points for both current-transmission and voltage-potential measurements.

Estimating resistivity is not a direct process. When current (I) is applied and voltage (V) is measured, Ohms law is assumed. The transfer resistance $(\mathrm{R})$ in units of ohms can be calculated:

$$
R=\frac{V}{I}
$$

Resistivity and transfer resistance are then related through a geometric factor over which the measurement is made. The simplest example is a solid cylinder with a cross sectional area of A and length, L:

$$
\rho=R \frac{A}{L}
$$

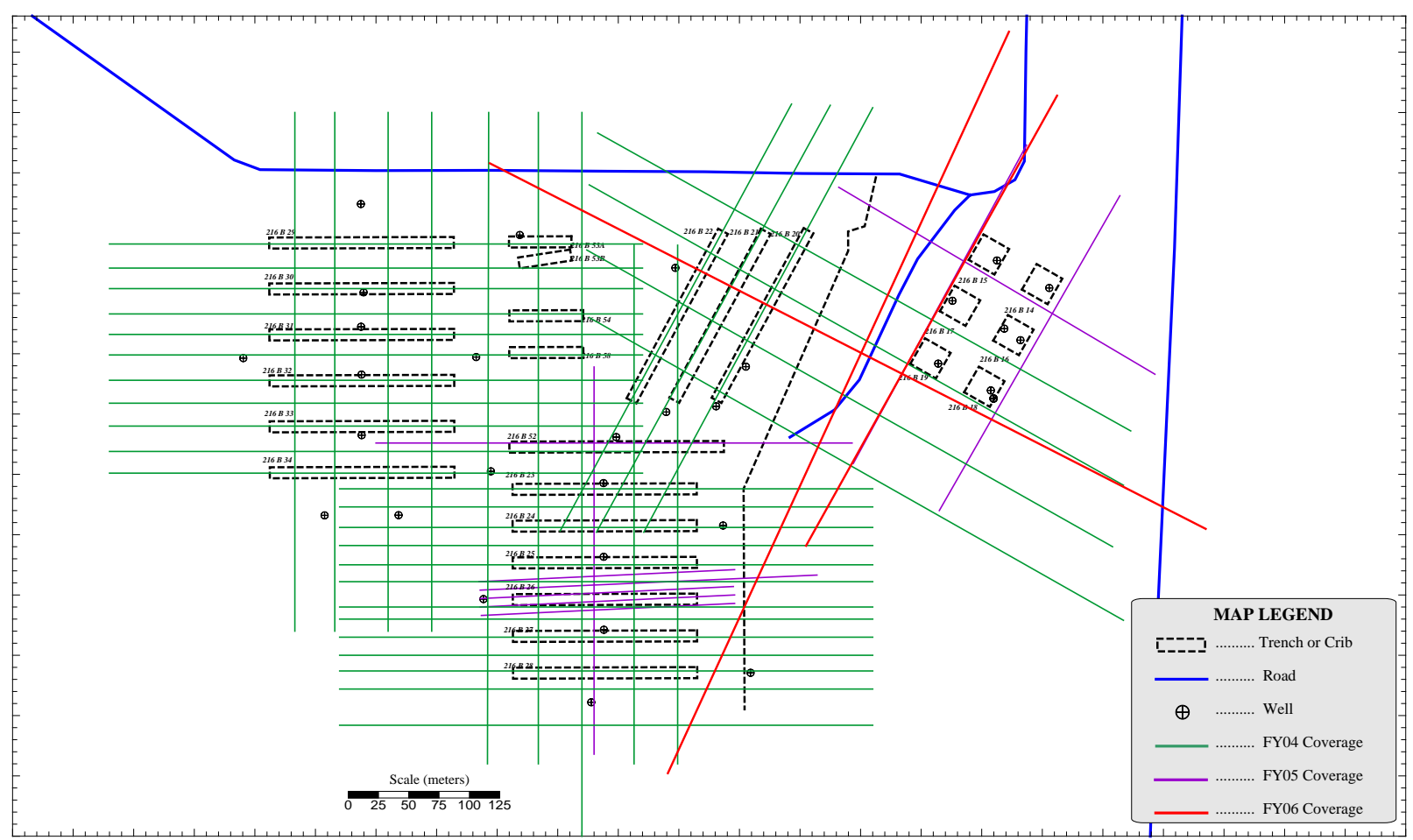

Figure 4.1. Electrical-Resistivity Line Layout over the BC Cribs and Trenches Site. North is to the top of the figure. 
Hence, resistivity can be calculated by knowing the voltage, current, and geometry over which the measurement is made. In the earth, a hemispherical geometry exists and is referred to as a half-space because all current applied at the surface travels into the ground; above the ground, air has an infinite resistivity.

Field data are acquired using an electrode array. A four-electrode array employs electric current injected into the earth through one pair of electrodes (transmitting dipole, C1 and C2) and the resultant voltage potential is measured by the other pair (receiving dipole, P1 and P2). The most common configurations are dipole-dipole, Wenner and Schlumberger arrays. Their use depends upon site conditions and the information desired. For the four-electrode array, the geometric factor, K, is

$$
K=2 \pi \frac{1}{\left(\frac{1}{r_{1}}-\frac{1}{r_{2}}\right)-\left(\frac{1}{r_{3}}-\frac{1}{r_{4}}\right)}
$$

where $r_{1}$ through $r_{4}$ are defined in Figure 4.2.

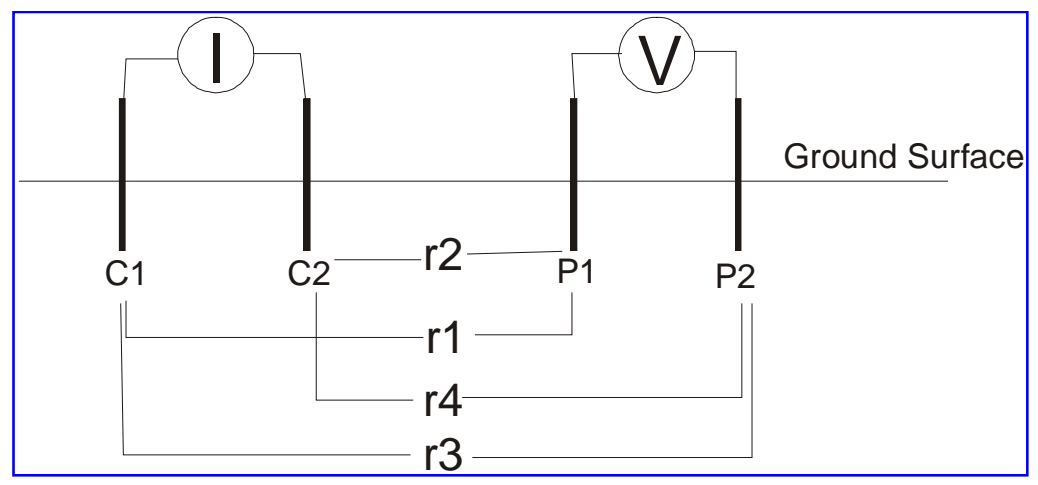

Figure 4.2. Geometry Factor for the Four Electrode Array

The earth property of resistivity is the desired product for interpretation and correlation. Thus, the measured voltage, the injected current strength, and the electrode geometry factor are used to compute a value of resistivity following Equation 4-2, substituting the area and length terms with the geometric factor, $K$, as defined by $4-3$. The resulting resistivity value is termed an apparent resistivity ( $\rho_{a}$ ) because the calculation assumes a homogenous earth through the region covered by the geometric factor calculation is needed to convert the measured voltage potential to resistivity. For the apparent resistivity $\left(\rho_{\mathrm{a}}\right)$ calculation, the inverse calculation assumes that each measurement of potential was a result of a homogeneous earth:

$$
\rho_{a}=2 \pi \frac{V}{I} K
$$

Other assumptions used in Equation (4-4) are isotropy (i.e., no directional dependence of resistivity), no displacement currents (using a DC or low-frequency current application), and constant resistivity throughout, such that Laplace's equation can be assumed. Since the degree of heterogeneity is not known 
a priori, a true resistivity is not calculated in the apparent-resistivity equation. To obtain a true resistivity, tomography is required, which generates a model of true resistivity given the measurements of apparent resistivity, electrode arrangement, and other boundary conditions. The tomographic inversion is nonlinear, thus requiring multiple forward solutions developed from educated guesses of the resistivity distribution.

Resistivity data were acquired using an Advanced Geosciences, Inc. (AGI) Super Sting R8 resistivity instrument in the pole-pole array configuration. A pole-pole array was chosen based on its capability to resolve deeper targets with shorter lines compared to other array types. The resistivity meter is a DCpowered, battery operated, low voltage, low amperage, automatic, eight-channel resistivity and induced polarization (IP) system. This system employs the SuperSting Swift general-purpose cables that can be attached in series. Each cable segment contains four smart electrodes. Each electrode has the capability of acting as either a low-amperage current transmitter or as a potential measuring receiver.

The Super Sting R-8 has the capability of automatically switching between electrodes without having to physically move the electrode connections after initial set-up. Automatic switching decreases physical labor, cuts down on human transcription and tracking errors, better allows the operator to control array logistics, and increases the rate and density of data acquired. Hydrogeologic Inc. (HGI) personnel took advantage of this capability and programmed the Super Sting R-8 to use a survey line spread of 72 smart electrodes with an inter-electrode spacing ranging from 2 to 150 meters. The survey line was moved forward incrementally by removing a 12-electrode segment from the trailing end of the survey line spread and placing it at the front of the spread between measurements.

The location of the endpoints of each resistivity line was initially established using a Javad real-time kinematic (RTK) global positioning survey (GPS) unit. Rebar stakes were placed in the ground as survey orientation guides at regular intervals along each line. After data acquisition, the same GPS was used for horizontal and vertical control of regular electrode locations. The Javad unit has $\pm 0.03-\mathrm{m}$ spherical accuracy. The elevation data were additionally quality checked against topographic contours on U.S. Geological Survey (USGS) 7.5-minute quadrangle maps.

Resistivity-data acquisition at BC Cribs and Trenches did not include making reciprocal measurements. For each pair of electrodes in the pole-pole acquisition, one electrode was the transmitter, and the other acted as the receiver. For reciprocal measurements, the pair is reversed, and the difference in voltage measurements between the forward and reverse readings is used to assess data-measurement error. Reciprocal measurements were not acquired because the acquisition time would have been doubled, making the cost of the survey prohibitively expensive. Repeat measurements are used to assess error for non-reciprocal data sets. Repeat measurements are conducted by acquiring two voltage measurements for the same transmitter-receiver pair in the same orientation. The error is computed to determine machine-level noise. It is customary to remove those data with an error above 2\%. Figure 4.3 shows an example data set of error values for FY05-line 4. For reference, Borehole C5923 (A) is located at position $153 \mathrm{~m}$ along Line 4 . The pseudo distance is calculated by averaging the positions of the transmitter and receiver along the line. Many electrode pairs may have the same pseudo distance. Error values are computed internally in the Super Sting R-8 and are recorded to the nearest tenth.

Measurement error also tends to increase with lower resistivity values. This phenomenon is easily explained when considering hardware, which has data-acquisition cards with a finite dynamic measurement range. From experience using the Super Sting R-8 (i.e., unpublished or referenced in the 
user manual), data reliability is high when the transfer resistance is above 0.01 ohms. Two factors will make the transfer resistance low, high EC and large electrode separations. Therefore, when removing data of low quality, the process of data rejection tends to remove those data that represent the deepest information in a profile and those data nearest the water table.

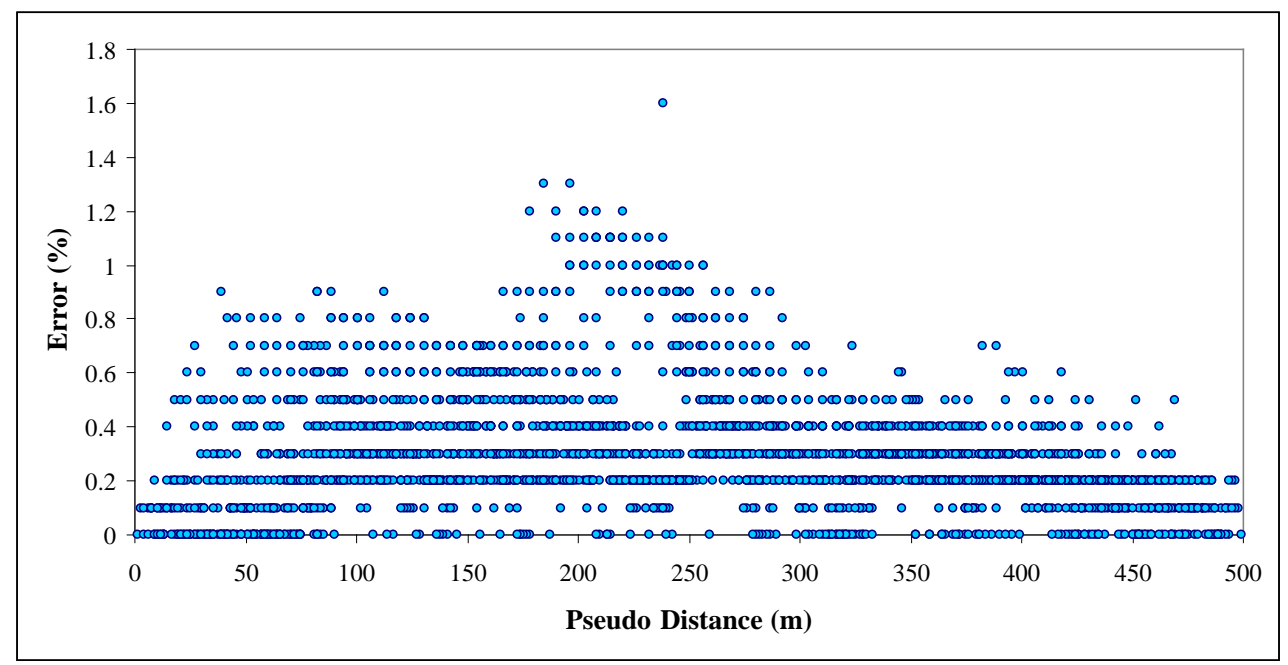

Figure 4.3. Example Error Values for FY05-Line 4

After data rejection based on measurement noise, data are evaluated for physical impossibilities based on potential field theory. This step requires that the transfer resistance (V/I) for each transmitter electrode be plotted with all of the receiver electrodes. The plot should show a smoothly varying function as the separation of the transmitter and receiver electrode increases. Large spikes in the function are physical impossibilities in natural media, and those data are removed from the data set. Figure 4.4 demonstrates an example of a data spike that is targeted for removal. The processing of data for spike rejection also includes the plotting of each receiver electrode individually with its associated transmitter electrode set.

\subsubsection{HRR Processing (ERC Processing)}

For the pole-pole array, one electrode from each of the current and potential pairs is fixed effectively at infinity, while the other current and potential electrodes act as "rover" electrodes. Practically, the infinite electrodes are spaced approximately 2 to 10 times the distance of the farthest separation of the rover electrodes, which can be up to 200 meters apart. The pole-pole array provides higher data density and increased signal-to-noise ratio, and it requires less transmitted energy. Roy and Apparao (1971) discuss the superiority of the pole-pole method when conducting shallow (near-surface) surveys. Rucker and Fink (2007) showed how the data from the pole-pole array can be used directly to interpret discrete conductive targets. 


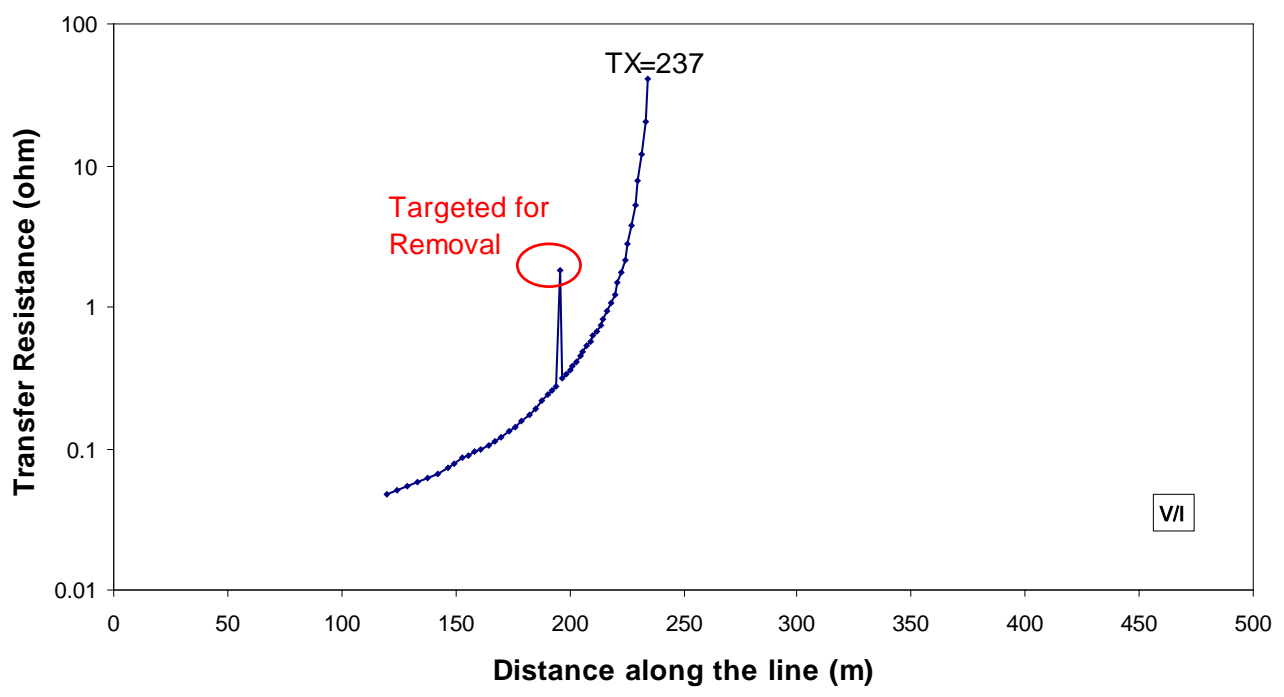

Figure 4.4. Example Data Removal Procedure

The calculation of apparent resistivity is simplified in the pole-pole array:

$$
\rho_{a}=2 \pi \frac{V}{I}(n * a)
$$

where $\mathrm{a}$ is the basic electrode spacing, and $\mathrm{n}$ is the integer multiplier as the current and potential electrodes incrementally separate. The schematic below demonstrates the idea of a linear transect of electrodes on the surface with the a-spacing being the separation between each electrode and the $n$ spacing increasing as the potential electrode moves away from the current electrode. The geophysical survey at the BC Cribs site included a fixed a-spacing of 3 meters and $\mathrm{n}$ increased from 1 to 27. For a complete survey, each electrode has one turn at transmission while potential measurements occur at all other electrodes in the array.

The linear transect arrangement produces a 2D data set of resistivity as a function of $\mathrm{x}$ and $\mathrm{z}$, where $\mathrm{z}$ is the dimension into the earth, and $\mathrm{x}$ is along the surface. Although resistivity is a function of the volume over which the measurement is made, its location is typically plotted as a point for ease of representation. The location of the point is a function of $\mathrm{n}$ and is referred to as the depth of investigation. Hallof (1957) demonstrated that the intersection of two $45^{\circ}$ lines (with respect to the surface) extending downward from each of the transmission and receiving electrodes would produce a suitable pseudosection for interpretation. In this fashion, the pole-pole array has depths plotted at:

$$
z=0.5 n a
$$

which is a linear plotting method. Figure 4.5 demonstrates this plotting methodology. 
PNNL-17821

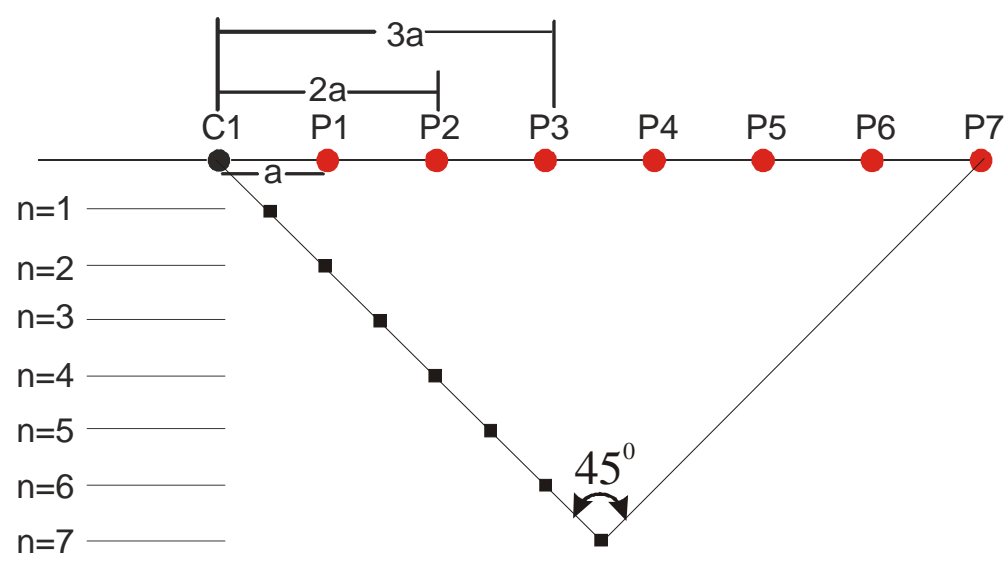

Figure 4.5. Linear Pseudosection Plotting of Apparent Resistivity Data

The traditional linear pseudo-section of Hallof (1957) has limitations with respect to a physical meaning of the earth. Therefore, many researchers have more closely examined the plotting method to allow for a more reasonable geological interpretation. The most widely accepted depth of investigation studies are those presented by Roy and Apparao (1971), Roy (1972), and Koefoed (1972), who defined a depth of investigation characteristics (DIC) model for determining the depth of a measurement. The DIC was determined by finding the depth at which a thin horizontal layer within a homogeneous background makes the maximum contribution to the total measured signal at the surface. The results were consistent in that the depth of investigation is a nearly logarithmic function of electrode spacing, regardless of how the depth of investigation is defined. This suggests a modification of the linear pseudo-section (Edwards 1977; Fink 1980).

To facilitate the nonlinear depth plotting of apparent-resistivity data, Rucker and Fink (2007) demonstrated that a function of the logarithm of the n-spacing value can be used. The logarithmic plotting algorithm of apparent-resistivity data is called high resolution resistivity (HRR). The coefficients of the function are determined by using collocated borehole data. The consequences of a nonlinear pseudo-section is shown in Figure 4.6, where the resistivity values near the surface are pushed deeper relative to the linear pseudo-section, and the deeper resistivity is pulled up relative to the linear pseudosection. At one point, the two plotting strategies have the same depth location for a given electrode separation.

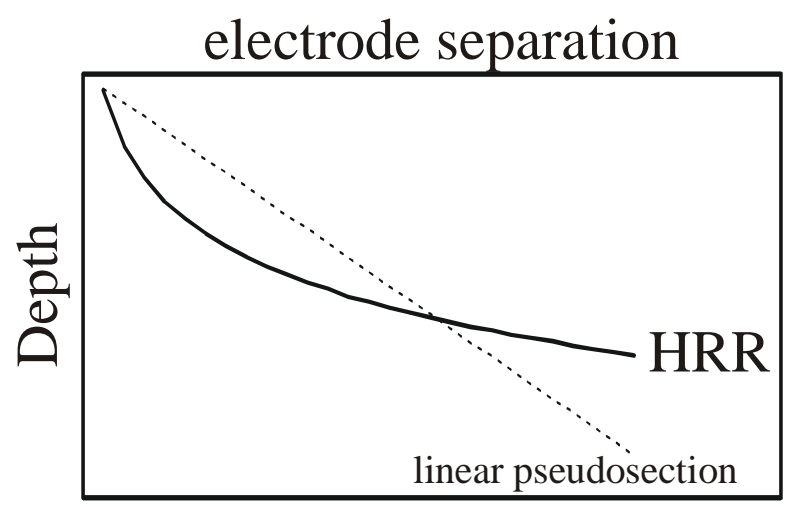

Figure 4.6. Depth Plotting of Apparent Resistivity Data Using the HRR Algorithm and Linear Pseudosection 
The depth of investigation and pseudo section plotting of data stem from a need to relate a measurement made at the surface to some particular depth so survey parameters can be optimized for target identification (Barker 1989). Before tomographic inversion was common practice among geophysicists to estimate the true resistivity from measured apparent resistivity, apparent-resistivity pseudo sections were used primarily to interpret subsurface electrical anomalies. Field practitioners became quite efficient at locating the depth to specific targets, such as ore bodies. The presentation of the pseudo-section is important in this regard. Additionally, the pole-pole array, above all others, provides the weakest edge effects, thereby facilitating the direct interpretation of these data more reliably (Robain et al. 1999).

To facilitate the nonlinear depth plotting of apparent-resistivity data, Rucker and Fink (2007) used the logarithm of the n-spacing value in a $2^{\text {nd }}$-order polynomial:

$$
-z_{\log }=u_{1} \log (n)^{2}+u_{2} \log (n)+u_{3}
$$

where $\mathrm{z}_{\log }$ is the new interpreted depth location of the apparent-resistivity value, and $\mathrm{u}_{1} \ldots \mathrm{u}_{3}$ are coefficients to be determined by using collocated target resistivity values. For this analysis, we are assuming that target data come from a borehole. The coefficients in Equation (4-7) can be determined using a nonlinear least-squares optimization procedure. An example of HRR plotting can be seen in Figure 4.7. The data represent lines acquired during the FY04 acquisition campaign over trench 216-B26. For reference, borehole C4191 is located approximately 93 meters along Line 1.

The depth locations of the nonlinear pseudosection were optimized based on the C4191 borehole data of EC, with coefficients of $\mathrm{u}=(3.97,22.4,3.97)$. The apparent-resistivity data show that the lowresistivity contours for transects 1-5 are primarily from 25 to $44 \mathrm{~m}$ bgs. The low-resistivity areas extend laterally out to the edges of the trench where the electrical resistivity increases to approximately 400 ohmm. For Line 7, which runs perpendicular over several trenches, the low-resistivity contours are again located at the expected depth of high EC measured in borehole C4191. However, the low-resistivity values extend from the surface beneath each of the trench locations in a triangular shape. In particular, trench 216-B-52 appears to have a much larger low-resistivity response, likely because it received the most liquid waste of any trench, approximately $8500 \mathrm{~m}^{3}$. Other HRR plots of specific lines can be seen in Rucker and Benecke (2006).

One major disadvantage of HRR processing is the superposition of potential fields from discrete targets to form false low-resistivity anomalies. The anomalies are generated mathematically through constructive interference. This was the case of several resistivity lines over BC Cribs, where the line crossed both trenches and cribs. A false anomaly was observed between the trenches and cribs at depth, which promoted the location of borehole C5925 (borehole C). The same superposition problem can be noticed with different types of conductive targets, including the water table and pipes. 


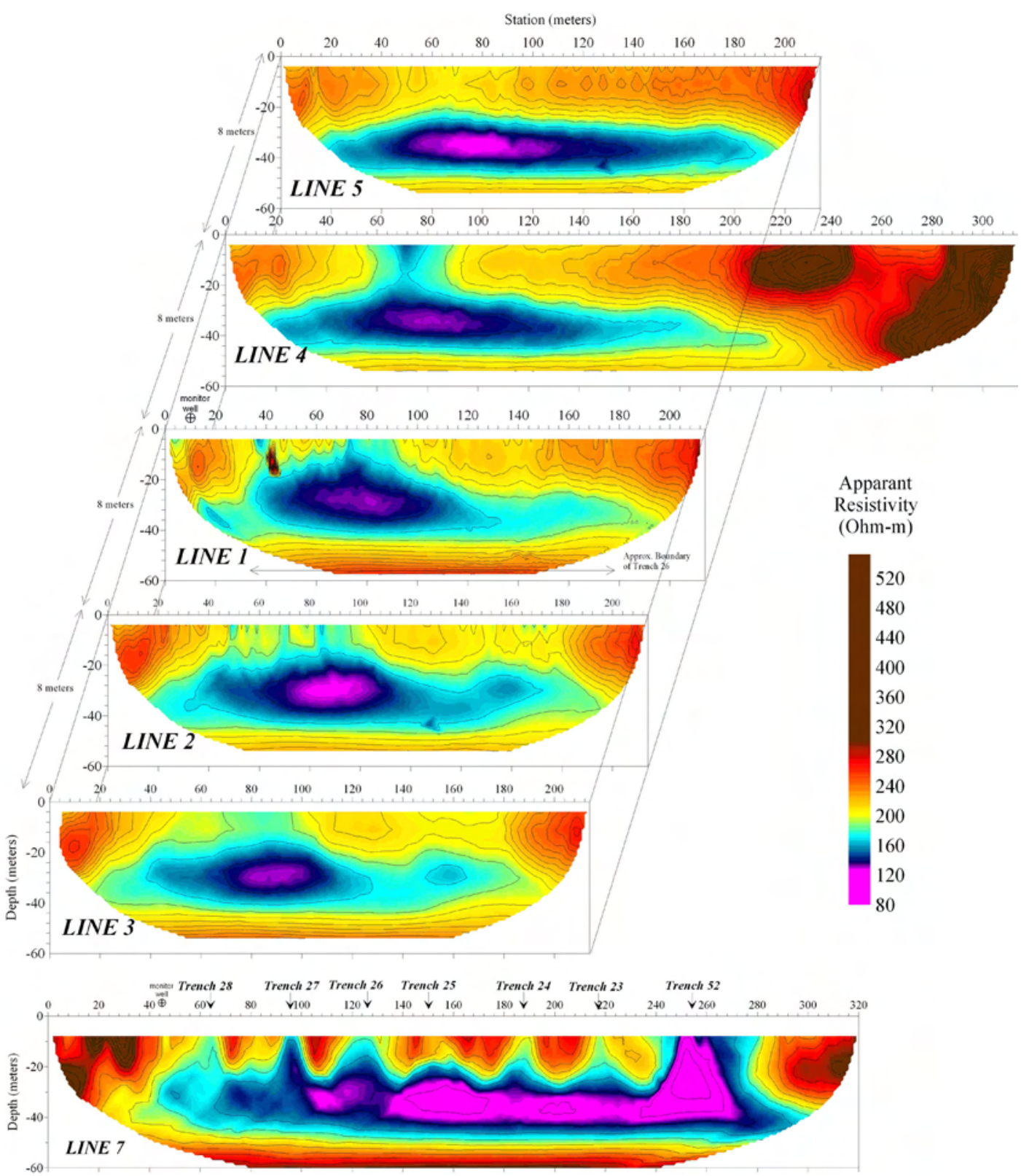

Figure 4.7. HRR plotting of data at BC Cribs. The data are from FY04 acquisition campaign.

Potential field theory describes the ideal flow of steady currents (or heat or fluid) in a homogeneous media. Laplace's equation is the mathematical differential function that is used to help formulate aspects of the theory. One main aspect of the theory that we will use to describe apparent resistivity is superposition. Superposition allows individual solutions of the voltage potential to be summed to obtain a final voltage potential field describing the subsurface. An example would be to consider a discrete body, say a plume or pipe, which is more electrically conductive than the host material. The total potential, as a function of space $\left(\mathrm{x}_{\mathrm{i}}, \mathrm{i}=1,2\right.$, or 3 dimensions) is:

$$
\Psi_{T}\left(x_{i}\right)=\Psi_{B}\left(x_{i}\right)+\Psi_{P}\left(x_{i}\right)
$$


where $\Psi_{\mathrm{T}}$ is the total potential, $\Psi_{\mathrm{B}}$ is the background potential, and $\Psi_{\mathrm{P}}$ is the potential of the conductive body (which is negative). If the conductive body did not exist, then the total potential would equal the background potential. Wait (1982) showed that the voltage potential from a single current source (i.e., pole-pole array) is:

$$
\Psi_{T}=\Psi_{B}=\frac{I \rho_{B}}{2 \pi r}
$$

where I is the current (amps), $\rho_{\mathrm{B}}$ is the background resistivity (ohm-m), and $\mathrm{r}$ is the distance between the current source and voltage potential measurement location (meters). The solution was obtained by solving Laplace's equation with a Neumann boundary condition at the surface (no current flux from the ground to the air, also referred to as a half-space), and Dirichlet boundary condition on the other three sides, where voltage potential was equal to zero at infinity.

Using this same concept, a numerical model was employed to calculate the potential field from a heterogeneous subsurface. For the examples below, the voltage potential will be converted to apparent resistivity using Equation 4-5 so that it can be directly compared to data collected at the BC Cribs. EarthImager2D (developed by AGI, Austin, TX) was used for the potential field modeling. For the first example, a plume of $10 \mathrm{ohm}-\mathrm{m}$ was placed in a background soil of $1000 \mathrm{ohm}-\mathrm{m}$. Figure 4.8 shows the results of the apparent resistivity from this geometry using the HRR plotting methodology. The blue outlined box shows the original location of the low-resistivity plume, whereas the black contour of apparent resistivity is approximately the 333-ohm-m value. The apparent resistivity shows a lowresistivity anomaly that matches the original location of the modeled 10 -ohm-m feature quite well. The exception is on the edges of the plume where it appears to have a decreased resistivity protruding downward. These protrusions are referred to as pantlegs and are inherent in the volumetric averaging of surface-resistivity measurements. As will be shown later, these pantlegs can cause some difficulties when interpreting HRR data.

The second example is of a water table only, located approximately 72 meters bgs. The water table has an apparent resistivity of $100 \mathrm{ohm}-\mathrm{m}$, and the background soil again is $1000 \mathrm{ohm}-\mathrm{m}$. This model for the water table is a simple two-layer geometry with a discrete decrease in electrical resistivity at the water table depth. Figure 4.9 shows the results of the apparent resistivity using this geometry. The blue horizontal line across the bottom of the color contour plot is the original location of the water table used for modeling.

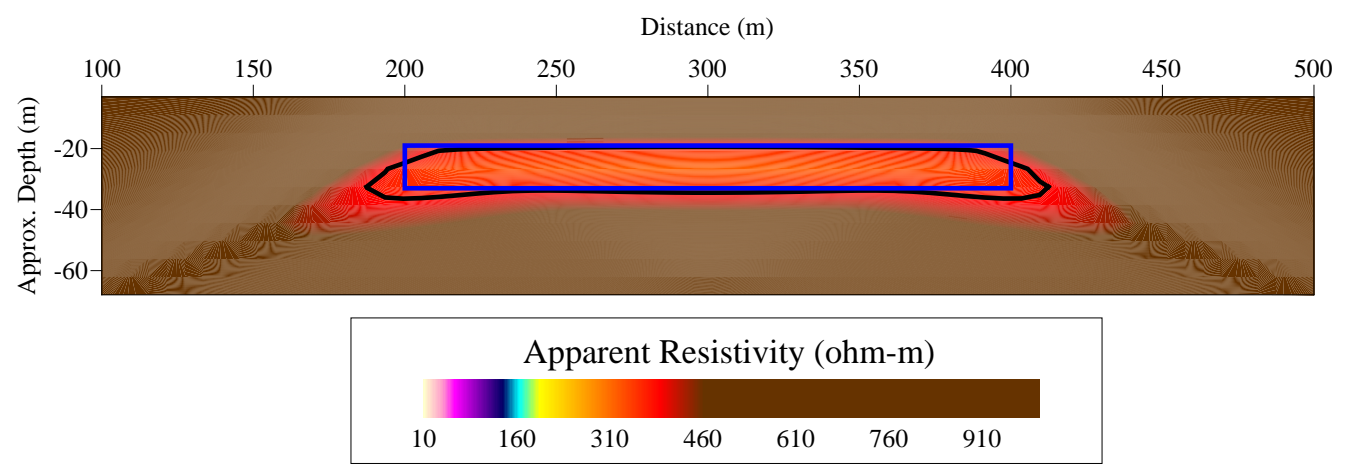

Figure 4.8. Numerical Simulation and HRR Plotting of a Low-Resistivity Anomaly in a Homogeneous Soil 
The apparent-resistivity plot shows that the water table, even at 72 meters, can be detected with the resistivity method. However, due to the volumetric averaging by the method, the water table can have an effect at a much more shallow location than anticipated. The apparent resistivity is also a smooth function, whereas the initial-resistivity model was discontinuous.

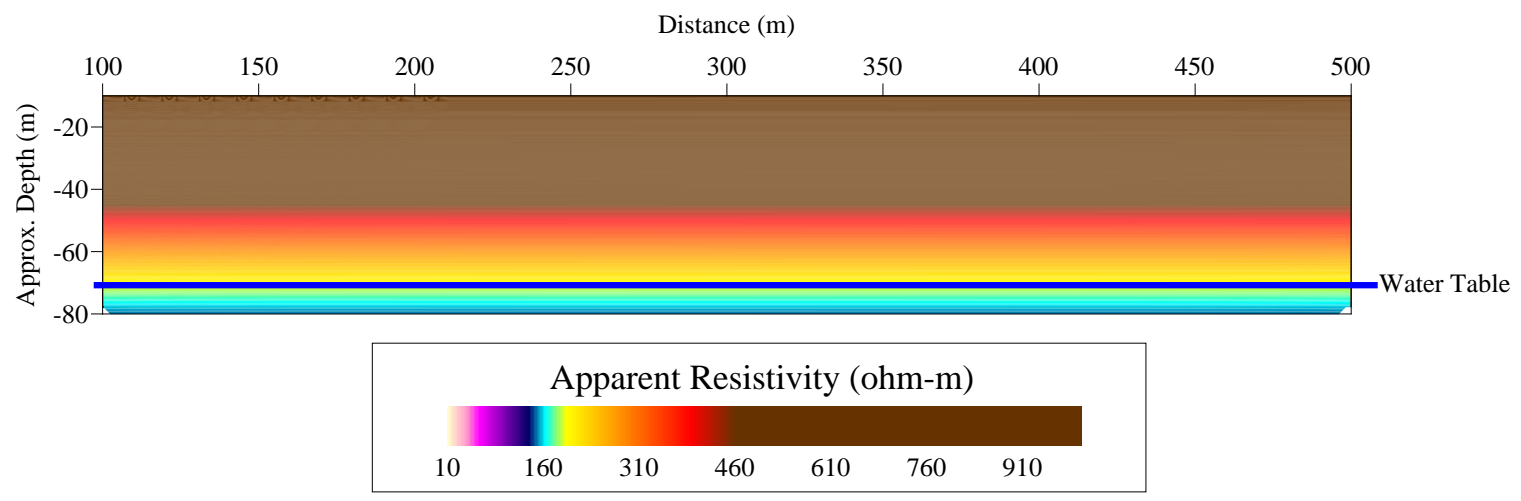

Figure 4.9. HRR Apparent-Resistivity Processing of a Water Table (100 ohm-m) in a Background Soil (1000 ohm-m).

The last example shows a combination of a low electrical-resistivity plume and a mid-value electrical-resistivity water table in a background homogeneous soil of high electrical resistivity. Figure 4.10 shows the results of the modeling with the top plot showing the starting conceptual model for the numerical algorithm. The middle plot shows the apparent resistivity with the HRR processing model. The plot shows that the edges of the plume have a more pronounced effect than shown in Figure 4.8. This is due to the additive effects of water table and plume to the total potential field solution. A cross section at 210 meters, showing depth vs apparent resistivity, reveals how the different components affect the final solution of apparent resistivity. Although apparent-resistivity functions are not directly additive, the plot does demonstrate the different effects. 

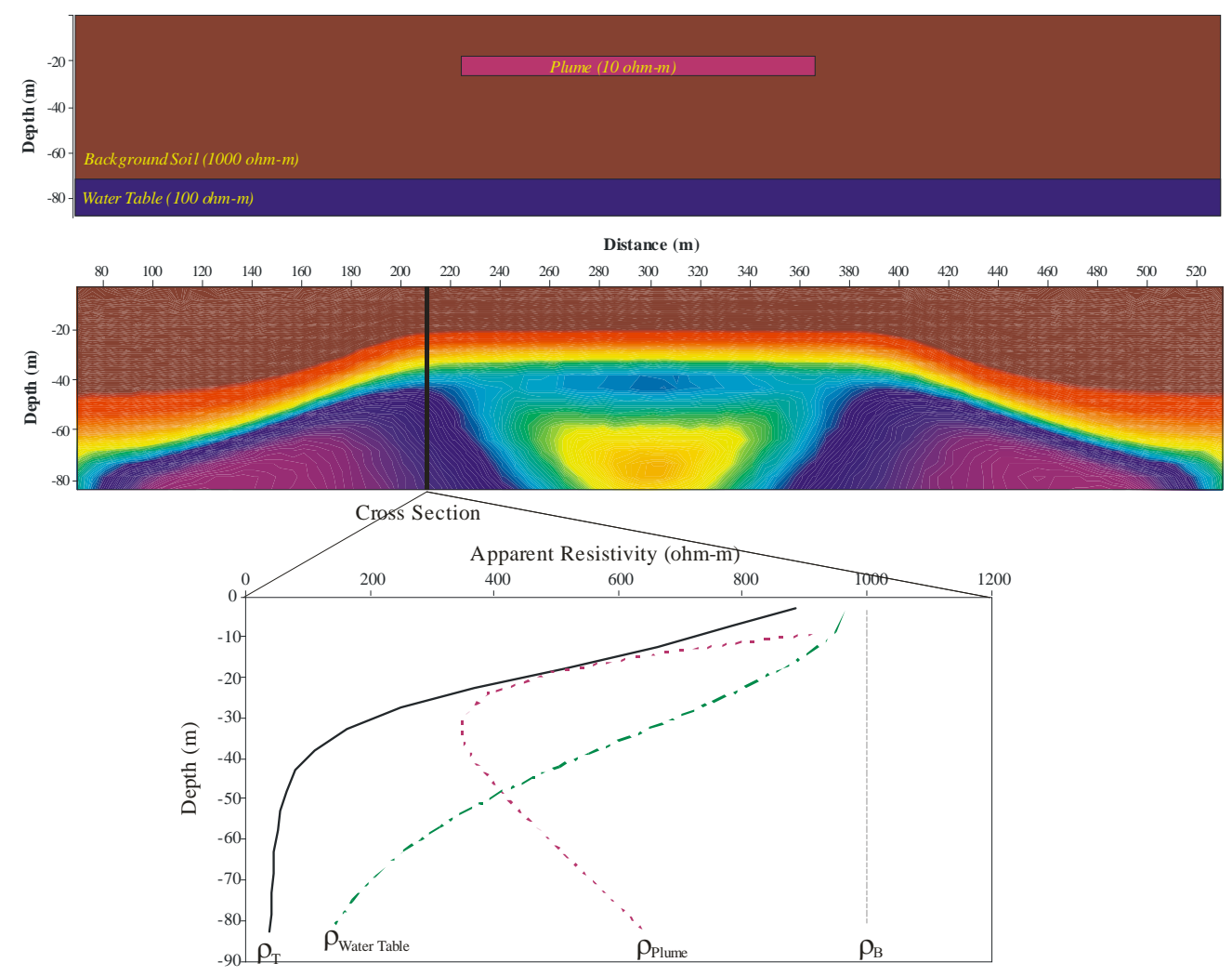

Figure 4.10. Forward Modeling of a Low-Resistivity (10 ohm-m target zone) And Water Table (100 ohm-m) in a Background Soil (1000 ohm-m)

The top image is the conceptual model, the middle image is the HRR apparent resistivity, and the bottom plot is a cross section at 210 meters from the edge showing the different components of the apparent resistivity used in formulating the total value plotted in the middle plot: $\rho_{t}=$ total combined resistivity, $\rho_{\text {water table }}=$ resistivity from water table only, $\rho_{\text {plume }}=$ resistivity from the plume only, $\rho_{\mathrm{b}}$ is background resistivity.

\subsubsection{D Inversion}

Rucker and Fink (2007) have shown that the spatial distribution of the raw (i.e., apparent) resistivity can be used to distinguish discrete targets. The accuracy of both spatial position and resistivity values can be improved by processing the raw data to account for surface topography and subsurface structure or layering. The process of calculating an estimate of the true resistivity model based on raw apparentresistivity values is called inversion. The goal of resistivity inversion is to automatically calculate the distribution of electrical resistivity of the subsurface so that the predicted voltage of the model is equivalent to the field-measured voltage data. Conversely, forward modeling is defined as the process of calculating the voltage data on the basis of the known values of input current, electrode configuration, and an assumed subsurface resistivity.

An experienced geophysicist can manually invert the raw data by trial-and-error forward numerical modeling using codes based on either finite-element or finite-difference methods. However, the trial-and-error approach inherently presents operator bias by introducing the unique experiences of the 
operator. To avoid biased results as well as to speed the process of modeling, automated inverse modeling techniques are used. Automated inverse-resistivity codes use a non-linear optimization algorithm that iteratively solves for the best-fit model of subsurface structure. A least-squares objective function is commonly used in the optimization algorithm and is commercially available in the codes: RES2DINV, RES3DINV, EarthImager 2D, and EarthImager 3D (see Daily et al. 2004a; Daily et al. 2004b; deGroot-Hedlin and Constable 1990; LaBrecque et al. 1996; LaBrecque and Yang 2001; Loke et al. 2003; Loke and Barker 1995a; Loke and Barker 1995b; Loke and Barker 1996b; Oldenburg and Li 1999; Oldenburg et al. 1998; Smith and Vozoff 1984; Stummer et al. 2004; and Tripp et al. 1984). The general form of the objective function (S) for the resistivity inversion is primarily based on the weighted least squares:

$$
S=\left(d_{\text {calc }}-d_{\text {meas }}\right)^{T} W_{d}\left(d_{\text {calc }}-d_{\text {meas }}\right)
$$

where $d_{\text {calc }}$ is the calculated voltage data from the numerical modeling at coincident locations with $d_{\text {meas }}$, which represents the measured voltage, $\mathrm{W}_{\mathrm{d}}$ is a weighted function based on the measurement errors and is equal to the inverse of the error covariance matrix, and $\mathrm{T}$ is the matrix transpose operator.

The objective function has been updated many times to include other terms, such as smooth model constraints (i.e., a smooth model based on minimizing the second spatial derivative of the resistivity). The final objective function for smooth model inversion is represented by:

$$
S(m)=\left(d_{\text {calc }}-d_{\text {meas }}\right)^{T} W_{d}\left(d_{\text {calc }}-d_{\text {meas }}\right)+\lambda\left(m-m_{0}\right)^{T} R\left(m-m_{0}\right)
$$

where second term $=$ model smoothness

$\lambda=$ dampening factor

$\mathrm{m}=$ model parameter of resistivity at every cell

$\mathrm{m}_{0}=$ a priori information and/or initial starting guess

$\mathrm{R}=$ difference operator for estimating model smoothness

$\mathrm{T}=$ transpose operator.

In general, the automated inversion routine proceeds as follows, which is shown graphically in Figure 4.11.

1. The Earth's voltage data have been measured and are discretized into grid nodes using a finitedifference or finite-element mesh. The meshing parameters depend on electrode spacing. The inversion will set out to estimate the true resistivity at every grid node.

2. The subsurface properties are initially estimated based on the literal translation of the pseudo-section to a true resistivity, a constant value, or some other distribution from a priori information. The forward model runs with this initial estimate to obtain the distribution of voltages in the subsurface. The root mean square (RMS) error is calculated between the measured voltage and the calculated voltage.

3. Based on the degree of match between simulated and measured voltage, the initial estimate of resistivity is changed and the forward model is rerun. The iterative method is linearizing a highly 
non-linear problem using Newton's method. Essentially, the program solves the linearized problem to obtain the change in modeled resistivity $(\Delta \mathrm{m})$ for the next iteration.

4. The resistivity model is updated using the general formula $m_{i+1}=m_{i}+\Delta m$, where $m_{i+1}$ is the resistivity in a model cell at the next iteration, and the $\mathrm{m}_{\mathrm{i}}$ is the current value.

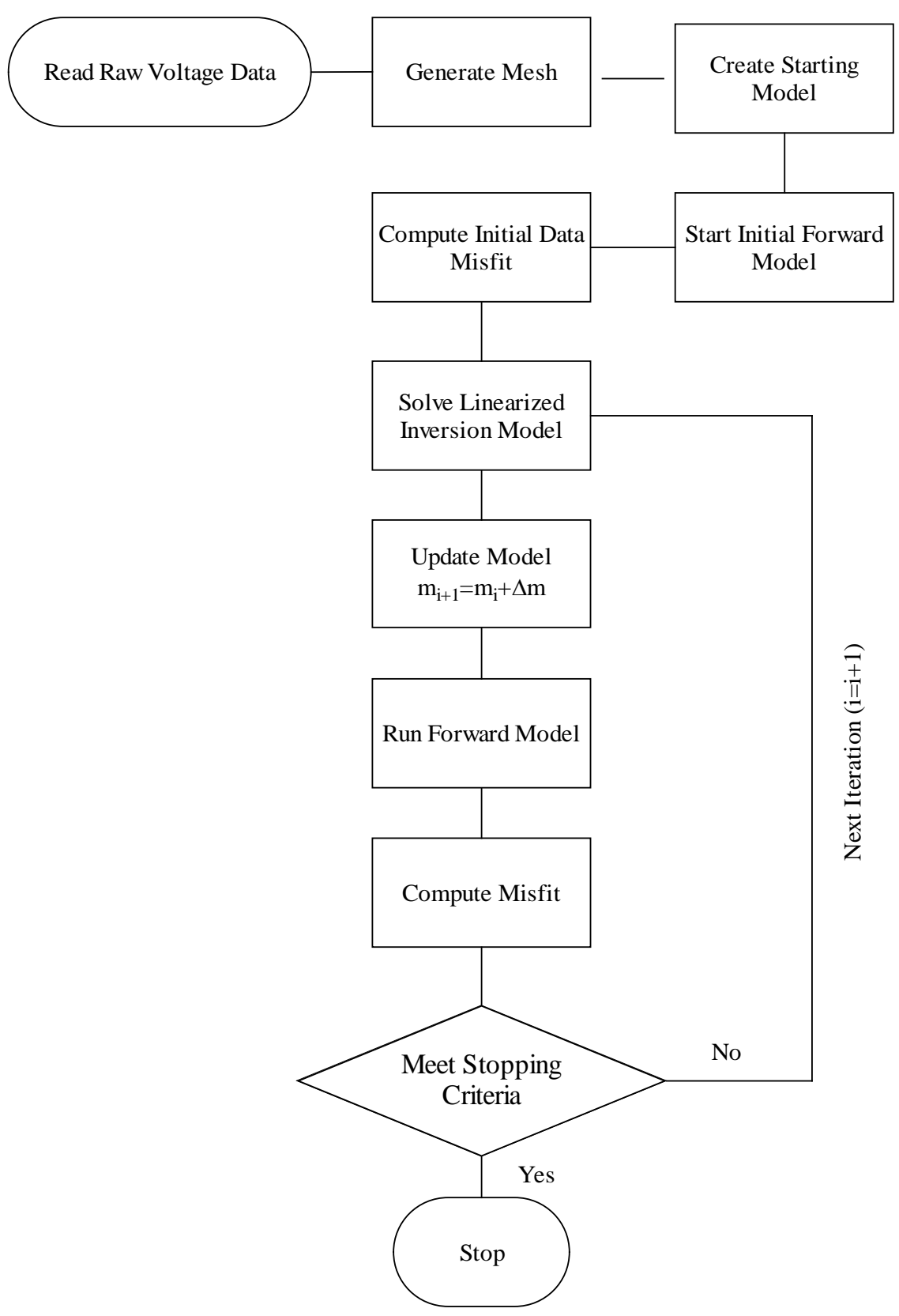

Figure 4.11. Flowchart of the Resistivity Inversion Process

1. Steps 3 and 4 are repeated until the RMS error change between successive iterations is less than 10 percent. 
The six resistivity lines shown in Figure 4.7 were inverted using EarthImager2D to demonstrate the outcome of an inversion. The initial estimate for the distribution of electrical resistivity within each resistivity line was the linear pseudosection. Other parameters include using a dampening and stabilization factor of 10.0, estimated error of $5 \%$ (for the covariance weighting matrix), and maximum and minimum resistivity of 10000 and $1 \mathrm{ohm}-\mathrm{m}$, respectively. The goodness-of-fit as well as other statistics relevant to the study are shown in Table 4.1. The inverted resistivity lines of Figure 4.12 show a similar result as the logarithmic HRR pseudosection of Figure 4.7, i.e., that a low-resistivity plume exists beneath the site likely due to the disposal activities 50 years prior. The inverted resistivity also shows the bottom edge of the plume to be less sharp than the borehole data suggest, which is a general consequence of inversion.

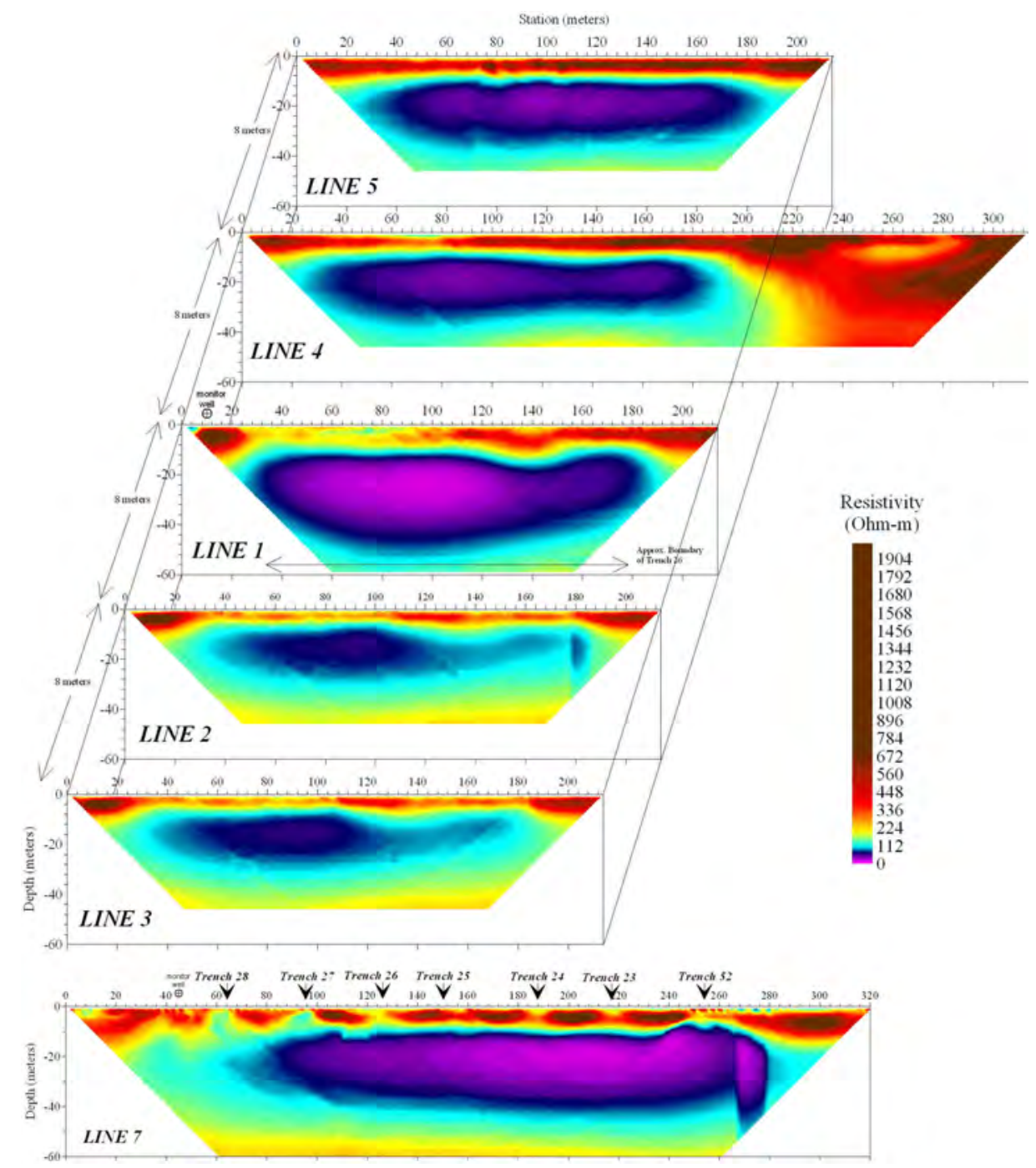

Figure 4.12. Inversion Results for the Resistivity Data Presented in Figure 4.7 
Table 4.1. Resistivity Data and 2D Inversion Statistics

\begin{tabular}{|c|c|c|c|c|c|c|}
\hline Statistic & Line 1 & Line 2 & Line 3 & Line 4 & Line 5 & Line 6 \\
\hline \multicolumn{7}{|c|}{ Data Statistics } \\
\hline Line Length (m) & 214 & 214 & 214 & 314 & 214 & 321 \\
\hline \# Electrodes & 108 & 108 & 108 & 208 & 108 & 108 \\
\hline Elect. Separation (m) & 2 & 2 & 2 & 2 & 2 & 3 \\
\hline Raw data count & 5371 & 1372 & 1372 & 1909 & 1372 & 1372 \\
\hline Filtered data count $^{(\mathrm{a})}$ & 4307 & 1273 & 1270 & 1800 & 1280 & 1289 \\
\hline Min $\rho_{\mathrm{a}}(\mathrm{ohm}-\mathrm{m})$ & 127 & 125 & 125 & 131 & 123 & 124 \\
\hline
\end{tabular}

(a) Filtering data eliminates those measurements with high error, negative values, and data spikes.

\begin{tabular}{ccccccc}
\multicolumn{8}{c}{ Inversion Statistics } \\
\hline Inversion Iterations & 3 & 2 & 2 & 3 & 3 & 3 \\
\hline $\begin{array}{c}\text { Minimum Calc. } \\
\rho \text { (ohm-m) }\end{array}$ & 18.9 & 46.6 & 45.9 & 38.8 & 34.3 & 8.56 \\
RMS (\%) & 3.81 & 3.50 & 4.56 & 3.46 & 3.53 & 3.23 \\
$\mathrm{~L}_{2}$-Norm & 0.58 & 0.49 & 0.83 & 0.48 & 0.50 & 0.42 \\
\hline
\end{tabular}

Other contour plots of inverted resistivity lines can be seen in Rucker and Benecke (2006).

\subsubsection{D Inversion}

Numerous authors have noted the problems inherent with resolving geophysical targets with 2D data acquisition techniques over a 3D earth (Dahlin et al. 2002; Bentley and Gharibi 2004; Gunther et al., 2006). However, the dimensional complexity of the target depends on the scale. In some cases, such as a simple layered earth, arbitrarily choosing a 3D imaging technique may not significantly improve the target resolution, and one can minimize the time spent acquiring data by being mindful of the problem's dimensionality. A class of targets that would likely benefit from a 3D inversion is a contaminant plume (Slater et al. 2000; 2002). These hydrogeologic targets are typically on the order of a few 10s of meters on a side and reside within the top 20 meters of the surface. The goal of imaging these targets is to understand the source and extent of the plume as well as any time-dependent dynamics that define the fate and transport of the contaminants (e.g., Singha and Gorelick 2006; Oldenborger et al. 2007).

Acquiring true 3D electrical resistivity data is time consuming and costly when compared to 2D methods. For 3D acquisition, the metal electrodes used to pass current and measure voltage can be distributed randomly in space, but are commonly placed in a grid pattern on the surface or at multiple depths in several boreholes. Two-dimensional acquisition is conducted along a line of evenly spaced electrodes. Several suggestions have been made to help migrate 2D techniques to 3D acquisition, including the serpentine roll-along (Loke and Barker 1996a) and the leap-frog roll-along (Dahlin and Berstone 1997; Dahlin et al. 2002). These enhanced 3D acquisition techniques are an improvement over the traditional methods of running individual wires to the electrodes because they use multi-electrode cables and multi-channeled meters.

The practicality of the 3D roll-along has proven itself to be limited to small problems, as a large number of cables and multiplexors are needed to upscale to larger 3D data acquisition. A technique that 
does appear suitable for the larger problems is the quasi-3D acquisition, where 2D data are collected but processed using a 3D code. The quasi-3D techniques include a series of closely spaced parallel lines (Ogilvy et al., 2002), a series of parallel and orthogonal lines within a grid (Freidel et al. 2006; Mansoor et al. 2007), radial lines around a common centroid (Nyquist et al. 2005), or concentric circles of increasing diameter (Brunner et al. 1999). Less time and equipment are needed to acquire 2D data, equating to a cheaper methodology that still provides a form of 3D interpretation of the subsurface. Gharibi and Bentley (2005) show that data acquired in a quasi-3D manner are suitable for processing and interpretation when using the proper geometric constraints, such as line and electrode spacing.

The 3D resistivity problem has also been limited by computer software and hardware constraints. Resistivity inversion is needed to reconstruct the electrical properties of the subsurface that give rise to the voltage measurements observed in the field. The resistivity inversion problem is non-linear, forcing the solution methodology to be conducted in an iterative procedure (Daily and Owen 1991; LaBrecque et al. 1996) that solves the forward model many times while changing the subsurface electrical properties. The software and hardware constraint is manifest in the large-computer-memory requirements needed to store the Jacobian matrix ( $\mathbf{J}$ ) of partial derivatives. The (NxM) $\mathbf{J}$ matrix contains the derivative of the simulated data measurements (N) with respect to the model parameters (M) (Gunther et al. 2006). Even on moderately sized problems, computing the $\mathbf{J}$ matrix can be the most time-consuming step during inversion (Loke and Dahlin 2002).

Three-dimensional inversion was applied to the BC Cribs and Trenches data set using the inversion code EarthImager3DCL (v. 1.0.1). Due to the size of the problem, the inversion was broken up into smaller domains to reduce computer-memory requirements. Figure 4.13 shows the domain boundaries and the results of the individual inversion trials; Table 4.2 lists the inversion statistics for the different models. The results are presented as a plan view of contoured data at a depth of $30 \mathrm{~m}$ bgs. For reference, the waste sites, resistivity lines, and boreholes used for "ground truthing” are plotted as well.

Table 4.2. Resistivity Data and 3D Inversion Statistics

\begin{tabular}{ccccc}
\hline Inversion Model Domain & 1 & 2 & 3 & 4 \\
\hline Data Count & 51,099 & 44,622 & 22,297 & 29,084 \\
Inversion Iterations & 4 & 4 & 3 & 4 \\
Minimum Calc. $\rho$ (ohm-m) & 9.47 & 3.60 & 12.97 & 6.94 \\
RMS (\%) & 4.26 & 4.99 & 6.98 & 4.75 \\
L $_{2}$-Norm & 0.56 & 0.81 & 0.57 & 0.90 \\
\hline
\end{tabular}

The inversion results show zones of low electrical resistivity that are conterminous with each of the waste sites, suggesting a causal relationship between the observed resistivity anomalies and past waste discharge. The mismatch of model results from smaller overlapping domains was also noted by Rucker et al. (2008). However, the model boundaries were designed to have the borehole locations near the center where more reliable inversion data could be used to correlate with geochemistry data. 


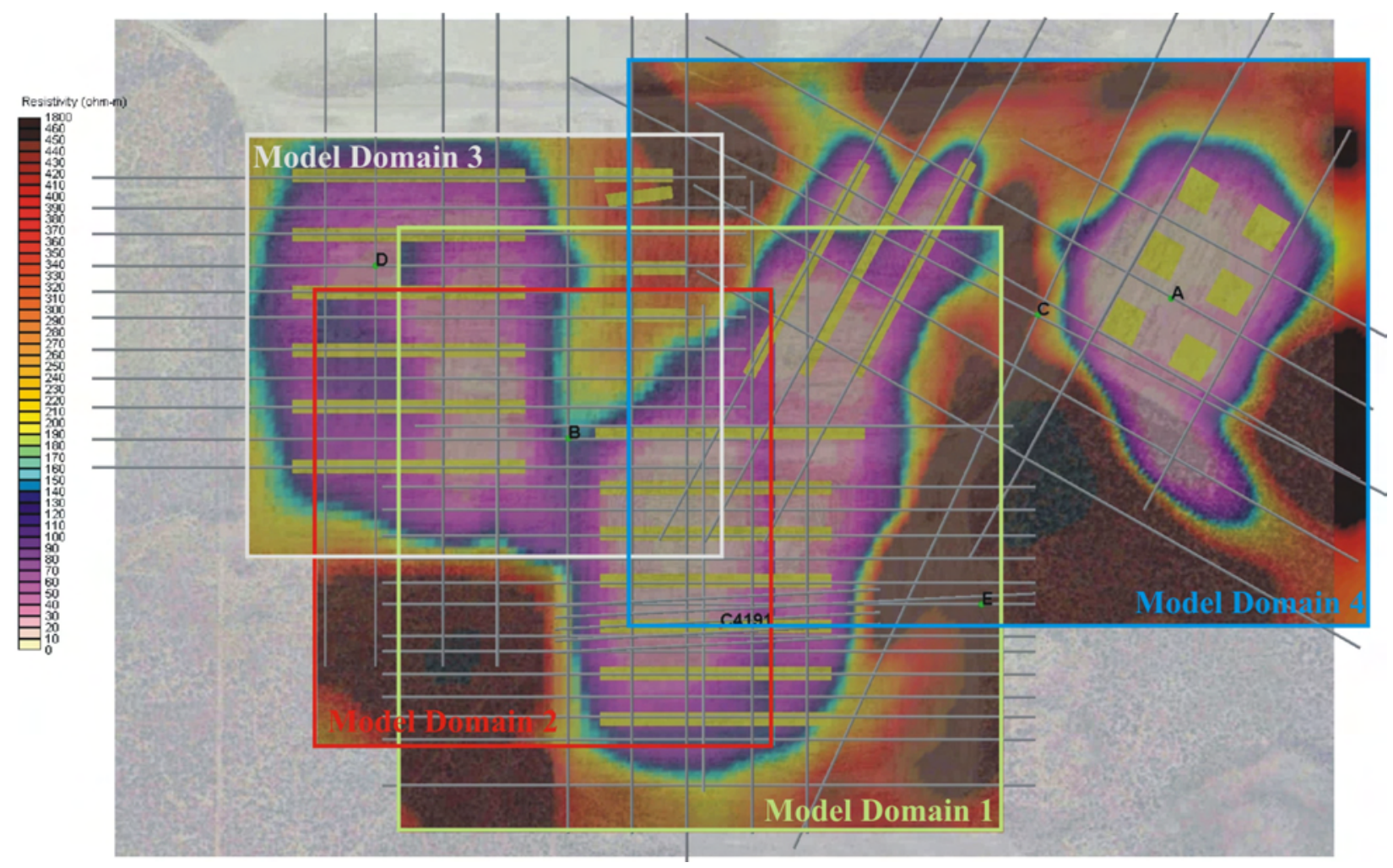

Figure 4.13. Results of the $3 \mathrm{D}$ inversion at BC Cribs—-Slice at $30 \mathrm{~m}$ bgs

\subsection{Electrical-Resistivity Laboratory Acquisition}

The electrical properties of soils are sensitive to a number of factors, including temperature, fluid composition (especially dissolved salt content) and conductivity, clay content, porosity, and other microstructural parameters. This sensitivity can be used to obtain information about basic physical properties that control water flow and contaminant transport. Electrical properties, including electrical resistivity and dielectric permittivity, are often used to infer water content in partially saturated rocks and soils based on field geophysical measurements. The relationships between the electrical properties, texture, and structural parameters are critical to the inversion and interpretation of field geophysical measurements. This section describes laboratory measurements of the electrical properties of saturated and partially saturated samples from Borehole C5923 (A) at room temperature. These measurements are used to provide a basis for estimating the dependence of ionic surface EC and bulk EC on lithology and the relation to ionic contaminant concentrations.

Laboratory measurements were performed on 175 samples from Borehole C5923 (A). The samples included 41 cores collected via split spoon sampling and 134 grab samples. Of the 39 cores, 20 were selected for measurements of PSD, SSA, and CEC to allow verification of ionic surface EC. Of these 20 cores, 12 were selected to measure the electrical properties as a function of saturation at room temperature. 


\subsubsection{Sample Preparation}

In general, samples were selected from fine-textured lenses and the next underlying coarse-textured layer; i.e. layer sequences that might constitute a capillary break. To perform measurements, samples were removed from the refrigerator and allowed to stand overnight on the counter top to equilibrate to room temperature.

Each core sample was fitted with two machined Plexiglas ${ }^{\circledR}$ collars, one at each end of the core liner. An end cap fitted with stainless steel electrodes was then attached to each collar. Each electrode was $3.99 \pm 0.01$ inches in diameter and 0.039 inch thick and was constructed from 316 stainless steel (Mott Corporation, Farmington CT, part number 4300-3.99DIA-.039-0.2-A) to create a porous plate with a mean pore size of $0.2 \mu \mathrm{m}$. A 2-inch long 3/33 stainless steel wire was welded to each electrode, about 1 inch from the outer edge, to allow connection to the instruments. The end caps had two openings, one for the introduction or extraction of fluid using a syringe pump and one through which the welded wire from the electrode exited for connection to the instrumentation. The electrode connections and pump tubing exited the end cap through ferruled compression fittings. For two electrode measurements, only the stainless steel electrodes in the endcaps were used. For 4-electrode measurements, an additional two electrodes were installed through the Lexan liner sidewall such that the spacing between the four electrodes was $3 \mathrm{~cm}$. The two additional electrodes were constructed of $1 / 4$-inch diameter 316 stainless steel and were 2 inches in length. Photographs in Figure 4.14 show different stages of column preparation for electrical measurements. For saturated sediment measurements, the cores were saturated with synthetic groundwater prepared to mimic uncontaminated Hanford formation pore water (specifically characterized at the 200-E Area's Integrated Disposal Facility [IDF]—see Um and Serne [2005] for details). Owing to the nature and levels of contaminants in the BC borehole C5923 cores, all work conducted on the cores was performed in a radiation control area. 


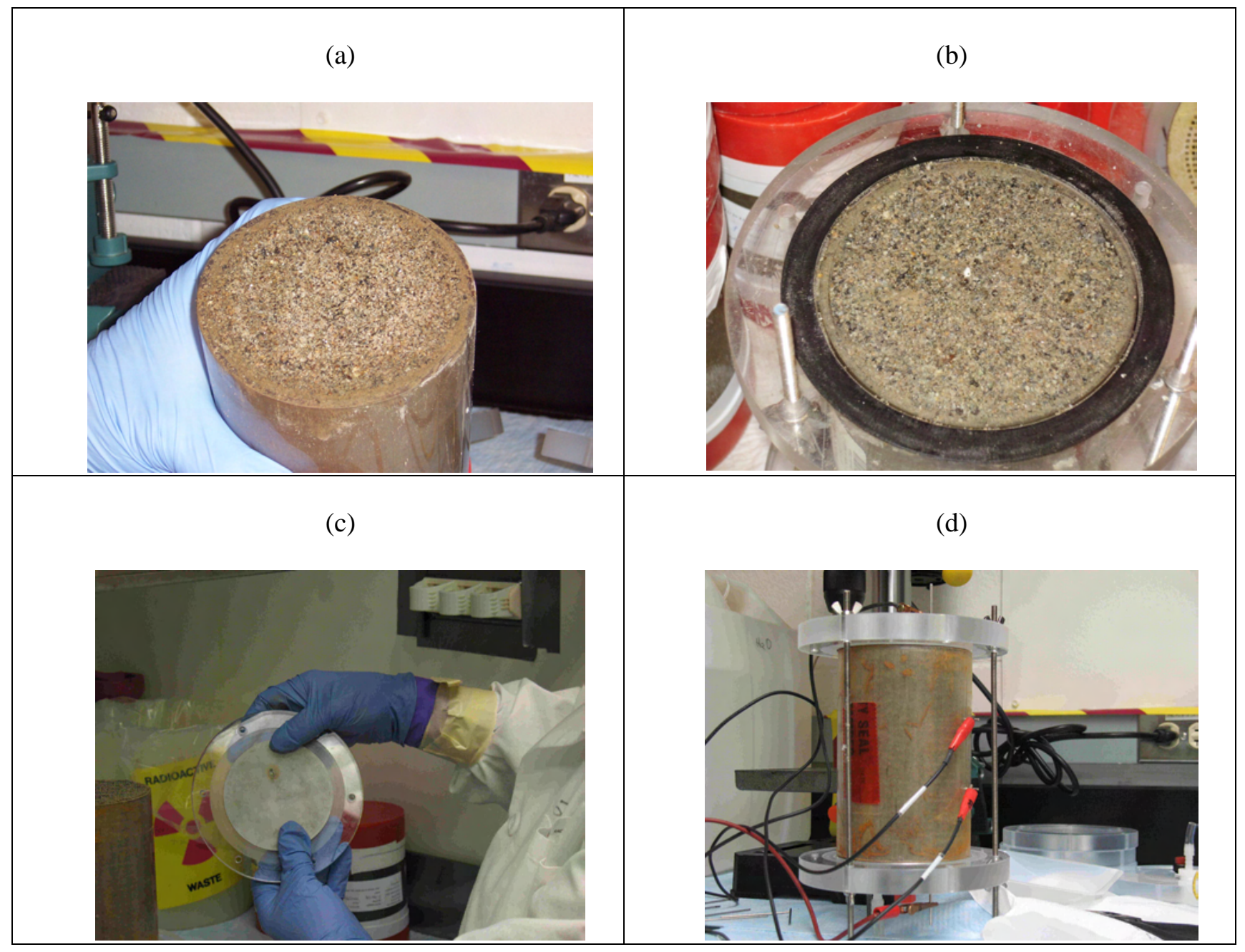

Figure 4.14. Stages of Core Preparation for Electrical Measurements, (a) Soil Core Just After Removal of End Caps, (b) Core After Attachment of the Collar Needed to Connect End Caps, (c) Porous Stainless Steel Electrode in End Cap, and (d) Fully Assembled Core with Collars and End Caps with Electrodes. Column shown is configured for 4-electrode measurements using a Wenner array.

\subsubsection{Electrical-Resistivity Measurements}

Electrical-resistivity and induced-polarization measurements were made using a Mini-Sting automatic earth resistivity and induced polarization system (AGI Geophysics). The Mini-Sting is a low-cost resistivity and IP meter especially designed for laboratory-scale resistivity surveys and is similar in operation to the Super Sting 8 instrument used in the field studies. Resistivity and induced polarization measurements were collected both on intact cores (within 4-inch diameter by 6-inch long Lexan liners) and grab samples of sediment using a four-electrode configuration based on a Wenner array. Figure 4.15 shows a schematic of the arrangement of the current and potential electrodes. 


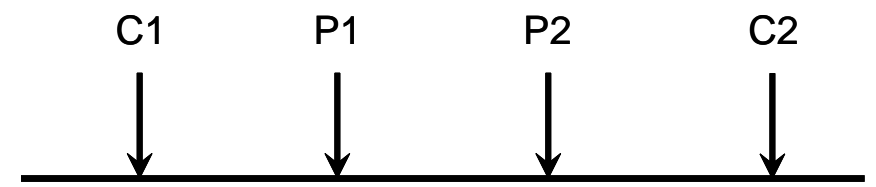

Figure 4.15. A Schematic of a Conventional Four-Electrode Array Used to Measure Subsurface Resistivity. C1 and C2 are current electrodes whereas P1 and P2 are potential electrodes used to measure voltage.

Measurements made at the scale used by the Mini-sting system represent a close approximation to the true bulk resistivity and chargeability of the sediment, assuming that small-scale heterogeneities are either not present or not significant within the sediment core and that such heterogeneities have been minimized by re-packing disaggregated grab-sample sediment into the measurement cell.

Resistivity measurements were made by applying a DC voltage over two current electrodes (C1, C2) and subsequently measuring the voltage across the other two electrodes, the potential electrodes (P1, P2). For multi-core measurements, the Mini-Sting was connected to a Swift Interface and multiplexor with 28 channels. This automatic switching afforded by the multiplexor allowed multiple measurements to be made simultaneously across multiple cores or re-packed grab samples.

Induced polarization (IP), like resistivity, measures parameters associated with voltages induced in the soil by direct application of an electrical current. While resistivity gives information on bulk soil resistivity, IP provides the capacitance or chargeability of the sediment by measuring the variation of voltage with time. Induced polarization is observed when a steady current through two electrodes is shut off: the voltage does not return to zero instantaneously, but rather decays slowly, indicating that electric charge has been stored in the soil or rock. These IP data are used to determine the ground capacitance or chargeability, which is related to soil texture, particularly through the surface conductance, CEC, and SSA. This effect can be measured in either the time domain by observing the rate of decay of voltage or in the frequency domain by measuring phase shifts between sinusoidal currents and voltages. The MiniSting was used to make time-domain measurements at time constants of 1,2 , 4, and 8 seconds.

To verify good data quality, significant effort was expended to verify good electrode-sediment contact. Any cavities observed after core opening were filled with glass beads of a similar grain size to the soil sample. Anomalously high-resistivity values (e.g., $>$ than 10 s to $100 \mathrm{~s}$ of $\mathrm{k} \Omega$ ) were indicative of poor electrode contact, in which case, the end electrodes were sprayed with a small amount of water. Data were stored in the internal memory of the resistivity meter and downloaded to a computer for further processing. Data were collected from both standard and reciprocal electrode configurations.

Measurements on the BC Crib borehole grab samples were done manually, packing sediment into a core and collecting the electrical data before processing the next sample. For the saturation-dependent measurements, data acquisition was fully automated and involved the sequential selection of two current electrodes and two potential electrodes on a core and the measurement of voltage and current across the electrode pairs. The Mini-Sting and the computer communicated with the AGI administrator software. 


\subsection{Borehole A (C5923) Results and Discussion}

This section presents the geochemical and physical characterization data collected on sediment (grab samples) from borehole C5923 (BC Cribs borehole A) recently emplaced directly south of the southeast corner of 216-B-17 Crib and directly west of the southwest corner of 216-B-16 crib (see Figure 1.1 for a location map). Besides the grab samples shown in Table 5.1, numerous 4-in.-diameter by 6-in.-long cores were obtained from select depths in borehole C5923. Many of these cores are being investigated in detail for soil resistivity and other geophysical and hydraulic properties that are discussed in Section 5.3. A listing of the cores is provided in Table 5.2. Once we discovered that the sediments in this borehole were quite contaminated with sodium nitrate salt, we decided to emphasize comparing the geochemical results with those from sediments fro borehole C4191 that was drilled right through the footprint of the 216-B-26 trench.

The first activities included tests that were inexpensive or that were key to determining the vertical distribution of mobile contaminants and moisture and major solutes in the vadose zone pore water. The latter two parameters directly relate to the soil resistivity and are key to performing the "ground-truthing" exercise. Information on the borehole sediments presented in this section includes moisture content, $\mathrm{pH}$, and EC of 1:1 sediment to water extracts, and measurements of major cations, anions, trace metals, and radionuclides in both the sediment and 1:1 sediment-to-water extracts. A GEA on selected grab samples was also performed to search for any detectable man-made gamma-emitting radionuclides. The PSD was determined on selected samples and the total chemical composition of selected sediment samples were measured by strong acid extracts. COPCs specifically measured in acid extracts of selected grab samples included RCRA metals and nickel-63. The particle-size measurements and strong acid extractable constituents performed in the tier 2 phase aid in selecting contacts between major geologic units. They also help assess whether immobile COCs were present that would require consideration in predicting baseline risk and selecting appropriate remedial alternatives for final site clean up.

\subsection{Geochemical Results from Borehole A (C5923)}

\subsubsection{Moisture Content}

The gravimetric moisture content of the sediment from the grab samples from C5923, which was emplaced via cable-tool drilling with grab samples taken approximately every $2.5 \mathrm{ft}$ from about 5 to $352 \mathrm{ft}$ bgs, is listed in Table 5.1 and presented as a graph in Figure 5.1. The sample IDs are the sample unique HEIS numbers assigned by FHI staff. The second column in each set shows the mid depth of the grab sample, and the final column is gravimetric moisture content. Interestingly, the only sediments with moisture contents equal to or greater than $8 \% \mathrm{wt}$ are found in the upper $46 \mathrm{ft}$ of the profile. Six grab samples, representing five thin lens of less than 2.5-ft thickness, are highlighted in the upper $46 \mathrm{ft}$ as being wetter than 8\% wt in Figure 5.1. Specific values are shown in Table 5.1. Other relatively finergrained lenses are found at deeper depths (see gray shading in Figure 5.1) but at moisture contents less than 8 wt\%. 
PNNL-17821

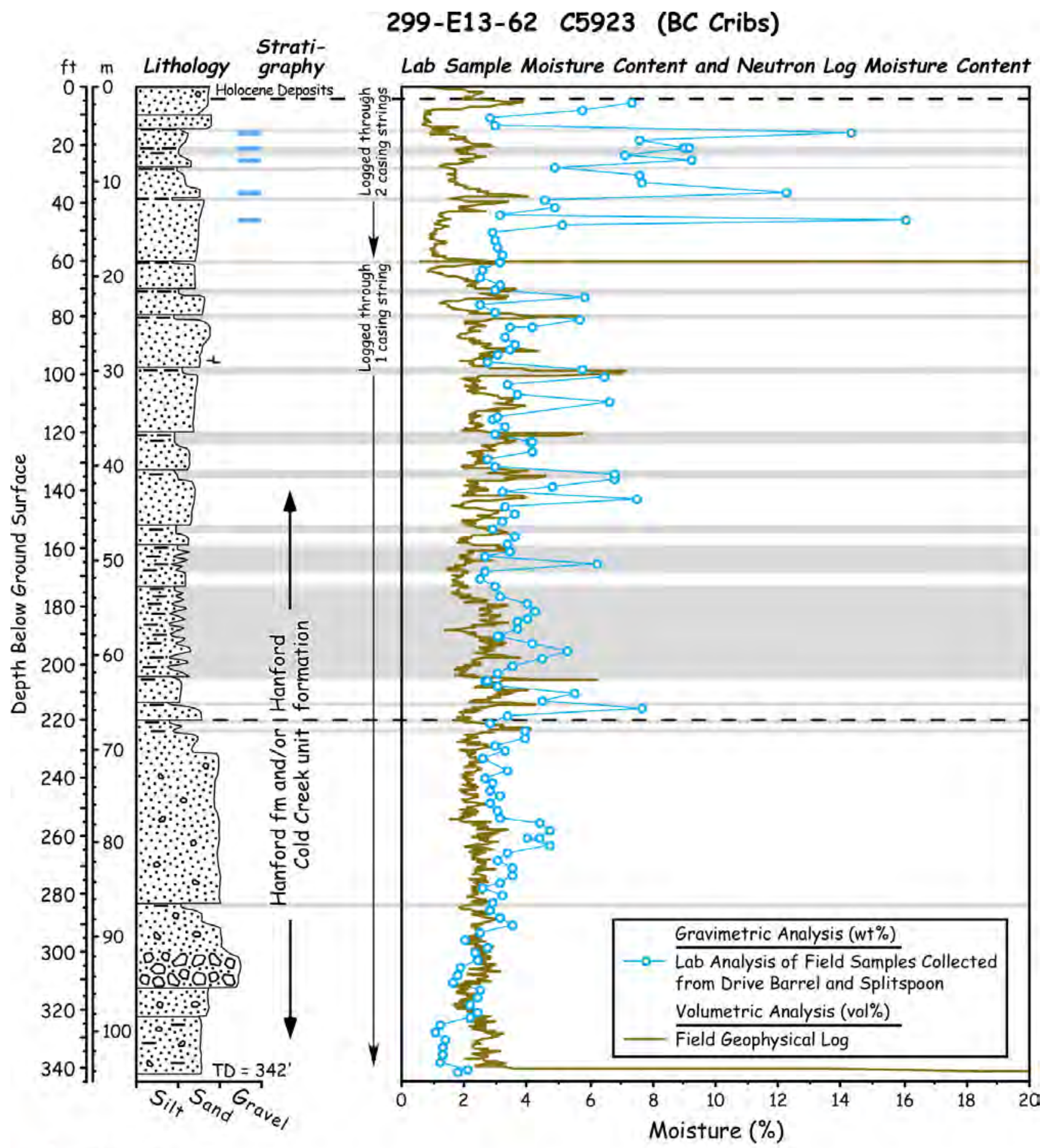

Fine-Grained Layer

$=>\mathrm{wt} \%$ Moisture

- Pedogenic Carbonate

- Silt $\because \because$ Sand 00 Gravel

$2008 / D C L / C 5923 / 002(07 / 24)$

Figure 5.1. Moisture Content of Grab Samples from C5923 Compared to Field Neutron Moisture Log 
Borehole C5923 contains fewer thin zones with higher moisture in the upper $110 \mathrm{ft}$ of the Hanford formation (H2 unit) than borehole C4191. As stated in the Geology section (2.0), the vadose zone beneath BC Cribs is dominated by a thick sand-dominated sequence of the Hanford formation (H2 unit), but internally, this sequence contains multiple beds of fine- to coarse-grained sand up to several meters thick that grade back and forth between coarse sand to fine sand multiple times before finally grading up into a silty fine sand to silt-textured cap. The texture and thickness of graded beds in the area appears to decrease upward within the Hanford formation $\mathrm{H} 2$ unit. The overall fining and thinning of beds in the shallower depths is probably related to Ice Age floods that became progressively smaller at the end of the Ice Age. This is significant to moisture and contaminant migration since there is an increased likelihood for lateral spreading in the upper Hanford formation. This is due to a higher frequency of fine-grained, silty, slackwater beds in the upper part of the Hanford formation. Flood beds that are thicker and coarser deeper in the profile as evidenced by the lack of any zones with moisture contents greater than $8 \% \mathrm{wt}$ below $46 \mathrm{ft}$ bgs. Additional discussion on the field moisture logging and a comparison to the laboratory gravimetric moisture contents and their correlation to the lithology are found in Section 2.2.1.4 and Figure 2.17. There is a larger volume of liquid waste disposed of per square foot of disposal facility footprint to the BC Cribs than any individual trench, excepting trench 216-B-52, and borehole C5923 appears to contain fewer thin relatively wet fine-grained lens (based on the field neutron logs and geologist's descriptions in Section 2.2.1.4). Therefore, one might expect the vertical distribution of mobile contaminants, which migrate coincident with the waste water, to have reached deeper depths than at borehole C4191. As shown below, this expectation of deeper mobile contaminant travel at C5923 is in fact observed.

Table 5.1. Gravimetric Moisture Content of Grab Samples Obtained from Borehole C5923

\begin{tabular}{|c|c|c|c|c|c|c|c|c|}
\hline ID & $\begin{array}{l}\text { Mid Depth } \\
\text { ft bgs }\end{array}$ & $\begin{array}{c}\text { \% Moisture } \\
\text { wt } \%\end{array}$ & ID & $\begin{array}{l}\text { Mid Depth } \\
\text { ft bgs }\end{array}$ & $\begin{array}{c}\text { \% Moisture } \\
\text { wt \% }\end{array}$ & ID & $\begin{array}{l}\text { Mid Depth } \\
\text { ft bgs }\end{array}$ & $\begin{array}{c}\text { \% Moisture } \\
\text { wt \% }\end{array}$ \\
\hline B1T740 & 5.5 & 7.29 & B1T818 & 123 & 4.11 & B1T9K7 & 239.3 & 2.65 \\
\hline B1T741 & 8 & 5.69 & B1T9L2 & 126.8 & 4.11 & В1Т9К8 & 241.8 & 2.87 \\
\hline B1T742 & 10.5 & 2.77 & B1T9L3 & 129.3 & 2.68 & В1T824 & 244.3 & 2.82 \\
\hline B1T743 & 13 & 2.94 & B1T9L4 & 131.8 & 2.95 & B1T7C4 & 245.5 & 3.09 \\
\hline B1T744 & 15.5 & 14.3 & B1T9L5 & 134.3 & 6.74 & B1T7C5 & 248 & 2.81 \\
\hline B1T745 & 18 & 7.56 & B1T778 & 135.5 & 6.77 & B1T7C6 & 250.5 & 3.05 \\
\hline B1T746 & 20.5 & 8.94 & B1T779 & 138 & 4.75 & B1T7C8 & 253 & 3.12 \\
\hline B1T816 & 20.5 & 9.11 & B1T780 & 140.5 & 3.15 & B1T7C7 & 255.5 & 4.36 \\
\hline B1T747 & 23 & 7.1 & B1T781 & 143 & 7.47 & В1Т7С9 & 258 & 4.68 \\
\hline B1T748 & 25.5 & 9.25 & B1T782 & 145.5 & 3.3 & B1T7D0 & 260.5 & 4.38 \\
\hline B1T749 & 28 & 4.81 & B1T783 & 148 & 3.55 & В1T822 & 260 & 4.01 \\
\hline B1T750 & 30.5 & 7.51 & B1T784 & 150.5 & 3.21 & B1T7D1 & 263 & 4.73 \\
\hline B1T751 & 33 & 7.59 & B1T785 & 153 & 2.83 & B1T7D2 & 265.5 & 3.38 \\
\hline B1T825 & 36.8 & 12.2 & B1T786 & 155.5 & 3.57 & B1T7D3 & 268 & 3.03 \\
\hline B1T826 & 39.3 & 4.54 & B1T787 & 158 & 3.38 & B1T7D4 & 270.5 & 3.5 \\
\hline В1Т827 & 41.8 & 4.82 & В1T788 & 160.5 & 3.43 & B1T7D5 & 273 & 3.53 \\
\hline В1T828 & 44.3 & 3.12 & B1T789 & 163 & 2.6 & B1T7D6 & 275.5 & 3.09 \\
\hline B1T752 & 45.5 & 16 & B1T790 & 165.5 & 6.23 & B1T7D7 & 278 & 2.54 \\
\hline
\end{tabular}


PNNL-17821

Table 5.1 (Contd)

\begin{tabular}{|c|c|c|c|c|c|c|c|c|}
\hline ID & $\begin{array}{l}\text { Mid Depth } \\
\text { ft bgs }\end{array}$ & $\begin{array}{c}\text { \% Moisture } \\
\text { wt \% }\end{array}$ & ID & $\begin{array}{l}\text { Mid Depth } \\
\text { ft bgs }\end{array}$ & $\begin{array}{c}\text { \% Moisture } \\
\text { wt \% }\end{array}$ & ID & $\begin{array}{l}\text { Mid Depth } \\
\text { ft bgs }\end{array}$ & $\begin{array}{c}\text { \% Moisture } \\
\text { wt \% }\end{array}$ \\
\hline B1T753 & 48 & 5.12 & B1T791 & 168 & 2.64 & B1T7D8 & 280.5 & 3.2 \\
\hline B1T754 & 50.5 & 2.85 & B1T792 & 170.5 & 2.46 & B1T7D9 & 283 & 2.83 \\
\hline B1T755 & 53 & 2.95 & B1T793 & 173 & 2.95 & B1T7F0 & 285.5 & 2.76 \\
\hline B1T756 & 55.5 & 3.02 & B1T9L6 & 176.8 & 3.14 & B1T7F1 & 288 & 3.13 \\
\hline B1T757 & 58 & 3.2 & B1T9L7 & 179.3 & 3.96 & B1T7F2 & 290.5 & 3.53 \\
\hline B1T758 & 60.5 & 3.11 & B1T9L8 & 181.8 & 4.21 & B1T7F3 & 293 & 2.45 \\
\hline B1T759 & 63 & 2.55 & B1T9L9 & 184.3 & 3.94 & B1T7F4 & 295.5 & 1.98 \\
\hline B1T760 & 65.5 & 2.48 & B1T794 & 185.5 & 3.67 & B1T7F5 & 298 & 2.68 \\
\hline B1T761 & 68 & 3.11 & B1T795 & 188 & 3.67 & B1T7F6 & 300.5 & 2.27 \\
\hline B1T762 & 70.5 & 2.96 & B1T796 & 190.5 & 3.14 & B1T7F7 & 303 & 2.37 \\
\hline B1T763 & 73 & 5.8 & B1T819 & 190.5 & 2.99 & B1T7F8 & 305.5 & 1.82 \\
\hline B1T764 & 75.5 & 2.45 & B1T797 & 193 & 4.16 & B1T7F9 & 308 & 1.75 \\
\hline B1T765 & 78 & 2.98 & B1T798 & 195.5 & 5.21 & B1T7H0 & 310.5 & 1.57 \\
\hline B1T766 & 80.5 & 5.62 & B1T799 & 198 & 4.49 & B1T7H1 & 313 & 2.45 \\
\hline B1T767 & 83 & 4.11 & B1T7B0 & 200.5 & 3.53 & B1T7H2 & 315.5 & 2.38 \\
\hline B1T817 & 83 & 3.42 & B1T7B1 & 203 & 3.06 & B1T7H3 & 318 & 2.17 \\
\hline B1T829 & 86.8 & 3.28 & B1T7B2 & 205.5 & 2.66 & B1T7H4 & 320.5 & 2.42 \\
\hline B1T985 & 89.3 & 3.55 & B1T820 & 205.5 & 2.72 & B1T7H5 & 323 & 2.12 \\
\hline B1T768 & 90.5 & 3.43 & B1T7B3 & 208 & 3 & B1T7H6 & 325.5 & 1.21 \\
\hline B1T769 & 93 & 3.06 & B1T7B4 & 210.5 & 5.49 & B1T7H7 & 328 & 1.04 \\
\hline B1T770 & 95.5 & 2.7 & B1T7B5 & 213 & 4.43 & В1T7H8 & 330.5 & 1.36 \\
\hline B1T771 & 98 & 5.72 & B1T7B6 & 215.5 & 7.65 & B1T823 & 330.5 & 1.38 \\
\hline B1T772 & 100.5 & 6.47 & B1T7B7 & 218 & 3.35 & В1Т7Н9 & 333 & 1.26 \\
\hline B1T773 & 103 & 3.35 & B1T7B8 & 220.5 & 2.8 & B1T7J0 & 335.5 & 1.26 \\
\hline В1Т9К9 & 106.8 & 3.67 & B1T7B9 & 223 & 3.88 & B1T7J1 & 338 & 1.2 \\
\hline B1T9L0 & 109.3 & 6.58 & B1T821 & 223 & 3.92 & B1T7J2 & 340.5 & 2.06 \\
\hline B1T9L1 & 114.3 & 2.99 & В1T7C0 & 225.5 & 3.93 & B1T984 & 341.5 & 1.73 \\
\hline B1T774 & 115.5 & 2.89 & B1T7C1 & 228 & 2.96 & B1V530 & 344 & 1.23 \\
\hline B1T775 & 118 & 3.24 & B1T7C2 & 230.5 & 3.24 & B1V531 & 346.5 & 2.99 \\
\hline B1T776 & 120.5 & 2.91 & В1T7C3 & 233 & 2.55 & B1V532 & 349 & 5.38 \\
\hline В1T777 & 123 & 4.09 & В1Т9К6 & 236.8 & 3.33 & B1V533 & 351.5 & 13.2 \\
\hline
\end{tabular}

\subsubsection{1:1 Sediment-to-Water Extracts}

As described in Section 3, selected grab samples were processed by adding known amounts of deionized water to aid in separating the native pore water in the relatively dry sediments. In this section, the water extract data are reported in both units of pore water concentration (most useful for comparing with soil-resistivity data) and units of mass per gram of dry sediment (useful for estimating vertical distribution of each species). 
PNNL-17821

Table 5.2. Core Liners Obtained from Borehole C5923

\begin{tabular}{|c|c|c|c|c|c|c|c|}
\hline C5923 & Split-sp & oon Sampler & Liner & C5923 & Split-sp & on Sampler & Liner \\
\hline Core Liner ID & top (ft bgs & ) bottom (ft bg & s) Mid Depth (ft bgs) & Core Liner ID & top (ft bgs) & bottom (ft bgs) & Mid Depth (ft bgs) \\
\hline B1T7J4-2 & 38.0 & 38.5 & 38.25 & B1T7K3-3 & 130.5 & 131.0 & 130.75 \\
\hline B1T7J3-3 & 38.0 & 38.5 & 38.25 & B1T7K3-2 & 131.0 & 131.5 & 131.25 \\
\hline B1T7J3-2 & 38.5 & 39.0 & 38.75 & B1T7K4-3 & 133.0 & 133.5 & 133.25 \\
\hline B1T7J5-3 & 40.5 & 41.0 & 40.75 & B1T7K4-2 & 133.5 & 134.0 & 133.75 \\
\hline B1T7J5-2 & 41.0 & 41.5 & 41.25 & B1T7K5-3 & 175.5 & 176.0 & 175.75 \\
\hline B1T7J6-3 & 43.0 & 43.5 & 43.25 & B1T7K5-2 & 176.0 & 176.5 & 176.25 \\
\hline B1T7J6-2 & 43.5 & 44.0 & 43.75 & B1T7K6-3 & 178.0 & 178.5 & 178.25 \\
\hline B1T7J7-3 & 85.5 & 86.0 & 85.75 & B1T7K6-2 & 178.5 & 179.0 & 178.75 \\
\hline B1T7J7-2 & 86.0 & 86.5 & 86.25 & B1T7K7-3 & 180.5 & 181.0 & 180.75 \\
\hline B1T7J8-3 & 88.0 & 88.5 & 88.25 & B1T7K7-2 & 181.0 & 181.5 & 181.25 \\
\hline B1T7J8-2 & 88.5 & 89.0 & 88.75 & B1T7K8-3 & 183.0 & 183.5 & 183.25 \\
\hline B1T7J9-3 & 105.5 & 106.0 & 105.75 & B1T7K8-2 & 183.5 & 184.0 & 183.75 \\
\hline B1T7J9-2 & 106.0 & 106.5 & 106.25 & B1T7K9-3 & 235.5 & 236.0 & 235.75 \\
\hline B1T7K0-3 & 108.0 & 108.5 & 108.25 & В1Т7К9-2 & 236.0 & 236.5 & 236.25 \\
\hline B1T7K0-2 & 108.5 & 109.0 & 108.75 & B1T7L0-3 & 238.0 & 238.5 & 238.25 \\
\hline B1T7L3-3 & 113.0 & 113.5 & 113.25 & B1T7L0-2 & 238.5 & 239.0 & 238.75 \\
\hline B1T7L3-2 & 113.5 & 114.0 & 113.75 & B1T7L1-3 & 240.5 & 241.0 & 240.75 \\
\hline B1T7K1-3 & 125.5 & 126.0 & 125.75 & B1T7L1-2 & 241.0 & 241.5 & 241.25 \\
\hline B1T7K1-2 & 126.0 & 126.5 & 126.25 & B1T7L2-3 & 243.0 & 243.5 & 243.25 \\
\hline B1T7K2-3 & 128.5 & 129.0 & 128.75 & B1T7L2-2 & 243.5 & 244.0. & 243.75 \\
\hline B1T7K2-2 & 129.0 & 129.5 & 129.25 & & & & \\
\hline
\end{tabular}

The $\mathrm{pH}$ and EC for the water extracts are shown in Table 5.3. Figure 5.2 shows the pore-water EC, pore-water total ionic strength, and pore-water major dissolved constituents. The $\mathrm{pH}$ profile shows a few samples with elevated values indicative of caustic waste in the depth region 8 to $13 \mathrm{ft}$ bgs and perhaps as deep as $18 \mathrm{ft}$ bgs. The crib bottoms were from 11 to $15 \mathrm{ft}$ bgs at the time of their use. We are not sure whether the current ground-surface elevation is the same as during the operations of the BC Cribs. If so, some of the shallow sediments near $8 \mathrm{ft}$ bgs with elevated $\mathrm{pH}$ are shallower than the bottom of the adjacent cribs, suggesting that caustic waste must have ponded in the cribs and also migrated horizontally up to a few hundred feet. The deepest sample analyzed to date at $340.5 \mathrm{ft}$ bgs also exhibits a higher than naturally occurring $\mathrm{pH}$ value at 8.78 , but this might be an erroneous measurement. We have never observed impacts of caustic waste on vadose zone or aquifer sediments this deep in sediments. Because there are no signs of $\mathrm{pH}$ values above the upper range of naturally occurring values (up to 8.5) anywhere else below $18 \mathrm{ft}$ bgs, we doubt that the $\mathrm{pH}$ value for sample B1T7J2 is correct. At the 216-B-26 trench, high $\mathrm{pH}$ values (above 9) were found from 17.5 to $37.5 \mathrm{ft}$ bgs. $\mathrm{pH}$ values above 9 but below 10 are observed below and adjacent to single-shell tanks that have leaked highly caustic waste but at more 
Table 5.3. $\mathrm{pH}$ and EC Values for 1:1 Sediment to Water Extracts from C5923

\begin{tabular}{|c|c|c|c|c|c|c|c|c|c|}
\hline HEIS \# ID & $\begin{array}{c}\text { Mid } \\
\text { Depth } \\
\text { ft bgs }\end{array}$ & $\begin{array}{c}1: 1 \\
\text { Extract } \\
\text { pH }\end{array}$ & $\begin{array}{c}\text { 1:1 Extract } \\
\text { Conductivity } \\
\mathrm{mS} / \mathrm{cm}\end{array}$ & $\begin{array}{l}\text { Conductivity } \\
\text { Dilution } \\
\text { Corrected (in } \\
\text { Pore Water) } \\
\text { (mS/cm) }\end{array}$ & HEIS \# ID & $\begin{array}{l}\text { Mid } \\
\text { Depth } \\
\text { ft bgs }\end{array}$ & $\begin{array}{c}1: 1 \\
\text { Extract } \\
\text { pH }\end{array}$ & $\begin{array}{c}1: 1 \text { Extract } \\
\text { Conductivity } \\
\mathrm{mS} / \mathrm{cm}\end{array}$ & $\begin{array}{l}\text { Conductivity } \\
\text { Dilution } \\
\text { Corrected } \\
\text { (in Pore } \\
\text { Water) } \\
\text { (mS/cm) }\end{array}$ \\
\hline B1T740 & 5.5 & 8.02 & 0.128 & 1.75 & B1T818 & 123.0 & 8.0 & 7.127 & 173.46 \\
\hline B1T741 & 8.0 & 9.24 & 0.239 & 4.20 & B1T9L2 & 126.8 & 7.68 & 7.717 & 188.69 \\
\hline B1T743 & 13.0 & 8.88 & 0.223 & 7.59 & B1T9L3 & 129.3 & 7.9 & 5.013 & 187.06 \\
\hline B1T744 & 15.5 & 8.32 & 0.26 & 1.81 & B1T9L4 & 131.8 & 7.6 & 5.979 & 202.68 \\
\hline B1T745 & 18.0 & 8.55 & 0.183 & 2.40 & B1T9L5 & 134.3 & 7.3 & 12.1 & 179.68 \\
\hline B1T746 & 20.5 & 8.44 & 0.243 & 2.72 & B1T781 & 143.0 & 7.17 & 8.66 & 115.72 \\
\hline B1T816 & 20.5 & 8.2 & 0.242 & 2.65 & B1T790 & 165.5 & 7.95 & 0.348 & 5.58 \\
\hline B1T747 & 23.0 & 8.32 & 0.205 & 2.88 & B1T793 & 173.0 & 8.05 & 0.201 & 6.82 \\
\hline B1T748 & 25.5 & 8.07 & 0.249 & 2.69 & B1T9L6 & 176.8 & 8.13 & 0.195 & 6.24 \\
\hline B1T749 & 28.0 & 7.31 & 1.8 & 39.52 & B1T9L7 & 179.3 & 8.04 & 0.212 & 5.35 \\
\hline B1T750 & 30.5 & 7.63 & 1.65 & 21.90 & B1T9L8 & 181.8 & 7.97 & 0.23 & 5.44 \\
\hline B1T751 & 33.0 & 7.83 & 0.426 & 5.62 & B1T9L9 & 184.3 & 8.14 & 0.205 & 5.22 \\
\hline B1T825 & 36.8 & 8.2 & 10.5 & 85.89 & B1T798 & 195.5 & 7.74 & 0.381 & 7.33 \\
\hline B1T826 & 39.3 & 8.0 & 3.47 & 76.42 & B1T7B4 & 210.5 & 7.51 & 9.58 & 173.94 \\
\hline B1T828 & 44.3 & 7.41 & 6.202 & 198.80 & B1T7B6 & 215.5 & 7.73 & 15.54 & 203.13 \\
\hline B1T752 & 45.5 & 7.3 & 26.4 & 179.66 & B1T7C2 & 230.5 & 7.14 & 7.48 & 232.07 \\
\hline B1T753 & 48.0 & 7.41 & 12.6 & 247.03 & В1T9K6 & 236.8 & 7.28 & 5.5 & 165.21 \\
\hline B1T755 & 53.0 & 7.3 & 6.02 & 204.10 & B1T9K7 & 239.3 & 7.26 & 3.868 & 145.97 \\
\hline B1T757 & 58.0 & 7.53 & 7.22 & 227.10 & В1Т9К8 & 241.8 & 7.35 & 3.088 & 107.63 \\
\hline B1T763 & 73.0 & 7.22 & 15 & 258.42 & B1T824 & 244.3 & 7.37 & 1.831 & 64.98 \\
\hline B1T766 & 80.5 & 7.07 & 15 & 266.57 & B1T7C4 & 245.5 & 7.52 & 1.548 & 50.18 \\
\hline B1T767 & 83.0 & 7.58 & 9.383 & 230.18 & B1T7C9 & 258.0 & 8.1 & 0.241 & 5.17 \\
\hline B1T817 & 83.0 & 7.9 & 7.886 & 230.60 & B1T7D1 & 263.0 & 8.05 & 0.217 & 4.59 \\
\hline B1T985 & 89.3 & 8.11 & 10.22 & 287.90 & B1T7D8 & 280.5 & 8.09 & 0.224 & 6.97 \\
\hline B1T768 & 90.5 & 7.46 & 10.04 & 292.87 & B1T7F2 & 290.5 & 7.85 & 0.26 & 7.32 \\
\hline B1T771 & 98.0 & 7.13 & 7.36 & 129.06 & B1T7H1 & 313.0 & 8.44 & 0.174 & 7.14 \\
\hline B1T773 & 103.0 & 7.35 & 4.156 & 126.57 & B1T7J2 & 340.5 & 8.78 & 0.215 & 10.50 \\
\hline В1Т9К9 & 106.8 & 7.51 & 4.074 & 111.01 & B1V530 & 344 & 8.61 & 0.23 & 18.62 \\
\hline B1T9L0 & 109.3 & 7.15 & 8.93 & 135.65 & B1V531 & 346.5 & 8.13 & 0.144 & 4.79 \\
\hline B1T9L1 & 114.3 & 7.41 & 3.264 & 109.21 & B1V532 & 349 & 7.71 & 0.12 & 2.23 \\
\hline B1T777 & 123.0 & 7.86 & 7.44 & 183.27 & B1V533 & 351.5 & 7.83 & 0.114 & 0.87 \\
\hline
\end{tabular}




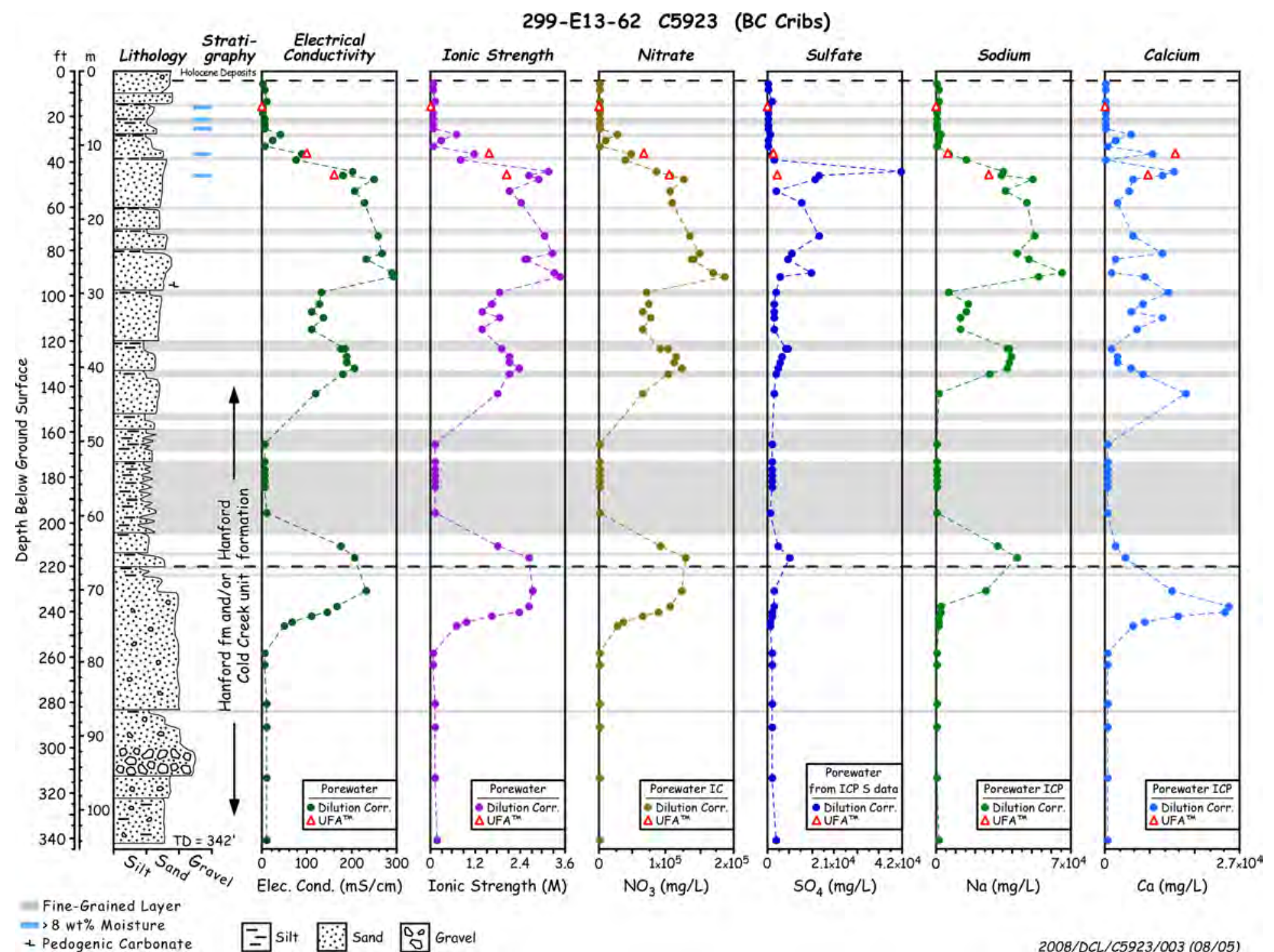

Figure 5.2. Pore-Water EC, Ionic Strength and Major Ions in Borehole C5923 
limited volumes than disposed of to cribs. The vertical extent of the elevated $\mathrm{pH}$ at borehole C5923 (approximately 5 to at most 10 vertical ft) is a bit less than the thicknesses of impacted sediment observed below several single-shell tanks and also about half the thickness of elevated $\mathrm{pH}$ observed at borehole C4191 emplaced directly through the 216-B-26 trench. The thinner impact zone of elevated $\mathrm{pH}$ at borehole C5923 is either caused by the combination of the likely lower free-base content in the BC Crib waste stream than released from single-shell tanks or the fact that all caustic-impacted vadose zone sediments at Hanford have been buffered to $\mathrm{pH}$ values between $~ 9$ and 9.8 over the 4 to 6 decades since the fluids were released. At present, almost all observations of caustic fluid attack on Hanford sediments exhibit water-extract $\mathrm{pH}$ values in this constrained range of approximately one $\mathrm{pH}$ unit, despite some of the waste streams that were projected to have $\mathrm{pH}$ values that ranged from 10 to greater than 14 .

The sediment from C5923 (to the side but near 216-B-16 and 216-B-17) cribs appears to show a trimodal peak in pore-water EC (i.e., exhibits the three maxima in pore-water EC). The shallowest lobe of high EC is by far the thickest lobe ( $\sim 55 \mathrm{ft}$ thick with maximum pore water EC of $293 \mathrm{mS} / \mathrm{cm}$ ); the middle lobe of the tri-modal distribution is thin ( $\sim 10 \mathrm{ft}$ thick with a maximum pore water EC $\sim 200 \mathrm{mS} / \mathrm{cm}$ ), and the deepest lobe is about $30 \mathrm{ft}$ thick with a maximum pore water EC of $230 \mathrm{mS} / \mathrm{cm}$. The depths bgs for the three EC maxima are 90, 132, and $230 \mathrm{ft}$ bgs, respectively. The deeper lobe of salt is considerably deeper than the bimodal salt plume at borehole C4191 drilled through 216-B-26 trench. The upper two lobes of salt maxima at C5923 occur at about the same depths as the bi-modal plume below the 216-B-26 trench. At both boreholes, C5923 and C4191, the shallowest lobe of the salt plumes has the highest electrical conductivities. The absolute value of the maximum EC at C5923 ( 293 mS/cm) is about two times larger than at C4191 (152 mS/cm). The total volume of waste disposed of to 216-B-16 and 216-B17 was 9 million liters in comparison to 4.75 million liters disposed of to the 216-B-26 trench based on estimates in Corbin et al. (2005). Thus, one might expect the observed deeper penetration of salt in borehole C5923 located near the cribs than at borehole C4191 based on the larger volume of waste disposed of near C5923.

\subsubsection{Water Extract Composition of the 1:1 Sediment to Water Extracts for C5923}

The 1:1 sediment-to-water extract anion composition, in units of $\mu \mathrm{g} / \mathrm{g}$ of dry sediment and in units of $\mathrm{mg} / \mathrm{L}$ for the calculated pore water, are shown in Table 5.4 and Table 5.5, respectively. Figure 5.2 shows the calculated pore-water concentrations of nitrate and sulfate, the two dominant anions. Figure 5.3 plots the nitrate concentration per gram of dry sediment as a function of depth. Values in Table 5.4 that appear to be elevated compared to the others are shown in bold type. The waste stream that was disposed of to cribs 216-B-16 and 216-B-17 was uranium recovery, and scavenging wastes from a tri-butylphosphatebased process was used to recover uranium from bismuth phosphate wastes retrieved from single-shell tanks. More details on the waste composition can be found in Corbin et al. (2005) and the appendixes to the DQO report, Benecke (2008). About 2.67 metric tons of dissolved salts consisting mainly of nitrate and sodium (combined, these represent 2.39 metric tons) and lesser amounts of sulfate, phosphate, fluoride, chloride, and potassium were disposed of in total to the 216-B-16 and 216-B-17 cribs. The vadose zone sediments in borehole C5923 outside the footprint of the BC cribs show elevated concentrations of most of the aforementioned anions with phosphate being immobilized in the upper $8 \mathrm{ft}$ bgs. Elevated sulfate concentrations are found in two regions, from 28 to 143 bgs and 210 to $246 \mathrm{ft}$ bgs, and elevated chloride concentrations are also found in the same two regions as the chloride. There are no 
distinctly elevated fluoride regions. The most elevated nitrate concentrations are found in the same two regions as the chloride and sulfate as shown in bold in Table 5.4. These depth distributions do not show any vertical differences between sulfate, chloride, and nitrate as was found in the borehole C4191 sediments right below the 216-B-26 trench. This lack of vertical discrimination of anions in the sediments at C5923 suggests that the contamination at this borehole has migrated into the region via horizontal flow so that we are not able to discern vertical separation of anions. The bimodal vertical distribution of anions in C5923 sediments suggests at least two disposal events, or two sources distributed the wastes.

The massive quantity on nitrate disposed makes it a good tracer of the waste-fluid plume location. Figure 5.2 shows that there is no difference in the vertical distribution of the major anions sulfate and nitrate or the major cations sodium and calcium. Again, this seems to indicate that waste fluids migrated horizontally into the sediments at borehole C5923. Three sediment samples were also processed by ultracentrifugation to extract directly vadose zone pore water. The chemical composition of the three pore waters are shown in Figure 5.2 and Figure 5.3 and in general show good agreement with the values calculated by dilution correcting the 1:1 sediment to de-ionized water extracts.

Table 5.4. Anion Composition of Water Extracts of C5923 (units $\mu \mathrm{g} / \mathrm{g}$ dry sediment)

\begin{tabular}{|c|c|c|c|c|c|c|c|c|}
\hline Sample ID & $\begin{array}{l}\text { Mid Depth } \\
\text { (ft bgs) }\end{array}$ & Fluoride & Chloride & Nitrite & Nitrate & Sulfate-IC & Phosphate-IC & $\begin{array}{l}\text { Alkalinity } \\
\text { (as } \mathrm{CaCO}_{3} \text { ) }\end{array}$ \\
\hline B1T740 & 5.5 & 0.787 & 0.631 & $<0.3$ & 5.01 & 1.93 & 9.43 & 54.7 \\
\hline B1T741 & 8 & 1.27 & 0.576 & $<0.3$ & 6.98 & 7.21 & 3.54 & 106.4 \\
\hline B1T743 & 13 & 0.756 & 0.629 & $<0.3$ & 5.76 & 31.9 & $<2.5$ & 65.4 \\
\hline B1T744 & 15.5 & 1.24 & 9.71 & $<0.3$ & 19.02 & 20.1 & $<2.5$ & 70.6 \\
\hline B1T745 & 18 & 0.84 & 3.69 & $<0.3$ & 10.85 & 6.99 & $<2.5$ & 64.6 \\
\hline B1T746 & 20.5 & 0.843 & 5.67 & $<0.3$ & 12.82 & 20.8 & $<2.5$ & 71.4 \\
\hline В1T816 & 20.5 & 0.907 & 5.58 & $<0.3$ & 12.59 & 21.4 & $<2.5$ & 72.9 \\
\hline B1T747 & 23 & 0.542 & 7.5 & $<0.3$ & 11.94 & 17.1 & $<2.5$ & 54 \\
\hline B1T748 & 25.5 & 0.604 & 7.08 & $<0.3$ & 15.33 & 28.1 & $<2.5$ & 63 \\
\hline B1T749 & 28 & $<0.4$ & $<0.4$ & $<323$ & $1.33 E+03$ & 837.9 & $<2.5$ & 32.3 \\
\hline B1T750 & 30.5 & 4.19 & 50.5 & $<30.3$ & 700.32 & 90.5 & $<2.5$ & 37.1 \\
\hline B1T751 & 33 & 0.87 & 23.3 & $<3.04$ & 104.77 & 19.4 & $<2.5$ & 47.8 \\
\hline В1T825 & 36.8 & $<0.4$ & 277.3 & $<305$ & $5.73 E+03$ & 881.9 & $<2.5$ & 32.7 \\
\hline В1Т826 & 39.3 & $<0.4$ & 255.1 & $<304$ & $1.72 E+03$ & 832.3 & $<2.5$ & 81.3 \\
\hline В1T828 & 44.3 & $<0.4$ & 92.0 & $<304$ & $2.61 E+03$ & 1289.1 & $<2.5$ & 19.8 \\
\hline B1T752 & 45.5 & $<0.4$ & 353.5 & $<332$ & $1.68 E+04$ & 2570 & $<250$ & 34.8 \\
\hline B1T753 & 48 & $<0.4$ & 272.4 & $<305$ & $6.43 E+03$ & 1240.8 & $<2.5$ & 29.7 \\
\hline B1T755 & 53 & $<0.4$ & 257.1 & $<304$ & $3.05 E+03$ & 800.3 & $<2.5$ & 24.3 \\
\hline B1T757 & 58 & $<0.4$ & 258.9 & $<304$ & $3.45 E+03$ & 1019.7 & $<2.5$ & 35.7 \\
\hline B1T763 & 73 & $<0.4$ & 280.9 & $<304$ & $7.78 E+03$ & 1368.4 & $<2.5$ & 27.3 \\
\hline B1T766 & 80.5 & $<0.4$ & 292.8 & $<304$ & 8.31E+03 & 1065.2 & $<2.5$ & 21.3 \\
\hline B1T767 & 83 & $<0.4$ & 107.9 & $<307$ & $5.78 E+03$ & 321.6 & $<2.5$ & 31.4 \\
\hline B1T817 & 83 & $<0.4$ & 102.0 & $<304$ & $4.69 E+03$ & 288.0 & $<2.5$ & 35.7 \\
\hline B1T985 & 89.3 & $<0.4$ & 106.0 & $<304$ & $6.02 E+03$ & 496.0 & $<2.5$ & 38.8 \\
\hline B1T768 & 90.5 & $<0.4$ & 107.1 & $<304$ & $6.37 E+03$ & 233.1 & $<2.5$ & 23.6 \\
\hline B1T771 & 98 & $<0.4$ & 260 & $<304$ & $3.95 E+03$ & 870.0 & $<2.5$ & 22 \\
\hline B1T773 & 103 & $<0.4$ & 88.8 & $<310$ & $2.48 E+03$ & 216.3 & $<2.5$ & 22.5 \\
\hline В1Т9К9 & 106.8 & $<0.4$ & 90.0 & $<304$ & $2.40 \mathrm{E}+03$ & 212 & $<2.5$ & 25.1 \\
\hline
\end{tabular}


PNNL-17821

Table 5.4 (contd)

\begin{tabular}{|c|c|c|c|c|c|c|c|c|}
\hline Sample ID & $\begin{array}{l}\text { Mid Depth } \\
\text { (ft bgs) }\end{array}$ & Fluoride & Chloride & Nitrite & Nitrate & Sulfate-IC & Phosphate-IC & $\begin{array}{c}\text { Alkalinity } \\
\left(\text { as } \mathrm{CaCO}_{3} \text { ) }\right. \\
\end{array}$ \\
\hline B1T9L0 & 109.3 & $<0.4$ & 271.9 & $<304$ & $4.92 E+03$ & 851.7 & $<2.5$ & 22 \\
\hline B1T9L1 & 114.3 & $<0.4$ & 86.0 & $<304$ & $1.90 E+03$ & 207.1 & $<2.5$ & 22 \\
\hline B1T777 & 123 & $<0.4$ & 257.8 & $<304$ & $3.68 E+03$ & 951.2 & $<2.5$ & 44 \\
\hline B1T818 & 123 & $<0.4$ & 97.0 & $<304$ & $4.14 E+03$ & 332.1 & $<2.5$ & 40.3 \\
\hline B1T9L2 & 126.8 & $<0.4$ & 99.5 & $<306$ & $4.65 E+03$ & 279.4 & $<2.5$ & 28.3 \\
\hline B1T9L3 & 129.3 & $<0.4$ & 94.0 & $<287$ & $2.94 E+03$ & 230.0 & $<2.5$ & 35 \\
\hline B1T9L4 & 131.8 & $<0.4$ & 105.0 & $<304$ & $3.61 E+03$ & 224 & $<2.5$ & 25.1 \\
\hline B1T9L5 & 134.3 & $<0.4$ & 269.8 & $<304$ & $6.77 E+03$ & 894.3 & $<2.5$ & 31.9 \\
\hline B1T781 & 143 & $<0.4$ & 264.1 & $<304$ & $4.80 E+03$ & 870.2 & $<2.5$ & 26.6 \\
\hline B1T790 & 165.5 & 0.9 & 5.0 & $<3.04$ & 35.84 & 70.1 & $<2.5$ & 53.2 \\
\hline B1T793 & 173 & 0.57 & 1.6 & $<0.3$ & 25.36 & 13.7 & $<2.5$ & 37.3 \\
\hline B1T9L6 & 176.8 & 0.61 & 1.6 & $<0.31$ & 19.42 & 13.7 & $<2.5$ & 39.7 \\
\hline B1T9L7 & 179.3 & 0.61 & 1.7 & $<0.3$ & 16.86 & 13.6 & $<2.5$ & 39.5 \\
\hline B1T9L8 & 181.8 & 0.578 & 1.7 & $<0.3$ & 8.98 & 49.1 & $<2.5$ & 49.4 \\
\hline B1T9L9 & 184.3 & 0.63 & 1.8 & $<0.31$ & 8.14 & 13.7 & $<2.5$ & 44.2 \\
\hline B1T798 & 195.5 & 0.81 & 3.9 & $<3.04$ & 81.88 & 50.2 & $<2.5$ & 44.8 \\
\hline B1T7B4 & 210.5 & 39.01 & 263.1 & $<304$ & $4.91 E+03$ & 922.3 & $<2.5$ & 38.8 \\
\hline B1T7B6 & 215.5 & $<0.4$ & 123.0 & $<304$ & $9.78 E+03$ & 13829.4 & $<250$ & 33.4 \\
\hline B1T7C2 & 230.5 & $<0.4$ & 258.9 & $<304$ & $3.90 E+03$ & 833.6 & $<2.5$ & 25.1 \\
\hline В1Т9К6 & 236.8 & 38.98 & 91.0 & $<304$ & $3.48 E+03$ & 13903.8 & $<2.5$ & 19 \\
\hline В1T9K7 & 239.3 & $<0.4$ & 86.0 & $<304$ & $2.28 E+03$ & 13910.4 & $<2.5$ & 17.5 \\
\hline В1Т9К8 & 241.8 & $<0.4$ & 83.0 & $<304$ & $1.85 E+03$ & 13913.8 & $<2.5$ & 20.5 \\
\hline В1T824 & 244.3 & 0.8 & 13.4 & $<30.5$ & $1.03 E+03$ & 1386.0 & $<2.5$ & 22.1 \\
\hline B1T7C4 & 245.5 & 0.9 & 11.7 & $<30.5$ & 856.85 & 1404.2 & $<2.5$ & 22.1 \\
\hline В1Т7C9 & 258 & 0.556 & 1.9 & $<0.31$ & 10.7 & 52.1 & $<2.5$ & 42 \\
\hline B1T7D1 & 263 & 0.59 & 1.9 & $<0.3$ & 10.24 & 13.8 & $<2.5$ & 42.6 \\
\hline B1T7D8 & 280.5 & 0.539 & 1.4 & $<0.3$ & 6.54 & 51.4 & $<2.5$ & 40.3 \\
\hline B1T7F2 & 290.5 & 0.57 & 3.2 & $<0.3$ & 8.63 & 54.7 & $<2.5$ & 50.2 \\
\hline B1T7H1 & 313 & 0.638 & 1.3 & $<0.3$ & 2.83 & 27.8 & $<2.5$ & 50.9 \\
\hline B1T7J2 & 340.5 & 0.753 & 2.9 & $<0.3$ & 1.76 & 40.8 & $<2.5$ & 47.9 \\
\hline B1V530 & 344 & 1.19 & 5.77 & $<1$ & 1.32 & 35.9 & $<1.5$ & 69.2 \\
\hline B1V531 & 346.5 & 1.03 & 2.23 & $<1$ & $<1$ & 18.6 & $<1.5$ & 55.5 \\
\hline B1V532 & 349 & 0.842 & 3.48 & $<1$ & $<1$ & 13 & $<1.5$ & 42 \\
\hline B1V533 & 351.5 & 0.562 & 1.99 & $<1$ & $<1$ & 11.3 & $<1.5$ & 50.8 \\
\hline
\end{tabular}

(a) Bold values are higher than others for given constituent.

Table 5.5 presents the same water-extract anion data but in units of $\mathrm{mg} / \mathrm{L}$ pore-water concentrations, which are the units most related to comparing with the soil-resistivity measurements. Figure 5.2 plots some of the more important pore-water anion and cation concentrations. It should be noted that because the sediments deep in the profile are very dry, a large dilution factor exists when performing the water extracts. Therefore, when the data are plotted as pore-water concentrations, very dry sediments often exhibit elevated (biased high) calculated pore-water concentrations. The deep apparently increased fluoride concentrations are an artifact of this calculation and a mediocre detection limit constraint that adds to the positive bias. 
PNNL-17821

Table 5.5. Water-Extractable Anions Converted to Pore Water Concentrations for C5923 Borehole Samples (mg/L)

\begin{tabular}{|c|c|c|c|c|c|c|c|c|c|c|}
\hline HEIS \# & $\begin{array}{l}\text { mid depth } \\
\text { (ft bgs) }\end{array}$ & Fluoride & Chloride & Nitrite & Nitrate & Sulfate-IC & $\begin{array}{l}\text { Sulfate- } \\
\text { ICP }\end{array}$ & $\begin{array}{l}\text { Phosphate- } \\
\text { IC }\end{array}$ & Phosphate-ICP & Alk \\
\hline B1T740 & 5.5 & 10.79 & 8.65 & $<4.2$ & 68.7 & $2.64 \mathrm{E}+01$ & $2.19 \mathrm{E}+01$ & 129.29 & $1.35 \mathrm{E}+02$ & 750.2 \\
\hline B1T741 & 8.0 & 22.25 & 10.12 & $<5.3$ & 122.7 & $1.27 \mathrm{E}+02$ & $1.26 \mathrm{E}+02$ & 62.19 & $6.31 \mathrm{E}+01$ & 1869.9 \\
\hline B1T743 & 13.0 & 25.73 & 21.4 & $<10.3$ & 195.9 & $1.09 \mathrm{E}+03$ & $1.16 \mathrm{E}+03$ & 49.1 & $3.96 \mathrm{E}+01$ & 2224.1 \\
\hline B1T744 & 15.5 & 8.63 & 67.74 & $<2.1$ & 132.7 & $1.40 \mathrm{E}+02$ & $1.56 \mathrm{E}+02$ & 7.38 & $2.65 \mathrm{E}+00$ & 492.9 \\
\hline B1T745 & 18.0 & 11.04 & 48.46 & $<4.0$ & 142.4 & $9.18 \mathrm{E}+01$ & $1.14 \mathrm{E}+02$ & 13.51 & $4.81 \mathrm{E}+00$ & 848.8 \\
\hline B1T746 & 20.5 & 9.44 & 63.49 & $<3.4$ & 143.4 & $2.33 \mathrm{E}+02$ & $2.67 \mathrm{E}+02$ & 11.35 & $5.78 \mathrm{E}+00$ & 798.6 \\
\hline В1T816 & 20.5 & 9.95 & 61.26 & $<3.3$ & 138.1 & $2.35 \mathrm{E}+02$ & $2.56 \mathrm{E}+02$ & 11.19 & $3.58 \mathrm{E}+00$ & 799.8 \\
\hline B1T747 & 23.0 & 7.6 & 105.25 & $<4.3$ & 167.5 & $2.40 \mathrm{E}+02$ & $2.58 \mathrm{E}+02$ & 13.34 & $3.38 \mathrm{E}+00$ & 756.8 \\
\hline B1T748 & 25.5 & 6.53 & 76.47 & $<3.3$ & 165.6 & $3.03 E+02$ & $3.19 \mathrm{E}+02$ & 10.19 & $2.51 \mathrm{E}+00$ & 680.8 \\
\hline B1T749 & 28.0 & $<20$ & 5642.53 & $<7092$ & $2.75 \mathrm{E}+04$ & $1.73 \mathrm{E}+04$ & $5.93 \mathrm{E}+02$ & $<20$ & $1.22 \mathrm{E}+01$ & 667.4 \\
\hline B1T750 & 30.5 & 55.73 & 672.79 & $<402$ & $9.33 E+03$ & $1.20 \mathrm{E}+03$ & $2.79 E+02$ & $<20$ & $6.29 E+00$ & 494.2 \\
\hline B1T751 & 33.0 & 11.47 & 307.59 & $<40.1$ & $1.38 \mathrm{E}+03$ & $2.56 \mathrm{E}+02$ & $2.16 \mathrm{E}+02$ & 120.37 & $1.91 \mathrm{E}+01$ & 631.3 \\
\hline B1T825 & 36.8 & $<20$ & 2265.95 & $<2495$ & $4.69 \mathrm{E}+04$ & $7.21 \mathrm{E}+03$ & $1.22 \mathrm{E}+03$ & $<20$ & $9.11 E+00$ & 267.3 \\
\hline B1T826 & 39.3 & $<20$ & 5615.72 & $<6695$ & $3.78 E+04$ & $1.83 \mathrm{E}+04$ & $1.64 \mathrm{E}+03$ & $<20$ & $4.45 \mathrm{E}+00$ & 1790.9 \\
\hline B1T828 & 44.3 & $<20$ & 2948.93 & $<9744$ & $8.36 \mathrm{E}+04$ & $4.13 \mathrm{E}+04$ & $4.13 E+04$ & $<20$ & $7.04 \mathrm{E}+01$ & 633.4 \\
\hline B1T752 & 45.5 & $<20$ & 2204.91 & $<2259$ & $1.05 \mathrm{E}+05$ & $1.61 \mathrm{E}+04$ & $1.58 \mathrm{E}+04$ & $<20$ & $1.22 \mathrm{E}+01$ & 217.2 \\
\hline B1T753 & 48.0 & $<20$ & 5332.72 & $<5980$ & $1.26 \mathrm{E}+05$ & $2.43 E+04$ & $1.49 \mathrm{E}+04$ & $<20$ & $4.95 \mathrm{E}+01$ & 581.1 \\
\hline B1T755 & 53.0 & $<20$ & 8713.09 & $<10307$ & $1.03 \mathrm{E}+05$ & $2.71 \mathrm{E}+04$ & $2.43 \mathrm{E}+03$ & $<20$ & $1.24 \mathrm{E}+01$ & 824.5 \\
\hline B1T757 & 58.0 & $<20$ & 8146.74 & $<9562$ & $1.09 \mathrm{E}+05$ & $3.21 \mathrm{E}+04$ & $1.03 \mathrm{E}+04$ & $<20$ & $1.19 \mathrm{E}+01$ & 1123.6 \\
\hline B1T763 & 73.0 & $<20$ & 4841.11 & $<5237$ & $1.34 \mathrm{E}+05$ & $2.36 \mathrm{E}+04$ & $1.58 \mathrm{E}+04$ & $<20$ & $1.45 \mathrm{E}+01$ & 471.4 \\
\hline B1T766 & 80.5 & $<20$ & 5207.01 & $<5402$ & $1.48 \mathrm{E}+05$ & $1.89 \mathrm{E}+04$ & $7.57 \mathrm{E}+03$ & $<20$ & $2.02 \mathrm{E}+01$ & 378.2 \\
\hline B1T767 & 83.0 & $<20$ & 2624.86 & $<7531$ & $1.41 \mathrm{E}+05$ & $7.83 E+03$ & $6.16 \mathrm{E}+03$ & $<20$ & $2.14 \mathrm{E}+01$ & 764.4 \\
\hline B1T817 & 83.0 & $<20$ & 2982.71 & $<8890$ & $1.37 \mathrm{E}+05$ & $8.42 E+03$ & $6.00 \mathrm{E}+03$ & $<20$ & $1.91 \mathrm{E}+01$ & 1044.5 \\
\hline В1T985 & 89.3 & $<20$ & 2986.08 & $<8564$ & $1.70 \mathrm{E}+05$ & $1.40 \mathrm{E}+04$ & $1.35 E+04$ & $<20$ & $1.74 \mathrm{E}+01$ & 1091.9 \\
\hline B1T768 & 90.5 & $<20$ & 3121.22 & $<8868$ & $1.86 \mathrm{E}+05$ & $6.80 \mathrm{E}+03$ & $3.80 \mathrm{E}+03$ & $<20$ & $4.32 \mathrm{E}+01$ & 687.3 \\
\hline B1T771 & 98.0 & $<20$ & 4559.1 & $<5331$ & $6.92 \mathrm{E}+04$ & $1.53 \mathrm{E}+04$ & $2.19 \mathrm{E}+03$ & $<20$ & $1.73 E+01$ & 386.5 \\
\hline B1T773 & 103.0 & $<20$ & 2649.52 & $<9441$ & $7.40 \mathrm{E}+04$ & $6.46 \mathrm{E}+03$ & $2.07 \mathrm{E}+03$ & $<20$ & $3.26 \mathrm{E}+01$ & 671.2 \\
\hline В1Т9К9 & 106.8 & $<20$ & 2452.37 & $<8284$ & $6.54 \mathrm{E}+04$ & $5.78 \mathrm{E}+03$ & $1.81 \mathrm{E}+03$ & $<20$ & $2.66 \mathrm{E}+01$ & 683.4 \\
\hline B1T9L0 & 109.3 & $<20$ & 4131.65 & $<4618$ & $7.48 \mathrm{E}+04$ & $1.29 \mathrm{E}+04$ & $1.71 \mathrm{E}+03$ & $<20$ & $1.61 \mathrm{E}+01$ & 334.8 \\
\hline B1T9L1 & 114.3 & $<20$ & 2877.34 & $<10171$ & $6.36 \mathrm{E}+04$ & $6.93 \mathrm{E}+03$ & $1.79 \mathrm{E}+03$ & $<20$ & $3.17 \mathrm{E}+01$ & 737.4 \\
\hline В1T777 & 123.0 & $<20$ & 6355.25 & $<7488$ & $9.08 \mathrm{E}+04$ & $2.35 E+04$ & $5.52 E+03$ & $<20$ & $8.23 E+00$ & 1085.8 \\
\hline B1T818 & 123.0 & $<20$ & 2360.81 & $<7399$ & $1.01 \mathrm{E}+05$ & $8.08 E+03$ & $5.96 \mathrm{E}+03$ & $<20$ & $1.26 \mathrm{E}+01$ & 980.3 \\
\hline B1T9L2 & 126.8 & $<20$ & 2420.68 & $<7482$ & $1.13 \mathrm{E}+05$ & $6.80 \mathrm{E}+03$ & $4.35 \mathrm{E}+03$ & $<20$ & $2.61 \mathrm{E}+01$ & 687.6 \\
\hline B1T9L3 & 129.3 & $<20$ & 3507.54 & $<10709$ & $1.10 \mathrm{E}+05$ & $8.58 \mathrm{E}+03$ & $3.49 E+03$ & $<20$ & $2.31 \mathrm{E}+01$ & 1304.5 \\
\hline B1T9L4 & 131.8 & $<20$ & 3559.39 & $<10305$ & $1.22 \mathrm{E}+05$ & $7.59 \mathrm{E}+03$ & $3.20 \mathrm{E}+03$ & $<20$ & $3.93 \mathrm{E}+01$ & 850.2 \\
\hline B1T9L5 & 134.3 & $<20$ & 4009.43 & $<4514$ & $1.01 \mathrm{E}+05$ & $1.33 \mathrm{E}+04$ & $2.39 \mathrm{E}+03$ & $<20$ & $1.99 \mathrm{E}+01$ & 474 \\
\hline B1T781 & 143.0 & $<20$ & 3527.69 & $<4062$ & $6.42 \mathrm{E}+04$ & $1.16 \mathrm{E}+04$ & $1.69 \mathrm{E}+03$ & $<20$ & $1.70 \mathrm{E}+01$ & 355.4 \\
\hline
\end{tabular}


PNNL-17821

Table 5.5 (contd)

\begin{tabular}{|c|c|c|c|c|c|c|c|c|c|c|}
\hline HEIS \# & $\begin{array}{l}\text { mid depth } \\
\text { (ft bgs) }\end{array}$ & Fluoride & Chloride & Nitrite & Nitrate & Sulfate-IC & $\begin{array}{l}\text { Sulfate- } \\
\text { ICP }\end{array}$ & $\begin{array}{c}\text { Phosphate- } \\
\text { IC }\end{array}$ & Phosphate-ICP & Alk \\
\hline B1T790 & 165.5 & 14.42 & 80.29 & $<48.7$ & 574.2 & $1.12 \mathrm{E}+03$ & $1.11 \mathrm{E}+03$ & $<20$ & $3.17 \mathrm{E}+00$ & $\overline{852.6}$ \\
\hline B1T793 & 173.0 & 19.19 & 52.59 & $<10.3$ & 859.5 & $4.63 E+02$ & $1.30 \mathrm{E}+03$ & 13.26 & $3.48 \mathrm{E}+00$ & 1262.8 \\
\hline B1T9L6 & 176.8 & 19.31 & 50.22 & $<9.8$ & 618.5 & $4.38 \mathrm{E}+02$ & $1.23 \mathrm{E}+03$ & 12.84 & $4.13 \mathrm{E}+00$ & 1265.6 \\
\hline B1T9L7 & 179.3 & 15.3 & 41.66 & $<7.7$ & 425.7 & $3.44 \mathrm{E}+02$ & $1.24 \mathrm{E}+03$ & 10.5 & $5.45 \mathrm{E}+00$ & 997.9 \\
\hline B1T9L8 & 181.8 & 13.67 & 39.02 & $<7.2$ & 212.6 & $1.16 \mathrm{E}+03$ & $1.21 \mathrm{E}+03$ & 21.12 & $3.11 \mathrm{E}+00$ & 1168.1 \\
\hline B1T9L9 & 184.3 & 15.91 & 45.52 & $<7.8$ & 206.6 & $3.47 \mathrm{E}+02$ & $1.26 \mathrm{E}+03$ & 9.47 & $2.56 \mathrm{E}+00$ & 1122.3 \\
\hline B1T798 & 195.5 & 15.59 & 75.64 & $<58.5$ & $1.58 \mathrm{E}+03$ & $9.66 \mathrm{E}+02$ & $8.51 \mathrm{E}+02$ & $<20$ & $1.74 \mathrm{E}+00$ & 863 \\
\hline B1T7B4 & 210.5 & 708.13 & 4775.31 & $<5520$ & $8.91 \mathrm{E}+04$ & $1.67 \mathrm{E}+04$ & $2.93 \mathrm{E}+03$ & $<20$ & $1.01 \mathrm{E}+01$ & 703.8 \\
\hline B1T7B6 & 215.5 & $<20$ & 1607.78 & $<3974$ & $1.28 \mathrm{E}+05$ & $1.81 \mathrm{E}+05$ & $6.62 \mathrm{E}+03$ & $<430$ & $2.30 \mathrm{E}+01$ & 437.1 \\
\hline B1T7C2 & 230.5 & 1209.98 & 8035.51 & $<9432$ & $1.21 \mathrm{E}+05$ & $2.59 \mathrm{E}+04$ & $2.02 E+03$ & $<20$ & $3.41 \mathrm{E}+01$ & 778.1 \\
\hline В1Т9К6 & 236.8 & $<20$ & 2733.48 & $<9132$ & $1.05 \mathrm{E}+05$ & $4.18 \mathrm{E}+05$ & $1.76 \mathrm{E}+03$ & $<20$ & $6.67 \mathrm{E}+01$ & 570.7 \\
\hline В1Т9К7 & 239.3 & $<20$ & 3245.38 & $<11472$ & $8.59 E+04$ & $5.25 E+05$ & $1.54 \mathrm{E}+03$ & $<20$ & $6.86 \mathrm{E}+01$ & 659.6 \\
\hline В1Т9К8 & 241.8 & $<20$ & 2892.79 & $<10595$ & $6.45 E+04$ & $4.85 E+05$ & $1.29 \mathrm{E}+03$ & $<20$ & $5.77 \mathrm{E}+01$ & 715.2 \\
\hline В1T824 & 244.3 & 28.39 & 475.52 & $<1082$ & $3.65 E+04$ & $4.91 \mathrm{E}+04$ & $9.38 \mathrm{E}+02$ & $<20$ & $4.24 \mathrm{E}+01$ & 782.1 \\
\hline B1T7C4 & 245.5 & 29.17 & 379.24 & $<989$ & $2.77 E+04$ & $4.54 \mathrm{E}+04$ & $8.80 \mathrm{E}+02$ & $<20$ & $3.37 \mathrm{E}+01$ & 714.4 \\
\hline B1T7C9 & 258.0 & 11.88 & 41.46 & $<6.5$ & 228.6 & $1.11 \mathrm{E}+03$ & $1.06 \mathrm{E}+03$ & 19.19 & $2.05 \mathrm{E}+00$ & 896.5 \\
\hline B1T7D1 & 263.0 & 12.56 & 41 & $<6.4$ & 216.4 & $2.91 \mathrm{E}+02$ & $1.18 \mathrm{E}+03$ & $<20$ & $3.39 E+00$ & 899.9 \\
\hline B1T7D8 & 280.5 & 16.78 & 43.14 & $<9.5$ & 203.5 & $1.60 \mathrm{E}+03$ & $1.47 \mathrm{E}+03$ & 27.89 & $4.24 \mathrm{E}+00$ & 1253.7 \\
\hline B1T7F2 & 290.5 & 16.04 & 88.62 & $<8.6$ & 242.6 & $1.54 \mathrm{E}+03$ & $1.49 \mathrm{E}+03$ & 24.79 & $1.49 \mathrm{E}+00$ & 1411.5 \\
\hline B1T7H1 & 313.0 & 26.24 & 53.09 & $<12.5$ & 116.4 & $1.14 \mathrm{E}+03$ & $1.14 \mathrm{E}+03$ & $<20$ & $5.47 \mathrm{E}+00$ & 2090.9 \\
\hline B1T7J2 & 340.5 & 36.78 & 143.72 & $<14.9$ & 86 & $1.99 \mathrm{E}+03$ & $2.20 \mathrm{E}+03$ & $<20$ & $5.08 \mathrm{E}+00$ & 2339 \\
\hline B1V530 & 344 & 96.36 & 467.22 & $<81$ & 106.9 & $2.91 \mathrm{E}+03$ & $3.55 E+03$ & $<120$ & $<260$ & 5603 \\
\hline B1V531 & 346.5 & 34.29 & 74.25 & $<33$ & $<33$ & $6.19 E+02$ & $6.95 \mathrm{E}+02$ & $<50$ & $<106$ & 1848 \\
\hline B1V532 & 349 & 15.66 & 64.72 & $<18$ & $<19$ & $2.41 \mathrm{E}+02$ & $2.81 \mathrm{E}+02$ & $<28$ & $<60$ & 781 \\
\hline B1V533 & 351.5 & 4.29 & 15.19 & $<8$ & $<8$ & $8.62 E+01$ & $9.46 \mathrm{E}+01$ & $<12$ & $<25$ & 388 \\
\hline
\end{tabular}

Table 5.6 shows the water-leachable concentrations of divalent and monovalent cations, in units of $\mu \mathrm{g}$ per gram of dry sediment for the grab samples analyzed from borehole C5923. Table 5.7 shows the same water-leachable cation data in units of $\mathrm{mg} / \mathrm{L}$ of pore water, which as mentioned is a better convention for comparing with the soil-resistivity data. Table 5.6 shows a complicated pattern (in comparison to C4191) of ion-exchange front dynamics that occurs when sodium-dominated liquid wastes are disposed of into native Hanford sediments that have their cation exchange surface sites naturally loaded with divalent cations such as calcium, magnesium, and strontium. When waste liquid percolates below a crib or trench bottom both vertically and horizontally into a sediment profile, the sodium in the waste replaces the native divalent cations (and to some extent native potassium) on the exchange sites and "pushes" the replaced divalent cations out in the leading edge of the waste plume. Table 5.6 shows depleted divalent cations over the depth range of 8 to $20.5 \mathrm{ft}$ bgs, but below this depth, there are three zones with elevated divalent cations with no zones of depleted (in comparison to native sediments) divalent cations between the elevated zones. The deeper zones of elevated divalent cations occur from 28 to 36, 44 to 143, and 210 to $246 \mathrm{ft}$ bgs. The lack of significantly depleted divalent cation zones in the depth ranges 35 to 44,65 to 70, 83 to 88, and 115 to $122 \mathrm{ft}$ bgs suggest that the predominant waste fluid flow patterns might have 
been horizontal at some of these regions, especially the two shallowest zones. At borehole C5923, the water-extractable Na shows elevated values over two thick zones, from 15 to 143 bgs and from 210 to $242 \mathrm{ft}$ bgs. However, thorough scrutiny of the sodium distribution shows five discrete maxima at 46 to 48, 73 to 83, 89 to 91, 123 to 134, and 211 to $216 \mathrm{ft}$ bgs. Thus, the waste fluid flow was strictly in the vertical direction. We would have expected to see a different distribution for the divalent cations as just discussed. The water-extractable Na and nitrate ( $\mu \mathrm{g} / \mathrm{g}$ units) are shown in Figure 5.3.

Compared to the water-extractable major cation distribution at borehole C4191 (directly below 216-B-26 trench), the profile at borehole C5923 off to the sides of the 216-B-16 and 216-B-17 cribs is much more complicated. Undoubtedly, the effects of lateral spreading from both the east and west from the two cribs and perhaps from the north and south from the other two rows of cribs has led to a complicated mixture of lateral ion exchange fronts where the sodium in the waste is replacing/displacing the native divalent cations and pushing the divalent cations out to the sides of the horizontally migrating waste liquid plumes. The complicated nature of the cation exchange distribution at borehole C5923 is shown in Figure 5.4. 


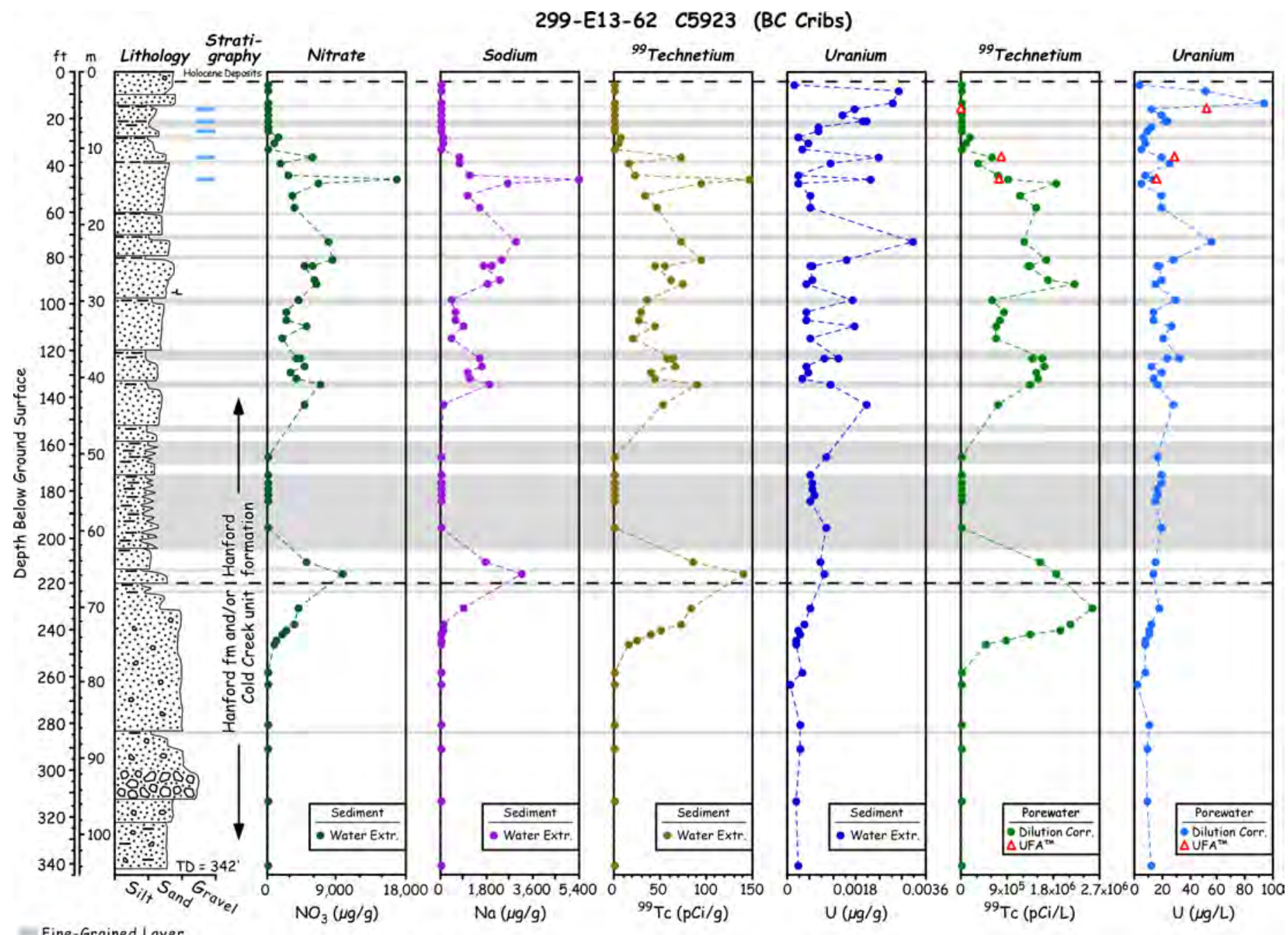

Fine-Grained Laye

$\stackrel{2}{\rightarrow} \mathrm{wt} \%$ Moisture

$\exists$ Silt Sand Gravel

2008/DCL/C5923/004 (07/27)

Figure 5.3. Water-Extractable Nitrate, Sodium, Technetium-99, and Uranium in Sediments from Borehole C5923 


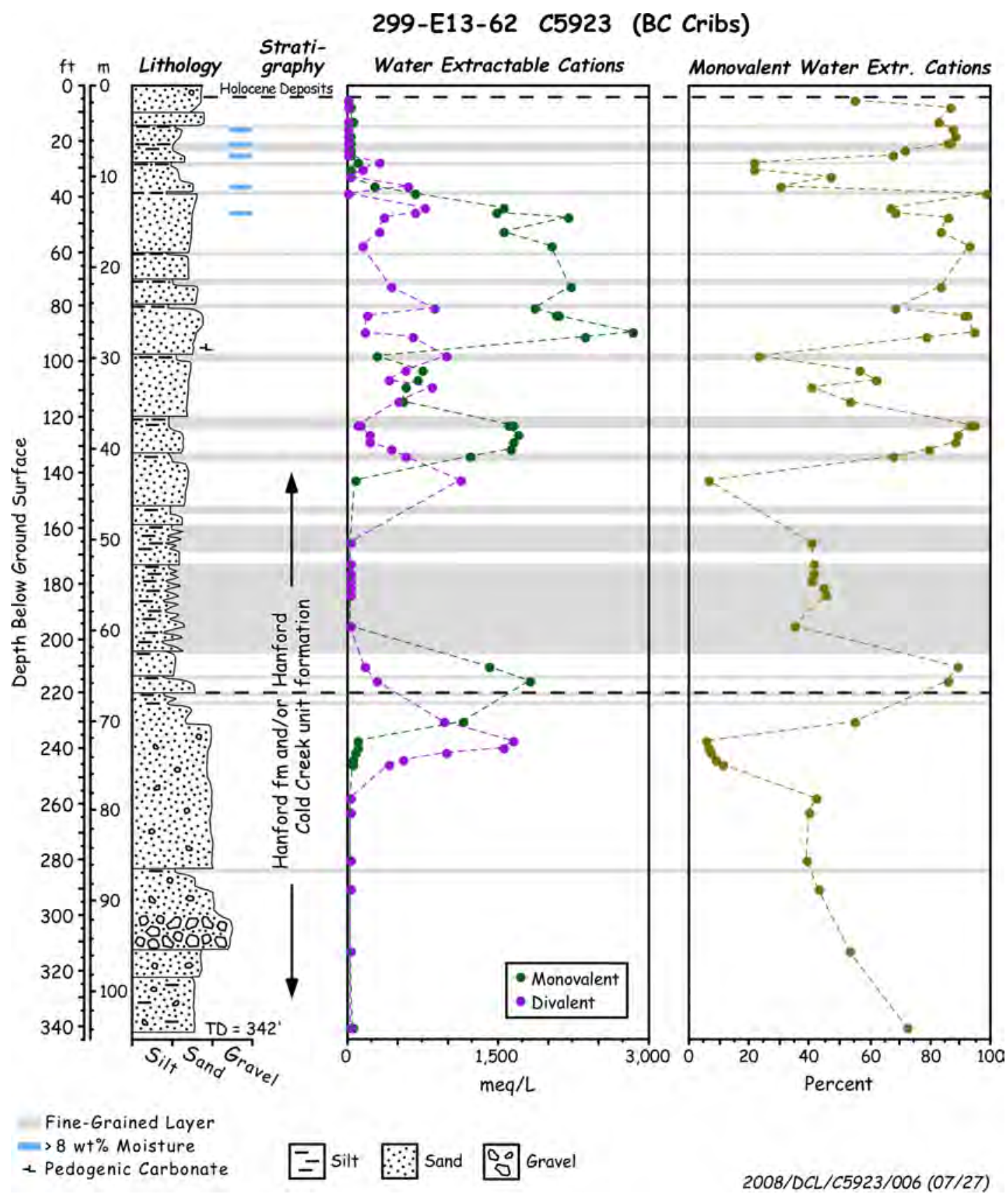

Figure 5.4. Distribution of Water Extractable Mono- and Di-valent Cations in Borehole C5923 Sediments

The anion and cation pore-water data suggest that waste fluids have descended down at least to $242 \mathrm{ft}$ bgs at borehole C5923. The leading edge of sodium plumes generally lags behind the leading edge of the more mobile nitrate, so based on data in Table 5.4, the nitrate data suggest that the waste liquids descended to depths below $246 \mathrm{ft}$ bgs, but perhaps not beyond $258 \mathrm{ft}$ bgs. The difference between the maximum extent of the sodium and nitrate distributions is caused by the ion exchange reactions wherein sodium is adsorbed on sediment surface cation exchange sites and is somewhat retarded in its descent with the waste fluids. 
Table 5.7 shows the same water-extract major cation data converted to pore-water concentrations where we used the simplifying assumption that adding de-ionized water to field moist sediment does not significantly dissolve solids and minerals; rather, it only dilutes and promotes the separation of the extant small volume of pore fluid. For highly contaminated vadose zone pore water, this assumption is fairly valid, but for slightly or uncontaminated pore water, the de-ionized water does dissolve some mildly soluble salts and thus over-estimates the true pore-water concentrations. Figure 5.5 shows the calculated pore-water EC and ionic strength for the pore water in sediments from borehole C5923 plotted along with the reciprocal of inverted field data to show a qualitative representation of the shapes of the depth distributions of these parameters. More discussion on correlating pore-water chemical composition with soil resistivity is found in Sections 5.2 and 5.3.

As part of the characterization of the water extracts, other chemical species such as aluminum, silicon, iron, manganese, zinc, and trace constituents such as arsenic, boron, barium, beryllium, bismuth, cadmium, cobalt, chromium, copper, lithium, molybdenum, nickel, lead, selenium, thallium, vanadium, titanium, and zirconium were measured. However, considering that their concentrations were generally low to non-detectable, the data are not presented in this ERC ground-truthing document. Table 5.5 compares the measurements of phosphorous and sulfur (reported as phosphate and sulfate) that were performed using the ICP-OES to corroborate the direct measurement of the anions phosphate and sulfate using the IC. The data from the two independent measurements compared well.

The only potential radiological COCs that were measurable in the water extracts were technetium-99 and uranium, and their concentrations on both a per gram of sediment basis and as pore-water concentrations are listed in Table 5.8. The technetium-99 data show elevated technetium-99 water-extract concentrations occurring in a complicated vertical profile from 28 to $245.5 \mathrm{ft}$ bgs. There appear to be two thick lobes to the distribution (28 to $143 \mathrm{ft}$ bgs and 210 to $245.5 \mathrm{ft}$ bgs). Within the lobes are local maxima at 36.8, 45.5, 86.5, 90.5, 134.3, and $215.5 \mathrm{ft}$ bgs. The deepest penetration of significant technetium-99 occurs at the same place as the significantly elevated nitrate at $245.5 \mathrm{ft}$ bgs. These two mobile contaminants are often found to travel and distribute in the vadose zone in a similar pattern. Elevated water-extractable concentrations of uranium are found both shallow in the vadose zone from 8 to $20.5 \mathrm{ft}$ bgs and deeper from 36.8 to $39.3,73$ to 80.5 , and 134 to $143 \mathrm{ft}$ bgs. The more significant waterleachable uranium concentrations are from 8 to 13, at 36 and at $73 \mathrm{ft} \mathrm{bgs.} \mathrm{This} \mathrm{suggests} \mathrm{that} \mathrm{uranium} \mathrm{is}$ less mobile than the technetium-99 and nitrate. Figure 5.3 shows the calculated pore-water concentration of water-extractable technetium-99 and uranium as a function of depth.

Table 5.8 also lists the total ionic strength of the calculated pore waters in the vadose zone profile at C5923. Of all the pore-water parameters, the total ionic strength should correlate best with the soilresistivity data, which are influenced by the total dissolved salt content in the sediment. The total ionic strength correlations with the field and laboratory resistivity measurements for borehole C5923 are discussed in sections 5.2 and 5.3 of this report. A qualitative view of the distribution of the pore water and field resistivity data is shown in Figure 5.5. The distribution of pore water EC and ionic strength at C5923 is more irregular and penetrates deeper than at C4191 placed through B-26 trench. Considering that twice as much water was disposed of to the two nearest cribs, B-16 and B-17, and four other cribs are quite close, one might expect deeper penetration at C5923 than at C4191. The peak ionic strengths at C5923 are somewhat higher, 2.5 to $3.5 \mathrm{M}$, in the more concentrated lobe of the plume from 44 to $90 \mathrm{ft}$ bgs than at C4191, which had a peak ionic strength of 2 to $2.3 \mathrm{M}$ near $91 \mathrm{ft}$ bgs. Two other localized peak ionic strengths are found at C5923 at $132 \mathrm{ft}$ bgs (2.36 M) and from 215 to $237 \mathrm{ft}$ bgs (2.6 M). At C4191, there are two local maxima in ionic strength at $101 \mathrm{ft}$ bgs $(1.6 \mathrm{M})$ and at $131 \mathrm{ft}$ bgs $(1.4 \mathrm{M})$. The total 
mass of salt disposed of in the vicinity of borehole C5923 is at least twice as large as the mass disposed of to the B-26 trench, so finding more residual salt in the pore water at C5923 might be expected; however, considering that the volume of liquid disposed of near C5923 was also twice as high as the volume disposed of at C4191, perhaps the concentration of the pore water at C5923 should be quite similar to the pore water below C4191 instead of showing more saline conditions.

Table 5.6. Water Extractable Cations in Borehole C5923 Sediments ( $\mu \mathrm{g} / \mathrm{g}$ dry soil)

\begin{tabular}{|c|c|c|c|c|c|c|}
\hline HEIS \# & $\begin{array}{c}\text { mid depth } \\
\text { ft bgs }\end{array}$ & $\begin{array}{c}\text { Ca } \\
\mu \mathrm{g} / \mathrm{g} \text { soil }\end{array}$ & $\begin{array}{c}\mathrm{Mg} \\
\mu \mathrm{g} / \mathrm{g} \text { soil }\end{array}$ & $\begin{array}{c}\text { Sr } \\
\mu \mathrm{g} / \mathrm{g} \text { soil }\end{array}$ & $\begin{array}{c}\text { Na } \\
\mu \mathrm{g} / \mathrm{g} \text { soil }\end{array}$ & $\begin{array}{c}\mathrm{K} \\
\mu \mathrm{g} / \mathrm{g} \text { soil }\end{array}$ \\
\hline B1T740 & 5.5 & $6.98 \mathrm{E}+00$ & $1.74 \mathrm{E}+00$ & 8.34E-03 & $1.04 \mathrm{E}+01$ & $5.62 \mathrm{E}+00$ \\
\hline B1T741 & 8 & $4.32 \mathrm{E}+00$ & $1.09 \mathrm{E}+00$ & (8.04E-03) & $4.43 E+01$ & $2.55 \mathrm{E}+00$ \\
\hline B1T743 & 13 & $4.45 E+00$ & $1.24 \mathrm{E}+00$ & (2.59E-03) & $3.39 E+01$ & $3.28 \mathrm{E}+00$ \\
\hline B1T744 & 15.5 & $3.91 \mathrm{E}+00$ & $9.68 \mathrm{E}-01$ & (6.91E-03) & $4.26 \mathrm{E}+01$ & $3.08 \mathrm{E}+00$ \\
\hline B1T745 & 18 & $2.78 \mathrm{E}+00$ & 5.65E-01 & $(1.24 \mathrm{E}-02)$ & $2.99 \mathrm{E}+01$ & $2.59 \mathrm{E}+00$ \\
\hline B1T746 & 20.5 & $5.01 \mathrm{E}+00$ & 8.00E-01 & (3.72E-03) & $4.07 \mathrm{E}+01$ & $3.73 E+00$ \\
\hline B1T816 & 20.5 & $4.34 \mathrm{E}+00$ & 7.66E-01 & (6.05E-03) & $3.81 \mathrm{E}+01$ & $3.48 \mathrm{E}+00$ \\
\hline B1T747 & 23 & $7.92 \mathrm{E}+00$ & $1.25 \mathrm{E}+00$ & 5.13E-03 & $2.67 \mathrm{E}+01$ & $3.92 \mathrm{E}+00$ \\
\hline B1T748 & 25.5 & $1.07 \mathrm{E}+01$ & $1.71 \mathrm{E}+00$ & $1.41 \mathrm{E}-02$ & $2.93 E+01$ & $4.69 \mathrm{E}+00$ \\
\hline В1T749 & 28 & $2.47 \mathrm{E}+02$ & $3.80 \mathrm{E}+01$ & 9.13E-01 & $8.85 E+01$ & $1.86 \mathrm{E}+01$ \\
\hline B1T750 & 30.5 & $1.60 \mathrm{E}+02$ & $2.92 \mathrm{E}+01$ & 6.63E-01 & $5.54 \mathrm{E}+01$ & $1.67 \mathrm{E}+01$ \\
\hline B1T751 & 33 & $2.77 \mathrm{E}+01$ & $5.49 \mathrm{E}+00$ & $1.00 \mathrm{E}-01$ & $3.18 \mathrm{E}+01$ & $8.37 \mathrm{E}+00$ \\
\hline B1T825 & 36.8 & $1.16 E+03$ & $1.87 \mathrm{E}+02$ & $5.28 \mathrm{E}+00$ & $7.18 \mathrm{E}+02$ & $4.45 \mathrm{E}+01$ \\
\hline B1T826 & 39.3 & $6.49 E+00$ & $1.58 \mathrm{E}+00$ & $1.62 \mathrm{E}-02$ & $6.88 \mathrm{E}+02$ & $8.01 \mathrm{E}+00$ \\
\hline В1T828 & 44.3 & $4.23 \mathrm{E}+02$ & $3.62 \mathrm{E}+01$ & $1.25 \mathrm{E}+00$ & $1.09 \mathrm{E}+03$ & $2.38 \mathrm{E}+01$ \\
\hline B1T752 & 45.5 & $1.85 E+03$ & $2.06 \mathrm{E}+02$ & $7.26 \mathrm{E}+00$ & $5.40 \mathrm{E}+03$ & $8.59 E+01$ \\
\hline B1T753 & 48 & $2.77 \mathrm{E}+02$ & $5.08 \mathrm{E}+01$ & $1.40 \mathrm{E}+00$ & $2.56 \mathrm{E}+03$ & $2.98 \mathrm{E}+01$ \\
\hline B1T755 & 53 & $1.39 \mathrm{E}+02$ & $2.93 \mathrm{E}+01$ & 8.89E-01 & $1.05 E+03$ & $1.12 \mathrm{E}+01$ \\
\hline B1T757 & 58 & $7.17 \mathrm{E}+01$ & $1.31 \mathrm{E}+01$ & 5.07E-01 & $1.47 \mathrm{E}+03$ & $1.24 \mathrm{E}+01$ \\
\hline B1T763 & 73 & $3.21 \mathrm{E}+02$ & $1.10 \mathrm{E}+02$ & $2.21 \mathrm{E}+00$ & $2.94 E+03$ & $3.74 \mathrm{E}+01$ \\
\hline B1T766 & 80.5 & $6.41 \mathrm{E}+02$ & $1.97 E+02$ & $5.28 \mathrm{E}+00$ & $2.37 E+03$ & $4.51 E+01$ \\
\hline B1T767 & 83 & $8.78 E+01$ & $4.12 \mathrm{E}+01$ & 9.17E-01 & $1.96 E+03$ & $2.64 \mathrm{E}+01$ \\
\hline В1T817 & 83 & $7.14 \mathrm{E}+01$ & $3.19 E+01$ & $7.56 \mathrm{E}-01$ & $1.62 \mathrm{E}+03$ & $2.31 \mathrm{E}+01$ \\
\hline B1T985 & 89.3 & $4.60 \mathrm{E}+01$ & $4.00 \mathrm{E}+01$ & 4.15E-01 & $2.29 \mathrm{E}+03$ & $3.11 \mathrm{E}+01$ \\
\hline B1T768 & 90.5 & $2.76 \mathrm{E}+02$ & $1.02 \mathrm{E}+02$ & $2.38 E+00$ & $1.83 E+03$ & $3.89 E+01$ \\
\hline B1T771 & 98 & $7.27 E+02$ & $2.41 E+02$ & $4.22 \mathrm{E}+00$ & $3.75 E+02$ & $2.52 \mathrm{E}+01$ \\
\hline B1T773 & 103 & $2.54 \mathrm{E}+02$ & $7.70 \mathrm{E}+01$ & $1.77 \mathrm{E}+00$ & $5.53 E+02$ & $2.14 \mathrm{E}+01$ \\
\hline В1Т9К9 & 106.8 & $1.89 \mathrm{E}+02$ & $6.94 \mathrm{E}+01$ & $1.31 \mathrm{E}+00$ & $5.64 \mathrm{E}+02$ & $2.25 E+01$ \\
\hline B1T9L0 & 109.3 & $7.44 \mathrm{E}+02$ & $2.12 \mathrm{E}+02$ & $4.82 E+00$ & $8.30 \mathrm{E}+02$ & $3.53 \mathrm{E}+01$ \\
\hline B1T9L1 & 114.3 & $1.87 \mathrm{E}+02$ & $6.88 \mathrm{E}+01$ & $1.13 \mathrm{E}+00$ & $3.76 \mathrm{E}+02$ & $1.70 \mathrm{E}+01$ \\
\hline B1T777 & 123 & $4.30 \mathrm{E}+01$ & $2.10 \mathrm{E}+01$ & 3.70E-01 & $1.51 E+03$ & $1.80 \mathrm{E}+01$ \\
\hline В1Т818 & 123 & $5.53 \mathrm{E}+01$ & $2.42 \mathrm{E}+01$ & $5.02 \mathrm{E}-01$ & $1.50 \mathrm{E}+03$ & $2.29 \mathrm{E}+01$ \\
\hline B1T9L2 & 126.8 & $9.58 \mathrm{E}+01$ & $4.62 \mathrm{E}+01$ & 8.29E-01 & $1.58 E+03$ & $2.43 \mathrm{E}+01$ \\
\hline B1T9L3 & 129.3 & $6.77 \mathrm{E}+01$ & $2.89 \mathrm{E}+01$ & 5.76E-01 & $1.00 \mathrm{E}+03$ & $2.11 \mathrm{E}+01$ \\
\hline
\end{tabular}


PNNL-17821

Table 5.6 (contd)

\begin{tabular}{|c|c|c|c|c|c|c|}
\hline HEIS \# & $\begin{array}{c}\text { mid depth } \\
\text { ft bgs }\end{array}$ & $\begin{array}{c}\text { Ca } \\
\mu \mathrm{g} / \mathrm{g} \text { soil }\end{array}$ & $\begin{array}{c}\text { Mg } \\
\mu g / g \text { soil }\end{array}$ & $\begin{array}{c}\mathrm{Sr} \\
\mu \mathrm{g} / \mathrm{g} \text { soil }\end{array}$ & $\begin{array}{c}\mathrm{Na} \\
\mu \mathrm{g} / \mathrm{g} \text { soil }\end{array}$ & $\begin{array}{c}\mathrm{K} \\
\mu \mathrm{g} / \mathrm{g} \text { soil }\end{array}$ \\
\hline B1T9L4 & 131.8 & $1.52 \mathrm{E}+02$ & $6.00 \mathrm{E}+01$ & $1.17 \mathrm{E}+00$ & $1.09 E+03$ & $2.25 \mathrm{E}+01$ \\
\hline B1T9L5 & 134.3 & $4.94 \mathrm{E}+02$ & $1.70 \mathrm{E}+02$ & $3.78 \mathrm{E}+00$ & $1.85 E+03$ & $3.80 \mathrm{E}+01$ \\
\hline B1T781 & 143 & $1.20 E+03$ & $2.90 \mathrm{E}+02$ & $6.00 \mathrm{E}+00$ & $1.12 \mathrm{E}+02$ & $2.49 \mathrm{E}+01$ \\
\hline B1T790 & 165.5 & $2.15 \mathrm{E}+01$ & $8.70 \mathrm{E}+00$ & $9.25 \mathrm{E}-02$ & $2.34 \mathrm{E}+01$ & $7.69 \mathrm{E}+00$ \\
\hline B1T793 & 173 & $1.38 \mathrm{E}+01$ & $4.68 \mathrm{E}+00$ & 7.37E-02 & $1.54 \mathrm{E}+01$ & $3.87 \mathrm{E}+00$ \\
\hline B1T9L6 & 176.8 & $1.45 \mathrm{E}+01$ & $4.56 \mathrm{E}+00$ & 7.82E-02 & $1.58 \mathrm{E}+01$ & $3.65 E+00$ \\
\hline B1T9L7 & 179.3 & $1.58 \mathrm{E}+01$ & $5.00 \mathrm{E}+00$ & 8.26E-02 & $1.66 \mathrm{E}+01$ & $3.58 \mathrm{E}+00$ \\
\hline B1T9L8 & 181.8 & $1.43 \mathrm{E}+01$ & $5.07 \mathrm{E}+00$ & 5.05E-02 & $1.82 \mathrm{E}+01$ & $4.85 \mathrm{E}+00$ \\
\hline B1T9L9 & 184.3 & $1.36 \mathrm{E}+01$ & $4.67 \mathrm{E}+00$ & 7.19E-02 & $1.72 \mathrm{E}+01$ & $4.75 \mathrm{E}+00$ \\
\hline B1T798 & 195.5 & $2.39 E+01$ & $9.21 \mathrm{E}+00$ & 9.34E-02 & $2.08 \mathrm{E}+01$ & $6.06 \mathrm{E}+00$ \\
\hline B1T7B4 & 210.5 & $1.19 \mathrm{E}+02$ & $4.59 \mathrm{E}+01$ & $9.28 \mathrm{E}-01$ & $1.76 E+03$ & $2.57 \mathrm{E}+01$ \\
\hline B1T7B6 & 215.5 & $2.97 \mathrm{E}+02$ & $9.59 \mathrm{E}+01$ & $2.54 \mathrm{E}+00$ & $3.17 E+03$ & $5.24 \mathrm{E}+01$ \\
\hline B1T7C2 & 230.5 & $4.24 \mathrm{E}+02$ & $1.17 \mathrm{E}+02$ & $3.15 E+00$ & $8.37 \mathrm{E}+02$ & $3.17 \mathrm{E}+01$ \\
\hline В1Т9К6 & 236.8 & $8.26 E+02$ & $1.63 E+02$ & $4.31 \mathrm{E}+00$ & $5.46 \mathrm{E}+01$ & $2.96 \mathrm{E}+01$ \\
\hline В1T9K7 & 239.3 & $6.31 \mathrm{E}+02$ & $1.13 \mathrm{E}+02$ & $3.59 \mathrm{E}+00$ & $4.84 \mathrm{E}+01$ & $2.89 \mathrm{E}+01$ \\
\hline В1Т9К8 & 241.8 & $4.20 \mathrm{E}+02$ & $9.08 \mathrm{E}+01$ & $2.19 \mathrm{E}+00$ & $3.58 \mathrm{E}+01$ & $2.11 \mathrm{E}+01$ \\
\hline B1T824 & 244.3 & $2.18 \mathrm{E}+02$ & $5.84 \mathrm{E}+01$ & $1.07 \mathrm{E}+00$ & $2.69 \mathrm{E}+01$ & $1.53 \mathrm{E}+01$ \\
\hline B1T7C4 & 245.5 & $1.75 E+02$ & $4.99 \mathrm{E}+01$ & 8.89E-01 & $2.92 \mathrm{E}+01$ & $1.55 \mathrm{E}+01$ \\
\hline B1T7C9 & 258 & $1.48 \mathrm{E}+01$ & $4.90 \mathrm{E}+00$ & 4.81E-02 & $1.61 \mathrm{E}+01$ & $5.15 \mathrm{E}+00$ \\
\hline B1T7D1 & 263 & $1.60 \mathrm{E}+01$ & $5.28 \mathrm{E}+00$ & 8.14E-02 & $1.55 \mathrm{E}+01$ & $5.53 \mathrm{E}+00$ \\
\hline B1T7D8 & 280.5 & $1.36 \mathrm{E}+01$ & $4.61 \mathrm{E}+00$ & 5.02E-02 & $1.24 \mathrm{E}+01$ & $5.10 \mathrm{E}+00$ \\
\hline B1T7F2 & 290.5 & $1.58 \mathrm{E}+01$ & $5.24 \mathrm{E}+00$ & $5.60 \mathrm{E}-02$ & $1.76 \mathrm{E}+01$ & $6.12 \mathrm{E}+00$ \\
\hline B1T7H1 & 313 & $8.53 \mathrm{E}+00$ & $2.57 \mathrm{E}+00$ & 2.03E-02 & $1.38 \mathrm{E}+01$ & $5.06 \mathrm{E}+00$ \\
\hline B1T7J2 & 340.5 & $6.30 \mathrm{E}+00$ & $1.80 \mathrm{E}+00$ & $1.59 \mathrm{E}-02$ & $2.33 \mathrm{E}+01$ & $7.45 \mathrm{E}+00$ \\
\hline B1V530 & 344 & $5.99 \mathrm{E}+00$ & $1.91 \mathrm{E}+00$ & $<5.6 \mathrm{E}-02$ & $3.86 \mathrm{E}+01$ & $9.32 \mathrm{E}+00$ \\
\hline B1V531 & 346.5 & $3.94 \mathrm{E}+00$ & $1.31 \mathrm{E}+00$ & $<5.6 \mathrm{E}-02$ & $2.26 \mathrm{E}+01$ & $4.94 \mathrm{E}+00$ \\
\hline B1V532 & 349 & $1.96 \mathrm{E}+00$ & $0.84 \mathrm{E}+00$ & $<5.6 \mathrm{E}-02$ & $2.06 \mathrm{E}+01$ & $4.59 \mathrm{E}+00$ \\
\hline B1V533 & 351.5 & $4.95 \mathrm{E}+00$ & $1.45 \mathrm{E}+00$ & $<5.6 \mathrm{E}-02$ & $1.55 \mathrm{E}+01$ & $4.71 \mathrm{E}+00$ \\
\hline
\end{tabular}

(a) Bold red values are elevated concentrations for given constituent.

(b) Bold blue values are lower than natural background for a given constituent.

(c) Parentheses signify values below level of quantitation but considered valid for this work. 
Table 5.7. Water-Extractable Cations as Pore Water Concentrations in Borehole C5923 Sediments (mg/L)

\begin{tabular}{|c|c|c|c|c|c|c|}
\hline HEIS \# & $\begin{array}{l}\text { mid depth } \\
\text { ft bgs }\end{array}$ & $\begin{array}{c}\mathrm{Ca} \\
\mathrm{mg} / \mathrm{L}\end{array}$ & $\begin{array}{c}\mathrm{Mg} \\
\mathrm{mg} / \mathrm{L}\end{array}$ & $\begin{array}{c}\mathrm{Sr} \\
\mathrm{mg} / \mathrm{L}\end{array}$ & $\begin{array}{c}\mathrm{Na} \\
\mathrm{mg} / \mathrm{L}\end{array}$ & $\begin{array}{c}\mathrm{K} \\
\mathrm{mg} / \mathrm{L}\end{array}$ \\
\hline В1T740 & 5.5 & $9.57 \mathrm{E}+01$ & $2.39 \mathrm{E}+01$ & $1.14 \mathrm{E}-01$ & $1.43 \mathrm{E}+02$ & $7.70 \mathrm{E}+01$ \\
\hline B1T741 & 8 & $7.59 \mathrm{E}+01$ & $1.92 \mathrm{E}+01$ & (1.41E-01) & $7.78 \mathrm{E}+02$ & $4.49 \mathrm{E}+01$ \\
\hline B1T743 & 13 & $1.51 \mathrm{E}+02$ & $4.23 \mathrm{E}+01$ & (8.80E-02) & $1.15 E+03$ & $1.12 \mathrm{E}+02$ \\
\hline B1T744 & 15.5 & $2.73 \mathrm{E}+01$ & $6.76 \mathrm{E}+00$ & $(4.82 \mathrm{E}-02)$ & $2.97 \mathrm{E}+02$ & $2.15 E+01$ \\
\hline B1T745 & 18 & $3.65 E+01$ & $7.42 \mathrm{E}+00$ & (1.62E-01) & $3.92 \mathrm{E}+02$ & $3.40 \mathrm{E}+01$ \\
\hline B1T746 & 20.5 & $5.61 \mathrm{E}+01$ & $8.95 E+00$ & (4.16E-02) & $4.56 \mathrm{E}+02$ & 4.17E+01 \\
\hline B1T816 & 20.5 & $4.76 \mathrm{E}+01$ & $8.40 \mathrm{E}+00$ & (6.64E-02) & $4.18 \mathrm{E}+02$ & $3.81 \mathrm{E}+01$ \\
\hline B1T747 & 23 & $1.11 \mathrm{E}+02$ & $1.76 \mathrm{E}+01$ & 7.20E-02 & $3.75 E+02$ & $5.49 \mathrm{E}+01$ \\
\hline B1T748 & 25.5 & $1.16 \mathrm{E}+02$ & $1.85 \mathrm{E}+01$ & $1.52 \mathrm{E}-01$ & $3.17 \mathrm{E}+02$ & $5.07 \mathrm{E}+01$ \\
\hline B1T749 & 28 & $5.11 \mathrm{E}+03$ & $7.86 \mathrm{E}+02$ & $1.89 \mathrm{E}+01$ & $1.83 \mathrm{E}+03$ & $3.84 \mathrm{E}+02$ \\
\hline B1T750 & 30.5 & $2.13 E+03$ & $3.89 E+02$ & $8.83 \mathrm{E}+00$ & $7.38 \mathrm{E}+02$ & $2.23 E+02$ \\
\hline B1T751 & 33 & $3.66 \mathrm{E}+02$ & $7.25 \mathrm{E}+01$ & $1.32 \mathrm{E}+00$ & $4.21 \mathrm{E}+02$ & $1.11 \mathrm{E}+02$ \\
\hline B1T825 & 36.8 & $9.51 \mathrm{E}+03$ & $1.53 E+03$ & $4.31 \mathrm{E}+01$ & $5.87 \mathrm{E}+03$ & $3.63 E+02$ \\
\hline B1T826 & 39.3 & $1.43 \mathrm{E}+02$ & $3.47 \mathrm{E}+01$ & 3.57E-01 & $1.52 \mathrm{E}+04$ & $1.76 \mathrm{E}+02$ \\
\hline В1T828 & 44.3 & $1.36 \mathrm{E}+04$ & $1.16 \mathrm{E}+03$ & $4.00 \mathrm{E}+01$ & $3.50 \mathrm{E}+04$ & $7.64 \mathrm{E}+02$ \\
\hline B1T752 & 45.5 & $1.15 \mathrm{E}+04$ & $1.28 \mathrm{E}+03$ & $4.53 \mathrm{E}+01$ & $3.37 \mathrm{E}+04$ & $5.36 \mathrm{E}+02$ \\
\hline B1T753 & 48 & $5.41 \mathrm{E}+03$ & $9.95 E+02$ & $2.73 \mathrm{E}+01$ & $5.00 \mathrm{E}+04$ & $5.83 E+02$ \\
\hline B1T755 & 53 & $4.72 \mathrm{E}+03$ & $9.94 \mathrm{E}+02$ & $3.01 \mathrm{E}+01$ & $3.55 E+04$ & $3.80 \mathrm{E}+02$ \\
\hline B1T757 & 58 & $2.26 \mathrm{E}+03$ & $4.12 \mathrm{E}+02$ & $1.60 \mathrm{E}+01$ & $4.63 \mathrm{E}+04$ & $3.90 \mathrm{E}+02$ \\
\hline B1T763 & 73 & $5.54 \mathrm{E}+03$ & $1.89 \mathrm{E}+03$ & $3.81 \mathrm{E}+01$ & $5.06 \mathrm{E}+04$ & $6.44 \mathrm{E}+02$ \\
\hline B1T766 & 80.5 & $1.14 \mathrm{E}+04$ & $3.50 \mathrm{E}+03$ & $9.38 \mathrm{E}+01$ & $4.22 \mathrm{E}+04$ & $8.02 E+02$ \\
\hline B1T767 & 83 & $2.14 \mathrm{E}+03$ & $1.00 \mathrm{E}+03$ & $2.23 \mathrm{E}+01$ & $4.77 \mathrm{E}+04$ & $6.42 \mathrm{E}+02$ \\
\hline B1T817 & 83 & $2.09 \mathrm{E}+03$ & $9.33 E+02$ & $2.21 \mathrm{E}+01$ & $4.74 \mathrm{E}+04$ & $6.76 \mathrm{E}+02$ \\
\hline B1T985 & 89.3 & $1.29 \mathrm{E}+03$ & $1.13 \mathrm{E}+03$ & $1.17 \mathrm{E}+01$ & $6.46 \mathrm{E}+04$ & $8.77 \mathrm{E}+02$ \\
\hline B1T768 & 90.5 & $8.04 \mathrm{E}+03$ & $2.98 E+03$ & $6.94 \mathrm{E}+01$ & $5.33 \mathrm{E}+04$ & $1.13 E+03$ \\
\hline B1T771 & 98 & $1.27 \mathrm{E}+04$ & $4.22 \mathrm{E}+03$ & $7.39 \mathrm{E}+01$ & $6.57 \mathrm{E}+03$ & $4.43 E+02$ \\
\hline B1T773 & 103 & $7.58 \mathrm{E}+03$ & $2.30 \mathrm{E}+03$ & $5.28 \mathrm{E}+01$ & $1.65 E+04$ & $6.39 E+02$ \\
\hline В1Т9К9 & 106.8 & $5.16 \mathrm{E}+03$ & $1.89 E+03$ & $3.58 \mathrm{E}+01$ & $1.54 \mathrm{E}+04$ & $6.13 E+02$ \\
\hline B1T9L0 & 109.3 & $1.13 \mathrm{E}+04$ & $3.22 \mathrm{E}+03$ & $7.33 \mathrm{E}+01$ & $1.26 \mathrm{E}+04$ & $5.36 \mathrm{E}+02$ \\
\hline B1T9L1 & 114.3 & $6.24 \mathrm{E}+03$ & $2.30 \mathrm{E}+03$ & $3.79 \mathrm{E}+01$ & $1.26 \mathrm{E}+04$ & $5.70 \mathrm{E}+02$ \\
\hline B1T777 & 123 & $1.06 \mathrm{E}+03$ & $5.17 \mathrm{E}+02$ & $9.12 \mathrm{E}+00$ & $3.73 E+04$ & $4.43 E+02$ \\
\hline В1T818 & 123 & $1.35 \mathrm{E}+03$ & $5.89 \mathrm{E}+02$ & $1.22 \mathrm{E}+01$ & $3.65 E+04$ & $5.58 \mathrm{E}+02$ \\
\hline B1T9L2 & 126.8 & $2.33 E+03$ & $1.12 \mathrm{E}+03$ & $2.02 \mathrm{E}+01$ & $3.85 E+04$ & $5.92 \mathrm{E}+02$ \\
\hline B1T9L3 & 129.3 & $2.53 \mathrm{E}+03$ & $1.08 \mathrm{E}+03$ & $2.15 \mathrm{E}+01$ & $3.75 E+04$ & $7.86 \mathrm{E}+02$ \\
\hline B1T9L4 & 131.8 & $5.17 \mathrm{E}+03$ & $2.03 E+03$ & $3.97 \mathrm{E}+01$ & $3.70 \mathrm{E}+04$ & $7.64 \mathrm{E}+02$ \\
\hline B1T9L5 & 134.3 & $7.34 \mathrm{E}+03$ & $2.52 E+03$ & $5.62 \mathrm{E}+01$ & $2.75 \mathrm{E}+04$ & $5.65 E+02$ \\
\hline B1T781 & 143 & $1.61 \mathrm{E}+04$ & $3.87 E+03$ & $8.01 \mathrm{E}+01$ & $1.49 \mathrm{E}+03$ & $3.32 E+02$ \\
\hline B1T790 & 165.5 & $3.44 \mathrm{E}+02$ & $1.39 \mathrm{E}+02$ & $1.48 \mathrm{E}+00$ & $3.75 \mathrm{E}+02$ & $1.23 \mathrm{E}+02$ \\
\hline
\end{tabular}


PNNL-17821

Table 5.7 (contd)

\begin{tabular}{|c|c|c|c|c|c|c|}
\hline HEIS \# & $\begin{array}{c}\text { mid depth } \\
\mathrm{ft} \text { bgs }\end{array}$ & $\begin{array}{c}\mathrm{Ca} \\
\mathrm{mg} / \mathrm{L} \\
\end{array}$ & $\begin{array}{c}\mathrm{Mg} \\
\mathrm{mg} / \mathrm{L}\end{array}$ & $\begin{array}{c}\mathrm{Sr} \\
\mathrm{mg} / \mathrm{L} \\
\end{array}$ & $\begin{array}{c}\mathrm{Na} \\
\mathrm{mg} / \mathrm{L}\end{array}$ & $\begin{array}{c}\mathrm{K} \\
\mathrm{mg} / \mathrm{L} \\
\end{array}$ \\
\hline B1T793 & 173 & $4.68 \mathrm{E}+02$ & $1.59 \mathrm{E}+02$ & $2.50 \mathrm{E}+00$ & $5.22 \mathrm{E}+02$ & $1.31 \mathrm{E}+02$ \\
\hline B1T9L6 & 176.8 & $4.61 \mathrm{E}+02$ & $1.45 \mathrm{E}+02$ & $2.49 \mathrm{E}+00$ & $5.03 E+02$ & $1.16 \mathrm{E}+02$ \\
\hline B1T9L7 & 179.3 & $3.99 \mathrm{E}+02$ & $1.26 \mathrm{E}+02$ & $2.09 E+00$ & $4.19 \mathrm{E}+02$ & $9.04 \mathrm{E}+01$ \\
\hline B1T9L8 & 181.8 & $3.39 E+02$ & $1.20 \mathrm{E}+02$ & $1.20 \mathrm{E}+00$ & $4.30 \mathrm{E}+02$ & $1.15 \mathrm{E}+02$ \\
\hline B1T9L9 & 184.3 & $3.44 \mathrm{E}+02$ & $1.19 \mathrm{E}+02$ & $1.82 \mathrm{E}+00$ & $4.38 \mathrm{E}+02$ & $1.21 \mathrm{E}+02$ \\
\hline B1T798 & 195.5 & $4.61 \mathrm{E}+02$ & $1.77 \mathrm{E}+02$ & $1.80 \mathrm{E}+00$ & $4.01 E+02$ & $1.17 \mathrm{E}+02$ \\
\hline B1T7B4 & 210.5 & $2.16 \mathrm{E}+03$ & 8.33E+02 & $1.68 \mathrm{E}+01$ & $3.19 E+04$ & $4.67 \mathrm{E}+02$ \\
\hline B1T7B6 & 215.5 & $3.89 E+03$ & $1.25 \mathrm{E}+03$ & $3.33 E+01$ & $4.14 \mathrm{E}+04$ & $6.85 \mathrm{E}+02$ \\
\hline B1T7C2 & 230.5 & $1.32 \mathrm{E}+04$ & $3.64 \mathrm{E}+03$ & $9.77 \mathrm{E}+01$ & $2.60 \mathrm{E}+04$ & $9.83 \mathrm{E}+02$ \\
\hline В1T9K6 & 236.8 & $2.48 \mathrm{E}+04$ & $4.90 \mathrm{E}+03$ & $1.30 \mathrm{E}+02$ & $1.64 \mathrm{E}+03$ & $8.89 E+02$ \\
\hline В1T9K7 & 239.3 & $2.38 E+04$ & $4.26 \mathrm{E}+03$ & $1.35 \mathrm{E}+02$ & $1.83 E+03$ & $1.09 \mathrm{E}+03$ \\
\hline В1Т9К8 & 241.8 & $1.46 \mathrm{E}+04$ & $3.16 \mathrm{E}+03$ & $7.63 \mathrm{E}+01$ & $1.25 E+03$ & $7.35 \mathrm{E}+02$ \\
\hline В1T824 & 244.3 & $7.74 \mathrm{E}+03$ & $2.07 \mathrm{E}+03$ & $3.79 E+01$ & $9.54 \mathrm{E}+02$ & $5.43 \mathrm{E}+02$ \\
\hline B1T7C4 & 245.5 & $5.67 \mathrm{E}+03$ & $1.62 \mathrm{E}+03$ & $2.88 \mathrm{E}+01$ & $9.44 \mathrm{E}+02$ & $5.02 \mathrm{E}+02$ \\
\hline B1T7C9 & 258 & $3.17 \mathrm{E}+02$ & $1.05 \mathrm{E}+02$ & $1.03 E+00$ & $3.44 \mathrm{E}+02$ & $1.10 \mathrm{E}+02$ \\
\hline B1T7D1 & 263 & $3.39 E+02$ & $1.12 \mathrm{E}+02$ & $1.72 \mathrm{E}+00$ & $3.29 E+02$ & $1.17 \mathrm{E}+02$ \\
\hline B1T7D8 & 280.5 & $4.22 \mathrm{E}+02$ & $1.43 \mathrm{E}+02$ & $1.56 \mathrm{E}+00$ & $3.85 E+02$ & $1.59 \mathrm{E}+02$ \\
\hline B1T7F2 & 290.5 & $4.45 \mathrm{E}+02$ & $1.47 \mathrm{E}+02$ & $1.58 \mathrm{E}+00$ & $4.96 \mathrm{E}+02$ & $1.72 \mathrm{E}+02$ \\
\hline B1T7H1 & 313 & $3.51 \mathrm{E}+02$ & $1.06 \mathrm{E}+02$ & 8.35E-01 & $5.66 \mathrm{E}+02$ & $2.08 \mathrm{E}+02$ \\
\hline B1T7J2 & 340.5 & $3.08 \mathrm{E}+02$ & $8.78 E+01$ & 7.77E-01 & $1.14 \mathrm{E}+03$ & $3.64 \mathrm{E}+02$ \\
\hline B1V530 & 344 & $4.87 \mathrm{E}+02$ & $1.55 \mathrm{E}+02$ & $<4.23 \mathrm{E}-00$ & $3.13 E+03$ & $7.58 \mathrm{E}+02$ \\
\hline B1V531 & 346.5 & $1.32 \mathrm{E}+02$ & $4.38 \mathrm{E}+01$ & $<1.74 \mathrm{E}-00$ & $7.56 \mathrm{E}+02$ & $1.65 \mathrm{E}+02$ \\
\hline B1V532 & 349 & $3.64 \mathrm{E}+01$ & $1.56 \mathrm{E}+01$ & $<0.97 \mathrm{E}+00$ & $3.83 E+02$ & $8.53 E+01$ \\
\hline B1V533 & 351.5 & $3.75 \mathrm{E}+01$ & $1.10 \mathrm{E}+01$ & $<0.4 \mathrm{E}+00$ & $1.17 \mathrm{E}+02$ & $3.57 \mathrm{E}+01$ \\
\hline
\end{tabular}

(a) Parentheses signify values below level of quantitation but considered valid for this work. 


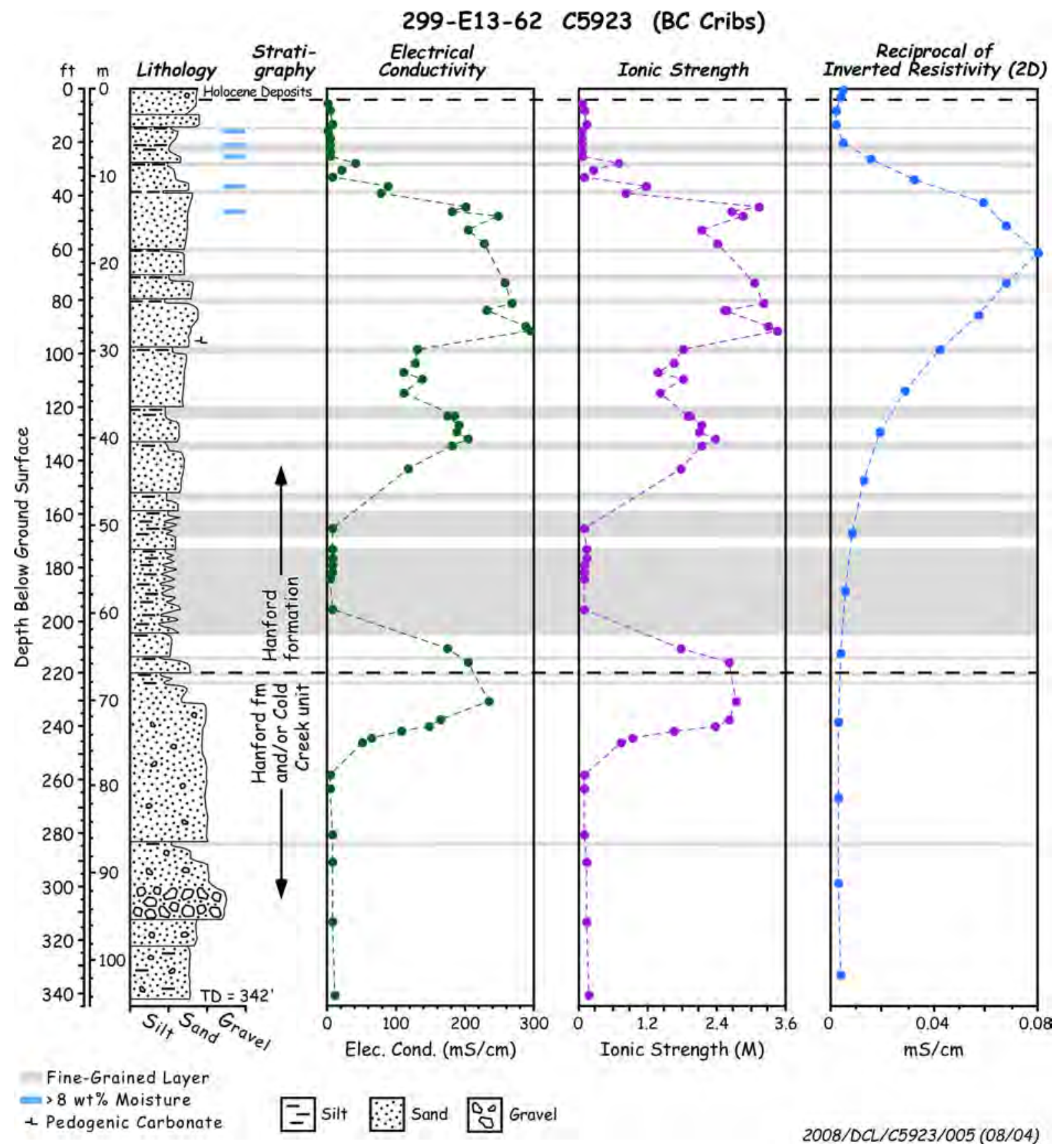

Figure 5.5. Pore Water Electrical Conductivity, Calculated Ionic Strength, and Reciprocal of Inverted Field Soil Resistivity Data for C5923 Borehole 
PNNL-17821

Table 5.8. Water-Extractable Radionuclides and Pore Water Total Ionic Strength

\begin{tabular}{|c|c|c|c|c|c|c|}
\hline HEIS \# & $\begin{array}{l}\text { mid depth } \\
\text { ft bgs }\end{array}$ & $\begin{array}{c}\text { Technetium-99 } \\
\text { pCi/g }\end{array}$ & $\begin{array}{c}\mathrm{U} \\
\mu \mathrm{g} / \mathrm{g}\end{array}$ & $\begin{array}{c}\text { Technetium-99 } \\
\text { pCi/L }\end{array}$ & $\begin{array}{c}\mathrm{U} \\
\mu \mathrm{g} / \mathrm{L}\end{array}$ & $\begin{array}{c}\text { PW Ionic } \\
\text { Strength } \\
\text { M }\end{array}$ \\
\hline B1T740 & 5.5 & $<0.424$ & $<5.64 \mathrm{E}-04$ & $<1.80 \mathrm{E}+03$ & $<2.55 \mathrm{E}+00$ & 0.03 \\
\hline B1T741 & 8 & $<0.424$ & $2.90 \mathrm{E}-03$ & $<1.69 \mathrm{E}+03$ & $5.10 \mathrm{E}+01$ & 0.07 \\
\hline B1T743 & 13 & $<0.424$ & 2.71E-03 & $<4.17 \mathrm{E}+03$ & $9.23 \mathrm{E}+01$ & 0.11 \\
\hline B1T744 & 15.5 & $<0.424$ & 1.73E-03 & $<9.20 \mathrm{E}+02$ & $1.20 \mathrm{E}+01$ & 0.02 \\
\hline B1T745 & 18 & $<0.424$ & $1.41 \mathrm{E}-03$ & $<1.59 \mathrm{E}+03$ & $1.85 \mathrm{E}+01$ & 0.03 \\
\hline B1T746 & 20.5 & $<0.424$ & $2.04 \mathrm{E}-03$ & $<1.54 \mathrm{E}+03$ & $2.28 \mathrm{E}+01$ & 0.04 \\
\hline B1T816 & 20.5 & $<0.424$ & $1.94 \mathrm{E}-03$ & $<1.52 \mathrm{E}+03$ & $2.12 \mathrm{E}+01$ & 0.04 \\
\hline B1T747 & 23 & $<0.424$ & 8.13E-04 & $<2.16 \mathrm{E}+03$ & $1.14 \mathrm{E}+01$ & 0.04 \\
\hline B1T748 & 25.5 & $<0.424$ & 7.62E-04 & $<1.55 \mathrm{E}+03$ & $8.24 \mathrm{E}+00$ & 0.04 \\
\hline B1T749 & 28 & 7.23 & $<5.64 \mathrm{E}-04$ & $1.494 \mathrm{E}+05$ & $<5.66 \mathrm{E}+00$ & 0.69 \\
\hline B1T750 & 30.5 & 4.82 & $<5.64 \mathrm{E}-04$ & $6.410 \mathrm{E}+04$ & $<7.18 \mathrm{E}+00$ & 0.26 \\
\hline B1T751 & 33 & 0.59 & $<5.64 \mathrm{E}-04$ & $7.791 \mathrm{E}+03$ & $<4.97 \mathrm{E}+00$ & 0.07 \\
\hline B1T825 & 36.8 & 72.14 & 2.35E-03 & $5.892 \mathrm{E}+05$ & $1.92 \mathrm{E}+01$ & 1.17 \\
\hline B1T826 & 39.3 & 14.37 & 1.12E-03 & $3.161 \mathrm{E}+05$ & $2.47 \mathrm{E}+01$ & 0.80 \\
\hline B1T828 & 44.3 & 22.65 & $2.44 \mathrm{E}-04$ & $7.256 \mathrm{E}+05$ & $7.82 \mathrm{E}+00$ & 3.13 \\
\hline B1T752 & 45.5 & 145.85 & $2.14 \mathrm{E}-03$ & $9.093 E+05$ & $1.34 \mathrm{E}+01$ & 2.63 \\
\hline B1T753 & 48 & 93.57 & $<5.64 \mathrm{E}-04$ & $1.831 \mathrm{E}+06$ & $<4.71 \mathrm{E}+00$ & 2.86 \\
\hline B1T755 & 53 & 33.80 & $<5.64 \mathrm{E}-04$ & $1.145 E+06$ & $<1.88 \mathrm{E}+01$ & 2.12 \\
\hline B1T757 & 58 & 46.71 & $5.90 \mathrm{E}-04$ & $1.469 \mathrm{E}+06$ & $1.86 \mathrm{E}+01$ & 2.38 \\
\hline B1T763 & 73 & 71.66 & 3.23E-03 & $1.234 \mathrm{E}+06$ & $5.57 \mathrm{E}+01$ & 3.03 \\
\hline B1T766 & 80.5 & 93.25 & $1.54 \mathrm{E}-03$ & $1.657 \mathrm{E}+06$ & $2.74 \mathrm{E}+01$ & 3.22 \\
\hline B1T767 & 83 & 54.08 & 6.38E-04 & $1.315 \mathrm{E}+06$ & $1.55 \mathrm{E}+01$ & 2.55 \\
\hline B1T817 & 83 & 43.86 & $5.88 \mathrm{E}-04$ & $1.282 \mathrm{E}+06$ & $1.72 \mathrm{E}+01$ & 2.52 \\
\hline B1T985 & 89.3 & 60.15 & $6.52 \mathrm{E}-04$ & $1.693 \mathrm{E}+06$ & $1.84 \mathrm{E}+01$ & 3.29 \\
\hline B1T768 & 90.5 & 74.75 & $<5.64 \mathrm{E}-04$ & $2.178 \mathrm{E}+06$ & $<1.43 \mathrm{E}+01$ & 3.46 \\
\hline B1T771 & 98 & 34.30 & $1.67 \mathrm{E}-03$ & $6.010 \mathrm{E}+05$ & $2.93 \mathrm{E}+01$ & 1.81 \\
\hline B1T773 & 103 & 28.10 & $<5.64 \mathrm{E}-04$ & $8.383 E+05$ & $<1.36 \mathrm{E}+01$ & 1.62 \\
\hline В1Т9К9 & 106.8 & 26.88 & $<5.64 \mathrm{E}-04$ & $7.320 \mathrm{E}+05$ & $<1.29 \mathrm{E}+01$ & 1.37 \\
\hline B1T9L0 & 109.3 & 44.54 & $1.75 \mathrm{E}-03$ & $6.764 \mathrm{E}+05$ & $2.66 \mathrm{E}+01$ & 1.81 \\
\hline B1T9L1 & 114.3 & 20.13 & 5.96E-04 & $6.729 \mathrm{E}+05$ & $1.99 \mathrm{E}+01$ & 1.39 \\
\hline B1T777 & 123 & 63.31 & $1.31 \mathrm{E}-03$ & $1.560 \mathrm{E}+06$ & $3.22 \mathrm{E}+01$ & 1.87 \\
\hline B1T818 & 123 & 56.88 & $9.40 \mathrm{E}-04$ & $1.383 \mathrm{E}+06$ & $2.29 \mathrm{E}+01$ & 1.91 \\
\hline B1T9L2 & 126.8 & 66.03 & $<5.64 \mathrm{E}-04$ & $1.606 \mathrm{E}+06$ & $<1.16 \mathrm{E}+01$ & 2.10 \\
\hline B1T9L3 & 129.3 & 38.65 & $<5.64 \mathrm{E}-04$ & $1.441 \mathrm{E}+06$ & $<1.89 \mathrm{E}+01$ & 2.07 \\
\hline B1T9L4 & 131.8 & 44.29 & $<5.64 \mathrm{E}-04$ & $1.501 \mathrm{E}+06$ & $<1.28 \mathrm{E}+01$ & 2.36 \\
\hline B1T9L5 & 134.3 & 89.99 & $1.12 \mathrm{E}-03$ & $1.337 \mathrm{E}+06$ & $1.67 \mathrm{E}+01$ & 2.11 \\
\hline B1T781 & 143 & 51.68 & $2.06 \mathrm{E}-03$ & $6.900 \mathrm{E}+05$ & $2.75 \mathrm{E}+01$ & 1.77 \\
\hline B1T790 & 165.5 & 0.44 & $9.96 \mathrm{E}-04$ & $6.982 \mathrm{E}+03$ & $1.60 \mathrm{E}+01$ & 0.08 \\
\hline
\end{tabular}


PNNL-17821

Table 5.8 (contd)

\begin{tabular}{|c|c|c|c|c|c|c|}
\hline HEIS \# & $\begin{array}{l}\text { mid depth } \\
\text { ft bgs }\end{array}$ & $\begin{array}{c}\text { Technetium-99 } \\
\text { pCi/g }\end{array}$ & $\begin{array}{c}\mathrm{U} \\
\mu \mathrm{g} / \mathrm{g}\end{array}$ & $\begin{array}{c}\text { Technetium-99 } \\
\text { pCi/L }\end{array}$ & $\begin{array}{c}\mathrm{U} \\
\mu \mathrm{g} / \mathrm{L}\end{array}$ & $\begin{array}{c}\text { PW Ionic Strength } \\
\text { M }\end{array}$ \\
\hline B1T793 & 173 & $<0.424$ & $<5.64 \mathrm{E}-04$ & $<7.52 \mathrm{E}+03$ & $<1.89 \mathrm{E}+01$ & 0.11 \\
\hline B1T9L6 & 176.8 & $<0.424$ & 6.12E-04 & $<6.23 \mathrm{E}+03$ & $1.95 \mathrm{E}+01$ & 0.11 \\
\hline B1T9L7 & 179.3 & $<0.424$ & 6.30E-04 & $<5.39 \mathrm{E}+03$ & $1.59 \mathrm{E}+01$ & 0.09 \\
\hline B1T9L8 & 181.8 & $<0.424$ & 6.83E-04 & $<4.68 \mathrm{E}+03$ & $1.62 \mathrm{E}+01$ & 0.09 \\
\hline B1T9L9 & 184.3 & $<0.424$ & $<5.64 \mathrm{E}-04$ & $<5.72 \mathrm{E}+03$ & $<1.41 \mathrm{E}+01$ & 0.09 \\
\hline B1T798 & 195.5 & 0.43 & 9.91E-04 & $8.259 \mathrm{E}+03$ & $1.91 \mathrm{E}+01$ & 0.10 \\
\hline B1T7B4 & 210.5 & 85.09 & 8.23E-04 & $1.544 \mathrm{E}+06$ & $1.49 \mathrm{E}+01$ & 1.76 \\
\hline B1T7B6 & 215.5 & 139.87 & $9.58 \mathrm{E}-04$ & $1.827 \mathrm{E}+06$ & $1.25 \mathrm{E}+01$ & 2.61 \\
\hline B1T7C2 & 230.5 & 82.53 & $<5.64 \mathrm{E}-04$ & $2.560 \mathrm{E}+06$ & $<1.74 \mathrm{E}+01$ & 2.71 \\
\hline В1Т9К6 & 236.8 & 71.19 & $<5.64 \mathrm{E}-04$ & $2.137 \mathrm{E}+06$ & $<1.22 \mathrm{E}+01$ & 2.62 \\
\hline В1Т9К7 & 239.3 & 50.81 & $<5.64 \mathrm{E}-04$ & $1.916 \mathrm{E}+06$ & $<1.04 \mathrm{E}+01$ & 2.38 \\
\hline В1Т9К8 & 241.8 & 38.88 & $<5.64 \mathrm{E}-04$ & $1.354 \mathrm{E}+06$ & $<1.06 \mathrm{E}+01$ & 1.63 \\
\hline B1T824 & 244.3 & 24.16 & $<5.64 \mathrm{E}-04$ & $8.562 E+05$ & $<6.89 \mathrm{E}+00$ & 0.92 \\
\hline B1T7C4 & 245.5 & 14.71 & $<5.64 \mathrm{E}-04$ & $4.759 \mathrm{E}+05$ & $<7.04 \mathrm{E}+00$ & 0.71 \\
\hline B1T7C9 & 258 & 0.55 & $<5.64 \mathrm{E}-04$ & $1.178 \mathrm{E}+04$ & $<8.04 \mathrm{E}+00$ & 0.08 \\
\hline B1T7D1 & 263 & $<0.424$ & $<5.64 \mathrm{E}-04$ & $<7.56 \mathrm{E}+02$ & $<1.36 \mathrm{E}+00$ & 0.08 \\
\hline B1T7D8 & 280.5 & $<0.424$ & $<5.64 \mathrm{E}-04$ & $<6.10 \mathrm{E}+03$ & $<9.95 \mathrm{E}+00$ & 0.10 \\
\hline B1T7F2 & 290.5 & $<0.424$ & $<5.64 \mathrm{E}-04$ & $<4.93 \mathrm{E}+03$ & $<8.33 \mathrm{E}+00$ & 0.11 \\
\hline B1T7H1 & 313 & $<0.424$ & $<5.64 \mathrm{E}-04$ & $<4.92 \mathrm{E}+03$ & $<9.28 \mathrm{E}+00$ & 0.11 \\
\hline B1T7J2 & 340.5 & $<0.424$ & $<5.64 \mathrm{E}-04$ & $<6.69 \mathrm{E}+03$ & $<1.18 \mathrm{E}+01$ & 0.15 \\
\hline B1V530 & 344 & $<0.388$ & $<5.61 \mathrm{E}-04$ & $<32$ & $<0.05$ & 0.30 \\
\hline B1V531 & 346.5 & $<0.388$ & $<5.61 \mathrm{E}-04$ & $<13$ & $<0.02$ & 0.082 \\
\hline B1V532 & 349 & $<0.388$ & $<5.61 \mathrm{E}-04$ & $<7.2$ & $<0.01$ & 0.035 \\
\hline B1V533 & 351.5 & $<0.388$ & $<5.61 \mathrm{E}-04$ & $<3.0$ & $<0.01$ & 0.016 \\
\hline
\end{tabular}

(a) $<$ values = below level of quantitation.

(b) Red type = values above natural background and bold red are peak values in various lobes of vertical distribution.

\subsection{4 $8 \mathrm{M}$ Nitric Acid Extractable Amounts of Selected Elements}

The amount of material that was extractable from the C5923 vadose zone sediment into $8 \mathrm{M}$ nitric acid is shown in Table 5.9 to Table 5.11. The 8-M nitric acid extraction is a protocol used by the U.S. Environmental Protection Agency to estimate the maximum concentrations of regulated metals in contaminated sediment that would be biologically available. Aliquots of sediment from borehole C5923 were subjected to the acid extraction to look for elevated quantities of selected constituents and radionuclides.

The acid extract data for grab samples from C5923 in general did not show higher values for constituents in the shallow depths (relative to known Hanford site background values) in contrast to shallow sediments from borehole C4191 sediments that received directly the waste disposed of to the 216-B-26 trench. The lack of inflated concentrations for selected elements in the acid-extracts from 
C5923 sediments, excepting perhaps acid-extractable iron (shown in Table 5.10), in comparison to sediments from C4191 reflects that fact that C5923 is not within the footprint of any of the cribs. Most highly reactive constituents in the liquid waste stream disposed of at the BC Cribs and Trenches reacted very close to the facility's bottom so that a sludge layer with reactive metals and radionuclide oxides,

Table 5.9. Acid-Extractable Light Elements in Borehole C5923 Sediments ( $\mu$ g/g dry sediment)

\begin{tabular}{|c|c|c|c|c|c|c|c|c|c|}
\hline $\begin{array}{c}\text { Sample } \\
\text { (HEIS ID) }\end{array}$ & $\begin{array}{c}\text { Depth } \\
\text { (ft bgs) }\end{array}$ & $\mathrm{Na}$ & $\mathrm{Mg}$ & $\mathrm{Al}$ & $\mathrm{P}$ & S & K & $\mathrm{Ca}$ & $\mathrm{Ti}$ \\
\hline B1T744 & 15.5 & $<1070$ & 4580 & 6570 & 1010 & $<236$ & 1080 & 5440 & 959 \\
\hline B1T748 & 25.5 & $<1030$ & 4890 & 7630 & 974 & $<228$ & 1300 & 11300 & 883 \\
\hline B1T749 & 28.0 & $<959$ & 3800 & 5420 & 946 & $<212$ & 817 & 10200 & 907 \\
\hline B1T825 & 36.0 & 1050 & 4780 & 7090 & 749 & $<227$ & 1300 & 14600 & 671 \\
\hline B1T752 & 45.5 & 3340 & 4260 & 6860 & 588 & 721 & 1240 & 9180 & 691 \\
\hline B1T757 & 58.0 & 1770 & 3770 & 5000 & 346 & $<213$ & 991 & 8450 & 414 \\
\hline B1T763 & 73.0 & 3270 & 4720 & 5730 & 435 & 368 & 1110 & 9330 & 434 \\
\hline B1T766 & 80.5 & 2600 & 4440 & 5350 & 394 & $<215$ & 1080 & 8730 & 433 \\
\hline B1T9L0 & 108.8 & $<1130$ & 4630 & 6250 & 377 & $<221$ & 1560 & 8510 & 513 \\
\hline B1T9L5 & 133.8 & 2180 & 4350 & 6240 & 451 & $<223$ & 1810 & 7810 & 410 \\
\hline B1T781 & 143.0 & $<1020$ & 4080 & 5070 & 499 & $<226$ & 1150 & 8480 & 364 \\
\hline B1T798 & 195.5 & $<997$ & 4110 & 6400 & 447 & $<221$ & 1380 & 9220 & 652 \\
\hline B1T7B4 & 210.5 & 2230 & 3890 & 5980 & 388 & $<249$ & 1490 & 7720 & 513 \\
\hline B1T7C2 & 230.5 & 1020 & 3980 & 5340 & 404 & $<216$ & 1060 & 6640 & 482 \\
\hline B1T7D1 & 263.0 & $<990$ & 3900 & 5780 & 458 & $<219$ & 1260 & 6160 & 635 \\
\hline B1T7F2 & 290.5 & $<961$ & 3480 & 5160 & 491 & $<212$ & 988 & 5700 & 680 \\
\hline B1T7H1 & 313.0 & $<1030$ & 3130 & 4580 & 446 & $<227$ & 760 & 4420 & 602 \\
\hline
\end{tabular}

Table 5.10. Acid-Extractable Heavy Elements in Borehole C5923 Sediments ( $\mu \mathrm{g} / \mathrm{g}$ dry sediment)

\begin{tabular}{ccccccccc}
\hline $\begin{array}{c}\text { Sample } \\
\text { (HEIS ID) }\end{array}$ & $\begin{array}{c}\text { Depth } \\
\text { (ft bgs) }\end{array}$ & $\mathrm{V}$ & $\mathrm{Mn}$ & $\mathrm{Fe}$ & $\mathrm{Co}$ & $\mathrm{Sr}$ & $\mathrm{Zr}$ & $\mathrm{Hg}$ \\
\hline B1T744 & 15.5 & 27.4 & 359 & 20100 & 10.9 & 25.4 & $<20.3$ & $<0.053$ \\
\hline B1T748 & 25.5 & 30.3 & 477 & 21400 & 13.1 & 33.5 & $<19.6$ & $<0.051$ \\
B1T749 & 28.0 & 30 & 407 & 18400 & 10.8 & 32.1 & 18.3 & $<0.048$ \\
B1T825 & 36.0 & 23.6 & 395 & 17400 & 11.1 & 48.8 & $<19.5$ & $<0.051$ \\
B1T752 & 45.5 & 22.4 & 303 & 14700 & 8.64 & 37.4 & $<20.9$ & 0.066 \\
B1T757 & 58.0 & 9.73 & 235 & 9630 & $<7.49$ & 28.6 & $<18.3$ & $<0.048$ \\
B1T763 & 73.0 & 9.6 & 241 & 11400 & $<7.8$ & 29.2 & $<19$ & $<0.05$ \\
B1T766 & 80.5 & 9.14 & 237 & 10700 & $<7.56$ & 32.1 & $<18.4$ & $<0.048$ \\
B1T9L0 & 108.8 & 11.9 & 273 & 11700 & $<7.79$ & 32.3 & $<19$ & $<0.05$ \\
B1T9L5 & 133.8 & 12.1 & 255 & 10600 & $<7.85$ & 33.9 & $<19.1$ & $<0.05$ \\
B1T781 & 143.0 & 11 & 233 & 9670 & $<7.96$ & 32.1 & $<19.4$ & $<0.051$ \\
\hline B1T798 & 195.5 & 17.2 & 268 & 12400 & $<7.77$ & 34.8 & $<18.9$ & $<0.05$ \\
B1T7B4 & 210.5 & 14.5 & 270 & 11000 & $<8.78$ & 29.9 & $<21.4$ & $<0.056$ \\
\hline B1T7C2 & 230.5 & 13.6 & 241 & 10300 & $<7.62$ & 31.3 & $<18.6$ & $<0.049$ \\
B1T7D1 & 263.0 & 17.5 & 238 & 11800 & $<7.71$ & 28.4 & $<18.8$ & $<0.049$ \\
B1T7F2 & 290.5 & 19 & 249 & 13200 & $<7.48$ & 25.7 & $<18.2$ & $<0.048$ \\
B1T7H1 & 313.0 & 17.8 & 185 & 10100 & $<8.01$ & 22.7 & $<19.5$ & $<0.051$ \\
\hline
\end{tabular}


Table 5.11. Acid Extractable Content for RCRA Metals and Radionuclides in Borehole C5923 Sediments (units $\mu \mathrm{g} / \mathrm{g}$ except Tc pCi/g)

\begin{tabular}{ccccccc}
\hline Sample (HEIS ID) & $\begin{array}{c}\text { Depth } \\
\text { (ft bgs) }\end{array}$ & $\mathrm{Cr}$ & $\mathrm{Cd}$ & $\mathrm{Pb}$ & $\mathrm{Tc} 99$ & $\mathrm{U}$ \\
\hline B1T744 & 15.5 & $(5.30 \mathrm{E}+00)^{(\mathrm{a})}$ & $7.24 \mathrm{E}-02$ & $2.99 \mathrm{E}+00$ & $2.02 \mathrm{E}+01$ & $3.49 \mathrm{E}-01$ \\
B1T748 & 25.5 & $(5.77 \mathrm{E}+00)$ & $7.18 \mathrm{E}-02$ & $3.57 \mathrm{E}+00$ & $2.00 \mathrm{E}+01$ & $4.18 \mathrm{E}-01$ \\
B1T749 & 28.0 & $(4.41 \mathrm{E}+00)$ & $6.98 \mathrm{E}-02$ & $2.38 \mathrm{E}+00$ & $2.90 \mathrm{E}+01$ & $3.87 \mathrm{E}-01$ \\
B1T825 & 36.0 & $(5.78 \mathrm{E}+00)$ & $7.98 \mathrm{E}-02$ & $3.76 \mathrm{E}+00$ & $7.80 \mathrm{E}+01$ & $4.00 \mathrm{E}-01$ \\
B1T752 & 45.5 & $(4.58 \mathrm{E}-02)$ & $1.26 \mathrm{E}-02$ & $4.44 \mathrm{E}-03$ & $8.22 \mathrm{E}+01$ & $3.53 \mathrm{E}-01$ \\
\hline B1T757 & 58.0 & $(7.41 \mathrm{E}+00)$ & $7.17 \mathrm{E}-02$ & $2.85 \mathrm{E}+00$ & $6.64 \mathrm{E}+01$ & $3.17 \mathrm{E}-01$ \\
B1T763 & 73.0 & $(8.28 \mathrm{E}+00)$ & $5.78 \mathrm{E}-02$ & $2.83 \mathrm{E}+00$ & $7.91 \mathrm{E}+01$ & $3.97 \mathrm{E}-01$ \\
\hline B1T766 & 80.5 & $(8.01 \mathrm{E}+00)$ & $6.34 \mathrm{E}-02$ & $3.49 \mathrm{E}+00$ & $1.08 \mathrm{E}+02$ & $3.72 \mathrm{E}-01$ \\
B1T9L0 & 108.8 & $(9.23 \mathrm{E}+00)$ & $6.96 \mathrm{E}-02$ & $2.91 \mathrm{E}+00$ & $4.65 \mathrm{E}+01$ & $3.91 \mathrm{E}-01$ \\
\hline B1T9L5 & 133.8 & $(1.05 \mathrm{E}+01)$ & $7.91 \mathrm{E}-02$ & $3.06 \mathrm{E}+00$ & $9.78 \mathrm{E}+01$ & $3.11 \mathrm{E}-01$ \\
B1T781 & 143.0 & $(9.39 \mathrm{E}+00)$ & $7.21 \mathrm{E}-02$ & $3.74 \mathrm{E}+00$ & $6.16 \mathrm{E}+01$ & $4.37 \mathrm{E}-01$ \\
\hline B1T798 & 195.5 & $(8.63 \mathrm{E}+00)$ & $6.18 \mathrm{E}-02$ & $2.42 \mathrm{E}+00$ & $1.97 \mathrm{E}+01$ & $4.28 \mathrm{E}-01$ \\
B1T7B4 & 210.5 & $(7.64 \mathrm{E}+00)$ & $5.77 \mathrm{E}-02$ & $2.97 \mathrm{E}+00$ & $9.41 \mathrm{E}+01$ & $3.48 \mathrm{E}-01$ \\
\hline B1T7C2 & 230.5 & $(9.46 \mathrm{E}+00)$ & $5.45 \mathrm{E}-02$ & $2.05 \mathrm{E}+00$ & $1.05 \mathrm{E}+02$ & $1.38 \mathrm{E}-01$ \\
\hline B1T7D1 & 263.0 & $(8.28 \mathrm{E}+00)$ & $5.78 \mathrm{E}-02$ & $2.13 \mathrm{E}+00$ & $1.43 \mathrm{E}+01$ & $5.49 \mathrm{E}-01$ \\
\hline B1T7F2 & 290.5 & $(7.81 \mathrm{E}+00)$ & $5.50 \mathrm{E}-02$ & $1.95 \mathrm{E}+00$ & $2.34 \mathrm{E}+01$ & $3.51 \mathrm{E}-01$ \\
B1T7H1 & 313.0 & $(6.57 \mathrm{E}+00)$ & $5.58 \mathrm{E}-02$ & $1.66 \mathrm{E}+00$ & $2.11 \mathrm{E}+01$ & $3.06 \mathrm{E}-01$ \\
\hline
\end{tabular}

(a) Parentheses signify values below level of quantitation but considered valid.

hydroxides, phosphates and maybe other insoluble salts are located within the footprint. The acid extract data for sediment samples from C5923 do not show any "waste laden" sludge signatures and the acid extract data are not of much relevancy to the ERC "ground-truthing" exercise. Further, as shown in Table 5.10, no measureable mercury was detected in any of the acid extracts. Similarly no elevated concentrations of other RCRA-regulated metals were found.

\subsubsection{Radionuclide Content in Vadose Zone Sediment from C5923}

Selected grab samples in zones that contained high salt content in the pore waters were directly counted for gamma radioactivity. One grab sample from borehole C5923 at $48 \mathrm{ft}$ bgs contained very minor amounts of cesium-137 right at the detection limit of $\sim 0.15 \mathrm{pCi} / \mathrm{g}$. Based on the cesium-137 distribution at the C4191 borehole directly below the 216-26 trench footprint, we feel that this detection of $0.16 \mathrm{pCi} / \mathrm{g}$ cesium-137 at $48 \mathrm{ft}$ bgs is more than likely counting uncertainties. The SG field logging performed by Stoller Inc. did detect a few pCi/g cesium-137 in the top few feet of sediment at borehole C5923 that is a more realistic finding for the cesium-137 distribution at borehole C5923. Table 5.12 shows that no other man-made gamma-emitting radionuclides were seen in the sediments from C5923. This contrasts with the very low activities in borehole C4191, which is deeper than the 216-B-26 bottom where some fission products were measured for several more feet into the sediments. This is similar to observations at other Hanford inactive disposal sites. The GEA of the selected grab samples from borehole C5923 did show background activities of natural potassium-40 and daughter products of natural uranium-238 and thorium-232. 
Table 5.12. Man-Made Fission Product GEA Data (pCi/g sediment) for Grab Samples from C5923

\begin{tabular}{lccccccc}
\hline HEIS \# & $\begin{array}{c}\text { mid depth } \\
\mathrm{ft} \text { bgs }\end{array}$ & $\begin{array}{c}\text { Co-60 } \\
\mathrm{pCi} / \mathrm{g}\end{array}$ & $\begin{array}{c}\text { Sb-125 } \\
\mathrm{pCi} / \mathrm{g}\end{array}$ & $\begin{array}{c}\mathrm{Cs}-137 \\
\mathrm{pCi} / \mathrm{g}\end{array}$ & $\begin{array}{c}\text { Eu-152 } \\
\mathrm{pCi} / \mathrm{g}\end{array}$ & $\begin{array}{c}\text { Eu-154 } \\
\mathrm{pCi} / \mathrm{g}\end{array}$ & $\begin{array}{c}\text { Eu-155 } \\
\mathrm{pCi} / \mathrm{g}\end{array}$ \\
\hline B1T741 & 8 & $<0.10$ & $<0.35$ & $<0.13$ & $<0.44$ & $<0.27$ & $<0.42$ \\
B1T752 & 45.5 & $<0.08$ & $<0.26$ & $<0.09$ & $<0.33$ & $<0.19$ & $<0.29$ \\
B1T753 & 48 & $<0.14$ & $<0.47$ & 0.16 & $<0.63$ & $<0.36$ & $<0.63$ \\
B1T754 & 50.5 & $<0.11$ & $<0.38$ & $<0.14$ & $<0.44$ & $<0.28$ & $<0.45$ \\
B1T763 & 73 & $<0.14$ & $<0.46$ & $<0.16$ & $<0.61$ & $<0.36$ & $<0.62$ \\
B1T771 & 98 & $<0.11$ & $<0.39$ & $<0.14$ & $<0.49$ & $<0.30$ & $<0.49$ \\
B1T9L5 & 134.3 & $<0.15$ & $<0.51$ & $<0.18$ & $<0.67$ & $<0.41$ & $<0.70$ \\
B1T781 & 143 & $<0.12$ & $<0.37$ & $<0.14$ & $<0.53$ & $<0.28$ & $<0.46$ \\
B1T7B4 & 210.5 & $<0.13$ & $<0.41$ & $<0.15$ & $<0.51$ & $<0.32$ & $<0.51$ \\
B1T7C2 & 230.5 & $<0.15$ & $<0.50$ & $<0.18$ & $<0.65$ & $<0.38$ & $<0.65$ \\
B1T7D8 & 280.5 & $<0.09$ & $<0.28$ & $<0.10$ & $<0.36$ & $<0.22$ & $<0.36$ \\
\hline
\end{tabular}

PNNL performed technetium-99 and uranium-238 analysis on the one-to-one sediment-to-water extracts and the sediment acid extracts. The uranium and technetium water-extractable contents were previously discussed above. PNNL also performed wet chemical separations on acid extracts of the grab samples shown in Table 5.13 to measure strontium-90 and nickel-63, two beta-emitting radionuclides that were found to be present in the shallow depths (right near the trench bottom) at C4191. The strontium-90 and nickel-63 analyses were all below detection limits for grab samples from C5923 as shown in Table 5.13. In contrast to the shallow sediments at C4191, which was emplaced directly through the footprint of the 216-B-26 trench, no strontium-90 or nickel-63 was found in the sediments obtained from borehole C5923. Considering that these radionuclides are quite immobile in the geochemical environment in Hanford's subsurface, given the nature of the waste stream disposed of at the BC Cribs and Trenches and the fact that borehole C5923 is several 10s of feet from crib footprints, it was expected that no detectable nickel-63 or strontium-90 would be found.

\subsubsection{Groundwater Analysis of Sample Obtained Prior to Decommissioning Borehole C5923}

At the completion of drilling C5923 in July 2008, one groundwater sample was obtained at a depth of $359.9 \mathrm{ft}$ bgs before the lower portion of the borehole was decommissioned. The water table was $350.6 \mathrm{ft}$ bgs in July 2008 or $395.4 \mathrm{ft}$ elevation based on data found in Table 2.2. This elevation is in line with the decreasing water table trend shown in Figure 2.22 and approximately $7.5 \mathrm{ft}$ above the preHanford water table. The composition of the groundwater was determined by the Waste Sampling and Characterization Facility (WSCF) and other commercial analytical laboratories. The water sample was taken at a depth of $359.9 \mathrm{ft}$ bgs, approximately $9 \mathrm{ft}$ below the water table. The results are shown in Table 5.14.

The major cations and several of the major anions were not measured, so it is not possible to perform cation-anion balances or to compare the total groundwater composition to the regional water composition. However, based on the measured nitrate concentration, there is a hint that groundwater at this borehole contains a trace of the disposed scavenged bismuth phosphate waste stream. This differs from the 
PNNL-17821

Table 5.13. Other Radionuclides Present in the C5923 Sediments

\begin{tabular}{cccc}
\hline HEIS \# & $\begin{array}{c}\text { mid depth } \\
\mathrm{ft} \text { bgs }\end{array}$ & $\begin{array}{c}\mathrm{Ni}-63 \\
\mathrm{pCi} / \mathrm{g}\end{array}$ & $\begin{array}{c}\text { Sr-90 } \\
\mathrm{pCi} / \mathrm{g}\end{array}$ \\
\hline B1T744 & 15.5 & $<12.2$ & $<48.6$ \\
B1T748 & 25.5 & $<11.8$ & $<49.2$ \\
B1T749 & 28 & $<11$ & $<47.6$ \\
B1T825 & 36.8 & $<11.7$ & $<47.5$ \\
B1T752 & 45.5 & $<12.5$ & $<49.2$ \\
B1T757 & 58 & $<11$ & $<48.4$ \\
B1T763 & 73 & $<11.4$ & $<49.2$ \\
B1T766 & 80.5 & $\mathrm{NA}$ & $<47.8$ \\
\hline B1T9L0 & 109.3 & $<11.4$ & $<48.8$ \\
B1T9L5 & 134.3 & $<11.5$ & $<49.1$ \\
\hline B1T781 & 143 & $\mathrm{NA}$ & $<49.4$ \\
B1T798 & 195.5 & $<11.4$ & $<49.3$ \\
B1T7B4 & 210.5 & $<12.9$ & $<55.6$ \\
B1T7C2 & 230.5 & $<11.2$ & $<49.3$ \\
\hline B1T7D1 & 263 & $<11.3$ & $<49.1$ \\
\hline B1T7F2 & 290.5 & $<11$ & $<48.2$ \\
B1T7H1 & 313 & $<11.7$ & $<52.2$ \\
\hline
\end{tabular}

Table 5.14. Groundwater Composition at Water Table at C5923 in July 2008

\begin{tabular}{|c|c|c|c|c|c|}
\hline \multirow{2}{*}{$7 / 15 / 2008$} & \multicolumn{2}{|r|}{ Water Table $350.6 \mathrm{ft}$ bgs } & \multicolumn{2}{|c|}{ Sampled at $359.9 \mathrm{ft}$ bgs } & \multirow[b]{2}{*}{ Value } \\
\hline & Units & Value & & Units & \\
\hline pH Measurement & & 8.12 & Iron & $\mu \mathrm{g} / \mathrm{L}$ & $<54.5$ \\
\hline Specific Conductance & $\mathrm{mS} / \mathrm{cm}$ & 1.196 & Lead & $\mu \mathrm{g} / \mathrm{L}$ & $<45$ \\
\hline Total organic carbon & $\mu \mathrm{g} / \mathrm{L}$ & -- & Magnesium & $\mathrm{mg} / \mathrm{L}$ & -- \\
\hline Alkalinity & $\mathrm{mg} / \mathrm{L}$ & -- & Manganese & $\mu \mathrm{g} / \mathrm{L}$ & $406 \pm 2$ \\
\hline Chloride & $\mathrm{mg} / \mathrm{L}$ & -- & Nickel & $\mu \mathrm{g} / \mathrm{L}$ & $<4$ \\
\hline Cyanide & $\mu \mathrm{g} / \mathrm{L}$ & -- & Potassium & $\mathrm{mg} / \mathrm{L}$ & -- \\
\hline Fluoride & $\mathrm{mg} / \mathrm{L}$ & $0.32 \pm 0.02$ & Sodium & $\mathrm{mg} / \mathrm{L}$ & -- \\
\hline Nitrate & $\mathrm{mg} / \mathrm{L}$ & $9.34 \pm 0.18$ & Thallium & $\mu g / L$ & $<37$ \\
\hline Nitrite & $\mathrm{mg} / \mathrm{L}$ & $0.21 \pm 0.02$ & Vanadium & $\mu \mathrm{g} / \mathrm{L}$ & $<12$ \\
\hline Sulfate & $\mathrm{mg} / \mathrm{L}$ & -- & Zinc & $\mu \mathrm{g} / \mathrm{L}$ & $<9$ \\
\hline Phosphate & $\mathrm{mg} / \mathrm{L}$ & -- & Technetium-99 & $\mathrm{pCi} / \mathrm{L}$ & $<5.9$ \\
\hline Aluminum & $\mu \mathrm{g} / \mathrm{L}$ & -- & Tritium & $\mathrm{pCi} / \mathrm{L}$ & $<270$ \\
\hline Antimony & $\mu \mathrm{g} / \mathrm{L}$ & $<56$ & Uranium & $\mu \mathrm{g} / \mathrm{L}$ & $2.18 \pm 0.07$ \\
\hline Arsenic & $\mu \mathrm{g} / \mathrm{L}$ & $<78$ & Sr-90 & $\mathrm{pCi} / \mathrm{L}$ & $<0.9$ \\
\hline Cadmium & $\mu \mathrm{g} / \mathrm{L}$ & $<4$ & Cs-137 & $\mathrm{pCi} / \mathrm{L}$ & -- \\
\hline Calcium & $\mathrm{mg} / \mathrm{L}$ & -- & I-129 & $\mathrm{pCi} / \mathrm{L}$ & $<0.828$ \\
\hline Chromium & $\mu \mathrm{g} / \mathrm{L}$ & $<13$ & Se-79 & $\mathrm{pCi} / \mathrm{L}$ & $<2$ \\
\hline
\end{tabular}


analysis of the vadose zone pore waters from the deepest portion of the core, which show no detectable water-extractable nitrate. However, detectable water-extractable nitrate and technetium-99 in the vadose zone sediments at borehole C5923 are present as deep as 290 and $260 \mathrm{ft}$ bgs, respectively, which is a much deeper penetration of water-extractable mobile and major contaminants than was found at borehole C4191 directly through the foot print of the 216-B-26 trench (too be discussed in Section 8). There is no detectable technetium-99 or other mobile radionuclides in the groundwater obtained in July 2008 from borehole C5923 (A). Neither the slightly-elevated nitrate nor the non-detectable technetium99 suggest that groundwater currently below the BC Cribs and Trenches area contains concentrations above drinking water standards for these two risk drivers. A review of past groundwater monitoring reports starting from July 1956 through June 1966 (see Appendix C for details) show only intermittent detection of gross beta (mainly ruthenium-106) and nitrate in monitoring wells surrounding the BC Cribs and Trenches. The active disposal period into the cribs and trenches was 1956 through 1957.

\subsection{Field Electrical-Resistivity Results at Borehole C5923 (A)}

Based on the descriptions provided in Section 4.1, the pole-pole resistivity data at BC Cribs and Trenches has been shown to be of sufficient quality to develop empirical models that relate the geochemistry and field soil-resistivity data. The instrument and environment noise was observed to be low such that a majority of the field measurements could be retained for HRR, 2D inversion, and 3D inversion processing. Additionally, variability in target strength was observed in all processing methods, allowing more complex analyses to be performed.

Empirical model development was conducted with several key geochemical parameters to test which parameter has the highest correlation to the soil resistivity as measured in the field. Several parameters suggest direct causation, such as ionic strength or pore-water EC. Other models, including correlation of soil resistivity with pore-water technetium-99 concentration, were developed to explore indirect causation. Clearly, the pore-water concentration of technetium-99 is too low to produce a target if it were the sole analyte. However, it is known that technetium-99 and nitrate have very similar transport mechanisms. The empirical model may be used to understand the distribution of technetium-99 at the BC Cribs and Trenches site if the correlations for technetium-99 and resistivity are similar among the different boreholes and the disposal ratio of nitrate to technetium-99 was constant among the individual waste sites.

Issues regarding how best to scale the borehole and surface-based data for developing empirical relationships are the subject of an intense academic debate. Later sections explore and propose methodologies to handle correlating the volume-averaging information (surface-based resistivity) against the discrete sample data (borehole). One particular issue is that the borehole information is collected at a much finer interval than the surface-based data, and thus the true subsurface complexity is not fully detailed by surface-based surveys.

\subsubsection{HRR at Borehole C5923 (A)}

Figure 5.6 shows the HRR apparent-resistivity results for FY05-Line 4. For reference, features such as trench and crib locations are shown on the figure. The figure shows two low-resistivity features close to the surface that correlate to the location of the cribs in the northeast portion of the site and trenches in the north central portion. A large and deep low-resistivity anomaly is located between the cribs and trenches, which is a false anomaly due to the superposition of the two plumes, and a deep low-resistivity 
layer (another conductive plume or water table). East of the cribs, the resistivity goes to background conditions over a very short distance.

To facilitate empirical model development, each of the new boreholes was placed along a resistivity line. Borehole C5923 (A) was placed $153 \mathrm{~m}$ from the eastern edge of FY05-Line 4. At Borehole C5923 (A), the resistivity data show a clear low-resistivity target at approximately 20 to 40 meters bgs. Above and below the target, resistivity increases, isolating the target. Variability can be seen in the target zone, as identified by the solid contour lines. The data also appear to be free from cultural interferences such as pipes and tanks known to exist in the area.

Equation 4-7 (Chapter 4) was used as the plotting algorithm to obtain the depth estimates of the apparent resistivity values shown in Figure 5.6, with coefficients of $u=(3.97,22.4,3.97)$. These coefficients were based on the least-squares fitting of target depth using co-located resistivity data from FY04-Line 1 and borehole C4191 (see Rucker and Fink 2007). Figure 5.7 shows the extracted resistivity profiles for the HRR, 2D-inverted, and 3D-inverted data collected at Borehole C5923 (A). The markers plotted along the vertical profiles represent the edge of the model cells and thus give an indication of the volume over which the electrical resistivity is either measured (HRR) or calculated (2D and 3D). Depending on how the numerical models were formulated, the cell size either grows with depth (as in the 3D inverted data), decreases with depth (as in HRR), or stays the same over the entire depth interval (as in the 2D inverted). Regardless of the analysis method used, the volumetric measurement that represents electrical resistivity still must be considered as a point estimate in order to compare directly with the borehole geochemistry data.

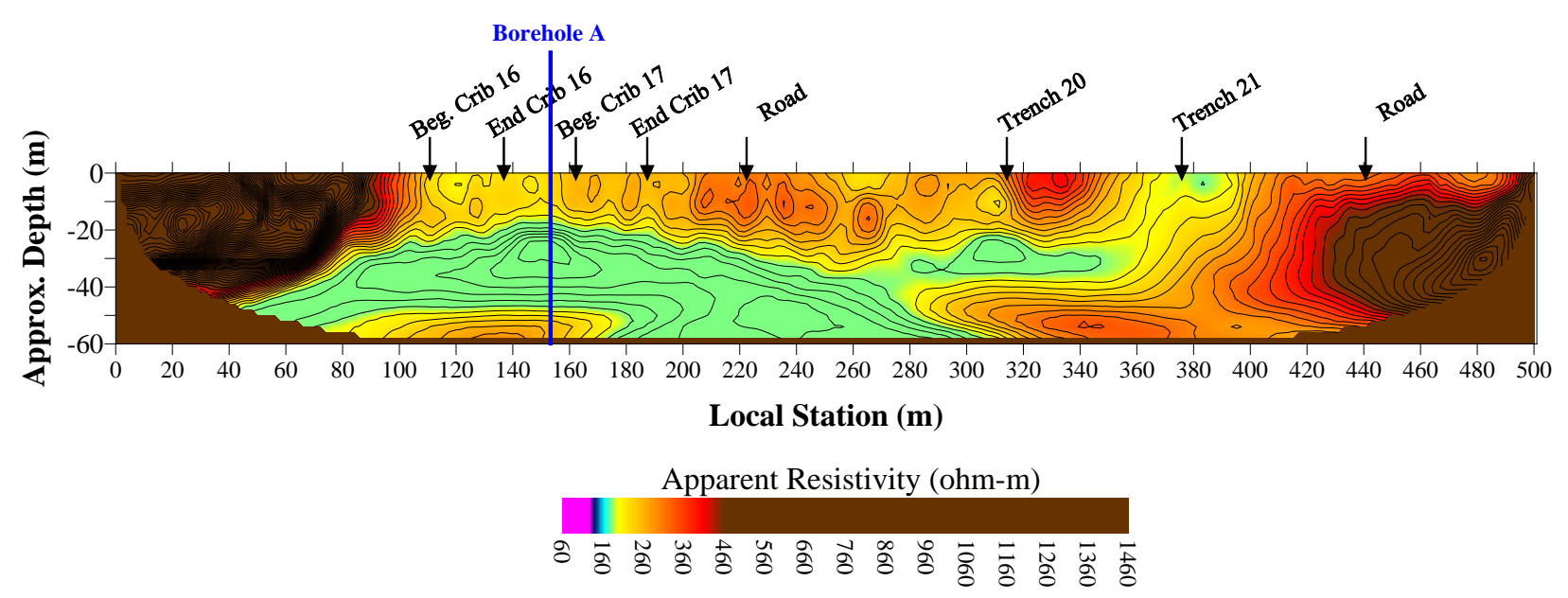

Figure 5.6. HRR Results of FY05-Line 4 
PNNL-17821

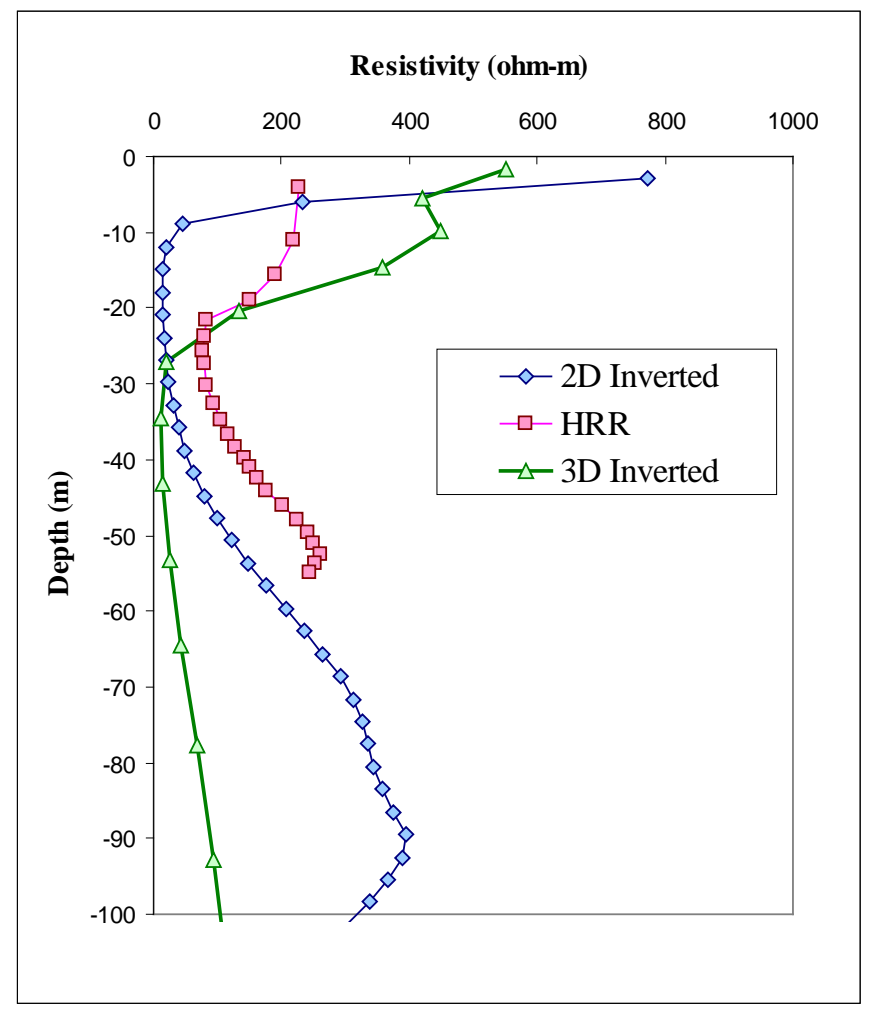

Figure 5.7. Vertical Profiles of HRR, 2D Inverted, and 3D Inverted Resistivity Data at the Location of Borehole C5923 (A)

The individual geochemical species in Borehole C5923 (A) were sampled at a much higher spatial frequency and at different depths than the field-acquired apparent-resistivity data. To calculate correlations and develop the empirical models, the measured (field) geophysical data were re-sampled at the soil sampling depths with linear interpolation. The other option included re-sampling geochemistry data to match the depths of the geophysical data. This second option was deemed inappropriate due to the high spatial variability of the geochemical data compared to the geophysical data. Additionally, the geophysical data were not extrapolated to depths beyond that calculated by HRR, and comparisons were only performed to depths of approximately $54 \mathrm{~m}(177 \mathrm{ft}) \mathrm{bgs}$.

Figure 5.8 shows the results of comparing the pore-water EC and HRR at Borehole C5923 (A). The plot on the left displays the profile of HRR and EC; the plot on the right shows the scatter of co-located EC and HRR data. Qualitatively, the data show a good inverse correlation. As the pore-water EC increases, the apparent soil resistivity decreases. Quantitatively, the scatter plot shows the linear regression model used to relate the HRR and EC, with an $\mathrm{R}^{2}=0.588$. Five data values, circled in both plots, demonstrate the limitations of surface-based geophysics. That is, small-scaled variability is averaged out by the field resistivity due to the volume-averaging electrical measurements. Additionally, Day-Lewis and Singha (2008) explained that conventional geochemical measurements preferentially sample from the mobile domain (pore space where fluid moves freely), and soil electrical resistivity is sensitive to the electrolytic solute in both the mobile and immobile domains. These differences in measurement domains would cause some of the variances observed in the scatter plot. 
It should be noted that slightly different coefficients for the HRR plotting could be used to gain better correlation with the geochemical data. The profile data of Figure 5.8 shows that the peak target values in the HRR data are lower in elevation than those of the geochemistry. Changing the last plotting coefficient from 3.97 to 0 increases the correlation to 0.673. However, the coefficients from Rucker and Fink (2007) are used here for consistency.
A) Profile
B) Scatter
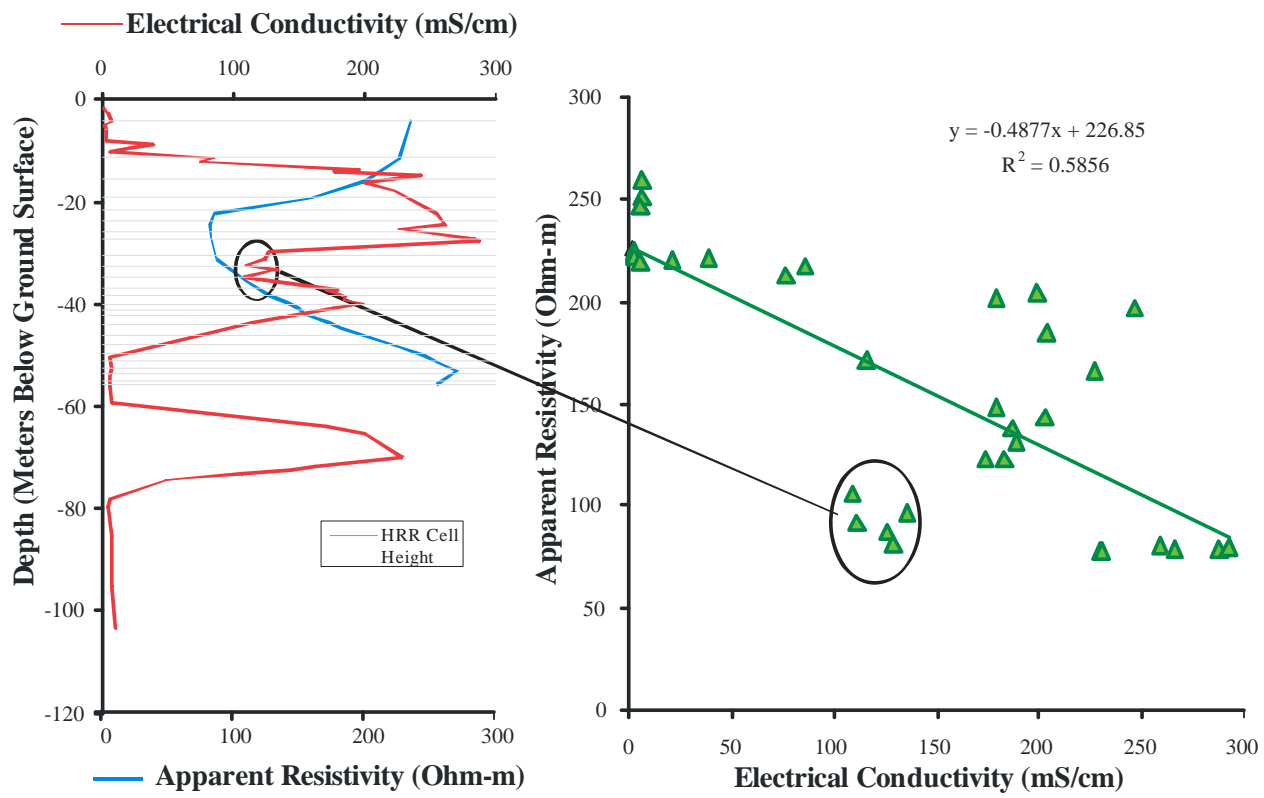

Figure 5.8. Profile and Scatter Plots for HRR and Pore-Water EC at Borehole C5923 (A)

The deepest HRR measurements show a slight decreasing trend in resistivity. The decrease could be the result of the high EC layer at $70 \mathrm{~m}$ depth. Unfortunately, the field resistivity data were not acquired deep enough to image this conductive layer. The plotting routine for HRR optimized the depth-plotting coefficients based on a target within the top $45 \mathrm{~m}$. As will be shown later, the shallow depth limitation of the HRR plotting routine does not affect the capability of the 2D or 3D inversion models to image down to the water table.

The scaling issues of large volume (and volume averaging) measurements for HRR and small-volume measurements of pore-water EC prevent the creation of more complex petrophysical models that relate the two measurements. As an example of the scaling, cell boundaries for the HRR algorithm are shown as gray lines through the profile plot (see left hand graphic in Figure 5.8); the cells are much larger than the sampling domain for the geochemistry. Many geochemical samples could comprise one HRR reading. Based on this mismatch in scales between the two types of measurements, the HRR and geochemistry are related through simple linear regression. Other more complex petrophysical models include the Archie's Equation (Archie 1942) for clean sands and Waxman-Smits (Waxman and Smits 1968) for more complex shaley sands.

Figure 5.9 through Figure 5.11 show the vertical profile and scatter plots for the C5923 vadose zone pore-water ionic strength and nitrate and technetium-99 concentrations, respectively. The ionic strength is the most appropriate variable to use for comparison since it accounts for all ionic species. However, 
the nitrate concentration appears to have the best correlation with the HRR data, with a $\mathrm{R}^{2}$ value of 0.639. The technetium-99 concentration has the worst correlation with HRR data with a $\mathrm{R}^{2}$ value of 0.54 .
A) Profile
B) Scatter
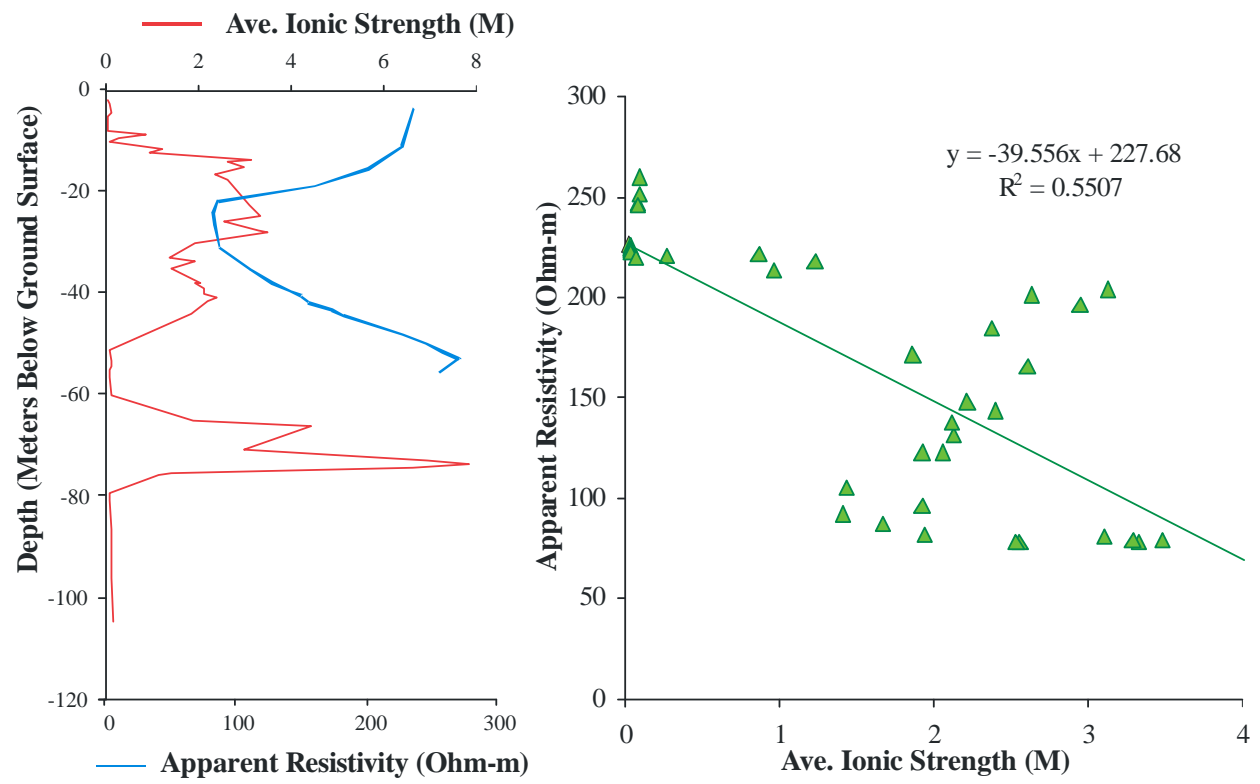

Figure 5.9. Profile and Scatter Plots for HRR and Ionic Strength at Borehole C5923 (A)
A) Profile
B) Scatter
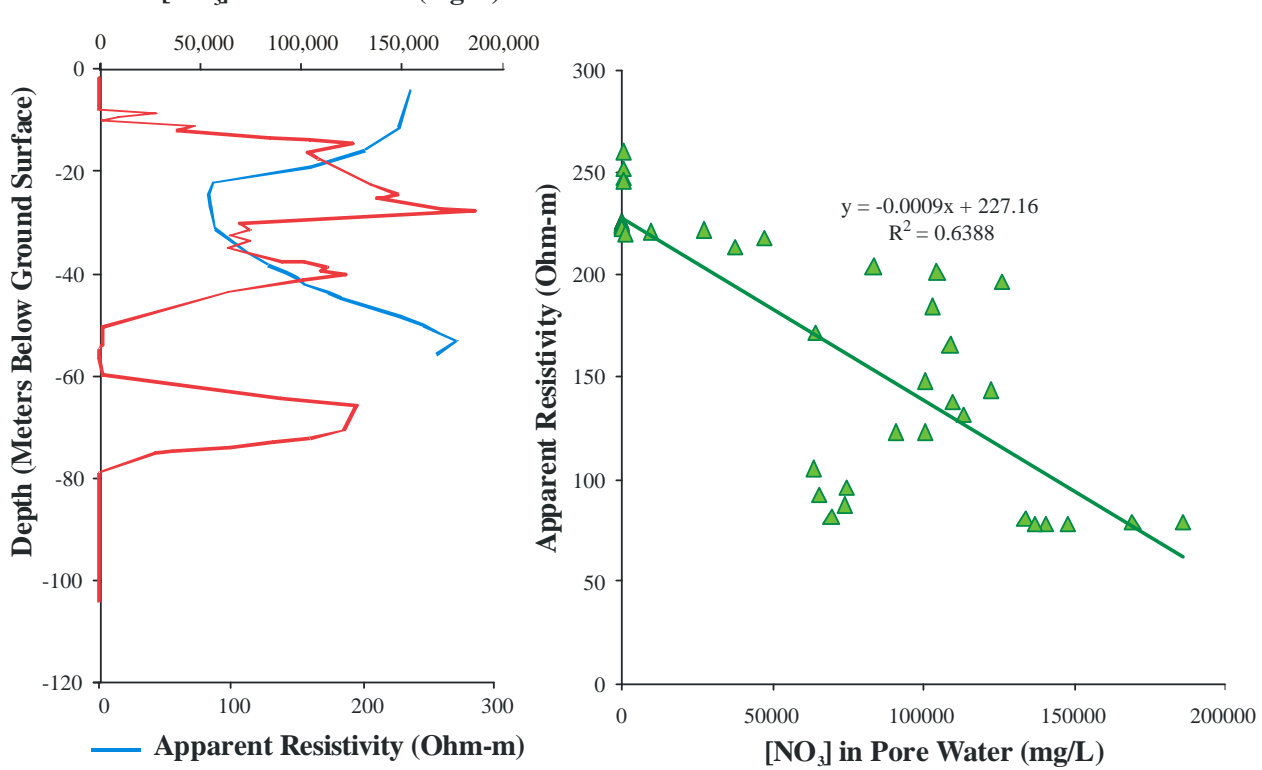

Figure 5.10. Profile and Scatter Plots for HRR and Nitrate Concentration at Borehole C5923 (A) 


\section{A) Profile}

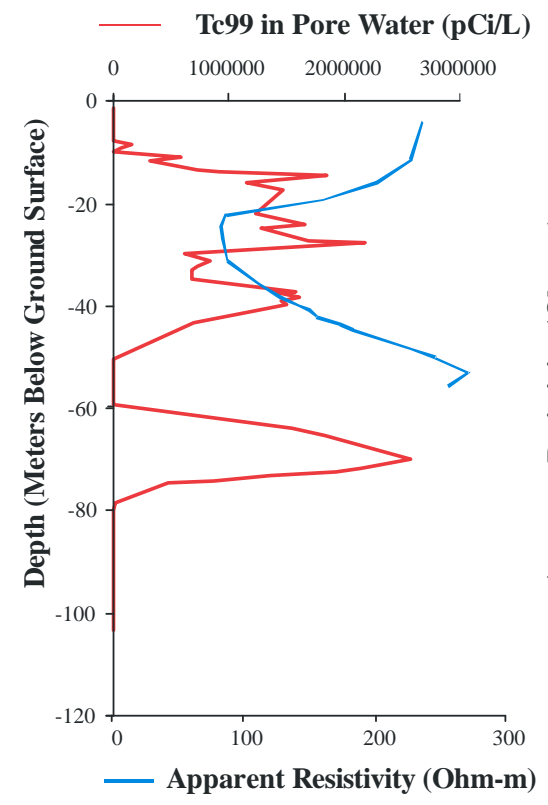

B) Scatter

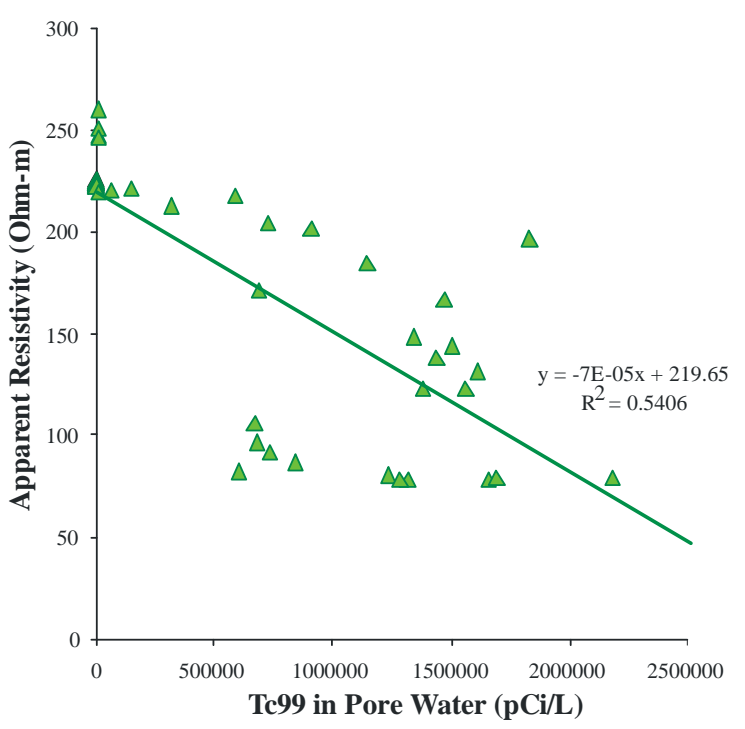

Figure 5.11. Profile and Scatter Plots for HRR and Technetium-99 Concentration at Borehole C5923 (A)

\subsubsection{D Inversion at Borehole C5923 (A)}

Figure 5.12 shows the inversion results for FY05-Line 4. For reference, features such as trench and crib locations are shown on the figure. The inversion was completed in three iterations using the smooth model inversion with a final root mean square error of 5.88\%. At Borehole C5923 (A), the resistivity model shows a clear low-resistivity target at approximately 8 to 50 meters bgs (Figure 5.7). Above and below the target, resistivity increases, isolating the target. Variability can be seen in the target zone, as identified by the solid contour lines. Other low-resistivity features in the plot include the plume beneath Trench 216-B-20 and the deep anomaly between the trenches and cribs.

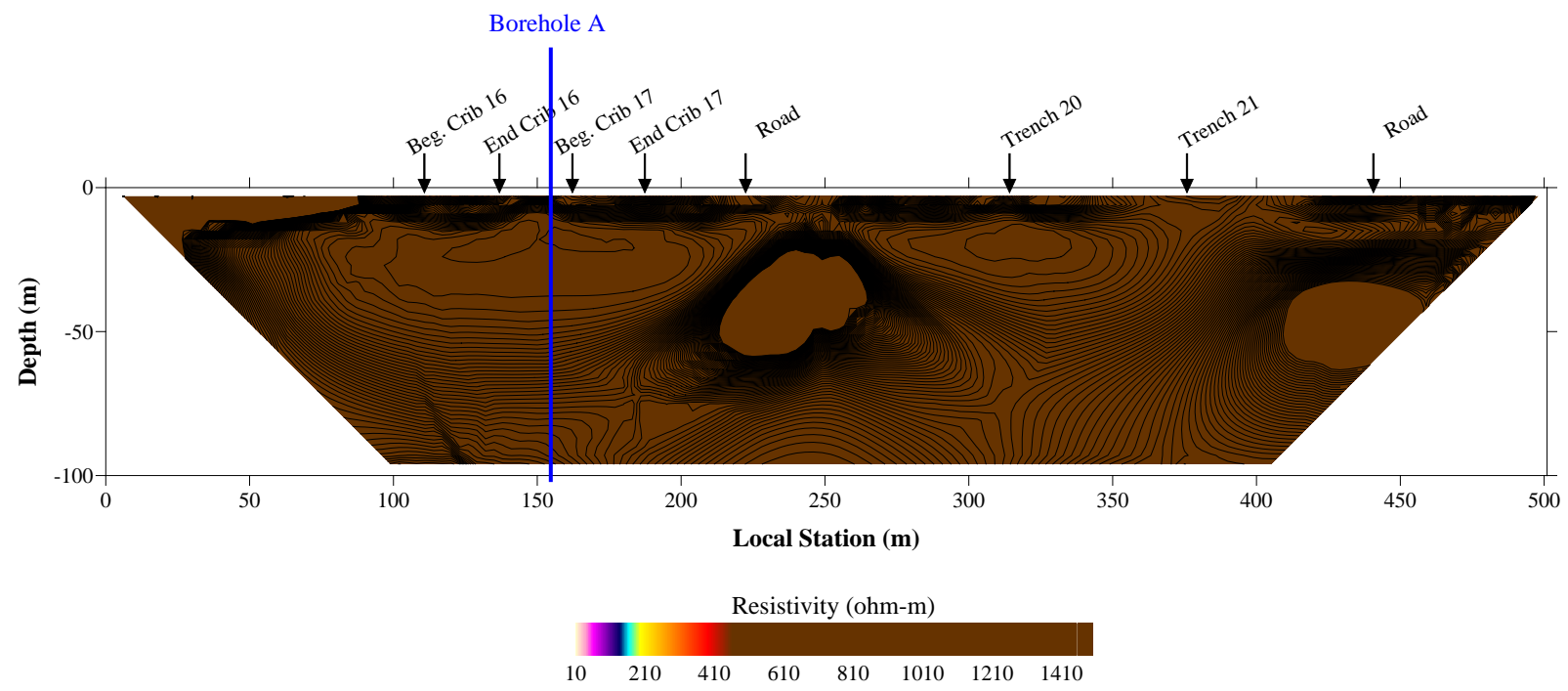

Figure 5.12. 2D Inversion Results of FY05-Line 4 
The pore-water EC from Borehole C5923 (A) and 2D inverted-resistivity data were evaluated at colocated positions. The profile in Figure 5.13 shows that the resistivity begins to decrease at higher elevation than the geochemistry data, likely causing the poor match seen in the scatter plot on the right. The scatter plot was developed using two strategies. The first strategy used all the data to formulate a linear regression model and correlation coefficient (red regression line). The second, per Rucker and Fink (2007), used only those resistivity data that were sensitive to changing EC values (green regression line), which is the upper $50 \mathrm{~m}$. Oldenburg and Li (1999) discussed the problem of sensitivity with depth using surface-based electrical resistivity. That is, the sensitivity of electrical resistivity in model cells deep in the section is much lower than the sensitivity of resistivity in cells closer to the surface. Therefore, preferentially picking the region that is most sensitive for correlation analysis shows how the electricalresistivity data could be used for estimating geochemical parameters in the very near surface.

Conversely, it demonstrates the low reliability of very deep resistivity measurements acquired below a low-resistivity anomaly. The focus of the upper $50 \mathrm{~m}$ for the sensitive region also allows a comparison with the HRR regression values.

A) Profile

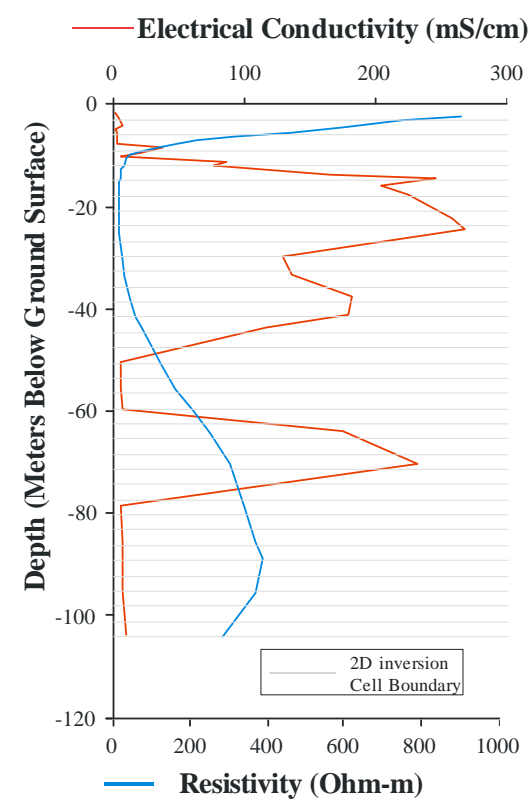

B) Scatter

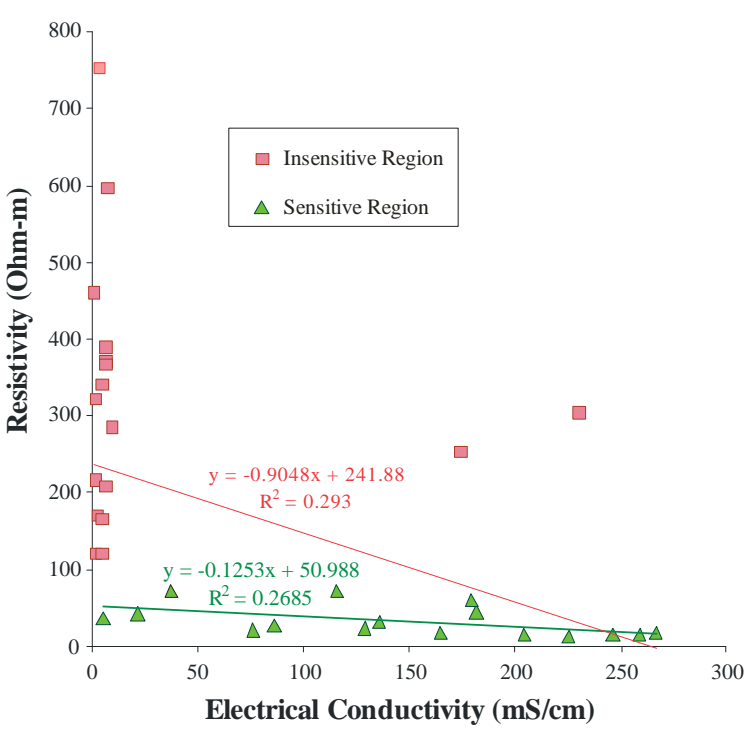

Figure 5.13. Profile and Scatter Plots for 2D Inversion and Pore-Water EC at Borehole C5923 (A)

In general, the regression of Figure 5.14 shows a poor fit due to 1) the high scatter and the insensitivity of the soil resistivity to the small-scale variability in pore-water EC and 2) the elevation mismatch of the targets. The issue of small-scale variability could be minimized by acquiring a lower number of samples in the borehole or averaging the borehole data over the cell volume of the electricalresistivity model cell. As an example of model cell size, the profile within Figure 5.14 shows the cell boundaries used in the inversion model. When the EC is averaged over the $2 \mathrm{D}$ inversion model cell domain, which reduces the data count from 58 to 28, the correlation coefficient increases from 0.269 to 0.340 for the most sensitive region (upper $50 \mathrm{~m}$ ). 
The issue of elevation accuracy for target identification in resistivity inversion results has been identified by several authors. Zhou et al. (2000) showed that estimated depths to the top of sink holes from inversion results ranged in error between 0 and $10 \mathrm{~m}$, with an average depth error of $2.4 \mathrm{~m}$. The differences in target elevation interpreted from boreholes and surface soil electrical resistivity may be due to out-of-plane effects (Bentley and Gharibi 2004) or to constraints imposed during the inversion to obtain a "unique" solution. For the BC Cribs and Trenches problem, a portion of the low-resistivity zone may be at a higher elevation adjacent to FY05-Line 4, causing the out-of-plane effects and an apparent upward shift in the modeled position of the low-resistivity zone on FY05-Line 4. Constraints used in the inversion program to obtain unique solutions (such as smoothness) could also cause a mismatch in target location. As shown in Figure 5.15, a 3.4-m downward shift of the model results improves the correlation with Borehole C5923 (A) geochemistry data and accounts for possible out-of-plane effects. The correlation coefficient increases for the most sensitive measurements from 0.214 to 0.514 due to the $3.4 \mathrm{~m}$ downward shift.

Another large elevation mismatch occurs with the high EC layer at $70 \mathrm{~m}$. The HRR plot (see, for example, Figure 5.6) shows the decreasing resistivity trend to begin at about $50 \mathrm{~m}$ and the inversion model places it at approximately $90 \mathrm{~m}$. This elevation mismatch is causing the large scatter in the regression analysis, decreasing the goodness of fit for all data (in red).
A) Profile
B) Scatter
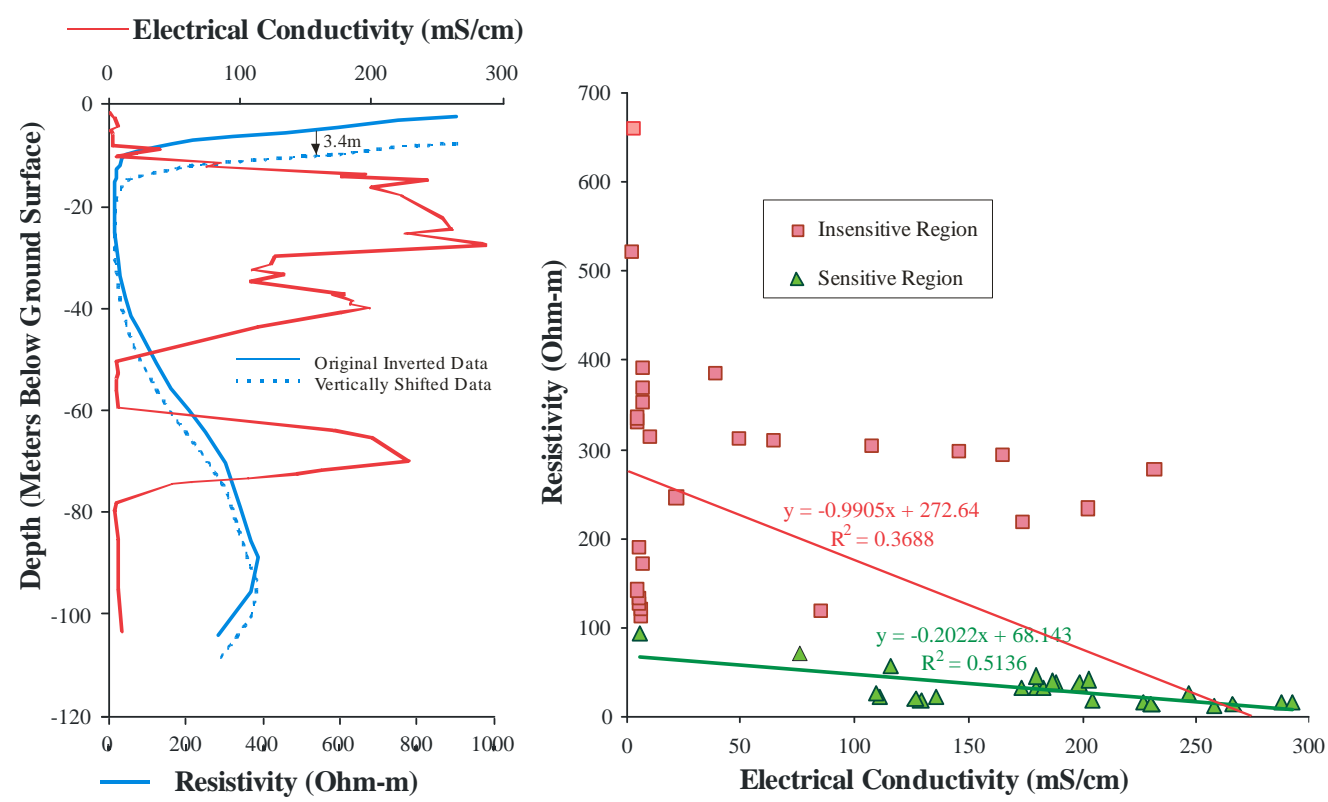

Figure 5.14. Profile and Scatter Plots for 2D Inversion and Pore-Water EC at Borehole C5923 (A), with Inversion Elevations Shifted by $3.4 \mathrm{~m}$

Figure 5.16 shows the linear regression correlations between the 2D model data and borehole data of ionic strength, nitrate concentration, and technetium-99 concentration. The scatter plot was created with data after a shift in elevation of $3.4 \mathrm{~m}$ (deeper). Again, the technetium-99 shows the worst correlation, and the EC regression of Figure 5.15 demonstrates the best correlation with 2D inverted resistivity. 


\subsubsection{D Inversion at Borehole C5923 (A)}

The 3D inversion results for model domain 3 (see Figure 4.13 for model domains) are shown in Figure 5.17. The figure is focused on the vicinity near Borehole C5923 (A) by showing vertical slices of contoured soil resistivity values. The figure shows a low-resistivity anomaly beneath all of the cribs, with the profile of extracted data shown in Figure 5.7. Compared to the HRR and 2D inversion, the 3D inversion shows the elevation of the target to be the deepest.

The regression and profile data for EC in Borehole C5923 (A) and 3D inversion results are shown in Figure 5.18. The profile data show that the target in the original inversion results at Borehole C5923 (A) does not match well to the geochemistry target. The inversion results indicate that the target is deeper than the geochemistry. To account for the apparent offset, the 3D inverted-resistivity data were shifted by $5 \mathrm{~m}$ upwards to match target depths with geochemistry.

The scatter and regression in Figure 5.18B shows a poor goodness of fit when considering all data. The data, however, appear to be of two populations that include a shallow and deep set. Separate regression analyses were run on these individual populations, and the shallow data alone appear to have a much better correlation. The shallow data are those with a depth of 0 to $50 \mathrm{~m}$ bgs. When the resistivity data are shifted by $5 \mathrm{~m}$ upwards, the correlation is even better, as demonstrated in Figure 5.18C. Considering that the 3D inversion accounts for out-of-plane effects, the apparent shift in resistivity data relative to borehole geochemistry can only be explained by the numeric implementation of the mathematics and the use of smoothing and dampening constraints. 
PNNL-17821

A) Ionic Strength Profile

B) Ionic Strength Scatter
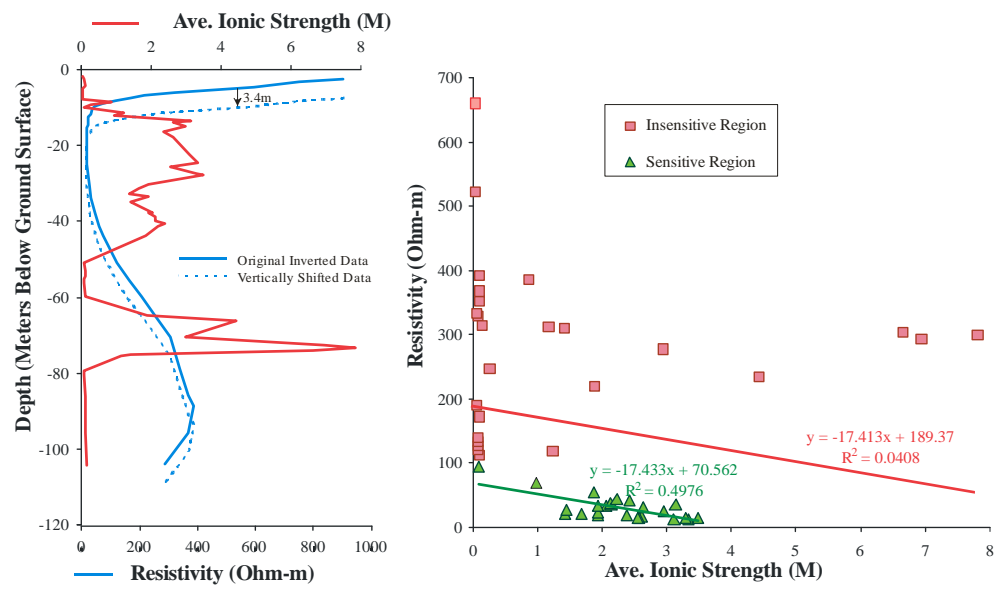

C) Nitrate Profile

D) Nitrate Scatter
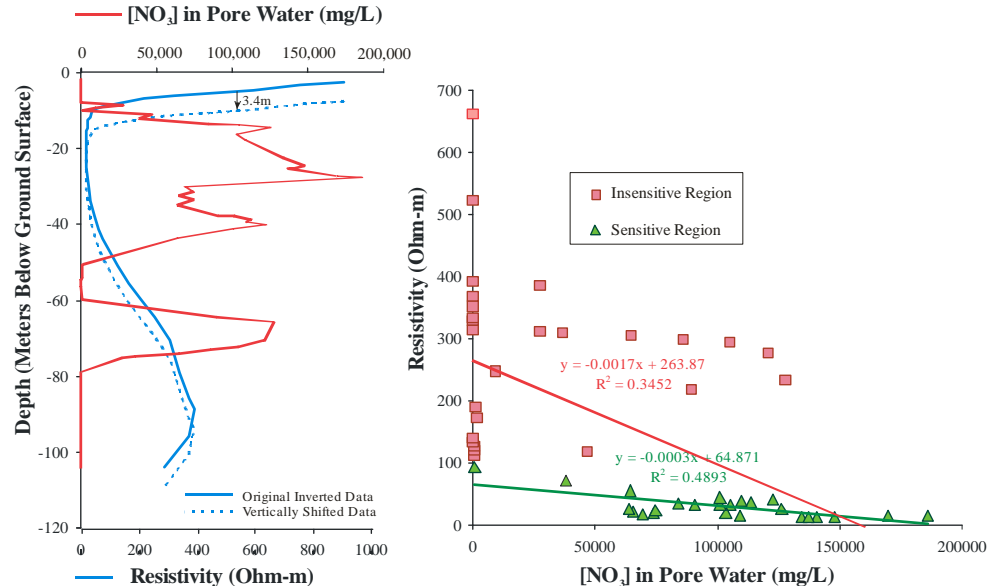

E) $\mathrm{Tc}^{99}$ Profile

F) $\mathrm{Tc}^{99}$ Scatter
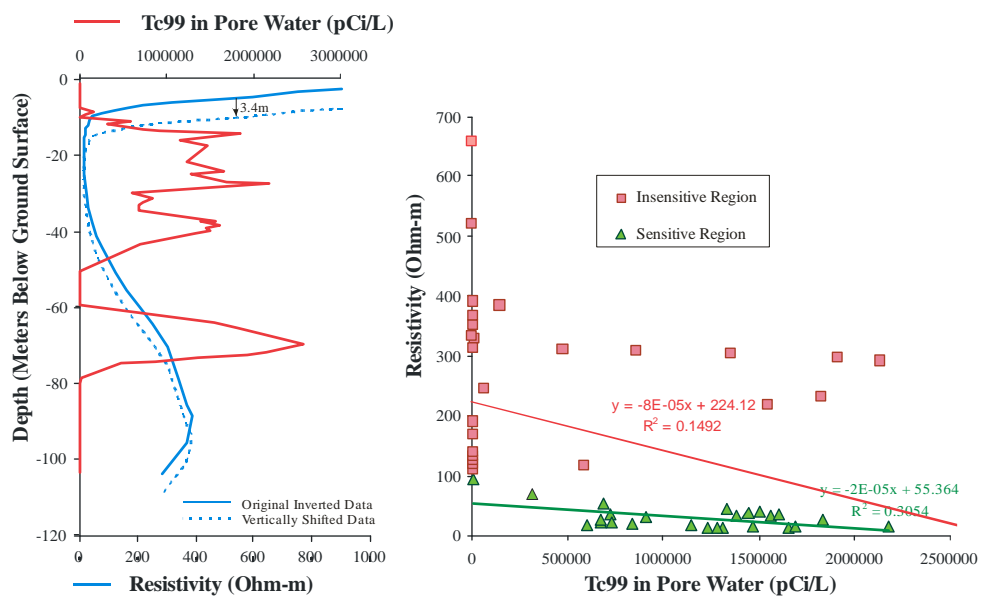

Figure 5.15. Profile and Scatter Plots of Geochemistry Data and 2D Inversion Results for Borehole C5923 (A), Including Ionic Strength, Nitrate Concentration, and Technetium-99 Concentration 


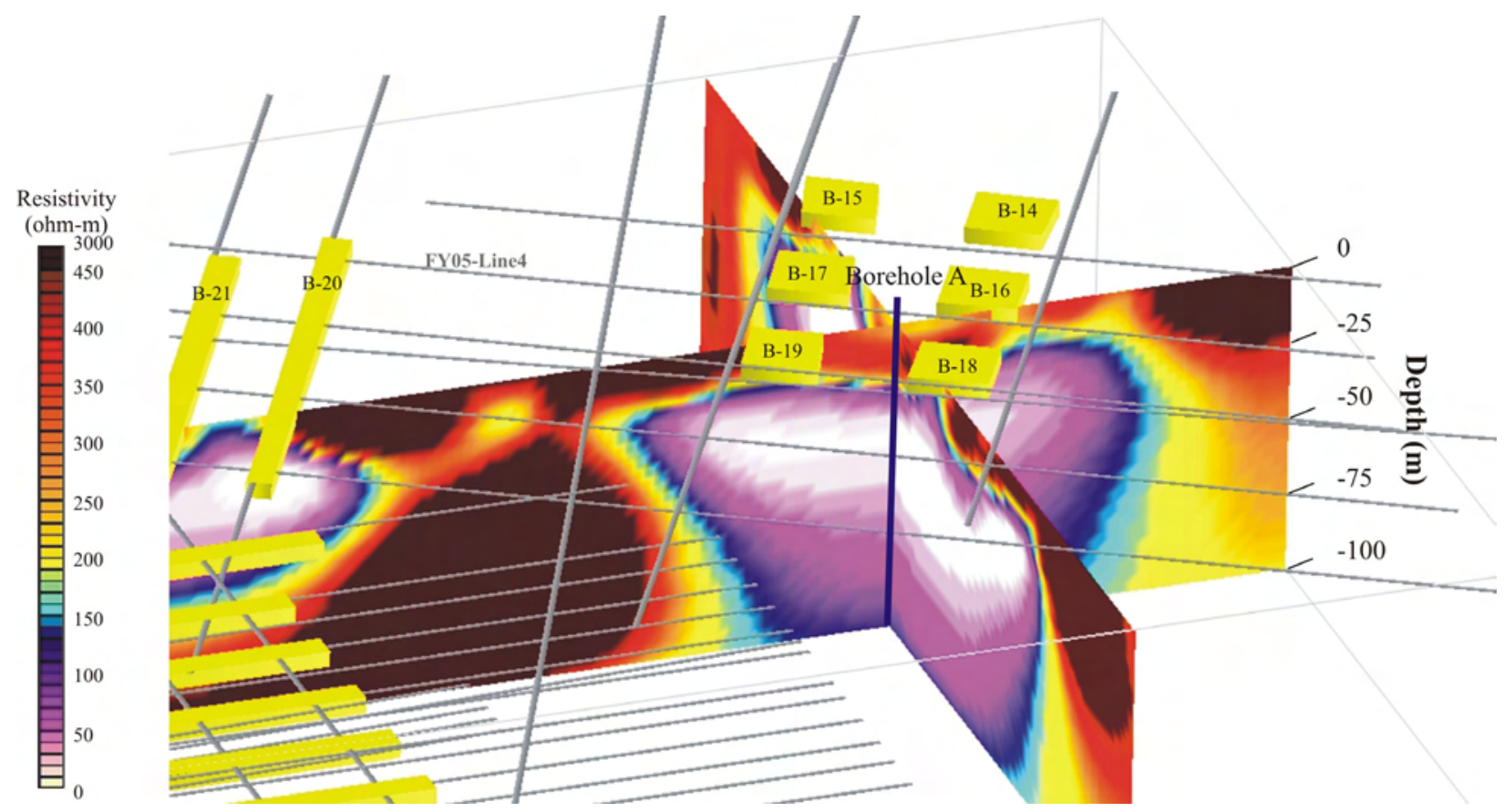

Figure 5.16. 3D Inversion Results of Model Domain 3 of the BC Cribs Site

Figure 5.18 shows the profile and scatter with regression for borehole C5923 vadose zone pore-water ionic strength, nitrate, and technetium-99 concentrations. The scatter plots were created with data after a shift of $5 \mathrm{~m}$ (upward) in elevation. Unexpectedly, the ionic strength shows the worst correlation, whereas the nitrate concentration shows the best correlation with 3D inverted resistivity. 
A) Profile

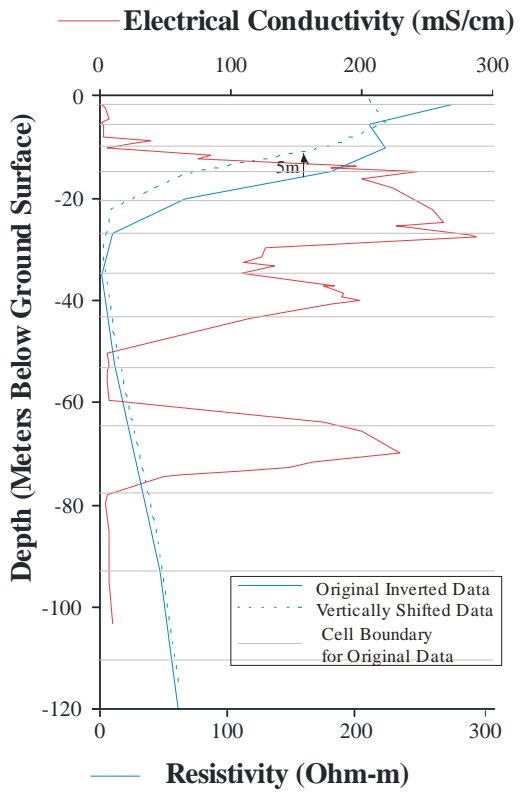

B) Scatter

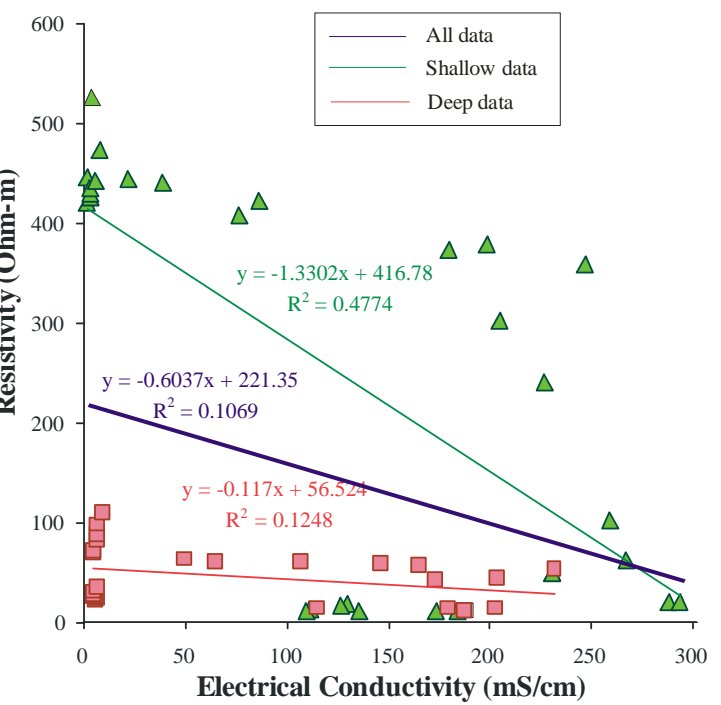

C) Scatter of Shifted Data

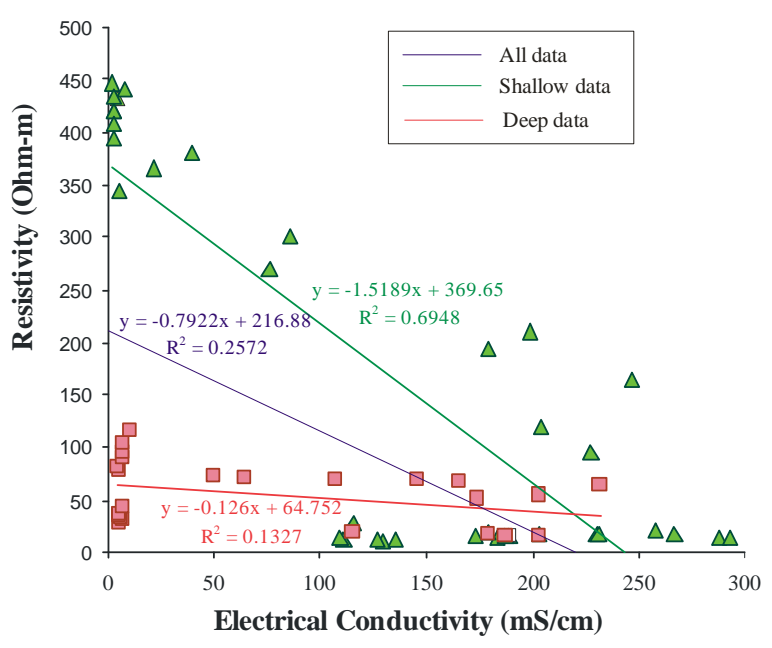

Figure 5.17. Profile and Scatter Plots for 3D Inversion and Pore-Water EC at Borehole C5923 (A)

A) Profile data with and without 5-m shift in resistivity elevation, B) scatter and regression of deep, shallow, and all data with no shift in resistivity, C) scatter and regression of deep, shallow, and all data with 5-m elevation shift in resistivity. 
PNNL-17821

A) Ionic Strength Profile

B) Ionic Strength Scatter

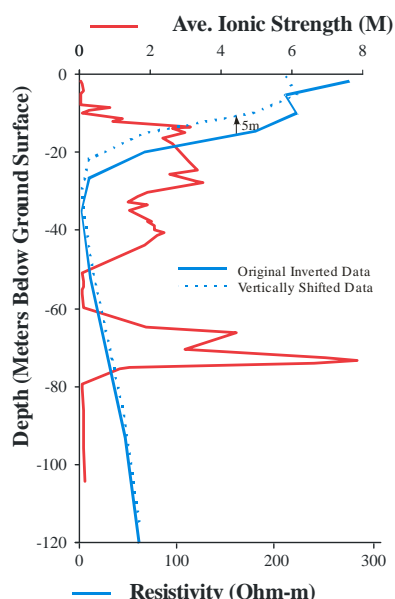

C) Nitrate Profile

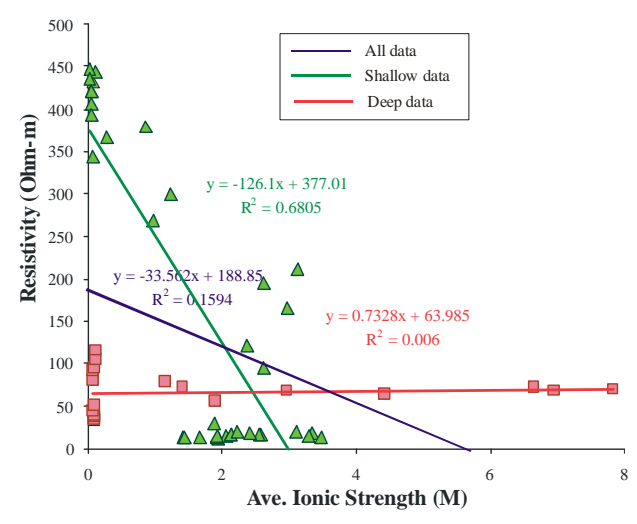

D) Nitrate Scatter

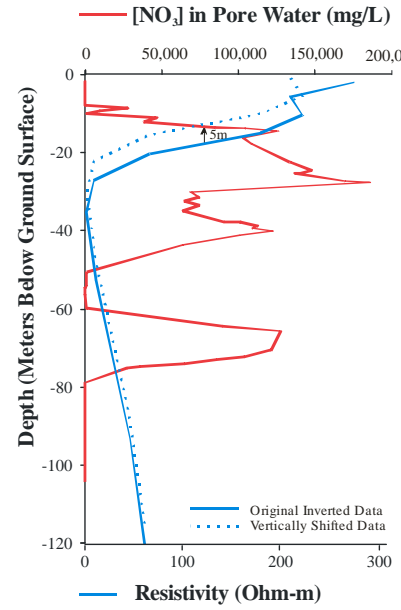

E) $\mathrm{TC}^{99}$ Profile

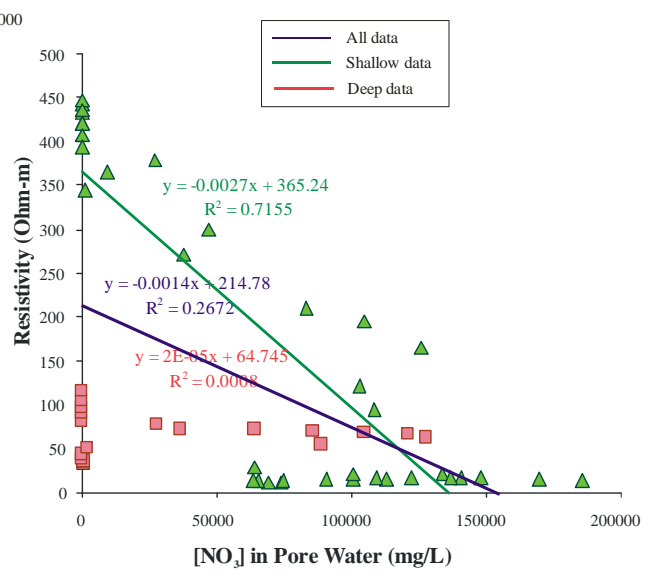

F) $\mathrm{TC}^{99}$ Scatter
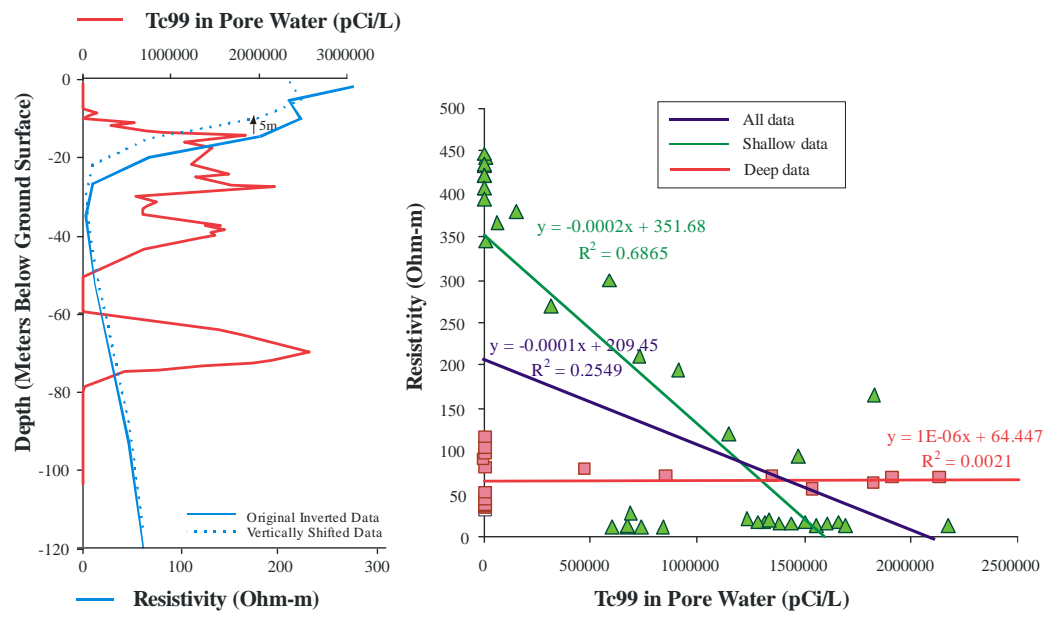

Figure 5.18. Profile and Scatter Plots of Geochemistry Data and 3D Inversion Results for Borehole C5923 (A), Including Ionic Strength, Nitrate Concentration, and Technetium-99 Concentration 


\subsection{Laboratory Geophysical Results at Borehole A (C5923)}

\subsubsection{Laboratory Measured Geo-Hydrological Parameters}

\subsubsection{Particle Size Distribution of Sediments in Borehole C5923 (A)}

Particle-size data for 20 selected grab samples were converted into size-fraction percent by weight, and the percent by weight passing each sieve was plotted as a curve on a semi-logarithmic scale to describe the C5923 vadose zone sediment size distribution for selected depths. The resulting data represent the percentage of particles retained and passing through each sieve. Laser particle-size analyses were used to characterize the $<\# 230$ fraction and to quantify silt and clay content. The percentage of each size fraction was used to determine texture according to the USDA classification and the Unified Soil Classification System (USCS) specified by ASTM D 2487 (ASTM 2000). The particle-size moments of the distributions, a range of cumulative percentile values (the grain size at which a specified percentage of the grains are coarser, e.g., $d_{16}, d_{50}, d_{85}$ ) and the related coefficients, e.g., coefficient of uniformity, $\mathrm{C}_{\mathrm{u}}$, and coefficient of curvature, $\mathrm{C}_{\mathrm{c}}$, c, were calculated from the grain-size distributions using the methods described by Folk (1980). In order to compare different sediments, grain-size distributions are often described by their deviation from a prescribed ideal distribution. Geometric scaling is usually employed to place equal emphasis on small differences in fine particles and larger differences in coarse particles. The logarithmic Udden-Wentworth grade scale (Udden 1914; Wentworth 1922) in which the boundaries between successive size classes differ by a factor of two is most often used.

Figure 5.19 is a plot of the size-distribution curves for 20 grab samples that were analyzed. Particlesize analysis of Borehole C5923 (A) samples yielded USDA textures ranging from sand to silt loam (Table 5.15). The clay content ranged from less than $1 \%$ to $12 \%$. The silt content ranged from $2 \%$ to $11 \%$, whereas the sand content ranged from $38 \%$ to $94 \%$. The coarse fraction ranged from 0 to $50 \%$ whereas the percentage of fines (<\#230 sieve) ranged from 3.4 to $17 \%$. A dry sieving approach, rather than wet sieving, was adopted to minimize waste generation. However, dry sieving is known to cause an over estimation of the coarse fraction, especially in sediments with high-fines content, as the fines can aggregate into sand and fine pebble-sized particles. Nevertheless, using LDS to characterize the $<\# 230$ $(<63 \mu \mathrm{m})$ fraction produced data of very high quality that showed good continuity with dry-sieve measurements. The $<63 \mu \mathrm{m}$ content ranged from 3.45 to 20.56 percent with a mean of 10.34 percent.

The particle-size data were used to calculate parameters that will be used for establishing correlations with physicochemical and hydrophysical properties. Figure 5.20 shows a plot of effective particle diameter, $d_{e}$, as a function of textural components, including mud (silt plus clay) mass fraction. The effective diameter is derived from the $\mathrm{d}_{10}$ value. The relationship to mud content is important as dry sieving typically does not separate silt and clay portions, but quantifies only their sum. As can be expected, the effective diameter decreases with increasing clay content. The same is true for silt, although the relationship is not as strong. The effective diameter increases exponentially with sand content. The relationship to mud content is also quite strong, especially if the two high-silt outliers are removed.

PSDs, particularly of sands and silts, have considerable practical value. Both theory and experiments have shown that permeability (air and water), surface area, and surface electrical conductance are strongly related to the effective particle diameter. These data are needed to develop constitutive properties for fate 
PNNL-17821

and transport models, which are needed to design appropriate remedies and for translating resistivity measurements into data that can be used to initialize such models. 
Table 5.15. Textural Composition and Particle-Size Statistics for Borehole C5923 (A) Samples

\begin{tabular}{|c|c|c|c|c|c|c|c|c|c|c|c|c|c|c|c|c|c|c|c|c|c|c|c|c|}
\hline \multirow[b]{2}{*}{ HEIS } & \multirow{2}{*}{$\begin{array}{c}\text { Depth } \\
\text { (ft) }\end{array}$} & \multirow[b]{2}{*}{ USCS Texture } & \multicolumn{5}{|c|}{ USDA Classification } & \multicolumn{3}{|c|}{ USCS Classification } & \multirow[b]{2}{*}{$\mathrm{D}_{5}$} & \multirow[b]{2}{*}{$D_{10}$} & \multirow[b]{2}{*}{$\mathrm{D}_{16}$} & \multirow[b]{2}{*}{$\mathrm{D}_{30}$} & \multirow[b]{2}{*}{$D_{50}$} & \multirow[b]{2}{*}{$D_{60}$} & \multirow[b]{2}{*}{$\mathrm{D}_{75}$} & \multirow[b]{2}{*}{$\mathrm{D}_{84}$} & \multirow[b]{2}{*}{$\mathrm{D}_{95}$} & \multirow{2}{*}{$\begin{array}{l}\text { Effective } \\
\text { Grain } \\
\text { Diameter } \\
\text { (mm) }\end{array}$} & \multirow{2}{*}{$\begin{array}{l}\text { Geometric } \\
\text { Mean Diameter } \\
(\mathrm{mm})\end{array}$} & \multirow[b]{2}{*}{$\begin{array}{l}\text { Sorting } \\
\text { Index }\end{array}$} & \multirow[b]{2}{*}{$\mathrm{C}_{\mathrm{c}}$} & \multirow[b]{2}{*}{$\mathrm{C}_{\mathrm{u}}$} \\
\hline & & & \% Clay & $\%$ Silt & $\%$ Sand & \% Gravel & $\%$ Clay & $\%$ Silt & $\%$ Sand & \% Gravel & & & & & & & & & & & & & & \\
\hline BIT741 & 8.0 & Silty sand & 2.05 & 7.81 & 78.59 & 11.54 & 2.88 & 10.37 & 82.78 & 3.96 & 0.016 & 0.051 & 0.096 & 0.208 & 0.421 & 0.579 & 0.985 & 1.505 & 3.966 & 0.078 & 0.627 & 0.185 & 1.470 & 11.343 \\
\hline BIT743 & 13.0 & Poorly graded sand & 1.13 & 2.09 & 93.96 & 2.83 & 1.41 & 2.55 & 95.93 & 0.10 & 0.110 & 0.254 & 0.374 & 0.557 & 0.755 & 0.855 & 1.044 & 1.217 & 1.713 & 0.206 & 0.582 & 0.368 & 1.431 & 3.367 \\
\hline BIT744 & 15.5 & Silty sand & 3.93 & 11.35 & 76.88 & 7.84 & 5.26 & 14.49 & 77.68 & 2.56 & 0.004 & 0.023 & 0.054 & 0.138 & 0.299 & 0.418 & 0.718 & 1.098 & 2.855 & 0.058 & 0.715 & 0.165 & 1.967 & 17.958 \\
\hline BIT752 & 45.5 & Silty sand & 1.66 & 10.15 & 83.65 & 4.53 & 2.50 & 14.68 & 81.50 & 1.31 & 0.017 & 0.041 & 0.070 & 0.135 & 0.250 & 0.331 & 0.532 & 0.779 & 1.866 & 0.074 & 0.776 & 0.219 & 1.331 & 8.005 \\
\hline BIT753 & 48.0 & $\begin{array}{l}\text { Poorly-graded sand } \\
\text { w/ silt }\end{array}$ & 1.31 & 4.62 & 92.28 & 1.79 & 1.79 & 6.48 & 91.50 & 0.23 & 0.039 & 0.092 & 0.142 & 0.235 & 0.359 & 0.433 & 0.587 & 0.746 & 1.283 & 0.098 & 0.750 & 0.308 & 1.388 & 4.708 \\
\hline BIT754 & 50.5 & Poorly graded sand & 0.96 & 2.74 & 93.41 & 2.89 & 1.27 & 3.63 & 94.82 & 0.27 & 0.077 & 0.163 & 0.239 & 0.371 & 0.538 & 0.632 & 0.825 & 1.016 & 1.626 & 0.134 & 0.661 & 0.333 & 1.339 & 3.885 \\
\hline BIT763 & 73.0 & $\begin{array}{l}\text { Well-graded sand } \\
\text { w/silt }\end{array}$ & 2.60 & 5.12 & 90.35 & 1.94 & 3.27 & 6.45 & 90.10 & 0.19 & 0.019 & 0.079 & 0.148 & 0.277 & 0.434 & 0.521 & 0.693 & 0.862 & 1.396 & 0.104 & 0.716 & 0.304 & 1.873 & 6.634 \\
\hline BIT771 & 98.0 & Silty sand & 2.00 & 8.55 & 89.19 & 0.26 & 2.76 & 13.04 & 84.18 & 0.03 & 0.018 & 0.047 & 0.076 & 0.128 & 0.193 & 0.231 & 0.307 & 0.384 & 0.633 & 0.067 & 0.860 & 0.315 & 1.497 & 4.899 \\
\hline BIT9L5 & 134.3 & Silty sand & 1.73 & 7.88 & 90.39 & 0.00 & 2.32 & 14.91 & 82.76 & 0.00 & 0.024 & 0.052 & 0.072 & 0.098 & 0.120 & 0.130 & 0.148 & 0.163 & 0.200 & 0.141 & 0.921 & 0.412 & 1.413 & 2.522 \\
\hline BIT778 & 135.5 & $\begin{array}{l}\text { Poorly-graded sand } \\
\text { w/silt }\end{array}$ & 1.04 & 5.80 & 92.39 & 0.78 & 1.50 & 9.08 & 89.32 & 0.10 & 0.036 & 0.071 & 0.104 & 0.165 & 0.248 & 0.298 & 0.404 & 0.514 & 0.891 & 0.239 & 0.818 & 0.314 & 1.282 & 4.174 \\
\hline BIT779 & 138.0 & Silty sand & 3.33 & 6.84 & 88.71 & 1.12 & 4.20 & 8.79 & 86.90 & 0.12 & 0.009 & 0.049 & 0.101 & 0.202 & 0.328 & 0.398 & 0.538 & 0.675 & 1.116 & 0.063 & 0.775 & 0.290 & 2.108 & 8.199 \\
\hline BIT781 & 143.0 & Silty sand & 2.21 & 9.42 & 88.36 & 0.01 & 3.00 & 15.57 & 81.43 & 0.00 & 0.016 & 0.043 & 0.067 & 0.104 & 0.144 & 0.165 & 0.203 & 0.238 & 0.338 & 0.053 & 0.902 & 0.358 & 1.548 & 3.863 \\
\hline BIT789 & 163.0 & Silty sand & 3.68 & 6.13 & 89.12 & 1.07 & 4.53 & 7.59 & 87.81 & 0.08 & 0.007 & 0.052 & 0.116 & 0.240 & 0.385 & 0.461 & 0.607 & 0.746 & 1.169 & 0.337 & 0.750 & 0.299 & 2.407 & 8.856 \\
\hline BIT790 & 165.5 & Silty sand & 4.05 & 9.50 & 86.34 & 0.12 & 5.13 & 13.06 & 81.80 & 0.01 & 0.005 & 0.029 & 0.064 & 0.127 & 0.200 & 0.238 & 0.310 & 0.378 & 0.583 & 0.045 & 0.862 & 0.307 & 2.312 & 8.082 \\
\hline BIT7B4 & 210.5 & Silty sand & 2.34 & 8.05 & 89.18 & 0.42 & 3.14 & 11.63 & 85.18 & 0.05 & 0.015 & 0.048 & 0.081 & 0.143 & 0.223 & 0.267 & 0.359 & 0.451 & 0.751 & 0.069 & 0.840 & 0.306 & 1.617 & 5.623 \\
\hline BIT7B6 & 215.5 & Silty sand & 1.03 & 10.36 & 88.16 & 0.44 & 1.63 & 17.85 & 80.45 & 0.07 & 0.024 & 0.045 & 0.065 & 0.103 & 0.158 & 0.192 & 0.266 & 0.346 & 0.631 & 0.190 & 0.877 & 0.304 & 1.231 & 4.266 \\
\hline BIT7C2 & 230.5 & Silty sand & 5.72 & 8.62 & 85.05 & 0.61 & 6.92 & 10.67 & 82.36 & 0.05 & 0.001 & 0.020 & 0.063 & 0.164 & 0.287 & 0.351 & 0.473 & 0.589 & 0.941 & 0.038 & 0.805 & 0.267 & 3.926 & 17.976 \\
\hline BIT7C9 & 258.0 & Silty sand w/gravel & 1.99 & 7.98 & 65.15 & 24.60 & 2.89 & 10.14 & 74.40 & 12.30 & 0.016 & 0.050 & 0.102 & 0.258 & 0.636 & 0.970 & 1.986 & 3.548 & 13.518 & 0.070 & 0.372 & 0.110 & 1.372 & 19.315 \\
\hline BIT7D8 & 280.5 & Silty sand w/gravel & 6.75 & 4.69 & 38.70 & 49.87 & 7.63 & 4.91 & 67.46 & 19.99 & 0.000 & 0.026 & 0.185 & 0.862 & 1.992 & 2.661 & 4.054 & 5.492 & 10.480 & 0.037 & 0.170 & 0.165 & 10.803 & 102.831 \\
\hline BIT7F2 & 290.5 & Silty sand & 2.78 & 7.54 & 79.20 & 10.47 & 3.69 & 9.63 & 83.54 & 3.13 & 0.011 & 0.047 & 0.098 & 0.223 & 0.444 & 0.599 & 0.979 & 1.438 & 3.427 & 0.063 & 0.633 & 0.196 & 1.751 & 12.640 \\
\hline ВІт7н2 & 315.5 & Silty sand & 2.55 & 5.62 & 65.70 & 26.08 & 3.31 & 6.80 & 79.39 & 10.44 & 0.016 & 0.073 & 0.160 & 0.395 & 0.855 & 1.200 & 2.097 & 3.257 & 8.829 & 0.085 & 0.373 & 0.163 & 1.770 & 16.338 \\
\hline ВІт7Н7 & 328.0 & Silty sand & 11.95 & 4.65 & 38.35 & 45.06 & 12.89 & 4.71 & 79.83 & 2.57 & 0.000 & 0.000 & 0.038 & 0.734 & 1.799 & 2.193 & 2.759 & 3.178 & 4.164 & 0.026 & 0.314 & 0.169 & 1685.761 & 15055.760 \\
\hline
\end{tabular}


PNNL-17821

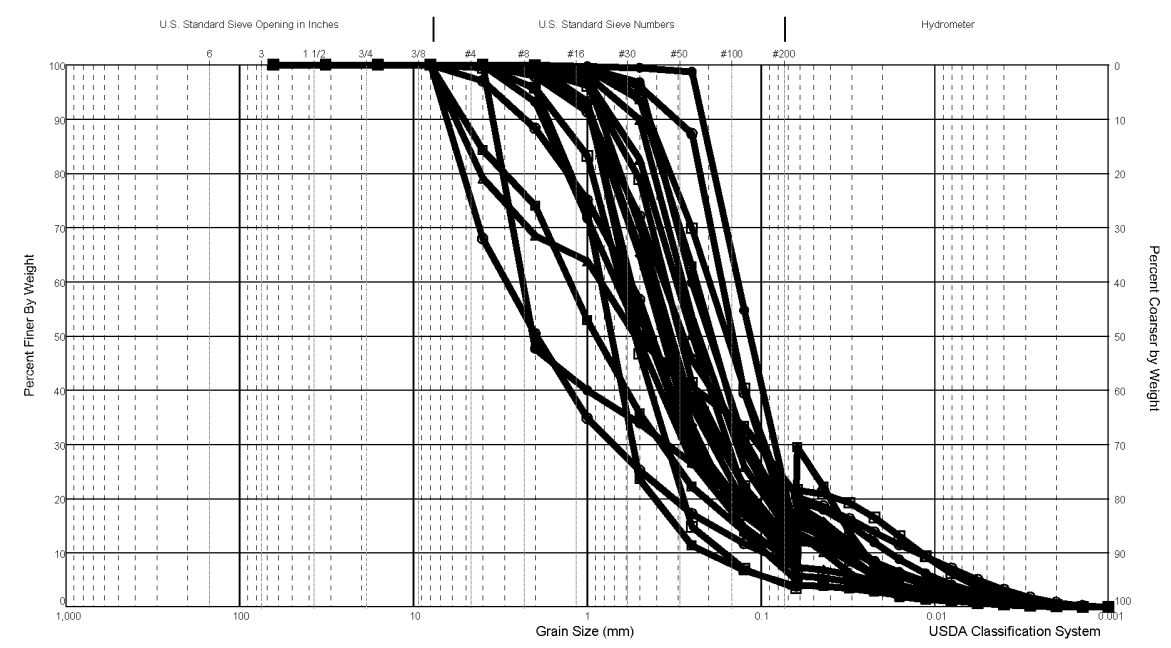

Figure 5.19. PSD Curves from Borehole C5923 (A) Showing Range of Textures
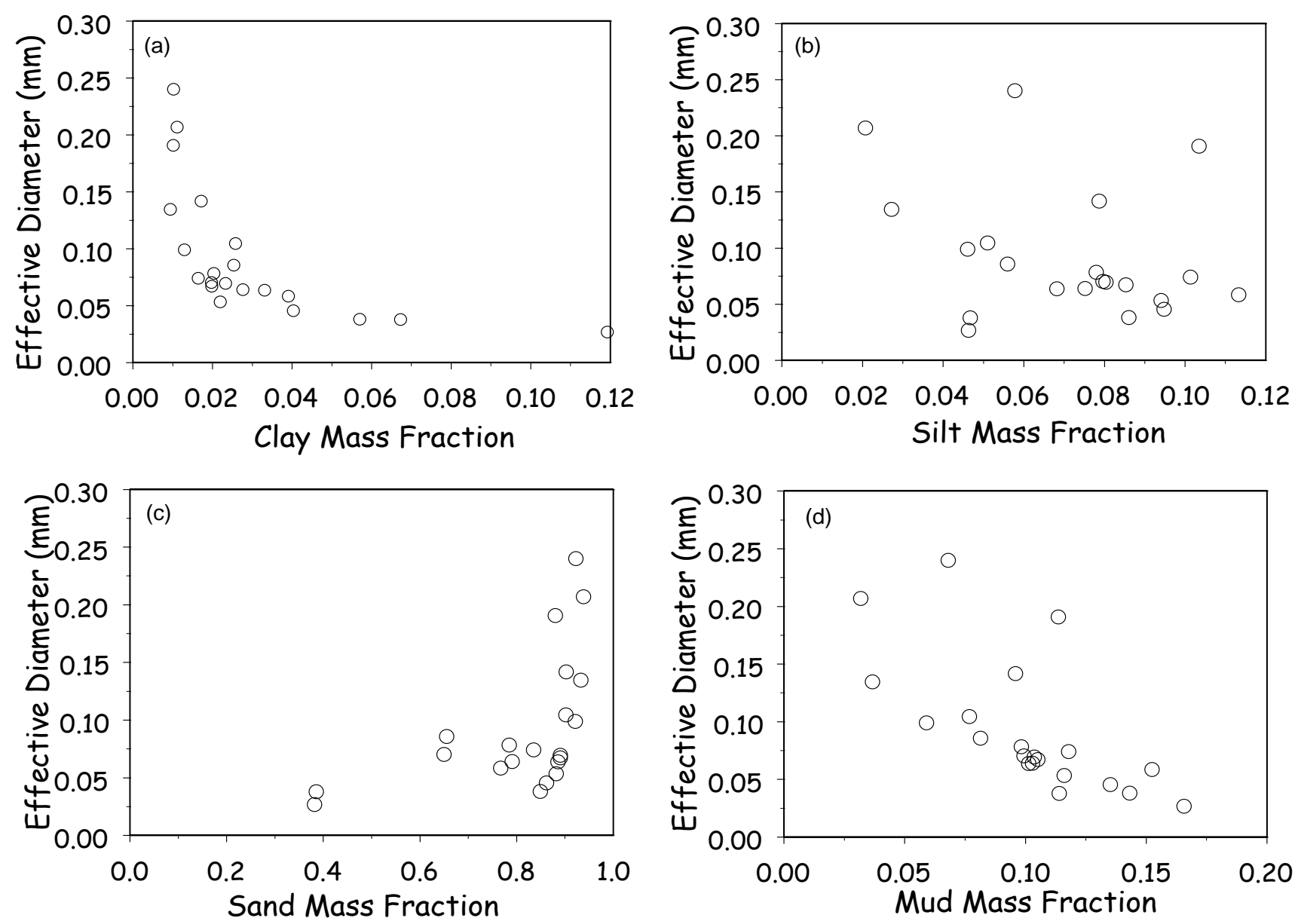

Figure 5.20. The Dependence of Effective Particle Diameter on Textural Components, (a) Clay Content, (b) Silt Content, (c) Sand Content, and (d) Mud Content (fraction passing the \#230 sieve consisting of silt and clay) 


\subsubsection{Particle-Size Dis tribution of Sediments in Borehole C5924 (B)}

Owing to the level of contaminants in Borehole C5923 (A), efforts to further characterize the grainsize distributions were focused on Borehole C5923 (B). In these analyses, 12 samples were separated into size fractions based on the logarithmic Udden-Wentworth grade scale (Udden 1914; Wentworth 1922). The mass of soil retained in each sieve was used to calculate the class weight in each particle-size class. The sediments passing the \#230 siver were used to calculate the content of fines. Figure 5.21 shows a histogram of the geometric grain size of the sediments from borehole C5924 (B), and Table 5.16 shows the grain-size frequency for these samples. The fines content (passing the \#230 sieve) ranged from 1.39 to 10.83 percent with a mean of 5.04 percent. These sediments were considerably coarser than those from Borehole 5923 (A) where fines content rangeD from 3.45 to 20.56 percent with a mean of 10.34 percent. The mode of the PSDs for C5924 (B) occur at the \#60 and \#120 sieve sizes except for sample B1T7D8 for which the mode occurs at the \#10 sieve size. Characterization of these size classes using gamma energy analysis to measure the natural potassium-40, uranium, and thorium forms the basis for estimating grain-size distributions from borehole gamma logs that is further discussed in Section 5.3.2.5.

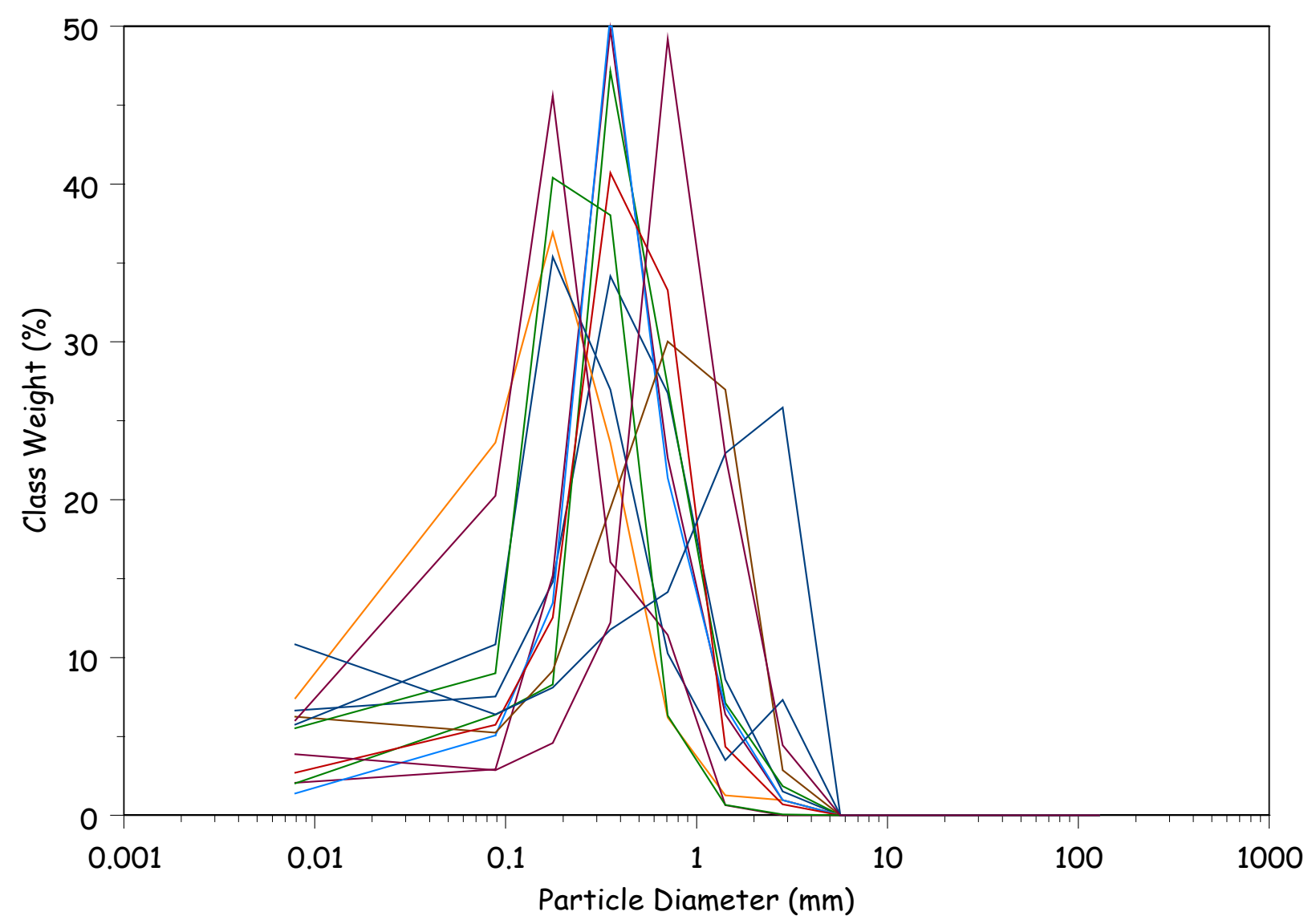

Figure 5.21. Grain-Size Frequency Histograms for Sediments from Borehole 5924 (B), Analyzed by Dry Sieving and Laser Granulometery. Grain diameter is plotted as a geometric size scale. 
PNNL-17821

Table 5.16. Grain Size Frequency for Borehole C5924 (B) Analyzed by Sieving and Laser Diffraction (> \#230)

\begin{tabular}{|c|c|c|c|c|c|c|c|c|c|c|c|c|c|c|c|}
\hline \multirow{2}{*}{\multicolumn{2}{|c|}{ Size Terms }} & \multirow[b]{2}{*}{$\mathrm{d}_{\mathrm{g}}(\mathrm{mm})$} & \multirow[b]{2}{*}{ Sieve Size } & \multicolumn{12}{|c|}{ Class Weight (gm) } \\
\hline & & & & BIT6D9 & BIT6F0 & BIT6F4 & BIT6F6 & BIT6F7 & BIT6H1 & BIT6H2 & BIT6H5 & BIT6H6 & BIT6J0 & B1T7D8 & BIT743 \\
\hline \multirow{6}{*}{ Gravel } & Cobble & 128.000 & $2-1 / 2^{\prime \prime}$ & 0.00 & 0.00 & 0.00 & 0.00 & 0.00 & 0.00 & 0.00 & 0.00 & 0.00 & 0.00 & 0.00 & 0.00 \\
\hline & very coarse & 45.255 & $1-1 / 4^{\prime \prime}$ & 0.00 & 0.00 & 0.00 & 0.00 & 0.00 & 0.00 & 0.00 & 0.00 & 0.00 & 0.00 & 0.00 & 0.00 \\
\hline & Coarse & 22.627 & 5/8" & 0.00 & 0.00 & 0.00 & 0.00 & 0.00 & 0.00 & 0.00 & 0.00 & 0.00 & 0.00 & 0.00 & 0.00 \\
\hline & Medium & 11.314 & 5/16" & 0.00 & 0.00 & 0.00 & 0.00 & 0.00 & 0.00 & 0.00 & 0.00 & 0.00 & 0.00 & 0.00 & 0.00 \\
\hline & Fine & 5.657 & \#5 & 0.00 & 0.00 & 0.00 & 0.00 & 0.00 & 0.00 & 0.00 & 0.00 & 0.00 & 0.00 & 0.00 & 0.00 \\
\hline & very fine & 2.828 & $\# 10$ & 1.52 & 0.96 & 1.86 & 0.97 & 0.96 & 2.86 & 0.70 & 7.31 & 0.00 & 0.07 & 25.84 & 4.44 \\
\hline \multirow[t]{5}{*}{ Sand } & very coarse & 1.414 & $\# 18$ & 8.61 & 6.40 & 7.13 & 1.27 & 6.87 & 26.97 & 4.35 & 3.50 & 0.65 & 0.66 & 22.94 & 22.83 \\
\hline & Coarse & 0.707 & $\# 35$ & 26.76 & 22.64 & 27.19 & 6.20 & 21.38 & 30.03 & 33.27 & 10.26 & 11.43 & 6.33 & 14.15 & 49.18 \\
\hline & Medium & 0.354 & $\# 60$ & 34.15 & 49.83 & 47.15 & 23.61 & 50.88 & 19.47 & 40.70 & 26.97 & 16.05 & 38.03 & 11.77 & 12.22 \\
\hline & Fine & 0.177 & $\# 120$ & 14.79 & 15.19 & 8.29 & 36.92 & 13.45 & 9.17 & 12.53 & 35.39 & 45.58 & 40.40 & 8.09 & 4.58 \\
\hline & very fine & 0.088 & $\# 230$ & 7.53 & 2.91 & 6.37 & 23.62 & 5.06 & 5.25 . & 5.74 & 10.83 & 20.25 & 9.00 & 6.39 & 2.87 \\
\hline Mud & & 0.008 & $<\# 230$ & 6.64 & 2.07 & 2.03 & 7.42 & 1.39 & 6.25 & 2.70 & 5.75 & 6.03 & 5.52 & 10.83 & 3.87 \\
\hline
\end{tabular}




\subsubsection{Porosity and Bulk Density of Intact Cores from Borehole C5923 (A)}

Dry-bulk densities were determined by oven drying the core samples following completion of the saturated hydraulic conductivity. Sediments were dried for $24 \mathrm{hrs}$ at $105^{\circ} \mathrm{C}$, and the dry weight was determined. A summary of measured dry-bulk densities of complementary porosity estimates on core samples from Borehole C5923 (A) is presented in Table 5.17.

Table 5.17. Summary of Hydro-Physical Properties for Core Samples from Borehole C5923 (A)

\begin{tabular}{|c|c|c|c|c|c|c|c|c|}
\hline HEIS & $\mathrm{Z}_{\text {top }}(\mathrm{ft})$ & $\mathrm{Z}_{\mathrm{bot}}(\mathrm{ft})$ & $\mathrm{Z}_{\text {mid }}(\mathrm{ft})$ & $\begin{array}{l}\text { Core Wet } \\
\text { Wt. (gm) }\end{array}$ & $\begin{array}{c}\text { Core } \\
\text { Dry Wt. } \\
\text { (gm) }\end{array}$ & $\begin{array}{c}\text { Dry Bulk } \\
\text { Density } \\
\left(\mathrm{gm} / \mathrm{cm}^{3}\right)\end{array}$ & $\begin{array}{l}\text { Porosity } \\
\left(\mathrm{cm}^{3} / \mathrm{cm}^{3}\right)\end{array}$ & $\begin{array}{c}\text { Saturated } \\
\text { Water } \\
\text { Content } \\
\left(\mathrm{cm}^{3} / \mathrm{cm}^{3}\right)\end{array}$ \\
\hline B1T7J3-2 & 38.0 & 38.5 & 38.25 & 2071.90 & 1583.17 & 1.481 & 0.4535 & 0.3978 \\
\hline B1T7J4-2 & 38.5 & 39.0 & 38.75 & 2349.80 & 1695.10 & 1.586 & 0.4149 & 0.3648 \\
\hline B1T7J5-2 & 41.0 & 41.5 & 41.25 & 2271.10 & 2111.42 & 1.975 & 0.2712 & 0.2178 \\
\hline B1T7J6-2 & 43.5 & 44.0 & 43.75 & 2349.30 & 1754.69 & 1.641 & 0.3943 & 0.3015 \\
\hline B1T7J7-2 & 86.0 & 86.5 & 86.25 & 2123.90 & 1596.06 & 1.542 & 0.4310 & 0.3078 \\
\hline B1T7J8-2 & 88.5 & 89.0 & 88.75 & 2168.50 & 1708.79 & 1.598 & 0.4102 & 0.3275 \\
\hline B1T7J9-2 & 106.0 & 106.5 & 106.25 & 2058.00 & 1698.44 & 1.677 & 0.3810 & 0.3009 \\
\hline В1T7K0-2 & 108.5 & 109.0 & 108.75 & 2265.40 & 1643.53 & 1.623 & 0.4010 & 0.3095 \\
\hline B1T7K1-2 & 126.0 & 126.5 & 126.25 & 1933.00 & 1730.64 & 1.877 & 0.3073 & 0.2199 \\
\hline B1T7K2-2 & 129.0 & 129.5 & 129.25 & 2240.00 & 1702.91 & 1.781 & 0.3426 & 0.2393 \\
\hline В1T7K3-2 & 131.0 & 131.5 & 131.25 & 2155.70 & 1770.71 & 1.711 & 0.3688 & 0.2787 \\
\hline B1T7K4-2 & 133.5 & 134.0 & 133.75 & 2195.30 & 1874.67 & 1.754 & 0.3529 & 0.2710 \\
\hline B1T7K5-2 & 176.0 & 176.5 & 176.25 & 2018.50 & 1738.29 & 1.736 & 0.3593 & 0.2781 \\
\hline В1T7K6-2 & 178.5 & 179.0 & 178.75 & 1904.50 & 1746.73 & 1.706 & 0.3704 & 0.3060 \\
\hline B1T7K7-2 & 181.0 & 181.5 & 181.25 & 2188.00 & 1988.70 & 1.900 & 0.2987 & 0.2196 \\
\hline B1T7K8-2 & 183.5 & 184.0 & 183.75 & 2330.00 & 1583.17 & 1.481 & 0.4535 & 0.3978 \\
\hline В1T7K9-2 & 236.0 & 236.5 & 236.25 & 2267.90 & 1695.10 & 1.586 & 0.4149 & 0.3648 \\
\hline B1T7L0-2 & 238.5 & 239.0 & 238.75 & 2263.90 & 2111.42 & 1.975 & 0.2712 & 0.2178 \\
\hline B1T7L1-2 & 241.0 & 241.5 & 241.25 & 2196.40 & 1754.69 & 1.641 & 0.3943 & 0.3015 \\
\hline B1T7L2-3 & 243.0 & 243.5 & 243.25 & 2243.80 & 1596.06 & 1.542 & 0.4310 & 0.3078 \\
\hline
\end{tabular}

Dry bulk density, $\rho_{\mathrm{b}}$, is used to establish the density-volume relationship of soils and sediments, especially porosity. The mean and standard error derived from Borehole C5923 (A) samples shown in Table 5.17 was $1.71 \pm 0.035 \mathrm{Mg} / \mathrm{m}^{3}$. This result is slightly higher than the typical 1.5 to $1.6 \mathrm{Mg} / \mathrm{m}^{3}$ observed in Hanford formation sediments and may be a reflection of drilling techniques and handling of the samples after collection. Soil compaction can have a strong impact on porosity, permeability to air and water, and electrical properties.

Particle density, $\rho_{\mathrm{s}}$, is also widely use for establishing the density-volume relationship of soils. It is typically used in the calculation of porosity. Measurements of $\rho_{\mathrm{s}}$ were made on the $<2 \mathrm{~mm}$ fraction of six samples from Borehole C5924 (B) using the pycnometer method (Blake and Hartge 1986a; ASTM 2006c). These measurements gave a mean and standard error of $2.72 \pm 0.007 \mathrm{Mg} / \mathrm{m}^{3}$. A $\rho_{\mathrm{s}}>2.65 \mathrm{Mg} / \mathrm{m}^{3}$ for Hanford sediments is not surprising. The widely used value of $2.65 \mathrm{Mg} / \mathrm{m}^{3}$ corresponds to the specific gravity of quartz. However, many silicate and nonsilicate minerals present in Hanford sediments, such as feldspars, micas, and kaolinite, exhibit densities ranging from 2.3 to $3.0 \mathrm{Mg} / \mathrm{m}^{3}$ whereas the density of 
iron-containing minerals like hematite and goethite, also present in Hanford sediments, often exceeds $3.3 \mathrm{Mg} / \mathrm{m}^{3}$. The particle density of a bulk soil is therefore a weighted average that depends on mineral composition and is calculated using a mass weighted mean of all the particles.

Porosity $(\phi)$ is the volume of voids in a sample (the air- and liquid-filled volume) divided by the total volume of the sample and was calculated from the bulk density and particle density as $\phi=1-\rho_{b} / \rho_{s}$. The particle density for a given parent material is generally invariant in space, so changes in the porosity are typically due to changes in $\rho_{\mathrm{b}}$. Estimates of porosity derived from bulk density and particle density measurements ranged from 0.2710 to $0.4535 \mathrm{~m}^{3} / \mathrm{m}^{3}$ with a mean and standard error of $0.3705 \pm 0.013$ $\mathrm{m}^{3} / \mathrm{m}^{3}$. These values are consistent with what can be expected for fine- to coarse-sands of the Hanford formation. Saturated water contents ranged from 0.2178 to $0.3978 \mathrm{~m}^{3} / \mathrm{m}^{3}$ with a mean and standard error of $0.2983 \pm 0.0135 \mathrm{~m}^{3} / \mathrm{m}^{3}$. Although the saturated water content is often assumed to be equivalent to the porosity, the results for the C5923 (A) cores show significant differences between the calculated total porosity and measured saturated water content. The difference between porosity and saturated water content is typically attributed to air entrapment. Although there are few published reports for Hanford sediments, a value of 10 to $15 \%$ is commonly reported in the literature. Table 5.17 shows differences between porosity and saturated water contents ranging from 0.05 to $0.1233 \mathrm{~m}^{3} / \mathrm{m}^{3}$ with a mean and standard error of $0.08 \pm 0.005 \mathrm{~m}^{3} / \mathrm{m}^{3}$.

\subsubsection{Specific Surface Area of Vadose Sediments from Borehole C5923 (A)}

The specific surface-area data for selected grab samples from C5923 (A) are shown in Table 5.18, whereas Figure 5.22 shows the dependence of SSA on textural components taken from Table 5.15. In general, SSA should increase with increasing clay and silt content and decrease with sand content. Similarly, SSA should decrease with increasing effective particle diameter. For the characterization of coarse sediments, which generally have small surface areas, the traditional nitrogen adsorption BET technique is not considered sufficiently accurate. For maximum accuracy for coarse grained sediments, krypton gas at liquid nitrogen temperature or gas flow techniques are better choices for measuring low surface area samples, because of lower krypton gas saturation pressure than nitrogen gas.

Most of the sediment samples collected at between 45 and 143 and 215 to $230 \mathrm{ft}$ bgs showed much higher SSA after the washing steps to remove pore-water salts that precipitated while drying the sediments for SSA measurement (Table 5.18). This indicated that the high sodium nitrate porewater precipitates impacted both measurements of SSA and CEC. None of the plots of measured SSA shown in Figure 5.22 have the expected relationships. Generally, SSA increases with increasing clay and silt contents and decreases with effective grain size. Instead, the plots show very poor correlation with textural components and size statistics, as exemplified in the plot against effective diameter. An explanation for the very poor correlations has not been found. Another option to estimate SSA for these low-surface-area samples would be to estimate SSA from the measured grain-size distributions. SSAs were calculated according to Bear (1988)

$$
S S A_{c}=\frac{6.0}{\rho_{s}} \sum \frac{C_{i}}{d_{i}}+\frac{2}{\rho_{s} Z}
$$


where $\mathrm{SSA}_{\mathrm{c}}=$ calculated SSA in $\mathrm{m}^{2} / \mathrm{g}$

$\rho_{\mathrm{s}}=$ particle density

$\mathrm{C}_{\mathrm{i}}=$ mass fraction of the $\mathrm{i}^{\text {th }}$ spherical particle (sand and silt assumed to be spherical)

$\mathrm{d}_{\mathrm{i}}=$ diameter of the $\mathrm{i}^{\text {th }}$ particle.

The contribution of the clay component is calculated with the second term in Eq. (5.1) in which $z$ is the thickness of the clay platelet. The estimated platelet thicknesses for montmorrilionite and illite are $10^{-9}$ and $10^{-11} \mathrm{~m}$ respectively.

The calculated SSA, SSAc, ranged from 16.84 to $98.47 \mathrm{~m}^{2} / \mathrm{g}$. Figure 5.22 shows a monotonic increase in SSAc with increasing clay content. The relationship with silt is less well defined whereas SSAc decreases with increasing sand content as would be expected (Figure 5.22). A plot of SSAc versus mud content (silt plus clay) also shows an increase in SSAc with increasing mud as would be expected. The SSA is most often used in predicting the sorption behavior of reactive contaminants. Of greater importance to this project is its relationship to the gas permeability and the surface electrical conductance of porous media. The gas adsorption isotherm derived during measurement of the surface area can also be used to extend the water-retention function to dry conditions.

Table 5.18. SSA and CEC for Borehole C5923 (A) Vadose Zone Sediments

\begin{tabular}{lccccc}
\hline & & \multicolumn{2}{c}{$2^{\text {nd }}$ run (with washing) } & \multicolumn{2}{c}{$1^{\text {st }}$ run (without washing) } \\
\cline { 3 - 6 } HEIS \# & Depth $(\mathrm{ft})$ & $\begin{array}{c}\text { SSA } \\
\left(\mathrm{m}^{2} / \mathrm{g}\right)\end{array}$ & $\begin{array}{c}\text { CEC } \\
(\mathrm{meq} / 100 \mathrm{~g})\end{array}$ & $\begin{array}{c}\text { SSA } \\
\left(\mathrm{m}^{2} / \mathrm{g}\right)\end{array}$ & $\begin{array}{c}\text { CEC } \\
(\mathrm{meq} / 100 \mathrm{~g})\end{array}$ \\
\hline BIT741 & 8 & $10.1 \pm 0.04$ & $9.28 \pm 0.95$ & $11.9 \pm 0.06$ & $11.21 \pm 0.65$ \\
BIT743 & 13 & $9.08 \pm 0.04$ & $7.27 \pm 0.65$ & $11.8 \pm 0.05$ & $9.25 \pm 0.75$ \\
\hline BIT744 & 15.5 & $10.0 \pm 0.05$ & $7.14 \pm 0.70$ & $13.1 \pm 0.06$ & $9.73 \pm 0.33$ \\
BIT752 & 45.5 & $9.61 \pm 0.04$ & $8.58 \pm 1.39$ & $2.21 \pm 0.01$ & $32.67 \pm 2.02$ \\
\hline BIT753 & 48 & $4.05 \pm 0.02$ & $5.65 \pm 0.14$ & $0.878 \pm 0.01$ & $18.39 \pm 0.35$ \\
BIT754 & 50.5 & $3.69 \pm 0.02$ & $7.10 \pm 1.23$ & $1.88 \pm 0.01$ & $14.55 \pm 0.27$ \\
\hline BIT763 & 73 & $3.50 \pm 0.01$ & $6.22 \pm 0.75$ & $0.855 \pm 0.004$ & $22.25 \pm 0.43$ \\
BIT771 & 98 & $5.32 \pm 0.02$ & $7.10 \pm 0.66$ & $1.01 \pm 0.003$ & $15.60 \pm 0.13$ \\
\hline BIT9L5 & 134.3 & $4.11 \pm 0.02$ & $7.84 \pm 0.22$ & $0.997 \pm 0.003$ & $19.54 \pm 0.38$ \\
BIT781 & 143 & $2.62 \pm 0.02$ & $7.53 \pm 0.06$ & $1.12 \pm 0.004$ & $15.35 \pm 0.83$ \\
\hline BIT789 & 163 & $3.22 \pm 0.02$ & $6.61 \pm 0.07$ & $4.13 \pm 0.02$ & $8.06 \pm 0.12$ \\
BIT790 & 165.5 & $3.76 \pm 0.02$ & $6.59 \pm 0.18$ & $3.53 \pm 0.02$ & $8.19 \pm 0.06$ \\
\hline BIT7B4 & 210.5 & $2.67 \pm 0.01$ & $8.00 \pm 0.15$ & $1.65 \pm 0.01$ & $17.21 \pm 0.16$ \\
\hline BIT7B6 & 215.5 & $4.39 \pm 0.02$ & $7.63 \pm 0.20$ & $1.08 \pm 0.005$ & $23.21 \pm 0.20$ \\
\hline BIT7C2 & 230.5 & $3.53 \pm 0.01$ & $6.91 \pm 0.15$ & $1.59 \pm 0.01$ & $15.37 \pm 0.28$ \\
\hline BIT7C9 & 258 & $5.53 \pm 0.02$ & $7.47 \pm 0.71$ & $8.14 \pm 0.02$ & $9.46 \pm 0.46$ \\
\hline BIT7D8 & 280.5 & $10.1 \pm 0.02$ & $9.00 \pm 0.08$ & $10.8 \pm 0.03$ & $10.35 \pm 0.38$ \\
\hline BIT7F2 & 290.5 & $5.83 \pm 0.03$ & $7.69 \pm 0.08$ & $8.85 \pm 0.03$ & $9.76 \pm 0.42$ \\
\hline BIT7H2 & 315.5 & $6.13 \pm 0.02$ & $6.27 \pm 0.23$ & $6.01 \pm 0.02$ & $8.17 \pm 0.12$ \\
BIT7H7 & 328 & $2.32 \pm 0.01$ & $3.23 \pm 0.36$ & $2.35 \pm 0.01$ & $5.44 \pm 0.20$ \\
\hline & & & & & \\
\hline
\end{tabular}



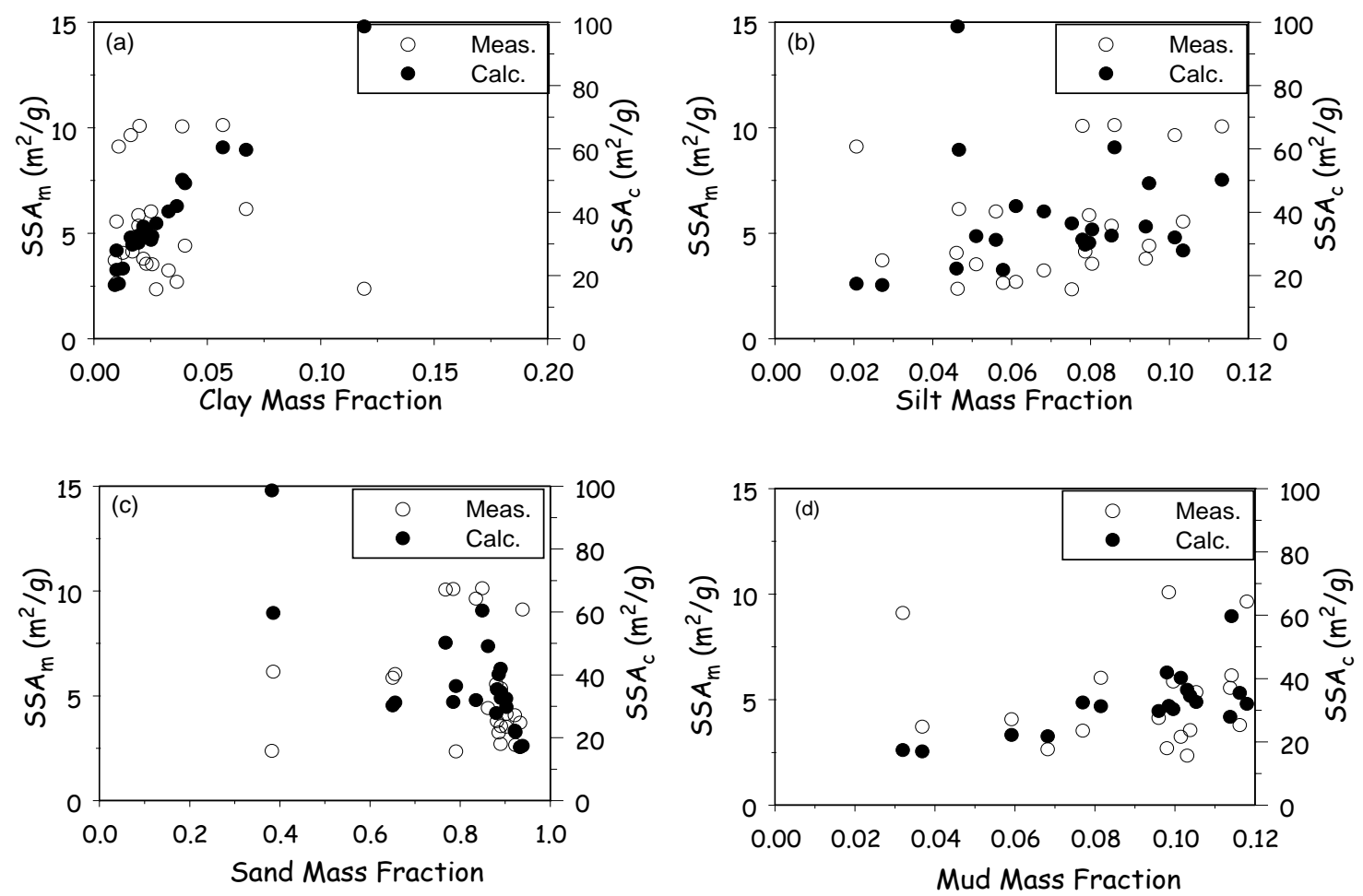

Figure 5.22. Measured (left axis) and Calculated (right axis) SSA as a Function of Texture for Borehole C5923 (A) Sediment

\subsubsection{Cation Exchange Capacity of Vadose Zone Sediments from Borehole C5923 (A)}

The CEC values of the pre-rinsed sediments and not-rinsed sediments from Borehole C5923 (A) are also shown in Table 5.18. Rinsed sediments usually show low CEC values compared to those from sediments without rinsing. The CEC data for the unrinsed sediments was biased high in depth regions where high sodium nitrate concentrations existed in the pore waters (between 45 and 143 and 215 to 230 $\mathrm{ft}$ bgs). Based on the exchangeable sodium data for the rinsed sediments, the values reported in Table 5.18 for the rinsed sediments in the zone of maximum sodium nitrate porewater concentration exist (46 to 73 and 210 to $216 \mathrm{ft}$ bgs) may still be biased high by between 0.2 to $0.4 \mathrm{meq} / 100 \mathrm{~g}$, despite the three rinse steps used to remove the salts. However, we have elected to use the measured values on the rinsed sediments and looked at the correlation of both CEC and SSA to each other and to the textural composition of the sediments as shown in Table 5.15. The correlations are shown in the XY scatter plots in Figure 5.23. 

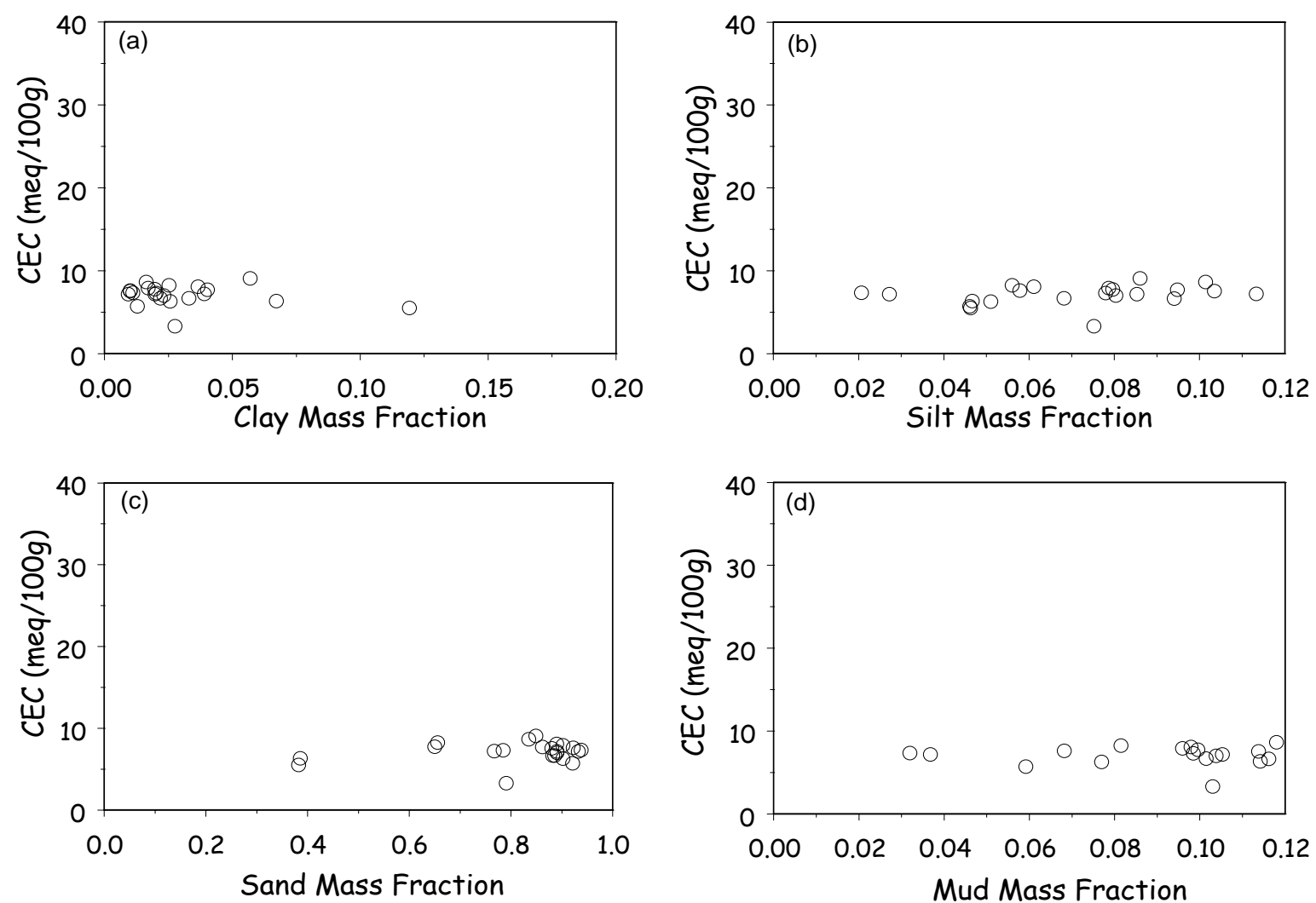

Figure 5.23. $\quad$ Measured CEC as a Function of Soil Textural Parameters for Borehole C5923 (A) Sediments

The CEC ranged from $3.23 \mathrm{meq} / 100 \mathrm{~g}$ to $9.28 \mathrm{meq} / 100 \mathrm{~g}$. The mean value for the sediments measured was 7.16 meq/100 g., which is quite low. Plots of CEC as a function of textural parameters fail to show meaningful relationships with clay content, silt, mud, or sand (Figure 5.23). In fact, the relationships are somewhat counter intuitive in that the lower the clay content, the larger the CEC. Unlike the surface areas, the correlations of CEC with silt and mud content (Figure 5.23b and d) are no better and show essentially the same lack of trend. This observation is not consistent with the relationships observed for other Hanford sediments. The CEC correlation with effective particle diameter (not plotted) also shows a lot of scatter, but does follow the correct inverse relationship where the CEC increases as mean particle diameter decreases.

A plausible explanation for the observation that the CEC correlation with the clay and sand content is opposite to the physically meaningful relationship is not available. We do not believe that residual sodium nitrate salts that were not washed out after the three rinses are causing enough bias to yield the counterintuitive relationship.

\subsubsection{Saturated Hydraulic Conductivity}

Table 5.19 contains the saturated hydraulic conductivity data obtained from selected intact cores from Borehole C5923 (A). Figure 5.24 shows example plots of discharge versus hydraulic head for four C5923 core samples. The two samples, B1TJ4-2 and B1TJ8-2, represent two extremes in hydraulic 
conductivity, $0.62 \mathrm{~cm} / \mathrm{hr}$ and $126.99 \mathrm{~cm} / \mathrm{hr}$, respectively, found at borehole C5923. Samples B1TJ6-2 and B1TK2-2 showed more intermediate values, $35.57 \mathrm{~cm} / \mathrm{hr}$ and $2.05 \mathrm{~cm} / \mathrm{hr}$, respectively. Discharge versus hydraulic head for all of the samples showed the expected linear response for heads between 10 and $30 \mathrm{~m}$ with a few requiring heads of over $80 \mathrm{~cm}$ to collect useful data in a reasonable time period. One sample, B1T7K4-2, produced no discharge and was removed from the test. These data were used to calculate saturated hydraulic conductivity as described in Section 3.3.13.

The mean $\mathrm{K}_{\mathrm{s}}$ and standard deviation for each sample are summarized in Table 5.19. These values were compared to published values of $\mathrm{K}_{\mathrm{s}}$, which are included in Table 5.19 as a reference. Figure 5.25 shows a plot of Ks versus depth, compared to effective grain diameter (Figure 5.25a) and mud mass fraction (Figure 5.25b). $\mathrm{K}_{\mathrm{s}}$ is perhaps one of the most variable hydraulic parameters with reported coefficients of variation of $100 \%$. Nevertheless, comparison with published values of similar soils is a useful exercise in determining whether the measured values are reasonable. The high degree of correlation between discharge and head and the similarity to published values for similar soils suggest that these C5923 sediment data are of good quality. 
Table 5.19. Saturated Hydraulic Conductivity for Borehole C5923 (A) Sediment Cores

\begin{tabular}{|c|c|c|c|c|c|c|c|c|c|c|c|}
\hline Sample & $Z_{\text {top }}(\mathrm{ft})$ & $\mathrm{Z}_{\text {bot }}(\mathrm{ft})$ & $Z_{\text {mid }}(\mathrm{ft})$ & Reps. & $\mathrm{K}_{\mathrm{s}}(\mathrm{cm} / \mathrm{s})$ & Std. Error & $\mathrm{K}_{\mathrm{s}}(\mathrm{ft} / \mathrm{d})$ & Std. Error & $\mathrm{K}_{\mathrm{s}}(\mathrm{cm} / \mathrm{hr})$ & $\begin{array}{c}\text { Std. } \\
\text { Error }\end{array}$ & Reference Values of $\mathrm{K}_{\mathrm{s}}(\mathrm{cm} / \mathrm{hr})$ \\
\hline B1T7J3-2 & 38.0 & 38.5 & 38.3 & 3 & 0.000783 & $2.80 \mathrm{E}-06$ & 2.2205823 & 0.007942 & 2.82 & 0.010085 & Sandy Loam \\
\hline B1T7J4-2 & 38.5 & 39.0 & 38.8 & 3 & 0.000173 & $1.14 \mathrm{E}-06$ & 0.4899727 & 0.003233 & 0.62 & 0.004105 & Silt Loam \\
\hline B1T7J5-2 & 41.0 & 41.5 & 41.3 & 3 & 0.001363 & 4.78E-06 & 3.8633363 & 0.013559 & 4.91 & 0.017218 & Loamy sand \\
\hline B1T7J6-2 & 43.5 & 44.0 & 43.8 & 3 & 0.009881 & 0.000553 & 28.012642 & 1.568338 & 35.57 & 1.991541 & Sand \\
\hline B1T7J7-2 & 86.0 & 86.5 & 86.3 & 3 & 0.004452 & 0.000237 & 12.620126 & 0.673127 & 16.03 & 0.854765 & Sand \\
\hline B1T7J8-2 & 88.5 & 89.0 & 88.8 & 3 & 0.00484 & 4.92E-05 & 13.722112 & 0.139369 & 17.42 & 0.176977 & Sand \\
\hline B1T7J9-2 & 106.0 & 106.5 & 106.3 & 3 & 0.006605 & 0.000153 & 18.725086 & 0.434098 & 23.78 & 0.551235 & Sand \\
\hline B1T7L3-2 & 112.5 & 115.0 & 113.8 & 3 & 0.008441 & 0.000312 & 23.929242 & 0.885411 & 30.39 & 1.124331 & Sand \\
\hline B1T7K1-2 & 126.0 & 126.5 & 126.3 & 3 & 0.001439 & 2.15E-05 & 4.0804802 & 0.060971 & 5.18 & 0.077424 & Loam sand \\
\hline B1T7K2-2 & 129.0 & 129.5 & 129.3 & 3 & 0.001415 & 5.33E-05 & 4.0113429 & 0.150973 & 5.09 & 0.191711 & Loamy sand \\
\hline В1T7K3-2 & 131.0 & 131.5 & 131.3 & 3 & 0.003083 & 4.94E-05 & 8.7405798 & 0.140042 & 11.1 & 0.177831 & Sand \\
\hline B1T7K4-2 & 133.5 & 134.0 & 133.8 & 3 & NA & NA & NA & NA & NA & NA & NA \\
\hline B1T7K5-2 & 176.0 & 176.5 & 176.3 & 3 & 0.001248 & 3.03E-05 & 3.53714 & 0.085778 & 4.49 & 0.108925 & Loamy Sand \\
\hline B1T7K6-2 & 178.5 & 179.0 & 178.8 & 3 & 0.000543 & 2.22E-05 & 1.5393317 & 0.063014 & 1.95 & 0.080018 & Loam \\
\hline B1T7K7-2 & 181.0 & 181.5 & 181.3 & 3 & 0.000667 & 2.91E-05 & 1.8900968 & 0.08264 & 2.4 & 0.104939 & Sandy loam \\
\hline B1T7J8-2 & 183.5 & 184.0 & 183.8 & 3 & 0.035251 & 0.001021 & 99.937869 & 2.895002 & 126.91 & 3.676193 & Coarse Sand \\
\hline
\end{tabular}


PNNL-17821
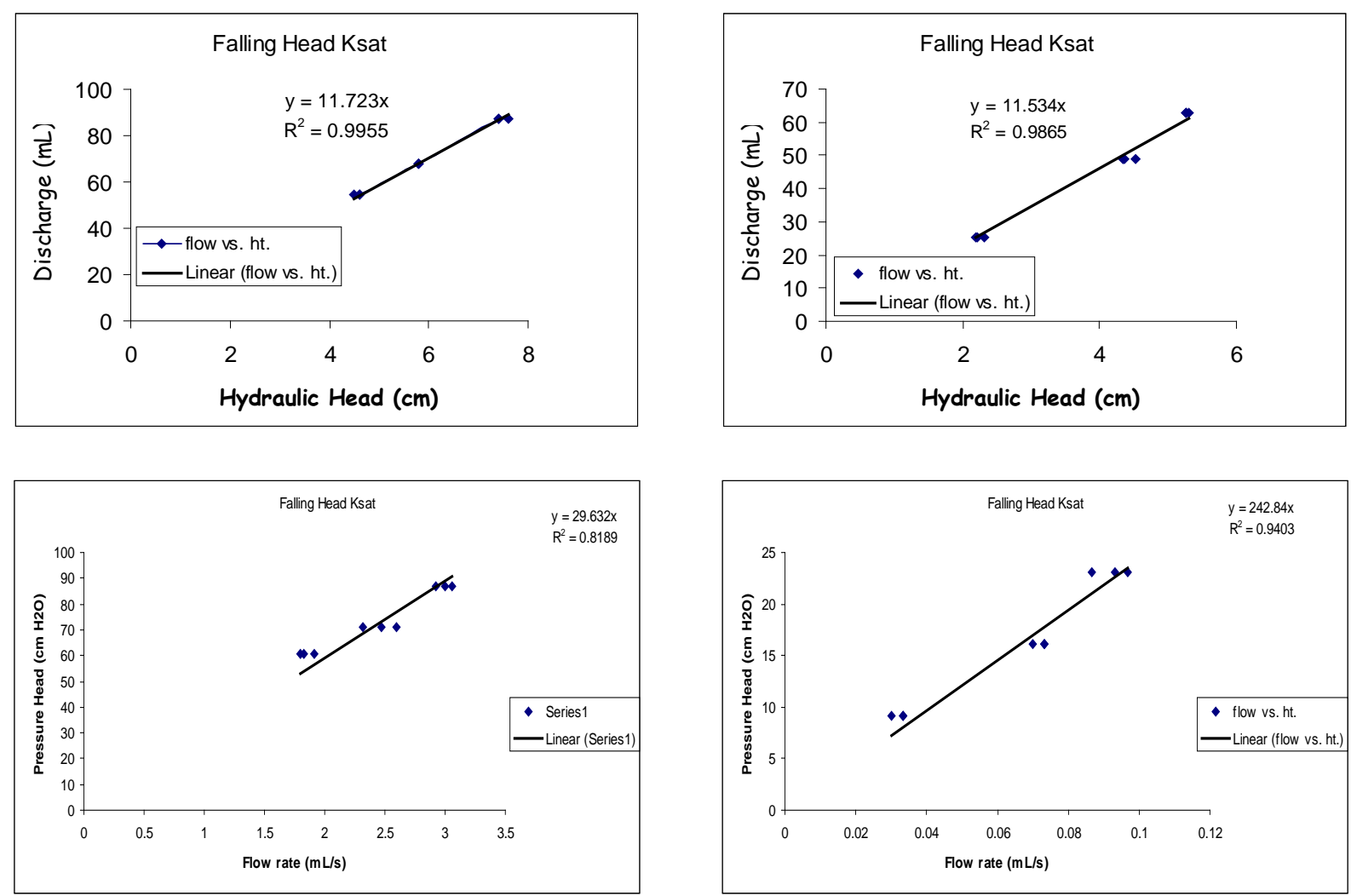

Figure 5.24. Plots of Discharge Versus Hydraulic Head for Borehole C5923 (A) Core Samples, (a) Core B1TJ4-2, and (b) B1TJ8-2, (c) B1TJ6-2, and (d) B1TK2-2 

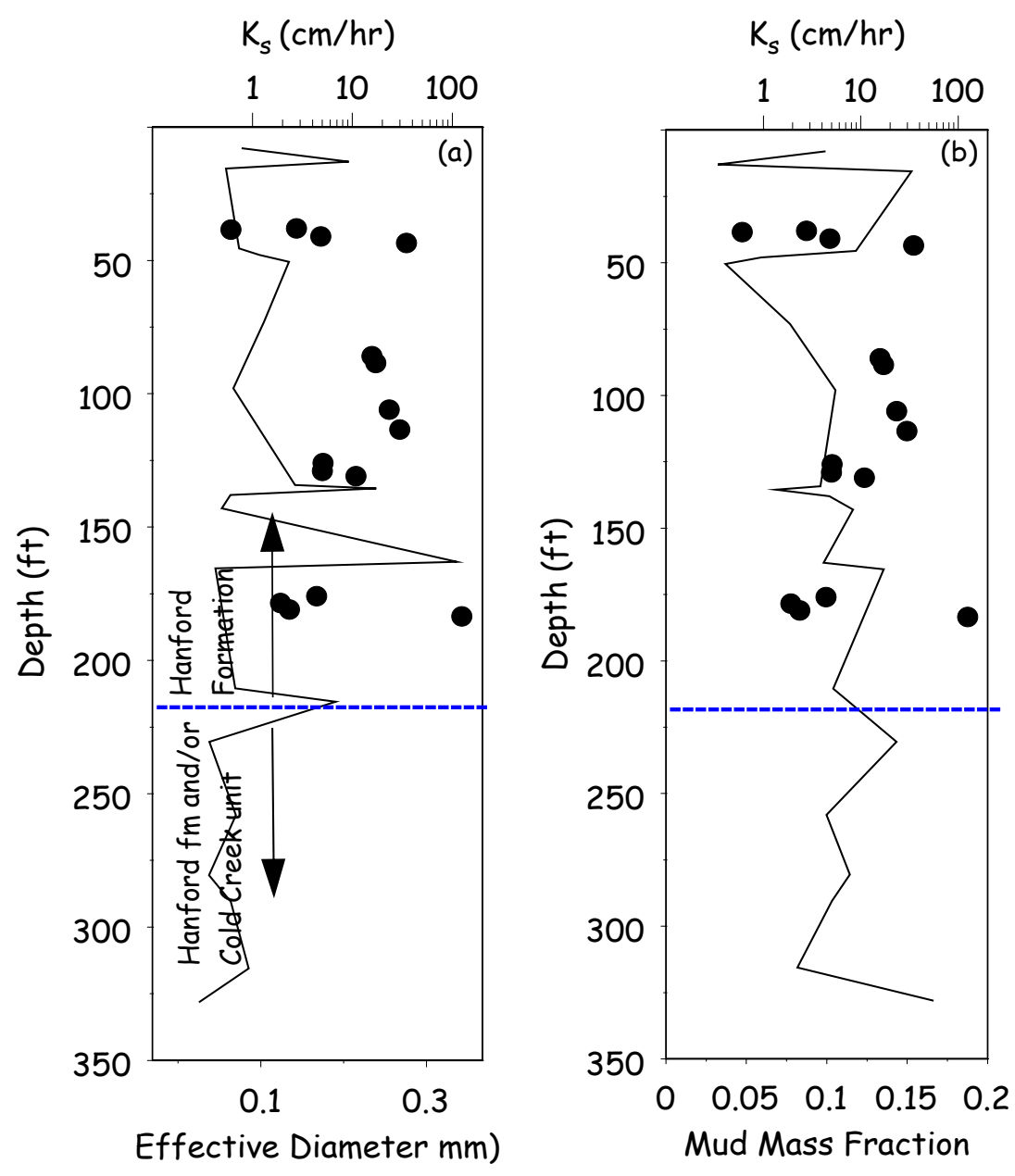

Figure 5.25. Plots of Saturated Hydraulic Conductivity for Borehole C5923 (A) Core Samples, (a) $K_{s}$ Compared to Effective Diameter from PSDs, (b) $\mathrm{K}_{\mathrm{s}}$ Compared to Mud (silt plus clay) Mass Fraction

\subsubsection{Air Permeability}

Table 5.20 presents a summary of the air permeability for core samples from Borehole C5923 (A). Although the procedure usually calls for drying of the sample, air permeability was measured at the antecedent moisture to gain insight into air permeability under field conditions. Such information is critical to the design and operation of the soil desiccation systems that may be used at the site. The values presented in Table 5.20 represent the intrinsic air permeability, $k_{a}$. Whereas the soil's hydraulic conductivity depends on properties of both the soil matrix and moving fluid, the soil permeability is a function of the soil's pore-space characteristics, that is, porosity, pore-size distribution, pore shape, pore tortuosity, and connectivity. The intrinsic air permeability is therefore a measure of the average crosssectional area of the pores conducting air and has dimensions of $\mathrm{m}^{2}$. An air-permeability value equivalent to the saturated hydraulic conductivity can be calculated as shown in Equation 5.2 following Table 5.20. 
PNNL-17821

Table 5.20. Air Permeability at Antecedent Soil Water Content for Borehole C5923 (A) Samples

\begin{tabular}{|c|c|c|c|c|c|}
\hline \multirow[b]{2}{*}{ HEIS ID } & \multicolumn{3}{|c|}{ Depth (ft) } & \multirow{2}{*}{$\begin{array}{c}\begin{array}{c}\text { Intrinsic Air } \\
\text { Permeability }\end{array} \\
k\left(\mathrm{~m}^{2}\right)\end{array}$} & \multirow{2}{*}{$\begin{array}{c}\begin{array}{c}\text { Air } \\
\text { Permeability }\end{array} \\
\mathrm{cm} / \mathrm{hr}\end{array}$} \\
\hline & Top & Bot & Zmid & & \\
\hline B1T7J3-2 & 35 & 37 & 36 & NA & \\
\hline B1T7J3-3 & 35 & 37 & 36 & 4.19E-12 & 0.0813 \\
\hline B1T7J4-3 & 35 & 37 & 36 & 4.03E-13 & 0.0078 \\
\hline B1T7J5-2 & 40 & 42 & 41 & NA & \\
\hline B1T7J5-3 & 40 & 42 & 41 & $1.55 \mathrm{E}-11$ & 0.3009 \\
\hline B1T7J6-2 & 43 & 45 & 44 & $1.21 \mathrm{E}-10$ & 2.3539 \\
\hline B1T7J6-3 & 43 & 45 & 44 & 3.95E-12 & 0.0767 \\
\hline B1T7J7-2 & 85 & 88 & 86.5 & 3.74E-11 & 0.7255 \\
\hline B1T7J7-3 & 85 & 88 & 86.5 & $3.26 \mathrm{E}-11$ & 0.6326 \\
\hline B1T7J8-3 & 88 & 90 & 89 & 4.39E-11 & 0.8517 \\
\hline B1T7J8-2 & 88 & 90 & 89 & 5.70E-12 & 0.1106 \\
\hline B1T7J9-2 & 105 & 108 & 106.5 & 1.12E-11 & 0.2179 \\
\hline B1T7J9-3 & 105 & 108 & 106.5 & $3.40 \mathrm{E}-11$ & 0.6607 \\
\hline B1T7K0-3 & 108 & 110 & 109 & $1.53 \mathrm{E}-11$ & 0.2976 \\
\hline B1T7K0-2 & 108 & 110 & 109 & NA & \\
\hline B1T7L3-3 & 113 & 115 & 114 & 5.94E-11 & 1.1537 \\
\hline B1T7L3-2 & 113 & 115 & 114 & 1.44E-11 & 0.2796 \\
\hline B1T7K1-3 & 125 & 128 & 126.5 & $1.40 \mathrm{E}-11$ & 0.2711 \\
\hline B1T7K1-2 & 125 & 128 & 126.5 & $1.88 \mathrm{E}-12$ & 0.0366 \\
\hline B1T7K2-3 & 128 & 130 & 129 & $1.55 \mathrm{E}-11$ & 0.3001 \\
\hline B1T7K2-2 & 128 & 130 & 129 & NA & \\
\hline B1T7K3-3 & 130 & 133 & 131.5 & 3.54E-11 & 0.6870 \\
\hline B1T7K3-2 & 130 & 133 & 131.5 & 2.44E-12 & 0.0474 \\
\hline B1T7K4-3 & 133 & 135 & 134 & $1.32 \mathrm{E}-11$ & 0.2567 \\
\hline B1T7K4-2 & 133 & 135 & 134 & 7.02E-13 & 0.0136 \\
\hline B1T7K5-2 & 175 & 177 & 176 & $6.18 \mathrm{E}-12$ & 0.1201 \\
\hline B1T7K5-3 & 175 & 177 & 176 & 2.61E-11 & 0.5070 \\
\hline B1T7K6-2 & 178 & 180 & 179 & $2.46 \mathrm{E}-12$ & 0.0477 \\
\hline B1T7K6-3 & 178 & 180 & 179 & $1.79 \mathrm{E}-11$ & 0.3483 \\
\hline B1T7K7-3 & 180 & 183 & 181.5 & $2.54 \mathrm{E}-12$ & 0.0493 \\
\hline B1T7K7-2 & 180 & 183 & 181.5 & $1.18 \mathrm{E}-12$ & 0.0229 \\
\hline B1T7K8-3 & 183 & 185 & 184 & $1.34 \mathrm{E}-11$ & 0.2611 \\
\hline B1T7K8-2 & 183 & 185 & 184 & NA & \\
\hline B1T7K9-3 & 235 & 238 & 236.5 & $5.22 \mathrm{E}-11$ & 1.0134 \\
\hline B1T7K9-2 & 235 & 238 & 236.5 & $2.80 \mathrm{E}-11$ & 0.5437 \\
\hline B1T7L0-2 & 238 & 240 & 239 & $5.22 \mathrm{E}-11$ & 1.0134 \\
\hline B1T7L0-3 & 238 & 240 & 239 & $7.90 \mathrm{E}-11$ & 1.5347 \\
\hline B1T7L1-3 & 240 & 243 & 241.5 & 8.30E-11 & 1.6126 \\
\hline B1T7L1-2 & 240 & 243 & 241.5 & $1.73 \mathrm{E}-10$ & 3.3643 \\
\hline B1T7L2-3 & 243 & 245 & 244 & $1.33 \mathrm{E}-11$ & 0.2592 \\
\hline B1T7L2-2 & 243 & 245 & 244 & $2.94 \mathrm{E}-11$ & 0.5704 \\
\hline
\end{tabular}




$$
K_{a}=\kappa_{a} \frac{\rho_{a} g}{\mu}
$$

where $K_{a}=$ pneumatic conductivity

$\rho_{\mathrm{a}}=$ density of air

$g=$ acceleration due to gravity

$\mu=$ dynamic viscosity of air.

The intrinsic air permeability ranged from $4 \times 10^{-13} \mathrm{~m}^{2}$ to $1.73 \times 10^{-10} \mathrm{~m}^{2}$ with a mean value of $2.95 \times 10^{-11} \mathrm{~m}^{2}$. The pneumatic conductivity ranged from $0.0078 \mathrm{~cm} / \mathrm{hr}$ to $3.36 \mathrm{~cm} / \mathrm{hr}$ with a mean value of $0.57 \mathrm{~cm} / \mathrm{hr}$.

Saturated hydraulic conductivity and air conductivity show similar trends with depth and a similar relation to texture parameters (see Figure 5.26). Samples that showed a high antecedent moisture were typically finer in texture and showed low conductivities for both air and water whereas coarser, drier samples showed high conductivities for both air and water. A striking difference, however, is the large difference in absolute values for air and water conductivities. Such differences can be expected to increase from cores to the undisturbed field conditions. Tuli et al. (2005) reported large differences between disturbed and undisturbed samples, suggesting a large impact of soil structure and pore-space characteristics on air flow. They reported that the permeability of both fluid phases (air and water) was greatly reduced for the disturbed samples, especially for soil air permeability, due to its greater dependency on soil aggregation and structure. An even more important observation was that regardless of soil disturbance, the tortuosity-connectivity parameter $(l)$ for the water permeability and air permeability functions were different. Our measurements of air permeability were not made at dry conditions, but the larger differences between air permeability and water permeability suggest that such a discrepancy might indeed exist. This would indicate a need to move away from the general practice of using the same parameter value for both the air and water phase permeabilities. Nonetheless, these data provide an important benchmark against which field measurements of air permeability for desiccation treatability testing can be compared. 
PNNL-17821

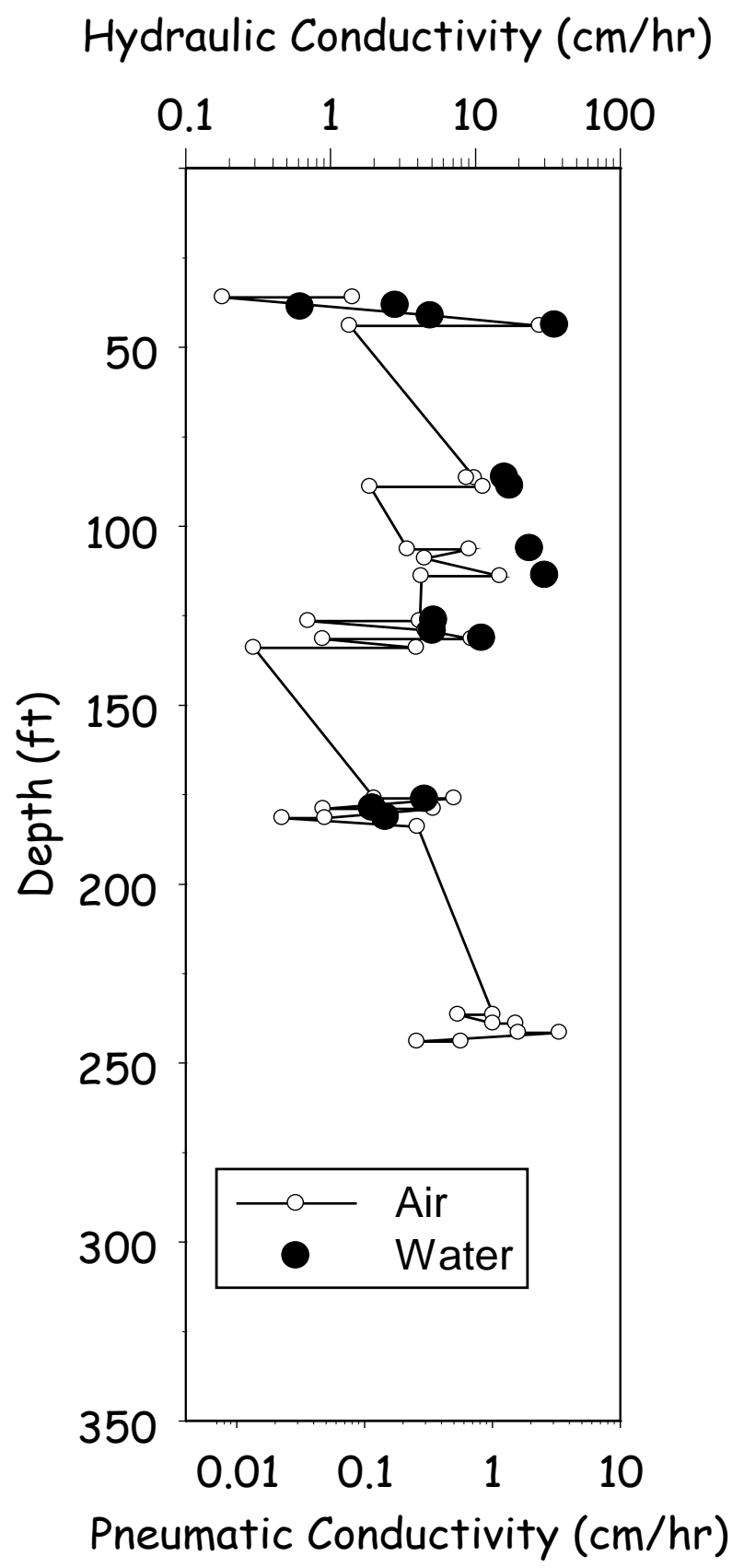

Figure 5.26. Plots of Air Conductivity at the Antecedent Moisture Content and Saturated Hydraulic Conductivity for Borehole C5923 (A) Core Samples

\subsubsection{Laboratory Electrical Results for Borehole C5923 (A)}

Resistivity measurements were made on all undisturbed cores and many repacked grab samples. The results of these measurements are summarized in Table 5.21. The resistivity ranged from $2.38 \mathrm{ohm}-\mathrm{m}$ to $13,909 \mathrm{ohm}-\mathrm{m}(\Omega \mathrm{m})$ whereas the injection current ranged from 1 to $100 \mathrm{~mA}$. Overall, repeatability was quite good with the standard deviation $(\sigma)$ of five replicate measurements generally falling between 0 and 
5\%. A small fraction of samples that showed somewhat higher values of $\sigma$ was typically coarse with low moisture content. Data quality was also assessed by calculating the reciprocity from measurements in which the current and potential electrodes were reversed. Ideally, measurements made with an electrode configuration must show full reciprocity. In other words, reciprocal measurements in which the current and potential electrodes are reversed should have the same apparent resistivity. In general, reciprocal measurements showed a reciprocity of between $5 \%$, which is considered good, and $1 \%$, which is considered very good. A dataset with $1 \%$ reciprocity represents the ideal dataset.

Of the total number of samples, there were 12 samples on which no resistivity measurements could be made with the MiniSting ${ }^{\circledR}$ (AGI-Advanced Geosciences, Inc., Austin, Texas) resistivity meter. These samples appeared too resistive to inject current into the sample. Even after sequentially reducing the injected current from $100 \mathrm{~mA}$ down to $1 \mathrm{~mA}$, it was impossible to determine the resistivity. In general, these samples were coarse textured and very low in moisture.

Table 5.21. Summary of Laboratory MiniSting Resistivity Measurements on Borehole C5923 (A) Samples

\begin{tabular}{llrrrrrrr}
\hline Type & HEIS \# & $\mathrm{Z}_{\text {top }}(\mathrm{ft})$ & $\mathrm{Z}_{\text {bot }}(\mathrm{ft})$ & $\mathrm{Z}_{\text {mid }}(\mathrm{ft})$ & \multicolumn{1}{l}{$\mathrm{V} / \mathrm{I}(\mathrm{W})$} & $\sigma(\%)$ & $\mathrm{I}(\mathrm{mA})$ & $\rho(\mathrm{Ohm}-\mathrm{m})$ \\
\hline Grab & B1T740 & 5.00 & 6.00 & 5.50 & 3767.80 & 12.30 & 5.00 & 977.74 \\
\hline Grab & B1T741 & 7.50 & 8.50 & 8.00 & 4340.00 & 0.20 & 5.00 & 1126.20 \\
\hline Grab & B1T742 & 10.00 & 11.00 & 10.50 & 14377.00 & 0.70 & 2.00 & 3730.90 \\
\hline Grab & B1T743 & 12.50 & 13.50 & 13.00 & 35630.00 & 1.00 & 1.00 & 9245.90 \\
\hline Grab & B1T744 & 15.00 & 16.00 & 15.50 & 1930.90 & 0.10 & 10.00 & 501.06 \\
\hline Grab & B1T745 & 17.50 & 18.50 & 18.00 & 5932.40 & 0.00 & 5.00 & 1539.40 \\
\hline Grab & B1T746 & 20.00 & 21.00 & 20.50 & 2273.09 & 0.00 & 10.00 & 591.23 \\
\hline Grab & B1T747 & 22.50 & 23.50 & 23.00 & 3641.90 & 0.00 & 2.00 & 945.04 \\
\hline Grab & B1T748 & 25.00 & 26.00 & 25.50 & 2970.30 & 0.20 & 10.00 & 770.79 \\
\hline Grab & B1T749 & 27.50 & 28.50 & 28.00 & 1697.50 & 0.30 & 10.00 & 440.50 \\
\hline Grab & B1T750 & 30.00 & 31.00 & 30.50 & 917.08 & 0.00 & 10.00 & 237.98 \\
\hline Grab & B1T751 & 32.50 & 33.50 & 33.00 & 2713.50 & 0.10 & 10.00 & 704.14 \\
\hline Grab & B1T825 & 36.50 & 37.00 & 36.75 & 100.59 & 47.40 & 2.00 & 26.10 \\
\hline Core & B1T7J3-3 & $\mathbf{3 8 . 0 0}$ & $\mathbf{3 8 . 5 0}$ & $\mathbf{3 8 . 2 5}$ & $\mathbf{1 1 1 . 3 6}$ & $\mathbf{0 . 0 0}$ & $\mathbf{5 . 0 0}$ & $\mathbf{3 4 . 9 9}$ \\
\hline Core & B1T7J3-2 & $\mathbf{3 8 . 5 0}$ & $\mathbf{3 9 . 0 0}$ & $\mathbf{3 8 . 7 5}$ & $\mathbf{5 6 . 8 0}$ & $\mathbf{0 . 1 0}$ & $\mathbf{1 0 0 . 0 0}$ & $\mathbf{1 7 . 8 4}$ \\
\hline Grab & B1T826 & 39.00 & 39.50 & 39.25 & 1405.10 & 0.00 & 10.00 & 364.62 \\
\hline Core & B1T7J5-3 & $\mathbf{4 0 . 5 0}$ & $\mathbf{4 1 . 0 0}$ & $\mathbf{4 0 . 7 5}$ & $\mathbf{1 1 . 8 1}$ & $\mathbf{0 . 4 0}$ & $\mathbf{5 . 0 0}$ & $\mathbf{3 . 7 1}$ \\
\hline Core & B1T7J5-2 & $\mathbf{4 1 . 0 0}$ & $\mathbf{4 1 . 5 0}$ & $\mathbf{4 1 . 2 5}$ & $\mathbf{1 4 1 . 4 1}$ & $\mathbf{0 . 1 0}$ & $\mathbf{1 0 0 . 0 0}$ & $\mathbf{4 4 . 4 3}$ \\
\hline Grab & B1T827 & 41.50 & 42.00 & 41.75 & N/A & N/A & N/A & N/A \\
\hline Core & B1T7J6-3 & $\mathbf{4 3 . 0 0}$ & $\mathbf{4 3 . 5 0}$ & $\mathbf{4 3 . 2 5}$ & $\mathbf{7 . 5 7}$ & $\mathbf{0 . 2 0}$ & $\mathbf{1 0 0 . 0 0}$ & $\mathbf{2 . 3 8}$ \\
\hline Core & B1T7J6-2 & $\mathbf{4 3 . 5 0}$ & $\mathbf{4 4 . 0 0}$ & $\mathbf{4 3 . 7 5}$ & $\mathbf{1 0 2 . 6 8}$ & $\mathbf{0 . 0 0}$ & $\mathbf{5 . 0 0}$ & $\mathbf{3 2 . 2 6}$ \\
\hline Grab & B1T828 & 44.00 & 44.50 & 44.25 & 945.58 & 0.10 & 10.00 & 245.37 \\
\hline Grab & B1T752 & 45.00 & 46.00 & 45.50 & 67.27 & 0.00 & 10.00 & 17.46 \\
\hline Grab & B1T753 & 47.50 & 48.50 & 48.00 & 298.71 & 0.50 & 10.00 & 77.51 \\
\hline Grab & B1T754 & 50.00 & 51.00 & 50.50 & 962.98 & 0.20 & 10.00 & 249.89 \\
\hline & & & & & & & & \\
\hline
\end{tabular}


Table 5.21 (Contd)

\begin{tabular}{|c|c|c|c|c|c|c|c|c|}
\hline Type & HEIS \# & $\mathrm{Z}_{\text {top }}(\mathrm{ft})$ & $\mathrm{Z}_{\text {bot }}(\mathrm{ft})$ & $\mathrm{Z}_{\text {mid }}(\mathrm{ft})$ & $\mathrm{V} / \mathrm{I}(\mathrm{W})$ & $\sigma(\%)$ & $\mathrm{I}(\mathrm{mA})$ & $\rho(\mathrm{Ohm}-\mathrm{m})$ \\
\hline Grab & B1T755 & 52.50 & 53.50 & 53.00 & 1096.40 & 0.10 & 10.00 & 284.50 \\
\hline Grab & B1T756 & 55.00 & 56.00 & 55.50 & N/A & N/A & N/A & N/A \\
\hline Grab & B1T757 & 57.50 & 58.50 & 58.00 & 722.49 & 1.10 & 10.00 & 187.48 \\
\hline Grab & B1T758 & 60.00 & 61.00 & 60.50 & 788.01 & 2.70 & 10.00 & 204.49 \\
\hline Grab & B1T759 & 62.50 & 63.50 & 63.00 & 2238.30 & 0.80 & 10.00 & 580.82 \\
\hline Grab & B1T760 & 65.00 & 66.00 & 65.50 & 1186.00 & 0.10 & 10.00 & 307.77 \\
\hline Grab & B1T761 & 67.50 & 68.50 & 68.00 & 539.08 & 0.30 & 10.00 & 139.89 \\
\hline Grab & B1T762 & 70.00 & 71.00 & 70.50 & 471.45 & 0.00 & 10.00 & 122.34 \\
\hline Grab & B1T763 & 72.50 & 73.50 & 73.00 & 109.84 & 16.20 & 10.00 & 28.50 \\
\hline Grab & B1T764 & 75.00 & 76.00 & 75.50 & 1654.60 & 0.10 & 10.00 & 429.37 \\
\hline Grab & B1T765 & 77.50 & 78.50 & 78.00 & 619.85 & 0.20 & 10.00 & 160.85 \\
\hline Grab & B1T766 & 80.00 & 81.00 & 80.50 & 79.49 & 0.00 & 10.00 & 20.63 \\
\hline Grab & B1T817 & 82.50 & 83.50 & 83.00 & 775.56 & 0.00 & 10.00 & 201.25 \\
\hline Core & B1T7J7-3 & 85.50 & 86.00 & 85.75 & 129.81 & 0.00 & 5.00 & 40.78 \\
\hline Core & B1T7J7-2 & 86.00 & 86.50 & 86.25 & 141.41 & 0.10 & 100.00 & 44.43 \\
\hline Grab & B1T829 & 86.50 & 87.00 & 86.75 & 645.13 & 0.00 & 10.00 & 167.41 \\
\hline Core & B1T7J8-3 & 88.00 & 88.50 & 88.25 & 101.87 & 0.00 & 5.00 & 32.00 \\
\hline Core & B1T7J8-2 & 88.50 & 89.00 & 88.75 & 78.42 & 0.20 & 100.00 & 24.64 \\
\hline Grab & B1T985 & 89.00 & 89.50 & 89.25 & 752.27 & 0.10 & 10.00 & 195.21 \\
\hline Grab & B1T768 & 90.00 & 91.00 & 90.50 & 465.32 & 0.20 & 10.00 & 120.75 \\
\hline Grab & B1T769 & 92.50 & 93.50 & 93.00 & 1307.00 & 0.00 & 5.00 & 339.16 \\
\hline Grab & B1T770 & 95.00 & 96.00 & 95.50 & 2251.70 & 0.50 & 10.00 & 584.31 \\
\hline Grab & B1T771 & 97.50 & 98.50 & 98.00 & 292.45 & 3.10 & 10.00 & 75.89 \\
\hline Grab & B1T772 & 100.00 & 101.00 & 100.50 & 155.36 & 0.20 & 10.00 & 40.32 \\
\hline Grab & B1T773 & 102.50 & 103.50 & 103.00 & 1460.50 & 0.20 & 10.00 & 378.98 \\
\hline Core & B1T7J9-3 & 105.50 & 106.00 & 105.75 & 207.45 & 0.10 & 5.00 & 65.17 \\
\hline Core & B1T7J9-2 & 106.00 & 106.50 & 106.25 & 246.67 & 0.00 & 20.00 & 77.49 \\
\hline Grab & В1Т9К9 & 106.50 & 107.00 & 106.75 & 1090.20 & 0.00 & 10.00 & 282.89 \\
\hline Core & В1Т7К0-3 & 108.00 & 108.50 & 108.25 & 233.49 & 0.00 & 5.00 & 73.35 \\
\hline Core & В1T7K0-2 & 108.50 & 109.00 & 108.75 & 41.69 & 0.00 & 20.00 & 13.10 \\
\hline Grab & B1T9L0 & 109.00 & 109.50 & 109.25 & 300.73 & 0.00 & 10.00 & 78.04 \\
\hline Core & B1T7L3-3 & 113.00 & 113.50 & 113.25 & 149.48 & 0.40 & 10.00 & 46.96 \\
\hline Core & B1T7L3-2 & 113.50 & 114.00 & 113.75 & 424.23 & 0.00 & 10.00 & 133.27 \\
\hline Grab & B1T9L1 & 114.00 & 114.50 & 114.25 & 918.82 & 0.10 & 10.00 & 238.43 \\
\hline Grab & B1T774 & 115.00 & 116.00 & 115.50 & 1499.80 & 0.50 & 10.00 & 389.19 \\
\hline Grab & B1T775 & 117.50 & 118.50 & 118.00 & N/A & N/A & N/A & N/A \\
\hline Grab & B1T776 & 120.00 & 121.00 & 120.50 & 1443.30 & 0.80 & 10.00 & 374.54 \\
\hline Grab & B1T777 & 122.50 & 123.50 & 123.00 & 257.63 & 52.70 & 2.00 & 66.85 \\
\hline Core & В1T7K1-3 & 125.50 & 126.00 & 125.75 & 164.35 & 0.20 & 5.00 & 51.63 \\
\hline Core & B1T7K1-2 & 126.00 & 126.50 & 126.25 & 95.71 & 0.10 & 20.00 & 30.07 \\
\hline Grab & B1T9L2 & 126.50 & 127.00 & 126.75 & 418.94 & 0.20 & 10.00 & 108.71 \\
\hline Grab & B1T9L3 & 129.00 & 129.50 & 129.25 & 1210.00 & 3.30 & 10.00 & 314.00 \\
\hline
\end{tabular}


Table 5.21 (Contd)

\begin{tabular}{|c|c|c|c|c|c|c|c|c|}
\hline Type & HEIS \# & $\mathrm{Z}_{\text {top }}(\mathrm{ft})$ & $\mathrm{Z}_{\text {bot }}(\mathrm{ft})$ & $\mathrm{Z}_{\text {mid }}(\mathrm{ft})$ & $\mathrm{V} / \mathrm{I}(\mathrm{W})$ & $\sigma(\%)$ & $\mathrm{I}(\mathrm{mA})$ & $\rho(\mathrm{Ohm}-\mathrm{m})$ \\
\hline Core & В1Т7К3-3 & 130.50 & 131.00 & 130.75 & 147.02 & 0.10 & 5.00 & 46.19 \\
\hline Core & В1T7K3-2 & 131.00 & 131.50 & 131.25 & 183.19 & 0.00 & 10.00 & 57.55 \\
\hline Grab & B1T9L4 & 131.50 & 132.00 & 131.75 & N/A & N/A & N/A & N/A \\
\hline Core & B1T7K4-3 & 133.00 & 133.50 & 133.25 & 334.71 & 0.00 & 5.00 & 105.15 \\
\hline Core & B1T7K4-2 & 133.50 & 134.00 & 133.75 & 36.81 & 0.00 & 10.00 & 11.56 \\
\hline Grab & B1T9L5 & 134.00 & 134.50 & 134.25 & 311.90 & 1.10 & 10.00 & 80.94 \\
\hline Grab & B1T778 & 135.00 & 136.00 & 135.50 & 164.16 & 0.10 & 10.00 & 42.60 \\
\hline Grab & B1T779 & 137.50 & 138.50 & 138.00 & 293.07 & 0.20 & 10.00 & 76.05 \\
\hline Grab & B1T780 & 140.00 & 141.00 & 140.50 & 1056.60 & 21.80 & 2.00 & 274.18 \\
\hline Grab & B1T781 & 142.50 & 143.50 & 143.00 & 242.23 & 0.10 & 10.00 & 62.86 \\
\hline Grab & B1T782 & 145.00 & 146.00 & 145.50 & 890.88 & 12.20 & 1.00 & 231.18 \\
\hline Grab & B1T783 & 147.50 & 148.50 & 148.00 & 836.86 & 4.70 & 10.00 & 217.16 \\
\hline Grab & B1T784 & 150.00 & 151.00 & 150.50 & 2757.00 & 0.30 & 5.00 & 715.42 \\
\hline Grab & B1T785 & 152.50 & 153.50 & 153.00 & 19790.00 & 1.60 & 1.00 & 5135.40 \\
\hline Grab & B1T786 & 155.00 & 156.00 & 155.50 & 4798.80 & 5.60 & 2.00 & 1245.30 \\
\hline Grab & B1T787 & 157.50 & 158.50 & 158.00 & 3267.50 & 1.00 & 5.00 & 847.90 \\
\hline Grab & B1T788 & 160.00 & 161.00 & 160.50 & 6883.20 & 2.00 & 2.00 & 1786.20 \\
\hline Grab & B1T789 & 162.50 & 163.50 & 163.00 & 26938.00 & 47.80 & 1.00 & 6990.30 \\
\hline Grab & B1T790 & 165.00 & 166.00 & 165.50 & 5907.80 & 1.70 & 5.00 & 1533.10 \\
\hline Grab & B1T791 & 167.50 & 168.50 & 168.00 & 393.39 & 0.00 & 10.00 & 102.08 \\
\hline Grab & B1T792 & 170.00 & 171.00 & 170.50 & 34359.00 & 0.20 & 2.00 & 8916.00 \\
\hline Grab & B1T793 & 172.50 & 173.50 & 173.00 & 20635.00 & 8.00 & 1.00 & 5354.60 \\
\hline Core & В1T7K5-3 & 175.50 & 176.00 & 175.75 & 4945.20 & 0.00 & 5.00 & 1553.60 \\
\hline Core & B1T7K5-2 & 176.00 & 176.50 & 176.25 & 4915.50 & 0.10 & 1.00 & 1544.30 \\
\hline Grab & B1T9L6 & 176.50 & 177.00 & 176.75 & 22115.00 & 0.20 & 2.00 & 5738.90 \\
\hline Core & В1T7K6-3 & 178.00 & 178.50 & 178.25 & 3093.90 & 0.00 & 5.00 & 971.97 \\
\hline Core & В1T7К6-2 & 178.50 & 179.00 & 178.75 & 3352.20 & 0.20 & 2.00 & 1053.10 \\
\hline Grab & B1T9L7 & 179.00 & 179.50 & 179.25 & 15435.00 & 1.30 & 1.00 & 4005.20 \\
\hline Core & B1T7K7-3 & 181.00 & 181.50 & 181.25 & 1758.70 & 0.00 & 5.00 & 552.51 \\
\hline Core & B1T7K7-2 & 181.50 & 181.50 & 181.50 & 1622.50 & 0.00 & 10.00 & 509.72 \\
\hline Grab & B1T9L8 & 181.50 & 182.00 & 181.75 & 19852.00 & 0.00 & 1.00 & 5151.40 \\
\hline Core & В1T7K8-3 & 183.00 & 183.50 & 183.25 & N/A & N/A & N/A & N/A \\
\hline Core & В1T7K8-2 & 183.50 & 184.00 & 183.75 & 1642.00 & 0.00 & 10.00 & 515.85 \\
\hline Grab & B1T9L9 & 184.00 & 184.50 & 184.25 & 20839.00 & 0.10 & 2.00 & 5407.60 \\
\hline Grab & B1T794 & 185.00 & 186.00 & 185.50 & 12225.00 & 0.50 & 2.00 & 3172.30 \\
\hline Grab & B1T795 & 187.50 & 188.50 & 188.00 & 11101.00 & 0.10 & 2.00 & 2880.70 \\
\hline Grab & B1T796 & 190.00 & 191.00 & 190.50 & 13411.00 & 3.80 & 2.00 & 3480.20 \\
\hline Grab & B1T819 & 190.00 & 191.00 & 190.50 & 14391.00 & 0.30 & 2.00 & 3734.40 \\
\hline Grab & B1T797 & 192.50 & 193.50 & 193.00 & 2471.80 & 3.60 & 10.00 & 641.41 \\
\hline Grab & В1T798 & 195.00 & 196.00 & 195.50 & 11679.00 & 1.50 & 2.00 & 3030.70 \\
\hline Grab & В1T799 & 197.50 & 198.50 & 198.00 & 22197.00 & 4.10 & 2.00 & 5760.10 \\
\hline Grab & B1T7B0 & 200.00 & 201.00 & 200.50 & 4180.20 & 0.10 & 5.00 & 1084.70 \\
\hline
\end{tabular}


Table 5.21 (Contd)

\begin{tabular}{|c|c|c|c|c|c|c|c|c|}
\hline Type & HEIS \# & $\mathrm{Z}_{\text {top }}(\mathrm{ft})$ & $\mathrm{Z}_{\text {bot }}(\mathrm{ft})$ & $\mathrm{Z}_{\text {mid }}(\mathrm{ft})$ & $\mathrm{V} / \mathrm{I}(\mathrm{W})$ & $\sigma(\%)$ & $\mathrm{I}(\mathrm{mA})$ & $\rho(\mathrm{Ohm}-\mathrm{m})$ \\
\hline Grab & B1T7B1 & 202.50 & 203.50 & 203.00 & 3181.60 & 0.20 & 10.00 & 825.62 \\
\hline Grab & B1T7B2 & 205.00 & 206.00 & 205.50 & 3460.90 & 0.00 & 5.00 & 898.08 \\
\hline Grab & B1T820 & 205.00 & 206.00 & 205.50 & 3255.40 & 0.00 & 5.00 & 844.75 \\
\hline Grab & B1T7B3 & 207.50 & 208.50 & 208.00 & 1314.70 & 0.20 & 10.00 & 341.15 \\
\hline Grab & B1T7B4 & 210.00 & 211.00 & 210.50 & 364.03 & 0.10 & 10.00 & 94.47 \\
\hline Grab & B1T7B5 & 212.50 & 213.50 & 213.00 & 350.72 & 0.00 & 10.00 & 91.01 \\
\hline Grab & B1T7B6 & 215.00 & 216.00 & 215.50 & 88.42 & 0.10 & 10.00 & 22.95 \\
\hline Grab & B1T7B7 & 217.50 & 218.50 & 218.00 & 677.12 & 0.20 & 10.00 & 175.71 \\
\hline Grab & B1T7B8 & 220.00 & 221.00 & 220.50 & 1053.20 & 0.40 & 10.00 & 273.31 \\
\hline Grab & B1T7B9 & 222.50 & 223.50 & 223.00 & 424.32 & 0.00 & 5.00 & 110.11 \\
\hline Grab & B1T7C0 & 225.00 & 226.00 & 225.50 & 550.88 & 0.10 & 10.00 & 142.95 \\
\hline Grab & B1T7C1 & 227.50 & 228.50 & 228.00 & 710.69 & 16.60 & 2.00 & 184.42 \\
\hline Grab & B1T7C2 & 230.00 & 231.00 & 230.50 & 628.91 & 0.00 & 10.00 & 163.20 \\
\hline Grab & B1T7C3 & 232.50 & 233.50 & 233.00 & 1737.90 & 0.10 & 10.00 & 450.98 \\
\hline Core & В1Т7К9-3 & 235.50 & 236.00 & 235.75 & 217.72 & 0.00 & 10.00 & 68.40 \\
\hline Core & В1Т7К9-2 & 236.00 & 236.50 & 236.25 & 175.91 & 0.10 & 10.00 & 55.26 \\
\hline Grab & В1Т9К6 & 236.50 & 237.00 & 236.75 & 2212.20 & 7.10 & 10.00 & 574.07 \\
\hline Core & B1T7L0-3 & 238.00 & 238.50 & 238.25 & N/A & N/A & N/A & N/A \\
\hline Core & B1T7L0-2 & 238.50 & 239.00 & 238.75 & 197.32 & 0.00 & 10.00 & 61.99 \\
\hline Grab & В1T9K7 & 239.00 & 239.50 & 239.25 & 2165.50 & 0.00 & 10.00 & 561.94 \\
\hline Core & B1T7L1-3 & 240.50 & 241.00 & 240.75 & 286.23 & 0.00 & 10.00 & 89.92 \\
\hline Core & B1T7L1-2 & 241.00 & 241.50 & 241.25 & 213.43 & 0.10 & 10.00 & 67.05 \\
\hline Grab & В1Т9К8 & 241.50 & 242.00 & 241.75 & 2473.60 & 3.20 & 10.00 & 641.88 \\
\hline Core & B1T7L2-3 & 243.00 & 243.50 & 243.25 & 361.38 & 0.00 & 5.00 & 113.53 \\
\hline Core & B1T7L2-2 & 243.50 & 244.00 & 243.75 & 406.77 & 3.90 & 1.00 & 127.79 \\
\hline Grab & B1T824 & 244.00 & 244.50 & 244.25 & 4607.60 & 0.00 & 10.00 & 1195.60 \\
\hline Grab & B1T7C4 & 245.00 & 246.00 & 245.50 & 3493.40 & 0.70 & 5.00 & 906.51 \\
\hline Grab & B1T7C5 & 247.50 & 248.50 & 248.00 & 3501.20 & 0.10 & 10.00 & 908.54 \\
\hline Grab & B1T7C6 & 250.00 & 251.00 & 250.50 & 20034.00 & 0.50 & 2.00 & 5198.70 \\
\hline Grab & B1T7C8 & 252.50 & 253.50 & 253.00 & 38572.00 & 0.40 & 1.00 & 10009.00 \\
\hline Grab & B1T7C7 & 255.00 & 256.00 & 255.50 & 11213.00 & 0.30 & 2.00 & 2909.80 \\
\hline Grab & B1T7C9 & 257.50 & 258.50 & 258.00 & 13426.00 & 0.20 & 1.00 & 3483.90 \\
\hline Grab & B1T7D0 & 260.00 & 261.00 & 260.50 & 28417.00 & 2.90 & 1.00 & 7374.20 \\
\hline Grab & B1T7D1 & 262.50 & 263.50 & 263.00 & 12168.00 & 0.20 & 2.00 & 3157.50 \\
\hline Grab & B1T7D2 & 265.00 & 266.00 & 265.50 & 44637.00 & 2.00 & 1.00 & 11583.00 \\
\hline Grab & B1T7D3 & 267.50 & 268.50 & 268.00 & 25208.00 & 0.80 & 1.00 & 6541.50 \\
\hline Grab & B1T7D4 & 270.00 & 271.00 & 270.50 & 22240.00 & 6.50 & 2.00 & 5771.10 \\
\hline Grab & B1T7D5 & 272.50 & 273.50 & 273.00 & 28127.00 & 3.20 & 1.00 & 7298.80 \\
\hline Grab & B1T7D6 & 275.00 & 276.00 & 275.50 & 20945.00 & 0.10 & 2.00 & 5435.00 \\
\hline Grab & B1T7D7 & 277.50 & 278.50 & 278.00 & 53599.00 & 12.80 & 1.00 & 13909.00 \\
\hline Grab & B1T7D8 & 280.00 & 281.00 & 280.50 & 32300.00 & 0.20 & 1.00 & 8381.70 \\
\hline Grab & B1T7D9 & 282.50 & 283.50 & 283.00 & N/A & N/A & N/A & N/A \\
\hline
\end{tabular}


Table 5.21 (Contd)

\begin{tabular}{|c|c|c|c|c|c|c|c|c|}
\hline Type & HEIS \# & $\mathrm{Z}_{\text {top }}(\mathrm{ft})$ & $\mathrm{Z}_{\text {bot }}(\mathrm{ft})$ & $\mathrm{Z}_{\text {mid }}(\mathrm{ft})$ & $\mathrm{V} / \mathrm{I}(\mathrm{W})$ & $\sigma(\%)$ & $\mathrm{I}(\mathrm{mA})$ & $\rho(\mathrm{Ohm}-\mathrm{m})$ \\
\hline Grab & B1T7F0 & 285.00 & 286.00 & 285.50 & 39543.00 & 0.80 & 1.00 & 10261.00 \\
\hline Grab & B1T7F1 & 287.50 & 288.50 & 288.00 & 32565.00 & 6.20 & 1.00 & 8450.60 \\
\hline Grab & B1T7F2 & 290.00 & 291.00 & 290.50 & 11060.00 & 2.40 & 2.00 & 2870.00 \\
\hline Grab & B1T7F3 & 292.50 & 293.50 & 293.00 & 20464.00 & 0.00 & 1.00 & 5310.40 \\
\hline Grab & B1T7F4 & 295.00 & 296.00 & 295.50 & 51541.00 & 0.10 & 1.00 & 13375.00 \\
\hline Grab & B1T7F5 & 297.50 & 298.50 & 298.00 & 34688.00 & 0.90 & 1.00 & 9001.30 \\
\hline Grab & B1T7F6 & 300.00 & 301.00 & 300.50 & 37640.00 & 0.00 & 1.00 & 9767.30 \\
\hline Grab & B1T7F7 & 302.50 & 303.50 & 303.00 & 53326.00 & 1.90 & 1.00 & 13838.00 \\
\hline Grab & B1T7F8 & 305.00 & 306.00 & 305.50 & 38879.00 & 0.20 & 1.00 & 10089.00 \\
\hline Grab & B1T7F9 & 307.50 & 308.50 & 308.00 & 33352.00 & 6.20 & 1.00 & 8654.60 \\
\hline Grab & В1T7H0 & 310.00 & 311.00 & 310.50 & 41038.00 & 5.20 & 1.00 & 10649.00 \\
\hline Grab & B1T7H1 & 312.50 & 313.50 & 313.00 & 49692.00 & 3.00 & 1.00 & 12895.00 \\
\hline Grab & B1T7H2 & 315.00 & 316.00 & 315.50 & 40213.00 & 0.20 & 1.00 & 10435.00 \\
\hline Grab & В1Т7Н3 & 317.50 & 318.50 & 318.00 & N/A & N/A & N/A & N/A \\
\hline Grab & B1T7H4 & 320.00 & 321.00 & 320.50 & 30189.00 & 0.10 & 1.00 & 7833.80 \\
\hline Grab & B1T7H5 & 322.50 & 323.50 & 323.00 & 32308.00 & 0.10 & 1.00 & 8383.80 \\
\hline Grab & B1T7H6 & 325.00 & 326.00 & 325.50 & 50499.00 & 0.70 & 1.00 & 13104.00 \\
\hline Grab & B1T7H7 & 327.50 & 328.50 & 328.00 & N/A & N/A & N/A & N/A \\
\hline Grab & В1T823 & 330.00 & 331.00 & 330.50 & 51564.00 & 0.30 & 1.00 & 13381.00 \\
\hline Grab & В1Т7Н9 & 332.50 & 333.50 & 333.00 & 47976.00 & 7.10 & 1.00 & 12450.00 \\
\hline Grab & B1T7J0 & 335.00 & 336.00 & 335.50 & N/A & N/A & N/A & N/A \\
\hline Grab & B1T7J1 & 337.50 & 338.50 & 338.00 & N/A & N/A & N/A & N/A \\
\hline Grab & B1T7J2 & 340.00 & 342.00 & 341.00 & 42405.00 & 2.60 & 1.00 & 11004.00 \\
\hline Grab & В1T984 & 341.00 & 342.00 & 341.50 & N/A & N/A & N/A & N/A \\
\hline Grab & B1V530 & 343.50 & 344.50 & 344.00 & N/A & N/A & N/A & N/A \\
\hline Grab & B1V531 & 346.00 & 347.00 & 346.50 & N/A & N/A & N/A & N/A \\
\hline Grab & B1V532 & 348.50 & 349.50 & 349.00 & N/A & N/A & N/A & N/A \\
\hline Grab & B1V533 & 351.00 & 352.00 & 351.50 & N/A & N/A & N/A & N/A \\
\hline
\end{tabular}

\subsubsection{Profile of Laboratory-Measured Soil Electrical Resistivity}

Figure 5.27 shows semi-log plots of the measured bulk-resistivity for all the samples analyzed and the resistivity separated by sample type for Borehole C5923 (A). Figure 5.27a shows a single plot of all resistivity values whereas Figure 5.27b separates resistivity into values measured on the cores and those measured on the grab samples. The resistivity profile shows essentially two scales of spatial variability, one at a relatively small scale and the other at a much larger scale. The small-scale variation in resistivity persists over the entire profile and is most likely associated with small-scale changes in texture and the effect of the equilibrium moisture content. These small-scale lithologic changes correlate well with the location of fine-textured layers as identified on the geologist's log (see Appendix A) and are known to 
affect the distribution of contaminants. Thus, these variations in texture and moisture content have a compounding effect on soil resistivity. Finally, the resistivity profile provides some insight into the locations of fine-textured layers and their impact on contaminant distribution.

The moist fine-grained layers typically exhibit relatively low resistivity because of water content and solute concentration that are higher than those in adjacent coarser materials. The top $15 \mathrm{ft}$ of sediments in borehole C5923 appears to be quite resistive with resistivity values ranging from around $1000 \mathrm{Ohm}-\mathrm{m}$ to $9000 \mathrm{Ohm}-\mathrm{m}$. The resistivity shows a sharp decline to around $700 \mathrm{Ohm}-\mathrm{m}$ between 15 and $33 \mathrm{ft}$ bgs after which it decreases to a mean value of around $150 \mathrm{Ohm}-\mathrm{m}$ between 33 and $150 \mathrm{ft}$ bgs. However, there are several instances where resistivity dropped below this value and provided a potentially strong target for detection. Strong targets occur between 40 and $60 \mathrm{ft}$, between 75 and $125 \mathrm{ft}$, and between 200 and $250 \mathrm{ft}$ bgs (Figure 5.27), with the strongest target centered between 40 and $60 \mathrm{ft}$. In this zone, the measured bulk resistivity decreased sharply to less than $10 \mathrm{Ohm}-\mathrm{m}$. Given the proximity to the surface, this response is likely due to the combined effects of high moisture, from natural recharge, and high porewater ionic strength from the past liquid-waste discharges. Measured resistivity values from 75 to $150 \mathrm{ft}$ bgs are also significantly less than the background resistivity of native pore waters and sediments, suggesting the presence of electrolytic contaminants. The small-scale variations in soil texture in this zone are likely acting as localized capillary breaks that would have been penetrated under large fluxes of water but would subsequently limit the downward migration of contaminants because of low hydraulic conductivities at the antecedent moisture. Another zone of low resistivity is evident between 200 and $250 \mathrm{ft}$ with a mean resistivity of around $200 \mathrm{Ohm}-\mathrm{m}$. Based on the geologist's logs, the $220 \mathrm{ft}$-depth is assumed to be the contact between the Hanford formation and Cold Creek unit and represents a major change in texture to coarser sediments. Under current recharge conditions, it is unlikely that there is a large accumulation of moisture at this depth. These resistivity values are again significantly lower than those expected for native coarse-textured sediments. Thus, the sharp decline in resistivity is most likely due to an accumulation of contaminants at or near the contact between these two sedimentary units. 
PNNL-17821
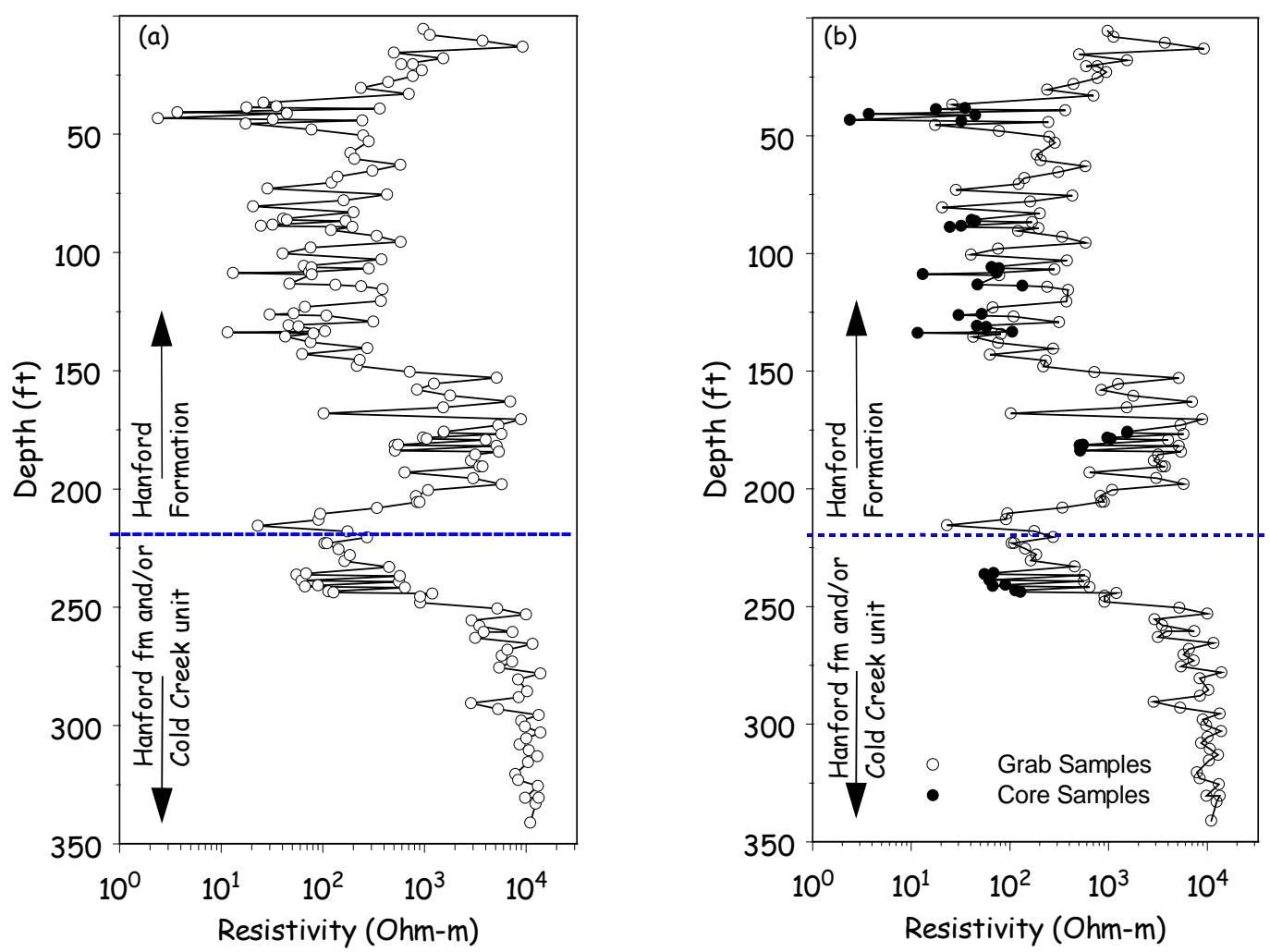

Figure 5.27. Semi-Log Plot of Vertical Resistivity Profile at the Location of Borehole C5923 (A), (a) Resistivity on all Samples, and (b) Resistivity Separated by Sample Type. Measurements were made on core and grab samples using a Mini-Sting resistivity meter with a 2" Wenner Array.

Most of the vertical resistivity variability is in the Hanford formation, above the 220-ft depth. Below this depth, small-scale fluctuations decrease dramatically, suggesting a more homogeneous distribution of texture and therefore less variation in moisture. The soil-resistivity profile is therefore interpreted to describe a pattern of contamination that can be attributed to the downward migration of waste fluids disposed of to the neighboring cribs. Owing to the low-resistivity values at depth (e.g., $250 \mathrm{ft}$ ), it can be surmised that waste fluids penetrated at least to this depth. This is consistent with the pore-water chemical analyses and the volume of water discharged at the neighboring cribs. Although the resistivity profile alone is insufficient to determine whether contaminants entered the groundwater, this profile provides some indication of the depth to which the most concentrated nitrate waste migrated. However, not all of the small-scale fluctuation is due to small-scale lithologic differences. Figure 5.27b shows that core-measured resistivities were generally lower than those measured on adjacent repacked grab samples. This discrepancy may be due to two factors: 1 ) differences in bulk density and packing arrangement between the less-disturbed cores and repacked samples and 2) possible differences in moisture content between the two samples. Although efforts were made to pack the grab samples to representative densities, it is essentially impossible to reproduce the packing arrangement and density of the cores. Further, there is always some small loss of water from the grab samples when they are being examined and/or processed in the dry laboratory atmosphere. 
Electrical conductivity is strongly dependent on the formation factor, which is essentially the inverse of the tortuosity factor. A repacked sample with a smaller tortuosity factor, hence a larger formation factor, would give rise to a more resistive medium under equivalent moisture contents and salt concentrations. While the cores remained capped and sealed between sampling and measurement, the grab samples were opened for sub-sampling to conduct chemical analyses, which would have made them susceptible to moisture loss. Lower moisture contents in the core would contribute to a larger bulk resistivity.

\subsubsection{Relationship Between Apparent Bulk Resistivity and Pore-water Chemistry}

Figure 5.28 compares the laboratory-measured soil resistivity profile with the calculated concentration of nitrate (dilution corrected 1:1 sediment to de-ionized water extracts). The trend in the pore-water nitrate profile is consistent with that observed in the laboratory soil resistivity profile. The nitrate concentration gradually increases from the surface down to about $25 \mathrm{ft}$ bgs after which it shows a sharp increase and reaches a peak at around $45 \mathrm{ft}$ bgs. Although the resistivity data show a lot more small-scale fluctuations than the nitrate data, the trends are quite consistent with resistivity decreasing as nitrate concentration increases. The nitrate concentration starts to decline from around $140 \mathrm{ft}$ bgs to reach a minimum at $175 \mathrm{ft}$ bgs whereas resistivity increases in the same interval. The nitrate plume is at least bimodal (if not tri-modal) with the deepest peak occurring at or near the interface between the Hanford and Cold Creek units. The soil resistivity shows a sharp decline in the same interval after which it increases to background levels from about $250 \mathrm{ft}$ bgs to the bottom of the borehole. Even though there is measurable nitrate at depths beyond $250 \mathrm{ft}$, the sediments were quite dry, and resistivity measurements, when possible, were quite high, on the order of $10 \mathrm{k} \mathrm{Ohm}-\mathrm{m}$. The high correlation between pore-water nitrate concentration and measured soil resistivity suggests that these data could be combined to allow inferences of spatial distribution of nitrate concentrations, or resistivity response, at the site.

Figure 5.29 shows a similar plot for pore-water ${ }^{99}$ Tc concentration as a function of depth. The concentration of ${ }^{99}$ Tc required to generate a decrease in the apparent resistivity is quite large, and as such, resistivity cannot be used to detect technetium-99. However, as seen in Figure 5.29b, the relationship between the resistivity and technetium-99 profiles is quite good and essentially mimics that of pore-water nitrate. Because technetium-99 mobility is similar to nitrate mobility, the correlation between technetium-99 and laboratory-measured apparent resistivity is actually caused by the nitrate in the pore water. Figure 5.30 shows the plot for pore-water total ionic strength, which theoretically best represents the electrical conductance properties of the pore water. The inverse relationship between the laboratory measured bulk resistivity and total ionic strength is equally strong, as might be expected. 
PNNL-17821
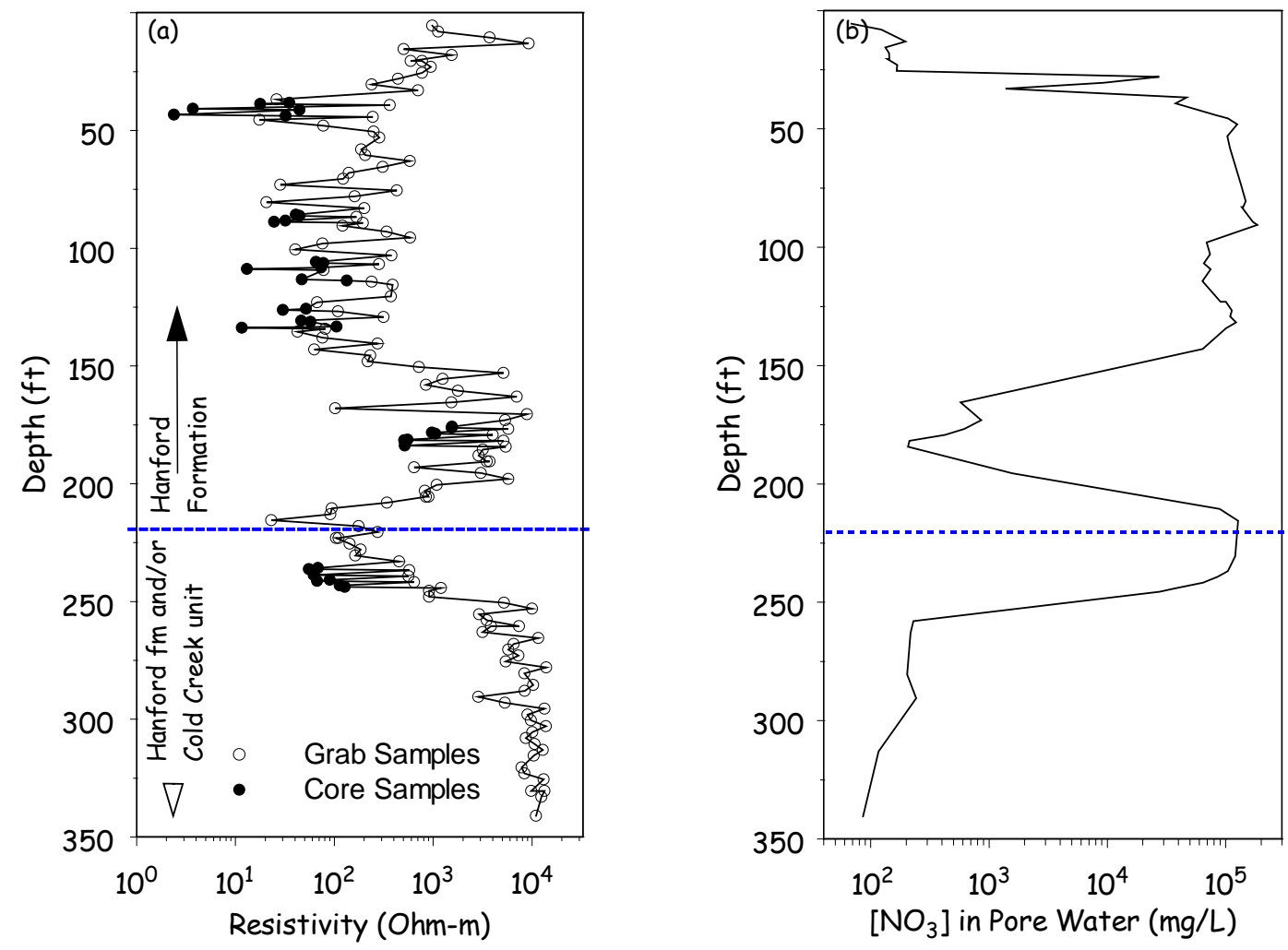

Figure 5.28. Semi-Log Plot of Vertical Resistivity Profile at the Location of Borehole C5923 (A), (a) Resistivity and (b) Pore Water Nitrate Concentration Extracted from Grab Samples 
PNNL-17821
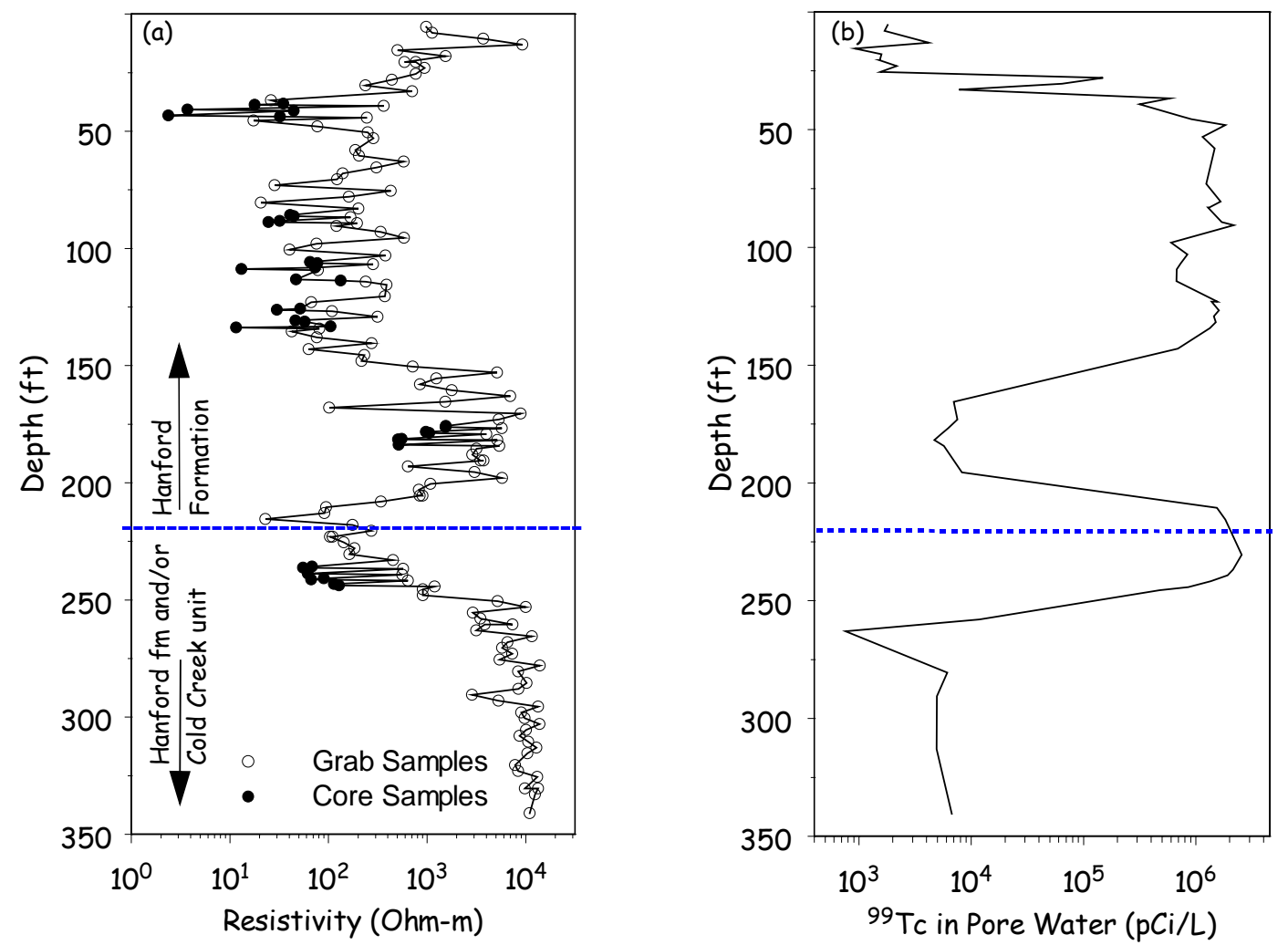

Figure 5.29. Semi-Log Plot of Vertical Resistivity Profile at the Location of Borehole C5923 (A), (a) Apparent Resistivity, and (b) Pore Water Technetium-99 Concentration Extracted from Grab Samples 

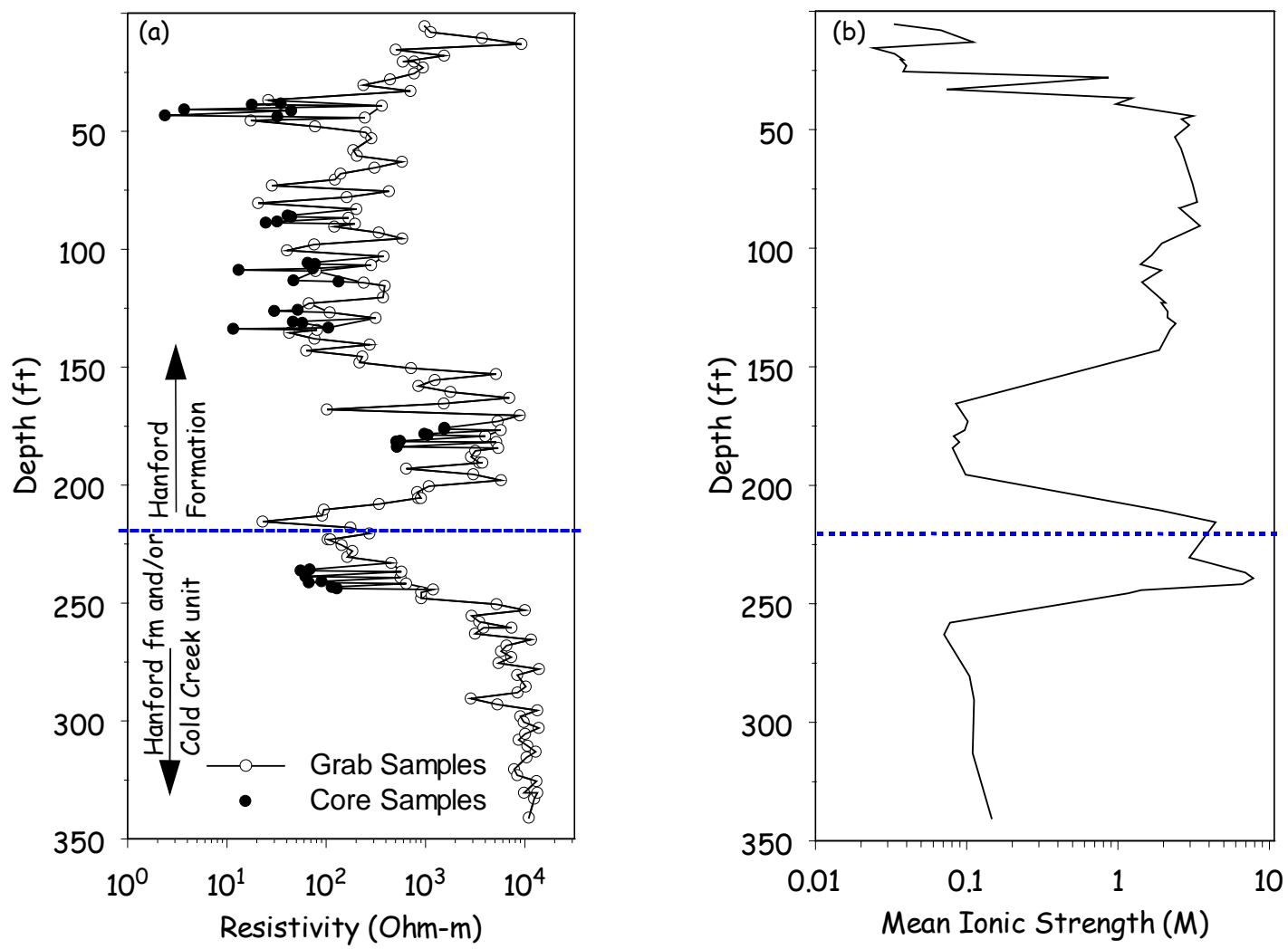

Figure 5.30. Semi-Log Plot of Vertical Resistivity Profile at the Location of Borehole C5923 (A), (a) Apparent Resistivity, and (b) Mean Ionic Strength Measured on Water Extracts from Grab Samples

\subsubsection{The Relationship Between Laboratory-Measured and Field Resistivity}

Comparisons of laboratory-measured resistivity to pore-water chemistry show good agreement. Of more importance to the overall objectives is the relationship between the laboratory-measured resistivity and the apparent resistivity derived from inversion of field resistivity surveys. Surface resistivity surveys conducted at the BC Cribs and Trenches site have been used to generate 2D soil resistivity profiles that intersect the location of Borehole C5923 (A). Figure 5.31 compares the laboratory-measured soil resistivity profiles with those derived from the interpolation of the field data. The most striking difference is the absence of small-scale detail in the inverted profiles from the field survey.

By the nature of the measurements, laboratory-measured resistivity reflects changes in lithology, the impacts of varying soil moisture, and other factors that influence resistivity at the scale of such heterogeneities. 
PNNL-17821
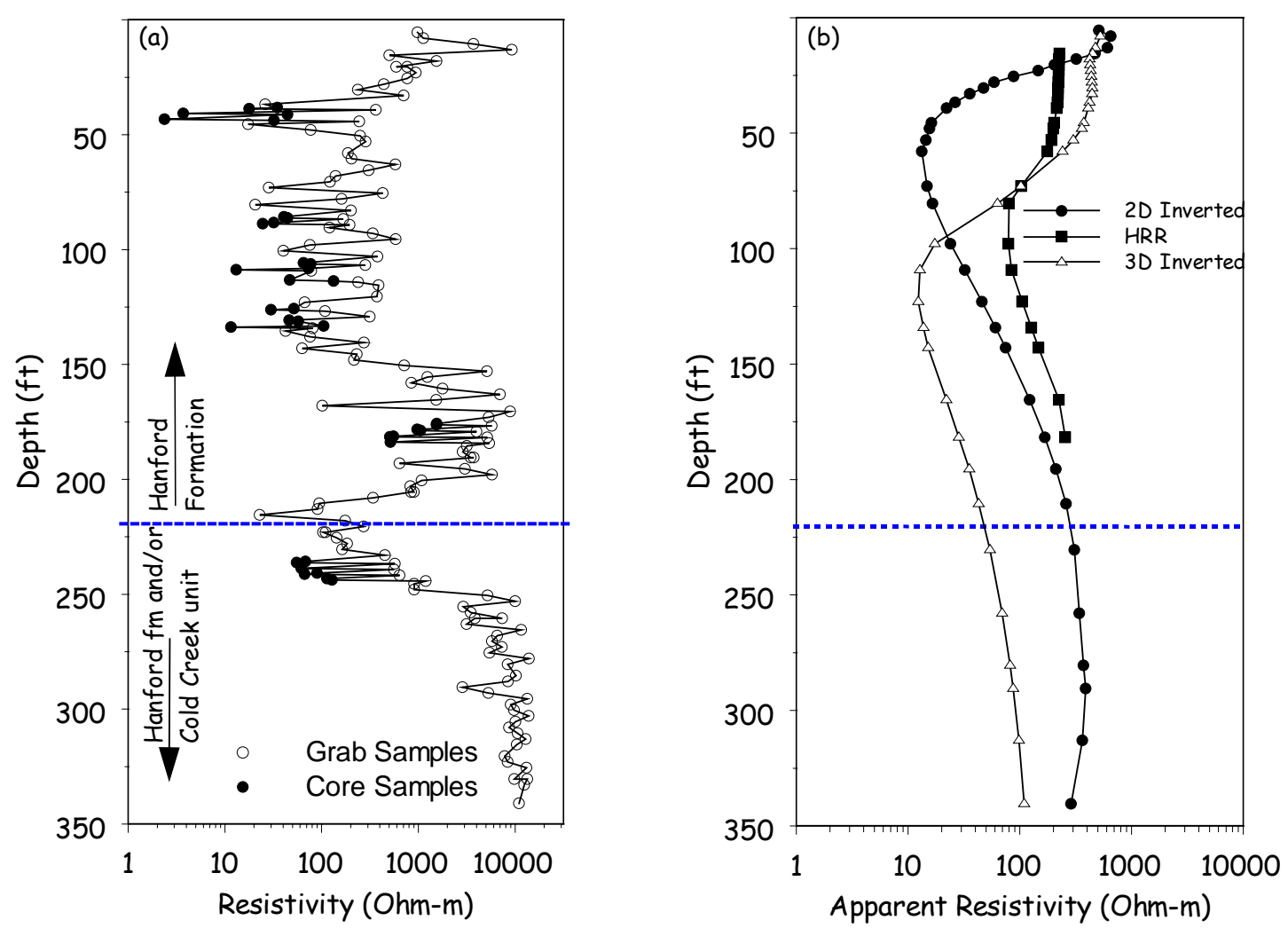

Figure 5.31. Profiles of Resistivity for Borehole C5923 (A), (a) Obtained from D.C. Resistivity Measurements on Borehole C5923 (A) Grab and Core Samples, (b) HRR, 2D Inverted, and 3D Inverted

Although surface-based field resistivity measurements reflect a pattern that is consistent with the distribution of contaminants in the subsurface, the vertical resistivity profiles extracted from the inversion-profile models only capture the shallowest low-resistivity zone or some average of the upper two lobes of the actual plume. Furthermore, the location of the low apparent resistivity feature appears to be dependent on the method of analysis. The HRR analysis indicates that the low-resistivity zone should occur between approximately 60 and $125 \mathrm{ft}$ bgs, with a decrease in resistivity consistent with the bulkaverage obtained from the MiniSting measurements on the grab samples and minimally disturbed cores. The 2D inverted profile of the field-survey data appears to focus on the zone of lowest measured resistivity near 40-ft bgs, though it predicts this lowest zone to occur closer to the 50 - to 60 -ft depth range. The 3D inverted profile of the field survey data suggests a much deeper low-resistivity zone centered near $125 \mathrm{ft}$ bgs. The maximum penetration depth of the HHR profile (depth to which the field measurements interrogate) was around $175 \mathrm{ft}$ bgs for the field survey conditions used in the vicinity of borehole C5923. The low-resistivity zone found by inverting the field data occurs around $60 \mathrm{ft}$ bgs for the 2D analysis and 100 to $110 \mathrm{ft}$ bgs for the 3D analysis, compared to between 40 and $50 \mathrm{ft}$ bgs based on laboratory measurements of soil resistivity and calculated pore-water compositions from 1:1 sedimentwater extracts. 
The 2D inverted profile as modeled extends to the depth of the borehole and captures the initial decline in resistivity from near-surface conditions as well the first low-resistivity zone. The first lowresistivity zone is fairly accurately modeled and is centered around 50 to $60 \mathrm{ft}$ bgs, an offset of 5 to $10 \mathrm{ft}$ from the actual highest concentration of pore-water solute concentration. However, below this depth, there is a monotonic increase in resistivity until around $275 \mathrm{ft}$ bgs, after which resistivity declines slightly. The inflection point between the shallow low-resistivity zone and the deeper high-resistivity zone occurs near 125 to $135 \mathrm{ft}$ bgs, which is 20 to $30 \mathrm{ft}$ higher in elevation from where the borehole-measured data (MiniSting, ionic-strength, nitrate, etc) mark the basal terminus of the upper salt plume. The 2D inverted profile of the field survey data, however, completely misses the deeper portions of the salt plume that exhibits another localized maxima located near the interface between the Hanford formation and the Cold Creek unit.

The 3D inverted profile of the field survey data also shows a decline in resistivity as the depth increases, but the first low-resistivity zone is pushed downward relative to the HRR and 2D profiles. The 3D inversion locates the first peak of the plume at a depth of about $110 \mathrm{ft}$ bgs, compared to $45 \mathrm{ft}$ bgs based on laboratory measurements. The low-resistivity zone from the 3D inversion extends from about $75 \mathrm{ft}$ to about $150 \mathrm{ft}$ bgs and appears to coincide with the low-resistivity zone observed between 75 and $125 \mathrm{ft}$ bgs. However, this profile also misses the deeper low-resistivity plume present in the C5923 borehole sediments at the transition from the Hanford formation to the Cold Creek unit at $220 \mathrm{ft}$. The inverted-resistivity calculated values also appear to be about an order of magnitude smaller than those measured in the laboratory. However, this can be expected, given the difference between the scale of laboratory observation and the scale of the inverse model.

The comparison of the resistivity profile derived from the laboratory measurements with the surface survey data is an essential part of the "ground-truthing" (verification) process and is needed to resolve the issues of non-uniqueness often associated with the interpretation of surface surveys. However, for a variety of reasons, such a comparison is not a trivial task. For one, the vertical resistivity profile derived from the laboratory-measured resistivities is made up of relatively dense, equi-spaced measurements on a linear depth scale, whereas vertical resistivity profiles obtained during electrode expansion in the typical surface-based field resistivity surveys are equi-spaced on a logarithmic scale to reflect the increase in volume averaging that occurs as the electrode arrays are expanded to allow obtaining measurements from greater depths (Pal 1991). Inherently, these two data sets will have different levels of accuracy and detail along the vertical axis, and because the field resistivity survey curve is characterized by averaging, there is a substantial loss of information with depth. The laboratory resistivity profile contains far more vertical spatial detail than can be retrieved from a resistivity field survey, and the difference in scales of observation must be first resolved. Although a given subsurface contaminant (resistivity) distribution will give rise to a unique resistivity survey curve at the surface, the retrieval of stratigraphic information from the inversion of the observed field survey curve is nearly impossible given all the geologic, physical, and geochemical variables that influence the resistivity response.

\subsubsection{Resolution of Electrical-Resistivity Measurements from the Surface}

The resolution of electrical-resistivity measurements taken solely from the ground surface is hampered partly due to observational limitations, partly due to interpretational limitations, and partly due to the subsurface resistivity heterogeneities that combine to limit the uniqueness of inversions. Observational limitations arise from the physical limitations of the surface survey methods. The 
electrical-resistivity method uses a pair of electrodes to pass current through a heterogeneous distribution of "resistive" soil particles while measuring the voltage drop over an adjacent pair of electrodes. When applied strictly from the ground surface, the voltage drop is measured through large volumes of the subsurface. As the distance between the voltage-measurement electrode and current-injection electrode pairs increases, the volume of soil over which the measurements are made increases. The consequence is a measured apparent-resistivity distribution that becomes smooth relative to the individual layers that comprise the earth.

Many have described the consequence of smoothing using electrical digital filter theory (Koefoed, 1970; Ghosh, 1971; Das and Verma, 1980; O’Neill and Merrick, 1984). Applied in this way, a resistivity kernel function, which is dependent on layer parameters (resistivity and thickness of each layer), is convolved with a function comprising the Bessel function of the first kind of order zero $\left(\mathrm{J}_{\mathrm{o}}\right)$. Das and Kerma (1984) showed that apparent resistivity $\left(\rho_{\mathrm{a}}\right)$ for the pole-pole electrode arrangement is represented by

$$
\rho_{a}(x)=\int_{-\infty}^{\infty} T(y)\left[-J_{o}\left(e^{x-y}\right) e^{x-y}\right] d y
$$

where $\quad \mathrm{x}=\ln (\mathrm{r})$

$r=$ transmitter and receiver electrode separation distance for the pole-pole array

$\mathrm{y}=\ln (1 / \lambda)$

$\lambda=$ dummy variable of integration

$\mathrm{T}(\mathrm{y})=$ input function of layer parameters and kernel function

and the terms in brackets represent the filter function.

Koefoed (1976) demonstrated that the first part of Eq. 5.3, the input function T, can be computed from a stacking process (or superposition since linearity is assumed) of layers beginning from the bottommost layer and moving upwards through the profile to the earth's surface. The second part of Eq. 5.3, the filter function involving the Bessel function, was tabulated by Koefoed et al. (1972). The filter function was represented by a discrete 61-point digital filter. Other sized filters were also tabulated by O’Neill and Merrick (1984). An example of the filter function for the pole-pole array is shown in Figure 5.32. The filter is similar to a sinc function (i.e., $\sin [(\mathrm{x}) / \mathrm{x}]$ ), which acts as a low-pass filter. That is, high-frequency components are removed, leaving only low-frequency components. High-frequency components are those that have variability over a very short distance.

The convolution of the input function with the filter function produces a $1 \mathrm{D}$ apparent-resistivity function. To demonstrate the process and resolution of surface-based electrical resistivity, the laboratorybased resistivity data acquired from MiniSting were convolved with the filter function to produce an “expected” apparent resistivity. To begin, Figure 5.33 shows the MiniSting resistivity data with an averaged resistivity function simulating the laboratory data. The original data (see Table 5.21) set contains 160 measurements, after removing duplicates. To actually implement the filtering, however, the number of resistivity layers in the measured profile has to be less than half the size of the filter. The averaging procedure of the MiniSting data involved discretizing layers along logical breaks in continuity and calculating the resulting 
PNNL-17821

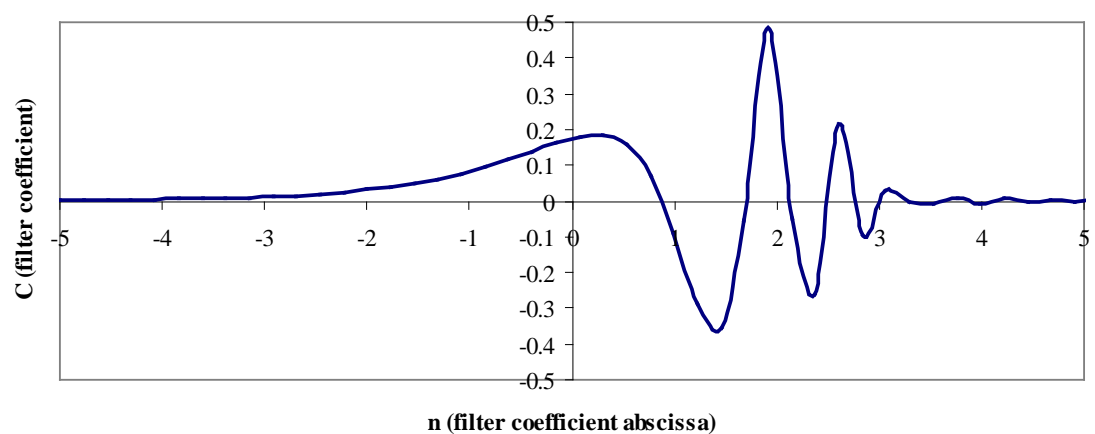

Figure 5.32. Example Pole-Pole Filter for Determining Apparent-Resistivity Values of a Layered Earth Using Digital Filter Theory
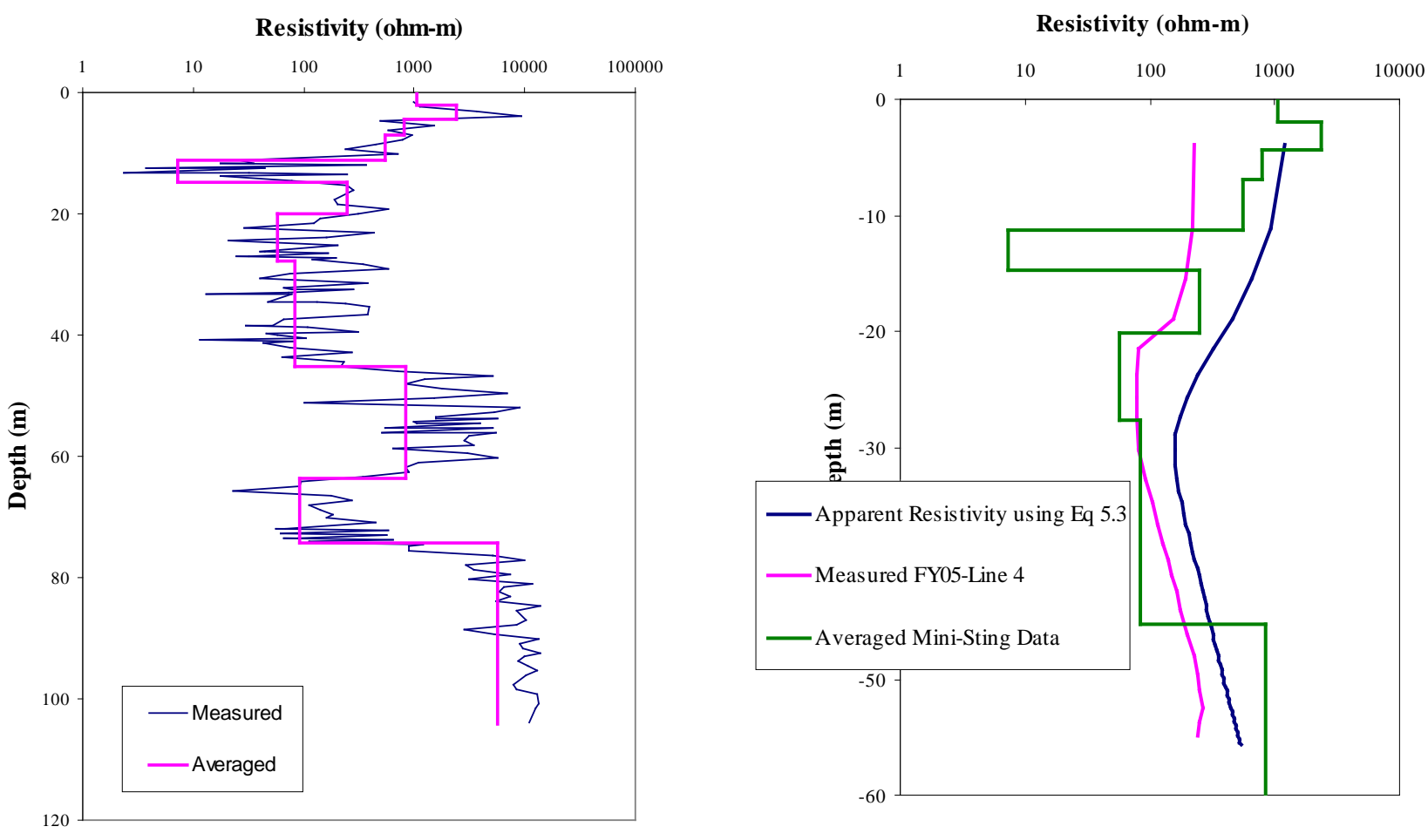

Figure 5.33. Reanalysis of MiniSting Data from Borehole 5923(A), (a) Data Averaged by Discretizing Layers Along Logical Breaks in Continuity and Calculating the Resulting Resistivity Values Within the Layer Using a Parallel Resistor Model and (b) D Filtering of Averaged MiniSting Data

resistivity values within the layer using a parallel resistor model. The parallel resistor model tends to favor the lower resistivity layers. The result, as shown in Figure 5.33a, is an 11-layer model.

The input function, $\mathrm{T}$, used the averaged 11-layer MiniSting data for calculating the expected apparent resistivity. Figure 5.33b shows the results of the convolution. The MiniSting apparentresistivity data were plotted using the HRR algorithm to allow direct comparison with apparent resistivity 
acquired in the field (Line 4 from FY05-see Section 5.2 for more details) directly over Borehole 5923(A). The comparison between laboratory-derived apparent resistivity and field-measured resistivity is very similar in shape but not in values. The laboratory-derived apparent resistivity is approximately 2 to 5 times that of the field-measured apparent resistivity. This difference could be caused by either or both of two phenomena (a) out-of-plane effects from the field measured data or (b) laboratory measurement bias.

The resolution of the technique can clearly be seen in the resulting apparent-resistivity function. The 3.5-m-thick layer of very low resistivity centered at about $15 \mathrm{~m}$ bgs was not observed in either of the apparent-resistivity profiles. There does exist a low apparent-resistivity bump in both laboratory and field measurements. The low values observed in the apparent resistivity are likely due to the moderately low MiniSting resistivity between 20 and $45 \mathrm{~m}$ bgs. These results bode well for the quality of field-acquired data as they produce theoretically defensible results. It may limit, however, the expectations of the methodology in general because of the problems arising from the so-called electrical equivalence of middle layers and its effect on surface resistivity measurements.

The effects of the electrical equivalence of middle layers have been discussed at length in the literature (Maillet 1947; Koefoed 1979; van Overmeeren 1989; Zohdy 1989). In fact, it has been shown that resolving the resistivity, $\rho_{\mathrm{i}}$, of the $\mathrm{i}^{\text {th }}$ layer in either a bowl-shaped (i.e., $\rho_{\mathrm{i}-1}>\rho_{\mathrm{i}}<\rho_{\mathrm{i}+1}$ ) or ascendingtype $\left(\rho_{\mathrm{i}-1}<\rho_{\mathrm{i}}<\rho_{\mathrm{i}+1}\right)$ profile is next to impossible. Different combinations of layer thicknesses $\left(h_{i}\right)$ and resistivities $\left(\rho_{\mathrm{i}}\right.$, ) will be electrically equivalent provided the longitudinal conductance $\left(\mathrm{h}_{\mathrm{i}} \sigma_{\mathrm{i}}=\mathrm{h}_{\mathrm{i}} / \rho_{\mathrm{i}}\right.$, where $\sigma_{\mathrm{i}}$ is the electrical conductivity of $\mathrm{i}^{\text {th }}$ layer) remains unchanged (Pal 1991). In the case of bell-shaped $\left(\rho_{\mathrm{i}-1}<\rho_{\mathrm{i}}<\rho_{\mathrm{i}+1}\right)$ and descending-type $\left(\rho_{\mathrm{i}-1}>\rho_{\mathrm{i}}>\rho_{\mathrm{i}+1}\right)$ sounding curves, the equivalent middle-layer parameters will be such that the transverse resistance $\left(h_{\mathrm{i}} \rho_{\mathrm{i}}\right)$ remains constant. In addition, thin layers having finite resistivities occurring deep in the profile, such as the deep low-resistivity layer in C5923, will tend to be suppressed in the surface resistivity curves.

Nonetheless, lithostratigraphy is rarely used to constrain the inversion or interpretation of the field resistivity measurements, and as such, they do no not reflect any of the heterogeneity observed at the site. This is not a reflection of the quality of the data, but more so, a reflection of the analysis. Commercially available software routinely used to invert 2D apparent-resistivity data can be classified into two groups: 1) those based on smooth inversion algorithms and 2) those based on block inversion algorithms. Smooth inversion is a cell-based inversion whereas polygons are employed to define layers and/or bodies of equal resistivity in block inversion (Olayinka and Yaramanci 2000). Thus, the ability of these two inversion approaches to define the geometry of subsurface structures and their resistivity is significantly different. In a comparison of smooth and block inversion approaches, Olayinka and Yaramanci (2000) compared the 2D inversions for different geologic models (a vertical fault, a graben, and a horst) using a Wenner array. The results showed that the images obtained from smooth inversion, while useful in determining the geometry of the structures, were able to provide only guides to the true resistivity because of the smearing effects. By using a plane layer earth model as the starting model for the block inversion, the inversion more adequately represented the true subsurface geology in terms of both the geometry and the formation resistivity (Olayinka and Yaramanci 2000). An improved inversion model could incorporate the observed differences in soil type, water contents, and even changes in pore-water chemistry in a block inversion approach to allow better interpretation of near-surface geophysical field surveys.

To further illustrate the limitations of the analysis method, the resistivity profile data from the laboratory measurements on C5923 sediments were used to investigate the effects of inhomogeneities on the predicted surface resistivity profile. In the first instance, a Walsh filter was used to obtain an "upscaled" resistivity profile to observe how and why the small-scale information in the profile is progressively lost with depth in going from the laboratory-measured profile to the field-measured survey 
curves. This approach is motivated by the fact that the resistivity layering in the laboratory-measured profile mimics a horizontally-layered Earth, suggesting that it can be better described by a discrete rather than continuous curve. A number of authors have shown that the retrieval of layers from continuously recorded logs can therefore be easily accomplished using Walsh sequence analysis (Lanning and Johnson 1983; Pal 1991; Maiti and Tiwari 2005). Walsh sequence analysis is similar to Fourier frequency analysis and is based on the decomposition of a given space series into a number of component functions (Harmuth 1972: Beauchamp 1975). The difference between the two analyses is that the component functions of Walsh sequence analysis are rectangular and discontinuous whereas they are continuous sinusoids in Fourier frequency analysis. The sequence is defined as one-half the number of times the function crosses zero (i.e., the baseline) within the interval of time or space within which that function is defined, in this case over the depth of the profile. In Walsh domain filtering, coefficients can only take values of 0 or 1 . Details on the Walsh sequence analysis and its application can be found in the cited works above. A MATLAB program was developed to perform the analysis using the laboratorymeasured resistivity data from C5923 sediments.

Perhaps one limitation of the Walsh sequence analysis is that it is well-defined only for signals of $\mathrm{N}$ samples, where $\mathrm{N}$ is an integer power of 2 (i.e., $\mathrm{y}=2^{\mathrm{N}}$ ). Consequently, the step width of any discrete signal resulting from sequence filtering is also a power of 2 . The number of samples analyzed from C5923 was 160 ( $\mathrm{N}=7.322)$, so data were re-sampled to create a data set for $\mathrm{N}=8$, i.e., 256 data points. Figure 5.34a shows a plot of the interpolated resistivity profile from Borehole C5923 (A) normalized between 0.0 and 1.0 over the sampling interval. Figure 5.34b shows the Walsh low-pass representation of the resistivity profile with the calculated boundaries between resistivity zones. These zones can then be used to calculate an upscaled or bulk average resistivity for comparison with the resistivity sounding or for input into a forward model to predict a sounding (e.g., surface-based field survey).

In practice, for a given desired step width or “minimum resolvable layer thickness (MRLT)," there is no reason not to include all sequence components that are compatible with it. Therefore, the only lowpass sequence filters of practical interest are those with a cutoff sequence equal to one less than a power of 2. For boundary identification, a Walsh check value of 0.07 was assigned by trial and error to produce reasonable and stable results. A correction to the depth of a boundary is indicated by Equation 5.4 (Lanning and Johnson, 1983; Maiti and Tiwari, 2005):

$$
B_{i}=W_{i} \pm 0.5 \Delta s w
$$

where $\mathrm{B}_{\mathrm{i}}$ is true location of the $\mathrm{i}^{\text {th }}$ boundary; $\mathrm{W}_{\mathrm{i}}$ is the depth detected by the Walsh method; and $\Delta \mathrm{sw}$ is the step width of the low-pass version of the resistivity log. For the second low-pass operation, relative energy build up is shifted, depending on the true position of the boundary. Hence, to obtain the true position of the boundary, two sets of zone boundaries can be averaged as a final estimate

$$
B_{i}=W_{i}^{\prime} \pm 0.5 \Delta s w
$$

where $\mathrm{W}_{\mathrm{i}}$ is the final $\mathrm{i}^{\text {th }}$ boundary detected by the Walsh method, which leads to an increase of resolution by a factor of 2 using two low-pass examples. 

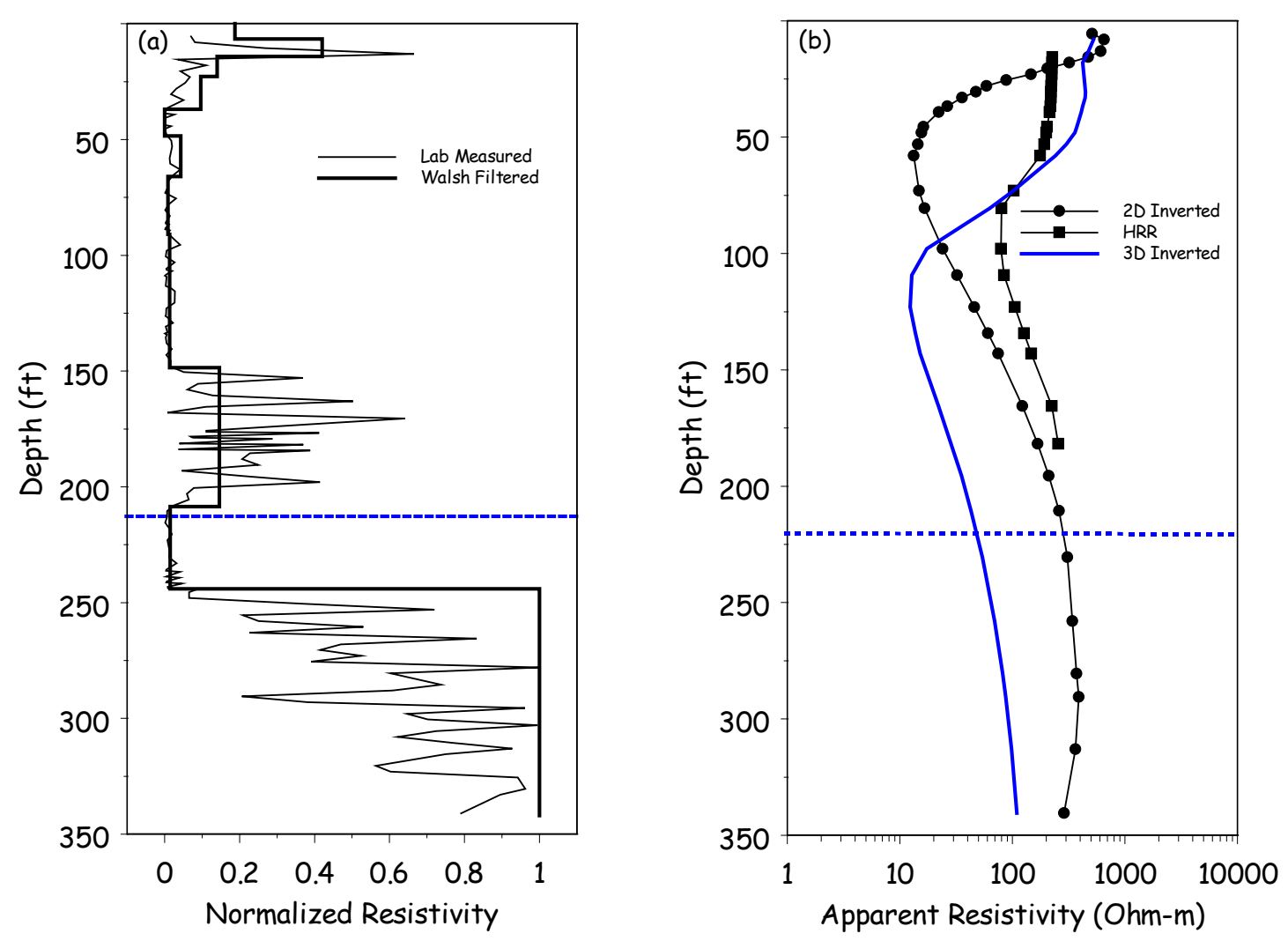

Figure 5.34. Comparison of Resistivity Profile and Sounding Curves from Borehole C5923 (A)

(a) Resistivity Normalized Between 0.0 and 1.0 over the Depth Interval and a Walsh LowPass Representation of the Resistivity Profile Showing the Calculated Boundaries Between Resistivity Zones, (b) Resistivity Soundings from HRR, 2D Inverted, and 3D Inverted

The Walsh low-pass filtering approach clearly shows a series of step functions that coincide quite well with the relatively sharp boundaries between resistivity zones. The resulting step width of $1.3 \mathrm{ft}$ (based on interpolating $340 \mathrm{ft}$ over 256 intervals) defines the maximum resolvable layer thickness over the profile. The step width is a function of the cut-off sequence used in the Walsh low-pass filtering operation and is therefore adjustable. This width was adjusted to minimize the discrepancy between boundary picks and obvious resistivity changes. These boundaries can then be used to calculate the bulk resistivity for more direct comparison with resistivity soundings. The similarity between the Walsh boundaries shown in Figure 5.34 and those derived from simple "eyeballing" of the zones in Figure 5.33 is quite remarkable.

In the second approach, the laboratory-measured resistivity profile was used as input to a forward resistivity model to simulate a hypothetical surface-based resistivity field survey while taking into consideration the inhomogeneities in resistivity and water content to define the starting model. The model uses a solution to the Poisson's equation to predict subsurface resistivity distributions and field surveys that would be observed with different electrode configurations (Pidlisecky et al. 2007). The laboratory-measured resistivities were projected onto a solution grid and assumed to represent a layered earth with each layer extending to the boundary. The model domain extended $500 \mathrm{~m}$ in the horizontal direction and $105 \mathrm{~m}$ in the vertical. For the simulation of the surface resistivity survey, we assumed a 
100-electrode system with spacing of $5 \mathrm{~m}$. The simulation assumed a Wenner configuration and an injection current of 1 A. Figure 5.35 shows a plot of the simulated pseudosection.

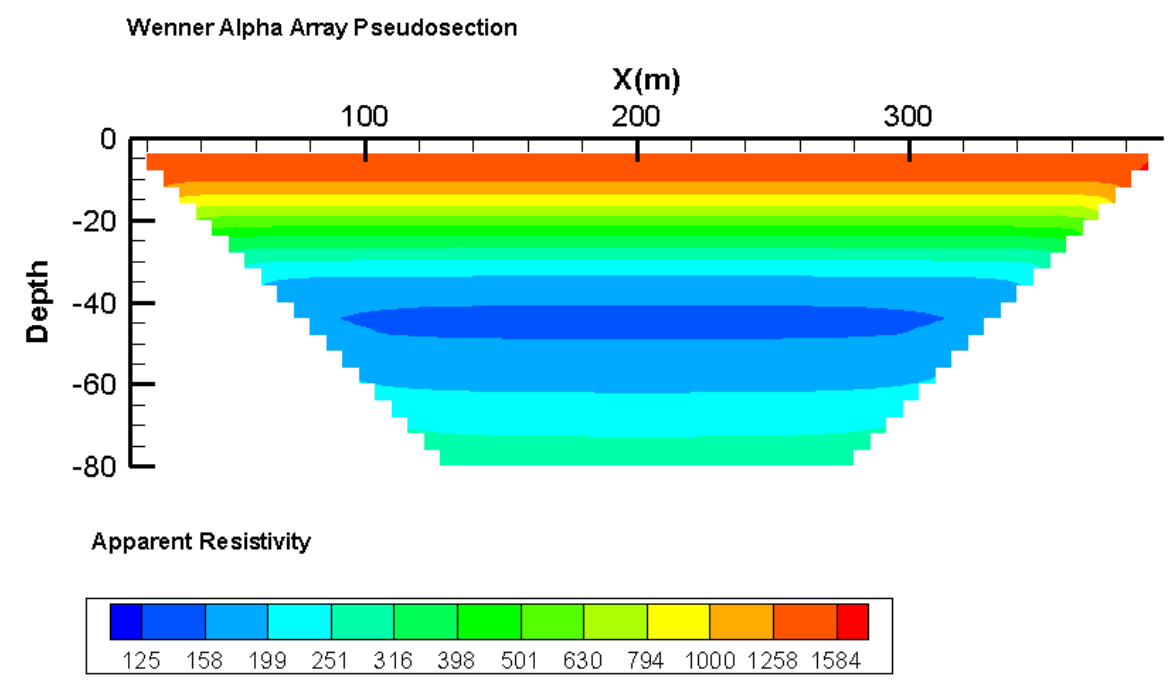

Figure 5.35. The Apparent-Resistivity Pseudosection (a rectangular prism) from a Simulated 2D Wenner Imaging Survey over the C5923 Borehole. The input resistivity model is based on the lab-measured resistivity profile.

Figure 5.36 shows that the pseudosection can be strongly distorted from the actual location and geometry of the original structure, such as shown in Figure 5.31.a. The pseudosection is merely a graphical representation of the apparent resistivity and gives only a very approximate picture of the true subsurface resistivity distribution. Essentially all of the small-scale information from the vertical resistivity profile is lost, suggesting that retrieval of fine-scale stratigraphic information from the inversion of the observed sounding curve would be essentially impossible. Nevertheless, the values of apparent resistivity within the top-most resistive and low-conductivity zones are within the range of the laboratory measurements.

Figure 5.36b shows a resistivity profile extracted from the pseudosection at the midpoint of the domain. The predicted apparent resistivities are in good agreement with those reported for the field measurements (see Rucker and Benecke 2006). The simulated field profile shows a peak resistivity of 1670 Ohm-m, which compares well with the block-averaged value for that zone. The lowest resistivity is observed around the 100-ft depth, which is consistent with lab and field observations. Below this depth, the curve shows a monotonic increase in resistivity with no evidence of the deeper solute front actually observed in the sediments at C5923. Again, these results are consistent with the results of the field survey. 

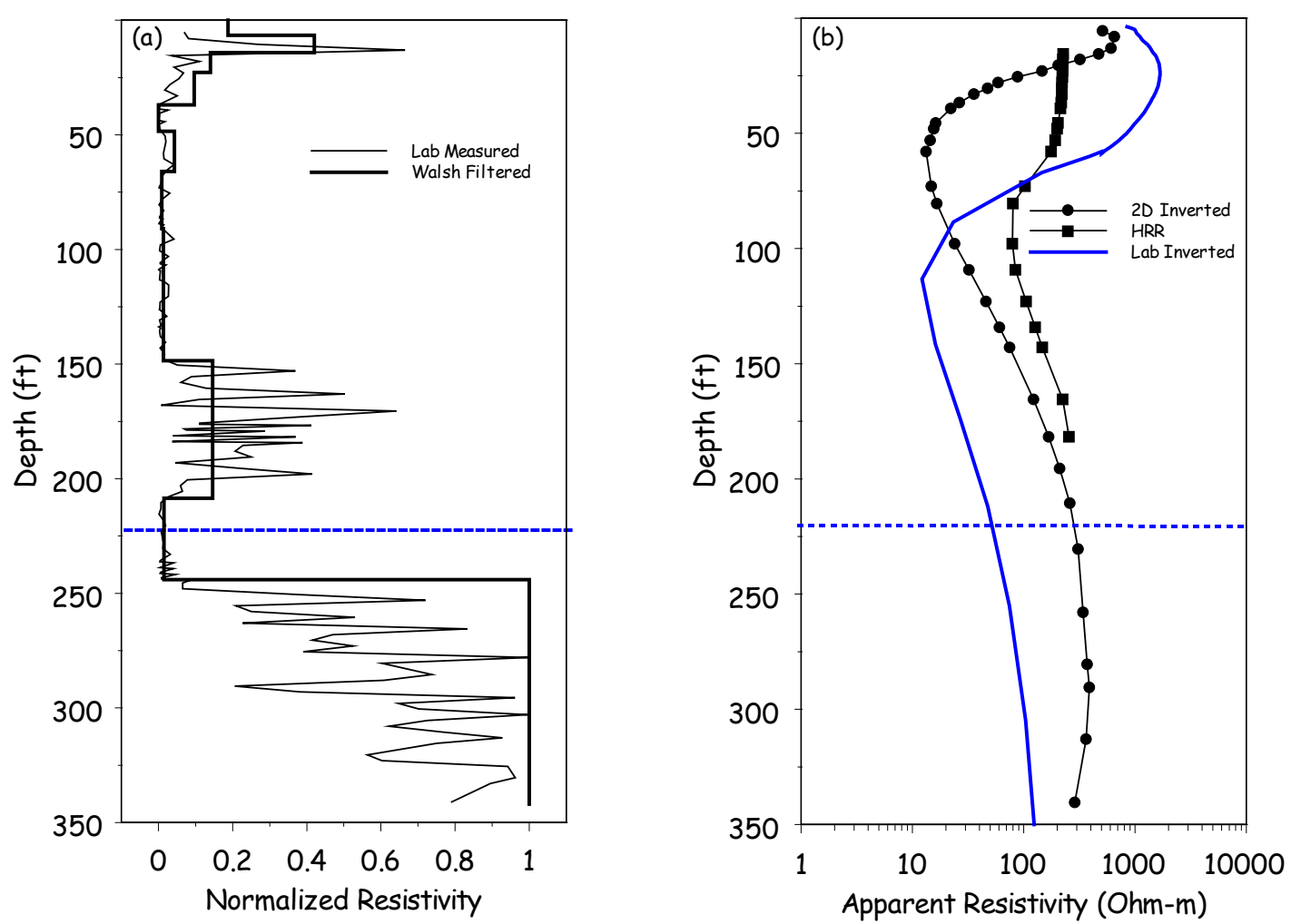

Figure 5.36. Comparison of Resistivity Profile and Sounding Curves from Borehole C5923 (A) (a) Resistivity Normalized Between 0.0 and 1.0 over the Depth Interval and a Walsh LowPass Representation of the Resistivity Profile Showing the Calculated Boundaries Between Resistivity Zones, (b) Resistivity Profiles from HRR, 2D Inversion of Field Data, and 3D Inversion of Field Data Compared to a Profile Derived from the Inversion of a Simulated Survey Using the Laboratory-Measured Profile as the Starting Mode

More importantly, these results highlight a very important point that the laboratory-measured profile and field surveys are inherently different and capture different levels of detail. Even with a model that considers observed inhomogeneities in bulk resistivity, it was essentially impossible to reproduce the laboratory-measured distribution used as the initial condition. It is therefore unlikely that inversion, with unresolved issues of non-uniqueness and the electrical equivalence of middle layers, can ever produce the same profile as that derived from the laboratory resistivity measurements on the intact cores and grab samples or one that explicitly matches the resistivity derived from the pore-water chemistry.

\subsubsection{The Relationship between the Soil Electrical Resistivity Profile and Borehole Logs}

A priori knowledge of the stratification in resistivity would minimize the problem of interpreting resistivity soundings (e.g. Flathe, 1976) but such information is typically not available. Different lithologic units may also have similar resistivities. These features cannot be distinguished from each other based on resistivity alone. For example, a hyper-saline zone at depth and a wet clay/silt layer could be equally conductive. Additional information such as hydrophysical properties (e.g. water content, clay 
content, PSD, SSA, CEC, or borehole natural gamma (potassium-40, uranium-238, and thorium-232) [KUT] logs) would be required to differentiate why the field sounding looks as measured. Another option could be to use multimodal investigations in the field. For example, a fine-textured conductive layer would have a different induced polarization signature than a layer whose low resistivity was due only to ionic (pore water) constituents. Water content/porosity measurements and $\gamma$-ray spectroscopy, used to quantify the natural isotopes ${ }^{40} \mathrm{~K},{ }^{238} \mathrm{U}$, and ${ }^{232} \mathrm{Th}$, have the potential to provide the required information. A priori lithologic data are often limited to geologist's logs whereas borehole SG logs are typically collected on every new borehole installed at the Hanford site, although they are rarely used to constrain lithology. Figure 5.37 compares the laboratory-measured resistivity and calculated electrical conductivity profiles with the normalized total gamma $\left(\mathrm{I}_{\mathrm{GR}}=\left(\gamma-\gamma_{\min }\right) /\left(\gamma_{\max }-\gamma_{\min }\right)\right.$ from Borehole C5923 (A). The total gamma response is due to the presence of potassium-40, uranium-238, and thorium-232, all of which are known to show a strong dependence on lithology. In general, $I_{G R}$ appears to be inversely proportional to resistivity and therefore directly proportional to electrical conductivity. The normalized total gamma, $\mathrm{I}_{\mathrm{GR}}$, shows essentially five main zones or facies, $0-50 \mathrm{ft}, 50-100 \mathrm{ft}, 100-150 \mathrm{ft}, 150-235 \mathrm{ft}$ and $>235 \mathrm{ft}$. The low in $I_{G R}$ at $20 \mathrm{ft}$ bgs coincides with the high-resistivity (low conductivity) anomaly at the same depth. The $I_{G R}$ in the $0-50 \mathrm{ft}$ zone shows the lowest values but increases sharply around $50 \mathrm{ft}$. The sharp change in $\mathrm{I}_{\mathrm{GR}}$ around $50 \mathrm{ft}$ bgs coincides with the low-resistivity zone (highest conductivity) at the same depth. Beyond this depth, there is a general increase in soil electrical resistivity and a decline in $I_{G R}$ to a minimum around $235 \mathrm{ft}$ bgs. These data suggest that the distribution of the salt plume is controlled by the lithology with major differences in resistivity coinciding with major changes in $I_{G R}$, which result from the lithologic differences. The minimum in $\mathrm{I}_{\mathrm{GR}}$ is most likely the true location of the contact between the Hanford formation and the Cold Creek Units. The negative correlation between soil electrical resistivity and $I_{G R}$ is caused by the dependence of the gamma response on lithology.

It is known that a significant part of sediment ${ }^{238} \mathrm{U}$ and ${ }^{232} \mathrm{Th}$ is bound in dark-colored, ferromagnetic minerals in the parent materials for siliclastic sediments (Kogan et al. 1969). This implies that the gamma-ray activities of Hanford formation sands should be a function of the grain size and particle density. Owing to the depositional environment, ${ }^{40} \mathrm{~K}$ is uniformly spread throughout the principal rockforming minerals, such as quartz and feldspar and sediments with the same parent materials, suggesting that similar grain sizes from different locations should show similar ${ }^{40} \mathrm{~K}$ activities. Elevated ${ }^{40} \mathrm{~K}$ activity levels can also be indicative of increased clay content. Figure 5.38 compares the trend in the resistivity from the laboratory measurements on $\mathrm{C} 5923$ sediments with that of the ${ }^{40} \mathrm{~K}$ from the KUT measurements. The similarity between the ${ }^{40} \mathrm{~K}$ and $\mathrm{I}_{\mathrm{GR}}$ profiles is expected because the ${ }^{40} \mathrm{~K}$ is the largest contributor to $\mathrm{I}_{\mathrm{GR}}$ in these sediments. These logs can therefore be used to identify the major architectural elements and dominant facies in the formation. Differences in gamma-ray activity from the natural distribution of radionuclides may therefore have some application in constraining the inversion model and in the interpretation of results. However, the challenge is to relate gamma-ray spectra to useful parameters, such as grain size statistics, which are beyond this project's work scope.

Figure 5.39 compares the normalized total gamma, $\mathrm{I}_{\mathrm{GR}}$, with laboratory measured soil resistivity with the geometric mean grain diameter and sorting index derived from grain-size distribution curves. Figure 5.39b essentially shows a coarsening upward in texture to the 250-ft depth, after which the particle size remains relatively constant. The sorting index shows a similar pattern with a high degree of sorting deep in the profile and a decrease towards the surface. Again the transitions between the different facies are evident and appear consistent with the gamma log and measured laboratory soil resistivity. More importantly, grain-size distributions and nuclear logs, such as gamma-ray, porosity, and density, will not 
be affected by the high ionic strengths in the pore waters observed at this site (and other waste sites where there are no long-lived gamma emitters remaining in the sediment profile) and as such can be used as unbiased indicators of the lithologic changes. Closer to the footprints of inactive disposal facilities the total gamma logs may require subtraction of the gamma activity of cesium-137 and cobalt-60 and perhaps actinides as well as compensation for Bremmstrahlung diffuse radiation from strontium-90. Based on these relationships, the following approximate values of soil resistivity can be assigned to the different Hanford BC Cribs and Trenches site facies; silt/clay: 20 to 100 Ohm-m; fine sand: 300 to 2,000 Ohm-m; coarse/dry sand: 3,000 to 10,000 Ohm-m.
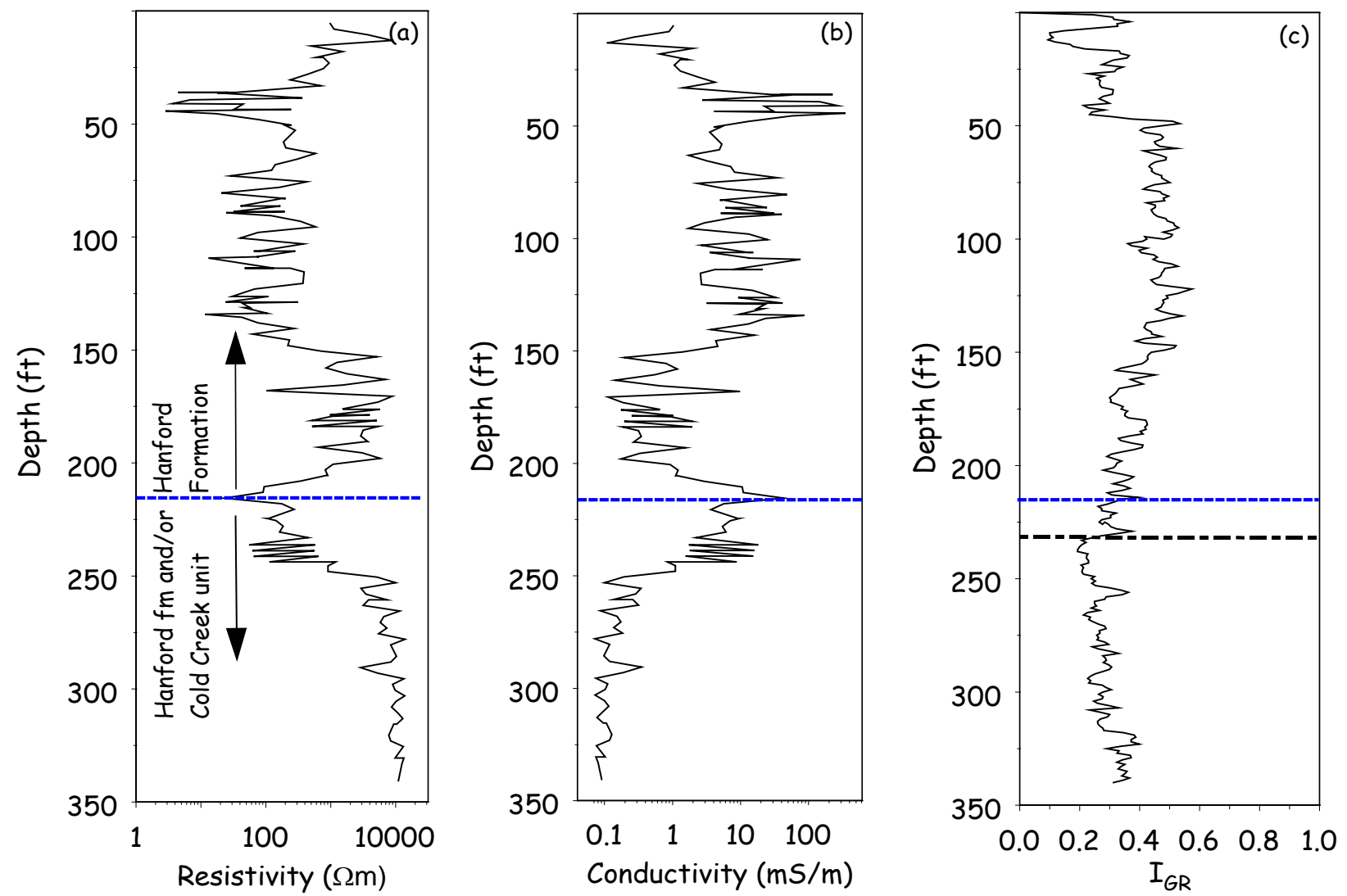

Figure 5.37. The Relationship Between Resistivity and SG Logs at Borehole C5923 (A), (a) Resistivity Based on Laboratory Measurements and (b) Electrical Conductivity Calculated from Resistivity, and (c) Normalized Total Gamma. The blue dotted line shows the location of the Hanford formation-Cold Creek contact based on geologist's logs whereas the black dashed line shows the contact based on scaled total gamma log. 
PNNL-17821
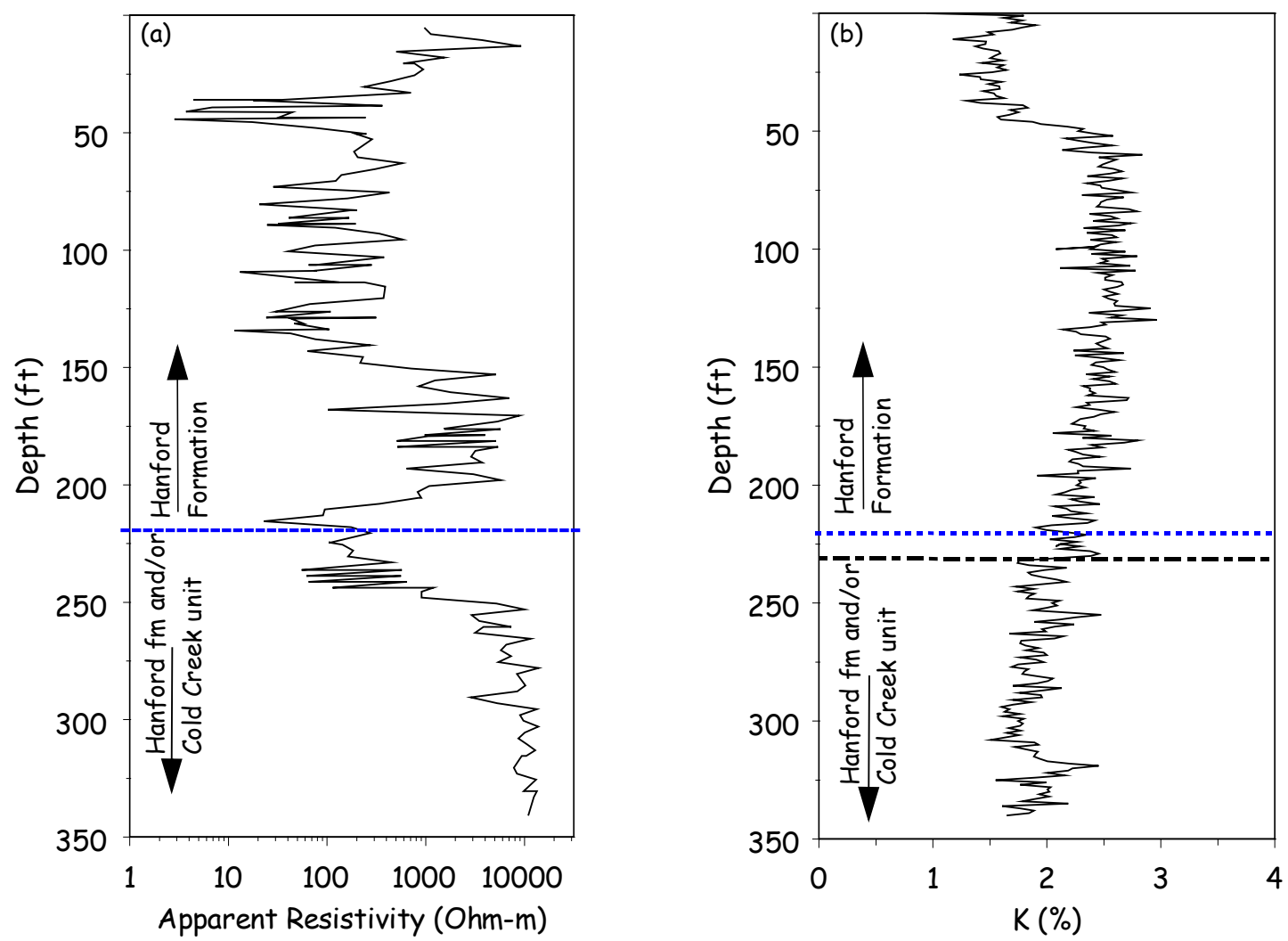

Figure 5.38. The Relationship Between Resistivity and SG Potassium-40 Logs at Borehole C5923 (A), (a) Apparent Resistivity Based on Laboratory Measurements and (b) Total Potassium Distribution Versus Depth from ${ }^{40} \mathrm{~K}$ log. The blue dotted line shows the location of the Hanford formation-Cold Creek contact based on geologist's logs whereas the black dashed line shows the contact based on scaled \%K. 

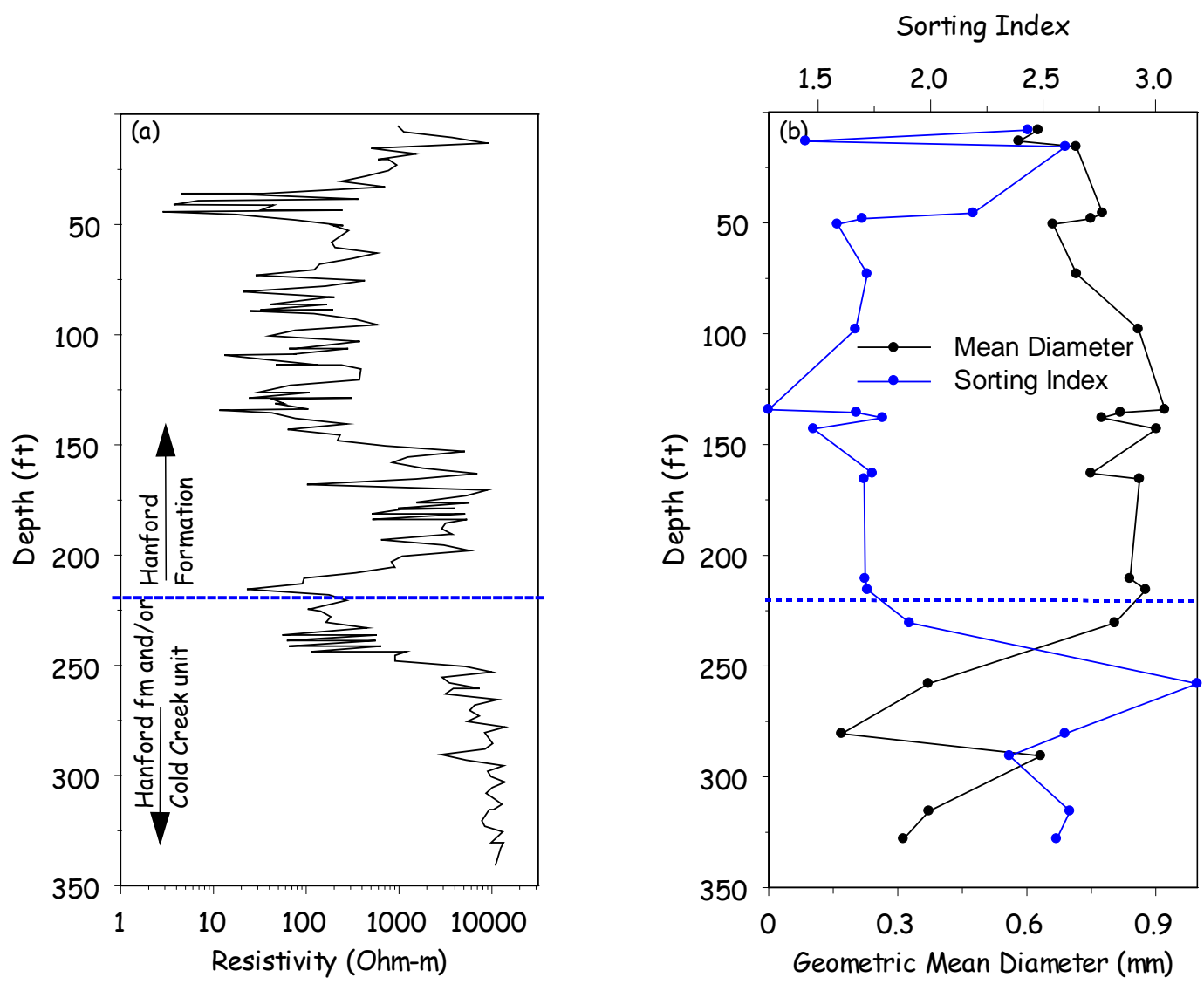

Figure 5.39. Relationship Between (a) Laboratory-Measured Resistivity and (b) Grain Size Distribution Indicators, Including the Geometric Mean Diameter and the Sorting Index

\subsubsection{The Relationship Between the Laboratory Measured Soil Electrical Resistivity Profile and Laboratory Measured PSD, SA, and CEC}

CEC and SSA were measured on select grab samples from Borehole C5923 (A). Figure 5.40a shows a plot of CEC whereas Figure 5.40b shows a plot of SSA as functions of depth. CEC ranged from 3.23 to $9.28 \mathrm{meq} / \mathrm{g}$ with a mean and standard error of $7.16 \pm 0.276 \mathrm{meq} / 100 \mathrm{~g}$. The SSA ranged from 2.32 to $10.1 \mathrm{~m}^{2} / \mathrm{g}$ with a mean and standard error of $5.48 \pm 0.586 \mathrm{~m}^{2} / \mathrm{g}$.

As shown in Figure 5.40, results were separated into high ionic strength (high salinity) and low ionic strength (low salinity) samples. At low ionic strengths, the CEC can be accurately estimated from the total soil extractable cations. However, in saline sediments, accurate determination of the CEC requires prewashing to remove soluble salts in the pore water. All of the samples were washed three times before analyses. CEC results after washing show significant differences between samples that were initially high in salinity and those that were initially low. For initially low ionic strength samples, the CEC ranged from 3.23 to 9.28 with a mean of $7.06 \pm 0.48 \mathrm{meq} / 100 \mathrm{~g}$. For initially high ionic strength samples, the CEC ranged from 5.65 to 8.58 with a mean $7.26 \pm 0.27 \mathrm{meq} / 100$. The SSA for initially low ionic strength samples ranged from 2.32 to $10.1 \mathrm{~m}^{2} / \mathrm{g}$ with a mean of $6.61 \pm 0.87 \mathrm{~m}^{2} / \mathrm{g}$. However, the initially high ionic 
strength samples ranged from 2.69 to $9.61 \mathrm{~m}^{2} / \mathrm{g}$ with a mean of $4.35 \pm 0.06 \mathrm{~m}^{2} / \mathrm{g}$. The means are significantly different.

Both CEC and SSA showed some variation with depth. To better understand these variations, results were analyzed to identify any dependence on lithology. As shown earlier, two major lithologic units have been identified at the site; the Hanford formation and Cold Creek unit with the contact occurring around $220 \mathrm{ft}$ bgs. Analytical results were separated into measurements made in the 0 - to 220-ft range and the $>220-\mathrm{ft}$ depth. Analysis of SSA data showed a range of mean and standard error of $5.44 \pm 0.721 \mathrm{~m}^{2} / \mathrm{g}$ in the 0 - to 220 -ft interval and $5.572 \pm 1.09 \mathrm{~m}^{2} / \mathrm{g}$ in the $>220$-ft depth interval. These results are not significantly different. A similar analysis of the CEC measurements show a mean and standard error of $7.32 \pm 0.235 \mathrm{meq} / 100 \mathrm{~g}$ in the 0 - to 220 -ft interval and $6.76 \pm 0.798 \mathrm{meq} / 100 \mathrm{~g}$ in the $>220$ - $\mathrm{ft}$ interval, which are statistically different.

\section{Relationship Between CEC, SSA, and Water Content}

The variation in CEC and SSA with depth has been shown to follow the variations in sediment texture, particularly the abundance of fines. If vertical variations in CEC and SSA are due entirely to lithologic variations, then these values should show a strong correlation to water content, textural composition, and grain-size moments. Figure 5.41shows depth profiles of CEC and SSA compared to water content for borehole C5923. Both CEC (Figure 5.41a) and SSA (Figure 5.41b) show their highest values on the 0 - to 50 -ft interval where moisture content was highest. Both CEC and SSA appear to roughly follow the trend in water content. There is a progressive decrease in water content with depth from the 0 - to 50 - $\mathrm{ft}$ zone, and this trend is accompanied by a general decrease in CEC (Figure 5.40a) and SSA (Figure 5.40b). To better understand the relationship, water content was regressed on CEC and SSA (Figure 5.42). Ideally, one would expect a positive correlation between water content, CEC, and SSA. Under equilibrium conditions, finer textured soils would tend to have higher CECs and SSAs because of higher clay contents and also would retain more water. Although Figure 5.42a shows a general increase in water content with CEC, the correlation is not very strong and has limited predictive capability. Figure 5.42b shows a slight increase in water content with increasing SSA but the relationship is not strong enough to be used for predictive purposes. Figure 5.43 shows plots of CEC versus soil texture parameters.

The lack of correlation between water content and CEC or SSA is an indication that most of the water may not be adsorbed by clay interlayer sites but may be retained by some other means. To further investigate these relationships, or lack thereof, CEC was regressed on soil textural parameters derived from PSDs. Figure 5.43 shows plots of CEC as a function of sand, silt, and mud mass fractions, and the Fredle index. Owing to the low clay content, clay and silt mass fractions were summed and reported as a mud mass fraction. The Fredle index is computed from the cumulative probability d-values as the ratio of the mean diameter to the sorting index. Ideally, CEC should decrease as sand mass fraction increases. 
PNNL-17821
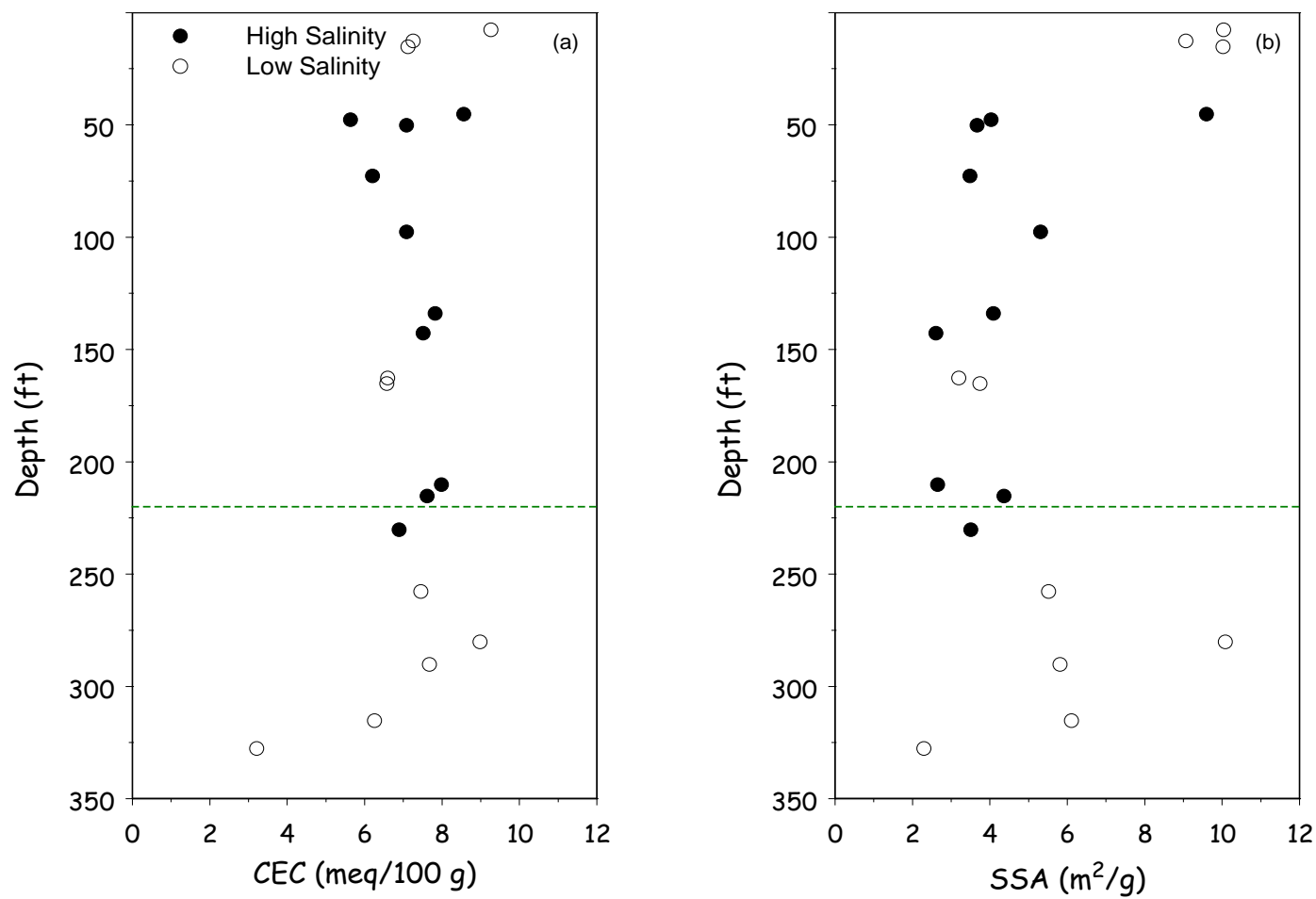

Figure 5.40. The Variation in CEC and SA with Depth at Borehole C5923 (A), (a) CEC, and (b) SSA Results Are Further Separated by Pre-Wash Ionic Strength. The dotted line shows the location of the Hanford formation-Cold Creek contact based on geologist's logs. 
PNNL-17821
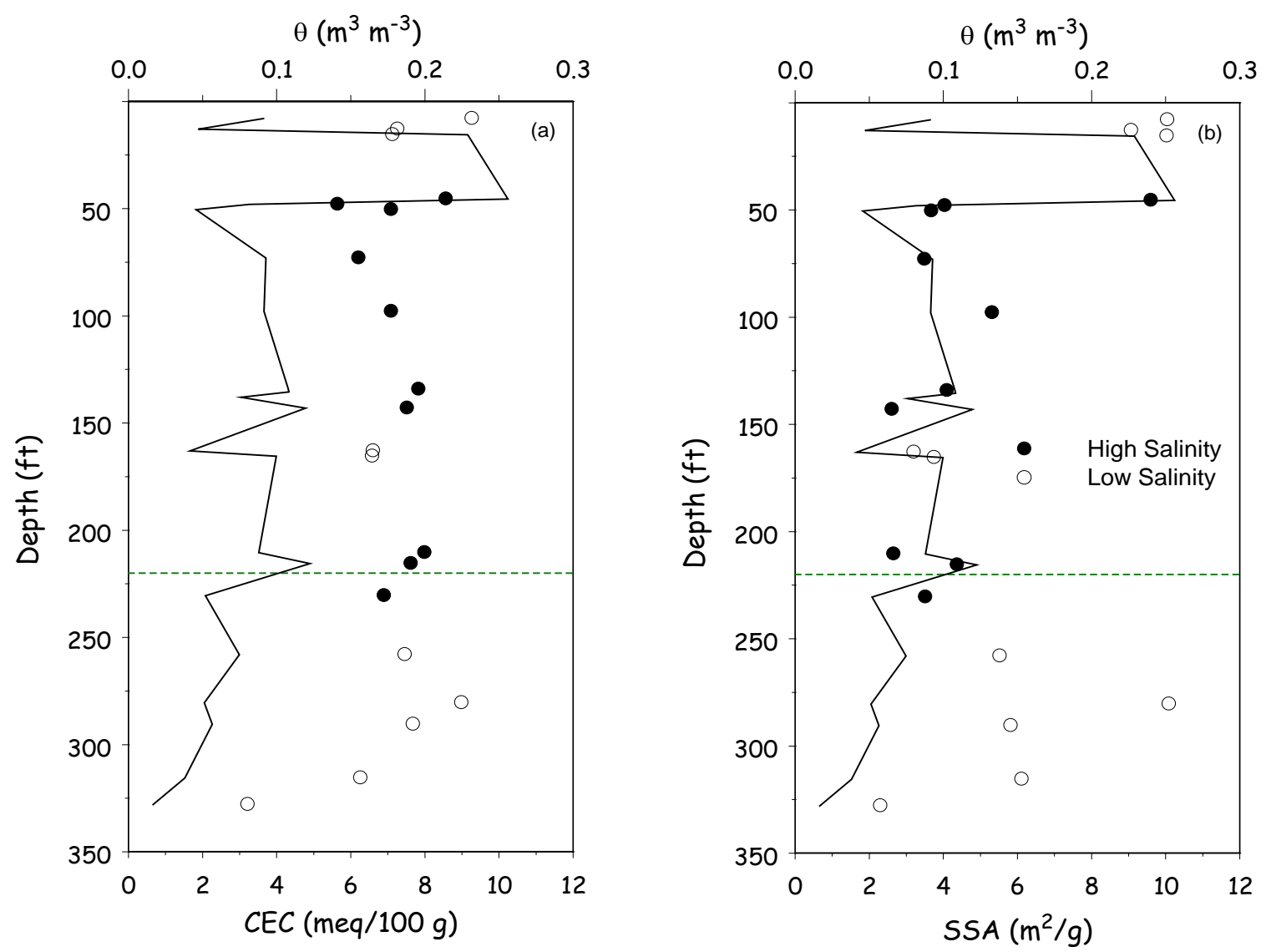

Figure 5.41. The Variation in CEC and SSA with Depth at Borehole C5923 (A) and the Relation to Water Content (a) CEC, and (b) SSA. Results are further separated by pre-wash ionic strength. The dotted line shows the location of the Hanford formation-Cold Creek contact based on geologist's logs.
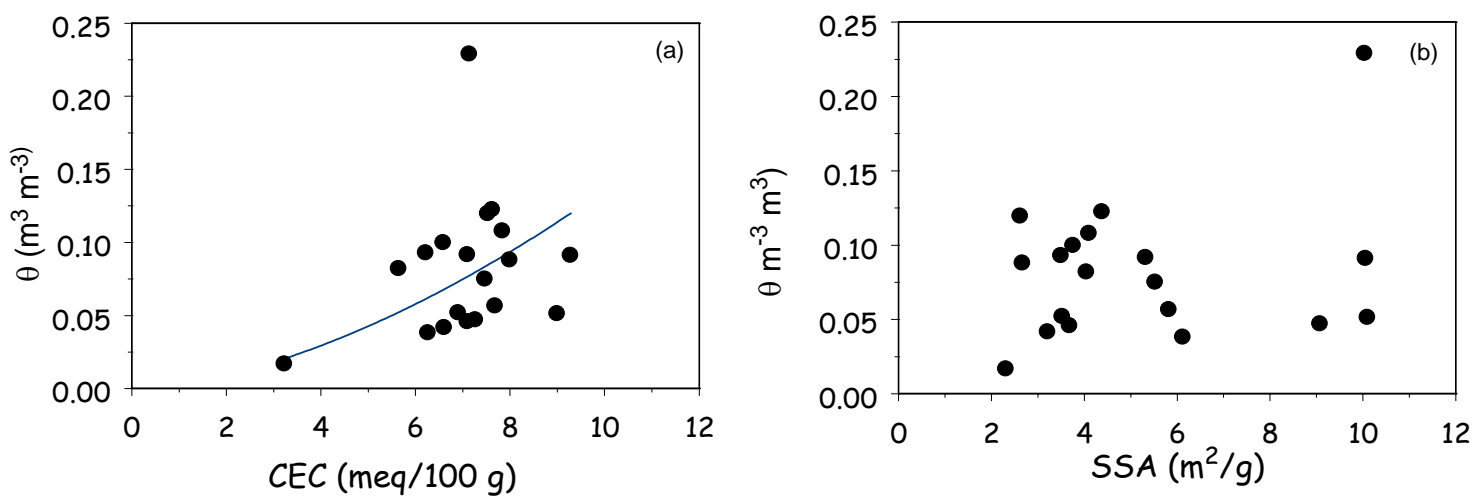

Figure 5.42. The Relationship Between Water Content and (a) CEC, (b) SSA Based on Measurements on Borehole C5923 (A)

However, as shown in Figure 5.43, there is no obvious relationship. This can be expected, given that the sediments contain a large amount sand and the generally low CEC of these materials. Figure 5.43b shows a general increase in CEC with silt mass fraction, although there appears to be two populations, one showing the expected increase and the other showing a decrease. The same relationship is apparent 
for the mud mass fraction and the Fredle index. The decrease in CEC with increasing Fredle index is due to the increase in the index as mean diameter increases. The reason for the apparent separation into two populations is uncertain but could be related to pore-water salinity.

Figure 5.44 shows a similar plot of SSA as a function of sand, silt, and mud mass fractions, and the Fredle index. Typically, the SSA should decrease with increasing mean particle diameter. Thus, the SSA should decrease with increasing sand fraction and increase with increasing silt, clay, or mud fraction. Owing to the low clay content, the range of SSA was quite small, and relationships to textural parameters are less apparent. However, the range of SSA observed for these sediments falls in the range of 9 to $12 \mathrm{~m}^{2} / \mathrm{g}$ observed for Hanford formation sediments (Ward et al. 2008). Figure 5.45 shows a plot of measured SSA versus measured CEC. In general, there is an increase in SSA with increasing CEC, although the correlation is not very strong. The existence of such a relationship yet with poor correlation with grain size statistics suggests that the relationship is being influenced by some other mechanism.
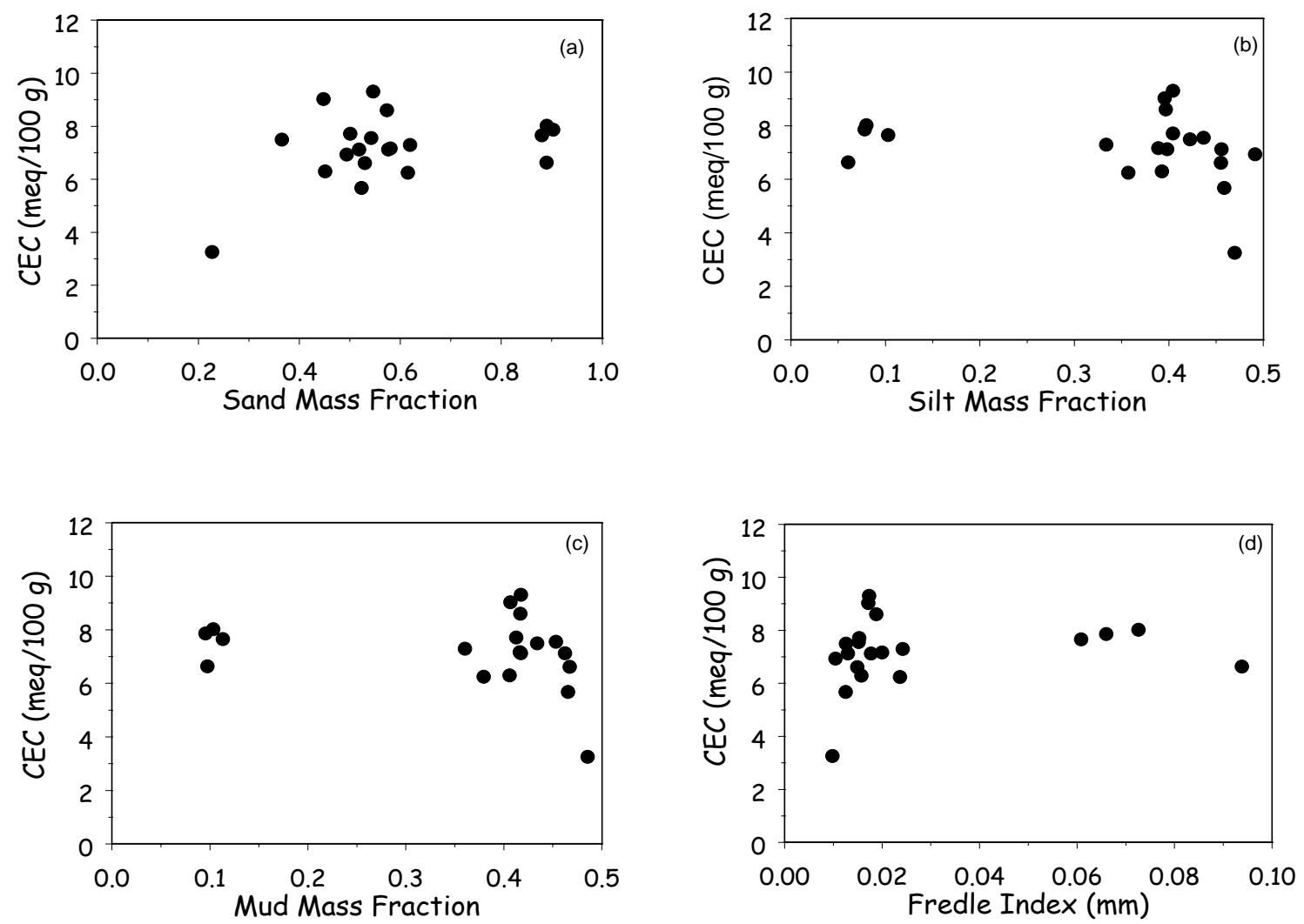

Figure 5.43. The Relationship Between CEC and Soil Textural Parameters (s) Sand Mass Fraction, (b) Silt Mass Fraction, (c) Mud, and (d) the Fredle index, Calculated as the Ratio of the Mean Diameter to the Sorting Index 

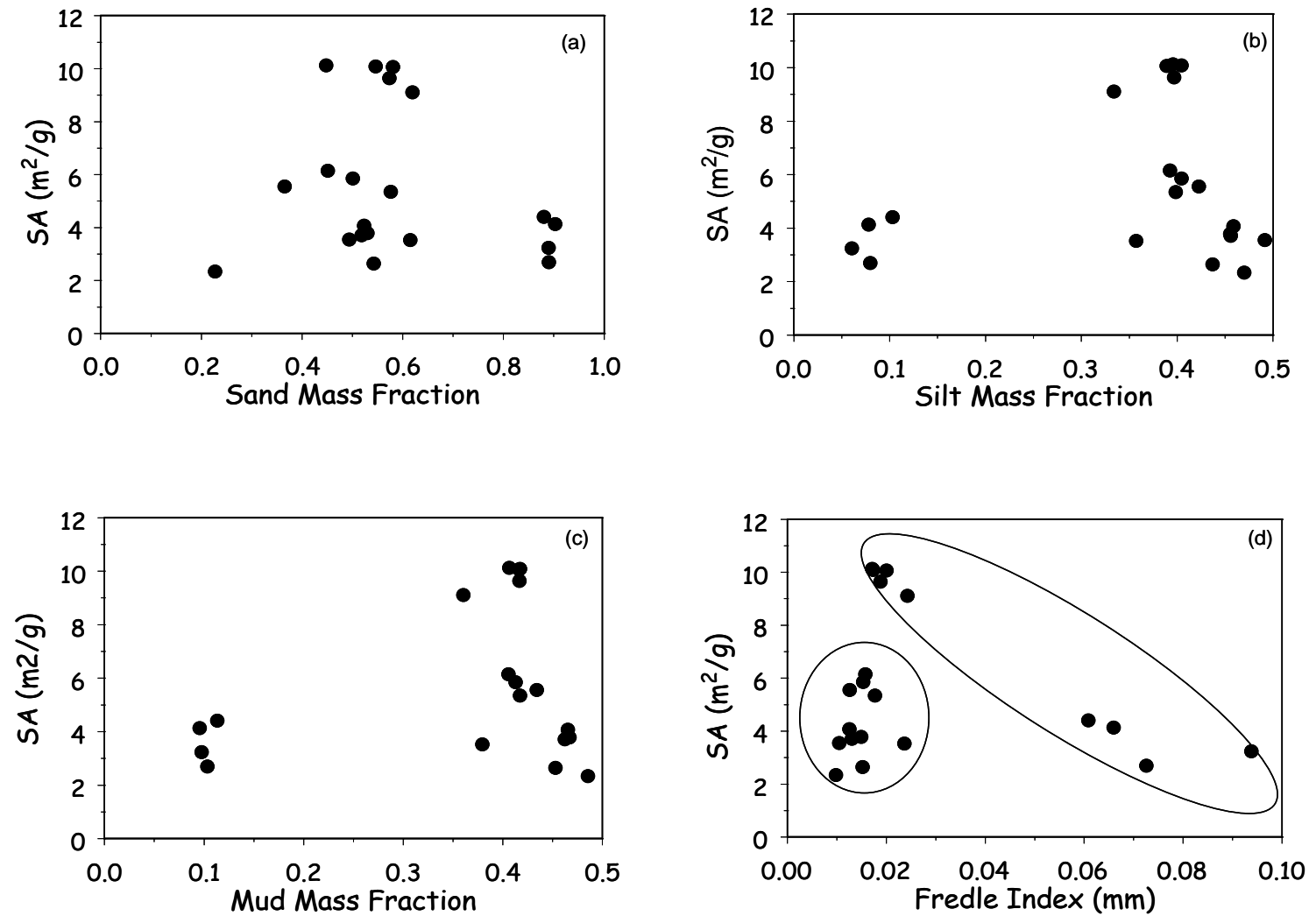

Figure 5.44. The Relationship Between SSA and Soil Textural Parameters (s) Sand Mass Fraction, (b) Silt Mass Fraction, (c) Mud, and (d) the Fredle index, Calculated as the Ratio of the Mean Diameter to the Sorting Index 
PNNL-17821

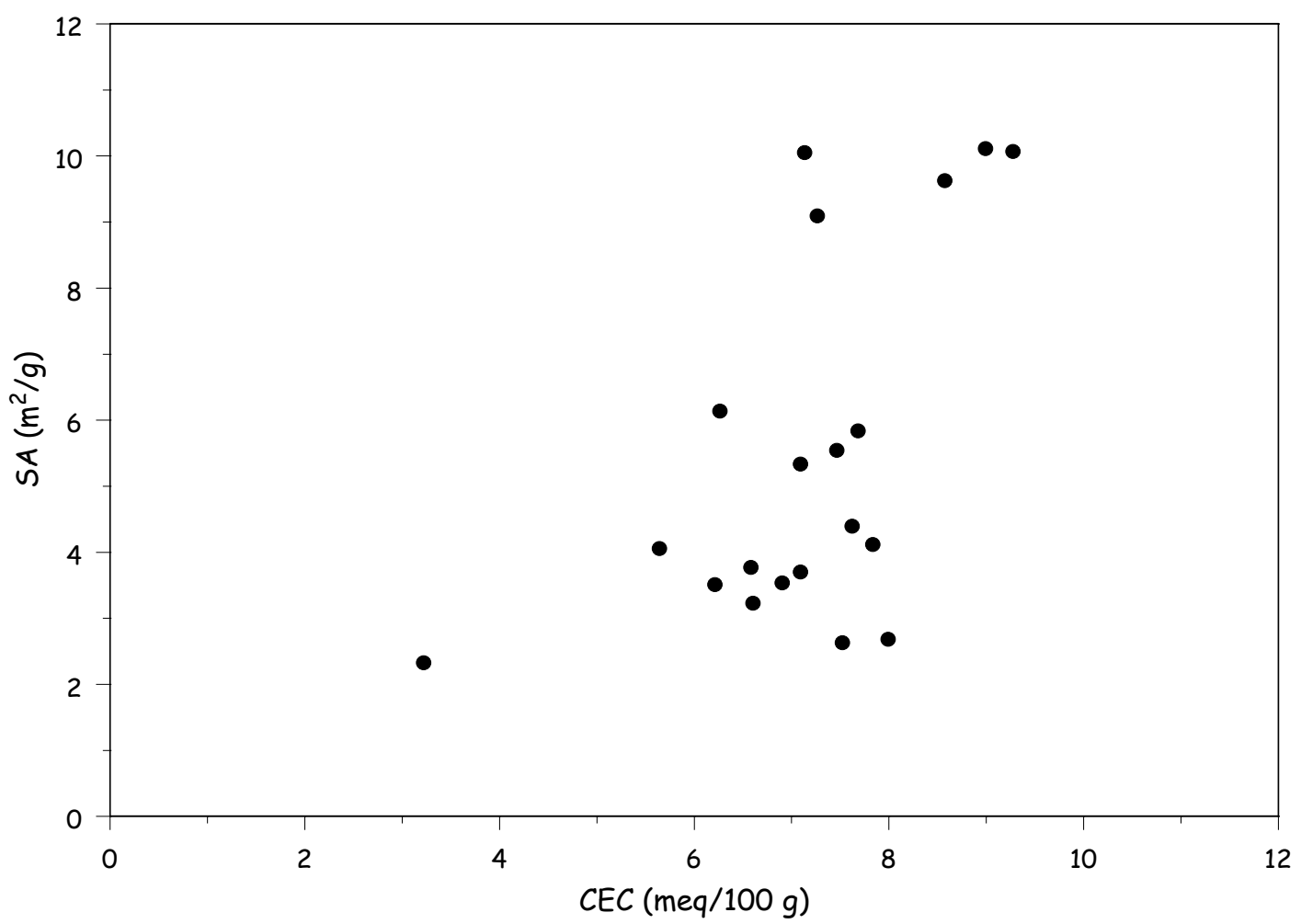

Figure 5.45. The Relationship Between SSA and CEC for Borehole C5923 (A)

\section{Relationship Between CEC, SSA and Electrical Conductivity}

Both the CEC and SSA data show significant variation with the grain-size data but do show a somewhat stronger cross correlation (Figure 5.45). Putting aside this large scatter in any of the correlations shown in Figures 5.43 through 5.45, there is slight indication of an inverse correlation between SSA and the laboratory-measured soil resistivity (Figure 5.46b). However, there appears to be no relationship between CEC and laboratory-measured soil resistivity (Figure 5.46a). This is not surprising as the bulk resistivity or its inverse conductivity is dominated by the pore fluids with very little contribution from individual grain-surface conductivity. This observation has important implications on the choice of model used to invert the field or laboratory soil resistivity data. There are several models, ranging from those based on Archies Law to more sophisticated models that account for particle surface conductivity. These data obtained in the laboratory using the sediments from borehole C5923 (A) suggest that Archie's law, developed for clean sandstones and applicable when clay content is close to zero, may suffice for the BC Cribs and Trenches site. 

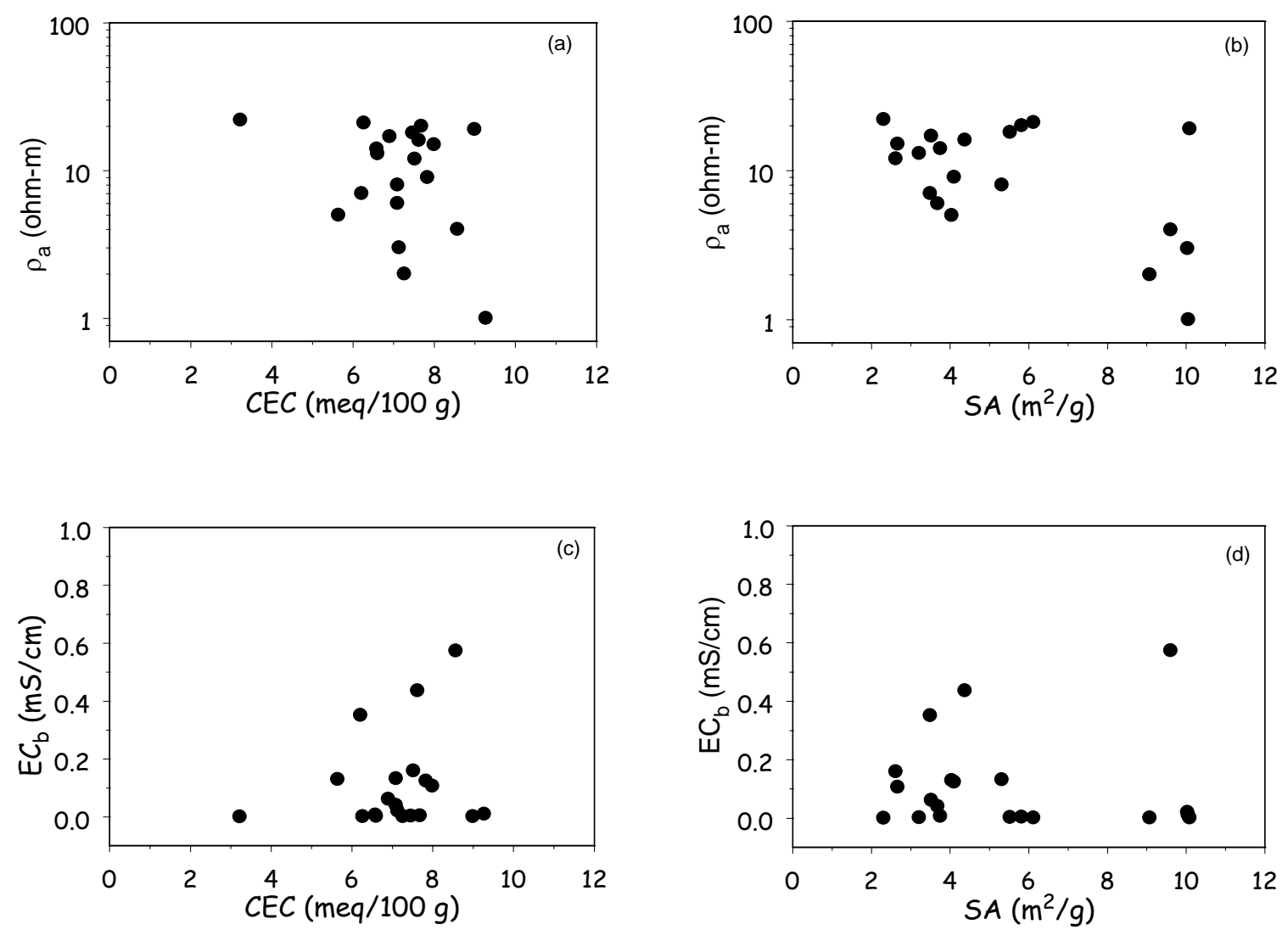

Figure 5.46. Relationship Between Electrical Properties, CEC, and SA for Borehole C5923 (A), (a) Resistivity vs. CEC, (b) Resistivity vs, SA, (c) Bulk Electrical Conductivity vs CEC and (d) Bulk Electrical Conductivity Versus SA 

PNNL-17821

\subsection{Borehole B (C5924) Results and Discussion}

\subsection{Geochemical Results from Borehole B (C5924)}

\subsubsection{Moisture Content}

The moisture contents of the 105 grab samples received from Borehole C5924 (B) are listed as a function of depth in Table 6.1 and shown in Figure 6.1. The moisture content profile from both laboratory and field measurements correlates with the lithology. Several samples (total 6) collected within the Hanford formation in the upper $120 \mathrm{ft}$ bgs exhibited much higher moisture contents, 8 to $12 \mathrm{wt} \%$, with the highest moisture content at $107 \mathrm{ft}$ bgs. These high moisture contents (>8 wt\%) indicated that certain depths contained more fine-grained particles than the average sediment (Figure 6.1). The typical sand-dominated Hanford formation had an average of 4 to $7 \mathrm{wt} \%$ of moisture content from 20 $\mathrm{ft}$ to $120 \mathrm{ft}$ bgs. In comparison, the surface sediment ( 0 to $20 \mathrm{ft}$ bgs) was composed of reworked Hanford sandy gravel and eolian silt and sand deposits, and/or backfill (anthropogenic) material, and coal plant ash ranged from 6 to $10 \mathrm{wt} \%$ moisture content. Moisture content in the Hanford formation below $120 \mathrm{ft}$ bgs dropped to an average of $\sim 3 \mathrm{wt} \%$ because the sediments coarsen with depth, especially in the underlying Cold Creek formation. In general, the more GD sediment deeper in the Hanford formation had low moisture contents with an average vadose zone moisture content of $\sim 2.0 \mathrm{wt} \%$ at the Hanford/Cold Creek formation below $205 \mathrm{ft}$ bgs.

The measured moisture contents of the samples can be used to qualitatively identify the location (depth) of finer-grained material in this borehole. This qualitative assessment confirms the lithology described in Sections 2.2.1.4 and 2.3.3 that indicate where the fine-grained layers in the Hanford formation reside. Additional discussions on the field moisture logging and a comparison to the laboratory gravimetric moisture contents and their correlation to the lithology for borehole C5924 are found in Section 2.3.3.

\subsubsection{1:1 Sediment: Water Extracts of Sediments from Borehole C5924 (B)}

A subset of the grab samples of sediments from Borehole C5924 (B) were characterized by performing 1:1 sediment:water extracts. Table 6.4 and Table 6.5 present the mass of a given constituent leached per gram of sediment as measured in the water extracts. Other tables and figures in Section 6.1.2 also show dilution-corrected values that represent concentrations in vadose zone pore water. Directly extracted pore water from a few sediments using ultracentrifugation are also compared with those determined by 1:1 water extracts. 
PNNL-17821

Table 6.1. Gravimetric Moisture Content of Samples Retrieved from Borehole B (C5924)

\begin{tabular}{|c|c|c|c|c|c|}
\hline $\begin{array}{c}\text { Sample Name } \\
\text { (HEIS ID) }\end{array}$ & $\begin{array}{l}\text { Moisture Content } \\
\text { (Weight \%) }\end{array}$ & $\begin{array}{c}\text { Sample Mid Depth } \\
\text { (ft bgs) }\end{array}$ & $\begin{array}{c}\text { Sample Name } \\
\text { (HEIS ID) }\end{array}$ & $\begin{array}{l}\text { Moisture Content } \\
\text { (Weight \%) }\end{array}$ & $\begin{array}{l}\text { Sample Mid Depth } \\
\text { (ft bgs) }\end{array}$ \\
\hline B1T677 & 7.05 & 5.25 & B1T6D3 & 3.90 & 120.25 \\
\hline B1T678 & 7.90 & 7.75 & B1T6D4 & 4.33 & 122.75 \\
\hline В1T679 & 8.04 & 9.75 & B1T6D5 & 3.55 & 125.25 \\
\hline В1T680 & 6.15 & 12.25 & B1T6D6 & 2.90 & 127.25 \\
\hline B1T681 & 4.86 & 14.75 & B1T6D7 & 2.57 & 130.25 \\
\hline B1T682 & 9.94 & 17.75 & B1T6D8 & 2.98 & 132.75 \\
\hline B1T683 & 8.38 & 19.75 & B1T6D9 & 2.39 & 135.25 \\
\hline B1T730 (DUP) & 9.12 & 19.75 & B1T6F0 & 2.00 & 137.75 \\
\hline B1T684 & 6.73 & 22.75 & B1T6F1 & 2.50 & 139.75 \\
\hline B1T685 & 5.20 & 25.25 & B1T6F2 & 2.68 & 142.25 \\
\hline B1T686 & 5.59 & 27.25 & B1T6F3 & 1.98 & 144.75 \\
\hline B1T687 & 6.49 & 29.75 & B1T6F4 & 2.29 & 147.25 \\
\hline B1T688 & 5.38 & 32.25 & B1T6F5 & 2.70 & 150.25 \\
\hline В1T689 & 8.77 & 34.75 & B1T733 (DUP) & 2.11 & 150.25 \\
\hline B1T690 & 8.19 & 37.25 & B1T6F6 & 2.26 & 153.25 \\
\hline B1T691 & 3.56 & 40.25 & B1T6F7 & 1.81 & 155.25 \\
\hline B1T692 & 3.84 & 42.75 & B1T6F8 & 2.59 & 157.75 \\
\hline В1T693 & 3.67 & 44.75 & B1T6F9 & 1.92 & 160.25 \\
\hline В1T694 & 2.91 & 47.25 & В1Т6H0 & 2.64 & 163 \\
\hline B1T695 & 3.31 & 50.75 & В1Т6H4 & 2.38 & 172.75 \\
\hline B1T696 & 4.23 & 52.75 & B1T6H5 & 2.32 & 175.25 \\
\hline В1T697 & 4.06 & 54.75 & В1T6H6 & 3.34 & 178.25 \\
\hline B1T698 & 3.27 & 57.25 & В1T6H7 & 2.29 & 181.25 \\
\hline В1T699 & 3.33 & 60.25 & В1Т6H8 & 2.37 & 182.75 \\
\hline B1T6B0 & 7.28 & 62.25 & В1Т6H9 & 2.98 & 184.75 \\
\hline B1T6B1 & 2.88 & 65.25 & B1T6J0 & 2.42 & 187.75 \\
\hline B1T731 (DUP) & 2.83 & 65.25 & B1T6J2 & 2.02 & 192.25 \\
\hline B1T6B2 & 3.32 & 67.75 & B1T6J3 & 2.41 & 195.25 \\
\hline B1T6B3 & 9.82 & 70.25 & B1T6J4 & 2.84 & 197.75 \\
\hline B1T6B4 & 2.79 & 72.75 & B1T6J5 & 1.72 & 201.25 \\
\hline B1T6B5 & 6.29 & 75.25 & B1T6J6 & 3.24 & 202.75 \\
\hline B1T6B6 & 5.72 & 77.25 & B1T6J7 & 2.32 & 205 \\
\hline B1T6B7 & 4.59 & 79.75 & B1T6J8 & 1.75 & 207.75 \\
\hline B1T6B8 & 2.68 & 82.75 & B1T6J9 & 2.24 & 210.75 \\
\hline B1T6B9 & 4.79 & 85.75 & В1Т6K0 & 2.29 & 212.25 \\
\hline
\end{tabular}


PNNL-17821

Table 6.1 (Contd)

\begin{tabular}{|c|c|c|c|c|c|}
\hline $\begin{array}{c}\text { Sample Name } \\
\text { (HEIS ID) }\end{array}$ & $\begin{array}{l}\text { Moisture Content } \\
\text { (Weight \%) }\end{array}$ & $\begin{array}{c}\text { Sample Mid Depth } \\
\text { (ft bgs) }\end{array}$ & $\begin{array}{c}\text { Sample Name } \\
\text { (HEIS ID) }\end{array}$ & $\begin{array}{l}\text { Moisture Content } \\
\text { (Weight \%) }\end{array}$ & $\begin{array}{c}\text { Sample Mid Depth } \\
\text { (ft bgs) }\end{array}$ \\
\hline B1T6C0 & 3.61 & 87.75 & B1T6K1 & 1.91 & 215.25 \\
\hline B1T6C1 & 3.27 & 90.25 & B1T734 (DUP) & 1.91 & 215.25 \\
\hline B1T6C2 & 3.87 & 92.25 & B1T6K2 & 1.90 & 217.25 \\
\hline B1T6C3 & 7.80 & 95.25 & В1T6K3 & 1.89 & 220.25 \\
\hline B1T6C4 & 4.22 & 97.75 & B1T6K4 & 2.18 & 222.75 \\
\hline B1T6C5 & 2.85 & 100.25 & B1T6K5 & 2.15 & 225.25 \\
\hline B1T6C6 & 3.21 & 102.75 & B1T6K6 & 2.37 & 227.25 \\
\hline B1T6C7 & 4.11 & 105.25 & B1T6K7 & 1.79 & 230.25 \\
\hline B1T732 (DUP) & 3.95 & 105.25 & В1T6K8 & 2.20 & 232.75 \\
\hline B1T6C8 & 12.20 & 107.25 & В1Т6К9 & 1.92 & 235.25 \\
\hline В1T6C9 & 5.35 & 110.25 & B1T6L0 & 1.92 & 237.75 \\
\hline B1T6D0 & 3.72 & 112.25 & B1T6L1 & 2.21 & 240.25 \\
\hline B1T6D1 & 3.54 & 115.25 & B1T6L2 & 2.52 & 243.25 \\
\hline \multirow[t]{2}{*}{ B1T6D2 } & 8.27 & 117.75 & B1T6L3 & 2.74 & 245.25 \\
\hline & & & B1T6L4 & 2.21 & 247.75 \\
\hline
\end{tabular}


PNNL-17821

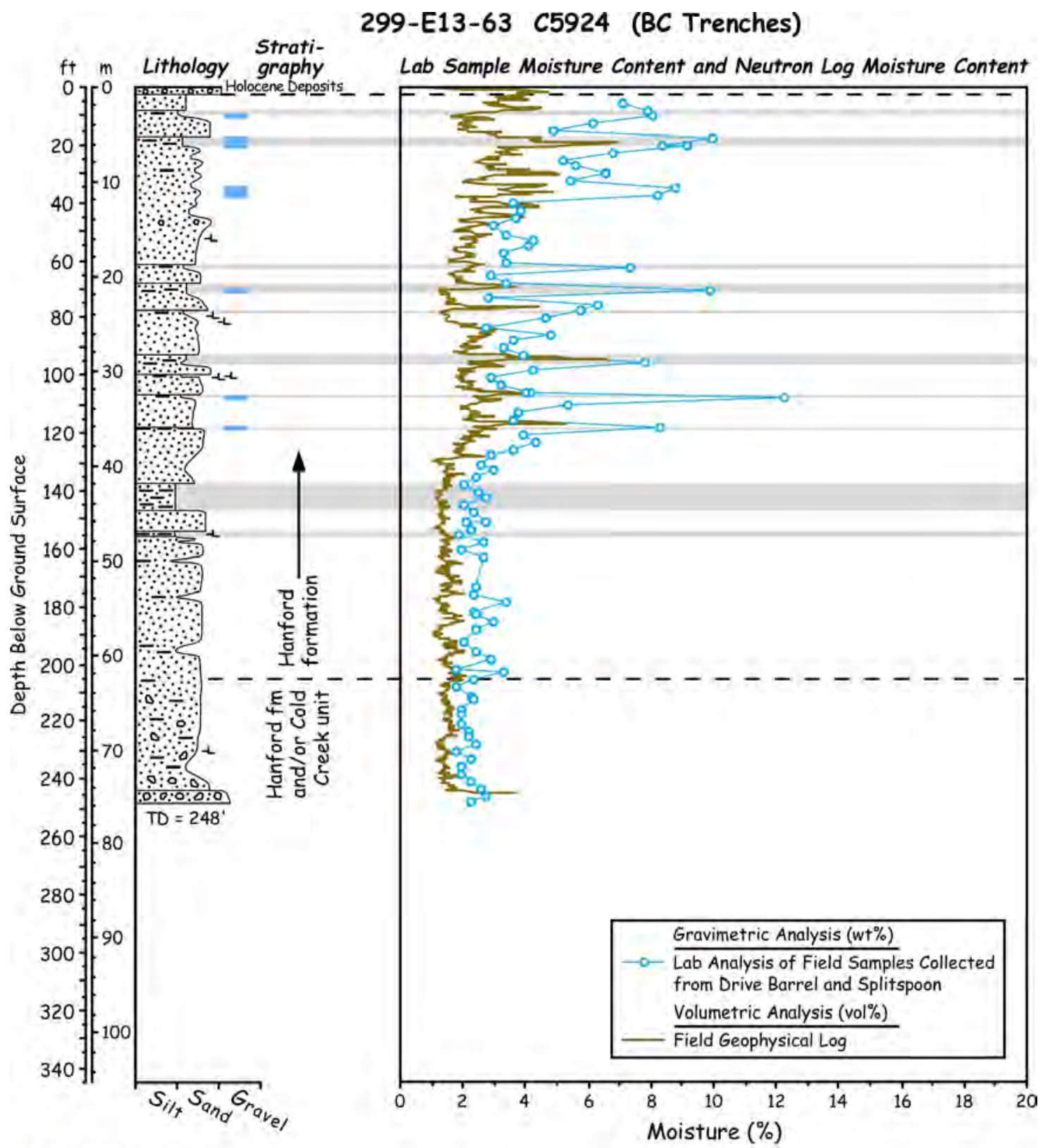

Fine-Grained Layer

$\Longrightarrow 8 w+\%$ Moisture

+ Pedogenic Carbonate

I silt $\because$ Sand $\because 0$ Gravel

2008/DCL/C5924/002 (07/24)

Figure 6.1. Laboratory and Field Measured Moisture Contents (wt\%) for Borehole C5924 (B) 
The $\mathrm{pH}$ and EC of the water extracts from selected grab samples from Borehole C5924 (B) are shown in Table 6.2 and Figure 6.2. EC was corrected back to a pore-water concentration based on field moisture and is reported as pore water, which is corrected in Table 6.2 and Figure 6.2. The $\mathrm{pH}$ profile shows slight hints ( $\mathrm{pH}$ values $>8.5$ ) of some caustic waste-sediment interaction from 17.75 to 34.75 and from 52.75 to $57.25 \mathrm{ft}$ bgs. The high $\mathrm{pH}$ of 8.8 was found at $25.25 \mathrm{ft}$ bgs. Compared to borehole C5923, the high $\mathrm{pH}$ range (8.55 to 9.24) was found from 8 to $18 \mathrm{ft}$ bgs. At C4191 (see Section 8.1.2), the sediments right below trench 216-B-26 show pH values that range from 8.65 to 9.59 between 17.5 to $43.5 \mathrm{ft}$ bgs. Thus, the sediment $\mathrm{pH}$ at $\mathrm{C} 5924$ is less caustic, but the depths with slightly elevated $\mathrm{pH}$ reach deeper into the profile than at the other two boreholes that show significant salt and technetium-99 contamination. Below the depth of $57.25 \mathrm{ft}$ bgs, excepting one sample at $112 \mathrm{ft}$ bgs, borehole C5924 sediments show normal pH values typical of uncontaminated sediments (7.2 and 8.5).

Table 6.2. $\mathrm{pH}$ for 1:1 Sediment: Water Extracts and Electrical Conductivity (EC) Values from Borehole C5924 (B)

\begin{tabular}{|c|c|c|c|c|c|c|c|c|c|}
\hline $\begin{array}{c}\text { Sample } \\
\text { Name }\end{array}$ & $\begin{array}{l}\text { Sample Mid } \\
\text { Depth }\end{array}$ & $\mathrm{pH}$ & $\begin{array}{c}\text { Electrical } \\
\text { conductivity }\end{array}$ & $\begin{array}{c}\text { Pore water } \\
\text { corrected } \\
\text { EC } \\
\end{array}$ & $\begin{array}{c}\text { Sample } \\
\text { Name } \\
\end{array}$ & $\begin{array}{c}\text { Sample Mid } \\
\text { Depth }\end{array}$ & $\mathrm{pH}$ & $\begin{array}{c}\text { Electrical } \\
\text { conductivity }\end{array}$ & $\begin{array}{c}\text { Pore water } \\
\text { corrected } \\
\text { EC } \\
\end{array}$ \\
\hline (HEIS ID) & (ft bgs) & & $(\mathrm{mS} / \mathrm{cm})$ & $(\mathrm{mS} / \mathrm{cm})$ & (HEIS ID) & (ft bgs) & & $(\mathrm{mS} / \mathrm{cm})$ & $(\mathrm{mS} / \mathrm{cm})$ \\
\hline B1T677 & 5.25 & 7.77 & 0.14 & 1.94 & В1Т6B9 & 85.75 & 7.79 & 1.03 & 21.57 \\
\hline B1T680 & 12.25 & 8.41 & 0.15 & 2.42 & B1T6C0 & 87.75 & 7.91 & 0.46 & 12.78 \\
\hline B1T682 & 17.75 & 8.52 & 0.26 & 2.56 & B1T6C1 & 90.25 & 8.11 & 0.24 & 7.74 \\
\hline B1T683 & 19.75 & 8.64 & 0.24 & 2.82 & B1T6C2 & 92.25 & 8.14 & 0.27 & 6.91 \\
\hline $\begin{array}{l}\text { B1T730 } \\
\text { (DUP) }\end{array}$ & 19.75 & 8.57 & 0.24 & 2.58 & B1T6C3 & 95.25 & 7.95 & 1.06 & 13.63 \\
\hline B1T685 & 25.25 & 8.8 & 0.2 & 3.84 & B1T6C4 & 97.75 & 7.62 & 0.59 & 14 \\
\hline B1T687 & 29.75 & 8.62 & 0.19 & 2.95 & B1T6C5 & 100.25 & 7.62 & 0.95 & 33.25 \\
\hline B1T689 & 34.75 & 8.53 & 0.19 & 2.19 & B1T6C6 & 102.75 & 7.56 & 1.09 & 33.99 \\
\hline B1T692 & 42.75 & 8.24 & 0.19 & 4.94 & B1T6C7 & 105.25 & 8.03 & 0.39 & 9.39 \\
\hline B1T693 & 44.75 & 8.36 & 0.17 & 4.34 & B1T6C8 & 107.25 & 8.27 & 0.42 & 3.41 \\
\hline В1T694 & 47.25 & 7.76 & 0.69 & 23.68 & В1Т6С9 & 110.25 & 7.81 & 0.25 & 5.24 \\
\hline B1T695 & 50.75 & 8.17 & 0.81 & 26.31 & B1T6D0 & 112.25 & 8.54 & 0.18 & 4.74 \\
\hline В1T696 & 52.75 & 8.83 & 0.94 & 22.14 & B1T6D1 & 115.25 & 8.46 & 0.16 & 4.56 \\
\hline В1T697 & 54.75 & 8.76 & 0.98 & 24.46 & B1T6D2 & 117.75 & 7.2 & 3.98 & 48.08 \\
\hline В1T698 & 57.25 & 8.6 & 1.16 & 35.47 & B1T6D3 & 120.25 & 7.64 & 0.79 & 20.34 \\
\hline B1T699 & 60.25 & 7.63 & 1.44 & 43.2 & B1T6D4 & 122.75 & 7.78 & 3.08 & 71.5 \\
\hline B1T6B0 & 62.25 & 7.74 & 3.73 & 51.23 & B1T6D6 & 127.25 & 7.78 & 0.42 & 14.45 \\
\hline B1T6B1 & 65.25 & 7.35 & 2.6 & 90.25 & B1T6D7 & 130.25 & 8.23 & 0.16 & 6.22 \\
\hline $\begin{array}{l}\text { B1T731 } \\
\text { (DUP) }\end{array}$ & 65.25 & 7.3 & 2.54 & 89.73 & B1T6D8 & 132.75 & 8.24 & 0.18 & 6.16 \\
\hline B1T6B2 & 67.75 & 7.31 & 3.08 & 92.69 & B1T6D9 & 135.25 & 8.48 & 0.14 & 6.24 \\
\hline В1T6B3 & 70.25 & 7.36 & 3.14 & 38.32 & B1T6F2 & 142.25 & 8.26 & 0.19 & 7.47 \\
\hline B1T6B4 & 72.75 & 7.66 & 0.68 & 24.22 & B1T6F5 & 150.25 & 8.16 & 0.15 & 5.68 \\
\hline B1T6B5 & 75.25 & 8.14 & 0.45 & 7.2 & В1T6H6 & 178.25 & 8.1 & 0.18 & 5.52 \\
\hline B1T6B6 & 77.25 & 7.45 & 1.72 & 30.06 & B1T6J6 & 202.75 & 8.31 & 0.15 & 4.76 \\
\hline B1T6B7 & 79.75 & 7.86 & 1.3 & 28.36 & B1T6K6 & 227.25 & 8.13 & 0.15 & 6.28 \\
\hline B1T6B8 & 82.75 & 7.61 & 0.76 & 29.29 & B1T6L3 & 245.25 & 8.25 & 0.15 & 5.37 \\
\hline
\end{tabular}

The pore-water-corrected EC data for borehole C5924 range from 1.94 to $90.3 \mathrm{mS} / \mathrm{cm}$ in the Hanford formation (see Figure 6.2). The EC data decrease significantly below $150 \mathrm{ft}$ bgs and show a narrow range of 5.4 to $7.5 \mathrm{mS} / \mathrm{cm}$ in the Hanford/Cold Creek formation. Two major peaks in pore-water-corrected EC values of 90.3 to $92.7 \mathrm{mS} / \mathrm{cm}$ at $67.8 \mathrm{ft}$ bgs and $71.5 \mathrm{mS} / \mathrm{cm}$ at $127.8 \mathrm{ft}$ bgs are indicative of a bimodal 
salt waste plume. Five grab samples were selected for ultracentrifugation from which pore water was extracted directly. The actual pore-water EC values fall within the range of the calculated pore-water EC values from 1:1 water extracts (Figure 6.2). This indicates that our water-extraction method used to remove extant pore water is providing realistic pore-water composition estimates. Despite disposing of the largest volumes of liquid wastes in the 216-B-52 trench compared to all other trenches, the mobile salt plume at C5924 has not traveled significantly deeper into the vadose zone profile than the waste profiles at C4191 (see Sections 8.1.2 and 8.1.5). Further, the salt plume at C5924 does not appear to have reached anywhere near the water table, likely because of thin fine-grained lenses, which provide several capillary breaks (contrasts between fine sand and coarse sand) that promote horizontal spreading in the upper portion of the Hanford formation.

The two peak values of pore water EC observed in the C5924 sediments are found at $67.75 \mathrm{ft}$ bgs $(92.69 \mathrm{mS} / \mathrm{cm})$ and at $117.75 \mathrm{ft}$ bgs $(45.08 \mathrm{mS} / \mathrm{cm})$. The total ionic strength (see data in Table 6.7) peaks occur at $67.75 \mathrm{ft}$ bgs $(1.26 \mathrm{M})$ and $122.75 \mathrm{ft}$ bgs $(1.09 \mathrm{M})$. The deeper peak in ionic strength is about $5 \mathrm{ft}$ lower than the peak in pore-water EC because of the high dissolved calcium and magnesium (displaced natural cations by sodium from the waste exchanging with the sediment cation exchange sites) in the pore water at $122.75 \mathrm{ft}$ bgs. In comparison, the highest pore-water EC values observed in the sediments at C5923 were 293 and $232 \mathrm{mS} / \mathrm{cm}$ at 90.5 and $230.5 \mathrm{ft}$ bgs, respectively. At borehole C4191, the highest pore-water EC values were 176 and $152 \mathrm{mS} / \mathrm{cm}$ at 93.5 and $133.5 \mathrm{ft}$ bgs (see Section 8.1-2). Thus, at borehole C5924, the pore-water EC values are slightly lower than right below Trench 216-B-26 (borehole C4191), but the two maxima are at similar depths for both boreholes. Comparing the salt plume at C5924 located between Trenches 216-B-52 and 216-B-33 and 216-B-34 with the plume at C5923 that is between the two rows of cribs, one can see that the boreholes (including C4191) near the trenches exhibit lower concentrations of salt in the profile and shallower depths for the deepest lobe of the plume than the salt distribution found in the vadose zone sediments near the cribs (C5923). 


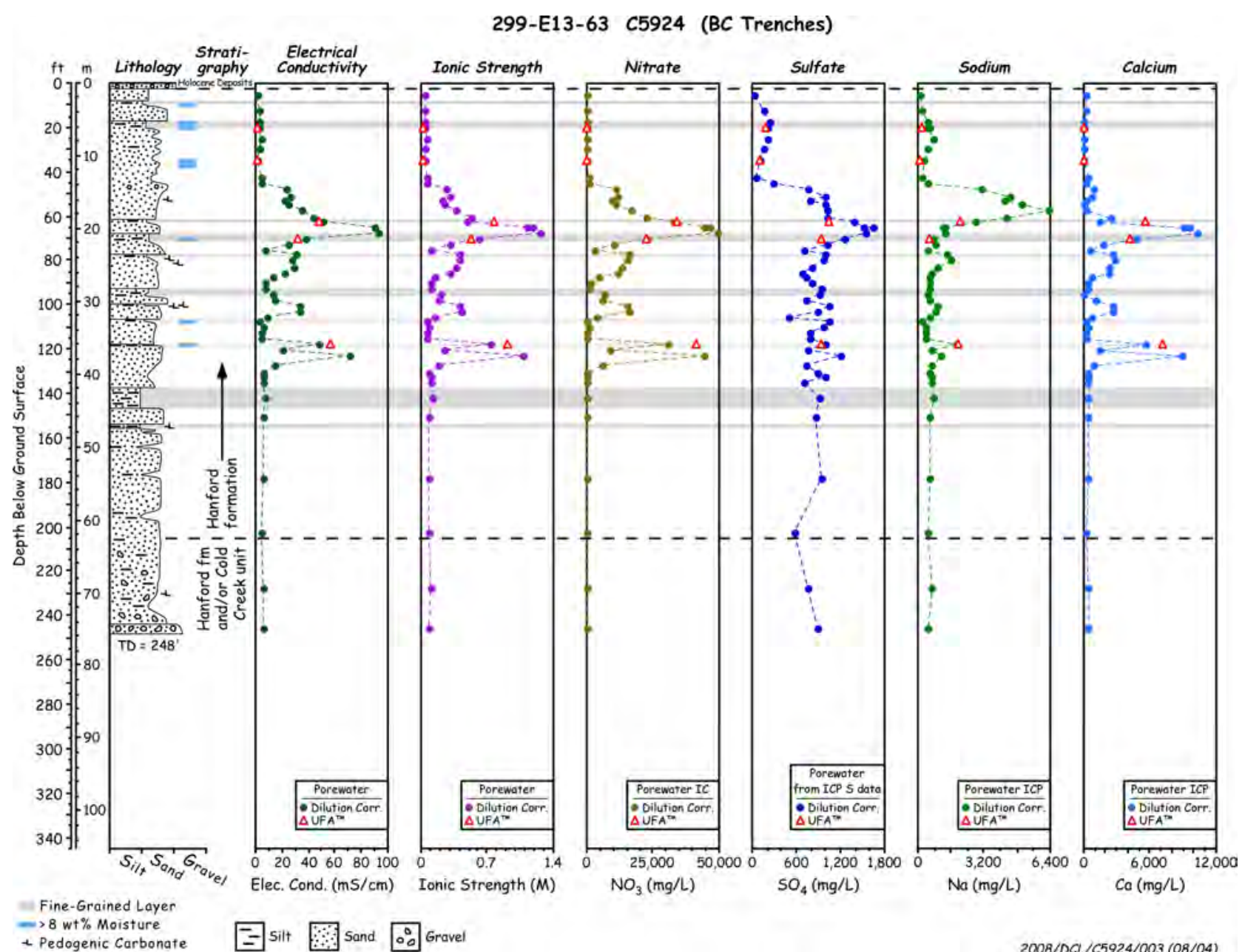

Figure 6.2. Pore Water EC, Calculated Ionic Strength, and Concentrations of Nitrate, Sulfate, Sodium, and Calcium for Borehole C5924 (B) 


\subsubsection{Composition of the 1:1 Sediment:Water Extracts from Borehole C5924 (B)}

The concentrations of major anions and cations as well as major contaminants and several trace constituents are discussed in this section. The anion data are tabulated in Table 6.3 in units of mg/L of pore water and in Table 6.4 in units of mass per gram of dry sediment. Figure 6.2 and Figure 6.3 are plots of the key anion data from these two tables along with other cations and contaminants. Table 6.3 and Figure 6.2 present water-extract anion data in units of $\mathrm{mg} / \mathrm{L}$ pore-water concentrations, which are the units most related to comparisons with the field- and laboratory-based soil resistivity measurements.

In Table 6.3, sulfate concentrations were measured by IC and compared with those calculated from total sulfur concentration determined by ICP-OES. Assuming that all water-leachable sulfur is in fact sulfate, the ICP method for determining sulfate has a more sensitive detection limit than the IC method for samples containing high nitrate concentrations. All the ionic strength calculations for borehole C5924 pore waters used sulfate concentrations determined by ICP. The most elevated pore-water sulfate concentrations are found near $65.3 \mathrm{ft}$ bgs.

Table 6.3. Water-Extractable Anions Converted to Pore Water Concentrations for Borehole C5924 (B) Sediments (mg/L)

\begin{tabular}{|c|c|c|c|c|c|c|c|c|c|}
\hline Sample ID & $\begin{array}{c}\text { Sample } \\
\text { Mid Depth }\end{array}$ & Fluoride & Chloride & Nitrite & Nitrate & Sulfate-IC & $\begin{array}{c}\text { Sulfate- } \\
\text { ICP }\end{array}$ & Phosphate-IC & $\operatorname{Alk}\left(\mathrm{CO}_{3}{ }^{2-}\right)$ \\
\hline (HEIS \#) & (ft bgs) & $(\mathrm{mg} / \mathrm{L})$ & $(\mathrm{mg} / \mathrm{L})$ & $(\mathrm{mg} / \mathrm{L})$ & $(\mathrm{mg} / \mathrm{L})$ & $(\mathrm{mg} / \mathrm{L})$ & $(\mathrm{mg} / \mathrm{L})$ & $(\mathrm{mg} / \mathrm{L})$ & $(\mathrm{mg} / \mathrm{L})$ \\
\hline B1T677 & 5.25 & 6.7 & 18.5 & ND & 150.6 & 41.9 & 32.9 & 10.5 & 884.1 \\
\hline B1T680 & 12.25 & 11.5 & 13.3 & ND & 249.4 & 158.1 & 158.9 & 6.4 & 852.1 \\
\hline B1T682 & 17.75 & 19.5 & 12.4 & ND & 241.9 & 236.5 & 232.5 & 4.2 & 855 \\
\hline B1T683 & 19.75 & 24.3 & 8.7 & ND & 206.2 & 222.5 & 219.3 & 5 & 906.7 \\
\hline $\begin{array}{c}\text { B1T730 } \\
\text { (DUP) }\end{array}$ & 19.75 & 22.5 & 8.6 & ND & 191.6 & 198.5 & 193.2 & 4.6 & 958.1 \\
\hline B1T685 & 25.25 & 25.7 & 13.7 & ND & 150.8 & 194.7 & 203.1 & 8.7 & 1598 \\
\hline B1T687 & 29.75 & 17.9 & 14.4 & ND & 200.6 & 158.8 & 157.1 & 5.8 & 1160.5 \\
\hline B1T689 & 34.75 & 10.7 & 25 & ND & 216.6 & 104.8 & 100.1 & 4.3 & 814.3 \\
\hline B1T692 & 42.75 & 10.7 & 98.1 & 10.4 & 1143.2 & 263.8 & 60.2 & 8.4 & 1066.2 \\
\hline B1T693 & 44.75 & 13 & 93.5 & ND & 601.7 & 272.8 & 279.5 & 63.9 & 1223.2 \\
\hline B1T694 & 47.25 & 16.8 & 319.3 & 84.2 & 10733 & 655.7 & 770.1 & 87.3 & 1144.3 \\
\hline B1T695 & 50.75 & 5.5 & 424.7 & 47.7 & 11753 & 784.1 & 986.4 & 24.2 & 1339.7 \\
\hline B1T696 & 52.75 & 13.5 & 287.1 & 58.4 & 9676.8 & 608.6 & 772.2 & 57.9 & 1113.6 \\
\hline B1T697 & 54.75 & 16 & 378.9 & 14.7 & 10666 & 868 & 984.6 & 9.2 & 832 \\
\hline B1T698 & 57.25 & 18 & 363.6 & 71.9 & 16915 & 758.7 & 1012.9 & 75.5 & 1766.4 \\
\hline B1T699 & 60.25 & 14.1 & 321 & 70.2 & 22492 & 743.6 & 1021.6 & ND & 2211.4 \\
\hline В1T6B0 & 62.25 & ND & 3.8 & ND & 32889 & 952.2 & 1376.1 & 4 & 688.9 \\
\hline B1T6B1 & 65.25 & 13.2 & 375.3 & ND & 43982 & 982.4 & 1524.2 & ND & 976.1 \\
\hline $\begin{array}{l}\text { B1T731 } \\
\text { (DUP) }\end{array}$ & 65.25 & 14.5 & 403.1 & 83 & 46408 & 1074.6 & 1653.5 & ND & 1020.2 \\
\hline B1T6B2 & 67.75 & 12.6 & 409.9 & 69.8 & 49404 & 919.4 & 1529.9 & ND & 709 \\
\hline B1T6B3 & 70.25 & ND & 194 & 147.7 & 22465.3 & 1050.8 & 1262 & 85.4 & 287.5 \\
\hline B1T6B4 & 72.75 & 16.8 & 143.3 & ND & 10474.8 & 959.4 & 1020.9 & ND & 953 \\
\hline B1T6B5 & 75.25 & 7.2 & 45 & 6.1 & 2937.5 & 700.8 & 696.4 & 4.5 & 508.4 \\
\hline B1T6B6 & 77.25 & 8.7 & 176.3 & 43.2 & 16091.6 & 792.4 & 982.9 & ND & 637.5 \\
\hline
\end{tabular}


PNNL-17821

Table 6.3 (contd)

\begin{tabular}{|c|c|c|c|c|c|c|c|c|c|}
\hline Sample ID & $\begin{array}{c}\text { Sample } \\
\text { Mid Depth }\end{array}$ & Fluoride & Chloride & Nitrite & Nitrate & Sulfate-IC & $\begin{array}{l}\text { Sulfate- } \\
\text { ICP }\end{array}$ & Phosphate-IC & Alk $\left(\mathrm{CO}_{3}{ }^{2-}\right)$ \\
\hline (HEIS \#) & (ft bgs) & (mg/L) & $(\mathrm{mg} / \mathrm{L})$ & $(\mathrm{mg} / \mathrm{L})$ & $(\mathrm{mg} / \mathrm{L})$ & $(\mathrm{mg} / \mathrm{L})$ & $(\mathrm{mg} / \mathrm{L})$ & $(\mathrm{mg} / \mathrm{L})$ & (mg/L) \\
\hline B1T6B7 & 79.75 & 10.6 & 197.8 & 16.1 & 15307.3 & 822.4 & 958.8 & 6.4 & 696.2 \\
\hline B1T6B8 & 82.75 & 15.7 & 147.2 & ND & 13198.8 & 738.3 & 811.6 & ND & 1281.8 \\
\hline В1Т6B9 & 85.75 & 7.9 & 119.8 & 8.9 & 11324.2 & 629 & 693.4 & 5.9 & 572.9 \\
\hline B1T6C0 & 87.75 & 13.3 & 77.4 & ND & 4670.9 & 664.3 & 727.3 & ND & 758.6 \\
\hline B1T6C1 & 90.25 & 11.6 & 45.4 & ND & 1816.4 & 772.5 & 810.3 & 3.6 & 1037.5 \\
\hline B1T6C2 & 92.25 & 14 & 63.2 & ND & 1131.9 & 882 & 937.6 & ND & 1161.2 \\
\hline B1T6C3 & 95.25 & 5.4 & 85.8 & 5.8 & 6606.3 & 902.9 & 916.6 & 3.6 & 410.6 \\
\hline B1T6C4 & 97.75 & 9.7 & 87.9 & ND & 5784.4 & 702.6 & 743.9 & ND & 666.1 \\
\hline B1T6C5 & 100.25 & 14 & 237.9 & 80.6 & 15413.1 & 991.4 & 1042.1 & ND & 825.4 \\
\hline B1T6C6 & 102.75 & 13.1 & 209.2 & 72 & 16105.8 & 848.1 & 899.9 & ND & 829.4 \\
\hline B1T6C7 & 105.25 & 10.8 & 75.7 & ND & 3934.5 & 515.2 & 498.6 & 6.8 & 921.8 \\
\hline B1T6C8 & 107.25 & 4.5 & 29.6 & ND & 430.1 & 1060.6 & 1046.9 & 2.5 & 342.3 \\
\hline В1T6C9 & 110.25 & 7.9 & 33.2 & 2.7 & 760.3 & 921.2 & 969.8 & 2.1 & 959.7 \\
\hline B1T6D0 & 112.25 & 15.3 & 50.9 & ND & 120.6 & 727.9 & 776.1 & ND & 1247.5 \\
\hline B1T6D1 & 115.25 & 14.3 & 50.6 & ND & 125.2 & 736.3 & 774.4 & ND & 1154.6 \\
\hline B1T6D2 & 117.75 & ND & 3.5 & ND & 30527 & 656.8 & 990.1 & 3.4 & 303 \\
\hline B1T6D3 & 120.25 & 11.8 & 101.6 & ND & 9115 & 664.5 & 757.9 & ND & 701.6 \\
\hline B1T6D4 & 122.75 & ND & 331.5 & ND & 43969 & 697.5 & 1191 & 6.5 & 476.3 \\
\hline B1T6D6 & 127.25 & 17.9 & 102.6 & ND & 6113.9 & 752.5 & 729.3 & ND & 1071.9 \\
\hline B1T6D7 & 130.25 & 23.7 & 57.5 & ND & 155.8 & 734.8 & 881.3 & ND & 1742.1 \\
\hline B1T6D8 & 132.75 & 31.3 & 47.3 & ND & 187.7 & 980.4 & 993.8 & 11.2 & 1908.2 \\
\hline B1T6D9 & 135.25 & 22.9 & 33.9 & ND & 93.4 & 642 & 710.4 & 5.1 & 1971.3 \\
\hline B1T6F2 & 142.25 & 36.8 & 58.1 & ND & 111.8 & 853.2 & 910 & 6.7 & 2252.4 \\
\hline B1T6F5 & 150.25 & 22.1 & 38.6 & ND & 115.7 & 845.6 & 852.1 & 11.3 & 1731.2 \\
\hline B1T6H6 & 178.25 & 23 & 46.2 & ND & 126.4 & 925.9 & 937.7 & 10.2 & 1640.2 \\
\hline B1T6J6 & 202.75 & 20.2 & 42.6 & ND & 136.9 & 603.9 & 585.7 & 9.4 & 1455.3 \\
\hline B1T6K6 & 227.25 & 31 & 50.7 & ND & 94.7 & 755.8 & 748.3 & 12.7 & 2160.4 \\
\hline B1T6L3 & 245.25 & 19.8 & 37.5 & ND & 108 & 902.7 & 901.7 & ND & 1583.5 \\
\hline
\end{tabular}




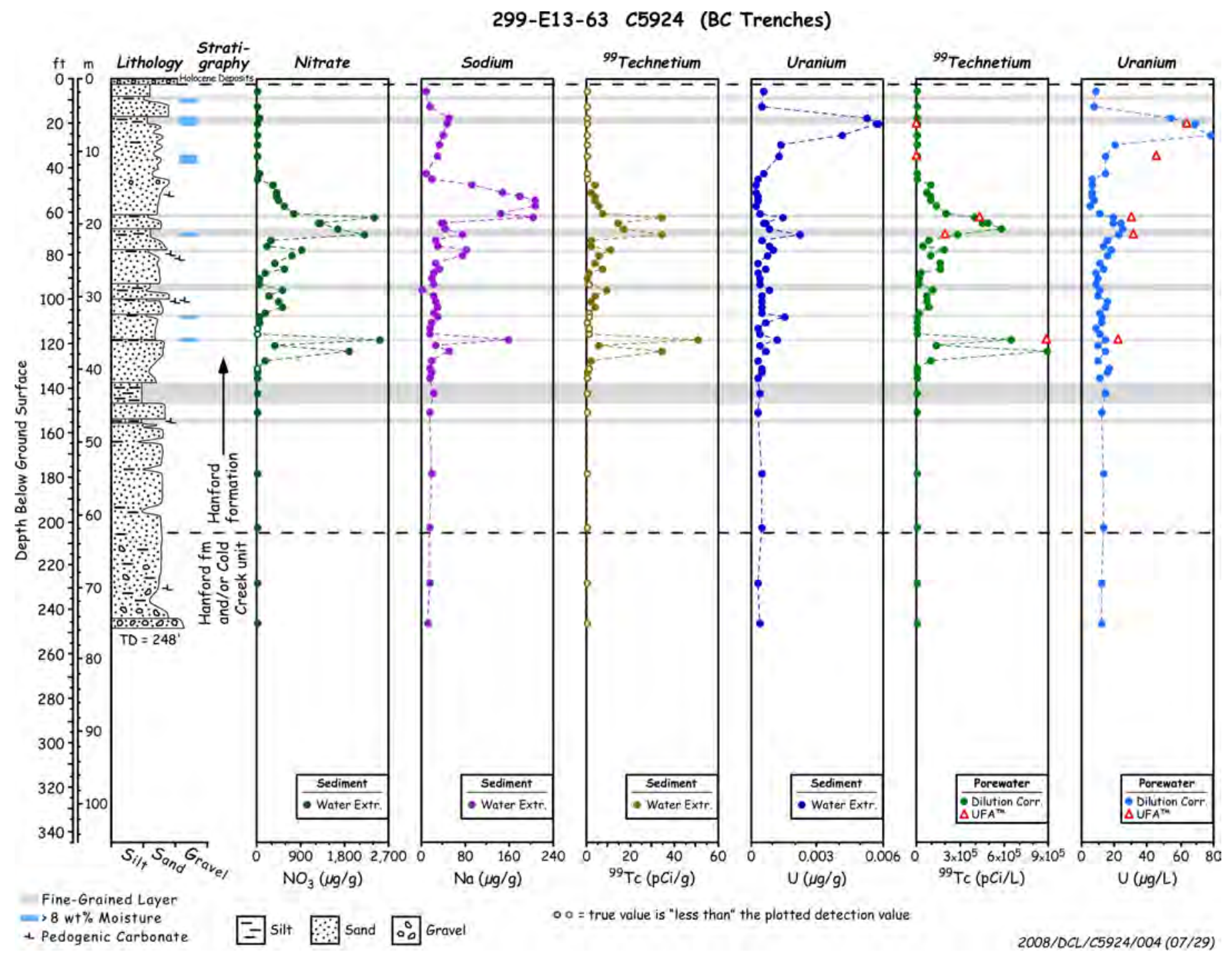

Figure 6.3. Measured Nitrate, Sodium, Technetium-99 and Uranium for Borehole C5924 (B) Sediments 
Since Borehole C5924 (B) is close to the 216-B-52 trench where $\sim 1.46 \times 10^{+6} \mathrm{~kg}$ of nitrate (the largest nitrate mass disposed to any given BC Area trench; see Corbin et al. 2005) was disposed of, the primary water-extractable anion in the sediments was nitrate. Five grab samples in the high-salt regions were selected for ultracentrifugation. The nitrate concentrations in pore waters obtained directly by ultracentrifugation showed similar results to the calculated nitrate concentrations obtained from the 1:1 water extracts (Figure 6.2). This agreement further establishes the use of the 1:1 sediment-to-water process to obtain estimates of pore-water concentrations. A bi-modal nitrate distribution (Figure 6.2 and Figure 6.3) was found with two peaks at 62 to $70 \mathrm{ft}$ bgs and 118 to $123 \mathrm{ft}$ bgs, which is closely related to the pore-water-corrected EC profile (Figure 6.2).

Table 6.4 and Figure 6.3 present the same water-extract anion data but in units of $\mu \mathrm{g} / \mathrm{g}$ of dry sediment. The most elevated nitrate concentration in the sediment $(2525 \mu \mathrm{g} / \mathrm{g})$ is found in a fine clay-rich layer at $120 \mathrm{ft}$ bgs. The depth distribution of nitrate (Table 6.4 and Figure 6.3) should be a good indicator of the deepest penetration of the waste fluids disposed of to the neighboring cribs because the mobility of nitrate is quite high (i.e., nitrate is not retained significantly on sediment particles and stays in the pore fluids). Because nitrate migrates with the percolating fluids without retardation, the massive quantity of nitrate (total $3.08 \times 10^{+6} \mathrm{~kg}$ based on Corbin et al. [2005] disposed of in the three nearest trenches) makes it a good tracer of the waste fluid plume location.

Table 6.4. Anion Composition of Water Extracts of Borehole C5924 (B) Sediment ( $\mu \mathrm{g} / \mathrm{g}$ dry sediment)

\begin{tabular}{|c|c|c|c|c|c|c|c|c|}
\hline $\begin{array}{c}\text { Sample } \\
\text { (HEIS ID) }\end{array}$ & $\begin{array}{l}\text { Sample Mid } \\
\text { Depth } \\
\text { (ft bgs) }\end{array}$ & $\begin{array}{l}\text { Fluoride } \\
\mu \mathrm{g} / \mathrm{g} \text { sed }\end{array}$ & $\begin{array}{l}\text { Chloride } \\
\mu \mathrm{g} / \mathrm{g} \text { sed }\end{array}$ & $\begin{array}{c}\text { Nitrite } \\
\mu \mathrm{g} / \mathrm{g} \text { sed }\end{array}$ & $\begin{array}{c}\text { Nitrate } \\
\mu g / g \text { sed }\end{array}$ & $\begin{array}{c}\text { Sulfate-IC } \\
\mu \mathrm{g} / \mathrm{g} \text { sed }\end{array}$ & $\begin{array}{c}\text { Phosphate-IC } \\
\mu \mathrm{g} / \mathrm{g} \text { sed }\end{array}$ & $\begin{array}{c}\mathrm{Alk}\left(\mathrm{CO}_{3}{ }^{2-}\right) \\
\mu \mathrm{g} / \mathrm{g} \text { sed }\end{array}$ \\
\hline В1T677 & 5.25 & 0.47 & 1.3 & ND & 10.6 & 3 & 0.7 & 62.3 \\
\hline B1T680 & 12.25 & 0.71 & 0.82 & ND & 15.3 & 9.7 & 0.4 & 52.4 \\
\hline B1T682 & 17.75 & 1.94 & 1.23 & ND & 24 & 23.5 & 0.4 & 85 \\
\hline B1T683 & 19.75 & 2.04 & 0.73 & ND & 17.3 & 18.7 & 0.4 & 76 \\
\hline $\begin{array}{l}\text { B1T730 } \\
\text { (DUP) }\end{array}$ & 19.75 & 2.06 & 0.79 & ND & 17.5 & 18.1 & 0.4 & 87.5 \\
\hline B1T685 & 25.25 & 1.33 & 0.71 & ND & 7.8 & 10.1 & 0.4 & 82.8 \\
\hline B1T687 & 29.75 & 1.16 & 0.93 & ND & 13 & 10.3 & 0.4 & 75.3 \\
\hline B1T689 & 34.75 & 0.94 & 2.19 & ND & 19 & 9.2 & 0.4 & 71.4 \\
\hline В1T692 & 42.75 & 0.41 & 3.77 & 0.4 & 44 & 10.2 & 0.3 & 41 \\
\hline В1T693 & 44.75 & 0.48 & 3.44 & ND & 22.2 & 10.1 & 2.4 & 45.1 \\
\hline B1T694 & 47.25 & 0.49 & 9.24 & 2.4 & 310.8 & 19 & 2.5 & 33.1 \\
\hline B1T695 & 50.75 & 0.18 & 14.06 & 1.6 & 389 & 26 & 0.8 & 44.3 \\
\hline B1T696 & 52.75 & 0.57 & 12.15 & 2.5 & 409.3 & 25.7 & 2.4 & 47.1 \\
\hline B1T697 & 54.75 & 0.65 & 15.39 & 0.6 & 433 & 35.2 & 0.4 & 33.8 \\
\hline B1T698 & 57.25 & 0.59 & 11.89 & 2.4 & 553.1 & 24.8 & 2.5 & 57.8 \\
\hline B1T699 & 60.25 & 0.47 & 10.69 & 2.3 & 749 & 24.8 & ND & 73.6 \\
\hline B1T6B0 & 62.25 & ND & 0.27 & ND & 2394.3 & 69.3 & 0.3 & 50.1 \\
\hline B1T6B1 & 65.25 & 0.38 & 10.81 & ND & 1266.7 & 28.3 & ND & 28.1 \\
\hline $\begin{array}{l}\text { B1T731 } \\
\text { (DUP) }\end{array}$ & 65.25 & 0.41 & 11.41 & 2.3 & 1313.3 & 30.4 & ND & 28.9 \\
\hline B1T6B2 & 67.75 & 0.42 & 13.61 & 2.3 & 1640.2 & 30.5 & ND & 23.5 \\
\hline B1T6B3 & 70.25 & ND & 19.06 & 14.5 & 2206.1 & 103.2 & 8.4 & 28.2 \\
\hline B1T6B4 & 72.75 & 0.47 & 4 & ND & 292.2 & 26.8 & ND & 26.6 \\
\hline B1T6B5 & 75.25 & 0.45 & 2.83 & 0.4 & 184.8 & 44.1 & 0.3 & 32 \\
\hline
\end{tabular}


PNNL-17821

Table 6.4 (contd)

\begin{tabular}{|c|c|c|c|c|c|c|c|c|}
\hline $\begin{array}{c}\text { Sample } \\
\text { (HEIS ID) }\end{array}$ & $\begin{array}{l}\text { Sample Mid } \\
\text { Depth } \\
\text { (ft bgs) }\end{array}$ & $\begin{array}{l}\text { Fluoride } \\
\mu \mathrm{g} / \mathrm{g} \text { sed }\end{array}$ & $\begin{array}{l}\text { Chloride } \\
\mu \mathrm{g} / \mathrm{g} \text { sed }\end{array}$ & $\begin{array}{c}\text { Nitrite } \\
\mu \mathrm{g} / \mathrm{g} \text { sed }\end{array}$ & $\begin{array}{c}\text { Nitrate } \\
\mu \mathrm{g} / \mathrm{g} \text { sed }\end{array}$ & $\begin{array}{c}\text { Sulfate-IC } \\
\mu \mathrm{g} / \mathrm{g} \text { sed }\end{array}$ & $\begin{array}{c}\text { Phosphate-IC } \\
\mu \mathrm{g} / \mathrm{g} \text { sed }\end{array}$ & $\begin{array}{c}\mathrm{Alk}\left(\mathrm{CO}_{3}{ }^{2-}\right) \\
\mu \mathrm{g} / \mathrm{g} \text { sed }\end{array}$ \\
\hline B1T6B6 & 77.25 & 0.5 & 10.09 & 2.5 & 920.4 & 45.3 & ND & 36.5 \\
\hline B1T6B7 & 79.75 & 0.49 & 9.08 & 0.7 & 702.6 & 37.8 & 0.3 & 32 \\
\hline B1T6B8 & 82.75 & 0.42 & 3.94 & ND & 353.7 & 19.8 & ND & 34.4 \\
\hline В1T6B9 & 85.75 & 0.38 & 5.74 & 0.4 & 542.4 & 30.1 & 0.3 & 27.4 \\
\hline B1T6C0 & 87.75 & 0.48 & 2.79 & ND & 168.6 & 24 & ND & 27.4 \\
\hline B1T6C1 & 90.25 & 0.38 & 1.48 & ND & 59.4 & 25.3 & 0.1 & 33.9 \\
\hline B1T6C2 & 92.25 & 0.54 & 2.45 & ND & 43.8 & 34.1 & ND & 44.9 \\
\hline B1T6C3 & 95.25 & 0.42 & 6.69 & 0.5 & 515.3 & 70.4 & 0.3 & 32 \\
\hline B1T6C4 & 97.75 & 0.41 & 3.71 & ND & 244.1 & 29.7 & ND & 28.1 \\
\hline B1T6C5 & 100.25 & 0.4 & 6.78 & 2.3 & 439.3 & 28.3 & ND & 23.5 \\
\hline B1T6C6 & 102.75 & 0.42 & 6.72 & 2.3 & 517 & 27.2 & ND & 26.6 \\
\hline B1T6C7 & 105.25 & 0.44 & 3.11 & ND & 161.7 & 21.2 & 0.3 & 37.9 \\
\hline B1T6C8 & 107.25 & 0.54 & 3.61 & ND & 52.5 & 129.4 & 0.3 & 41.8 \\
\hline B1T6C9 & 110.25 & 0.42 & 1.78 & 0.1 & 40.7 & 49.3 & 0.1 & 51.3 \\
\hline B1T6D0 & 112.25 & 0.57 & 1.89 & ND & 4.5 & 27.1 & ND & 46.4 \\
\hline B1T6D1 & 115.25 & 0.51 & 1.8 & ND & 4.4 & 26.2 & ND & 41 \\
\hline B1T6D2 & 117.75 & 0 & 0.29 & ND & 2524.5 & 54.3 & 0.3 & 25.1 \\
\hline B1T6D3 & 120.25 & 0.46 & 3.96 & ND & 355.5 & 25.9 & ND & 27.4 \\
\hline B1T6D4 & 122.75 & 0 & 14.36 & ND & 1903.9 & 30.2 & 0.3 & 20.6 \\
\hline B1T6D6 & 127.25 & 0.46 & 2.64 & ND & 157.3 & 19.4 & ND & 31.1 \\
\hline B1T6D7 & 130.25 & 0.69 & 1.67 & ND & 4.5 & 21.3 & ND & 44.8 \\
\hline B1T6D8 & 132.75 & 0.93 & 1.41 & ND & 5.6 & 29.2 & 0.3 & 56.9 \\
\hline B1T6D9 & 135.25 & 0.55 & 0.81 & ND & 2.2 & 15.3 & 0.1 & 47.1 \\
\hline B1T6F2 & 142.25 & 0.99 & 1.56 & ND & 3 & 22.9 & 0.2 & 60.4 \\
\hline B1T6F5 & 150.25 & 0.6 & 1.04 & ND & 3.1 & 22.8 & 0.3 & 46.7 \\
\hline B1T6H6 & 178.25 & 0.77 & 1.54 & ND & 4.2 & 30.9 & 0.3 & 54.8 \\
\hline B1T6J6 & 202.75 & 0.65 & 1.38 & ND & 4.4 & 19.6 & 0.3 & 47.2 \\
\hline B1T6K6 & 227.25 & 0.74 & 1.2 & ND & 2.2 & 17.9 & 0.3 & 51.2 \\
\hline B1T6L3 & 245.25 & 0.54 & 1.03 & ND & 3 & 24.7 & ND & 43.4 \\
\hline
\end{tabular}

(a) Bold values are higher than others for given constituent; ND indicates not detected.

Despite the disposal of 18.2 ML (mega liters total) as estimated by Corbin et al. (2005) to the three nearby trenches (216-B33, 216-B34, and 216-B52), the fluids appear to remain in the upper $130 \mathrm{ft}$, which is much shallower than the water table (estimated to be $\sim 345 \mathrm{ft}$ bgs).

Table 6.5 and Table 6.6 show the water-leachable concentrations of major divalent (Ca, Sr, and Mg) and monovalent ( $\mathrm{Na}$ and $\mathrm{K}$ ) cations in units of $\mu \mathrm{g}$ per gram of dry sediment and in units of $\mathrm{mg} / \mathrm{L}$ of pore water, respectively, for the grab samples analyzed from Borehole C5924 (B). Table 6.5 and Figure 6.4 indicate the commonly observed ion-exchange front below Hanford waste sites wherein the sodium in the liquid wastes replaces the native divalent cations off of the sediments' cation exchange sites. Sodium concentrations in the pore water (Figure 6.3) show a similar distribution pattern to nitrate with a slight retardation in the shallow maximum of the plume. Slightly retarded sodium transport in the shallow region is attributed to sodium adsorption on the sediment compared to the un-reactive nitrate. 
PNNL-17821

Table 6.5. Water Extractable Cations in Borehole C5924 (B) Sediments ( $\mu$ g/g dry soil)

\begin{tabular}{|c|c|c|c|c|c|c|}
\hline Sample (HEIS ID) & Mid Depth (ft bgs) & $\mathrm{Ca}$ & $\mathrm{Mg}$ & $\mathrm{Sr}$ & $\mathrm{Na}$ & $\mathrm{K}$ \\
\hline B1T677 & 5.25 & $1.34 \mathrm{E}+01$ & $2.49 \mathrm{E}+00$ & $4.18 \mathrm{E}-02$ & $7.19 \mathrm{E}+00$ & $5.37 \mathrm{E}+00$ \\
\hline В1T680 & 12.25 & $8.31 \mathrm{E}+00$ & $4.28 \mathrm{E}+00$ & 8.91E-02 & $1.28 \mathrm{E}+01$ & $1.78 \mathrm{E}+00$ \\
\hline В1T682 & 17.75 & $2.76 \mathrm{E}+00$ & $6.66 \mathrm{E}-01$ & $1.24 \mathrm{E}-02$ & $4.89 \mathrm{E}+01$ & $3.66 \mathrm{E}+00$ \\
\hline B1T683 & 19.75 & $2.65 E+00$ & 6.37E-01 & $1.16 \mathrm{E}-02$ & $4.61 \mathrm{E}+01$ & $3.56 \mathrm{E}+00$ \\
\hline B1T730 (DUP) & 19.75 & $2.47 \mathrm{E}+00$ & 5.99E-01 & 1.10E-02 & $4.68 \mathrm{E}+01$ & $3.42 E+00$ \\
\hline B1T685 & 25.25 & $2.18 \mathrm{E}+00$ & 5.88E-01 & $1.02 \mathrm{E}-02$ & $3.93 \mathrm{E}+01$ & $2.95 \mathrm{E}+00$ \\
\hline В1T687 & 29.75 & $5.26 \mathrm{E}+00$ & $1.19 \mathrm{E}+00$ & 2.47E-02 & $3.13 \mathrm{E}+01$ & $4.01 \mathrm{E}+00$ \\
\hline B1T689 & 34.75 & $7.97 \mathrm{E}+00$ & $1.63 \mathrm{E}+00$ & 3.79E-02 & $2.65 \mathrm{E}+01$ & $4.81 \mathrm{E}+00$ \\
\hline В1T692 & 42.75 & $1.33 \mathrm{E}+01$ & $2.49 \mathrm{E}+00$ & 4.18E-02 & $7.19 \mathrm{E}+00$ & $5.37 \mathrm{E}+00$ \\
\hline В1T693 & 44.75 & $7.82 \mathrm{E}+00$ & $1.73 E+00$ & 4.09E-02 & $1.76 \mathrm{E}+01$ & $3.08 \mathrm{E}+00$ \\
\hline В1T694 & 47.25 & $2.78 \mathrm{E}+01$ & $6.25 \mathrm{E}+00$ & $1.64 \mathrm{E}-01$ & $8.92 E+01$ & $6.44 \mathrm{E}+00$ \\
\hline B1T695 & 50.75 & $2.13 \mathrm{E}+01$ & $6.32 \mathrm{E}+00$ & $1.20 \mathrm{E}-01$ & $1.48 E+02$ & $1.06 \mathrm{E}+01$ \\
\hline B1T696 & 52.75 & $5.06 \mathrm{E}+00$ & $1.58 \mathrm{E}+00$ & 3.59E-02 & $1.77 E+02$ & $5.71 \mathrm{E}+00$ \\
\hline B1T697 & 54.75 & $3.99 \mathrm{E}+00$ & $1.11 \mathrm{E}+00$ & 2.69E-02 & $2.04 E+02$ & $5.05 \mathrm{E}+00$ \\
\hline B1T698 & 57.25 & $8.70 \mathrm{E}+00$ & $2.61 \mathrm{E}+00$ & 6.61E-02 & $2.06 E+02$ & $7.17 \mathrm{E}+00$ \\
\hline B1T699 & 60.25 & $8.07 \mathrm{E}+01$ & $2.64 \mathrm{E}+01$ & 5.02E-01 & $1.44 E+02$ & $1.28 \mathrm{E}+01$ \\
\hline В1T6B0 & 62.25 & $1.02 E+02$ & $3.40 \mathrm{E}+01$ & $2.20 \mathrm{E}+00$ & $2.01 E+02$ & $2.24 \mathrm{E}+01$ \\
\hline B1T6B1 & 65.25 & $2.59 E+02$ & $7.50 \mathrm{E}+01$ & $1.44 \mathrm{E}+00$ & $3.49 \mathrm{E}+01$ & $1.47 \mathrm{E}+01$ \\
\hline B1T731 (DUP) & 65.25 & $2.72 E+02$ & $7.91 E+01$ & $1.55 \mathrm{E}+00$ & $3.71 \mathrm{E}+01$ & $1.58 \mathrm{E}+01$ \\
\hline B1T6B2 & 67.75 & $3.43 E+02$ & $1.05 E+02$ & $1.86 \mathrm{E}+00$ & $4.30 \mathrm{E}+01$ & $1.80 \mathrm{E}+01$ \\
\hline В1T6B3 & 70.25 & $4.70 \mathrm{E}+02$ & $1.49 E+02$ & $2.30 \mathrm{E}+00$ & $7.42 E+01$ & $2.31 \mathrm{E}+01$ \\
\hline B1T6B4 & 72.75 & $4.88 \mathrm{E}+01$ & $2.05 E+01$ & $2.64 \mathrm{E}-01$ & $2.39 \mathrm{E}+01$ & $9.00 \mathrm{E}+00$ \\
\hline B1T6B5 & 75.25 & $3.61 \mathrm{E}+01$ & $1.40 \mathrm{E}+01$ & $1.72 \mathrm{E}-01$ & $2.95 \mathrm{E}+01$ & $5.70 \mathrm{E}+00$ \\
\hline B1T6B6 & 77.25 & $1.53 E+02$ & $5.40 \mathrm{E}+01$ & 8.34E-01 & $7.90 \mathrm{E}+01$ & $1.76 \mathrm{E}+01$ \\
\hline B1T6B7 & 79.75 & $1.25 E+02$ & $4.03 \mathrm{E}+01$ & $6.74 \mathrm{E}-01$ & $7.22 \mathrm{E}+01$ & $1.46 \mathrm{E}+01$ \\
\hline B1T6B8 & 82.75 & $6.02 \mathrm{E}+01$ & $2.51 \mathrm{E}+01$ & 2.91E-01 & $2.55 \mathrm{E}+01$ & $8.77 \mathrm{E}+00$ \\
\hline B1T6B9 & 85.75 & $1.06 \mathrm{E}+02$ & $3.67 \mathrm{E}+01$ & 4.62E-01 & $3.30 \mathrm{E}+01$ & $9.80 \mathrm{E}+00$ \\
\hline B1T6C0 & 87.75 & $2.82 \mathrm{E}+01$ & $1.28 \mathrm{E}+01$ & $1.55 \mathrm{E}-01$ & $2.14 \mathrm{E}+01$ & $8.24 \mathrm{E}+00$ \\
\hline B1T6C1 & 90.25 & $1.47 \mathrm{E}+01$ & $6.05 E+00$ & 7.77E-02 & $1.87 \mathrm{E}+01$ & $5.86 \mathrm{E}+00$ \\
\hline B1T6C2 & 92.25 & $1.46 \mathrm{E}+01$ & $5.75 \mathrm{E}+00$ & 7.63E-02 & $2.03 \mathrm{E}+01$ & $6.44 \mathrm{E}+00$ \\
\hline В1T6C3 & 95.25 & $1.13 \mathrm{E}+01$ & $3.64 \mathrm{E}+01$ & 5.12E-01 & $3.79 \mathrm{E}+01$ & $9.70 \mathrm{E}+00$ \\
\hline B1T6C4 & 97.75 & $4.54 \mathrm{E}+01$ & $1.98 \mathrm{E}+01$ & 2.17E-01 & $2.28 \mathrm{E}+01$ & $8.75 E+00$ \\
\hline B1T6C5 & 100.25 & $7.40 \mathrm{E}+01$ & $3.27 \mathrm{E}+01$ & 3.68E-01 & $2.63 \mathrm{E}+01$ & $1.07 \mathrm{E}+01$ \\
\hline B1T6C6 & 102.75 & $8.35 \mathrm{E}+01$ & $3.84 \mathrm{E}+01$ & 4.57E-01 & $2.76 \mathrm{E}+01$ & $1.16 \mathrm{E}+01$ \\
\hline B1T6C7 & 105.25 & $2.92 \mathrm{E}+01$ & $1.27 \mathrm{E}+01$ & $1.54 \mathrm{E}-01$ & $2.22 \mathrm{E}+01$ & $7.05 \mathrm{E}+00$ \\
\hline B1T6C8 & 107.25 & $3.26 \mathrm{E}+01$ & $1.41 \mathrm{E}+01$ & $1.57 \mathrm{E}-01$ & $2.79 \mathrm{E}+01$ & $7.01 \mathrm{E}+00$ \\
\hline В1T6C9 & 110.25 & $1.64 \mathrm{E}+01$ & $7.80 \mathrm{E}+00$ & 9.03E-02 & $1.94 \mathrm{E}+01$ & $6.80 \mathrm{E}+00$ \\
\hline B1T6D0 & 112.25 & $7.37 \mathrm{E}+00$ & $3.30 \mathrm{E}+00$ & 4.23E-02 & $1.46 \mathrm{E}+01$ & $5.11 \mathrm{E}+00$ \\
\hline B1T6D1 & 115.25 & $7.29 \mathrm{E}+00$ & $3.18 \mathrm{E}+00$ & 4.10E-02 & $1.36 \mathrm{E}+01$ & $4.03 E+00$ \\
\hline B1T6D2 & 117.75 & $4.64 E+02$ & $1.25 E+02$ & $2.54 \mathrm{E}+00$ & $1.58 E+02$ & $2.15 \mathrm{E}+01$ \\
\hline B1T6D3 & 120.25 & $5.81 \mathrm{E}+01$ & $2.51 \mathrm{E}+01$ & 3.13E-01 & $2.46 \mathrm{E}+01$ & $1.11 \mathrm{E}+01$ \\
\hline B1T6D4 & 122.75 & $3.85 E+02$ & $1.15 E+02$ & $1.97 E+00$ & $4.80 \mathrm{E}+01$ & $2.00 \mathrm{E}+01$ \\
\hline B1T6D6 & 127.25 & $2.73 E+01$ & $1.15 \mathrm{E}+01$ & $1.48 \mathrm{E}-01$ & $1.93 \mathrm{E}+01$ & $6.31 \mathrm{E}+00$ \\
\hline B1T6D7 & 130.25 & $8.18 \mathrm{E}+00$ & $2.54 \mathrm{E}+00$ & 4.45E-02 & $1.34 \mathrm{E}+01$ & $2.89 \mathrm{E}+00$ \\
\hline B1T6D8 & 132.75 & $1.07 \mathrm{E}+01$ & $3.35 E+00$ & 5.56E-02 & $1.85 \mathrm{E}+01$ & $3.92 \mathrm{E}+00$ \\
\hline B1T6D9 & 135.25 & $7.13 \mathrm{E}+00$ & $2.83 \mathrm{E}+00$ & 3.57E-02 & $1.48 \mathrm{E}+01$ & $4.00 \mathrm{E}+00$ \\
\hline B1T6F2 & 142.25 & $1.05 \mathrm{E}+01$ & $3.21 \mathrm{E}+00$ & 5.53E-02 & $2.00 \mathrm{E}+01$ & $5.32 \mathrm{E}+00$ \\
\hline B1T6F5 & 150.25 & $7.70 \mathrm{E}+00$ & $2.79 E+00$ & 3.72E-02 & $1.48 \mathrm{E}+01$ & $3.35 \mathrm{E}+00$ \\
\hline В1T6H6 & 178.25 & $1.00 \mathrm{E}+01$ & $3.24 \mathrm{E}+00$ & 5.10E-02 & $1.82 \mathrm{E}+01$ & $3.50 \mathrm{E}+00$ \\
\hline B1T6J6 & 202.75 & $7.25 \mathrm{E}+00$ & $2.58 \mathrm{E}+00$ & 3.50E-02 & $1.55 \mathrm{E}+01$ & $4.25 E+00$ \\
\hline B1T6K6 & 227.25 & $7.06 \mathrm{E}+00$ & $2.42 \mathrm{E}+00$ & $3.70 \mathrm{E}-02$ & $1.53 \mathrm{E}+01$ & $4.55 \mathrm{E}+00$ \\
\hline B1T6L3 & 245.25 & $8.68 E+00$ & $2.77 E+00$ & 4.32E-02 & $1.18 \mathrm{E}+01$ & $4.37 E+00$ \\
\hline
\end{tabular}


The calcium and magnesium in pore water show a bi-modal distribution similar to pore-water EC and nitrate concentrations; however, the pore water sodium's deeper lobe of the bi-modal peak is very muted (Figure 6.2). Peak pore-water concentrations in the shallow lobe for sodium and calcium occurred at 57.25 and $67.75 \mathrm{ft}$ bgs, respectively. The lag in sodium's peak occurs because of the ion exchange interactions of the waste solution percolating through the sediments with a strong vertical component.

Low concentrations of monovalent and divalent cations in pore water (Figure 6.4) below $130 \mathrm{ft}$ bgs indicate that no sodium-dominant waste plume percolated below this depth. Two ion exchange fronts (where the monovalent cation concentrations are low and divalent cation concentrations are high relative to each other) were found at depths around 70 and $125 \mathrm{ft}$ bgs. At shallower depths ( 0 to $50 \mathrm{ft}$ bgs), low concentrations of both monovalent and divalent cations result from displacement and perhaps dilution of the disposed waste by post disposal natural recharge.

As part of the characterization of the water extracts, other chemical species, such as aluminum, silicon, iron, manganese, zinc, and trace constituents such as arsenic, boron, barium, beryllium, bismuth, cadmium, cobalt, chromium, copper, lithium, molybdenum, nickel, lead, selenium, thallium, vanadium, titanium, and zirconium, were measured, but since their concentrations were generally low to nondetectable, the data are not presented in this ERC ground-truthing document.

Technetium-99 and uranium were the only potential radiological COCs that were measurable in the water extracts. Their concentrations on both a per gram of sediment basis and as pore-water concentrations are listed in Table 6.7 and plotted in Figure 6.3. The technetium-99 data show elevated technetium-99 water extract concentrations occurring from 60 to $70 \mathrm{ft}$ bgs and 118 to $122 \mathrm{ft}$ bgs. The deepest penetration of significant technetium-99 contamination occurs at the same place as the significantly elevated nitrate at about 120 to $130 \mathrm{ft}$ bgs because they are mobile contaminants and distribute in the vadose zone in a similar pattern. 


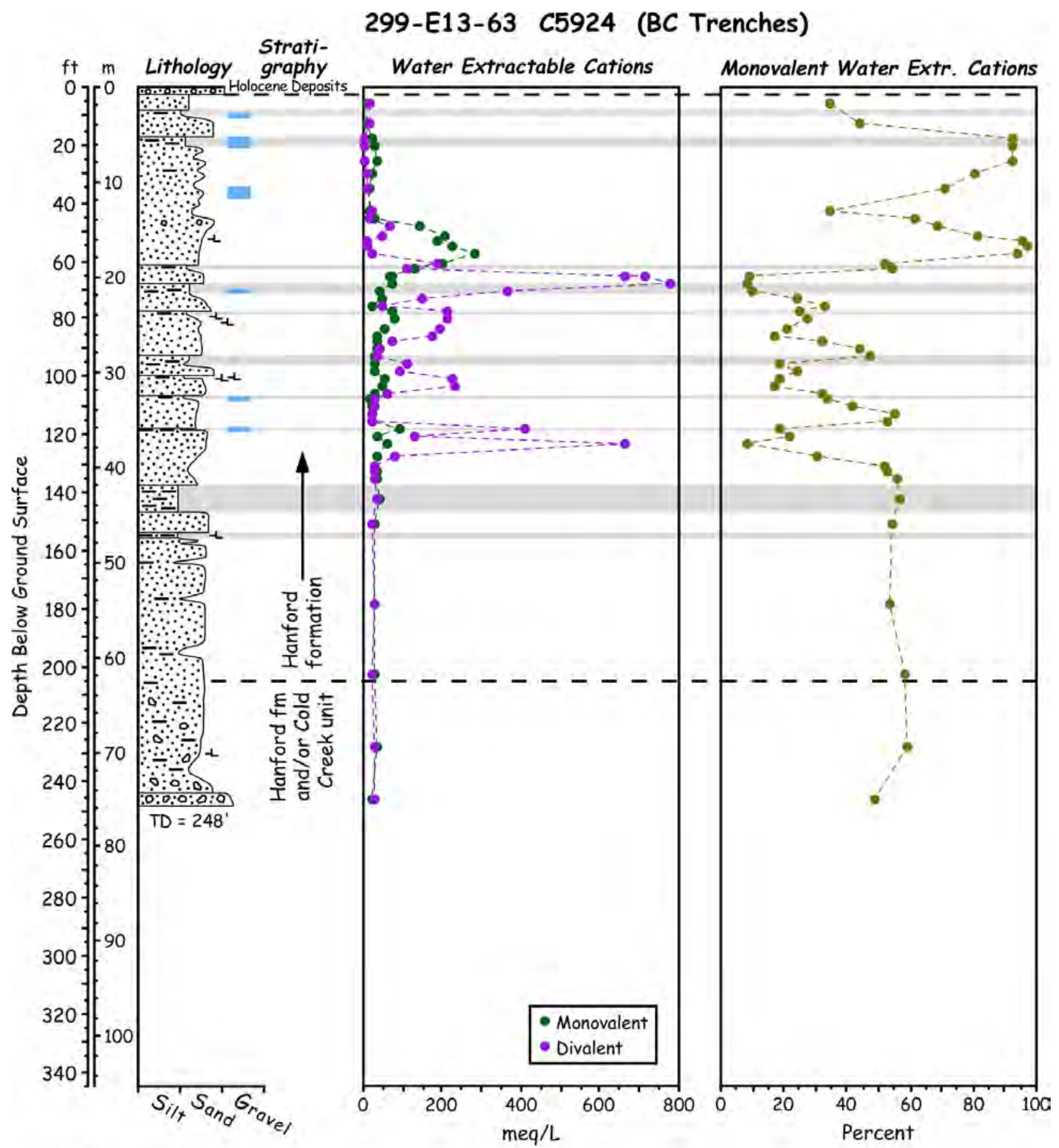

Fine-Grained Layer $=8 w+\%$ Moisture

$\downarrow$ Pedogenic Carbonate

I Silt $\because \because$ Sand 0 Gravel

Figure 6.4. Water Leachable Mono-Valent and Divalent Cations for Borehole C5924 (B) Sediments 
Table 6.6. Water-Extractable Cations as Pore Water Concentrations in Borehole C5924 (B) Sediments (mg/L)

\begin{tabular}{|c|c|c|c|c|c|c|}
\hline Sample (HEIS ID) & Mid Depth (ft bgs) & $\mathrm{Ca}$ & $\mathrm{Mg}$ & $\mathrm{Sr}$ & $\mathrm{Na}$ & $\mathrm{K}$ \\
\hline B1T677 & 5.25 & $1.89 \mathrm{E}+02$ & $3.53 \mathrm{E}+01$ & (5.93E-01) & $1.02 \mathrm{E}+02$ & $7.62 \mathrm{E}+01$ \\
\hline B1T680 & 12.25 & $1.35 \mathrm{E}+02$ & $6.96 \mathrm{E}+01$ & $1.45 \mathrm{E}+00$ & $2.08 \mathrm{E}+02$ & $2.89 \mathrm{E}+01$ \\
\hline B1T682 & 17.75 & $2.78 \mathrm{E}+01$ & $6.70 \mathrm{E}+00$ & (1.25E-01) & $4.92 \mathrm{E}+02$ & $3.68 \mathrm{E}+01$ \\
\hline B1T683 & 19.75 & $3.17 \mathrm{E}+01$ & $7.60 \mathrm{E}+00$ & (1.38E-01) & $5.49 \mathrm{E}+02$ & $4.25 \mathrm{E}+01$ \\
\hline B1T730 (DUP) & 19.75 & $2.70 \mathrm{E}+01$ & $6.55 \mathrm{E}+00$ & $(1.20 \mathrm{E}-01)$ & $5.12 \mathrm{E}+02$ & $3.75 E+01$ \\
\hline B1T685 & 25.25 & $4.21 \mathrm{E}+01$ & $1.14 \mathrm{E}+01$ & (1.96E-01) & $7.58 \mathrm{E}+02$ & $5.70 \mathrm{E}+01$ \\
\hline B1T687 & 29.75 & $8.11 \mathrm{E}+01$ & $1.83 \mathrm{E}+01$ & (3.80E-01) & $4.82 \mathrm{E}+02$ & $6.18 \mathrm{E}+01$ \\
\hline B1T689 & 34.75 & $9.09 \mathrm{E}+01$ & $1.86 \mathrm{E}+01$ & (4.32E-01) & $3.02 \mathrm{E}+02$ & $5.48 \mathrm{E}+01$ \\
\hline B1T692 & 42.75 & $3.47 \mathrm{E}+02$ & $6.47 \mathrm{E}+01$ & $(1.09 \mathrm{E}+00)$ & $1.87 \mathrm{E}+02$ & $1.40 \mathrm{E}+02$ \\
\hline B1T693 & 44.75 & $2.12 \mathrm{E}+02$ & $4.70 \mathrm{E}+01$ & $(1.11 \mathrm{E}+00)$ & $4.78 \mathrm{E}+02$ & $8.35 \mathrm{E}+01$ \\
\hline B1T694 & 47.25 & $9.59 \mathrm{E}+02$ & $2.16 \mathrm{E}+02$ & $5.66 \mathrm{E}+00$ & $3.08 \mathrm{E}+03$ & $2.22 \mathrm{E}+02$ \\
\hline B1T695 & 50.75 & $6.45 \mathrm{E}+02$ & $1.91 \mathrm{E}+02$ & $3.61 \mathrm{E}+00$ & $4.47 \mathrm{E}+03$ & $3.19 \mathrm{E}+02$ \\
\hline B1T696 & 52.75 & $1.20 \mathrm{E}+02$ & $3.73 \mathrm{E}+01$ & (8.49E-01) & $4.19 \mathrm{E}+03$ & $1.35 \mathrm{E}+02$ \\
\hline B1T697 & 54.75 & $9.82 \mathrm{E}+01$ & $2.73 \mathrm{E}+01$ & (6.64E-01) & $5.03 \mathrm{E}+03$ & $1.24 \mathrm{E}+02$ \\
\hline B1T698 & 57.25 & $2.66 \mathrm{E}+02$ & $7.98 \mathrm{E}+01$ & $2.02 \mathrm{E}+00$ & $6.29 \mathrm{E}+03$ & $2.19 \mathrm{E}+02$ \\
\hline B1T699 & 60.25 & $2.42 \mathrm{E}+03$ & $7.94 \mathrm{E}+02$ & $1.51 \mathrm{E}+01$ & $4.31 \mathrm{E}+03$ & $3.83 \mathrm{E}+02$ \\
\hline B1T6B0 & 62.25 & $1.40 \mathrm{E}+03$ & $4.67 \mathrm{E}+02$ & $3.02 E+01$ & $2.76 \mathrm{E}+03$ & $3.08 \mathrm{E}+02$ \\
\hline B1T6B1 & 65.25 & $9.01 \mathrm{E}+03$ & $2.61 \mathrm{E}+03$ & $5.02 \mathrm{E}+01$ & $1.21 \mathrm{E}+03$ & $5.11 \mathrm{E}+02$ \\
\hline B1T731 (DUP) & 65.25 & $9.61 \mathrm{E}+03$ & $2.80 \mathrm{E}+03$ & $5.49 \mathrm{E}+01$ & $1.31 \mathrm{E}+03$ & $5.58 \mathrm{E}+02$ \\
\hline B1T6B2 & 67.75 & $1.03 E+04$ & $3.15 \mathrm{E}+03$ & $5.61 \mathrm{E}+01$ & $1.30 \mathrm{E}+03$ & $5.43 \mathrm{E}+02$ \\
\hline В1Т6В3 & 70.25 & $4.78 \mathrm{E}+03$ & $1.52 \mathrm{E}+03$ & $2.35 \mathrm{E}+01$ & $7.56 \mathrm{E}+02$ & $2.35 \mathrm{E}+02$ \\
\hline B1T6B4 & 72.75 & $1.75 E+03$ & $7.36 \mathrm{E}+02$ & $9.45 \mathrm{E}+00$ & $8.58 \mathrm{E}+02$ & $3.23 \mathrm{E}+02$ \\
\hline B1T6B5 & 75.25 & $5.74 \mathrm{E}+02$ & $2.23 \mathrm{E}+02$ & $2.74 \mathrm{E}+00$ & $4.69 \mathrm{E}+02$ & $9.05 \mathrm{E}+01$ \\
\hline B1T6B6 & 77.25 & $2.67 \mathrm{E}+03$ & $9.45 \mathrm{E}+02$ & $1.46 \mathrm{E}+01$ & $1.38 \mathrm{E}+03$ & $3.08 \mathrm{E}+02$ \\
\hline B1T6B7 & 79.75 & $2.72 E+03$ & $8.79 \mathrm{E}+02$ & $1.47 \mathrm{E}+01$ & $1.57 \mathrm{E}+03$ & $3.18 \mathrm{E}+02$ \\
\hline B1T6B8 & 82.75 & $2.25 E+03$ & $9.35 \mathrm{E}+02$ & $1.08 \mathrm{E}+01$ & $9.50 \mathrm{E}+02$ & $3.27 \mathrm{E}+02$ \\
\hline В1Т6В9 & 85.75 & $2.22 \mathrm{E}+03$ & $7.66 \mathrm{E}+02$ & $9.64 \mathrm{E}+00$ & $6.88 \mathrm{E}+02$ & $2.05 \mathrm{E}+02$ \\
\hline B1T6C0 & 87.75 & $7.83 \mathrm{E}+02$ & $3.53 \mathrm{E}+02$ & $4.29 \mathrm{E}+00$ & $5.92 \mathrm{E}+02$ & $2.28 \mathrm{E}+02$ \\
\hline B1T6C1 & 90.25 & $4.49 \mathrm{E}+02$ & $1.85 \mathrm{E}+02$ & $2.38 \mathrm{E}+00$ & $5.73 E+02$ & $1.79 \mathrm{E}+02$ \\
\hline B1T6C2 & 92.25 & $3.77 \mathrm{E}+02$ & $1.49 \mathrm{E}+02$ & $1.97 \mathrm{E}+00$ & $5.26 \mathrm{E}+02$ & $1.66 \mathrm{E}+02$ \\
\hline B1T6C3 & 95.25 & $1.45 \mathrm{E}+03$ & $4.67 \mathrm{E}+02$ & $6.56 \mathrm{E}+00$ & $4.86 \mathrm{E}+02$ & $1.24 \mathrm{E}+02$ \\
\hline B1T6C4 & 97.75 & $1.08 \mathrm{E}+03$ & $4.68 \mathrm{E}+02$ & $5.14 \mathrm{E}+00$ & $5.41 \mathrm{E}+02$ & $2.07 \mathrm{E}+02$ \\
\hline B1T6C5 & 100.25 & $2.60 \mathrm{E}+03$ & $1.15 \mathrm{E}+03$ & $1.29 \mathrm{E}+01$ & $9.21 \mathrm{E}+02$ & $3.75 \mathrm{E}+02$ \\
\hline B1T6C6 & 102.75 & $2.60 \mathrm{E}+03$ & $1.19 \mathrm{E}+03$ & $1.42 \mathrm{E}+01$ & $8.60 \mathrm{E}+02$ & $3.63 \mathrm{E}+02$ \\
\hline B1T6C7 & 105.25 & $7.10 \mathrm{E}+02$ & $3.09 \mathrm{E}+02$ & $3.74 \mathrm{E}+00$ & $5.41 \mathrm{E}+02$ & $1.71 \mathrm{E}+02$ \\
\hline B1T6C8 & 107.25 & $2.67 \mathrm{E}+02$ & $1.16 \mathrm{E}+02$ & $1.29 \mathrm{E}+00$ & $2.29 \mathrm{E}+02$ & $5.75 \mathrm{E}+01$ \\
\hline
\end{tabular}


PNNL-17821

Table 6.6 (contd)

\begin{tabular}{|c|c|c|c|c|c|c|}
\hline Sample (HEIS ID) & $\begin{array}{l}\text { Mid Depth (ft } \\
\text { bgs) }\end{array}$ & $\mathrm{Ca}$ & $\mathrm{Mg}$ & $\mathrm{Sr}$ & $\mathrm{Na}$ & $\mathrm{K}$ \\
\hline В1T6C9 & 110.25 & $3.07 \mathrm{E}+02$ & $1.46 \mathrm{E}+02$ & $1.69 \mathrm{E}+00$ & $3.62 \mathrm{E}+02$ & $1.27 \mathrm{E}+02$ \\
\hline B1T6D0 & 112.25 & $1.98 \mathrm{E}+02$ & $8.87 \mathrm{E}+01$ & $1.14 \mathrm{E}+00$ & $3.93 E+02$ & $1.37 \mathrm{E}+02$ \\
\hline B1T6D1 & 115.25 & $2.05 E+02$ & $8.94 \mathrm{E}+01$ & $1.15 E+00$ & $3.82 E+02$ & $1.13 E+02$ \\
\hline B1T6D2 & 117.75 & $5.61 \mathrm{E}+03$ & $1.52 \mathrm{E}+03$ & $3.07 \mathrm{E}+01$ & $1.91 \mathrm{E}+03$ & $2.61 \mathrm{E}+02$ \\
\hline B1T6D3 & 120.25 & $1.49 \mathrm{E}+03$ & $6.43 E+02$ & $8.03 E+00$ & $6.32 \mathrm{E}+02$ & $2.85 E+02$ \\
\hline B1T6D4 & 122.75 & $8.90 \mathrm{E}+03$ & $2.66 \mathrm{E}+03$ & $4.55 \mathrm{E}+01$ & $1.11 \mathrm{E}+03$ & $4.62 E+02$ \\
\hline B1T6D6 & 127.25 & $9.41 \mathrm{E}+02$ & $3.96 \mathrm{E}+02$ & $5.09 \mathrm{E}+00$ & $6.67 \mathrm{E}+02$ & $2.18 \mathrm{E}+02$ \\
\hline B1T6D7 & 130.25 & $3.18 \mathrm{E}+02$ & $9.86 \mathrm{E}+01$ & $1.73 \mathrm{E}+00$ & $5.23 \mathrm{E}+02$ & $1.12 \mathrm{E}+02$ \\
\hline B1T6D8 & 132.75 & $3.58 \mathrm{E}+02$ & $1.12 \mathrm{E}+02$ & $1.86 \mathrm{E}+00$ & $6.21 \mathrm{E}+02$ & $1.32 \mathrm{E}+02$ \\
\hline B1T6D9 & 135.25 & $2.98 \mathrm{E}+02$ & $1.19 \mathrm{E}+02$ & $1.49 \mathrm{E}+00$ & $6.17 \mathrm{E}+02$ & $1.68 \mathrm{E}+02$ \\
\hline B1T6F2 & 142.25 & $3.93 \mathrm{E}+02$ & $1.20 \mathrm{E}+02$ & $2.06 \mathrm{E}+00$ & $7.48 \mathrm{E}+02$ & $1.99 \mathrm{E}+02$ \\
\hline B1T6F5 & 150.25 & $2.85 E+02$ & $1.03 \mathrm{E}+02$ & $(1.38 \mathrm{E}+00)$ & $5.47 \mathrm{E}+02$ & $1.24 \mathrm{E}+02$ \\
\hline В1T6H6 & 178.25 & $3.00 \mathrm{E}+02$ & $9.69 \mathrm{E}+01$ & $(1.53 \mathrm{E}+00)$ & $5.44 \mathrm{E}+02$ & $1.05 E+02$ \\
\hline B1T6J6 & 202.75 & $2.24 \mathrm{E}+02$ & $7.96 \mathrm{E}+01$ & $(1.08 \mathrm{E}+00)$ & $4.79 \mathrm{E}+02$ & $1.31 \mathrm{E}+02$ \\
\hline B1T6K6 & 227.25 & $2.98 \mathrm{E}+02$ & $1.02 \mathrm{E}+02$ & $(1.56 \mathrm{E}+00)$ & $6.45 E+02$ & $1.92 E+02$ \\
\hline B1T6L3 & 245.25 & $3.17 \mathrm{E}+02$ & $1.01 \mathrm{E}+02$ & $(1.58 \mathrm{E}+00)$ & $4.30 \mathrm{E}+02$ & $1.59 \mathrm{E}+02$ \\
\hline
\end{tabular}

(a) Parentheses signify values below level of quantitation but considered valid for this work. 
PNNL-17821

Table 6.7. Water-Extractable Radionuclides and Pore Water Total Ionic Strength for Borehole C5924 (B)

\begin{tabular}{|c|c|c|c|c|c|c|}
\hline Sample (HEIS ID) & $\begin{array}{l}\text { Mid Depth } \\
\text { (ft bgs) }\end{array}$ & $\begin{array}{l}\text { Tc- } 99 \\
(\mathrm{pCi} / \mathrm{g})\end{array}$ & $\mathrm{U}(\mu \mathrm{g} / \mathrm{g})$ & Тс $99(\mathrm{pCi} / \mathrm{L})$ & $\mathrm{U}(\mu \mathrm{g} / \mathrm{L})$ & $\begin{array}{c}\text { PW Ionic } \\
\text { Strength (M) }\end{array}$ \\
\hline B1T677 & 5.25 & $<1.53 \mathrm{E}-01$ & 5.59E-04 & $3.35 \mathrm{E}+02$ & $7.93 \mathrm{E}+00$ & 3.61E-02 \\
\hline B1T680 & 12.25 & $<1.53 \mathrm{E}-01$ & 4.30E-04 & $4.57 \mathrm{E}+02$ & $6.99 \mathrm{E}+00$ & 4.05E-02 \\
\hline B1T682 & 17.75 & $<1.53 \mathrm{E}-01$ & $5.26 \mathrm{E}-03$ & $3.23 \mathrm{E}+02$ & $5.29 \mathrm{E}+01$ & 3.79E-02 \\
\hline B1T683 & 19.75 & $<1.53 \mathrm{E}-01$ & 5.77E-03 & $3.16 \mathrm{E}+02$ & $6.89 \mathrm{E}+01$ & 4.01E-02 \\
\hline B1T730 (DUP) & 19.75 & $<1.53 \mathrm{E}-01$ & 5.69E-03 & $2.41 \mathrm{E}+02$ & $6.23 \mathrm{E}+01$ & 3.92E-02 \\
\hline B1T685 & 25.25 & $<1.53 \mathrm{E}-01$ & 4.06E-03 & $7.37 \mathrm{E}+02$ & $7.83 \mathrm{E}+01$ & 5.90E-02 \\
\hline B1T687 & 29.75 & $<1.53 \mathrm{E}-01$ & $1.28 \mathrm{E}-03$ & $6.57 \mathrm{E}+02$ & $1.97 \mathrm{E}+01$ & 4.59E-02 \\
\hline B1T689 & 34.75 & $<1.53 \mathrm{E}-01$ & 1.23E-03 & $3.59 \mathrm{E}+02$ & $1.40 \mathrm{E}+01$ & 3.43E-02 \\
\hline B1T692 & 42.75 & 3.39E-01 & 5.59E-04 & $6.14 \mathrm{E}+02$ & $1.45 \mathrm{E}+01$ & 6.23E-02 \\
\hline B1T693 & 44.75 & $<3.39 \mathrm{E}-01$ & 2.32E-04 & $3.77 E+03$ & $6.31 \mathrm{E}+00$ & $6.58 \mathrm{E}-02$ \\
\hline B1T694 & 47.25 & $3.39 \mathrm{E}+00$ & $1.65 \mathrm{E}-04$ & $9.11 \mathrm{E}+04$ & $5.71 \mathrm{E}+00$ & 2.70E-01 \\
\hline B1T695 & 50.75 & $1.70 \mathrm{E}+00$ & $1.85 \mathrm{E}-04$ & $6.66 \mathrm{E}+04$ & $5.60 \mathrm{E}+00$ & 2.99E-01 \\
\hline B1T696 & 52.75 & $3.39 E+00$ & 2.72E-04 & $9.39 \mathrm{E}+04$ & $6.42 \mathrm{E}+00$ & 2.26E-01 \\
\hline B1T697 & 54.75 & $3.39 \mathrm{E}+00$ & $2.86 \mathrm{E}-04$ & $9.73 E+04$ & $7.05 \mathrm{E}+00$ & 2.47E-01 \\
\hline В1T698 & 57.25 & $5.09 \mathrm{E}+00$ & 1.67E-04 & $1.33 \mathrm{E}+05$ & $5.10 \mathrm{E}+00$ & 3.61E-01 \\
\hline B1T699 & 60.25 & $6.78 \mathrm{E}+00$ & 3.49E-04 & $1.97 \mathrm{E}+05$ & $1.05 \mathrm{E}+01$ & 5.37E-01 \\
\hline B1T6B0 & 62.25 & $3.39 \mathrm{E}+01$ & $1.40 \mathrm{E}-03$ & $3.91 \mathrm{E}+05$ & $1.92 \mathrm{E}+01$ & 4.80E-01 \\
\hline B1T6B1 & 65.25 & $1.36 \mathrm{E}+01$ & 5.53E-04 & $4.49 \mathrm{E}+05$ & $1.92 \mathrm{E}+01$ & $1.11 E+00$ \\
\hline B1T731 (DUP) & 65.25 & $1.36 \mathrm{E}+01$ & 6.47E-04 & $4.79 \mathrm{E}+05$ & $2.29 \mathrm{E}+01$ & $1.18 E+00$ \\
\hline B1T6B2 & 67.75 & $1.70 \mathrm{E}+01$ & 8.04E-04 & $5.77 \mathrm{E}+05$ & $2.42 \mathrm{E}+01$ & $1.26 \mathrm{E}+00$ \\
\hline B1T6B3 & 70.25 & $3.39 \mathrm{E}+01$ & $2.22 \mathrm{E}-03$ & $2.70 \mathrm{E}+05$ & $2.26 \mathrm{E}+01$ & 6.02E-01 \\
\hline B1T6B4 & 72.75 & $1.70 \mathrm{E}+00$ & 4.09E-04 & $7.91 \mathrm{E}+04$ & $1.46 \mathrm{E}+01$ & 2.98E-01 \\
\hline B1T6B5 & 75.25 & $1.70 \mathrm{E}+00$ & 7.80E-04 & $4.02 \mathrm{E}+04$ & $1.24 \mathrm{E}+01$ & $1.08 \mathrm{E}-01$ \\
\hline B1T6B6 & 77.25 & $1.02 E+01$ & $9.82 \mathrm{E}-04$ & $1.89 \mathrm{E}+05$ & $1.72 \mathrm{E}+01$ & 4.11E-01 \\
\hline B1T6B7 & 79.75 & $5.09 \mathrm{E}+00$ & 6.88E-04 & $9.55 E+04$ & $1.50 \mathrm{E}+01$ & 4.07E-01 \\
\hline B1T6B8 & 82.75 & $3.39 \mathrm{E}+00$ & 2.83E-04 & $1.53 \mathrm{E}+05$ & $1.06 \mathrm{E}+01$ & 3.65E-01 \\
\hline B1T6B9 & 85.75 & $6.78 \mathrm{E}+00$ & $6.13 \mathrm{E}-04$ & $1.57 \mathrm{E}+05$ & $1.28 \mathrm{E}+01$ & 3.11E-01 \\
\hline B1T6C0 & 87.75 & $1.19 \mathrm{E}+00$ & 2.77E-04 & $3.18 \mathrm{E}+04$ & $7.68 \mathrm{E}+00$ & $1.53 \mathrm{E}-01$ \\
\hline B1T6C1 & 90.25 & 3.39E-01 & $3.21 \mathrm{E}-04$ & $1.24 \mathrm{E}+04$ & $9.83 \mathrm{E}+00$ & $1.06 \mathrm{E}-01$ \\
\hline B1T6C2 & 92.25 & $<8.48 \mathrm{E}-01$ & $3.40 \mathrm{E}-04$ & $1.34 \mathrm{E}+04$ & $8.78 \mathrm{E}+00$ & $9.78 \mathrm{E}-02$ \\
\hline B1T6C3 & 95.25 & $8.48 \mathrm{E}+00$ & 8.17E-04 & $1.07 \mathrm{E}+05$ & $1.05 \mathrm{E}+01$ & 2.05E-01 \\
\hline B1T6C4 & 97.75 & $3.39 E+00$ & 4.01E-04 & $6.95 E+04$ & $9.50 \mathrm{E}+00$ & $1.84 \mathrm{E}-01$ \\
\hline B1T6C5 & 100.25 & $1.70 \mathrm{E}+00$ & 4.30E-04 & $7.10 \mathrm{E}+04$ & $1.51 \mathrm{E}+01$ & 4.15E-01 \\
\hline B1T6C6 & 102.75 & $3.39 \mathrm{E}+00$ & $4.50 \mathrm{E}-04$ & $8.39 \mathrm{E}+04$ & $1.40 \mathrm{E}+01$ & 4.20E-01 \\
\hline B1T6C7 & 105.25 & $<8.48 \mathrm{E}-01$ & 4.43E-04 & $1.66 \mathrm{E}+04$ & $1.08 \mathrm{E}+01$ & 1.37E-01 \\
\hline B1T6C8 & 107.25 & $<8.48 \mathrm{E}-01$ & $1.49 \mathrm{E}-03$ & $3.82 E+03$ & $1.22 \mathrm{E}+01$ & 6.14E-02 \\
\hline В1T6C9 & 110.25 & $<1.70 \mathrm{E}-01$ & $6.23 \mathrm{E}-04$ & $1.67 \mathrm{E}+03$ & $1.16 \mathrm{E}+01$ & 8.31E-02 \\
\hline B1T6D0 & 112.25 & $<8.48 \mathrm{E}-01$ & 2.89E-04 & $3.88 \mathrm{E}+03$ & $7.78 \mathrm{E}+00$ & 7.07E-02 \\
\hline B1T6D1 & 115.25 & $<8.48 \mathrm{E}-01$ & 3.62E-04 & $3.97 E+03$ & $1.02 \mathrm{E}+01$ & 6.87E-02 \\
\hline B1T6D2 & 117.75 & $5.09 \mathrm{E}+01$ & $1.18 \mathrm{E}-03$ & $6.38 \mathrm{E}+05$ & $1.42 \mathrm{E}+01$ & 7.23E-01 \\
\hline B1T6D3 & 120.25 & $5.09 \mathrm{E}+00$ & $3.46 \mathrm{E}-04$ & $1.35 \mathrm{E}+05$ & $8.86 \mathrm{E}+00$ & $2.50 \mathrm{E}-01$ \\
\hline B1T6D4 & 122.75 & $3.39 \mathrm{E}+01$ & $6.29 \mathrm{E}-04$ & $8.87 \mathrm{E}+05$ & $1.45 \mathrm{E}+01$ & $1.09 E+00$ \\
\hline B1T6D6 & 127.25 & $1.70 \mathrm{E}+00$ & 2.60E-04 & $8.62 E+04$ & $8.96 \mathrm{E}+00$ & $1.85 \mathrm{E}-01$ \\
\hline B1T6D7 & 130.25 & $<8.48 \mathrm{E}-01$ & 4.30E-04 & $5.12 E+03$ & $1.67 \mathrm{E}+01$ & $9.27 \mathrm{E}-02$ \\
\hline B1T6D8 & 132.75 & $1.70 \mathrm{E}-01$ & 4.68E-04 & $6.03 E+03$ & $1.57 \mathrm{E}+01$ & $1.05 \mathrm{E}-01$ \\
\hline B1T6D9 & 135.25 & $<1.70 \mathrm{E}-01$ & 2.63E-04 & $2.36 \mathrm{E}+03$ & $1.10 \mathrm{E}+01$ & 9.65E-02 \\
\hline
\end{tabular}


PNNL-17821

Table 6.7 (contd)

\begin{tabular}{|c|c|c|c|c|c|c|}
\hline Sample (HEIS ID) & $\begin{array}{l}\text { Mid Depth } \\
\text { (ft bgs) }\end{array}$ & $\begin{array}{c}\text { Tc- } 99 \\
(\mathrm{pCi} / \mathrm{g})\end{array}$ & $\mathrm{U}(\mu \mathrm{g} / \mathrm{g})$ & Тс $99(\mathrm{pCi} / \mathrm{L})$ & $\mathrm{U}(\mu \mathrm{g} / \mathrm{L})$ & $\begin{array}{c}\text { PW Ionic } \\
\text { Strength }(\mathrm{M})\end{array}$ \\
\hline B1T6F2 & 142.25 & $<1.70 \mathrm{E}-01$ & 3.89E-04 & $1.76 \mathrm{E}+03$ & $1.45 \mathrm{E}+01$ & $1.15 \mathrm{E}-01$ \\
\hline B1T6F5 & 150.25 & $<1.53 \mathrm{E}-01$ & 3.09E-04 & $3.11 \mathrm{E}+03$ & $1.14 \mathrm{E}+01$ & $9.12 \mathrm{E}-02$ \\
\hline B1T6H6 & 178.25 & $<1.53 \mathrm{E}-01$ & 4.18E-04 & $1.88 \mathrm{E}+03$ & $1.25 \mathrm{E}+01$ & 9.12E-02 \\
\hline B1T6J6 & 202.75 & $<1.53 \mathrm{E}-01$ & 4.19E-04 & $1.19 \mathrm{E}+03$ & $1.29 \mathrm{E}+01$ & 7.38E-02 \\
\hline В1T6K6 & 227.25 & $<1.53 \mathrm{E}-01$ & 2.65E-04 & $1.38 \mathrm{E}+03$ & $1.12 \mathrm{E}+01$ & $1.01 \mathrm{E}-01$ \\
\hline B1T6L3 & 245.25 & $<1.53 \mathrm{E}-01$ & $3.14 \mathrm{E}-04$ & $1.30 \mathrm{E}+03$ & $1.15 \mathrm{E}+01$ & 8.79E-02 \\
\hline
\end{tabular}

Slightly elevated water-extractable concentrations of uranium are found at shallow depths within the vadose zone from 17 to $25 \mathrm{ft}$ bgs. This suggests that uranium transport is more retarded than the transport of technetium-99 and nitrate. Five grab samples from borehole C5924 were selected for ultracentrifugation in the UFA apparatus to obtain pore water directly. The concentrations of technetium-99 and uranium in the actual pore water were quite similar to the calculated pore-water concentrations from the 1:1 sediment to de-ionized water extracts. The comparison is shown in Figure 6.3 in the two panels in the far right of the figure. Again, the agreement between the actual and calculated pore-water concentrations for technetium-99 and uranium supports the accuracy of all the calculated pore-water concentration (from the 1:1 sediment to water extracts) throughout the depth profile.

The total ionic strengths of the calculated pore waters in the vadose zone profile at Borehole C5924 (B) are shown in Figure 6.2 and Table 6.7. The total ionic strength distribution is closely related to the EC and nitrate distributions in the borehole pore water. Because of the ion exchange reactions, the total ionic strength correlation to sodium is a bit worse, and the ionic strength in the deeper sediments is influenced by the pore water calcium and magnesium and more so than the sodium. Of all the pore-water parameters, the total ionic strength should correlate best with the soil resistivity data, which are influenced by the total dissolved salt content in the sediment. The calculated total ionic strength is highly correlated with pore water EC (Figure 6.5). However, a 2D inversion of the field-measured apparent soil resistivity data did not match very well with the laboratory-measured EC and calculated ionic strengths (see right hand panel of Figure 6.5. Although the 2D inversion of the HRR data suggests a broad zone of high conductivity from 80 to $110 \mathrm{ft}$ bgs, the highest conductivity (or reciprocal soil resistivity) at $100 \mathrm{ft}$ bgs for the 2D inverted field HRR data deviate $30 \mathrm{ft}$ deeper than the highest values of EC and the ionic strength based on the laboratory measurement. In addition, the 2D inverted HRR data did not capture the bi-modal distribution of contaminants, especially the deeper lobe. The total ionic strength correlation with the field and laboratory resistivity measurements is discussed in more detail in Section 6.2. 


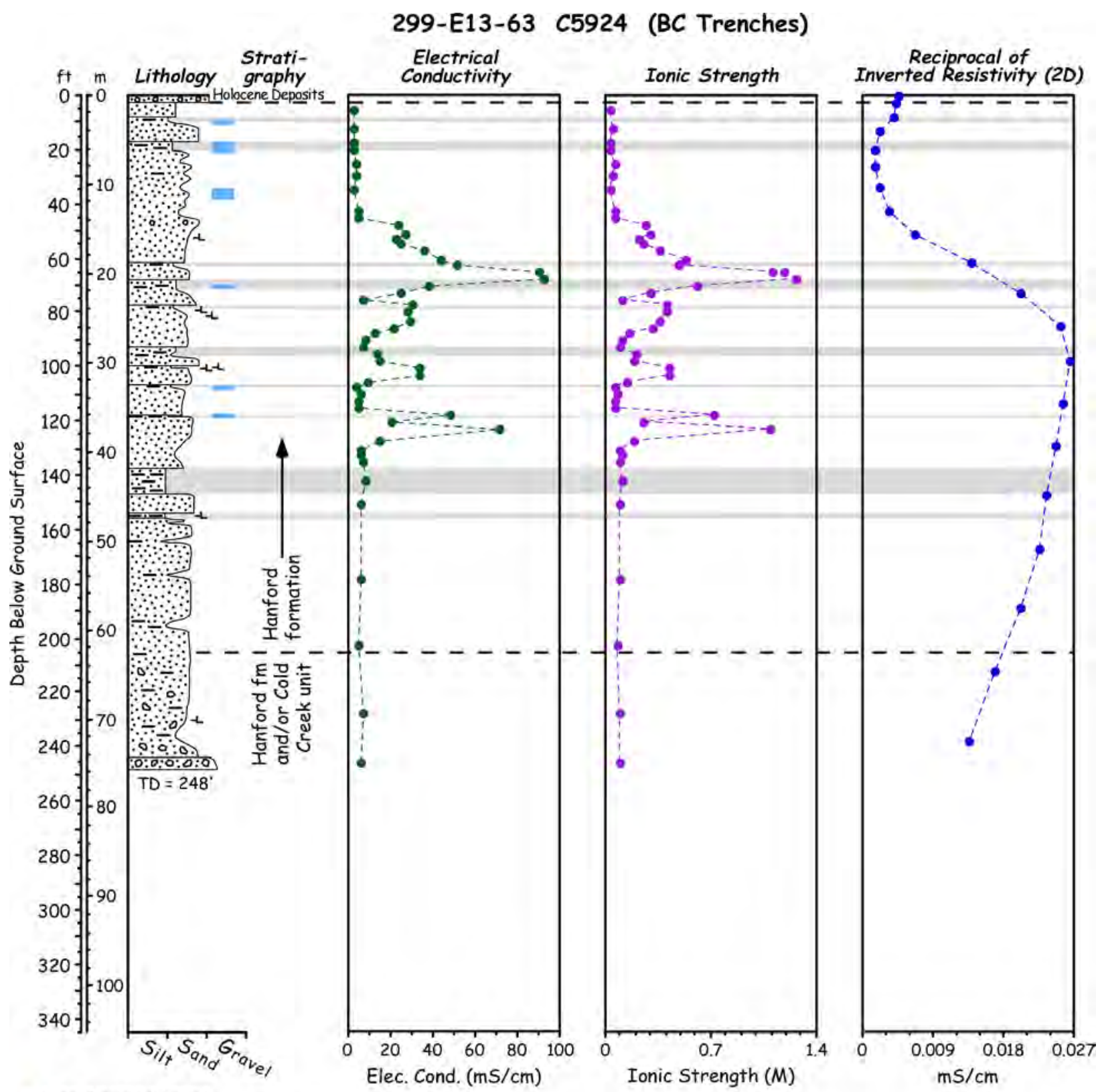

Fine-Grained Layer $\Longrightarrow 8 \mathrm{wt} \%$ Moisture

+ Pedogenic Carbonate $\quad$ Silt Sand $\therefore$ Gravel

2008/DCL/C5924/005 (08/04)

Figure 6.5. Pore-water EC, Ionic Strength, And Field Measured Reciprocal Inverted Resistivity (2D) for Borehole C5924 (B)

\subsection{4 $8 \mathrm{M}$ Nitric Acid Extractable Amounts of Selected Elements}

The amount of material that was extractable from the vadose zone sediment into $8 \mathrm{M}$ nitric acid is shown in Table 6.8 through Table 6.10. The $8 \mathrm{M}$ nitric acid extraction is a protocol used by the U.S. Environmental Protection Agency to estimate the maximum (or total) concentrations of regulated metals in contaminated sediment that would be biologically available. Aliquots of sediment from Borehole 
C5924 (B) were subjected to the acid extraction to look for elevated quantities of selected constituents and radionuclides.

The acid-extract data for grab samples from Borehole C5924 (B) in general showed high values in the shallow depths for a few constituents (relative to known Hanford site background values and values for Borehole C5924 (B) sediments below $160 \mathrm{ft}$ bgs that are considered uncontaminated based on the findings that the waste fluids disposed of to the nearby 216-B-52, 216-B-33, and 216-B-34 trenches appear to still reside in the upper $130 \mathrm{ft}$ of sediment). The elements and radionuclides that showed elevated acid-extractable concentrations in the shallowest sample studied (19.8 ft bgs) include $\mathrm{Na}, \mathrm{Mg}, \mathrm{P}$, $\mathrm{Mn}, \mathrm{Fe}$, and $\mathrm{Pb}$. These elevated acid-extractable concentrations might be indicative of some precipitated wastes or the presence of less-stable secondary mineral phases formed upon caustic waste attack on native sediments. There was high acid-extractable $\mathrm{Ca}$ and $\mathrm{Mg}$ at $62 \mathrm{ft}$ bgs likely, which is indicative of the native divalent cations pushed in front of the sodium waste ion exchange front. No elevated acidextractable concentrations were found for $\mathrm{Al}, \mathrm{S}, \mathrm{K}, \mathrm{Ti}, \mathrm{V}, \mathrm{Co}, \mathrm{Cr}, \mathrm{Cd}, \mathrm{Zr}$, and U. No detectable Hg was found in the acid extracts from Borehole C5924 (B) sediments (Table 6.9), suggesting that there is detectable $\mathrm{Hg}$ outside the footprints of the BC cribs proximal to borehole C5924.

Table 6.8. $\quad$ Acid-Extractable Light Elements in Borehole C5924 (B) Sediments ( $\mu$ g/g dry sediment)

\begin{tabular}{cccccccccc}
\hline $\begin{array}{c}\text { Sample } \\
\text { (HEIS ID) }\end{array}$ & $\begin{array}{c}\text { Depth } \\
\text { (ft bgs) }\end{array}$ & $\mathrm{Na}$ & $\mathrm{Mg}$ & $\mathrm{Al}$ & $\mathrm{P}$ & $\mathrm{S}$ & $\mathrm{K}$ & $\mathrm{Ca}$ & $\mathrm{Ti}$ \\
\hline B1T730 & 19.8 & $\mathbf{3 4 7}$ & $\mathbf{4 2 6 0}$ & 5050 & $\mathbf{8 1 1}$ & $<81$ & 1130 & 7640 & 597 \\
B1T6B0 & 62.3 & 284 & $\mathbf{3 8 8 0}$ & 4550 & 349 & $<81$ & 1280 & $\mathbf{8 9 3 0}$ & 323 \\
B1T6B3 & 70.3 & 166 & 3750 & 4550 & 355 & $<81$ & 1280 & 8070 & 302 \\
B1T6C2 & 92.3 & 131 & 3630 & 4700 & 339 & $<81$ & 1130 & 7430 & 335 \\
B1T6C5 & 100.3 & 138 & 3490 & 4390 & 375 & $<81$ & 1020 & 7620 & 375 \\
B1T6D2 & 117.8 & 308 & 3480 & 4640 & 544 & $<81$ & 1140 & 8350 & 285 \\
B1T6D4 & 122.8 & 136 & 3380 & 4230 & 349 & $<81$ & 1160 & 8150 & 328 \\
B1T6D9 & 135.3 & 136 & 3560 & 4690 & 342 & $<81$ & 1140 & 7320 & 381 \\
B1T6H6 & 178.3 & 144 & 3750 & 5170 & 342 & $<81$ & 1480 & 5950 & 386 \\
B1T6K6 & 227.3 & 256 & 3090 & 4370 & 499 & $<81$ & 823 & 5450 & 574 \\
\hline
\end{tabular}

Table 6.9. Acid-Extractable Heavy Elements in Borehole C5924 (B) Sediments ( $\mu \mathrm{g} / \mathrm{g}$ dry sediment)

\begin{tabular}{ccccccccc}
\hline $\begin{array}{c}\text { Sample } \\
\text { (HEIS ID) }\end{array}$ & $\begin{array}{l}\text { Depth } \\
\text { (ft bgs) }\end{array}$ & $\mathrm{V}$ & $\mathrm{Mn}$ & $\mathrm{Fe}$ & $\mathrm{Co}$ & $\mathrm{Sr}$ & $\mathrm{Zr}$ & $\mathrm{Hg}$ \\
\hline B1T730 & 19.8 & 17.9 & $\mathbf{3 2 4}$ & $\mathbf{1 5 7 0 0}$ & 11.4 & 26 & 8.50 & $<0.02$ \\
B1T6B0 & 62.3 & 8.03 & 214 & 8550 & 6.65 & 29 & 3.23 & $<0.02$ \\
B1T6B3 & 70.3 & 7.46 & 205 & 7990 & 6.24 & 28.9 & 2.75 & $<0.02$ \\
B1T6C2 & 92.3 & 9.35 & 221 & 9050 & 6.49 & 24.2 & 3.06 & $<0.02$ \\
B1T6C5 & 100.3 & 9.95 & 225 & 9190 & 6.21 & 24.4 & 3.92 & $<0.02$ \\
B1T6D2 & 117.8 & 9.16 & 197 & 8130 & 6.21 & 30.9 & 2.94 & $<0.02$ \\
B1T6D4 & 122.8 & 8.96 & 200 & 8420 & 6.18 & 26.1 & 3.19 & $<0.02$ \\
\hline B1T6D9 & 135.3 & 10.6 & 233 & 9180 & 6.9 & 24.2 & 3.69 & $<0.02$ \\
B1T6H6 & 178.3 & 11.2 & 218 & 9020 & 6.97 & 25.2 & 2.87 & $<0.02$ \\
\hline B1T6K6 & 227.3 & 16.9 & 200 & 10300 & 7.45 & 25.1 & 7.58 & $<0.02$ \\
\hline
\end{tabular}


Table 6.10. Acid Extractable Content for RCRA Metals and Radionuclides in Borehole C5924 (B) (units $\mu \mathrm{g} / \mathrm{g}$ except Tc pCi/g)

\begin{tabular}{ccccccc}
\hline Sample (HEIS ID) & $\begin{array}{c}\text { Depth } \\
\text { (ft bgs) }\end{array}$ & Cr & Cd & Pb & Tc- 99 & U- 238 \\
\hline B1T730 & 19.8 & 5.54 & 0.082 & 4.39 & $<2.18 \mathrm{E}+01$ & $3.10 \mathrm{E}-01$ \\
B1T6B0 & 62.3 & 7.37 & 0.068 & 3.3 & $5.09 \mathrm{E}+01$ & $3.63 \mathrm{E}-01$ \\
B1T6B3 & 70.3 & 7.84 & 0.068 & 2.8 & $5.36 \mathrm{E}+01$ & $2.98 \mathrm{E}-01$ \\
B1T6C2 & 92.3 & 8.04 & 0.062 & 2.72 & $<2.19 \mathrm{E}+01$ & $3.35 \mathrm{E}-01$ \\
B1T6C5 & 100.3 & 7.05 & 0.051 & 2.51 & $<2.27 \mathrm{E}+01$ & $3.18 \mathrm{E}-01$ \\
B1T6D2 & 117.8 & 8.37 & 0.084 & 3.18 & $9.03 \mathrm{E}+01$ & $3.57 \mathrm{E}-01$ \\
B1T6D4 & 122.8 & 7.51 & 0.063 & 2.71 & $5.97 \mathrm{E}+01$ & $3.22 \mathrm{E}-01$ \\
B1T6D9 & 135.3 & 8.94 & 0.064 & 2.58 & $<1.92 \mathrm{E}+01$ & $3.14 \mathrm{E}-01$ \\
B1T6H6 & 178.3 & 11 & 0.071 & 2.56 & $<1.90 \mathrm{E}+01$ & $3.48 \mathrm{E}-01$ \\
B1T6K6 & 227.3 & 7.19 & 0.061 & 1.8 & $<2.08 \mathrm{E}+01$ & $3.22 \mathrm{E}-01$ \\
\hline
\end{tabular}

A comparison of the water-leachable and acid-leachable contents of the sediments from Borehole C5924 (B) shows that a range of 0.8 to $1.8 \%$ of the acid-extractable $U$ is water leachable. A range of 0.1 to $64 \%$ of the acid-extractable technetium is also water leachable. Because the wastes disposed of in BC Cribs and Trenches did not contain high concentrations of $U$, it appears that regions of elevated precipitated uranium may only exist at the very bottoms of the inactive cribs and trenches as was found at borehole C4191 (drilled right through the 216-B-26 footprint).

\subsubsection{Radionuclide Content in Vadose Zone Sediment from Borehole C5924 (B)}

Table 6.11 shows the selected grab samples that were analyzed for radionuclides by GEA on aliquots of dry sediment or after acid digestion and wet chemical separations (nickel-63 and strontium-90). The sediment from Borehole C5924 (B) did not contain significant amounts of man-made gamma radioactivity in the grab samples analyzed by PNNL's ESL laboratory. Cesium-137 was found in the shallower depths of 5.3 and $9.8 \mathrm{ft}$ bgs at concentrations below $1 \mathrm{pCi} / \mathrm{g}$. The sediments also contain natural amounts (10 to $25 \mathrm{pCi} / \mathrm{g}$ ) of potassium-40 and a few pCi/g of some of the daughters of natural uranium and thorium as background levels. No other man-made radionuclides such as antimony-125, europium-155, strontium-90, and nickel-63 were found in Borehole C5924 (B) sediments.

Table 6.11. Man-Made Fission Product Data (pCi/g sed) for Grab Samples from Borehole C5924 (B)

\begin{tabular}{cccccccc}
\hline Sample (HEIS ID) & Ft bgs & Sb-125 & Cs-137 & $1 \sigma$ error & Eu-155 & Ni-63 & Sr-90 \\
\hline B1T677 & 5.25 & $<0.54$ & 0.522 & $4.468 E-02$ & $<0.69$ & NA & NA \\
B1T678 & 7.75 & $<0.41$ & $<0.17$ & & $<0.51$ & NA & NA \\
B1T679 & 9.75 & $<0.52$ & 0.667 & $4.635 E-02$ & $<0.65$ & NA & NA \\
B1T680 & 12.25 & $<0.37$ & $<0.14$ & & $<0.47$ & NA & NA \\
B1T730 & 19.75 & $<0.56$ & $<0.20$ & & $<0.75$ & $<11.4$ & $<10.6$ \\
B1T689 & 34.75 & $<0.42$ & $<0.15$ & & $<0.51$ & $<11.4$ & $<10.6$ \\
B1T6B0 & 62.25 & $<0.52$ & $<0.18$ & $<0.65$ & $<11.3$ & $<10.7$ \\
B1T6B3 & 70.25 & $<0.42$ & $<0.15$ & & $<0.50$ & $<11.2$ & $<10.4$ \\
B1T6C2 & 92.25 & NA & NA & & NA & $<11$ & $<10.7$ \\
B1T6C5 & 100.25 & NA & NA & & $<10.7$ & $<10.6$ \\
B1T6D2 & 117.75 & $<0.52$ & $<0.19$ & & $<0.71$ & $<11.3$ & $<10.6$ \\
B1T6D4 & 122.75 & $<0.40$ & $<0.15$ & & $<10.9$ & $<10.6$ \\
B1T6D9 & 135.25 & NA & NA & NA & $<10.1$ & $<9.97$ \\
B1T6H6 & 178.25 & NA & NA & & NA & $<10.6$ & $<10.4$ \\
B1T6K6 & 227.25 & NA & NA & & & $<10.8$ & $<10.7$ \\
\hline
\end{tabular}




\subsection{Field Electrical-Resistivity Results at Borehole B (C5924)}

\subsubsection{HRR at Borehole C5924 (B)}

Figure 6.6 shows the HRR apparent-resistivity results for FY05-Line 30 and FY05-Line 25. Borehole C5924 (B) was placed at the intersection of both lines. For reference, features such as trench and crib locations are shown on the figure. Both cross sections show a low-resistivity feature deep below the ground surface. In FY05-Line 30 and east of the trench 216-B-23 (east of station 380), the apparentresistivity values go to background conditions. In Line FY05-25, background conditions resume north of the road leading into the site (the borrow pit area). Background values for resistivity are generally considered to be upwards of 500 ohm-m.

Borehole C5924 (B) was placed $122 \mathrm{~m}$ from the western edge of FY05-Line 30 and $226 \mathrm{~m}$ from the southern boundary of FY05-Line 25. At Borehole C5924 (B), the apparent-resistivity data show a clear low-resistivity target at approximately 30 to 50 meters bgs, which is deeper than the observed shallow lobe of high conductivity in the laboratory analyses of sediments at Borehole C5924 (B). Above and below the target, apparent resistivity increases, isolating the target. Variability can be seen in the target zone, as identified by the solid contour lines. The data also appear to be free from most cultural interferences known to exist in the area. Well 13-10 appears to have a slight influence on FY05-Line 25. Figure 6.7 shows the extracted apparent-resistivity data profile at Borehole C5924 (B) along both lines.
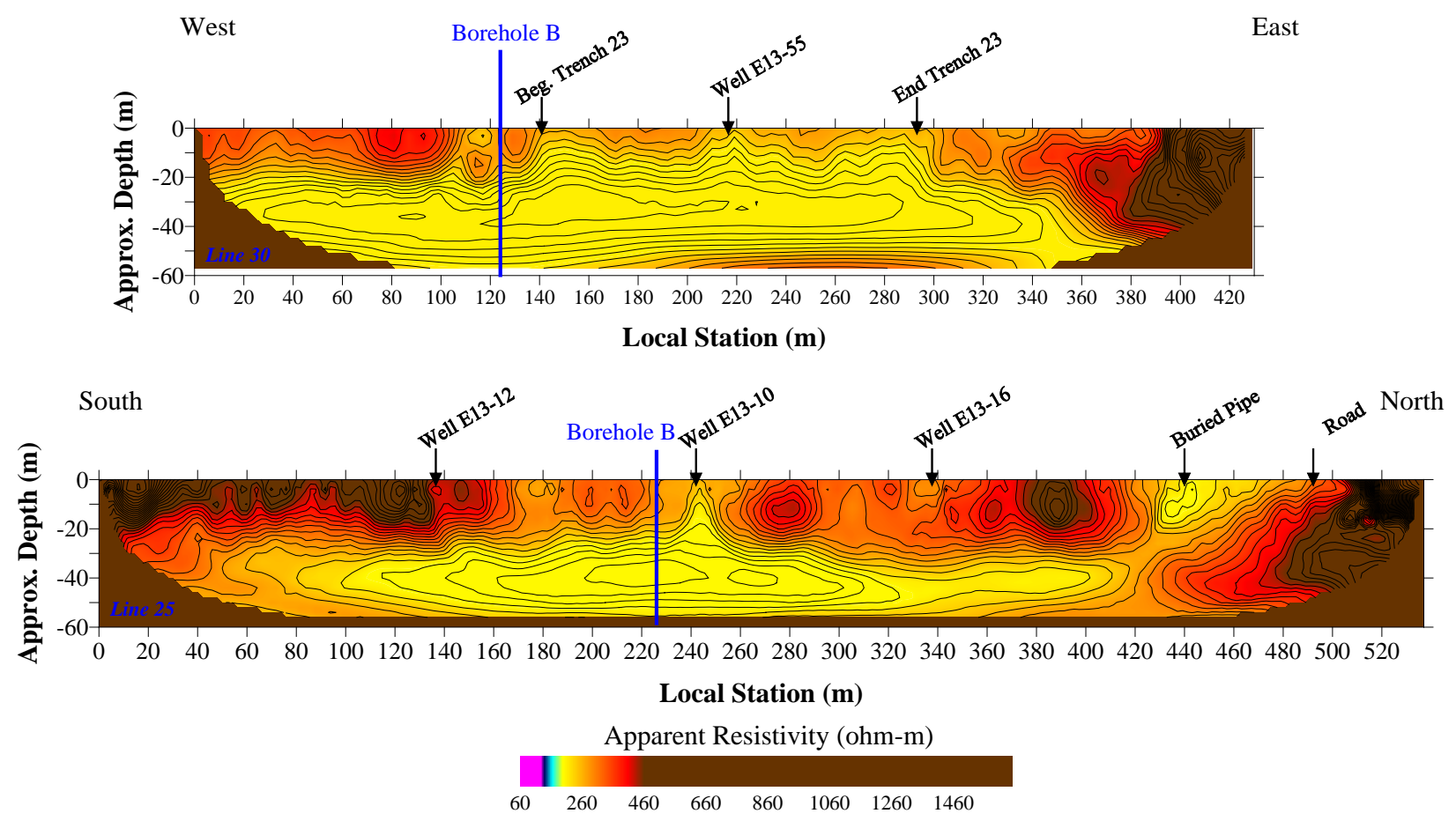

Figure 6.6. HRR Results of FY05-Line 30 and FY05-Line 25 
PNNL-17821

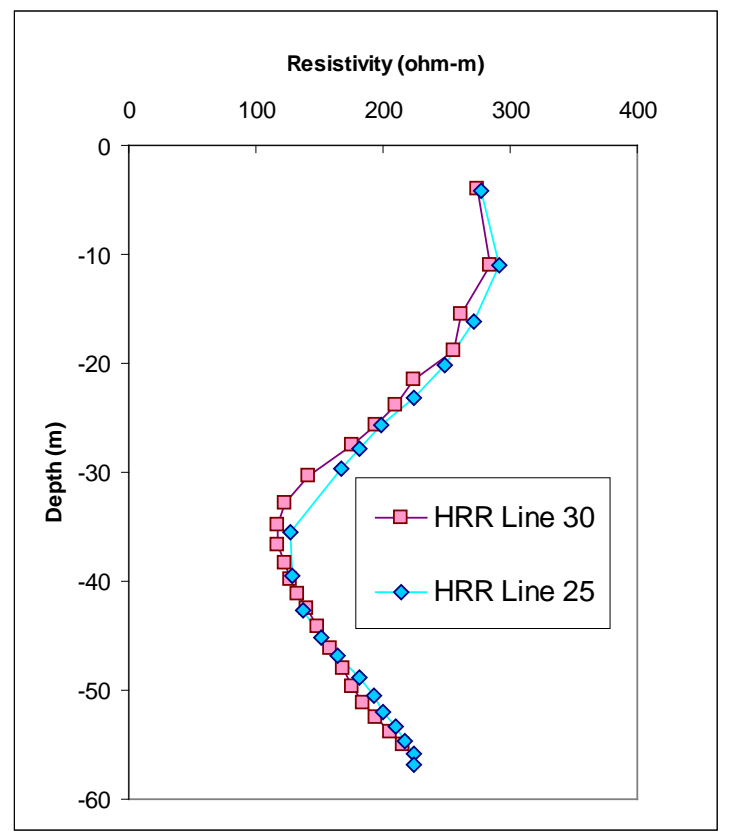

Figure 6.7. Profiles of HRR at the Location of Borehole C5924 (B)

The individual geochemical species in the pore water at Borehole C5924 (B) were sampled at a much higher spatial frequency and at different depths than the field acquired apparent soil resistivity data. To calculate correlations and to develop the empirical models, the measured field geophysical data were resampled at the soil sampling depths, using linear interpolation.

Figure 6.8 shows the results of comparing the pore-water EC and HRR at Borehole C5924 (B). The top set of plots used Equation 4-7 (Chapter 4.1.2) as the plotting algorithm to obtain the depth estimates of the apparent-resistivity values with coefficients of $u=(3.97,22.4,3.97)$. These coefficients were based on the least-squares fitting of target depth using co-located resistivity data from FY04-Line 1 and borehole C4191 (see Rucker and Fink 2007). The bottom set of plots is from an optimized set of coefficients, $\mathrm{u}=(11.5,3.84,1)$, specific to the new C5924 (B) borehole data. The optimized coefficients followed the procedure outlined in Rucker and Fink (2007). The profiles show that the apparentresistivity field data places the highest conductivity zone deeper than the shallower lobe of high conductivity pore water in the C5924 borehole but between the two high-conductivity lobes; in essence, the field data average the depths of the two targets. Using the optimized coefficients, the HRR profile clearly produces a better match to the shallow higher conductivity lobe of the borehole data. Given that the EC in Borehole C5923 (A) is about three times that of Borehole C5924 (B), the geophysical method appears to be better at distinguishing target intensity and not target depth when considering a single sitewide set of coefficients. 


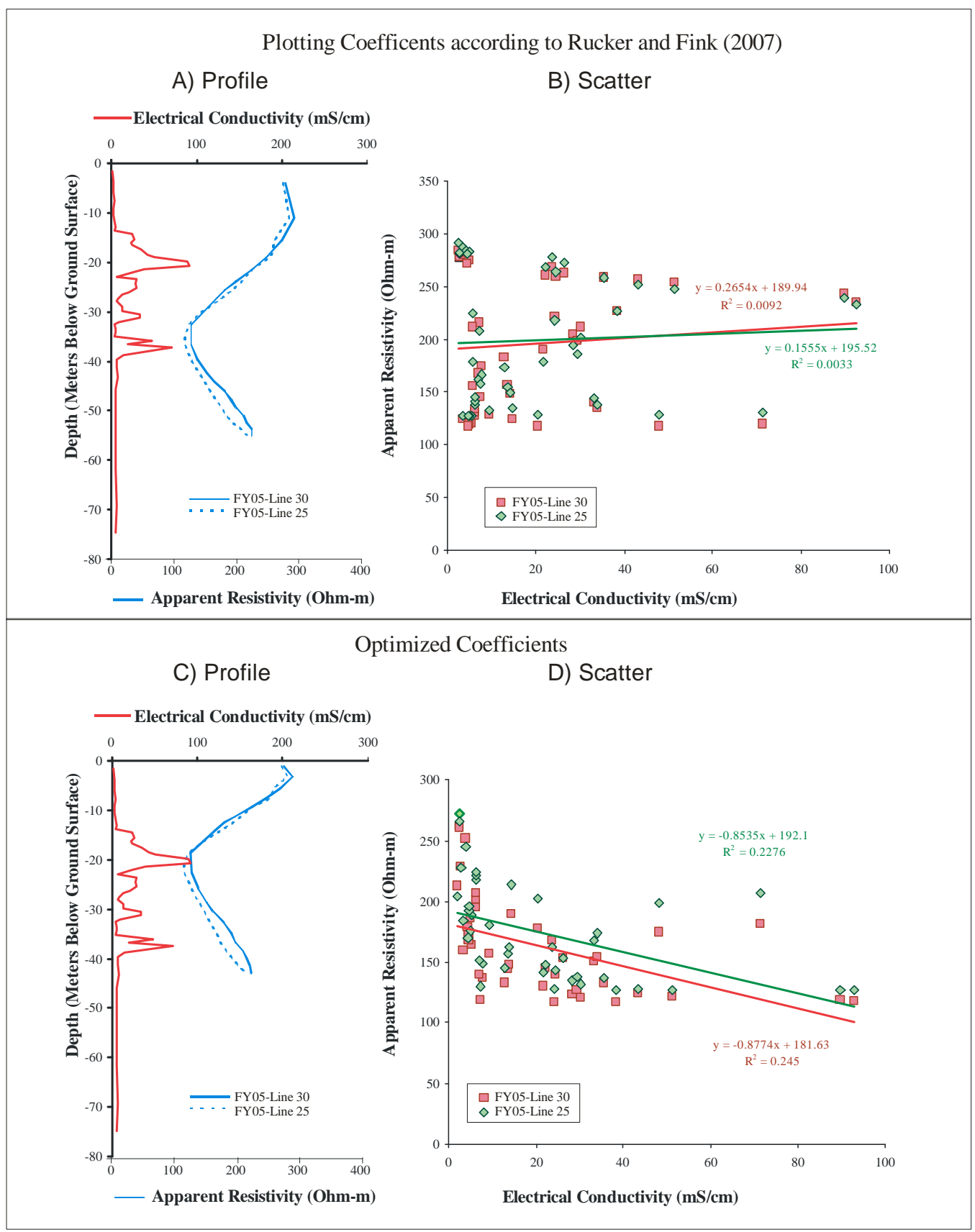

Figure 6.8. Profile and Scatterplots for HRR and Pore-Water EC at Borehole C5924 (B) with Coefficients from Rucker and Fink (2007) and Optimized Coefficients Using Data From Borehole C5924 (B) as Calibration

Figure 6.9 shows the profile and scatter plots for pore-water ionic strength and nitrate and technetium-99 concentrations. The HRR data were formulated with the optimized coefficients (using C5924 data). The ionic strength is the most appropriate variable to use for comparison since it accounts for all ionic species. However, the nitrate concentration appears to have the best correlation with the FY05-Line 25 HRR data, with an $\mathrm{R}^{2}$ value of 0.269 . The technetium-99 concentration has the worst 
PNNL-17821

A) Ionic Strength Profile

B) Ionic Strength Scatter

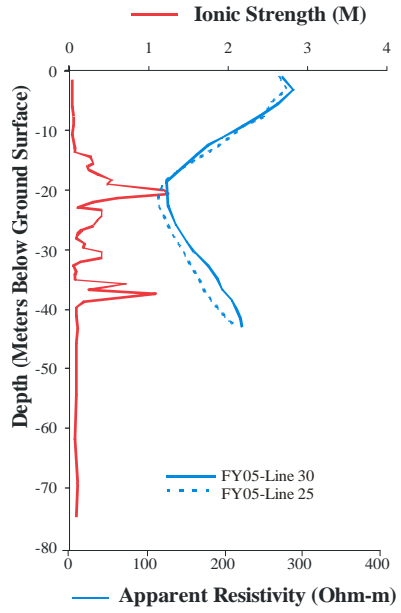

C) Nitrate Profile

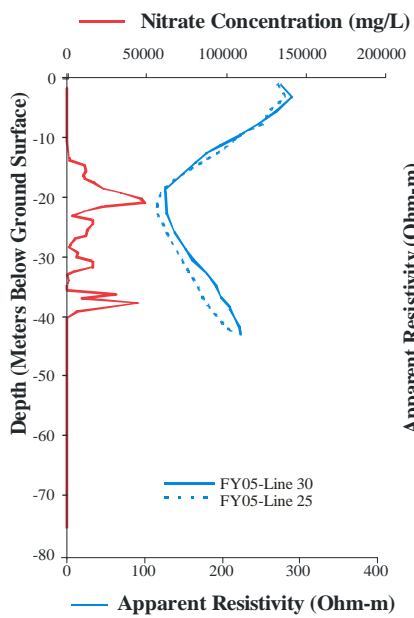

E) $\mathrm{TC}^{99}$ Profile
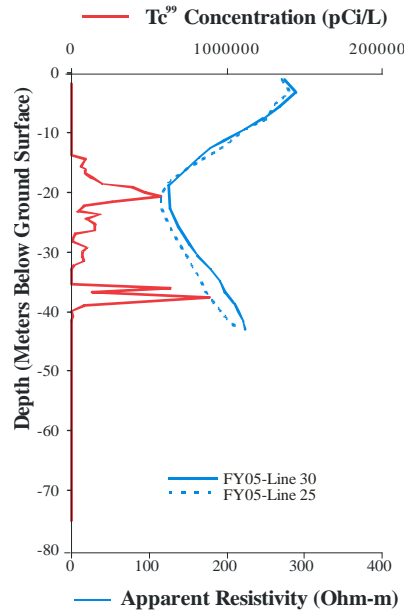

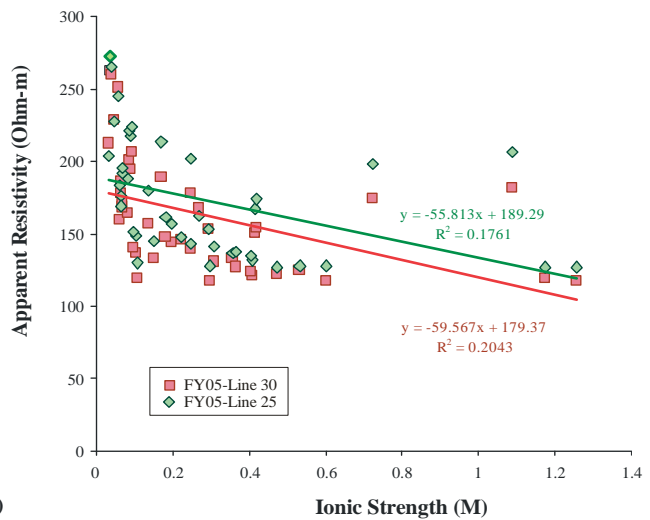

D) Nitrate Scatter

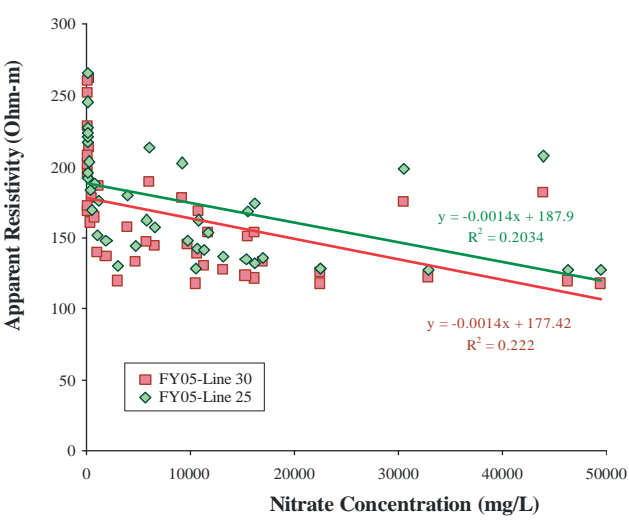

F) $\mathrm{TC}^{99}$ Scatter

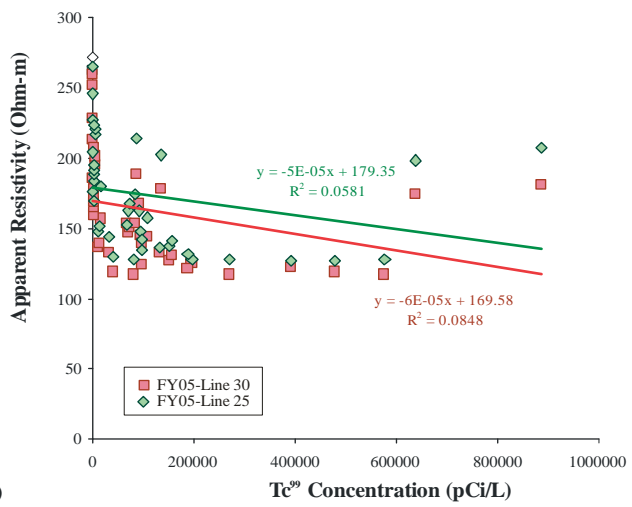

Figure 6.9. Profile and Scatter Plots of Geochemistry Data and HRR Results for Borehole C5924 (B), Including Ionic Strength, Nitrate Concentration, and Technetium-99 Concentration. Correlations developed with optimized coefficients. 
correlation with HRR data with an $\mathrm{R}^{2}$ value of 0.238 . These observations are consistent with the findings from Borehole C5923 (A).

\subsubsection{D Inversion at Borehole C5924 (B)}

Figure 6.10 shows the inversion results for FY05-Line 19 and FY05-Line 25. For reference, features such as trench and crib locations are shown on the figure. The inversion for FY05-Line 30 was completed in three iterations using the smooth model inversion with a final root-mean square error of $5.0 \%$. The inversion for FY05-Line 25 finished in three iterations with a final error of $3.58 \%$. At Borehole C5924 (B), the resistivity data show a clear low-resistivity target (Figure 6.11). Above the target, resistivity increases, isolating the target. The bottom of the target is much less defined. Variability can be seen in the target zone, as identified by the solid contour lines.
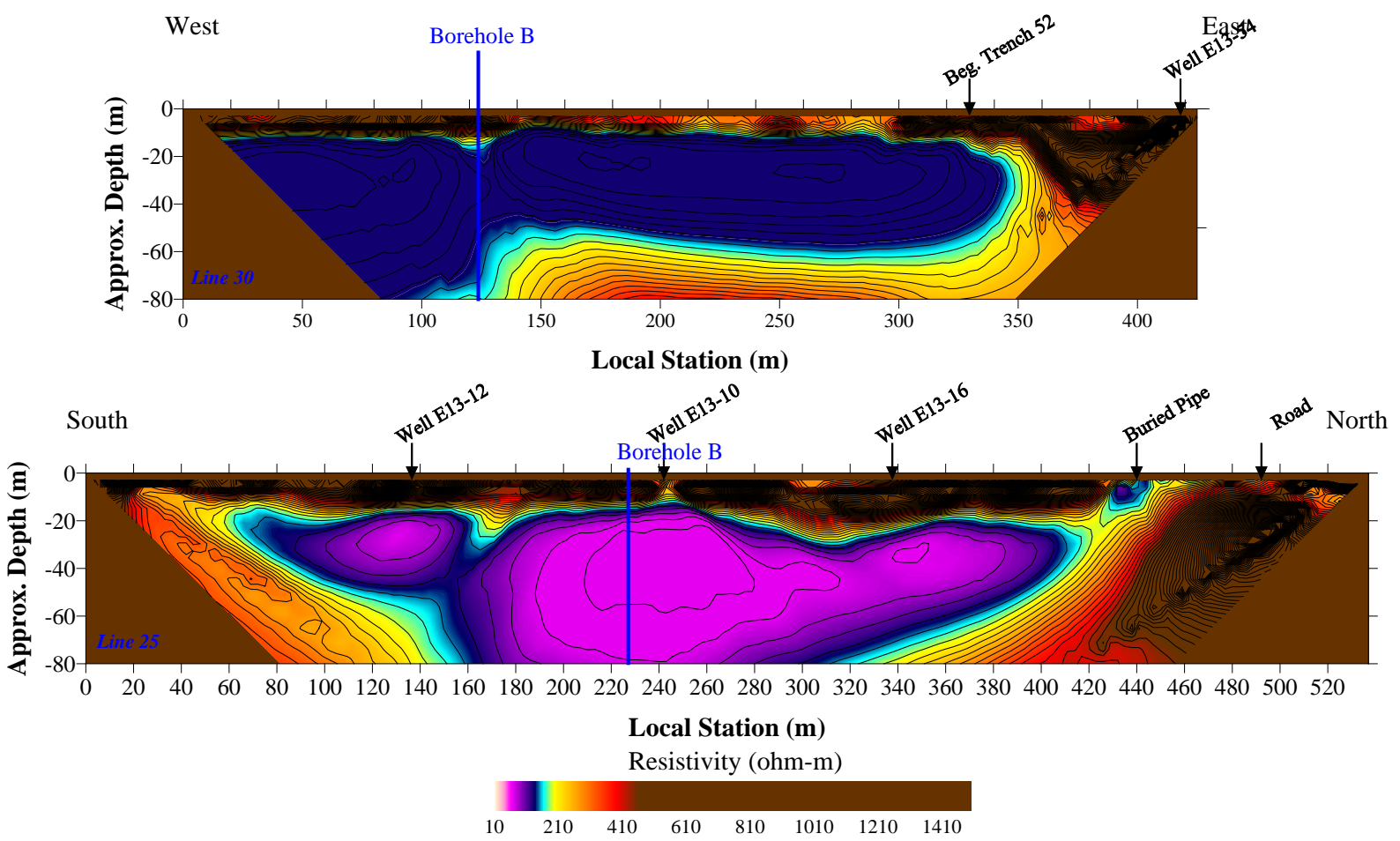

Figure 6.10. 2D Inversion Results of FY05-Line 30 and FY05-Line 25 


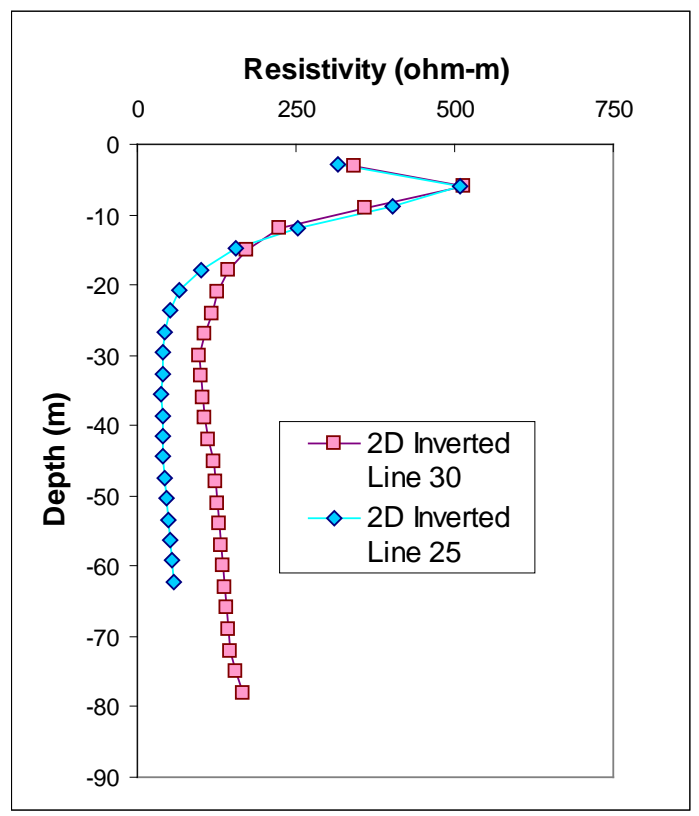

Figure 6.11. Profiles of 2D Inversion at the Location of Borehole C5924 (B)

The pore-water EC and ionic strength from Borehole C5924 (B) and 2D inverted resistivity data were evaluated at co-located positions (Figure 6.12). The profiles in Figure 6.12 show that the electrical resistivity can identify a high EC or high-ionic-strength target, but the depth to the target does not match the depth of the highest EC and/or the ionic strength actually measured on water extracts of the sediments. The soil resistivity begins to decrease at higher elevations than the geochemical measurements on the borehole sediments would suggest. Therefore, the correlations are poor when comparing co-located data directly as shown in the scatter plots. Improvements could be made by shifting the geophysical data to elevations that match the geochemical high EC or ionic-strength peak in the borehole profile, similar to the depth offsets used for Borehole C5923 (A).

Another factor for the poor correlation between 2D inversion and geochemistry may be the superposition problem and the additive effect of multiple low-resistivity features observed in the sediment. For FY05-Line 30, the HRR data show two low-resistivity anomalies on either side of Borehole C5924 (B). These effects could be adding together to form an enhanced low-resistivity anomaly at the borehole's location. The geochemistry shows conclusively that a plume with an irregular vertical distribution does reside at this location, but the $2 \mathrm{D}$ electrical-resistivity results could be affected by outof-plane anomalies.

Figure 6.13 shows the profile and scatter plot with regression for pore-water nitrate and technetium-99 concentrations. Again, the technetium-99 shows the worst correlation, and the ionicstrength regression of Figure 6.12 demonstrates the best correlation with 2D inverted soil resistivity. 
PNNL-17821
A) Profile
B) Scatter
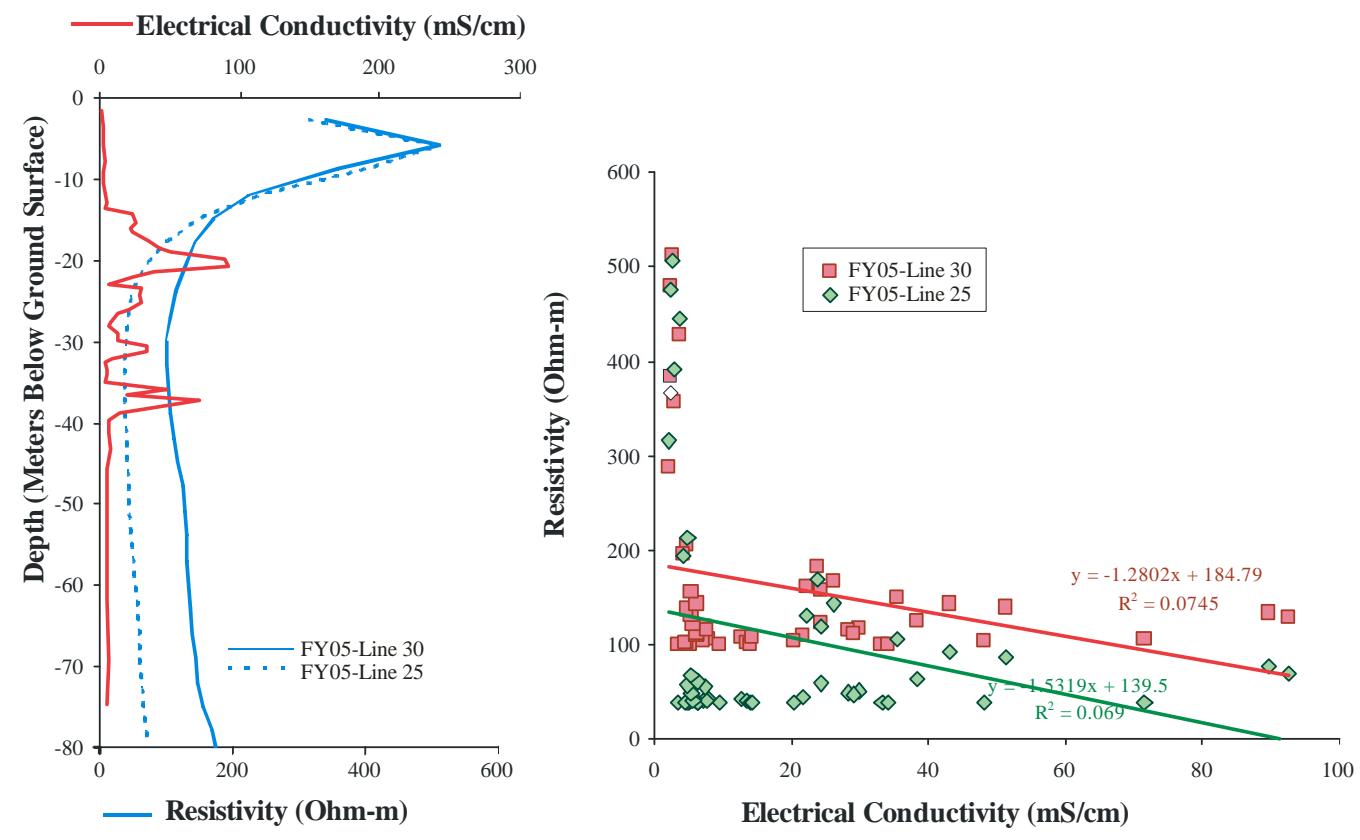

C) Profile

D) Scatter
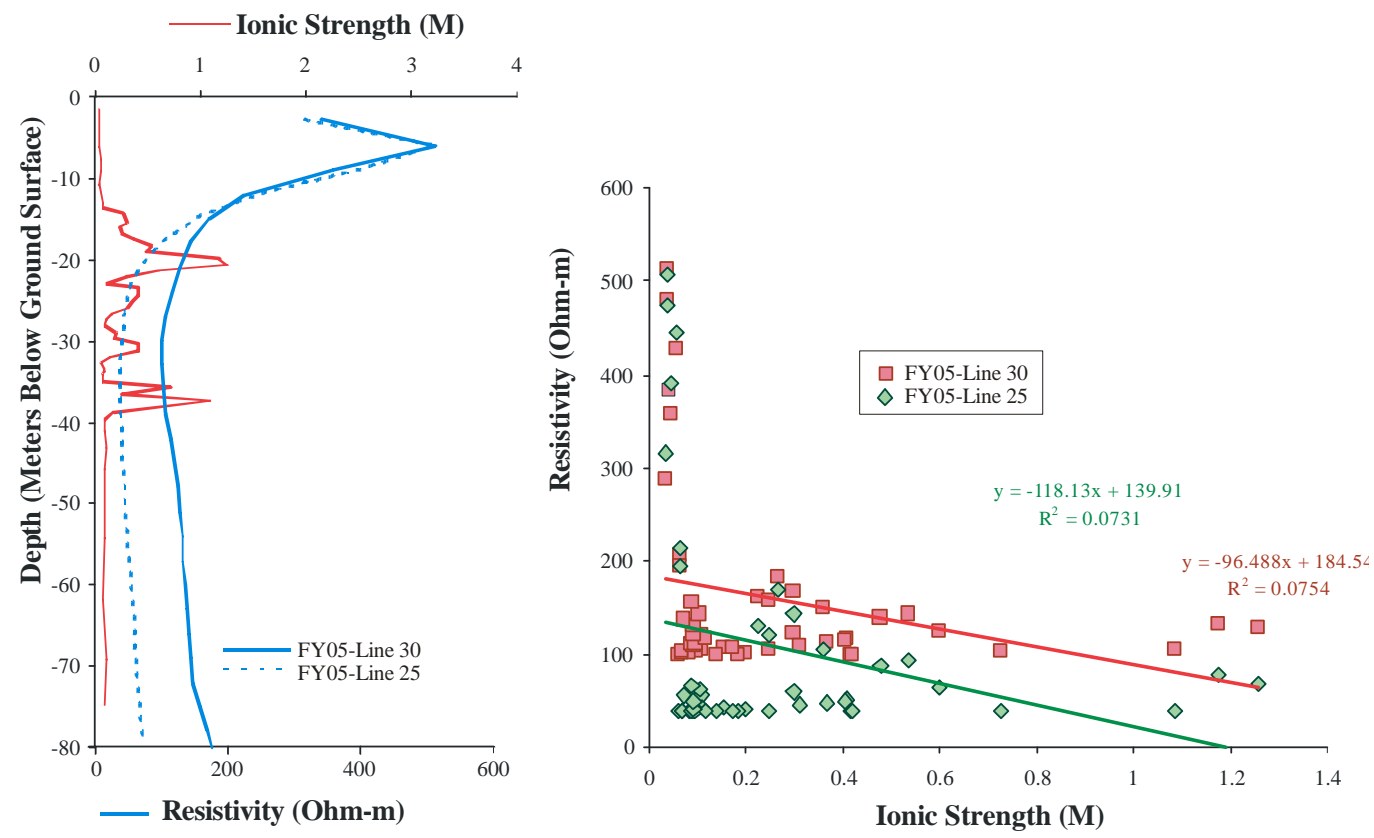

Figure 6.12. Profile and Scatter Plots for $2 \mathrm{D}$ Inversion. (top) Pore-Water EC (bottom) Ionic Strength at Borehole C5924 (B) 
PNNL-17821

B) Scatter
A) Profile

C) Profile

(1)
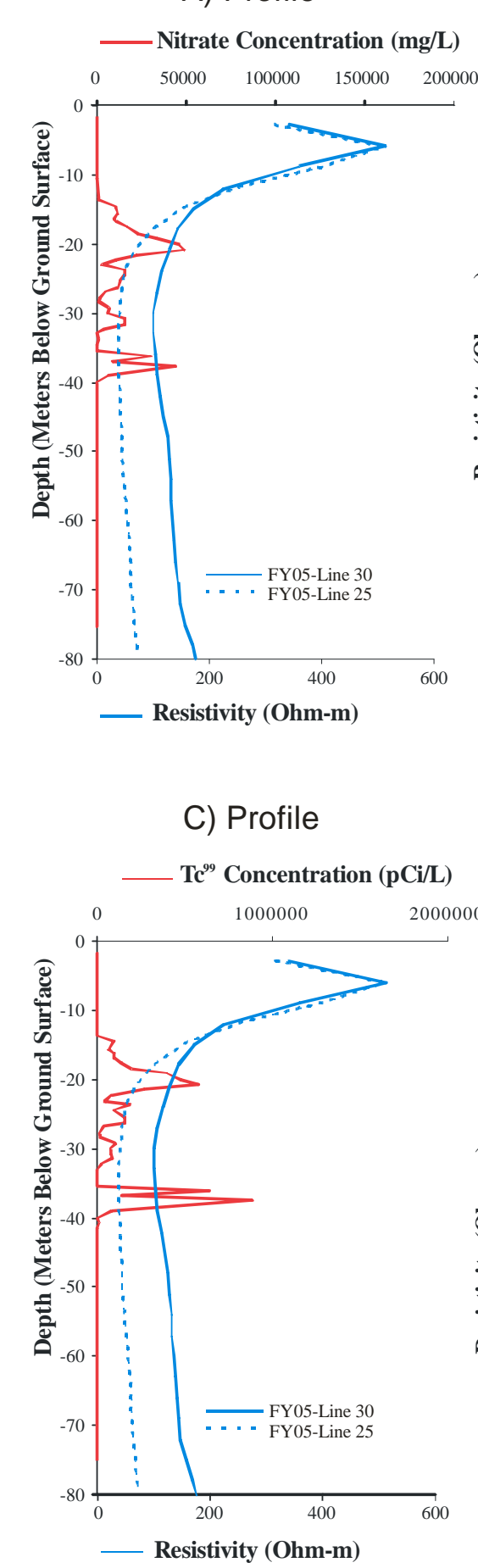

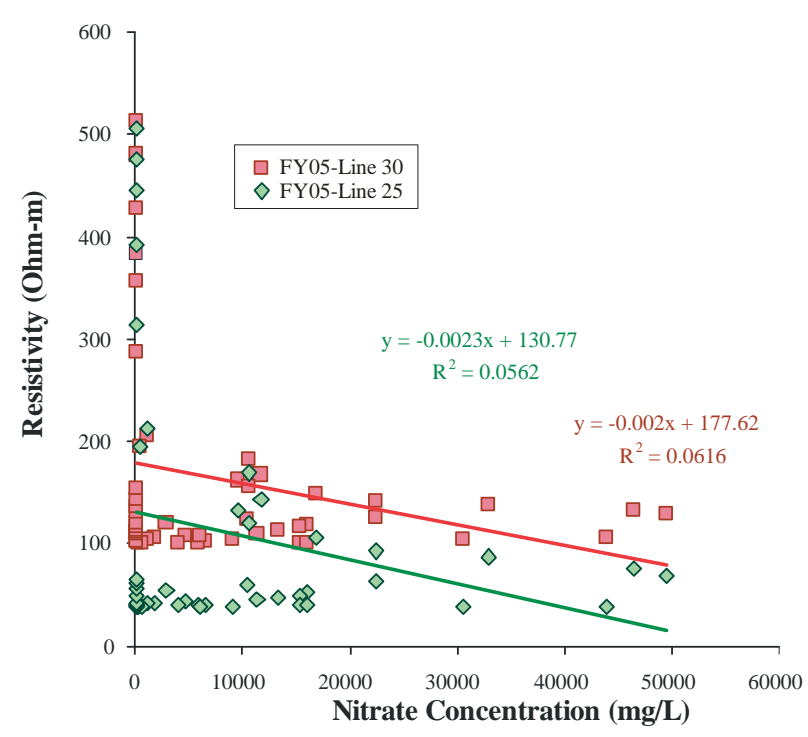

D) Scatter

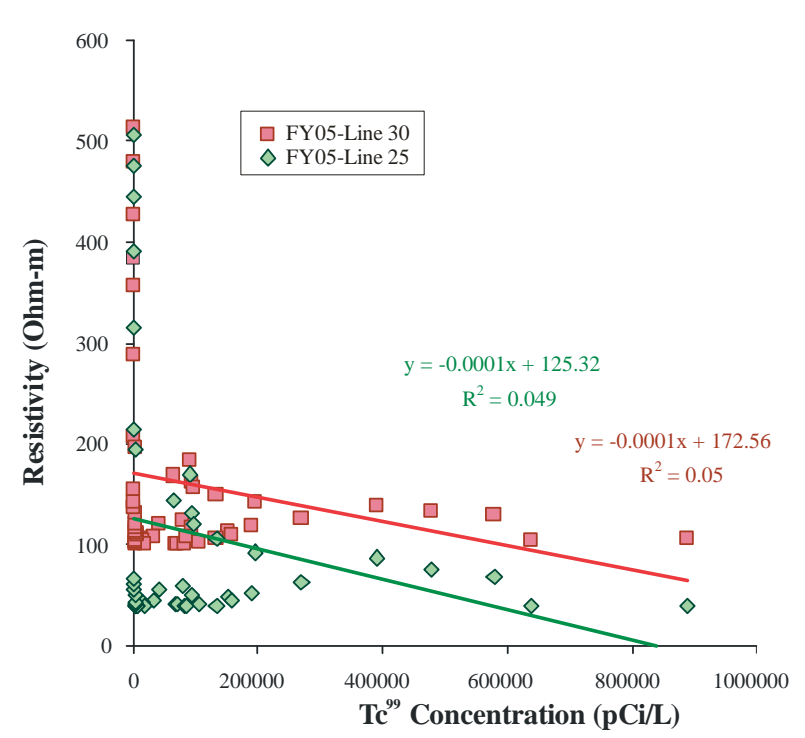

Figure 6.13. Profile and Scatter Plots for 2D Inversion and Pore-Water EC at Borehole C5924 (B) 


\subsubsection{D Inversion at Borehole C5924 (B)}

The 3D inversion results for model domain 1 are shown in Figure 6.14. The figure focuses on data near Borehole C5924 (B) by showing vertical slices of contoured resistivity values, centered on the borehole's location. The figure shows a low-resistivity anomaly to the east of the borehole that is coincident with trench 216-B-23 and a low-resistivity anomaly to the west of the borehole that is coincident with trench 216-B-34. South of Borehole C5924 (B), a few near-surface anomalies appear immediately west of the 216-B-52 and 216-B-23 trenches, likely the result of waste migration.

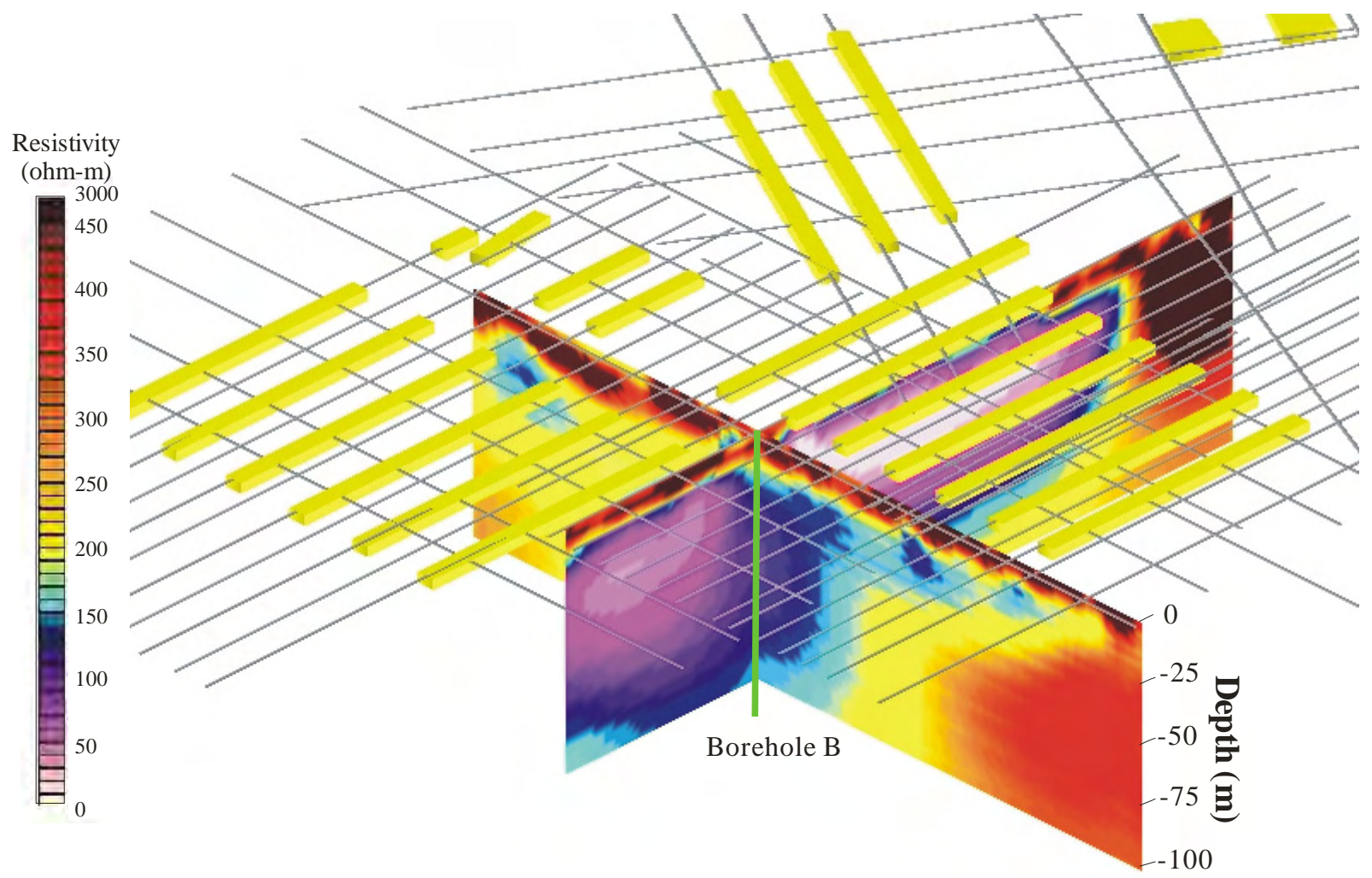

Figure 6.14. 3D Inversion Results of Model Domain 1 of the BC Cribs Site

The regression and profile data for EC and ionic strength in Borehole C5924 (B) with 3D inversion results are shown in Figure 6.15. The profile data show that the target in the original inversion results at Borehole C5924 (B) matches the geochemistry to some degree. The point at which the resistivity is less than 100 ohm-m appears to coincide with the top of the EC and ionic strength target. However, the large variability in EC and ionic strength from 15 to $40 \mathrm{~m}$ bgs does not manifest in the 3D inversion of field geophysics. This small-scale geochemical variability makes it appear that the correlation with the 3D inverted field geophysics is very poor. Rucker and Fink (2007) also noticed a low correlation when considering the dataset as a whole. If, however, the dataset is divided into a sensitive/insensitive region where electrical resistivity below $100 \mathrm{ohm}-\mathrm{m}$ is segregated from those above $100 \mathrm{ohm}-\mathrm{m}$, then correlations for the most sensitive region increase. Section 5.2 explores this option with Borehole 5923 (A). 
PNNL-17821
A) Profile
B) Scatter

Electrical Conductivity (mS/cm)
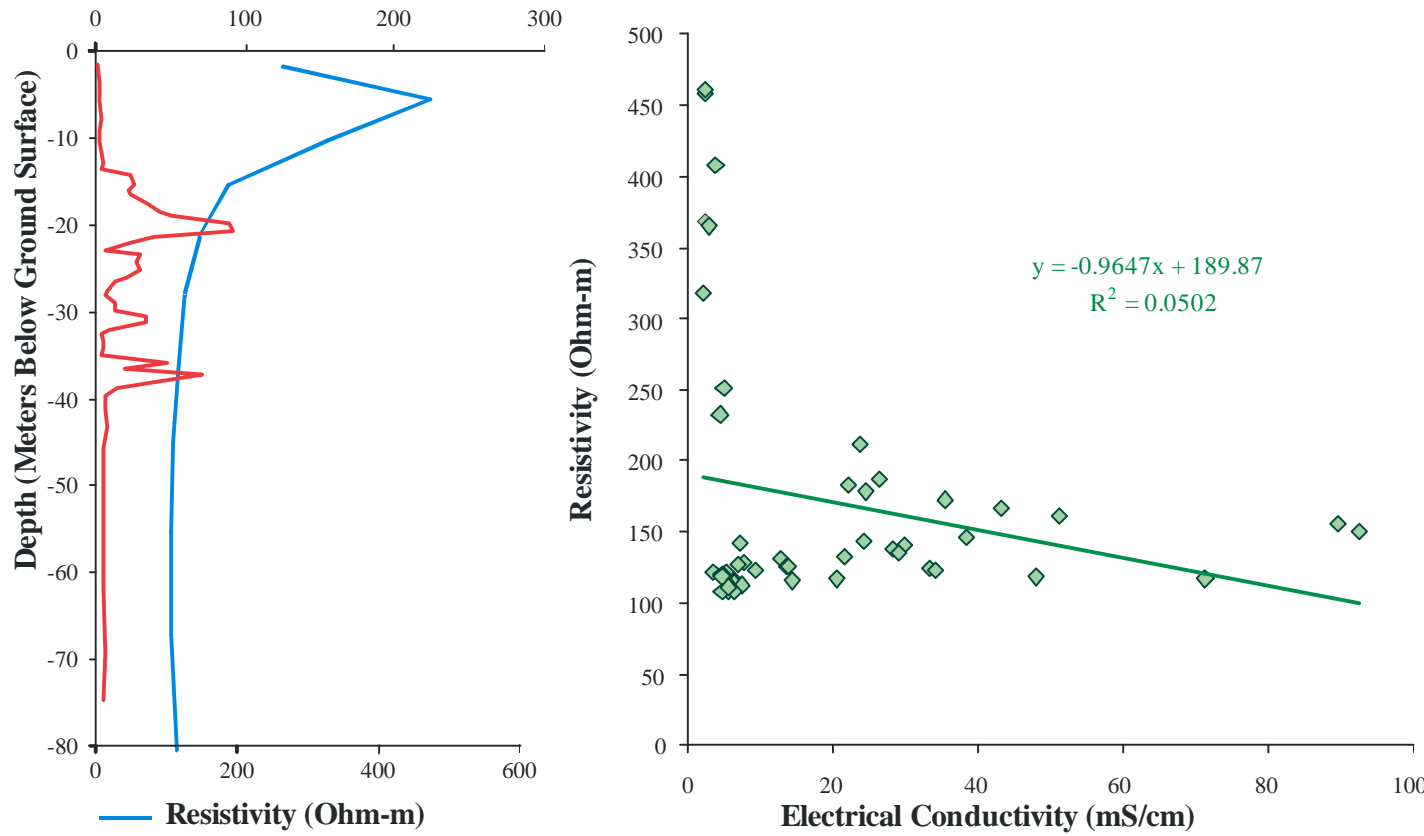

C) Profile

D) Scatter
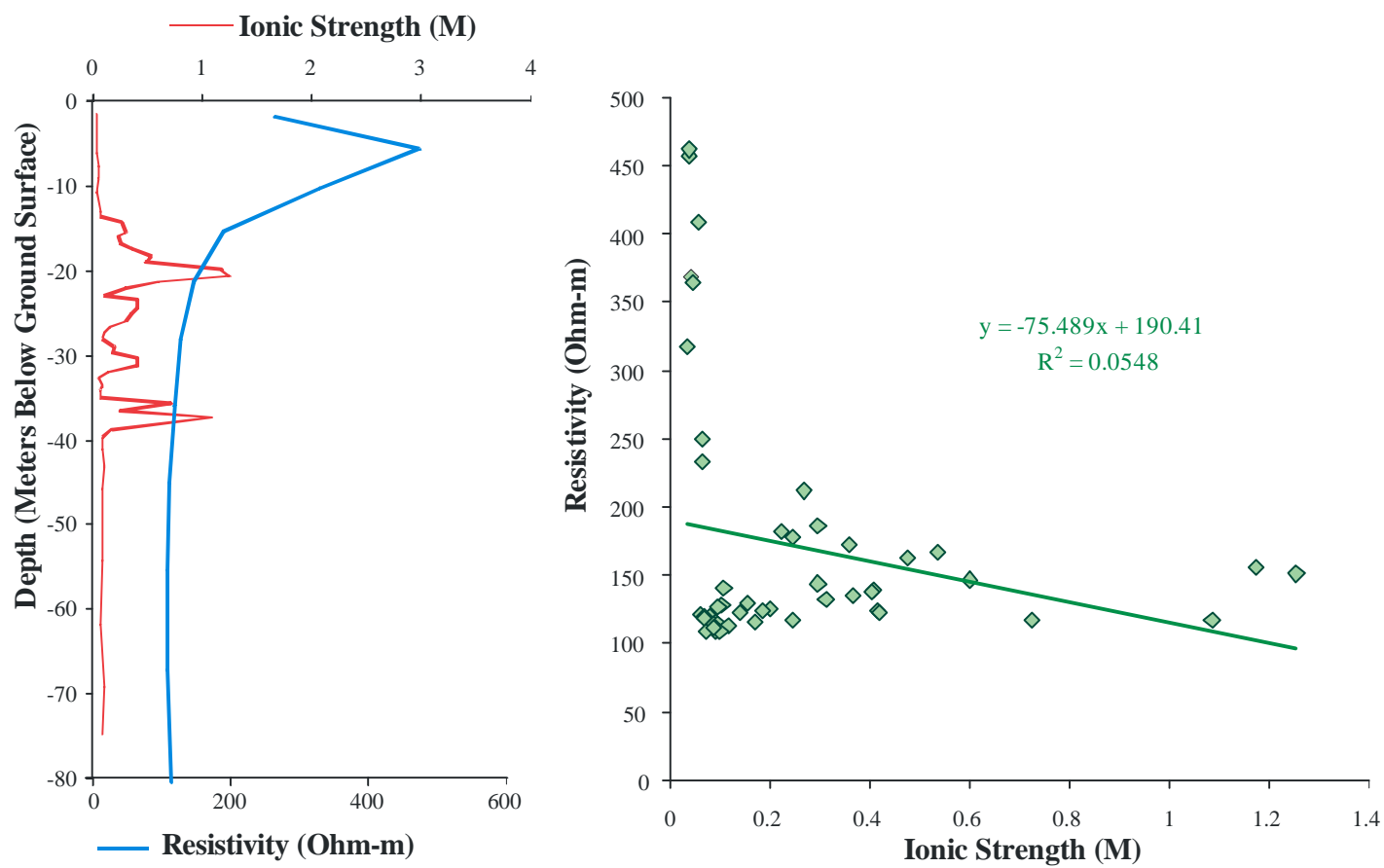

Figure 6.15. Profile and Scatter Plots for $3 D$ Inversion with Pore-Water EC and Ionic Strength at Borehole C5924 (B) 
Figure 6.16 shows the profile and scatter with regression for nitrate concentration and technetium-99 concentration. Because of the large variability in pore-water composition from 15 to $40 \mathrm{~m}$ bgs, the correlation of measured pore-water nitrate and technetium-99 with the 3D inverted field geophysics is very poor. This variability was likely caused by small-scale horizontal migration of waste fluids from the nearby trenches along fine-grained thin lenses, which is not captured in the 3D inversion of fieldresistivity data.
A) Profile
B) Scatter
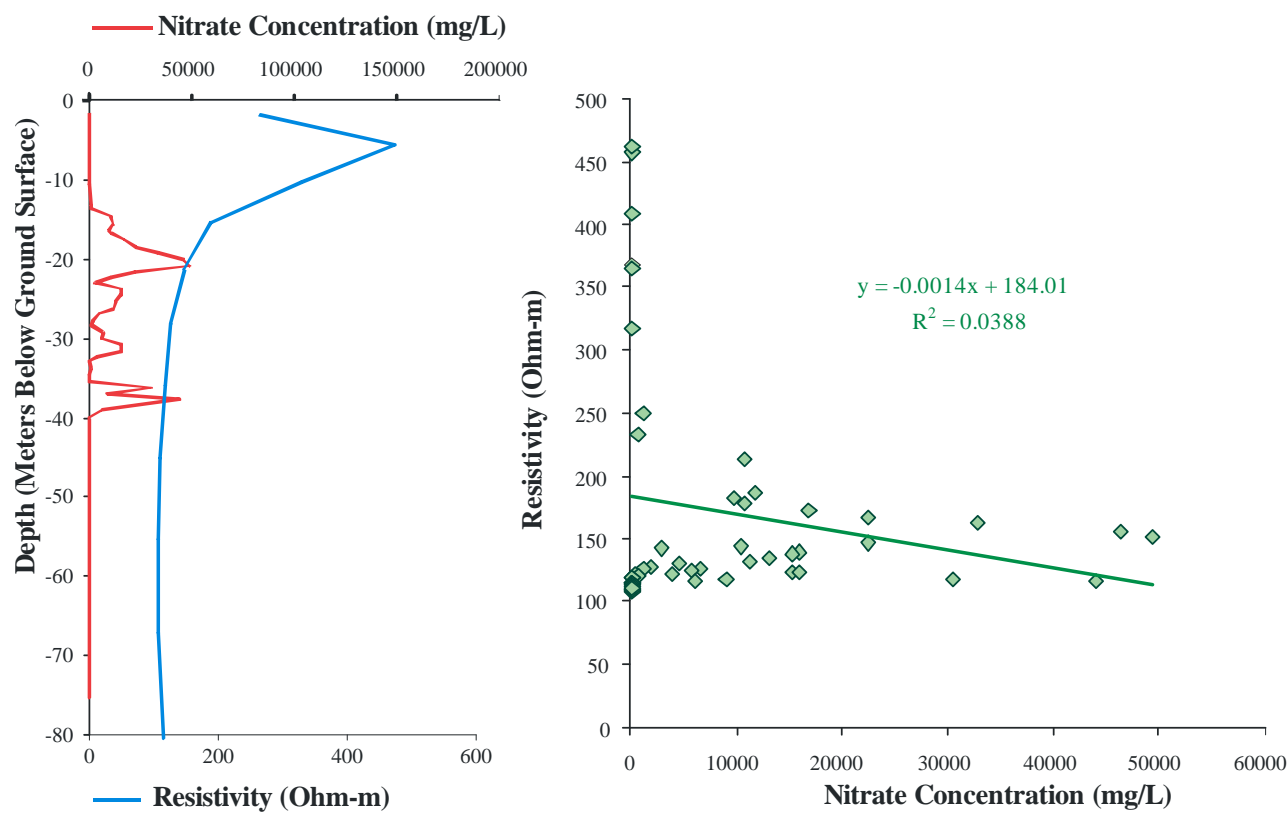

C) Profile

D) Scatter
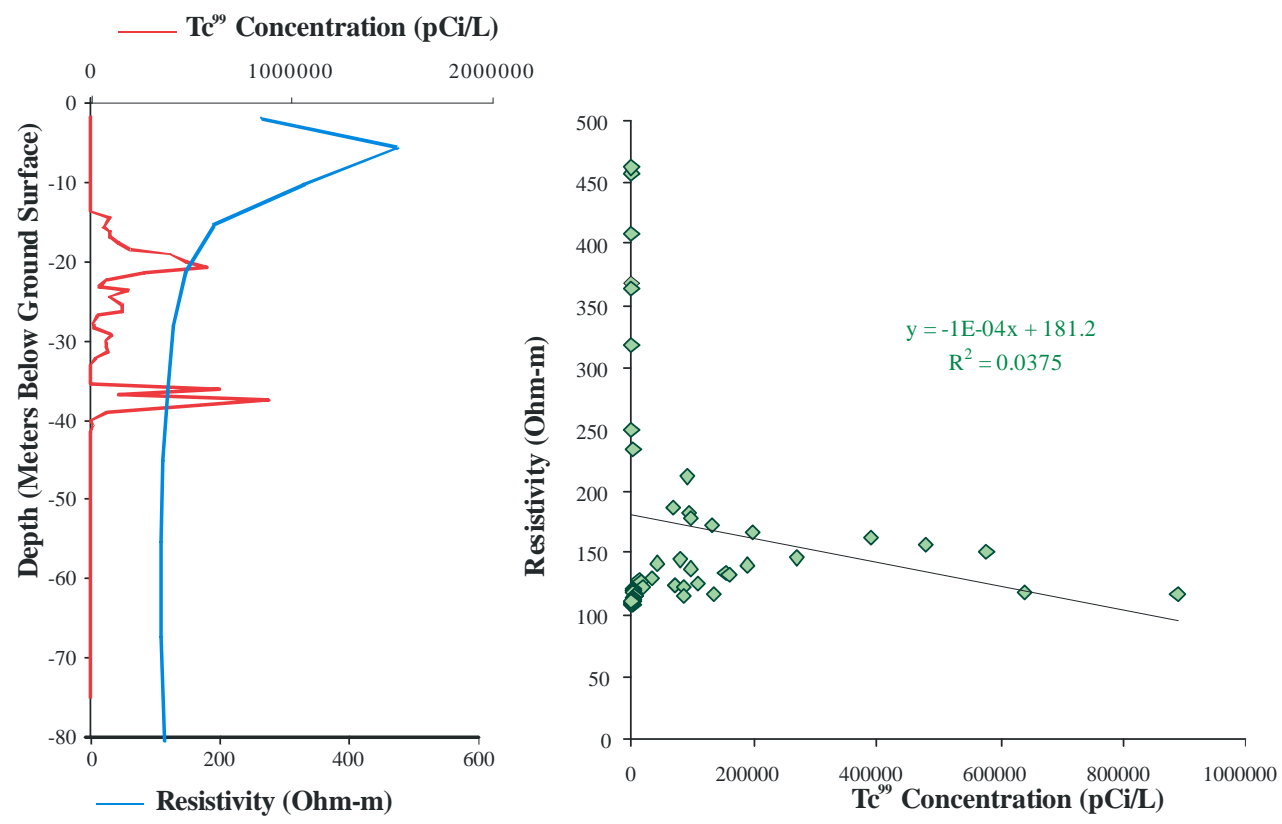

Figure 6.16. Profile and Scatter Plots for $3 D$ Inversion for Nitrate Concentration and Technetium99 Concentration at Borehole C5924 (B). 

PNNL-17821

\subsection{Borehole C (C5925) Results and Discussion}

\subsection{Geochemical Results from Borehole C (C5925)}

\subsubsection{Moisture Content}

The moisture contents of 84 grab samples received from Borehole C5925 (C) are listed as a function of depth in Table 7.1 and shown in Figure 7.1. The moisture content profile from both laboratory and field measurements shows the same trend and correlates with the lithology. Seven samples collected within the Hanford formation in the upper $40 \mathrm{ft}$ exhibited relatively high moisture contents, 8.9 to $19 \mathrm{wt} \%$. The high moisture ( $>8 \mathrm{wt} \%$ ) indicated that certain depths contained more fine-grained layers (Figure 7.1). Other sand-dominated Hanford formation samples in the upper $65 \mathrm{ft}$ bgs had moisture contents from 4 to $7 \mathrm{wt} \%$. Moisture contents in Hanford formation sediments below $65 \mathrm{ft}$ bgs dropped to the range of 2 to $3 \mathrm{wt} \%$ because of texture coarsening (larger \% of gravel is present).

Table 7.1. Gravimetric Moisture Content of Samples Retrieved from Borehole C (C5925)

\begin{tabular}{|c|c|c|c|c|c|}
\hline $\begin{array}{l}\text { Sample Name } \\
\text { (HEIS ID) }\end{array}$ & $\begin{array}{l}\text { Moisture Content } \\
\text { (Weight \%) }\end{array}$ & $\begin{array}{l}\text { Sample Mid Depth } \\
\text { (ft bgs) }\end{array}$ & $\begin{array}{l}\text { Sample Name } \\
\text { (HEIS ID) }\end{array}$ & $\begin{array}{l}\text { Moisture Content } \\
\text { (Weight \%) }\end{array}$ & $\begin{array}{l}\text { Sample Mid Depth } \\
\text { (ft bgs) }\end{array}$ \\
\hline B1T884 & 5.7 & 5.25 & B1T8D6 & 2.55 & 108.25 \\
\hline В1T885 & 10.5 & 7.75 & B1T8D7 & 2.36 & 110.75 \\
\hline B1T886 & 3.49 & 10.25 & B1T8D8 & 2.23 & 110.75 \\
\hline В1T887 & 3.25 & 12.75 & B1T8D9 & 2.73 & 112.75 \\
\hline В1T888 & 3.81 & 16.25 & B1T8F0 & 2.09 & 115.25 \\
\hline В1T889 & 4.56 & 18.25 & B1T8F1 & 2.23 & 117.75 \\
\hline В1Т890 & 14.3 & 20.25 & B1T8F2 & 1.87 & 120.25 \\
\hline В1Т891 & 11.4 & 23.25 & B1T8F3 & 2.42 & 123.25 \\
\hline B1T892 & 5.96 & 24.75 & B1T8F4 & 2.01 & 125.75 \\
\hline B1T893 & 14.2 & 28.25 & B1T8F5 & 2.17 & 127.75 \\
\hline В1T894 & 4.42 & 30.25 & B1T8F6 & 1.99 & 130.75 \\
\hline B1T895 & 8.87 & 32.75 & B1T8F7 & 3.65 & 132.75 \\
\hline B1T896 & 10.8 & 35.25 & B1T8F8 & 3.39 & 135.25 \\
\hline В1Т897 & 18.9 & 37.75 & B1T8F9 & 1.93 & 137.75 \\
\hline В1T898 & 3.47 & 40.25 & В1Т8H0 & 2.28 & 140.25 \\
\hline В1Т899 & 4.19 & 42.75 & В1Т8Н1 & 4.38 & 142.75 \\
\hline B1T8B0 & 4.14 & 45.25 & В1Т8Н2 & 2.21 & 145.75 \\
\hline B1T8B1 & 6.51 & 47.75 & В1Т8Н3 & 1.89 & 148.25 \\
\hline В1Т8B2 & 3.1 & 50.25 & В1Т8H4 & 2.11 & 150.25 \\
\hline В1T8B3 & 5.92 & 52.5 & В1T8H5 & 1.96 & 153.25 \\
\hline B1T8B4 & 6.46 & 55.25 & В1T8H6 & 3.52 & 155.25 \\
\hline B1T8B5 & 3.69 & 57.25 & B1T8H7 & 2.21 & 158.25 \\
\hline B1T8B6 & 4.76 & 60.5 & В1Т8Н8 & 2.07 & 160.25 \\
\hline B1T8B7 & 3.04 & 62.75 & В1Т8Н9 & 1.85 & 162.75 \\
\hline В1T8B8 & 3.28 & 65.75 & B1T8J0 & 1.78 & 162.75 \\
\hline В1Т8В9 & 3.37 & 65.75 & B1T8J1 & 2.25 & 165.75 \\
\hline B1T8C0 & 1.74 & 67.75 & B1T8J2 & 1.85 & 167.75 \\
\hline B1T8C1 & 1.64 & 70.25 & B1T8J3 & 2.01 & 170.25 \\
\hline B1T8C2 & 1.47 & 73.25 & B1T8J4 & 1.91 & 172.75 \\
\hline В1T8C3 & 1.7 & 75.75 & B1T8J5 & 1.72 & 175.25 \\
\hline
\end{tabular}


PNNL-17821

Table 7.1 (contd)

\begin{tabular}{cccccc}
\hline $\begin{array}{c}\text { Sample Name } \\
\text { (HEIS ID) }\end{array}$ & $\begin{array}{c}\text { Moisture Content } \\
\text { (Weight \%) }\end{array}$ & $\begin{array}{c}\text { Sample Mid Depth } \\
\text { (ft bgs) }\end{array}$ & $\begin{array}{c}\text { Sample Name } \\
\text { (HEIS ID) }\end{array}$ & $\begin{array}{c}\text { Moisture Content } \\
\text { (Weight \%) }\end{array}$ & $\begin{array}{c}\text { Sample Mid Depth } \\
\text { (ft bgs) }\end{array}$ \\
\hline B1T8C4 & 2.22 & 77.75 & B1T8J6 & 2.25 & 177.75 \\
B1T8C5 & 2.15 & 80.25 & B1T8J7 & 2.92 & 180.5 \\
B1T8C6 & 1.91 & 82.75 & B1T8J8 & 1.89 & 182.75 \\
B1T8C7 & 1.78 & 85.75 & B1T8J9 & 1.77 & 185.25 \\
B1T8C8 & 2.02 & 87.75 & B1T8K0 & 1.67 & 187.75 \\
B1T8C9 & 2.06 & 90.75 & B1T8K1 & 2.38 & 190.25 \\
B1T8D0 & 2.39 & 93.25 & B1T8K2 & 3.41 & 192.75 \\
B1T8D1 & 2.33 & 95.25 & B1T8K3 & 2.63 & 195.25 \\
B1T8D2 & 2.16 & 97.75 & B1T8K4 & 2.24 & 197.75 \\
B1T8D3 & 3.41 & 100.25 & B1T8K5 & 2.14 & 200.25 \\
B1T8D4 & 2.25 & 102.75 & B1T8K6 & 2.11 & 200.25 \\
B1T8D5 & 2.16 & 105.25 & B1T8K7 & 1.92 & 203.25 \\
\hline
\end{tabular}

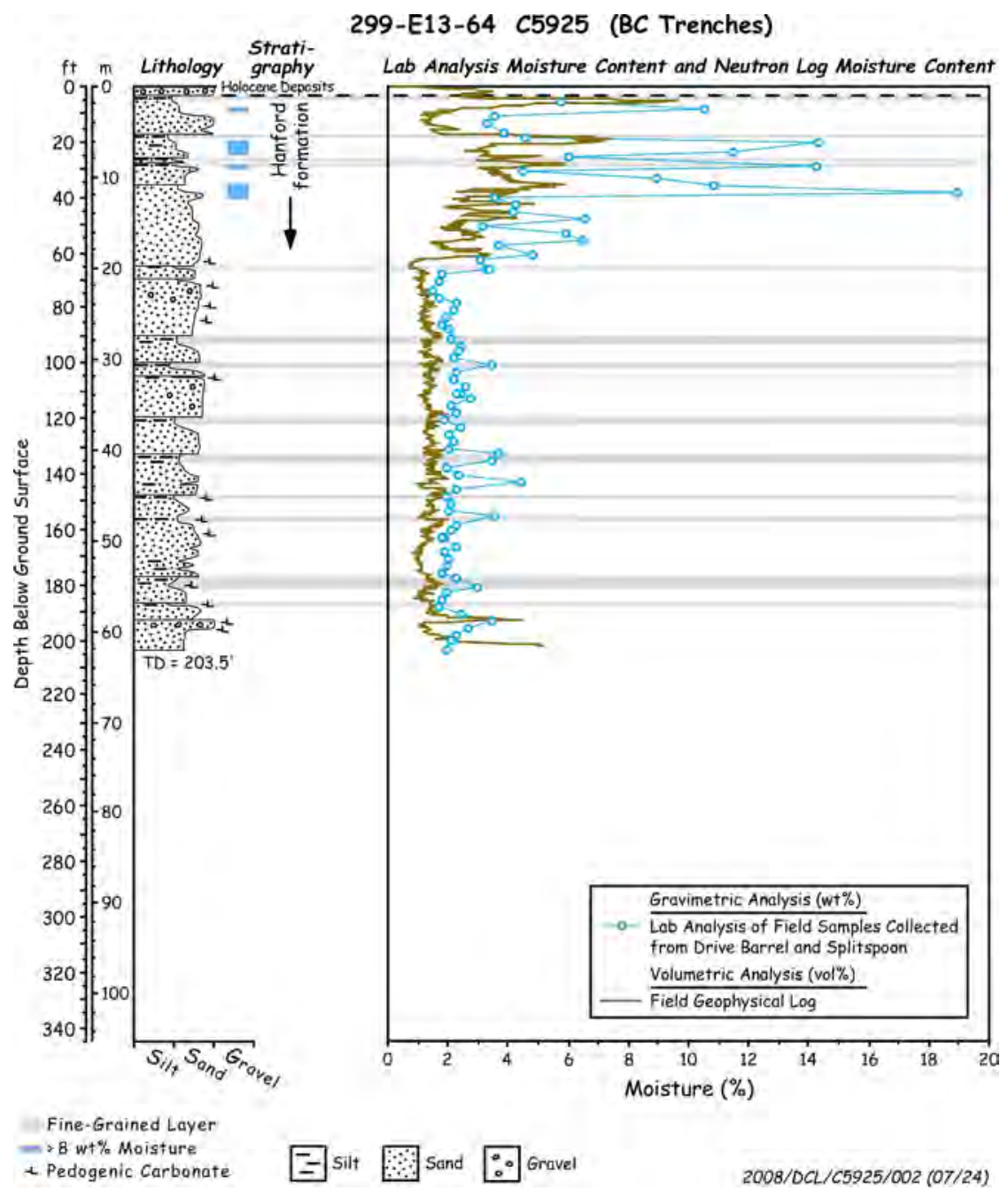

Figure 7.1. Laboratory and Field Measured Moisture Contents (wt\%) for Borehole C5925 (C) 


\subsubsection{1:1 Sediment: Water Extracts of Sediments from Borehole C (C5925)}

Several sediment samples (14) from Borehole C5925 (C) were characterized by performing 1:1 sediment: water extracts. Once the data on these 14 samples suggested that the borehole was either uncontaminated or at worst very faintly contaminated by fluids discharged to the BC Cribs and Trenches, further characterization was stopped. The following tables and figures present the mass of a given constituent leached per gram of sediment and as dilution-corrected concentrations in vadose zone pore water.

The $\mathrm{pH}$ and EC of the water extracts from select samples from Borehole C5925 (C) are shown in Table 7.2 and Figure 7.2. The measured water extract EC was corrected for the de-ionized water added to yield estimates of the pore-water EC. Pore-water EC estimates are reported in the last column in Table 7.2 and plotted in Figure 7.2. The $\mathrm{pH}$ profile is fairly constant with all values from 7.9 to 8.5 (the typical range for Hanford sediments), suggesting that no significant waste contact occurred in the sediments in this borehole.

Table 7.2. $\quad \mathrm{pH}$ for 1:1 Sediment: Water Extracts and Electrical Conductivity (EC) Values from Borehole C5925 (C)

\begin{tabular}{ccccc}
\hline Sample HEIS \# & Mid Depth (ft bgs) & pH & $\begin{array}{c}1: 1 \text { Electrical } \\
\text { Conductivity }(\mathrm{mS} / \mathrm{cm})\end{array}$ & $\begin{array}{c}\text { Pore water corrected } \\
\text { EC (mS/cm) }\end{array}$ \\
\hline B1T890 & 20.25 & 8.4 & 0.178 & 1.246 \\
B1T893 & 28.25 & 8.25 & 0.234 & 1.637 \\
B1T897 & 37.75 & 8.38 & 0.285 & 1.522 \\
B1T8B2 & 50.25 & 8.27 & 0.146 & 4.695 \\
\hline B1T8C5 & 80.25 & 8.57 & 0.147 & 6.710 \\
B1T8D3 & 100.25 & 8.13 & 0.188 & 5.481 \\
\hline B1T8D7 & 110.75 & 8.16 & 0.147 & 6.485 \\
B1T8F7 & 132.75 & 8.12 & 0.204 & 5.586 \\
\hline B1T8F8 & 135.25 & 7.89 & 0.199 & 6.247 \\
B1T8H1 & 142.75 & 8.04 & 0.208 & 4.720 \\
B1T8H6 & 155.25 & 8.06 & 0.182 & 5.174 \\
B1T8J3 & 170.25 & 7.95 & 0.138 & 6.728 \\
B1T8K2 & 192.75 & 8.24 & 0.191 & 5.626 \\
B1T8K7 & 203.25 & 8.11 & 0.164 & 8.286 \\
\hline
\end{tabular}

The pore-water-corrected EC data range from 1.2 to $8.8 \mathrm{mS} / \mathrm{cm}$ in the Hanford formation. Compared to the pore-water EC values for C5923, C5924, and C4191, the EC values for sediments in Borehole C5925 (C) are very low, consistent with the hypothesis that no waste plume is present or has percolated through these sediments. Pore water EC in sediments from C5925 is closely related to calculated ionic strength, which was dominated by sulfate, calcium, and sodium concentrations, rather than nitrate concentrations (Figure 7.2), again suggesting that these sediments have not been contacted with nitraterich waste fluids. If a waste plume had percolated through these sediments, high concentrations of waterleachable nitrate and sodium (at a somewhat shallower depth) and calcium (deeper than the sodium peak because of the ion exchange interactions ) should be found in pore water as shown in C5923, C5924, and C4191 constituent profiles. 


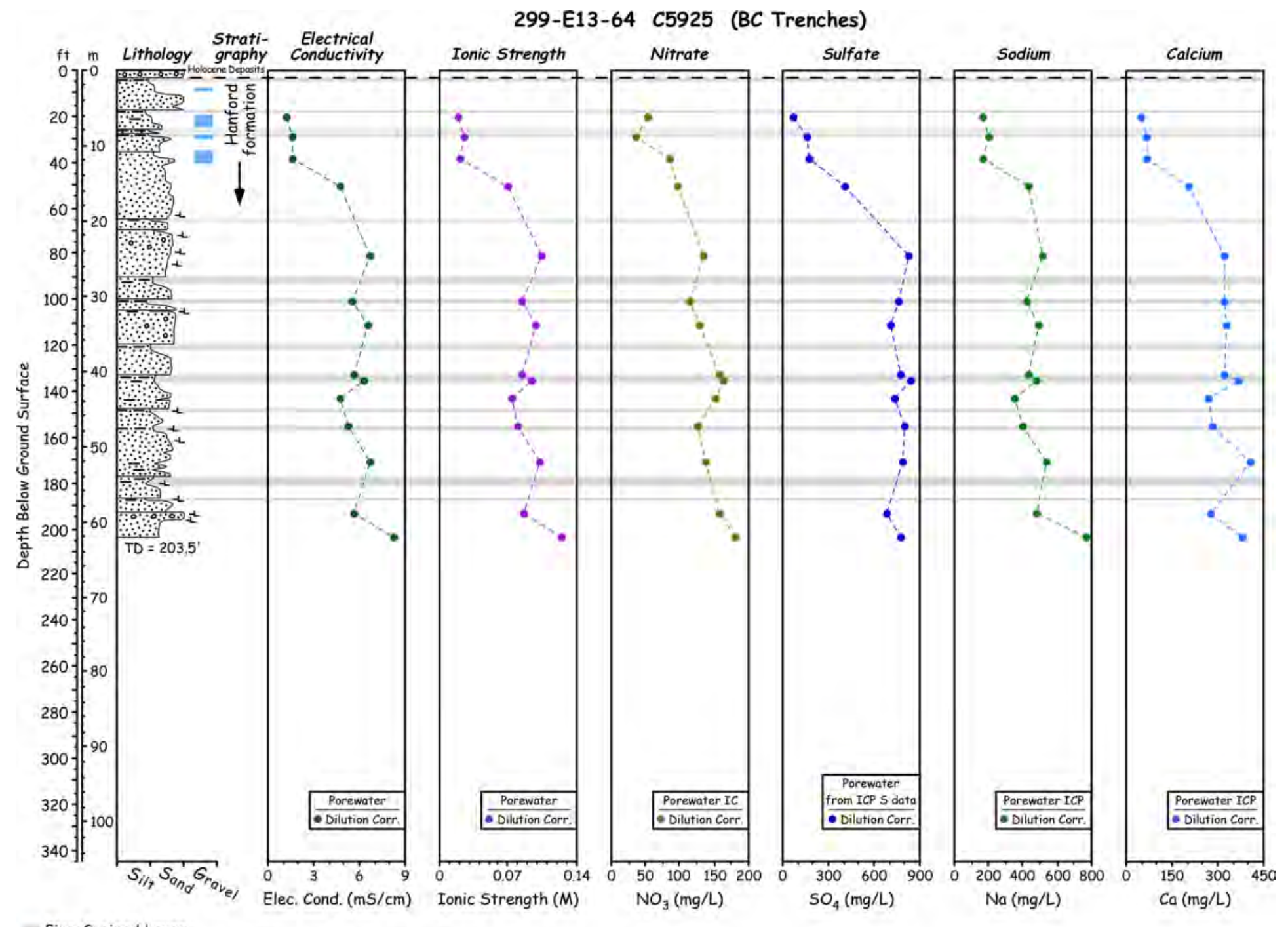

Fine-Grained Layer

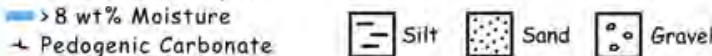

Figure 7.2. Pore water EC, Calculated Ionic Strength, and Concentrations of Nitrate, Sulfate, Sodium, and Calcium for Borehole C5925 (C) 


\subsubsection{Composition of the 1:1 Sediment:Water Extracts from Borehole C5925 (C)}

The concentrations of major anions, cations, commonly found contaminants and other trace constituents are discussed in this section. The anion data are tabulated in Table 7.3 in units of $\mathrm{mg} / \mathrm{L}$ as pore water and in Table 7.4 in units of mass per gram of dry sediment. Figure 7.2 and Figure 7.3 are plots of the key anion data from these two tables along with cations and key contaminants. Table 7.3 and Figure 7.2 present water-extract anion data in units of $\mathrm{mg} / \mathrm{L}$ pore-water concentrations, which are the units most related to the soil resistivity measurements.

In Table 7.3, sulfate concentrations measured by IC were compared with those calculated from total sulfur concentrations determined by ICP-OES. Assuming that all water leachable sulfur is in fact sulfate, the ICP method for determining sulfate has a more sensitive detection limit than the IC method when the water extracts contain high nitrate concentrations. Because there was no nitrate-rich waste plume in the C5925 sediments, the two sulfate-concentration results from two different methods are very similar (no comparison was $>20 \%$ in difference as seen in Table 7.3. Abnormally high sulfate and nitrate concentrations, indicative of waste disposal were not found in Borehole C5925 (C) sediments.

Table 7.4 and Figure 7.3 present the same water extract anion data but in units of $\mu \mathrm{g} / \mathrm{g}$ of dry sediment. Most of the nitrate concentrations in the sediment are below $10 \mu \mathrm{g} / \mathrm{g}$, which is consistent with uncontaminated Hanford formation sediments. Sulfate and carbonate are the dominant anions in Borehole C5925 (C) sediments in agreement with uncontaminated sediments.

Table 7.5 and Table 7.6 show the water-leachable concentrations of major divalent (Ca, Sr, and $\mathrm{Mg}$ ) and monovalent ( $\mathrm{Na}$ and $\mathrm{K}$ ) cations, in units of $\mu \mathrm{g}$ per gram of dry sediment and in units of $\mathrm{mg} / \mathrm{L}$ of pore water, respectively, for the grab samples analyzed from Borehole C5925 (C). Table 7.5 and Figure 7.4 indicate that no noticeable ion-exchange front is present. The equivalents of mono-and divalent cations remain fairly constant throughout the sediment profile. The relative $\%$ of monovalent to divalent cations is constant with an average of $70 \%$ with $\pm 10 \%$. Major monovalent and divalent cations as well as sodium and calcium concentrations in pore-water solutions show a similar pattern as a function of depth (Table 7.6 and Figure 7.4). Higher sodium concentrations were found in water extracts (and thus calculated pore water) than calcium for most of the sediments because calcium is more strongly retained as adsorbed species on the sediment's ion exchange sites. 


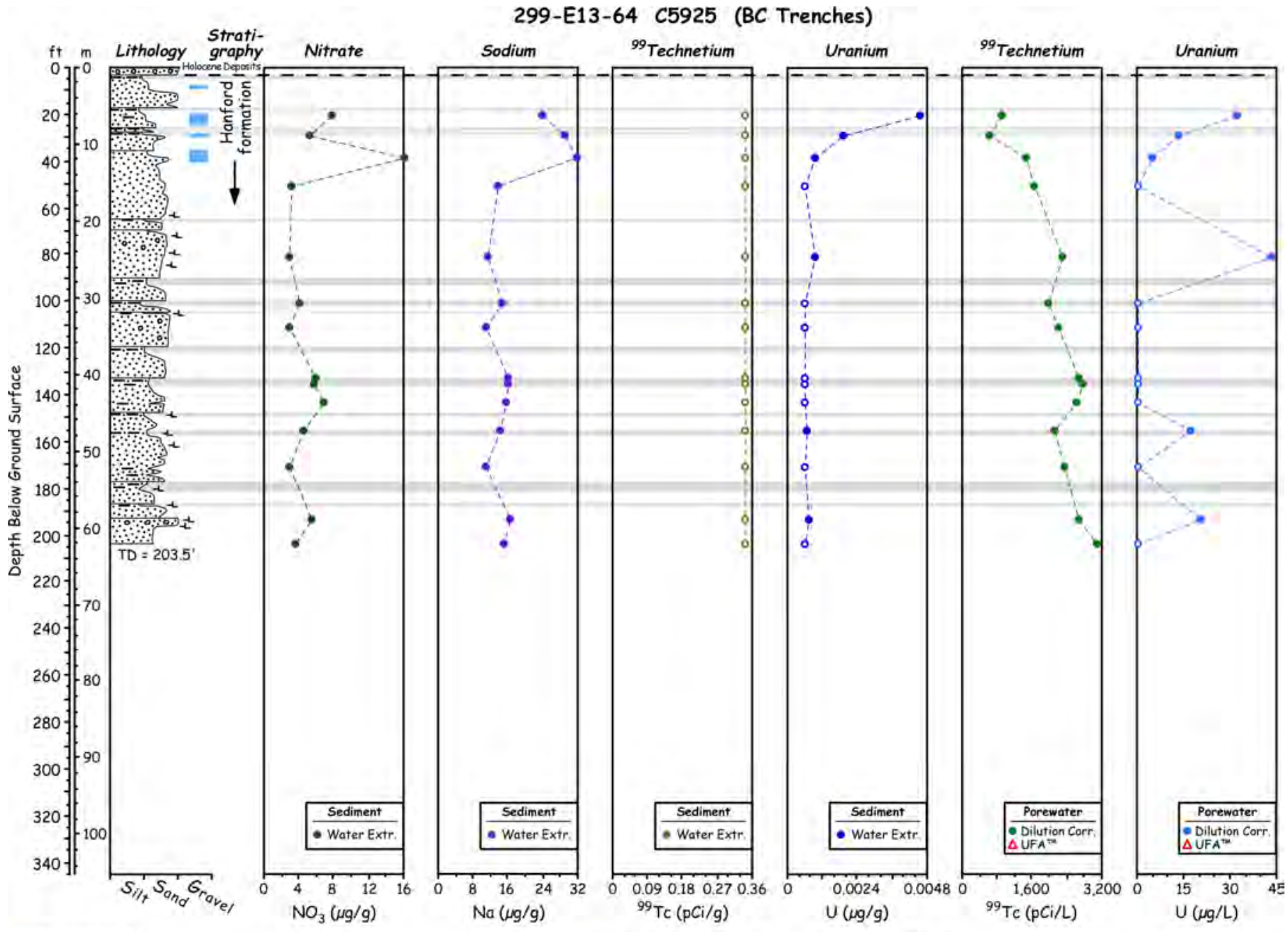

Fine-Grained Layer

$\rightarrow 8 \mathrm{wt} \%$ Moisture

国 silt ${ }^{\text {Sand }}:$ Gravel

000 = true value is "less than" the plotted detection value

Figure 7.3. Measured Nitrate, Sodium, Tc and U for Borehole C5925 (C) Sediments 
PNNL-17821

Table 7.3. Water-Extractable Anions Converted to Pore Water Concentrations for Borehole C5925 (C) Sediments (mg/L)

\begin{tabular}{|c|c|c|c|c|c|c|c|c|}
\hline Sample (HEIS ID) & Fluoride & Chloride & Nitrite & Nitrate & Sulfate-IC & Sulfate-ICP & Phosphate-IC & Alk $\left(\mathrm{CO}_{3}{ }^{2-}\right)$ \\
\hline B1T890 & 5.12 & 6.49 & ND & 53.59 & 69.62 & 83.78 & 5.43 & 473.30 \\
\hline В1T893 & 5.25 & 5.07 & ND & 35.75 & 162.89 & 180.78 & 4.95 & 537.03 \\
\hline В1T897 & 3.03 & 49.04 & ND & 84.39 & 171.68 & 189.73 & 3.98 & 361.14 \\
\hline B1T8B2 & 11.51 & 70.85 & ND & 95.16 & 409.98 & 471.35 & 9.46 & 1490.94 \\
\hline B1T8C5 & 17.44 & 56.05 & ND & 133.97 & 822.69 & 910.35 & 12.87 & 2081.38 \\
\hline B1T8D3 & 17.73 & 48.95 & ND & 114.61 & 761.04 & 818.61 & 20.29 & 1484.65 \\
\hline B1T8D7 & 18.71 & 49.85 & ND & 127.94 & 710.94 & 783.68 & 0.00 & 1978.18 \\
\hline B1T8F7 & 21.03 & 56.08 & 9.88 & 156.70 & 767.27 & 830.49 & 18.95 & 1415.04 \\
\hline B1T8F8 & 21.94 & 57.42 & ND & 162.84 & 839.49 & 886.09 & 10.64 & 1622.40 \\
\hline B1T8H1 & 14.82 & 51.58 & ND & 152.17 & 733.45 & 801.60 & 15.27 & 1172.71 \\
\hline В1T8H6 & 16.09 & 44.15 & ND & 123.69 & 802.21 & 871.28 & 19.30 & 1317.87 \\
\hline B1T8J3 & 23.45 & 50.36 & ND & 136.85 & 790.25 & 870.51 & 0.00 & 1889.71 \\
\hline B1T8K2 & 22.06 & 49.72 & ND & 157.09 & 674.20 & 731.79 & 18.65 & 1611.86 \\
\hline B1T8K7 & 32.84 & 65.23 & ND & 181.28 & 765.74 & 855.34 & 0.00 & 2611.08 \\
\hline
\end{tabular}

Table 7.4. Anion Composition of Water Extracts of Borehole C5925 (C) Sediment ( $\mu \mathrm{g} / \mathrm{g}$ dry sediment)

\begin{tabular}{|c|c|c|c|c|c|c|c|}
\hline Sample (HEIS ID) & $\begin{array}{l}\text { Mid Depth (ft } \\
\text { bgs) }\end{array}$ & Fluoride & Chloride & Nitrate & Sulfate-IC & Phosphate-IC & $\mathrm{Alk}\left(\mathrm{CO}_{3}{ }^{2-}\right)$ \\
\hline В1Т890 & 20.25 & 0.73 & 0.93 & 7.66 & 10.0 & 0.78 & 67.7 \\
\hline В1Т893 & 28.25 & 0.75 & 0.72 & 5.10 & 23.2 & 0.71 & 76.7 \\
\hline В1Т897 & 37.75 & 0.57 & 9.26 & 15.9 & 32.4 & 0.75 & 68.2 \\
\hline В1T8B2 & 50.25 & 0.36 & 2.21 & 2.97 & 12.8 & 0.29 & 46.5 \\
\hline В1T8C5 & 80.25 & 0.38 & 1.21 & 2.88 & 17.7 & 0.28 & 44.8 \\
\hline B1T8D3 & 100.25 & 0.61 & 1.68 & 3.93 & 26.1 & 0.70 & 50.9 \\
\hline B1T8D7 & 110.75 & 0.42 & 1.11 & 2.86 & 15.9 & ND & 44.2 \\
\hline B1T8F7 & 132.75 & 0.77 & 2.05 & 5.72 & 28.0 & 0.69 & 51.6 \\
\hline B1T8F8 & 135.25 & 0.74 & 1.94 & 5.51 & 28.4 & 0.36 & 54.9 \\
\hline В1T8H1 & 142.75 & 0.65 & 2.27 & 6.69 & 32.2 & 0.67 & 51.6 \\
\hline В1Т8H6 & 155.25 & 0.57 & 1.55 & 4.36 & 28.2 & 0.68 & 46.4 \\
\hline В1T8J3 & 170.25 & 0.47 & 1.01 & 2.75 & 15.9 & ND & 38.0 \\
\hline В1T8K2 & 192.75 & 0.75 & 1.69 & 5.33 & 22.9 & 0.63 & 54.7 \\
\hline B1T8K7 & 203.25 & 0.64 & 1.27 & 3.52 & 14.9 & ND & 50.6 \\
\hline
\end{tabular}


PNNL-17821

Table 7.5. Water-Extractable Cations in Borehole C5925 (C) Sediments ( $\mu \mathrm{g} / \mathrm{g}$ dry soil)

\begin{tabular}{lrccccc}
\hline Sample HEIS \# & Mid Depth $(\mathrm{ft}$ bgs) & $\mathrm{Ca}(\mu \mathrm{g} / \mathrm{g})$ & $\mathrm{Mg}(\mu \mathrm{g} / \mathrm{g})$ & $\mathrm{Sr}(\mu \mathrm{g} / \mathrm{g})$ & $\mathrm{Na}(\mu \mathrm{g} / \mathrm{g})$ & $\mathrm{K}(\mu \mathrm{g} / \mathrm{g})$ \\
\hline B1T890 & 20.25 & 6.66 & 0.98 & $3.13 \mathrm{E}-04$ & 23.70 & 3.39 \\
B1T893 & 28.25 & 9.55 & 1.61 & $1.36 \mathrm{E}-02$ & 29.00 & 4.74 \\
B1T897 & 37.75 & 13.00 & 2.52 & $3.78 \mathrm{E}-02$ & 31.80 & 5.46 \\
B1T8B2 & 50.25 & 6.36 & 2.12 & $1.40 \mathrm{E}-02$ & 13.50 & 4.17 \\
B1T8C5 & 80.25 & 6.96 & 2.85 & $1.82 \mathrm{E}-02$ & 11.10 & 3.69 \\
B1T8D3 & 100.25 & 10.90 & 3.28 & $3.13 \mathrm{E}-02$ & 14.40 & 3.83 \\
B1T8D7 & 110.75 & 7.34 & 2.64 & $1.32 \mathrm{E}-02$ & 10.80 & 3.53 \\
B1T8F7 & 132.75 & 11.60 & 3.57 & $3.18 \mathrm{E}-02$ & 15.80 & 3.69 \\
B1T8F8 & 135.25 & 12.40 & 3.58 & $3.39 \mathrm{E}-02$ & 16.00 & 3.74 \\
B1T8H1 & 142.75 & 11.90 & 3.92 & $3.28 \mathrm{E}-02$ & 15.50 & 3.88 \\
B1T8H6 & 155.25 & 9.85 & 3.34 & $2.58 \mathrm{E}-02$ & 13.80 & 3.40 \\
B1T8J3 & 170.25 & 8.17 & 2.33 & $1.75 \mathrm{E}-02$ & 10.90 & 2.81 \\
B1T8K2 & 192.75 & 9.38 & 3.32 & $2.78 \mathrm{E}-02$ & 16.30 & 4.50 \\
B1T8K7 & 203.25 & 7.36 & 2.74 & $1.58 \mathrm{E}-02$ & 14.80 & 5.40 \\
\hline
\end{tabular}


PNNL-17821

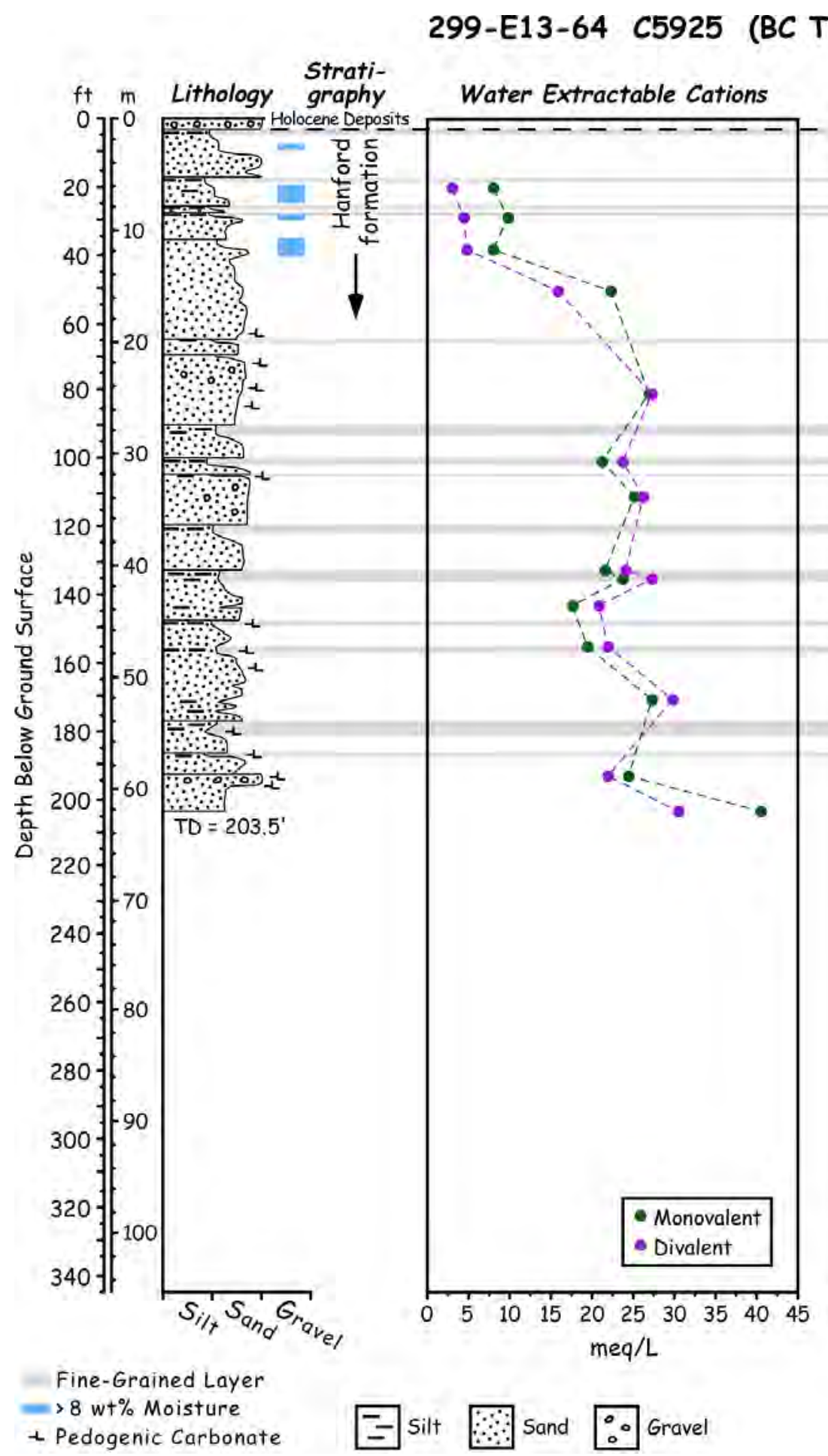

Monovalent Water Extr. Cations

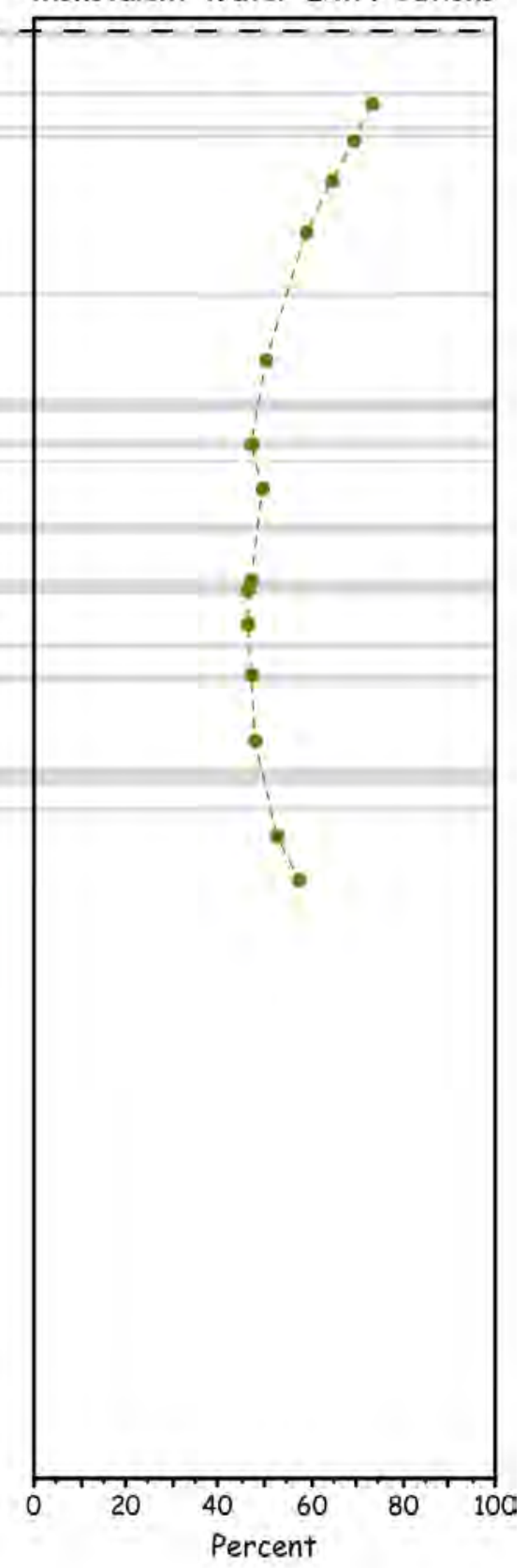

Figure 7.4. Water-Leachable Mono-Valent and Divalent Cations for Borehole C5925 (C) Sediments 
Table 7.6. Water-Extractable Cations as Pore Water Concentrations in Borehole C5925 (C) Sediments $(\mathrm{mg} / \mathrm{L})$

\begin{tabular}{lcccccc}
\hline Sample HEIS \# & $\begin{array}{c}\text { Mid Depth (ft } \\
\text { bgs) }\end{array}$ & Ca (mg/L) & Mg $(\mathrm{mg} / \mathrm{L})$ & $\mathrm{Sr}(\mathrm{mg} / \mathrm{L})$ & $\mathrm{Na}(\mathrm{mg} / \mathrm{L})$ & $\mathrm{K}(\mathrm{mg} / \mathrm{L})$ \\
\hline B1T890 & 20.25 & 46.6 & 6.9 & $2.19 \mathrm{E}-03$ & 166.0 & 23.7 \\
B1T893 & 28.25 & 66.9 & 11.3 & $9.53 \mathrm{E}-02$ & 203.0 & 33.2 \\
B1T897 & 37.75 & 68.7 & 13.3 & $2.00 \mathrm{E}-01$ & 168.0 & 28.9 \\
B1T8B2 & 50.25 & 204.0 & 68.0 & $4.50 \mathrm{E}-01$ & 432.0 & 134.0 \\
B1T8C5 & 80.25 & 323.0 & 132.0 & $8.44 \mathrm{E}-01$ & 516.0 & 171.0 \\
B1T8D3 & 100.25 & 318.0 & 95.6 & $9.12 \mathrm{E}-01$ & 420.0 & 112.0 \\
B1T8D7 & 110.75 & 329.0 & 118.0 & $5.90 \mathrm{E}-01$ & 484.0 & 158.0 \\
B1T8F7 & 132.75 & 319.0 & 97.8 & $8.71 \mathrm{E}-01$ & 434.0 & 101.0 \\
B1T8F8 & 135.25 & 367.0 & 106.0 & $1.00 \mathrm{E}+00$ & 474.0 & 110.0 \\
B1T8H1 & 142.75 & 270.0 & 89.2 & $7.47 \mathrm{E}-01$ & 353.0 & 88.3 \\
B1T8H6 & 155.25 & 280.0 & 94.8 & $7.33 \mathrm{E}-01$ & 392.0 & 96.5 \\
B1T8J3 & 170.25 & 406.0 & 116.0 & $8.69 \mathrm{E}-01$ & 539.0 & 139.0 \\
B1T8K2 & 192.75 & 276.0 & 97.8 & $8.18 \mathrm{E}-01$ & 480.0 & 132.0 \\
B1T8K7 & 203.25 & 379.0 & 141.0 & $8.17 \mathrm{E}-01$ & 764.0 & 279.0 \\
\hline
\end{tabular}

Other water-extractable chemical species, such as aluminum, silicon, iron, manganese, zinc, and trace constituents, such as arsenic, boron, barium, beryllium, bismuth, cadmium, cobalt, chromium, copper, lithium, molybdenum, nickel, lead, selenium, thallium, vanadium, titanium, and zirconium, were measured, but their concentrations were generally low to non-detectable. The only potential radiological COCs in the water extracts were technetium-99 and uranium, and their concentrations on both a per gram of sediment basis and as pore water concentrations are listed in Table 7.7 and Figure 7.3. Both technetium-99 and uranium data show no elevated radioactivity in water extracts.

The total ionic strength of the calculated pore waters in the vadose zone profile at Borehole C5925 (C) are shown in Figure 7.2 and Table 7.7. The total ionic strength distribution ranges from 0.019 to 0.12 $\mathrm{M}$, which is in the range of uncontaminated Hanford formation pore-water values. Because of the low ionic strengths, the reciprocal of the inverted field-measured resistivity (becomes conductivity via taking the reciprocal) shows the low values for most of the sediments from Borehole C5925 (C) (Figure 7.5). The reciprocal of the inverted 2D resistivity is rather featureless from $15 \mathrm{ft}$ bgs and below where all the samples analyzed in the laboratory were taken. The apparent high conductivity in the very shallow sediments shown in the plot of the reciprocal of the inverted field data might reflect very near-surface salt from natural evaporative processes or, alternatively, some artifact in the inversion. As stated, the shallowest grab sample analyzed in the laboratory was from $20.25 \mathrm{ft}$ bgs. Section 8.2 of this report provides additional discussion on correlating the laboratory-generated data on sediment water extracts with the HRR field data.

\subsection{4 $8 \mathrm{M}$ Nitric Acid Extractable Amounts of Selected Elements}

The amount of material that was extractable from the vadose zone sediment into $8 \mathrm{M}$ nitric acid is shown in Table 7.8 through Table 7.10. The $8 \mathrm{M}$ nitric acid extraction is a protocol used by the U.S. Environmental Protection Agency to estimate the maximum (or total) concentrations of regulated metals 
in contaminated sediment that would be biologically available. Aliquots of sediment from Borehole C5925 (C) were subjected to the acid extraction to look for elevated quantities of selected constituents and radionuclides.

The acid extract data for grab samples from Borehole C5925 (C) in general showed slightly higher values in the shallow region from 27 to $38 \mathrm{ft}$ bgs for a few constituents (see the bold type in the tables) relative to the deeper sediments. However, we do not believe these higher concentrations are related to disposed wastes, but rather are caused by the presence of more fine-grained sediments that naturally contain higher concentrations of the constituents. Further, compared to the shallow sediments from borehole C4191 (see Section 8.1-3), emplaced directly in the footprint of the 216-B-26 trench, the acidextract concentrations of those elements noted in bold in Table 7.8 through Table 7.10 are about a factor of 10 to 100 lower. Assuming that the acid-extractable concentrations shown in Section 8.1.3 for the C4191 shallow sediments represent typical concentrations of the listed constituents when waste is present, the concentrations shown in bold type are much lower. The one exception is the acid-leachable calcium concentration for sample B1T893 (see Table 7.8). The high-acid-extractable calcium in this sample is likely caused by the presence of calcite in the sample. As shown in Appendix A, this sample was a slightly muddy fine sand that showed a strong reaction to contact with several drops of dilute hydrochloric acid, which indicates the presence of calcium carbonate. Also, no detectable Hg was found in the acid extracts from Borehole C5925 (C) sediments (Table 7.9). Therefore, the sediments in the BC Cribs and Trenches area outside the footprints of the inactive trenches and cribs do not appear to contain measureable concentrations of mercury. The sediments at borehole C5925 also do not contain detectable technetium-99 or elevated amounts of acid-leachable uranium, again suggesting that the sediment at this location down to the total depth of the borehole is not significantly impacted by past waste-disposal activities. Further, based on finding the deepest impact of waste salts to have reached

Table 7.7. Water-Extractable Radionuclides and Pore Water Total Ionic Strength for Borehole C5925 (C)

\begin{tabular}{ccccccr}
\hline $\begin{array}{c}\text { Sample (HEIS } \\
\text { ID) }\end{array}$ & $\begin{array}{c}\text { Mid Depth } \\
(\mathrm{ft} b g s)\end{array}$ & $\begin{array}{c}\text { Tc } 99 \\
(\mathrm{pCi} / \mathrm{g})\end{array}$ & $\mathrm{U}(\mu \mathrm{g} / \mathrm{g})$ & Tc 99 $(\mathrm{pCi} / \mathrm{L})$ & $\mathrm{U}(\mu \mathrm{g} / \mathrm{L})$ & $\begin{array}{c}\text { PW Ionic } \\
\text { Strength }(\mathrm{M})\end{array}$ \\
\hline B1T890 & 20.25 & $<3.4 \mathrm{E}-01$ & $4.55 \mathrm{E}-03$ & $<2.38 \mathrm{E}+03$ & $3.18 \mathrm{E}+01$ & $1.89 \mathrm{E}-02$ \\
B1T893 & 28.25 & $<3.4 \mathrm{E}-01$ & $1.88 \mathrm{E}-03$ & $<2.38 \mathrm{E}+03$ & $1.32 \mathrm{E}+01$ & $2.44 \mathrm{E}-02$ \\
B1T897 & 37.75 & $<3.4 \mathrm{E}-01$ & $9.01 \mathrm{E}-04$ & $<1.82 \mathrm{E}+03$ & $4.77 \mathrm{E}+00$ & $2.14 \mathrm{E}-02$ \\
B1T8B2 & 50.25 & $<3.4 \mathrm{E}-01$ & $2.80 \mathrm{E}-04$ & $<1.09 \mathrm{E}+04$ & $8.98 \mathrm{E}+00$ & $6.90 \mathrm{E}-02$ \\
B1T8C5 & 80.25 & $<3.4 \mathrm{E}-01$ & $9.27 \mathrm{E}-04$ & $<1.55 \mathrm{E}+04$ & $4.31 \mathrm{E}+01$ & $1.04 \mathrm{E}-01$ \\
B1T8D3 & 100.25 & $<3.4 \mathrm{E}-01$ & $5.63 \mathrm{E}-04$ & $<9.91 \mathrm{E}+03$ & $1.64 \mathrm{E}+01$ & $8.41 \mathrm{E}-02$ \\
B1T8D7 & 110.75 & $<3.4 \mathrm{E}-01$ & $4.67 \mathrm{E}-04$ & $<1.50 \mathrm{E}+04$ & $2.09 \mathrm{E}+01$ & $9.68 \mathrm{E}-02$ \\
B1T8F7 & 132.75 & $<3.4 \mathrm{E}-01$ & $5.63 \mathrm{E}-04$ & $<9.31 \mathrm{E}+03$ & $1.54 \mathrm{E}+01$ & $8.38 \mathrm{E}-02$ \\
B1T8F8 & 135.25 & $<3.4 \mathrm{E}-01$ & $5.41 \mathrm{E}-04$ & $<1.07 \mathrm{E}+04$ & $1.60 \mathrm{E}+01$ & $9.29 \mathrm{E}-02$ \\
B1T8H1 & 142.75 & $<3.4 \mathrm{E}-01$ & $5.62 \mathrm{E}-04$ & $<7.72 \mathrm{E}+03$ & $1.28 \mathrm{E}+01$ & $7.28 \mathrm{E}-02$ \\
B1T8H6 & 155.25 & $<3.4 \mathrm{E}-01$ & $5.99 \mathrm{E}-04$ & $<9.67 \mathrm{E}+03$ & $1.70 \mathrm{E}+01$ & $7.90 \mathrm{E}-02$ \\
B1T8J3 & 170.25 & $<3.4 \mathrm{E}-01$ & $3.16 \mathrm{E}-04$ & $<1.66 \mathrm{E}+04$ & $1.57 \mathrm{E}+01$ & $1.02 \mathrm{E}-01$ \\
B1T8K2 & 192.75 & $<3.4 \mathrm{E}-01$ & $6.79 \mathrm{E}-04$ & $<1.00 \mathrm{E}+04$ & $2.00 \mathrm{E}+01$ & $8.49 \mathrm{E}-02$ \\
B1T8K7 & 203.25 & $<3.4 \mathrm{E}-01$ & $2.31 \mathrm{E}-04$ & $<1.72 \mathrm{E}+04$ & $1.19 \mathrm{E}+01$ & $1.24 \mathrm{E}-01$ \\
\hline
\end{tabular}




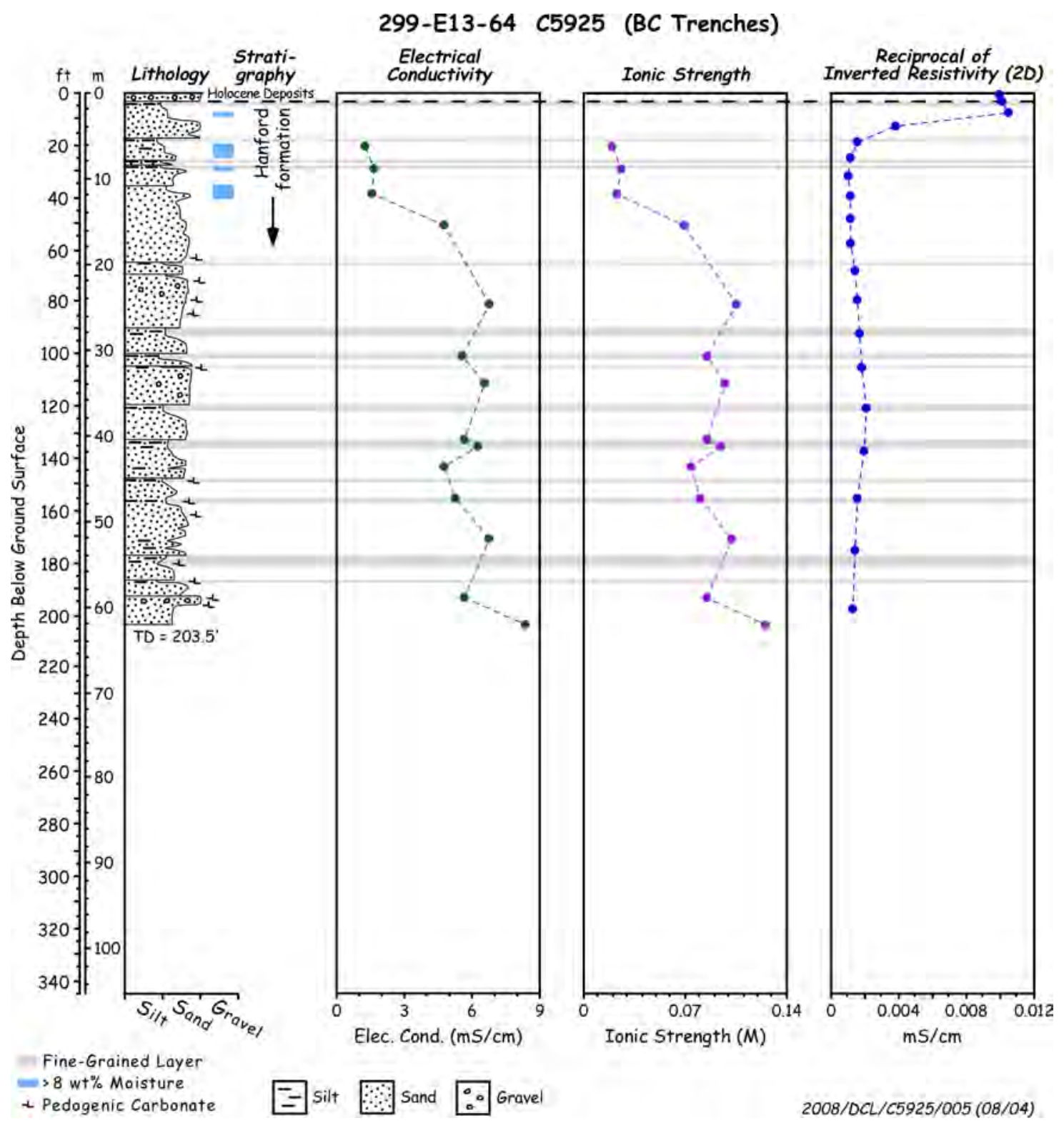

Figure 7.5. $\quad$ Pore water EC, Ionic Strength, and Field Measured Reciprocal Inverted Resistivity (2D) for Borehole C5925 (C)

$\sim 130 \mathrm{ft}$ bgs at borehole C5924 and $160 \mathrm{ft}$ bgs at C4191, it is highly unlikely that wastes are present below the depth penetrated by borehole C5925 (203.5 ft bgs) unless crib waste has migrated in an easterly to south-easterly direction from the cribs in the northeast corner of the BC Cribs and Trenches area. 
Table 7.8. Acid-Extractable Light Elements in Borehole C5925 (C) Sediments ( $\mu$ g/g dry sediment)

\begin{tabular}{cccccccccc}
\hline $\begin{array}{c}\text { Sample } \\
\text { (HEIS ID) }\end{array}$ & $\begin{array}{c}\text { Mid- } \\
\text { Depth } \\
\text { (ft bgs) }\end{array}$ & $\mathrm{Na}$ & $\mathrm{Mg}$ & $\mathrm{Al}$ & $\mathrm{P}$ & $\mathrm{S}$ & $\mathrm{K}$ & $\mathrm{Ca}$ & $\mathrm{Ti}$ \\
\hline B1T893 & 28.25 & $\mathbf{2 6 6}$ & 4100 & $\mathbf{6 1 9 0}$ & $\mathbf{7 0 5}$ & $<80$ & 1250 & $\mathbf{1 2 8 0 0}$ & $\mathbf{5 7 9}$ \\
B1T897 & 37.75 & $\mathbf{2 9 4}$ & 3660 & $\mathbf{6 2 5 0}$ & $\mathbf{6 9 9}$ & $<80$ & 1080 & $\mathbf{9 2 9 0}$ & $\mathbf{7 6 0}$ \\
B1T8B2 & 50.25 & 136 & 3290 & 4070 & 358 & $<80$ & 900 & 7380 & 362 \\
B1T8C5 & 80.25 & 122 & 3240 & 4350 & 328 & $<80$ & 1060 & 8270 & 406 \\
B1T8D7 & 110.75 & 129 & 3950 & 5080 & 417 & $<80$ & 1230 & 8490 & 361 \\
B1T8F8 & 135.25 & 136 & 3890 & 5610 & 385 & $<80$ & 1890 & 6090 & 410 \\
B1T8J3 & 170.25 & 120 & 3200 & 4030 & 304 & $<80$ & 978 & 5840 & 307 \\
B1T8K7 & 203.25 & 168 & 3060 & 4500 & 339 & $<80$ & 1270 & 6430 & 415 \\
\hline
\end{tabular}

Table 7.9. Acid-Extractable Heavy Elements in Borehole C5925 (C) Sediments ( $\mu$ g/g dry sediment)

\begin{tabular}{ccrrrrrrr}
\hline $\begin{array}{c}\text { Sample } \\
\text { (HEIS ID) }\end{array}$ & $\begin{array}{c}\text { Mid- } \\
\text { Depth }(\mathrm{ft} \\
\text { bgs) }\end{array}$ & \multicolumn{1}{c}{ V } & Mn & Fe & Co & Sr & Zr & Hg \\
\hline B1T893 & 28.25 & $\mathbf{2 1 . 5}$ & $\mathbf{3 4 9}$ & $\mathbf{1 5 4 0 0}$ & 11.6 & 36.1 & $\mathbf{8 . 8 7}$ & $<0.02$ \\
B1T897 & 37.75 & $\mathbf{2 7 . 4}$ & $\mathbf{3 4 7}$ & $\mathbf{1 6 0 0 0}$ & 11.9 & 32.5 & $\mathbf{9 . 4 4}$ & $<0.02$ \\
B1T8B2 & 50.25 & 9.8 & 196 & 8640 & 5.89 & 26.4 & 3.39 & $<0.02$ \\
B1T8C5 & 80.25 & 10.1 & 193 & 8510 & 6.03 & 36.2 & 4.16 & $<0.02$ \\
B1T8D7 & 110.75 & 10.2 & 231 & 9830 & 6.92 & 25.5 & 3.70 & $<0.02$ \\
B1T8F8 & 135.25 & 12.7 & 234 & 9900 & 7.69 & 24.5 & 2.77 & $<0.02$ \\
B1T8J3 & 170.25 & 9.8 & 191 & 7310 & 5.75 & 23.9 & 2.11 & $<0.02$ \\
B1T8K7 & 203.25 & 12.4 & 206 & 8410 & 6.45 & 25.8 & 3.93 & $<0.02$ \\
\hline
\end{tabular}

Table 7.10.Acid Extractable Content for RCRA Metals and Uranium in Borehole C5925 (C) (units $\mu \mathrm{g} / \mathrm{g}$ )

\begin{tabular}{lccccc}
\hline \multicolumn{1}{c}{ Sample (HEIS ID) } & $\begin{array}{c}\text { Mid-Depth (ft } \\
\text { bgs) }\end{array}$ & $\mathrm{Cr}$ & $\mathrm{Cd}$ & $\mathrm{Pb}$ & $\mathrm{U} 238$ \\
\hline B1T893 & 28.25 & 6.64 & 0.097 & $\mathbf{4 . 2 8}$ & $3.64 \mathrm{E}-01$ \\
B1T897 & 37.75 & 5.23 & 0.074 & 2.81 & $3.29 \mathrm{E}-01$ \\
B1T8B2 & 50.25 & 6.32 & 0.055 & 2.75 & $2.83 \mathrm{E}-01$ \\
B1T8C5 & 80.25 & 6.21 & 0.053 & 2.31 & $3.03 \mathrm{E}-01$ \\
B1T8D7 & 110.75 & 8.53 & 0.068 & 3.38 & $3.25 \mathrm{E}-01$ \\
B1T8F8 & 135.25 & 10.8 & 0.088 & 2.83 & $3.59 \mathrm{E}-01$ \\
B1T8J3 & 170.25 & 8.3 & 0.059 & 1.9 & $2.36 \mathrm{E}-01$ \\
B1T8K7 & 203.25 & 7.54 & 0.052 & 2.25 & $4.11 \mathrm{E}-01$ \\
\hline
\end{tabular}

\subsubsection{Radionuclide Content in Vadose Zone Sediment from Borehole C5925 (C)}

The sediment from Borehole C5925 (C) did not contain measurable concentrations of man-made gamma, nickel-63, or strontium-90 radioactivity in the grab samples analyzed by PNNL's ESL laboratory (Table 7.11 and Table 7.12). GEAs were performed only on shallow samples based on the fact that manmade gamma nuclides were only found in the shallow sediments at the other boreholes in the BC Cribs 
and Trenches area. Natural concentrations of potassium-40 and several daughter products of uranium-238 and thorium-232 were found in the sediments analyzed by GEA as would be expected. Wet chemical separations were performed on aliquots of the $8 \mathrm{M}$ nitric acid sediment extracts to look for nickel-63 and strontium-90, but none was found. For one sample, B1T8C5, the nickel-63 analyses contained some type of interference that raised the liquid scintillation background to a value about 4 times higher than for all other acid extracts.

Table 7.11.Man-Made Fission Product GEA Data (pCi/g sed) for Grab Samples from Borehole C5925 (C)

\begin{tabular}{|c|c|c|c|c|}
\hline Sample (HEIS ID) & Mid-Depth (ft bgs) & Sb-125 & Cs-137 & Eu-155 \\
\hline B1T884 & 5.25 & $<0.45$ & $<0.16$ & $<0.60$ \\
\hline B1T885 & 7.75 & $<0.35$ & $<0.13$ & $<0.44$ \\
\hline B1T886 & 10.25 & $<0.44$ & $<0.16$ & $<0.58$ \\
\hline B1T887 & 12.75 & $<0.35$ & $<0.12$ & $<0.40$ \\
\hline B1T888 & 16.25 & $<0.43$ & $<0.15$ & $<0.59$ \\
\hline
\end{tabular}

Table 7.12. Fission Product Data (pCi/g sed) for Grab Samples from Borehole C5925 (C)

\begin{tabular}{lcccc}
\hline \multicolumn{1}{c}{ Sample (HEIS ID) } & $\begin{array}{c}\text { Mid-Depth (ft } \\
\text { bgs) }\end{array}$ & Ni-63 & Sr-90 & Tc- 99 \\
\hline B1T893 & 28.25 & $<11.9$ & $<9.26$ & $3.392 \mathrm{E}+01$ \\
B1T897 & 37.75 & $<11.5$ & $<8.6$ & $<1.70 \mathrm{E}+01$ \\
B1T8B2 & 50.25 & $<10.4$ & $<8.96$ & $<1.70 \mathrm{E}+01$ \\
B1T8C5 & 80.25 & $<40.7$ & $<9.23$ & $<1.70 \mathrm{E}+01$ \\
B1T8D7 & 110.75 & $<10.9$ & $<9.48$ & $<1.70 \mathrm{E}+01$ \\
B1T8F8 & 135.25 & $<10.9$ & $<9.35$ & $<1.70 \mathrm{E}+01$ \\
B1T8J3 & 170.25 & $<10.4$ & $<9.02$ & $<1.70 \mathrm{E}+01$ \\
B1T8K7 & 203.25 & $<10.6$ & $<9.22$ & $<1.70 \mathrm{E}+01$ \\
\hline
\end{tabular}

\subsection{Field Resistivity Results at Borehole C (C5925)}

\subsubsection{HRR at Borehole C5925 (C)}

Figure 7.6 shows the HRR apparent-resistivity results for FY06-Line 1 and FY06-Line 2. Borehole C5925 (C) was placed at the intersection of both lines. Low-resistivity values can be seen in the center of the sections. In FY06-Line 1, the apparent-resistivity values go to background conditions north of station 500. In Line FY06-2, background conditions resume east of station 500, which is east of the BC cribs area. Background is generally considered to be reached at apparent-resistivity values above 500 ohm-m.

Borehole C5925 (C) was placed $384 \mathrm{~m}$ from the southern edge of FY06-Line 1 and $344 \mathrm{~m}$ from the western boundary of FY06-Line 2. The HRR data show a low-resistivity target at Borehole C5925 (C), which is likely the result of out-of-plane effects in FY06-Line1 or superposition in FY06-Line 2. In FY06-Line 2, the low resistivity beneath the cribs to the east and trenches to the west form an additive effect at Borehole C5925 (C). If this were a true anomaly, the same large low-resistivity feature would be visible in FY06-Line 1. Instead, a weak response is seen and is most likely from the adjacent cribs area. However, there is a deep low-resistivity feature seen in FY06-Line 1 at station 300. This feature is the 
result of the superposition of the water table and the low-resistivity anomaly at station 425. As discussed in Section 7.2.3, 3D inversion reconciles the out-of-plane effects and superposition problems.

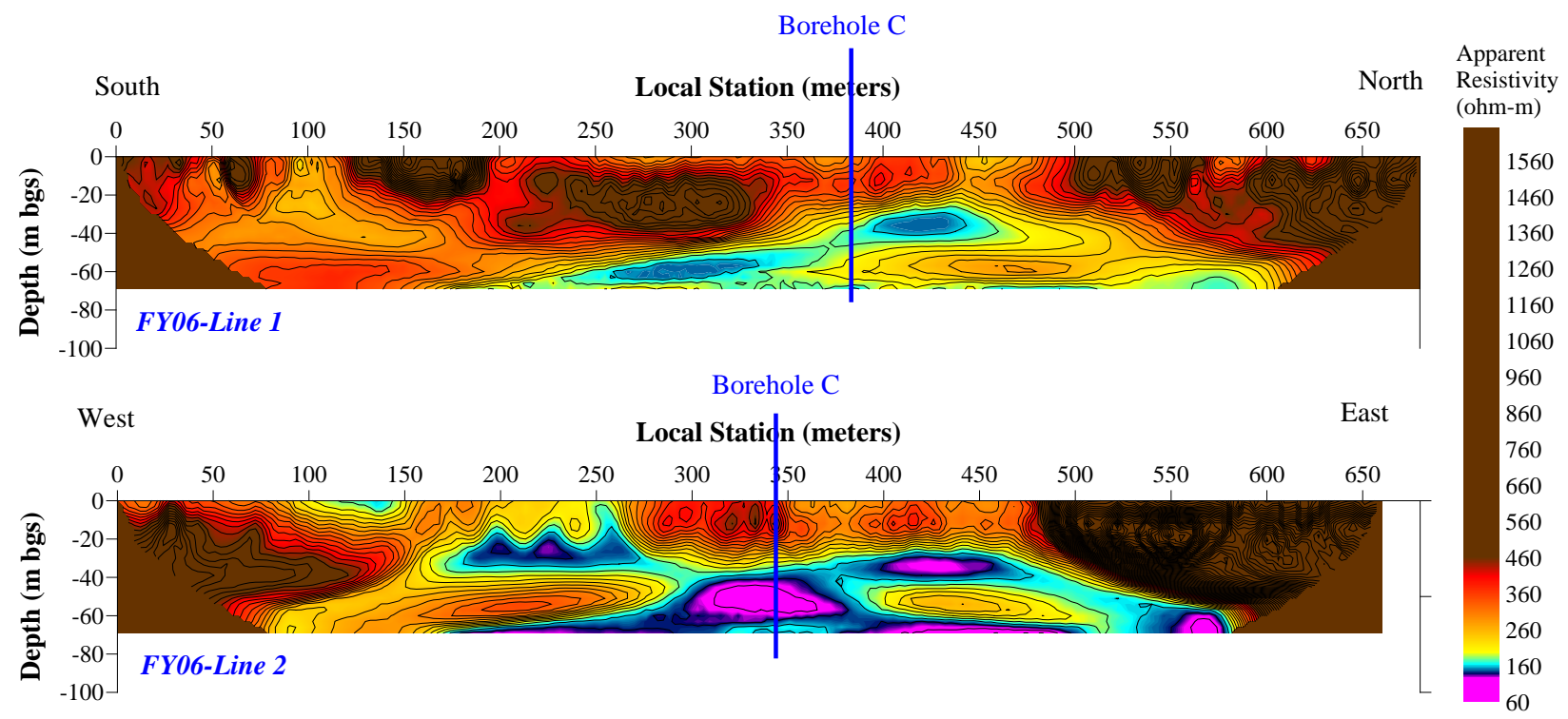

Figure 7.6. HRR Results of FY06-Line 1 and FY06-Line 2

Figure 7.7 shows the extracted apparent-resistivity data profile at Borehole C5925 (C) along both lines. The differences in target strength between the two HRR datasets are clearly seen. The grab samples from which the individual geochemical pore-water species in Borehole C5925 (C) were measured were collected at a lower spatial frequency and at different depths than the field-acquired data. To calculate correlations and to develop the empirical models, the measured field geophysical data were re-sampled at the soil sampling depths with linear interpolation. 


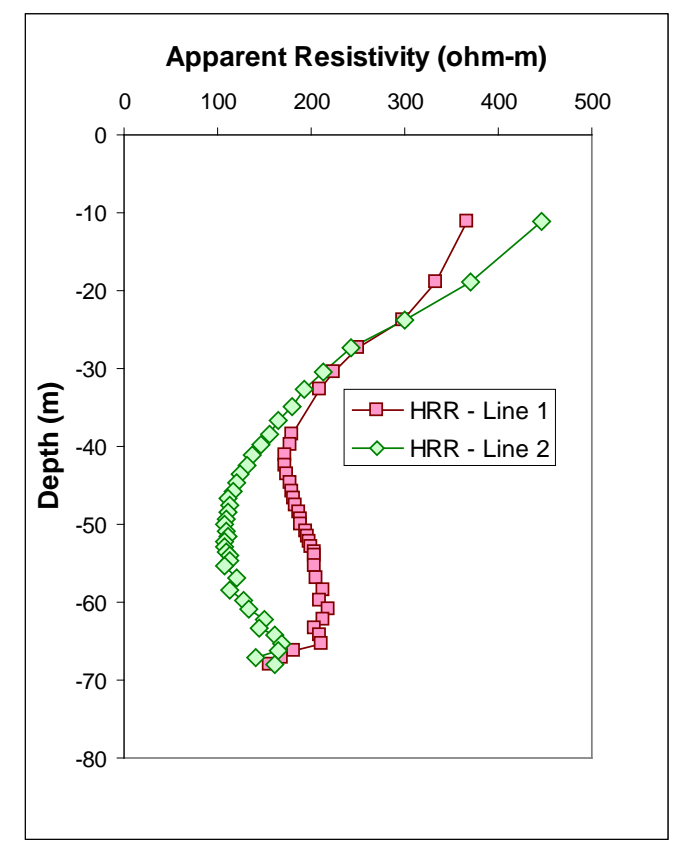

Figure 7.7. Profiles of HRR at the Location of Borehole C5925 (C)

Figure 7.8 shows the results of comparing the pore-water EC and ionic strength with HRR at Borehole C5925 (C). The set of plots used Equation 4-7 (Chapter 4) as the plotting algorithm to obtain the depth estimates of the apparent-resistivity values with coefficients of $u=(3.97,22.4,3.97)$. The profiles show that the apparent-resistivity data match well with the trend of the pore-water geochemical composition. Similarly, Figure 7.9 shows the profile and scatter plots for nitrate. Even though the ionic strength is the most appropriate variable to use for comparison since it accounts for all ionic species, the nitrate concentrations produce the most favorable correlations for C5925. This is somewhat problematical given the fact that nitrate concentrations in the C5925 pore waters are low and no different than natural background concentrations. Additionally, the C5925 pore-water ionic strength is dominated by sulfate, bicarbonate, and calcium.

The HRR results are somewhat misleading because of the false anomalies seen in the HRR plots. The total ionic strength at Borehole C5925 (C) is much lower than that of Borehole C5923 (A) or C5924 (B), yet the HRR shows almost a similar response in soil resistivity. The false anomalies are due to the out-ofplane effects. The removal of these out-of-plane effects is demonstrated in Section 7.2.3 by using 3D inversion.

No scatter plot for technetium-99 was constructed because the C5925 pore waters did not contain measurable concentrations of technetium-99.

\subsubsection{D Inversion at Borehole C5925 (C)}

Figure 7.10 shows the inversion results for FY06-Line 1 and FY06-Line 2. The inversion for FY06Line 1 was completed in three iterations using the smooth model inversion with a final root mean square error of 4.21\%. The inversion for FY06-Line 2 finished in five iterations with a final error of 3.57\%. The two lines show different resistivity signatures at Borehole C5925 (C). In FY06-Line 1, the borehole is located at the southern expression of a low-resistivity feature. At FY06-Line 2, the borehole is located 
between the two plumes in a high-resistivity area. The inversion was able to reconcile the additive effects of the plumes from the trenches and cribs for FY06-Line 2. The 2D inversion profiles at Borehole C5925 (C) can be seen in Figure 7.11, and the plot underscores the differences in the two datasets.

The pore-water EC and ionic strength from Borehole C5925 (C) and 2D inverted resistivity data were evaluated at co-located positions (Figure 7.12). The profile for FY06-Line 1 in Figure 7.12 shows a strong decrease in resistivity and coincides well with the increase in EC and ionic strength. The correlation with this line is very high. On the other hand, the resistivity of FY06-Line 2 changes very little over the depth profile, and the correlation is much worse than for FY06-Line 1.

Figure 7.13 shows the profile and scatter with regression for nitrate concentration. The correlation coefficient for the inverted 2D resistivity data to C5925 pore-water nitrate is quite good despite the fact that nitrate concentrations in the C5925 pore water are low in comparison to sulfate and bicarbonate.

\subsubsection{D Inversion at Borehole C5925 (C)}

The 3D inversion results for model domain 3 are shown in Figure 7.14. The figure focuses on data near Borehole C5925 (C) by showing vertical slices of contoured resistivity values, centered on the borehole's location. The figure shows a low-resistivity anomaly to the east of the borehole that is coincident with the cribs and a low-resistivity anomaly to the west of the borehole that is coincident with trenches B-20 through B-22. South of Borehole C5925 (C), the resistivity is very high and indicates background conditions. However, there does appear to be a slight low-resistivity feature near Borehole C5925 (C).

The regression and profile data for pore-water EC and ionic strength in Borehole C5925 (C) with 3D inversion results are shown in Figure 7.15. The regression and profile data for nitrate concentration in Borehole C5925 (C) with 3D inversion results are shown in Figure 7.16. The profile data show a large variability in resistivity from 1100 to $300 \mathrm{ohm}-\mathrm{m}$. The lowest resistivity values are around 20-m depth, and coincide with the yellow contours south of the borehole seen in Figure 7.14. The scatter plots show a very poor correlation with the data. However, the 3D inverted resistivity values are generally high compared to the other locations and indicate a background (uncontaminated) condition as the pore-water geochemistry also suggests. 
PNNL-17821

A) Profile

\section{-Electrical Conductivity (mS/cm)}

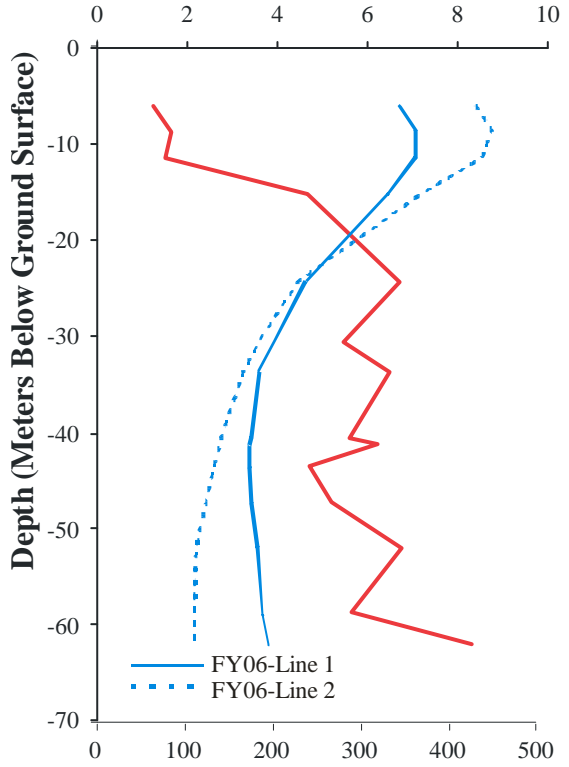

— Apparent Resistivity (Ohm-m)

C) Profile

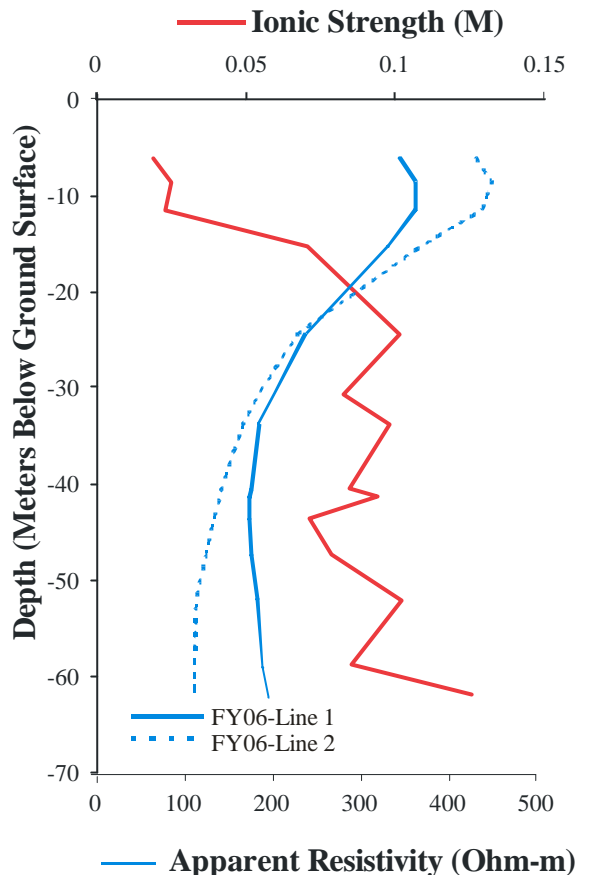

B) Scatter

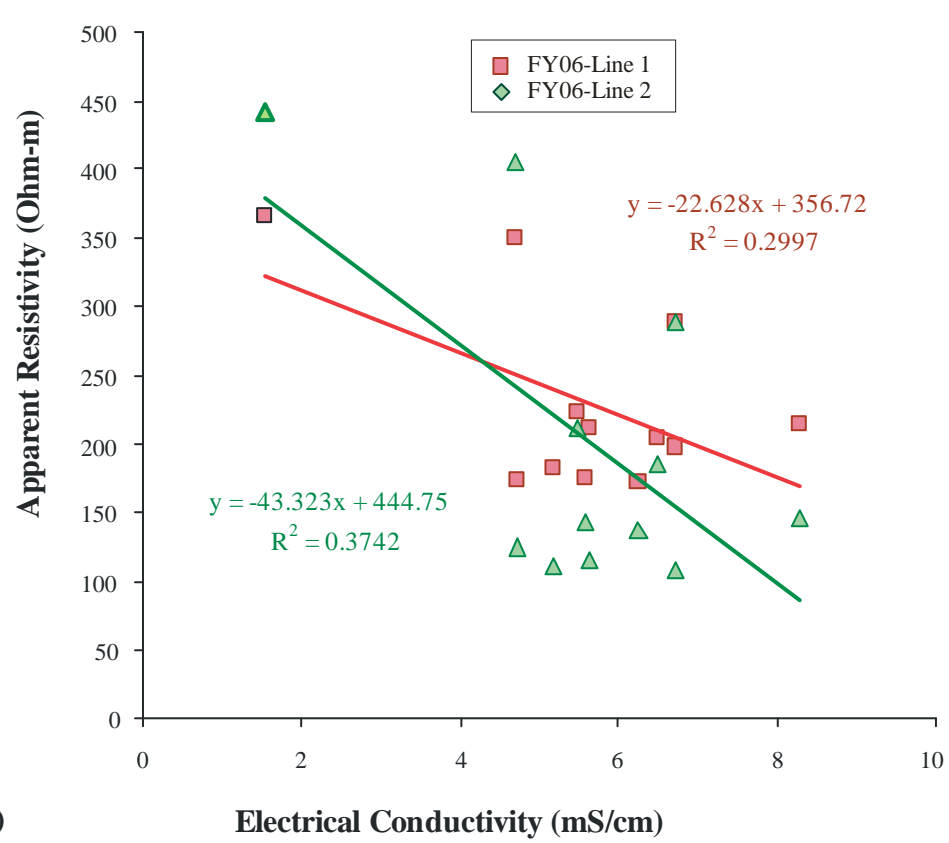

D) Scatter

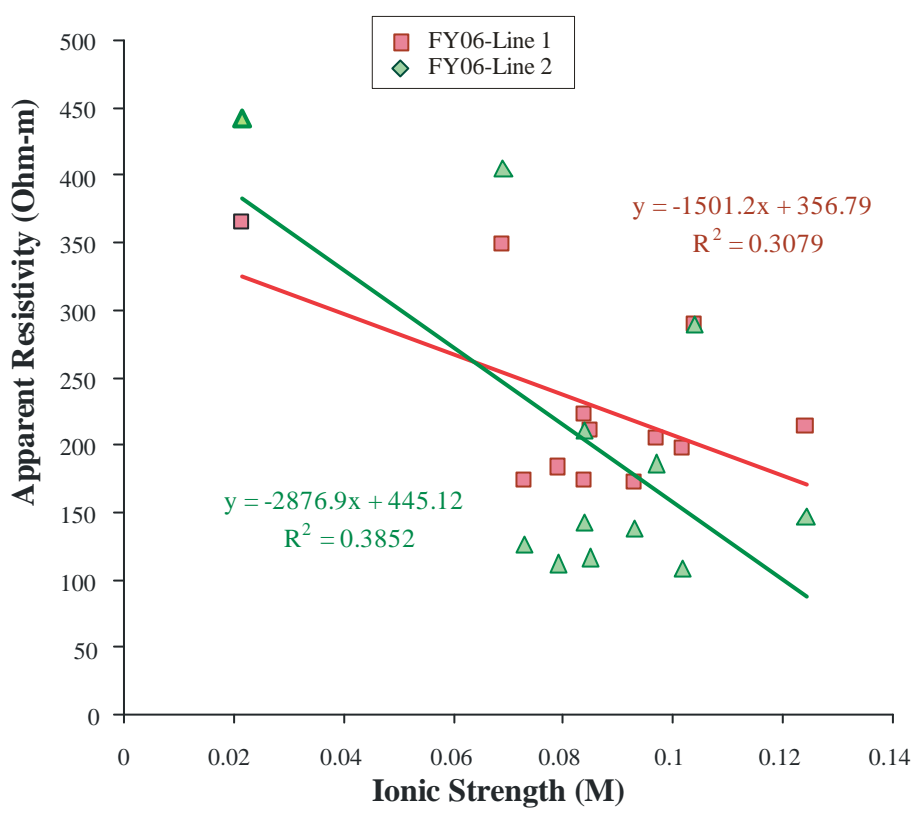

Figure 7.8. Profile and Scatter Plots for HRR with Pore-Water EC and Ionic Strength at Borehole C5925 (C) 

A) Profile
B) Scatter
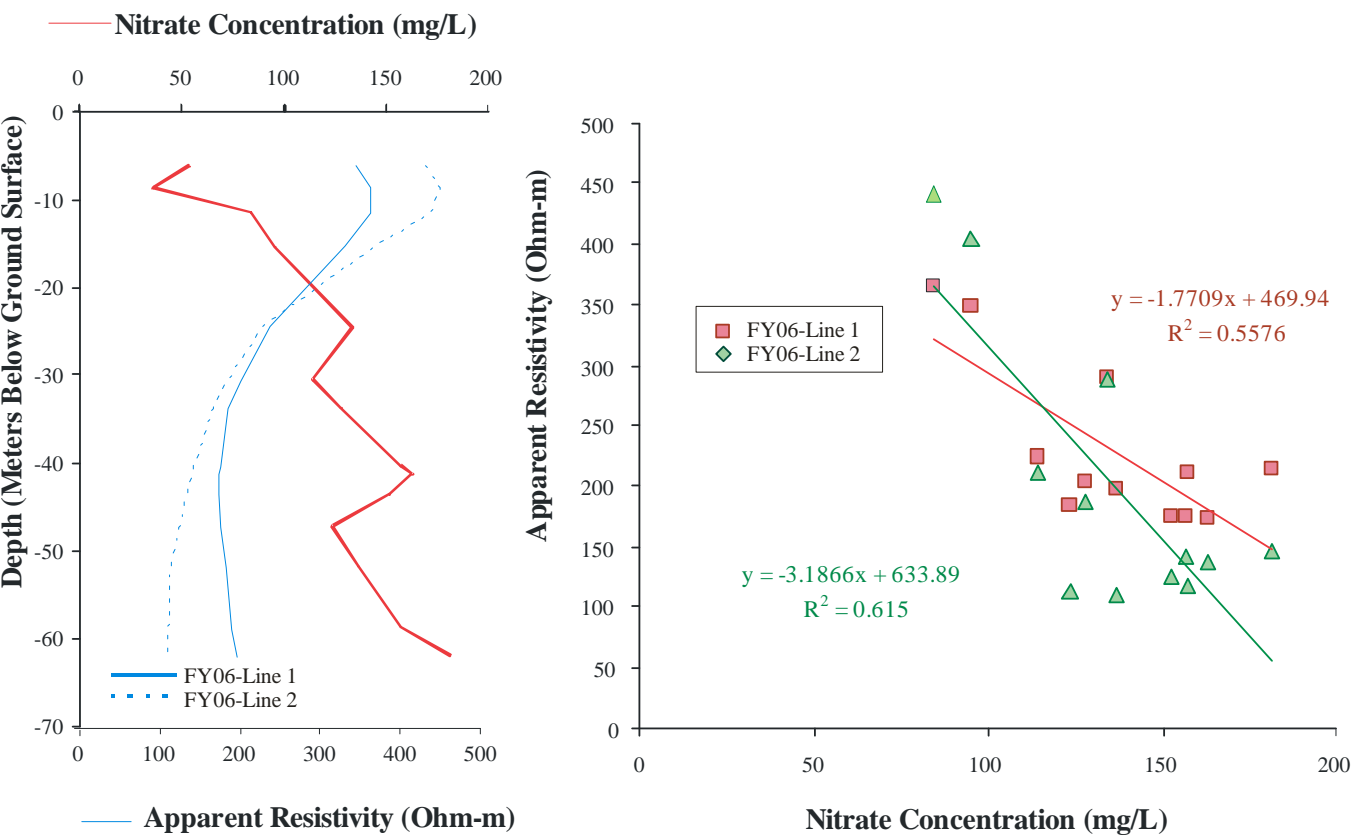

Figure 7.9. Profile and Scatter Plots for HRR with Nitrate Concentrations at Borehole C5925 (C)

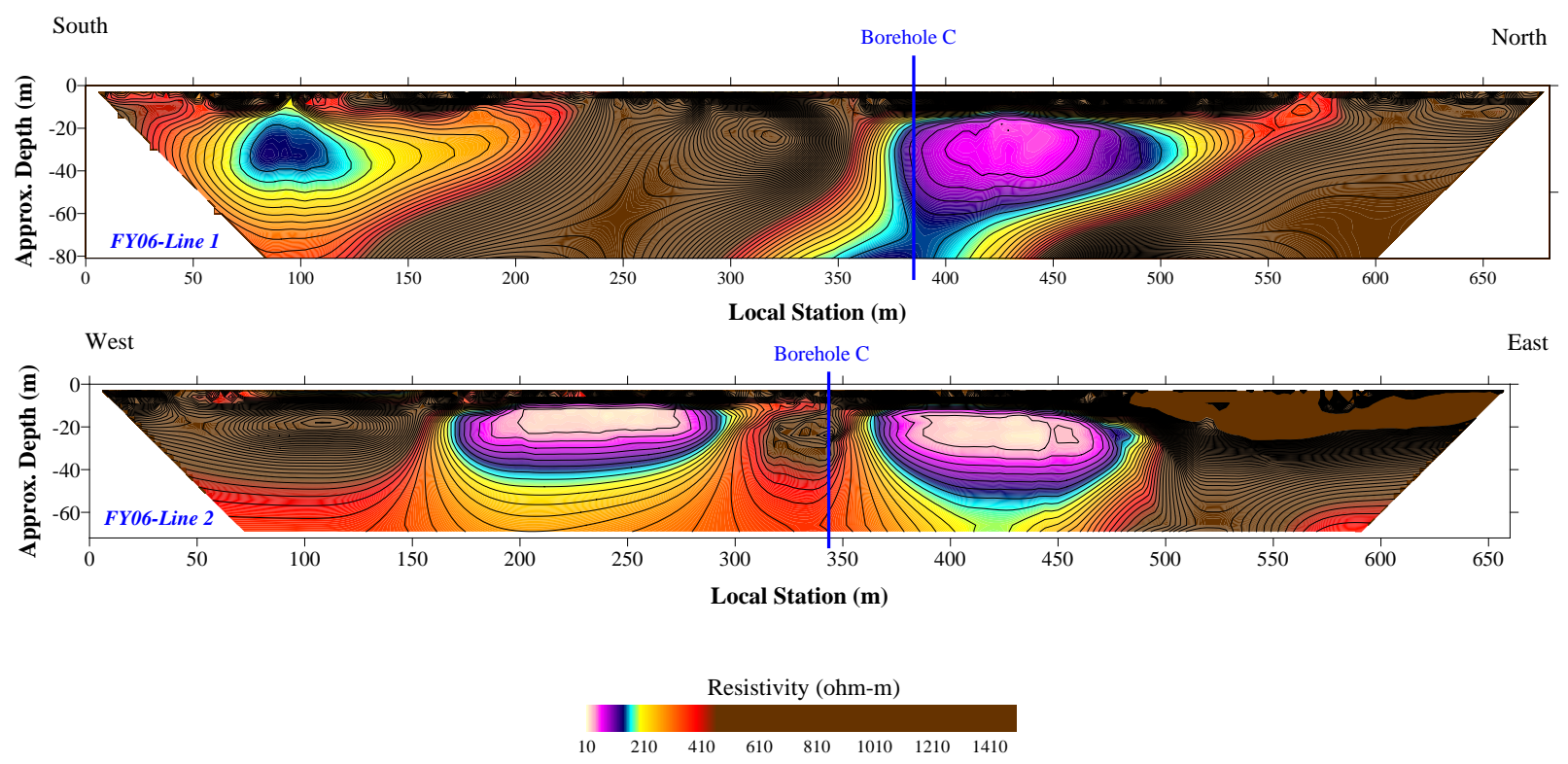

Figure 7.10. 2D Inversion Results of FY06-Line 1 and FY06-Line 2 
PNNL-17821

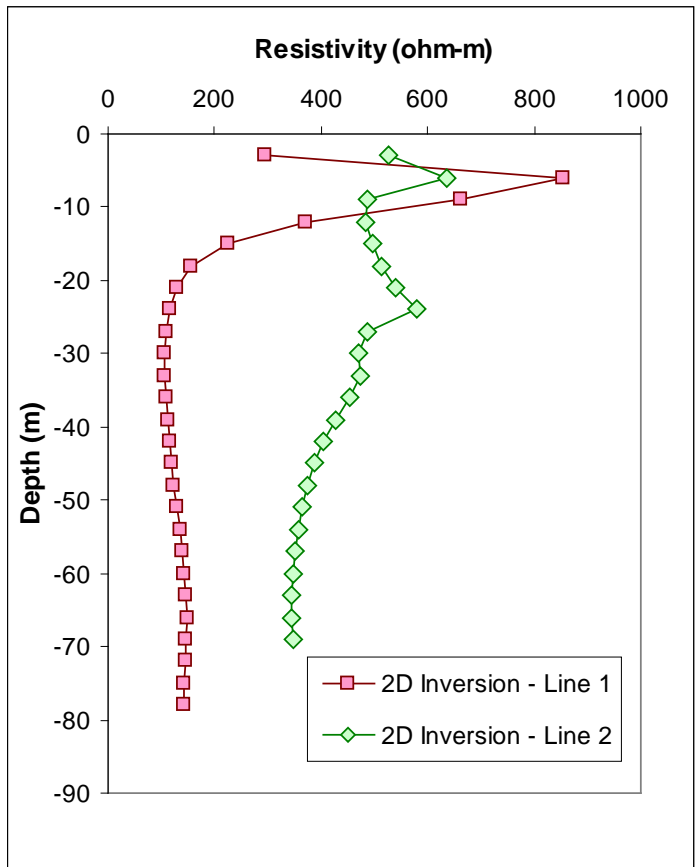

Figure 7.11. Profiles of 2D Inversion at the Location of Borehole C5925 (C)

Figure 7.16 shows the profile and scatter with regression for pore-water nitrate concentrations. 
PNNL-17821

A) Profile Electrical Conductivity $(\mathrm{mS} / \mathrm{cm})$

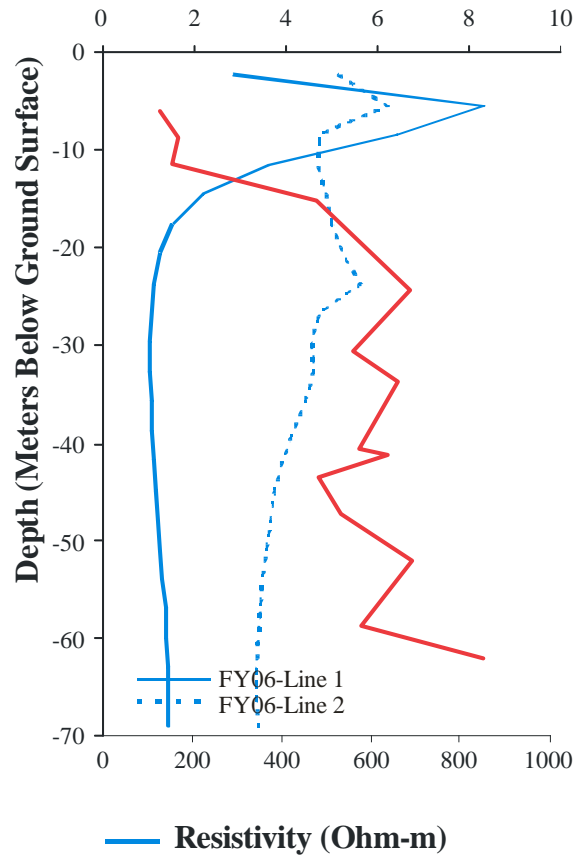

C) Profile

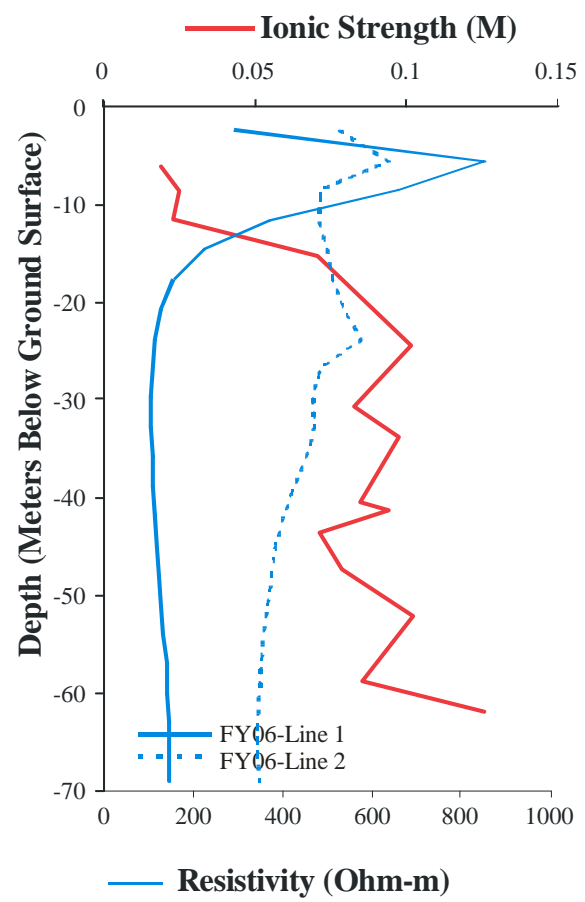

B) Scatter

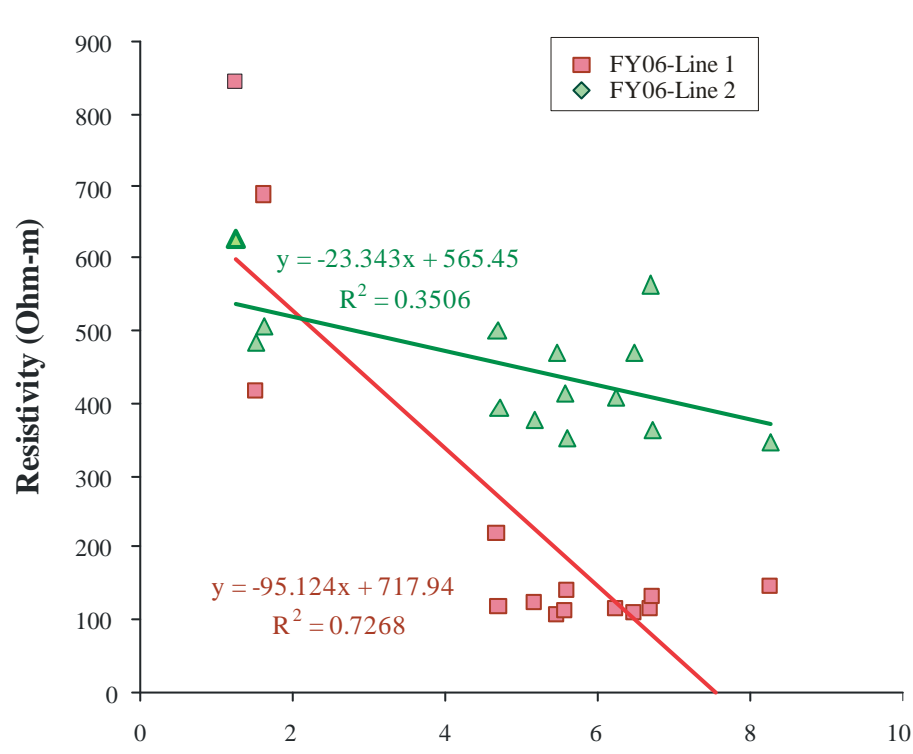

Electrical Conductivity $(\mathrm{mS} / \mathrm{cm})$

D) Scatter

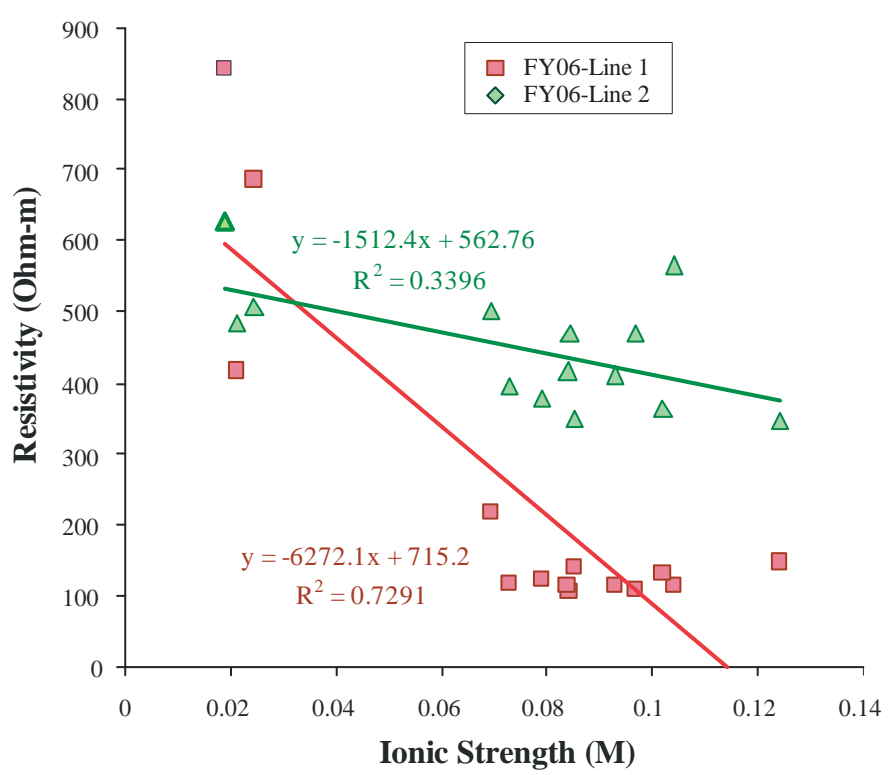

Figure 7.12. Profile and Scatter Plots for $2 \mathrm{D}$ Inversion with Pore-Water EC and Ionic Strength at Borehole C5925 (C) 
PNNL-17821
A) Profile
B) Scatter

\section{— Nitrate Concentration (mg/L)}
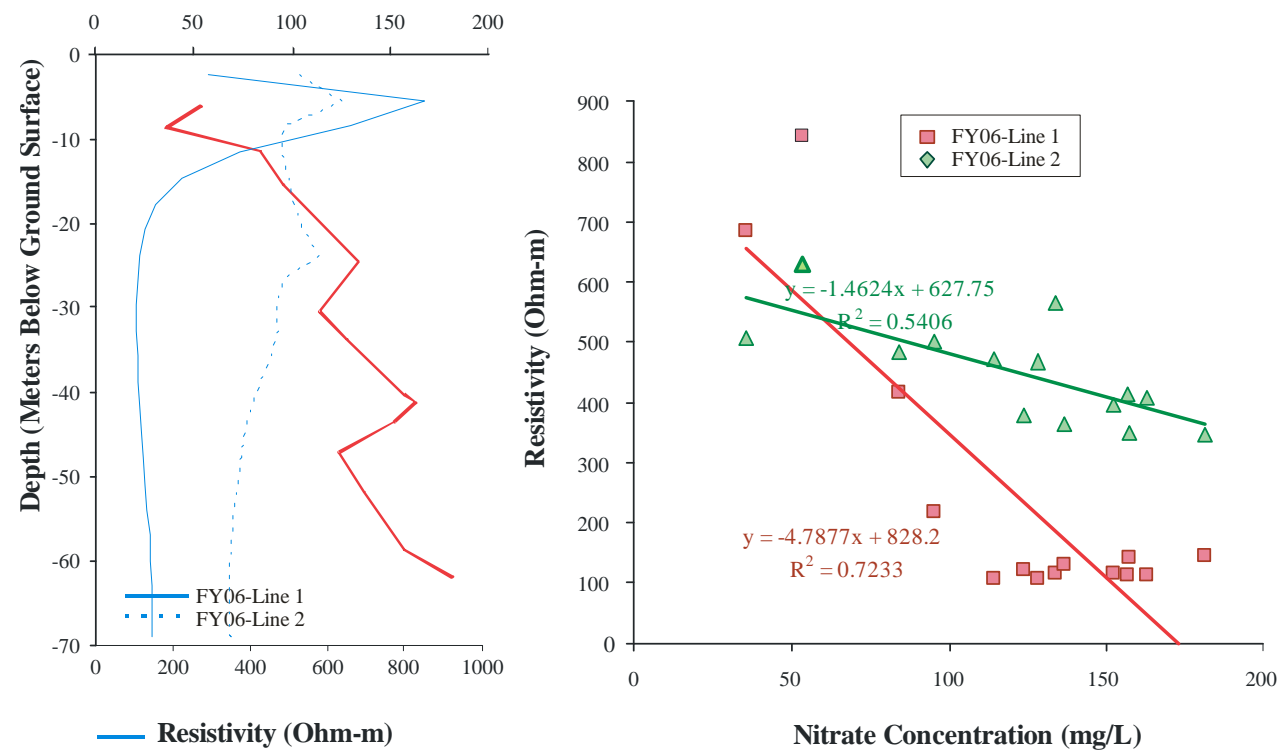

Figure 7.13. Profile and Scatter Plots for 2D Inversion with Nitrate Concentration at Borehole C5925

(C)

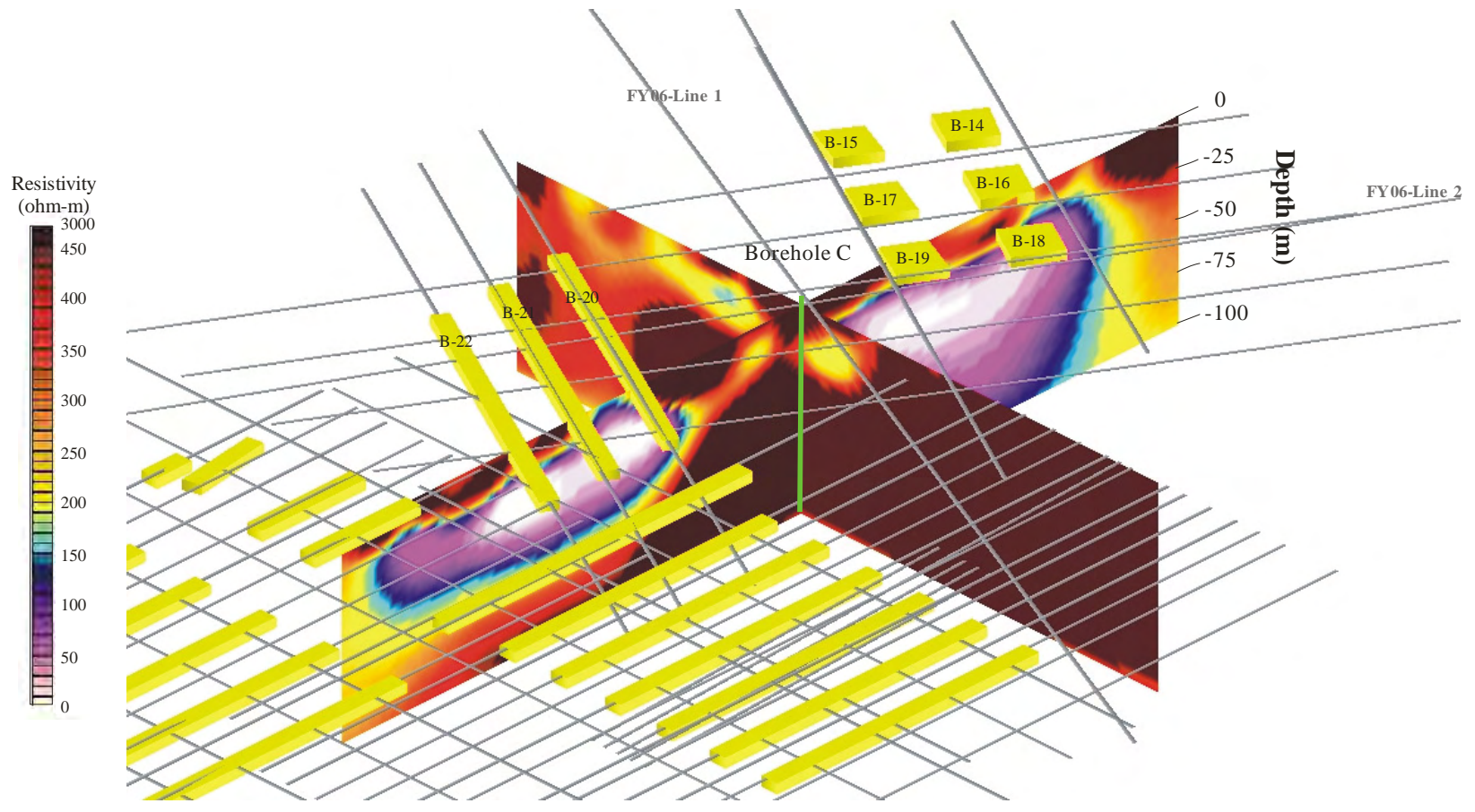

Figure 7.14. 3D Inversion Results of Model Domain 3 of the BC Cribs Site 
PNNL-17821
A) Profile
B) Scatter

Electrical Conductivity (mS/cm)
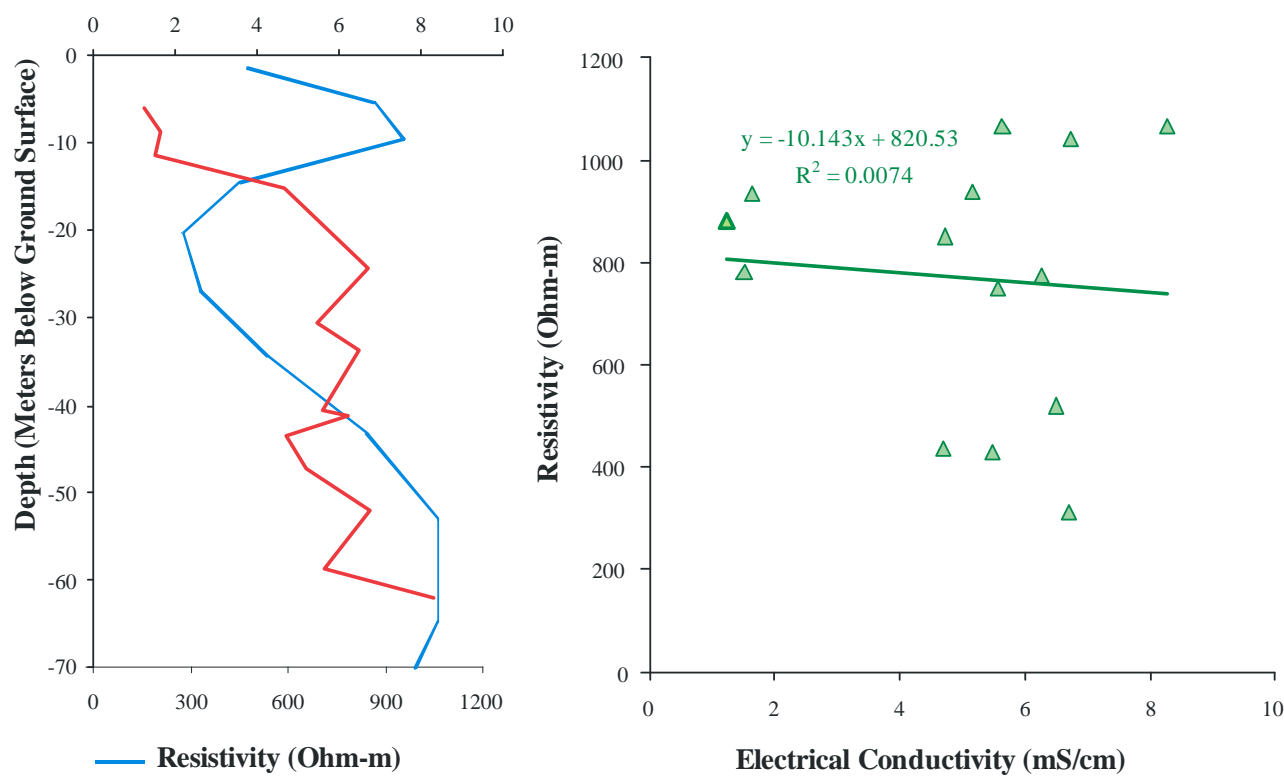

C) Profile

D) Scatter
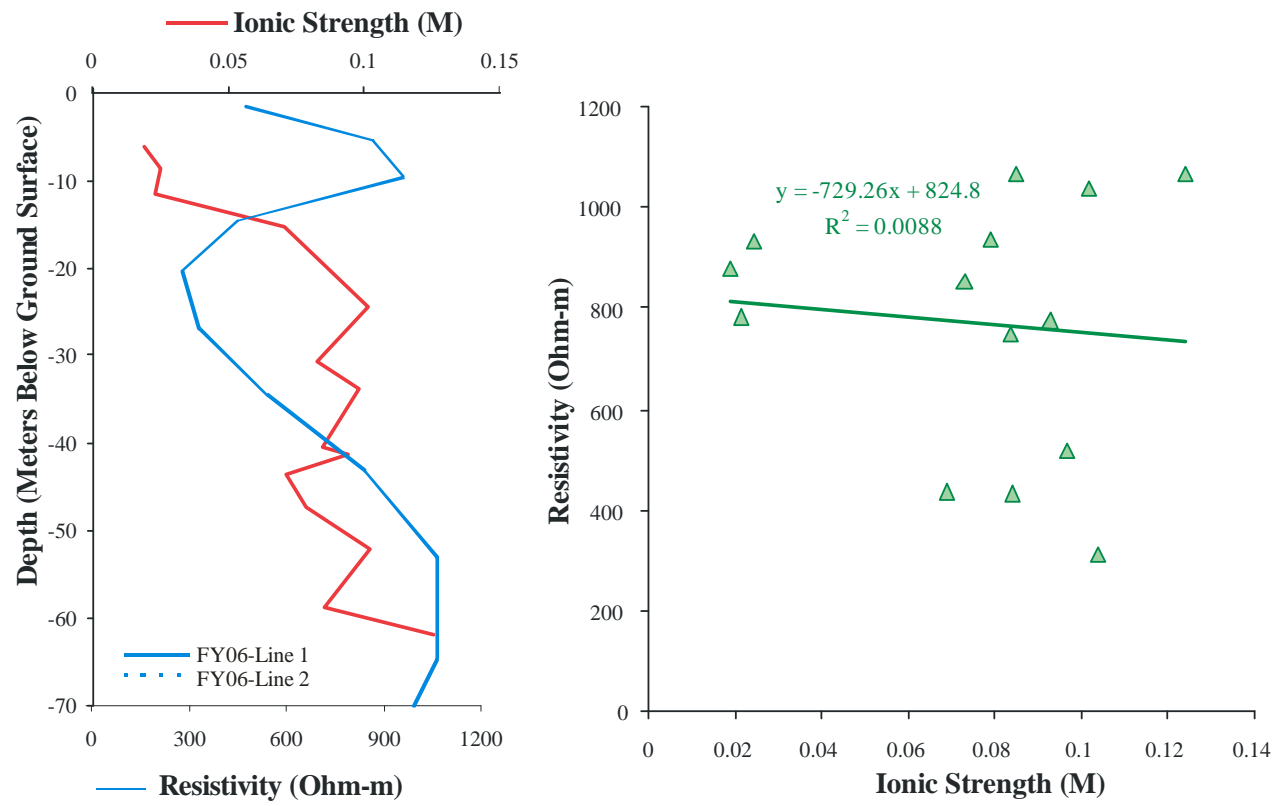

Figure 7.15. Profile and Scatter Plots for 3D Inversion with Porewater EC and Ionic Strength at Borehole C5925 (C) 
PNNL-17821

A) Profile

Nitrate Concentration (mg/L)

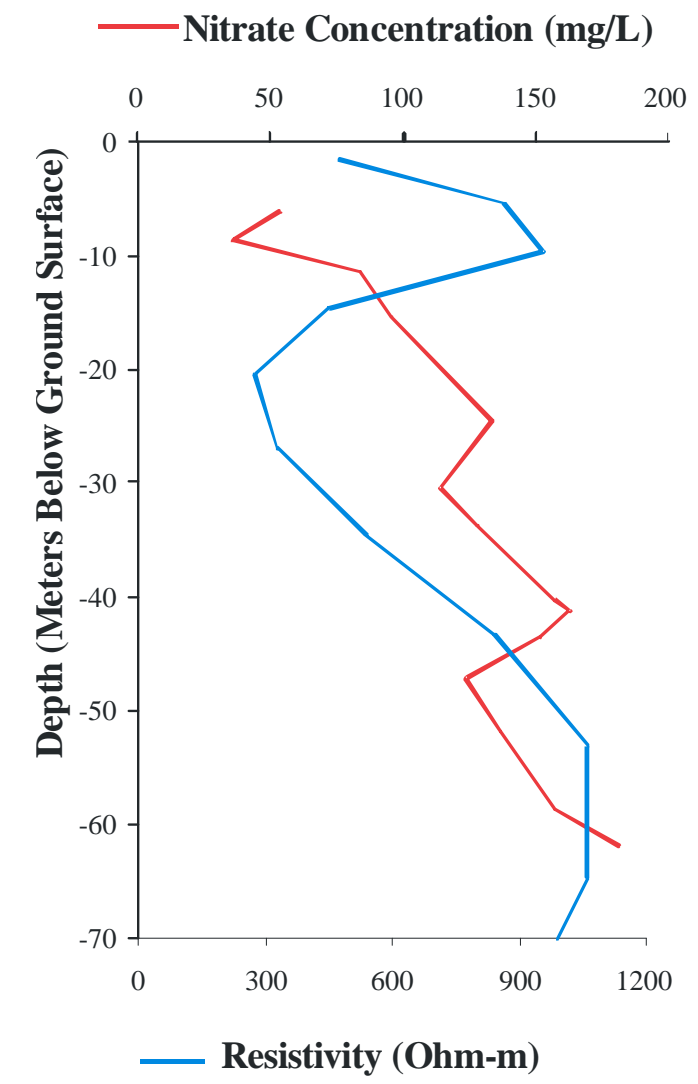

B) Scatter

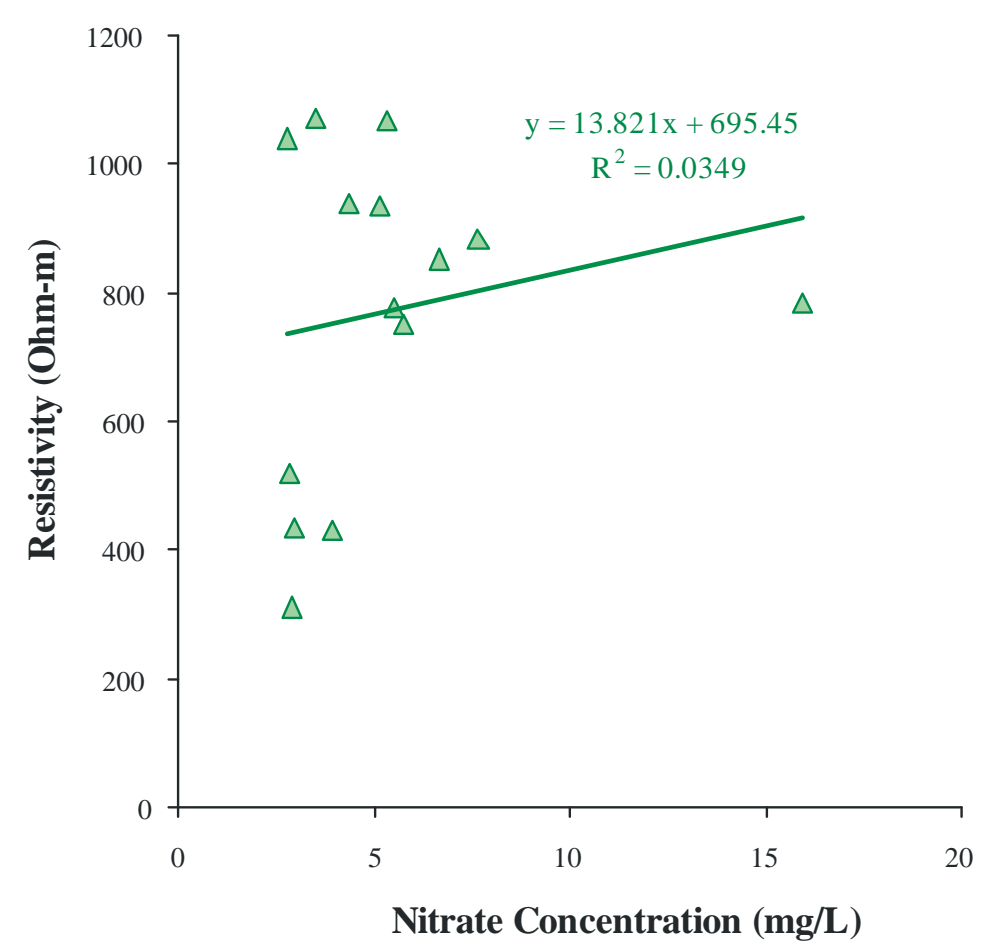

Figure 7.16. Profile and Scatter Plots for 3D Inversion for Nitrate Concentrations at Borehole C5925 (C) 


\subsection{Borehole C4191 Results and Discussion}

\subsection{Geochemical Results from Borehole C4191}

\subsubsection{Moisture Content}

The gravimetric moisture content of the sediment from the grab samples from C4191, which was emplaced via cable-tool with grab samples taken approximately every $2.5 \mathrm{ft}$ from about 13 to $341 \mathrm{ft}$ bgs, is listed in Table 8.1 and presented as a graph in Figure 8.1. Each sample ID includes the borehole number and the approximate depth of each sample. This is a different convention from the other BC Crib and Trench area borehole sediment samples that were each given a unique HEIS number. Grab sampling at the C4191 borehole in 2003 was done without a chain of custody protocol from cuttings during a cable tool campaign. However, the field geologist was keeping track of the borehole depth, and the sample depths are just as accurate as for the other newer boreholes that have formal chain of custody and unique HEIS numbers. For many of the grab samples between the depths of 43 and $148 \mathrm{ft}$, two separate aliquots were processed about 4 months apart. In general, little to no desiccation occurred during storage of the sediments. Six thin zones with higher moisture are observed in the upper $110 \mathrm{ft}$ of the Hanford formation (H2 unit). As stated in Section 2.0, the vadose zone beneath the BC Cribs is dominated by a thick sanddominated sequence of the Hanford formation (H2 unit), but internally, this sequence contains multiple beds of fine- to coarse-grained sand up to several meters thick. These beds grade back and forth between coarse sand to fine sand multiple times before finally grading up into a silty fine sand to silt-textured cap. The texture and thickness of graded beds in the area appears to decrease upward within the Hanford formation $\mathrm{H} 2$ unit. The overall fining and thinning of beds in the shallower depths is probably related to Ice Age floods that became progressively smaller at the end of the Ice Age. This is significant to moisture and contaminant migration since, due to a higher frequency of fine-grained, silty, slack-water beds in the upper part of the Hanford formation, there is increased likelihood for lateral spreading in the upper Hanford formation. Thicker and coarser flood beds are deeper in the profile, as evidenced by the lack of any zones with moisture contents greater than $8 \%$ wt below $110 \mathrm{ft}$ bgs. Section 2.2.1.4 and Figure 2.17 provide additional discussion on the field moisture logging and a comparison of the laboratory gravimetric moisture contents and their correlation to the lithology.

Table 8.1. Gravimetric Moisture Content of Grab Samples Obtained from Borehole C4191

\begin{tabular}{cccccc}
\hline \multicolumn{1}{c}{$\mathrm{ID}^{(\mathrm{a})}$} & \% Moisture & \% Moisture & ID & \% Moisture & \% Moisture \\
\hline & Jan-04 & May-04 & & Jan-04 & May-04 \\
C4191-13 & $6.58 \%$ & & C4191-186 & $2.79 \%$ & \\
C4191-17.5 & $8.84 \%$ & & C4191-188.5 & $2.41 \%$ & \\
C4191-22.5 & $6.57 \%$ & & C4191-191 & $3.44 \%$ & \\
C4191-27.5 & $10.09 \%$ & & C4191-193.5 & $1.84 \%$ & \\
C4191-37.5 & $4.38 \%$ & & C4191-196 & $1.68 \%$ & \\
C4191-41 & $9.86 \%$ & & C4191-198.5 & $2.72 \%$ & \\
C4191-43.5 & $4.49 \%$ & $5.00 \%$ & C4191-201 & $2.33 \%$ & \\
C4191-46 & $3.41 \%$ & & C4191-203.5 & $2.10 \%$ & \\
\hline
\end{tabular}


PNNL-17821

Table 8.1 (contd)

\begin{tabular}{|c|c|c|c|c|c|}
\hline $\mathrm{ID}^{(\mathrm{a})}$ & $\begin{array}{l}\text { \% Moisture } \\
\text { Jan-04 } \\
\end{array}$ & $\begin{array}{c}\text { \% Moisture } \\
\text { May-04 } \\
\end{array}$ & ID & $\begin{array}{c}\text { \% Moisture } \\
\text { Jan-04 } \\
\end{array}$ & $\begin{array}{c}\text { \% Moisture } \\
\text { May-04 } \\
\end{array}$ \\
\hline C4191-48.5 & $3.68 \%$ & $3.29 \%$ & C4191-206 & $1.69 \%$ & \\
\hline C4191-51 & $3.84 \%$ & & C4191-208.5 & $1.93 \%$ & \\
\hline C4191-53.5 & $3.56 \%$ & $3.26 \%$ & C4191-211 & $1.90 \%$ & \\
\hline C4191-56 & $7.66 \%$ & $5.67 \%$ & C4191-213.5 & $1.84 \%$ & \\
\hline C4191-58.5 & $3.60 \%$ & $3.32 \%$ & C4191-216 & $1.96 \%$ & \\
\hline C4191-61 & $3.69 \%$ & & C4191-218.5 & $2.03 \%$ & \\
\hline C4191-63.5 & $11.10 \%$ & $13.75 \%$ & C4191-221 & $4.87 \%$ & \\
\hline C4191-66 & $5.95 \%$ & $5.00 \%$ & C4191-223.5 & $3.04 \%$ & \\
\hline C4191-68.5 & $3.44 \%$ & $3.41 \%$ & C4191-226 & $2.17 \%$ & \\
\hline C4191-71 & $3.41 \%$ & & C4191-228.5 & $2.40 \%$ & \\
\hline C4191-73.5 & $5.34 \%$ & $4.93 \%$ & C4191-231 & $2.56 \%$ & \\
\hline C4191-76 & $4.47 \%$ & $4.52 \%$ & C4191-233.5 & $2.16 \%$ & \\
\hline C4191-78.5 & $5.03 \%$ & $4.47 \%$ & C4191-236 & $2.51 \%$ & \\
\hline C4191-81 & $4.34 \%$ & & C4191-238.5 & $2.69 \%$ & \\
\hline C4191-83.5 & $4.18 \%$ & $3.53 \%$ & C4191-241 & $3.08 \%$ & \\
\hline C4191-86 & $9.50 \%$ & $8.93 \%$ & C4191-243.5 & $2.91 \%$ & \\
\hline C4191-88.5 & $5.95 \%$ & $6.24 \%$ & C4191-246 & $1.67 \%$ & \\
\hline C4191-91 & $7.62 \%$ & & C4191-248.5 & $1.87 \%$ & \\
\hline C4191-93.5 & $7.26 \%$ & $6.23 \%$ & C4191-251 & $2.05 \%$ & \\
\hline C4191-96 & $3.47 \%$ & $3.35 \%$ & C4191-253.5 & $1.71 \%$ & \\
\hline C4191-98.5 & $5.42 \%$ & $5.54 \%$ & C4191-256 & $1.91 \%$ & \\
\hline C4191-101 & $7.26 \%$ & & C4191-258.5 & $1.72 \%$ & \\
\hline C4191-103.5 & $7.62 \%$ & $6.67 \%$ & C4191-261 & $2.02 \%$ & \\
\hline C4191-106 & $4.65 \%$ & $4.10 \%$ & C4191-263.5 & $1.67 \%$ & \\
\hline C4191-108.5 & $4.83 \%$ & $4.70 \%$ & C4191-266 & $1.63 \%$ & \\
\hline C4191-111 & $4.57 \%$ & & C4191-268.5 & $1.53 \%$ & \\
\hline C4191-113.5 & $9.33 \%$ & $7.71 \%$ & C4191-271 & $1.49 \%$ & \\
\hline C4191-116 & $7.22 \%$ & $6.15 \%$ & C4191-273.5 & $1.46 \%$ & \\
\hline C4191-118.5 & $4.37 \%$ & $4.18 \%$ & C4191-276 & $1.54 \%$ & \\
\hline C4191-121 & $4.80 \%$ & & C4191-278.5 & $1.65 \%$ & \\
\hline C4191-123.5 & $4.21 \%$ & $4.01 \%$ & C4191-281 & $1.58 \%$ & \\
\hline C4191-126 & $6.41 \%$ & $6.07 \%$ & C4191-283.5 & $2.03 \%$ & \\
\hline C4191-128.5 & $4.25 \%$ & $4.24 \%$ & C4191-286 & $2.08 \%$ & \\
\hline C4191-131 & $7.03 \%$ & & C4191-288.5 & $1.61 \%$ & \\
\hline C4191-133.5 & $4.02 \%$ & $3.79 \%$ & C4191-291 & $1.94 \%$ & \\
\hline C4191-136 & $5.08 \%$ & $4.40 \%$ & C4191-293.5 & $1.70 \%$ & \\
\hline C4191-138.5 & $6.75 \%$ & $6.55 \%$ & C4191-296 & $1.90 \%$ & \\
\hline
\end{tabular}


PNNL-17821

Table 8.1 (contd)

\begin{tabular}{|c|c|c|c|c|c|}
\hline $\mathrm{ID}^{(\mathrm{a})}$ & $\begin{array}{l}\text { \% Moisture } \\
\text { Jan-04 } \\
\end{array}$ & $\begin{array}{c}\text { \% Moisture } \\
\text { May-04 } \\
\end{array}$ & ID & $\begin{array}{c}\text { \% Moisture } \\
\text { Jan-04 } \\
\end{array}$ & $\begin{array}{c}\text { \% Moisture } \\
\text { May-04 }\end{array}$ \\
\hline C4191-141 & $4.41 \%$ & & C4191-298.5 & $1.44 \%$ & \\
\hline C4191-143.5 & $4.45 \%$ & $3.88 \%$ & C4191-301 & $1.27 \%$ & \\
\hline C4191-146 & $4.35 \%$ & $4.11 \%$ & C4191-303.5 & $0.89 \%$ & \\
\hline C4191-148.5 & $3.86 \%$ & $3.52 \%$ & C4191-306 & $0.92 \%$ & \\
\hline C4191-151 & $4.71 \%$ & & C4191-308.5 & $0.85 \%$ & \\
\hline C4191-153.5 & $4.48 \%$ & & C4191-311 & $1.15 \%$ & \\
\hline C4191-156 & $5.39 \%$ & & C4191-313.5 & $1.36 \%$ & \\
\hline C4191-158.5 & $6.97 \%$ & & C4191-316 & $1.34 \%$ & \\
\hline C4191-161 & $3.80 \%$ & & C4191-318.5 & $0.93 \%$ & \\
\hline C4191-163.5 & $4.09 \%$ & & C4191-321 & $1.37 \%$ & \\
\hline C4191-166 & $5.30 \%$ & & C4191-323.5 & $1.87 \%$ & \\
\hline C4191-168.5 & $5.29 \%$ & & C4191-326 & $1.17 \%$ & \\
\hline C4191-171 & $6.25 \%$ & & C4191-328.5 & $1.45 \%$ & \\
\hline C4191-173.5 & $5.78 \%$ & & C4191-331 & $3.32 \%$ & \\
\hline C4191-176 & $4.62 \%$ & & C4191-333.5 & $2.06 \%$ & \\
\hline C4191-178.5 & $5.05 \%$ & & C4191-336 & $6.45 \%$ & \\
\hline C4191-181 & $3.73 \%$ & & C4191-338.5 & $10.54 \%$ & \\
\hline C4191-183.5 & $3.64 \%$ & & C4191-341 & $9.86 \%$ & \\
\hline
\end{tabular}

(a) The sample IDs include the borehole number and the approximate depth of each sample

\subsubsection{1:1 Sediment-to-Water Extracts for Borehole C4191}

As described in Section 3, selected grab samples were processed by adding known amounts of de-ionized water to aid in separating the native pore water in the relatively dry sediments. In this section, the water extract data are reported in both units of pore water concentration (most useful for comparing with soil resistivity data) and units of mass per gram of dry sediment (useful for estimating vertical distribution of each species).

The $\mathrm{pH}$ and EC for the water extracts are shown in Table 8.2 and Figure 8.1. The $\mathrm{pH}$ is plotted as measured in the 1:1 sediment-to-water extracts, but the EC is corrected for dilution and plotted as if it were actual pore water.

The $\mathrm{pH}$ profile shows that caustic waste has impacted the sediments from near the bottom of the 216-B-26 trench down to a depth of about $48 \mathrm{ft}$ bgs. The highest $\mathrm{pH}$ values (above 9 ) are found from 17.5 to $37.5 \mathrm{ft}$ bgs. These $\mathrm{pH}$ values are similar to values observed below and adjacent to single-shell tanks that have leaked highly caustic waste, but at more limited volumes than disposed of to the cribs. The vertical extent of the elevated $\mathrm{pH}$ (approximately 20 vertical ft) is also similar or a bit less than the thicknesses of impacted sediment observed below several single-shell tanks. This similarity in the zone of caustic-impacted sediment is either caused by 1) the combination of the likely lower free-base content in the 216-B-26 trench waste stream — but a higher volume was disposed of (4.75 million liters; Corbin et 
al. 2005) than was released from single-shell tanks — or 2) the fact that all caustic-impacted vadose zone sediments at Hanford have been buffered to $\mathrm{pH}$ values from $\sim 9$ to 9.8 over the 4 to 6 decades since the fluids were released. At present, almost all observations of caustic fluid attack on Hanford sediments exhibit water extract $\mathrm{pH}$ values in this constrained range of approximately one $\mathrm{pH}$ unit despite some of the waste streams that were projected to have $\mathrm{pH}$ values that ranged from 10 to greater than 14 .

Below the 216-B-26 trench, the sediments appear to show a bi-modal peak in pore water EC with the two maxima residing at 91 to 94 and 133.5 to $136 \mathrm{ft}$ bgs with the shallow lobe being slightly more concentrated. It was quite surprising to find that the high-conductivity zones below 216-B-26 trench were as shallow as observed, given the much larger volume of waste disposed of at 216-B-26 (4.75 million liters) compared to volumes released from single-shell tanks that had been studied previously, such as T-106 (released 0.435 million liters), BX-102 (released 0.347 million liters), or SX-108 (released 0.132 million liters), based on current estimates in Field and Jones (2006). Despite disposing volumes from 10 to 36 times greater than the three largest documented tank releases to the sediment below the 216-B-26 trench, the mobile salt plume has not traveled significantly deeper into the vadose zone profile than the tank releases. As described in the geology section, the thin fine-grained lens and numerous contrasts between fine sand and coarse sand observed in the upper portion of the Hanford formation appear to be effective horizontal spreading horizons for the disposed fluid.

Table 8.2. $\quad$ pH and EC Values for 1:1 Sediment to Water Extracts from C4191

\begin{tabular}{|c|c|c|c|c|c|c|c|}
\hline $\mathrm{ID}^{(\mathrm{a})}$ & $\begin{array}{c}\text { 1:1 Extract } \\
\text { pH }\end{array}$ & $\begin{array}{c}\text { 1:1 Extract } \\
\text { Conductivity } \\
\mathrm{mS} / \mathrm{cm}\end{array}$ & $\begin{array}{l}\text { Conductivity } \\
\text { (mS/cm) } \\
\text { Dilution } \\
\text { Corrected (in } \\
\text { Pore Water) }\end{array}$ & ID & $\begin{array}{c}1: 1 \\
\text { Extract } \\
\text { pH }\end{array}$ & $\begin{array}{c}\text { 1:1 Extract } \\
\text { Conductivity } \\
\mathrm{mS} / \mathrm{cm}\end{array}$ & $\begin{array}{l}\text { Conductivity } \\
\text { (mS/cm) } \\
\text { Dilution } \\
\text { Corrected (in } \\
\text { Pore Water) }\end{array}$ \\
\hline C4191-13 & 8.49 & 0.262 & 3.981 & C4191-118.5 & 7.32 & 3.985 & 95.245 \\
\hline C4191-17.5 & 9.11 & 1.266 & 14.338 & C4191-121 & 7.28 & 4.639 & 96.660 \\
\hline C4191-22.5 & 9.25 & 1.278 & 19.469 & C4191-123.5 & 7.54 & 4.791 & 119.576 \\
\hline C4191-27.5 & 9.59 & 1.174 & 27.097 & C4191-126 & 7.29 & 7.328 & 120.784 \\
\hline C4191-37.5 & 9.48 & 0.899 & 20.536 & C4191-128.5 & 7.25 & 5.550 & 131.004 \\
\hline C4191-41 & 8.69 & 1.530 & 15.536 & C4191-131 & 7.22 & 7.310 & 104.001 \\
\hline C4191-43.5 & 8.65 & 1.206 & 24.113 & C4191-131 DUP & 7.25 & 7.008 & 99.729 \\
\hline C4191-48.5 & 8.40 & 1.029 & 31.243 & C4191-133.5 & 7.15 & 5.765 & 151.959 \\
\hline C4191-51 & 8.33 & 1.059 & 27.552 & C4191-136 & 7.01 & 6.347 & 144.292 \\
\hline C4191-53.5 & 8.34 & 1.051 & 32.213 & C4191-138.5 & 7.11 & 6.582 & 100.478 \\
\hline C4191-56 & 8.18 & 1.712 & 30.185 & C4191-141 & 7.43 & 1.191 & 27.043 \\
\hline C4191-58.5 & 8.17 & 1.038 & 31.287 & C4191-143.5 & 7.50 & 0.994 & 25.612 \\
\hline C4191-61 & 8.22 & 1.000 & 27.107 & C4191-146 & 7.47 & 0.833 & 20.282 \\
\hline C4191-63.5 & 8.23 & 2.408 & 17.520 & C4191-151 & 7.57 & 0.524 & 11.127 \\
\hline C4191-66 & 8.32 & 1.261 & 25.227 & C4191-161 & 7.83 & 0.162 & 4.268 \\
\hline C4191-68.5 & 8.40 & 1.290 & 37.885 & C4191-171 & 7.85 & 0.215 & 3.440 \\
\hline C4191-71 & 8.22 & 1.466 & 43.007 & C4191-181 & 7.69 & 0.200 & 5.363 \\
\hline C4191-73.5 & 8.14 & 2.864 & 58.070 & C4191-191 & 7.81 & 0.196 & 5.692 \\
\hline C4191-76 & 8.22 & 2.678 & 61.850 & C4191-201 & 7.64 & 0.150 & 6.459 \\
\hline C4191-78.5 & 8.06 & 2.871 & 64.540 & C4191-211 & 7.69 & 0.147 & 7.739 \\
\hline
\end{tabular}


Table 8.2 (contd)

\begin{tabular}{|c|c|c|c|c|c|c|c|}
\hline $\mathrm{ID}^{(\mathrm{a})}$ & $\begin{array}{c}\text { 1:1 Extract } \\
\mathrm{pH}\end{array}$ & $\begin{array}{c}\text { 1:1 Extract } \\
\text { Conductivity } \\
\mathrm{mS} / \mathrm{cm}\end{array}$ & $\begin{array}{l}\text { Conductivity } \\
\text { (mS/cm) } \\
\text { Dilution } \\
\text { Corrected (in } \\
\text { Pore Water) }\end{array}$ & ID & $\begin{array}{c}1: 1 \\
\text { Extract } \\
\text { pH }\end{array}$ & $\begin{array}{c}\text { 1:1 Extract } \\
\text { Conductivity } \\
\text { mS/cm }\end{array}$ & $\begin{array}{l}\text { Conductivity } \\
\text { (mS/cm) } \\
\text { Dilution } \\
\text { Corrected (in } \\
\text { Pore Water) }\end{array}$ \\
\hline C4191-81 & 8.02 & 2.978 & 68.555 & C4191-221 & 7.70 & 0.161 & 3.497 \\
\hline C4191-83.5 & 8.00 & 3.343 & 94.711 & C4191-221 DUP & 7.67 & 0.151 & 3.280 \\
\hline C4191-88.5 & 7.21 & 10.050 & 161.113 & C4191-231 & 7.61 & 0.131 & 5.529 \\
\hline C4191-91 & 7.43 & 11.960 & 157.073 & C4191-241 & 7.77 & 0.159 & 5.170 \\
\hline C4191-91 DUP & 7.35 & 12.700 & 166.766 & C4191-251 & 7.68 & 0.150 & 7.315 \\
\hline C4191-93.5 & 7.14 & 10.950 & 175.568 & C4191-261 & 7.66 & 0.142 & 7.644 \\
\hline C4191-96 & 7.20 & 5.478 & 163.481 & C4191-271 & 7.64 & 0.126 & 8.437 \\
\hline C4191-98.5 & 7.25 & 7.973 & 143.983 & C4191-281 & 7.66 & 0.134 & 8.477 \\
\hline C4191-101 & 7.43 & 9.525 & 131.283 & C4191-291 & 7.91 & 0.203 & 10.450 \\
\hline C4191-103.5 & 7.04 & 9.989 & 149.822 & C4191-301 & 8.13 & 0.207 & 16.656 \\
\hline C4191-108.5 & 7.20 & 6.253 & 132.954 & C4191-311 & 8.07 & 0.206 & 17.919 \\
\hline C4191-111 & 7.10 & 4.659 & 107.533 & C4191-321 & 7.69 & 0.177 & 12.962 \\
\hline C4191-113.5 & 7.16 & 8.458 & 110.230 & C4191-331 & 7.88 & 0.195 & 5.879 \\
\hline C4191-116 & 7.23 & 7.814 & 127.010 & C4191-341 & 7.76 & 0.156 & 1.582 \\
\hline
\end{tabular}

(a) The sample IDs include the borehole number and the approximate depth of each sample

\subsubsection{Water Extract Composition of the 1:1 Sediment to Water Extracts for C4191}

The 1:1 sediment-to-water extract anion composition, in units of $\mu \mathrm{g} / \mathrm{g}$ of dry sediment and in units of $\mathrm{mg} / \mathrm{L}$ for the calculated pore water are shown in Table 8.3 and Table 8.4, respectively. Figure 8.2 and Figure 8.3 are plots of the key anion data from these two tables. Values in Table 8.3 that appear to be elevated compared to the others are shown in bold type. The waste stream that was disposed of to the 216-B-26 trench was uranium recovery and scavenging wastes from a tri-butyl-phosphate-based process to recover uranium from bismuth phosphate wastes retrieved from single-shell tanks. More details on the waste composition can be found in Corbin et al. (2005) and the appendixes to the DQO report (Benecke 2008). About 1.5 metric tons of dissolved salts, consisting mainly of nitrate and sodium (combined, these represent 1.38 metric tons) and lesser amounts of sulfate, phosphate, fluoride, chloride, and potassium were disposed of. The vadose zone sediments below the 216-B-26 trench show elevated concentrations of most of the aforementioned anions with phosphate being immobilized in the upper $45 \mathrm{ft}$ bgs, the most elevated fluoride concentrations are found from 51 to $91 \mathrm{ft}$ bgs, the most elevated sulfate concentrations are found from 41 to $131 \mathrm{ft}$ bgs, the most elevated chloride concentrations are found from 91 to $131 \mathrm{ft}$ bgs and the most elevated nitrate concentrations are found from 41 to $158.5 \mathrm{ft}$ bgs as shown in bold in Table 8.3. These depth distributions are both a function of species mobility in Hanford sediments (phosphate is highly interactive and readily sorbs/precipitates; fluoride is somewhat interactive with sediments, sulfate is slightly interactive with sediments, and chloride and nitrate are not retained significantly in the sediments and migrate with the percolating fluids). The massive quantity of nitrate disposed of makes it a good tracer of the waste-fluid plume location. Figure 8.2 shows this relative anion mobility distribution versus depth and also shows a comparison of some independent data provided by the FHI contract analytical laboratory on cores collected at specified depths that were used to determine contaminant vertical distributions in the vadose zone profile. In general, agreement is good where the two laboratories made comparable measurements. 

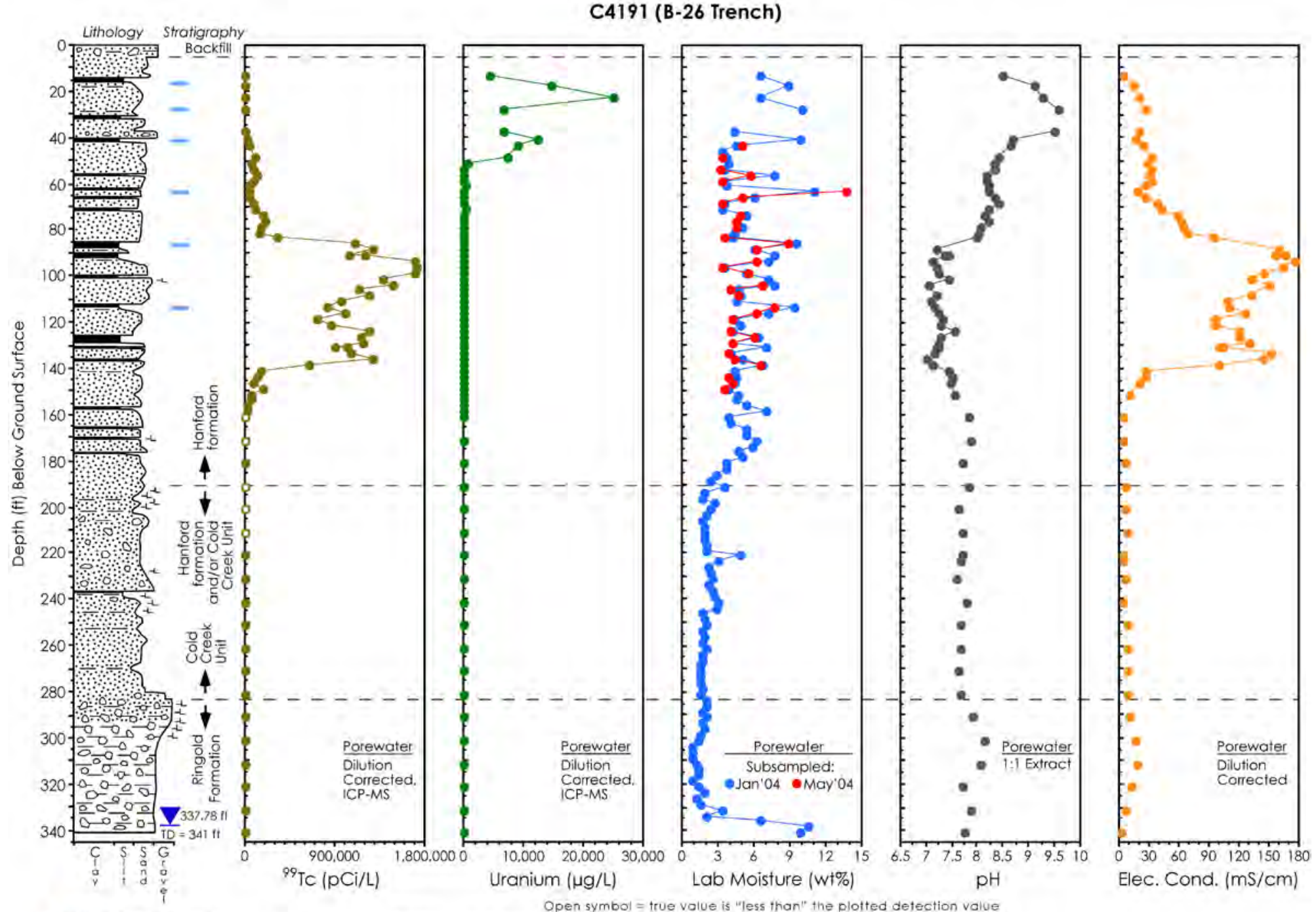

- Fine-Grained Layer

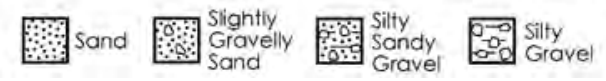

$\mathrm{pH}$

4. Pedogenic Carbonat

Figure 8.1. Pore water Tc and U, Gravimetric Moisture Content, $\mathrm{pH}$ and Electrical Conductivity for Borehole C4191 Samples 
Table 8.3. Anion Composition of Water Extracts of C4191 Sediment (units $\mu \mathrm{g} / \mathrm{g}$ dry sediment)

\begin{tabular}{|c|c|c|c|c|c|c|c|}
\hline Sample ID ${ }^{(a)}$ & Fluoride & Chloride & Nitrite & Nitrate & Sulfate-IC & Phosphate-IC & Alk \\
\hline C4191-13 & 0.35 & $<0.24$ & $<0.45$ & 9.52 & 2.94 & 7.91 & 114.23 \\
\hline C4191-17.5 & 0.08 & 0.69 & $<0.45$ & 11.71 & 13.71 & $64.13^{(b)}$ & $607.09^{(b)}$ \\
\hline C4191-22.5 & 0.07 & 0.41 & $<0.45$ & 3.01 & 12.6 & 35.16 & 616.39 \\
\hline C4191-27.5 & 0.04 & 0.7 & $<0.45$ & 15.12 & 15.02 & 53.06 & 636.59 \\
\hline C4191-37.5 & 0.16 & 0.53 & $<0.45$ & 12.78 & 14.34 & 23.7 & 411.48 \\
\hline C4191-41 & 0.2 & 2.03 & $<0.45$ & $165.94^{(b)}$ & 74.29 & 74.1 & 526.7 \\
\hline C4191-43.5 & 0.33 & 1.23 & $<0.45$ & 138.11 & 67.17 & 24.91 & $\mathrm{NA}^{\odot}$ \\
\hline C4191-48.5 & 0.72 & 1.49 & $<0.45$ & 179.87 & $106.98^{(b)}$ & 0.98 & NA \\
\hline C4191-51 & 0.62 & 1.47 & $<0.45$ & 152.76 & 168.03 & 0.6 & 193.16 \\
\hline C4191-53.5 & 0.61 & 1.57 & $<0.45$ & 177.42 & 157.6 & 0.8 & NA \\
\hline C4191-56 & 0.7 & 3.51 & $<0.45$ & 247.14 & 295.67 & 0.7 & NA \\
\hline C4191-58.5 & 0.46 & 1.65 & $<0.45$ & 193.14 & 196.75 & $<0.51$ & NA \\
\hline C4191-61 & 0.63 & 1.56 & 0.6 & 159.35 & 181.42 & 0.59 & 151.64 \\
\hline C4191-63.5 & 0.76 & 3.16 & 0.7 & 248.1 & 522.73 & 0.87 & NA \\
\hline C4191-66 & 0.6 & 1.35 & $3.01^{(b)}$ & 129.19 & 311.5 & 0.9 & NA \\
\hline C4191-68.5 & 0.71 & 2.17 & $<0.45$ & 207.12 & 242.48 & 0.58 & NA \\
\hline C4191-71 & 0.78 & 3.19 & 0.38 & 351.17 & 242.63 & 0.52 & 156.41 \\
\hline C4191-73.5 & $1.37^{(\mathbf{b})}$ & 7.21 & 2.13 & 364.5 & 261.76 & 1.19 & NA \\
\hline C4191-76 & 1.18 & 6.81 & 0.77 & 374.21 & 297.68 & $<0.53$ & NA \\
\hline C4191-78.5 & 1.28 & 7.5 & 1.72 & 369.06 & 322.87 & $<0.51$ & NA \\
\hline C4191-81 & 1.89 & 8.13 & 2.76 & 787.63 & 828.47 & $<0.50$ & 112.2 \\
\hline C4191-83.5 & 1.42 & 8.34 & 0.91 & 540.77 & 496.21 & 0.54 & NA \\
\hline C4191-86 & 0.52 & $42.46^{(b)}$ & 2.58 & 9819.85 & 1341.91 & $<0.51$ & NA \\
\hline C4191-88.5 & $<0.12$ & 38.98 & 2.86 & $1.37 E+04$ & 230.79 & $<0.50$ & NA \\
\hline C4191-91 & 0.44 & 48.68 & 4.42 & 7602.25 & 224.99 & $<0.51$ & 36.72 \\
\hline C4191-91 DUP & 0.7 & 57.32 & 5.2 & 8960.51 & 269.74 & $<0.50$ & 42.16 \\
\hline C4191-93.5 & $<0.12$ & 40.42 & 1.22 & $1.22 E+04$ & 199.93 & $<0.50$ & NA \\
\hline C4191-96 & 0.44 & 19.03 & $<0.45$ & $1.57 E+04$ & 69.79 & $<0.51$ & NA \\
\hline C4191-98.5 & 0.58 & 28.39 & $<0.45$ & 8868.99 & 183.89 & $<0.50$ & NA \\
\hline C4191-101 & 0.18 & 37.42 & 1.1 & 6082.52 & 242.85 & $<0.50$ & 31.28 \\
\hline C4191-103.5 & 0.19 & 39.56 & 1.13 & $1.12 E+04$ & 149.99 & $<0.51$ & NA \\
\hline C4191-106 & 0.21 & 23.32 & 0.87 & 5175.46 & 136.08 & $<0.51$ & NA \\
\hline C4191-108.5 & 0.34 & 23.89 & 0.72 & $1.10 \mathrm{E}+04$ & 105.3 & $<0.50$ & NA \\
\hline C4191-111 & 0.4 & 19.43 & 0.75 & 2732.79 & 90.16 & $<0.53$ & 26.51 \\
\hline C4191-113.5 & 0.33 & 33.06 & $<0.45$ & $1.97 E+04$ & 204.22 & $<0.51$ & NA \\
\hline C4191-116 & 0.65 & 30.14 & 2.1 & 7936.05 & 281.01 & 0.91 & NA \\
\hline C4191-118.5 & 0.36 & 16.78 & 0.7 & 1860.81 & 123.27 & $<0.50$ & NA \\
\hline C4191-121 & 0.4 & 20.63 & 0.88 & 2451.57 & 100.48 & 0.78 & 34.01 \\
\hline C4191-123.5 & 0.42 & 20.81 & $<0.45$ & 4823.38 & 80.79 & $<0.50$ & NA \\
\hline C4191-126 & 0.71 & 29.43 & 1.58 & 5480.1 & 139.44 & $<0.50$ & NA \\
\hline C4191-128.5 & 0.4 & 20.97 & 0.72 & 4774.02 & 82.43 & $<0.50$ & NA \\
\hline C4191-131 & 0.61 & 29.69 & 0.72 & 5196.65 & 111.89 & $<0.50$ & 27.2 \\
\hline C4191-131 DUP & 0.44 & 31.51 & 0.83 & 5071.59 & 117.71 & $<0.51$ & 27.88 \\
\hline C4191-133.5 & 0.39 & 21.33 & $<0.45$ & 6811.8 & 67.96 & $<0.51$ & NA \\
\hline C4191-136 & 0.37 & 24.8 & 0.66 & 2876.94 & 74.04 & $<0.51$ & NA \\
\hline C4191-138.5 & 0.35 & 25.96 & $<0.45$ & 7479.73 & 30.29 & $<0.51$ & NA \\
\hline C4191-141 & 0.52 & 6.65 & 0.67 & 600.41 & 13.53 & $<0.51$ & 34.69 \\
\hline C4191-143.5 & 0.44 & 5.71 & $<0.45$ & 243.97 & 13.31 & $<0.51$ & NA \\
\hline
\end{tabular}


PNNL-17821

Table 8.3 (contd)

\begin{tabular}{cccccccc}
\hline Sample ID $^{(a)}$ & Fluoride & Chloride & Nitrite & Nitrate & Sulfate-IC & Phosphate-IC & Alk \\
\hline C4191-146 & 0.45 & 4.71 & $<0.45$ & $\mathbf{3 7 1 . 5 3}$ & 12.59 & $<0.51$ & NA \\
C4191-148.5 & 0.38 & 4.71 & $<0.45$ & $\mathbf{4 2 3 . 0 1}$ & 13.39 & $<0.50$ & NA \\
C4191-151 & 0.61 & 3.98 & $<0.45$ & $\mathbf{2 0 4 . 3 5}$ & 12.82 & $<0.51$ & 38.78 \\
C4191-153.5 & 0.47 & 4.16 & $<0.45$ & $\mathbf{2 7 3 . 9 1}$ & 12.27 & 2.24 & 29.24 \\
C4191-156 & 0.6 & 4.44 & $<0.45$ & $\mathbf{1 2 2 . 6 5}$ & 15.56 & 1.51 & 40.8 \\
C4191-158.5 & 0.58 & 5.28 & $<0.45$ & $\mathbf{1 7 3 . 9 4}$ & 16.85 & $<0.51$ & 34.7 \\
C4191-158.5-DUP & 0.59 & 4.82 & $<0.45$ & $\mathbf{1 6 2 . 6 5}$ & 15.85 & $<0.51$ & 31.45 \\
C4191-161 & 0.6 & 2.17 & $<0.45$ & 3.37 & 13.26 & $<0.51$ & 51.69 \\
C4191-171 & 0.76 & 4.29 & $<0.45$ & 4.45 & 24.5 & $<0.51$ & 64.62 \\
C4191-181 & 0.73 & 2.45 & $<0.45$ & 3.09 & 18.99 & $<0.51$ & 60.53 \\
C4191-191 & 0.74 & 1.55 & $<0.45$ & 0.43 & 14.73 & $<0.51$ & 69.37 \\
C4191-201 & 0.69 & 1.32 & $<0.45$ & 0.43 & 11.46 & $<0.51$ & 58.67 \\
C4191-211 & 0.6 & 0.86 & $<0.45$ & 1.4 & 8.87 & $<0.51$ & 51.01 \\
C4191-221 & 0.65 & 0.86 & $<0.48$ & 0.21 & 13.23 & $<0.53$ & 55.42 \\
C4191-221 DUP & 0.57 & 0.78 & $<0.48$ & 0.6 & 11.28 & $<0.53$ & 54.71 \\
C4191-231 & 0.61 & 0.58 & $<0.49$ & 2.45 & 10.68 & $<0.54$ & 47.69 \\
C4191-241 & 0.65 & 1 & $<0.45$ & 4.03 & 14.85 & $<0.51$ & 53.08 \\
C4191-251 & 0.55 & 1.12 & $<0.45$ & 3.25 & 12.14 & $<0.51$ & 45.57 \\
C4191-261 & 0.46 & 1.01 & $<0.49$ & 2.15 & 9.47 & $<0.55$ & 45.89 \\
C4191-271 & 0.44 & 0.81 & $<0.45$ & 1.64 & 7.85 & $<0.51$ & 40.82 \\
C4191-281 & 0.62 & 1.28 & $<0.45$ & 2.43 & 11.67 & $<0.51$ & 47.61 \\
C4191-291 & $\mathbf{1 . 0 1}$ & 1.89 & $<0.45$ & 2.7 & 19.45 & $<0.51$ & 59.85 \\
C4191-301 & $\mathbf{0 . 9 1}$ & 2.33 & $<0.46$ & 1.18 & 25.5 & $<0.52$ & 59.98 \\
C4191-311 & $\mathbf{1 . 0 7}$ & 2.8 & $<0.45$ & 0.6 & 22.85 & $<0.51$ & 58.49 \\
C4191-321 & 0.77 & 2.17 & $<0.45$ & 2.09 & 24.58 & $<0.50$ & 38.76 \\
C4191-331 & 0.77 & 2.51 & $<0.45$ & 0.17 & 24.79 & $<0.51$ & 58.48 \\
C4191-341 & 0.61 & 1.87 & $<0.45$ & 0.24 & 17.2 & $<0.51$ & 45.56 \\
\hline
\end{tabular}

(a) The sample IDs include the borehole number and the approximate depth of each sample

(b) bold values are higher than others for given constituent.

(c) $\mathrm{NA}=$ not analyzed

Table 8.4 presents the same water-extract anion data but in units of $\mathrm{mg} / \mathrm{L}$ pore-water concentrations, which are the units most related to comparing with the soil resistivity measurements. Figure 8.3 plots some of the more important pore-water anion concentrations. Table 8.4 and Figure 8.2 also show the comparison of two independent methods for determining the sulfate and phosphate contents of the water extracts. In Table 8.4, the legend IC stands for ion chromatography, the most common method of measuring anions, and the legend ICP stands for inductively coupled plasma emission spectroscopy, which can directly measure total sulfur and total phosphate in a sample. We have assumed that all waterleachable sulfur is in fact sulfate and that water-leachable phosphorous is phosphate. At the Hanford site, the former assumption appears valid and is based on the good agreement between the two phosphate values for each sample. Our assumption that all water-leachable phosphorous is phosphate is thus corroborated. In general, the ICP method for determining phosphorous has a more sensitive detection limit than the IC method, so lower values can be quantitated.

It should be noted that because the sediments deep in the profile are very dry, a large dilution factor occurs when performing the water extracts, and when data are plotted as pore-water concentrations, very 
PNNL-17821

dry sediments often exhibit elevated (biased high) calculated pore-water concentrations. The deep apparent increased fluoride concentrations are an artifact of this calculation and a mediocre detection limit constraint that adds to the positive bias.

Table 8.4. Water-Extractable Anions Converted to Pore-Water Concentrations for C4191 Borehole Samples (mg/L)

\begin{tabular}{|c|c|c|c|c|c|c|c|c|c|}
\hline Sample ID ${ }^{(a)}$ & Fluoride & Chloride & Nitrite & Nitrate & Sulfate-IC & Sulfate-ICP & Phosphate-IC & Phosphate-ICP & Alk \\
\hline C4191-13 & 5.36 & $<3.59$ & $<6.85$ & 144.71 & 44.68 & 46.62 & 120.2 & 117.91 & 1736.05 \\
\hline C4191-17.5 & 0.89 & 7.85 & $<5.11$ & 132.52 & 155.15 & 190.49 & 725.73 & 832.9 & 6869.75 \\
\hline C4191-22.5 & 1.01 & 6.31 & $<6.87$ & 45.79 & 191.84 & 192.67 & 535.33 & 546.22 & 9385.44 \\
\hline C4191-27.5 & 0.44 & 6.9 & $<4.47$ & 149.87 & 148.92 & 145.01 & 526.03 & 521.23 & 6311.5 \\
\hline C4191-37.5 & 3.54 & 12.03 & $<10.30$ & 291.84 & 327.42 & 372.32 & 541.23 & 623.22 & 9397.46 \\
\hline C4191-41 & 2.05 & 20.57 & $<4.58$ & 1683.77 & 753.78 & 753.76 & 751.88 & 761.38 & 5344.46 \\
\hline C4191-43.5 & 6.51 & 24.52 & $<9.02$ & 2759.74 & 1342.34 & NA & 497.82 & NA & NA \\
\hline C4191-48.5 & 21.80 & 45.09 & $<13.69$ & 5460.63 & 3247.7 & NA & 29.72 & NA & NA \\
\hline C4191-51 & 16.1 & 38.18 & $<11.73$ & 3973.69 & 4370.76 & 4670.66 & 15.62 & 20.48 & 5024.46 \\
\hline C4191-53.5 & 18.59 & 48.27 & $<13.82$ & 5438.05 & 4830.47 & NA & 24.56 & NA & NA \\
\hline C4191-56 & 12.41 & 61.9 & $<7.95$ & 4355.43 & 5210.76 & NA & 12.35 & NA & NA \\
\hline C4191-58.5 & 13.97 & 49.76 & $<13.59$ & 5821.47 & 5930.4 & NA & $<15.22$ & NA & NA \\
\hline C4191-61 & 17.13 & 42.36 & 16.23 & 4319.67 & 4917.96 & 5008.69 & 15.97 & 18.43 & 4110.56 \\
\hline C4191-63.5 & 5.51 & 23 & 5.06 & 1804.44 & 3801.83 & NA & 6.31 & NA & NA \\
\hline C4191-66 & 11.93 & 26.93 & 60.21 & 2583.88 & 6229.95 & NA & 17.9 & NA & NA \\
\hline C4191-68.5 & 20.74 & 63.73 & $<13.25$ & 6082.5 & 7121.04 & NA & 17.03 & NA & NA \\
\hline C4191-71 & 22.84 & 93.48 & 11.13 & $1.03 E+04$ & 7117.15 & 7386.19 & 15.26 & 18.6 & 4588.15 \\
\hline C4191-73.5 & 27.77 & 146.1 & 43.2 & 7386.64 & 5304.55 & NA & 24.19 & NA & NA \\
\hline C4191-76 & 26.17 & 150.73 & 17.11 & 8277.44 & 6584.58 & NA & $<11.66$ & NA & NA \\
\hline C4191-78.5 & 28.66 & 167.77 & 38.57 & 8252.62 & 7219.73 & NA & $<11.35$ & NA & NA \\
\hline C4191-81 & 43.43 & 187.21 & 63.57 & $1.81 \mathrm{E}+04$ & $1.91 \mathrm{E}+04$ & $1.66 \mathrm{E}+04$ & $<11.63$ & 10.29 & 2582.88 \\
\hline C4191-83.5 & 40.36 & 236.18 & 25.88 & $1.53 E+04$ & $1.41 \mathrm{E}+04$ & NA & 15.18 & NA & NA \\
\hline C4191-86 & 5.80 & 475.61 & 28.91 & $1.10 \mathrm{E}+05$ & $1.50 \mathrm{E}+04$ & NA & $<5.66$ & NA & NA \\
\hline C4191-88.5 & $<1.88$ & 625.05 & 45.9 & $2.19 \mathrm{E}+05$ & 3700.57 & NA & $<8.10$ & NA & NA \\
\hline C4191-91 & 5.8 & 639.31 & 58.06 & $9.98 \mathrm{E}+04$ & 2954.56 & 3336.2 & $<6.63$ & 17.96 & 482.25 \\
\hline C4191-91 DUP & 9.18 & 752.75 & 68.23 & $1.18 \mathrm{E}+05$ & 3542.16 & 4026.63 & $<6.63$ & 19.97 & 553.61 \\
\hline C4191-93.5 & $<1.88$ & 648.55 & 19.64 & $1.95 \mathrm{E}+05$ & 3207.77 & NA & $<8.10$ & NA & NA \\
\hline C4191-96 & 13.14 & 568 & $<13.46$ & $4.69 \mathrm{E}+05$ & 2082.76 & NA & $<15.07$ & NA & NA \\
\hline C4191-98.5 & 10.46 & 512.76 & $<8.14$ & $1.60 \mathrm{E}+05$ & 3321.19 & NA & $<9.12$ & NA & NA \\
\hline C4191-101 & 2.47 & 515.83 & 15.22 & $8.38 \mathrm{E}+04$ & 3347.29 & 3683.54 & $<6.96$ & 15.22 & 431.13 \\
\hline C4191-103.5 & 2.86 & 593.14 & 16.97 & $1.68 \mathrm{E}+05$ & 2248.61 & NA & $<7.57$ & NA & NA \\
\hline C4191-106 & 5.24 & 568.93 & 21.29 & $1.26 \mathrm{E}+05$ & 3320 & NA & $<12.35$ & NA & NA \\
\hline C4191-108.5 & 7.15 & 508.06 & 15.41 & $2.34 \mathrm{E}+05$ & 2239.16 & NA & $<10.74$ & NA & NA \\
\hline C4191-111 & 8.69 & 425.55 & 16.5 & $5.99 \mathrm{E}+04$ & 1974.95 & 2233.93 & $<11.66$ & 17.11 & 580.71 \\
\hline C4191-113.5 & 4.26 & 429.06 & $<5.88$ & $2.56 \mathrm{E}+05$ & 2650.2 & NA & $<6.58$ & NA & NA \\
\hline C4191-116 & 10.57 & 489.7 & 34.05 & $1.29 \mathrm{E}+05$ & 4566.46 & NA & 14.85 & NA & NA \\
\hline
\end{tabular}


PNNL-17821

Table 8.4 (contd)

\begin{tabular}{|c|c|c|c|c|c|c|c|c|c|}
\hline Sample ID $^{(\mathrm{a})}$ & Fluoride & Chloride & Nitrite & Nitrate & Sulfate-IC & Sulfate-ICP & Phosphate-IC & Phosphate-ICP & Alk \\
\hline C4191-118.5 & 8.67 & 401.16 & 16.8 & $4.45 E+04$ & 2946.44 & NA & $<12.07$ & NA & NA \\
\hline C4191-121 & 8.3 & 429.74 & 18.27 & $5.11 \mathrm{E}+04$ & 2093.2 & 2279.01 & 16.35 & 12.4 & 708.44 \\
\hline C4191-123.5 & 10.60 & 519.54 & $<11.26$ & $1.20 \mathrm{E}+05$ & 2016.88 & NA & $<12.60$ & NA & NA \\
\hline C4191-126 & 11.67 & 485.18 & 26.09 & $9.04 \mathrm{E}+04$ & 2299 & NA & $<8.32$ & NA & NA \\
\hline C4191-128.5 & 9.53 & 495.14 & 16.96 & $1.13 E+05$ & 1946.02 & NA & $<11.92$ & NA & NA \\
\hline C4191-131 & 8.67 & 422.45 & 10.24 & 7.39E+04 & 1591.98 & 1924.88 & $<7.18$ & 16.15 & 386.98 \\
\hline C4191-131 DUP & 6.27 & 448.35 & 11.87 & $7.22 \mathrm{E}+04$ & 1674.77 & 1957.61 & $<7.19$ & 17.01 & 396.75 \\
\hline C4191-133.5 & 10.16 & 562.14 & $<11.89$ & $1.80 \mathrm{E}+05$ & 1791.11 & NA & $<13.31$ & NA & NA \\
\hline C4191-136 & 8.36 & 563.79 & 14.89 & $6.54 \mathrm{E}+04$ & 1683.01 & NA & $<11.48$ & NA & NA \\
\hline C4191-138.5 & 5.42 & 396.16 & $<6.87$ & $1.14 \mathrm{E}+05$ & 462.29 & NA & $<7.71$ & NA & NA \\
\hline C4191-141 & 11.7 & 150.92 & 15.29 & $1.36 \mathrm{E}+04$ & 307.22 & 365.46 & $<11.47$ & 7.56 & 787.45 \\
\hline C4191-143.5 & 11.22 & 147.21 & $<11.59$ & 6286.26 & 343.02 & NA & $<13.01$ & NA & NA \\
\hline C4191-146 & 10.85 & 114.7 & $<10.96$ & 9045.8 & 306.56 & NA & $<12.30$ & NA & NA \\
\hline C4191-148.5 & 10.75 & 133.78 & $<12.78$ & $1.20 \mathrm{E}+04$ & 380.21 & NA & $<14.34$ & NA & NA \\
\hline C4191-151 & 12.93 & 84.49 & $<9.58$ & 4336.42 & 271.97 & 291.39 & $<10.72$ & 1.71 & 823.02 \\
\hline C4191-153.5 & 10.51 & 92.95 & $<10.08$ & 6118.87 & 274.18 & 304.49 & 50.15 & 1.47 & 653.28 \\
\hline C4191-156 & 11.14 & 82.39 & $<8.38$ & 2277.65 & 289.03 & 306.24 & 27.97 & 1.3 & 757.74 \\
\hline C4191-158.5 & 8.3 & 75.78 & $<6.47$ & 2494.88 & 241.7 & 257.6 & $<7.25$ & 1.5 & 497.74 \\
\hline C4191-158.5-DUP & 8.39 & 69.15 & $<6.50$ & 2333.03 & 227.3 & 244.31 & $<7.28$ & 2.76 & 451.12 \\
\hline C4191-161 & 15.74 & 57.3 & $<11.88$ & 88.83 & 349.23 & 354.67 & $<13.31$ & 3.72 & 1361.63 \\
\hline C4191-171 & 12.12 & 68.67 & $<7.22$ & 71.17 & 391.8 & 399.45 & $<8.08$ & 2.69 & 1033.6 \\
\hline C4191-181 & 19.69 & 65.78 & $<12.09$ & 82.89 & 509.2 & 526.81 & $<13.54$ & 7.44 & 1622.92 \\
\hline C4191-191 & 21.42 & 44.88 & $<13.10$ & 12.51 & 427.6 & 434.03 & $<14.67$ & 9.43 & 2014.28 \\
\hline C4191-201 & 29.83 & 56.47 & $<19.42$ & 18.39 & 491.82 & 505.31 & $<21.75$ & 6.44 & 2518.19 \\
\hline C4191-211 & 31.75 & 45.41 & $<23.74$ & 73.87 & 467.05 & 480.65 & $<26.59$ & $<33$ & 2685.12 \\
\hline C4191-221 & 13.44 & 17.73 & $<9.80$ & 4.26 & 271.51 & 274.09 & $<10.97$ & 32.13 & 1137.24 \\
\hline C4191-221 DUP & 11.78 & 16.03 & $<9.80$ & 12.24 & 231.41 & 242.89 & $<10.97$ & 29.91 & 1122.63 \\
\hline C4191-231 & 23.88 & 22.55 & $<19.03$ & 95.69 & 417.84 & 419.18 & $<21.31$ & 3.84 & 1865.37 \\
\hline C4191-241 & 21.05 & 32.39 & $<14.66$ & 130.98 & 482.43 & 487.39 & $<16.42$ & 1.62 & 1724.5 \\
\hline C4191-251 & 26.62 & 54.44 & $<21.99$ & 158.27 & 592.1 & 597.15 & $<24.63$ & $<30$ & 2221.9 \\
\hline C4191-261 & 22.86 & 50.11 & $<24.28$ & 106.29 & 468.52 & 469.96 & $<27.19$ & 1.72 & 2269.62 \\
\hline C4191-271 & 29.39 & 54.16 & $<30.20$ & 109.46 & 525.15 & 539.08 & $<33.81$ & 10.12 & 2731.92 \\
\hline C4191-281 & 38.93 & 81.2 & $<28.53$ & 153.48 & 738.01 & 771.94 & $<31.95$ & 10.25 & 3011.28 \\
\hline C4191-291 & 52.17 & 97.14 & $<23.22$ & 138.71 & 1000.8 & 1119.1 & $<26.00$ & 7.3 & 3080.38 \\
\hline C4191-301 & 71.69 & 182.77 & $<36.29$ & 92.25 & 2000.21 & 2107.9 & $<40.63$ & 26.04 & 4705.43 \\
\hline C4191-311 & 92.7 & 243.69 & $<39.23$ & 52.6 & 1987.06 & 2109.59 & $<43.93$ & 67.69 & 5086.97 \\
\hline C4191-321 & 56.39 & 159.08 & $<33.03$ & 153.23 & 1799.94 & 2022.08 & $<36.98$ & 6.52 & 2838.47 \\
\hline C4191-331 & 23.29 & 75.74 & $<13.60$ & 5.1 & 747.46 & 789.39 & $<15.23$ & 8.61 & 1763.22 \\
\hline C4191-341 & 6.15 & 18.97 & $<4.57$ & 2.44 & 174.48 & 193.65 & $<5.12$ & 2.31 & 462.09 \\
\hline
\end{tabular}

(a) The sample IDs include the borehole number and the approximate depth of each sample 
Table 8.5 shows the water-leachable concentrations of divalent and monovalent cations in units of $\mu \mathrm{g}$ per gram of dry sediment for the grab samples analyzed from borehole C4191. Table 8.6 shows the same water-leachable cation data in units of $\mathrm{mg} / \mathrm{L}$ of pore water, which was a better convention for comparing with the soil resistivity data. Table 8.5 shows the commonly observed ion-exchange front dynamics that occur when sodium-dominated liquid wastes are disposed of into native Hanford sediments that have their cation exchange surface sites naturally loaded with divalent cations such as calcium, magnesium, and strontium. When waste liquid percolates vertically into a sediment profile, the sodium in the waste replaces the native divalent cations (and to some extent native potassium) on the exchange sites and "pushes" the replaced divalent cations out in the leading edge of the waste plume. This is what is observed by looking at the vertical distribution of the mass of major cations in water leached from the grab samples from borehole C4191. As shown in bold blue type in Table 8.5, the waterextractable calcium, magnesium, and strontium concentrations are quite low (depleted) from the shallowest sample (13 ft bgs) down to about $81 \mathrm{ft}$ bgs in comparison to the values below about $161 \mathrm{ft}$ bgs that in our opinion represents native sediments not significantly impacted by liquid waste. The waterextractable potassium also shows the shallow depletion zone from 13 to $\sim 51 \mathrm{ft}$ bgs, which is not as deep as the divalent cation depletion zone because potassium is held more strongly to many Hanford minerals than sodium, thus making its cation exchange slightly more difficult. From 91 to 153 to $158.5 \mathrm{ft}$ bgs, all the divalent cations show elevated water-extractable concentrations in comparison to the deeper sediments not impacted by the waste solution.

This zone represents the front of the waste plume. Elevated potassium is observed from 81 to $141 \mathrm{ft}$ bgs. In contrast, the water-exchangeable sodium distribution shows elevated concentrations from the shallowest sample (13 ft bgs) down to $141 \mathrm{ft}$ bgs, with extremely high values from 91 to $131 \mathrm{ft}$ bgs. The narrower zone (91 to $131 \mathrm{ft}$ bgs) represents the active cation exchange front where reactions are still occurring as natural recharge slowly pushes the waste plume ever deeper. Shallower, from 13 to $81 \mathrm{ft}$ bgs, the pore waters are a mixture of natural recharge from post disposal and the last of the liquid disposed of to the 216-B-26 trench.

Table 8.6 shows the same water-extract major cation data converted to pore-water concentrations, using the simplifying assumption that adding de-ionized water to field moist sediment does not significantly dissolve solids and minerals, but rather only dilutes and promotes the separation of the extant small volume of pore fluid. For highly contaminated vadose zone pore water, this assumption is fairly valid, but for slightly or uncontaminated pore water, the de-ionized water does dissolve some mildly soluble salts and thus overestimates the true pore-water concentrations. As mentioned, the calculated pore-water concentrations are needed to correlate with the field soil resistivity data, which is the subject of the "ground-truthing" exercise. Table 8.3 shows that elevated nitrate is observed down to the maximum depth of $158.5 \mathrm{ft}$ bgs and Table 8.5 shows that elevated sodium is found to a depth of $141 \mathrm{ft}$ bgs. The difference is caused by the ion exchange reactions wherein sodium is adsorbed on sediment surface cation exchange sites, and its transport is somewhat retarded in its descent with the waste fluids. The calcium and magnesium elevated concentrations (also shown in Table 8.5) show a maximum descent to $158.5 \mathrm{ft}$ bgs in agreement with the nitrate. The divalent cations that are displaced from the native sediments travel at the front of the plume, effectively being pushed ahead by the high sodium in the waste. Figure 8.4 shows the water-extract cation data in units of $\mu \mathrm{g} / \mathrm{g}$ sediment as a function of depth, and Figure 8.5 shows them as pore-water concentrations (mg/L). 


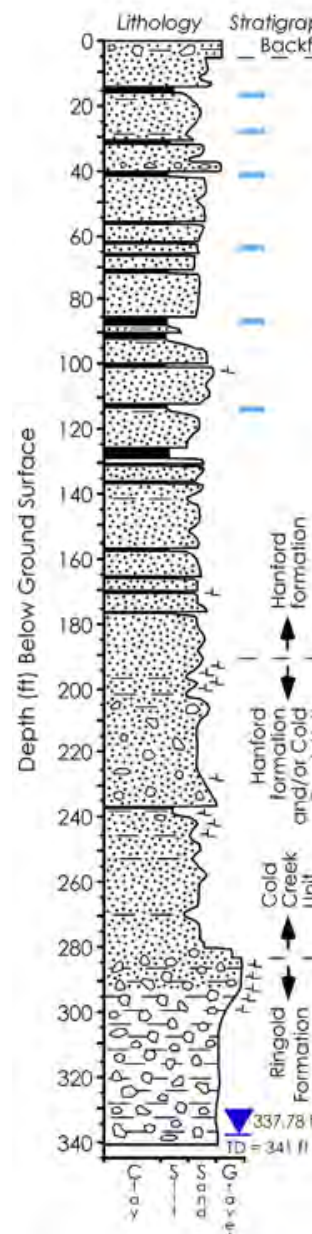

- Fine-Grained Laye

In $>8$ wis Moisture

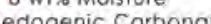

C4191 (B-26 Trench)
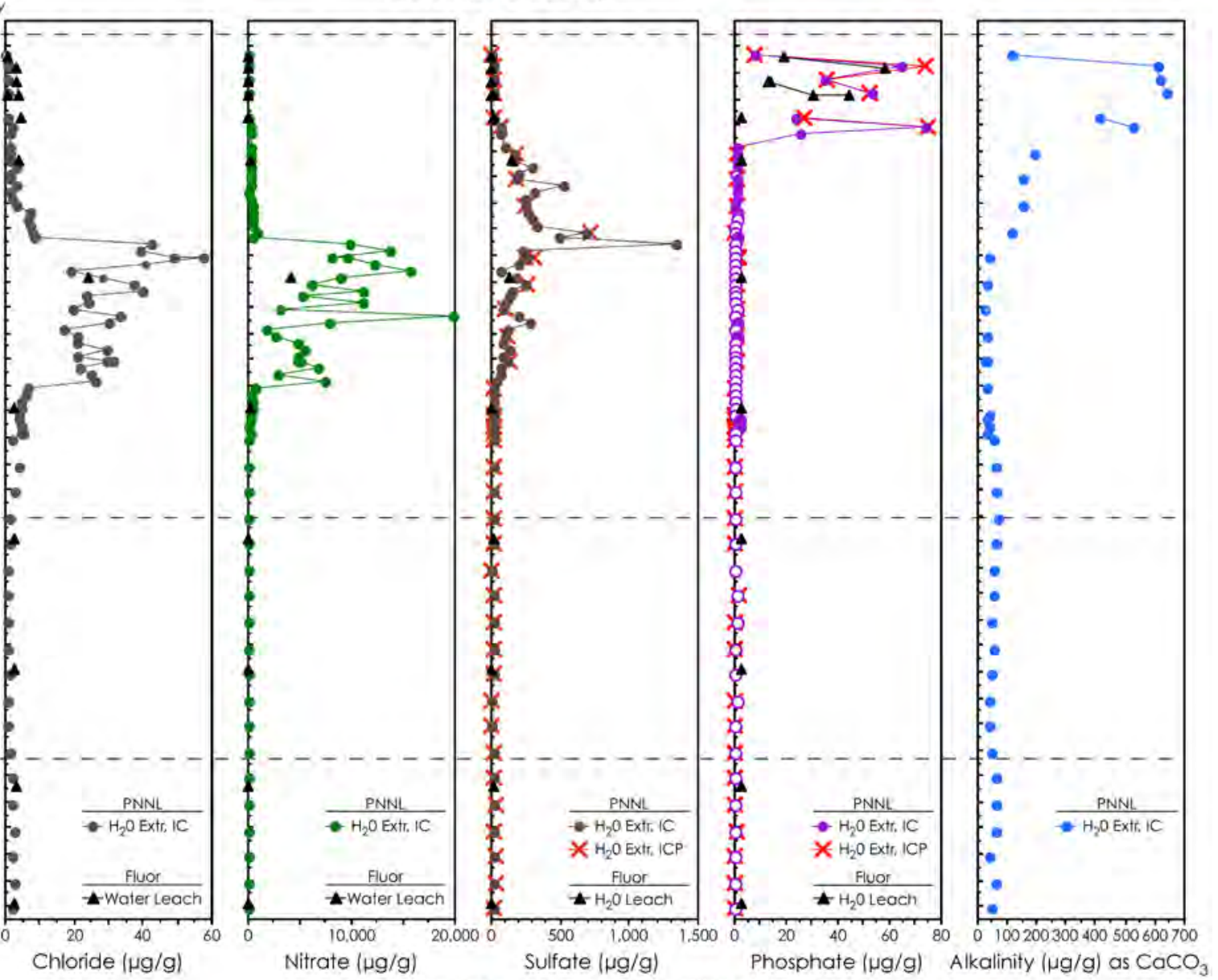

2004/DCL/C4191/023 (11/09)

Figure 8.2. Major Anions (in 1:1 sediment-to-water extracts) from Borehole C4191 


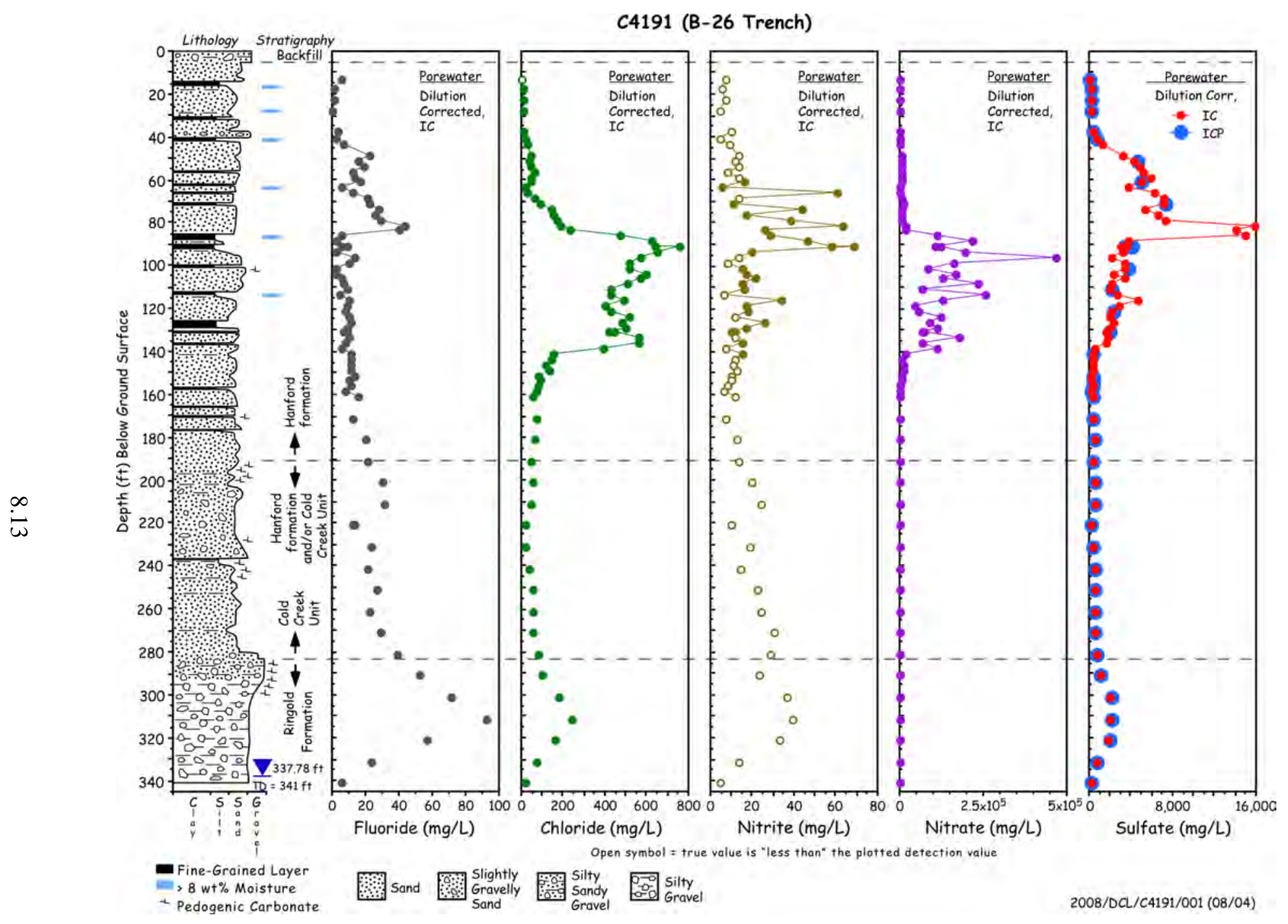

Figure 8.3. Calculated C4191 Pore Water Concentrations of Major Anions 
PNNL-17821

Table 8.5. Water Extractable Cations in Borehole C4191 Sediments ( $\mu \mathrm{g} / \mathrm{g}$ dry soil)

\begin{tabular}{|c|c|c|c|c|c|}
\hline $\begin{array}{c}\text { Sample } \\
\text { ID }^{(a)}\end{array}$ & $\begin{array}{c}\text { Ca } \\
\mu \mathrm{g} / \mathrm{g} \text { soil }\end{array}$ & $\begin{array}{c}\text { Mg } \\
\mu g / g \text { soil }\end{array}$ & $\begin{array}{c}\mathrm{Sr} \\
\mu \mathrm{g} / \mathrm{g} \text { soil }\end{array}$ & $\begin{array}{c}\mathrm{Na} \\
\mu \mathrm{g} / \mathrm{g} \text { soil }\end{array}$ & $\begin{array}{c}\mathrm{K} \\
\mu \mathrm{g} / \mathrm{g} \text { soil }\end{array}$ \\
\hline C4191-13 WE & $1.0 \mathrm{E}+00^{\odot}$ & 3.3E-01 & (5.2E-03) & $6.2 \mathrm{E}+01^{(\mathrm{b})}$ & (7.0E-01) \\
\hline C4191-17.5 WE & $(3.9 \mathrm{E}-01)^{(\mathrm{d})}$ & (2.3E-01) & (1.0E-03) & $3.3 \mathrm{E}+02$ & (8.8E-01) \\
\hline C4191-22.5 WE & 6.5E-01 & 5.8E-01 & (1.6E-03) & $3.3 E+02$ & $(1.2 E+00)$ \\
\hline C4191-27.5 WE & $(4.0 \mathrm{E}-01)$ & (5.9E-02) & (3.6E-04) & $3.4 \mathrm{E}+02$ & $1.5 \mathrm{E}+00$ \\
\hline C4191-37.5 WE & 7.1E-01 & $(4.8 \mathrm{E}-02)$ & (5.3E-03) & $2.3 \mathrm{E}+02$ & $1.7 E+00$ \\
\hline C4191-41 WE & $6.2 E-01$ & (3.1E-01) & (1.1E-02) & $3.8 \mathrm{E}+02$ & $2.7 E+00$ \\
\hline C4191-51 WE & $6.8 \mathrm{E}-01$ & (1.3E-01) & (5.5E-03) & $2.4 \mathrm{E}+02$ & $2.3 E+00$ \\
\hline C4191-61 WE & 8.8E-01 & (1.7E-01) & (6.7E-03) & $2.1 \mathrm{E}+02$ & $2.5 \mathrm{E}+00$ \\
\hline C4191-71 WE & $1.0 \mathrm{E}+00$ & $(2.2 E-01)$ & (6.5E-03) & $3.2 \mathrm{E}+02$ & $3.5 \mathrm{E}+00$ \\
\hline C4191-81 WE & $5.1 \mathrm{E}+00$ & $1.6 \mathrm{E}+00$ & (3.6E-02) & $6.6 \mathrm{E}+02$ & $9.2 \mathrm{E}+00$ \\
\hline C4191-91 WE & $4.0 \mathrm{E}+02$ & $1.3 E+02$ & $2.8 \mathrm{E}+00$ & $2.3 E+03$ & $4.8 \mathrm{E}+01$ \\
\hline C4191-91 WE dup & $4.7 E+02$ & $1.5 E+02$ & $3.4 \mathrm{E}+00$ & $2.7 E+03$ & $5.4 \mathrm{E}+01$ \\
\hline C4191-101 WE & $2.5 E+02$ & $8.3 E+01$ & $1.7 E+00$ & $1.9 E+03$ & $3.3 E+01$ \\
\hline C4191-111 WE & $2.5 \mathrm{E}+02$ & $6.0 \mathrm{E}+01$ & $1.4 \mathrm{E}+00$ & $7.3 E+02$ & $2.3 E+01$ \\
\hline C4191-121 WE & $2.1 E+02$ & $6.7 E+01$ & $1.2 E+00$ & $6.6 E+02$ & $2.4 \mathrm{E}+01$ \\
\hline C4191-131 WE & $4.1 \mathrm{E}+02$ & $1.0 \mathrm{E}+02$ & $2.3 E+00$ & $1.1 \mathrm{E}+03$ & $2.7 E+01$ \\
\hline C4191-131 WE dup & $4.4 \mathrm{E}+02$ & $1.1 \mathrm{E}+02$ & $2.5 E+00$ & $1.2 \mathrm{E}+03$ & $2.8 \mathrm{E}+01$ \\
\hline C4191-141 WE & $1.2 \mathrm{E}+02$ & $4.4 \mathrm{E}+01$ & 7.2E-01 & $4.0 \mathrm{E}+01$ & $1.7 \mathrm{E}+01$ \\
\hline C4191-151 WE & $4.2 \mathrm{E}+01$ & $1.5 \mathrm{E}+01$ & 2.6E-01 & $2.8 \mathrm{E}+01$ & $8.7 \mathrm{E}+00$ \\
\hline C4191-153.5 WE & $4.2 \mathrm{E}+01$ & $1.6 \mathrm{E}+01$ & 2.6E-01 & $2.5 \mathrm{E}+01$ & $9.0 \mathrm{E}+00$ \\
\hline C4191-156 WE & $2.3 E+01$ & $9.0 \mathrm{E}+00$ & $(1.4 \mathrm{E}-01)$ & $2.4 \mathrm{E}+01$ & $7.1 \mathrm{E}+00$ \\
\hline C4191-158.5 WE & $3.3 E+01$ & $1.2 \mathrm{E}+01$ & $(2.0 \mathrm{E}-01)$ & $2.7 \mathrm{E}+01$ & $6.5 \mathrm{E}+00$ \\
\hline C4191-158.5 WE dup & $3.1 \mathrm{E}+01$ & $1.1 \mathrm{E}+01$ & $(1.9 \mathrm{E}-01)$ & $2.5 \mathrm{E}+01$ & $6.2 \mathrm{E}+00$ \\
\hline C4191-161 WE & $7.9 \mathrm{E}+00$ & $3.0 \mathrm{E}+00$ & $(4.4 \mathrm{E}-02)$ & $1.5 \mathrm{E}+01$ & $3.9 \mathrm{E}+00$ \\
\hline C4191-171 WE & $1.3 \mathrm{E}+01$ & $4.1 \mathrm{E}+00$ & $(8.2 \mathrm{E}-02)$ & $2.1 \mathrm{E}+01$ & $5.0 \mathrm{E}+00$ \\
\hline C4191-181 WE & $1.0 \mathrm{E}+01$ & $3.3 \mathrm{E}+00$ & $(7.0 \mathrm{E}-02)$ & $1.9 \mathrm{E}+01$ & $4.9 \mathrm{E}+00$ \\
\hline C4191-191 WE & $1.1 \mathrm{E}+01$ & $3.7 \mathrm{E}+00$ & $(6.4 \mathrm{E}-02)$ & $1.9 \mathrm{E}+01$ & $5.7 \mathrm{E}+00$ \\
\hline C4191-201 WE & $8.2 \mathrm{E}+00$ & $2.8 \mathrm{E}+00$ & $(4.5 E-02)$ & $1.8 \mathrm{E}+01$ & $4.9 \mathrm{E}+00$ \\
\hline C4191-211 WE & $6.1 \mathrm{E}+00$ & $2.1 \mathrm{E}+00$ & $(3.1 \mathrm{E}-02)$ & $1.5 \mathrm{E}+01$ & $4.6 \mathrm{E}+00$ \\
\hline C4191-221 WE & $7.4 \mathrm{E}+00$ & $2.5 \mathrm{E}+00$ & (3.6E-02) & $1.8 \mathrm{E}+01$ & $5.4 \mathrm{E}+00$ \\
\hline C4191-221 WE dup & $7.4 \mathrm{E}+00$ & $2.4 \mathrm{E}+00$ & $(3.5 E-02)$ & $1.6 \mathrm{E}+01$ & $5.0 \mathrm{E}+00$ \\
\hline C4191-231 WE & $6.5 \mathrm{E}+00$ & $2.2 \mathrm{E}+00$ & $(3.2 \mathrm{E}-02)$ & $1.3 \mathrm{E}+01$ & $4.5 \mathrm{E}+00$ \\
\hline C4191-241 WE & $7.5 \mathrm{E}+00$ & $2.2 \mathrm{E}+00$ & $(3.9 \mathrm{E}-02)$ & $1.5 \mathrm{E}+01$ & $4.6 \mathrm{E}+00$ \\
\hline C4191-251 WE & $6.2 \mathrm{E}+00$ & $1.8 \mathrm{E}+00$ & (3.3E-02) & $1.5 \mathrm{E}+01$ & $4.5 \mathrm{E}+00$ \\
\hline C4191-261 WE & $6.4 \mathrm{E}+00$ & $1.6 \mathrm{E}+00$ & $(3.3 E-02)$ & $1.3 \mathrm{E}+01$ & $3.9 \mathrm{E}+00$ \\
\hline C4191-271 WE & $6.2 \mathrm{E}+00$ & $1.5 \mathrm{E}+00$ & $(4.3 \mathrm{E}-02)$ & $1.2 \mathrm{E}+01$ & $3.1 \mathrm{E}+00$ \\
\hline C4191-281 WE & $5.9 \mathrm{E}+00$ & $1.6 \mathrm{E}+00$ & $(3.4 \mathrm{E}-02)$ & $1.5 \mathrm{E}+01$ & $3.6 \mathrm{E}+00$ \\
\hline C4191-291 WE & $8.0 \mathrm{E}+00$ & $2.4 \mathrm{E}+00$ & $(4.5 E-02)$ & $2.4 \mathrm{E}+01$ & $6.2 \mathrm{E}+00$ \\
\hline
\end{tabular}


PNNL-17821

Table 8.5 (contd)

\begin{tabular}{|c|c|c|c|c|c|}
\hline $\begin{array}{c}\text { Sample } \\
\text { ID }^{(a)}\end{array}$ & $\begin{array}{c}\text { Ca } \\
\mu \mathrm{g} / \mathrm{g} \text { soil }\end{array}$ & $\begin{array}{c}\mathrm{Mg} \\
\mu \mathrm{g} / \mathrm{g} \text { soil } \\
\end{array}$ & $\begin{array}{c}\mathrm{Sr} \\
\mu \mathrm{g} / \mathrm{g} \text { soil } \\
\end{array}$ & $\begin{array}{c}\mathrm{Na} \\
\mu \mathrm{g} / \mathrm{g} \text { soil }\end{array}$ & $\begin{array}{c}\mathrm{K} \\
\mu \mathrm{g} / \mathrm{g} \text { soil }\end{array}$ \\
\hline C4191-301 WE & $6.9 \mathrm{E}+00$ & $2.1 \mathrm{E}+00$ & $(4.1 \mathrm{E}-02)$ & $2.6 \mathrm{E}+01$ & $6.8 \mathrm{E}+00$ \\
\hline C4191-311 WE & $4.4 \mathrm{E}+00$ & $1.1 \mathrm{E}+00$ & $(2.6 \mathrm{E}-02)$ & $3.0 \mathrm{E}+01$ & $6.8 \mathrm{E}+00$ \\
\hline C4191-321 WE & $5.6 \mathrm{E}+00$ & $1.8 \mathrm{E}+00$ & $(3.1 \mathrm{E}-02)$ & $2.2 \mathrm{E}+01$ & $6.0 \mathrm{E}+00$ \\
\hline C4191-331 WE & $7.6 \mathrm{E}+00$ & $2.4 \mathrm{E}+00$ & $(4.1 \mathrm{E}-02)$ & $2.4 \mathrm{E}+01$ & $7.1 \mathrm{E}+00$ \\
\hline C4191-341 WE & $8.3 \mathrm{E}+00$ & $2.7 \mathrm{E}+00$ & $(3.9 \mathrm{E}-02)$ & $1.3 \mathrm{E}+01$ & $4.3 \mathrm{E}+00$ \\
\hline \multicolumn{6}{|c|}{$\begin{array}{l}\text { (a) The sample IDs include the borehole number and the approximate depth of each sample. } \\
\text { (b) Bold red values are elevated concentrations for given constituent. } \\
\text { (c) Bold blue values are lower than natural background for a given constituent. } \\
\text { (d) Parentheses signify values below the level of quantitation but considered valid for this work. }\end{array}$} \\
\hline
\end{tabular}

Table 8.6. Water-Extractable Cations as Pore Water Concentrations in Borehole C4191

Sediments (mg/L)

\begin{tabular}{|c|c|c|c|c|c|}
\hline $\begin{array}{l}\text { Sample } \\
\text { ID }^{\text {(a) }}\end{array}$ & $\begin{array}{c}\mathrm{Ca} \\
\mathrm{mg} / \mathrm{L}\end{array}$ & $\begin{array}{c}\mathrm{Mg} \\
\mathrm{mg} / \mathrm{L}\end{array}$ & $\begin{array}{c}\mathrm{Sr} \\
\mathrm{mg} / \mathrm{L}\end{array}$ & $\begin{array}{c}\mathrm{Na} \\
\mathrm{mg} / \mathrm{L}\end{array}$ & $\begin{array}{c}\mathrm{K} \\
\mathrm{mg} / \mathrm{L}\end{array}$ \\
\hline C4191-13 & $1.5 \mathrm{E}+01$ & $5.1 \mathrm{E}+00$ & (7.9E-02) & $9.4 \mathrm{E}+02$ & $(1.1 \mathrm{E}+01)$ \\
\hline C4191-17.5 & $(4.5 \mathrm{E}+00)^{(\mathrm{b})}$ & $(2.6 \mathrm{E}+00)$ & $(1.2 \mathrm{E}-02)$ & $3.7 E+03$ & $(9.9 E+00)$ \\
\hline C4191-22.5 & $9.8 \mathrm{E}+00$ & $8.9 \mathrm{E}+00$ & $(2.5 \mathrm{E}-02)$ & $5.1 \mathrm{E}+03$ & $(1.9 \mathrm{E}+01)$ \\
\hline C4191-27.5 & $(4.0 \mathrm{E}+00)$ & $(5.8 \mathrm{E}-01)$ & (3.5E-03) & $3.4 \mathrm{E}+03$ & $1.5 \mathrm{E}+01$ \\
\hline C4191-37.5 & $1.6 \mathrm{E}+01$ & $(1.1 \mathrm{E}+00)$ & $(1.2 \mathrm{E}-01)$ & $5.3 \mathrm{E}+03$ & $4.0 \mathrm{E}+01$ \\
\hline C4191-41 & $6.3 \mathrm{E}+00$ & $(3.1 \mathrm{E}+00)$ & $(1.1 \mathrm{E}-01)$ & $3.9 \mathrm{E}+03$ & $2.8 \mathrm{E}+01$ \\
\hline C4191-51 & $1.8 \mathrm{E}+01$ & $(3.3 E+00)$ & $(1.4 \mathrm{E}-01)$ & $6.2 \mathrm{E}+03$ & $6.1 \mathrm{E}+01$ \\
\hline C4191-61 & $2.4 \mathrm{E}+01$ & $(4.5 \mathrm{E}+00)$ & $(1.8 \mathrm{E}-01)$ & $5.8 \mathrm{E}+03$ & $6.8 \mathrm{E}+01$ \\
\hline C4191-71 & $3.1 \mathrm{E}+01$ & $(6.5 E+00)$ & $(1.9 \mathrm{E}-01)$ & $9.5 E+03$ & $1.0 \mathrm{E}+02$ \\
\hline C4191-81 & $1.2 \mathrm{E}+02$ & $3.6 \mathrm{E}+01$ & (8.3E-01) & $1.5 \mathrm{E}+04$ & $2.1 \mathrm{E}+02$ \\
\hline C4191-91 & $5.2 \mathrm{E}+03$ & $1.6 \mathrm{E}+03$ & $3.7 \mathrm{E}+01$ & $3.1 \mathrm{E}+04$ & $6.3 \mathrm{E}+02$ \\
\hline C4191-91 dup & $6.2 \mathrm{E}+03$ & $1.9 \mathrm{E}+03$ & $4.4 \mathrm{E}+01$ & $3.5 E+04$ & $7.1 \mathrm{E}+02$ \\
\hline C4191-101 & $3.5 \mathrm{E}+03$ & $1.1 \mathrm{E}+03$ & $2.4 \mathrm{E}+01$ & $2.6 \mathrm{E}+04$ & $4.6 \mathrm{E}+02$ \\
\hline C4191-111 & $5.4 \mathrm{E}+03$ & $1.3 \mathrm{E}+03$ & $3.2 \mathrm{E}+01$ & $1.6 \mathrm{E}+04$ & $5.1 \mathrm{E}+02$ \\
\hline C4191-121 & $4.4 \mathrm{E}+03$ & $1.4 \mathrm{E}+03$ & $2.5 \mathrm{E}+01$ & $1.4 \mathrm{E}+04$ & $5.0 \mathrm{E}+02$ \\
\hline C4191-131 & $5.8 \mathrm{E}+03$ & $1.5 \mathrm{E}+03$ & $3.3 \mathrm{E}+01$ & $1.6 \mathrm{E}+04$ & $3.8 \mathrm{E}+02$ \\
\hline C4191-131 dup & $6.2 \mathrm{E}+03$ & $1.6 \mathrm{E}+03$ & $3.5 \mathrm{E}+01$ & $1.6 \mathrm{E}+04$ & $4.0 \mathrm{E}+02$ \\
\hline C4191-141 & $2.7 \mathrm{E}+03$ & $1.0 \mathrm{E}+03$ & $1.6 \mathrm{E}+01$ & $9.1 \mathrm{E}+02$ & $3.9 \mathrm{E}+02$ \\
\hline C4191-151 & $8.8 \mathrm{E}+02$ & $3.3 E+02$ & $5.5 \mathrm{E}+00$ & $6.0 \mathrm{E}+02$ & $1.9 \mathrm{E}+02$ \\
\hline C4191-153.5 & $9.4 \mathrm{E}+02$ & $3.6 \mathrm{E}+02$ & $5.9 \mathrm{E}+00$ & $5.7 \mathrm{E}+02$ & $2.0 \mathrm{E}+02$ \\
\hline C4191-156 & $4.3 \mathrm{E}+02$ & $1.7 \mathrm{E}+02$ & $(2.6 \mathrm{E}+00)$ & $4.5 \mathrm{E}+02$ & $1.3 \mathrm{E}+02$ \\
\hline C4191-158.5 & $4.7 \mathrm{E}+02$ & $1.7 \mathrm{E}+02$ & $(2.9 \mathrm{E}+00)$ & $3.8 \mathrm{E}+02$ & $9.4 \mathrm{E}+01$ \\
\hline C4191-158.5 dup & $4.5 \mathrm{E}+02$ & $1.6 \mathrm{E}+02$ & $(2.7 \mathrm{E}+00)$ & $3.7 \mathrm{E}+02$ & $8.8 \mathrm{E}+01$ \\
\hline C4191-161 & $2.1 \mathrm{E}+02$ & $8.0 \mathrm{E}+01$ & $(1.2 \mathrm{E}+00)$ & $3.9 \mathrm{E}+02$ & $1.0 \mathrm{E}+02$ \\
\hline C4191-171 & $2.0 \mathrm{E}+02$ & $6.5 \mathrm{E}+01$ & $(1.3 \mathrm{E}+00)$ & $3.3 \mathrm{E}+02$ & $8.1 \mathrm{E}+01$ \\
\hline C4191-181 & $2.7 \mathrm{E}+02$ & $8.8 \mathrm{E}+01$ & $(1.9 \mathrm{E}+00)$ & $5.0 \mathrm{E}+02$ & $1.3 \mathrm{E}+02$ \\
\hline C4191-191 & $3.1 \mathrm{E}+02$ & $1.1 \mathrm{E}+02$ & $(1.9 \mathrm{E}+00)$ & $5.6 \mathrm{E}+02$ & $1.7 \mathrm{E}+02$ \\
\hline C4191-201 & $3.5 \mathrm{E}+02$ & $1.2 \mathrm{E}+02$ & $(1.9 \mathrm{E}+00)$ & $7.5 \mathrm{E}+02$ & $2.1 \mathrm{E}+02$ \\
\hline C4191-211 & $3.2 \mathrm{E}+02$ & $1.1 \mathrm{E}+02$ & $(1.6 \mathrm{E}+00)$ & $7.9 \mathrm{E}+02$ & $2.4 \mathrm{E}+02$ \\
\hline
\end{tabular}


PNNL-17821

Table 8.6 (contd)

\begin{tabular}{lccccc}
\hline $\begin{array}{l}\text { Sample } \\
\text { ID }{ }^{\text {(a) }}\end{array}$ & $\begin{array}{c}\mathrm{Ca} \\
\mathrm{mg} / \mathrm{L}\end{array}$ & $\begin{array}{c}\mathrm{Mg} \\
\mathrm{mg} / \mathrm{L}\end{array}$ & $\begin{array}{c}\mathrm{Sr} \\
\mathrm{mg} / \mathrm{L}\end{array}$ & $\begin{array}{c}\mathrm{Na} \\
\mathrm{mg} / \mathrm{L}\end{array}$ & $\begin{array}{c}\mathrm{K} \\
\mathrm{mg} / \mathrm{L}\end{array}$ \\
\hline C4191-221 & $1.5 \mathrm{E}+02$ & $5.2 \mathrm{E}+01$ & $(7.5 \mathrm{E}-01)$ & $3.7 \mathrm{E}+02$ & $1.1 \mathrm{E}+02$ \\
C4191-221 dup & $1.5 \mathrm{E}+02$ & $4.9 \mathrm{E}+01$ & $(7.2 \mathrm{E}-01)$ & $3.2 \mathrm{E}+02$ & $1.0 \mathrm{E}+02$ \\
C4191-231 & $2.6 \mathrm{E}+02$ & $8.6 \mathrm{E}+01$ & $(1.2 \mathrm{E}+00)$ & $5.2 \mathrm{E}+02$ & $1.8 \mathrm{E}+02$ \\
C4191-241 & $2.4 \mathrm{E}+02$ & $7.1 \mathrm{E}+01$ & $(1.3 \mathrm{E}+00)$ & $5.0 \mathrm{E}+02$ & $1.5 \mathrm{E}+02$ \\
C4191-251 & $3.0 \mathrm{E}+02$ & $8.6 \mathrm{E}+01$ & $(1.6 \mathrm{E}+00)$ & $7.4 \mathrm{E}+02$ & $2.2 \mathrm{E}+02$ \\
C4191-261 & $3.2 \mathrm{E}+02$ & $8.1 \mathrm{E}+01$ & $(1.6 \mathrm{E}+00)$ & $6.6 \mathrm{E}+02$ & $1.9 \mathrm{E}+02$ \\
C4191-271 & $4.1 \mathrm{E}+02$ & $1.0 \mathrm{E}+02$ & $(2.9 \mathrm{E}+00)$ & $8.1 \mathrm{E}+02$ & $2.1 \mathrm{E}+02$ \\
C4191-281 & $3.7 \mathrm{E}+02$ & $1.0 \mathrm{E}+02$ & $(2.2 \mathrm{E}+00)$ & $9.6 \mathrm{E}+02$ & $2.3 \mathrm{E}+02$ \\
C4191-291 & $4.1 \mathrm{E}+02$ & $1.2 \mathrm{E}+02$ & $(2.3 \mathrm{E}+00)$ & $1.2 \mathrm{E}+03$ & $3.2 \mathrm{E}+02$ \\
C4191-301 & $5.4 \mathrm{E}+02$ & $1.7 \mathrm{E}+02$ & $(3.2 \mathrm{E}+00)$ & $2.0 \mathrm{E}+03$ & $5.3 \mathrm{E}+02$ \\
C4191-311 & $3.8 \mathrm{E}+02$ & $9.8 \mathrm{E}+01$ & $(2.2 \mathrm{E}+00)$ & $2.6 \mathrm{E}+03$ & $6.0 \mathrm{E}+02$ \\
C4191-321 & $4.1 \mathrm{E}+02$ & $1.3 \mathrm{E}+02$ & $(2.3 \mathrm{E}+00)$ & $1.6 \mathrm{E}+03$ & $4.4 \mathrm{E}+02$ \\
C4191-331 & $2.3 \mathrm{E}+02$ & $7.1 \mathrm{E}+01$ & $(1.2 \mathrm{E}+00)$ & $7.4 \mathrm{E}+02$ & $2.1 \mathrm{E}+02$ \\
C4191-341 & $8.4 \mathrm{E}+01$ & $2.7 \mathrm{E}+01$ & $(4.0 \mathrm{E}-01)$ & $1.3 \mathrm{E}+02$ & $4.4 \mathrm{E}+01$ \\
\hline (a) The sample IDs include the borehole number and the approximate depth of each sample. & & \\
(b) Parentheses signify values below level of quantitation but considered valid for this work. & & &
\end{tabular}




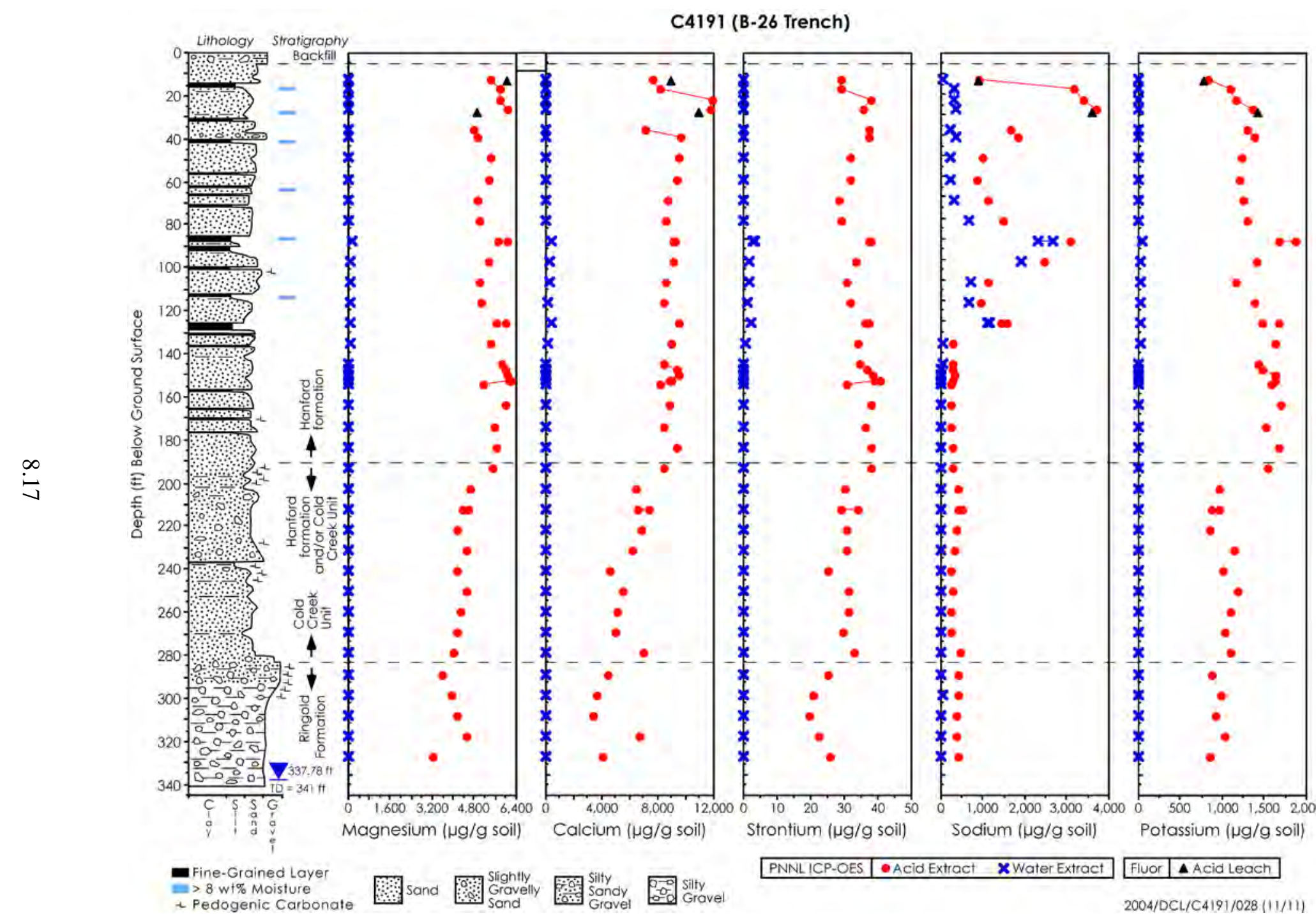

Figure 8.4. Cations in 1:1 Sediment-to-Water Extracts and Acid Extracts for Borehole C4191 


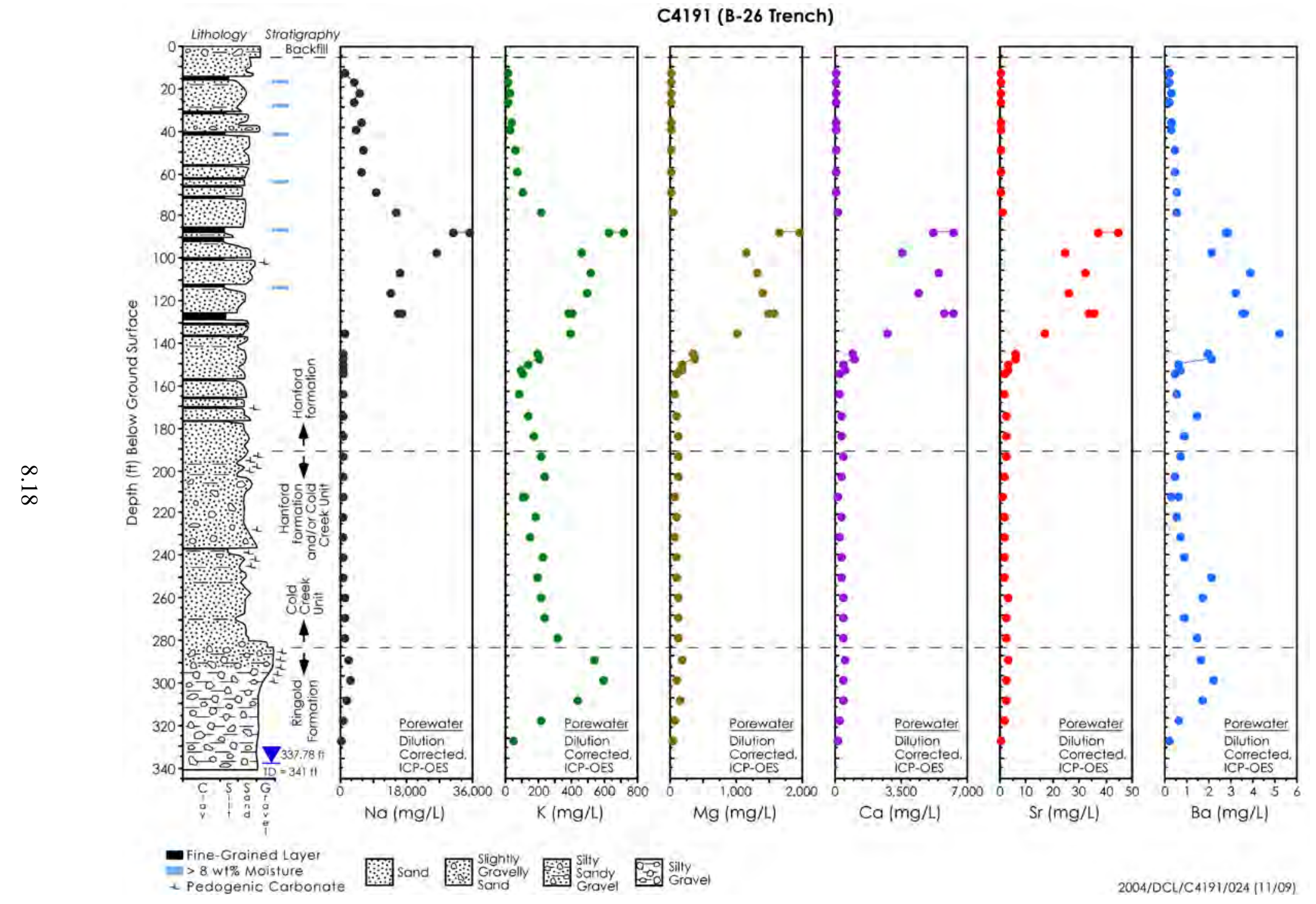

Figure 8.5. Calculated Cations Concentrations in Borehole C4191 Pore Water 
As part of the characterization of the water extracts, other chemical species, such as aluminum, silicon, iron, manganese, zinc, and trace constituents, such as arsenic, boron, barium, beryllium, bismuth, cadmium, cobalt, chromium, copper, lithium, molybdenum, nickel, lead, selenium, thallium, vanadium, titanium, and zirconium, were measured. However, considering that their concentrations were generally low to non-detectable, the data are not presented in this ERC ground-truthing document. Measurements of phosphorous and sulfur that were performed using ICP-OES to corroborate the direct measurement of the anions phosphate and sulfate using IC were discussed previously. The data from the two independent measurements compared well.

The only potential radiological COCs that were measurable in the water extracts were technetium-99 and uranium and their concentrations on both a per gram of sediment basis and as pore-water concentrations are listed in Table 8.7. The technetium-99 data show elevated technetium-99 water-extract concentrations occurring from 37.5 to $158.5 \mathrm{ft}$ bgs. The deepest penetration of significant technetium-99 occurs at the same place as the significantly elevated nitrate. These two mobile contaminants are often found to travel and distribute in the vadose zone in a similar pattern. Elevated waterextractable concentrations of uranium are found shallow in the vadose zone from 13 to $51 \mathrm{ft}$ bgs. This suggests that uranium is less mobile than technetium-99 and nitrate. Figure 8.6 shows the calculated pore-water concentration of water-extractable technetium-99 and uranium as a function of depth. Table 8.7 also lists the total ionic strength of the calculated pore waters in the vadose zone profile at C4191. Of all the pore water parameters, the total ionic strength should correlate best with the soil resistivity data, which are influenced by the total dissolved salt content in the sediment. The total ionic strength correlations with the field soil resistivity measurements are discussed in the next section of this report. Laboratory-scale soil resistivity measurements were performed only on sediments from C5923 and are described in Section 5.3.

\subsubsection{M Nitric Acid Extractable Amounts of Selected Elements}

The amount of material that was extractable from the vadose zone sediment into $8 \mathrm{M}$ nitric acid is shown in Table 8.8 through Table 8.10 as well as Figure 8.4 and Figure 8.7 through Figure 8.9. The $8 \mathrm{M}$ nitric acid extraction is a protocol used by the U.S. Environmental Protection Agency to estimate the maximum concentrations of regulated metals in contaminated sediment that would be biologically available. Aliquots of sediment from borehole C4191 were subjected to acid extraction to look for elevated quantities of selected constituents and radionuclides.

The acid-extract data for grab samples from C4191 in general showed high values in the shallow depths for a few constituents (relative to known Hanford site background values and values for C4191 sediments below $160 \mathrm{ft}$ bgs that are considered uncontaminated based on the findings that the waste fluids disposed of to the 216-B-26 trench appear to still reside in the upper $158.5 \mathrm{ft}$ of sediment). The elements and radionuclides that showed elevated acid-extractable concentrations and the depth zone where concentrations were elevated include sodium (elevated from 13 to $131 \mathrm{ft} \mathrm{bgs}$ ), aluminum (elevated from 17.5 to $27.5 \mathrm{ft}$ bgs), phosphorous, vanadium, manganese, iron, cobalt, zinc, zirconium, and barium (all elevated from 13 to $27.5 \mathrm{ft}$ bgs), sulfur (elevated from 51 to $101 \mathrm{ft}$ bgs), uranium (elevated from 13 to $41 \mathrm{ft}$ bgs) and technetium-99 (elevated from 81 to $131 \mathrm{ft}$ bgs). As shown in Table 8.2 and Figure 8.1, the $\mathrm{pH}$ of the sediments is elevated because of residual caustic from the waste disposed of from 17 to $43.5 \mathrm{ft}$ bgs with the most elevated values found from 17 to $37.5 \mathrm{ft}$ bgs. This zone of elevated $\mathrm{pH}$ coincides fairly well with the zone where many of the major elements that make up sediments show elevated 
PNNL-17821

Table 8.7. Water-Extractable Radionuclides and Pore Water Total Ionic Strength for Borehole C4191

\begin{tabular}{|c|c|c|c|c|c|}
\hline $\begin{array}{c}\text { Sample } \\
\text { ID }^{\text {(a) }}\end{array}$ & $\begin{array}{l}\text { Tc-99 } \\
\mathrm{pCi} / \mathrm{g}\end{array}$ & $\begin{array}{c}U \\
\mu g / g\end{array}$ & $\begin{array}{l}\text { Tc-99 } \\
\mathrm{pCi} / \mathrm{L}\end{array}$ & $\begin{array}{c}\mathrm{U} \\
\mu \mathrm{g} / \mathrm{L}\end{array}$ & $\begin{array}{c}\text { PW Ionic Strength } \\
\text { M }\end{array}$ \\
\hline C4191-13 & 7.63E-02 & 2.96E-01 & $1.16 \mathrm{E}+03$ & $4.49 \mathrm{E}+03$ & $6.46 \mathrm{E}-02$ \\
\hline C4191-17.5 & $(3.39 \mathrm{E}-02)^{(\mathrm{b})}$ & $1.29 \mathrm{E}+00$ & $(3.84 E+02)$ & $1.46 \mathrm{E}+04$ & 2.58E-01 \\
\hline C4191-22.5 & $(1.70 \mathrm{E}-02)$ & $1.64 \mathrm{E}+00$ & $(2.58 \mathrm{E}+02)$ & $2.50 \mathrm{E}+04$ & 3.30E-01 \\
\hline C4191-27.5 & (8.48E-03) & $6.66 \mathrm{E}-01$ & $(8.41 \mathrm{E}+01)$ & $6.60 \mathrm{E}+03$ & 2.30E-01 \\
\hline C4191-37.5 & 2.23E-01 & 2.97E-01 & $5.08 \mathrm{E}+03$ & $6.79 \mathrm{E}+03$ & 3.41E-01 \\
\hline C4191-41 & $2.46 \mathrm{E}+00$ & $1.22 \mathrm{E}+00$ & $2.50 \mathrm{E}+04$ & $1.24 \mathrm{E}+04$ & 2.57E-01 \\
\hline C4191-43.5 & $2.53 \mathrm{E}+00$ & 4.52E-01 & $5.06 \mathrm{E}+04$ & $9.02 E+03$ & $\mathrm{NA}^{\circledR}$ \\
\hline C4191-48.5 & $3.52 \mathrm{E}+00$ & $2.44 \mathrm{E}-01$ & $1.07 \mathrm{E}+05$ & $7.41 \mathrm{E}+03$ & NA \\
\hline C4191-51 & $2.15 E+00$ & 2.37E-02 & $5.60 \mathrm{E}+04$ & $6.16 \mathrm{E}+02$ & 3.69E-01 \\
\hline C4191-53.5 & $2.78 \mathrm{E}+00$ & 3.75E-03 & $8.51 \mathrm{E}+04$ & $1.15 \mathrm{E}+02$ & NA \\
\hline C4191-56 & $6.93 \mathrm{E}+00$ & 4.33E-03 & $1.22 \mathrm{E}+05$ & $7.63 \mathrm{E}+01$ & NA \\
\hline C4191-58.5 & $2.65 E+00$ & 2.54E-03 & $7.97 \mathrm{E}+04$ & $7.65 \mathrm{E}+01$ & NA \\
\hline C4191-61 WE & $1.73 \mathrm{E}+00$ & 8.67E-03 & $4.69 \mathrm{E}+04$ & $2.35 \mathrm{E}+02$ & 3.52E-01 \\
\hline C4191-63.5 & $5.59 \mathrm{E}+00$ & 7.09E-03 & $4.07 E+04$ & $5.16 \mathrm{E}+01$ & NA \\
\hline C4191-66 & $2.17 \mathrm{E}+00$ & 6.13E-03 & $4.35 E+04$ & $1.23 \mathrm{E}+02$ & NA \\
\hline C4191-68.5 & $2.62 \mathrm{E}+00$ & 5.38E-03 & $7.70 \mathrm{E}+04$ & $1.58 \mathrm{E}+02$ & NA \\
\hline C4191-71 & $3.76 \mathrm{E}+00$ & $9.40 \mathrm{E}-03$ & $1.10 \mathrm{E}+05$ & $2.76 \mathrm{E}+02$ & 5.40E-01 \\
\hline C4191-73.5 & $9.03 E+00$ & 4.31E-03 & $1.83 \mathrm{E}+05$ & $8.73 E+01$ & NA \\
\hline C4191-76 & $9.02 E+00$ & 2.94E-03 & $1.99 \mathrm{E}+05$ & $6.51 \mathrm{E}+01$ & NA \\
\hline C4191-78.5 & $7.09 \mathrm{E}+00$ & 2.57E-03 & $1.59 \mathrm{E}+05$ & $5.75 \mathrm{E}+01$ & NA \\
\hline C4191-81 & $5.97 \mathrm{E}+00$ & $5.48 \mathrm{E}-03$ & $1.37 \mathrm{E}+05$ & $1.26 \mathrm{E}+02$ & 8.91E-01 \\
\hline C4191-83.5 & $1.16 \mathrm{E}+01$ & $1.75 \mathrm{E}-03$ & $3.29 E+05$ & $4.96 \mathrm{E}+01$ & NA \\
\hline C4191-86 & $9.93 \mathrm{E}+01$ & $1.59 \mathrm{E}-03$ & $1.11 \mathrm{E}+06$ & $1.78 \mathrm{E}+01$ & NA \\
\hline C4191-88.5 & $7.96 \mathrm{E}+01$ & $1.25 \mathrm{E}-03$ & $1.28 \mathrm{E}+06$ & $2.01 \mathrm{E}+01$ & NA \\
\hline C4191-91 & $7.88 \mathrm{E}+01$ & 4.70E-03 & $1.04 \mathrm{E}+06$ & $6.17 \mathrm{E}+01$ & $1.96 \mathrm{E}+00$ \\
\hline C4191-91 dup & $9.24 \mathrm{E}+01$ & 5.79E-03 & $1.21 \mathrm{E}+06$ & $7.60 \mathrm{E}+01$ & $2.30 \mathrm{E}+00$ \\
\hline C4191-93.5 & $1.07 \mathrm{E}+02$ & 8.31E-04 & $1.71 \mathrm{E}+06$ & $1.33 \mathrm{E}+01$ & NA \\
\hline C4191-96 & $5.76 \mathrm{E}+01$ & 4.49E-04 & $1.72 \mathrm{E}+06$ & $1.34 \mathrm{E}+01$ & NA \\
\hline C4191-98.5 & $9.48 \mathrm{E}+01$ & 6.29E-04 & $1.71 \mathrm{E}+06$ & $1.14 \mathrm{E}+01$ & NA \\
\hline C4191-101 & $1.00 \mathrm{E}+02$ & $2.26 \mathrm{E}-03$ & $1.39 \mathrm{E}+06$ & $3.11 \mathrm{E}+01$ & $1.61 \mathrm{E}+00$ \\
\hline C4191-103.5 & $9.96 \mathrm{E}+01$ & 8.21E-04 & $1.49 \mathrm{E}+06$ & $1.23 \mathrm{E}+01$ & NA \\
\hline C4191-106 & $4.69 \mathrm{E}+01$ & 6.94E-04 & $1.14 \mathrm{E}+06$ & $1.69 \mathrm{E}+01$ & NA \\
\hline C4191-108.5 & $5.89 \mathrm{E}+01$ & 6.73E-04 & $1.25 \mathrm{E}+06$ & $1.43 \mathrm{E}+01$ & NA \\
\hline C4191-111 & $4.35 \mathrm{E}+01$ & 6.08E-04 & $9.54 \mathrm{E}+05$ & $1.33 \mathrm{E}+01$ & $1.28 \mathrm{E}+00$ \\
\hline C4191-113.5 & $6.39 \mathrm{E}+01$ & $1.44 \mathrm{E}-03$ & $8.30 \mathrm{E}+05$ & $1.87 \mathrm{E}+01$ & NA \\
\hline C4191-116 & $6.12 \mathrm{E}+01$ & $9.58 \mathrm{E}-04$ & $9.95 E+05$ & $1.56 \mathrm{E}+01$ & NA \\
\hline C4191-118.5 & $3.03 \mathrm{E}+01$ & $5.28 \mathrm{E}-04$ & $7.24 \mathrm{E}+05$ & $1.26 \mathrm{E}+01$ & NA \\
\hline C4191-121 & $4.15 \mathrm{E}+01$ & 1.43E-03 & $8.66 \mathrm{E}+05$ & $2.98 \mathrm{E}+01$ & $1.12 \mathrm{E}+00$ \\
\hline C4191-123.5 & $4.95 \mathrm{E}+01$ & 6.12E-04 & $1.24 \mathrm{E}+06$ & $1.53 \mathrm{E}+01$ & NA \\
\hline C4191-126 & $7.05 \mathrm{E}+01$ & $5.60 \mathrm{E}-04$ & $1.16 \mathrm{E}+06$ & $9.23 \mathrm{E}+00$ & NA \\
\hline C4191-128.5 & $5.05 E+01$ & 4.66E-04 & $1.19 \mathrm{E}+06$ & $1.10 \mathrm{E}+01$ & NA \\
\hline C4191-131 & $6.29 \mathrm{E}+01$ & $1.40 \mathrm{E}-03$ & $8.95 E+05$ & $2.00 \mathrm{E}+01$ & $1.41 \mathrm{E}+00$ \\
\hline C4191-131 dup & $7.17 \mathrm{E}+01$ & 1.37E-03 & $1.02 \mathrm{E}+06$ & $1.95 \mathrm{E}+01$ & $1.44 \mathrm{E}+00$ \\
\hline C4191-133 & $4.06 \mathrm{E}+01$ & 5.62E-04 & $1.07 \mathrm{E}+06$ & $1.48 \mathrm{E}+01$ & NA \\
\hline C4191-136 & $5.67 \mathrm{E}+01$ & $6.50 \mathrm{E}-04$ & $1.29 \mathrm{E}+06$ & $1.48 \mathrm{E}+01$ & NA \\
\hline C4191-138.5 & $4.21 \mathrm{E}+01$ & 9.95E-04 & $6.43 \mathrm{E}+05$ & $1.52 \mathrm{E}+01$ & NA \\
\hline C4191-141 & $7.14 \mathrm{E}+00$ & 6.53E-04 & $1.62 \mathrm{E}+05$ & $1.48 \mathrm{E}+01$ & 3.79E-01 \\
\hline C4191-143.5 & $4.38 \mathrm{E}+00$ & 3.19E-04 & $1.13 \mathrm{E}+05$ & $8.21 \mathrm{E}+00$ & NA \\
\hline
\end{tabular}


PNNL-17821

Table 8.7 (contd)

\begin{tabular}{|c|c|c|c|c|c|}
\hline $\begin{array}{l}\text { Sample } \\
\text { ID }^{(a)}\end{array}$ & $\begin{array}{l}\text { Tc-99 } \\
\text { pCi/g }\end{array}$ & $\begin{array}{c}\mathrm{U} \\
\mu \mathrm{g} / \mathrm{g}\end{array}$ & $\begin{array}{l}\text { Tc-99 } \\
\mathrm{pCi} / \mathrm{L}\end{array}$ & $\begin{array}{c}\mathrm{U} \\
\mu \mathrm{g} / \mathrm{L}\end{array}$ & $\begin{array}{c}\text { PW Ionic Strength } \\
\text { M }\end{array}$ \\
\hline C4191-146 & $3.48 \mathrm{E}+00$ & 4.00E-04 & $8.47 E+04$ & $9.73 \mathrm{E}+00$ & NA \\
\hline C4191-148.5 & $6.44 \mathrm{E}+00$ & 4.42E-04 & $1.83 \mathrm{E}+05$ & $1.26 \mathrm{E}+01$ & NA \\
\hline C4191-151 & $2.75 \mathrm{E}+00$ & $6.98 \mathrm{E}-04$ & $5.83 E+04$ & $1.48 \mathrm{E}+01$ & $1.46 \mathrm{E}-01$ \\
\hline C4191-153.5 & $2.45 \mathrm{E}+00$ & 3.91E-04 & $5.48 \mathrm{E}+04$ & $8.73 \mathrm{E}+00$ & $1.65 \mathrm{E}-01$ \\
\hline C4191-156 & 8.48E-01 & 4.46E-04 & $1.57 \mathrm{E}+04$ & $8.27 \mathrm{E}+00$ & 8.93E-02 \\
\hline C4191-158.5 & 9.97E-01 & 6.49E-04 & $1.43 \mathrm{E}+04$ & $9.31 \mathrm{E}+00$ & 8.10E-02 \\
\hline C4191-158.5 dup & 9.63E-01 & $6.28 \mathrm{E}-04$ & $1.38 \mathrm{E}+04$ & $9.01 \mathrm{E}+00$ & NA \\
\hline C4191-161 & $(0.00 \mathrm{E}+00)$ & 6.87E-04 & $(0.00 \mathrm{E}+00)$ & $1.81 \mathrm{E}+01$ & 6.34E-02 \\
\hline C4191-171 & $(0.00 \mathrm{E}+00)$ & $9.66 \mathrm{E}-04$ & $(0.00 \mathrm{E}+00)$ & $1.55 \mathrm{E}+01$ & $5.46 \mathrm{E}-02$ \\
\hline C4191-181 & (3.39E-02) & 7.34E-04 & $(9.10 \mathrm{E}+02)$ & $1.97 \mathrm{E}+01$ & 7.89E-02 \\
\hline C4191-191 & $(0.00 \mathrm{E}+00)$ & $9.74 \mathrm{E}-04$ & $(0.00 \mathrm{E}+00)$ & $2.83 \mathrm{E}+01$ & 8.93E-02 \\
\hline C4191-201 & $<8.51 \mathrm{E}-02$ & 8.70E-04 & $<3.65 \mathrm{E}+03$ & $3.73 \mathrm{E}+01$ & 1.09E-01 \\
\hline C4191-211 & $<8.48 \mathrm{E}-02$ & 3.54E-04 & $<4.46 \mathrm{E}+03$ & $1.86 \mathrm{E}+01$ & $1.11 \mathrm{E}-01$ \\
\hline C4191-221 & (8.98E-02) & 6.73E-04 & $(1.84 \mathrm{E}+03)$ & $1.38 \mathrm{E}+01$ & 5.06E-02 \\
\hline C4191-221 dup & (8.98E-03) & 6.13E-04 & $(1.84 \mathrm{E}+02)$ & $1.26 \mathrm{E}+01$ & 4.81E-02 \\
\hline C4191-231 & (9.15E-03) & 5.51E-04 & $(3.58 \mathrm{E}+02)$ & $2.15 \mathrm{E}+01$ & 8.13E-02 \\
\hline C4191-241 & (1.70E-02) & 5.18E-04 & $(5.51 \mathrm{E}+02)$ & $1.68 \mathrm{E}+01$ & 7.76E-02 \\
\hline C4191-251 & (8.48E-03) & 3.07E-04 & $(4.14 \mathrm{E}+02)$ & $1.49 \mathrm{E}+01$ & $1.01 \mathrm{E}-01$ \\
\hline C4191-261 & (2.77E-02) & 2.99E-04 & $(1.37 \mathrm{E}+03)$ & $1.48 \mathrm{E}+01$ & 9.69E-02 \\
\hline C4191-271 & $(1.70 \mathrm{E}-02)$ & 3.03E-04 & $(1.14 \mathrm{E}+03)$ & $2.03 \mathrm{E}+01$ & $1.18 \mathrm{E}-01$ \\
\hline C4191-281 & $(4.24 \mathrm{E}-02)$ & 3.17E-04 & $(2.68 \mathrm{E}+03)$ & $2.01 \mathrm{E}+01$ & 1.31E-01 \\
\hline C4191-291 & (3.39E-02) & 8.05E-04 & $(1.75 \mathrm{E}+03)$ & $4.15 \mathrm{E}+01$ & $1.50 \mathrm{E}-01$ \\
\hline C4191-301 & (5.22E-02) & 5.13E-04 & $(4.09 \mathrm{E}+03)$ & $4.03 \mathrm{E}+01$ & 2.35E-01 \\
\hline C4191-311 & (5.09E-02) & 5.74E-04 & $(4.43 E+03)$ & $4.99 \mathrm{E}+01$ & 2.44E-01 \\
\hline C4191-321 & (6.78E-02) & 3.20E-04 & $(4.97 \mathrm{E}+03)$ & $2.35 \mathrm{E}+01$ & $1.76 \mathrm{E}-01$ \\
\hline C4191-331 & 9.33E-02 & 4.42E-04 & $2.81 E+03$ & $1.33 \mathrm{E}+01$ & 8.95E-02 \\
\hline C4191-341 & 1.27E-01 & $1.81 \mathrm{E}-04$ & $1.29 \mathrm{E}+03$ & $1.83 \mathrm{E}+00$ & 2.36E-02 \\
\hline $\begin{array}{l}\text { a) The sample IDs } \\
\text { b) parentheses sign } \\
\text { c) NA = not availa }\end{array}$ & e the boreho & $\begin{array}{l}\text { antitation } \\
\text { ations or }\end{array}$ & e not meast & jater extract. & \\
\hline
\end{tabular}

acid-extractable concentrations. This suggests that the sediments interact with the caustic waste fluids through dissolution and precipitation/neutralization reactions that likely form more leachable amorphous solid phases and metal hydroxides/oxides in contrast with more stable alumino-silicate and crystalline metal oxides. The high acid-extractable sodium zone from 13 to $131 \mathrm{ft}$ bgs reflects the massive amount of sodium in the waste solution that interacts with the native sediments through cation exchange and other sediment dissolution/precipitation reactions. Because $8 \mathrm{M}$ nitric acid was used for the solvent in the acid extractions, elevated nitrate concentrations in the vadose zone sediments cannot be tracked using the acid extract data. However, as described in the water extract discussions, nitrate is elevated down to $158.5 \mathrm{ft}$ bgs. 


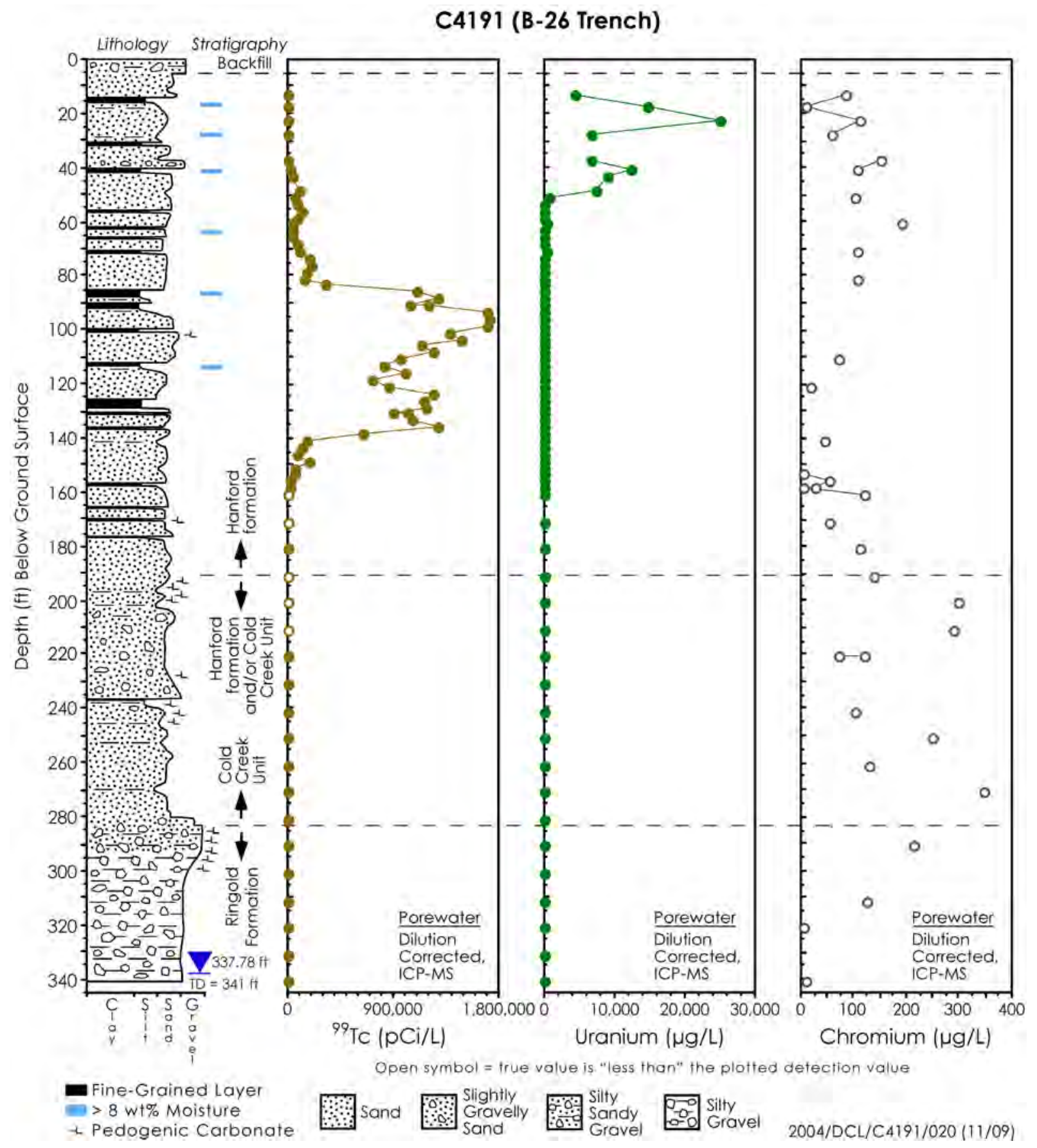

Figure 8.6. Calculated Technetium-99 and Uranium Pore-Water Concentrations in C4191 Sediments vs Depth 
PNNL-17821

Table 8.8. Acid-Extractable Light Elements in Borehole C4191 Sediments ( $\mu$ g/g dry sediment)

\begin{tabular}{|c|c|c|c|c|c|c|c|c|}
\hline ID \& ft bgs & $\mathrm{Na}$ & $\mathrm{Mg}$ & $\mathrm{Al}$ & $\mathrm{P}$ & $\mathrm{S}$ & $\mathrm{K}$ & $\mathrm{Ca}$ & $\mathrm{Ti}$ \\
\hline C4191-13 & $8.9 \mathrm{E}+02$ & $5.4 \mathrm{E}+03$ & $6.8 \mathrm{E}+03$ & $1.6 \mathrm{E}+03$ & $1.0 \mathrm{E}+02$ & $8.1 \mathrm{E}+02$ & $7.6 \mathrm{E}+03$ & $1.6 \mathrm{E}+03$ \\
\hline C4191-17.5 & $3.2 \mathrm{E}+03$ & $5.8 \mathrm{E}+03$ & $9.1 \mathrm{E}+03$ & $1.5 \mathrm{E}+03$ & $8.5 \mathrm{E}+01$ & $1.1 \mathrm{E}+03$ & $8.2 \mathrm{E}+03$ & $1.7 \mathrm{E}+03$ \\
\hline C4191-22.5 & $3.4 \mathrm{E}+03$ & $5.7 \mathrm{E}+03$ & $9.9 \mathrm{E}+03$ & $1.7 \mathrm{E}+03$ & $9.3 \mathrm{E}+01$ & $1.2 \mathrm{E}+03$ & $1.2 \mathrm{E}+04$ & $2.0 \mathrm{E}+03$ \\
\hline C4191-27.5 & $3.7 E+03$ & $6.0 \mathrm{E}+03$ & $1.0 \mathrm{E}+04$ & $1.8 \mathrm{E}+03$ & $9.1 \mathrm{E}+01$ & $1.4 \mathrm{E}+03$ & $1.2 \mathrm{E}+04$ & $1.7 \mathrm{E}+03$ \\
\hline C4191-37.5 & $1.6 \mathrm{E}+03$ & $4.8 \mathrm{E}+03$ & $8.0 \mathrm{E}+03$ & $6.4 \mathrm{E}+02$ & 7.3E+01 & $1.3 \mathrm{E}+03$ & $7.1 \mathrm{E}+03$ & $9.6 \mathrm{E}+02$ \\
\hline C4191-41 & $1.8 \mathrm{E}+03$ & $4.9 \mathrm{E}+03$ & $7.0 \mathrm{E}+03$ & $6.6 \mathrm{E}+02$ & $1.0 \mathrm{E}+02$ & $1.4 \mathrm{E}+03$ & $9.6 \mathrm{E}+03$ & $5.7 \mathrm{E}+02$ \\
\hline C4191-51 & $9.7 \mathrm{E}+02$ & $5.4 \mathrm{E}+03$ & $6.8 \mathrm{E}+03$ & $4.6 \mathrm{E}+02$ & $1.4 \mathrm{E}+02$ & $1.2 \mathrm{E}+03$ & $9.5 \mathrm{E}+03$ & $5.6 \mathrm{E}+02$ \\
\hline C4191-61 & $8.6 \mathrm{E}+02$ & $5.3 E+03$ & $6.7 \mathrm{E}+03$ & $4.7 \mathrm{E}+02$ & $1.3 \mathrm{E}+02$ & $1.2 \mathrm{E}+03$ & $9.4 \mathrm{E}+03$ & $5.7 \mathrm{E}+02$ \\
\hline C4191-71 & $1.1 \mathrm{E}+03$ & $4.9 \mathrm{E}+03$ & $6.1 \mathrm{E}+03$ & $4.5 \mathrm{E}+02$ & $1.5 \mathrm{E}+02$ & $1.3 \mathrm{E}+03$ & $8.7 E+03$ & $3.7 \mathrm{E}+02$ \\
\hline C4191-81 & $1.5 \mathrm{E}+03$ & $5.0 \mathrm{E}+03$ & $6.6 \mathrm{E}+03$ & $4.5 E+02$ & $2.9 \mathrm{E}+02$ & $1.3 \mathrm{E}+03$ & $8.5 E+03$ & $5.2 \mathrm{E}+02$ \\
\hline C4191-91 & $3.1 \mathrm{E}+03$ & $6.1 \mathrm{E}+03$ & $8.7 \mathrm{E}+03$ & $5.0 \mathrm{E}+02$ & $1.6 \mathrm{E}+02$ & $1.9 \mathrm{E}+03$ & $9.2 \mathrm{E}+03$ & $6.9 \mathrm{E}+02$ \\
\hline C4191-91 dup & $3.1 \mathrm{E}+03$ & $5.7 \mathrm{E}+03$ & $7.9 \mathrm{E}+03$ & $5.2 \mathrm{E}+02$ & $1.6 \mathrm{E}+02$ & $1.7 \mathrm{E}+03$ & $9.1 \mathrm{E}+03$ & $6.0 \mathrm{E}+02$ \\
\hline C4191-101 & $2.5 \mathrm{E}+03$ & $5.3 E+03$ & $6.8 \mathrm{E}+03$ & $5.0 \mathrm{E}+02$ & $2.0 \mathrm{E}+02$ & $1.4 \mathrm{E}+03$ & $9.1 \mathrm{E}+03$ & $4.2 \mathrm{E}+02$ \\
\hline C4191-111 & $1.1 \mathrm{E}+03$ & $5.0 \mathrm{E}+03$ & $6.6 \mathrm{E}+03$ & $4.9 \mathrm{E}+02$ & $1.1 \mathrm{E}+02$ & $1.2 \mathrm{E}+03$ & $8.6 \mathrm{E}+03$ & $5.3 \mathrm{E}+02$ \\
\hline C4191-121 & $9.4 \mathrm{E}+02$ & $5.1 \mathrm{E}+03$ & $6.3 \mathrm{E}+03$ & $4.7 \mathrm{E}+02$ & $1.0 \mathrm{E}+02$ & $1.4 \mathrm{E}+03$ & $8.4 \mathrm{E}+03$ & $3.8 \mathrm{E}+02$ \\
\hline C4191-131 & $1.4 \mathrm{E}+03$ & $5.7 E+03$ & $7.4 \mathrm{E}+03$ & $5.4 \mathrm{E}+02$ & $1.3 \mathrm{E}+02$ & $1.5 \mathrm{E}+03$ & $9.5 \mathrm{E}+03$ & $5.4 \mathrm{E}+02$ \\
\hline C4191-131 dup & $1.6 \mathrm{E}+03$ & $6.0 \mathrm{E}+03$ & $8.4 \mathrm{E}+03$ & $5.2 \mathrm{E}+02$ & $1.2 \mathrm{E}+02$ & $1.7 \mathrm{E}+03$ & $9.4 \mathrm{E}+03$ & $7.2 \mathrm{E}+02$ \\
\hline C4191-141 & $2.9 \mathrm{E}+02$ & $5.4 \mathrm{E}+03$ & $7.6 \mathrm{E}+03$ & $4.5 \mathrm{E}+02$ & $8.6 \mathrm{E}+01$ & $1.6 \mathrm{E}+03$ & $8.9 \mathrm{E}+03$ & $6.8 \mathrm{E}+02$ \\
\hline C4191-151 & $(2.6 \mathrm{E}+02)$ & $5.8 \mathrm{E}+03$ & $7.4 \mathrm{E}+03$ & $5.1 \mathrm{E}+02$ & $8.7 \mathrm{E}+01$ & $1.4 \mathrm{E}+03$ & $8.5 E+03$ & $5.8 \mathrm{E}+02$ \\
\hline C4191-153.5 & $2.8 \mathrm{E}+02$ & $6.0 \mathrm{E}+03$ & 8.3E+03 & $5.3 \mathrm{E}+02$ & $8.0 \mathrm{E}+01$ & $1.5 \mathrm{E}+03$ & $9.3 \mathrm{E}+03$ & $8.3 \mathrm{E}+02$ \\
\hline C4191-156 & $(2.9 E+02)$ & $6.0 \mathrm{E}+03$ & 8.7E+03 & $5.4 \mathrm{E}+02$ & $8.2 \mathrm{E}+01$ & $1.6 \mathrm{E}+03$ & $9.4 \mathrm{E}+03$ & $8.4 \mathrm{E}+02$ \\
\hline C4191-158.5 & $(2.7 \mathrm{E}+02)$ & $6.1 \mathrm{E}+03$ & $8.5 \mathrm{E}+03$ & $5.5 \mathrm{E}+02$ & $6.9 \mathrm{E}+01$ & $1.6 \mathrm{E}+03$ & $8.8 \mathrm{E}+03$ & $6.8 \mathrm{E}+02$ \\
\hline C4191-158.5 dup & $(2.8 \mathrm{E}+02)$ & $6.2 \mathrm{E}+03$ & $8.5 E+03$ & $5.4 \mathrm{E}+02$ & $6.3 \mathrm{E}+01$ & $1.6 \mathrm{E}+03$ & $8.9 E+03$ & $6.9 \mathrm{E}+02$ \\
\hline C4191-161 & $(2.2 \mathrm{E}+02)$ & $5.1 \mathrm{E}+03$ & $6.5 E+03$ & $4.7 \mathrm{E}+02$ & $7.9 \mathrm{E}+01$ & $1.6 \mathrm{E}+03$ & $8.1 \mathrm{E}+03$ & $4.8 \mathrm{E}+02$ \\
\hline C4191-171 & $2.4 \mathrm{E}+02$ & $6.0 \mathrm{E}+03$ & $8.4 \mathrm{E}+03$ & $5.5 \mathrm{E}+02$ & $7.7 \mathrm{E}+01$ & $1.7 \mathrm{E}+03$ & $8.9 E+03$ & $6.3 \mathrm{E}+02$ \\
\hline C4191-181 & $(2.3 \mathrm{E}+02)$ & $5.5 \mathrm{E}+03$ & $6.9 \mathrm{E}+03$ & $5.4 \mathrm{E}+02$ & $8.4 \mathrm{E}+01$ & $1.5 \mathrm{E}+03$ & $8.4 \mathrm{E}+03$ & $3.8 \mathrm{E}+02$ \\
\hline C4191-191 & $2.8 \mathrm{E}+02$ & $5.6 \mathrm{E}+03$ & $7.9 \mathrm{E}+03$ & $5.1 \mathrm{E}+02$ & $8.9 E+01$ & $1.7 \mathrm{E}+03$ & $9.4 \mathrm{E}+03$ & $6.7 \mathrm{E}+02$ \\
\hline C4191-201 & $2.8 \mathrm{E}+02$ & $5.4 \mathrm{E}+03$ & 7.7E+03 & $5.1 \mathrm{E}+02$ & 7.7E+01 & $1.5 \mathrm{E}+03$ & $8.4 \mathrm{E}+03$ & $7.9 \mathrm{E}+02$ \\
\hline C4191-211 & $3.9 \mathrm{E}+02$ & $4.6 \mathrm{E}+03$ & $6.3 \mathrm{E}+03$ & $7.8 \mathrm{E}+02$ & $8.0 \mathrm{E}+01$ & $9.5 \mathrm{E}+02$ & $6.4 \mathrm{E}+03$ & $1.2 \mathrm{E}+03$ \\
\hline C4191-221 & $4.9 \mathrm{E}+02$ & $4.6 \mathrm{E}+03$ & $7.0 \mathrm{E}+03$ & $7.6 \mathrm{E}+02$ & $8.4 \mathrm{E}+01$ & $9.5 \mathrm{E}+02$ & $7.3 E+03$ & $1.4 \mathrm{E}+03$ \\
\hline C4191-221 dup & $4.1 \mathrm{E}+02$ & $4.3 \mathrm{E}+03$ & $6.3 \mathrm{E}+03$ & $7.3 \mathrm{E}+02$ & $7.8 \mathrm{E}+01$ & $8.6 \mathrm{E}+02$ & $6.6 \mathrm{E}+03$ & $1.1 \mathrm{E}+03$ \\
\hline C4191-231 & $3.5 \mathrm{E}+02$ & $4.1 \mathrm{E}+03$ & $6.0 \mathrm{E}+03$ & $7.5 \mathrm{E}+02$ & $7.8 \mathrm{E}+01$ & $8.6 \mathrm{E}+02$ & $6.8 \mathrm{E}+03$ & $9.1 \mathrm{E}+02$ \\
\hline C4191-241 & $2.9 \mathrm{E}+02$ & $4.5 \mathrm{E}+03$ & $6.8 \mathrm{E}+03$ & $5.0 \mathrm{E}+02$ & $7.0 \mathrm{E}+01$ & $1.1 \mathrm{E}+03$ & $6.2 \mathrm{E}+03$ & $8.2 \mathrm{E}+02$ \\
\hline C4191-251 & $(2.3 E+02)$ & $4.1 \mathrm{E}+03$ & $5.5 \mathrm{E}+03$ & $4.4 \mathrm{E}+02$ & $(48)$ & $1.0 \mathrm{E}+03$ & $4.5 \mathrm{E}+03$ & $5.5 \mathrm{E}+02$ \\
\hline C4191-261 & $(2.6 \mathrm{E}+02)$ & $4.5 \mathrm{E}+03$ & $6.7 \mathrm{E}+03$ & $4.0 \mathrm{E}+02$ & (52) & $1.2 \mathrm{E}+03$ & $5.5 \mathrm{E}+03$ & $6.3 \mathrm{E}+02$ \\
\hline C4191-271 & $(2.5 \mathrm{E}+02)$ & $4.3 \mathrm{E}+03$ & $6.2 \mathrm{E}+03$ & $4.0 \mathrm{E}+02$ & (51) & $1.1 \mathrm{E}+03$ & $5.1 \mathrm{E}+03$ & $5.8 \mathrm{E}+02$ \\
\hline C4191-281 & $(2.2 \mathrm{E}+02)$ & $4.2 \mathrm{E}+03$ & $6.0 \mathrm{E}+03$ & $4.0 \mathrm{E}+02$ & $(47)$ & $1.0 \mathrm{E}+03$ & $4.9 \mathrm{E}+03$ & $5.6 \mathrm{E}+02$ \\
\hline C4191-291 & $4.3 \mathrm{E}+02$ & $4.0 \mathrm{E}+03$ & $6.4 \mathrm{E}+03$ & $5.5 \mathrm{E}+02$ & $9.7 \mathrm{E}+01$ & $1.1 \mathrm{E}+03$ & $7.0 \mathrm{E}+03$ & $7.2 \mathrm{E}+02$ \\
\hline C4191-301 & $4.2 \mathrm{E}+02$ & $3.6 \mathrm{E}+03$ & $5.5 \mathrm{E}+03$ & $5.4 \mathrm{E}+02$ & $7.3 \mathrm{E}+01$ & $8.6 \mathrm{E}+02$ & $4.5 \mathrm{E}+03$ & $6.6 \mathrm{E}+02$ \\
\hline C4191-311 & $4.2 \mathrm{E}+02$ & $4.0 \mathrm{E}+03$ & $5.8 \mathrm{E}+03$ & $3.7 \mathrm{E}+02$ & $7.2 \mathrm{E}+01$ & $9.9 \mathrm{E}+02$ & $3.6 \mathrm{E}+03$ & $4.9 \mathrm{E}+02$ \\
\hline C4191-321 & $3.7 \mathrm{E}+02$ & $4.2 \mathrm{E}+03$ & $5.2 \mathrm{E}+03$ & $4.6 \mathrm{E}+02$ & $7.8 \mathrm{E}+01$ & $9.1 \mathrm{E}+02$ & $3.4 \mathrm{E}+03$ & $5.2 \mathrm{E}+02$ \\
\hline C4191-331 & $3.7 \mathrm{E}+02$ & $4.5 \mathrm{E}+03$ & $5.9 \mathrm{E}+03$ & $4.9 \mathrm{E}+02$ & $1.1 \mathrm{E}+02$ & $1.0 \mathrm{E}+03$ & $6.7 \mathrm{E}+03$ & $4.7 \mathrm{E}+02$ \\
\hline C4191-341 & $4.1 \mathrm{E}+02$ & $3.2 \mathrm{E}+03$ & $5.8 \mathrm{E}+03$ & $8.1 \mathrm{E}+02$ & $9.7 \mathrm{E}+01$ & $8.6 \mathrm{E}+02$ & $4.0 \mathrm{E}+03$ & $5.7 \mathrm{E}+02$ \\
\hline
\end{tabular}


PNNL-17821

Table 8.9. Acid-Extractable Heavy Elements in Borehole C4191 Sediments ( $\mu \mathrm{g} / \mathrm{g}$ dry sediment)

\begin{tabular}{|c|c|c|c|c|c|c|c|c|}
\hline ID \& ft bgs & V & Mn & $\mathrm{Fe}$ & Co & $\mathrm{Zn}$ & $\mathrm{Sr}$ & $\mathrm{Zr}$ & $\mathrm{Ba}$ \\
\hline C4191-13 & $4.9 \mathrm{E}+01$ & $4.0 \mathrm{E}+02$ & $2.7 \mathrm{E}+04$ & $1.3 \mathrm{E}+01$ & $4.6 \mathrm{E}+01$ & $2.9 \mathrm{E}+01$ & $2.8 \mathrm{E}+01$ & $1.0 \mathrm{E}+02$ \\
\hline C4191-17.5 & $6.0 \mathrm{E}+01$ & $5.0 \mathrm{E}+02$ & $3.1 \mathrm{E}+04$ & $1.5 \mathrm{E}+01$ & $5.3 \mathrm{E}+01$ & $2.9 \mathrm{E}+01$ & $3.0 \mathrm{E}+01$ & $1.1 \mathrm{E}+02$ \\
\hline C4191-22.5 & $7.1 \mathrm{E}+01$ & $5.4 \mathrm{E}+02$ & $3.2 \mathrm{E}+04$ & $1.6 \mathrm{E}+01$ & $5.4 \mathrm{E}+01$ & $3.8 \mathrm{E}+01$ & $3.2 \mathrm{E}+01$ & $1.2 \mathrm{E}+02$ \\
\hline C4191-27.5 & $6.1 \mathrm{E}+01$ & $5.5 \mathrm{E}+02$ & $3.2 \mathrm{E}+04$ & $1.5 \mathrm{E}+01$ & $5.3 \mathrm{E}+01$ & $3.6 \mathrm{E}+01$ & $3.1 \mathrm{E}+01$ & $1.3 \mathrm{E}+02$ \\
\hline C4191-37.5 & $3.7 \mathrm{E}+01$ & $3.3 E+02$ & $1.8 \mathrm{E}+04$ & $8.1 \mathrm{E}+00$ & $3.8 \mathrm{E}+01$ & $3.7 E+01$ & $1.1 \mathrm{E}+01$ & $9.0 \mathrm{E}+01$ \\
\hline C4191-41 & $2.5 \mathrm{E}+01$ & $3.2 \mathrm{E}+02$ & $1.6 \mathrm{E}+04$ & $7.4 \mathrm{E}+00$ & $3.6 \mathrm{E}+01$ & $3.8 \mathrm{E}+01$ & $1.0 \mathrm{E}+01$ & $9.7 \mathrm{E}+01$ \\
\hline C4191-51 & $2.3 \mathrm{E}+01$ & $2.8 \mathrm{E}+02$ & $1.4 \mathrm{E}+04$ & $(6.1 \mathrm{E}+00)$ & $3.6 \mathrm{E}+01$ & $3.2 E+01$ & $(6.4 \mathrm{E}+00)$ & $7.0 \mathrm{E}+01$ \\
\hline C4191-61 & $2.1 \mathrm{E}+01$ & $2.8 \mathrm{E}+02$ & $1.4 \mathrm{E}+04$ & $(6.2 \mathrm{E}+00)$ & $3.6 \mathrm{E}+01$ & $3.2 \mathrm{E}+01$ & $(6.6 \mathrm{E}+00)$ & $6.8 \mathrm{E}+01$ \\
\hline C4191-71 & $1.7 \mathrm{E}+01$ & $2.8 \mathrm{E}+02$ & $1.3 \mathrm{E}+04$ & $(5.4 \mathrm{E}+00)$ & $3.3 \mathrm{E}+01$ & $2.9 \mathrm{E}+01$ & $(5.8 \mathrm{E}+00)$ & $6.9 \mathrm{E}+01$ \\
\hline C4191-81 & $2.1 \mathrm{E}+01$ & $2.9 \mathrm{E}+02$ & $1.4 \mathrm{E}+04$ & $(6.2 \mathrm{E}+00)$ & $3.4 \mathrm{E}+01$ & $2.9 \mathrm{E}+01$ & $6.7 \mathrm{E}+00$ & $7.3 \mathrm{E}+01$ \\
\hline C4191-91 & $2.6 \mathrm{E}+01$ & $3.2 \mathrm{E}+02$ & $1.7 \mathrm{E}+04$ & $7.6 \mathrm{E}+00$ & $4.2 \mathrm{E}+01$ & $3.8 \mathrm{E}+01$ & $7.2 \mathrm{E}+00$ & $9.3 \mathrm{E}+01$ \\
\hline C4191-91 dup & $2.4 \mathrm{E}+01$ & $3.1 \mathrm{E}+02$ & $1.6 \mathrm{E}+04$ & $7.2 \mathrm{E}+00$ & $4.0 \mathrm{E}+01$ & $3.7 \mathrm{E}+01$ & $6.8 \mathrm{E}+00$ & $7.5 \mathrm{E}+01$ \\
\hline C4191-101 & $1.9 \mathrm{E}+01$ & $3.0 \mathrm{E}+02$ & $1.4 \mathrm{E}+04$ & $6.1 \mathrm{E}+00$ & $3.6 \mathrm{E}+01$ & $3.3 \mathrm{E}+01$ & $6.6 \mathrm{E}+00$ & $7.4 \mathrm{E}+01$ \\
\hline C4191-111 & $2.1 \mathrm{E}+01$ & $2.7 \mathrm{E}+02$ & $1.4 \mathrm{E}+04$ & $(5.9 \mathrm{E}+00)$ & $3.4 \mathrm{E}+01$ & $3.1 \mathrm{E}+01$ & $7.1 \mathrm{E}+00$ & $6.2 \mathrm{E}+01$ \\
\hline C4191-121 & $1.8 \mathrm{E}+01$ & $2.9 \mathrm{E}+02$ & $1.3 \mathrm{E}+04$ & $(6.1 \mathrm{E}+00)$ & $3.3 E+01$ & $3.2 \mathrm{E}+01$ & $(5.9 \mathrm{E}+00)$ & $7.3 \mathrm{E}+01$ \\
\hline C4191-131 & $2.4 \mathrm{E}+01$ & $3.2 \mathrm{E}+02$ & $1.5 \mathrm{E}+04$ & $(7.0 \mathrm{E}+00)$ & 3.7E+01 & $3.6 \mathrm{E}+01$ & $7.2 \mathrm{E}+00$ & $9.4 \mathrm{E}+01$ \\
\hline C4191-131 dup & $3.1 \mathrm{E}+01$ & $3.3 \mathrm{E}+02$ & $1.8 \mathrm{E}+04$ & $7.8 \mathrm{E}+00$ & $4.1 \mathrm{E}+01$ & $3.7 \mathrm{E}+01$ & $7.4 \mathrm{E}+00$ & $8.4 \mathrm{E}+01$ \\
\hline C4191-141 & $2.8 \mathrm{E}+01$ & $3.1 \mathrm{E}+02$ & $1.6 \mathrm{E}+04$ & $7.2 \mathrm{E}+00$ & 3.7E+01 & $3.4 \mathrm{E}+01$ & $7.1 \mathrm{E}+00$ & 7.7E+01 \\
\hline C4191-151 & $2.6 \mathrm{E}+01$ & $3.1 \mathrm{E}+02$ & $1.5 \mathrm{E}+04$ & $7.0 \mathrm{E}+00$ & 3.6E+01 & $3.5 \mathrm{E}+01$ & $(6.0 \mathrm{E}+00)$ & $8.2 \mathrm{E}+01$ \\
\hline C4191-153.5 & $3.1 \mathrm{E}+01$ & $3.3 \mathrm{E}+02$ & $1.7 \mathrm{E}+04$ & $7.7 \mathrm{E}+00$ & $3.9 \mathrm{E}+01$ & $3.6 \mathrm{E}+01$ & $8.1 \mathrm{E}+00$ & $7.8 \mathrm{E}+01$ \\
\hline C4191-156 & $3.4 \mathrm{E}+01$ & $3.4 \mathrm{E}+02$ & $1.8 \mathrm{E}+04$ & $8.1 \mathrm{E}+00$ & $4.1 \mathrm{E}+01$ & $3.9 \mathrm{E}+01$ & $8.7 \mathrm{E}+00$ & $8.2 \mathrm{E}+01$ \\
\hline C4191-158.5 & $3.0 \mathrm{E}+01$ & $3.3 \mathrm{E}+02$ & $1.6 \mathrm{E}+04$ & $7.8 \mathrm{E}+00$ & $4.0 \mathrm{E}+01$ & $3.9 \mathrm{E}+01$ & $(5.6 \mathrm{E}+00)$ & $8.1 \mathrm{E}+01$ \\
\hline C4191-158.5 dup & $2.8 \mathrm{E}+01$ & $3.3 \mathrm{E}+02$ & $1.6 \mathrm{E}+04$ & $7.9 \mathrm{E}+00$ & $4.0 \mathrm{E}+01$ & $4.1 \mathrm{E}+01$ & $(5.5 E+00)$ & $8.6 \mathrm{E}+01$ \\
\hline C4191-161 & $2.2 \mathrm{E}+01$ & $3.0 \mathrm{E}+02$ & $1.3 \mathrm{E}+04$ & $(6.2 \mathrm{E}+00)$ & $3.5 \mathrm{E}+01$ & $3.0 \mathrm{E}+01$ & $(6.3 E+00)$ & $7.5 \mathrm{E}+01$ \\
\hline C4191-171 & $2.5 \mathrm{E}+01$ & $3.4 \mathrm{E}+02$ & $1.6 \mathrm{E}+04$ & $7.7 \mathrm{E}+00$ & $4.2 \mathrm{E}+01$ & $3.8 \mathrm{E}+01$ & $6.6 \mathrm{E}+00$ & $9.5 \mathrm{E}+01$ \\
\hline C4191-181 & $2.0 \mathrm{E}+01$ & $3.0 \mathrm{E}+02$ & $1.3 \mathrm{E}+04$ & $(6.6 \mathrm{E}+00)$ & $3.6 \mathrm{E}+01$ & $3.6 \mathrm{E}+01$ & $(4.7 \mathrm{E}+00)$ & $8.1 \mathrm{E}+01$ \\
\hline C4191-191 & $2.8 \mathrm{E}+01$ & $3.4 \mathrm{E}+02$ & $1.7 \mathrm{E}+04$ & $7.8 \mathrm{E}+00$ & $4.1 \mathrm{E}+01$ & $3.8 \mathrm{E}+01$ & $9.5 \mathrm{E}+00$ & $8.6 \mathrm{E}+01$ \\
\hline C4191-201 & $2.9 \mathrm{E}+01$ & $3.1 \mathrm{E}+02$ & $1.6 \mathrm{E}+04$ & $7.9 \mathrm{E}+00$ & $3.8 \mathrm{E}+01$ & $3.8 \mathrm{E}+01$ & $9.6 \mathrm{E}+00$ & $8.0 \mathrm{E}+01$ \\
\hline C4191-211 & $3.9 \mathrm{E}+01$ & $2.6 \mathrm{E}+02$ & $1.9 \mathrm{E}+04$ & $8.7 \mathrm{E}+00$ & $3.5 \mathrm{E}+01$ & $3.0 \mathrm{E}+01$ & $1.6 \mathrm{E}+01$ & $6.5 \mathrm{E}+01$ \\
\hline C4191-221 & $4.5 \mathrm{E}+01$ & $2.7 \mathrm{E}+02$ & $1.9 \mathrm{E}+04$ & $9.3 \mathrm{E}+00$ & $3.8 \mathrm{E}+01$ & $3.4 \mathrm{E}+01$ & $1.8 \mathrm{E}+01$ & $6.8 \mathrm{E}+01$ \\
\hline C4191-221 dup & $3.5 \mathrm{E}+01$ & $2.5 \mathrm{E}+02$ & $1.7 \mathrm{E}+04$ & $7.9 \mathrm{E}+00$ & $3.4 \mathrm{E}+01$ & $2.9 \mathrm{E}+01$ & $1.6 \mathrm{E}+01$ & $6.4 \mathrm{E}+01$ \\
\hline C4191-231 & $2.8 \mathrm{E}+01$ & $2.4 \mathrm{E}+02$ & $1.5 \mathrm{E}+04$ & $7.5 \mathrm{E}+00$ & $3.2 \mathrm{E}+01$ & $3.0 \mathrm{E}+01$ & $1.8 \mathrm{E}+01$ & $6.4 \mathrm{E}+01$ \\
\hline C4191-241 & $2.9 \mathrm{E}+01$ & $2.7 \mathrm{E}+02$ & $1.5 \mathrm{E}+04$ & $7.0 \mathrm{E}+00$ & $3.4 \mathrm{E}+01$ & $3.1 \mathrm{E}+01$ & $9.6 \mathrm{E}+00$ & $6.8 \mathrm{E}+01$ \\
\hline C4191-251 & $2.1 \mathrm{E}+01$ & $2.3 \mathrm{E}+02$ & $1.1 \mathrm{E}+04$ & $(5.3 \mathrm{E}+00)$ & $2.9 \mathrm{E}+01$ & $2.5 \mathrm{E}+01$ & $(6.0 \mathrm{E}+00)$ & $5.6 \mathrm{E}+01$ \\
\hline C4191-261 & $2.3 \mathrm{E}+01$ & $2.5 \mathrm{E}+02$ & $1.2 \mathrm{E}+04$ & $(5.9 \mathrm{E}+00)$ & $3.2 \mathrm{E}+01$ & $3.1 \mathrm{E}+01$ & $(5.3 E+00)$ & $5.8 \mathrm{E}+01$ \\
\hline C4191-271 & $2.2 \mathrm{E}+01$ & $2.4 \mathrm{E}+02$ & $1.2 \mathrm{E}+04$ & $(6.1 \mathrm{E}+00)$ & $3.1 \mathrm{E}+01$ & $3.1 \mathrm{E}+01$ & $(4.9 \mathrm{E}+00)$ & $5.8 \mathrm{E}+01$ \\
\hline C4191-281 & $2.1 \mathrm{E}+01$ & $2.4 \mathrm{E}+02$ & $1.2 \mathrm{E}+04$ & $(5.6 \mathrm{E}+00)$ & $3.1 \mathrm{E}+01$ & $2.9 \mathrm{E}+01$ & $(5.0 \mathrm{E}+00)$ & $5.5 \mathrm{E}+01$ \\
\hline C4191-291 & $2.4 \mathrm{E}+01$ & $2.4 \mathrm{E}+02$ & $1.3 \mathrm{E}+04$ & $(6.2 \mathrm{E}+00)$ & $3.1 \mathrm{E}+01$ & $3.3 E+01$ & $1.0 \mathrm{E}+01$ & $7.6 \mathrm{E}+01$ \\
\hline C4191-301 & $2.2 \mathrm{E}+01$ & $2.2 \mathrm{E}+02$ & $1.2 \mathrm{E}+04$ & $(5.9 E+00)$ & $2.9 \mathrm{E}+01$ & $2.5 \mathrm{E}+01$ & $9.2 \mathrm{E}+00$ & $6.6 \mathrm{E}+01$ \\
\hline C4191-311 & $2.0 \mathrm{E}+01$ & $2.5 \mathrm{E}+02$ & $1.1 \mathrm{E}+04$ & $(5.6 \mathrm{E}+00)$ & $3.3 \mathrm{E}+01$ & $2.1 \mathrm{E}+01$ & $(5.0 \mathrm{E}+00)$ & $6.4 \mathrm{E}+01$ \\
\hline C4191-321 & $2.0 \mathrm{E}+01$ & $2.5 \mathrm{E}+02$ & $1.1 \mathrm{E}+04$ & $(5.5 \mathrm{E}+00)$ & $2.5 \mathrm{E}+01$ & $1.9 \mathrm{E}+01$ & $(6.0 \mathrm{E}+00)$ & $6.5 \mathrm{E}+01$ \\
\hline C4191-331 & $2.0 \mathrm{E}+01$ & $2.4 \mathrm{E}+02$ & $1.1 \mathrm{E}+04$ & $(5.7 E+00)$ & $3.3 \mathrm{E}+01$ & $2.2 \mathrm{E}+01$ & $(5.1 \mathrm{E}+00)$ & $6.6 \mathrm{E}+01$ \\
\hline C4191-341 & $2.1 \mathrm{E}+01$ & $2.4 \mathrm{E}+02$ & $1.2 \mathrm{E}+04$ & $6.4 \mathrm{E}+00$ & $2.8 \mathrm{E}+01$ & $2.5 \mathrm{E}+01$ & $9.6 \mathrm{E}+00$ & $7.6 \mathrm{E}+01$ \\
\hline
\end{tabular}


PNNL-17821

Table 8.10. Acid Extractable Content for RCRA Metals and Radionuclides in Borehole C4191 Sediments (units $\mu \mathrm{g} / \mathrm{g}$ except Tc pCi/g)

\begin{tabular}{|c|c|c|c|c|c|}
\hline ID \& ft bgs & $\mathrm{Cr}$ & $\mathrm{Cd}$ & $\mathrm{Pb}$ & Tc- 99 & U-238 \\
\hline C4191-13 & $(5.8 \mathrm{E}+00)$ & $1.19 \mathrm{E}+01$ & $5.56 \mathrm{E}+02$ & $(9.85 E+00)$ & $4.74 \mathrm{E}+01$ \\
\hline C4191-17.5 & $8.6 \mathrm{E}+00$ & $1.47 \mathrm{E}+01$ & $7.94 \mathrm{E}+02$ & $(8.94 \mathrm{E}+00)$ & $2.65 E+01$ \\
\hline C4191-22.5 & $8.7 \mathrm{E}+00$ & $1.47 \mathrm{E}+01$ & $6.97 \mathrm{E}+02$ & $(1.09 \mathrm{E}+01)$ & $2.59 \mathrm{E}+01$ \\
\hline C4191-27.5 & $9.5 \mathrm{E}+00$ & $1.72 \mathrm{E}+01$ & $8.26 \mathrm{E}+02$ & $(1.05 E+01)$ & $8.33 \mathrm{E}+00$ \\
\hline C4191-37.5 & $1.1 \mathrm{E}+01$ & $(9.56 \mathrm{E}+00)$ & $4.39 \mathrm{E}+02$ & $(1.25 E+01)$ & $1.20 \mathrm{E}+00$ \\
\hline C4191-41 & $9.1 \mathrm{E}+00$ & $1.13 \mathrm{E}+01$ & $6.97 \mathrm{E}+02$ & $<3.99 \mathrm{E}+02$ & $2.92 \mathrm{E}+00$ \\
\hline C4191-51 & $1.0 \mathrm{E}+01$ & $1.09 \mathrm{E}+01$ & $8.77 E+02$ & $9.08 \mathrm{E}+00$ & 4.68E-01 \\
\hline C4191-61 & $1.1 \mathrm{E}+01$ & $1.41 \mathrm{E}+01$ & $6.90 \mathrm{E}+02$ & $(7.46 \mathrm{E}+00)$ & $5.20 \mathrm{E}-01$ \\
\hline C4191-71 & $1.0 \mathrm{E}+01$ & $1.02 \mathrm{E}+01$ & $6.83 \mathrm{E}+02$ & $1.45 \mathrm{E}+01$ & 4.05E-01 \\
\hline C4191-81 & $1.0 \mathrm{E}+01$ & $1.16 \mathrm{E}+01$ & $6.85 E+02$ & $2.06 \mathrm{E}+01$ & 4.23E-01 \\
\hline C4191-91 & $1.4 \mathrm{E}+01$ & $1.42 \mathrm{E}+01$ & $8.95 E+02$ & $1.40 \mathrm{E}+02$ & 5.47E-01 \\
\hline C4191-91 dup & $1.4 \mathrm{E}+01$ & $1.35 \mathrm{E}+01$ & $8.25 E+02$ & $1.62 \mathrm{E}+02$ & $5.86 \mathrm{E}-01$ \\
\hline C4191-101 & $1.1 \mathrm{E}+01$ & $1.39 \mathrm{E}+01$ & $8.89 E+02$ & $1.63 \mathrm{E}+02$ & 4.49E-01 \\
\hline C4191-111 & $1.0 \mathrm{E}+01$ & $1.30 \mathrm{E}+01$ & $7.00 \mathrm{E}+02$ & $6.40 \mathrm{E}+01$ & 4.48E-01 \\
\hline C4191-121 & $1.0 \mathrm{E}+01$ & $1.22 \mathrm{E}+01$ & $7.68 \mathrm{E}+02$ & $4.49 \mathrm{E}+01$ & 3.76E-01 \\
\hline C4191-131 & $1.3 \mathrm{E}+01$ & $1.46 \mathrm{E}+01$ & $6.91 \mathrm{E}+02$ & $8.06 \mathrm{E}+01$ & 4.75E-01 \\
\hline C4191-131 dup & $1.5 \mathrm{E}+01$ & $1.56 \mathrm{E}+01$ & $8.94 \mathrm{E}+02$ & $8.76 \mathrm{E}+01$ & 5.19E-01 \\
\hline C4191-141 & $1.2 \mathrm{E}+01$ & $1.42 \mathrm{E}+01$ & $8.94 \mathrm{E}+02$ & $1.46 \mathrm{E}+01$ & 5.19E-01 \\
\hline C4191-151 & $1.4 \mathrm{E}+01$ & $1.24 \mathrm{E}+01$ & $6.62 \mathrm{E}+02$ & $(6.32 \mathrm{E}+00)$ & 4.93E-01 \\
\hline C4191-153.5 & $1.4 \mathrm{E}+01$ & $1.14 \mathrm{E}+01$ & $6.62 \mathrm{E}+02$ & $(1.70 \mathrm{E}+01)$ & 6.67E-01 \\
\hline C4191-156 & $1.5 \mathrm{E}+01$ & $1.17 \mathrm{E}+01$ & $6.69 \mathrm{E}+02$ & $(1.62 \mathrm{E}+01)$ & 5.08E-01 \\
\hline C4191-158.5 & $1.7 \mathrm{E}+01$ & $1.27 \mathrm{E}+01$ & $6.72 \mathrm{E}+02$ & $(1.84 \mathrm{E}+01)$ & $5.28 \mathrm{E}-01$ \\
\hline C4191-158.5 dup & $1.6 \mathrm{E}+01$ & $1.32 \mathrm{E}+01$ & $6.37 \mathrm{E}+02$ & $(1.54 \mathrm{E}+01)$ & 5.15E-01 \\
\hline C4191-161 & $1.1 \mathrm{E}+01$ & $(9.99 \mathrm{E}+00)$ & $5.96 \mathrm{E}+02$ & $(4.15 E+00)$ & 3.90E-01 \\
\hline C4191-171 & $1.5 \mathrm{E}+01$ & $1.63 \mathrm{E}+01$ & $7.97 \mathrm{E}+02$ & $(4.87 E+00)$ & 4.96E-01 \\
\hline C4191-181 & $1.3 \mathrm{E}+01$ & $1.29 \mathrm{E}+01$ & $6.42 \mathrm{E}+02$ & $(2.81 \mathrm{E}+00)$ & 4.64E-01 \\
\hline C4191-191 & $1.2 \mathrm{E}+01$ & $1.27 \mathrm{E}+01$ & $8.51 \mathrm{E}+02$ & $(5.24 \mathrm{E}+00)$ & 4.37E-01 \\
\hline C4191-201 & $1.1 \mathrm{E}+01$ & $1.23 \mathrm{E}+01$ & $6.49 \mathrm{E}+02$ & $(9.55 \mathrm{E}+00)$ & 4.72E-01 \\
\hline C4191-211 & $9.9 \mathrm{E}+00$ & $1.11 \mathrm{E}+01$ & $5.10 \mathrm{E}+02$ & $(1.04 \mathrm{E}+01)$ & 4.21E-01 \\
\hline C4191-221 & $9.1 \mathrm{E}+00$ & $1.52 \mathrm{E}+01$ & $5.36 \mathrm{E}+02$ & $(8.97 \mathrm{E}+00)$ & 4.67E-01 \\
\hline C4191-221 dup & $9.3 \mathrm{E}+00$ & $1.20 \mathrm{E}+01$ & $4.05 E+02$ & $(1.12 \mathrm{E}+01)$ & 3.98E-01 \\
\hline C4191-231 & $8.1 \mathrm{E}+00$ & $1.13 \mathrm{E}+01$ & $4.05 E+02$ & $(1.17 \mathrm{E}+01)$ & 4.05E-01 \\
\hline C4191-241 & $1.1 \mathrm{E}+01$ & $1.19 \mathrm{E}+01$ & $5.54 \mathrm{E}+02$ & $(1.23 \mathrm{E}+01)$ & 4.51E-01 \\
\hline C4191-251 & $9.7 \mathrm{E}+00$ & $(8.66 \mathrm{E}+00)$ & $4.18 \mathrm{E}+02$ & $(1.25 E+01)$ & 4.25E-01 \\
\hline C4191-261 & $1.2 \mathrm{E}+01$ & $1.08 \mathrm{E}+01$ & $5.36 \mathrm{E}+02$ & $(1.08 \mathrm{E}+01)$ & 4.25E-01 \\
\hline C4191-271 & $1.2 \mathrm{E}+01$ & $1.07 \mathrm{E}+01$ & $4.93 E+02$ & $(1.11 \mathrm{E}+01)$ & 3.75E-01 \\
\hline C4191-281 & $1.3 \mathrm{E}+01$ & $1.14 \mathrm{E}+01$ & $5.11 \mathrm{E}+02$ & $(1.36 \mathrm{E}+01)$ & 4.83E-01 \\
\hline C4191-291 & $1.0 \mathrm{E}+01$ & $1.12 \mathrm{E}+01$ & $4.59 \mathrm{E}+02$ & $(1.12 \mathrm{E}+01)$ & 4.25E-01 \\
\hline C4191-301 & $8.1 \mathrm{E}+00$ & $1.34 \mathrm{E}+01$ & $5.31 \mathrm{E}+02$ & $(1.23 \mathrm{E}+01)$ & 3.77E-01 \\
\hline C4191-311 & $1.1 \mathrm{E}+01$ & $(8.24 \mathrm{E}+00)$ & $4.56 \mathrm{E}+02$ & $(1.06 \mathrm{E}+01)$ & 3.79E-01 \\
\hline C4191-321 & $1.2 \mathrm{E}+01$ & $1.05 \mathrm{E}+01$ & $4.05 E+02$ & $(1.21 \mathrm{E}+01)$ & 3.20E-01 \\
\hline C4191-331 & $1.4 \mathrm{E}+01$ & $1.31 \mathrm{E}+01$ & $5.30 \mathrm{E}+02$ & $(1.33 E+01)$ & $3.60 \mathrm{E}-01$ \\
\hline C4191-341 & $8.4 \mathrm{E}+00$ & $1.26 \mathrm{E}+01$ & $4.77 \mathrm{E}+02$ & $(1.14 \mathrm{E}+01)$ & 4.36E-01 \\
\hline
\end{tabular}

(a) Bold values are higher than others for given constituent; (b) italicized values are lower than others for a given constituent; (c) parentheses signify values below level of quantitation but considered valid. 
A comparison of the water-leachable and acid-leachable contents of the sediments from borehole C4191 (data for sulfate and phosphate shown in Table 8.13 and for major cations in Table 8.15 versus acid extract values in Table 8.8) s shows that on average, less than $0.1 \%$ of the acid-extractable quantities of the following elements are water leachable: $\mathrm{Al}, \mathrm{Ba}, \mathrm{Fe}, \mathrm{Mn}, \mathrm{Zr}, \mathrm{Cr}, \mathrm{Ag}$, and $\mathrm{Pb}$. On average, less than $0.3 \%$ of the acid-extractable phosphorous, $\mathrm{Cd}, \mathrm{Zn}$, and natural $\mathrm{U}$ is water leachable. Less than $2 \%$ of the acid-extractable Ca, $\mathrm{K}, \mathrm{Mg}$, As, and Se is water extractable. About $7 \%$ of the acid-extractable Mo is water extractable. Up to $20 \%$ of the acid-extractable $\mathrm{Na}$ and sulfate is water extractable. Where technetium-99 is present at high concentrations, the percentage of acid-extractable technetium that is also water extractable ranges from 20 to $90 \%$, suggesting that it is one of the more mobile COCs but that small amounts may be interacting with the sediments. Figure 8.4 shows the comparison of the water to acid extractable major cations and Figure 8.7 through Figure 8.9 compare the water to acidextractable quantities for several other constituents. On some of these figures, acidextractable concentrations from core samples analyzed by the FHI contract laboratory WSCF are also shown. The PNNL ESL laboratory and WSCF use a very similar acid-extraction methodology, and the comparisons are reasonable for most constituents. Based on the depth profiles for acid-extractable metals such as chromium, nickel, and lead, there are no elevated concentrations in the shallow sediments, suggesting that these metals had no significant inventory in the wastes disposed of to the 216-B-26 trench. As mentioned earlier, there appears to be slightly elevated concentrations of zinc, copper, iron, and manganese in the shallow sediments, but this might be caused by the caustic waste reactions with natural sediments or perhaps are an indication that the caustic waste contained some of these metals that interacted with the sediments and precipitated near the trench bottom.

\subsubsection{Radionuclide Content in Vadose Zone Sediment from C4191}

The sediment from borehole C4191 contains some man-made gamma radioactivity in some of the shallow grab samples analyzed by PNNL's ESL laboratory. Further, FHI took 13 split-spoon samples at selected depths that yielded about twenty six 6-in.-long by 4-in.-diameter cores, many of which were processed to measure inorganic, organic, and radionuclide COPCs. The radioanalytical analyses performed on the sediment included direct GEA and alpha-, beta-, and GEAs on selected acid extracts. The GEA data are reported in Table 8.11 and Table 8.12. Essentially, the only significant gamma activity observed is cesium-137 in the first few samples from 13 and $27.5 \mathrm{ft}$ bgs. The samples at 13 to $14 \mathrm{ft}$ bgs contain from $5 \times 10^{+5}$ to $1 \times 10^{+6} \mathrm{pCi} / \mathrm{g}$ cesium-137, and sediments deeper down to $27.5 \mathrm{ft}$ bgs contain about $10 \mathrm{pCi} / \mathrm{g}$ or less. In addition a few pCi/g of shorter-lived antimony-125 and europium-155 were detected in isolated samples. Sub pCi/g activities of cobalt-60 were also detected in a few samples with no consistent depth profile. No other gamma emitters were detected by either analytical laboratory. In general, the agreement between the two laboratories was excellent. PNNL performed technetium-99 and uranium-238 analysis on the one-to-one sediment-to-water extracts and the sediment acid extracts. The uranium and technetium water-extractable contents were previously discussed above. The WSCF (FHI) analytical data for technetium-99 and uranium, although performed on fewer samples as a function of depth, agree with the PNNL depth profiles. WSCF also had contract laboratories do additional radioanalytical measurements of the core samples, and Table 8.13 shows that the shallow sediments contain substantial concentrations of strontium-90 and some nickel-63. Tritium was also observed from 28 to $149 \mathrm{ft}$ bgs. No americium-241, carbon-14, or neptunium-237 were detected in the core samples that covered the depth range from 13 to $339 \mathrm{ft}$ bgs. Natural background amounts of potassium-40, thorium232, uranium-238, and 235 and many of their daughter products were also detected in the sediment cores. 

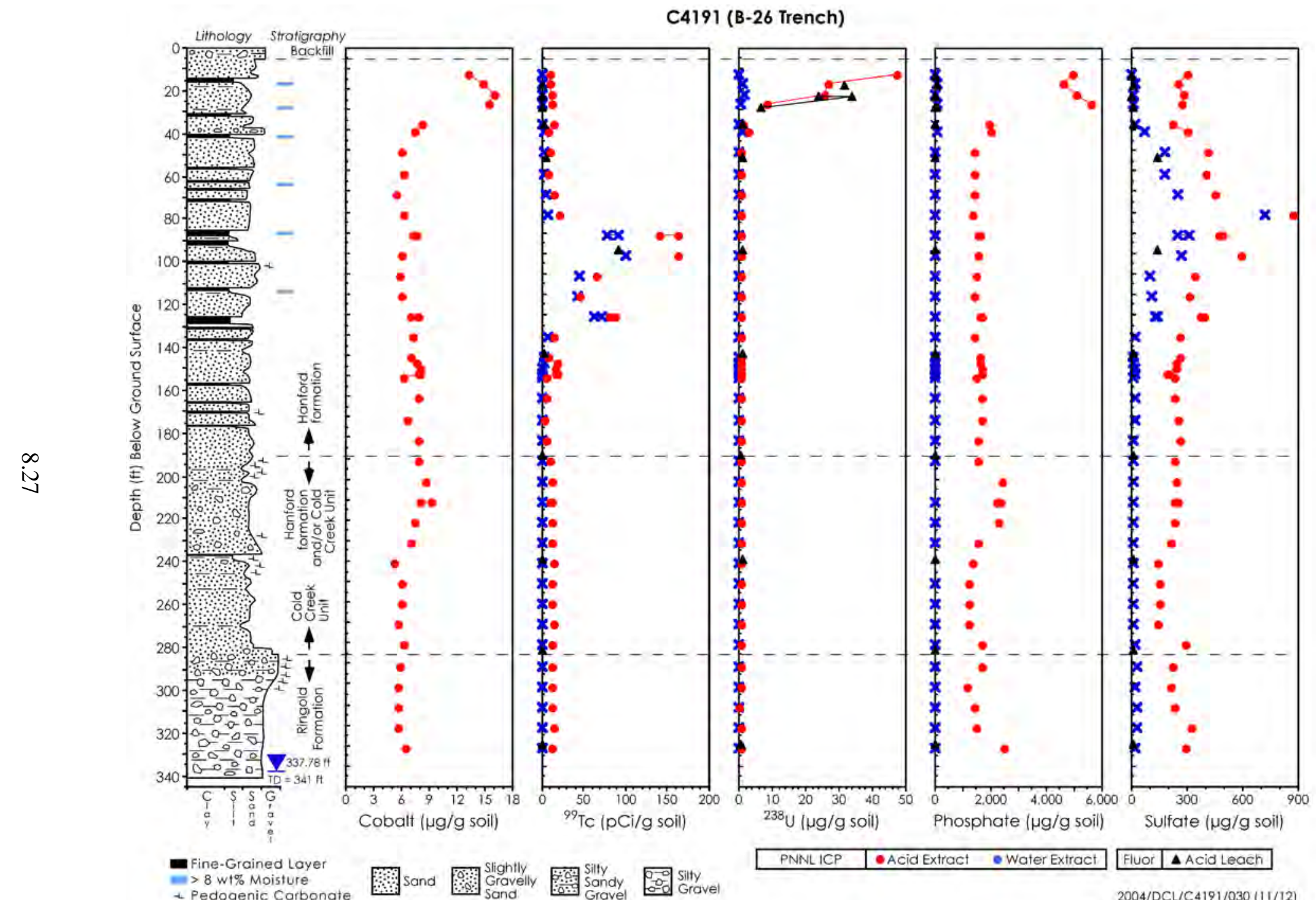

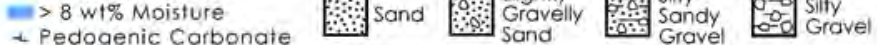

2004/DCL/C4191/030 (11/12)

Figure 8.7. Water- and Acid-Extractable Concentrations of Key Contaminants in Borehole C4191 Sediment 


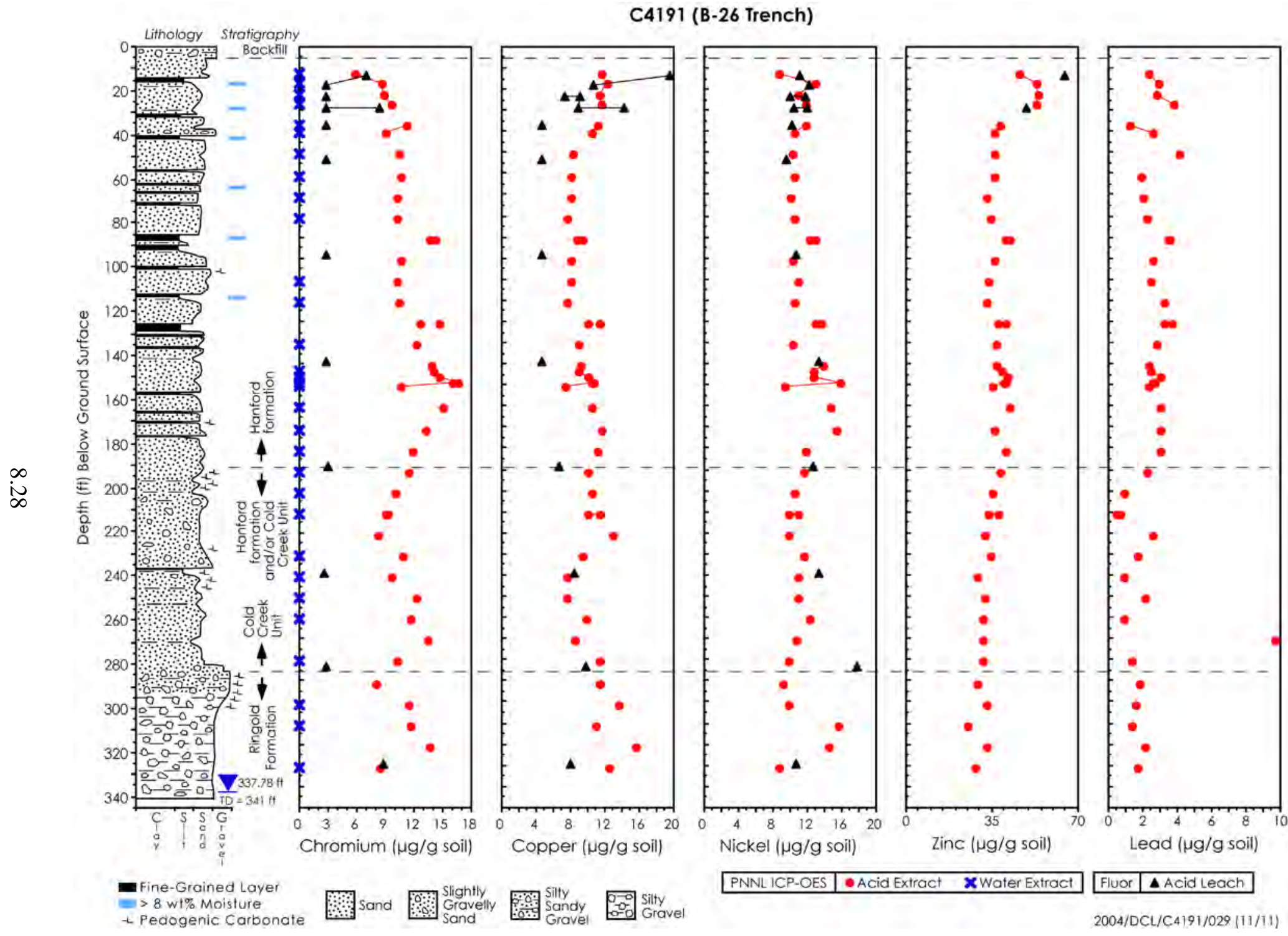

Figure 8.8. Acid-Extractable Concentrations of Selected Metals C4191 Sediments 


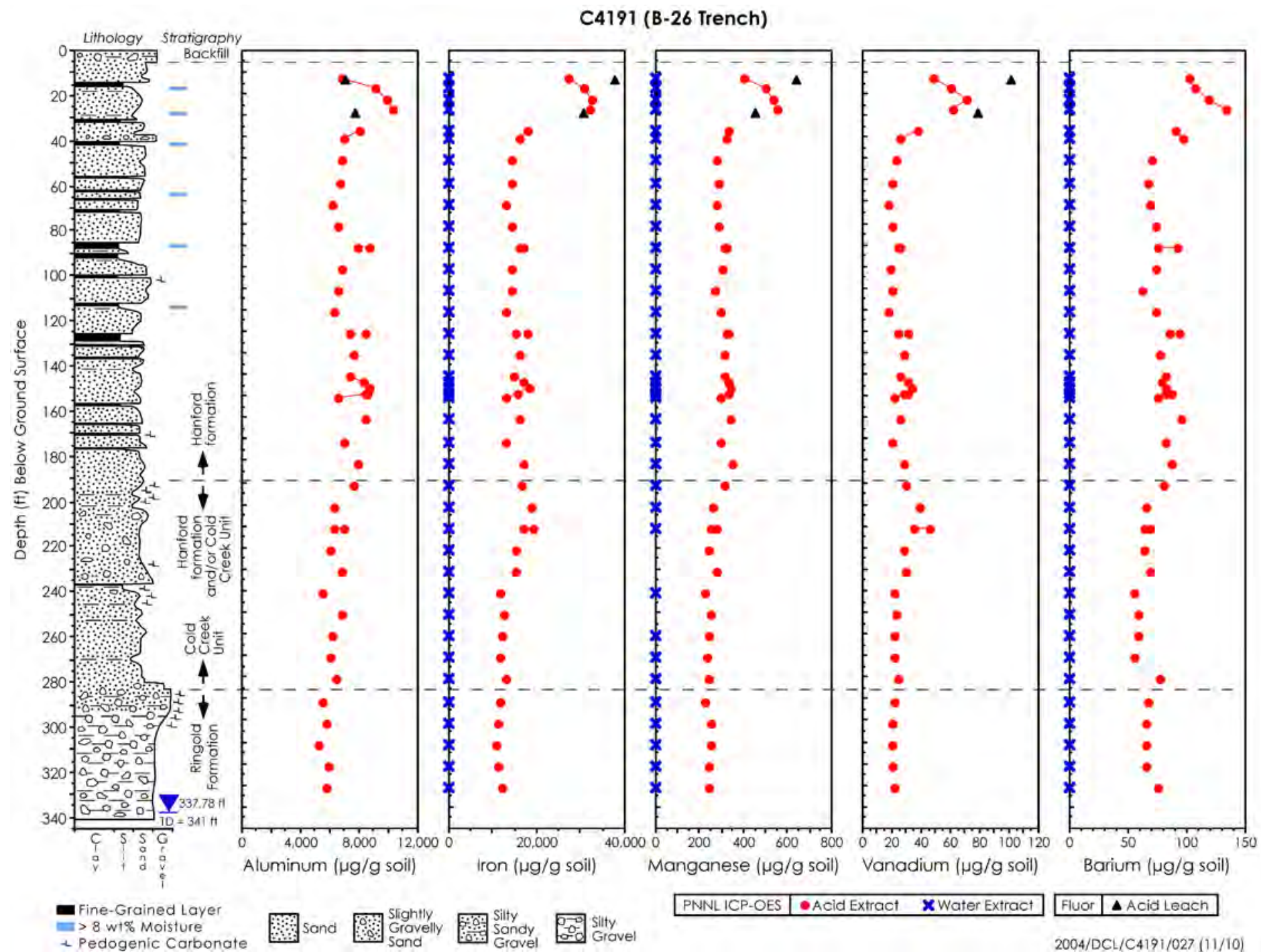

Figure 8.9. Concentration of Aluminum, Iron, Manganese, Vanadium, and Barium Acid and Water Extracts from Borehole C4191 Sediment 
PNNL-17821

Table 8.11. Man-Made Fission Product GEA Data (pCi/g sed) for Grab Samples from C4191

\begin{tabular}{|c|c|c|c|c|c|c|}
\hline Sample ID ${ }^{(\mathrm{a}, \mathrm{b})}$ & Sb-125 & $1-\sigma$ error & Cs-137 & $1-\sigma$ error & Eu-155 & $1-\sigma$ error \\
\hline C4191_13_Soil & $*$ & & $8.968 \mathrm{E}+05$ & $3.258 \mathrm{E}+04$ & $*$ & \\
\hline C4191_17.5_Soil & $1.936 \mathrm{E}+00$ & 8.168E-01 & $3.562 \mathrm{E}+00$ & $1.244 \mathrm{E}-01$ & $<1$ & \\
\hline C4191_22.5_Soil & $1.182 \mathrm{E}+00$ & $1.878 \mathrm{E}-01$ & 4.835E-01 & 2.716E-02 & $<0.6$ & \\
\hline C4191_27.5_Soil & $1.006 \mathrm{E}+00$ & 3.606E-01 & $4.258 \mathrm{E}+00$ & $1.409 \mathrm{E}-01$ & $<0.6$ & \\
\hline C4191_37.5_Soil & $<0.4$ & & $1.732 \mathrm{E}-01$ & $5.436 \mathrm{E}-02$ & $<0.6$ & \\
\hline C4191_41_AE & $<0.4$ & & $3.580 \mathrm{E}-01$ & 6.318E-02 & $<0.6$ & \\
\hline C4191_51_AE & $<0.4$ & & 3.045E-01 & 5.089E-02 & $<0.6$ & \\
\hline C4191_61_AE & $<0.4$ & & $3.220 \mathrm{E}-01$ & $1.111 \mathrm{E}-01$ & $<0.6$ & \\
\hline C4191_71_AE & $<0.4$ & & $5.888 \mathrm{E}-02$ & 7.295E-02 & $<0.6$ & \\
\hline C4191_81_AE & $<0.4$ & & $<0.2$ & & $<0.6$ & \\
\hline C4191_91_AE & $<0.4$ & & $1.250 \mathrm{E}-01$ & 7.382E-02 & $<0.6$ & \\
\hline C4191_91Dup_AE & $<0.4$ & & $<0.2$ & & $<0.6$ & \\
\hline C4191_101_AE & $<0.4$ & & $<0.2$ & & $<0.6$ & \\
\hline C4191_111_AE & $<0.4$ & & 2.618E-01 & 1.637E-01 & $<0.6$ & \\
\hline C4191_121_AE & $<0.4$ & & $<0.2$ & & $<0.6$ & \\
\hline C4191_131_AE & $<0.4$ & & $<0.2$ & & $<0.6$ & \\
\hline C4191_131Dup_AE & $<0.4$ & & $<0.2$ & & $<0.6$ & \\
\hline C4191_141_AE & $<0.4$ & & $<0.2$ & & 5.875E-01 & 5.367E-01 \\
\hline C4191_151_AE & $<0.4$ & & $<0.2$ & & $<0.6$ & \\
\hline C4191_161_AE & $<0.4$ & & $<0.2$ & & $<0.6$ & \\
\hline C4191_171_AE & $<0.4$ & & $<0.2$ & & $<0.6$ & \\
\hline C4191_181_AE & $<0.4$ & & $<0.2$ & & $<0.6$ & \\
\hline C4191_191_AE & $<0.4$ & & 2.632E-01 & $1.276 \mathrm{E}-01$ & $<0.6$ & \\
\hline C4191_201_Soil & $<0.4$ & & $<0.2$ & & $<0.6$ & \\
\hline C4191_211_Soil & $<0.4$ & & $<0.2$ & & $<0.6$ & \\
\hline C4191_221_Soil & $<0.4$ & & $<0.2$ & & $<0.6$ & \\
\hline C4191_221Dup_Soil & $<0.4$ & & $<0.2$ & & $<0.6$ & \\
\hline C4191_231_Soil & $<0.4$ & & $<0.2$ & & $<0.6$ & \\
\hline C4191_241_Soil & $<0.4$ & & $<0.2$ & & $<0.6$ & \\
\hline C4191_251_Soil & $<0.4$ & & $<0.2$ & & $<0.6$ & \\
\hline
\end{tabular}


PNNL-17821

Table 8.11 (contd)

\begin{tabular}{|c|c|c|c|c|c|c|}
\hline Sample ID ${ }^{(a, b)}$ & Sb-125 & $1-\sigma$ error & Cs-137 & $1-\sigma$ error & Eu-155 & $1-\sigma$ error \\
\hline C4191_261_Soil & $<0.4$ & & $<0.2$ & & $<0.6$ & \\
\hline C4191_271_Soil & $<0.4$ & & $<0.2$ & & $<0.6$ & \\
\hline C4191_281_Soil & $<0.4$ & & $<0.2$ & & $<0.6$ & \\
\hline $\begin{array}{l}\text { (a) The sample IDs include t } \\
\text { (b) Soil = Direct count of sec } \\
\text { (c) = high activity of Cs-137 }\end{array}$ & $\begin{array}{l}\text { mber and } \\
\text { sA on a } \\
\text { ating othe }\end{array}$ & $\begin{array}{l}\text { ximate dep } \\
\text { solution. } \\
\text { reas at reas }\end{array}$ & $\begin{array}{l}\text { sample. } \\
\text { tection liı }\end{array}$ & & & \\
\hline
\end{tabular}


PNNL-17821

Table 8.12. Gamma Energy Analysis Results for C4191 Core Samples

\begin{tabular}{|c|c|c|c|c|c|}
\hline ID & Depth (ft bgs) & Sb-125 pCi/g & Cs-137 pCi/g & Co-60 pCi/g & Eu-155 pCi/g \\
\hline B183L6 & 13.75 & $<900$ & $5.29 \mathrm{E}+05$ & $<89$ & $<580$ \\
\hline B183M0 & 18.75 & 2.28 & 7.87 & $<0.037$ & $<0.055$ \\
\hline B183L9 & 18.75 & NA & 3.98 & $<0.26$ & $<0.36$ \\
\hline B183M3 & 23.75 & 1.37 & 0.94 & 0.032 & $<0.027$ \\
\hline B183L8 & 23.75 & NA & 0.84 & $<0.29$ & $<0.37$ \\
\hline B183M2 & 23.75 & 1.31 & 11.3 & 0.043 & $-<0.014$ \\
\hline B183M1 & 23.75 & NA & 1.28 & $<0.3$ & $<0.48$ \\
\hline B183M6 & 28.75 & 0.921 & 1.17 & $<0.06$ & $<0.041$ \\
\hline B183M5 & 28.75 & 0.945 & 1.15 & 0.052 & 0.096 \\
\hline B183M4 & 28.75 & NA & 0.691 & $<0.12$ & $<0.16$ \\
\hline B183M8 & 37.24 & $<0.004$ & 0.171 & 0.013 & $<0.029$ \\
\hline B183M7 & 37.24 & NA & 0.153 & $<0.2$ & $<0.28$ \\
\hline B183N0 & 53.74 & $<0.011$ & 0.019 & $<0.017$ & $<0.029$ \\
\hline В183M9 & 53.74 & NA & $<0.074$ & $<0.089$ & $<0.14$ \\
\hline B183N2 & 98.75 & $-<0.018$ & 0.051 & 0.069 & $<0.024$ \\
\hline B183N1 & 98.75 & $<0.26$ & 0.437 & $<0.19$ & $<0.27$ \\
\hline B183N5 & 148.75 & $<0.001$ & 0.013 & $<0.002$ & $<0.048$ \\
\hline B183N4 & 148.75 & $<0.1$ & $<0.066$ & $<0.056$ & $<0.097$ \\
\hline B183N7 & 198.75 & $<0.002$ & 0.219 & $<0.006$ & $<0.04$ \\
\hline B183N6 & 198.75 & $<0.19$ & 0.165 & $<0.1$ & $<0.16$ \\
\hline B183N9 & 248.75 & $<0.013$ & $<0.003$ & $<0$ & 0.049 \\
\hline B183P2 & 293.76 & $<0.025$ & $-<0.006$ & $-<0.006$ & $-<0.009$ \\
\hline B183P1 & 293.76 & NA & $<0.034$ & $<0.04$ & $<0.096$ \\
\hline B183N8 & 301.74 & NA & $<0.022$ & $<0.022$ & $<0.059$ \\
\hline B183P4 & 339.21 & $<0.012$ & $<0.001$ & $-<0.001$ & 0.065 \\
\hline B183P3 & 339.21 & NA & $<0.025$ & $<0.027$ & $<0.07$ \\
\hline
\end{tabular}


Table 8.13. Other Radionuclides Present in the C4191 Core Samples Obtained by FHI

\begin{tabular}{|c|c|c|c|c|c|}
\hline ID & Depth (ft bgs) & Ni-63 pCi/g & Tc-99 pCi/g & Sr-89/90 pCi/g & Tritium pCi/g \\
\hline B183L6 & 13.75 & 2110 & $<2.46$ & $9.74 \mathrm{E}+05$ & $-<0.753$ \\
\hline B183L9 & 18.75 & 2.73 & 0.613 & 4.46 & 0.881 \\
\hline B183M1 & 23.75 & $<2.16$ & 0.556 & 1.17 & $<0.077$ \\
\hline B183L8 & 23.75 & $<2.29$ & 0.75 & 1.79 & $<0.078$ \\
\hline B183M6 & 28.75 & 8.71 & 0.764 & 1.53 & 0.302 \\
\hline B183M4 & 28.75 & $<2.33$ & $<0.258$ & 1.42 & 0.498 \\
\hline B183M7 & 37.24 & $<1.33$ & 2.11 & 0.335 & 0.845 \\
\hline B183M9 & 53.74 & $<0.736$ & 5.03 & $<0.067$ & 7.04 \\
\hline B183N1 & 98.75 & $<1.55$ & 92 & $<0.124$ & 42.9 \\
\hline B183N4 & 148.75 & $<1.25$ & 3.3 & $<0.002$ & 0.317 \\
\hline B183N6 & 198.75 & 2.05 & $-<0.004$ & $-<0.016$ & $-<0.068$ \\
\hline B183N8 & 301.74 & $<0.408$ & $<0.076$ & $<0.094$ & $-<0.05$ \\
\hline B183P1 & 293.76 & $-<1.08$ & $-<0.014$ & $-<0.075$ & $-<0.106$ \\
\hline B183P3 & 339.21 & $-<2.1$ & $-<0.002$ & $<0.071$ & $-<0.013$ \\
\hline
\end{tabular}

\subsubsection{Total Carbon, Calcium Carbonate, and Organic Carbon Content of Vadose Zone Sediment from Borehole C4191}

Table 8.14 shows the total carbon, inorganic carbon, and organic carbon contents of the vadose zone sediment at selected depths. The inorganic carbon was also converted to the equivalent calcium carbonate content. The sediment in the Hanford $\mathrm{H} 2$ unit is relatively low in calcium carbonate ( $<1$ to a maximum of $3.2 \mathrm{wt} \%)$ and organic carbon. During the original grab sample processing, six zones $(102,170,193$ to 202, 230, 240 to 245, and 285) to $300 \mathrm{ft}$ bgs reacted more vigorously with hydrochloric acid than other grab samples. The measured inorganic carbon content of the sediments in these zones shows no exceptionally high calcite contents (0.8 to $2.9 \% \mathrm{wt}$ ).

Table 8.14. Total, Inorganic and Organic Carbon Content of Vadose Zone Sediments from Borehole C4191

\begin{tabular}{lcccc}
\hline Sample ID & Total Carbon & $\begin{array}{c}\text { Inorganic Carbon } \\
\text { Mean Conc. }\end{array}$ & $\begin{array}{c}\text { Organic Carbon } \\
\text { by Difference }\end{array}$ & $\begin{array}{c}\text { IC as } \\
\text { Wt CaCO }^{\text {(a) }}\end{array}$ \\
\hline C4191_13 & 0.12 & 0.09 & 0.03 & 0.75 \\
C4191_17.5 & 0.16 & 0.15 & 0.02 & 1.22 \\
C4191_22.5 & 0.24 & 0.24 & 0.00 & 1.97 \\
C4191_27.5 & 0.30 & 0.31 & -0.01 & 2.59 \\
C4191_37.5 & 0.18 & 0.17 & 0.01 & 1.39 \\
C4191_41 & 0.28 & 0.27 & 0.02 & 2.21 \\
C4191_51 & 0.36 & 0.38 & -0.02 & 3.21 \\
C4191_61 & 0.30 & 0.32 & -0.02 & 2.68 \\
C4191_71 & 0.27 & 0.27 & 0.00 & 2.24 \\
C4191_81 & 0.30 & 0.29 & 0.01 & 2.41 \\
C4191_91 & 0.28 & 0.26 & 0.02 & 2.20 \\
\hline
\end{tabular}


PNNL-17821

Table 8.14 (contd)

\begin{tabular}{|c|c|c|c|c|}
\hline Sample ID $^{(a)}$ & $\begin{array}{l}\text { Total Carbon } \\
\text { Mean Conc. }\end{array}$ & $\begin{array}{c}\text { Inorganic Carbon } \\
\text { Mean Conc. }\end{array}$ & $\begin{array}{c}\text { Organic Carbon } \\
\text { by Difference }\end{array}$ & $\begin{array}{c}\mathrm{IC} \text { as } \\
\mathrm{Wt} \% \mathrm{CaCO}_{3}\end{array}$ \\
\hline C4191_91Dup & 0.31 & 0.28 & 0.03 & 2.33 \\
\hline C4191_101 & 0.35 & 0.35 & 0.00 & 2.89 \\
\hline C4191_111 & 0.36 & 0.38 & -0.02 & 3.15 \\
\hline C4191_121 & 0.28 & 0.26 & 0.02 & 2.20 \\
\hline C4191_131 & 0.28 & 0.25 & 0.03 & 2.09 \\
\hline C4191_131Dup & 0.29 & 0.29 & 0.01 & 2.38 \\
\hline C4191_141 & 0.28 & 0.27 & 0.01 & 2.26 \\
\hline C4191_151 & 0.27 & 0.25 & 0.01 & 2.09 \\
\hline C4191_153.5 & 0.25 & 0.25 & 0.01 & 2.04 \\
\hline C4191_156 & 0.26 & 0.27 & -0.01 & 2.23 \\
\hline C4191_158.5 & 0.24 & 0.24 & 0.01 & 1.97 \\
\hline C4191_158.5 Dup & 0.24 & 0.24 & 0.00 & 2.00 \\
\hline C4191_161 & 0.28 & 0.27 & 0.01 & 2.21 \\
\hline C4191_171 & 0.27 & 0.27 & 0.00 & 2.25 \\
\hline C4191_181 & 0.25 & 0.25 & 0.00 & 2.06 \\
\hline C4191_191 & 0.26 & 0.27 & -0.01 & 2.27 \\
\hline C4191_201 & 0.30 & 0.31 & -0.01 & 2.56 \\
\hline C4191_211 & 0.13 & 0.10 & 0.03 & 0.80 \\
\hline C4191_221 & 0.15 & 0.11 & 0.04 & 0.93 \\
\hline C4191_221Dup & 0.08 & 0.03 & 0.06 & 0.23 \\
\hline C4191_231 & 0.16 & 0.14 & 0.02 & 1.18 \\
\hline C4191_241 & 0.16 & 0.13 & 0.03 & 1.12 \\
\hline C4191_251 & 0.13 & 0.11 & 0.02 & 0.90 \\
\hline C4191_261 & 0.12 & 0.10 & 0.02 & 0.84 \\
\hline C4191_271 & 0.13 & 0.10 & 0.03 & 0.82 \\
\hline C4191_281 & 0.12 & 0.10 & 0.02 & 0.84 \\
\hline C4191_291 & 0.17 & 0.14 & 0.03 & 1.13 \\
\hline C4191_301 & 0.13 & 0.10 & 0.03 & 0.83 \\
\hline C4191_311 & 0.08 & 0.04 & 0.04 & 0.35 \\
\hline C4191_321 & 0.06 & 0.04 & 0.02 & 0.31 \\
\hline C4191_331 & 0.25 & 0.22 & 0.03 & 1.86 \\
\hline C4191_341 & 0.03 & 0.01 & 0.02 & 0.07 \\
\hline
\end{tabular}

(a) The sample IDs include the borehole number and the approximate depth of each sample.

(b) Pink highlighted depth reacted more vigorously with hydrochloric acid during geologic description.

\subsubsection{Groundwater Analysis of Sample Obtained Prior to Decommissioning Borehole C4191}

At the completion of drilling C4191 in January 2004, one groundwater sample was obtained in late January before the borehole was decommissioned. The composition of the groundwater is shown in Table 8.15. The groundwater composition suggests that the water below C4191 is not contaminated with waste fluids that were disposed of to the various BC Cribs and Trenches above the water table. The groundwater composition is that of natural uncontaminated Hanford Site water aside from a low strontium-90 activity, which is likely not real. Natural Hanford site groundwaters are calciummagnesium-sodium-bicarbonate-sulfate dominated as is the water composition shown in Table 8.15. The fact that the groundwater directly below the 216-B-26 trench appears to be uncontaminated corroborates 
the findings that the mobile salts (sodium and nitrate predominately) in the vadose zone profile at the C4191 borehole have not descended below about $158.5 \mathrm{ft}$ bgs. The salts and presumably the residual waste fluids from the mid 1950s disposal time horizon still reside well above the water table (337.8 ft bgs).

Table 8.15. Groundwater Composition at Water Table in C4191 in Jan. 2004

\begin{tabular}{|c|c|c|c|c|c|}
\hline \multirow[t]{2}{*}{$1 / 28 / 2004$} & & \multirow{2}{*}{$\begin{array}{l}\text { Water Table at } \\
337.8 \mathrm{ft} \text { bgs }\end{array}$} & \multirow[t]{2}{*}{$1 / 28 / 2004$} & \multicolumn{2}{|c|}{ Water Table at } \\
\hline & Units & & & Units & $337.8 \mathrm{ft}$ bgs \\
\hline pH Measurement & & 7.37 & Copper & $\mu \mathrm{g} / \mathrm{L}$ & $<2.9$ \\
\hline Specific Conductance & $\mathrm{mS} / \mathrm{cm}$ & 0.368 & Iron & $\mu \mathrm{g} / \mathrm{L}$ & $<54.5$ \\
\hline Total organic carbon & $\mu \mathrm{g} / \mathrm{L}$ & -- & Magnesium & $\mathrm{mg} / \mathrm{L}$ & 9.23 \\
\hline Alkalinity & $\mathrm{mg} / \mathrm{L}$ & 123.8 & Manganese & $\mu \mathrm{g} / \mathrm{L}$ & 208 \\
\hline Chloride & $\mathrm{mg} / \mathrm{L}$ & 9.8 & Nickel & $\mu \mathrm{g} / \mathrm{L}$ & $<14$ \\
\hline Cyanide & $\mu \mathrm{g} / \mathrm{L}$ & $<4.7$ & Potassium & $\mathrm{mg} / \mathrm{L}$ & 11.1 \\
\hline Fluoride & $\mathrm{mg} / \mathrm{L}$ & 0.87 & Sodium & $\mathrm{mg} / \mathrm{L}$ & 37 \\
\hline Nitrate & $\mathrm{mg} / \mathrm{L}$ & 0.22 & Strontium & $\mathrm{mg} / \mathrm{L}$ & 0.163 \\
\hline Nitrite & $\mathrm{mg} / \mathrm{L}$ & $<0.08$ & Silicon & $\mathrm{mg} / \mathrm{L}$ & -- \\
\hline Sulfate & $\mathrm{mg} / \mathrm{L}$ & 46.6 & Zinc & $\mu \mathrm{g} / \mathrm{L}$ & $<2.7$ \\
\hline Phosphate & $\mathrm{mg} / \mathrm{L}$ & -- & Technetium-99 & $\mathrm{pCi} / \mathrm{L}$ & $<4.68$ \\
\hline Aluminum & $\mu \mathrm{g} / \mathrm{L}$ & $<34.2$ & Tritium & $\mathrm{pCi} / \mathrm{L}$ & $<164$ \\
\hline Barium & $\mu \mathrm{g} / \mathrm{L}$ & 58.4 & Uranium & $\mu \mathrm{g} / \mathrm{L}$ & -- \\
\hline Cadmium & $\mu \mathrm{g} / \mathrm{L}$ & $<3.3$ & Sr-90 & $\mathrm{pCi} / \mathrm{L}$ & $1.59 \pm 0.44$ \\
\hline Calcium & $\mathrm{mg} / \mathrm{L}$ & 22.4 & Cs-137 & $\mathrm{pCi} / \mathrm{L}$ & $<0.436$ \\
\hline Chromium & $\mu \mathrm{g} / \mathrm{L}$ & $<4.4$ & I-129 & $\mathrm{pCi} / \mathrm{L}$ & $<0.0821$ \\
\hline Cobalt & $\mu \mathrm{g} / \mathrm{L}$ & $<4.8$ & & & \\
\hline
\end{tabular}

\subsection{Field Resistivity Results at Borehole C4191}

\subsubsection{HRR at Borehole C4191}

Figure 4.7 shows the HRR apparent-resistivity results for FY04-Line 1 and FY04-Line 7. Borehole C4191 was near the intersection of both lines. Low-resistivity values can be seen in the center of the sections and coincide with the footprint of the trenches. In FY04-Line 1, the background conditions are not fully achieved because the line is not long enough. In Line FY04-7, background conditions resume south of station 40 , which is south of trench $216-\mathrm{B}-28$.

Borehole C4191 was placed $91 \mathrm{~m}$ from the western edge of FY04-Line 1 and $133 \mathrm{~m}$ from the southern boundary of FY04-Line 7. The HRR data show a low-resistivity target at Borehole C4191, which is likely the result of the historical disposal of liquid waste. A more complete description of the HRR lines around trench 216-B-26 can be found in Rucker and Fink (2007). Figure 8.10 shows the extracted apparent-resistivity data profile at Borehole C4191 along both lines. The datasets are very similar in resistivity range and depth to target. 
PNNL-17821

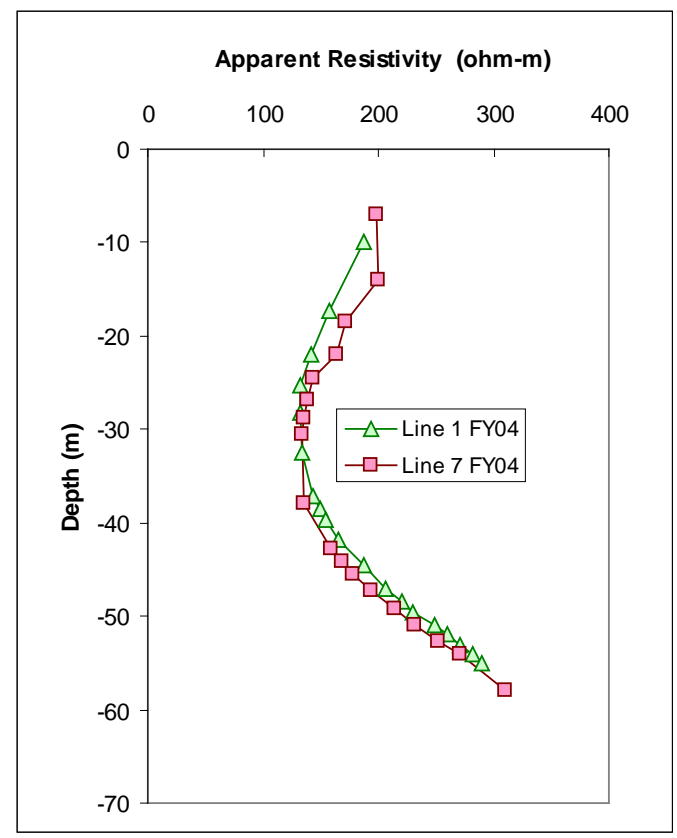

Figure 8.10. Profiles of HRR at the location of Borehole C4191

The sediment at Borehole C4191 was sampled at a higher spatial frequency and at different depths than the field-acquired data. To calculate correlations and develop the empirical models, the measured field apparent soil resistivity data were re-sampled at the soil sampling depths, using linear interpolation.

Figure 8.11 shows the results of comparing the pore-water EC and ionic strength with HRR at Borehole C4191. The set of plots used Equation 4-7 (Chapter 4) as the plotting algorithm to obtain the depth estimates of the apparent-resistivity values with coefficients of $u=(3.97,22.4,3.97)$. The profiles show that the apparent-resistivity data match well with the trend of the pore-water geochemistry. Similarly, Figure 8.12 shows the profile and scatter plots for the arithmetic and logarithm concentrations of nitrate. The arithmetic scatter plots are presented for comparison with other boreholes. However, since the nitrate concentration data span several orders of magnitude, logarithmic transformation of the data are warranted. Further, Rucker and Fink (2007) demonstrated that the logarithm of the nitrate concentration produces a very good correlation with HRR apparent resistivity. Figure 8.13 demonstrates similar plots with technetium-99. Even though the ionic strength is the most appropriate variable to use for comparison since it accounts for all ionic species, the pore-water nitrate and technetium-99 concentrations produce the most favorable correlations 
PNNL-17821

A) Profile

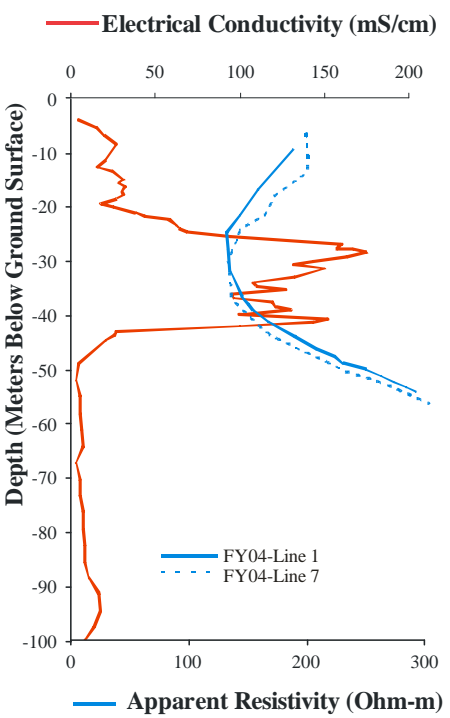

C) Profile

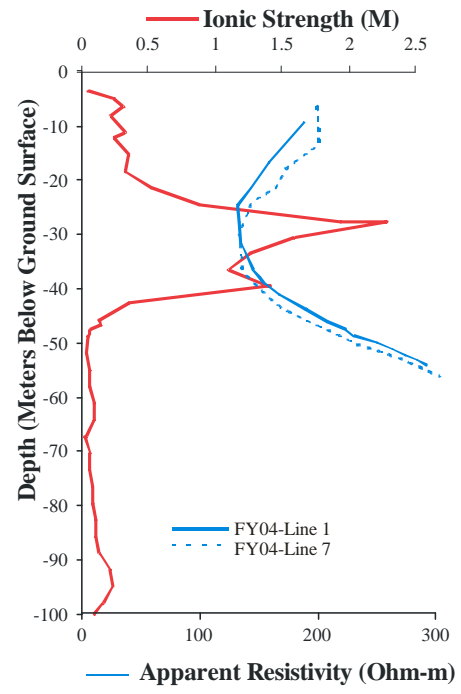

B) Scatter

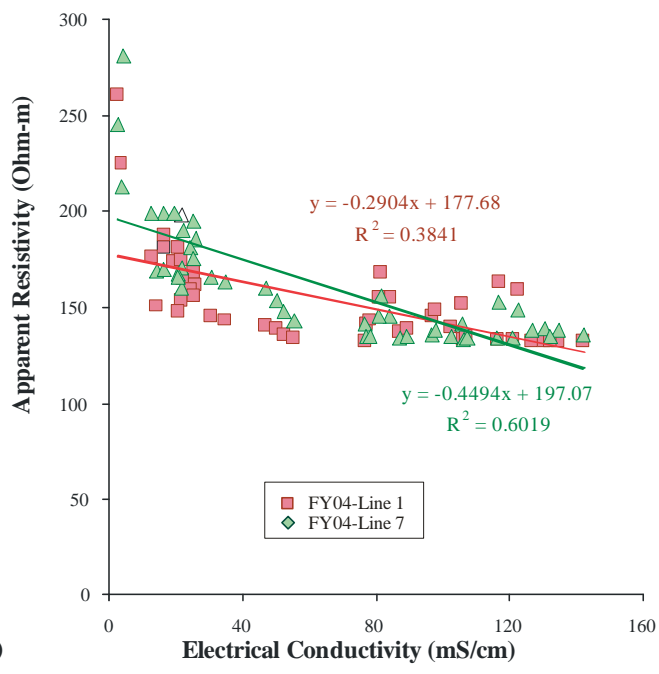

D) Scatter

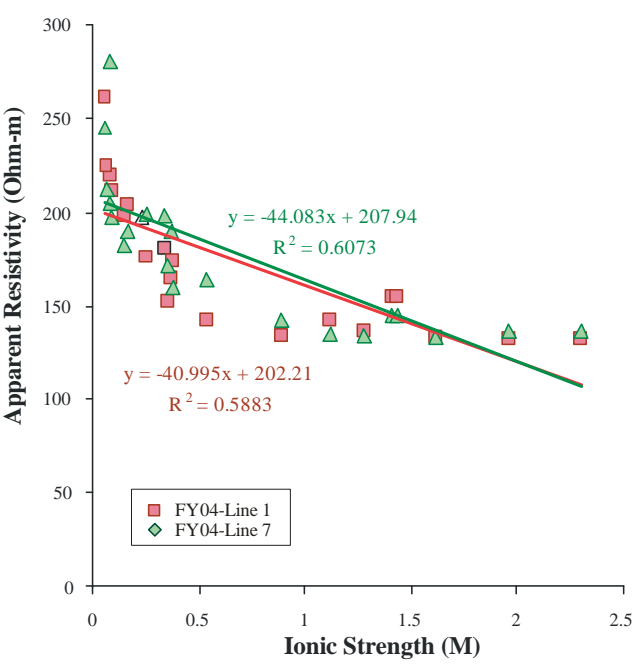

Figure 8.11. Profile and Scatter Plots for HRR with Pore-Water EC and Ionic Strength at Borehole C4191 
PNNL-17821

A) Profile

B) Scatter

\section{- Nitrate Concentration (mg/L)}
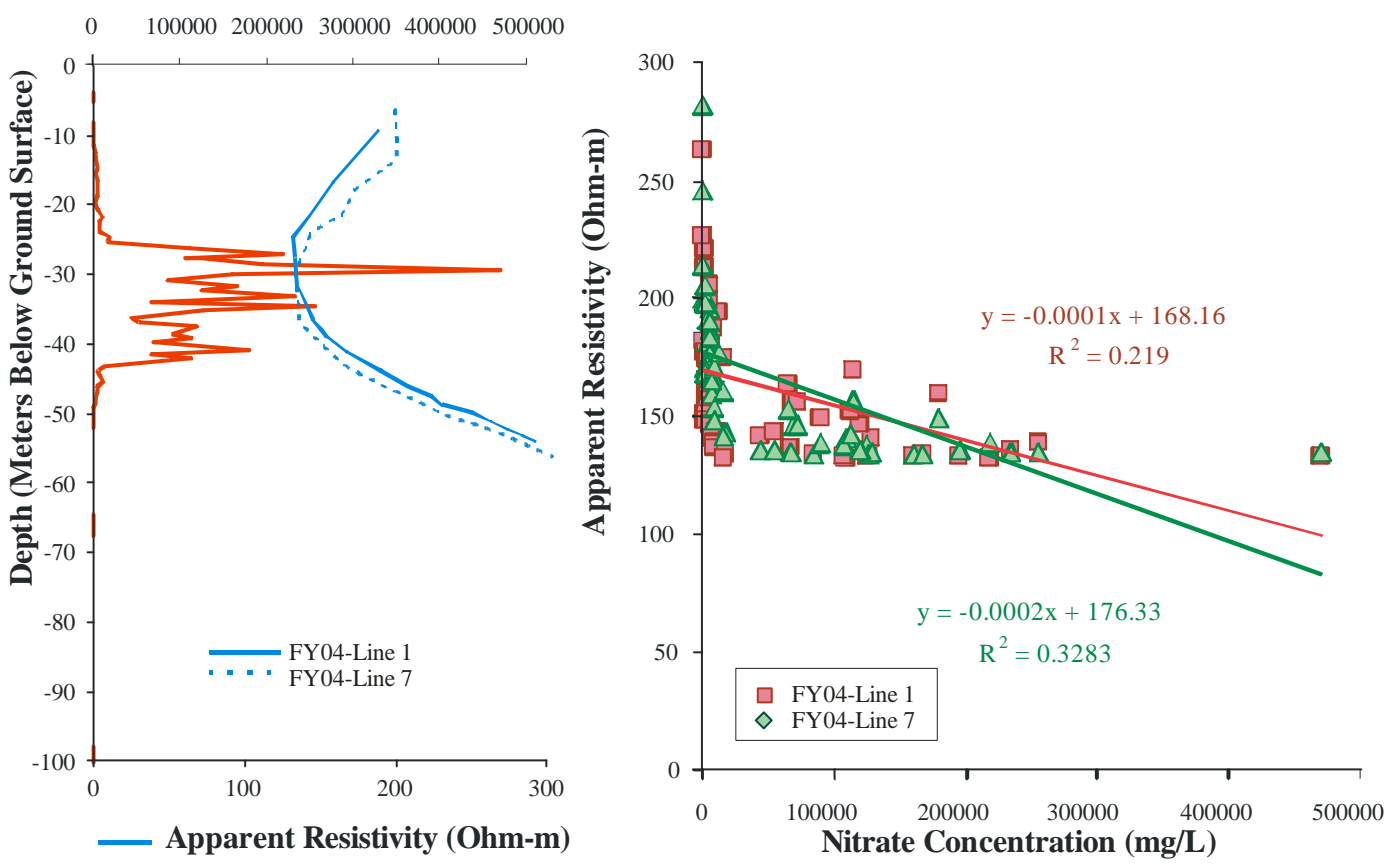

C) Scatter of log Nitrate

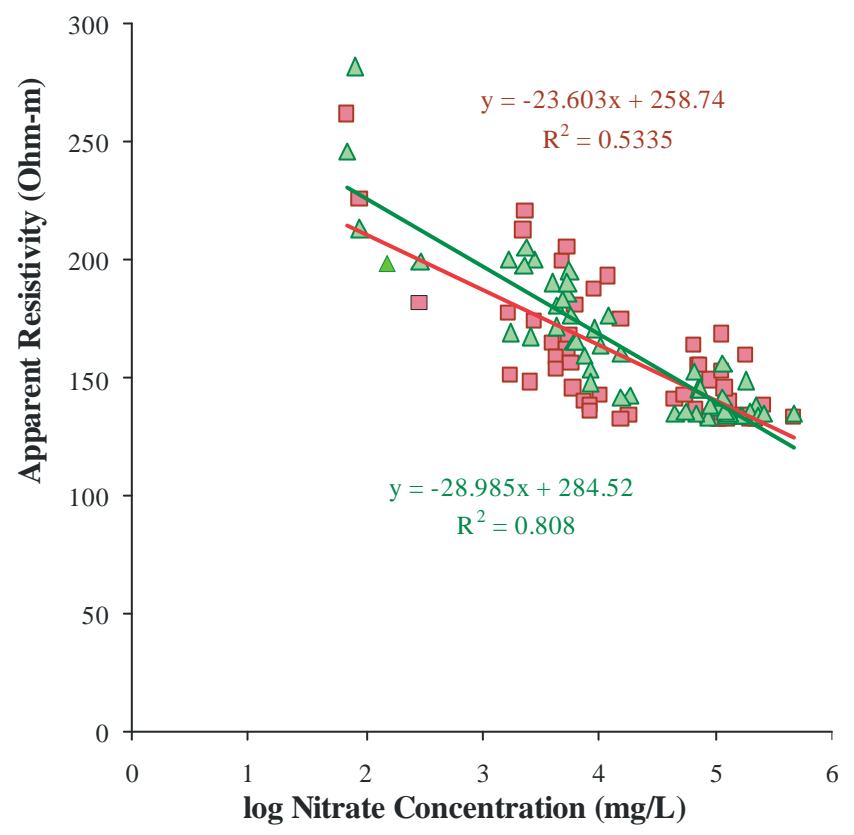

Figure 8.12. Profile and Scatter Plots for HRR With Nitrate and the Logarithm of Nitrate Concentrations at Borehole C4191 
A) Profile

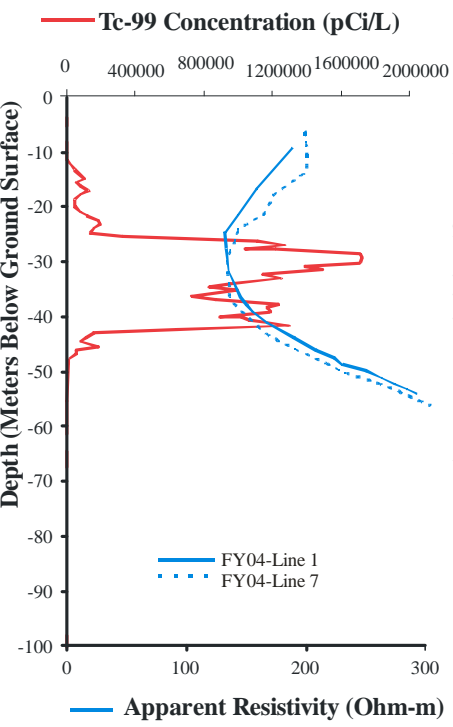

B) Scatter

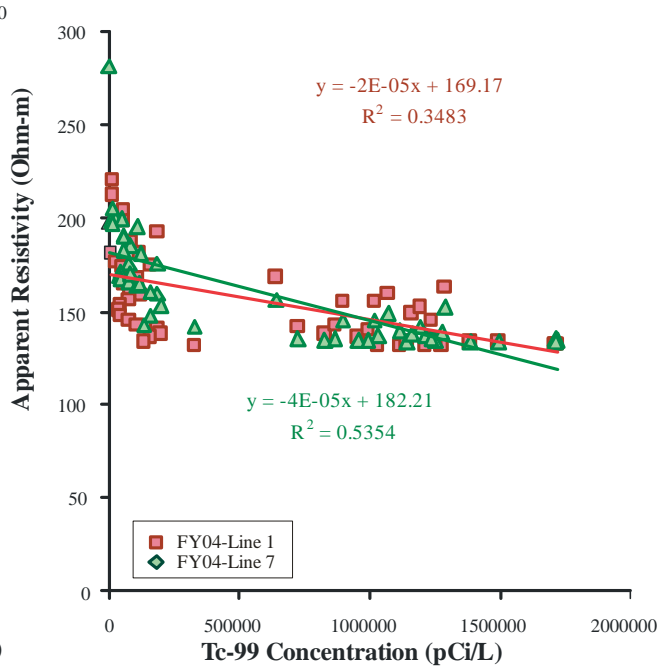

C) Scatter of log Technetium

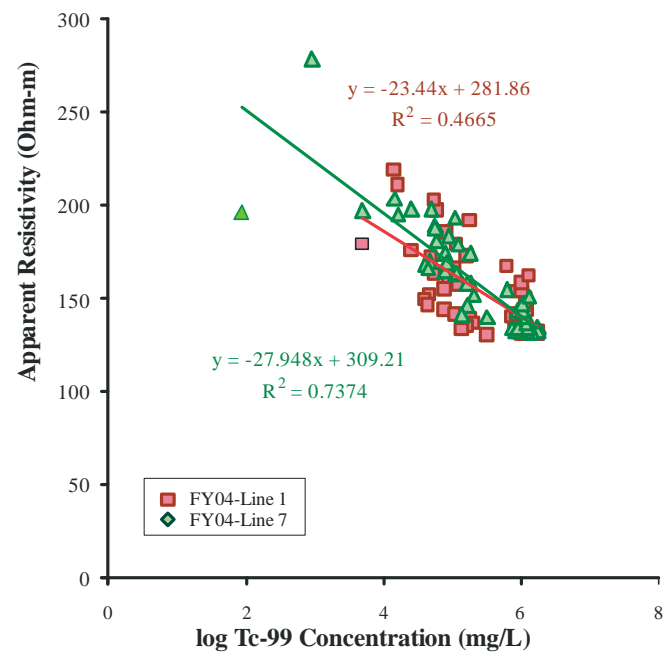

Figure 8.13. Profile and Scatter Plots for HRR with Technetium-99 and the Logarithm of Technetium99 Concentrations at Borehole C4191

\subsubsection{D Inversion at Borehole C4191}

Figure 4.12 and Table 4.1 show the inversion results for FY04-Line 1 and FY04-Line 7. The 2D inversion profiles at Borehole C4191 can be seen in Figure 8.14. The profiles show that the estimated target depth is slightly different in the two lines. FY04-Line 7 shows the target elevation approximately $10 \mathrm{~m}$ higher than FY04-Line 1. Additionally, the ranges in inverted resistivity values along C4191 are different.

The pore-water EC from Borehole C4191 and 2D inverted resistivity data were evaluated at colocated positions (Figure 8.15). The profile for FY04-Line 1 in Figure 4.12 shows a strong decrease in 
resistivity and coincides marginally well with the increase in pore-water EC. The correlation with this line is low because of the elevation mismatch. Correlation plots for Borehole C5923 (A) showed that shifting the estimated depth of the geophysical field measurements closer to the target can improve correlation dramatically. A demonstration of the effects of shifting for Borehole C4191 (Figure 8.15C and D) also shows a marked increase in correlation. Additionally, considering only those geophysical measurements that are in the sensitive range can produce higher correlations.

Figure 8.16 through Figure 8.18 show the profile and scatter with regression for ionic strength (arithmetic scale only) and pore-water nitrate and technetium-99 concentrations (arithmetic and logarithmic scales), respectively. The nitrate plots show a good correlation with the inverted resistivity, despite the target depth mismatch. In each case, FY04-Line 1 tends to have more favorable correlations than FY04-Line 7.

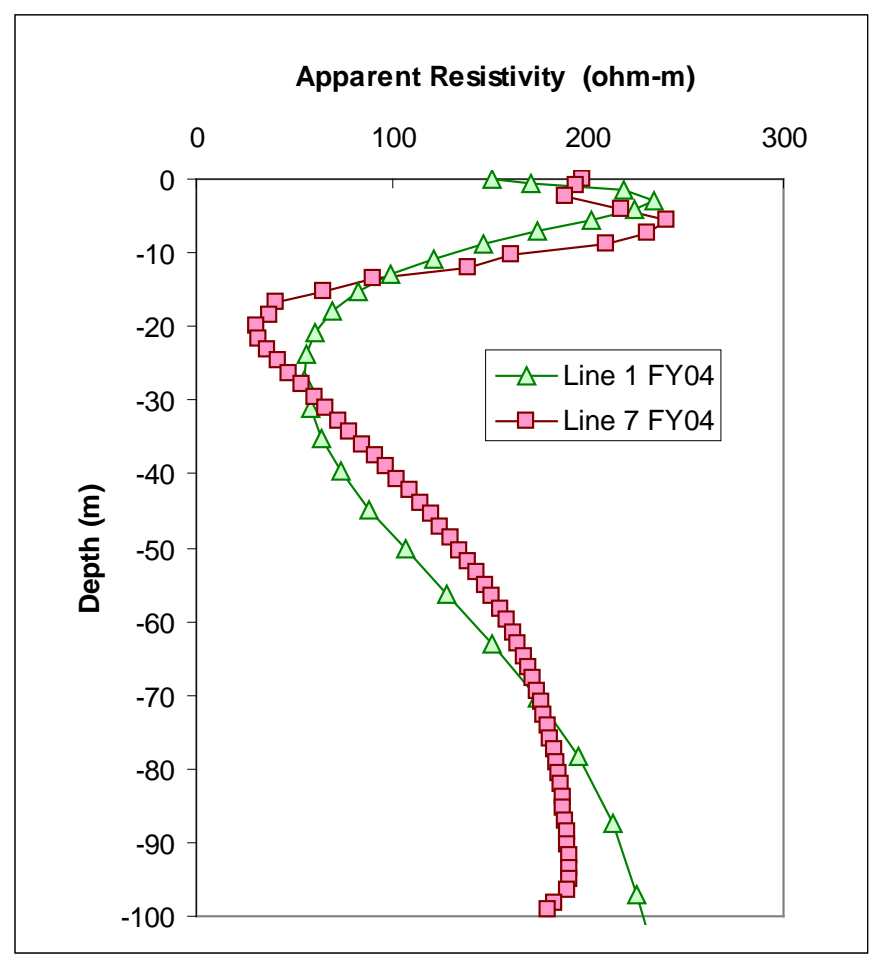

Figure 8.14. Profiles of 2D Inversion at the Location of Borehole C4191 
PNNL-17821
A) Profile
B) Scatter

Electrical Conductivity $(\mathrm{mS} / \mathrm{cm})$
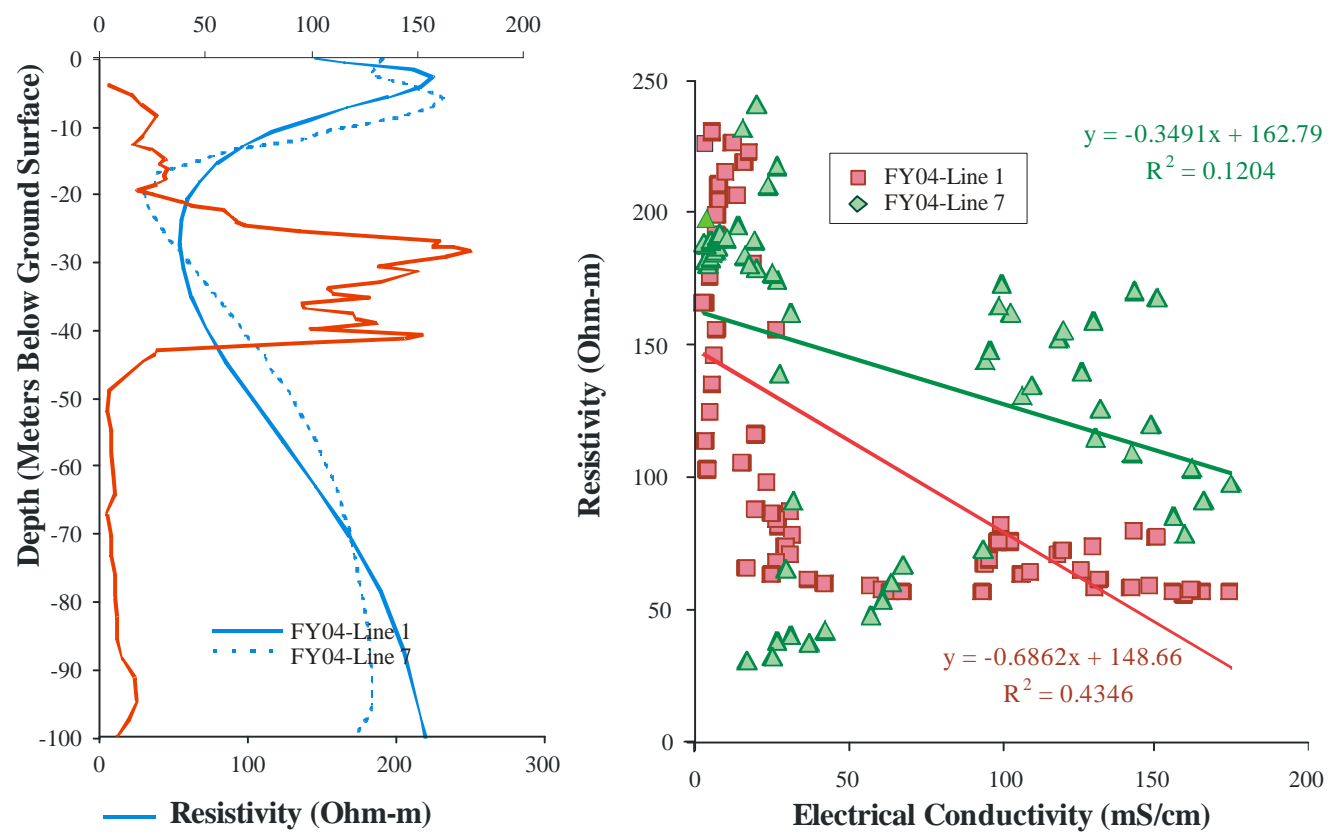

C) Profile of Shifted Data

D) Scatter of Shifted Data

Electrical Conductivity (mS/cm)
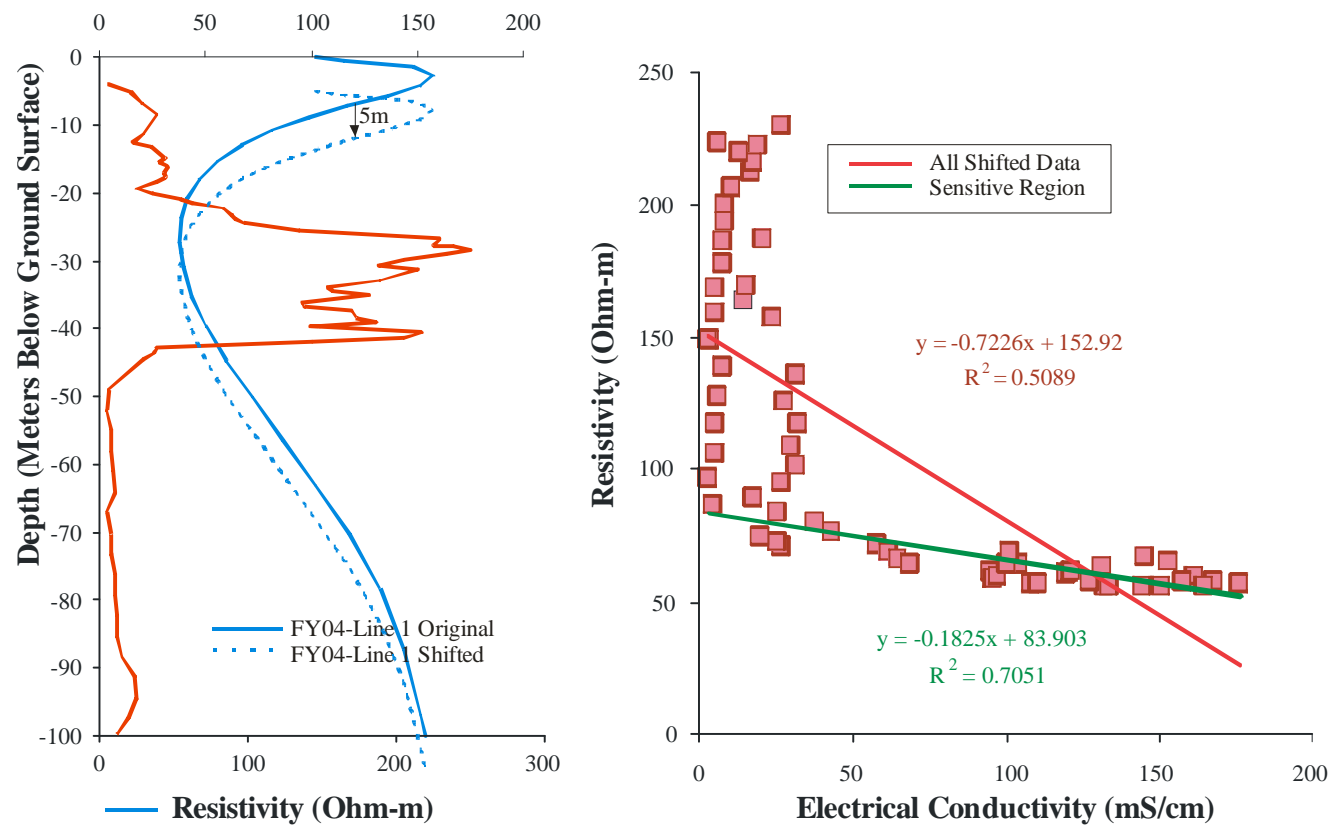

Figure 8.15. Profile and Scatter Plots for 2D Inversion with Pore-Water EC at Borehole C4191 for Shifted And Unshifted Data 
PNNL-17821

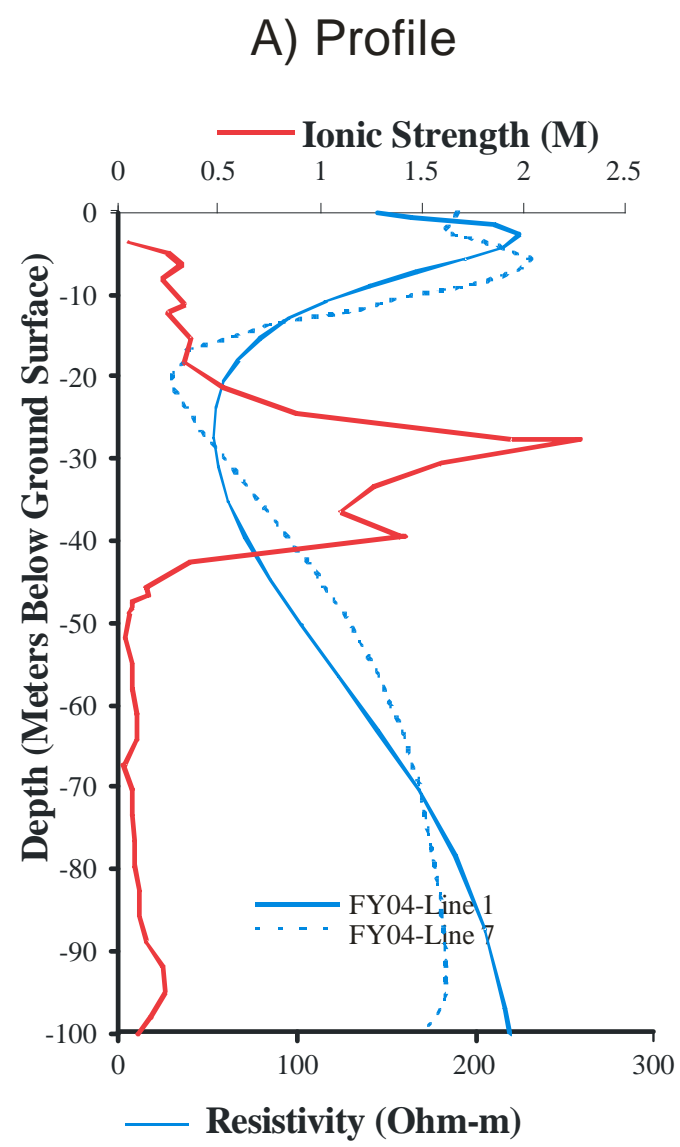

B) Scatter

$\square$ FY04-Line 1

$\diamond$ FY04-Line 7

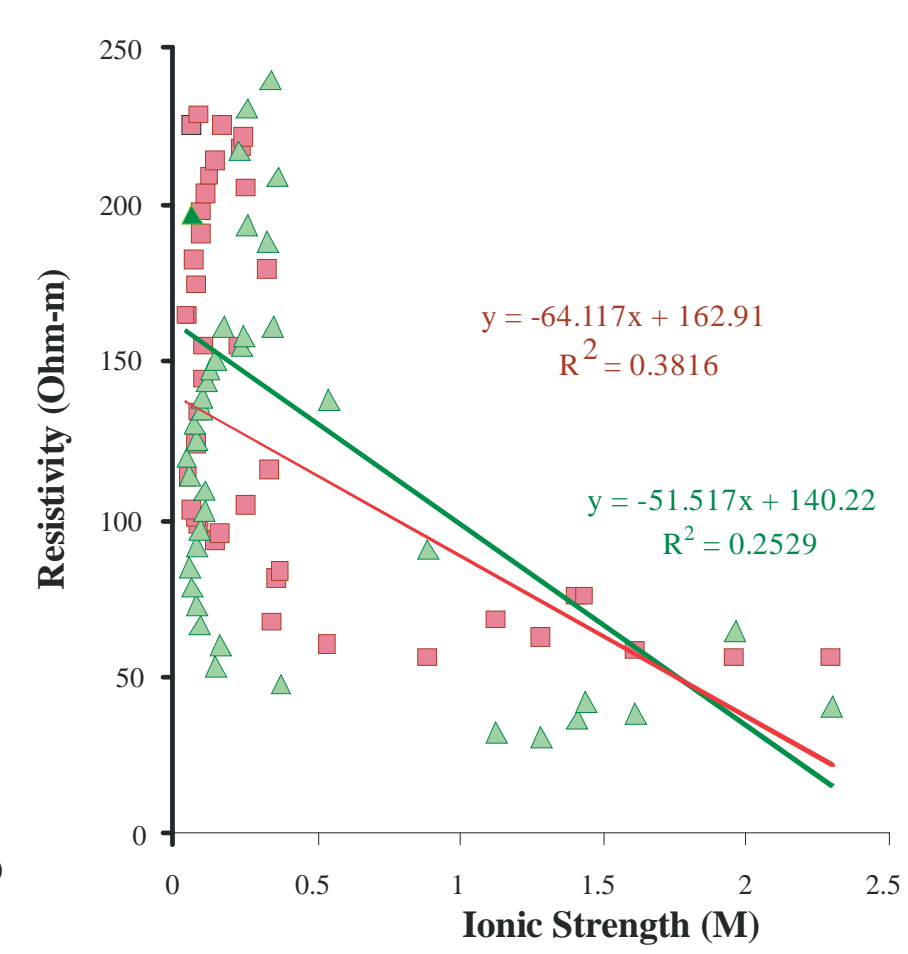

Figure 8.16. Profile and Scatter Plots for 2D Inversion with Ionic Strength at Borehole C4191 
PNNL-17821

A) Profile

B) Scatter

\section{- Nitrate Concentration $(\mathrm{mg} / \mathrm{L})$}
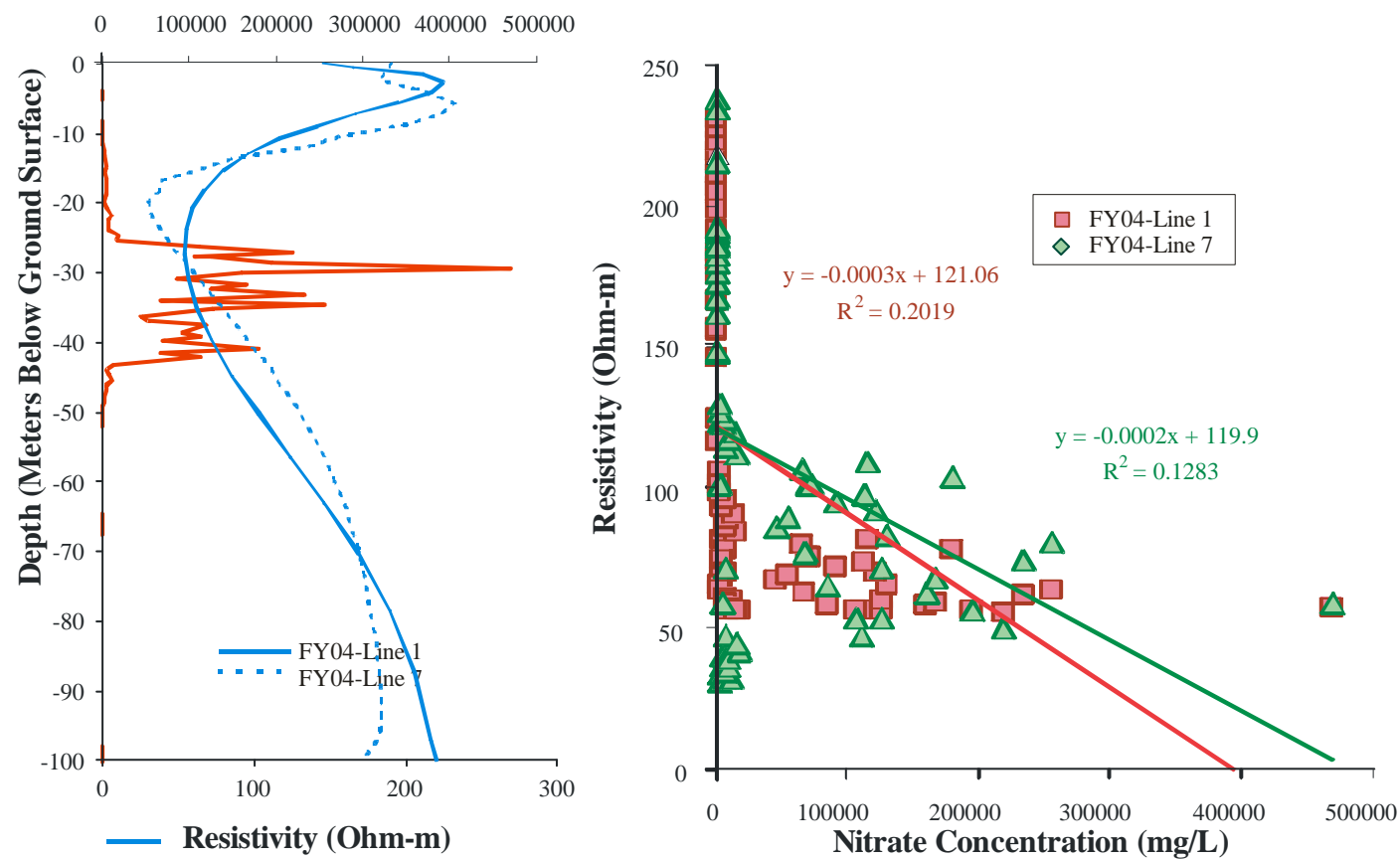

C) Scatter of log Nitrate

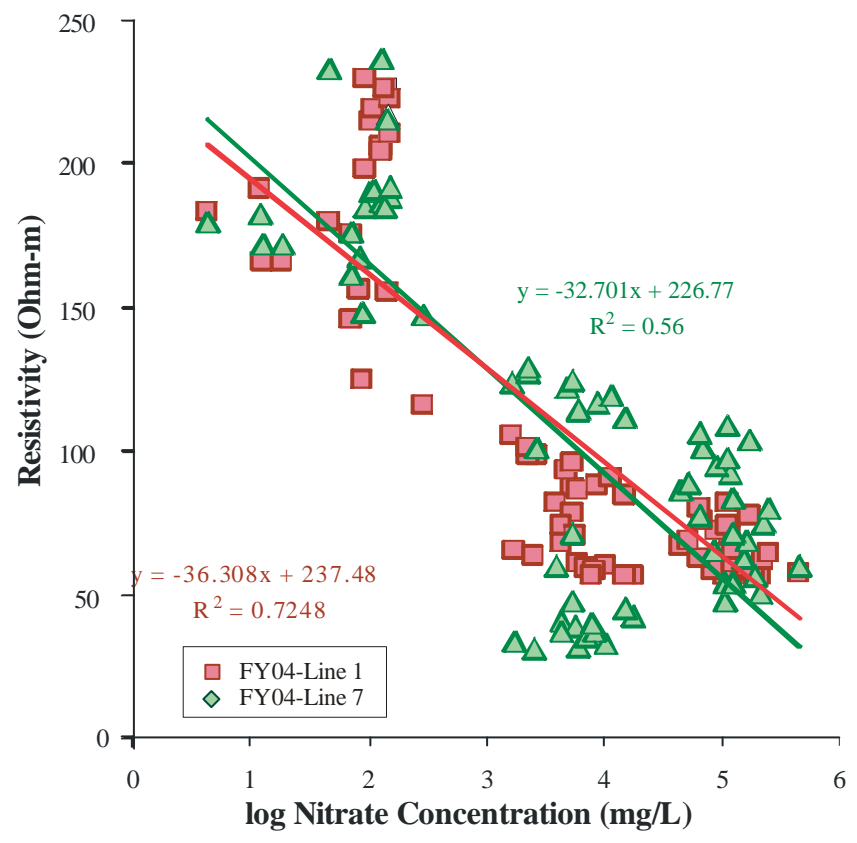

Figure 8.17. Profile and Scatter Plots for $2 D$ Inversion with the Nitrate and Logarithm of Nitrate Concentrations at Borehole C4191 
PNNL-17821
A) Profile
B) Scatter

_Tc-99 Concentration (pCi/L)
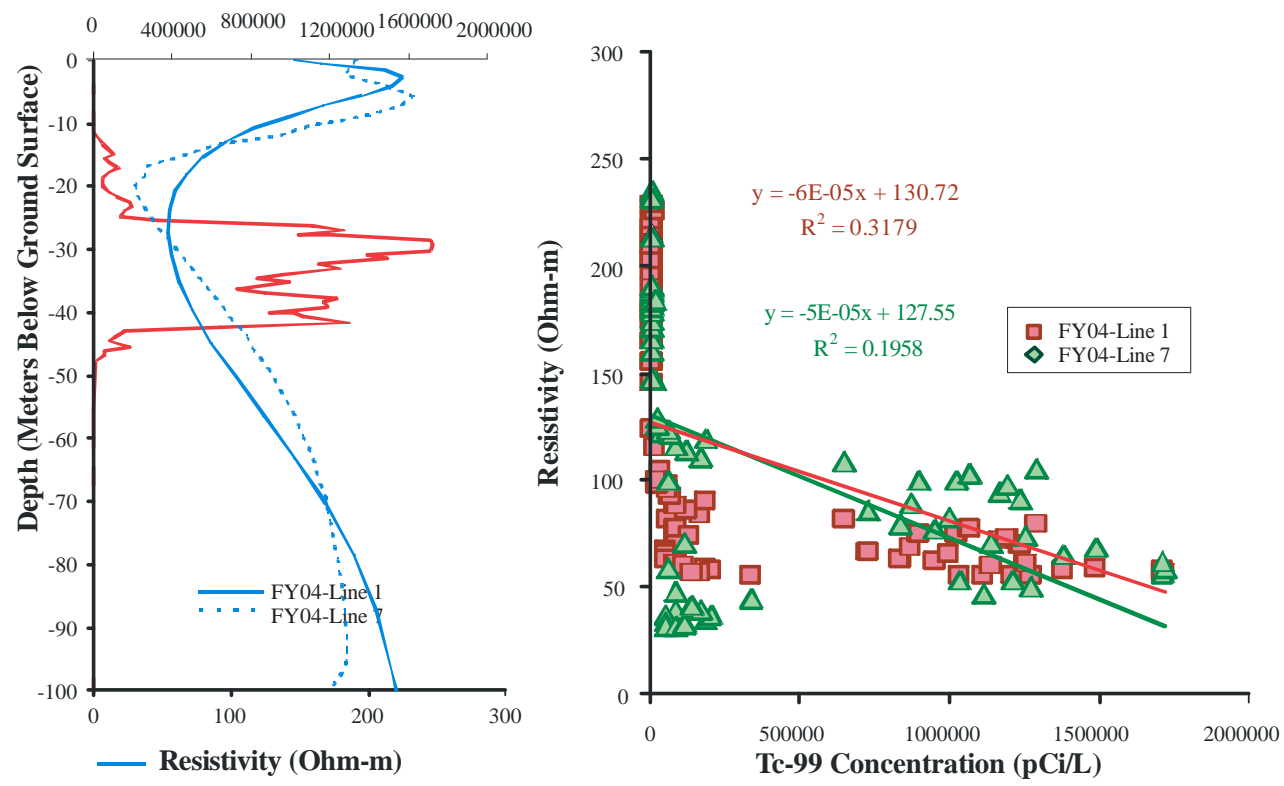

C) Scatter of log Technetium

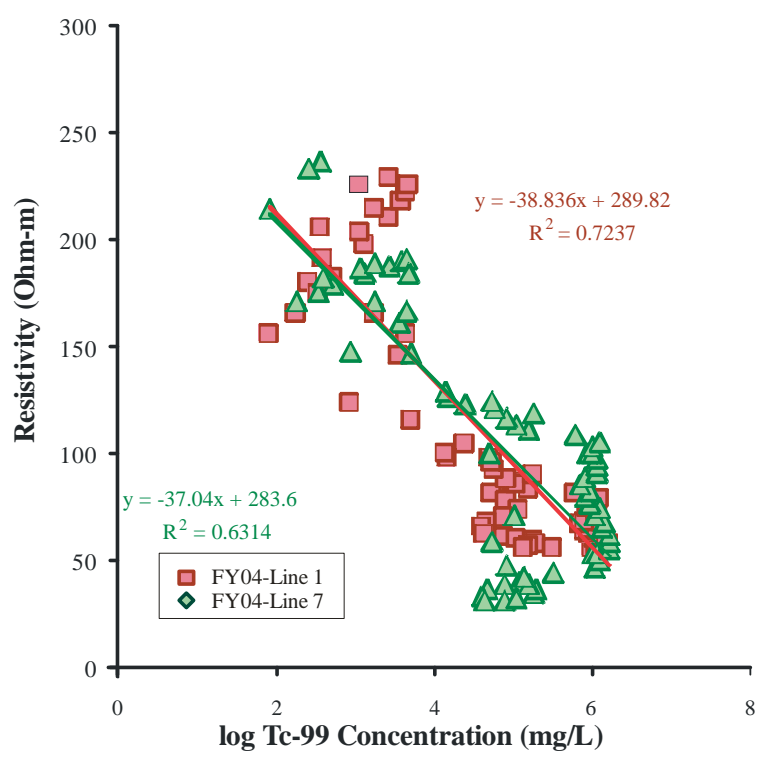

Figure 8.18. Profile and Scatter Plots for $2 \mathrm{D}$ Inversion with the Technetium-99 and Logarithm of Technetium-99 Concentrations at Borehole C4191 


\subsubsection{D Inversion at Borehole C4191}

The 3D inversion results for model domain 3 are shown in Figure 8.19. The figure focuses on data near Borehole C4191 by showing vertical slices of contoured resistivity values, centered on the borehole's location. The figure shows a low-resistivity anomaly in all directions from the borehole, which is coincident with the footprint of the trenches. In particular, low-resistivity peaks come to the surface immediately below each trench demonstrating the resolution of the method at the very near surface.

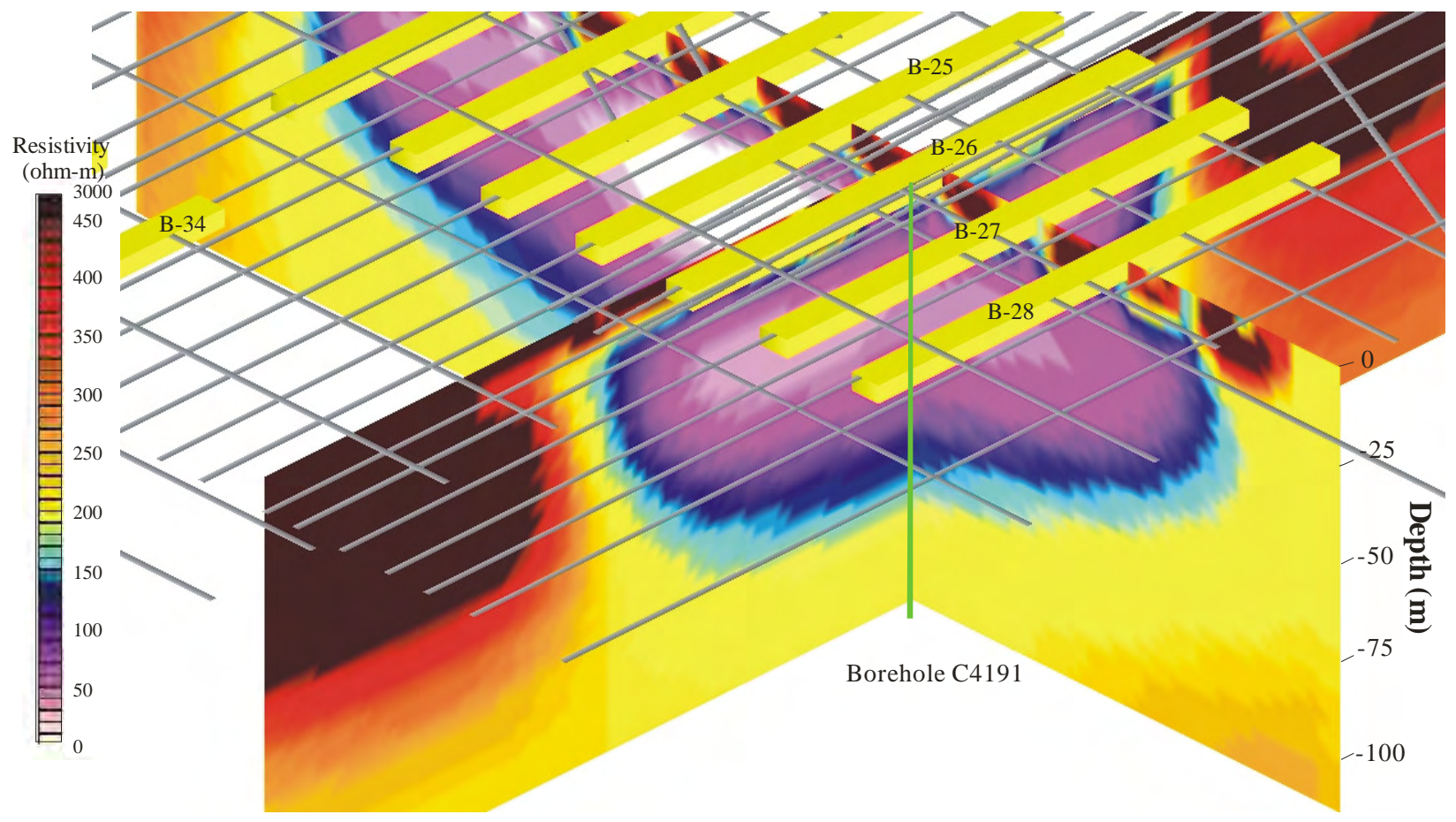

Figure 8.19. 3D Inversion Results of Model Domain 1 of the BC Cribs Site.

The regression and profile data for pore-water EC and ionic strength in Borehole C4191 with 3D inversion results are shown in Figure 8.20. The regression and profile data for the logarithm of porewater nitrate and technetium-99 concentrations in Borehole C4191 are shown in Figure 8.21. The correlation with the arithmetically scaled concentration values are not presented because they are much worse than the logarithmically scaled concentration values. The profile data show a large variability in resistivity in the near surface down to about $10 \mathrm{~m}$. The 3D resistivity target is at a much higher elevation than the pore-water geochemistry would suggest, likely causing the poor fit with the linear regression. Additionally, the lowest resistivity value, which should correspond to the highest pore-water concentrations of nitrate, is approximately $10 \mathrm{~m}$ lower than the borehole pore-water data. 
PNNL-17821

A) Profile

-Electrical Conductivity (mS/cm)

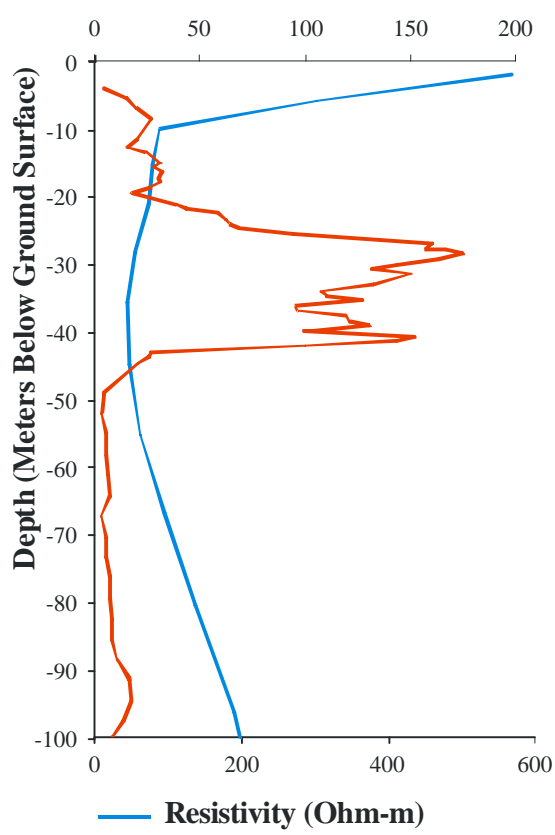

C) Profile
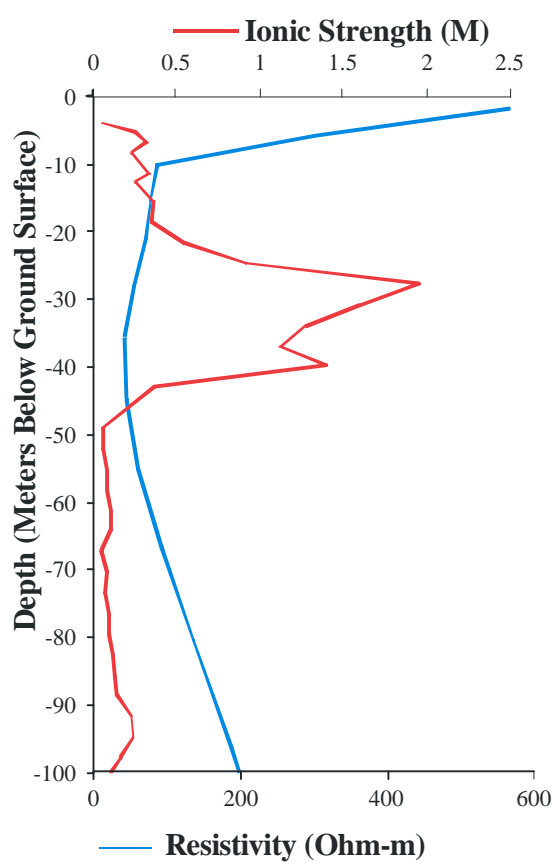

B) Scatter

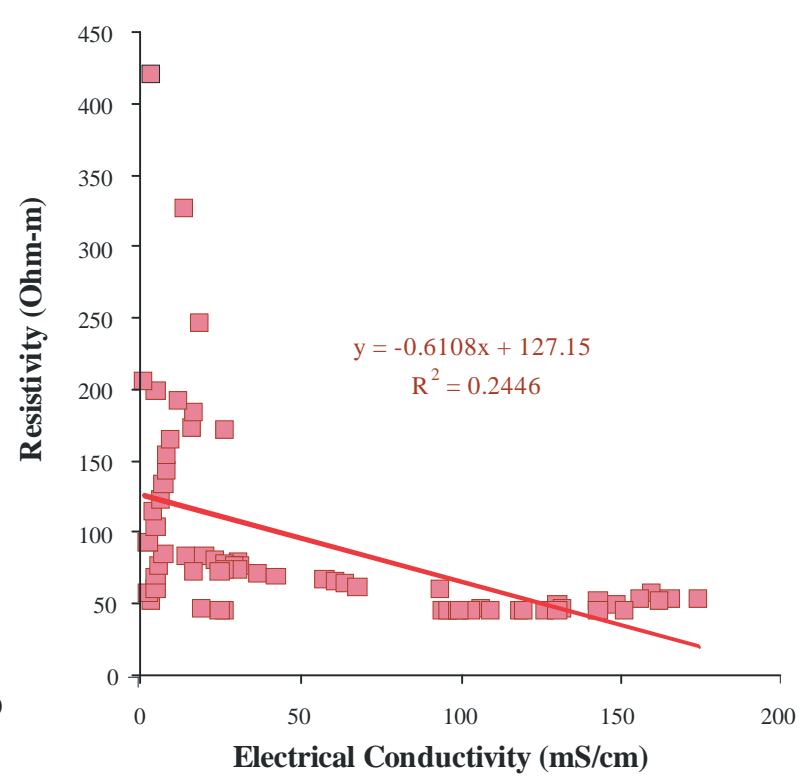

D) Scatter

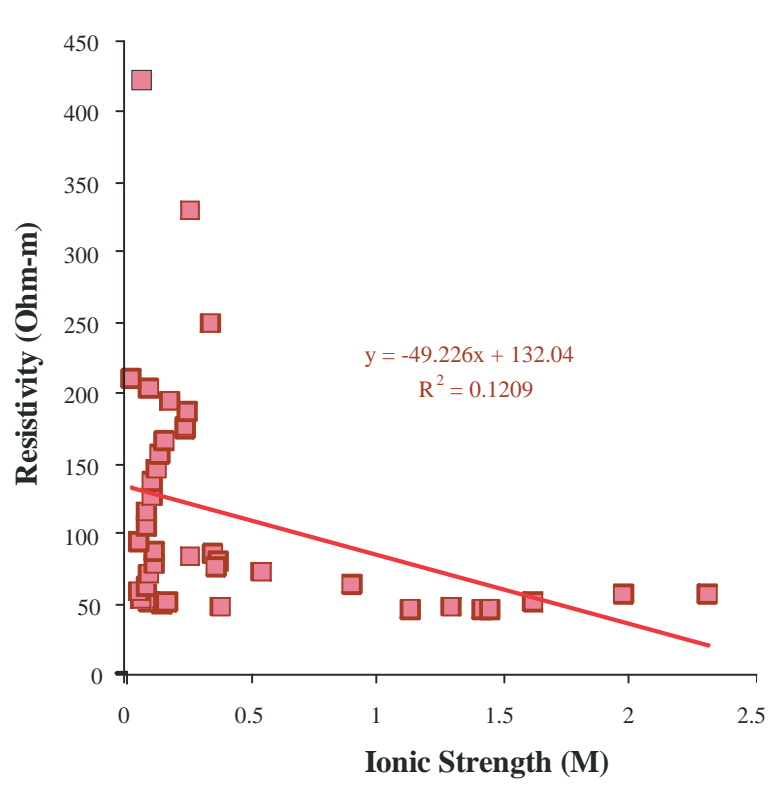

Figure 8.20. Profile and Scatter Plots for $3 D$ Inversion with Pore-Water EC and Ionic Strength at Borehole C4191 
PNNL-17821

A) Profile

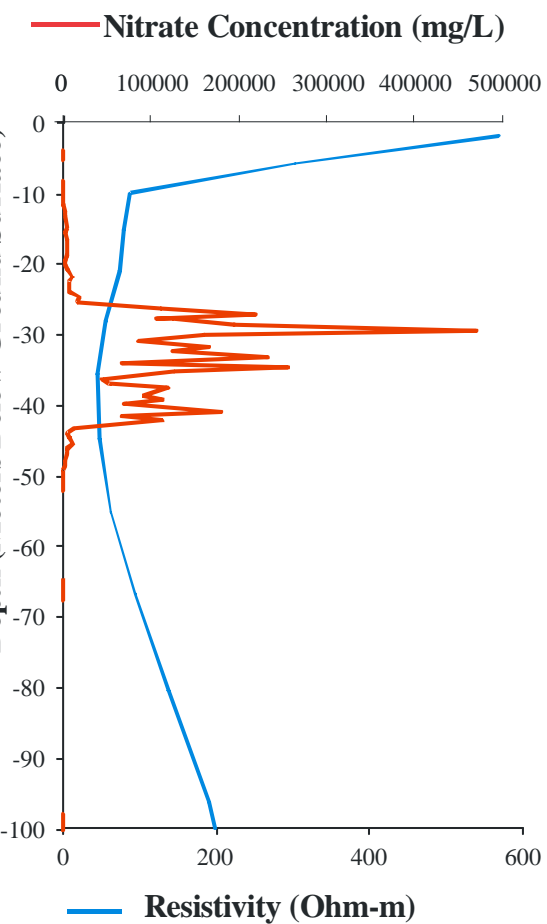

\section{C) Profile}

$-\mathrm{Tc}^{99}$ Concentration (pCi/L)

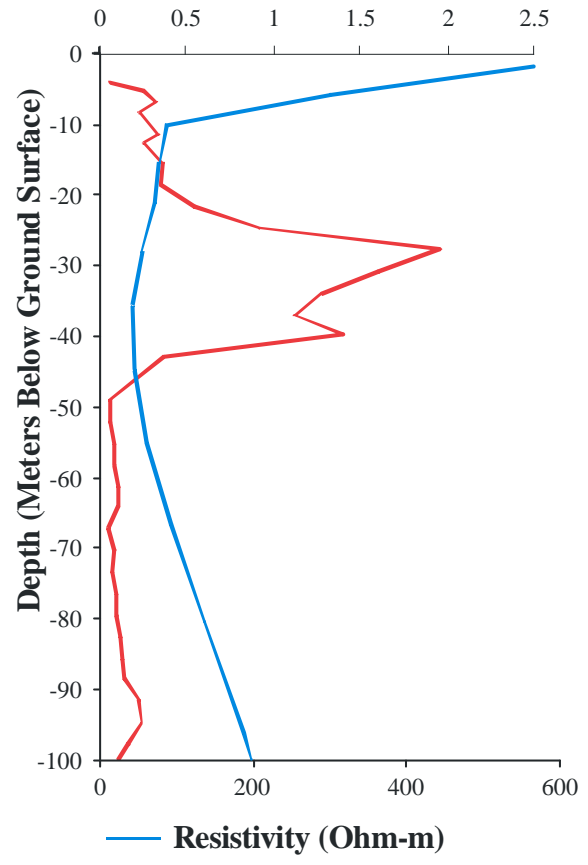

B) Scatter

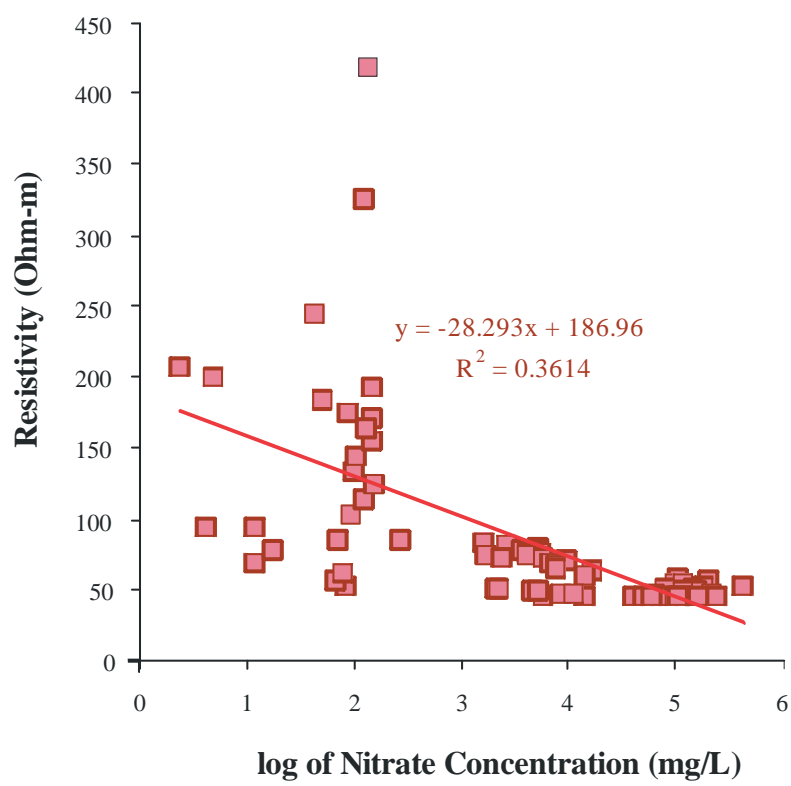

D) Scatter

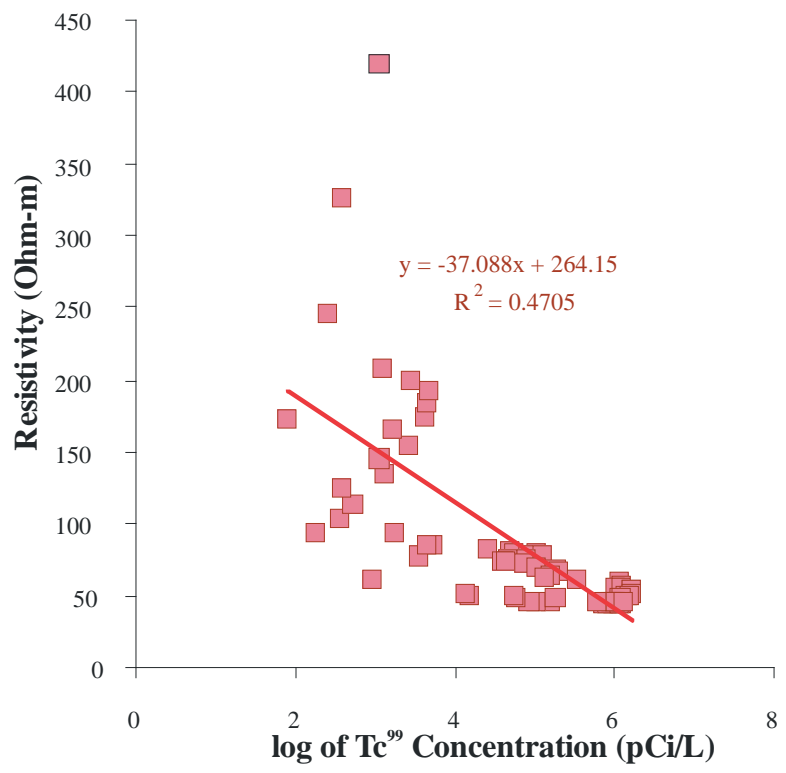

Figure 8.21. Profile and Scatter Plots for 3D Inversion with the Logarithm of Nitrate and Technetium-99 Concentration at Borehole C4191. 



\subsection{Summary and Conclusions}

This section contains four sections that provide a summary of the geological and geochemical findings on the sediments obtained from the four boreholes, a final analysis of all the field survey resistivity data merged into one data set, a summary of the laboratory soil resistivity measurement performed on C5923 sediments and comparison with the field survey data, and a discussion of the findings in this report as they relate to the three DQO decision statements.

\subsection{Drilling and Sampling Summary at the BC Cribs and Trenches}

This technical report documents the results of geochemical characterization of grab samples and one groundwater sample obtained from four boreholes emplaced in the BC Cribs and Trench area, and it correlates results from surface-based geophysical surveys with the pore-water compositions (water extracts of the sediments) from all four boreholes. It also describes the direct measurement of resistivity on small aliquots of the sediment from borehole C5925. The four boreholes were C4191 (located in the 216-B-26 trench footprint), C5923 (located between cribs 216-B-17 and 216-B-16), C5924 (located 28 $\mathrm{m}$ west of 216-B-52 trench), and C5925 (located 50 m west of 216-B-19 crib). Grab samples were obtained using cable-tool drive barrel techniques at a frequency of about every $2.5 \mathrm{ft}$ from approximately $5 \mathrm{ft}$ bgs to the borehole total depth. At borehole C5923, 19 split-spoon sampling campaigns were also performed at selected depths, and thirty-nine 4-in.-diameter by 6-in.-long cores were obtained and kept in as intact a condition as possible. Total depths reached in the four boreholes were 341, 352, 248, and $203.5 \mathrm{ft}$ bgs, respectively, for C4191, C5923, C5924, and C5925. In total, 505 grab samples and thirtynine 6-in.-long cores were obtained for characterization. Boreholes C4191 and C5923 were drilled to the water table, and one groundwater sample at each location was taken for characterization before decommissioning the boreholes (an analysis of the groundwater sample from the C5923 borehole is not included in this report). This vadose zone sediment suite represents the largest data set ever collected at the Hanford site for correlating with surface-based soil resistivity field measurements.

The first goal of the grab sample characterization was to provide data on the geochemical composition of the vadose zone pore water as a function of depth to allow comparison to surface-based electrical-resistivity surveys that had been conducted in three campaigns before the drilling campaign that emplaced C5923-C5925 and after the drilling of borehole C4191. The 39 intact cores and many of the grab samples from C5923 were also measured for soil resistivity with a smaller version of the instrumentation used in the field surveys. Other physical properties of sediments from C5923, such as PSD, SSA, saturated hydraulic conductivity, and moisture retention, are being measured, but many of the measurements are not available at this time. The pore-water chemical composition data, laboratory-scale soil resistivity, and other ancillary physical and hydrologic measurements and analyses described in this report are designed to provide a crucial link between direct measurements of geochemical and hydraulic properties as well as soil resistivity of subsurface material and the surface-based electrical-resistivity information obtained via field surveys.

A second goal of the geochemical characterization activities on the grab samples was to measure the total and water-leachable concentrations of key COCs in the sediments as a function of depth and distance from the footprints of inactive disposal facilities in the BC Cribs and Trenches area. The total and waterleachable concentrations of key contaminants will be used to update contaminant distribution conceptual models and to provide more data for baseline risk predictions and remedial alternative selections. 
As part of the vadose zone sediment characterization, each of the $~ 500$ sediment grab samples was digitally photographed, described by Hanford site experienced geologists, and sub-sampled for moisture content determination. These activities were combined with field geophysical logging of moisture (neutron logging) and SG logging through the temporary casing to quantify natural and man-made fission (contaminant) gamma-ray activities and other regional bore-hole geologic data. This allowed us to generate very detailed information on the local stratigraphy in the BC Cribs and Trenches area. The geologic framework of the vadose zone sediments controls the migration of the liquid waste and dissolved contaminants within the waste as they travel towards the unconfined aquifer.

These four new boreholes and others emplaced in the past at the BC Cribs and Trenches area suggest that there is a relatively thick (up to $15 \mathrm{ft}$ ) layer of fine silty sand to sandy silt, which lies at a depth of $\sim 120$ to $130 \mathrm{ft}$ bgs, and may be contiguous across the BC Cribs and Trenches area. This thick finegrained layer lies within a zone of elevated technetium-99 and EC observed in boreholes C4191, C5923, and C5924. Another correlative boundary within the Hanford formation is a sudden increase in total gamma activity from 40 to $50 \mathrm{ft}$ bgs in the four boreholes. There is no evidence for a distinct stratigraphic boundary at this depth, but the SG logs may conform to a mineralogical change from more to less basaltic sand starting at this depth. Other thin lenses of finer-grained sediment with slightly elevated moisture contents were found in the shallow portion of the vadose zone at all four boreholes. These thin, relatively moist sediments can act as horizontal spreading zones for slowly percolating liquid wastes or natural recharge waters.

The following paragraphs summarize the geochemical characterization of the grab samples from each of the four boreholes. Key measurements performed include moisture content, $\mathrm{pH}$, and EC of 1:1 sediment to water extracts, and measurements of major cations, anions, trace metals, and radionuclides in both the sediment and 1:1 sediment-to-water extracts. The most important geochemical parameters that were measured to "ground truth" the surface-based field resistivity surveys at the BC Cribs and Trenches region were vadose zone pore-water major dissolved salts. Pore-water, EC, and the major ions sodium and nitrate are especially relevant. Theoretically, the pore-water parameter that could be best correlated would be total ionic strength, which accounts for the total ion conductivity of the pore water.

A GEA on selected grab samples was also performed to search for any detectable man-made gammaemitting radionuclides. The total chemical composition of selected sediment samples was measured by strong nitric acid extraction. COPCs specifically measured in acid extracts of selected grab samples included RCRA metals, with an emphasis on mercury, and strontium-90 and nickel-63. Gross-beta and gross-alpha analyses of the acid extracts were used to assess whether we had overlooked any radionuclides of potential concern. The gross alpha and beta results for the acid extracts did not show any signs of unaccounted radioactivity beyond that found in the specific analyses.

\subsubsection{C5923 Geochemical Results}

The vadose zone sediments at C5923, located between the two rows of cribs in the northeast portion of the BC Cribs and Trenches area, show elevated moisture contents (equal to or greater than $8 \% \mathrm{wt}$ ) only in the upper $46 \mathrm{ft}$ of the profile. Six grab samples, representing five thin lenses of less than $2.5 \mathrm{ft}$

thickness, were found in the upper $46 \mathrm{ft}$. Other relatively finer-grained lenses are found at deeper depths, but at moisture contents that are $<8 \%$ wt. Borehole C5923 contains fewer of the thin higher-moisture zones in the upper $110 \mathrm{ft}$ of the Hanford formation (H2 unit) than borehole C4191. 
The $\mathrm{pH}$ profile in the C5923 vadose zone sediments shows a few samples with elevated values indicative of caustic waste in the depth region of 8 to $13 \mathrm{ft}$ bgs and perhaps as deep as $18 \mathrm{ft}$ bgs. The crib bottoms were from 11 to $15 \mathrm{ft}$ bgs at the time of their use. We are not sure whether the current ground surface elevation is the greater than during the operations of the BC Cribs. If so, some of the shallow sediments with elevated $\mathrm{pH}$ near $8 \mathrm{ft}$ bgs are shallower than the bottom of the nearby cribs, suggesting that caustic waste must have ponded in the cribs and also migrated horizontally up to several tens of feet. At borehole C4191 in the 216-B-26 trench footprint, high pH values (above 9) were found at deeper depths (from 17.5 to $37.5 \mathrm{ft}$ bgs). The vertical extent of the elevated $\mathrm{pH}$ at borehole C5923 (approximately 5 to at most 10 vertical $\mathrm{ft}$ ) is a bit less than the thicknesses of impacted sediment observed below several single-shell tanks and also about half the thickness of elevated $\mathrm{pH}$ observed at borehole C4191 emplaced directly through the 216-B-26 trench.

The sediment from C5923 (to the side but near 216-B-16 and 216-B-17 cribs) appears to show a trimodal peak in pore water EC (i.e., exhibits three maxima in pore-water EC). The shallowest lobe of high EC is by far the thickest lobe ( $\sim 5 \mathrm{ft}$ thick with maximum pore-water EC of $293 \mathrm{mS} / \mathrm{cm}$ ); the middle lobe of the tri-modal distribution is thin ( 10-ft thick with a maximum pore-water EC $200 \mathrm{mS} / \mathrm{cm}$ ), and the deepest lobe is about 30-ft thick with a maximum pore water EC of $230 \mathrm{mS} / \mathrm{cm}$. The depths for the three EC maxima are 90, 132, and $230 \mathrm{ft}$ bgs, respectively. The deeper lobe of anomalous conductivity (i.e., sodium nitrate salt) is considerably deeper than the bimodal conductivity anomaly at borehole C4191, which was drilled through the 216-B-26 trench. The upper two lobes of salt maxima at C5923 occur at about the same depths as the bi-modal plume anomaly below the 216-B-26 trench. At both boreholes, C5923 and C4191, the shallowest lobe of the salt plumes has the highest electrical conductivities. The absolute value of the maximum EC at C5923 ( 293 mS/cm) is about two times larger than at C4191 (152 $\mathrm{mS} / \mathrm{cm})$. The distribution of pore-water EC and ionic strength at C5923 is more irregular and penetrates deeper than at C4191, placed through the 216-B-26 trench. Considering that twice as much water was disposed of to the two nearest cribs (216-B-16 and 216-B-17) than was disposed of to the 216-B-26 trench and that four other cribs are quite close, one might expect deeper penetration at C5923 than at C4191.

The vadose zone sediments in borehole C5923 show elevated concentrations of most of the anions found in the uranium recovery and scavenging waste stream disposed of to most of the BC Crib and Trenches facilities. Phosphate is immobilized in the upper $8 \mathrm{ft}$ bgs, the most elevated sulfate concentrations are found at about $46 \mathrm{ft}$ bgs, and the most elevated nitrate concentrations are found from 28 to $245 \mathrm{ft}$ bgs. These depth distributions are both a function of species mobility in Hanford sediments (phosphate is highly interactive and readily sorbs/precipitates; sulfate is slightly interactive with sediments, and nitrate is not retained significantly in the sediments and migrates with the percolating fluids). The massive quantity of nitrate disposed of makes it a good tracer of the waste fluid plume location.

The water-extractable concentrations of major cations in the C5923 vadose zone sediments do not show consistent differences in the vertical distribution of the native divalent versus the waste sodium (monovalent) in each lobe of the high EC anomalies. This seems to indicate that waste fluids migrated with a more significant horizontal pathway than vertical pathway, especially in the shallowest lobe of the tri-modal salt plume into the sediments at borehole C5923. When the waste liquids migrate predominately in a vertical fashion through the sediments, a borehole thus emplaced generally exhibits an ion-exchange front where the native divalent cations ( $\mathrm{Ca}$ and $\mathrm{Mg}$ ) are displaced and pushed ahead of the water-extractable sodium, which fills the sediment cation exchange sites and is thus slightly retarded in 
travel deeper into the sediment profile at each vertical exchange front. Compared to the waterextractable major cation distribution at borehole C4191 (directly below the 216-B-26 trench), the profile at borehole C5923 (off to the sides of the 216-B-16 and 216-B-17 cribs) is much more complicated and appears to lack the monovalent-divalent offsets for some of the high conductivity lobes. Undoubtedly, the effects of lateral spreading from both the east and west from the two near-by cribs and perhaps from the north and south from the other two rows of cribs has led to a complicated mixture of lateral and vertical ion exchange fronts.

The three C5923 sediments that were ultra-centrifuged to directly obtain vadose zone pore water had quite similar values for most of the measured constituents, which were quite similar to the dilutioncorrected pore-water concentrations calculated from the water extracts. Thus, we feel confident that the more ubiquitous dilution corrected pore-water values for all the grab samples represent the true porewater composition.

In contrast to the shallow sediments at C4191, which was emplaced directly through the footprint of the 216-B-26 trench, no strontium-90 or nickel-63 was found in the sediments obtained from borehole C5923. We did not expect to find detectable strontium-90 or nickel-63 because these radionuclides are rather immobile in the geochemical environment in Hanford's subsurface given the nature of the waste stream disposed of at the BC Cribs and Trenches and the fact that borehole C5923 is several tens of feet from crib footprints. The sediment samples from C5923 also did not contain detectable concentrations of mercury, and concentrations of other RCRA metals were low. Thus, outside the crib footprints, the vadose zone sediments do not appear to contain elevated concentrations of RCRA or radionuclides, except technetium-99.

\subsubsection{C5924 Geochemical Results}

The characterization of C5924 grab samples and the neutron moisture log showed six thin zones within the Hanford formation in the upper $120 \mathrm{ft}$ bgs that exhibited higher moisture contents, 8 to 12 wt\%, with the highest moisture content at $107 \mathrm{ft}$ bgs. The typical sand-dominated Hanford formation sediments had moisture contents that ranged from 4 to $7 \mathrm{wt} \%$ from $20 \mathrm{ft}$ to $120 \mathrm{ft}$ bgs. The moisture content in the Hanford formation below $120 \mathrm{ft}$ bgs and in the underlying Cold Creek formation dropped to $\sim 3 \mathrm{wt} \%$ because the sediments coarsen with depth. The more gravel-dominated sediment deeper in the borehole had low moisture contents with an average vadose zone moisture content of $\sim 2.0 \mathrm{wt} \%$ within the Hanford and Cold Creek formations below $205 \mathrm{ft}$ bgs.

The $\mathrm{pH}$ profile in the $\mathrm{C} 5924$ sediment water extracts shows slight hints ( $\mathrm{pH}$ values $>8.5$ ) of some caustic waste-sediment interaction from 17.75 to 34.75 and from 52.75 to $57.25 \mathrm{ft}$ bgs. The highest pH (8.8) was found at $25.25 \mathrm{ft}$ bgs. In comparison, at borehole C5923, the high $\mathrm{pH}$ range (8.55 to 9.24) is found from 8 to $18 \mathrm{ft}$ bgs, and at C4191, the sediments right below trench 216-B-26 show pH values that range from 8.65 to 9.59 from 17.5 to $43.5 \mathrm{ft}$ bgs. Thus, the sediment $\mathrm{pH}$ at $\mathrm{C} 5924$ is less caustic, but the depths with slightly elevated $\mathrm{pH}$ reach deeper into the profile than at the other two boreholes cited.

The pore-water-corrected EC data for borehole C5924 range from 1.94 to $92.7 \mathrm{mS} / \mathrm{cm}$ in the Hanford formation. The EC data decrease significantly below $150 \mathrm{ft}$ bgs and show a narrow range of 5.4 to $7.5 \mathrm{mS} / \mathrm{cm}$ in the deeper Hanford and Cold Creek formations. Two major peaks in pore-water-corrected EC values of 90.3 to $92.7 \mathrm{mS} / \mathrm{cm}$ at $67.8 \mathrm{ft}$ bgs and $71.5 \mathrm{mS} / \mathrm{cm}$ at $122.75 \mathrm{ft}$ bgs are indicative of a bimodal salt waste plume (EC anomaly) at borehole C5924. The conductivity anomaly at C5924, drilled 
between two rows of trenches, does not appear to have reached anywhere near the water table, likely because of thin, fine-grained lenses, which provide several capillary breaks (contrasts between fine sand and coarse sand) that promote horizontal spreading in the upper portion of the Hanford formation. Borehole C4191, drilled within the 216-B-26 trench footprint, also exhibited the bimodal conductivity anomaly with the highest pore-water EC values being 176 and $152 \mathrm{mS} / \mathrm{cm}$ at 93.5 and $133.5 \mathrm{ft}$ bgs. Borehole C5923, drilled between two rows of cribs, appears to have a trimodal conductivity anomaly with the lowest lobe much deeper in the Hanford formation sediments. In comparison, the highest pore-water EC values observed in the sediments at C5923 were 293 and $232 \mathrm{mS} / \mathrm{cm}$ at 90.5 and $230.5 \mathrm{ft}$ bgs, respectively.

The C5924 pore-water total ionic strength peaks occur at $67.75 \mathrm{ft}$ bgs $(1.26 \mathrm{M})$ and $122.75 \mathrm{ft}$ bgs $(1.09 \mathrm{M})$. Thus, at borehole C5924, the pore-water EC and total ionic strength values are slightly lower than the pore waters below Trench 216-B-26 (borehole C4191), but the two maxima are at similar depths. Comparing the salt plume at C5924 located between Trenches 216-B-52 and 216-B-33 and 216-B-33 with the plume at C5923 that is close to the cribs in the northeast corner of BC Cribs and Trenches area, one can see that the boreholes (including C4191) near trenches exhibit lower concentrations of salt in the profile and shallower depths for the deepest lobe of the plume than the distribution found near cribs based on the findings at C5923. On an areal basis, the BC cribs received much larger volumes of liquid waste than the BC trenches so that the deeper penetration of the salt plume at C5923 makes sense. Further, as noted, the sediments underlying C5923 appear to exhibit fewer finer-grained lenses that promote horizontal spreading of wastes.

At borehole C5924, a bi-modal nitrate distribution was found with two peaks at 62 to $70 \mathrm{ft}$ bgs and 118 to $123 \mathrm{ft}$ bgs, which is closely related to the pore-water-corrected EC profile. The depth distribution of nitrate should be a good indicator of the deepest penetration of the waste fluids disposed of to the neighboring cribs because the mobility of nitrate is quite high (i.e., nitrate is not retained significantly on sediment particles and stays in the pore fluids). Because nitrate migrates with the percolating fluids without retardation, the massive quantity of nitrate disposed of makes it a good tracer of the waste fluid plume location.

At borehole C5924, two ion exchange fronts (where the monovalent cation concentrations are low and divalent cation concentrations are high relative to each other) were found at depths around 70 and $125 \mathrm{ft}$ bgs, suggesting a significant vertical flow pattern for disposed waste liquids in the vicinity of the borehole. The two ion exchange fronts at boreholes C5924 and C4191 are readily discernable in contrast to the water extract cation distribution at borehole C5923 that is complex and not easily interpreted.

As part of the characterization of the C5924 water extracts, other chemical species such as aluminum, silicon, iron, manganese, zinc, and trace constituents, such as arsenic, boron, barium, beryllium, bismuth, cadmium, cobalt, chromium, copper, lithium, molybdenum, nickel, lead, selenium, thallium, vanadium, titanium, and zirconium, were measured, but because their concentrations were generally low to nondetectable, the data are not presented in this ERC ground-truthing document.

The borehole C5924 water extract data for technetium-99 data show elevated technetium-99 concentrations occurring from 60 to $70 \mathrm{ft}$ bgs and 118 to $122 \mathrm{ft}$ bgs. The deepest penetration of significant technetium-99 contamination occurs at the same place as the significantly elevated nitrate because they are mobile contaminants and distribute in the vadose zone in a similar pattern. 
The five C5924 sediments that were ultra-centrifuged to directly obtain vadose zone pore water had quite similar values for most of the measured constituents as the dilution-corrected pore-water concentrations calculated from the water extracts. Thus, we feel confident that the more ubiquitous dilution-corrected pore-water values for all the C5924 grab samples characterized represent the true porewater composition.

Acid extracts of shallow sediments at C5924 exhibit some elevated concentrations of some major sediment constituents that might be indicative of some precipitated wastes or the presence of lessstable secondary mineral phases formed upon caustic waste attack on native sediments. No detectable mercury, strontium-90, or nickel-63 were found in the acid extracts from Borehole C5924 (B) sediments, suggesting that there is no risk potential for these COCs outside the footprints of the BC cribs proximal to borehole C5924. Because the wastes disposed of in the BC Cribs and Trenches did not contain high concentrations of uranium, it appears that regions of elevated precipitated uranium may only exist right at the bottoms of the inactive cribs and trenches as was found at borehole C4191 (drilled right through the 216-B-26 footprint). The sediment from Borehole C5924 (B) also did not contain significant amounts of man-made gamma radioactivity in the grab samples. Cesium-137 was only found in the shallower depths (5.3 and $9.8 \mathrm{ft}$ bgs) at concentrations below $1 \mathrm{pCi} / \mathrm{g}$. The sediments also contain natural amounts (10 to $25 \mathrm{pCi} / \mathrm{g}$ ) of potassium-40 and a few pCi/g of some of the daughters of natural uranium and thorium at natural background levels.

\subsubsection{C5925 Geochemical Results}

At borehole C5925, seven grab samples collected within the Hanford formation in the upper $40 \mathrm{ft}$ exhibited relatively high moisture contents, 8.9 to $19 \mathrm{wt} \%$, which is indicative that at least seven thin, fine-grained layers exist in the shallow Hanford formation. Other sand-dominated Hanford formation samples in the upper $65 \mathrm{ft}$ bgs had moisture contents ranging from 4 to $7 \mathrm{wt} \%$. Moisture contents in Hanford formation sediments below $65 \mathrm{ft}$ bgs dropped to the range of 2 to $3 \mathrm{wt} \%$ because of texture coarsening (larger \% of gravel is present).

The $\mathrm{pH}$ profile for the water extracts of C5925 sediments is fairly constant with all values from 7.9 to 8.5 (the typical range for Hanford sediments), suggesting that no significant waste contact occurred in the sediments in this borehole. The pore-water-corrected EC data for C5925 pore waters ranged from 1.2 to $8.8 \mathrm{mS} / \mathrm{cm}$. Compared to the pore-water EC values for C5923, C5924, and C4191, the EC values for sediments in Borehole C5925 (C) are very low, consistent with the hypothesis that no waste plume is present or has percolated through these sediments. The total ionic strength distribution ranges from 0.019 to $0.12 \mathrm{M}$, which is in the range of uncontaminated Hanford formation pore-water values.

Sulfate and carbonate are the dominant anions in C5925 water extracts, which is in agreement with the hypothesis that borehole C5925 sediments are not contaminated with the highly concentrated sodium nitrate waste disposed of to nearby BC Cribs and Trenches. The water-extract cation data indicate that no noticeable ion-exchange front is present. Both the water and acid extracts for technetium-99 and uranium, the acid extracts for mercury, the other RCRA metals, strontium-90, nickel-63, and common elements found in sediments show no elevated concentrations. Because borehole C5925 sediments appeared to be uncontaminated, only 14 of the available 84 grab samples were characterized in detail. However, the 14 samples covered the depth range from 20 to $203 \mathrm{ft}$ bgs, and based on finding that the deepest impact of waste salts reached $\sim 130 \mathrm{ft}$ bgs at borehole C5924 and $160 \mathrm{ft}$ bgs at C4191, it is 
highly unlikely that wastes are present below the depth penetrated by borehole C5925 (203.5 ft bgs), unless crib waste has migrated in an easterly to south-easterly direction from the six cribs in the northeast corner of BC Cribs and Trenches area.

\subsubsection{C4191 Geochemical Results}

At borehole C4191, six thin zones with higher moisture are observed in the upper $110 \mathrm{ft}$ of the Hanford formation (H2 unit). This is significant to moisture and contaminant migration because, due to a higher frequency of fine-grained, silty, slack-water beds in the upper part of the Hanford formation, there is increased likelihood for lateral spreading in the upper Hanford formation and a reduced tendency toward vertical migration. Thicker and coarser flood beds are deeper in the profile as evidenced by the lack of any zones with moisture contents greater than $8 \mathrm{wt} \%$ below $110 \mathrm{ft}$ bgs.

The C4191 water extract $\mathrm{pH}$ profile shows that caustic waste has impacted the sediments from near the bottom of the 216-B-26 trench down to a depth of about $48 \mathrm{ft}$ bgs. The highest $\mathrm{pH}$ values (above 9) are found from 17.5 to $37.5 \mathrm{ft}$ bgs. The vertical extent of the elevated $\mathrm{pH}$ (approximately 20 vertical ft) is also similar or a bit less than the thicknesses of impacted sediment observed below several single-shell tanks. Below the 216-B-26 trench, the sediments appear to show a bi-modal peak in pore water EC with the two maxima residing at 91 to 94 and 133.5 to $136 \mathrm{ft}$ bgs with the shallow lobe being slightly more concentrated. It was quite surprising to find that the high-conductivity zones below the 216-B-26 trench were as shallow as observed given the much larger volume of waste disposed of at 216-B-26 (4.75 million liters) compared to volumes released from single-shell tanks that had been studied previously, such as T106 (released 0.435 million liters), BX-102 (released 0.347 million liters) or SX-108 (released 0.132 million liters), based on current estimates in Field and Jones (2006). Despite disposing of volumes from 10 to 36 times greater than the three largest documented tank releases to the sediment below the 216-B-26 trench, the mobile salt plume has not traveled significantly deeper into the vadose zone profile than the tank releases.

The massive quantity of nitrate disposed of makes it a good tracer of the waste fluid plume location. When waste liquid percolates vertically into a sediment profile, the sodium in the waste replaces the native divalent cations (and to some extent native potassium) on the exchange sites and "pushes" the replaced divalent cations out in the leading edge of the waste plume. This is what is observed by looking at the vertical distribution of the mass of major cations water leached from the grab samples from borehole C4191. From 91 to $158.5 \mathrm{ft}$ bgs, all the divalent cations show elevated waterextractable concentrations in comparison to the deeper sediments not impacted by the waste solution. This zone represents the front of the waste plume. In contrast, the water-exchangeable sodium distribution shows elevated concentrations from the shallowest sample (13 ft bgs) down to $141 \mathrm{ft}$ bgs, with extremely high values from 91 to $131 \mathrm{ft}$ bgs. The narrower zone (91 to $131 \mathrm{ft}$ bgs) represents the active cation exchange zone where reactions are still occurring as natural recharge slowly pushes the waste plume ever deeper. Shallower, from 13 to $81 \mathrm{ft}$ bgs, the pore waters are a mixture of natural recharge from post disposal and the last of the liquid disposed of to the 216-B-26 trench.

The pore-water data show that elevated nitrate is observed down to the maximum depth of $158.5 \mathrm{ft}$ bgs, and elevated sodium is found to a depth of $141 \mathrm{ft}$ bgs. The difference is caused by the ion exchange reactions wherein sodium is adsorbed on the sediment surface cation exchange sites, and its transport is somewhat retarded in its descent with the waste fluids. The calcium and magnesium elevated 
concentrations (also shown in Table 8.5) show a maximum descent to $158.5 \mathrm{ft}$ bgs in agreement with the nitrate.

As part of the characterization of the water extracts, other chemical species, such as aluminum, silicon, iron, manganese, zinc, and trace constituents, such as arsenic, boron, barium, beryllium, bismuth, cadmium, cobalt, chromium, copper, lithium, molybdenum, nickel, lead, selenium, thallium, vanadium, titanium, and zirconium, were measured, but considering that their concentrations were generally low to non-detectable, the data are not presented in this ERC ground-truthing document.

The sediment from borehole C4191 contains some man-made gamma radioactivity in some of the shallow grab samples. Essentially, the only significant gamma activity observed is cesium-137 in the first few samples from 13 and $27.5 \mathrm{ft}$ bgs. The samples at 13 to $14 \mathrm{ft}$ bgs contain from $5 \times 10^{+5}$ to $1 \times 10^{+6}$ pCi/g cesium-137 and sediments deeper down to $27.5 \mathrm{ft}$ bgs contain about $10 \mathrm{pCi} / \mathrm{g}$ or less. In addition, a few pCi/g of shorter-lived antimony-125 and europium-155 were detected in isolated samples. Sub pCi/g activities of cobalt-60 were also detected in a few samples with no consistent depth profile. The only potential radiological COCs that were measurable in the water extracts were technetium-99 and uranium. The technetium-99 data show elevated technetium-99 water-extract concentrations occurring from 37.5 to $158.5 \mathrm{ft}$ bgs. The deepest penetration of significant technetium-99 occurs at the same place as the significantly elevated nitrate. These two mobile contaminants are often found to travel and distribute in the vadose zone in a similar pattern. Elevated water-extractable concentrations of uranium are found shallow in the vadose zone from 13 to $51 \mathrm{ft}$ bgs. This suggests that uranium is less mobile than the technetium-99 and nitrate.

The zone of elevated $\mathrm{pH}$ (17 to $37.5 \mathrm{ft}$ bgs) coincides fairly well with the zone where many of the major elements that make up sediments show elevated acid-extractable concentrations. This suggests that the sediments interact with the caustic waste fluids through dissolution and precipitation/neutralization reactions that likely form more leachable amorphous solid phases and metal hydroxides/oxides in contrast with more stable alumino-silicate and crystalline metal oxides. The high acid-extractable sodium zone from 13 to $131 \mathrm{ft}$ bgs reflects the massive amount of sodium in the waste solution that interacts with the native sediments through cation exchange and other sediment dissolution/precipitation reactions.

\subsubsection{Groundwater Analyses}

One groundwater sample was taken at the bottom of borehole C5923 (A) and C4191 at the end of the sediment sampling activities. Limited groundwater analyses of the C5923 (A) were performed by the WSCF laboratory so that the total common cations and anions were not determined. Nitrate and technetium-99 were measured, $9.3 \mathrm{mg} / \mathrm{L}$ and $<6 \mathrm{pCi} / \mathrm{L}$ (see Table 5.14 for all available data). The nitrate value is very slightly elevated compared to nitrate background concentrations $(5.7 \mathrm{mg} / \mathrm{L})$ found in uncontaminated groundwater on the Hanford Reservation (see DOE 1997). More recently, the Site-wide Groundwater Monitoring Program has been using two wells (Well 699-49-100C is located at the Yakima barricade, and Well 699-19-88 is located in the Dry Creek Valley, southwest of Highway 240) as uncontaminated groundwaters in Program QA/QC activities. The two wells are sampled quarterly and used as "standards" to monitor the analytical laboratories performance as described in more detail in Horton (2007). In fiscal year 2005, the average nitrate concentration in Well 699-49-100C averaged $12.0 \mathrm{mg} / \mathrm{L}$ and in Well 699-19-88 averaged $1.75 \mathrm{mg} / \mathrm{L}$. Horton suggested that Well 699-49-100C was showing elevated nitrate from upgradient agricultural activities. Based on historical groundwater 
monitoring records and the highly elevated deep vadose zone nitrate concentrations, we hypothesize that there remains low concentrations of nitrate and other mobile contaminants from the mid 1950s disposal of scavenged bismuth phosphate waste in the groundwater below the BC cribs. The concentration of nitrate is significantly below the drinking water standard of $45 \mathrm{mg} / \mathrm{L}$. There was no detectable technetium-99 in the groundwater at the bottom of borehole C5923 (A) as would be expected for uncontaminated and very faintly contaminated groundwater.

The groundwater sample taken at the bottom of borehole C4191 was characterized in detail as shown in Table 8.15. The nitrate concentration was low $0.22 \mathrm{mg} / \mathrm{L}$ and the technetium-99 activity was less than its detection limit $(<4.7 \mathrm{pCi} / \mathrm{L})$. The groundwater composition was dominated by calcium bicarbonate similar to the two background wells used by the Site-wide Groundwater Monitoring Program (see Horton 2007 for more discussion). Based on these groundwater results, the vadose zone sediment distribution of nitrate and technetium-99 (deepest descent found more that $100 \mathrm{ft}$ above the water table) and the historical records reviewed in Appendix C, we hypothesize that groundwater below most of the BC trenches is not contaminated with residual scavenged bismuth phosphate wastes today nor was the groundwater below the $\mathrm{BC}$ trenches contaminated significantly in the past during and within a decade after the active disposal in the mid 1950s.

\subsection{Summary of Field Geophysical Acquisition at the BC Cribs and Trenches}

The comparison of the three processing methodologies of field resistivity data with the measured pore-water compositions at the individual boreholes showed mixed results. In general, the high concentrations of anions and cations in the pore waters produced a low electrical resistivity, and variability could be seen in the resistivity data that could relate to the variability in concentrations. Porewater samples with low ionic-strength levels $(<0.3 \mathrm{M})$ show extremely poor correlation with the field electrical-resistivity information, suggesting that the observed low-resistivity zones are primarily related to the salt-laden plumes as opposed to the other parameters that can influence soil resisitivty (e.g., moisture content, particle surface charge, porosity). The best example was the C4191, where the HRR field data were optimized to the sediment pore-water geochemical profile. The greatest issue controlling the correlation between the field soil electrical resistivity and laboratory pore-water data sets, however, is the differing sampling rates or resolution of the borehole vadose zone sediment measurements and field surface-based resistivity measurements. In all boreholes except C5925 (C), the field geophysical measurements were not capable of producing a high correlation coefficient with the more detailed and smaller scale pore-water measurements. The resolution of the surface geophysics is less than the scale at which the geochemical sampling was conducted. The large variation in pore-water composition in the thin, fine-grained sediments in comparison to the composition of the bulk sand sediments is impossible for the geophysics to replicate, and the field geophysical measurements act as a low-pass filter. That is, high-frequency components (observed large variations in pore-water composition over a few feet) are not observed in the raw apparent-resistivity measurements. Then during inversion, the same smooth apparent-resistivity data used as input to the inversion model produce a smooth estimate of the true soil resistivity. The inversion cannot recreate the high-frequency components that were removed during the original measurements; it is a problem of aliasing.

The field-based geophysical data also seemed to suffer from a sort of myopia, where looking strictly down from the surface, the target (e.g., maximum pore-water salt concentration) depth was difficult to 
resolve. This was certainly the case in comparing the field HRR survey data and its various inversions with the vertical distribution of major pore-water constituents in Borehole C5923 (A). Improvements in the comparisons of field ERC surveys with the actual sediment pore-water distribution were obtained by shifting the geophysical response either downwards for the 2D inversion or upwards for the 3D inversion to gain a better correlation. The shift was on the order of the thickness ( 3 to $5 \mathrm{~m}$ ) for an individual layer used in the finite-difference numerical model used to represent the "earth" model in the inversion process. The apparent depth shift in the surface-based geophysics could have been the consequence of the smoothing constraints and stabilization function, which are implemented in all commercial inversion codes that are based on Tikhonov regularization theory (Tikhonov and Arsenin 1977). To combat this problem, several mathematicians have been studying methods to sharpen images and form more realistic geologic interpretations of geophysical data (e.g., Portniaguine and Zhdanov 1999; Blaschek et al. 2008). It will be some time, however, before these new methods make it to mainstream commercial use.

Up to this point, the surface-based resistivity data have been compared on individual borehole bases to examine depth resolution. Lateral resolution of the geophysical data is best conducted by comparing an aggregate set of geophysical data on all boreholes together. The following sections describe the correlations of pore-water geochemistry and geophysics with both arithmetic and logarithmic scaled data to assess the horizontal resolution of the waste salt plumes.

\subsubsection{HRR}

Figure 9.1 through Figure 9.4 show the scatter and regression of geochemical data and HRR apparentresistivity data. Individual boreholes are identified by different symbols in the plots. The data show that as the pore water increases with electrolytic content, the resistivity decreases. This observation fits with the physical laws governing HRR response to soil pore-water salinity and demonstrates the lateral resolution of the geophysical method. The scatter plots and regression analyses also show that generally the logarithm of the geochemical measurements produces the best correlation. The pore-water technetium-99 correlation is shown to be the highest for the four constituents used in the regression because Borehole C5925 (C) sediments were not used in the regression as they did not contain detectable technetium-99. Using data from Borehole C5925 (C) appears to decrease the other correlations between apparent resisitivity and pore-water constituents as evidenced by the four high apparentresistivity readings that are far outside the normal regression fit in each of the first three figures. Eliminating Borehole C5925 (C) data from the nitrate regression, for example, increases the correlation coefficient for the rest of logarithmically scaled pore-water EC data from 0.404 to 0.432 . 
PNNL-17821
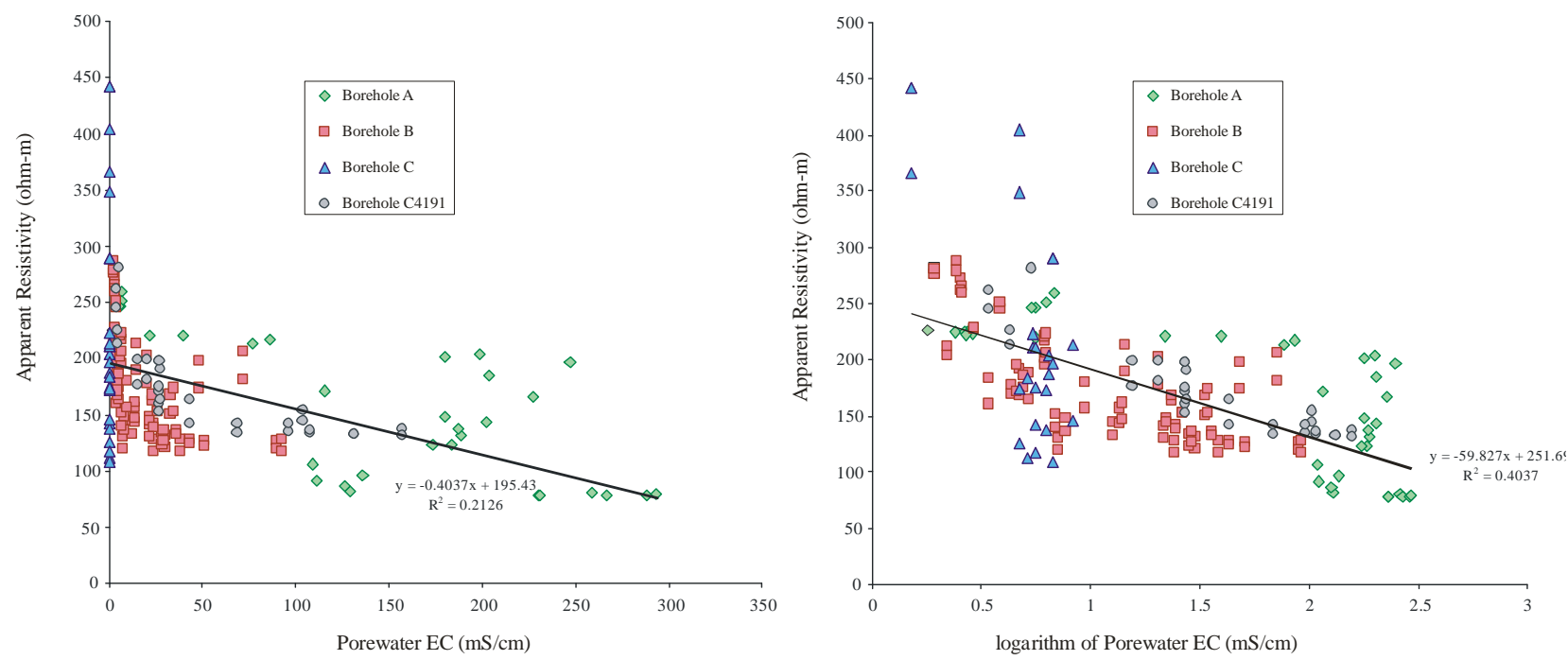

Figure 9.1. Scatter Plot of Pore-Water EC and HRR Apparent Resistivity for All Boreholes
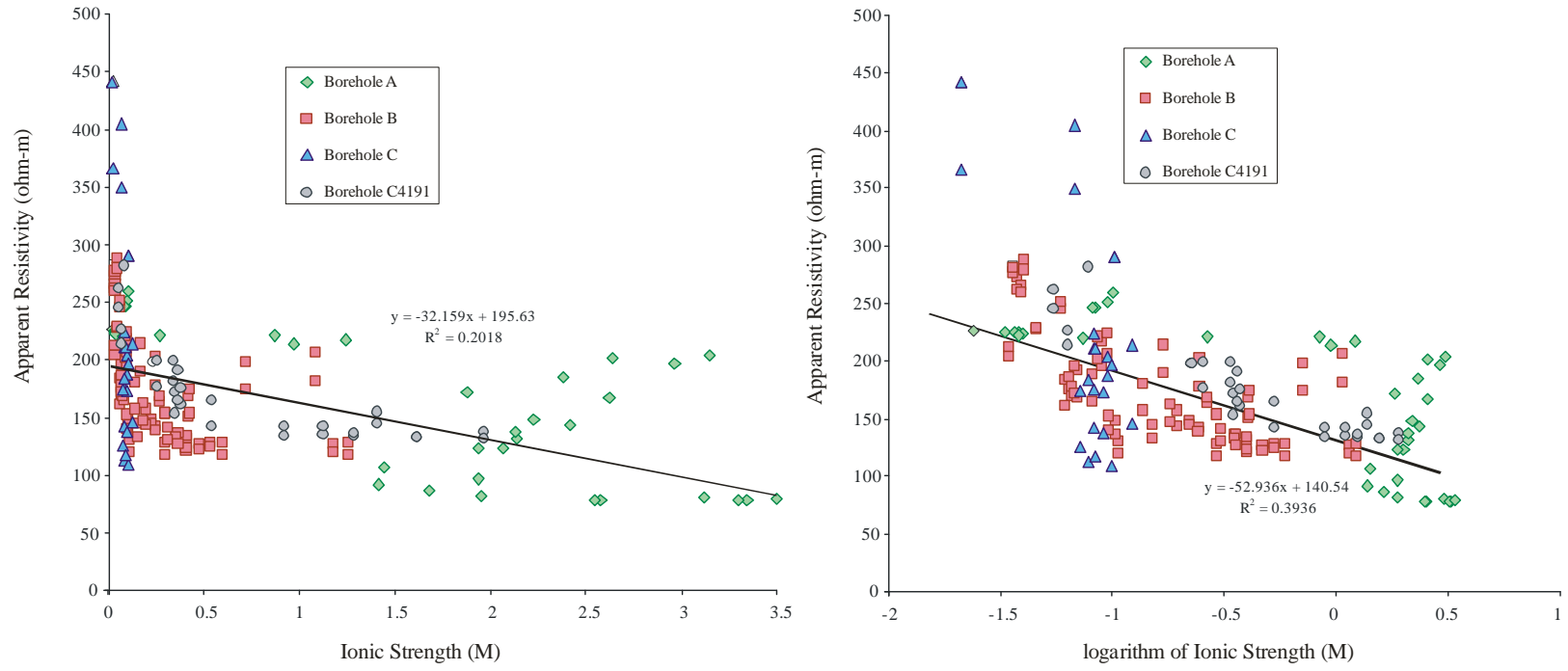

Figure 9.2. Scatter Plot of Ionic Strength and HRR Apparent Resistivity for All Boreholes 
PNNL-17821
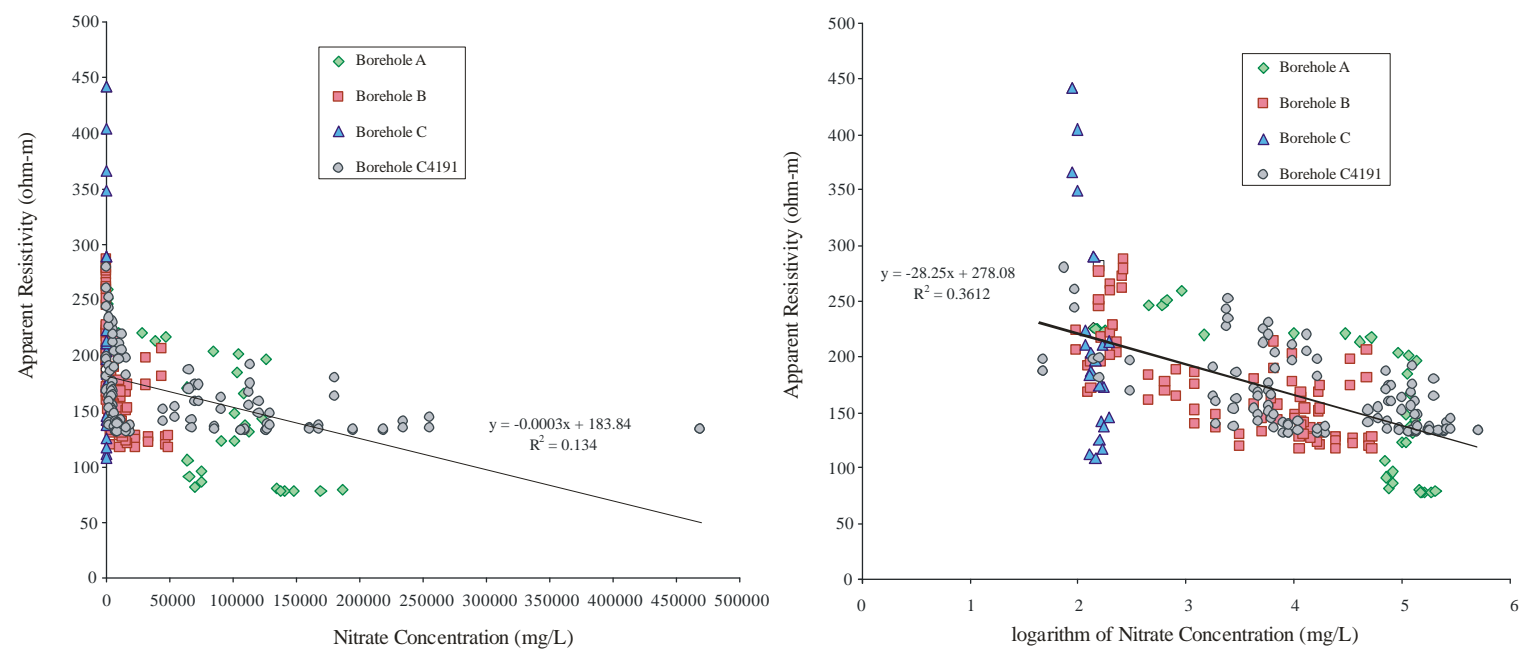

Figure 9.3. Scatter Plot of Nitrate Concentration and HRR Apparent Resistivity for All Boreholes
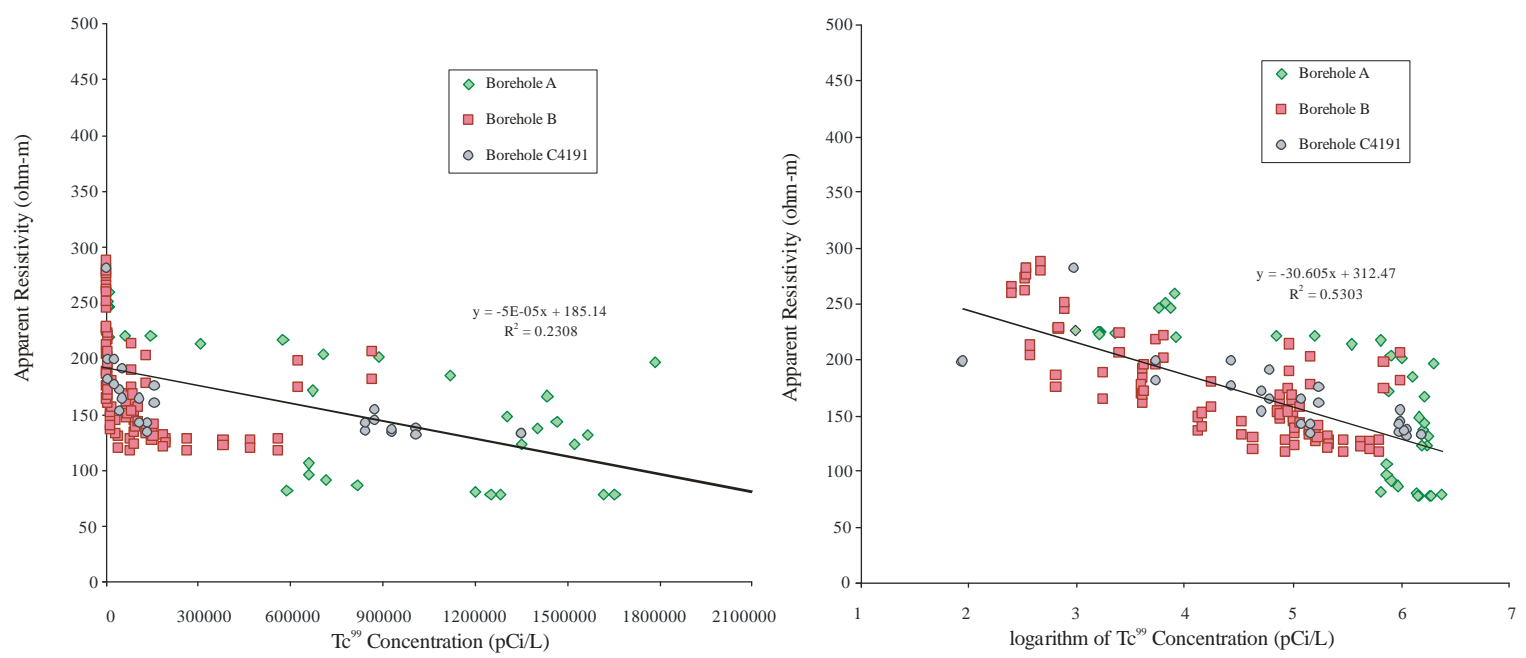

Figure 9.4. Scatter Plot of Technetium-99 Concentration and HRR Apparent Resistivity for All Boreholes

\subsubsection{D Inversion}

Figure 9.5 through Figure 9.8 show the scatter plots and regression of pore-water geochemical data and 2D inverted soil resistivity data. The geophysical data were compiled from original model outputs, and no vertical shifting was implemented (as discussed with Borehole C5923 (A) in Section 5.2.2). Regressions were conducted with a linear function as well as a power function for arithmetic and logarithmic pore-water composition data. The power function was chosen based on the shape of the scatter plot. In all, the regression plots the dotted line, which represents the best-fit curve to the power function, and the solid line represents the best fit to the linear function. Ionic strength (in Molarity) does not show a power fit for the logarithmic data because the logarithmically scaled ionic strength data dip below zero. 
The comparisons show that as the pore water increases slightly in electrolyte content, the 2D soil resistivity data fall precipitously, and the linear regression does not fully capture this dynamic. The regression with the power function greatly improves the correlation between pore-water geochemical and geophysical data. The logarithmic transformation of the pore-water geochemical parameters improves the correlation for the linear regression between each pore-water parameter and the 2D inverted resistivity function but only marginally improves the correlation for the power-function relationships between the pore-water parameter and the 2D inverted resistivity. The latter observation of marginal improvement with the logarithm of pore-water constituents is likely because the power function model itself is similar to logarithmic scaling of the pore-water constituents.

In each of the scatter plots, Borehole C5923 (A) stands out as a large variance from the overall fit. In particular, the poor fit in the data is from the increased contamination observed at the 60 to $80 \mathrm{~m}$ depth that was not replicated in the inversion results. Removal of this data from the EC scatter, for example, would increase the correlation coefficient from 0.355 to 0.451 in the power fit of the logarithmic transformed plot.
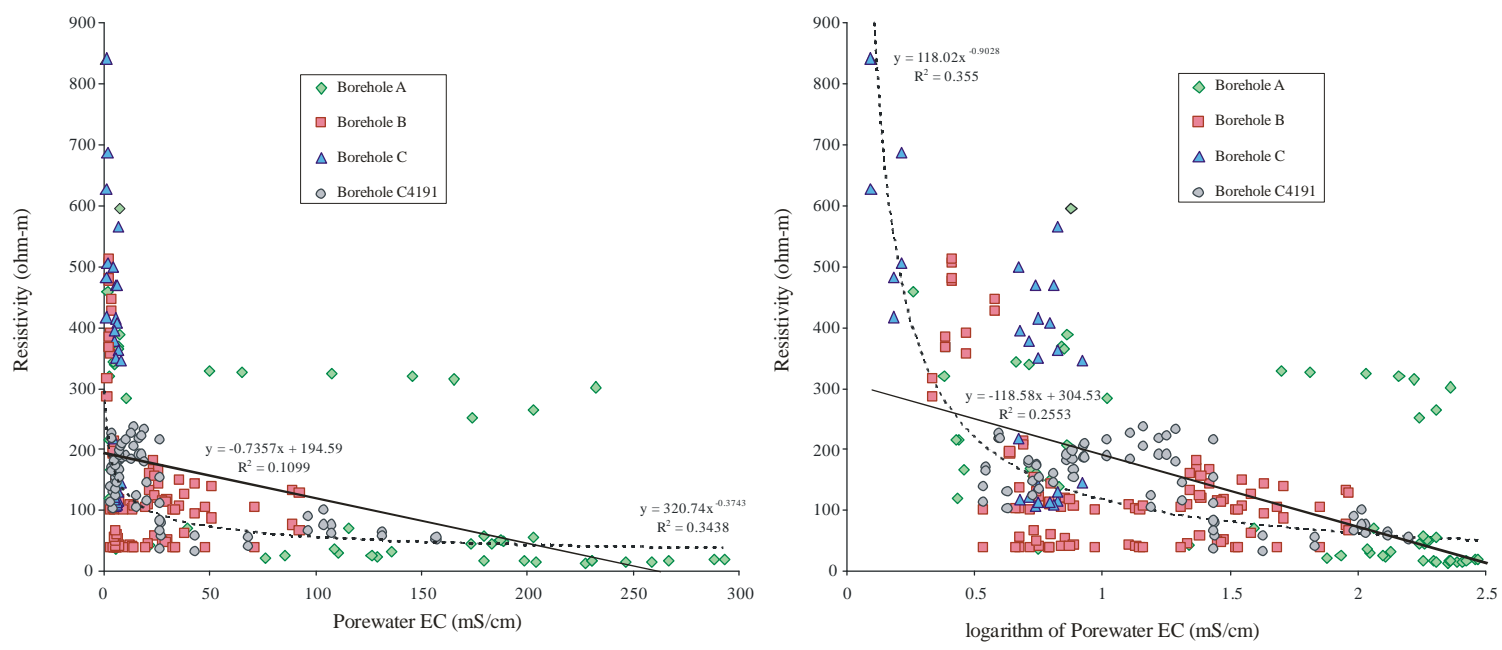

Figure 9.5. Scatter Plot of Pore-Water EC and 2D Inverted Resistivity for All Boreholes 
PNNL-17821
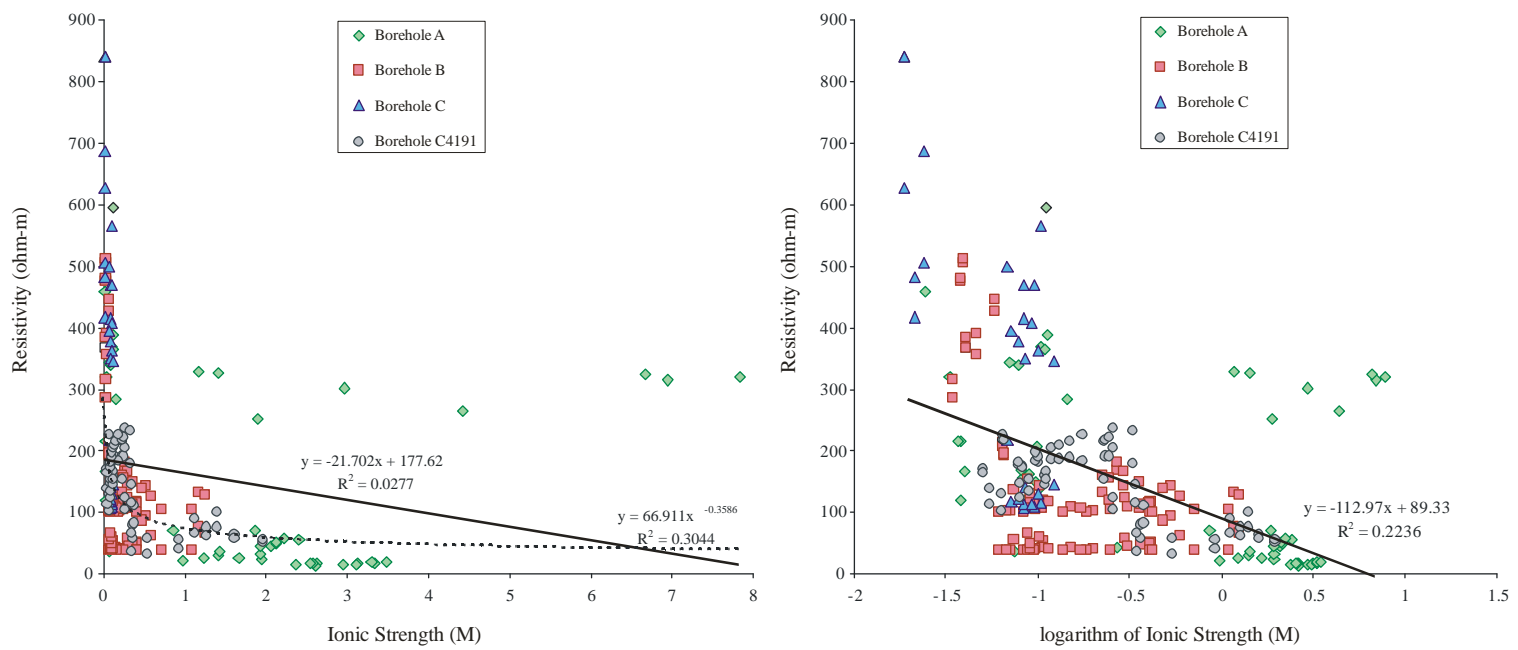

Figure 9.6. Scatter Plot of Ionic Strength and 2D Inverted Resistivity for All Boreholes
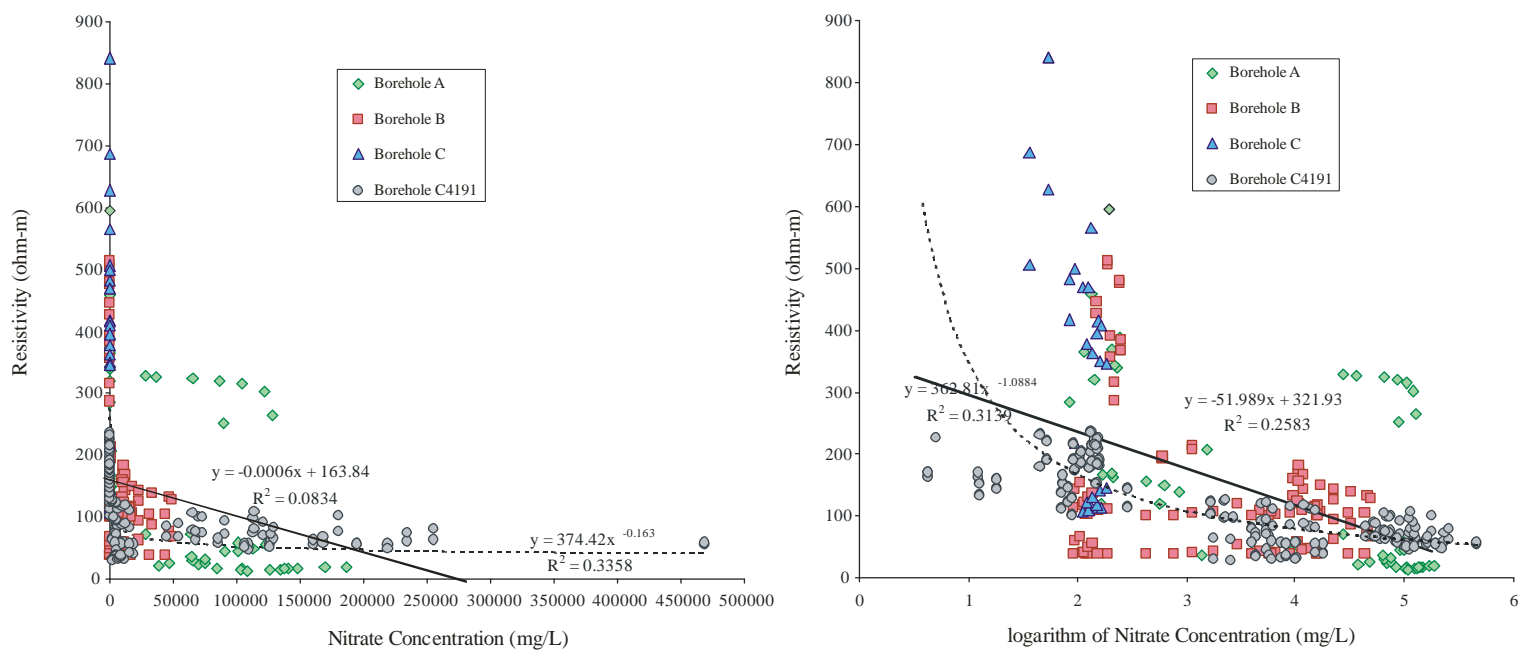

Figure 9.7. Scatter Plot of Nitrate Concentration and 2D Inverted Resistivity for All Boreholes 
PNNL-17821
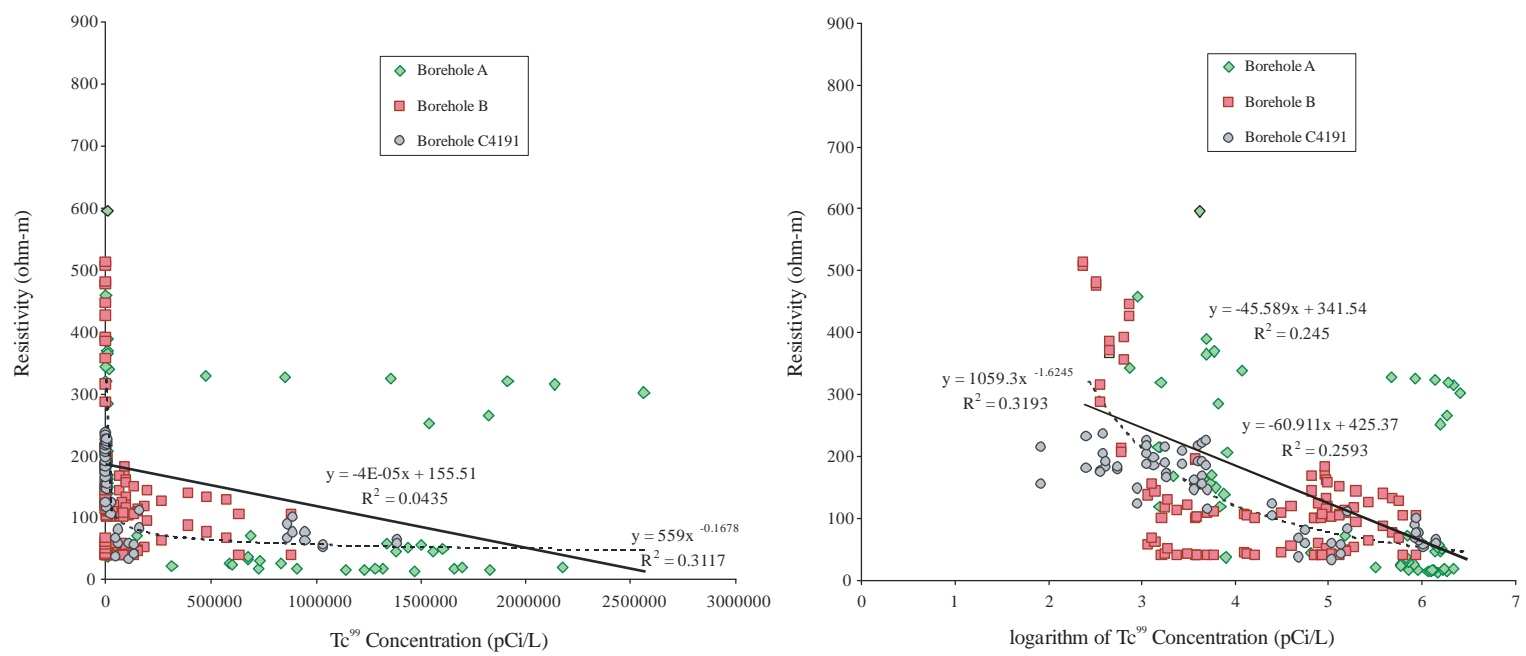

Figure 9.8. Scatter Plot of Technetium-99 Concentration and 2D Inverted Resistivity for All Boreholes

\subsubsection{D Inversion}

Figure 9.9 through Figure 9.12 show the scatter plots and the regression of pore-water geochemical data and 3D inverted-resistivity data. In all, the regression plots the dotted line, which represents the bestfit curve to the power function, and the solid line represents the best fit to the linear function. The geophysical data were compiled from original model outputs, and no vertical shifting was implemented (as discussed with Borehole C5923 [A] in Section 5.2.3). The correlation coefficients generally are lower than those shown for the 2D inversion. This is likely because the model resolution of the 3D inversion is lower than the 2D inversion. The cell size within the 3D inversion model is limited by computer memory and was typically on the order of $6 \mathrm{~m}$ per side. The cell sizes in the 2D inversion models were half the size of the 3D inversion models (i.e., $3 \mathrm{~m}$ per side).
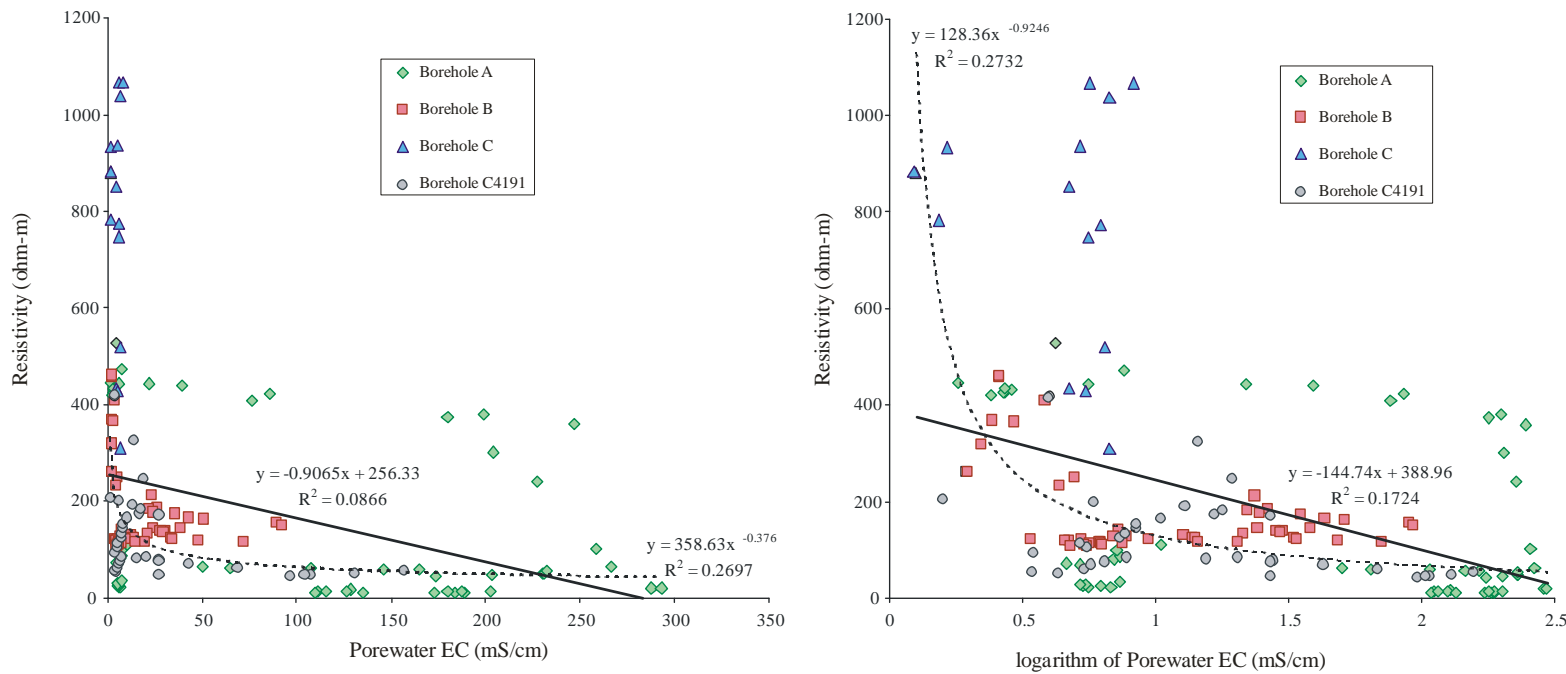

Figure 9.9. Scatter Plot of Pore-Water EC and 3D Inverted Resistivity for All Boreholes 
PNNL-17821
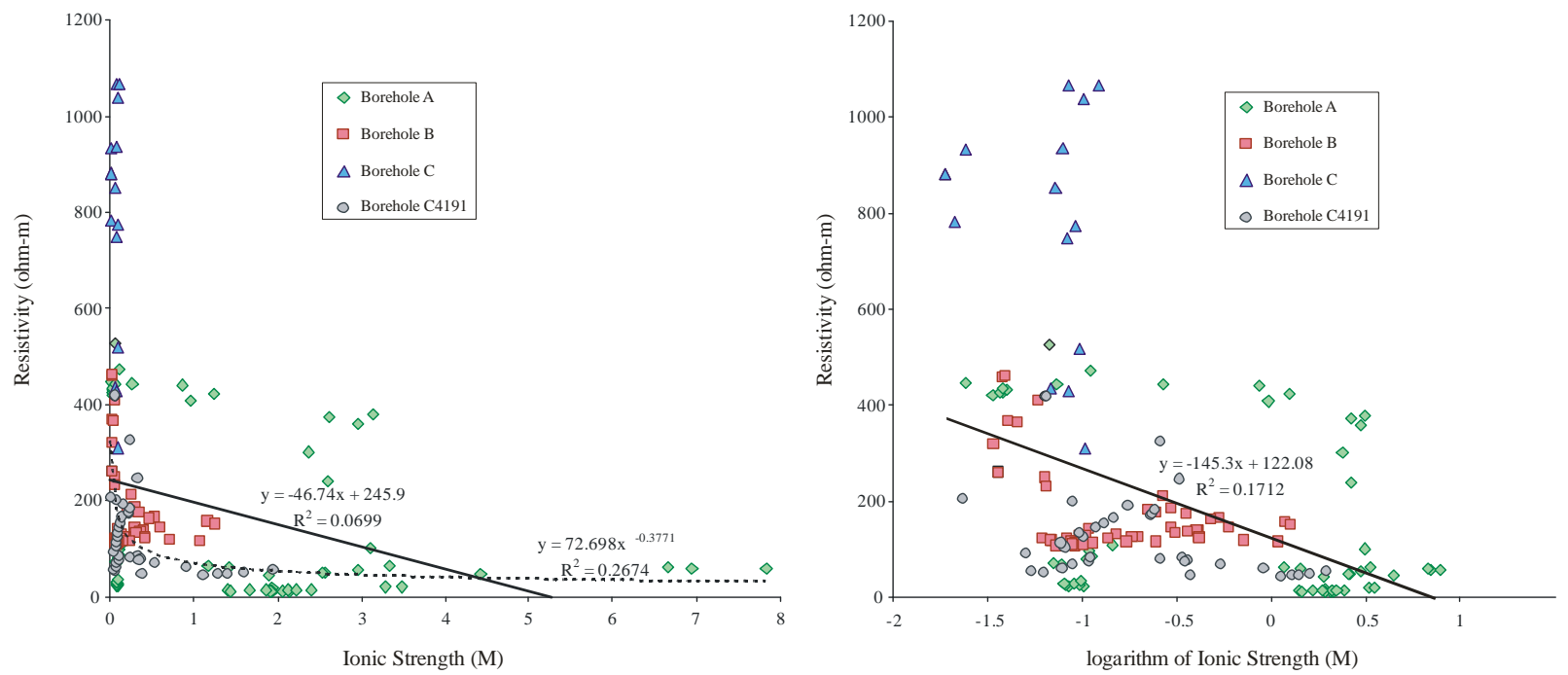

Figure 9.10. Scatter Plot of Pore-Water Ionic Strength and 3D Inverted Resistivity for All Boreholes
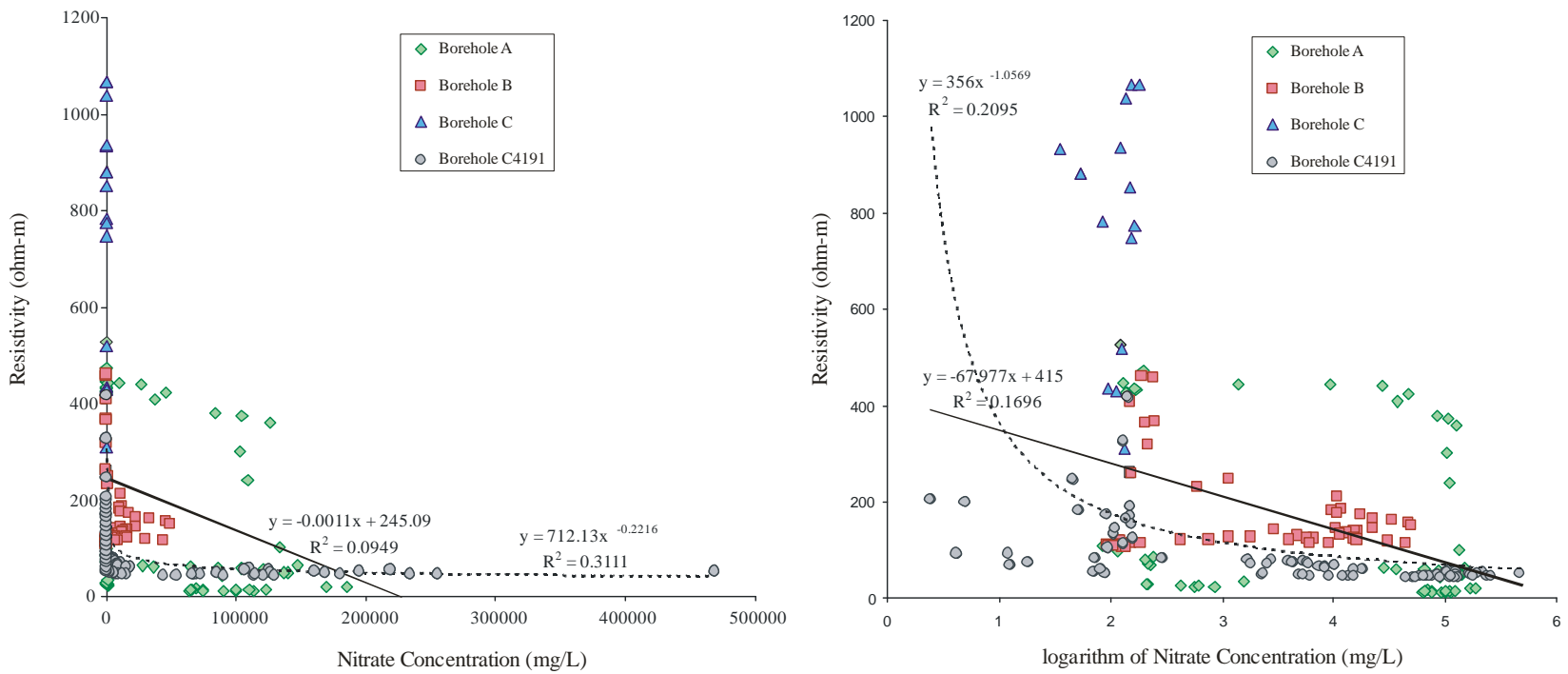

Figure 9.11. Scatter Plot of Pore-Water Nitrate Concentration and 3D Inverted Resistivity for All Boreholes 
PNNL-17821
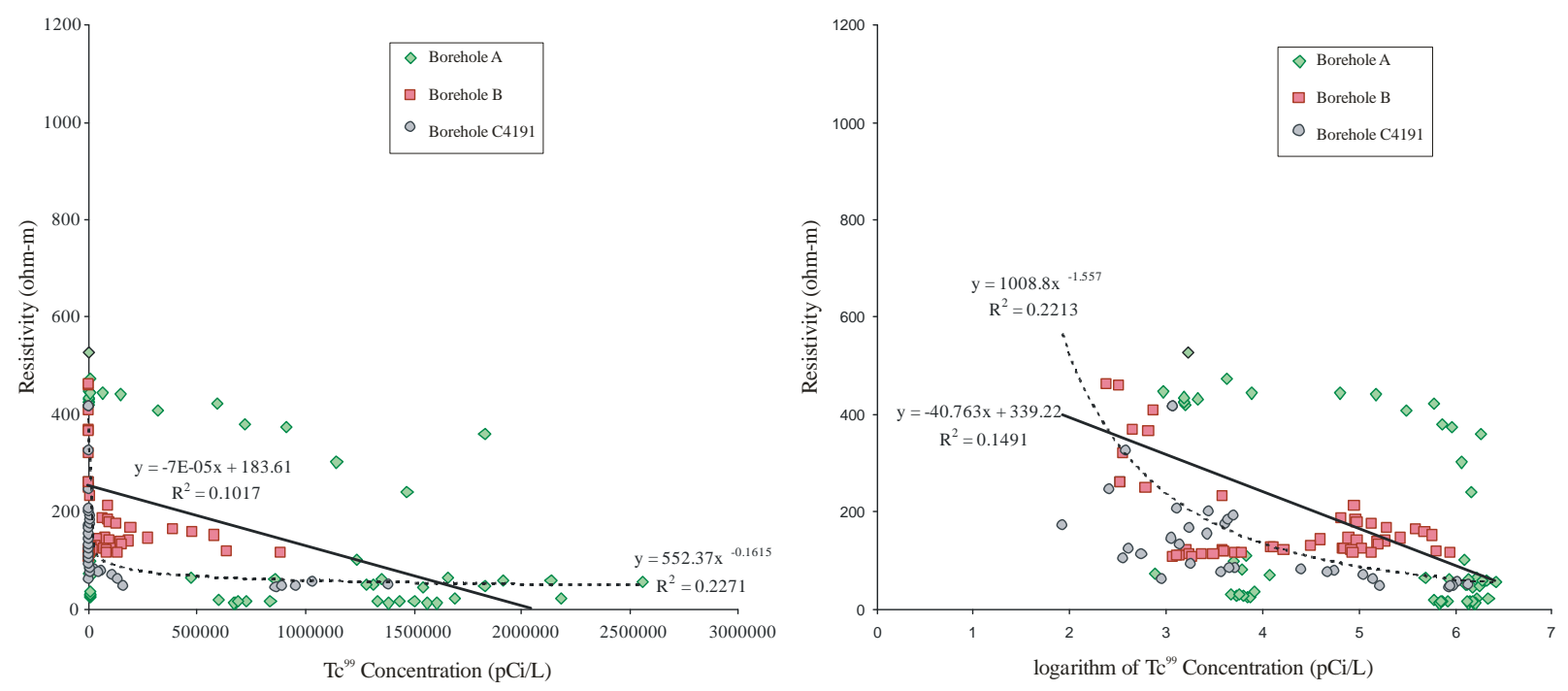

Figure 9.12. Scatter Plot of Pore-Water Technetium-99 Concentration and 3D Inverted Resistivity for All Boreholes

\subsubsection{Estimated Lateral Extent}

To estimate the lateral extent of contamination from historical disposal in the BC Cribs and Trenches area, the resistivity data were converted to ionic strength using the least squares regression formula shown in the left hand portion of Figure 9.10. The inversion results from the 3D resistivity were chosen for this exercise based on its reasonable reconciliation of the resistivity in the northeast corner between the cribs and trenches (near borehole $\mathrm{C}$ ). In addition, the exponential function from the arithmetically scaled ionic strength data in Figure 9.10 (left hand plot) was chosen because it produced the highest correlation between the co-located field resistivity (geophysical) and laboratory pore-water (geochemical) data. The right-hand portion of Figure 9.10 shows a logarithmically scaled ionic strength correlation with 3D inverted resistivity but was not used in this lateral extent analysis because the correlation was worse.

Figure 9.13 shows the distribution of ionic strength calculated from the 3D inverted field resistivity. The 3D inversion results were composed of four individual models that encompass overlapping domains. Figure 9.13 was created by stacking the results of the four models. The figure shows the solid body renderings of calculated ionic strength constant isopleths of $0.3 \mathrm{M}$ and $1.0 \mathrm{M}$ in plan view (i.e., from directly overhead). From the scatterplots of co-located data, it appears that the soil resistivity in the field becomes insensitive to ionic strengths less than $0.3 \mathrm{M}$, thus providing a lower end of measurement sensitivity for this particular survey.

A more accurate interpretation could be conducted if all field-derived resistivity data were inverted together in one model; but currently available computing hardware and software preclude timely analysis. The $0.3 \mathrm{M}$ isopleth covers the area of the footprints of the individual liquid disposal trenches as well as the area between each of the trenches, suggesting that liquids from each trench mixed in the sediments below each trench and coalesced into one larger plume in each north-south row of trenches. In the middle of the trenches near the location of borehole B (C5924), the $0.3 \mathrm{M}$ isopleth is continuous between the two westernmost rows of trenches. The total volume of waste and total mass of salt disposed of into each of the five cribs closest to this region with continuous salt plume (216-B-33, 216-B-34, 216-B-52, 216-B23, 
and 216-B-24) averages over 5 million liters and 1.5 million $\mathrm{kg}$ of nitrate (see the DQO document [Benecke (2008)] appendices for the volume and mass of nitrate data).

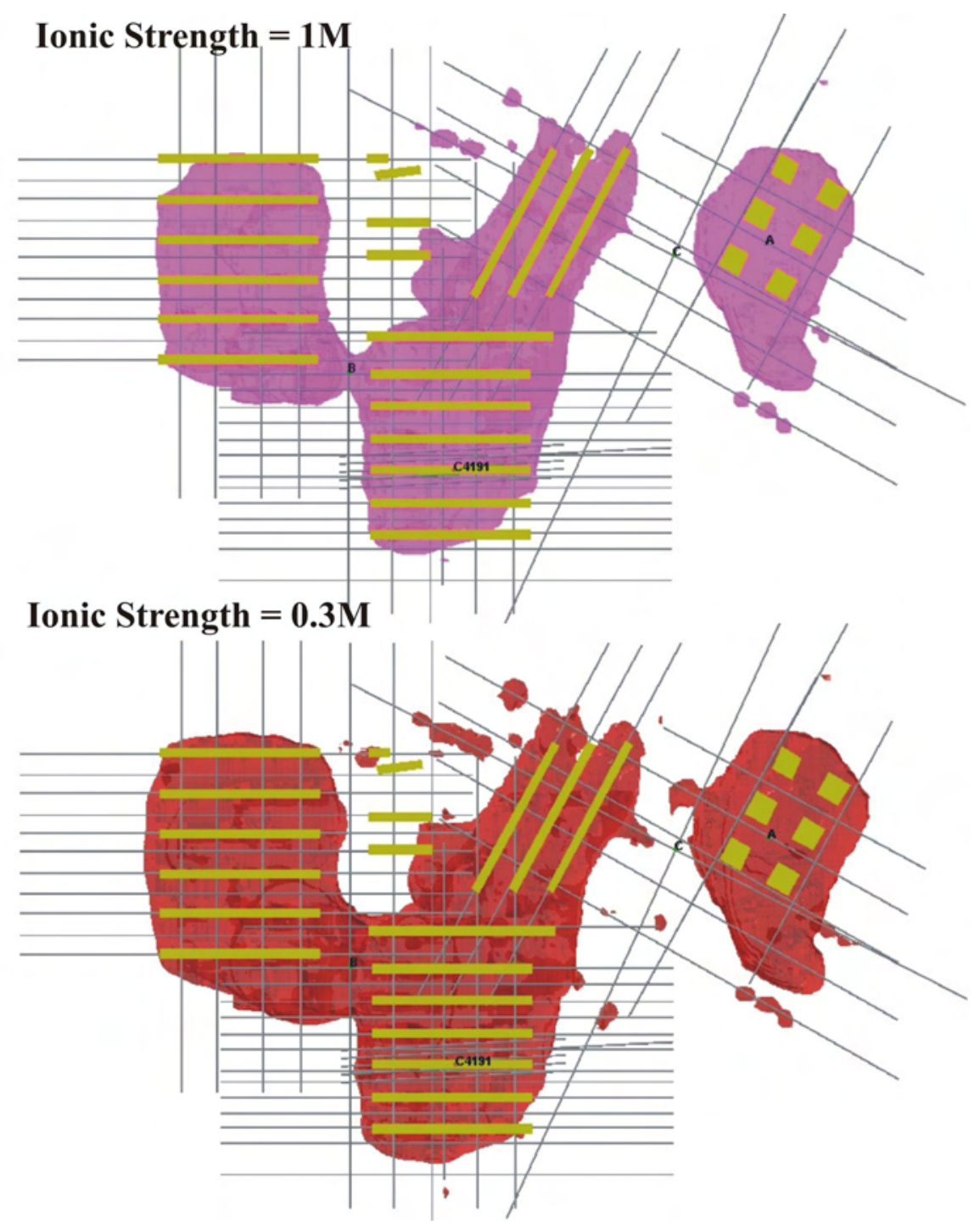

Figure 9.13. Conversion of 3D Resistivity to Ionic Strength, Presented for $0.3 \mathrm{M}$ and $1 \mathrm{M}$

The other trench region with lateral continuity of the salt plume is between the northern diagonal trenches (216-B-22, 216-B-21, 216-B-20) and 216-B-52. The total volume of wastewater disposed of to each of these four trenches averages close to 6 million liters, and the nitrate mass released averages over 1 million kg. Based on the field resistivity surveys, the region below the four smaller trenches in the northern middle region of the trenches (216-B-53A, 216-B-53B, 216-B-54, and 216-B-58) does not show any evidence of a continuous subsurface salt plume. This is likely related to differences in waste inventory received by this group of trenches. The volumes of liquid waste and the total mass of nitrate disposed of in each of these four trenches are much lower than for the rest of the disposal facilities in the BC Cribs and Trenches area. The total volume of liquid disposed to these four trenches ranges from 20,000 to one million liters, and the mass of nitrate ranges from 700 to $1500 \mathrm{~kg}$. The other trenches 
received almost 5 million liters of wastewater and over 1 million $\mathrm{kg}$ of nitrate. The total area that encompasses the $0.3 \mathrm{M}$ isopleths in the region of the $\mathrm{BC}$ trenches is 11.3 hectares.

In the northeast corner of the BC Cribs and Trenches area, where the six cribs are located, the subsurface salt plume is continuous and much larger than the footprint of the individual cribs. Both the moderate ionic strength $(0.3 \mathrm{M})$ and high ionic strength $(1 \mathrm{M})$ isopleths extend approximately 90 m south of crib B-18 (southeastern corner of crib complex). Both isopleths show a southeasterly divergence outside the boundary of the crib complex that is consistent with observations of subsurface plume migration at the nearby Sisson and Lu Site (see the following reports for details on the Sisson and Lu Site: Gee and Ward 2001, Sisson and Lu 1984, 2002, 2000, 2001, 2003; Ward et al. 2006b). This trend has been attributed to a southerly dip in the vadose zone lithology at both locations. The total area that encompasses the $0.3 \mathrm{M}$ isopleths in the $\mathrm{BC}$ cribs region is 2.7 hectares.

The lateral extent of the salt plumes analysis shown in Figure 9.13 predicts that at the location of borehole C (C5925), there is no contamination with salt at or above $0.3 \mathrm{M}$. This is corroborated by the actual sediment analyses (see section 8) that show pore-water ionic strengths throughout the depth profile (20 to $203 \mathrm{ft}$ bgs) ranging from 0.02 to $0.12 \mathrm{M}$. We conclude that the surface-based ERC survey at the BC Cribs and Trenches area provides a good estimate of lateral extent of sub-surface contamination where the calculated pore-water ionic strength is near to or above $0.3 \mathrm{M}$.

The isopleth for 1-M calculated ionic strength is only slightly smaller in area than the area for the 0.3 $\mathrm{M}$ isopleth, indicating that a large spatial gradient exists between the two isopleths; that is, the high ionic strength plume appears to rapidly disperse away from the facility footprints. The gradient likely indicates a transition zone in resistivity, and only exists from the smoothing of resistivity during inversion. This is further evidence that the surface-based field resistivity survey is sensitive to pore-water chemistry, especially ionic strength near to or above $0.3 \mathrm{M}$ for the BC Cribs and Trenches area.

This effort to combine all the field survey data to estimate the overall lateral extent of the subsurface salt plumes also suggests that there may be a dip to the south in the vadose zone stratigraphy based on the plan view shape of the two calculated ionic-strength isopleths. The geology description in Section 2 did not have sufficient data (borehole coverage) in the north-south direction to speculate on vadose zone stratigraphic dip. However, as mentioned, liquids injected at the Sisson and Lu site, which is 1550 m north of the BC Cribs and Trenches area, also showed plume migration to the south.

\subsection{Summary of Laboratory Geophysical Results at Borehole A (C5923)}

Both laboratory and field-measured electrical properties of soils are sensitive to dissolved salt content, soil type, and water content. The comparison of resistivity measurements made on cores and grab samples from C5923 with those derived from field resistivity surveys is therefore essential to the verification process. In view of this, laboratory measurements were performed on 173 samples from Borehole C5923 (A) to characterize electrical properties as well as other hydrophysical properties that influence the distribution of ionic contaminants and ultimately the field-scale resistivity response. The samples included 39 cores collected via split-spoon sampling and 134 grab samples. 
Dry-sieve analysis coupled with laser diffraction measurements allowed the full PSD curve to be characterized. These analyses yielded soil textures ranging from sand to silt loam with effective diameters, $d_{e}$, ranging from $0.026 \mathrm{~mm}$ to $0.337 \mathrm{~mm}$ and geometric mean diameters, $d_{g}$, ranging from $0.170 \mathrm{~mm}$ to $0.921 \mathrm{~mm}$. The clay content ranged from less than $1 \%$ to $12 \%$; the silt content ranged from $2 \%$ to $11 \%$; whereas the sand content ranged from $38 \%$ to $94 \%$. Even though these samples were mostly from the sand-dominated upper Hanford formation that is typically assumed to be hydrologically and even electrically uniform, the wide variation in PSD suggests that treating these sediments as uniform could adversely affect the interpretation of current contaminant distributions and predictions of future migration. Grain-size distribution (texture) is a fundamental physical characteristic of soils, and its detailed study yields information about the physical mechanisms that occurred during transport, deposition, and digenesis, all of which affect the transport of mass (water, air, solutes) and energy (electricity, heat). These data will be invaluable in establishing correlations between laboratory and field measurements.

Resistivity measurements were made on all undisturbed cores and repacked grab samples using the MiniSting Resistivity/IP meter. Resistivity in sediments from C5923 ranged from 2.38 ohm-m to 13909 ohm-m. Overall, the repeatability of measurements was quite good with the standard deviation $(\sigma)$ of five replicate measurements generally falling between 0 and $5 \%$ and with good reciprocity. The separation of resistivity measurements by sample type (core vs. repacked grab sample) shows that the core samples typically had a lower resistivity than adjacent grab samples. This is due to a combination of lower water contents in the unsealed grab samples and difficulty in achieving the same packing arrangement as the undisturbed sediments. Nevertheless, the resulting measurements allowed the construction of a resistivity profile for Borehole C5923 (A) for comparison with the sounding curves derived from the field surveys. It should be mentioned that the performance (capability to precisely measure voltage) of the laboratoryscale MiniSting Resistivity meter and the field-scale SuperSting 8 Resistivity system is equivalent. Thus, any differences in measurements between the two systems are "scale" issues. The resulting laboratorymeasured resistivity profile shows essentially two scales of vertical variability, one that can be attributed to fine-scale heterogeneity, which was overlaid on the other one, large-scale lithologic differences. On the one hand, differences in scale can be expected, but approaches for resolving such discrepancies are relatively undeveloped in the science of near-surface geophysics. On the other hand, significant progress has been made in developing methodologies for up- and down-scaling of hydraulic properties and flow variables. Some of these techniques may find application in analysis and interpretation of resistivity data that vary across spatial scales.

Comparison of the laboratory-measured soil resistivity profile with the pore-water concentrations of nitrate and technetium-99 show good agreement; resistivity decreases as nitrate and technetium-99 concentration increased and vice versa. However, the resistivity data showed significantly more smallscale fluctuations than the pore-water concentrations. This apparent discrepancy is due to a difference in the way the measurements were made or perhaps reported. Resistivity is a bulk soil measurement that integrates the contribution of the solid and liquid phases and is therefore influenced by bulk density and porosity. Nitrate and technetium-99 are reported as a concentration in the pore water, which ignores the solid phase and other hydrophysical properties. However because of the very high dissolved salt contents in borehole C5923 (A) pore water, the electrical conductivity response is assumed to be dominated by the dissolved salt. A comparison between bulk resistivity and solute concentration expressed in terms of the solid phase (e.g., mg $\mathrm{NO}_{3}$ /gm soil) did not eliminate the discrepancy, partly because not all the sediment samples that were measured for soil resistivity were extracted with deionized water to generate the same 
amount of nitrate data. The other reason for the significantly more small-scale fluctuations in the soil resistivity data than the water-extract nitrate data must reflect heterogeneities associated with the sediment particles themselves that contribute to the bulk resistivity.

Comparing the laboratory-measured soil resistivity profile with that derived from the field profile was less favorable. The most striking difference between the two was the absence of small-scale detail in the sounding curves derived from the field surveys (i.e., HRR, 2D, and 3D inversion). The very nature of the laboratory measurements verifies that these data will register the impact of local-scale changes in lithology, water content, pore-water composition, and other factors that influence resistivity at the scale of the subsurface sediments' heterogeneities. This gives rise to a data set that is inherently different from the field surveys in terms of accuracy and spatial detail. Unlike the laboratory-measured profile, the field resistivity sounding curve is derived by averaging, which results in a substantial loss of information with depth. As expected, vertical resistivity profiles derived from the field resistivity surveys identified a nearsurface low-resistivity feature at borehole C5923 corresponding to the nitrate peak between 50 and $100 \mathrm{ft}$ bgs. However, none of the interpretational methods were able to identify the deeper peak between 200 and $250 \mathrm{ft}$ bgs. This is partly due to observational and partly due to interpretational limitations compounded by the electrical equivalence of middle layers. A number of studies have shown that resolving the resistivity, $\rho_{\mathrm{i}}$, of the $\mathrm{i}^{\text {th }}$ layer in either a bowl-shaped anomaly, such as present at between 25 and $150 \mathrm{ft}$ bgs at C5923, in which $\rho_{\mathrm{i}-1}>\rho_{\mathrm{i}}<\rho_{\mathrm{i}+1}$, or an ascending anomaly $\left(\rho_{\mathrm{i}-1}<\rho_{\mathrm{I}}<\rho_{\mathrm{i}+1}\right)$, such as present between 150 and $200 \mathrm{ft}$ bgs or between 250 and $340 \mathrm{ft}$ bgs, is nearly impossible using a surfacebased field survey. This was confirmed by using the laboratory-measured resistivities, with all the finescale variability, to generate a starting model for a numerical simulation of a sounding curve. Results show that thin layers with low resistivity occurring deep in the profile (e.g., 200 to $250 \mathrm{ft}$ bgs) are suppressed in the vertical profiles based on the field resistivity surveys.

Such interpretational limitations suggest that a priori knowledge of the stratification in lithology or resistivity might minimize the problem of interpreting surface-based field resistivity measurements in heterogeneous formations. However, different lithologic units may have similar resistivities and cannot be distinguished from each other based on resistivity alone. Given that gamma-spectroscopy logs are routinely collected in all new boreholes at the Hanford site, the development of correlations between gamma-ray logs and lithologic attributes is highly desirable. The total gamma response is due to the presence of potassium-40, uranium-238, and thorium-232, all of which show strong dependence on lithology. Neutron and gamma logs from C5923 correlate well the vertical changes in lithology, suggesting some potential for constraining lithology. Information on the location of vertical boundaries and the ability to interpolate these boundaries between boreholes has proven invaluable for stabilizing the inverse problem while avoiding superfluous detail (e.g., Ellis and Oldenburg 1994; Smith et al. 1999; Smith et al. 1999; Olayinka and Yaramanci 2000). Such information forms the basis of the blockconstrained inversion approaches, which assume that the subsurface consists of distinct homogeneous regions separated by sharp interfaces rather than smoothly varying resistivity. Changing the assumptions underlying resistivity inversion could have a significant impact on the ability to adequately represent the true subsurface geology in terms of both the geometry and the formation resistivity.

The geophysical laboratory studies on C5923 grab and intact cores, described in Section 5.3, suggest that sediments below the BC Cribs and Trenches area show very weak relationships between CEC and SSA to laboratory-measured soil resistivity (Figure 5.46). This is not surprising because the bulk sediment resistivity in the BC Crib and Trench area is dominated by the pore fluids with very little 
contribution from individual grain-surface conductivity (i.e., the pore waters have up to several molar concentrations of dissolved salts, and the sediments are dominated by sand-sized grains with low CEC and low SSA). Therefore, for the BC Crib and Trenches specific site, the geophysical data obtained in the laboratory suggest that Archie's law, developed for clean sandstones and applicable when clay content is close to zero, may suffice for the BC Cribs and Trenches site. However, at other contaminated sites at Hanford, one does need to consider that measurements of CEC and SSA along with particle size and moisture content could be valuable at choosing a technically defensible model to invert field or laboratory soil resistivity data.

\subsection{Discussion of How Findings in this Report Relate to DQO Decision Statements}

In this section, we use data and analyses from this project to explicitly address the three DQO decision statements. See Benecke (2008) for the entire documentation of the DQO process, including more discussion on the intent of each decision statement.

\subsubsection{Decision STATEMENT 1}

Estimate the degree of correlation between electrical-resistivity data and the distribution (i.e., concentration and location) of the vadose zone-targeted parameters that are listed in Table 9.1 (Table 1-8 in the DQO; Benecke 2008).

As described in Section 5.3.2.3 and 9.3 in detail and mentioned briefly in other places, the signal measured by the field survey equipment is influenced by the total dissolved ions in the vadose zone sediment's pore water, the moisture content of the sediments, the residual electrical charge on the particles' surfaces, the packing density (porosity) of the sediments, and perhaps other variables. The residual electrical charge on the sediment's surfaces is a function of the grain size and shape of the particles, the mineralogy of the sediment particles, and the nature of the pore water within the sediment's pores. The porosity of the sediments is also a function of the PSD and the forces (loading, which is a function of depth) that influence particle arrangements or packing density. Therefore, it should be easy to comprehend that there are many variables that potentially can contribute to the electrical resistivity (or its reciprocal electrical conductivity) that is measured by the ERC field instrumentation. 
Table 9.1. Targeted Parameters for Electrical Resistivity Evaluation

\begin{tabular}{|c|c|c|c|}
\hline Risk-Based COPCs ${ }^{(a)}$ & Other COPCs ${ }^{(b)}$ & Anions and Cations & Geochemical and Physical Properties \\
\hline Nitrate (as nitrogen) ${ }^{(\mathrm{c}, \mathrm{d})}$ & Aluminum & Calcium & Moisture content \\
\hline Selenium $^{(\mathrm{e})}$ & Manganese & Chloride & Electrical resistivity of soil/sediment \\
\hline Uranium $^{(\mathrm{c}, \mathrm{d})}$ & Mercury & Fluoride $^{(b)}$ & $\begin{array}{l}\text { Specific electrical conductivity of pore } \\
\text { water }\end{array}$ \\
\hline Cesium-137 (c, d, e) & Nickel-63 & Magnesium & Ionic strength of pore water \\
\hline Cobalt- $60^{(\mathrm{e})}$ & Nitrite & Nitrite (as nitrogen) ${ }^{(b)}$ & Alkalinity (bicarbonate) of pore water \\
\hline Plutonium-239/240 & Radium-226 & Potassium & $\begin{array}{l}\text { Borehole neutron and natural gamma } \\
\text { logs }\end{array}$ \\
\hline Strontium-90 (c, d, e) & -- & Phosphate & -- \\
\hline Technetium-99(c, d) & -- & Sodium & -- \\
\hline-- & -- & Sulfate ${ }^{(b)}$ & -- \\
\hline
\end{tabular}

(a) Concentrations of risk-based COPCs that were identified in Table 3-1 of DOE/RL-2004-66.

(b) Concentration of other COPCs identified in Table 3-1 of DOE/RL-2004-66 that could correlate with electricalresistivity data based on results for Borehole C4191.

(c) Applies to the 216-B-26 Trench representative site and analogous sites as presented in DOE/RL-2004-66.

(d) Applies to the 216-B-46 Crib (representative site in BY Tank Farm) and analogous sites as presented in DOE/RL-2004-66.

(e) Applies to the 216-B-58 Trench representative site and analogous sites as presented in DOE/RL-2004-66.

DOE/RL-2004-66, Focused Feasibility Study for the BC Cribs and Trenches Area Waste Sites. $\mathrm{COPC}=$ contaminant of potential concern.

However, for the subsurface high-salt plumes below the BC Cribs and Trenches area (and in general below all Hanford inactive disposal facilities and underground storage tanks), the dominant parameter that contributes the bulk of the low-resistivity signal is the concentration of total dissolved ions in the pore water. Bear in mind that the signals measured by the field survey equipment cannot differentiate individual chemical species. Rather, the equipment registers "bulk" apparent resistivity for the subsurface area/volume interrogated by each electrode pair. Therefore, individual chemical species listed in Table 1-8 in the DQO document (reproduced above as Table 9.1) cannot be distinguished from each other by the field or laboratory ERC studies. Only a bulk measurement is obtained. Because the contaminated pore waters in the sediments from the BC Cribs and Trenches area are dominated by nitrate and the fact that nitrate is very mobile (travels with the waste fluids), the field ERC measurements do "track" the location and semi-quantitatively the concentration of the nitrate. Because most waste streams disposed of or leaked to Hanford's subsurface are dominated by sodium nitrate, the ERC technique can be used to "track" nitrate at the Hanford site. Further, because technetium-99 in most instances exhibits the same transport attributes as nitrate, the ERC technique can give a good estimate of the locations where technetium-99 might exist. By assuming that the waste stream had a fixed ratio of nitrate to technetium99 over the entire duration of the active disposal, one can assume that the ERC measurements yield the same semi-quantitative estimate of technetium-99 concentration at any given location as the technique gives for nitrate. If the waste stream's composition were dominated by another fairly mobile salt, such as sodium sulfate, the ERC technique would yield similar correlations to sulfate; however, sulfate concentrations in most Hanford waste streams are not as large as nitrate. Sulfate does interact more so than nitrate with Hanford sediments such that its mobility is not as great as nitrate, and the natural subsurface sediments and pore waters contain significant concentrations of native sulfate. These three 
facts would hinder the ERC technique from giving as good an indication of the location and relative concentrations of sulfate in subsurface contaminant plumes.

The ion-exchange reactions between the predominately sodium-rich waste streams ubiquitously disposed of at Hanford causes native calcium and magnesium, which are naturally bound to the sediments' surface exchange sites, to be stripped off the sediments and placed in the leading edge of the contaminated waste plumes. Waste sodium takes the place of the native calcium and magnesium on the sediments' surfaces such that the sodium concentration in the percolating waste fluids is not as good an indicator of the waste fluid plume's leading edges.

Therefore, to answer this DQO question, we take two lines of attack. One discussion starts with the premise that the subsurface either has a pore water that contains elevated concentrations of dissolved salts or that the subsurface is uncontaminated with waste liquids but still contains native vadose zone pore water at concentrations in general at least 10 times more concentrated than uncontaminated groundwater. This assumption that uncontaminated Hanford Site vadose zone pore waters contain at least 10 times higher concentrations than uncontaminated groundwater comes from a few dozen measurements of vadose zone pore waters using ultracentrifugation as well as hundreds of 1:1 sediment-to-de-ionized water extracts of Hanford sediments. These sediments have been dilution corrected to yield estimates of the composition of the actual pore waters (see details in Serne et al. [2002a, b, c, d, e, and f and 2004a and b] and citations within). Sections 5.1, 6.1, 7.1, and 8.1 provide the pore-water composition in sediments from C5923, C5924, C5925, and C4191, respectively. From all these data, specific to the four BC Crib and Trench area boreholes, one observes that the range in total ionic strength is $0.02 \mathrm{M}$ for uncontaminated regions in all the boreholes to 1) $0.12 \mathrm{M}$ in the C5927 pore waters (considered an uncontaminated borehole), 2) 1.3 M in borehole C5924, 3) $2.3 \mathrm{M}$ in borehole C4191, and 4) $3.5 \mathrm{M}$ in borehole C5923. The main contributors to the total ionic strength are nitrate, sulfate, and sodium from the waste fluids, and calcium, magnesium, and bicarbonate, mainly from the natural subsurface sediments reacting with the waste fluids. Thus, for another mobile contaminant to compete with nitrate or sodium as the dominant ion influencing the bulk resistivity measurement, the contaminant would need to be present in molar concentrations in the typical subsurface contaminant plume below Hanford's central plateau. This is a rather implausible condition for almost all of the constituents listed in the DQO's Table 1-8 (reproduced above as Table 9.1).

Further consider that the ERC signal, which responds to the mass concentration of dissolved constituents, is controlled by the major constituents in pore water, and most of the constituents listed in DQO Table 1-8 are present at trace $\left(10^{-6} \mathrm{M}\right.$ or less) mass concentrations. To illustrate the significance of this fact, the HEIS database was queried to determine the range of concentrations found in groundwater for each constituent in DQO Table 1-8. Because the HEIS database does not at this time include data on vadose zone pore-water concentrations, we must rely on groundwater data. As mentioned above, uncontaminated vadose zone pore-water concentrations of constituents are generally at least 10 times higher than in groundwater. Table 9.2 lists the results of querying the HEIS groundwater database for all available measurements of the concentration of the most of the species listed in DQO Table 1-8. Table 9.2 lists the total number of measurements available in the electronic database for each selected constituent, the number of groundwater samples with measurements above the detection limit, the range of values encountered (lowest to highest concentration), the arithmetic mean of all the detectable values, 
PNNL-17821

Table 9.2. Range of Groundwater Concentrations of Selected Constituents in M (moles/L)

\begin{tabular}{|c|c|c|c|c|c|c|c|c|c|c|}
\hline Species & \# Analyses Performed & \# above DL & $\begin{array}{c}\text { Low } \\
\text { Value }\end{array}$ & $\begin{array}{l}\text { High } \\
\text { Value }\end{array}$ & Ave & Median & $\begin{array}{l}\text { HEIS } \\
\text { Units } \\
\end{array}$ & $\begin{array}{c}\text { M } \\
\text { High } \\
\end{array}$ & $\begin{array}{c}\text { M } \\
\text { Ave } \\
\end{array}$ & $\begin{array}{c}\text { M } \\
\text { Median } \\
\end{array}$ \\
\hline${ }^{60} \mathrm{Co}$ & 20,566 & 9,345 & 0 & $4.30 \mathrm{E}+07$ & $1.80 \mathrm{E}+04$ & 19.5 & $\mathrm{pCi} / \mathrm{L}$ & $6.34 \mathrm{E}-10$ & 2.65E-13 & $2.88 \mathrm{E}-16$ \\
\hline${ }^{63} \mathrm{Ni}$ & 78 & 47 & 0.378 & 836 & 71.45 & 6.13 & $\mathrm{pCi} / \mathrm{L}$ & $2.34 \mathrm{E}-13$ & $2.00 \mathrm{E}-14$ & $1.72 \mathrm{E}-15$ \\
\hline${ }^{90} \mathrm{Sr}$ & 19,037 & 12,122 & 0 & $2.80 \mathrm{E}+07$ & $1.29 \mathrm{E}+04$ & 70 & $\mathrm{pCi} / \mathrm{L}$ & 2.25E-09 & $1.04 \mathrm{E}-12$ & $5.64 \mathrm{E}-15$ \\
\hline${ }^{99} \mathrm{Tc}$ & 13,924 & 10,926 & 0 & $1.88 \mathrm{E}+05$ & 1931.60 & 135 & $\mathrm{pCi} / \mathrm{L}$ & $1.11 \mathrm{E}-07$ & $1.14 \mathrm{E}-09$ & 7.97E-11 \\
\hline${ }^{137} \mathrm{Cs}$ & 20,546 & 8,587 & 0 & $5.10 \mathrm{E}+06$ & 2306.18 & 52 & $\mathrm{pCi} / \mathrm{L}$ & $4.29 \mathrm{E}-10$ & $1.94 \mathrm{E}-13$ & 4.37E-15 \\
\hline${ }^{240} \mathrm{Pu}$ & 2,354 & 434 & 0 & 2670 & 12.15 & 0.0114 & $\mathrm{pCi} / \mathrm{L}$ & $4.90 \mathrm{E}-11$ & $2.23 \mathrm{E}-13$ & $2.09 \mathrm{E}-16$ \\
\hline Se & 13,887 & 2,106 & 0.3 & 191 & 5.00 & 3.1 & $\mu \mathrm{g} / \mathrm{L}$ & $2.42 \mathrm{E}-06$ & $6.33 \mathrm{E}-08$ & 3.93E-08 \\
\hline $\mathrm{U}$ & 19,890 & 19,420 & 0 & $7.14 \mathrm{E}+05$ & $2.78 \mathrm{E}+02$ & $7.85 \mathrm{E}+00$ & $\mu \mathrm{g} / \mathrm{L}$ & $3.00 \mathrm{E}-03$ & 1.17E-06 & $3.30 \mathrm{E}-08$ \\
\hline Mn & 35,878 & 21,096 & 0.003 & $1.73 \mathrm{E}+05$ & 169.91 & 7 & $\mu \mathrm{g} / \mathrm{L}$ & 3.18E-03 & 3.12E-06 & $1.29 \mathrm{E}-07$ \\
\hline $\mathrm{Hg}$ & 14854 & 535 & 0.046 & 37.3 & 0.52 & 0.12 & $\mu \mathrm{g} / \mathrm{L}$ & $1.86 \mathrm{E}-07$ & $2.60 \mathrm{E}-09$ & $5.98 \mathrm{E}-10$ \\
\hline
\end{tabular}


and the median value for those waters with detectable concentrations. The data (both inorganic and radionuclide species) are converted to molarity (M) so that we can compare them with the ionic-strength values cited above for the subsurface pore waters in the four BC Crib and Trench boreholes.

Table 9.2 shows conclusively that the radionuclide COPCs are found at infinitesimally low molar concentrations compared to the more common cations and anions found in natural waters and waste streams. In most cases, even if the pore waters contained a million times higher concentrations, the radionuclide contaminants would not influence the soil resistivity signals. Phosphate, uranium, and manganese, if present at a hundred to a thousand times higher concentrations than found the most contaminated groundwater present in the HEIS database, would start to reach molar concentrations in the range of the sodium nitrate salt plume observed at the BC Crib and Trench boreholes.

The above illustration is simplistic in the sense that some of the ERC signal is responding to attributes of the subsurface besides the pore-water salt concentrations. But at this time, the contribution of chemical species, either bound to the sediment surfaces or precipitated as coatings on the sediment particles, would in theory be readily dismissed as inconsequential, especially considering the very high salinity of the measured pore waters in the sediments at C5923, C5924, and C4191. A more detailed analysis of the contributions of non-pore-water parameters will be performed in the future when data become available for use in more detailed petrophysical models of soil resistivity (see the discussion in Section 10 regarding the use of the Waxman-Smits model).

A second approach to discussing why most of the constituents in DQO Table 1-8 are not directly measured by ERC techniques follows. Contamination in the waste fluids might be shallow near the bottoms of the inactive disposal facilities in a dissolved state but become immobilized via interactions with the sediments before ever reaching the groundwater. To estimate the highest concentrations of waste fluids that are present near the bottoms of inactive facilities, we also queried the waste-stream-data representative of the three wastes disposed of to the BC Crib and Trench facilities to estimate the initial waste-stream concentrations of the specific constituents listed in DQO Table 1-8. The highest concentrations are shown in Table 9.3; data are available in appendices in the DQO document (Benecke 2008) which were excerpted from Corbin et al. (2005).

The DQO document (Benecke 2008) contains several appendices excerpted from Corbin et al. (2005), the Soil Inventory Model, Rev. 1, which used historical disposal records, waste process flow sheets, and simple chemistry models to predict the waste composition of the liquids and suspended solids sent to each disposal facility at the Hanford Site.

The data in Table 9.3 show that radionuclides present in the three waste types disposed to the cribs and trenches have very low mass concentrations that cannot have a measureable effect on the resistivity signal produced by the salt plume. As previously known, the waste compositions disposed of to the BC Cribs and Trenches are dominated by sodium and nitrate with nitrite, sulfate, and carbonate contributing a few percent each to the total ionic strength.

The parameters in DQO Table 1-8 that are not individual chemical constituents, namely moisture content, electrical resistivity of soil/sediment, and specific electrical conductivity of pore water, ionic strength of pore water, and borehole neutron and natural gamma logs, are discussed next. The field ERC technique and signals generated do respond to vadose zone moisture content, but given the high salt 
concentrations observed in the subsurface below the BC Cribs and Trenches, the major portion of the measured ERC signal is controlled by the dissolved salt content. At other sites where there is not a large dissolved salt plume present, the ERC measurements should correlate to a moderate degree with sediment moisture content. We did not attempt to quantify the correlation between the moisture content of the

Table 9.3. Composition of the Three Waste Types Disposed to BC Cribs and Trenches

\begin{tabular}{|c|c|c|c|}
\hline $\begin{array}{c}\text { \% of Total Volume } \\
\text { Disposed to BC Cribs } \\
\text { \& Trenches }\end{array}$ & $5.6 \%$ & $34.9 \%$ & $59.5 \%$ \\
\hline Type of Waste & PFeCN1 (BT1) & PFeCN2 (BT2) & TFeCN (BT2) \\
\hline Constituent & $\mathrm{M}$ & $\mathrm{M}$ & $\mathrm{M}$ \\
\hline${ }^{60} \mathrm{Co}$ & $2.77 \mathrm{E}-12$ & $2.77 \mathrm{E}-12$ & 4.39E-12 \\
\hline${ }^{63} \mathrm{Ni}$ & $1.00 \mathrm{E}-10$ & $2.56 \mathrm{E}-10$ & 1.95E-10 \\
\hline${ }^{90} \mathrm{Sr}$ & 1.08E-08 & 2.14E-09 & 1.96E-09 \\
\hline${ }^{99} \mathrm{Tc}$ & 2.24E-06 & $2.24 \mathrm{E}-06$ & 1.70E-06 \\
\hline${ }^{137} \mathrm{Cs}$ & 2.95E-09 & 2.95E-09 & 2.95E-09 \\
\hline${ }^{226} \mathrm{Ra}$ & 2.33E-13 & 2.33E-13 & $1.88 \mathrm{E}-13$ \\
\hline${ }^{239} \mathrm{Pu}$ & 5.37E-08 & 5.37E-08 & 5.36E-08 \\
\hline${ }^{240} \mathrm{Pu}$ & 1.57E-09 & 1.57E-09 & 1.65E-09 \\
\hline Se & NA & NA & NA \\
\hline $\mathrm{U}$ & $1.30 \mathrm{E}-04$ & $1.30 \mathrm{E}-04$ & $1.28 \mathrm{E}-04$ \\
\hline Mn & $0.00 \mathrm{E}+00$ & $0.00 \mathrm{E}+00$ & $0.00 \mathrm{E}+00$ \\
\hline $\mathrm{Hg}$ & 1.62E-06 & 1.62E-06 & 1.30E-06 \\
\hline $\mathrm{F}$ & 2.17E-01 & 2.17E-01 & 9.60E-02 \\
\hline $\mathrm{PO}_{4}$ & 7.06E-02 & 7.06E-02 & 6.30E-02 \\
\hline $\mathrm{Na}$ & $3.95 E+00$ & $3.95 E+00$ & $3.63 E+00$ \\
\hline $\mathrm{Al}$ & $0.00 \mathrm{E}+00$ & $0.00 \mathrm{E}+00$ & $0.00 \mathrm{E}+00$ \\
\hline $\mathrm{Fe}$ & $1.87 \mathrm{E}-03$ & $1.88 \mathrm{E}-03$ & 1.69E-03 \\
\hline $\mathrm{Cr}$ & 3.31E-03 & 3.31E-03 & 4.70E-03 \\
\hline $\mathrm{Bi}$ & $1.86 \mathrm{E}-04$ & $1.86 \mathrm{E}-04$ & 2.56E-04 \\
\hline $\mathrm{Zr}$ & $0.00 \mathrm{E}+00$ & $0.00 \mathrm{E}+00$ & 7.53E-05 \\
\hline $\mathrm{Pb}$ & $0.00 \mathrm{E}+00$ & $0.00 \mathrm{E}+00$ & 6.63E-06 \\
\hline $\mathrm{Ni}$ & $1.82 \mathrm{E}-03$ & $1.82 \mathrm{E}-03$ & 1.82E-03 \\
\hline Ag & 2.78E-08 & 8.88E-06 & 5.04E-09 \\
\hline $\mathrm{Ca}$ & 3.75E-03 & 3.75E-03 & 3.75E-03 \\
\hline $\mathrm{K}$ & $1.71 \mathrm{E}-02$ & 1.71E-02 & $1.51 \mathrm{E}-02$ \\
\hline $\mathrm{NO}_{3}$ & $2.55 E+00$ & $2.55 E+00$ & $2.15 E+00$ \\
\hline $\mathrm{NO}_{2}$ & 2.10E-03 & 7.09E-04 & 1.22E-01 \\
\hline $\mathrm{CO}_{3}$ & 3.75E-03 & 3.75E-03 & 9.78E-02 \\
\hline $\mathrm{SO}_{4}$ & 1.24E-01 & 1.24E-01 & 1.16E-01 \\
\hline $\mathrm{Cl}$ & 7.87E-02 & 7.87E-02 & 8.38E-02 \\
\hline $\mathrm{NH}_{3}$ & 6.81E-08 & 7.76E-09 & 2.61E-02 \\
\hline
\end{tabular}

sediments at the four BC Crib and Trench area boreholes during this project because we knew that there was high salt concentrations in the subsurface. At Hanford, moisture content in the vadose zone sediments correlates well with particle size (higher moisture in finer grained sediments) as shown in Figure 5.1, Figure 6.1, Figure 7.1, and Figure 8.1. In each of the four boreholes studied at BC Cribs and 
Trench Area, especially close to ground surface, one can find one of two thin zones of higher moisture content where the dissolved salt content of the pore water is not particularly elevated above background. These thin zones with higher moisture but low pore-water electrical conductivity are always associated with fine-grained sediment. As a corollary, other zones with higher moisture content associated with high pore-water electrical conductivity also are always associated with the presence of fine-grained sediments. That is, higher moisture content in Hanford vadose zone sediments is indicative of the presence of finegrained sediments and not the presence of excess residual waste fluids. It would appear that the moisture at most all of the disposal facilities and tank release sites studied to date at Hanford have re-equilibrated such that no excess residual waste fluids are found in the sediments. Fine-grained sediments retain more moisture because of their inherent higher capillary tension attributes when compared to typical Hanford formation sands and gravels.

The neutron moisture log is the best method to estimate subsurface moisture content, and such logs are generally performed at all new boreholes. If neutron logging were not performed right after a borehole was emplaced, returning later to perform the neutron logging after well completion is problematical. If the well completion included packing the annulus around the casing with bentonite (or other materials such as cement), the neutron logging measurements can be biased by the process where the well completion material draws water from the surrounding formation sediments and confounds the measurement of moisture in the formation. The field ERC should correlate well with direct laboratory measurements of electrical resistivity because both techniques are attempting to measure the same parameter. However, as shown in this report, the laboratory measurement on soil resistivity exhibited large variations between samples that were within 2.5 feet of each other. The variation is real because the repetitive measurements on the same grab or core sample were quite precise, and the results of switching the introduction of the current into the sediments between the two electrode pairs yielded very similar results (see Section 5.3 for more discussion). This process, called reciprocity, and the finding of similar voltage values show that the laboratory-scale soil resistivity measurements are satisfactory. As discussed throughout this report, the field ERC surface-based survey results correlated at best only semiquantitatively with the laboratory-scale soil resistivity measurements because of the difference in measurement scales as opposed to differing equipment measurement performance. The correlation of the field ERC with the ionic strength of the pore water was a key comparison used in this report, and again the correlation was at best mediocre because of the same scaling issues. The correlation of field-scale ERC with other field-scale techniques, such as borehole neutron logs and natural gamma logs, is being done under separate funding efforts. We have already mentioned that because of the high salt content in the BC Crib and Trenches subsurface sediments, the field ERC surveys respond much more to the salt than moisture. The natural gamma logs do in fact give an indication of sediment mineralogy and can be used to precondition the "Earth" model used to invert the raw field data. Efforts to improve the inverse process using complementary data from other measurements have been underway on the sediments from the four BC Cribs and Trenches area boreholes using separate funding and will be the subject of another report likely within the next year (see some additional discussions in Section 10-Path Forward and Recommendations.

\subsubsection{Decision Statement 2}

The following sub-section addresses decision statement 2. 


\section{Determine whether electrical resistivity and analytical data correlate sufficiently to use electrical resistivity data to assist in updating the existing CSM and evaluating remedial alternatives.}

The field surface-based ERC technique gives a qualitative to semi-quantitative basis for locating the lateral extent and to some level of confidence the depth distribution of the major dissolved constituents below the BC Cribs and Trenches area (or at any other Hanford inactive waste site that has been subjected to the disposal of typical Hanford liquid wastes). The field ERC technique does not address the location of highly immobile trace (on a mass basis) constituents, such as most of the species of concern for human health and environmental risk listed in the DQO Table 1-8. At this time, ERC, such as that performed at the BC Cribs and Trenches area, has not significantly improved our knowledge on the conceptual model for immobile COCs, but it has corroborated our understanding/beliefs on the conceptual models for mobile contaminants that behave very similarly with the major waste constituent, nitrate.

The surface-based ERC technique is useful for determining the lateral extent and to some degree the vertical distribution of mobile species, including two COPCs, nitrate and technetium-99. As discussed in this report, especially Sections 4, 9, and 10, more robust ERC techniques that include true 3D subsurface interrogations can improve the correlation between the field ERC survey results with the major constituent's distribution with depth (and for that matter, lateral extent-which is already adequately covered by the current surface-based methodology). Although not tested in this work, we doubt that the more robust 3D ERC techniques themselves could improve our knowledge of the transport behavior of immobile COCs. Knowing the lateral and vertical extent of contaminants in the subsurface in itself does allow some remedial alternatives to be ranked for efficacy, based solely on cost and feasibility of implementation. For example, construction of surface barriers has been predicted to not be effective at significantly delaying the migration of mobile contaminants that currently reside deep in the vadose zone (e.g., $200 \mathrm{ft}$ bgs or deeper) from reaching Hanford's upper unconfined water table (see DOE/ORP 2006).

Excavation and disposal of contaminated sediments for the entire high-concentration vadose zone salt plume present around borehole C5923 would also seem impractical given the results of the field ERC that shows a very deep vadose zone plume that contains high concentrations of nitrate and technetium-99 as deep as $260 \mathrm{ft}$ bgs.

The correlation between the laboratory geochemical measurements on borehole C5925 sediments and the surface-based ERC was useful in determining that the high-salt plume below the BC cribs in the northeast corner of the BC Cribs and Trenches area is distinctly separated from the high salt plume below the trenches in the middle of the BC Cribs and Trenches area. Previously, there was some uncertainty caused by out-of-plane effects that suggested the two plumes might be connected (see Rucker and Benecke 2006).

\subsubsection{Decision Statement 3}

The following sub-section addresses decision statement 3.

Determine whether electrical-resistivity data interpretations are useful for guiding soil/sediment sampling for targeted COPCs in the vadose zone.

As described throughout this report, the field surface-based ERC technique has been shown to be useful for guiding where to drill to collect sediment samples for suspected mobile COPCs. The technique 
also was useful in confirming current conceptual models that consider that immobile contaminants do not migrate more than several meters to at most a few 10 s of meters both laterally and vertically outside the inactive disposal facility footprints. As discussed in detail in Sections 5.1, 6.1, 7.1, and 8.1, immobile contaminants such as cesium-137, nickel-63, strontium-90, mercury, and most other regulated RCRA metals were found either at very low concentrations or not found at all at detectable concentrations in the three boreholes, C5923, C5924, and C5925; all were drilled outside facility footprints. The data for these immobile constituents in the C4191 sediments, directly in the 216-B-26 trench footprint, also showed very rapid decreases in concentrations below the trench bottom.

In summary, surface-based ERC is most valuable in providing excellent guidance for identifying where to place boreholes and direct push holes to obtain sediments to quantify mobile and semi-mobile COPCs. The surface-based technique might also be valuable to survey for unknown disposal sites that accepted high concentrations of liquid wastes should they exist on the Hanford Reservation.

\subsection{Final Observations}

The lateral extent of the salt plumes analysis shown in Figure 9.13 predicts that at the location of borehole C (C5925), there is no contamination with salt at or above $0.3 \mathrm{M}$. This is corroborated by the actual sediment analyses (see Section 8) that shows pore-water ionic strengths throughout the depth profile (20 to $203 \mathrm{ft}$ bgs) ranging from 0.02 to $0.12 \mathrm{M}$. We conclude that the surface-based ERC survey at the BC Cribs and Trenches area provides a good estimate of the lateral extent of sub-surface contamination where the calculated pore-water ionic strength is near to or above $0.3 \mathrm{M}$. The surfacebased ERC technique had problems delineating the vertical location of the salt plumes at the BC Cribs and Trenches area, especially because the plumes exhibited multiple peaks or lobes as a function of depth. It would be useful to apply truly 3D ERC techniques at the BC Cribs to evaluate whether such methodology (and the installation of deep electrodes at several locations) would significantly improve the capability of ERC techniques to delineate the vertical locations of high salt plumes.

The use of spectral-gamma logs in existing or new boreholes at the BC Cribs and Trenches area (and most other disposal facilities at Hanford) would not improve the delineation of the lateral and vertical extent of contamination because there are no long-lived gamma-emitting radionuclides that exhibit low to zero adsorption properties with the vadose zone sediments. In the early years of waste disposal at Hanford, gamma-emitting isotopes such as ruthenium-106, antimony-125, iodine-131, and chromium-51 were present in some of the waste streams, and these short-lived isotopes did travel rapidly through the sediments such that they were useful indicators of the lateral and vertical extent of waste-water plume migration. At the present time, there have been few studies of other borehole logging tools or field techniques that might detect some mobile contaminant present in subsurface waste-water plumes. Neutron moisture logging in boreholes has been useful in delineating zones of higher moisture as a function of depth, but the higher moisture has been indicative of only the presence of fine-grained sediments and not waste-water salt or contaminant locations. This observation suggests that liquid wastes disposed of to subsurface structures several decades ago have drained into the vadose zone and in some instances already reached the water table such that field-capacity or moisture equilibrium has already been re-established.

Thus, as described in Section 9.4.3, currently surface-based ERC is most valuable in providing excellent guidance for identifying where to place boreholes and direct push holes to obtain sediments to 
PNNL-17821

quantify directly the concentrations and locations of mobile and semi-mobile COPCs. Section 10 provides some recommendations on other activities that might lead to the ability to measure the lateral and vertical extent of sub-surface salt plumes without the need for extensive direct borehole or push-hole sediment sampling. 



\subsection{Path Forward and Recommendations}

This section offers some discussion on continued activities that would better solidify the groundtruthing activities between various ERC techniques (including both surface-based only and combined surface and sub-surface based) using both available borehole sediments and future sediments from one more proposed boreholes in the BC Cribs and Trench area.

\subsection{Resistivity Acquisition}

The original intent of the electrical resistivity characterization at the BC Cribs and Trenches area was to define the shape and extent of the nitrate plume for a surface cap design. The cap was meant to minimize recharge and the mobilization of COCs. The electrical-resistivity information was acquired on the surface along a set of orthogonal lines, creating a large set of 2D data. Collating the processed datasets of HRR and the 2D inversion into a rendered volumetric body produced a quasi-3D map of the resistivity distribution. From these maps, it was clear that 3D effects, i.e., measurements influenced by out-of-plane low-resistivity bodies, were affecting the data acquired in the 2D methodology. The out-ofplane effects were noticeable when evaluating two resistivity lines crossing the same location at different angles; resistivity values at co-located points were slightly different. Regardless of these effects, the quasi-3D map showed the lateral extent of the low-resistivity body beneath the BC Crib and Trench liquid-waste disposal facilities.

To account for the 3D effects in the data, a 3D inversion was completed on small subsets of data. The 3D inversion requires much more computer memory and time, especially considering the entire area over which the BC Cribs and Trenches data set was acquired. Thus, the model was adjusted to reduce memory and time requirements by reducing the total model cells used in the numerical modeling. The cell number reduction was also necessary to accommodate the relatively low number of total measurements. Had the resistivity data been collected in true $3 \mathrm{D}$, using a grid of electrodes as opposed to single lines of electrodes, the dataset would have been much larger. A larger number of measurements would have allowed a larger number of cells, owing to the uniqueness issue inherent in any inversion process. As a result of a lower number of cells and larger overall cell size, the resolution of the 3D inversion results is low.

It is likely that acquiring data in a true 3D fashion simultaneously along a 2D grid of electrodes would eliminate some of the resolution issues. However, the surface-only measurements still suffer from depthperspective as seen by comparing the vertically shifted inversion results to borehole pore-water data. It was difficult to match the top and bottom of the low-resistivity bodies in each of the inverted 2D sections with the borehole geochemistry targets. Additional measurements from electrodes buried deeply within and below the low-resistivity targets would likely rectify this positioning error. The buried electrodes would also potentially provide a higher resolution of subsurface resistivity and show more detail in the final inverted product, allowing a better correlation with the detailed pore-water geochemistry data. Emplacement of deep buried electrodes should be considered during any future direct-push or traditional cable-tool borehole drilling activities in the BC Cribs and Trenches Area.

The comparison, and perhaps integration, of the resistivity profile derived from the laboratory measurements with the surface survey data is an essential part of the verification process and is needed to resolve issues of non-uniqueness associated with the interpretation of surface surveys. However, for a 
variety of reasons, such a comparison is not a trivial task as inherently, these two data sets will have different levels of accuracy and detail along the vertical axis. A priori knowledge of the geological stratification and actual soil resistivity as a function of stratigraphy would minimize the challenge of interpreting such resistivity surveys, but such information is typically not available. Additional information can be derived from borehole logs (e.g., borehole resistivities, induction logs, or porosity logs). Therefore, we recommend that such complementary logging tools be employed. Some consideration should be given to the use of multimodal investigations in the field, such as resistivity combined with induced polarization. For example, a fine-textured conductive layer would have a different induced polarization signature than a layer whose low resistivity was due only to an ionic contaminant. Downhole methods could also give high vertical resolution of the electrical resistivity, which could be directly incorporated into the resistivity inversion models. However, either modifications to the casing material (use of non-metallic materials) or use of through-casing techniques are needed to acquire the downhole geophysical data.

\subsection{Resistivity Processing}

The BC Crib and Trench area surface-based resistivity data were processed using standard resistivity inversion software. Only the measured resistivity data were used in the processing, and the results were the best estimate provided by the inversion code with a given set of constraints (including smoothing). A new processing strategy that could be implemented in relatively short order would be to incorporate the new borehole geochemistry data as a priori information. This would allow the inversion code to develop a new set of constraints that are closer to reality. A methodology for implementing the constraints would need to be addressed, such as the conversion of the pore-water electrical conductivity to bulk resistivity and an equivalent cell resistivity at a scale amenable to the inversion model. This feedback of groundtruth information should produce an estimate of the resistivity distribution that more closely resembles the actual field conditions.

If the eventual goal of the electrical-resistivity measurements is to identify the individual COCs and their concentrations, then a serious attempt should be made to directly couple geophysical and hydrological modeling algorithms. Resistivity alone cannot provide all of the components; the measured resistivity value results from the interplay of several variables, including soil water content, chemical composition (ionic strength) of the pore water, and lithology, via the surface conductance as well as the formation factor (inverse of the tortuosity). However, if the flow-and-transport modeling results are used as a priori information in the resistivity inversion code, and the resistivity inversion is used to verify the hydrological modeling, then both contaminant and resistivity distribution would be internally consistent. The problems of shifted target elevations and lack of detail in the resistivity inversions would be mostly eliminated. The extent to which these issues can be resolved also depends on the assumptions made about the subsurface and how they are implemented as constraints on the inversion.

The accuracy of the results will depend strongly on whether the physical formation actually conforms to the assumptions about the resistivity distribution in the subsurface and those on which the analysis is based. Commercially available software for resistivity inversion, including those that have been successfully coupled to hydrologic models, can be classified into two groups: 1) those based on smoothinversion algorithms and 2) those based on block-inversion algorithms. The capability of these two inversion approaches to define the geometry of subsurface structures and their resistivity is significantly different. The underlying assumption of the smoothness-constrained method is that subsurface resistivity 
varies smoothly in space. Implementation of the smoothness-constrained approach attempts to minimize the changes in resistivity using a least squares method. This method has been shown to perform well when subsurface resistivity varies in a smooth manner, e.g., contaminant plumes in relatively homogenous geologic formations. In contrast, the block inversion method assumes that the subsurface consists of several homogeneous regions separated by sharp interfaces. This assumption would be more applicable to heterogeneous formations with sharp boundaries and would be needed to determine both the location of contacts between units (layers) and the associated resistivities of these layers. Practical improvements in resistivity processing for waste sites typical of the Hanford formation may then require some flexibility in specifying the underlying assumptions. A key decision is choosing the most appropriate inversion algorithm because not all sites under investigation will require the additional computation demands of block inversions as opposed to the widely used smoothness-constrained inversion.

\subsection{Resistivity and Geochemistry Comparisons}

The overall goal of this report was to present a comparison between the measured electrical resistivity from the surface and the geochemical properties of the 1:1 sediment to de-ionized water extracts (surrogate for actual pore water) from the borehole sediments. The comparison was accomplished by showing correlations of the two types of measurements at co-located points. The comparisons also rely on the fact that the MiniSting used in the laboratory soil resistivity measurements and SuperSting 8 electrical resistivity system used in the field, both purchased from Advanced Geosciences, Inc. (AGI; Austin, Texas), have equivalent performance specifications and thus do not contribute to any observed differences. The two main issues that arose during this process were 1) how to reconcile the mismatch in scale (e.g., sampling density) between the two types of measurements and 2) how to interpolate either data set to obtain co-located measurements of key parameters. Scaling issues have been problematic in all sciences that deal with measurement. In this particular study at the BC Cribs and Trenches area, the geochemistry (sediment pore water constituents) was measured at a scale on the order of 10s of cubic centimeters of sediment on discrete samples obtained at about 2.5-ft intervals in the vertical boreholes whereas the field soil resistivity was measured on a scale of 10 s of cubic meters. This report, as a firstorder approximation, treated the two data sets as equal in scale and simply presented one measurement versus the other. The results showed that these direct correlations were marginal to poor. Therefore, additional work may be warranted to understand up-scaling of geochemistry data for more direct comparison with the field survey resistivity data. It would be cost prohibitive to attempt to repeat the surface-based field soil resistivity survey at the much smaller scale used for the pore-water constituents. Further, any additional field-survey activities should focus on true 3D surface-based data collection or the utilization of several deeply buried electrodes to allow more thorough interrogation of the subsurface.

The issue of co-located data also stems from the mismatch in scales between resistivity and borehole samples. To accommodate the need for data at the same location in this report, the resistivity data were linearly interpolated to the borehole sampling elevations (depths below ground surface). It was reasoned that since the resistivity was a smoothly varying function, the interpolation of this dataset is more easily accomplished than up-scaling the sediment geochemical data. Despite the reality that thin fine-grained layers occur with the thick Hanford formation sands that have significantly different moisture contents and pore-water chemical compositions, it is recommended that an "upscaling" procedure be developed that justifies the averaging, interpolation, and scaling of borehole sediment water extracts to match the location of resistivity measurements. Such up-scaling procedures, where laboratory measurements on 
small samples are manipulated to represent field-scale volumes of sediment, are also required to estimate the parameters such as hydraulic conductivity, porosity, bulk density needed for field-scale hydrologic modeling of water flow, and contaminant migration. Thus, there is a need for up-scaling laboratory data of many kinds in many earth-science disciplines and, the topic is actively being studied by many researchers. Perhaps a review of these efforts would lead to some productive suggestions for the BC Cribs and Trenches field versus laboratory soil-electrical resistivity issues.

\subsection{Specific Recommendations}

Earlier in this report, an observation was made that the correlation between inverted field data and the vadose zone pore-water compositions deteriorated when the total ionic strength was low. Additional grab samples at the four boreholes are available in regions of low contamination that could be processed in the laboratory for both chemical composition and soil resistivity using the MiniSting instrumentation. The goal would be to ascertain at what pore-water ionic strength the correlations for both laboratory resistivity and inverted field data became insignificant. This would establish a lower threshold of ionic strength below which surface-based resistivity techniques become limited for characterizing subsurface resistivity anomalies. Using these limits and waste stream compositions from the Soil Inventory Model-Rev. 1 (Corbin et al. 2005) to calculate waste-stream ionic strengths, the sites at which this technique might be applicable could be determined a priori. If a given facility has a starting waste composition with ionic strengths below the cut off value determined from the BC Crib and Trench area sediments, it would likely not be fruitful to perform surface-based resistivity measurements. Because the Hanford formation sediments at the BC Cribs and Trenches area are representative of the vadose zone geologic strata throughout most of the Hanford Site's Central Plateau, the results of determining the proposed ionic strength cut off should be applicable across the Central Plateau.

In addition, it is recommended that grain-size distribution measurements become an integral part of future sampling and analysis plans and be completed for many of the samples from at least one of the boreholes recently emplaced at the BC Cribs and Trenches site or a future borehole. The MiniSting soil resistivity measurements and 1:1 sediment to deionized water extracts should also be performed on the same sediments. The measured soil resistivity can be strongly influenced by grain-size distribution (soil texture or lithology) through surface conductance of the individual particles. Because different size soil particles have different physical, chemical, and electrical characteristics, grain-size distributions could play a critical role in characterizing the resistivity response. Yet, particle size measurements are not part of the typical sampling and analysis plan (e.g., the original C4191 study). Data collected for this report show that dry-sieve analysis coupled with laser-diffraction measurements can be used to characterize the full PSD curve for sediments with coarse (>2 mm) fractions. For samples dominated by PSDs less than 2 $\mathrm{mm}$, laser diffraction alone can be used to characterize the entire PSD curve, taking about 30 minutes per sample.

In describing electrical properties and how they are impacted by water saturation, the soil is assumed to be composed of two parallel resistors. One represents the resistance due to the free electrolyte in the pore space and the other a resistance due to conductive mineral (e.g., clay), the conductance of which is brought about by cation exchange. Water is assumed to be partitioned between free water and water bound in the diffuse double layer, with the amount bound being controlled by the SSA and the thickness of the diffuse double layer. The SSA and the CEC are therefore critical to the interpretation of electrical properties as they control the surface charge density and ultimately the "excess charge" or surface 
conductivity. This information is needed to guide selection of the most appropriate petrophysical models (i.e., those based on the assumption of clean sands with no surface conductance vs. those that assume shaley sands with surface conductance) for interpreting resistivity measurements. For example, the Waxman and Smits (1968) model uses the product of $C E C$ and the equivalent ionic conductance of clay exchange ions, divided by the water saturation (i.e., $Q_{v} B / S_{w}$ ), to quantify the specific conductance of the clay counter-ions, the primary contributor to matrix conductivity. The geophysical laboratory studies on C5923 grab and intact cores, described in Section 5.3, suggest that sediments below the BC Cribs and Trenches area show no meaningful relationship between CEC and SSA and laboratory-measured soil resistivity. This is not surprising because the bulk sediment resistivity in the BC Crib and Trench area is dominated by the pore fluids with very little contribution from individual grain-surface conductivity (i.e., the pore waters have up to several molar concentrations of dissolved salts, and the sediments are dominated by sand-sized grains with low CEC and low SSA). Therefore, for this specific site, we do not recommend that SSA and CEC measurements be performed on additional sediments should more groundtruthing exercises be performed. The geophysical data obtained in the laboratory using the sediments from borehole C5923 (A) suggest that Archie's law, developed for clean sandstones and applicable when clay content is close to zero, may suffice for the BC Cribs and Trenches site. However, at other contaminated sites at Hanford, one does need to consider that measurements of CEC and SSA along with particle size and moisture content could be valuable at choosing a technically defensible model to invert field or laboratory soil resistivity data.

Soil resistivity measurements, as a function of saturation, should be made on selected samples using pore waters of different chemical composition as a means to quantify the relative contributions of water content and lithology to the bulk resistivity response. The measured resistivity is controlled by interactions between soil water content, chemical composition (ionic strength) of the pore water, tortuosity, and lithology (via the surface conductance). The results of such measurements would have numerous benefits. They will allow accurate identification of the range of moistures and ionic strengths over which resistivity measurements would be applicable. Limits in resolving the resistivity, $\rho_{\mathrm{i}}$, of the $\mathrm{i}^{\text {th }}$ layer in different types of anomalies, e.g., bowl-shaped resistivity anomalies $\left(\rho_{\mathrm{i}-1}>\rho_{\mathrm{i}}<\rho_{\mathrm{i}+1}\right)$, ascending anomalies $\left(\rho_{\mathrm{i}-1}<\rho_{\mathrm{i}}<\rho_{\mathrm{i}+1}\right)$, or descending anomalies $\left(\rho_{\mathrm{i}-1}>\rho_{\mathrm{i}}>\rho_{\mathrm{i}+1}\right)$, would be better defined if these recommendations are accepted. These data will allow the formation factor, an important variable in petrophysical models for resistivity, to be characterized. More importantly, they will provide data that could be used to validate joint inversions of hydrologic and resistivity data.

Accurate information on the location of vertical boundaries for sediment layering and their interpolation between boreholes is also needed. Such information has been shown to stabilize resistivity inversions and to allow adequate representation of the true subsurface geology, in terms of both the geometry and the formation resistivity, using block-inversion algorithms. Given that gamma-spectroscopy logs are routinely collected in all new boreholes at the Hanford site, the development of correlations between gamma-ray logs and lithologic attributes, including specific conductance, is highly desirable. The total gamma response in uncontaminated or contaminated sediments, such as in the BC Crib and Trench where man-made gammas are localized right below the facility, the footprint is due to the presence of potassium-40, uranium-238, and thorium-232, all of which show strong dependence on lithology. Neutron and gamma logs from C5923 correlate well with the vertical changes in lithology, suggesting that such logs have potential for constraining lithology. Given the time and high costs associated with characterizing the hydrophysical properties of radioactively contaminated sediments in the laboratory, such relationships would prove a worthwhile addition to the site characterization toolbox. 
To make the most use of these data, data-interpretation techniques that couple flow and transport models with resistivity predictions or inversions may be needed. Such tools would allow the pre-screening of waste sites to 1) evaluate the applicability of resistivity surveys, 2) design the most appropriate surveys to map features of interest, and 3) locate new boreholes and sampling points.

Finally, we recommend that ERC technical experts, programmatic staff, and stakeholders be convened to optimize the location of the fourth borehole (D), identified in the original DQO (Benecke 2008) and to discuss whether other ERC activities should be planned at the BC Cribs and Trenches area. To date, the four boreholes described in this report and a fifth shallow 70-ft borehole (C7047), near C5923 (A) and between BC cribs 216-B-17 and 216-B-16, have been used to obtain sediment samples at intervals of at least every $5 \mathrm{ft}$. Most of the sediments have been characterized in detail in the laboratory such that they provide an excellent data set to "groundtruth" the ERC methodology. We recommend that the fourth borehole described in the original DQO be used to emplace a number of nested deep electrodes after sediment collection so that combined surface-deep electrode ERC field survey data can be calibrated. The deep electrodes will allow for greater sensitivity and depth discrimination of the ERC method and should provide a better estimation of vertical migration of high ionic-strength pore waters through the vadose zone. Further, if any of the existing boreholes (C5923, C5924, C5925, and C4191) are still in place, they should also be outfitted with deep electrode arrays to further calibrate surface-based ERC field survey data.

Following completion of the ongoing soil desiccation demonstration, borehole C7047 and accompanying direct push probes, we recommend that they also be outfitted with deep electrode arrays so that additional ERC data could be collected in regions where the vadose zone sediment salt plumes are well known. It would also be useful to use some of the old monitoring wells that surround the BC Cribs and Trenches as electrodes, as has been done at several of the Tank Farms (e.g., Rucker et al. 2007) so that well to well (WTW) and surface to well (STW) and deep electrode to well (DETW) field survey data can be collected and calibrated. There are eight boreholes (299-E13-1 through 299-E13-6, 299-E13-20, and 299-E13-21) distributed throughout the cribs area with a frequency of roughly one well per crib. In the past, these wells have been logged to their full extent $(\approx 340 \mathrm{ft})$ with spectral gamma tools, but neutron moisture logging has been limited to around $160 \mathrm{ft}$. Neutron data in combination with spectral gamma data would provide greater insight into the heterogeneity within the crib region.

Again, there is no other region at Hanford that has such a comprehensive data base of characterized sediments; so BC Cribs and Trenches is the best available "groundtruthing" test bed for all types of ERC field survey techniques. WTW and STW field survey data were especially called out for needing calibration or "groundtruthing" with actual sediment pore-water data in Rucker et al. (2007).

The original goal of borehole $\mathrm{D}$ was to help identify the lower limits of resistivity measurements; however, we believe that the data analyses presented in this report have partially resolved the issue on the lower limit of salt concentration needed for effective use of field ERC data. Thus, other ERC "data gaps/issues” should now be considered more or at least equally important. One other suggestion that needs to be vetted follows.

From the field-based resistivity measurements performed in FY04-FY06 at the BC Cribs and Trenches area, the north area of the western trenches appears to be a weaker target than those beneath the central trenches and northeastern cribs. If a borehole were placed through the center of 216-B-29 (see Figure 1.1), it would allow a comparison for correlative purposes through a trench that is on the lower end 
of the ionic-strength scale. Going through the center of the trench would also minimize the effects of outof-plane imaging that may have affected the past correlation using the 2D inversion analysis. Further, using a borehole through 216-B-29 in conjunction with emplacement of deep electrodes and using old monitoring well casings as electrodes would allow for new integrated field ERC data collection, new sediment characterization, and analysis of all of the data (existing and new) in an integrated fashion. Analysis similar to that described in this report as well as forward modeling ${ }^{(a)}$ of all the existing and recommended soil resistivity data, using ever improving computer codes and tools, should improve significantly the surface-only ERC "groundtruthing” results described in this report. Soil electrical resistivity is becoming established as a very effective method for mapping saline-contaminant plumes in Hanford's complex subsurface formations. Within the raw field data inversion framework discussed in detail in Section 4, a forward model must be solved multiple times, and the quality of the inversion depends strongly on the starting "theoretical" conceptual model and its numerical counterpart. Forward modeling of flow and transport at the 216-B-26 trench (see Ward et al. 2006c) using the waste release volume, constituent mass inventories, and disposal time history was able to successfully match the vadose zone plume distribution derived from direct sediment sampling at borehole C4191 (see Section 8) and surface-based ERC field resistivity (see Rucker and Benecke 2007 and Rucker and Fink 2007). A similar forward modeling approach coupling flow and transport modeling with resistivity predictions, if applied to the BC cribs, would provide greater insight into the effects of subsurface heterogeneity on the distribution of disposed saline waste fluids and allow a robust evaluation of remedial options for the site.

(a) Forward modeling of soil resistivity begins with the numerical solution of an equation that factors in all the parameters that contribute to observed raw electrical resistance or conductivity data. The "theoretical or predictive" conceptual model is constrained by various boundary conditions and assumptions, whose possible variation should be explored by running a set of different test cases, and then comparing the model outputs with the field observations. Subsurface lithology, moisture content, pore-water ionic strength, surface charge on individual sediment grains are examples of parameters that control the observed signals. Factors that could be included in the theoretical model are discussed in more detail in Sections 4.1, 5.3, and 10.2. The idea is then to compare the theoretically predicted electrical resistivity results with the observed data acquired in the field. If the two agree to within an acceptable level of accuracy, the given geological model can be taken to be a reasonably accurate model of the subsurface. If not, the conceptual geological model is altered, and new predictions are computed and compared with the actual field data. This process continues iteratively until a satisfactory match is obtained between the predicted and the real data. 

PNNL-17821

\subsection{References Cited}

Allen T. 1996. Particle Size Measurements. 5th Ed. Chapman \& Hall, London.

American Society for Testing and Materials (ASTM). 1993. Standard Practice for Description and Identification of Soils (Visual-Manual Procedure). D2488-93, ASTM, West Conshohocken, Pennsylvania.

American Society for Testing and Materials (ASTM). 1998. Test Method for Laboratory Determination of Water (Moisture) Content of Soil and Rock by Mass. D22 16-98, ASTM, West Conshohocken, Pennsylvania.

American Society for Testing and Materials (ASTM). 2001. Standard Test Methods for Analysis of Metal Bearing Ores and Related Materials by Combustion Infrared Absorption Spectrometry. E1915-01, American Society for Testing and Materials, West Conshohocken, Pennsylvania.

American Society of Agronomy (ASA). 1996. "Methods of Soil Analysis-Part 3, Chemical Methods, SSSA Book Series 5.” DL Sparks, Editor. Soil Science Society of America, Madison, Wisconsin.

American Society of Testing and Materials (ASTM). 2000a. Standard Test Methods for Determination of the Soil Water Characteristic Curve for Desorption Using a Hanging Column, Pressure Extractor, Chilled Mirror Hygrometer, and/or Centrifuge. ASTM D6836-02, ASTM, Philadelphia, Pennsylvania.

American Society of Testing and Materials (ASTM). 2000b. Standard Test Methods for Standard Classification of Soils for Engineering Purposes (Unified Soil Classification System). ASTM D 2487, ASTM, Philadelphia, Pennsylvania.

American Society of Testing and Materials (ASTM). 2006c. Standard Test Methods for Specific Gravity of Soil Solids by Water Pycnometer. ASTM D 854-06, ASTM, West Conshohocken, Pennsylvania.

American Society of Testing and Materials (ASTM). 2006a. Standard Test Method for Particle-Size Analysis of Soils. ASTM D422-63, ASTM, West Conshohocken, Pennsylvania.

American Society of Testing and Materials (ASTM). 2006b. Standard Test Method for Permeability of Granular Soils (Constant Head). ASTM D2434-68, ASTM, Philadelphia, Pennsylvania.

Archie GE. 1942. "The Electrical Resistivity Log as an Aid in Determining Some Reservoir Characteristics.” Transactions of the American Institute of Mining, Metallurgy and Petroleum Engineers 146:54-67.

Baker VR, BN Bjornstad, AJ Busacca, KR Fecht, EP Kiver, UL Moody, JG Rigby, DF Stradling, and AM Tallman. 1991. “Quaternary Geology of the Columbia Plateau.” In: Quaternary Nonglacial Geology: DRB Morrison, Editor. Geological Society of America, Boulder, Colorado, pp. 216-250.

Barker R.D. 1989. "Depth of investigation of collinear symmetrical four-electrode arrays.” Geophysics 54(8):1031-1037. 
Bear J. 1988. Dynamics of Fluids in Porous Media. Dover Publications, New York.

Beauchamp KG. 1975. Walsh Functions and their Applications. Academic Press, New York.

Benecke MW. 2008. Data Quality Objectives Summary Report for the BC Cribs and Trenches AreaHigh-Resolution Resistivity Correlation (DQO). SGW-32480, Rev. 0. Fluor Hanford, Inc., Richland, Washington.

Bentley LR and M Gharibi. 2004. "Two- and Three-Dimensional Electrical Resistivity Imaging at a Heterogeneous Remediation Site.” Geophysics 69:674-680.

Berg CR. 1995. “A Simple, Effective-Medium Model for Water Saturation in Porous Rocks.” Geophysics 60(4):1070-1080.

Bjornstad BN, GV Last, and DG Horton. 2003. “Hydrogeology of the Hanford Site Vadose Zone.” The 4th Symposium on the Hydrogeology of Washington State, Program and Abstracts. Washington State Department of Ecology, Olympia, Washington, p. 61. Available at: http://www.ecy.wa.gov/events/hg/PastSymposia/abstracts2003.pdf. Accessed 09-20-2008.

Bjornstad BN, KR Fecht, and CJ Pluhar. 2001. "Long History of Pre-Wisconsin, Ice Age Cataclysmic Floods: Evidence from Southeastern Washington State.” Journal of Geology 109(6):695-713.

Bjornstad BN. 2006. On the Trail of the Ice Age Floods: A Geological Field Guide to the Mid-Columbia Basin. Keokee Co. Publishing, Inc., Sandpoint, Idaho, 307 p.

Blake GR and KH Hartge. 1986. "Particle Density.” In: Methods of Soil Analysis, Part 1. Agronomy Volume 9, A. Klute, Editor. American Society of Agronomy, Soil Science Society of America, Madison, Wisconsin 9:377-382.

Blaschek R, A Hordt, and A Kemna. 2008. “A new sensitivity-controlled focusing regularization scheme for the inversion of induced polarization data based on the minimum gradient support.” Geophysics 73:F45-F54.

Brooks RH and AT Corey. 1964. Hydraulic Properties of Porous Media. Hydrology Paper 3. Colorado State University, Fort Collins, Colorado.

Brown CF, RJ Serne, BN Bjornstad, DG Horton, and DC Lanigan. 2006. Characterization of Vadose Zone Sediments Below the C Tank Farm: Borehole C4297 and RCRA Borehole 299-E27-22.

PNNL-15503, Pacific Northwest National Laboratory, Richland, Washington.

Brown CF, RJ Serne, HT Schaef, BA Williams, MM Valenta, VL LeGore, MJ Lindberg, KN Geiszler, SR Baum, IV Kutnyakov, TS Vickerman, and RE Clayton. 2005. Investigation of Accelerated Casing Corrosion in Wells from Waste Management Area A-AX: Wells 299-E24-19 and 299-E25-46.

PNNL-15141, Pacific Northwest National Laboratory, Richland, Washington.

Brunauer S, PH Emmett, and E Teller. 1938. “Adsorption of Gases in Multimolecular Layers.” Journal of the American Chemical Society 60:309-319. 
Brunner I, S Friedel, F Jacobs, and E Danckwardt. 1999. "Investigation of a Tertiary Maar Structure Using Three-Dimensional Resistivity Imaging.” Geophysical Journal International 136:771-780.

Busenberg E and CV Clemency. 1973. "Determination of the Cation Exchange Capacity of Clays and Soils Using an Ammonia Electrode.” Clays and Clay Minerals 21:213-217.

Cantrell KJ, RJ Serne, and GV Last. 2003. Hanford Contaminant Distribution Coeficient Database and Users Guide. PNNL-13895 Rev. 1, Pacific Northwest National Laboratory, Richland, Washington.

Connelly MP, JV Borghese, CD Delaney, BH Ford, JW Lindberg, and SJ Trent. 1992. Hydrogeologic Model for the 200 East Groundwater Aggregate Area. WHC-SD-EN-TI-019, Westinghouse Hanford Company, Richland, Washington.

Corbin RA, BC Simpson, MJ Anderson, WF Danielson III, JG Field, TE Jones, and CT Kincaid. 2005. Hanford Soil Inventory Model, Rev 1. RPP-26744, CH2M-HILL Hanford Group, Inc., Richland, Washington. This document was also released at the same time as PNNL-15367 by Pacific Northwest National Laboratory, Richland, Washington.

Crumpler JD. 2003. Site Specific SST Phase 1 RFI/CMS Work Plan Addendum for WMAs C, A-AX and U. RPP-16608, CH2M HILL Hanford Group, Inc., Richland, Washington.

Dahlin T and C Bernstone. 1997. "A Roll-Along Technique for 3D Resistivity Data Acquisition with Multi-Electrode Arrays.” In: Proceedings of the Symposium on the Application of Geophysics to Engineering and Environmental Problems, Volume 2. The Society, Golden, Colorado, pp. 927-935.

Dahlin T, C Bernstone, and MH Loke. 2002. “A 3-D Resistivity Investigation of a Contaminated Site at Lernacken, Sweden.” Geophysics 67(6):1692-1700.

Daily W, and E Owen. 1991. “Cross-Borehole Resistivity Tomography.” Geophysics 56:1228-1235.

Daily W, A Ramirez, A Binley, and D Labrecque. 2004a. “Electrical Resistance Tomography.” Leading Edge 23(5):438-442.

Daily W, A Ramirez, R Newmark, and K Masica. 2004b. "Low-Cost Reservoir Tomographs of Electrical Resistivity.” The Leading Edge 23(5):472-480.

Das UC and SK Verma. 1980. "Digital Linear Filter for Computing Type Curves for the Two-Electrode System of Resistivity Sounding.” Geophysical Prospecting 28:610-619.

Day-Lewis FD and K Singha. 2008. "Geoelectrical Inference of Mass Transfer Parameters Using Temporal Moments.” Water Resources Research 44: Art. No. W05201, doi:10.1029/2007WR006750.

de Lima OAL. 1995. "Water Saturation and Permeability from Resistivity, Dielectric, and Porosity Logs.” Geophysics 60:1756-1764.

deGroot-Hedlin C, and S Constable. 1990. "Occam's Inversion to Generate Smooth, Two-Dimensional Models from Magnetotelluric Data.” Geophysics 55:1613-1624. 
PNNL-17821

DOE (see U.S. Department of Energy)

Edwards LS. 1977. “A Modified Pseudo-Section for Resistivity and IP.” Geophysics 43(5):1020-1036.

Ellis RG, and DW Oldenburg. 1994. “Applied geophysical inversion.” Geophys. J. Int. 116:5-11.

EPA (see U.S. Environmental Protection Agency)

Fecht KR, BN Bjornstad, DG Horton, GV Last, SP Reidel, and KA Lindsey. 1999. Clastic Injection Dikes of the Pasco Basin and Vicinity: Geologic Atlas Series. BHI-01103, Rev. 0, Bechtel Hanford Company, Richland, Washington.

Fecht KR, SP Reidel, and AM Tallman. 1987. "Paleodrainage of the Columbia River System on the Columbia Plateau of Washington State-A Summary.” Washington Division of Geology and Earth Resources Bulletin 77:219-248.

Field JG and TE Jones. 2006. Tank Farm Vadose Zone Contamination Volume Estimates. RPP-23405 Rev. 2, CH2MHILL Hanford Group, Inc., Richland, Washington.

Fink JB. 1980. "Logarithmic Pseudo-Sections.” Abstract. In: Proceedings of the 50th Annual Meeting of the Society of Exploration Geophysicists.

Flathe H. 1976. "The Role of a Geologic Concept in Geophysical Research Work for Solving Hydrogeological Problems.” Geoexploration 14:195-206.

Folk RL. 1968. Petrology of Sedimentary Rocks. Hemphill, Austin, Texas.

Friedel S, A Thielen, and SM Springman. 2006. "Investigation of a Slope Endangered by RainfallInduced Landslides Using 3D Resistivity Tomography and Geotechnical Testing.” Journal of Applied Geophysics 60(2):100-114.

Gee GW and AL Ward. 2001. Vadose Zone Transport Field Study: Status Report. PNNL-13679, Pacific Northwest National Laboratory, Richland, Washington.

Gephart RE, RC Arnett, RG Baca, LS Leonhart, and FA Spane. 1979. Hydrologic Studies Within the Columbia Plateau, Washington, An Integration of Current Knowledge. RHO-BWI-ST-5, Rockwell Hanford Operations, Richland, Washington.

Gharibi M, and LR Bentley. 2005. "Resolution of 3-D Electrical Resistivity Images from Inversions of 2-D Orthogonal Lines.” Journal of Environmental and Engineering Geophysics 10(4):339-349.

Ghosh DP. 1971. "The Application of Linear Filter Theory to the Direct Interpretation of Geoelectric Resistivity Sounding Measurements.” Geophysical Prospecting 19:192-217.

Gibbs A. 1999. Compilation of Recent Radionuclide Data for Specific Activity, Specific Heat and Fission Product Yields. WSRC-TR-99-00344, Westinghouse Savannah River Complex, Aiken, South Carolina. 
Goggin DJ, RL Thrasher, and LW Lake. 1988. "A Theoretical and Experimental Analysis of Minipermeameter Response Including Gas Slippage and High Velocity Flow Effects, In Situ.” 12(1-2):79-116.

Gunther T, C Rucker, and K Spitzer. 2006. “Three-Dimensional Modelling and Inversion of DC Resistivity Data Incorporating Topography - II. Inversion.” Geophysical Journal International 166:506-517.

Hallof PG. 1957. On the Interpretation of Resistivity and Induced Polarization Measurements. Ph.D. Thesis, Massachusetts Institute of Technology, Cambridge, Massachusetts.

Hanai T. 1960. "Theory of the Dielectric Dispersion due to the Interfacial Polarisation and its Application to Emulsions.” Colloid \& Polymer Science 171:23-31.

Harmuth HF. 1972. Transmission of Information by Orthogonal Functions. Springer-Verlag, Berlin.

Higley BA, DE Place, RA Corbin, and BC Simpson. 2004. Hanford Defined Waste Model- Revision 5.0. RPP-19822, Rev 0, CH2M HILL Hanford Group, Inc., Richland, Washington.

Horton DG. 2007. Data Package for Past and Current Groundwater Flow and Contamination beneath Single-Shell Tank Waste Management Areas. PNNL-15837, Pacific Northwest National Laboratory, Richland, Washington.

Horton DG and SM Narbutovskih. 2001. RCRA Groundwater Monitoring Plan for Single-Shell Tank Waste Management Area C at the Hanford Site. PNNL- 13024, Pacific Northwest National Laboratory, Richland, Washington.

Hunt GR, GR Johnson, GR Olhoeft, DE Watson, and K Watson. 1979. “Electrical Properties.” In: Initial Report of the Petrophysics Laboratory. U.S. Geological Survey (USGS) Circular 789, 1-26. USGS, Denver, Colorado.

Koefoed O. 1970. "A Fast Method for Determining the Layer Distribution from the Raised Kernel Function in Geoelectrical Sounding.” Geophysical Prospecting 18:564-570.

Koefoed O. 1979. Geosounding Principles, I. Resistivity Sounding Measurements. Elsevier Science Ltd., Amsterdam.

Koefoed O, DP Ghosh, and GJ Polman. 1972. "Computation of Type Curves for Electromagnetic Depth Sounding with a Horizontal Transmitting Coil by Means of a Digital Linear Filter.” Geophysical Prospecting 20:406-420.

Koefoed O. 1972. “On Depth of Investigation in Direct Current Methods.” A Roy and A Apparao, Editors. Geophysics 37(5)703-704.

Koefoed O. 1976. "Progress in the Direct Interpretation of Resistivity Soundings: An algorithm.” Geophysical Prospecting 24:233-240. 
Kogan RM, IM Nazarov, and ShD Fridman. 1969. Gamma Spectrometry of Natural Environments and Formations, Jerusalem, Israel Program for Scientific Translations. Moskva Atomizdat, Moscow.

LaBrecque DJ, and X Yang. 2001. "Difference Inversion of ERT Data; a Fast Inversion Method for 3-D In Situ Monitoring.” Journal of Environmental and Engineering Geophysics 6(2):83-89.

LaBrecque DJ, M Miletto, W Daily, A Ramirez, and E Owen. 1996. "Effects of Noise on Occam's Inversion of Resistivity Tomography Data.” Geophysics 61(2):538.

Lanning EN and DM Johnson. 1983. "Automated Identification of Rock Boundaries: An Application of the Walsh Transform to Geophysical Well-Log Analysis.” Geophysics 48:197-205.

Lindsey KA, BN Bjornstad, JW Lindberg, and KM Hoffman. 1992. Geologic Setting of the 200 East Area - An Update. WHC-SD-EN-TI-012, Westinghouse Hanford Company, Richland, Washington.

Lindsey KA, KD Reynolds, and VM Johnson. 2004. 241-C Tank Farm Geologic and Stratigraphic Analysis. RPP-18290, Rev. 1, CH2M HILL Hanford Group, Inc., Richland, Washington.

Lindsey KA. 1995. Miocene-to Pliocene-Aged Suprabasalt Sediments of the Hanford Site, SouthCentral Washington. BHI-00184, Bechtel Hanford, Inc., Richland, Washington.

Lockner DA, and JD Byerlee. 1985. “Complex Resistivity Measurements of Confined Rock.” Journal of Geophysical Research 90:7837-7847.

Loke MH and RD Barker. 1995a. "Improvements to the Zohdy Method for the Inversion of Resistivity Sounding and Pseudosection Data.” Computers \& Geosciences 21(2):321.

Loke MH and RD Barker. 1996a. "Practical Techniques for 3D Resistivity Surveys and Data Inversion.” Geophysical Prospecting 44(3):499-523.

Loke MH and RD Barker. 1996b, "Rapid Least-Squares Inversion of Apparent Resistivity PseudoSections by a Quasi-Newton Method.” Geophysical Prospecting 44(1):131-152.

Loke MH, and T Dahlin. 2002. “A Comparison of the Gauss-Newton and Quasi-Newton Methods in Resistivity Imaging Inversion.” Journal of Applied Geophysics 49(3):149-162.

Loke MH, and RD Barker. 1995b. "Least-Squares Deconvolution of Apparent Resistivity Pseudosections.” Geophysics 60(6):1682.

Loke MH, I Acworth, and T Dahlin. 2003. “A Comparison of Smooth and Blocky Inversion Methods in 2D Electrical Imaging Surveys.” Exploration Geophysics 34(3):182-187.

Macdonald JR. 1985. “Generalizations of 'Universal Dielectric Response’ and a General Distributionof-Activation-Energies Model for Dielectric and Conducting Systems.” Journal of Applied Physics 58:1971-1978.

Maiti S and RK Tiwari. 2005. “Automatic Detection of Lithologic Boundaries Using the Walsh Transform: A Case Study from the KTB Borehole.” Computers \& Geosciences 31:949-955 
PNNL-17821

Mansoor M, and L Slater. 2007. “Aquatic Electrical Resistivity Imaging of Shallow-Water Wetlands. Geophysics 72(5):F211-F221.

Mualem Y. 1976. “A New Model for Predicting the Hydraulic Conductivity of Unsaturated Porous Media.” Water Resources Research 12:513-522.

Nyquist JE, and MJS Roth. 2005. "Improved 3D Pole-Dipole Resistivity Surveys using Radial Measurement Pairs.” Geophysical Research Letters 32: Art. No. L21416.

O’Neill DJ, and NP Merrick. 1984. "A Digital Linear Filter for Resistivity Sounding with a Generalized Array.” Geophysical Prospecting 32:105-123.

Ogilvy R, P Meldrum, J Chambers, and G Williams. 2002. "The Use of 3D Electrical Resistivity Tomography to Characterise Waste and Leachate Distributions within a Closed Landfill, Thriplow, UK.” Journal of Environmental and Engineering Geophysics 7:11-18.

Olayinka AI, and U Yaramanci. 2000. "Use of block inversion in the 2-D interpretation of apparent resistivity data and its comparison with smooth inversion.” Journal of Applied Geophysics 45:63-81.

Oldenborger GA, MD Knoll, PS Routh, and DJ LaBrecque. 2007. “Time-Lapse ERT Monitoring of an Injection/Withdrawal Experiment in a Shallow Unconfined Aquifer.” Geophysics 72(4):F177-F187.

Oldenburg DW and Y Li. 1999. "Estimating Depth of Investigation in DC Resistivity and IP surveys.” Geophysics 64(2):403-416.

Olenburg DW, Y Li, CG Farquharson, P Kowalczyk, T Aravanis, A King, P Zhang, and A Watts. 1998. "Applications of Geophysical Inversions in Mineral Exploration.” The Leading Edge 17(4):461-465.

Olhoeft GR. 1979. Electrical Properties. In: Initial Report of the Petrophysics Laboratory.

Olhoeft GR. 1985. “Low-Frequency Electrical Properties.” Geophysics 50:2492-2503.

Pacific Northwest Laboratory (PNL). 1990. Procedures for Groundwater Investigations. PNL MA-567, Pacific Northwest Laboratory, Richland, Washington.

Pacific Northwest National Laboratory (PNNL). 1997. Gamma Energy Analysis Operation and Instrument Verification Using the Genie2000 TM Support Software. PNNL-RRL-01, Pacific Northwest National Laboratory, Richland, Washington.

Pacific Northwest National Laboratory (PNNL). 1998. Inductively Coupled Plasma Mass Spectrometric (ICP-MS) Analysis. PNNL-AGG-415, Pacific Northwest National Laboratory, Richland, Washington.

Pacific Northwest National Laboratory (PNNL). 2005. Soil Water Content. PNNL-AGG-WC-001 Rev. 0, Pacific Northwest National Laboratory, Richland, Washington.

Pal PC. 1991. “A Waslsh sequency filtration method for integrating the resistivity log and sounding data.” Geophysics 56(8):1259-1266. 
PNNL-17821

Pidlisecky A, E Haber, and R Knight. 2007. RESINVM3D: A 3D resistivity inversion package GEOPHYSICS,72(2): H1-H10, DOI 10.1190/1.2402499.

Pluhar CJ, BN Bjornstad, SP Reidel, RS Coe, and PB Nelson. 2006. "Magnetostratigraphic Evidence from the Cold Creek Bar for Onset of Ice-age Cataclysmic Floods in Eastern Washington during the Early Pleistocene.” Quaternary Research 65:123-135.

Portniaguine O, and MS Zhdanov. 1999. “Focusing Geophysical Inversion Images.” Geophysics 64:874-887.

Price WH, and KR Fecht. 1976. Geology of the 241-C Tank Farm. ARH-LD- 132, Atlantic Richfield Hanford Company, Richland, Washington.

Raats PAC, ZF Zhang, AL Ward, and GW Gee. 2004. “The Relative Connectivity-Tortuosity Tensor for Conduction of Water in Anisotropic Unsaturated Soils.” Vadose Zone Journal 3(4):1471-1478.

Randall R, and R Price. 2005. Small Diameter Geophysical Logging at the 241-C-152 Diversion Box. RPP-34643, CH2M HILL Hanford Group, Inc, Richland, Washington.

Reidel SP, and KR Fecht. 2005. Geology of the Integrated Disposal Facility. PNNL-15237, Pacific Northwest National Laboratory, Richland, Washington.

Reidel SP, and MA Chamness. 2007. Geology Data Package for the Single-Shell Tank Waste Management Areas at the Hanford Site. PNNL-15955, Pacific Northwest National Laboratory, Richland, Washington.

Reidel SP, and PR Hooper. 1989. Volcanism and Tectonism in the Columbia River Flood-Basalt Province. GSA Special Paper \#239, Geological Society of America, Boulder, Colorado, 386 p.

Reidel SP, NP Campbell, KR Fecht, and KA Lindsey. 1994. Late Cenozoic Structure and Stratigraphy of South-Central Washington. Bulletin 80, Washington Division of Geology and Earth Resources. Washington Department of Natural Resources, Olympia, Washington.

Rhoades JD. 1996. "Salinity: Electrical Conductivity and Total Dissolved Solids.” In: Methods of Soil Analysis Part 3, JM Bigham, Editor, pp. 417-435. American Society of Agronomy, Madison, Wisconsin.

Robain H, YM Albouy, M Dabas, C Descloitres, P Camerlynck, P Mechler, and A Tabbagh. 1999. “The Location of Infinite Electrodes in Pole-Pole Electrical Surveys: Consequences for 2D Imaging.” Journal of Applied Geophysics 41(4):313-333.

Roberts JJ. 2002. "Electrical Properties of Microporous Rock as a Function of Saturation and Temperature.” Journal of Applied Physics 91(3):1687-1694.

Roberts JR, and W Lin. 1997. "Electrical Properties of Partially Saturated Tonopah Spring Tuff: Water Distribution as a Function of Saturation.” Water Resources Research 33(4):577-587. 
Rounds SA. 2006. “Alkalinity and Acid Neutralizing Capacity (version 3.0).” U.S. Geological Survey Techniques of Water-Resources Investigations, Book 9. Chapter A6. Available at: http://pubs.water.usgs.gov/twri9A6/. Accessed 09-20-2008.

Roy A. and A Apparao. 1971. "Depth of Investigation in Direct Current Methods.” Geophysics 36(5):943-959.

Roy A. 1972. "Depth of Investigation in Wenner, Three-Electrode, and Dipole-Dipole DC Resistivity Methods.” Geophysical Prospecting 20:329-340.

Rucker D, M Levitt, M. Bergeron, J. Greenwood, G O’Brien, M McNeill, B Cubbage, R McGill, S Gerring, and C Henderson. 2007. Surface Geophysical Exploration of the B, BX, and BY Tank Farms at the Hanford Site. RPP-34690, Rev. 0, CH2M-HILL Hanford Group, Inc., Richland, Washington.

Rucker DF and JB Fink. 2007. "Inorganic Plume Delineation Using Surface High-Resolution Electrical Resistivity at the BC Cribs and Trenches Site, Hanford.” Vadose Zone Journal 6(4):946-958.

Rucker DF, and MW Benecke. 2006. Geophysical Investigations by High Resolution Resistivity for the BC Cribs and Trenches Area, 2004-2006, Rev. 0. D\&D-31659, Fluor Hanford, Inc., Richland, Washington.

Rucker DF, MT Levitt, and WJ Greenwood. 2008. “Three-Dimensional Electrical Resistivity Model of a Nuclear Waste Disposal Site.” Submitted to Journal of Applied Geophysics (in review).

Schaap MG, and FJ Leij. 1998. "Database-Related Accuracy and Uncertainty of Pedotransfer Functions.” Soil Sciences 163:765-779.

Schuh WM, and RL Cline. 1990. "Effect of Soil Properties on Unsaturated Hydraulic Conductivity Pore-Interaction Factors.” Soil Science Society of America Journal 54:1509-1519.

Serne RJ, HT Schaef, BN Bjornstad, BA Williams, DC Lanigan, DG Horton, RE Clayton, VL LeGore, MJ O’Hara, CF Brown, KE Parker, IV Kutnyakov, JN Serne, AV Mitroshkov, GV Last, SC Smith, CW Lindenmeier, JM Zachara, and DS Burke. 2002a. Characterization of Vadose Zone Sediment: Uncontaminated RCRA Borehole Core Samples and Composite Samples. PNNL- 13757-1, Pacific Northwest National Laboratory, Richland, Washington.

Serne RJ, HT Schaef, BN Bjornstad, DC Lanigan, GW Gee, CW Lindenmeier, RE Clayton, VL LeGore, MJ O’Hara, CF Brown, RD Orr, GV Last, IV Kutnyakov, DS Burke, TC Wilson, and BA Williams. 2002b. Characterization of Vadose Zone Sediment: Borehole 299-W23-19 [SX-115] in the S-SX Waste Management Area. PNNL- 13757-2, Pacific Northwest National Laboratory, Richland, Washington.

Serne RJ, GV Last, HT Schaef, DC Lanigan, CW Lindenmeier, CC Ainsworth, RE Clayton, VL LeGore, MJ O’Hara, CF Brown, RD Orr, IV Kutnyakov, TC Wilson, KB Wagnon, BA Williams, and DB Burke. 2002c. Characterization of Vadose Zone Sediment, Part 4: Slant Borehole SX-108 in the S-SX Waste Management Area. PNNL- 13757-4, Pacific Northwest National Laboratory, Richland, Washington.

Serne RJ, GV Last, GW Gee, HT Schaef, DC Lanigan, CW Lindenmeier, RE Clayton, VL LeGore, RD Orr, MJ O’Hara, CF Brown, DS Burke, AT Owen, IV Kutnyakov, and TC Wilson. 2002d. 
Characterization of Vadose Zone Sediment: Borehole 41-09-3 9 in the S-SX Waste Management Area. PNNL-13757-3, Pacific Northwest National Laboratory, Richland, Washington.

Serne RJ, GV Last, GW Gee, HT Schaef, DC Lanigan, CW Lindenmeier, MJ Lindberg, RE Clayton, VL LeGore, RD Orr, IV Kutnyakov, SR Baum, KN Geiszler, CF Brown, MM Valenta, and TS Vickerman. 2002e. Characterization of Vadose Zone Sediment: Borehole 299-E33-45 Near BX-102 in the B-BX-BY Waste Management Area. PNNL- 14083, Pacific Northwest National Laboratory, Richland, Washington.

Serne RJ, BN Bjornstad, GW Gee, HT Schaef, DC Lanigan, CW Lindenmeier, RD Orr, VL LeGore, RE Clayton, MJ Lindberg, IV Kutnyakov, SR Baum, KN Geiszler, MM Valenta, TS Vickerman, and LJ Royack. 2002f. Characterization of Vadose Zone Sediment: Borehole 299-E33-46 Near B-110 in the BBX-BY Waste Management Area. PNNL-141 19, Pacific Northwest National Laboratory, Richland, Washington.

Serne RJ, BN Bjornstad, DG Horton, DC Lanigan, CW Lindenmeier, MJ Lindberg, RE Clayton, VL LeGore, RD Orr, IV Kutnyakov, SR Baum, KN Geiszler, MM Valenta, and TS Vickerman. 2004a. Characterization of Vadose Zone Sediments Below the TX Tank Farm: Boreholes C3830, C3831, C3832 and RCRA Borehole 299- W10-2 7. PNNL-14594, Pacific Northwest National Laboratory, Richland, Washington.

Serne RJ, BN Bjornstad, DG Horton, DC Lanigan, HT Schaef, CW Lindenmeier, MJ Lindberg, RE Clayton, VL LeGore, KN Geiszler, SR Baum, MM Valenta, IV Kutnyakov, TS Vickerman, RD Orr, and CF Brown. 2004b. Characterization of Vadose Zone Sediments Below the T Tank Farm: Boreholes C4104, C4105, 299-W10-196, and RCRA Borehole 299-W11-39. PNNL-14849, Pacific Northwest National Laboratory, Richland, Washington.

Silva O, and J Grifoll. 2007. “A Soil-Water Retention Function that Includes the Hyper-Dry Region through the BET Adsorption Isotherm.” Water Resources Research 43: Art. No. W11420. doi:10.1029/2006WR005325

Singha K, and SM Gorelick. 2006. "Effects of Spatially Variable Resolution on Field-Scale Estimates of Tracer Concentration from Electrical Inversions Using Archie’s Law.” Geophysics 71(3):G83-G91.

Sisson JB and A Lu. 1984. Field Calibration of Computer Models for Application to Buried Liquid Discharges: A Status Report. RHO-ST-46 P, Rockwell Hanford Operations, Richland, Washington.

Slater L, A Binley, R Versteeg, G Cassiani, R Birkin, and S Sandberg. 2002. “A 3D ERT Study of Solute Transport in a Large Experimental Tank.” Journal of Applied Geophysics 49(4):211-229.

Slater L, AM Binley, W Daily, and R Johnson. 2000. "Cross-Hole Electrical Imaging of a Controlled Saline Tracer Injection.” Journal of Applied Geophysics 44(2-3):85-102.

Smith GA. 1993. "Missoula Flood Dynamics and Magnitudes Inferred from Sedimentology of SlackWater Deposits on the Columbia Plateau.” Geological Society of American Bulletin 195:77-100.

Smith NC and K Vozoff. 1984. “Two-Dimensional DC Resistivity Inversion for Dipole-Dipole Data.” IEEE Transactions on Geoscience Remote Sensing 22:21-28. 
Smith T, M Hoversten, E Gasperikova, and F Morrison. 1999. "Sharp boundary inversion of 2D magnetotelluric data.” Geophys. Prospect. 47:469-486.

Stummer P, H Maurer, and AG Green. 2004. "Experimental Design; Electrical Resistivity Data Sets that Provide Optimum Subsurface Information.” Geophysics 69(1):120-139.

Suarez DL. 1996. “Chapter 20- Beryllium, Magnesium, Calcium, Strontium, and Barium.” In: American Society of Agronomy (ASA). Methods of Soil Analysis-Part 3. Chemical Methods, SSSA Book Series 5.” DL Sparks, Editor. Soil Science Society of America, Madison, Wisconsin.

Tallman AM, KR Fecht, M Marratt, and GV Last. 1979. Geology of the Separations Areas, Hanford Site, South-Central Washington. RHO-ST-23, Rockwell Hanford Operations, Richland, Washington.

Taylor S and R Barker. 2006. "Modeling the DC Electrical Response of Fully and Partially Saturated Permo-Triassic Sandstone.” Geophysical Prospecting 54:351-367.

Tidwell VC and JL Wilson. 1999. "Permeability Upscaling Measured on a Block of Berea Sandstone: Results and Interpretation.” Mathematical Geology 31(7):749-769.

Tidwell VC and JL Wilson. 1997. "Laboratory Method for Investigating Permeability Upscaling." Water Resources Research 33(7):1607-1616.

Tikhonov AN, and VY Arsenin. 1977. Solution of Ill-Posed Problems. V H Winston and Sons.

Tripp AC, GW Hohmann, and JCM Swift. 1984. “Two-Dimensional Resistivity Inversion.” Geophysics 49(10):1708-1717.

Tuli A, JW Hopmansa, DE Rolston, and P Moldrup. 2005. “Comparison of Air and Water Permeability between Disturbed and Undisturbed Soils.” Soil Sci. Soc. Am. J. 69:1361-1371.

U.S. Department of Energy (DOE). 1998. Vadose Zone Characterization Project at the Hanford Tank Farms, C Tank Farm Report. GJO-HAN-27. Prepared by U.S. Department of Energy Grand Junction Office, for U.S. Department of Energy, Richland Operations Office, Richland, Washington.

U.S. Department of Energy-Richland Operations Office (DOE/RL). 1988. Consultation Draft Site Characterization Plan. DOE/RL-0164, 9 Volumes, DOE/RL, Richland, Washington.

U.S. Department of Energy-Richland Operations Office (DOE/RL). 1997. Hanford Site Background: Part 3, Groundwater Background. DOE/RL-96-61, Rev. 0, U.S. Department of Energy, Richland, Washington.

U.S. Department of Energy-Richland Operations Office (DOE/RL). 1999. Phase 1 RCRA Facility Investigation/Corrective Measures Study Work Plan for the Single-Shell Tank Waste Management Areas. DOE/RL-99-36, Rev. 0, DOE/RL, Richland, Washington.

U.S. Department of Energy-Richland Operations Office (DOE/RL). 2002. Standardized Stratigraphic Nomenclature for Post-Ringold-Formation Sediments Within the Central Pasco Basin. DOE/RL-200239, U.S. DOE/RL, Richland, Washington. 
U.S. Department of Energy-Office of River Protection (DOE/ORP). 2006. Initial Single-Shell Tank Performance Assessment for the Hanford Site. DOE/ORP-2005-01, Richland, Washington.

U.S. Environmental Protection Agency (EPA). 1984. "EPA Method 300.0A.” Test Method for the Determination of Inorganic Anions in Water by Ion Chromatography. EPA-600/4-84-0 17, EPA, Washington, D.C.

U.S. Environmental Protection Agency (EPA). 2000a. EPA Method 3050B. “Acid Digestion of Sediments, Sludges, and Soils.” Test Methods for Evaluating Solid Waste, Physical/Chemical Methods. EPA Publication SW-846, EPA, Washington, D.C. Online manual. Available at: http://www.epa.gov/epaoswer/hazwaste/test/sw846.htm. Accessed 09-20-2008.

U.S. Environmental Protection Agency (EPA). 2000b. EPA Method 6010B. "Inductively Coupled Plasma-Atomic Emission Spectrometry.” Test Methods for Evaluating Solid Waste, Physical/Chemical Methods. EPA Publication SW-846, EPA, Washington, D.C. Online manual. Available at: http://www.epa.gov/epaoswer/hazwaste/test/sw846.htm. Accessed 09-20-2008.

U.S. Environmental Protection Agency (EPA). 2000c. EPA Method 6020. "Inductively Coupled Plasma-Mass Spectrometry.” Test Methods for Evaluating Solid Waste, Physical/Chemical Methods. EPA Publication SW-846, EPA, Washington, D.C. Online manual. Available at: http://www.epa.gov/epaoswer/hazwaste/test/sw846.htm. Accessed 09-20-2008.

U.S. Geological Survey (USGS). 2004. “Alkalinity and Acid Neutralizing Capacity.” National Field Manual for the Collection of Water-Quality Data, Second Edition. SA Rounds and FD Wilde, Editors. March 23, 2004. Available at:

http://water.usgs.gov/owq/FieldManual/Chapter6/section6.6/html/section6.6.htm. Accessed 09-20-2008.

Udden JA. 1914. "Mechanical Composition of Clastic Sediments.” Geol. Soc. Am. Bull. 25: 655-744.

Um W, and RJ Serne. 2005. "Sorption and Transport Behavior of Radionuclides in the Proposed LowLevel Radioactive Waste Facility at the Hanford Site, Washington.” Radiochimica Acta 93:57-63.

van Genuchten MT. 1980. “A Closed-Form Equation for Predicting the Hydraulic Conductivity of Unsaturated Soils.” Soil Science Society of America Journal 44:892-898.

van Overmeeren RA. 1989. "Aquifer Boundaries Explored by Geoelectrical Measurements in the Central Plains of Yemen: A Case of Equivalence.” Geophysics 54: 38-48.

Wait JR. 1982. Geo-Electromagnetism. Academic Press, New York.

Waitt RB, Jr. 1980. “About Forty Last-Glacial Jokulhlaups Through Southern Washington.” Journal of Geology 88:653-679.

Ward AL and GW Gee. 2000. Vadose Zone Transport Field Study: Detailed Test Plan for Simulated Leak Tests. PNNL-13263, Pacific Northwest National Laboratory, Richland, Washington.

Ward AL and GW Gee. 2001. Vadose Zone Transport Field Study: FY 2001 Test Plan. PNNL-13451, Rev. 1., Pacific Northwest National Laboratory, Richland, Washington. 
Ward AL and GW Gee. 2002. Vadose Zone Transport Field Study: FY 2002 Test Plan. PNNL-13857, Pacific Northwest National Laboratory, Richland, Washington.

Ward AL, and GW Gee. 2003. Vadose Zone Transport Field Study FY 2003 Test Plan. PNNL-14240, Pacific Northwest National Laboratory, Richland, Washington.

Ward AL, ZF Zhang, and GW Gee. 2006a. "Upscaling Unsaturated Hydraulic Parameters for Flow through Heterogeneous Anisotropic Sediments.” Advances in Water Resources 29:268-280.

Ward AL, ME Conrad, WD Daily, JB Fink, VL Freedman, GW Gee, GM Hoversten, JM Keller, EL Majer, CJ Murray, MD White, SB Yabusaki, and ZF Zhang. 2006b. Vadose Zone Transport Field Study: Summary Report. PNNL-15443, Pacific Northwest National Laboratory, Richland, Washington.

Ward AL, GW Gee, ZF Zhang, and JM Keller. 2006c. Vadose Zone Contaminant Fate-And-Transport Analysis for the 216-B-26 Trench. PNNL-14907, Pacific Northwest National Laboratory, Richland, Washington.

Waxman MH, and LJM Smits. 1968. "Electrical Conductivities in Oilbearing Shaly-Sand.” Journal of the Society of Petroleum Engineering 8:107-122.

Weiner BB. 1984. “Particle and Droplet Sizing Using Fraunhofer Diffraction.” In: Modern Methods of Particle Size Analysis. HG Barch, Editor, p 135, John Wiley \& Sons, New York.

Wentworth CK. 1922. “A Grade Scale and Class Terms for Clastic Sediments.” Journal of Geology 30:377-392.

Williams BA, BN Bjornstad, R Schalla, and WD Webber. 2000. Revised Hydrogeology for the Suprabasalt Aquifer System, 200-East Area and Vicinity, Hanford Site, Washington. PNNL-12261, Pacific Northwest National Laboratory, Richland, Washington.

Winfield, KA and JR Nimmo. 2002. "Controlled Liquid Volume.” In: Methods of Soil Analysis, Part 4-Physical Methods, Soil Science Society of America, Madison, Wisconsin, pp. 698-703.

Wood MI, TE Jones, BN Bjornstad, DG Horton, SM Narbutovskih, and R Schalla. 2003. Subsurface Conditions Description of the C and A-AX Waste Management Areas. RPP- 14430, Rev. 0, CH2M HILL Hanford Group, Inc., Richland, Washington.

Worthington PF, and RD Barker. 1972. "Methods for the Calculation of True Formation Factors in the Bunter Sandstone of Northwest England.” Engineering Geology 6:213-228.

Zhang ZF, AL Ward, and GW Gee. 2003. “A Tensorial Connectivity-Tortuosity Concept to Describe the Unsaturated Hydraulic Properties of Anisotropic Soils.” Vadose Zone Journal 2:313-321.

Zhang ZF, AL Ward, and GW Gee. 2004. A Parameter Scaling Concept for Estimating Field-Scale Hydraulic Functions of Layered Soils.” Journal of Hydraulic Research 42:93-103. 
Zhou W, BF Beck, and JB Stephenson. 2000. "Reliability of Dipole-Dipole Electrical Resistivity Tomography for Defining Depth to Bedrock in Covered Karst Terranes.” Environmental Geology 39(7):760-766.

Zohdy AAR. 1989. “A New Method for the Automated Interpretation of Schlumberger and Wenner Sounding Curves.” Geophysics 54:245-253. 


\section{Appendix A}

\section{Geologist Logs for Samples Opened in the Lab From} Boreholes in the BC Cribs and Trenches Area 


\section{Appendix A \\ Geologist Logs for Samples Opened in the Lab From Boreholes in the BC Cribs and Trenches Area}

$\underline{B C}$ Cribs and Trenches Boreholes - Lab Sample Geologist Logs

Geologic Logs for Lab Samples from Borehole C5923 (299-E13-62)..

Geologic Logs for Lab Samples from Borehole C5924 (299-E13-63)

Geologic Logs for Lab Samples from Borehole C5925 (299-E13-64).

A.26 


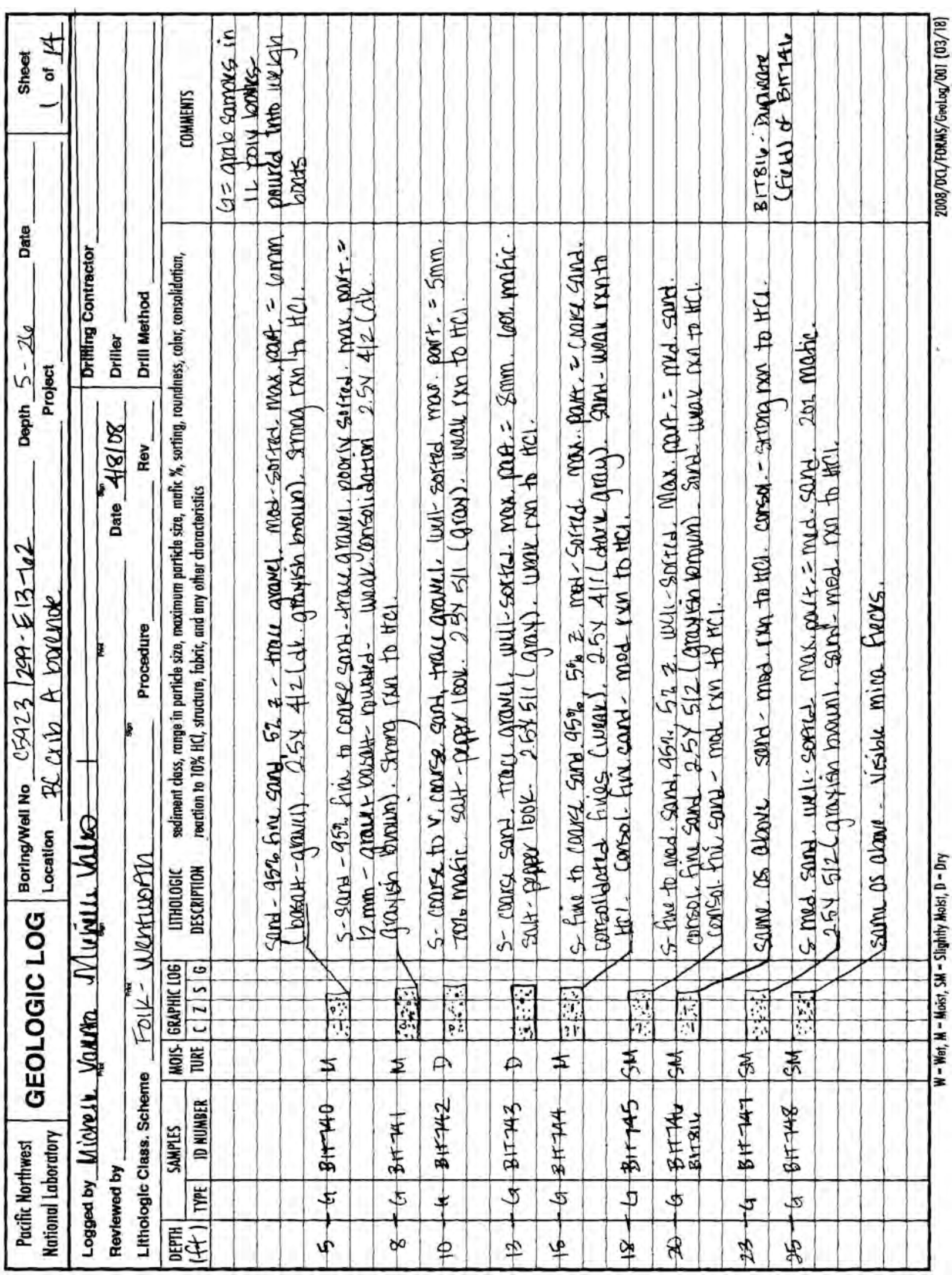




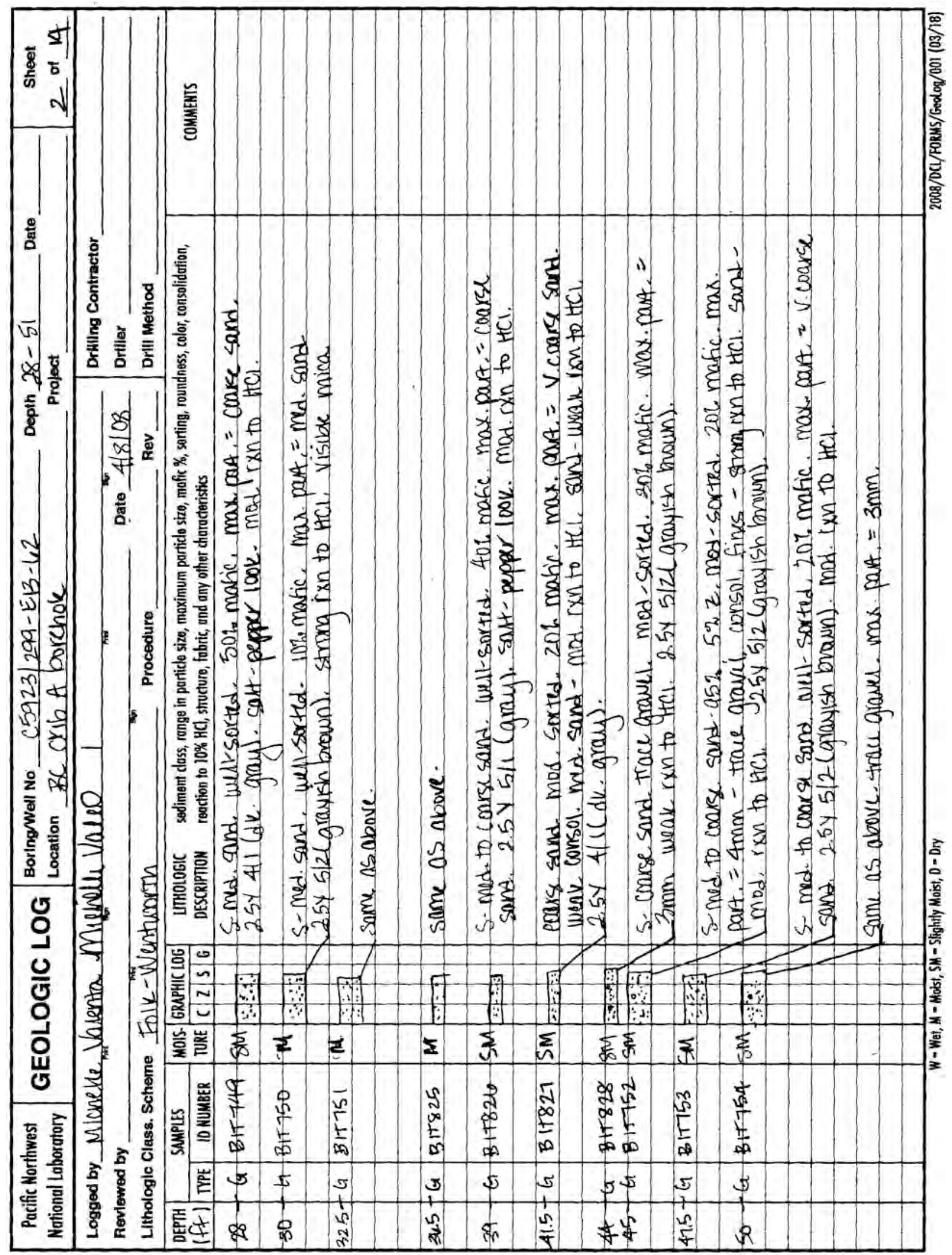




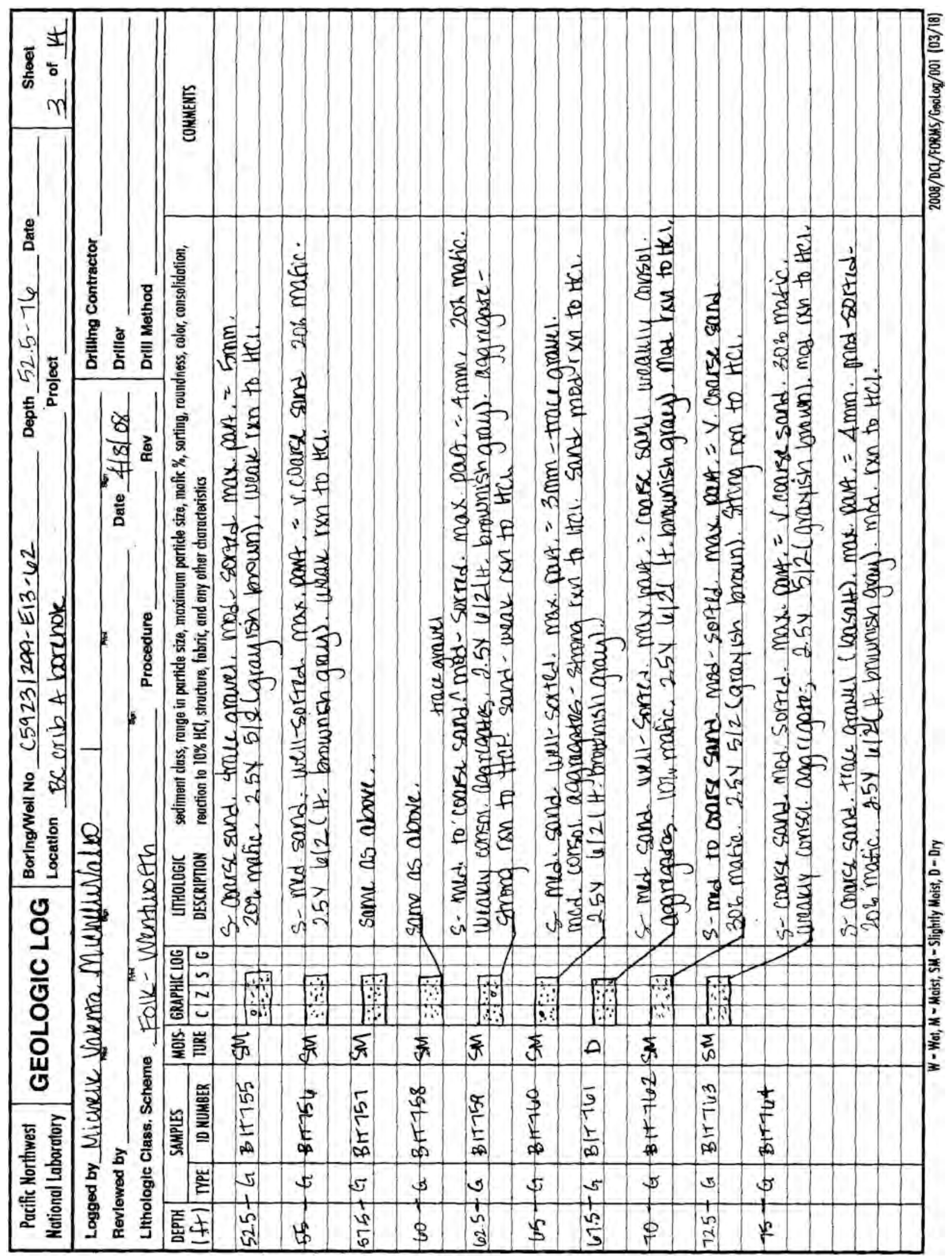




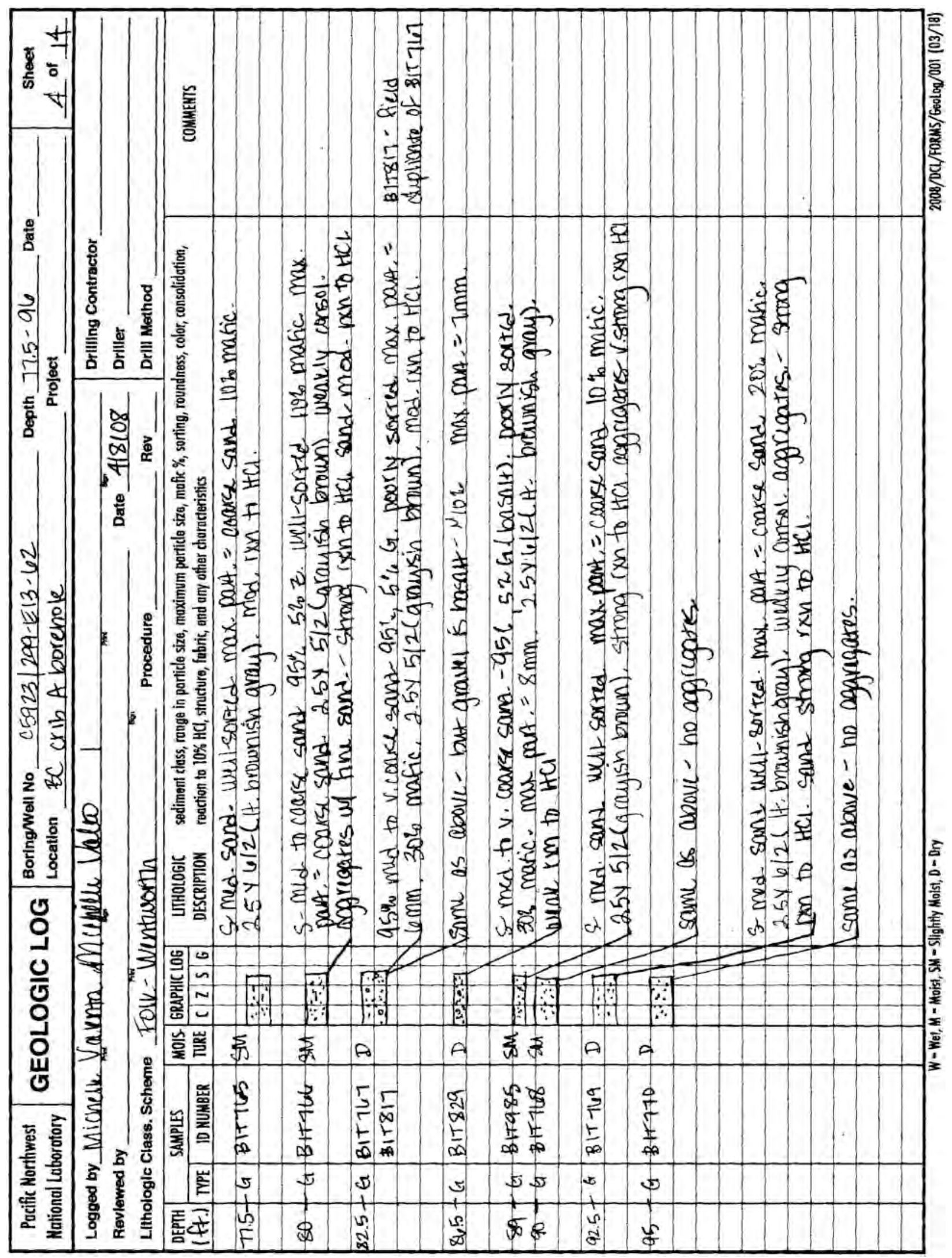


PNNL-17821

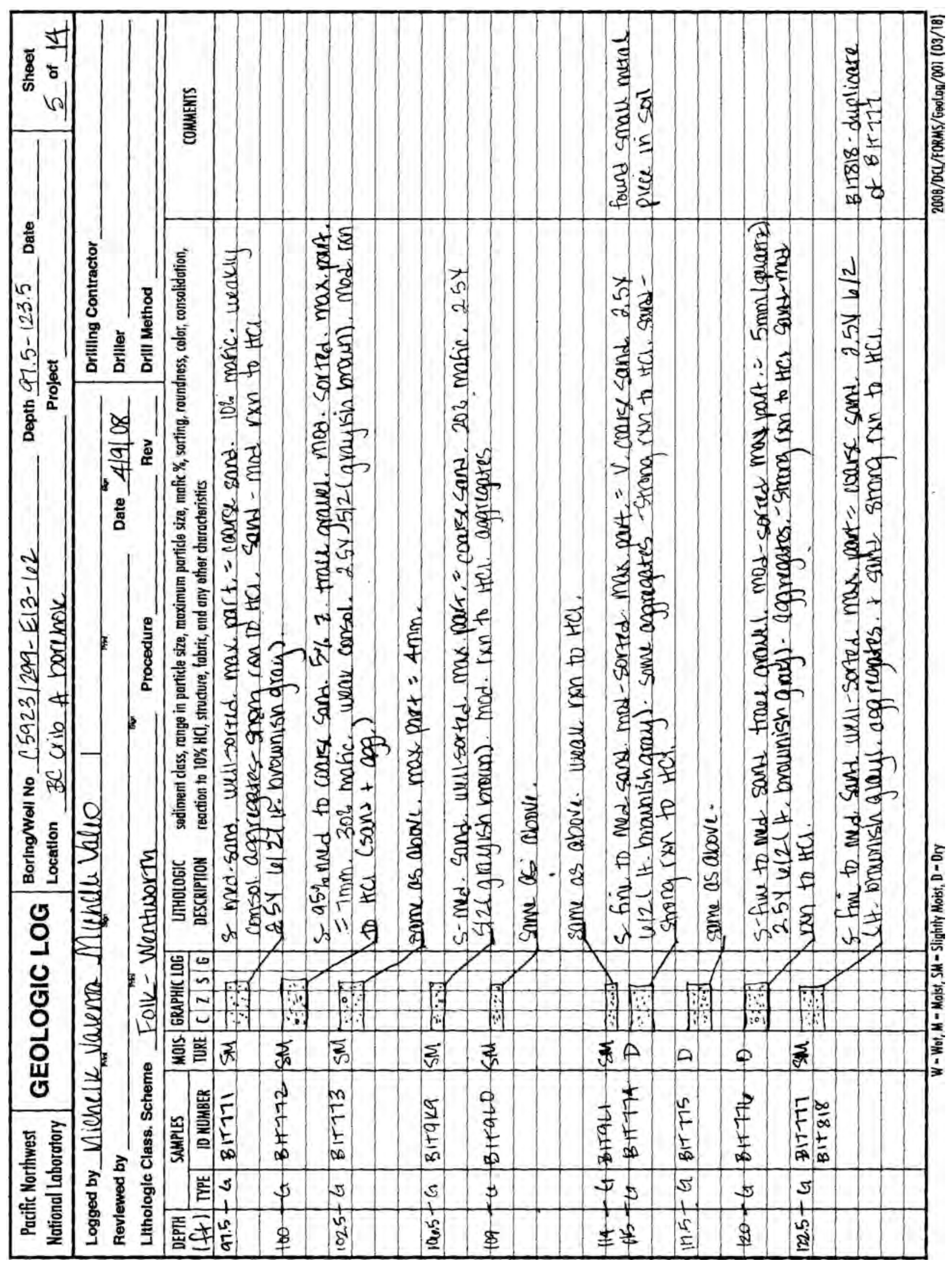




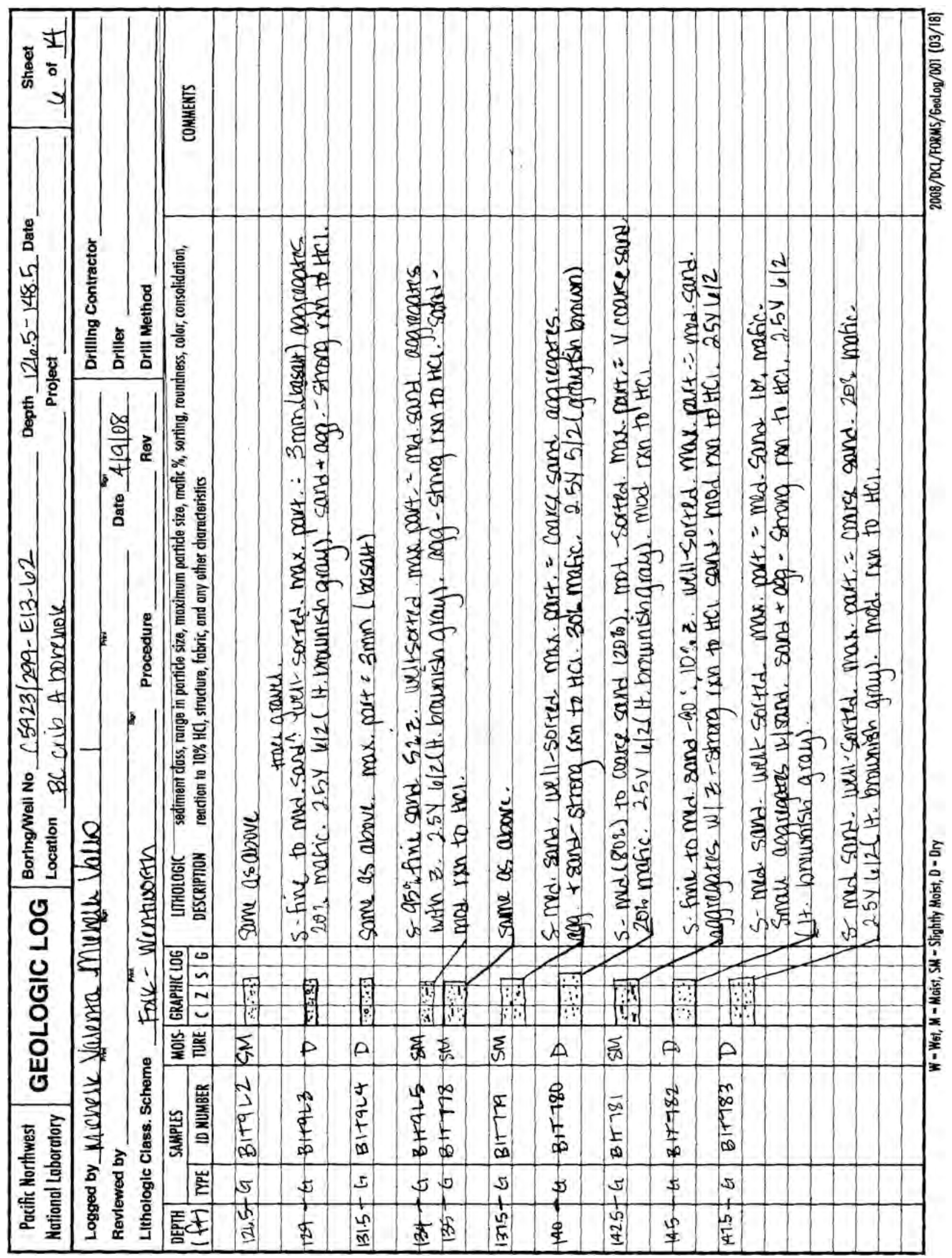




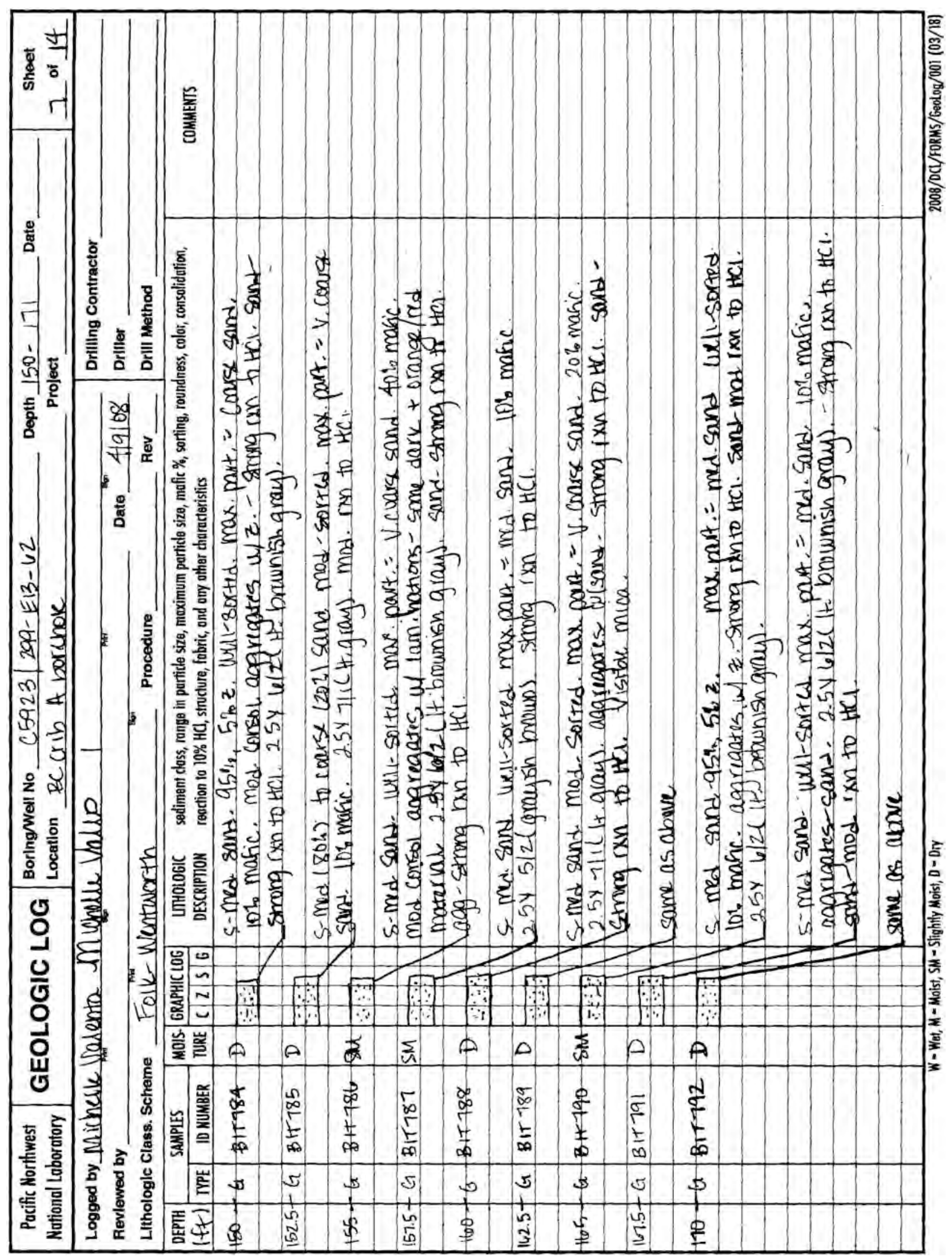




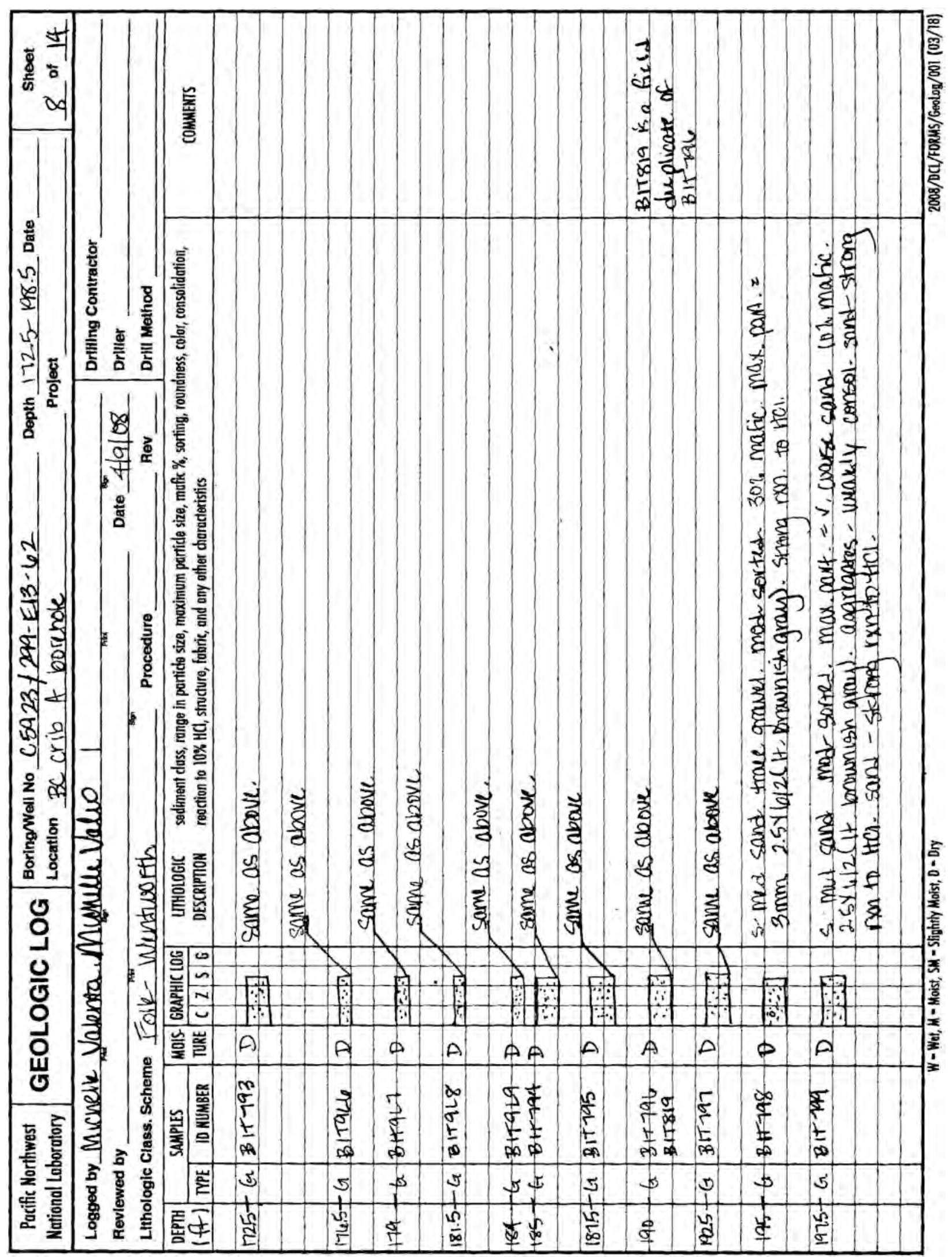




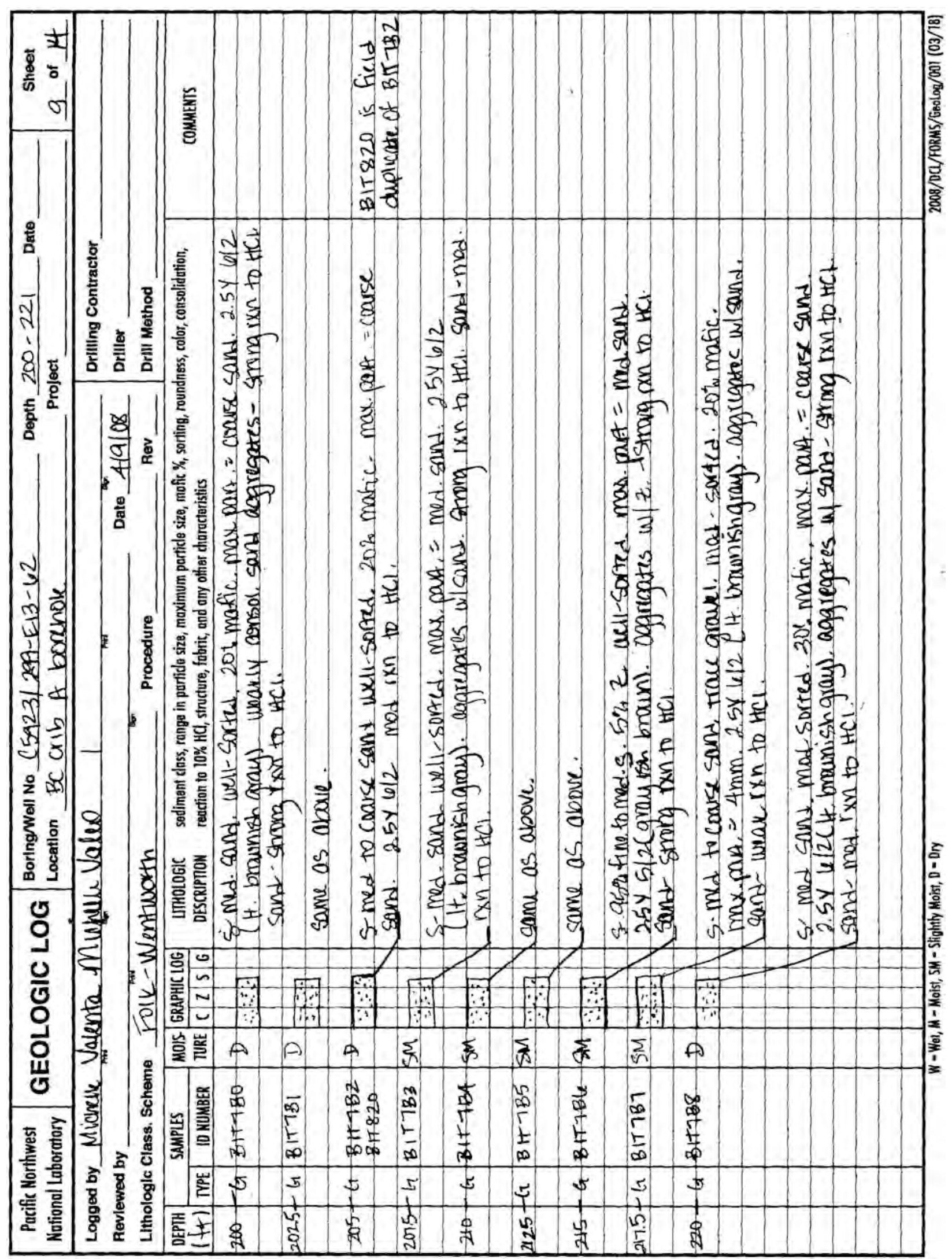




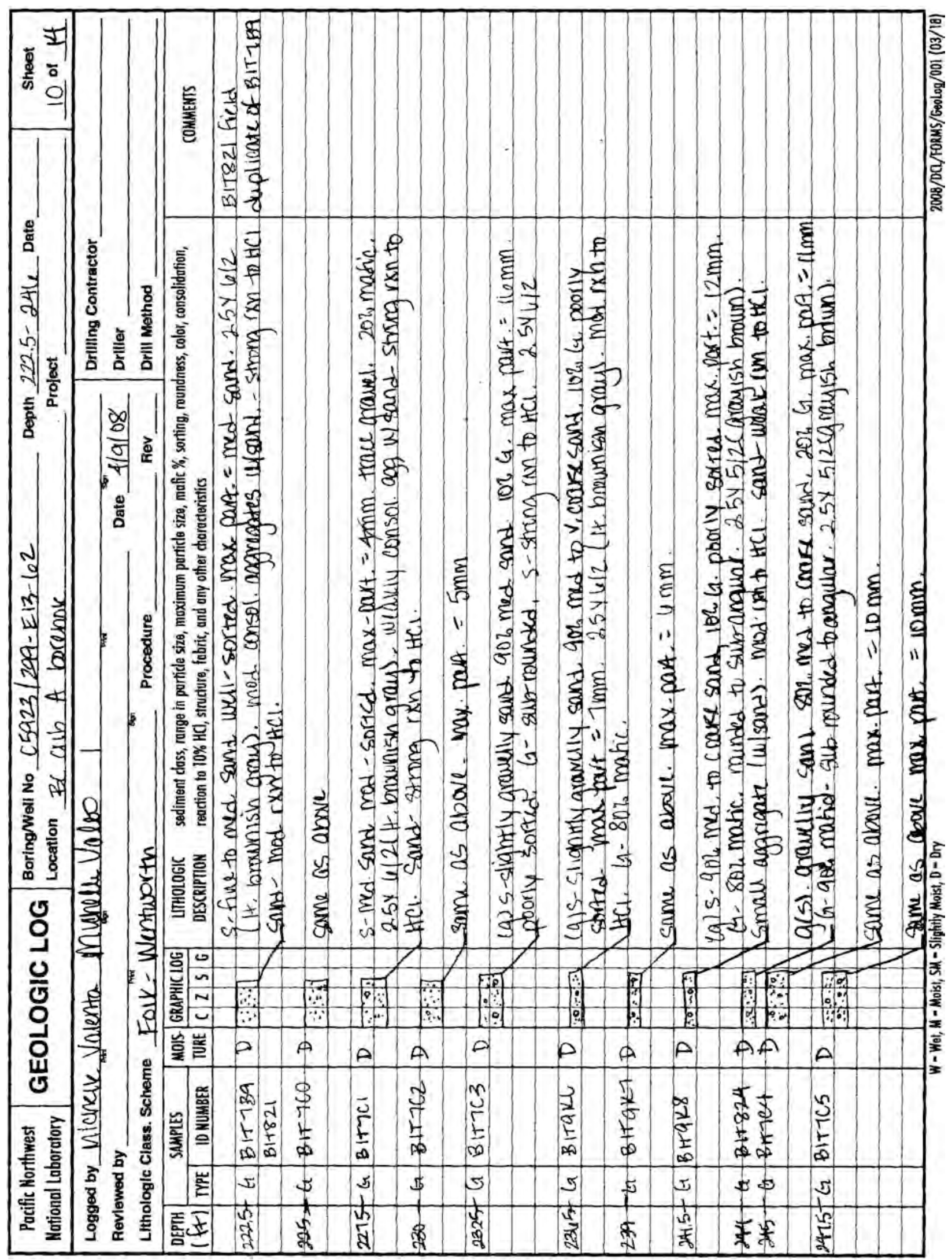




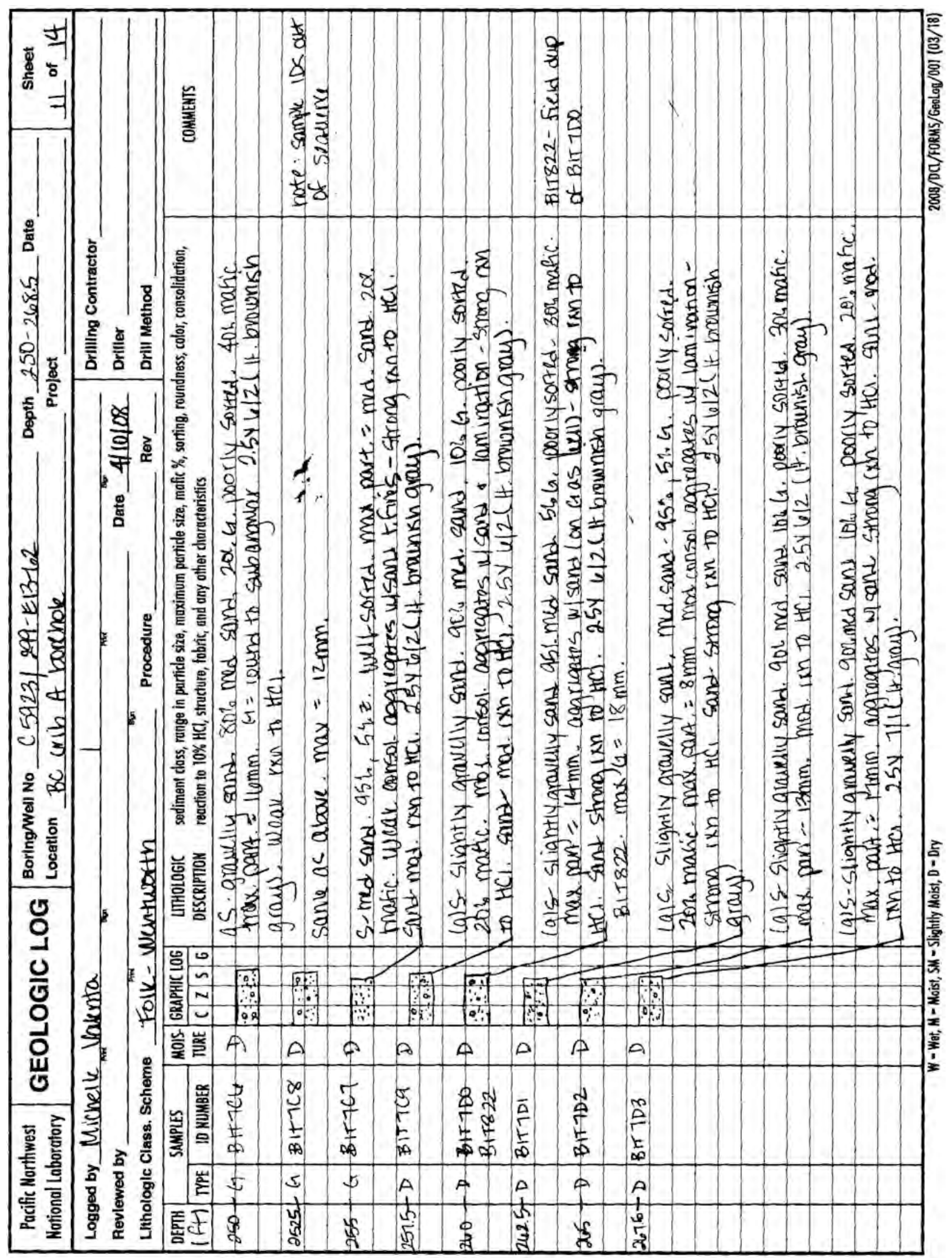




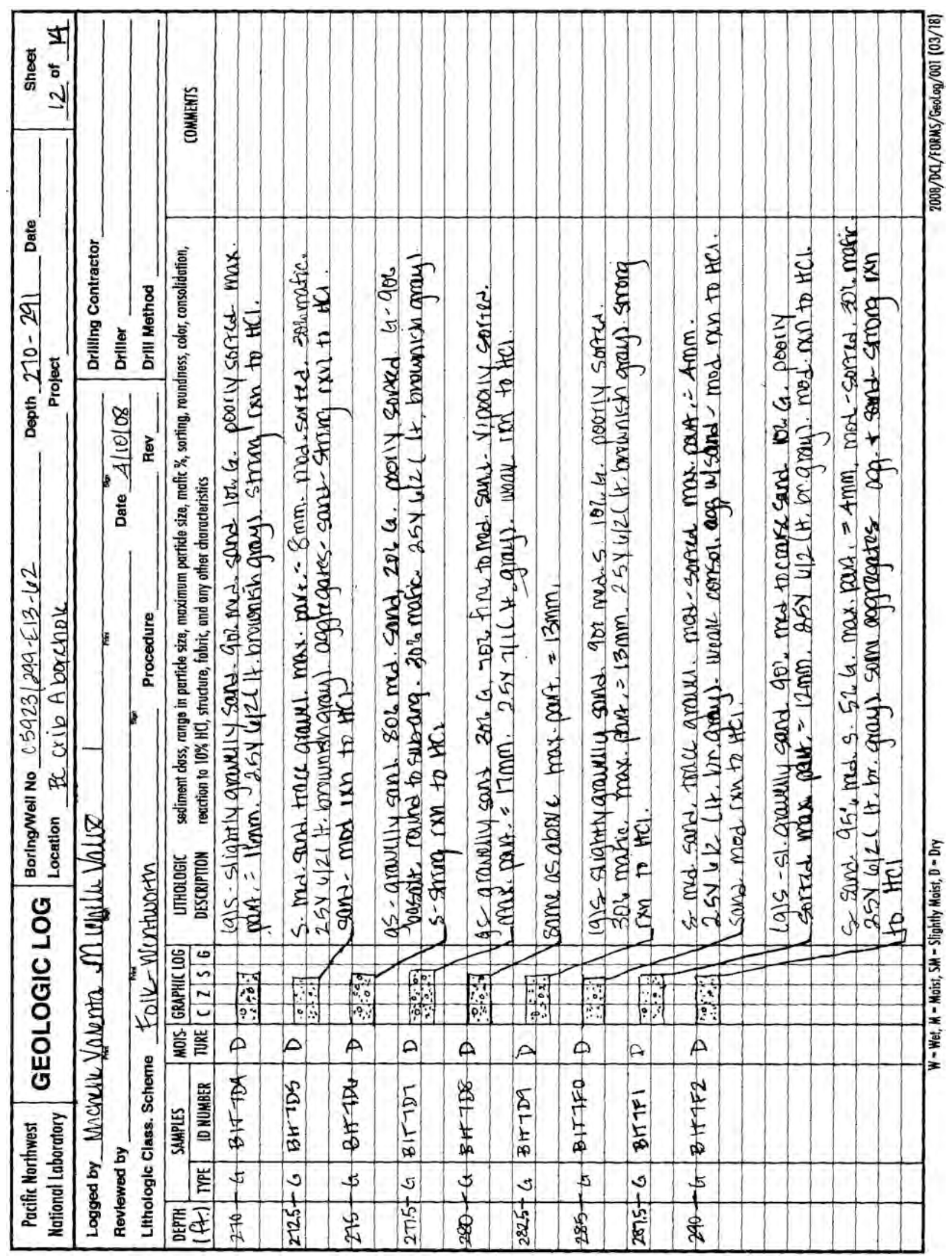




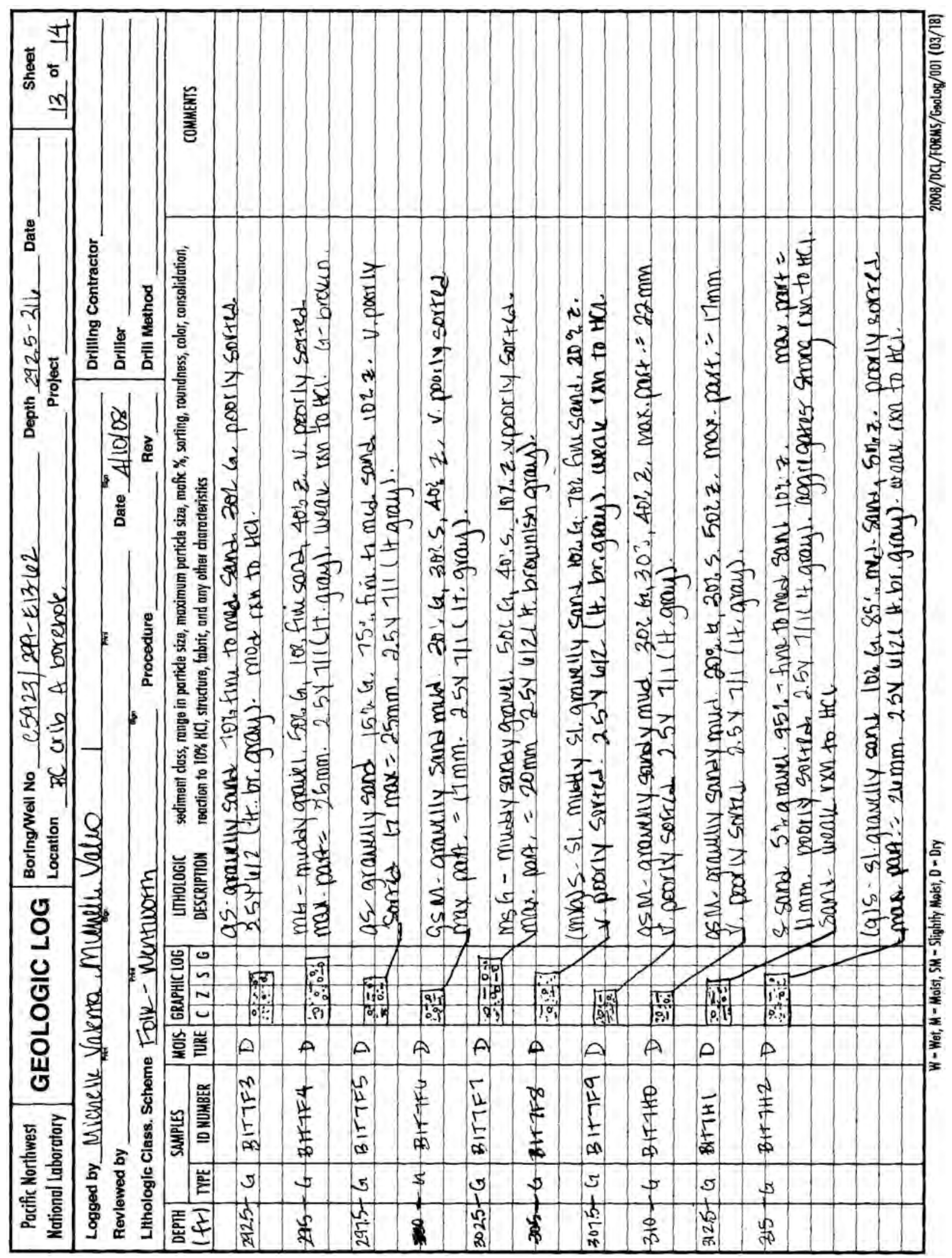




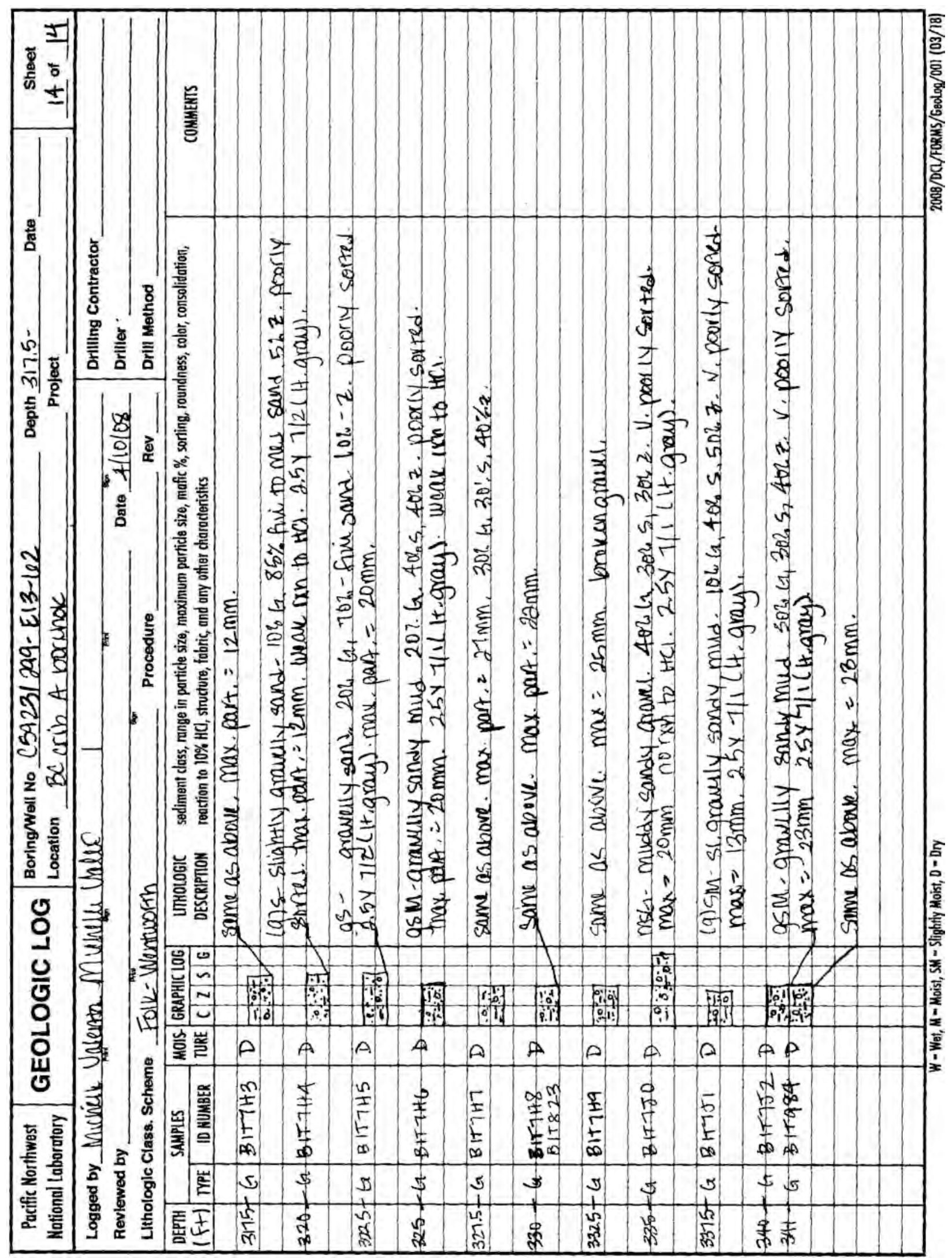




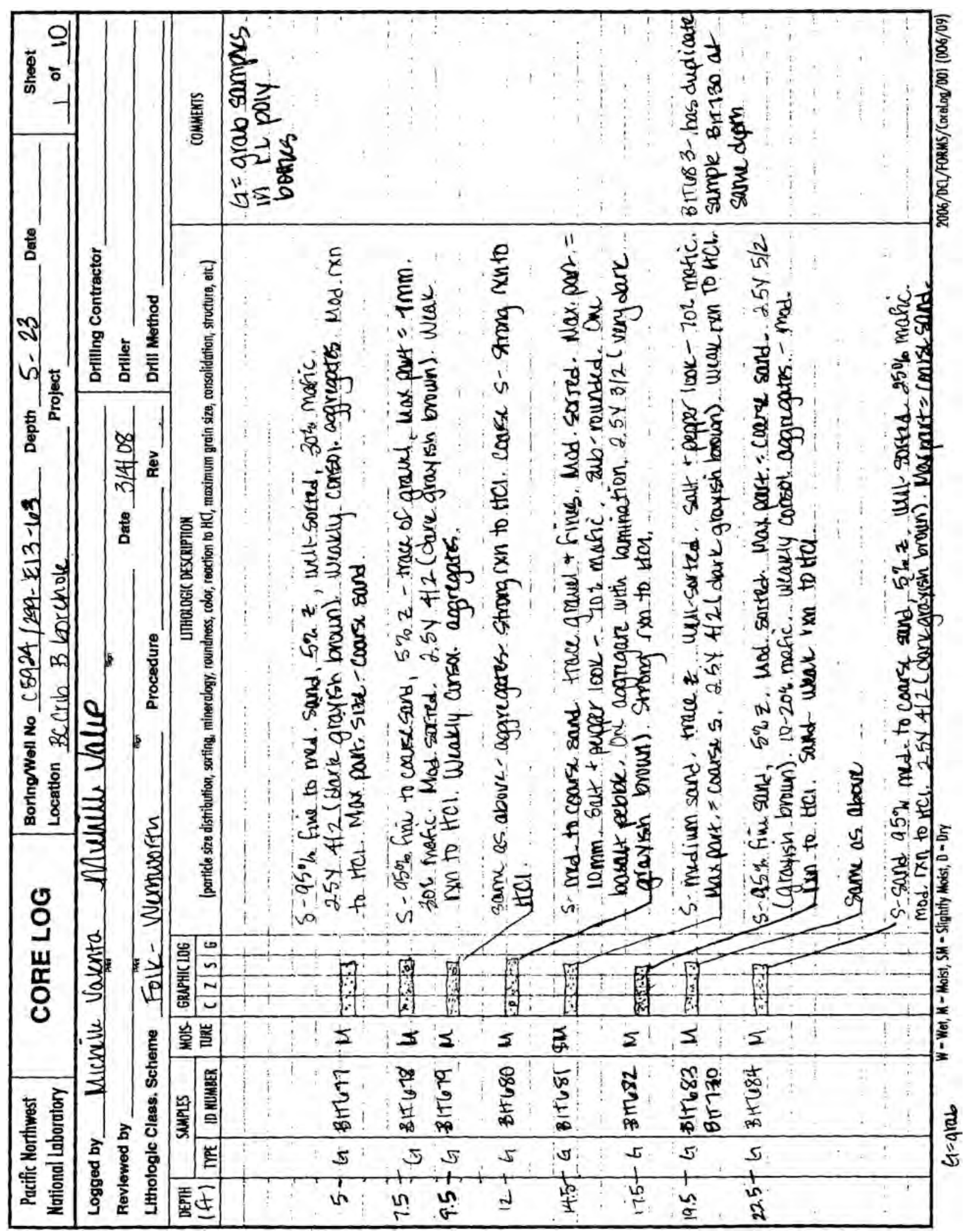




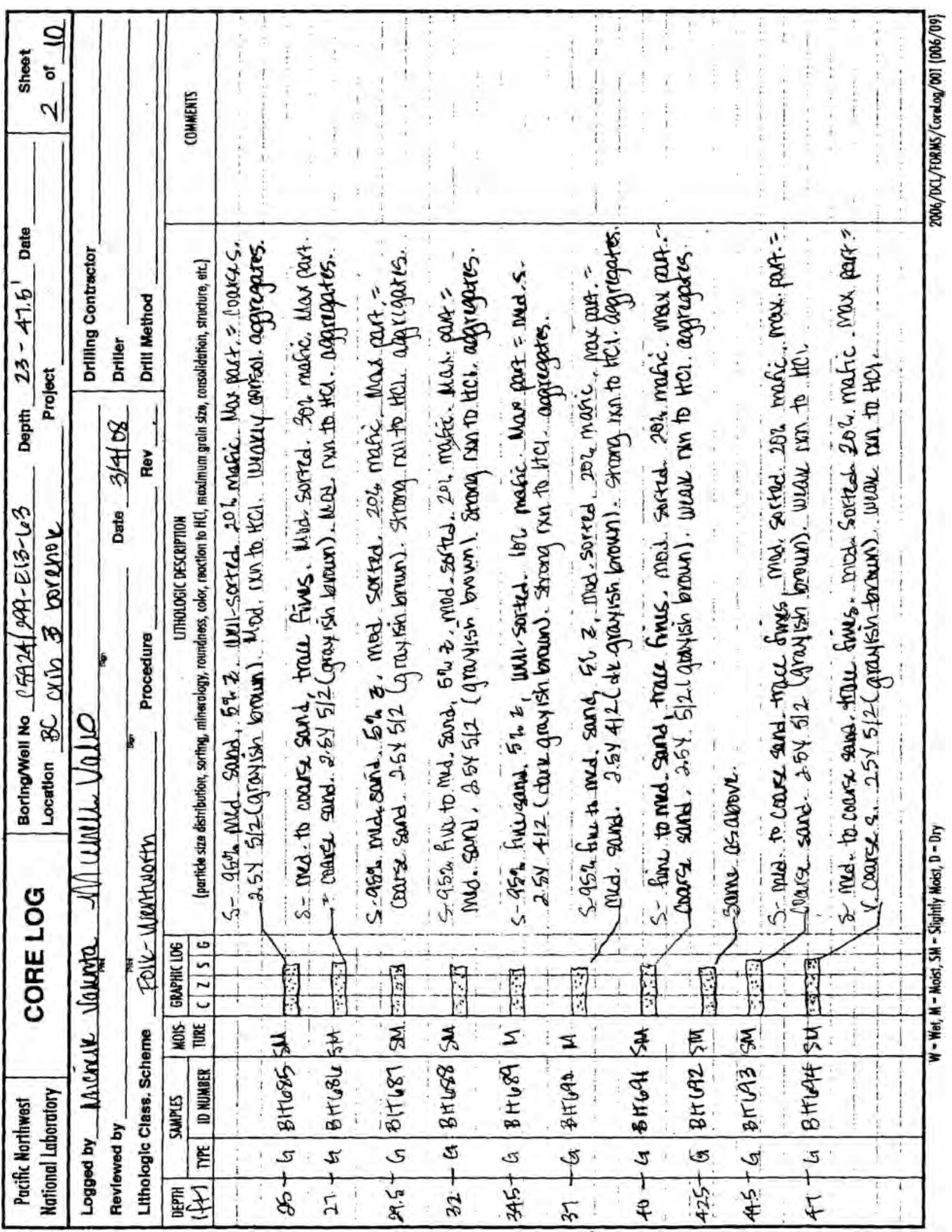




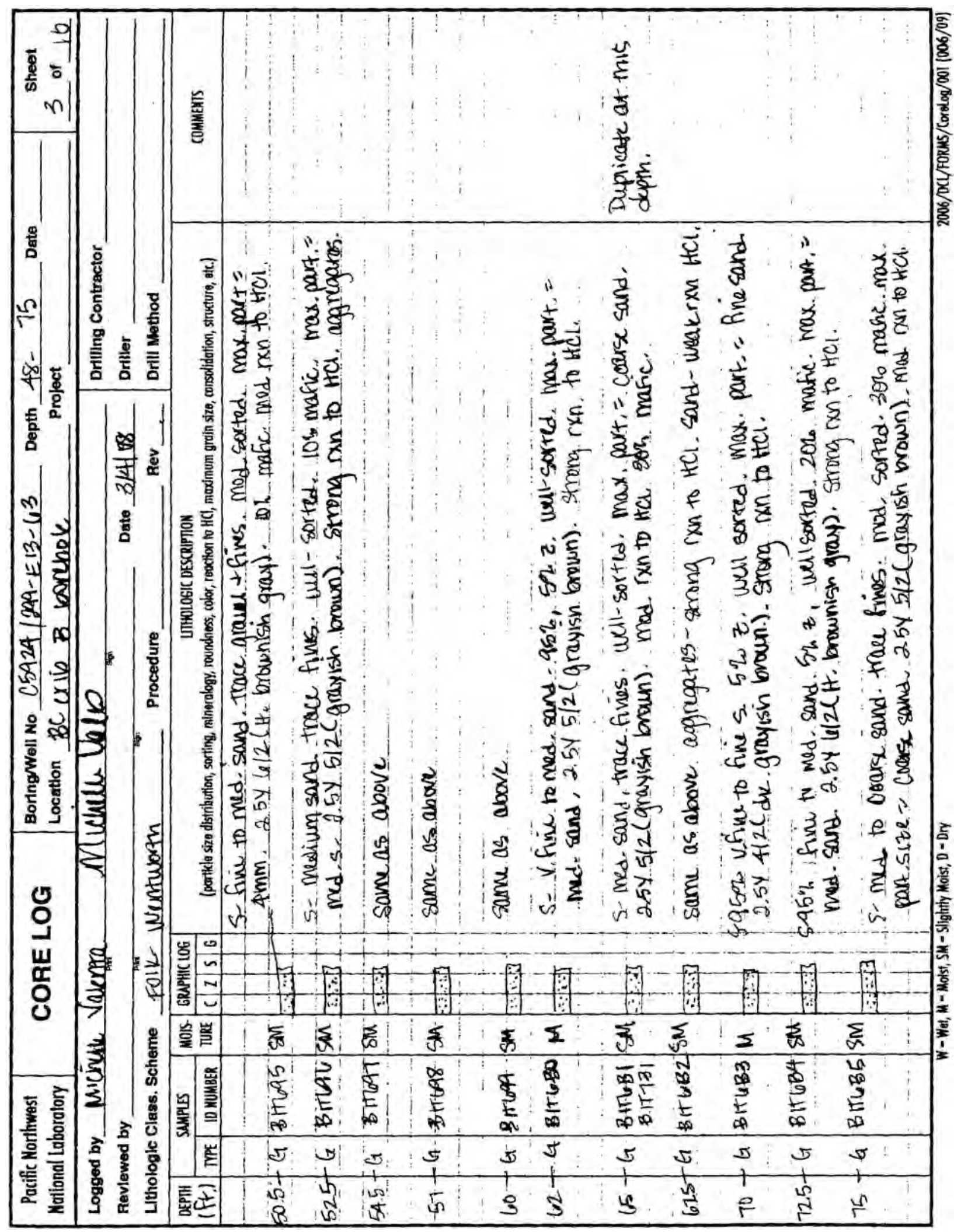




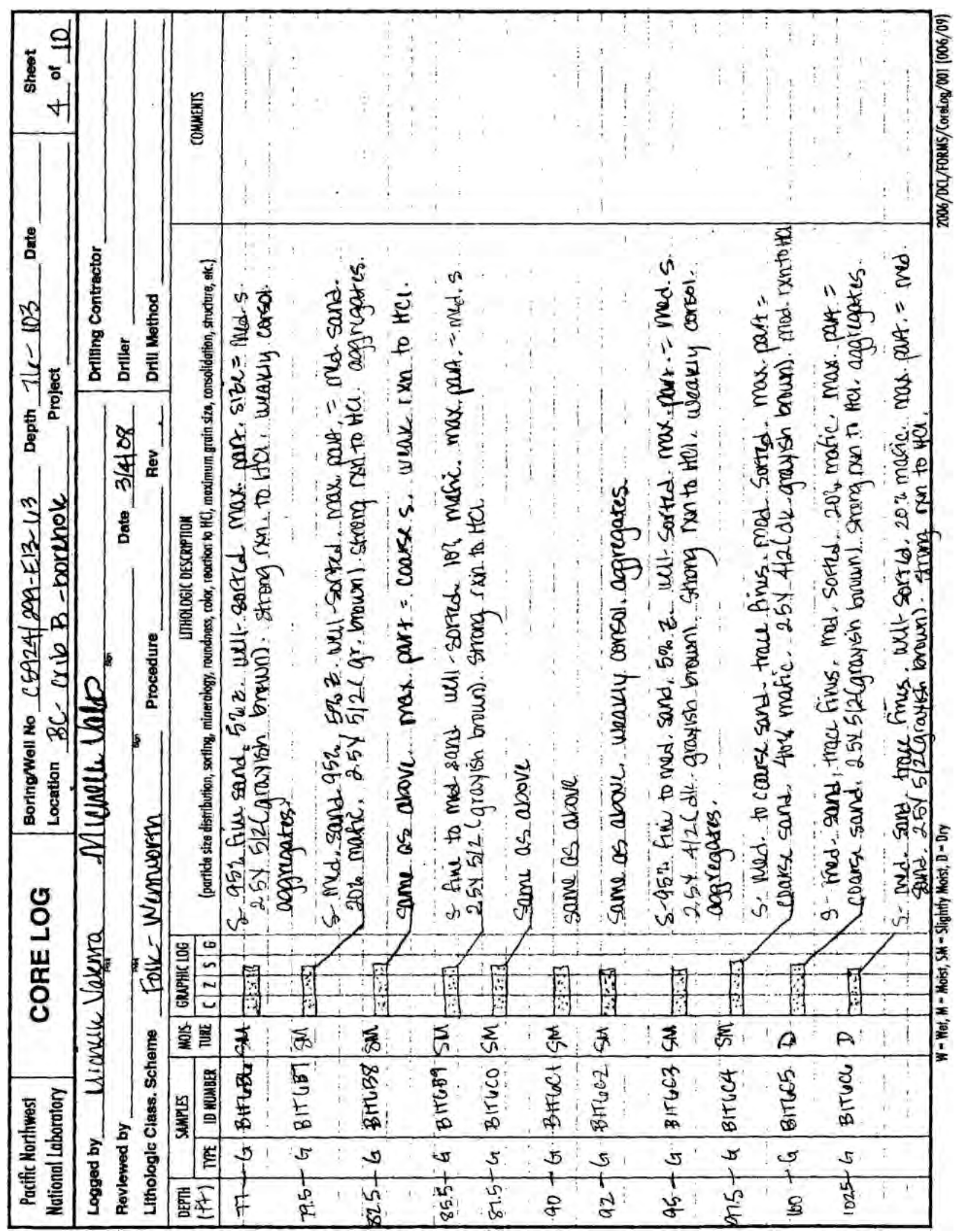




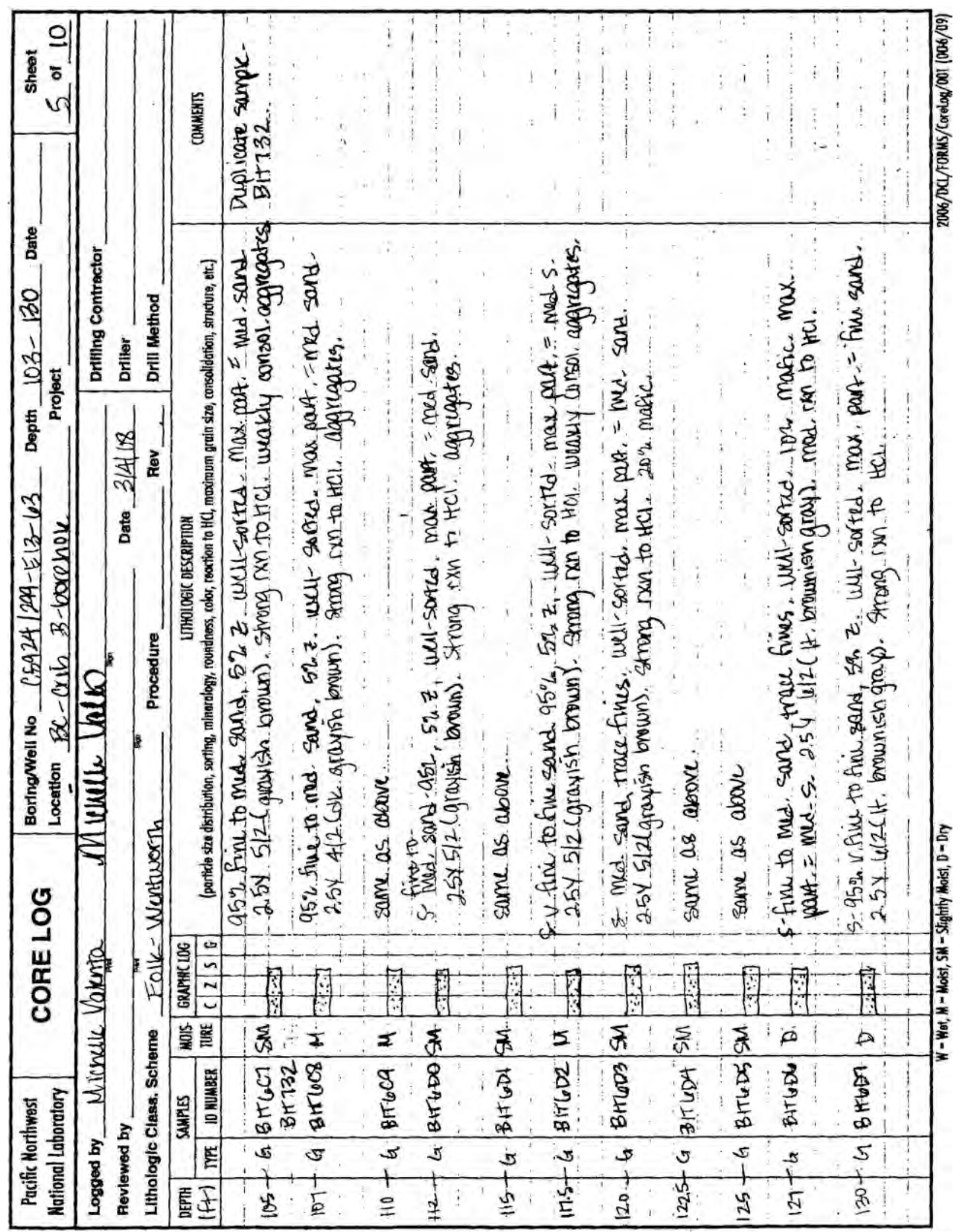




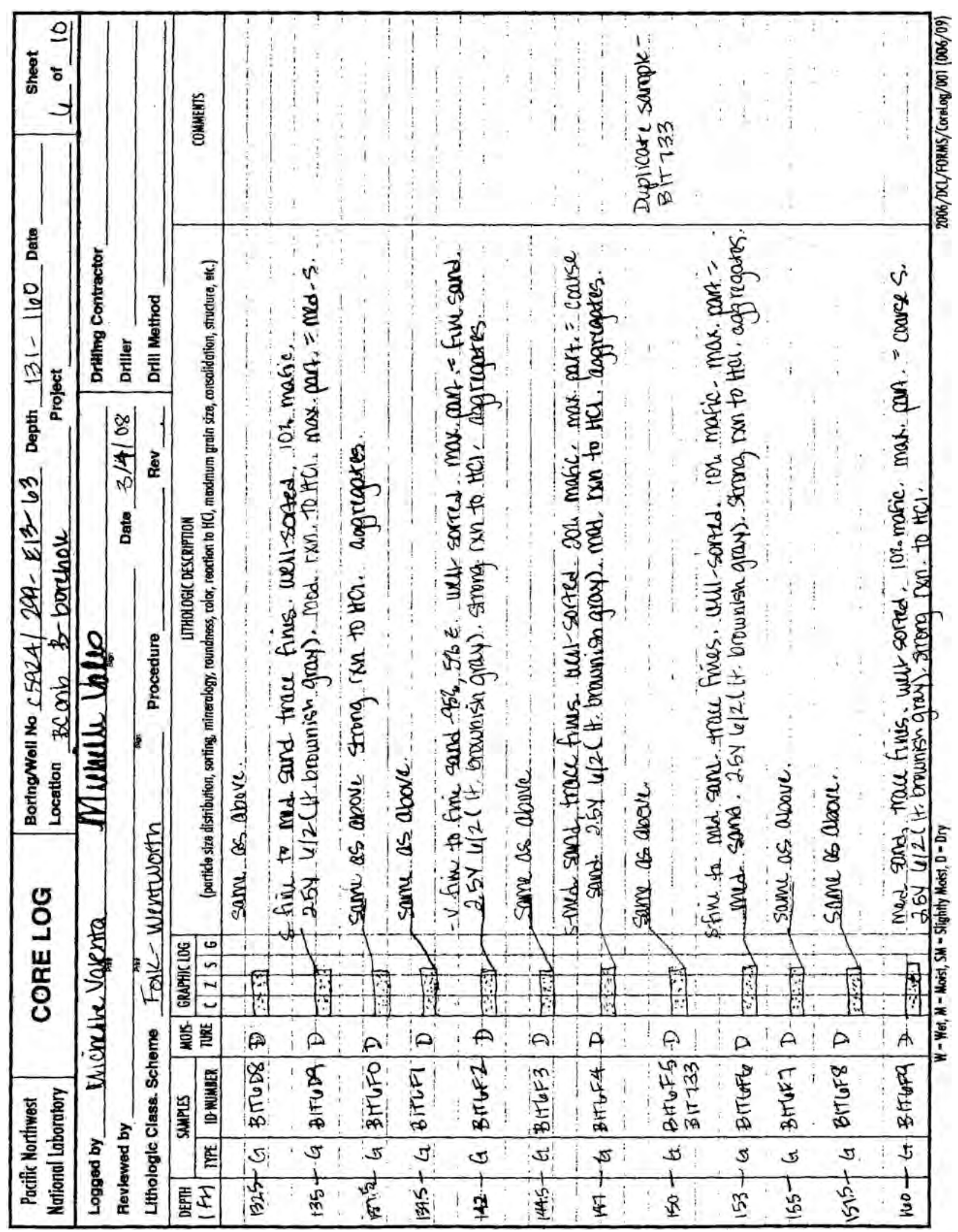




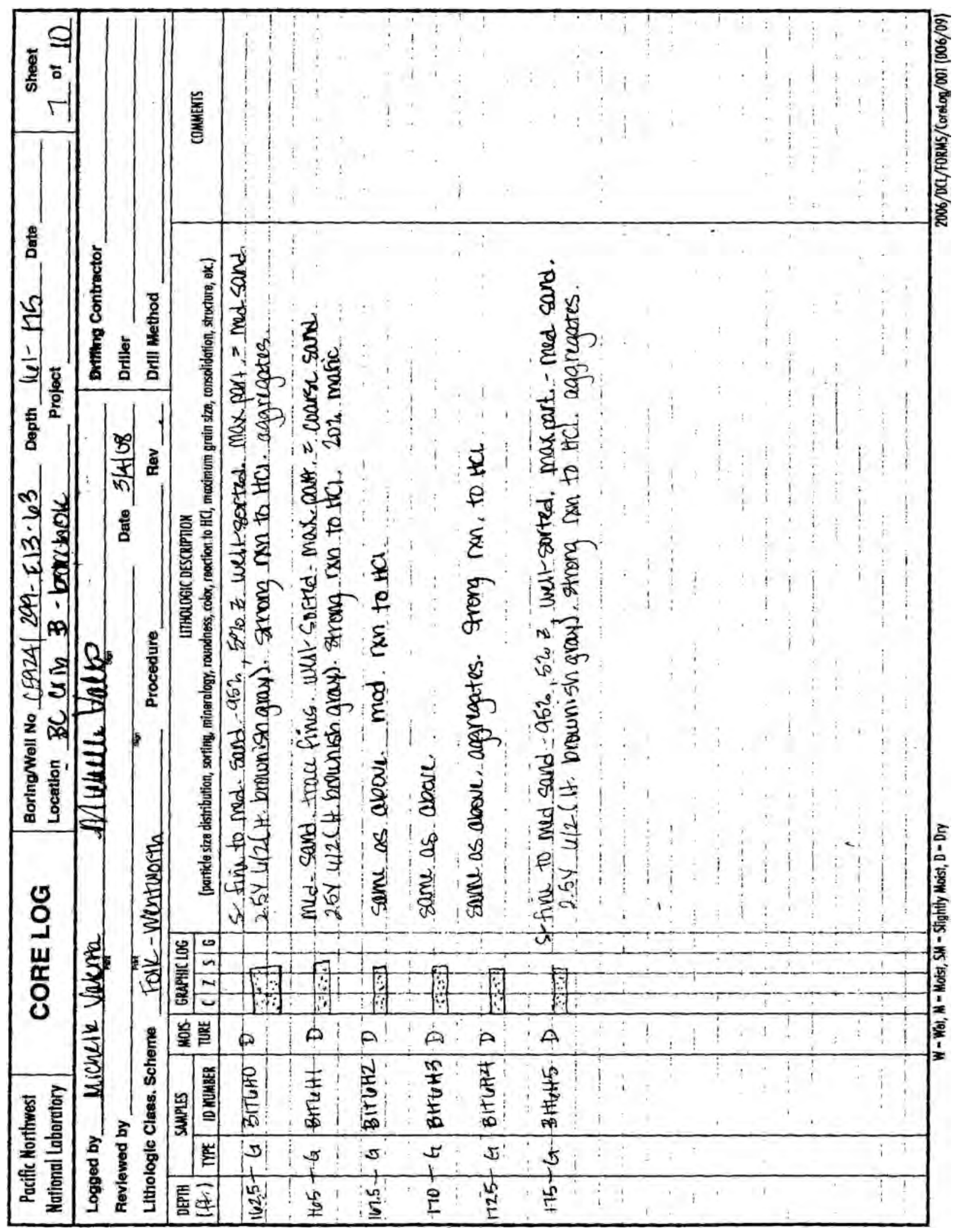




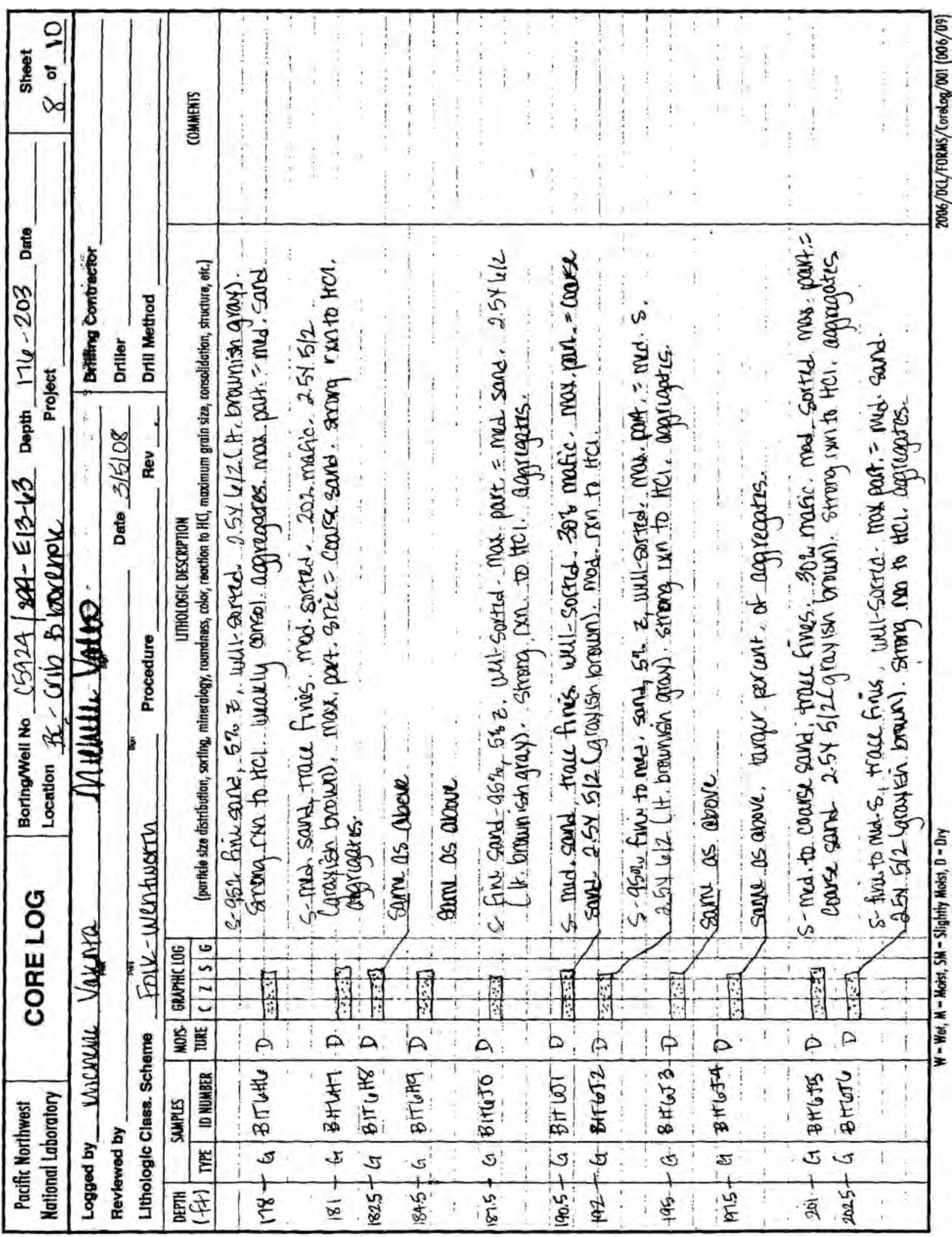




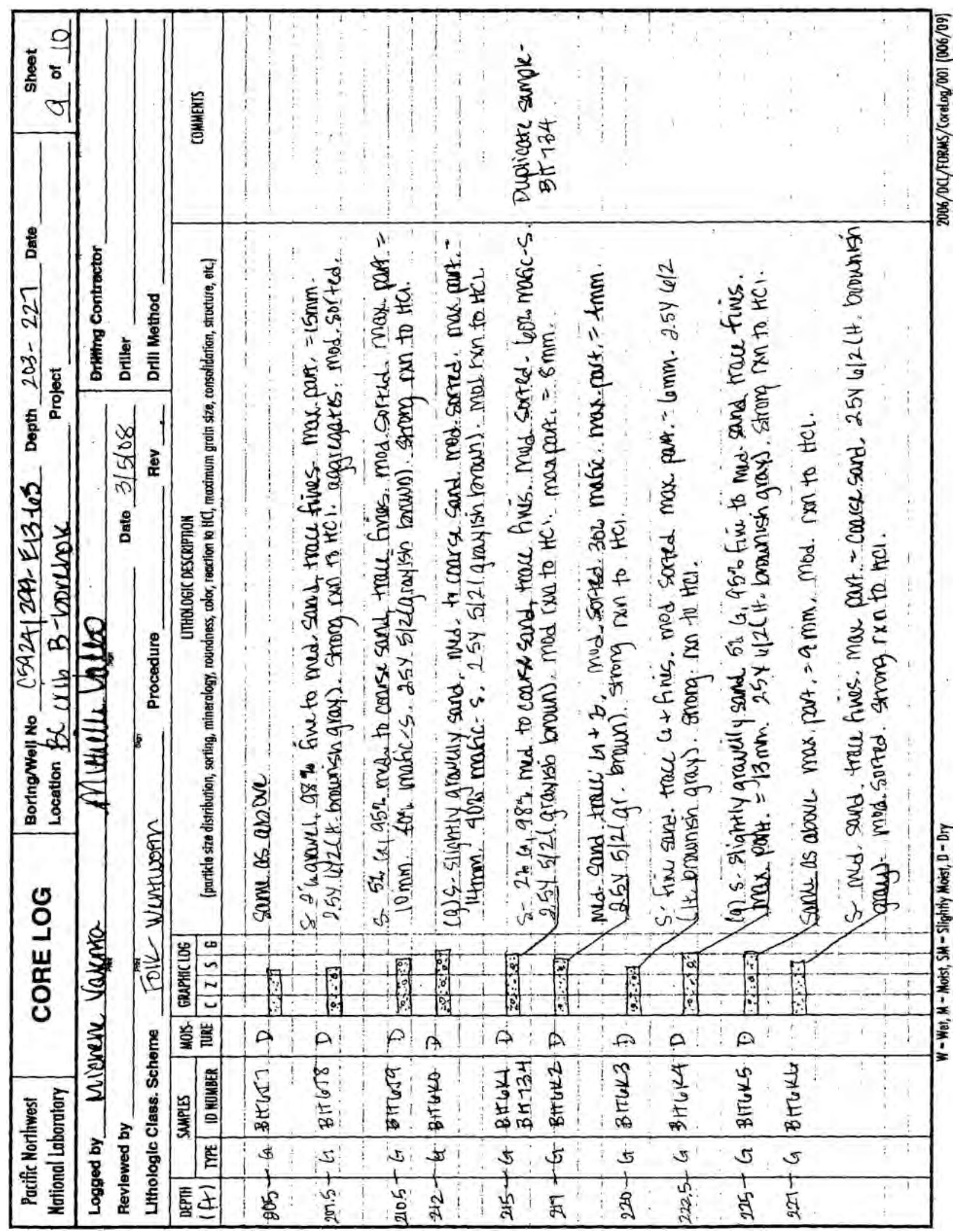




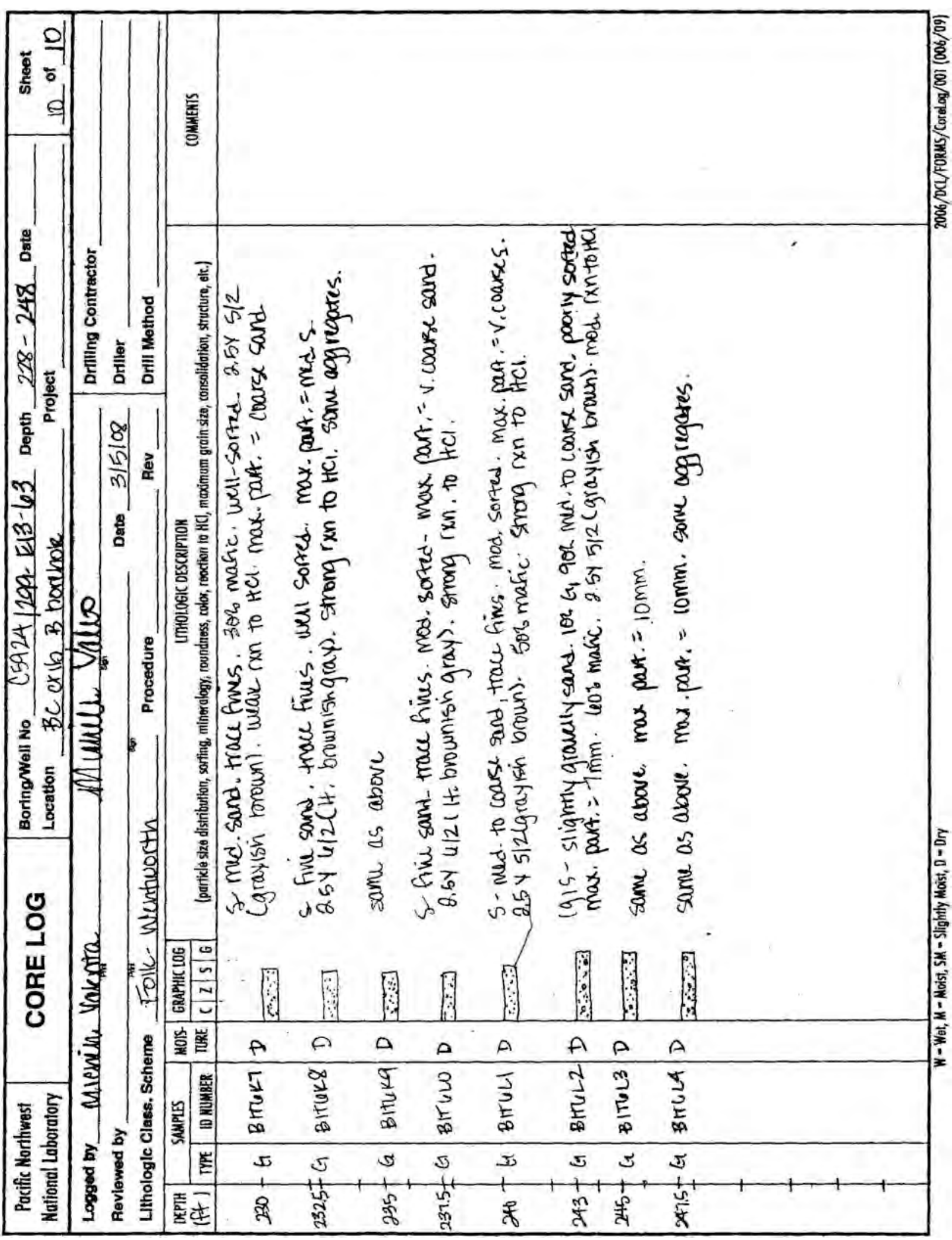




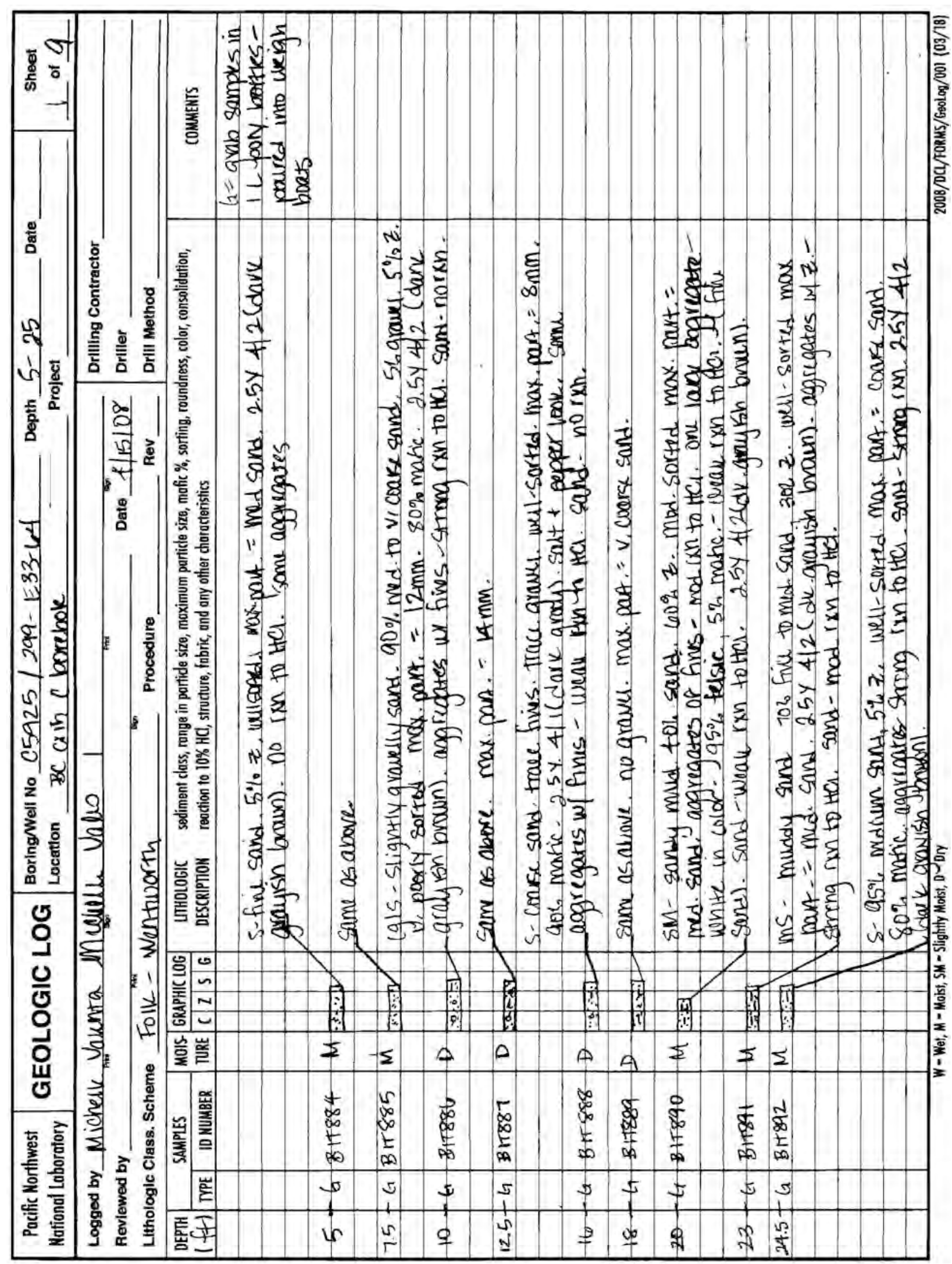




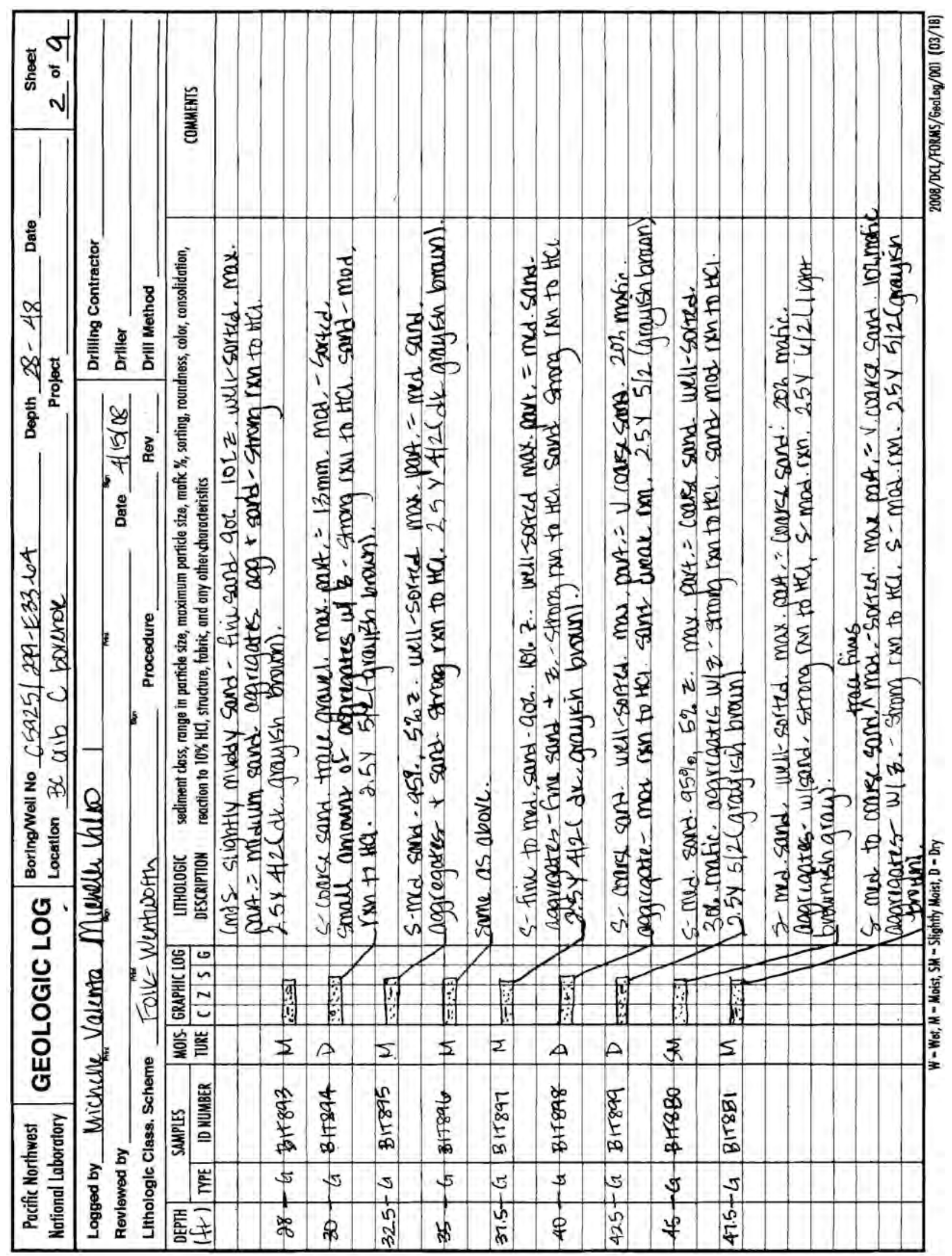




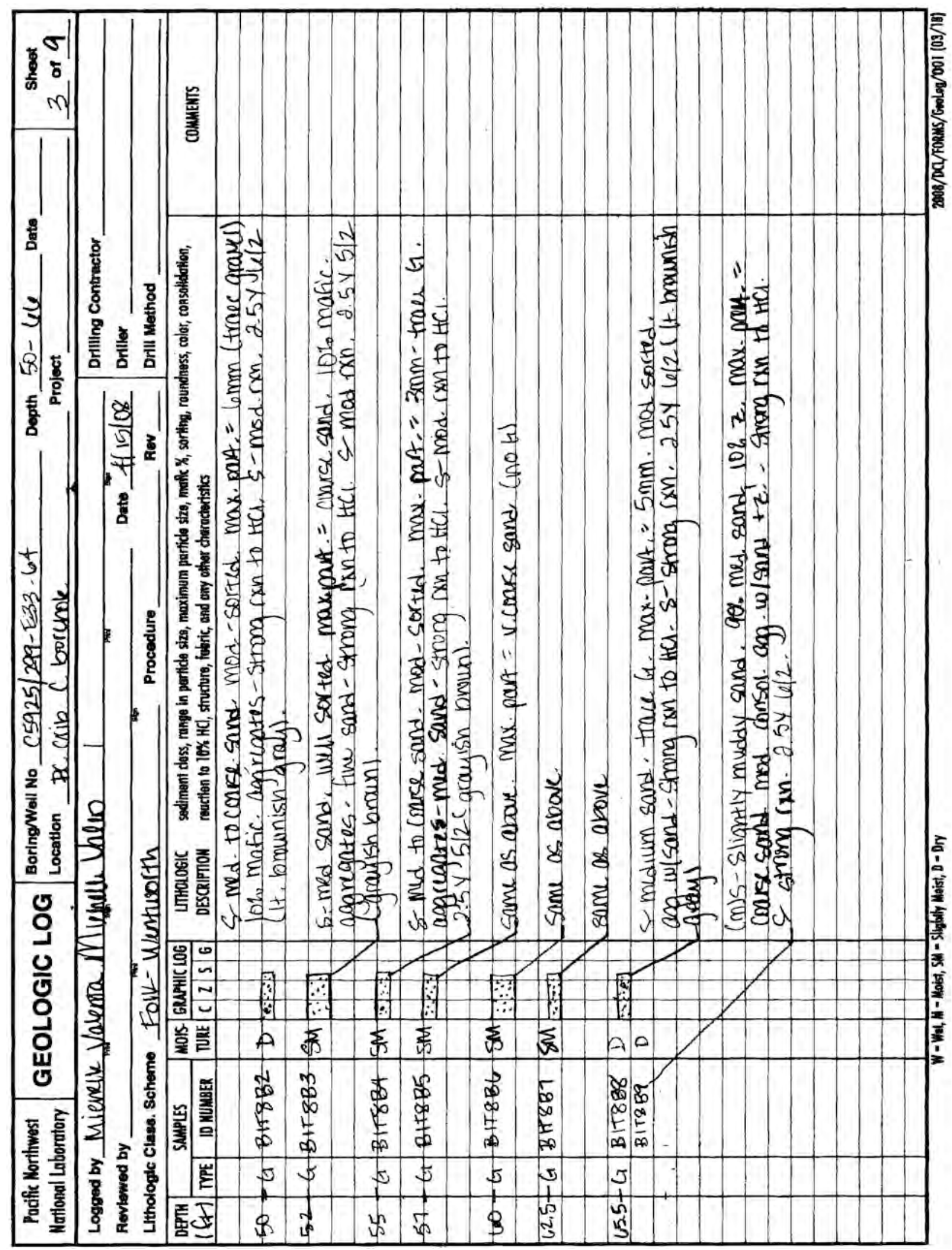




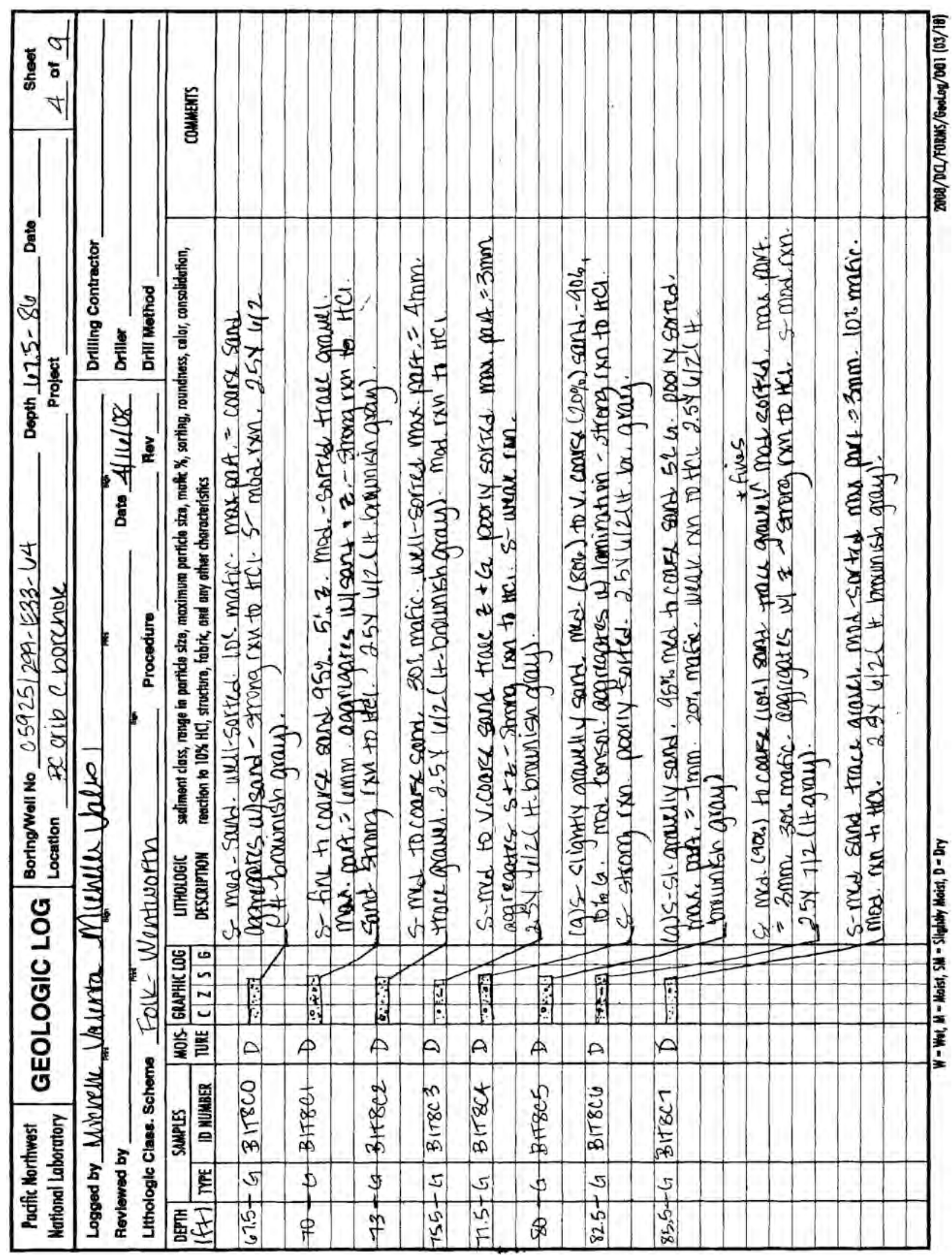




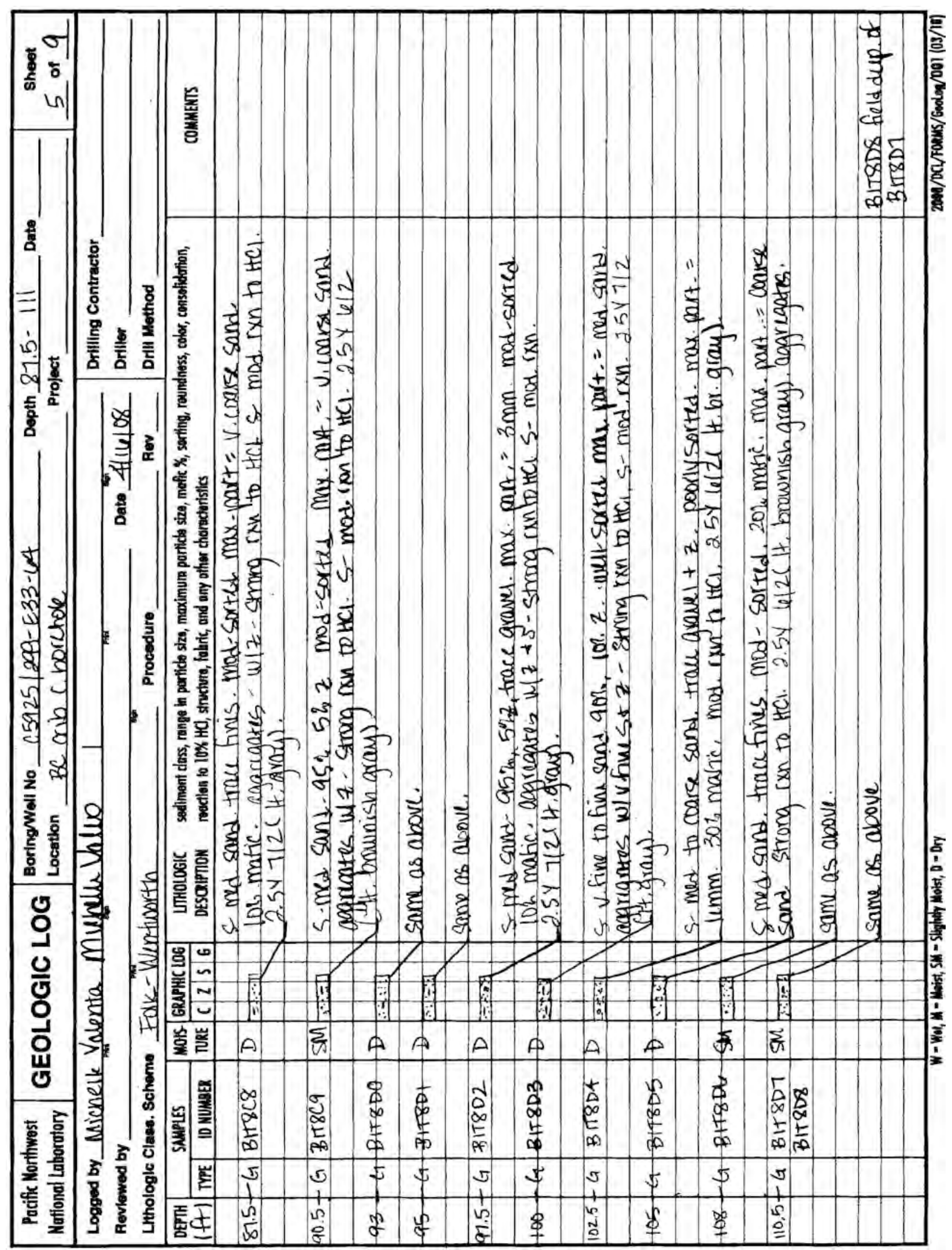




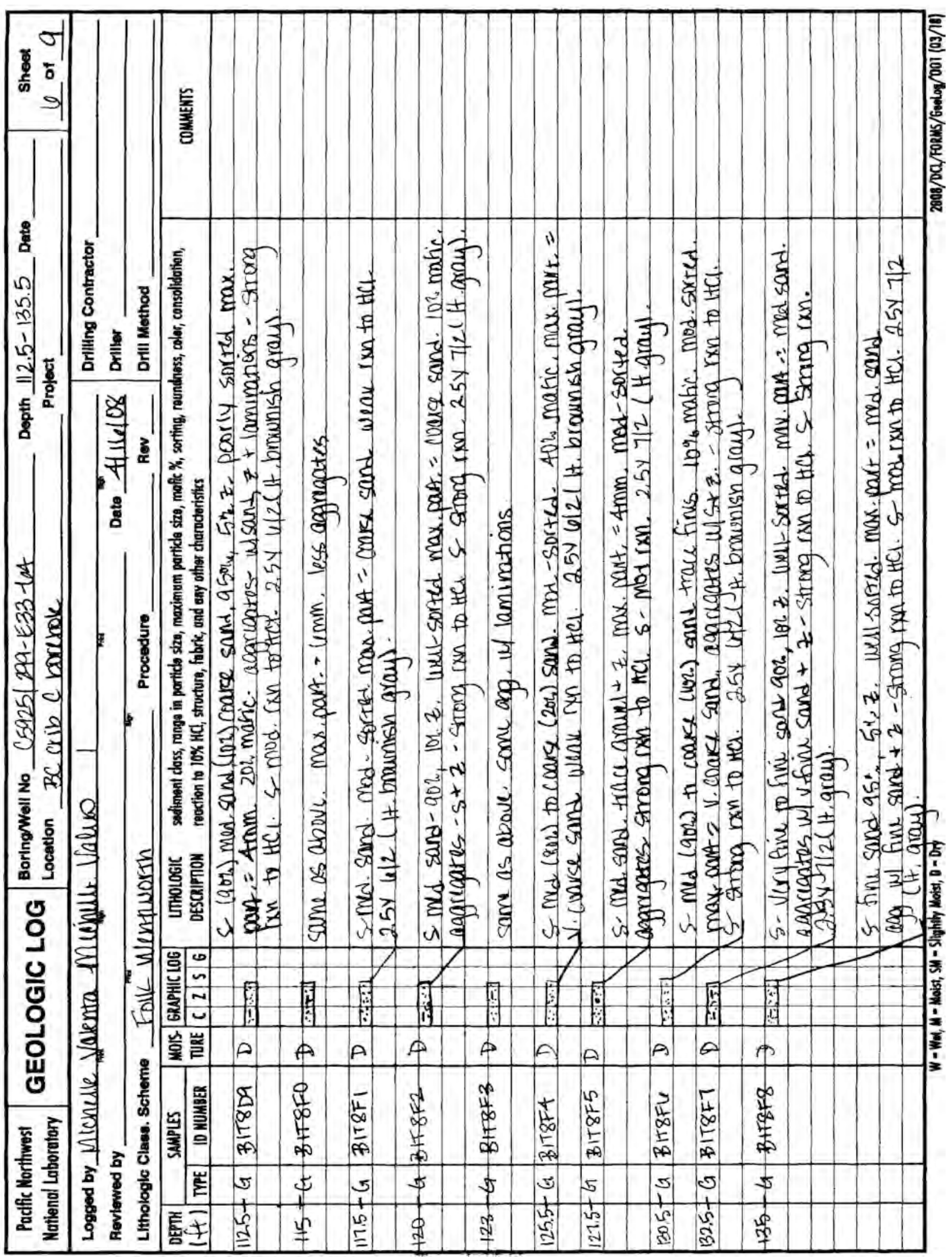




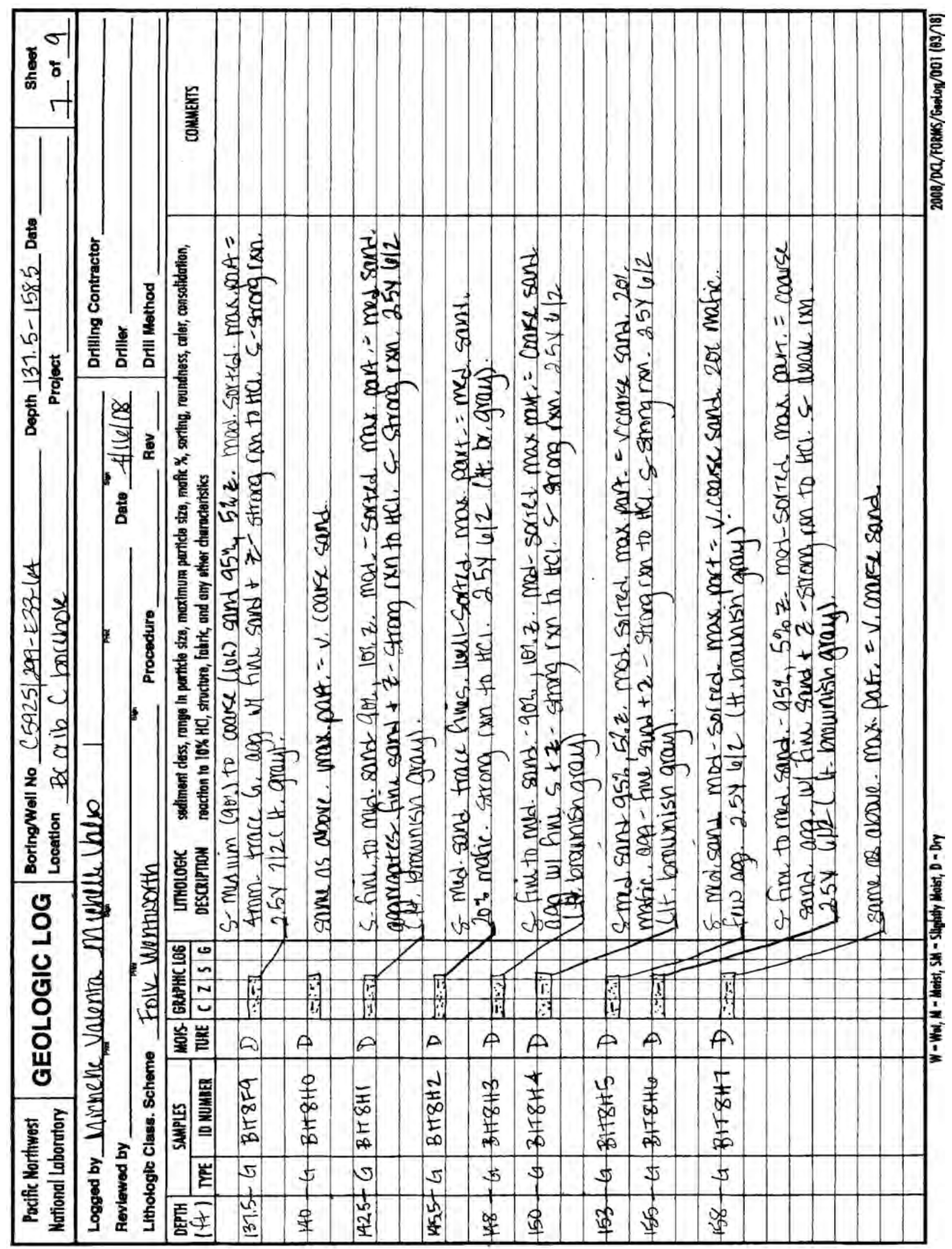




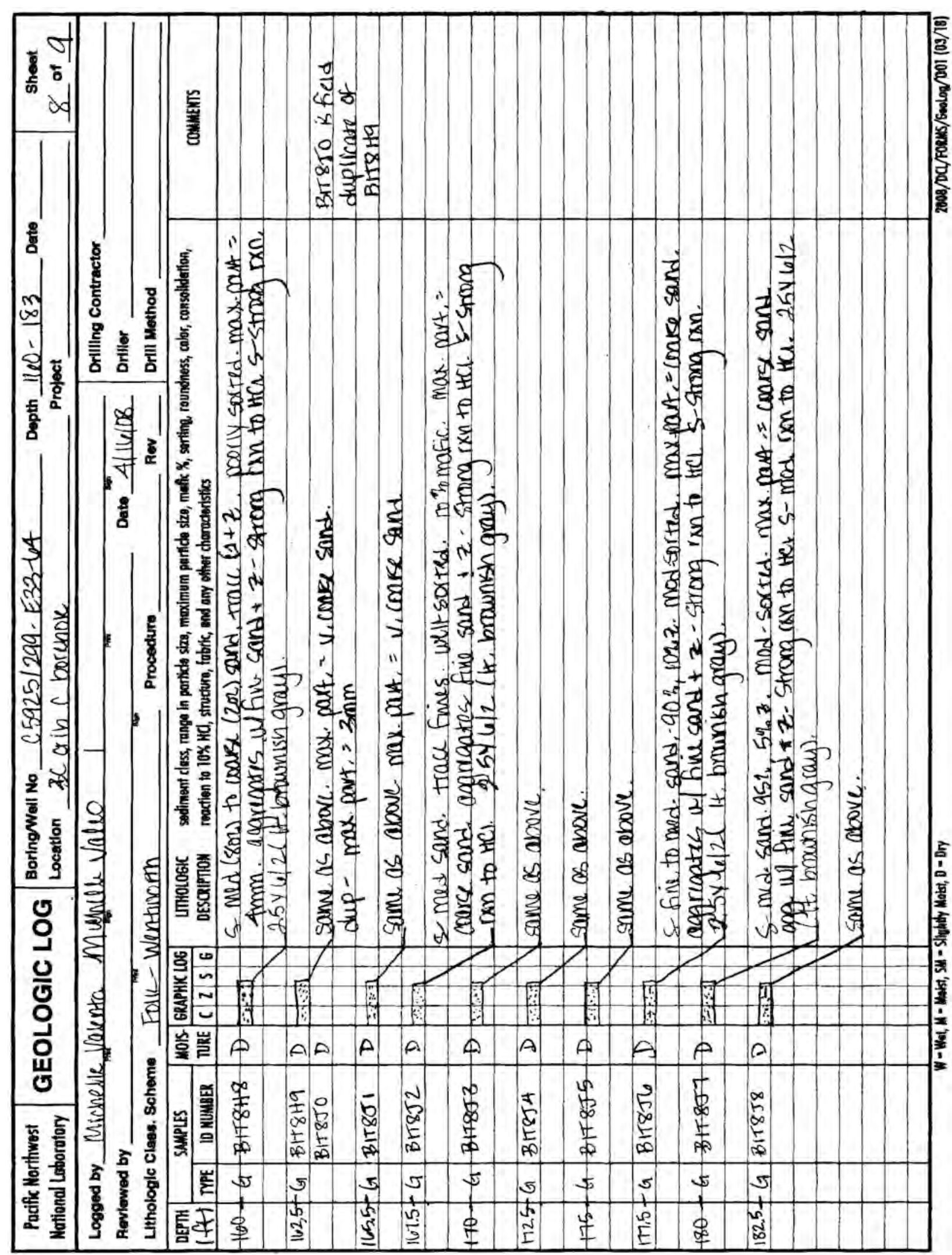




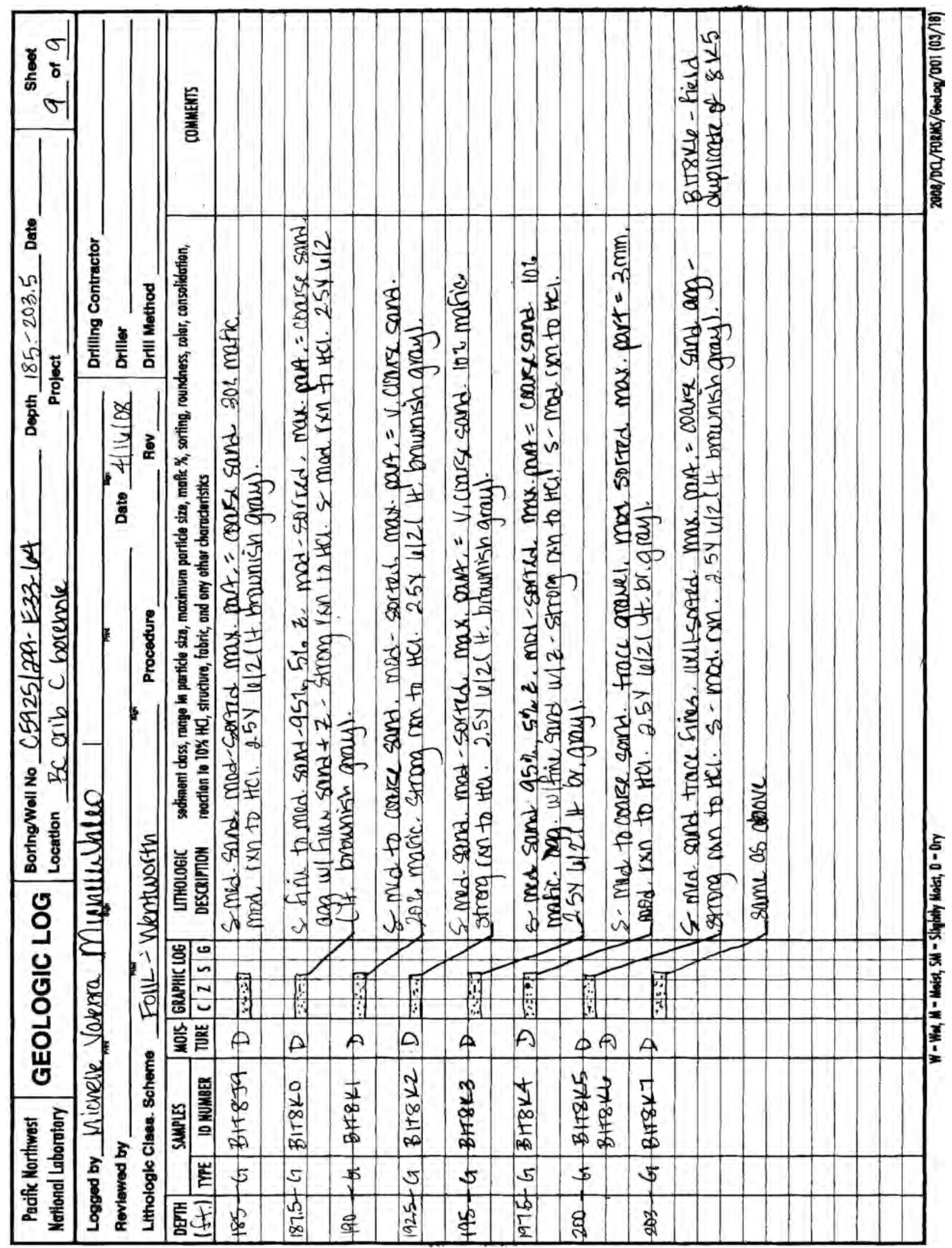


Appendix B

PHOTOGRAPHS OF SEDIMENT SAMPLES OPENED IN THE LAB FROM BOREHOLES IN THE BC CRIBS

AND TRENCHES AREA 


\section{APPENDIX B}

\section{PHOTOGRAPHS OF SEDIMENT SAMPLES OPENED IN THE LAB FROM BOREHOLES IN THE BC CRIBS AND TRENCHES AREA}

$\underline{B C}$ Cribs and Trenches Boreholes - Sample Photos

Samples from Borehole C5923 (299-E13-62) ...................................................................... B.2

Samples from Borehole C5924 (299-E13-63) ........................................................................... B.74

Samples from Borehole C5925 (299-E13-64) ............................................................................ B.177

Samples from Borehole C4191 ............................................................................................... B. B.219 
PNNL-17821

Samples from Borehole C5923 (299-E13-62)
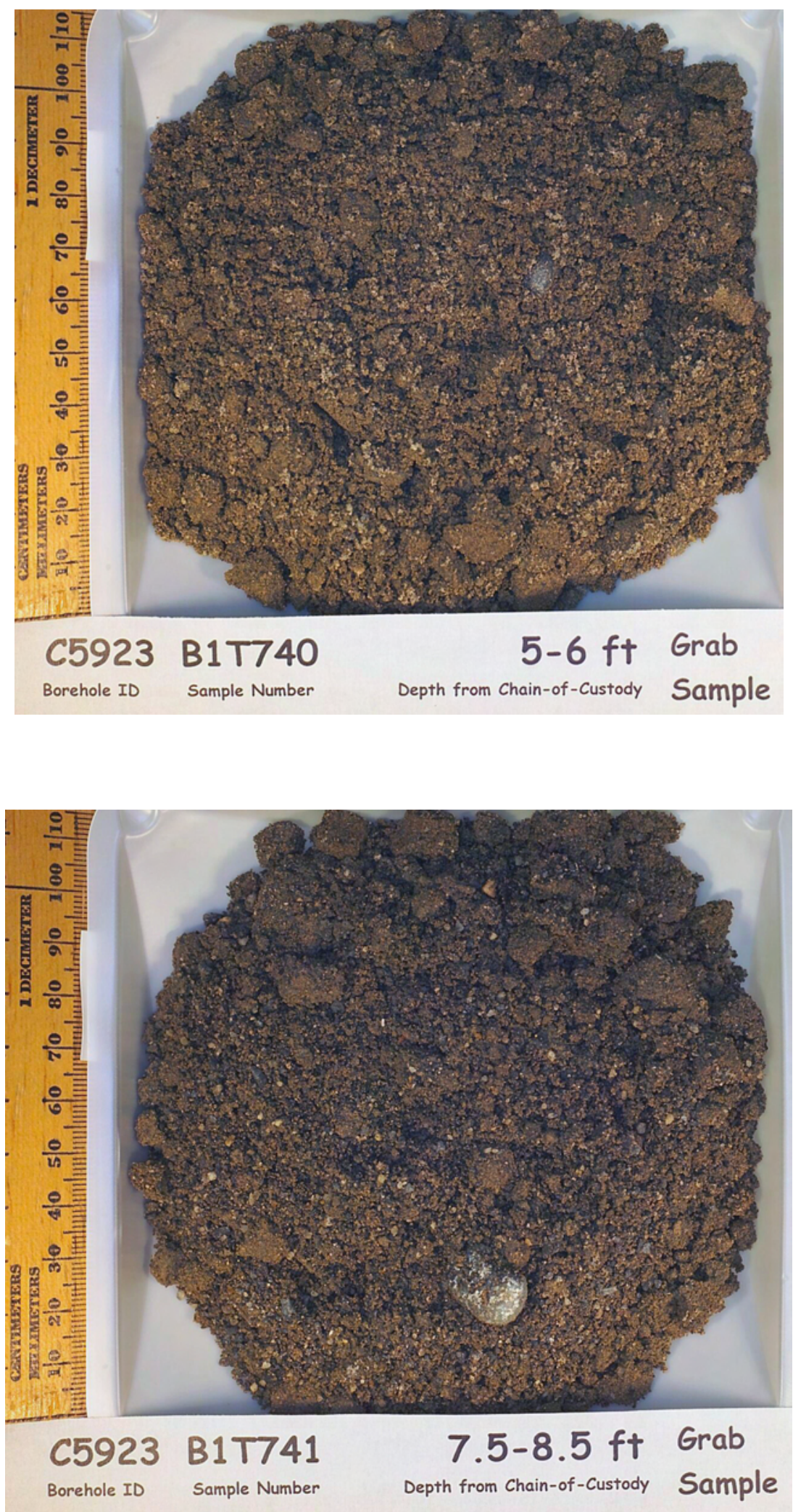
PNNL-17821
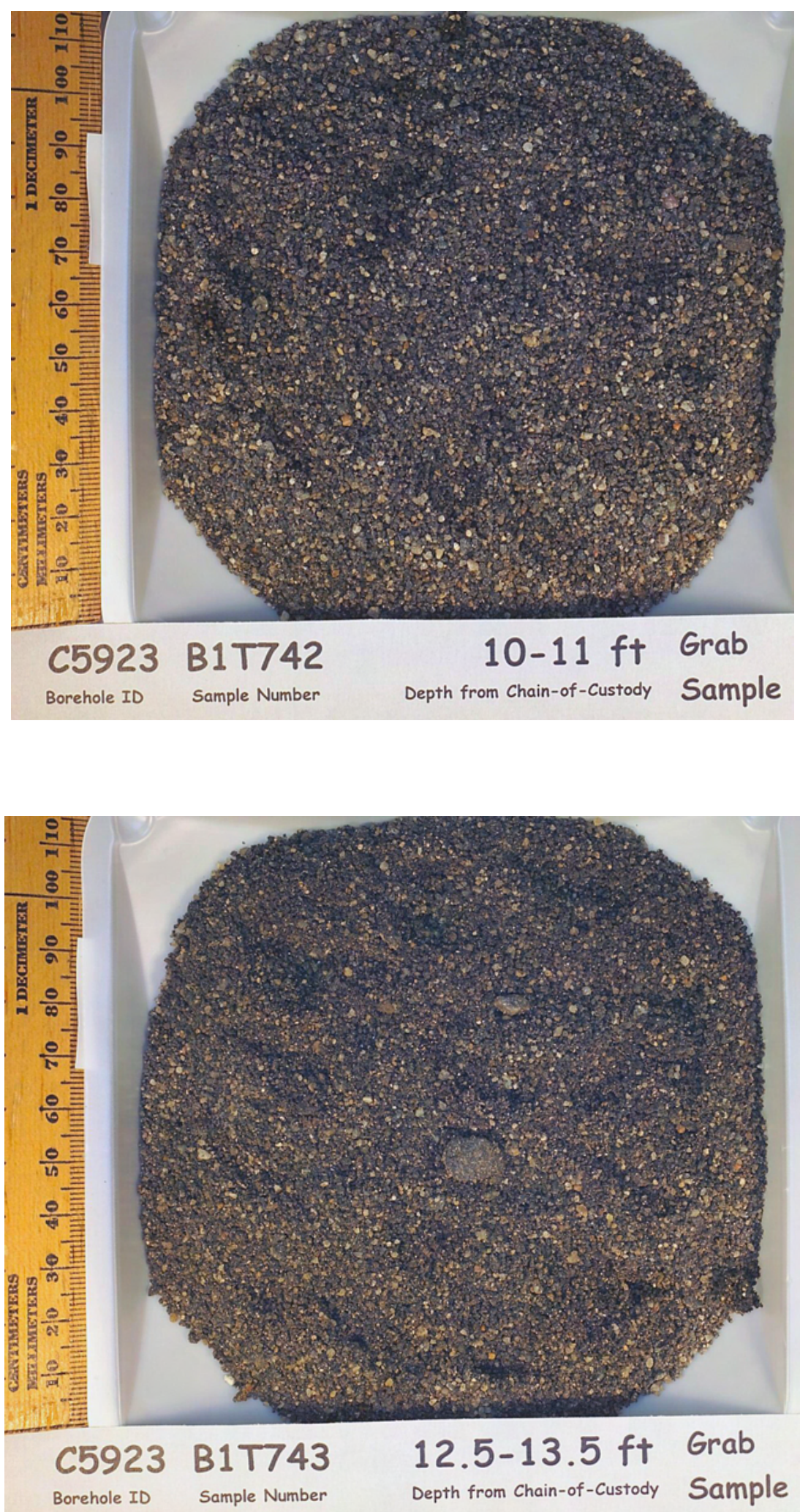
PNNL-17821
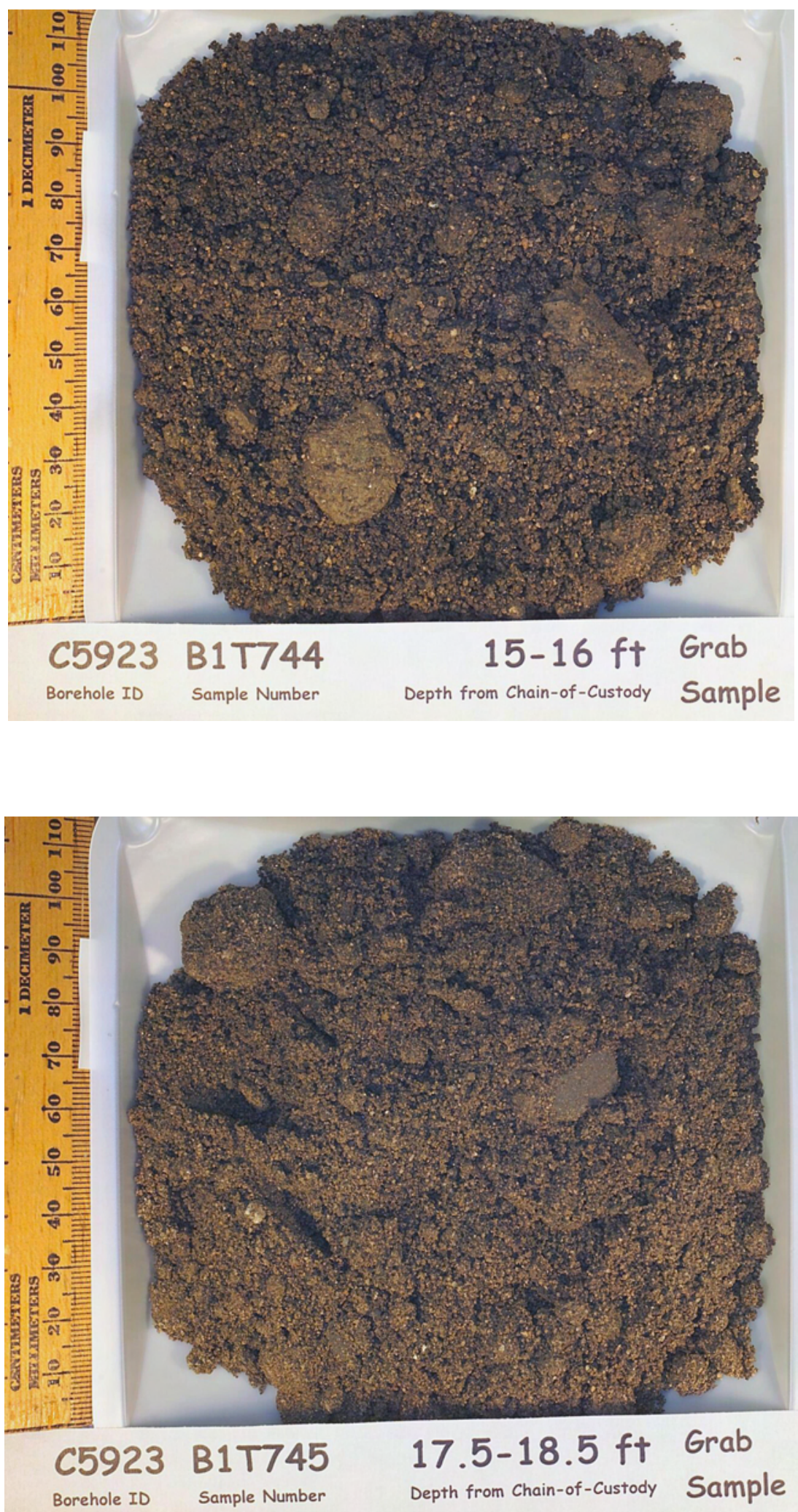
PNNL-17821
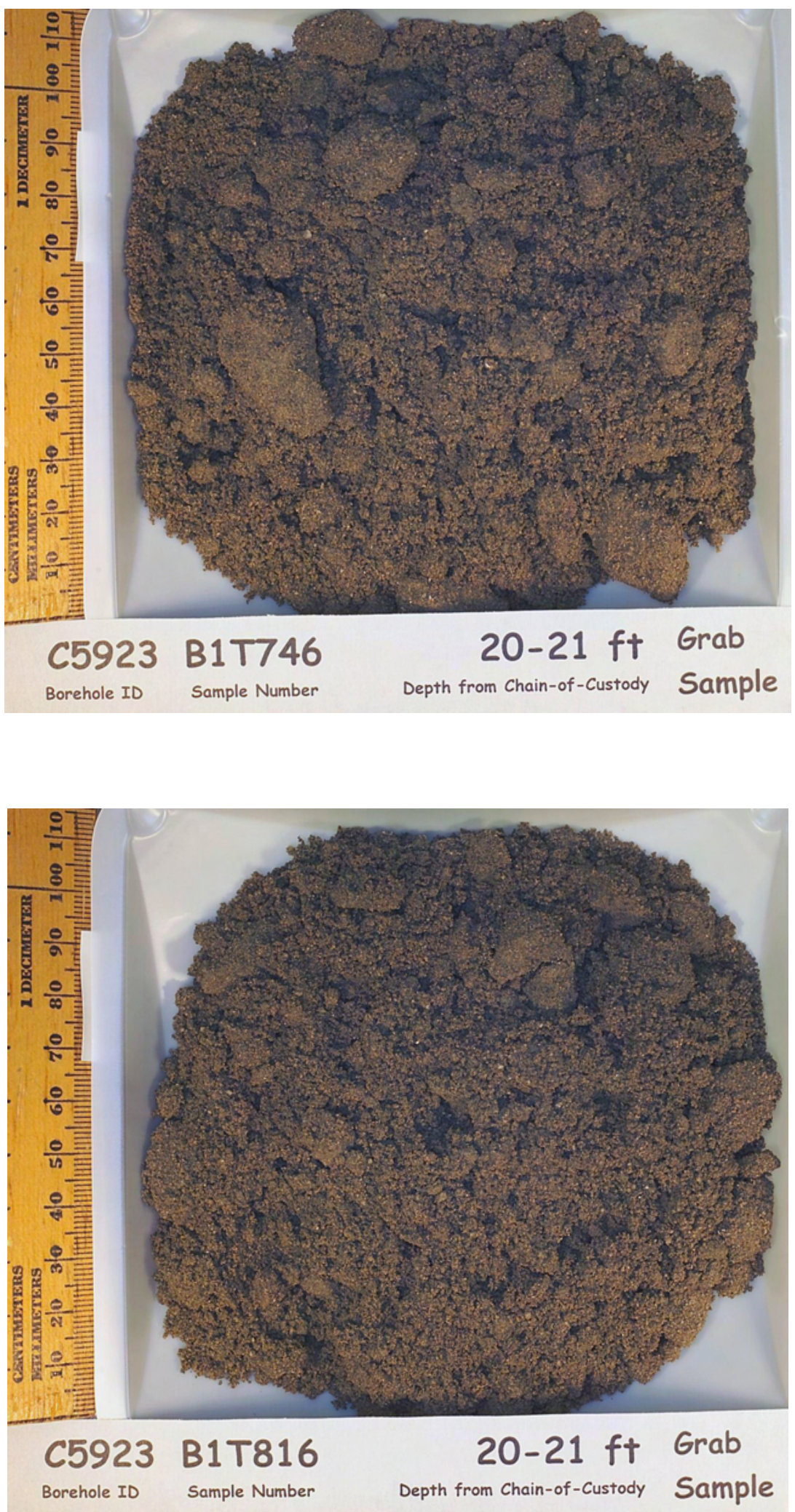
PNNL-17821
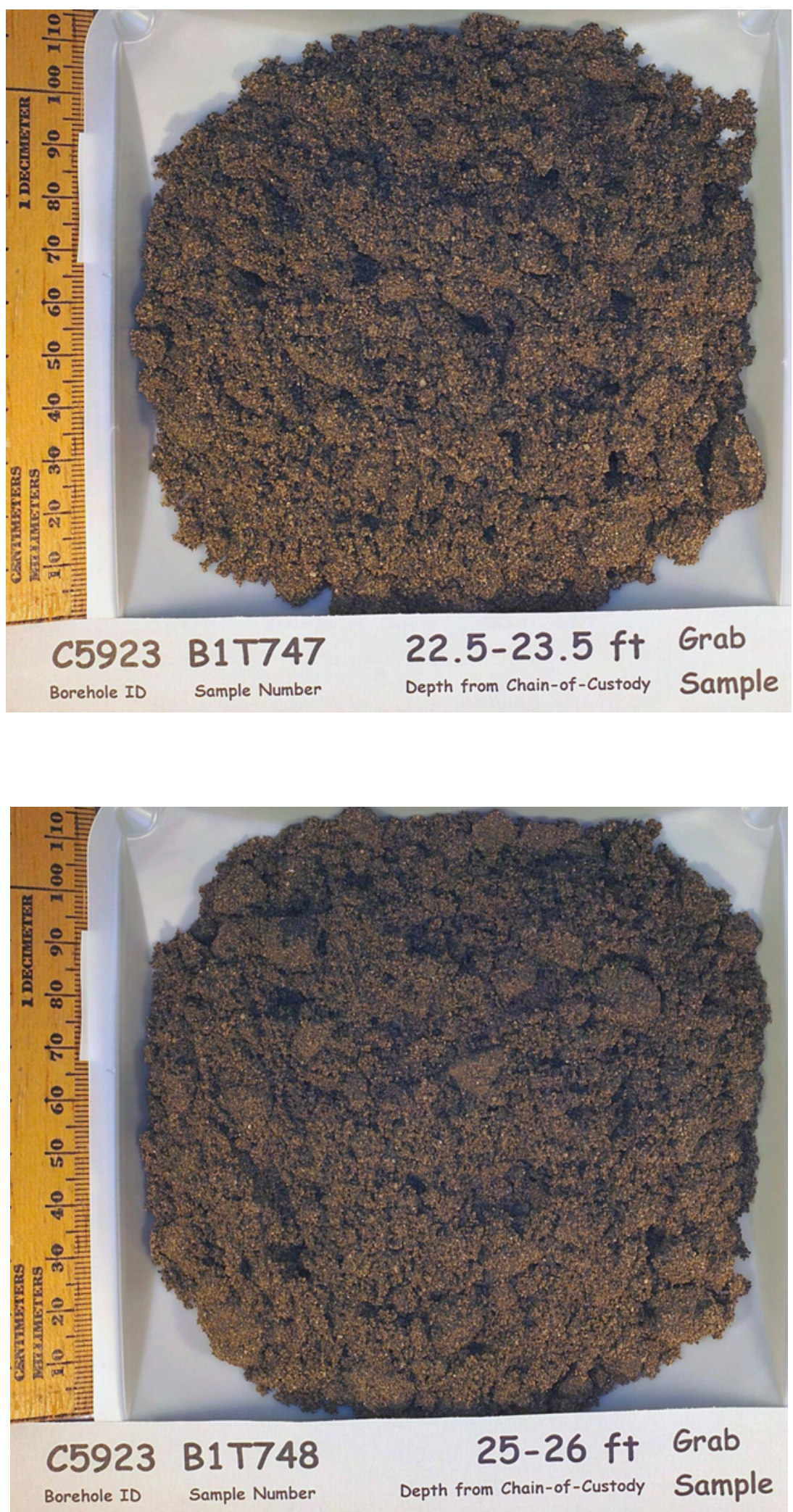

B. 6 
PNNL-17821
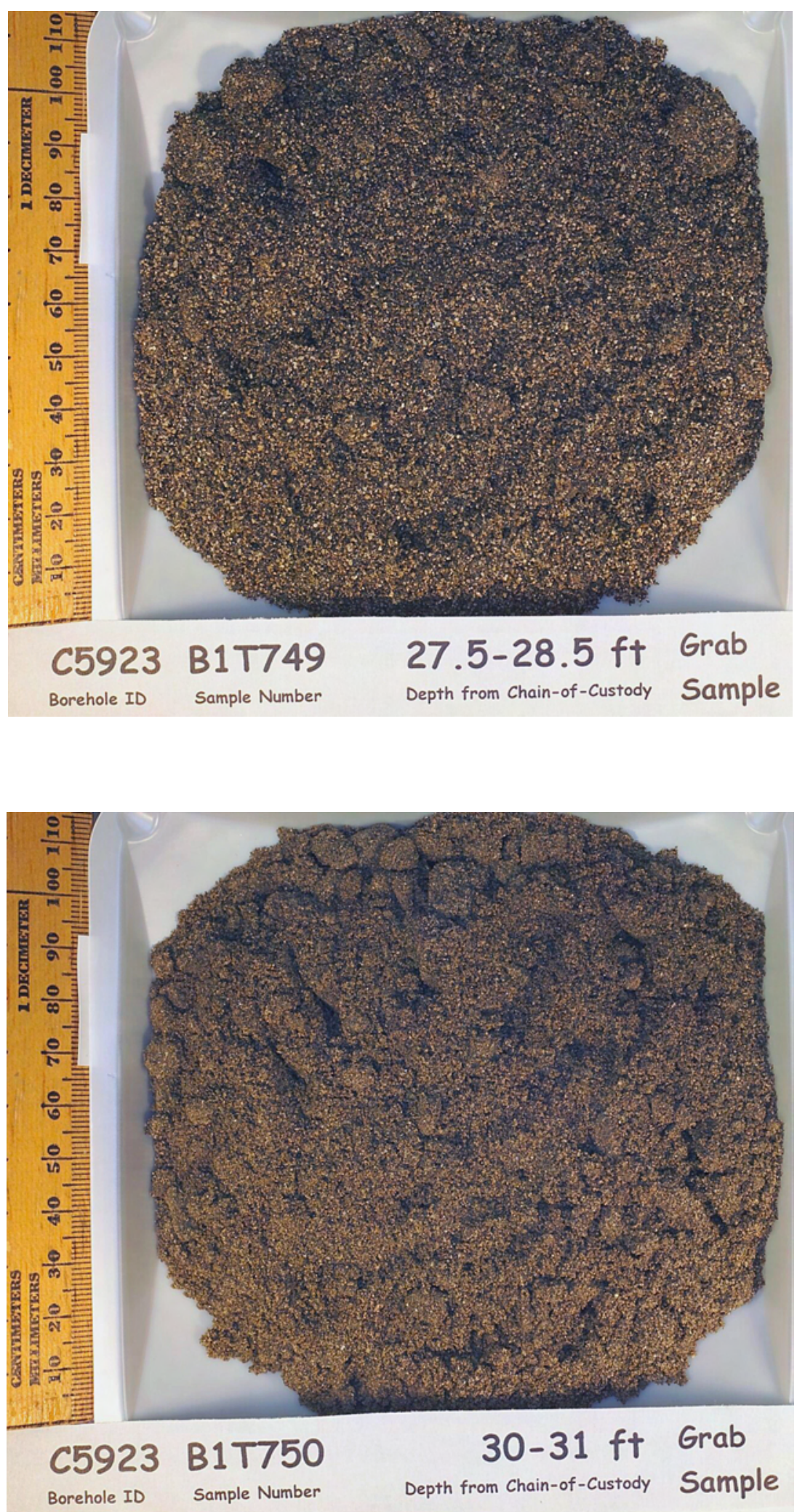

B. 7 
PNNL-17821
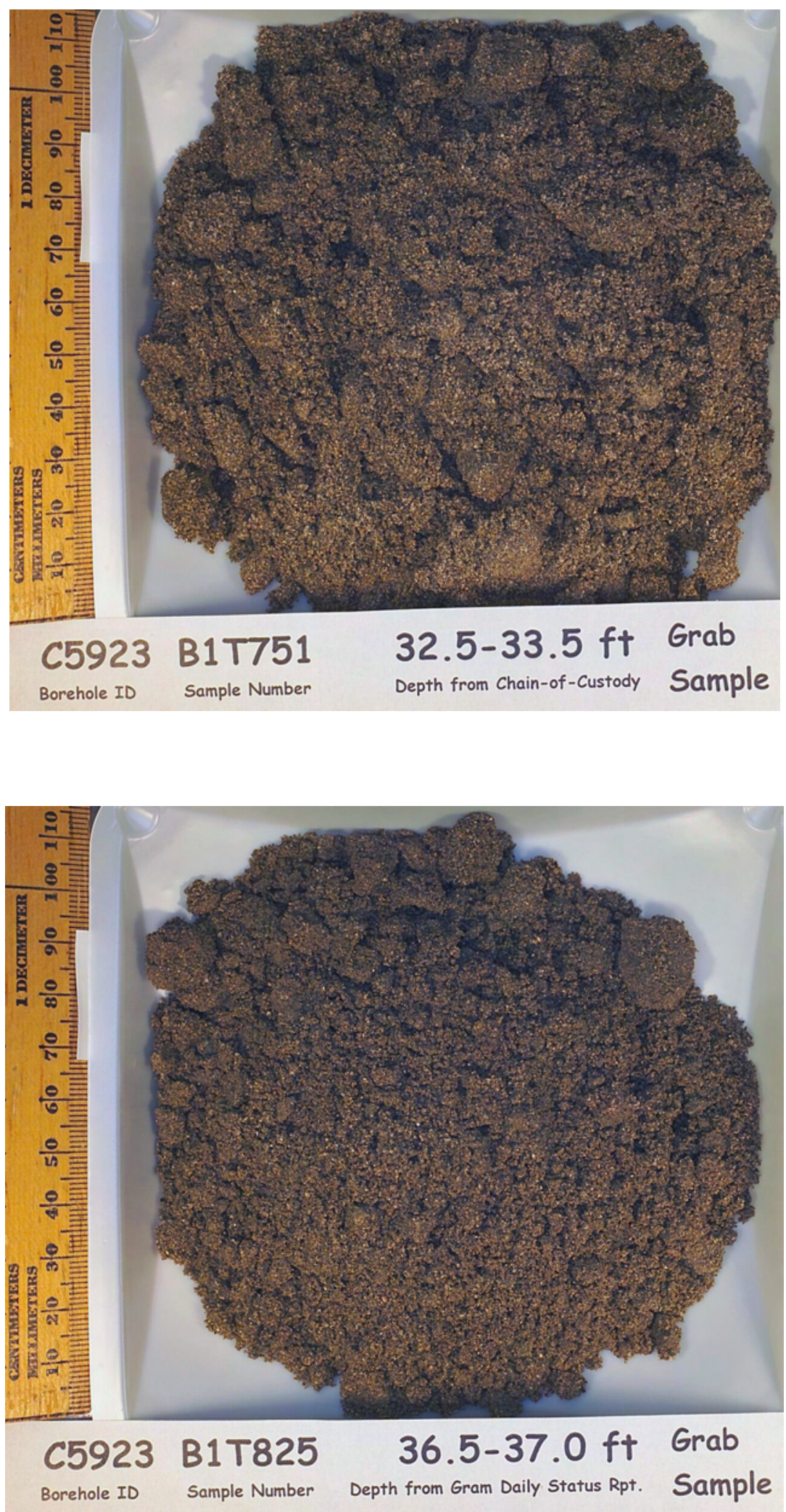
PNNL-17821
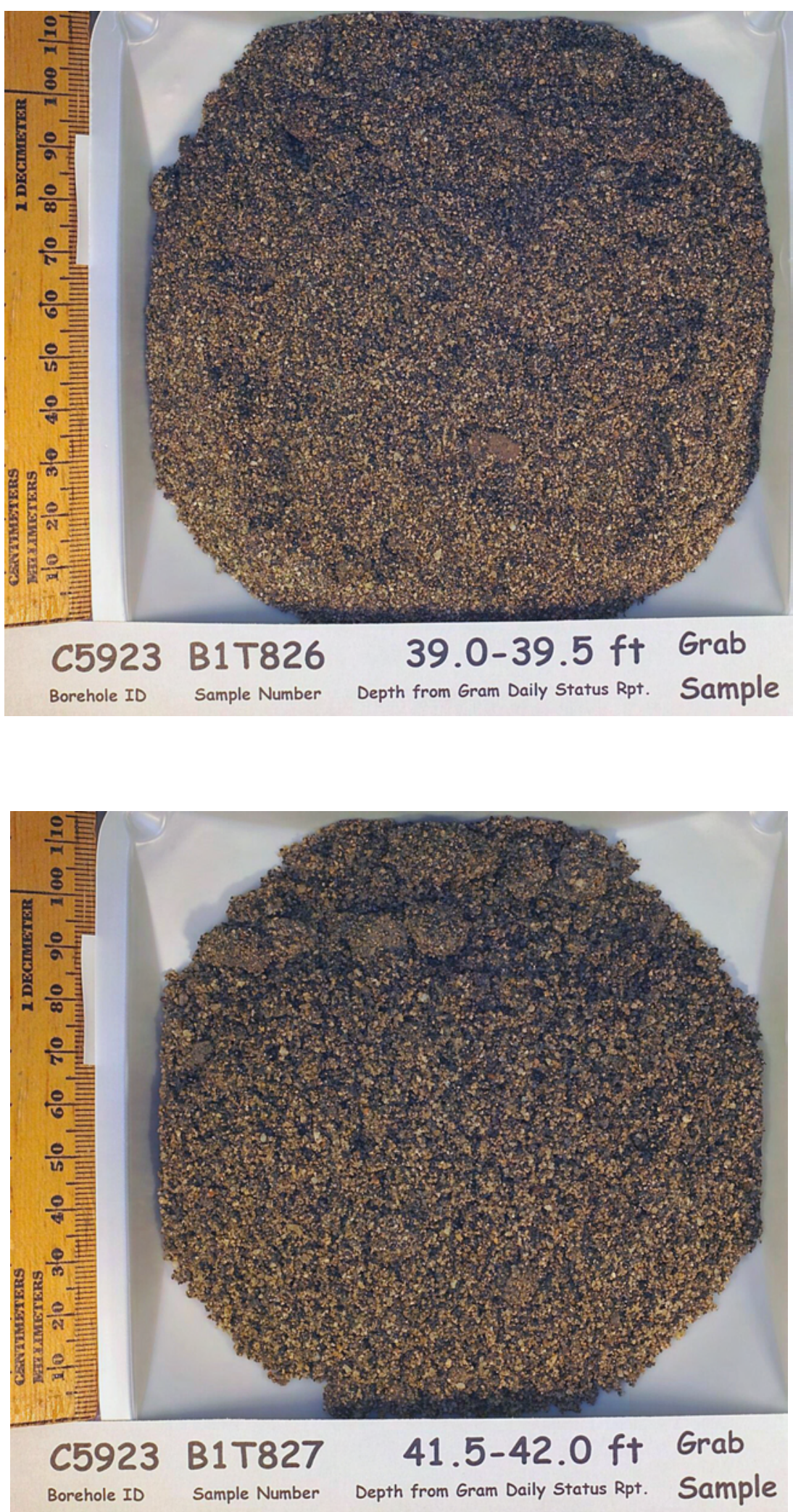
PNNL-17821
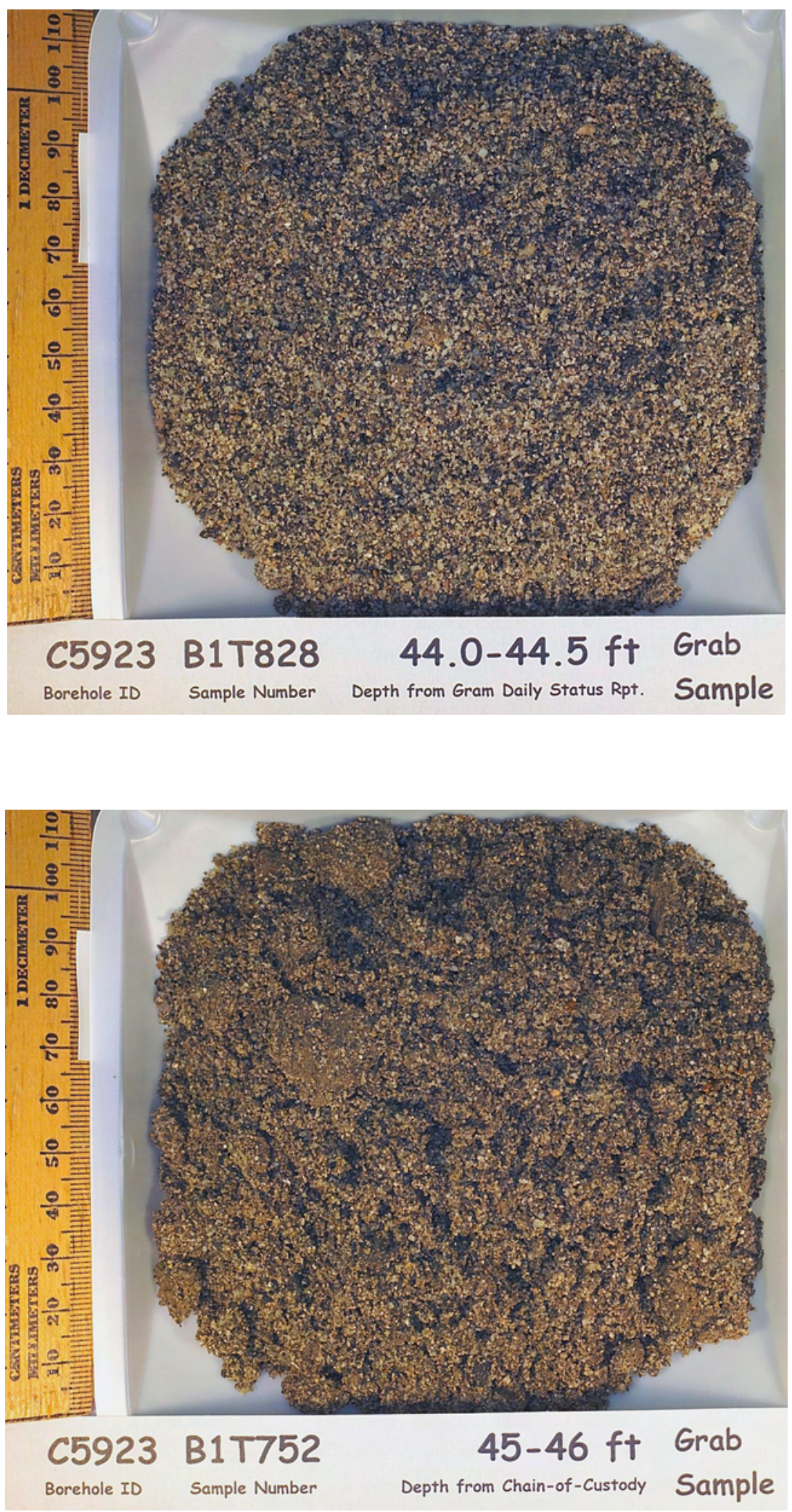
PNNL-17821
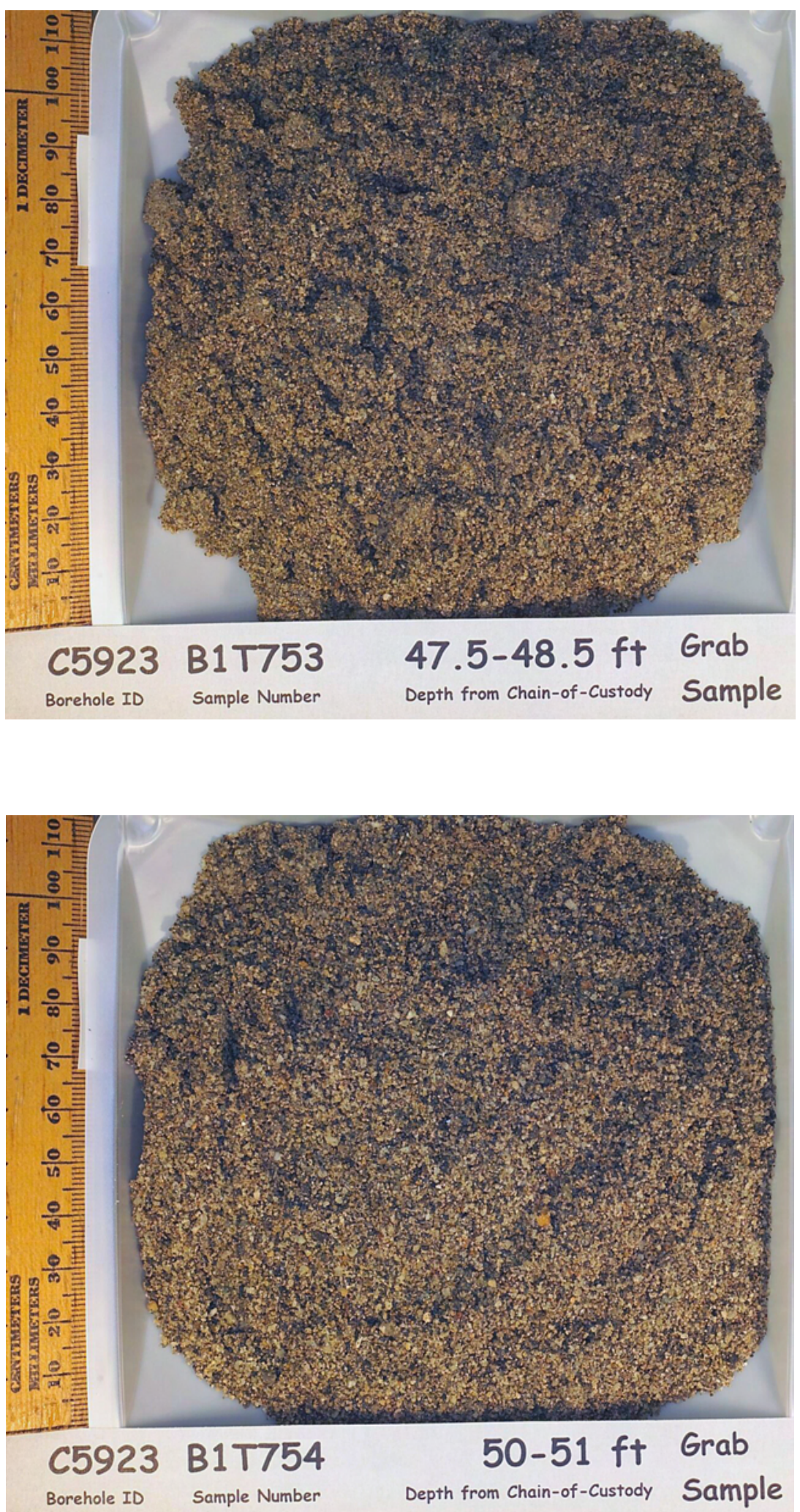

B.11 
PNNL-17821
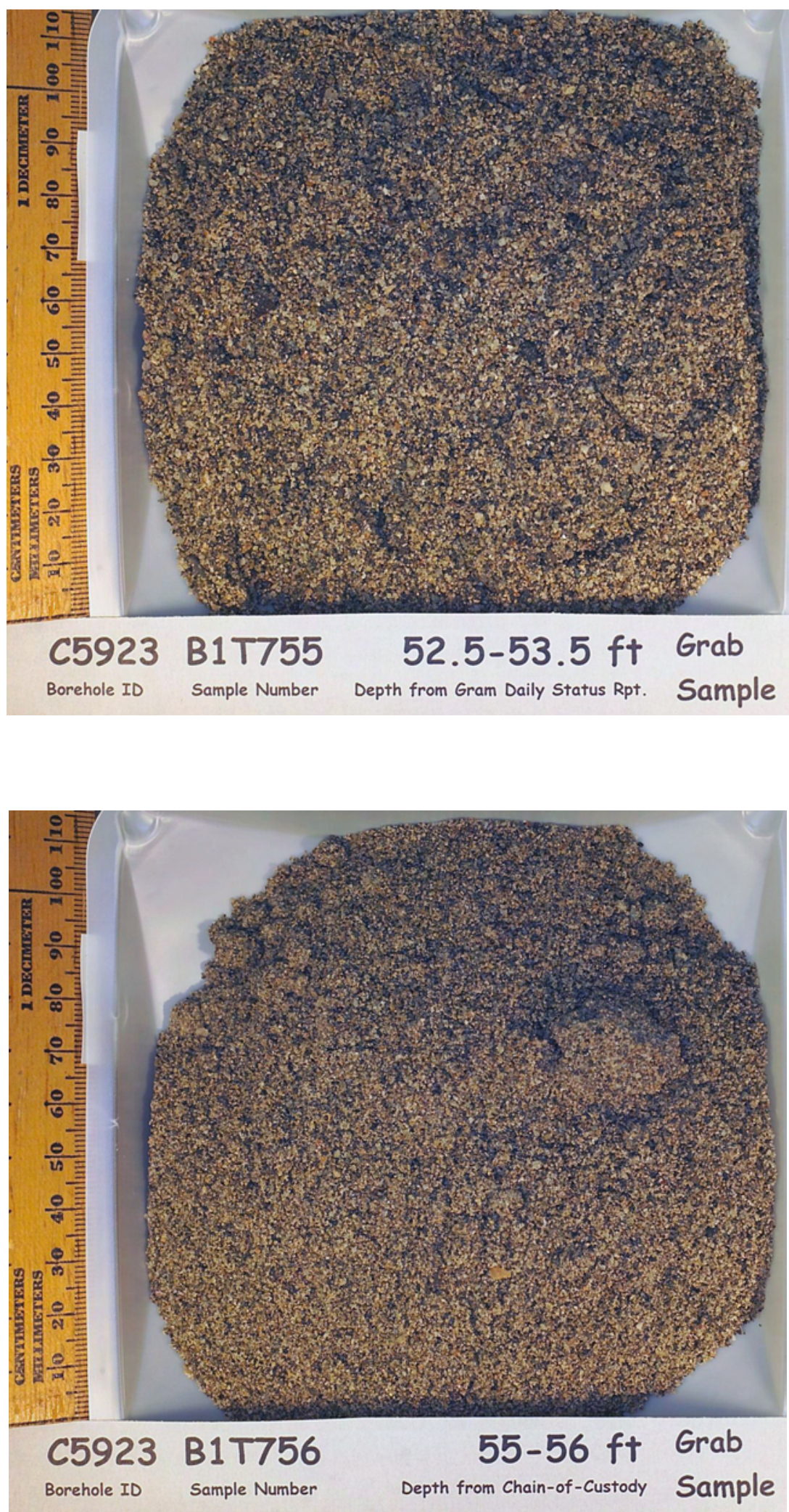
PNNL-17821
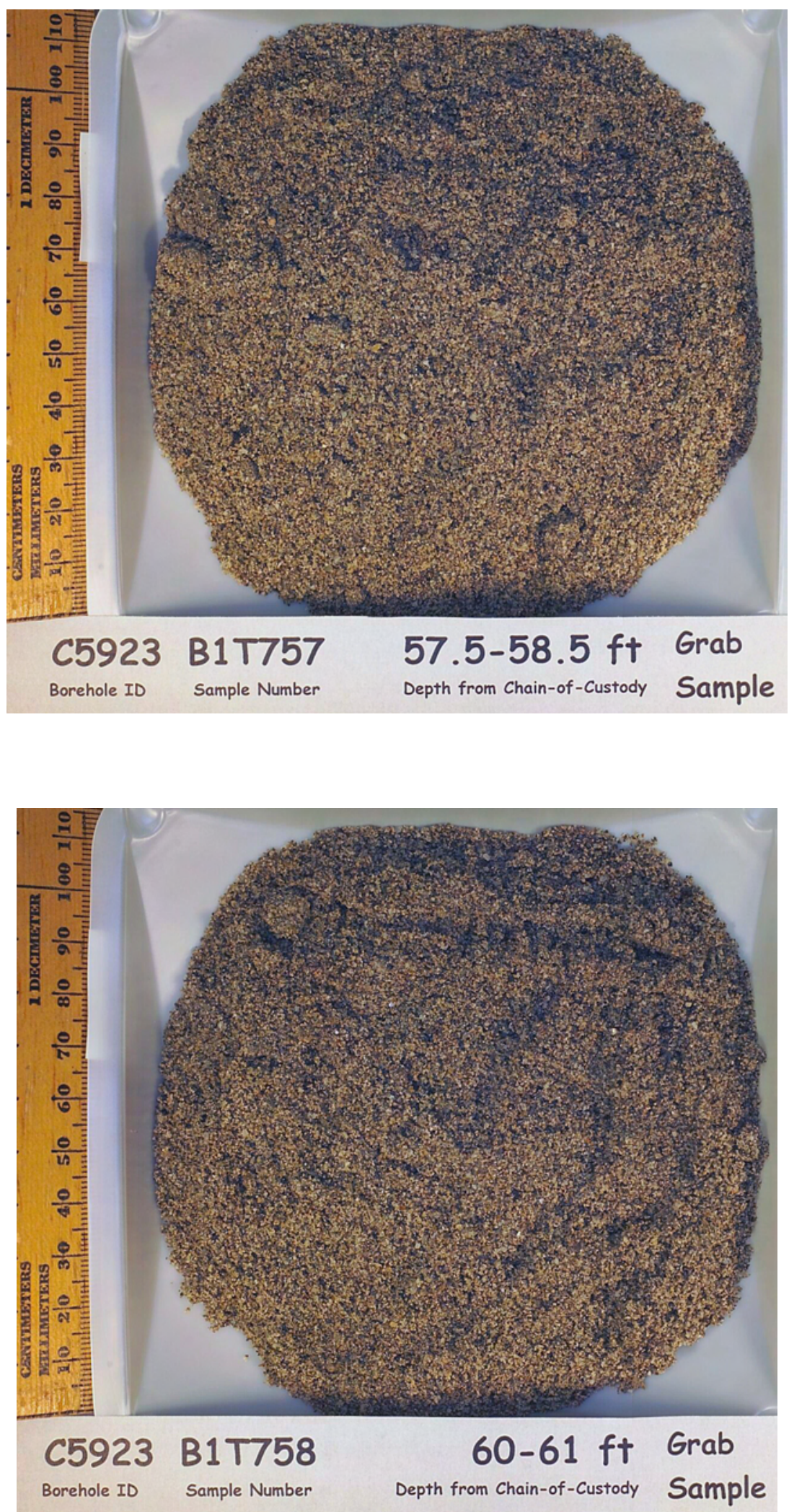
PNNL-17821

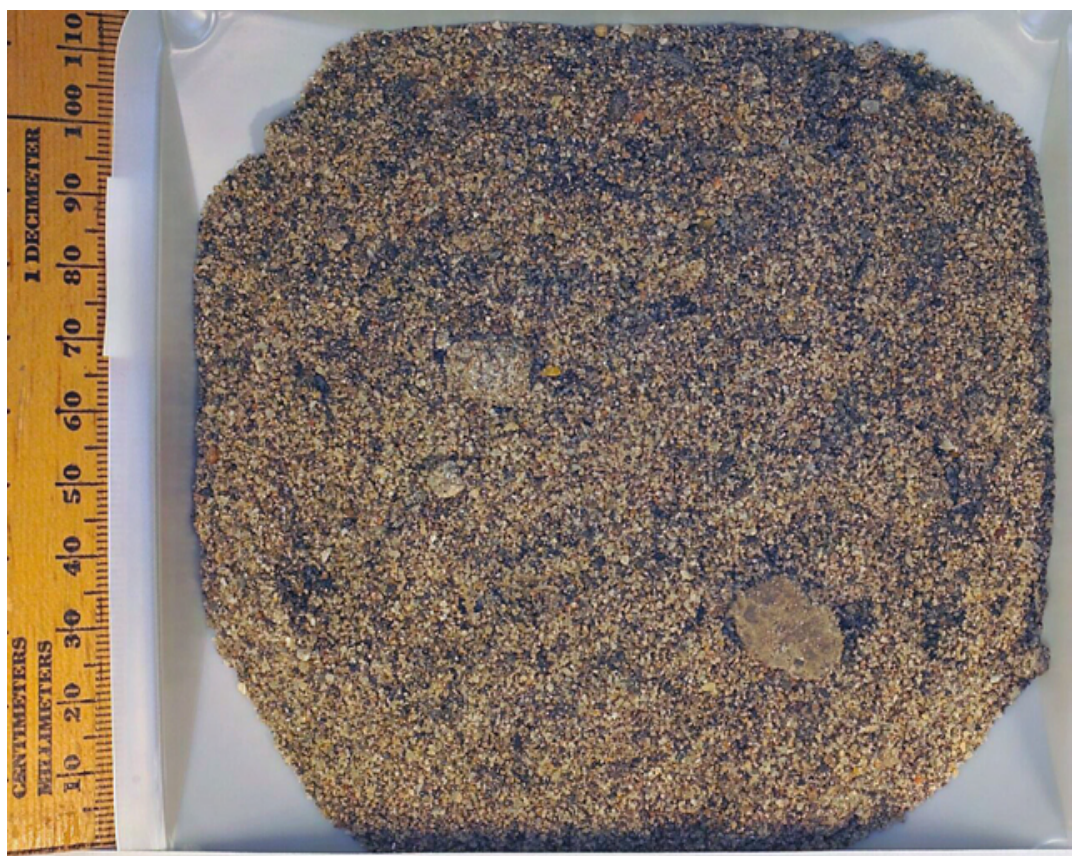

C5923 B1T759 62.5-63.5 ft Grab

Borehole ID Sample Number Depth from Chain-of-Custody Sample

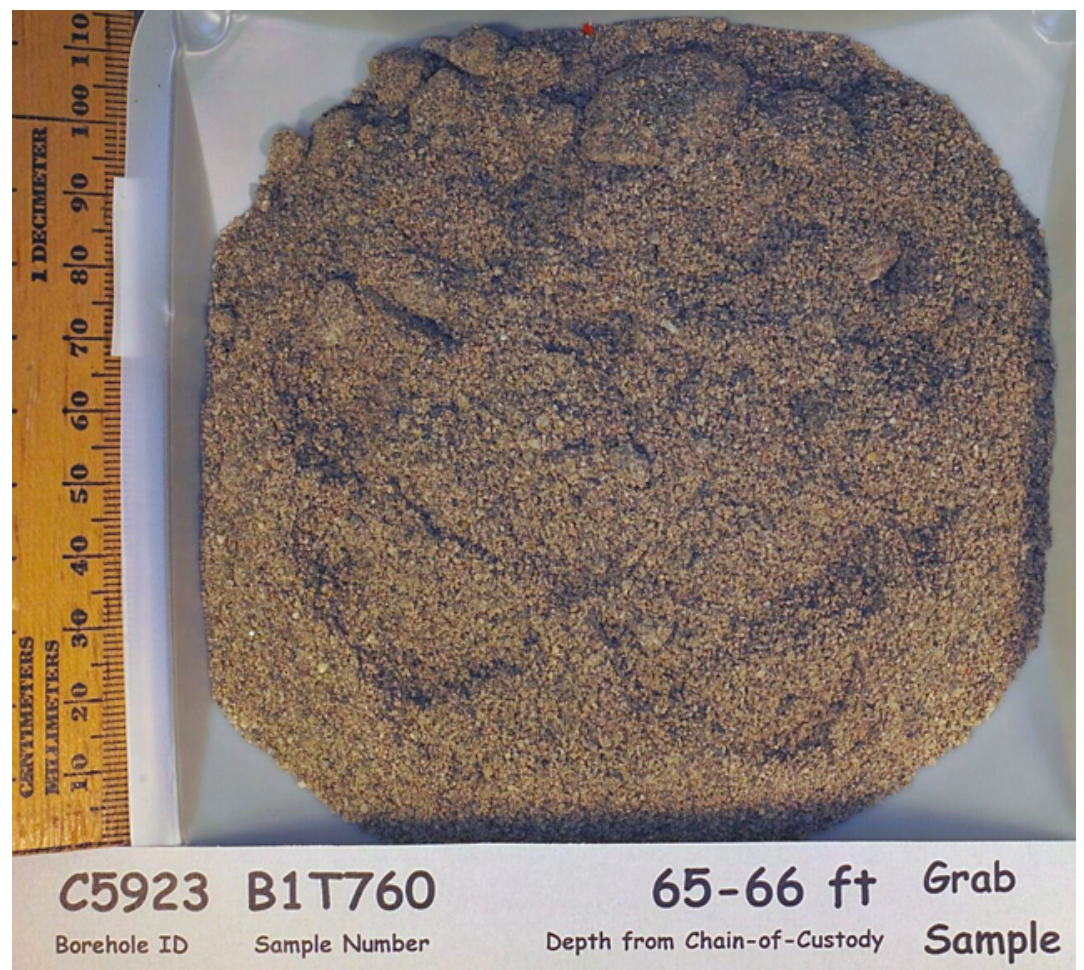


PNNL-17821
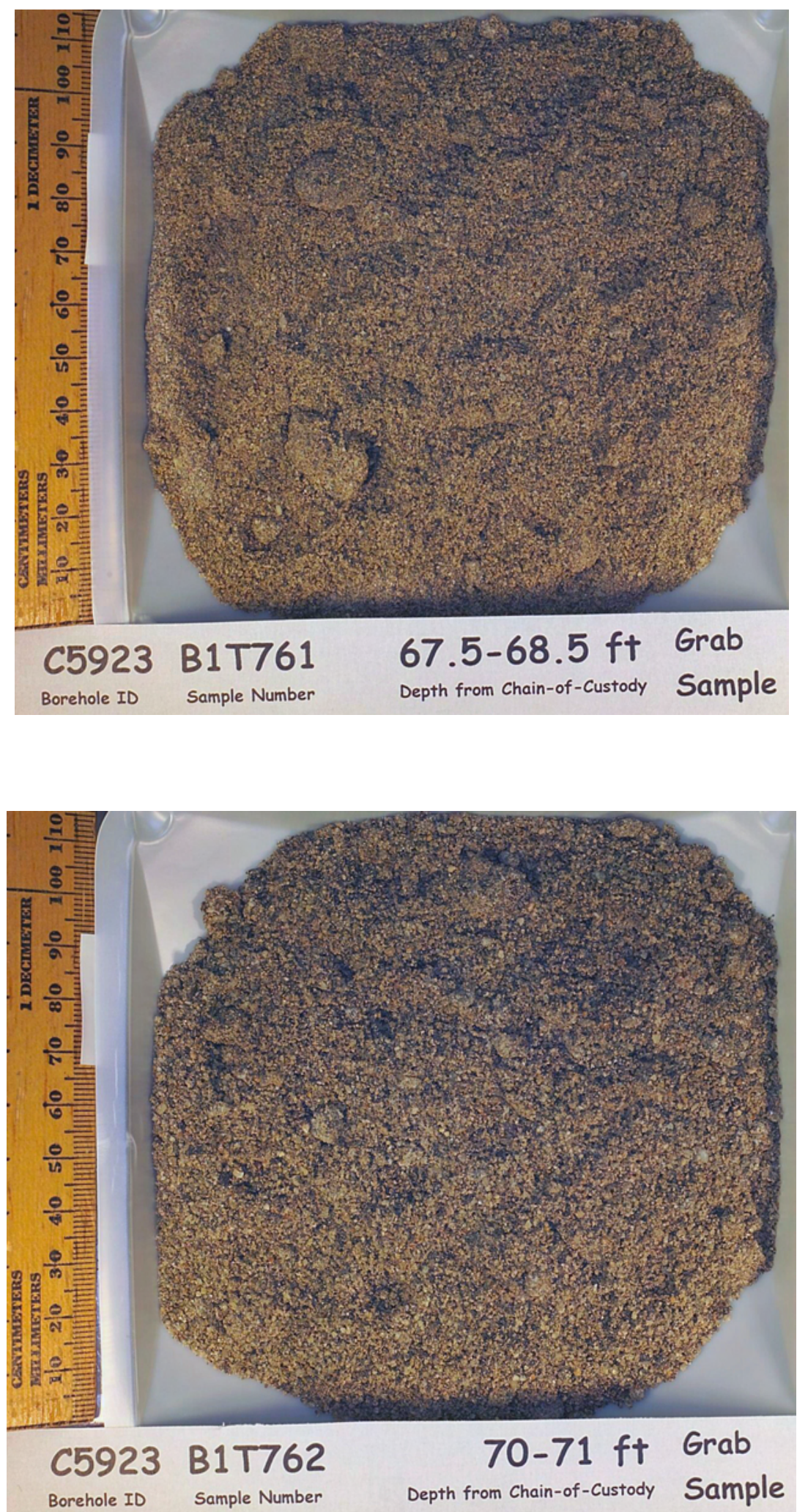
PNNL-17821
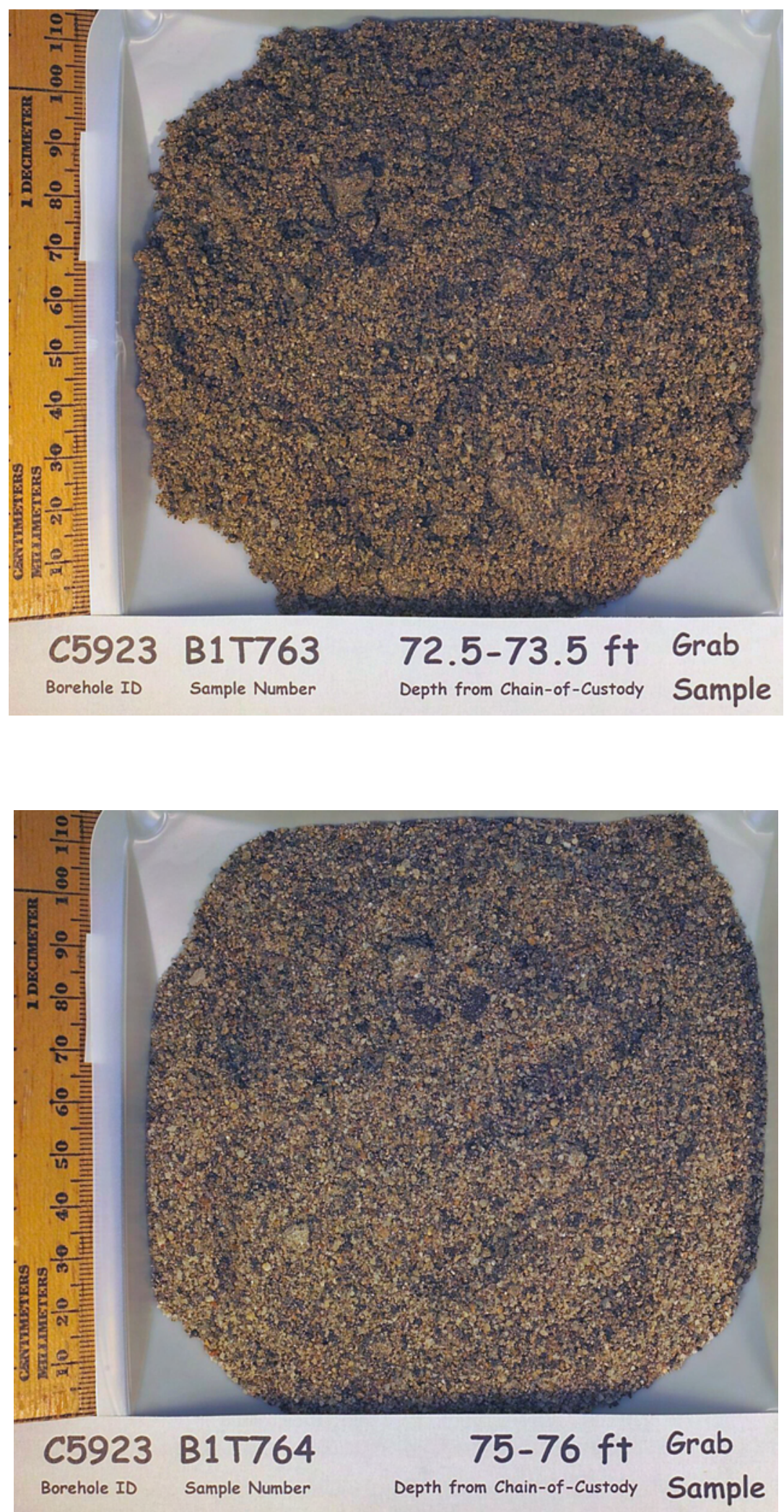
PNNL-17821
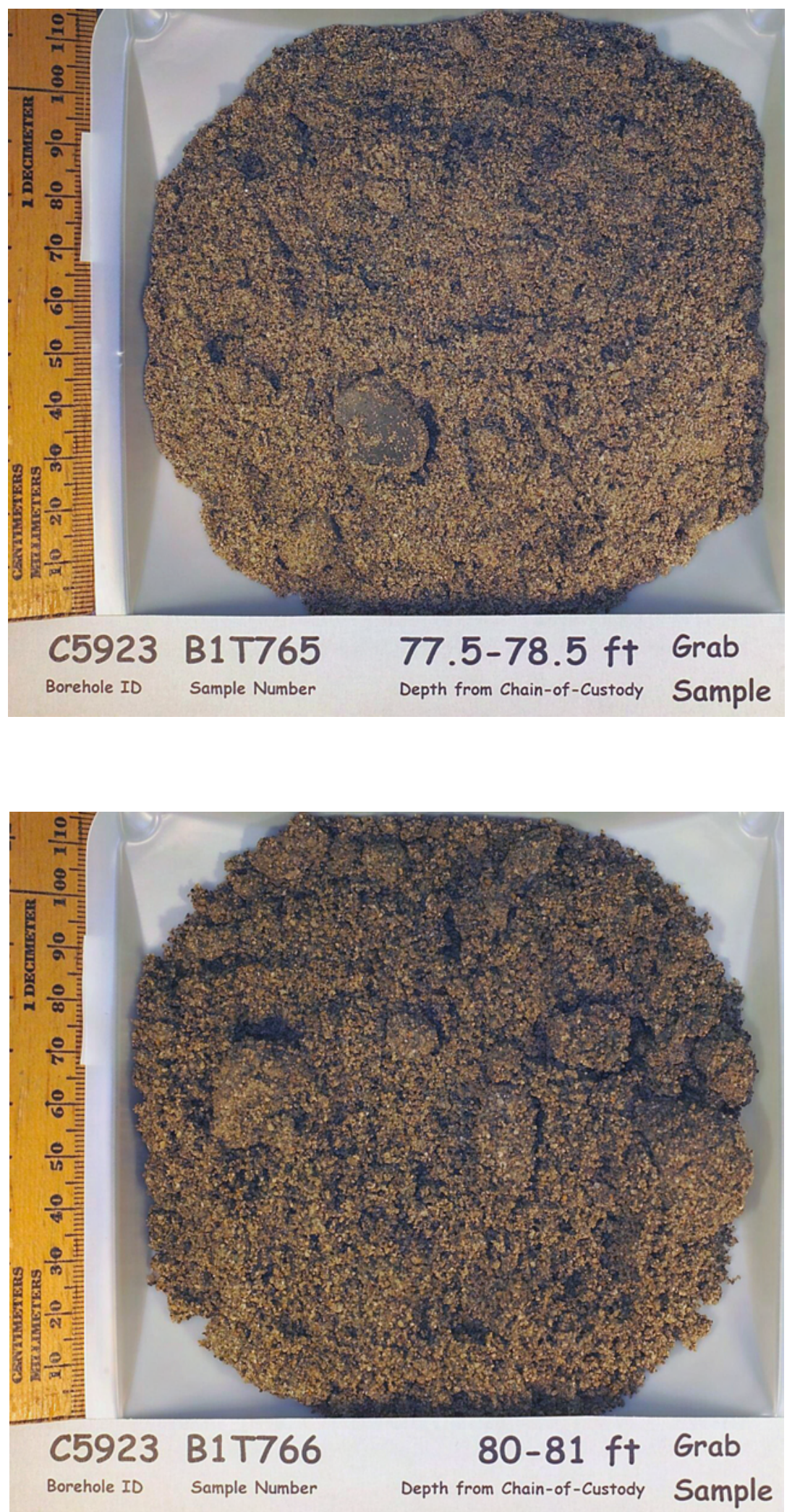
PNNL-17821
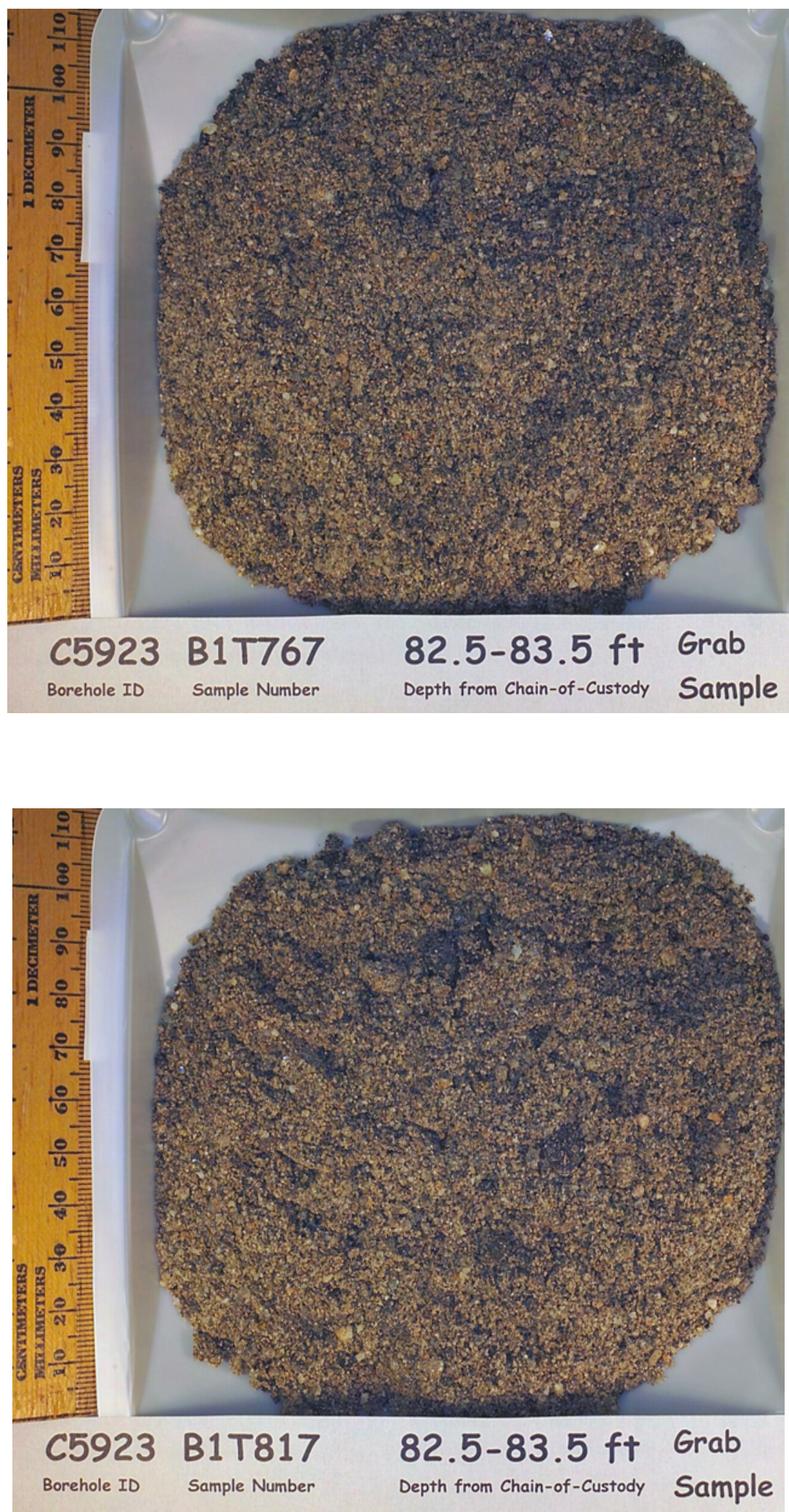
PNNL-17821
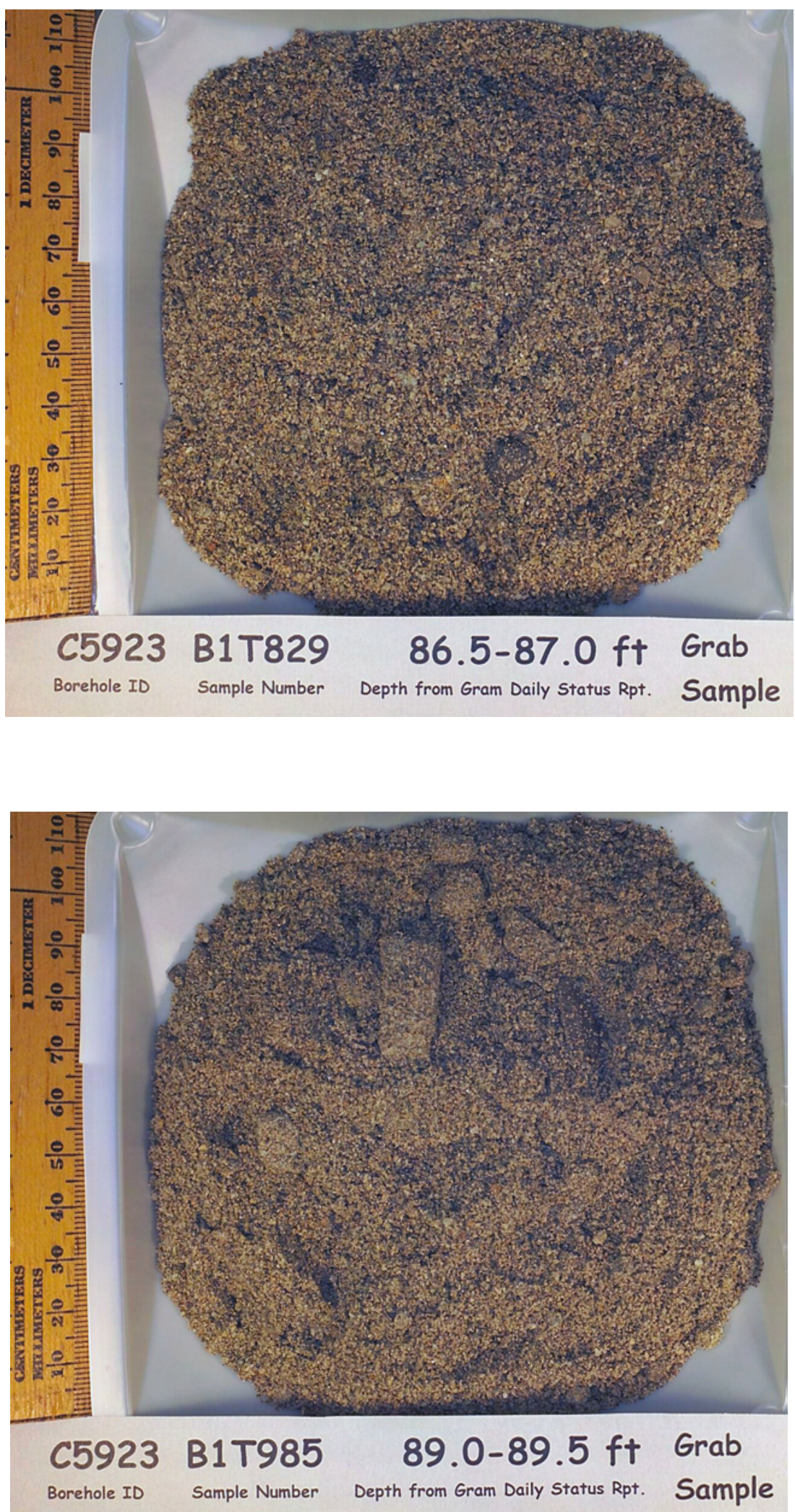
PNNL-17821
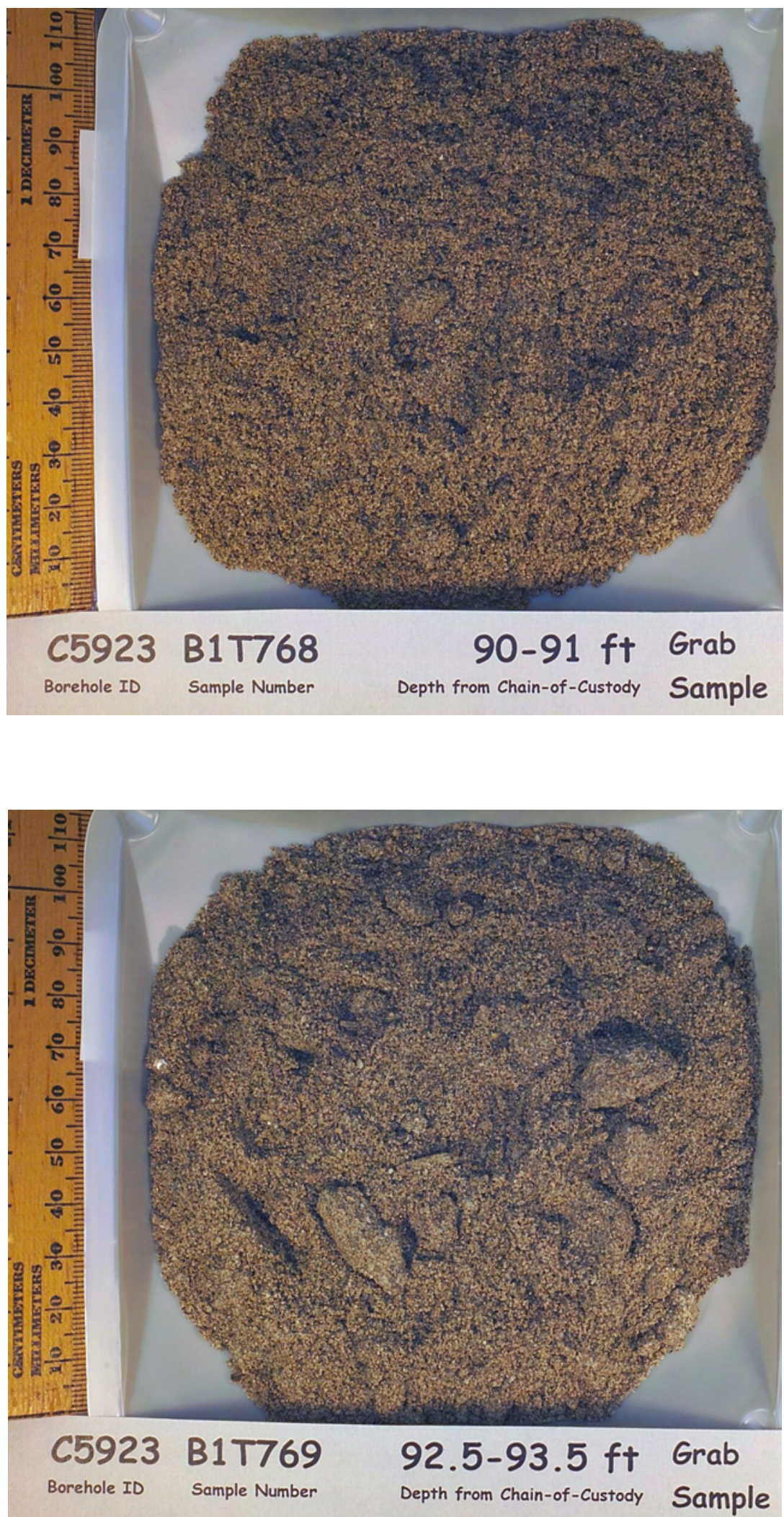
PNNL-17821
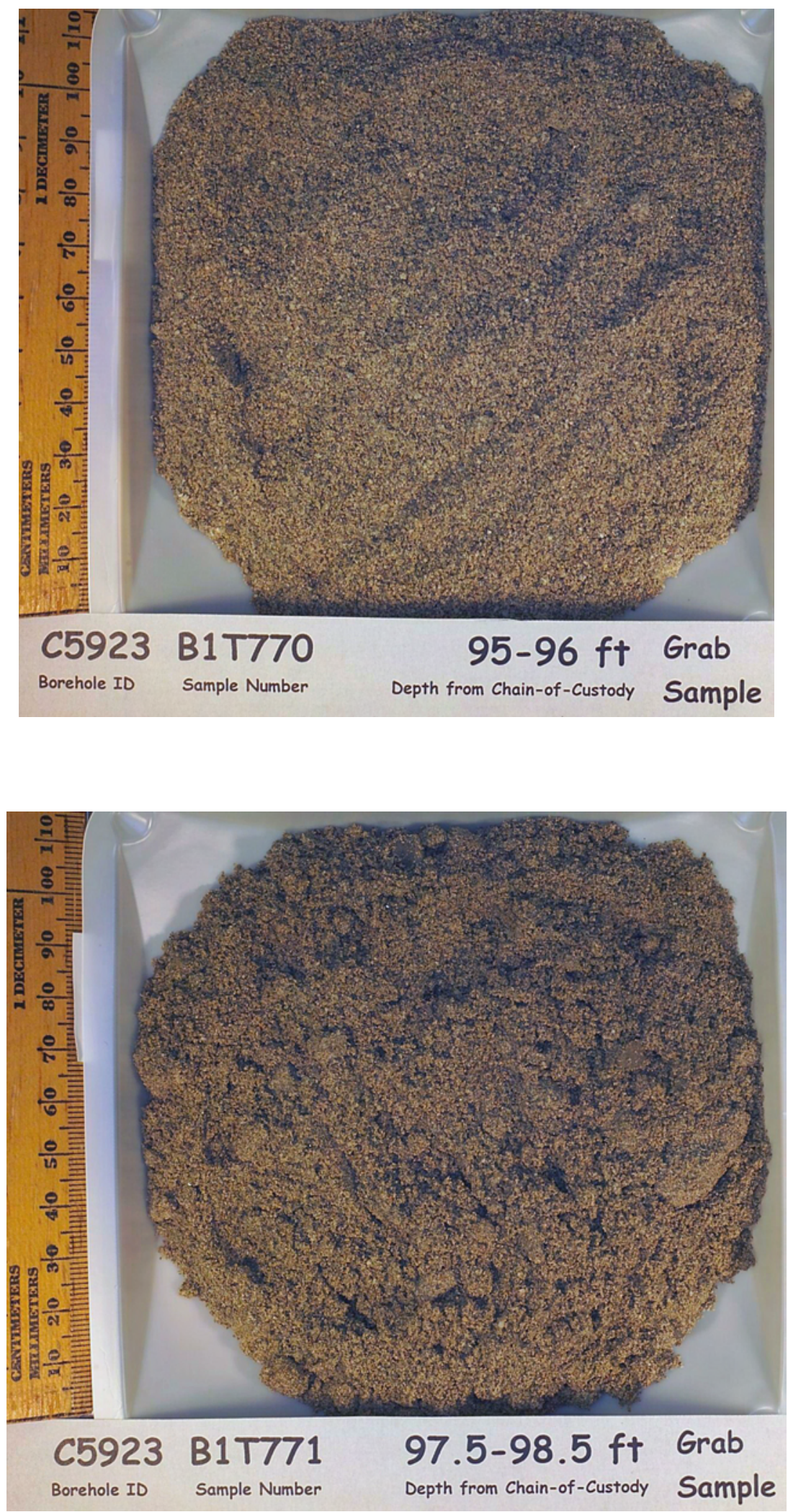
PNNL-17821
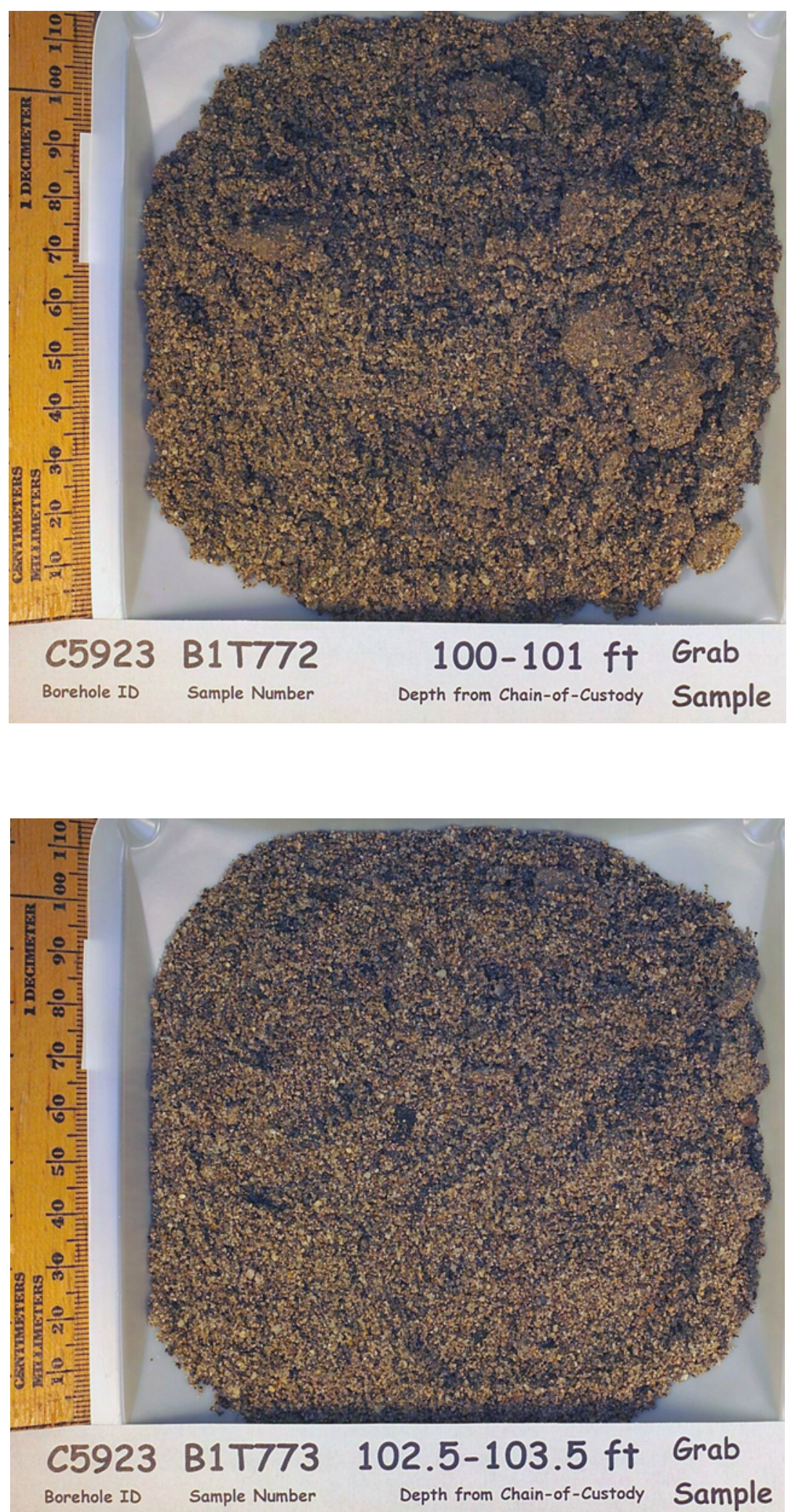
PNNL-17821

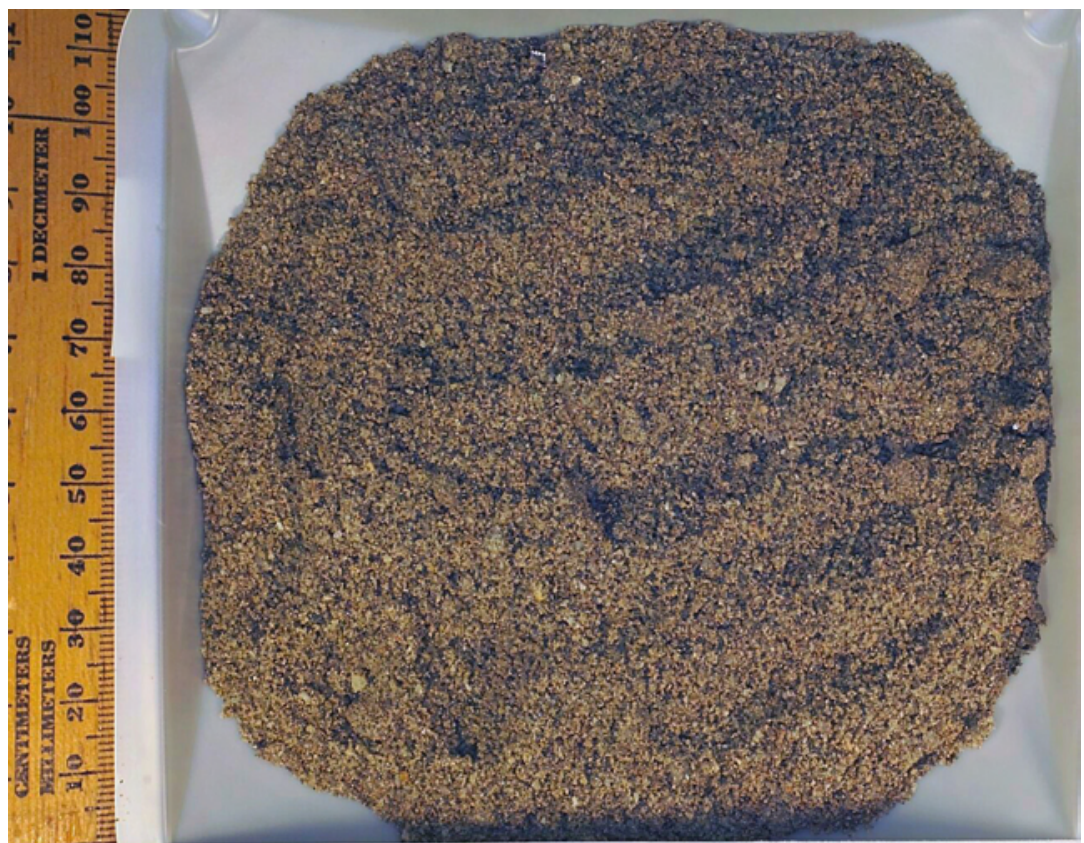

C5923 B1T9K9 106.5-107.0 ft Grab

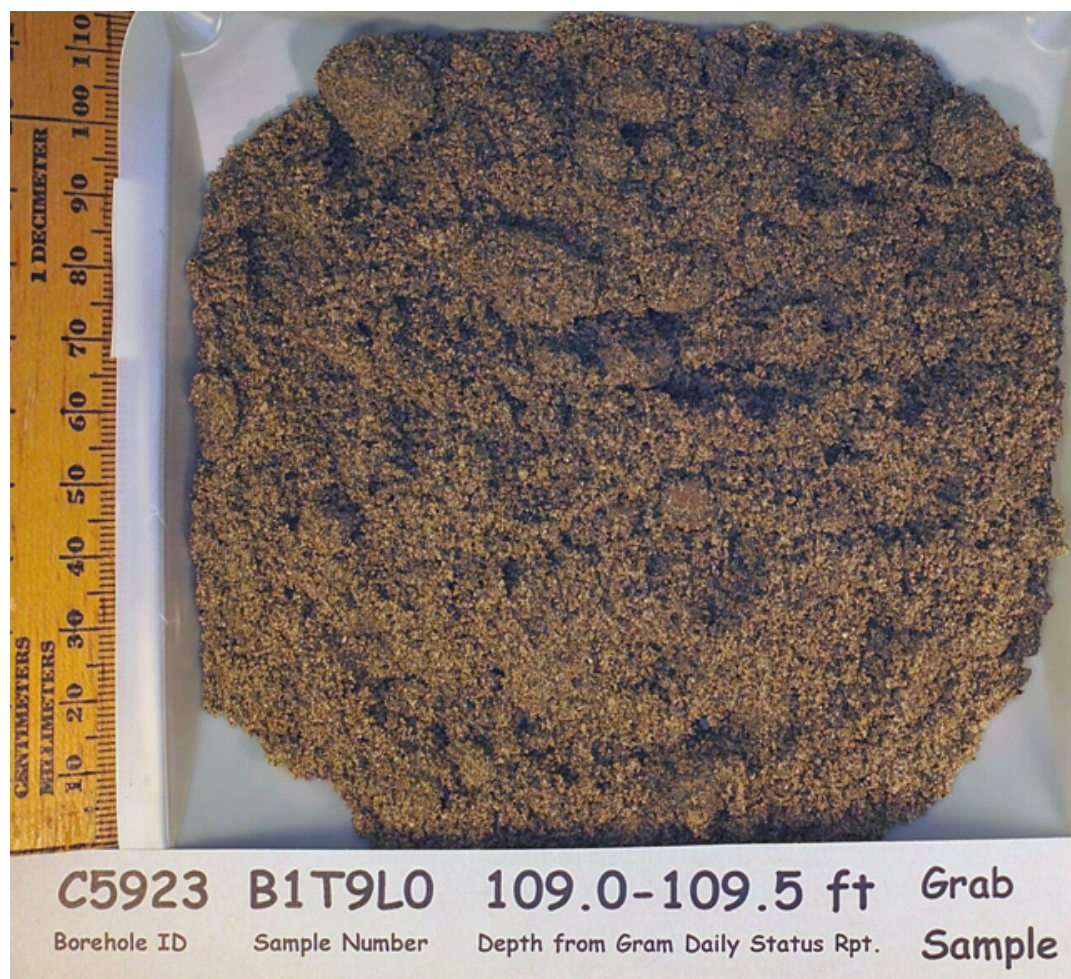


PNNL-17821

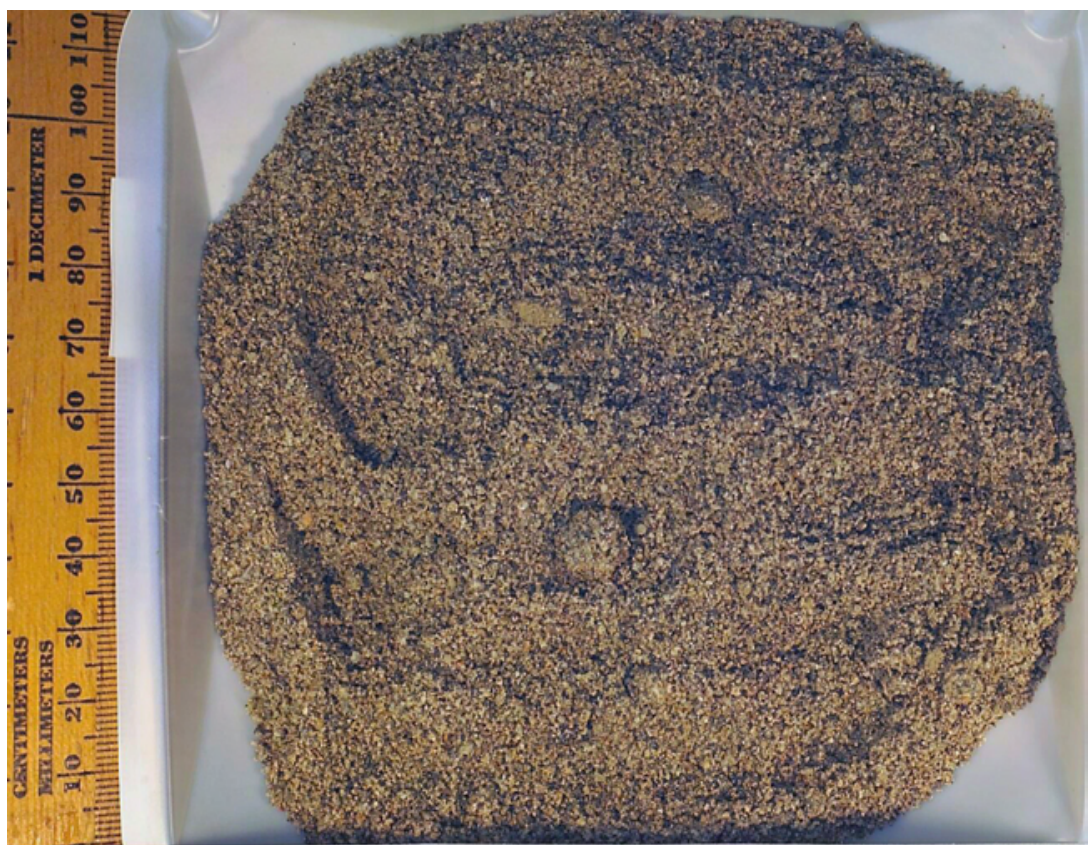

$\begin{array}{lll}\text { C5923 B1T9L1 } & 114.0-114.5 \mathrm{ft} & \text { Grab } \\ \text { Borehole ID } & \text { Sample Number } & \text { Depth from Gram Daily Status Rpt. Sample }\end{array}$

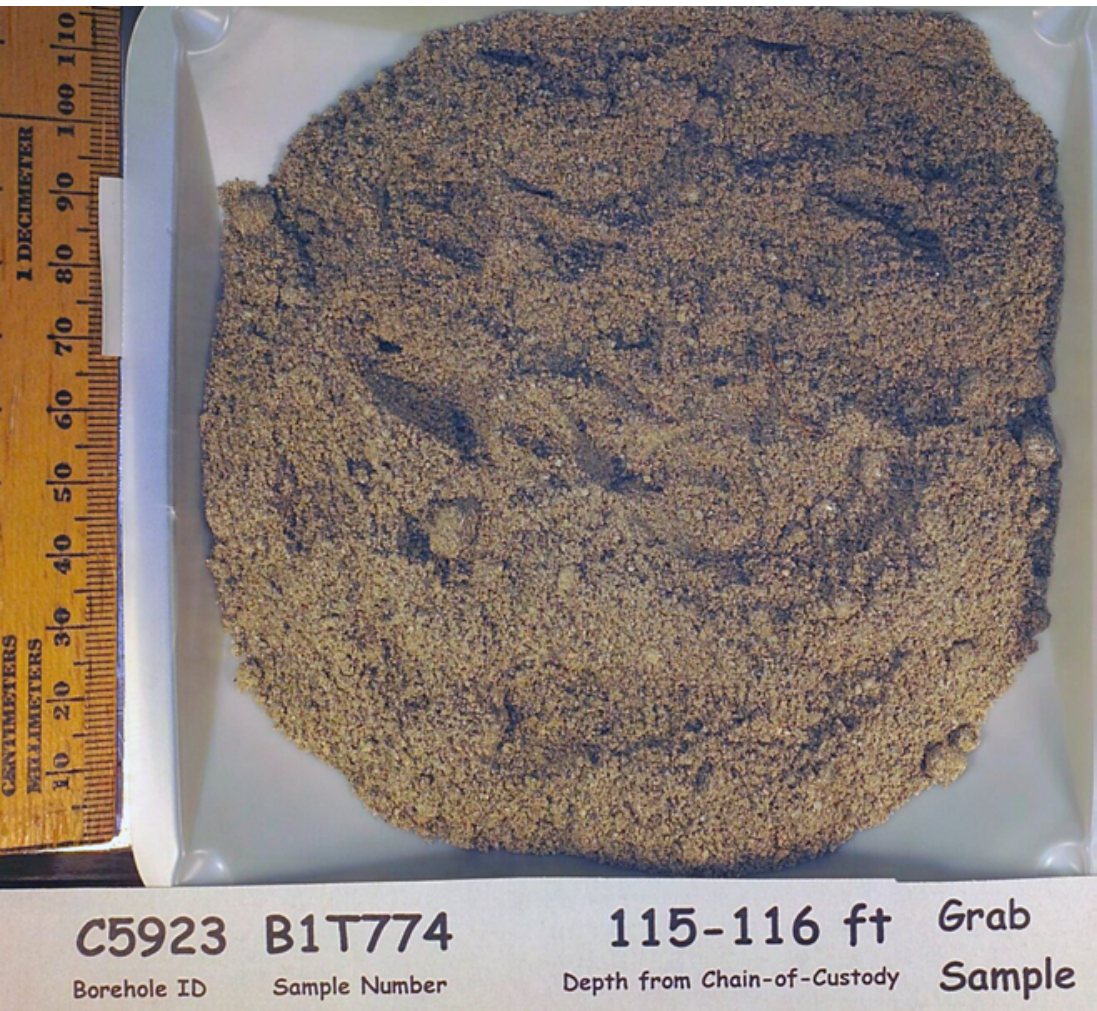


PNNL-17821
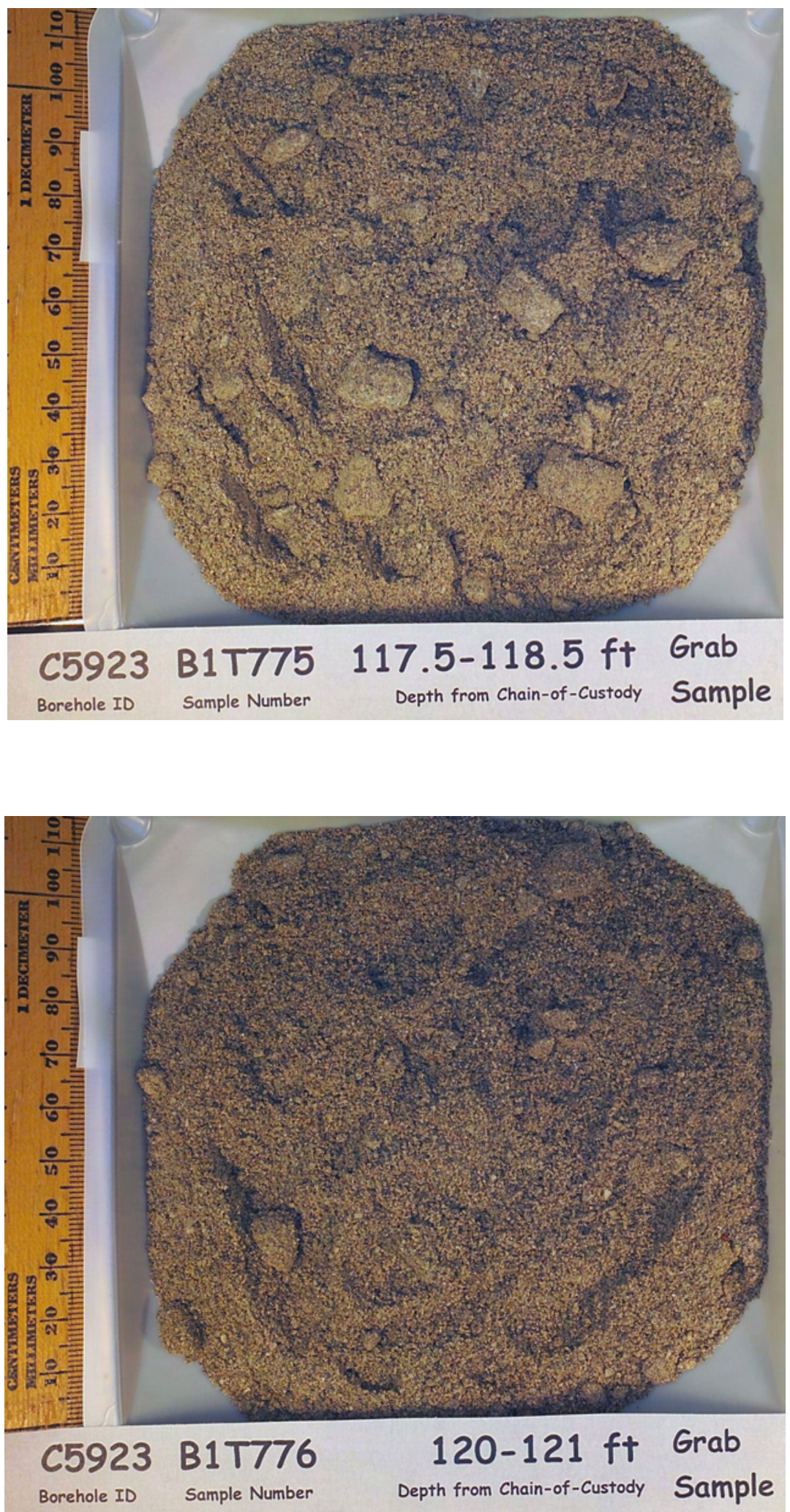
PNNL-17821

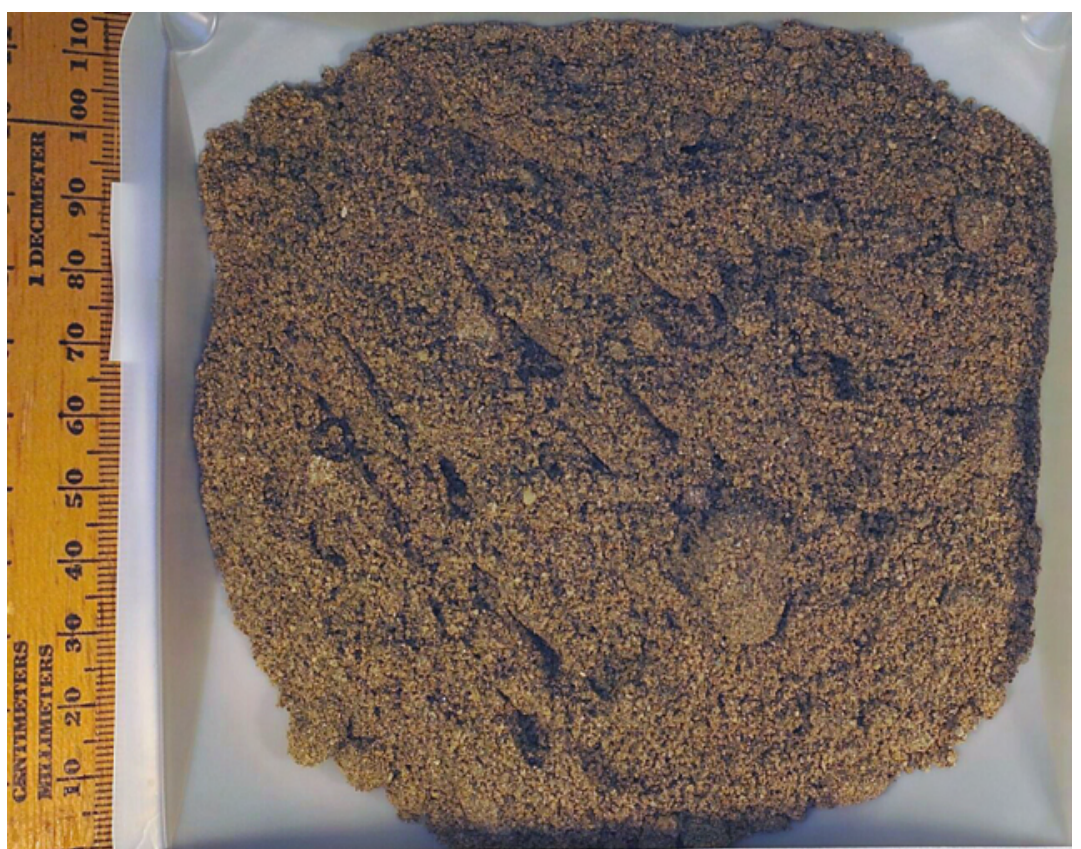

C5923 B1T777 122.5-123.5 ft Grab

Borehole ID

Sample Number

Depth from Chain-of-Custody Sample

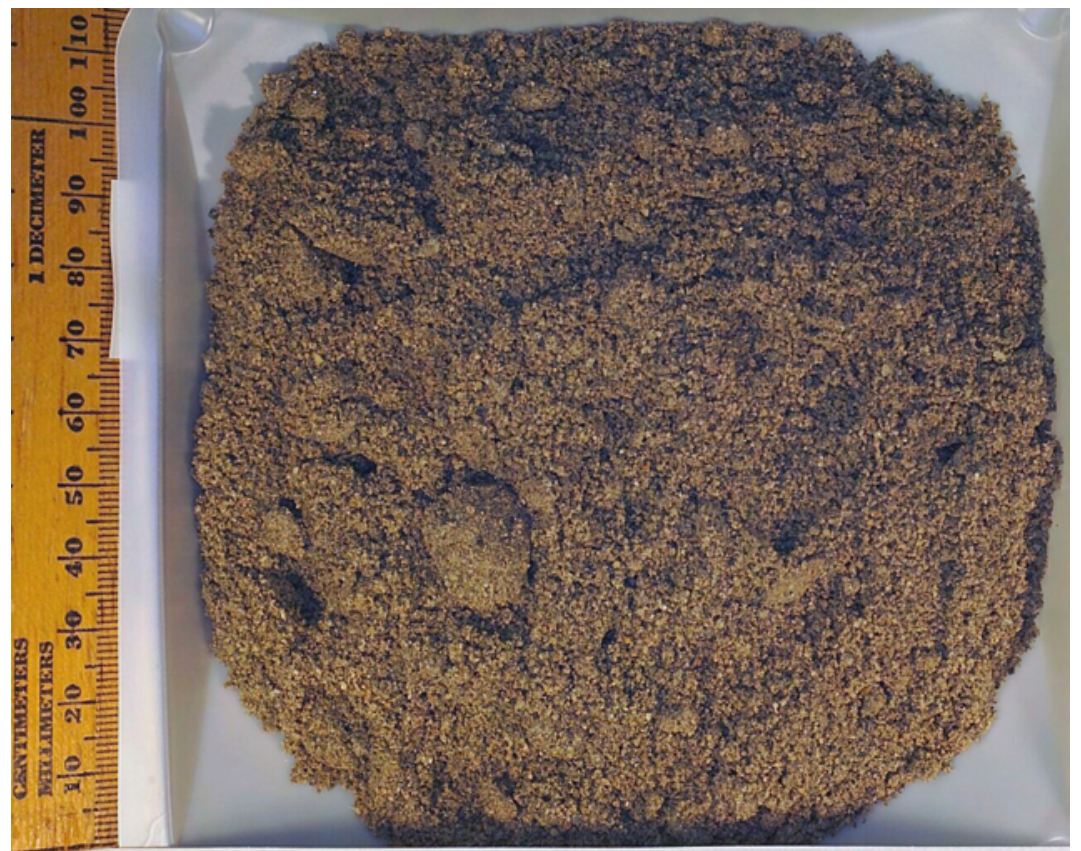

C5923 B1T818 122.5-123.5 ft Grab

Borehole ID

Sample Number

Depth from Chain-of-Custody Sample 
PNNL-17821

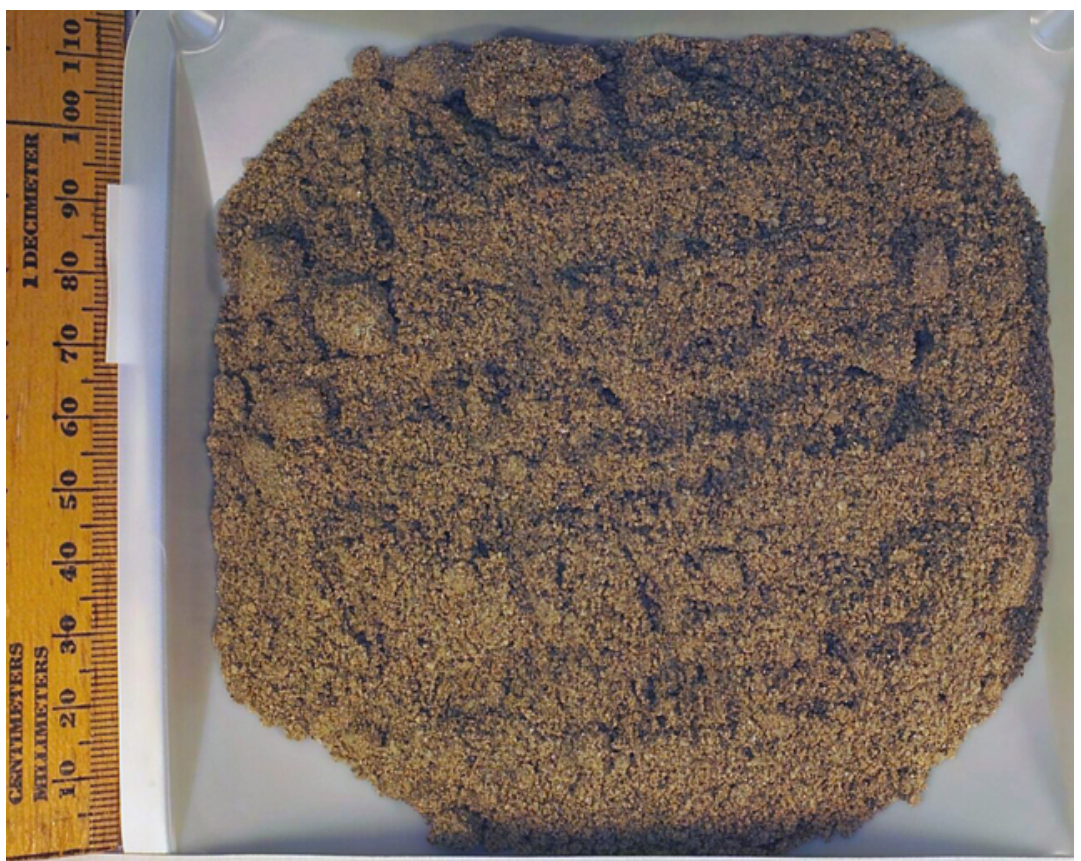

C5923 B1T9L2 126.5-127.0 ft Grab

Borehole ID Sample Number Depth from Gram Daily Status Rpt. Sample

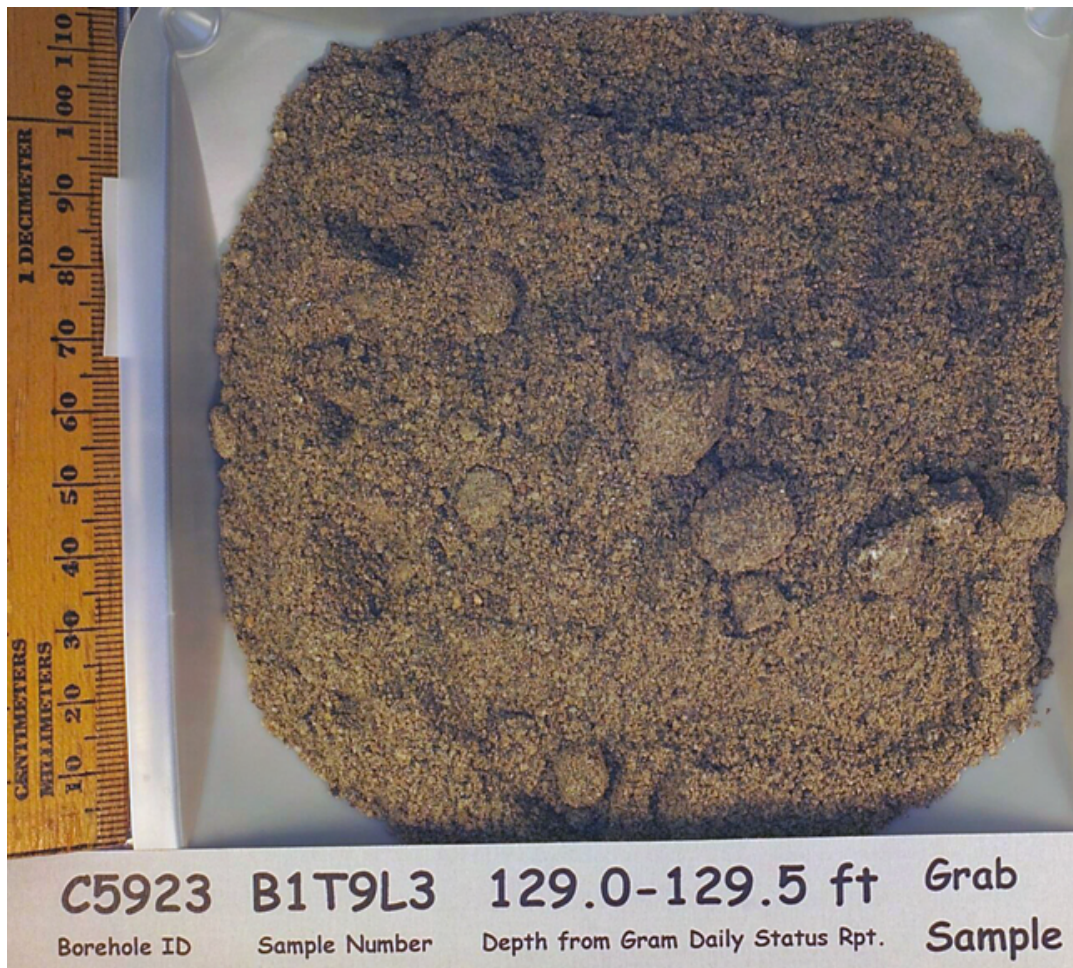


PNNL-17821

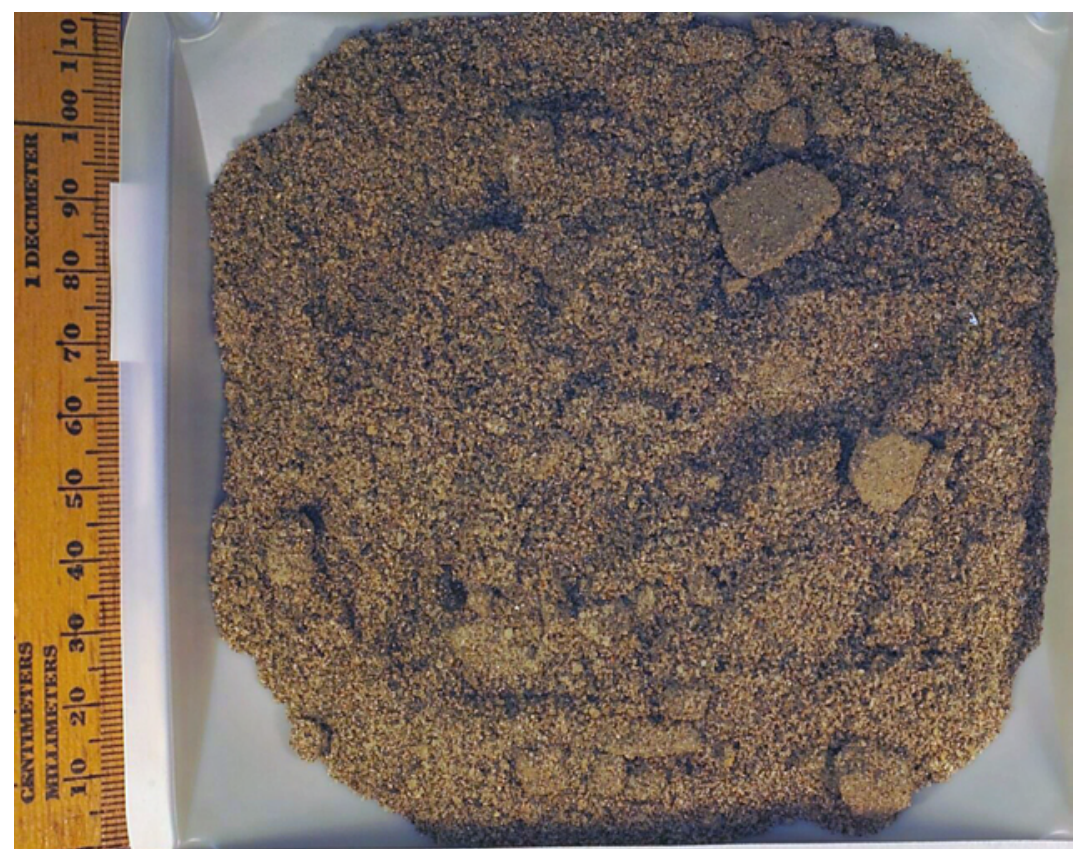

C5923 B1T9L4
Borehole ID
Sample Number

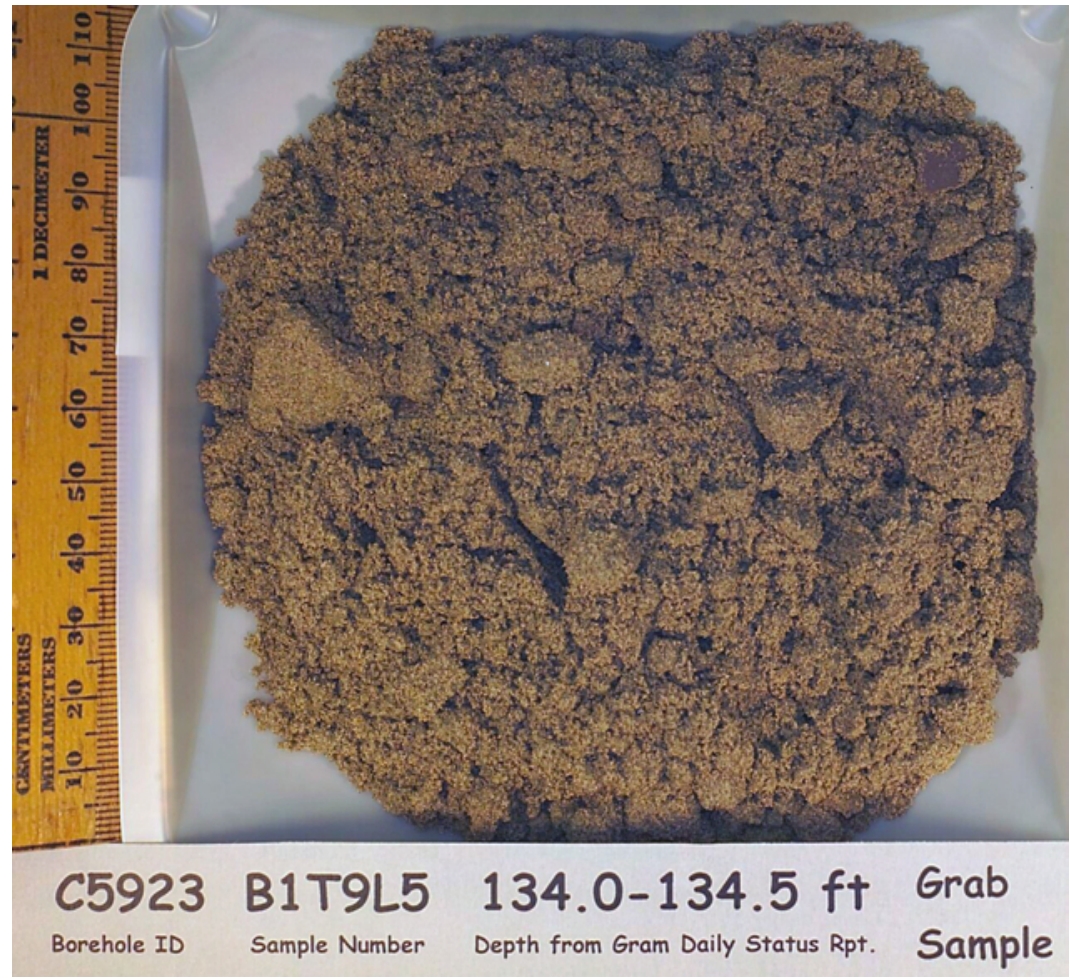


PNNL-17821
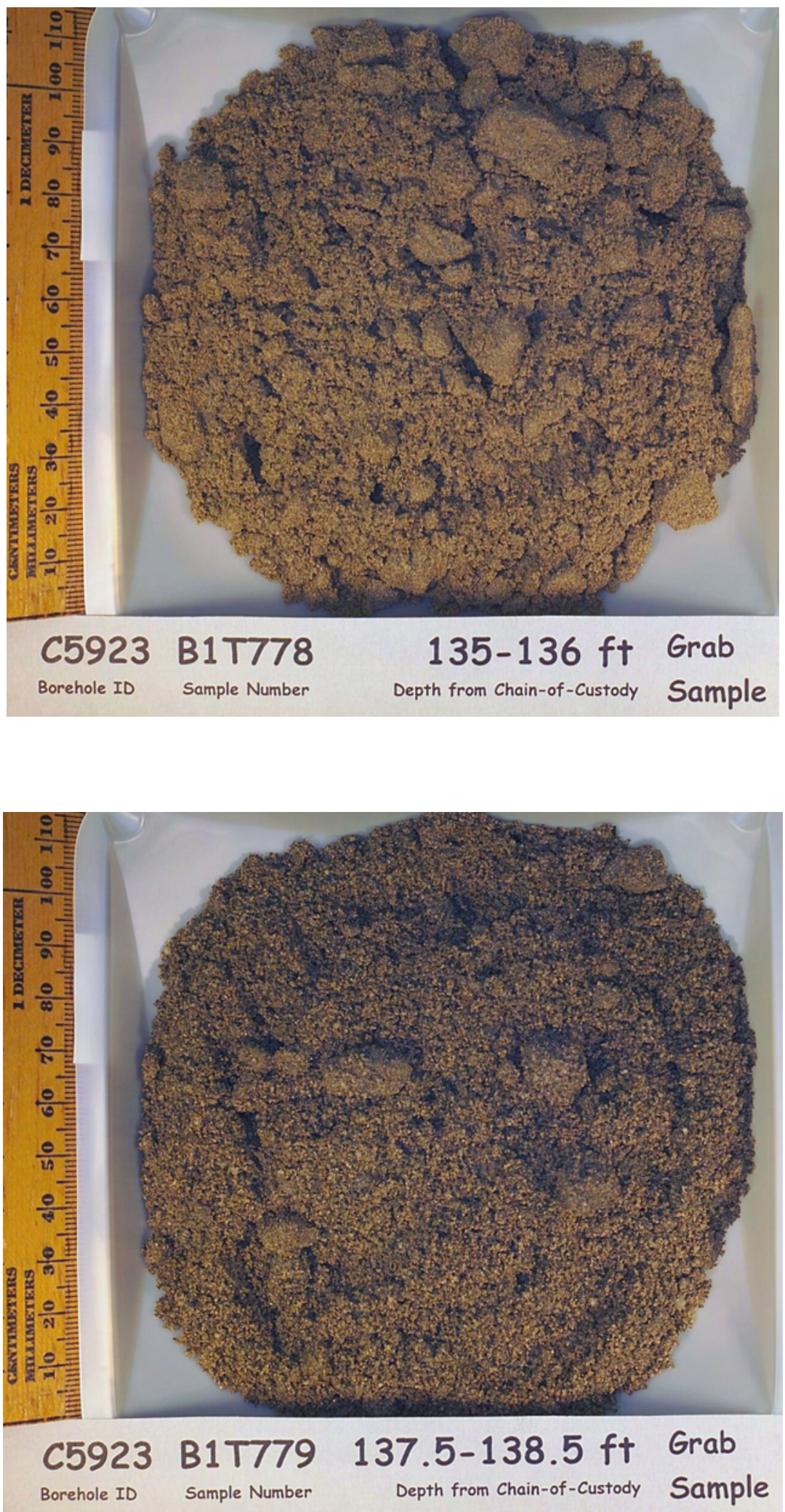
PNNL-17821
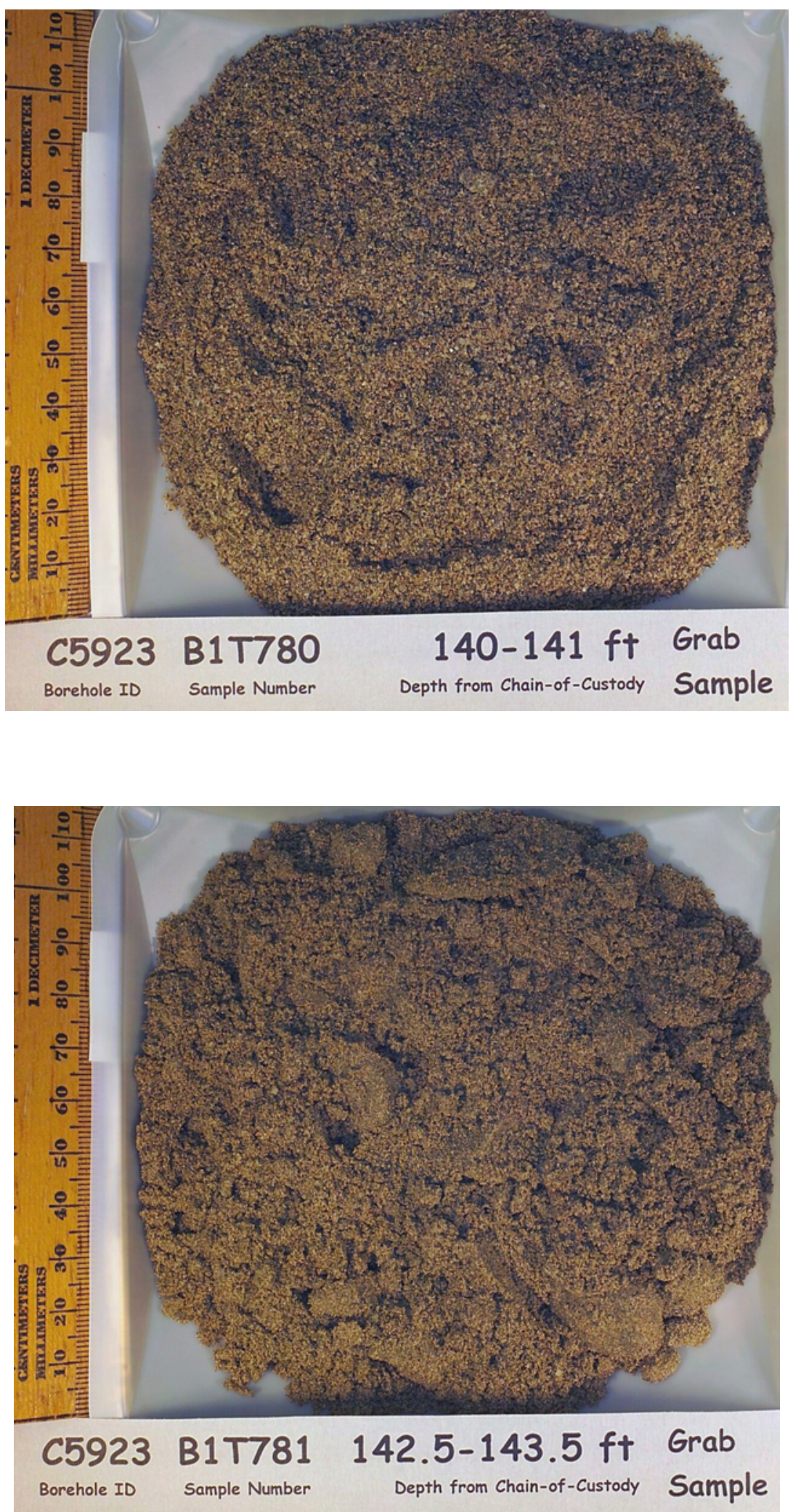
PNNL-17821
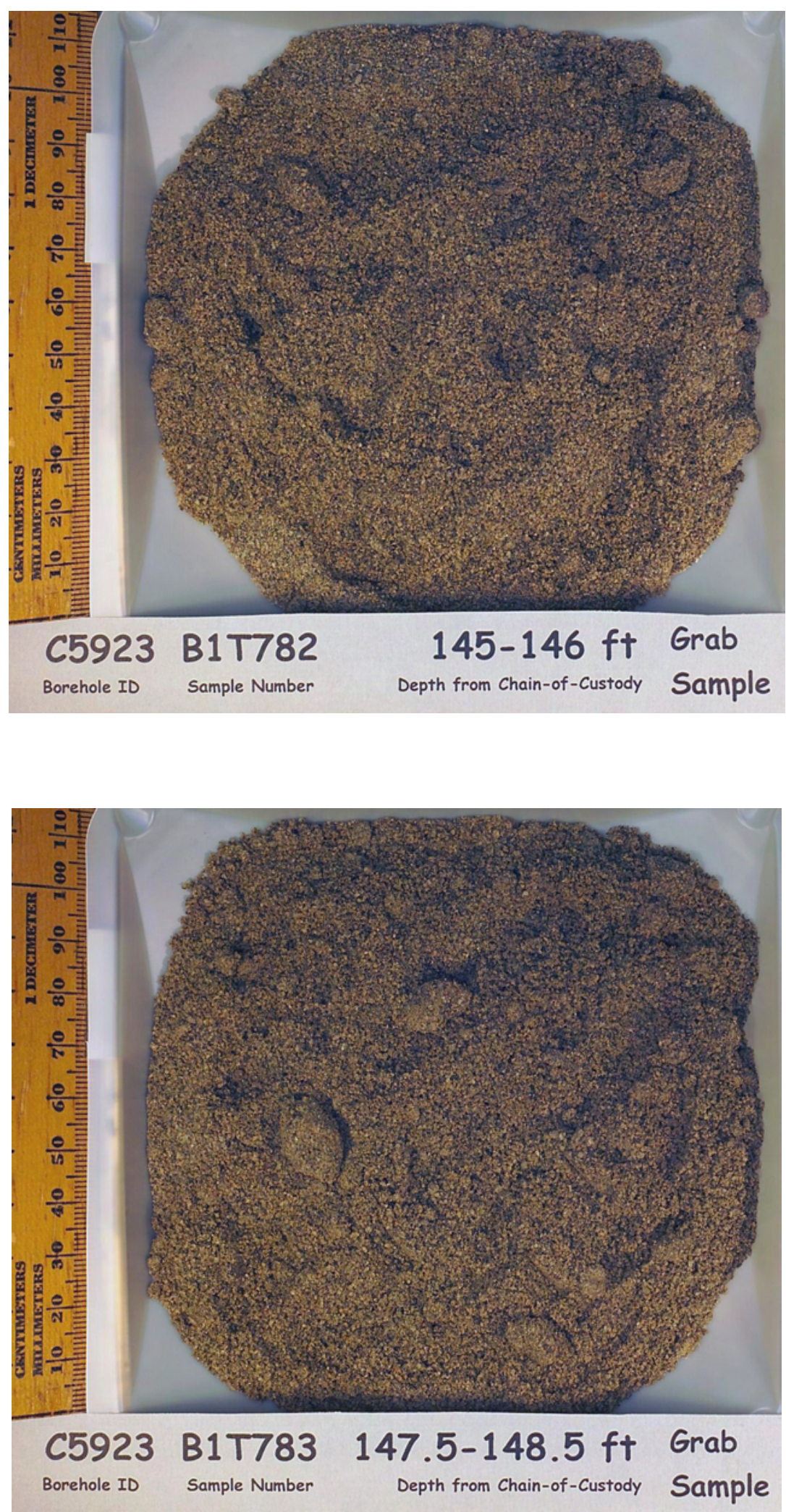
PNNL-17821
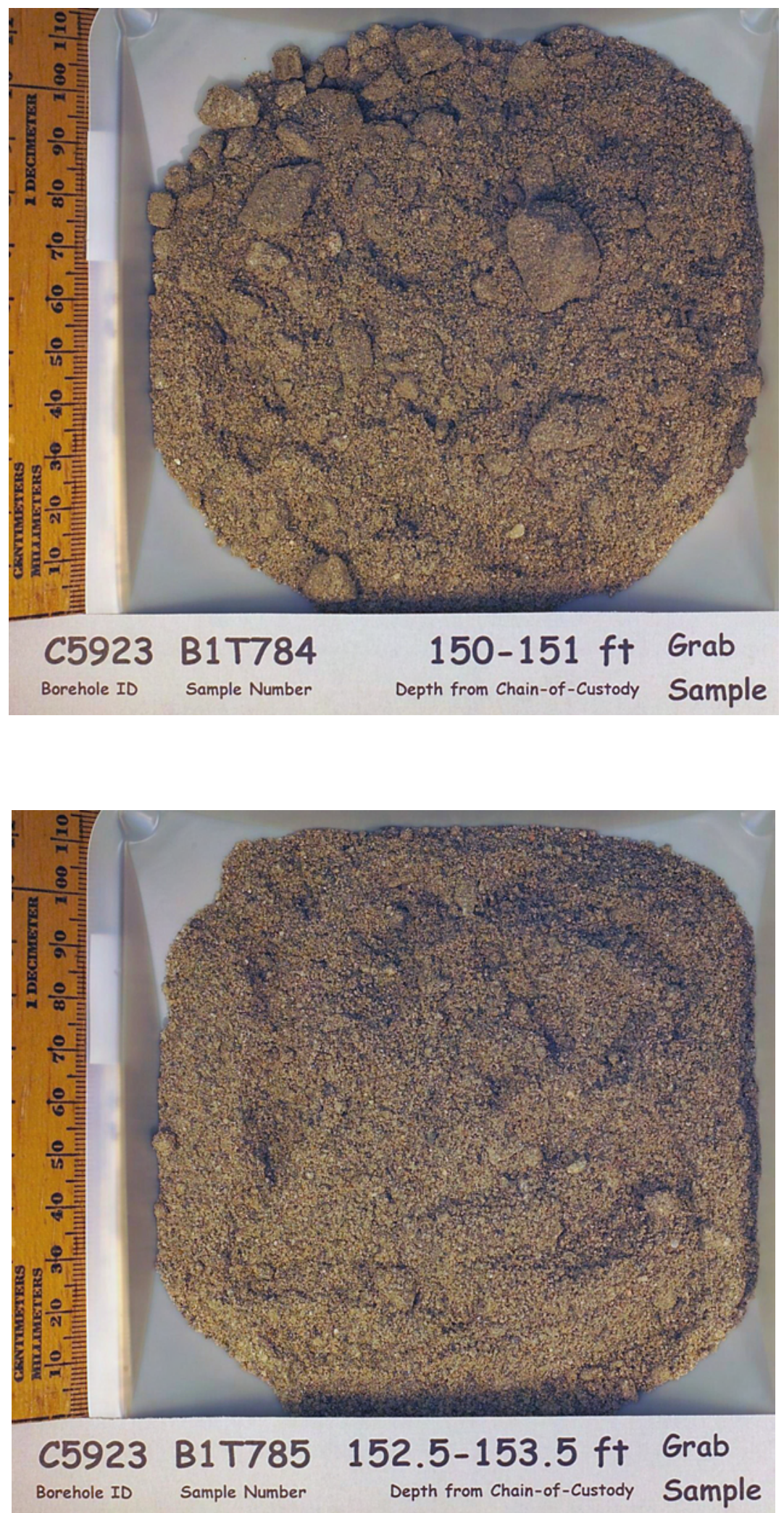
PNNL-17821
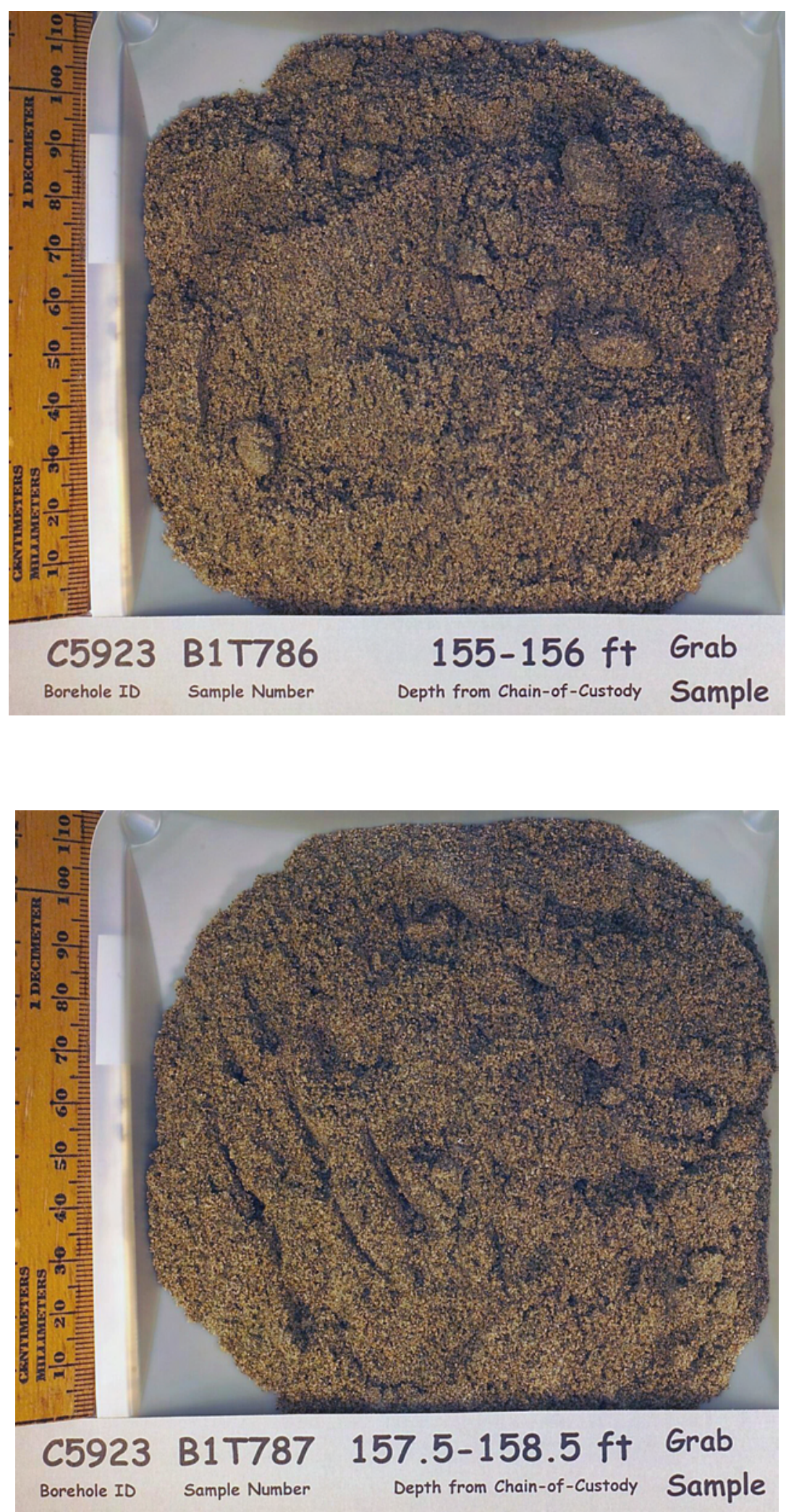
PNNL-17821
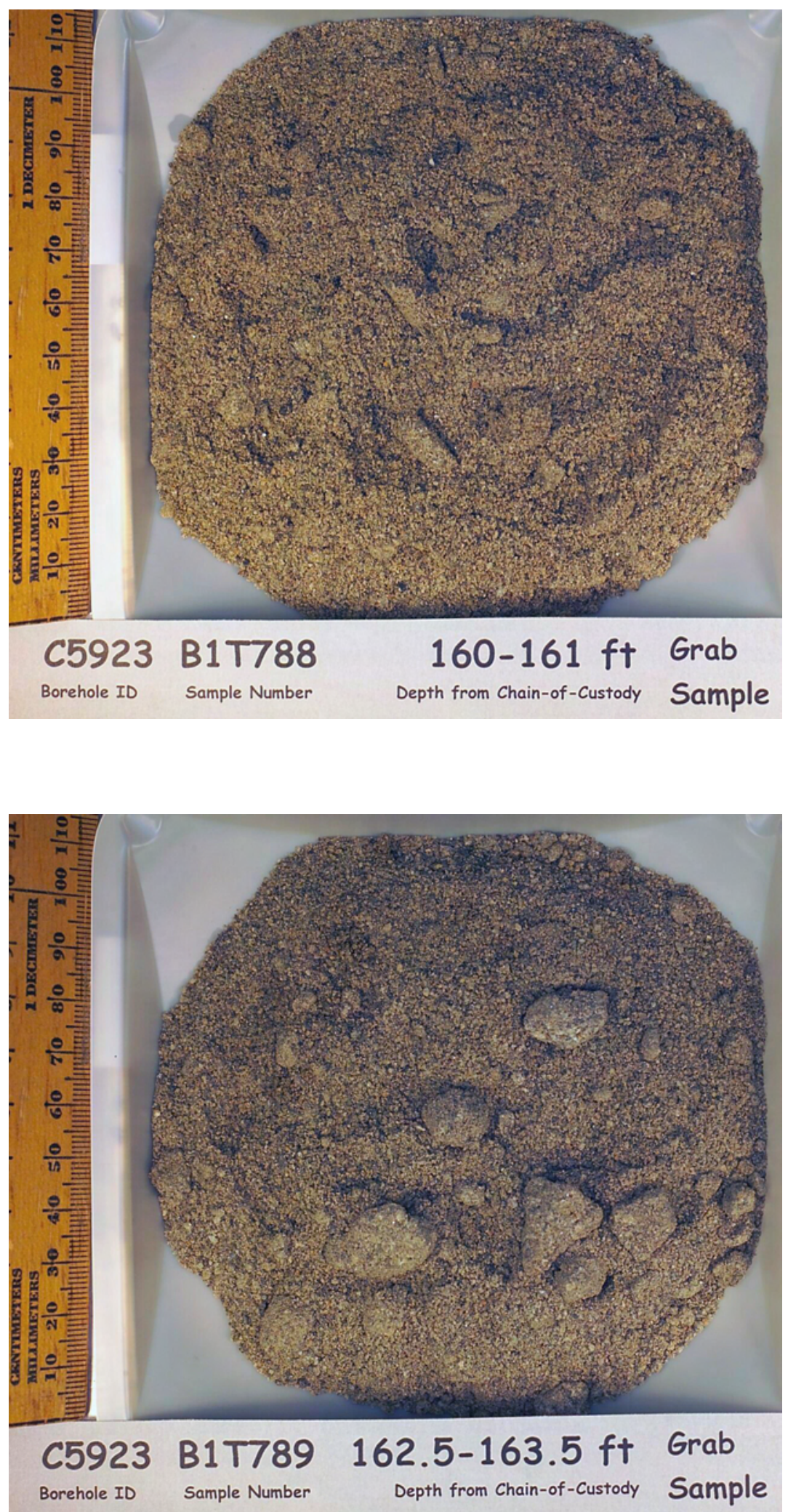
PNNL-17821
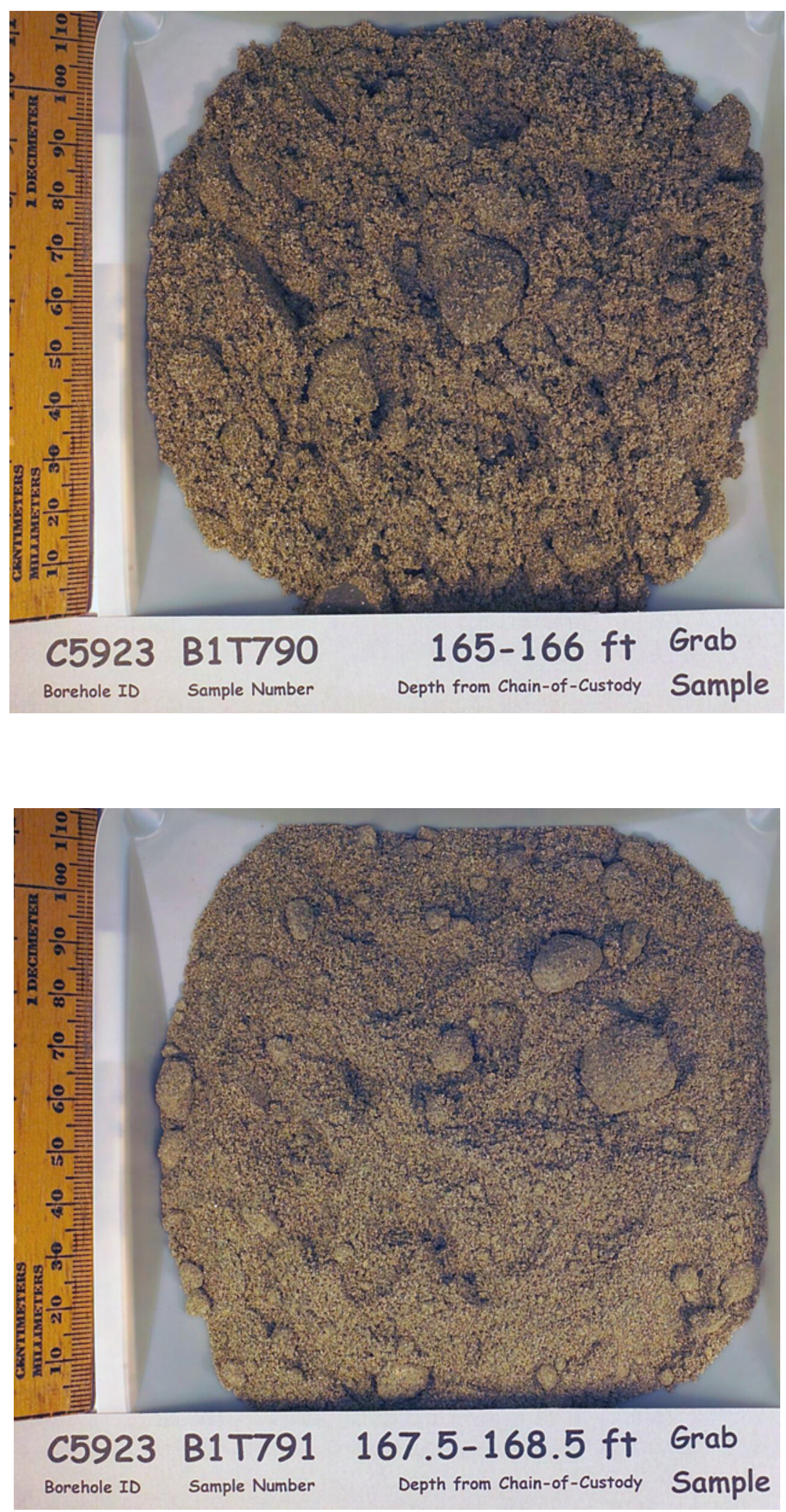
PNNL-17821
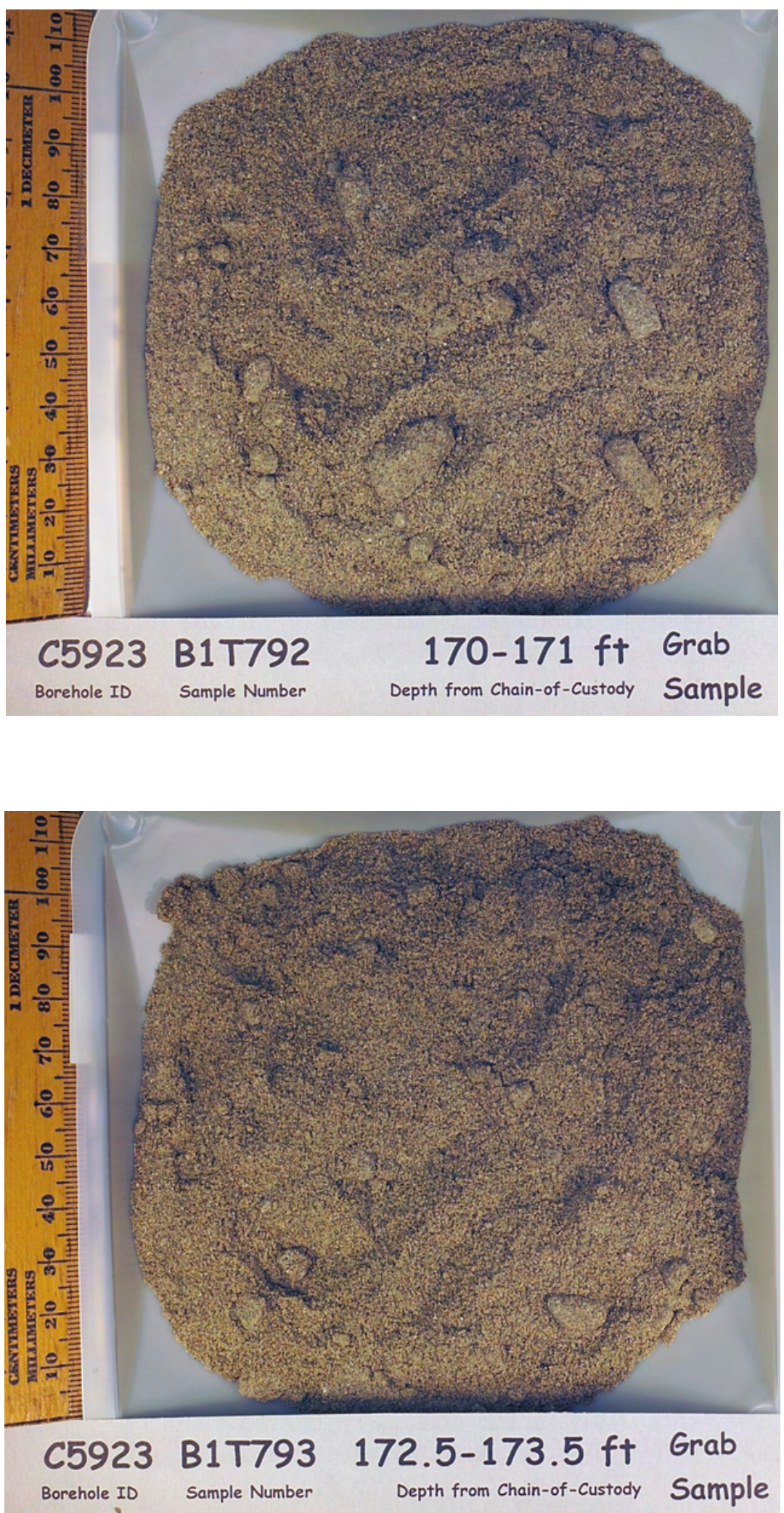
PNNL-17821
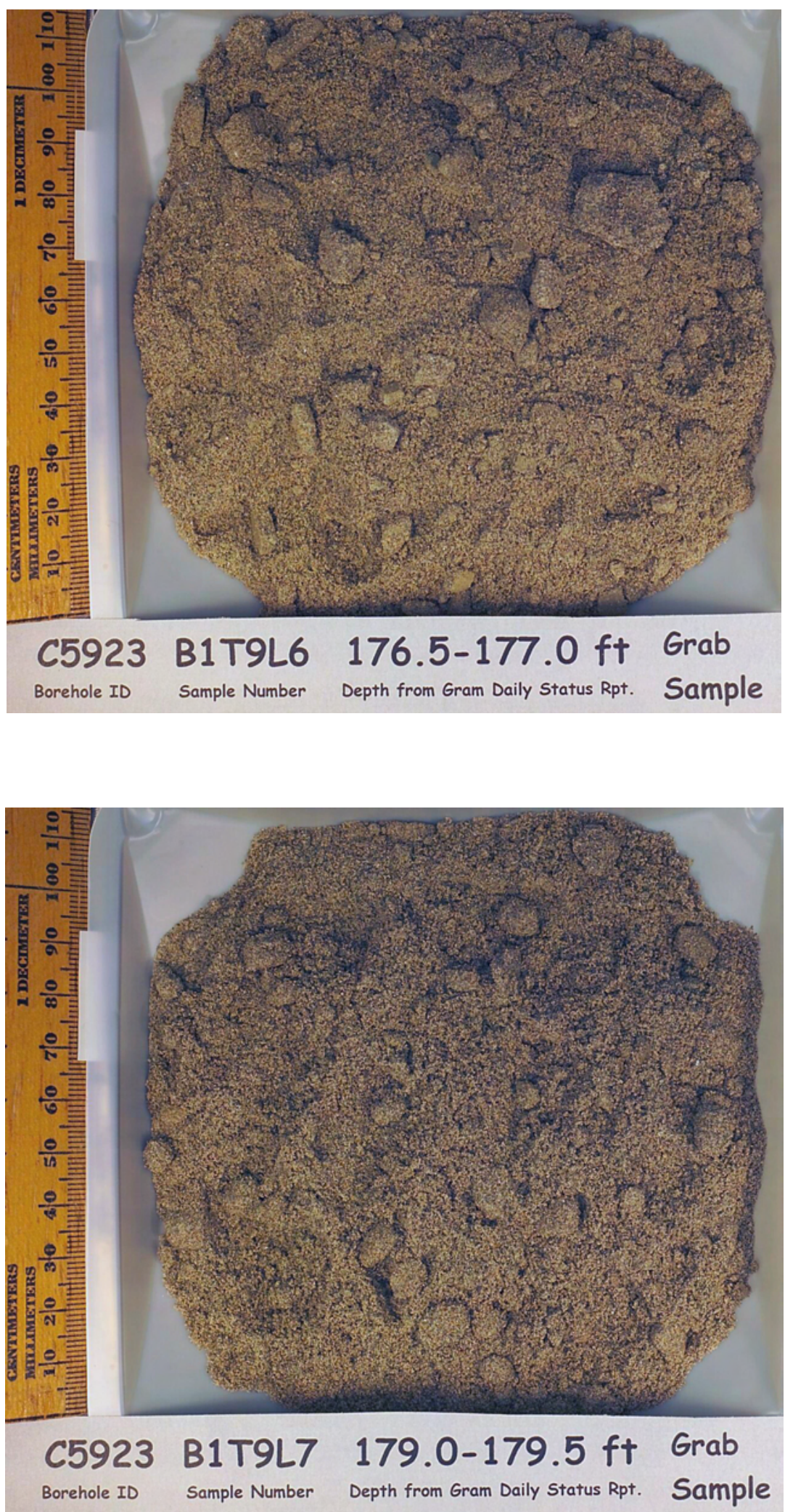
PNNL-17821
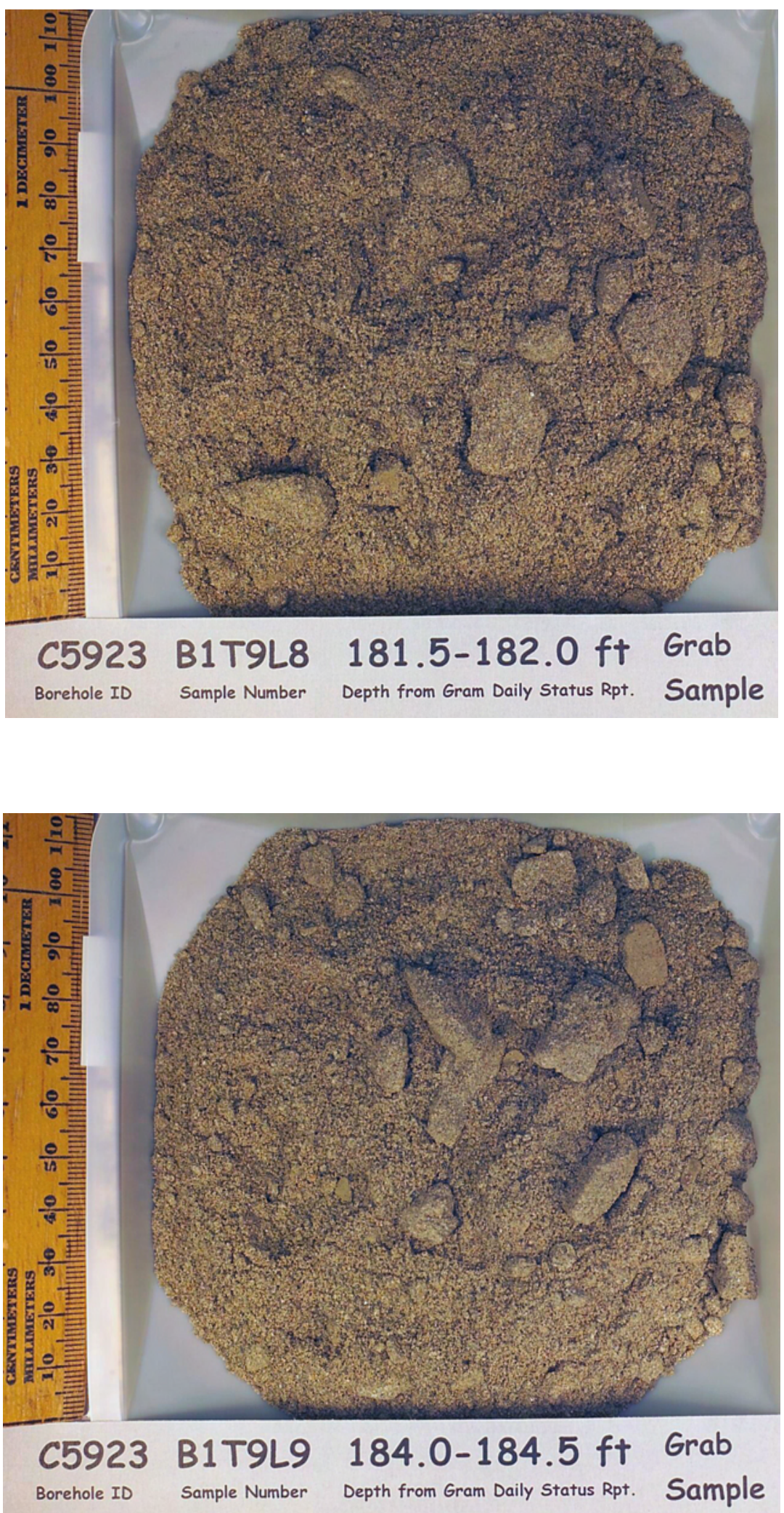
PNNL-17821
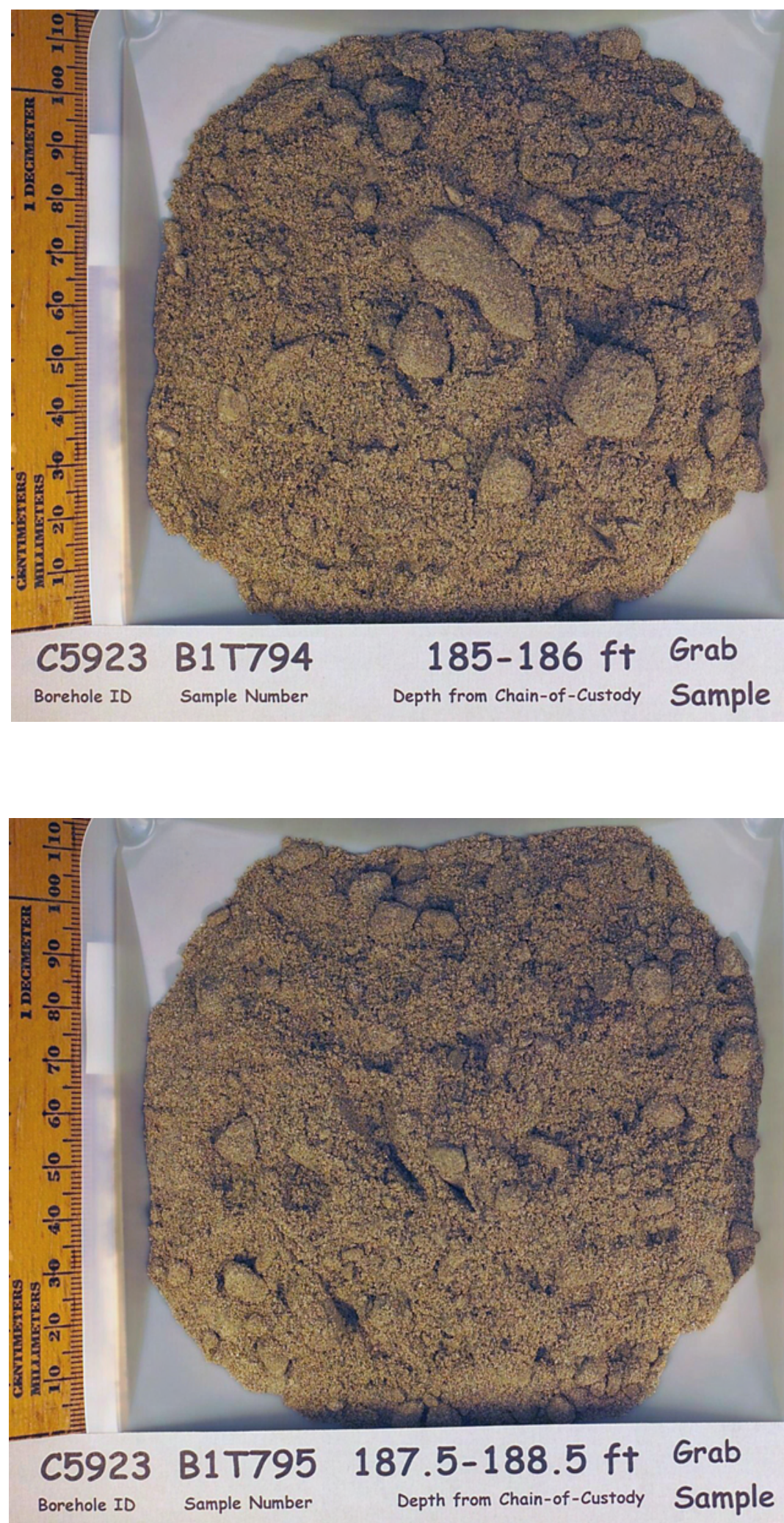
PNNL-17821
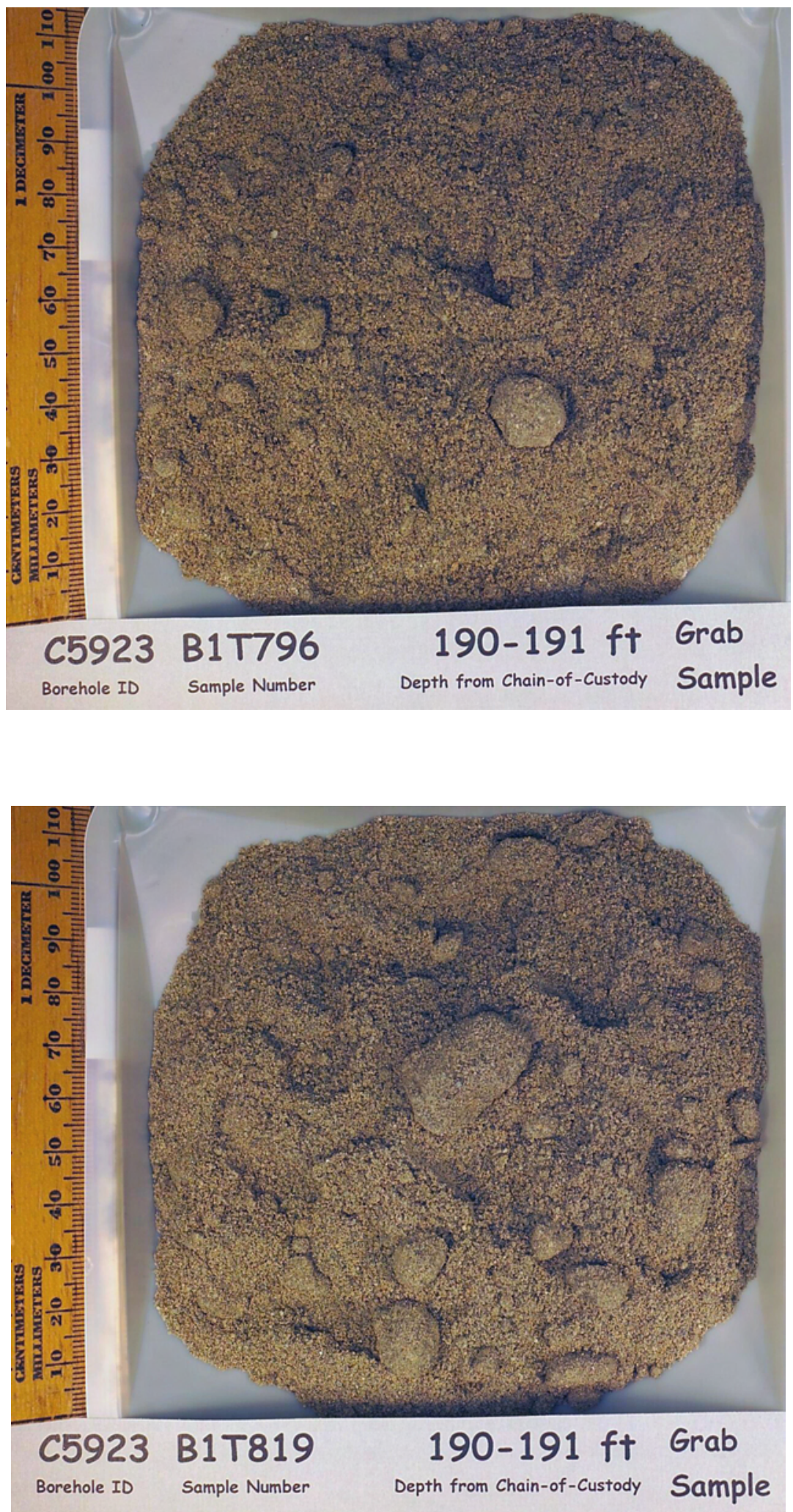
PNNL-17821
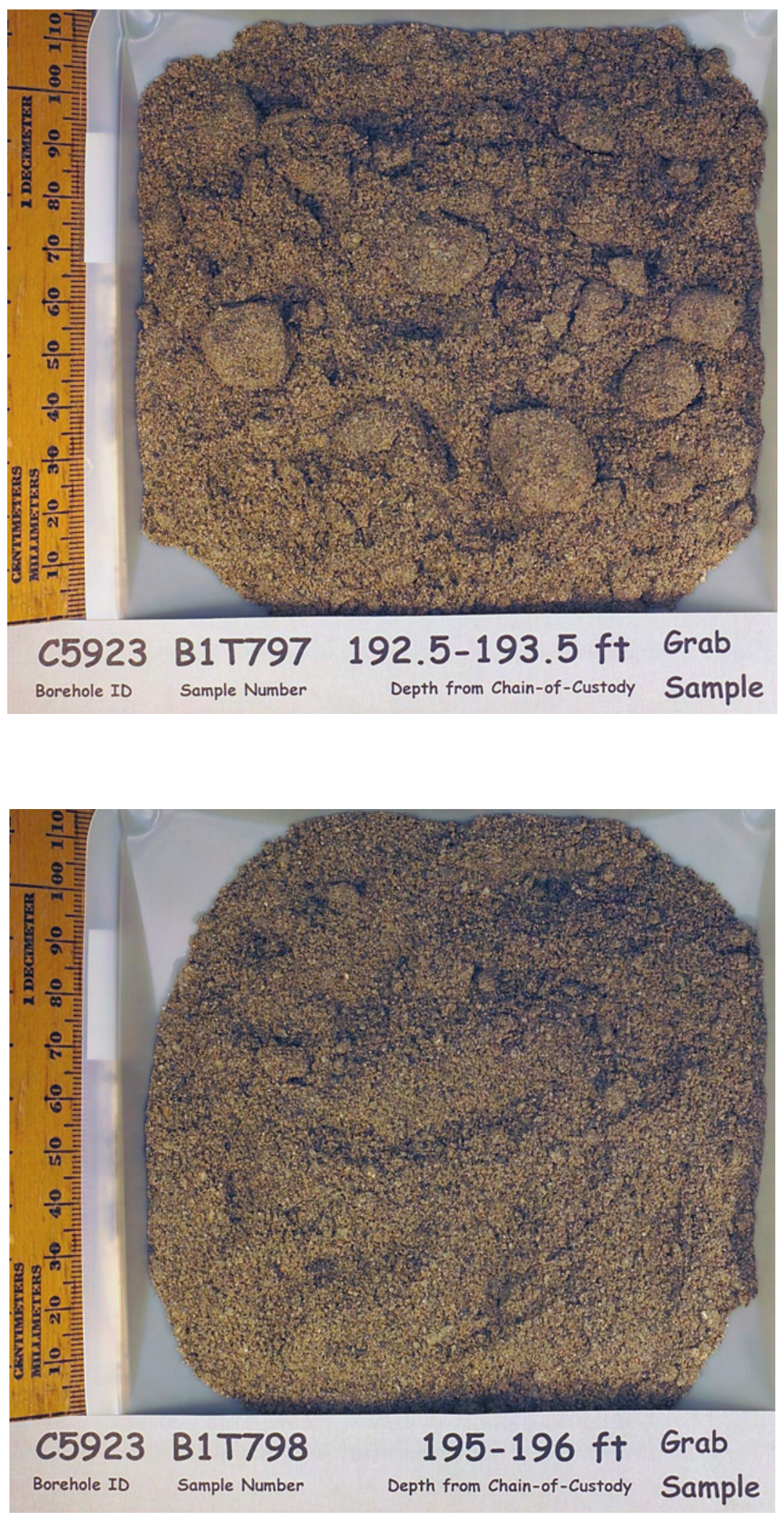
PNNL-17821
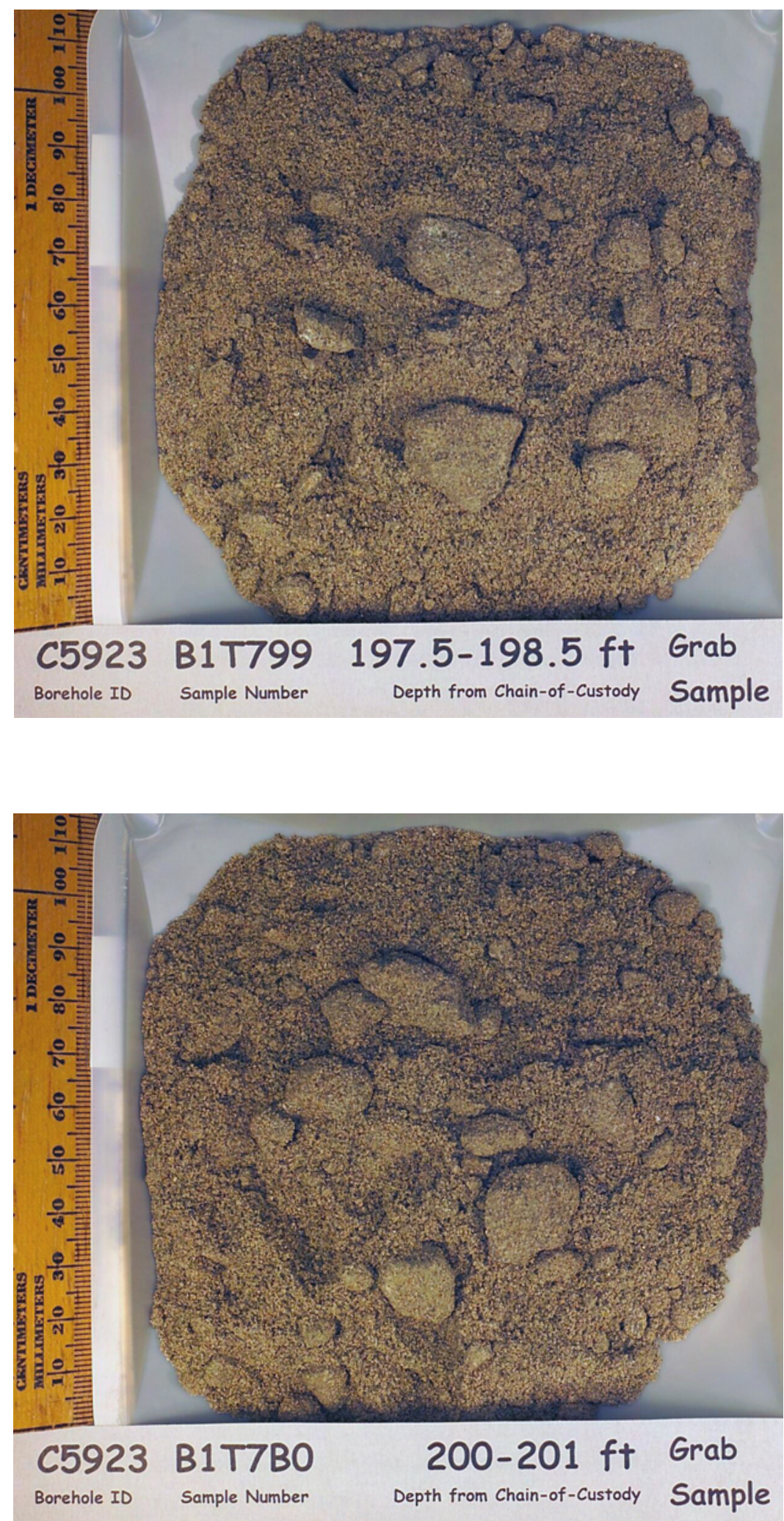
PNNL-17821

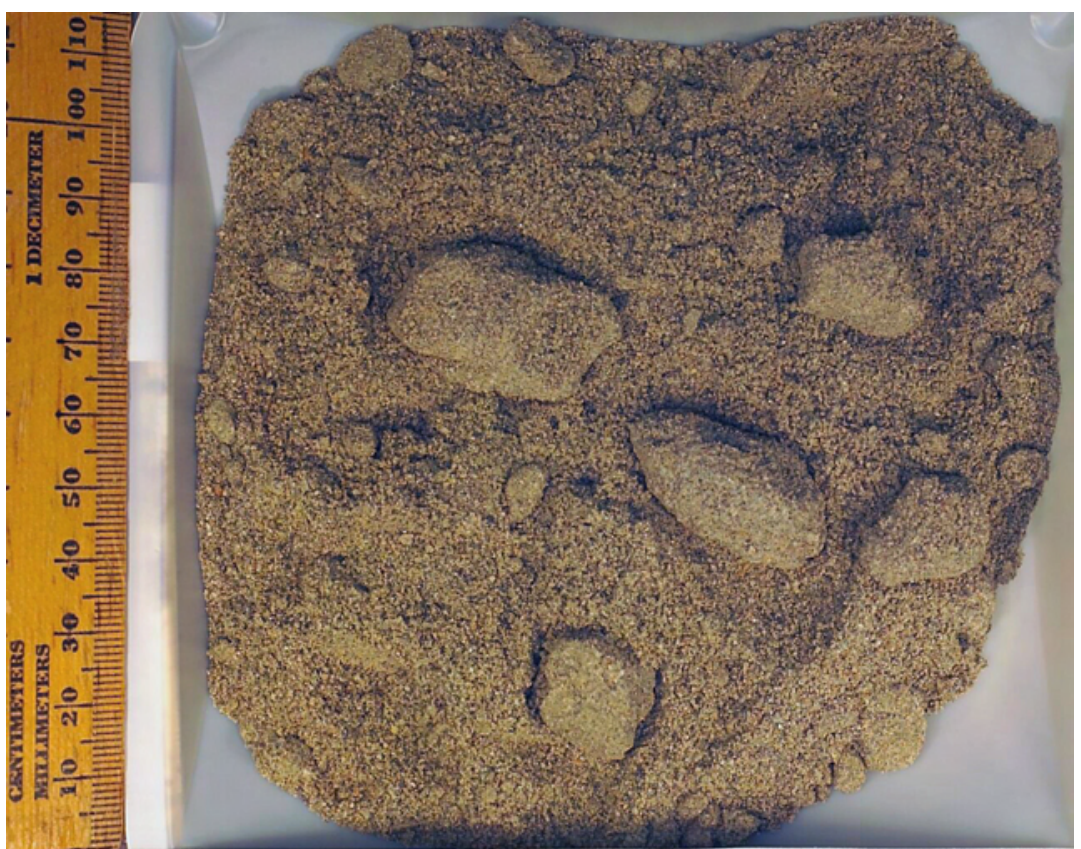

$\begin{array}{llrl}\text { C5923 B1T7B1 } & 202.5-203.5 \mathrm{ft} & \text { Grab } \\ \text { Borehole ID } & \begin{array}{l}\text { Sample Number } \\ \text { Depth from Chain-of-Custody Sample }\end{array}\end{array}$

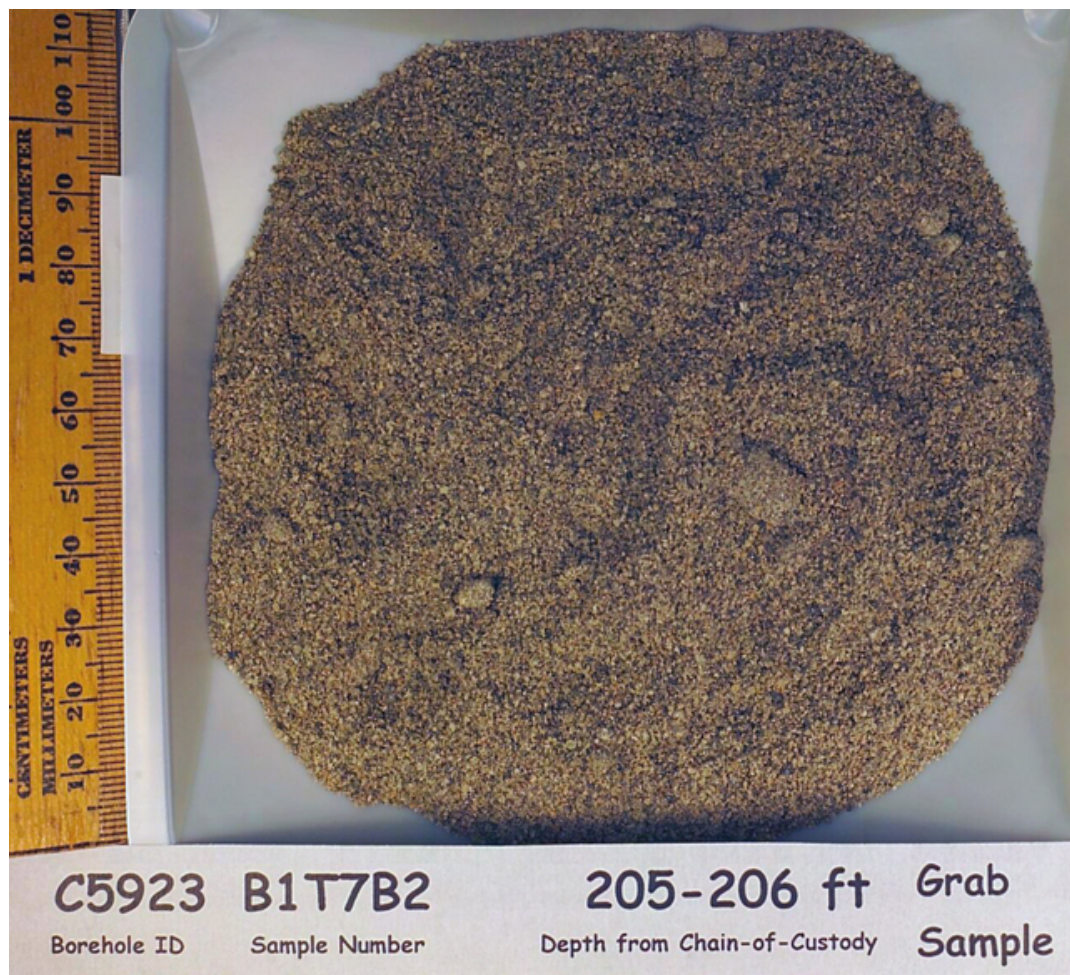


PNNL-17821
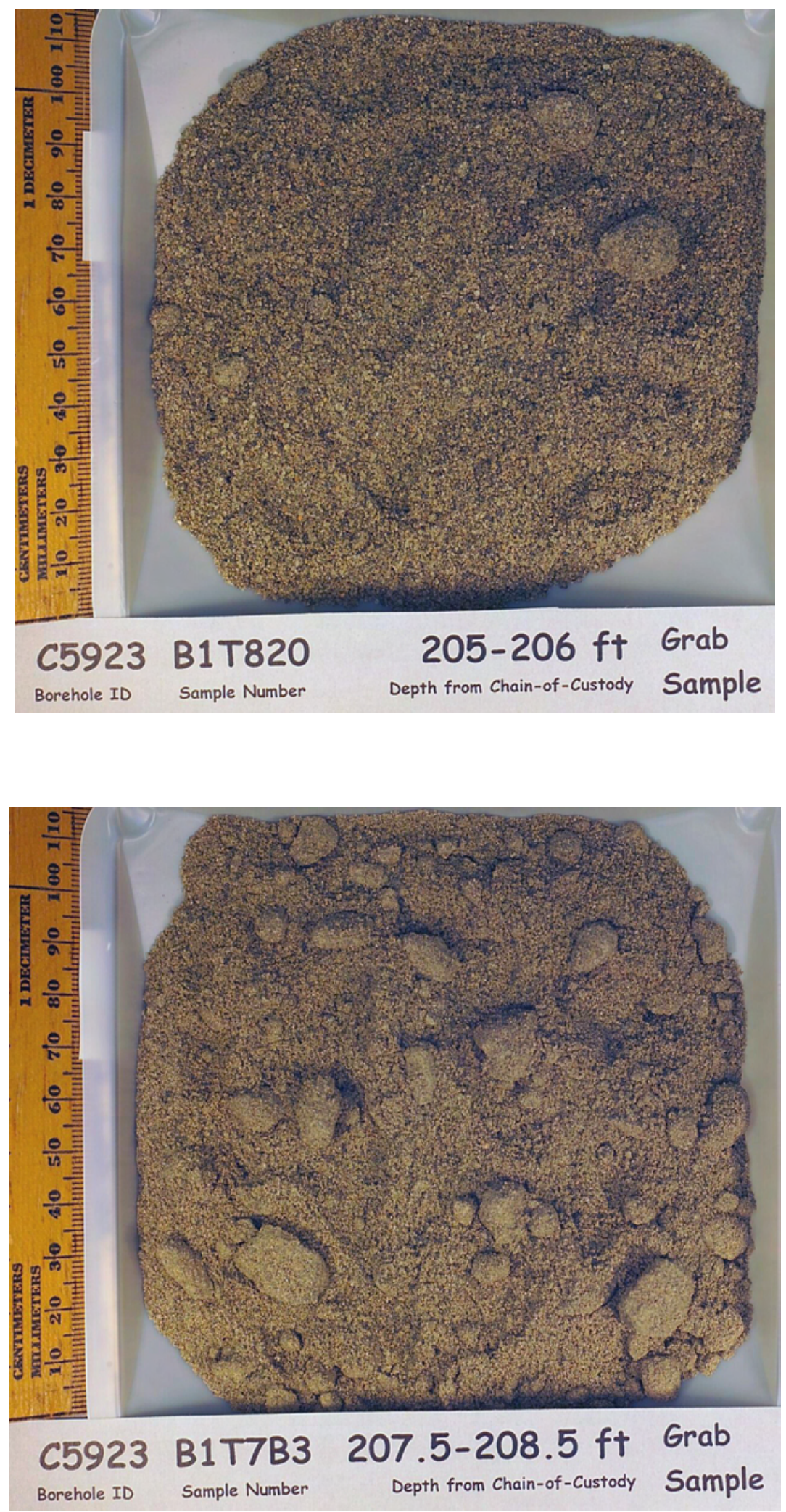
PNNL-17821
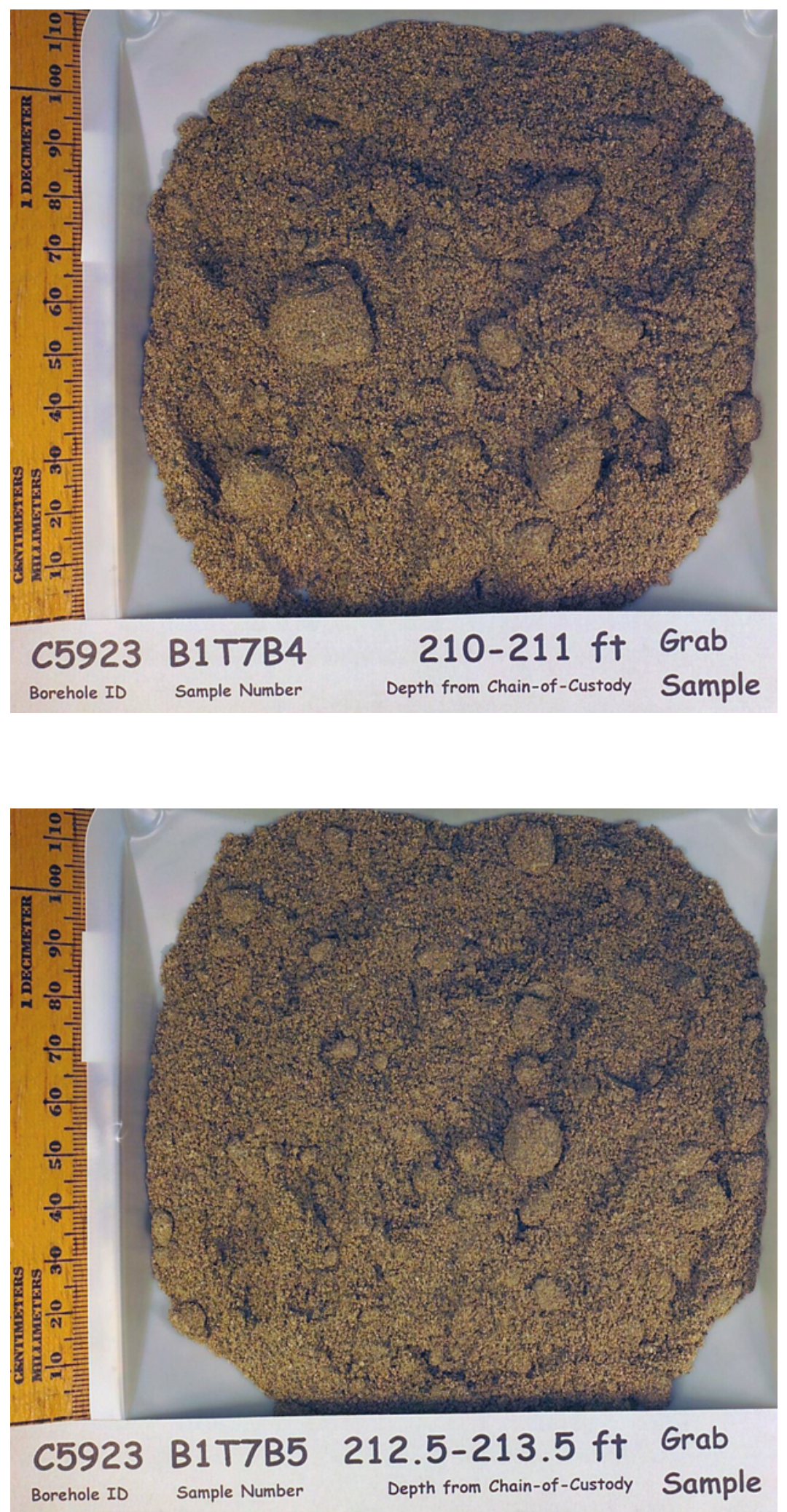
PNNL-17821
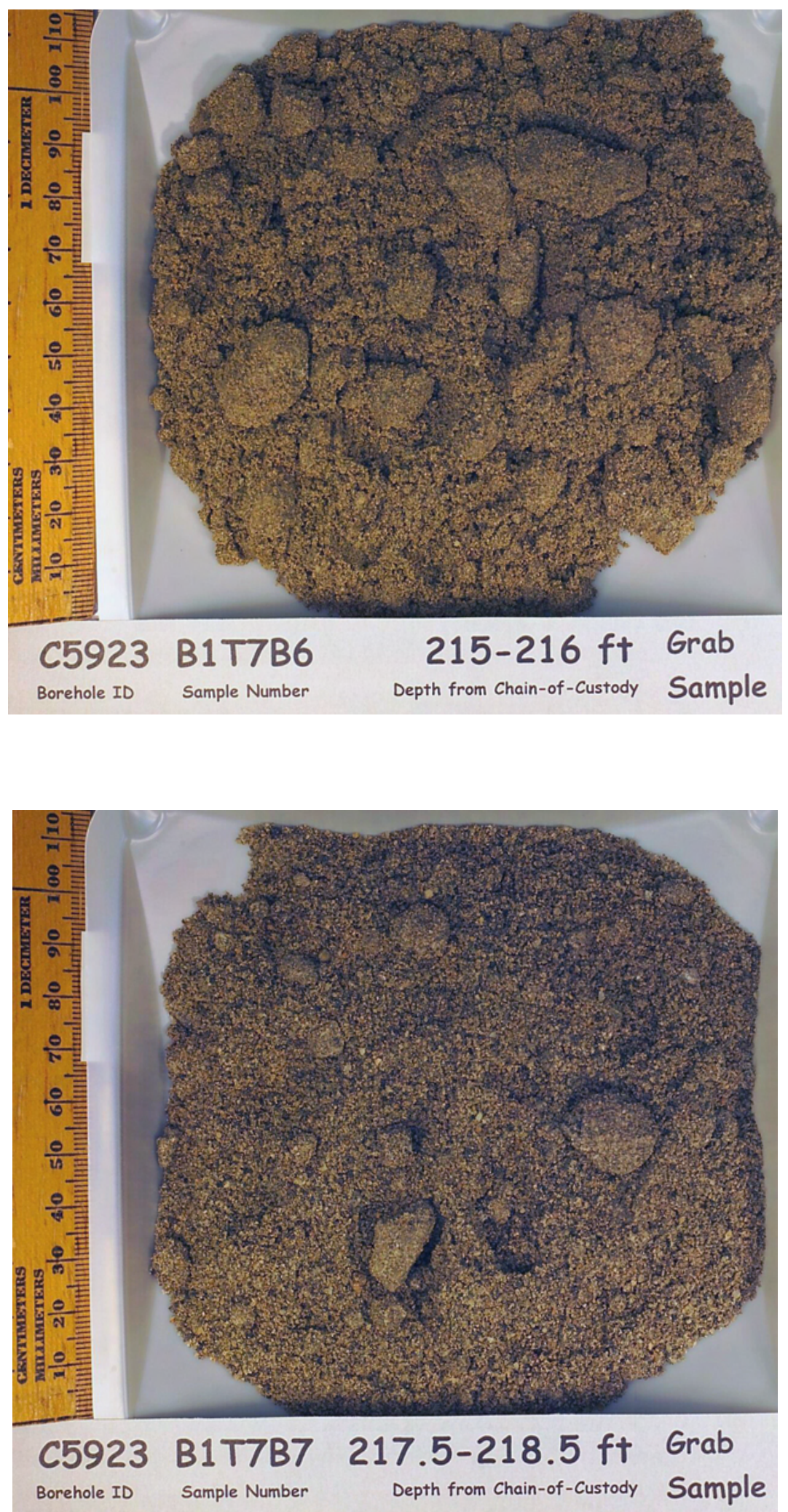
PNNL-17821
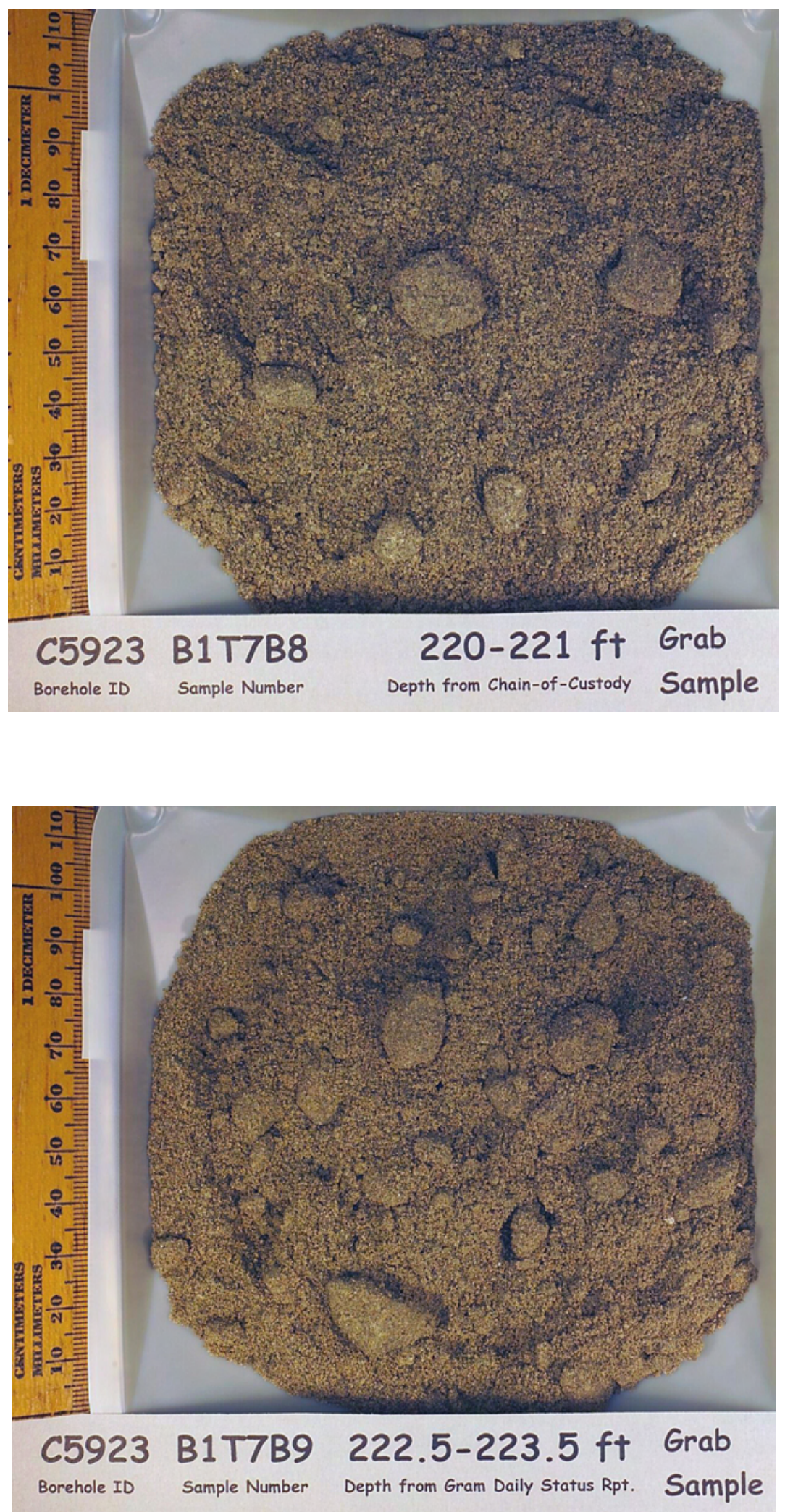
PNNL-17821
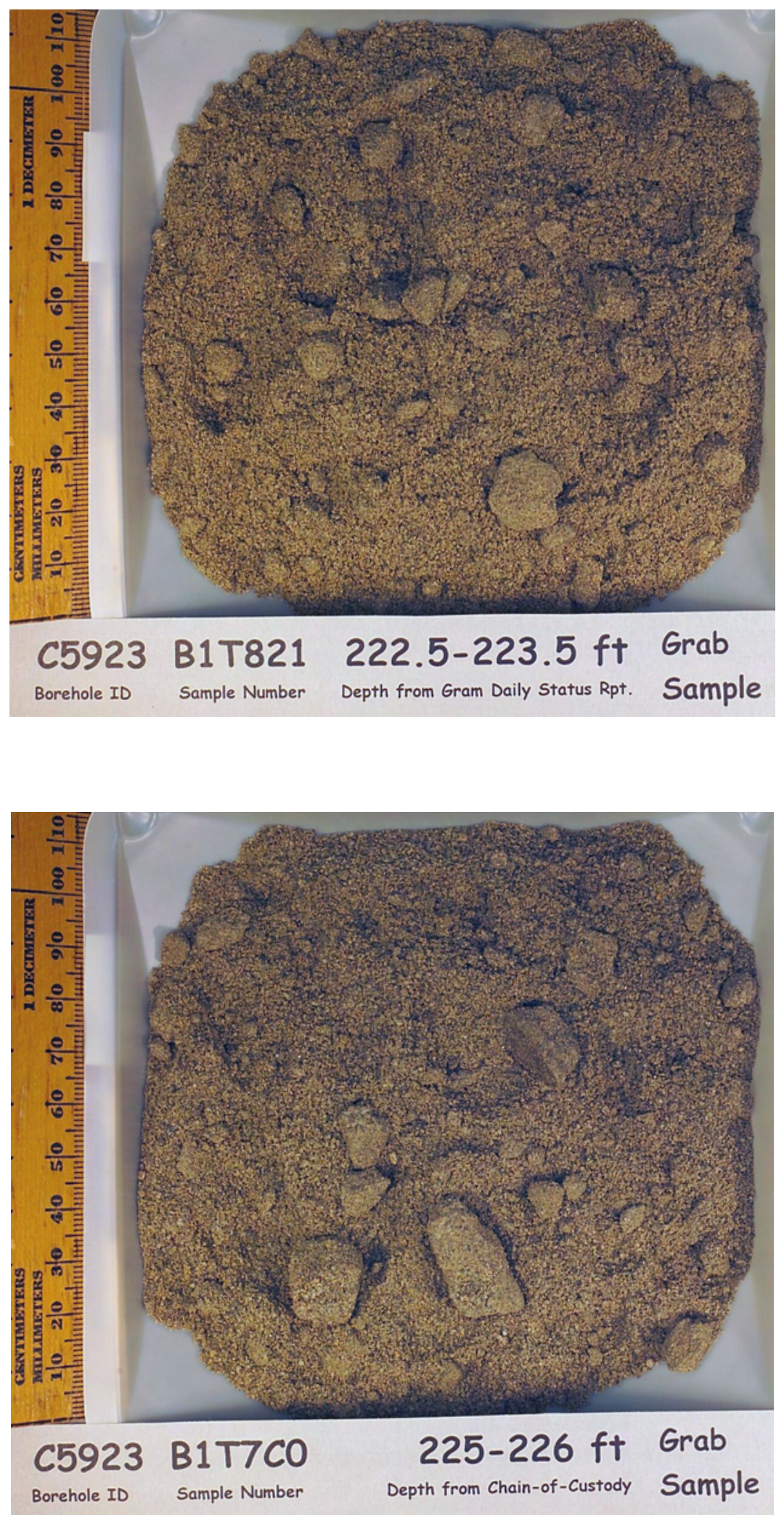
PNNL-17821
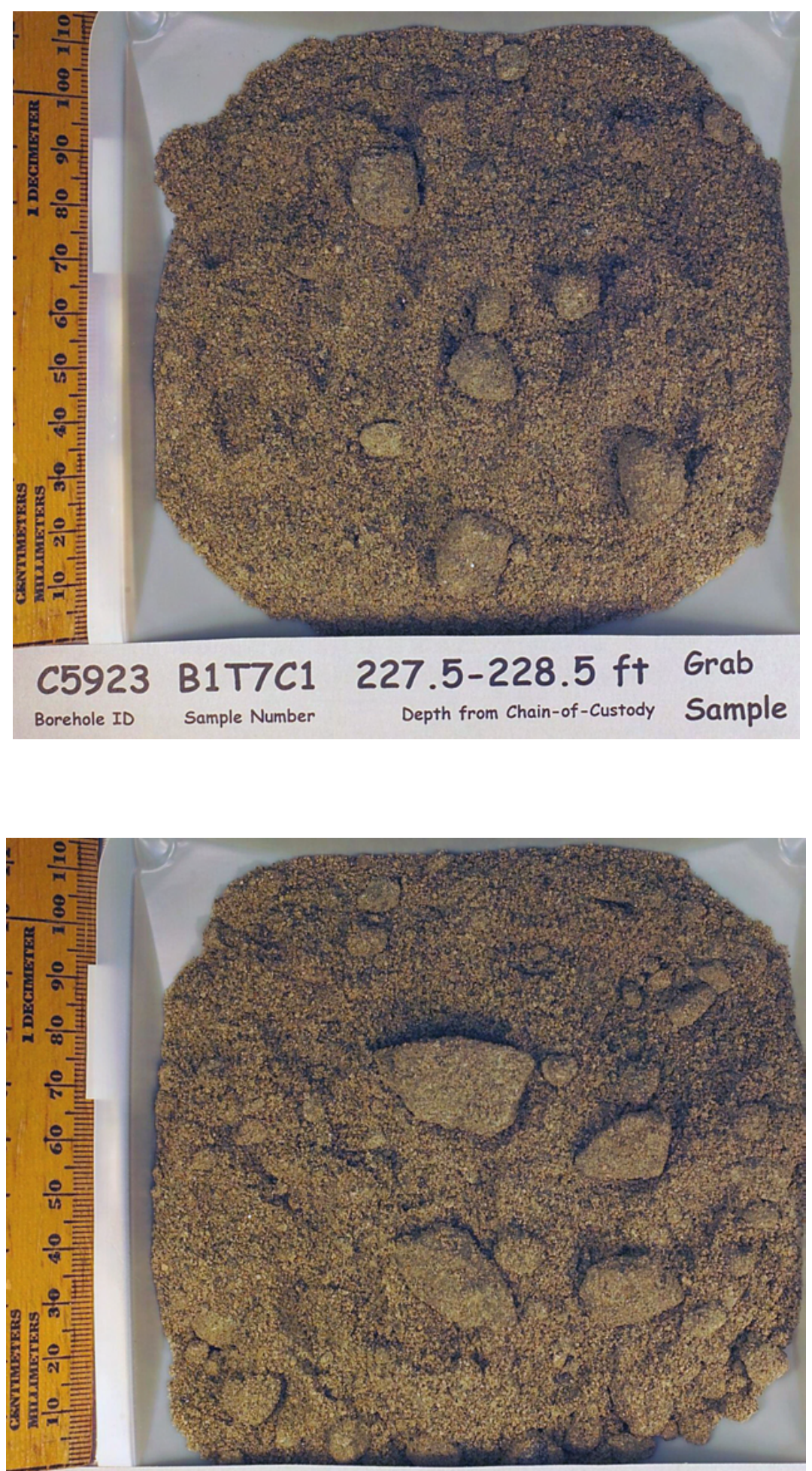

C5923 B1T7C2

230-231 ft Grab

Borehole ID

Sample Number

Depth from Chain-of-Custody Sample 
PNNL-17821
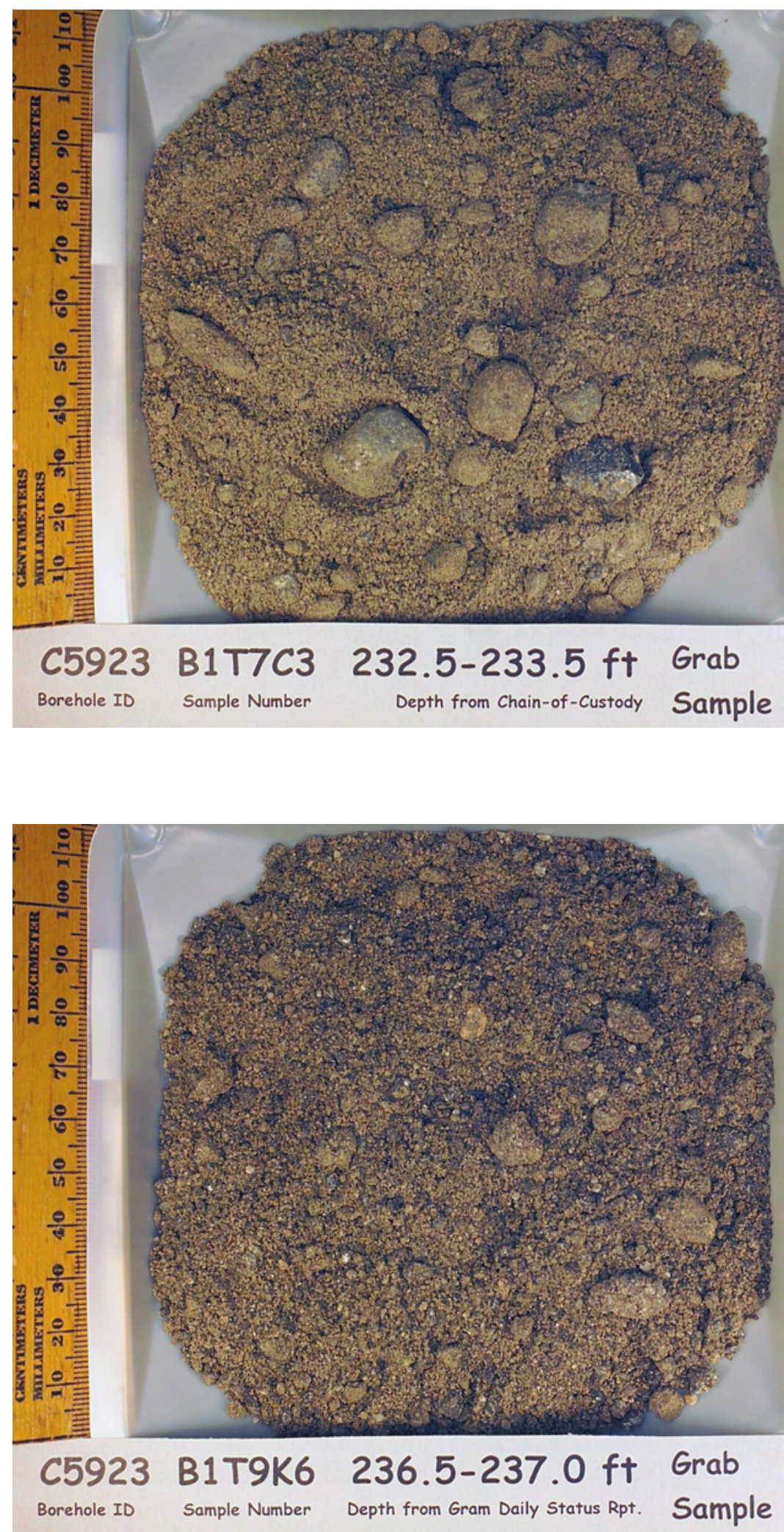

B.50 
PNNL-17821
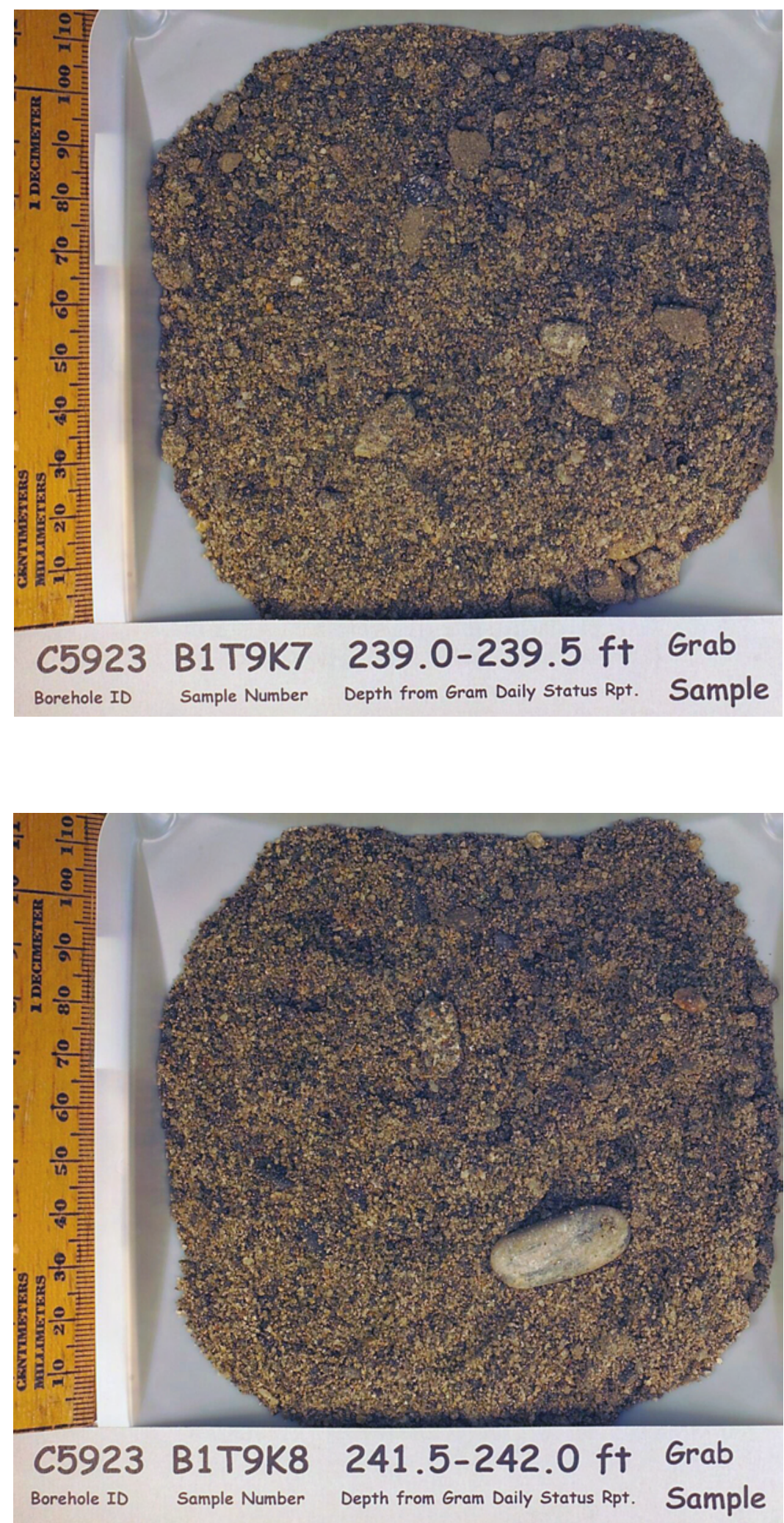

B.51 
PNNL-17821
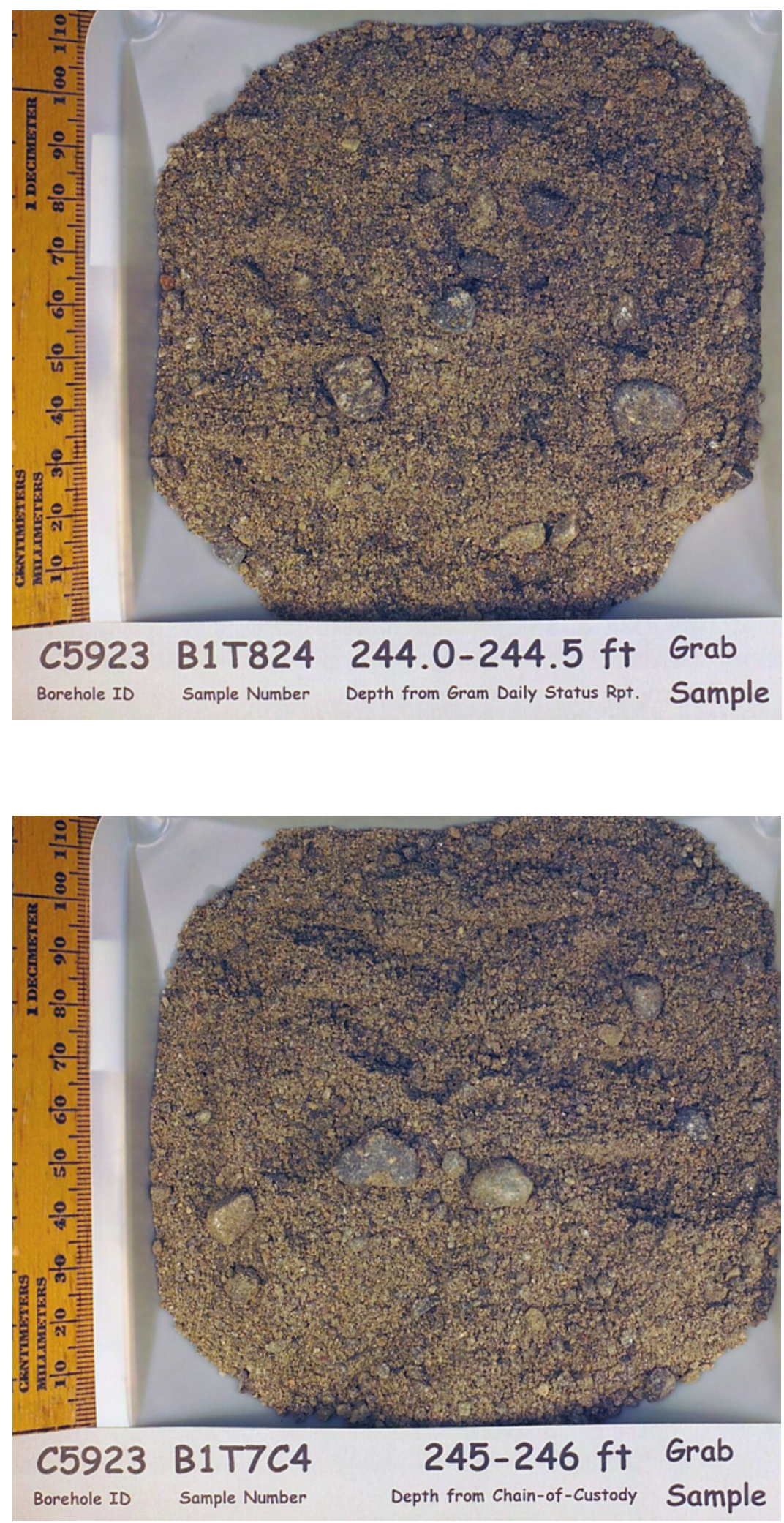
PNNL-17821
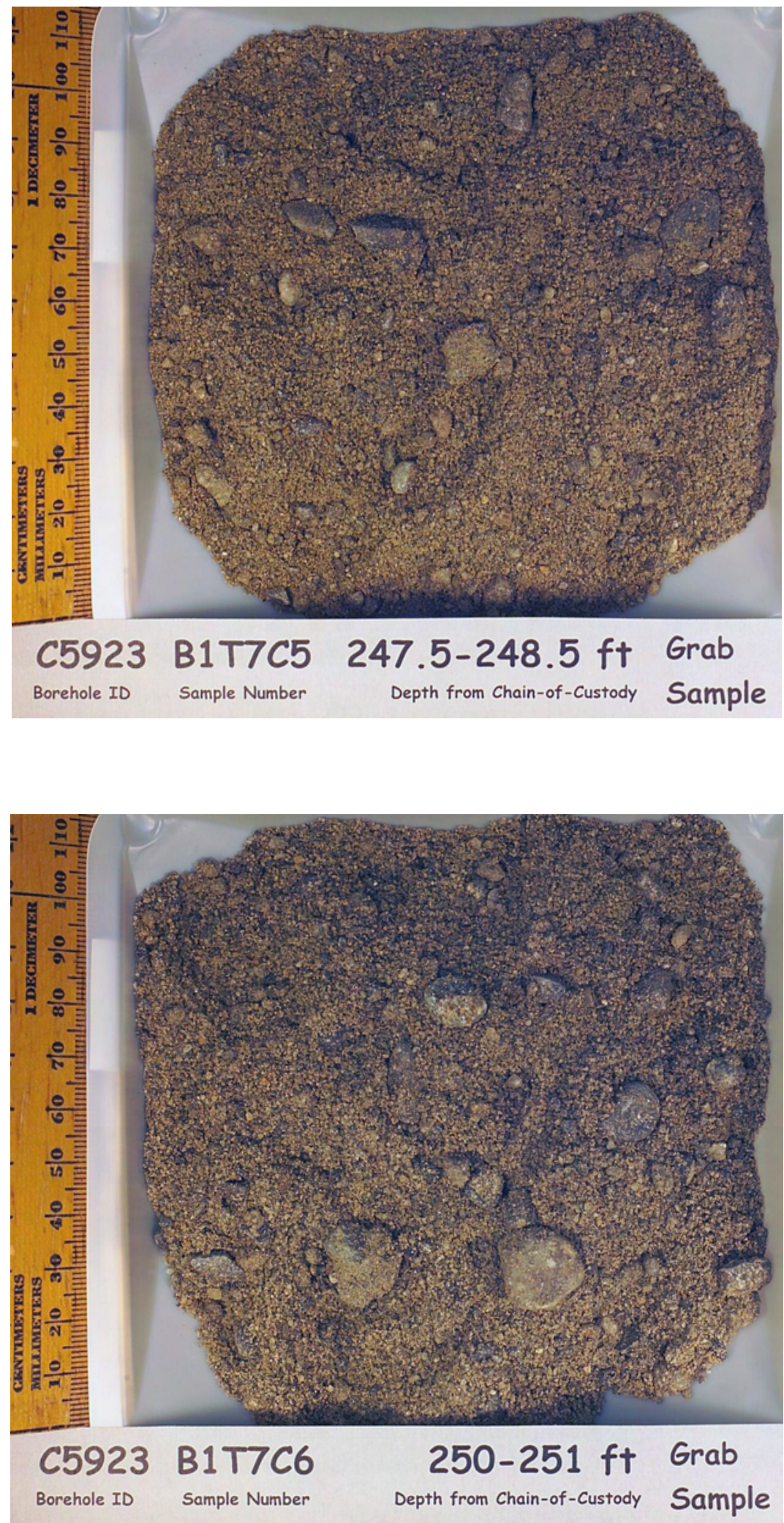
PNNL-17821
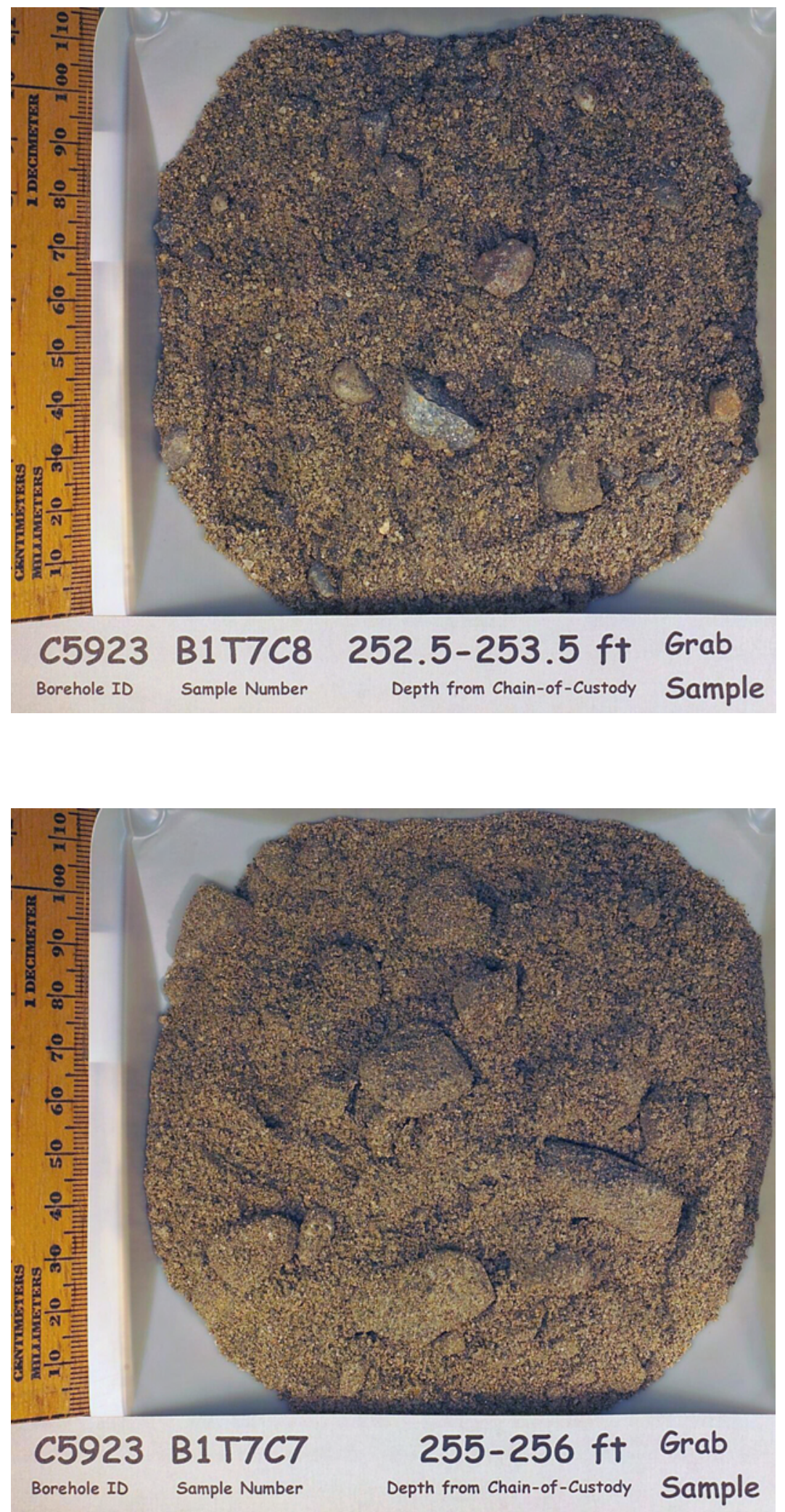
PNNL-17821
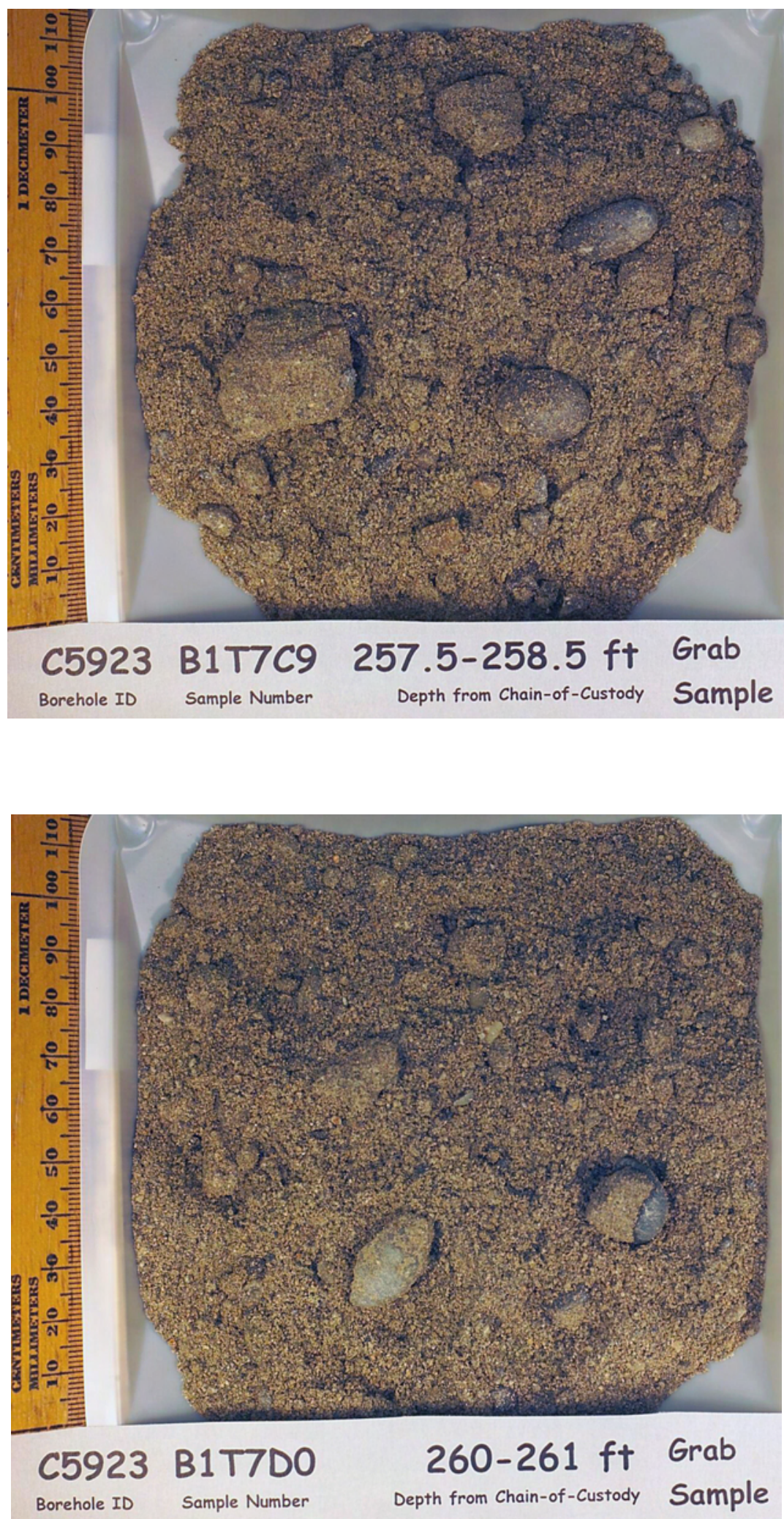
PNNL-17821
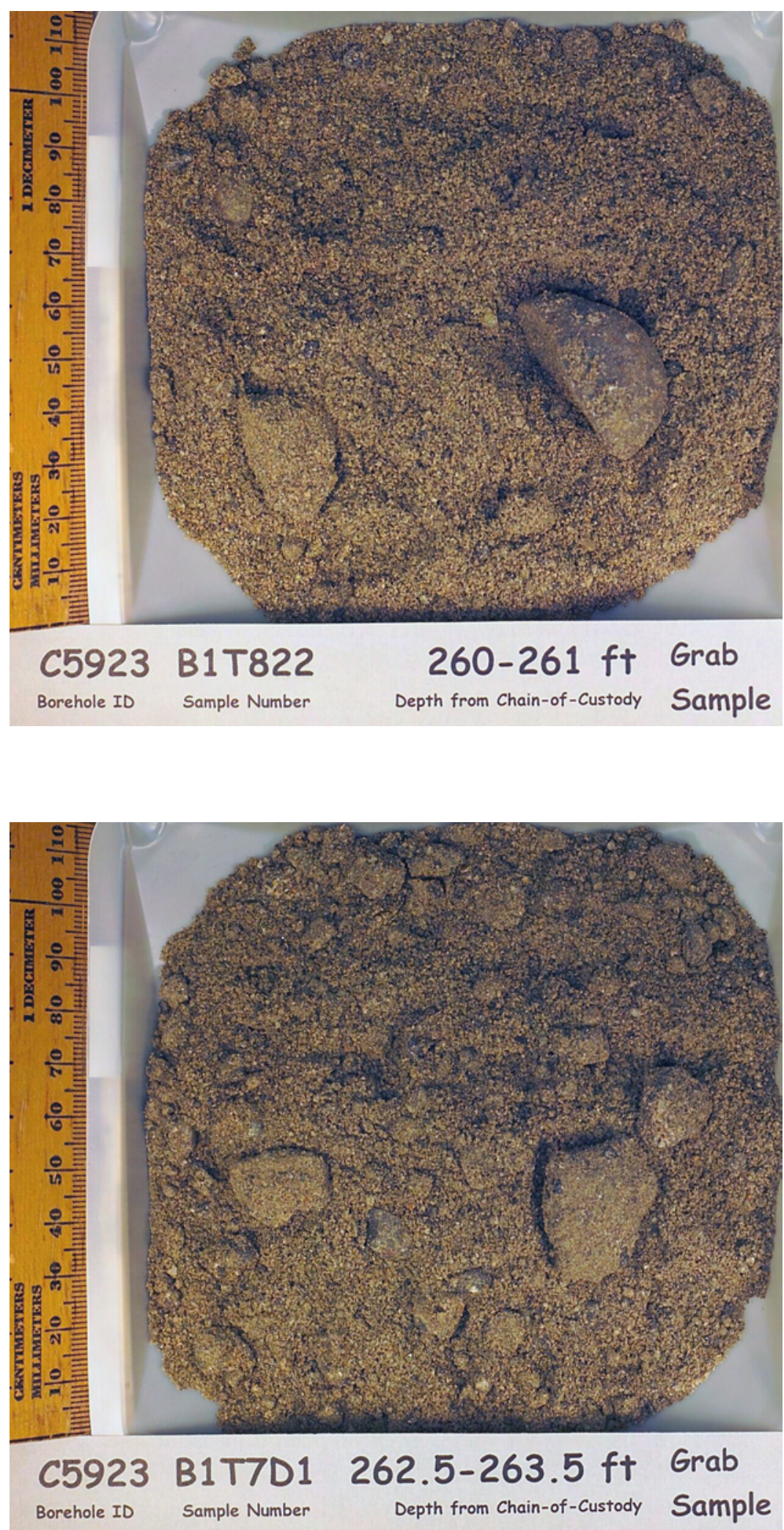
PNNL-17821
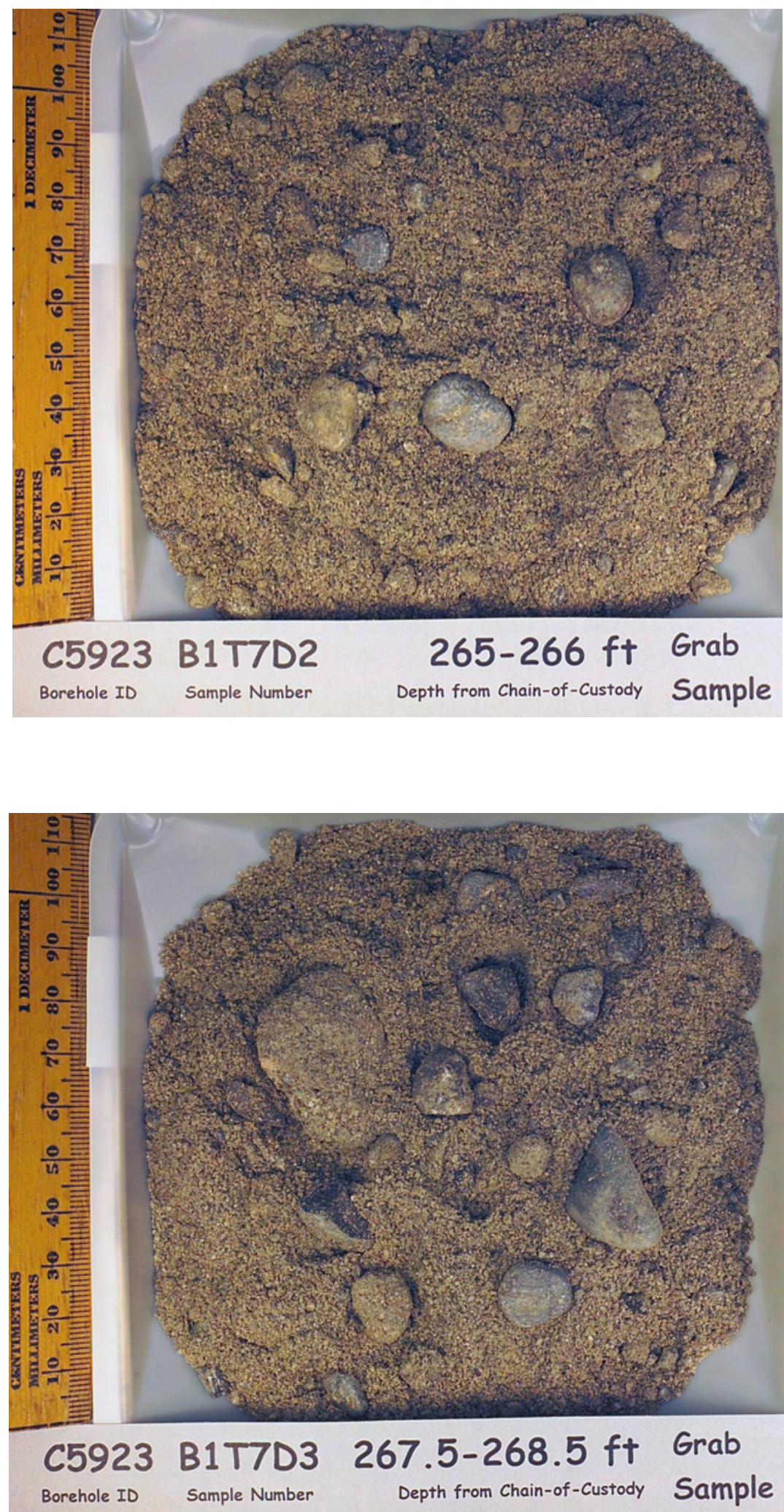
PNNL-17821
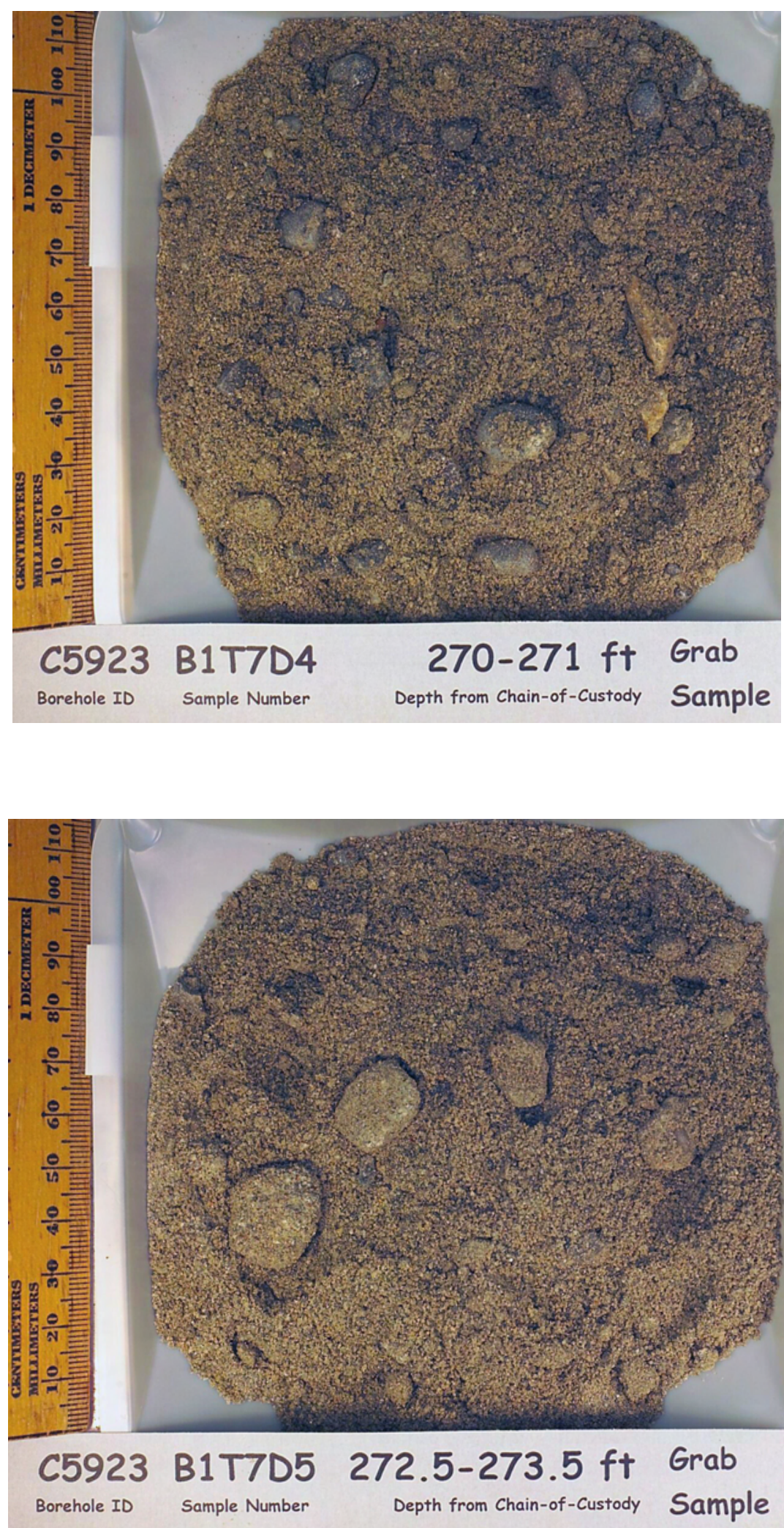
PNNL-17821
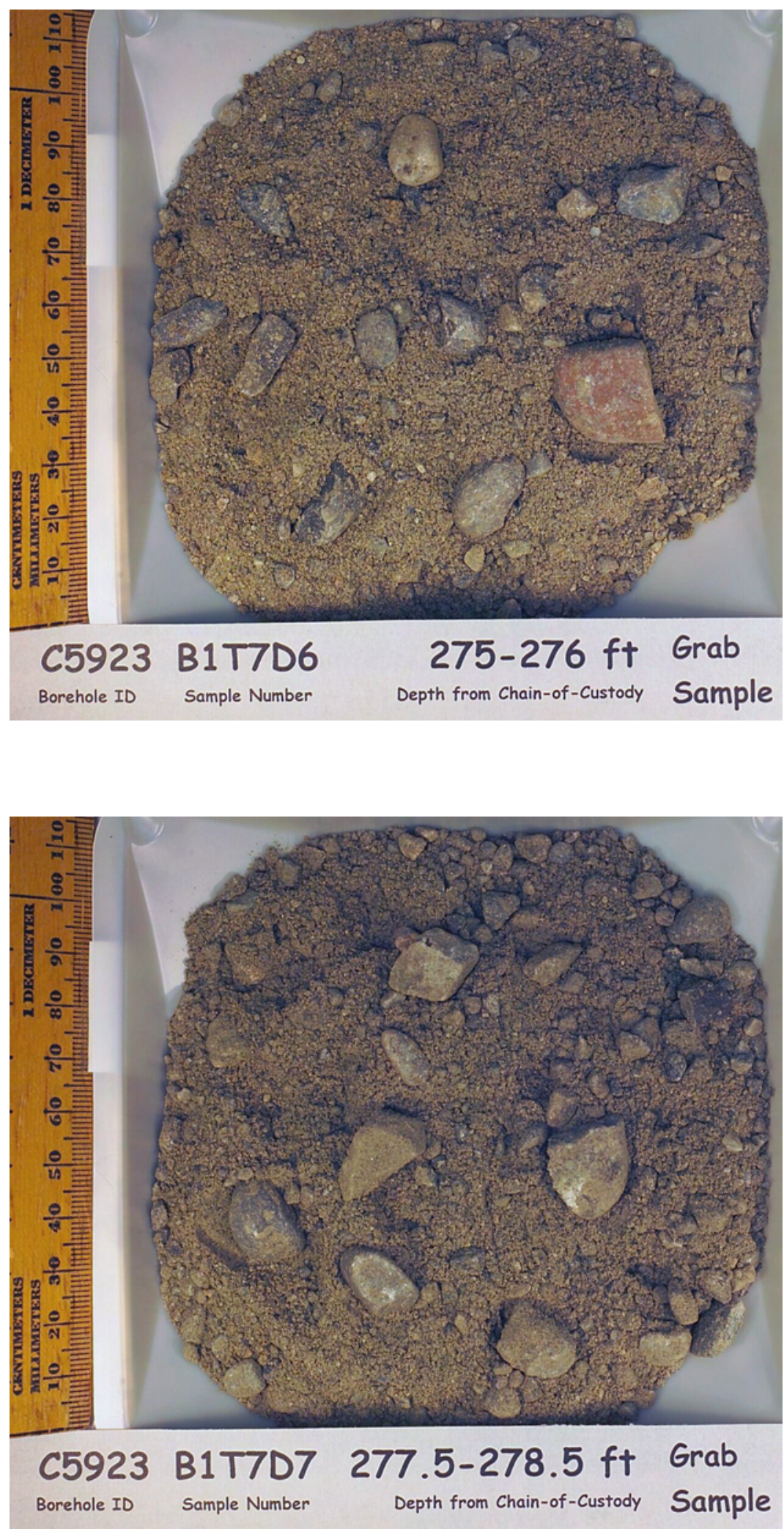
PNNL-17821
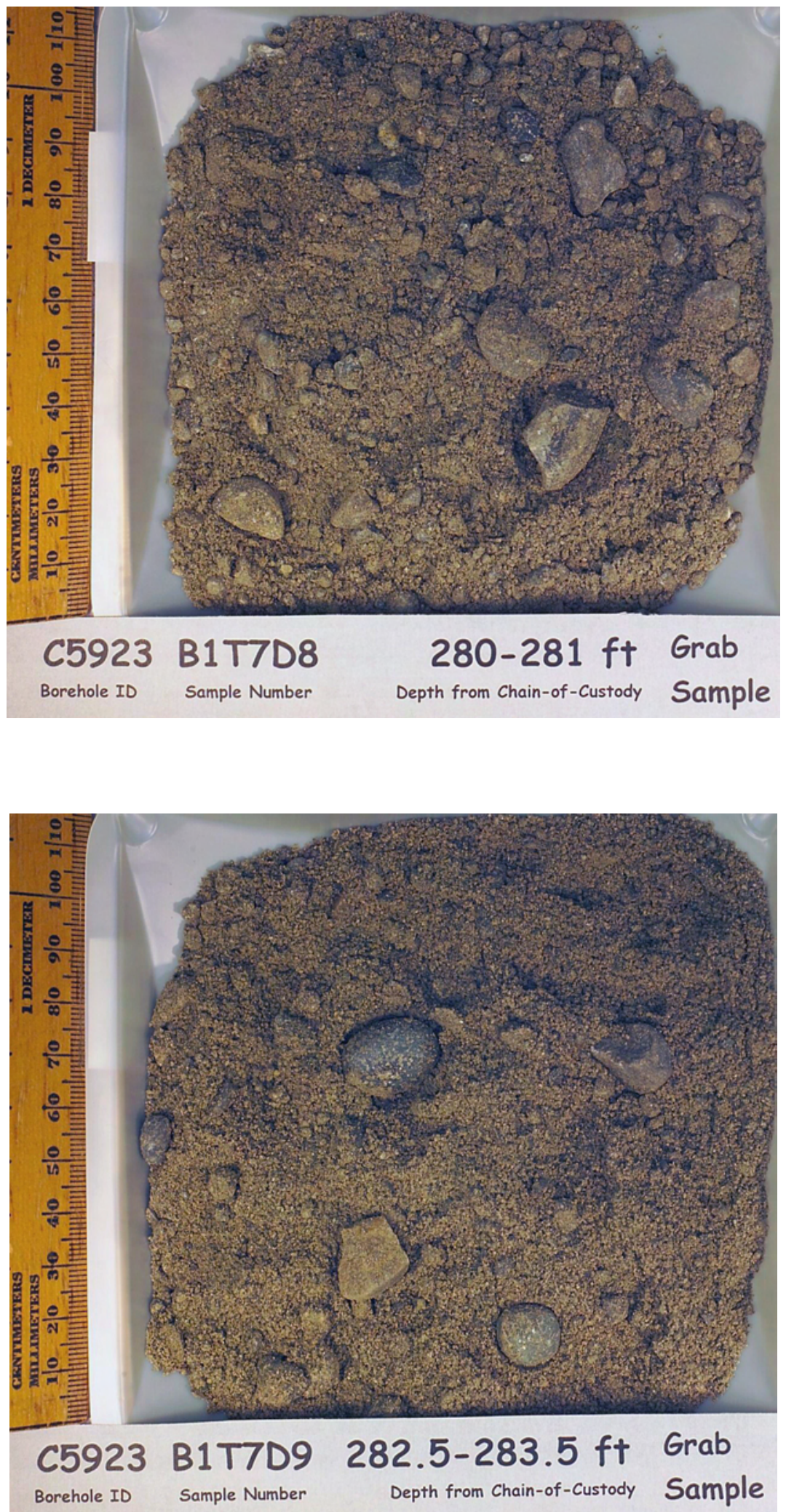

B. 60 
PNNL-17821
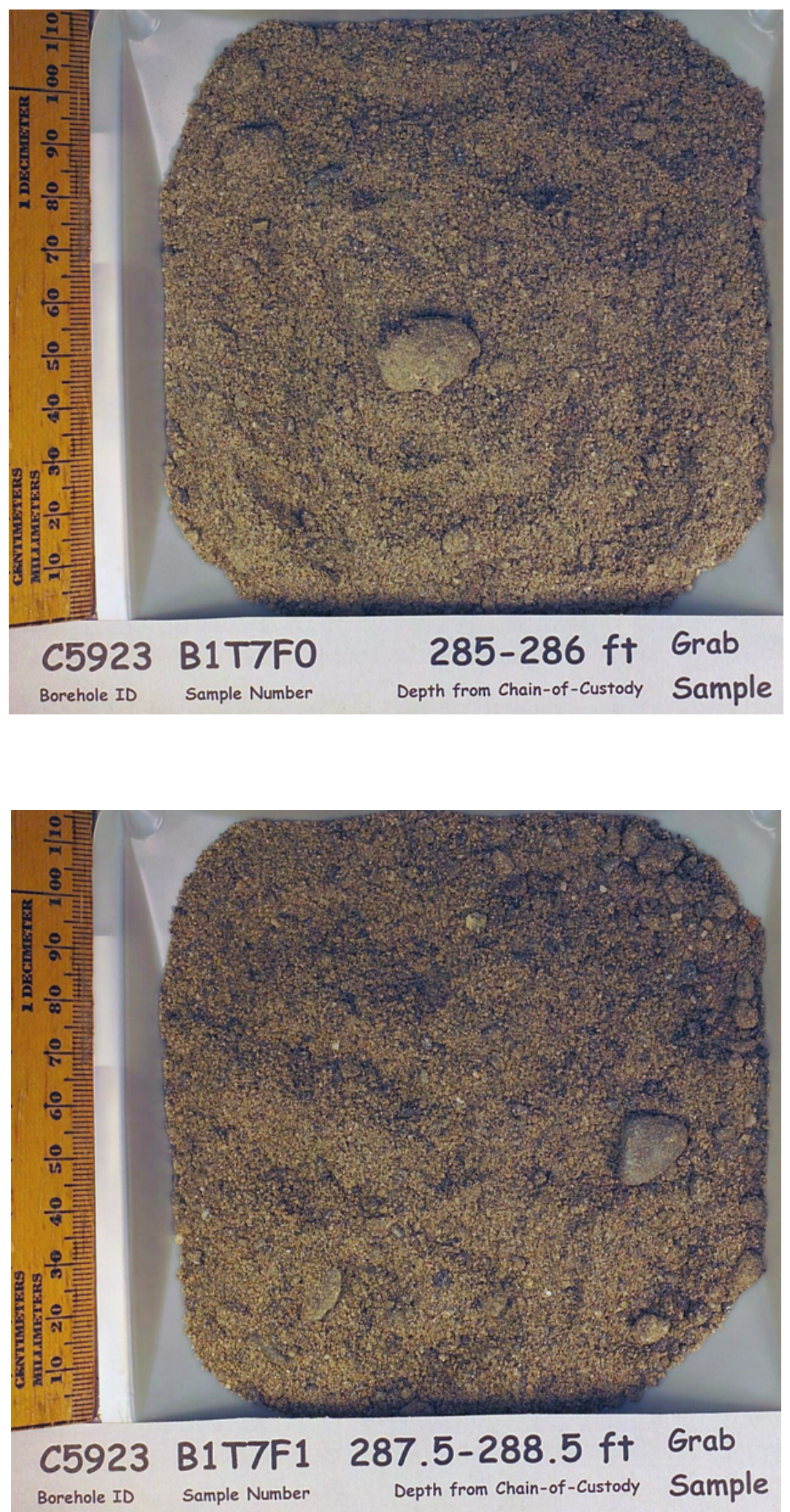

B. 61 
PNNL-17821
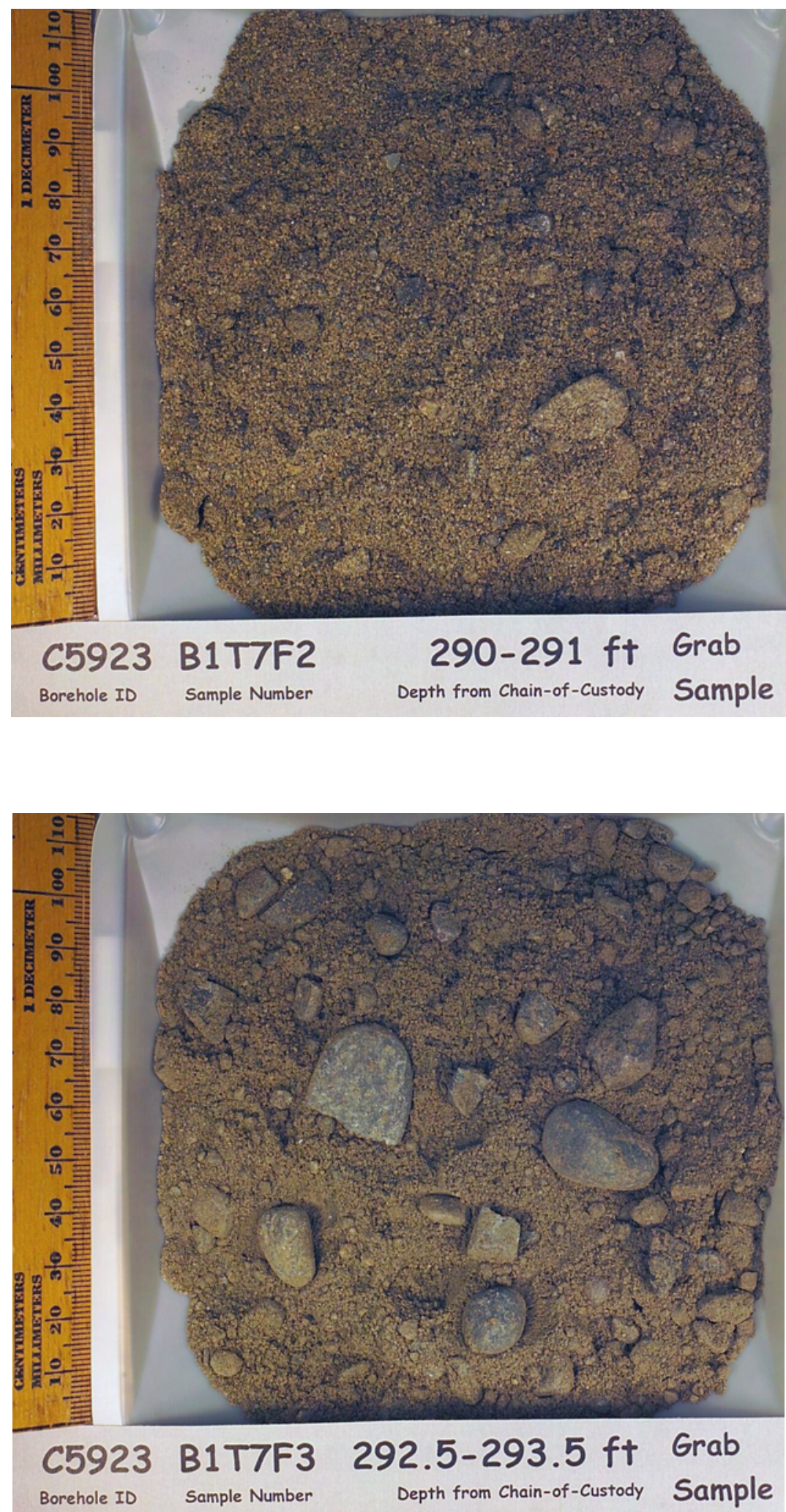
PNNL-17821
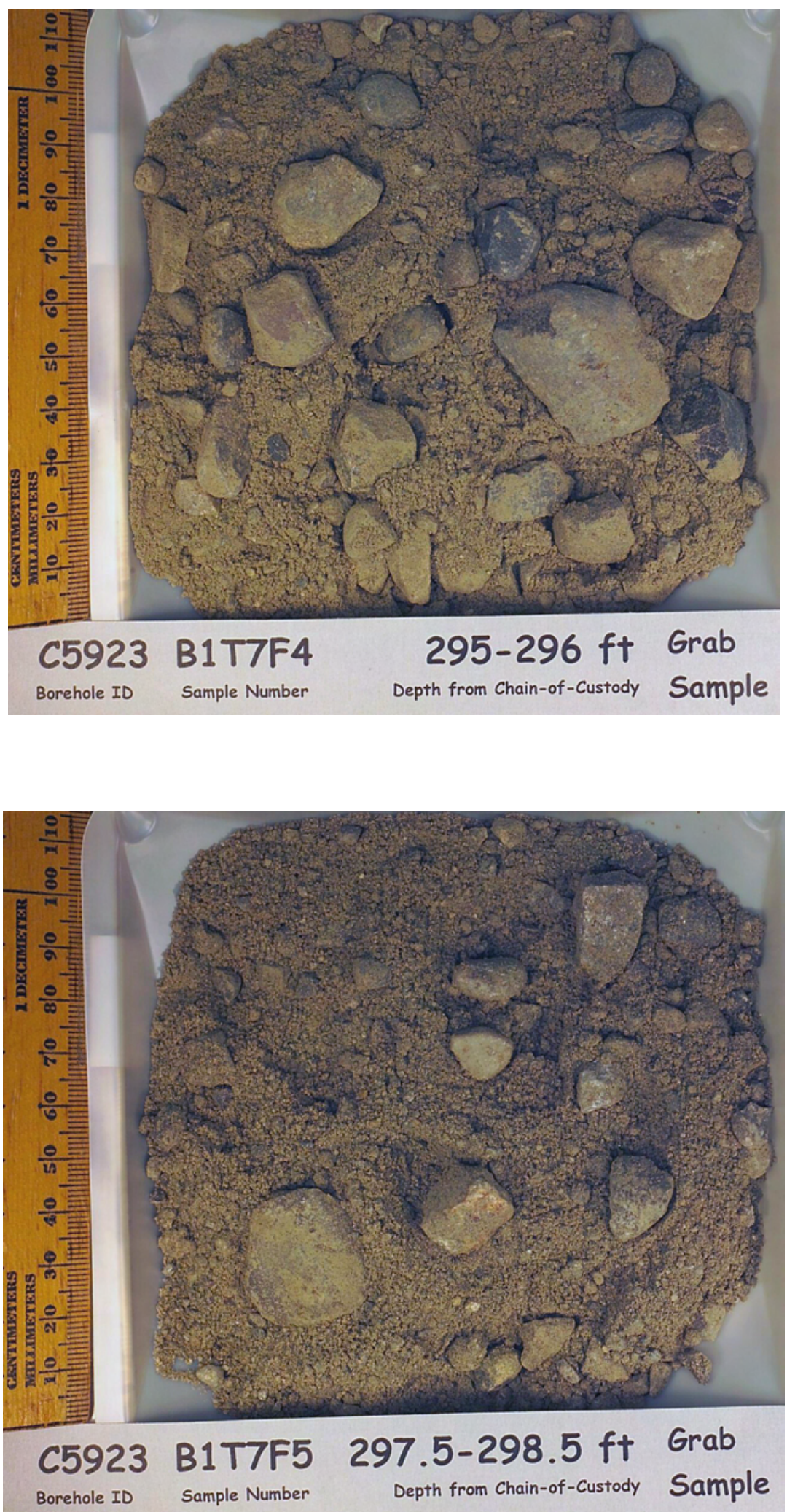
PNNL-17821
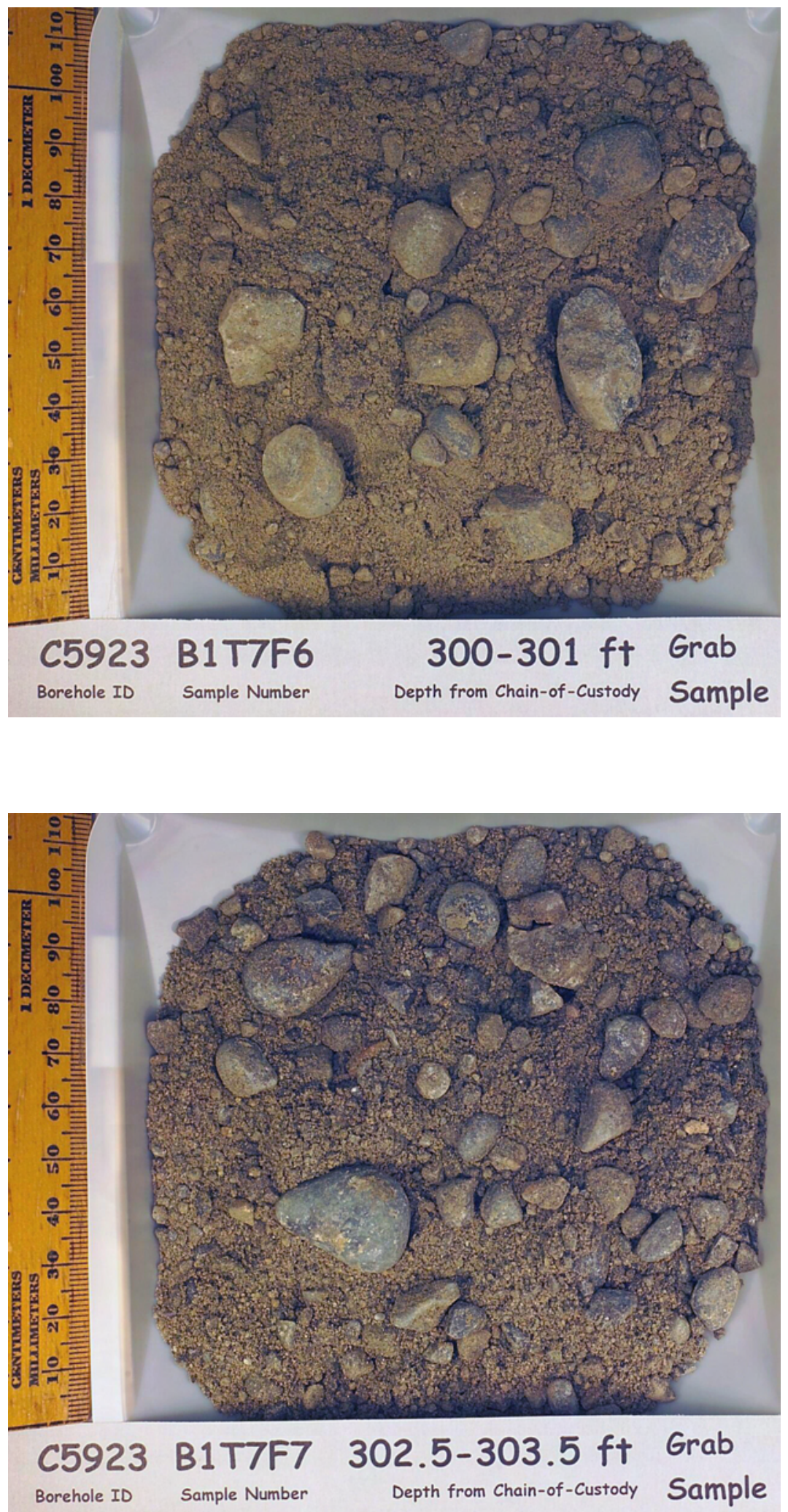
PNNL-17821
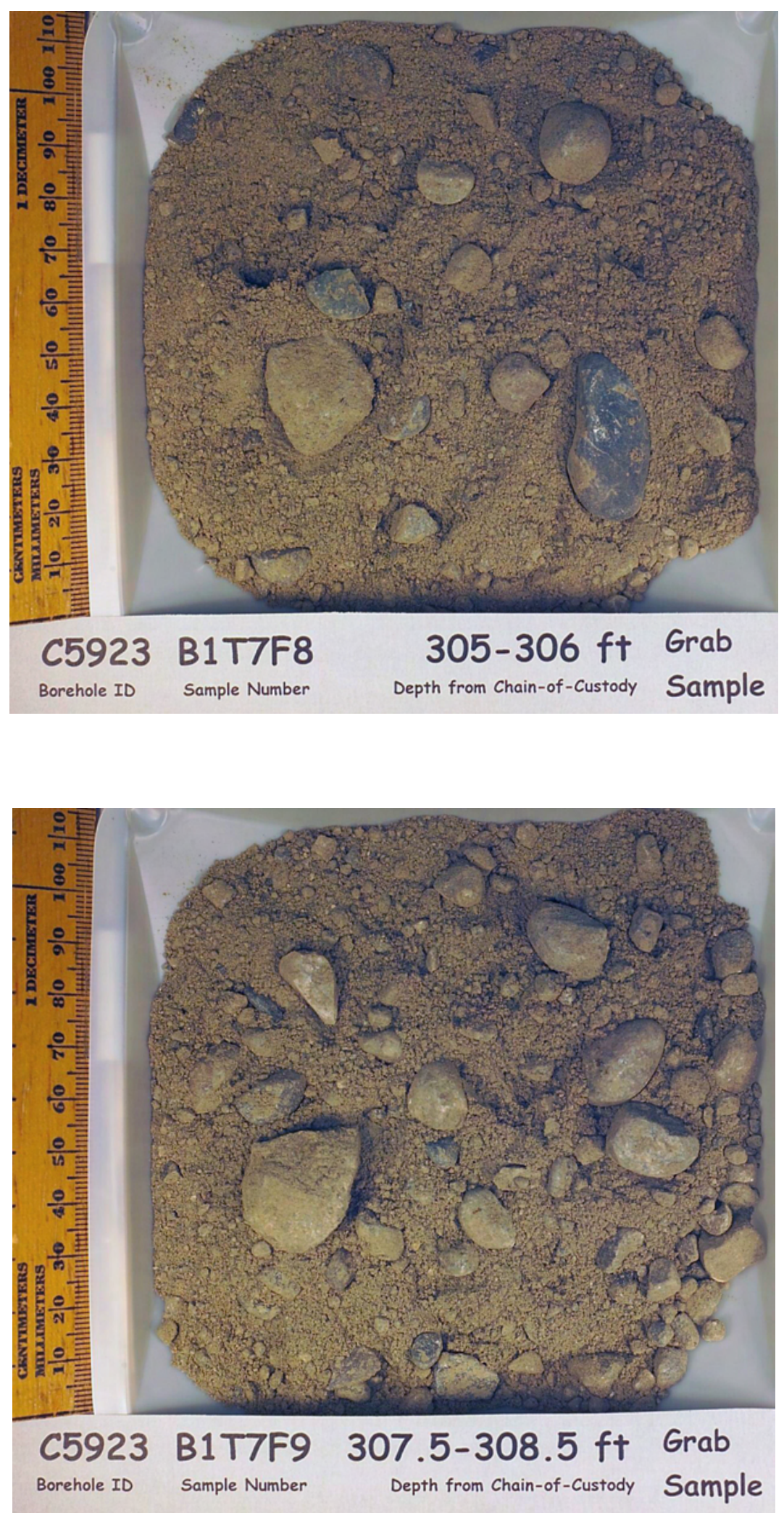

B. 65 
PNNL-17821
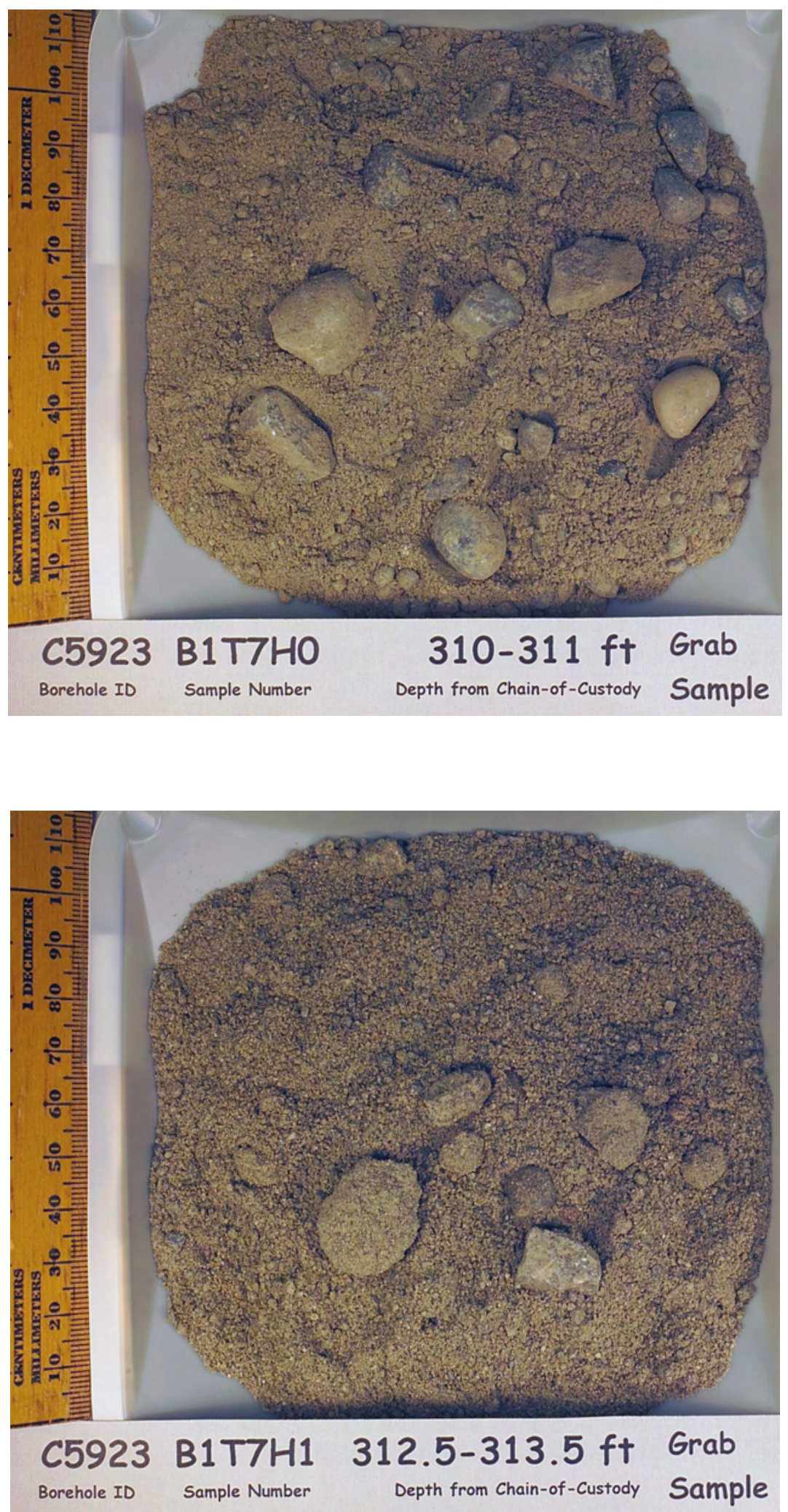

B. 66 
PNNL-17821
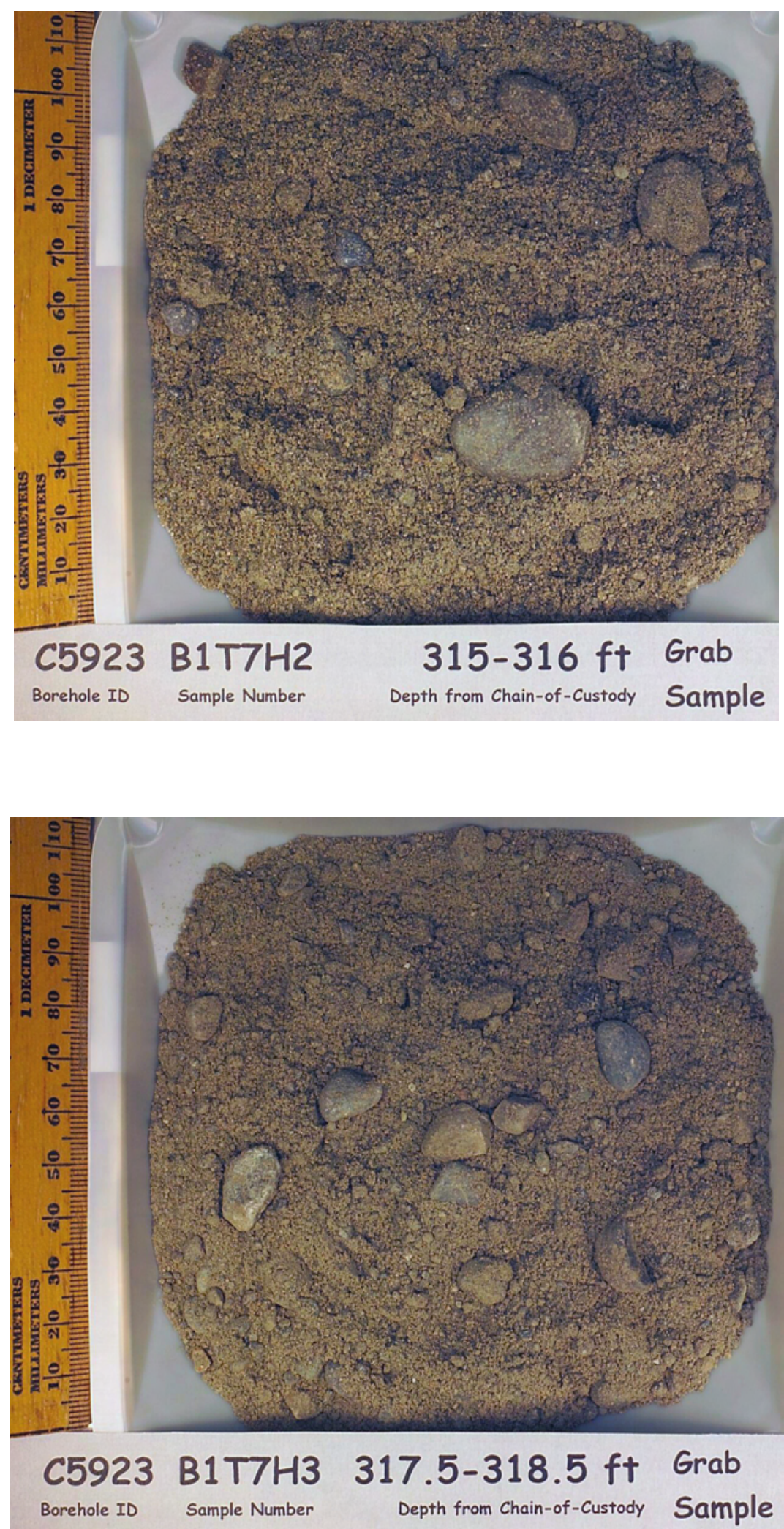

B. 67 
PNNL-17821
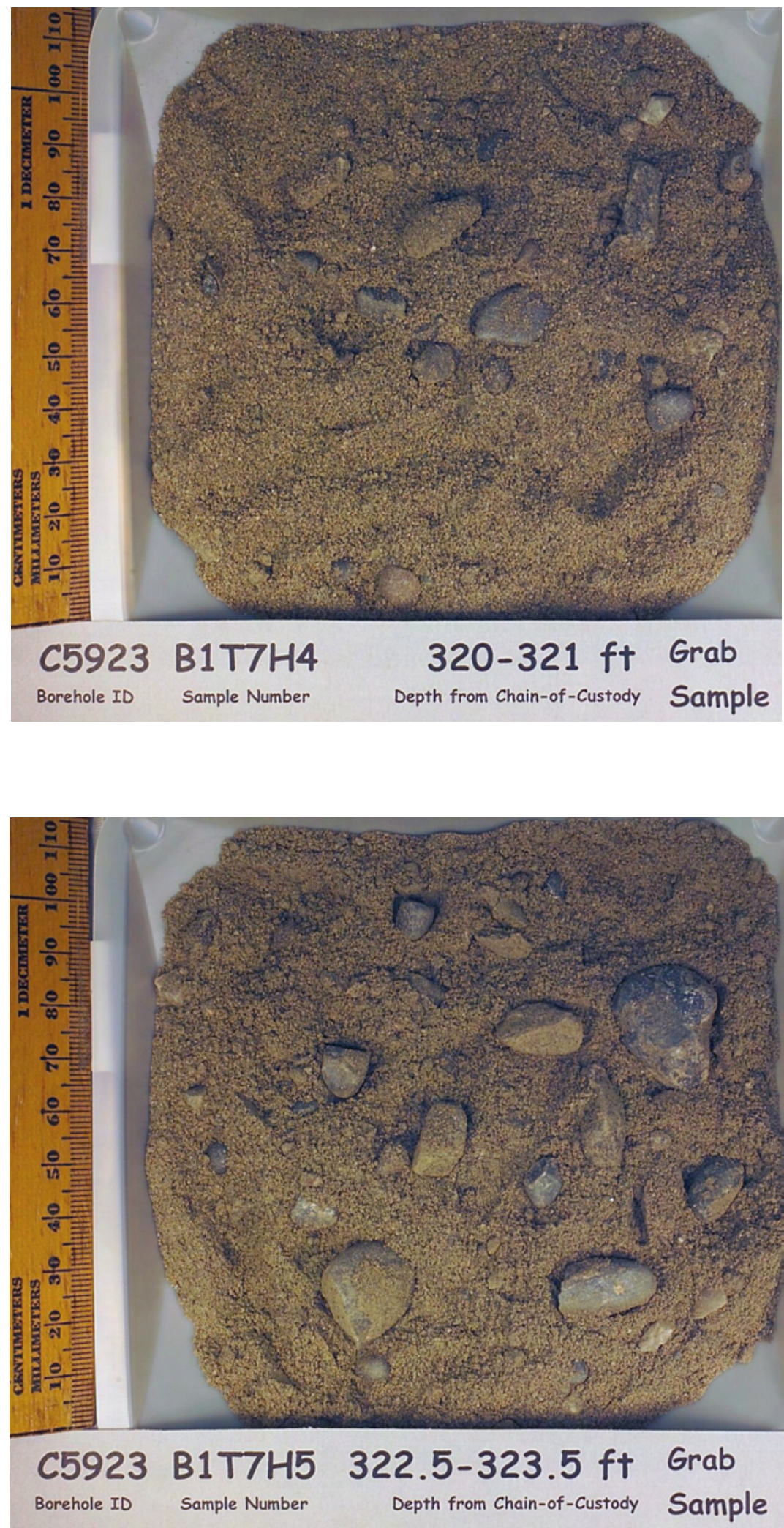

B.68 
PNNL-17821
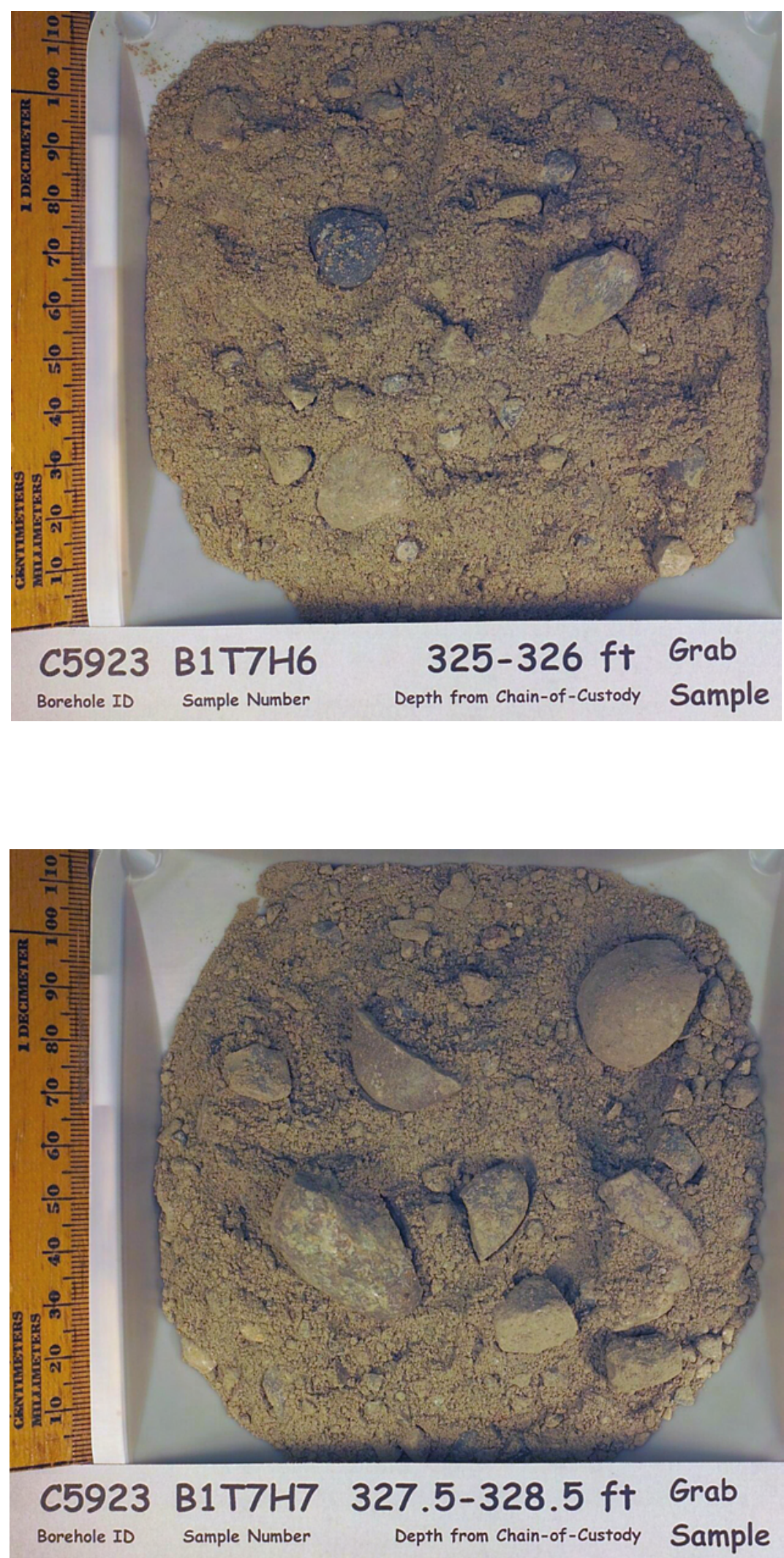

B. 69 
PNNL-17821
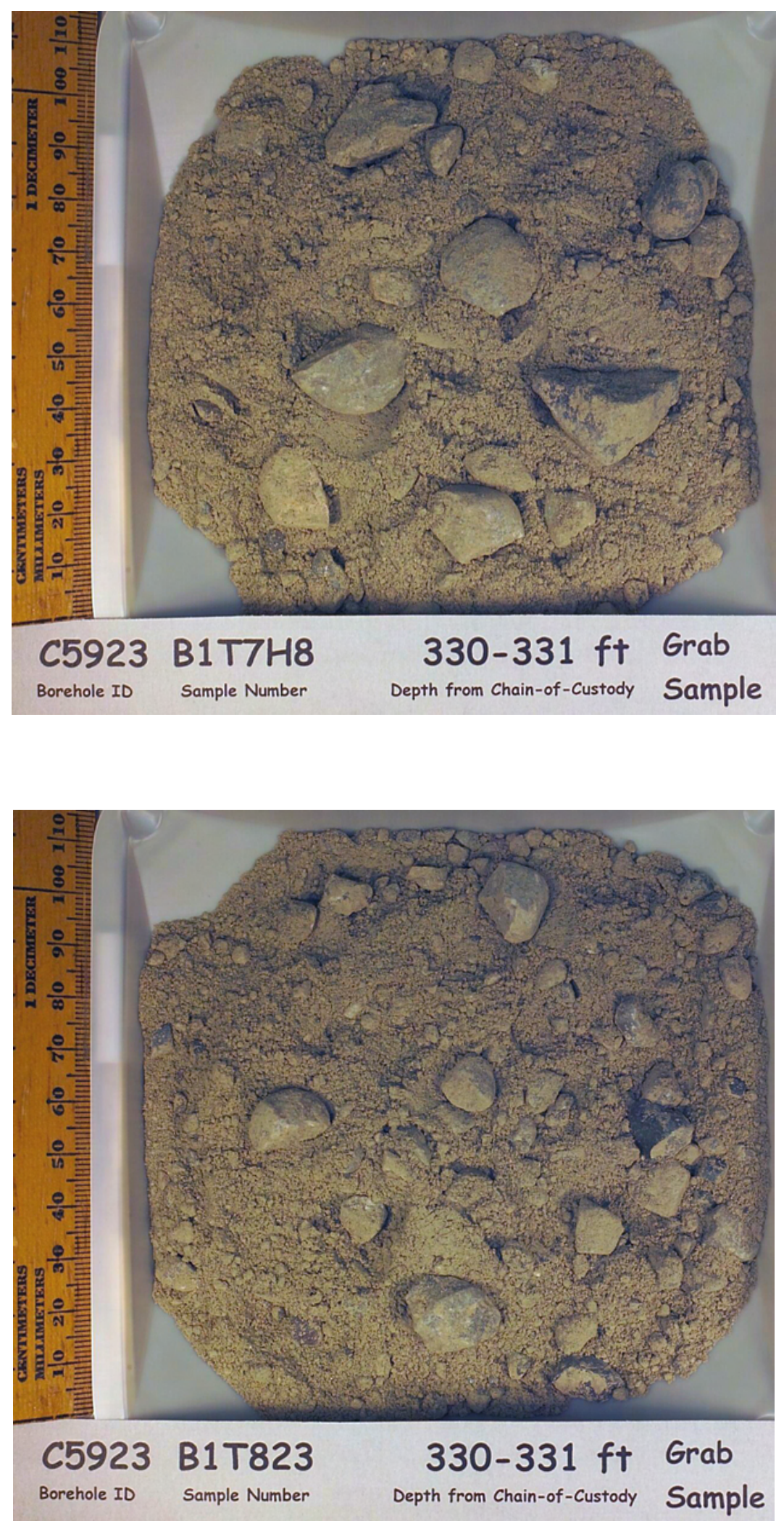

B. 70 
PNNL-17821

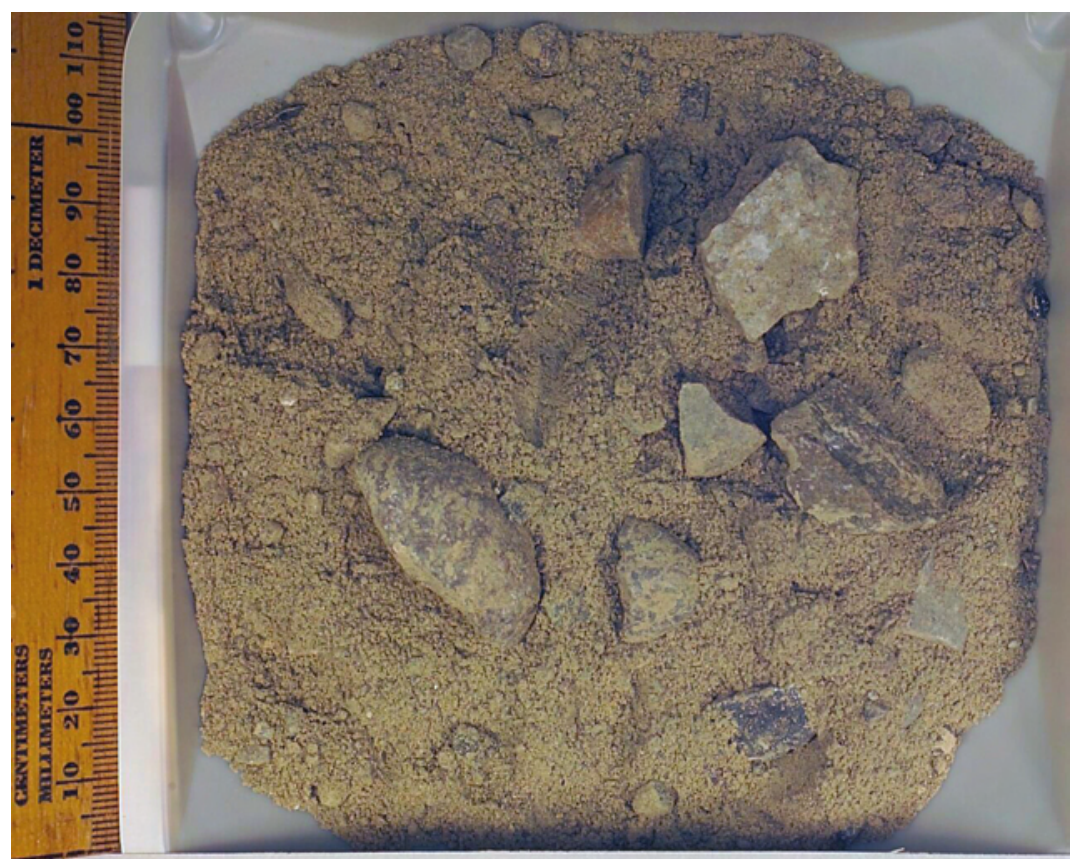

C5923 B1T7H9 332.5-333.5 ft Grab Borehole ID Sample Number Depth from Chain-of-Custody Sample

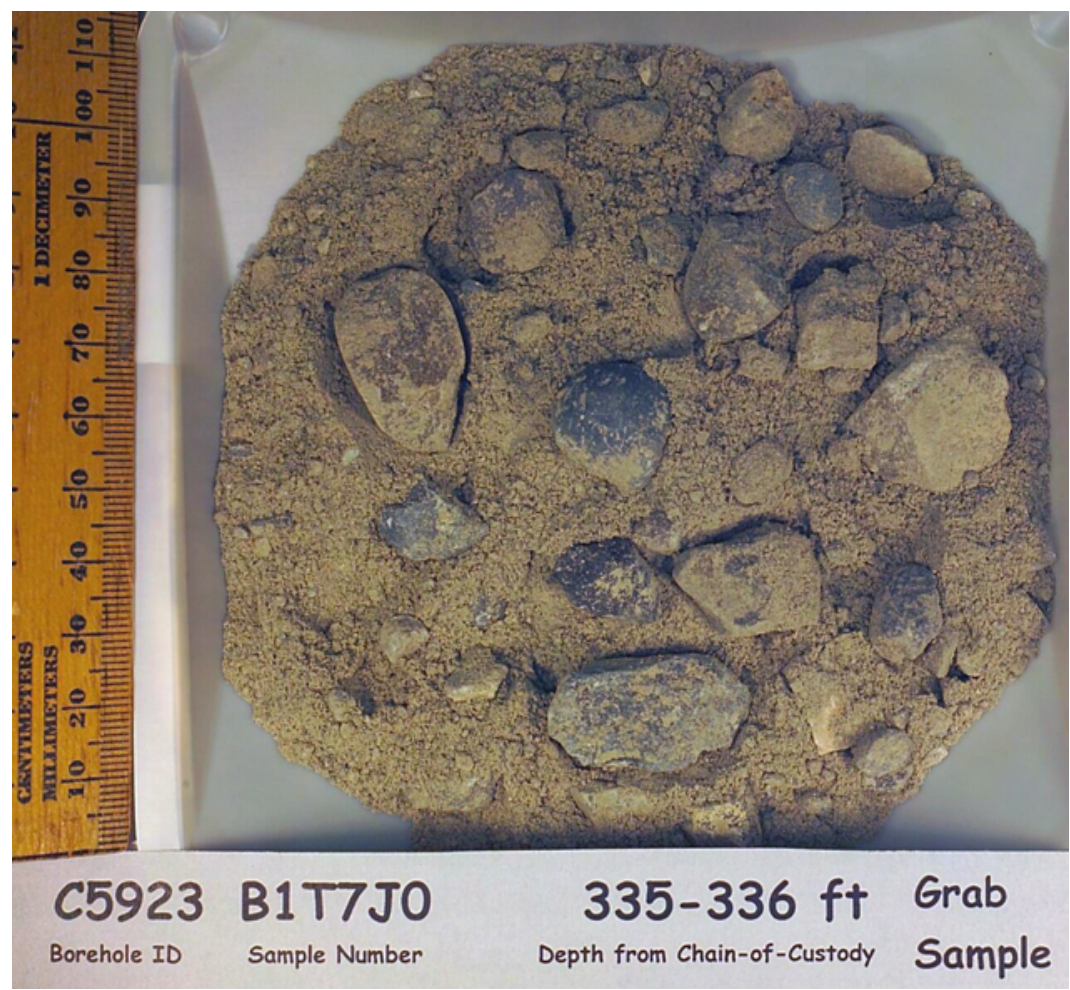

B.71 
PNNL-17821
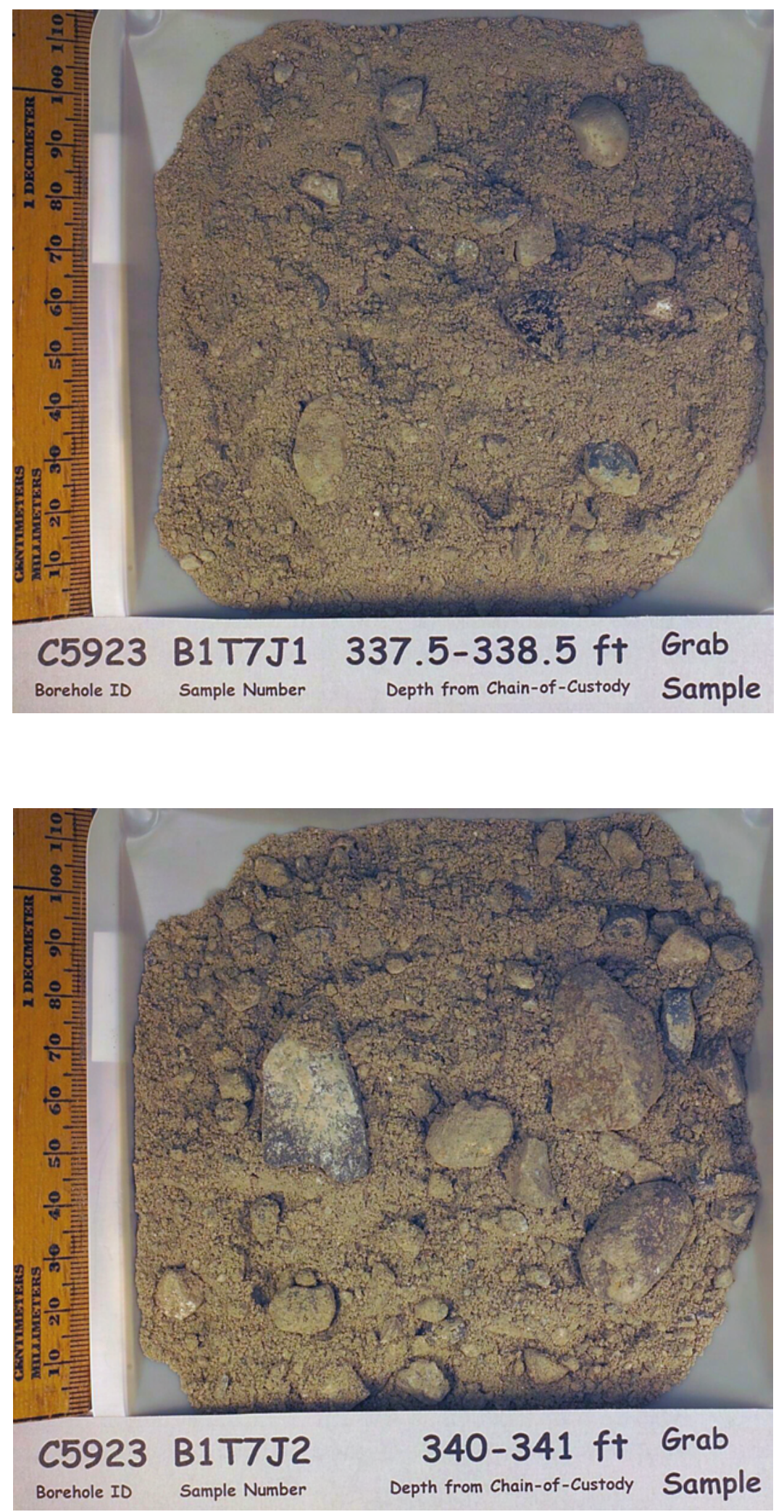

B.72 
PNNL-17821

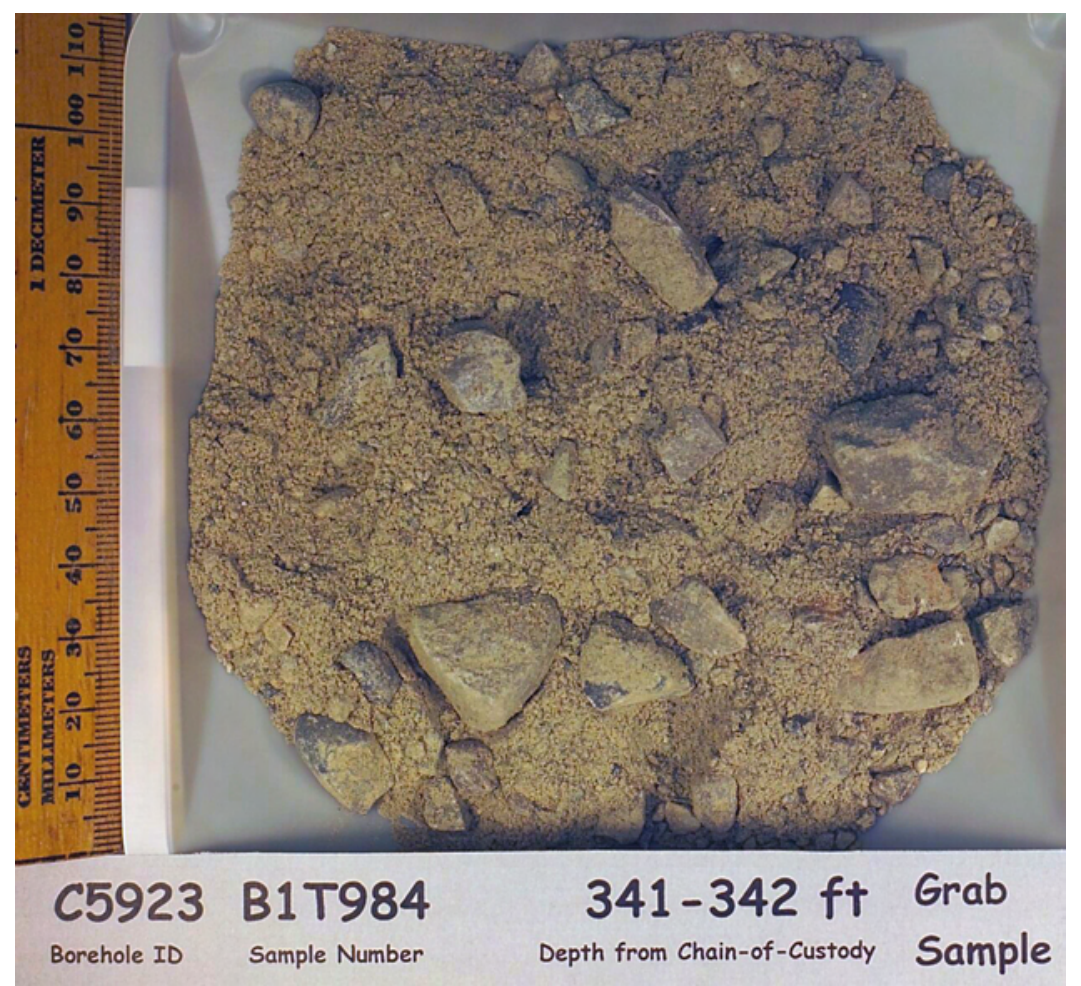

B.73 
PNNL-17821

Samples from Borehole C5924 (299-E13-63)

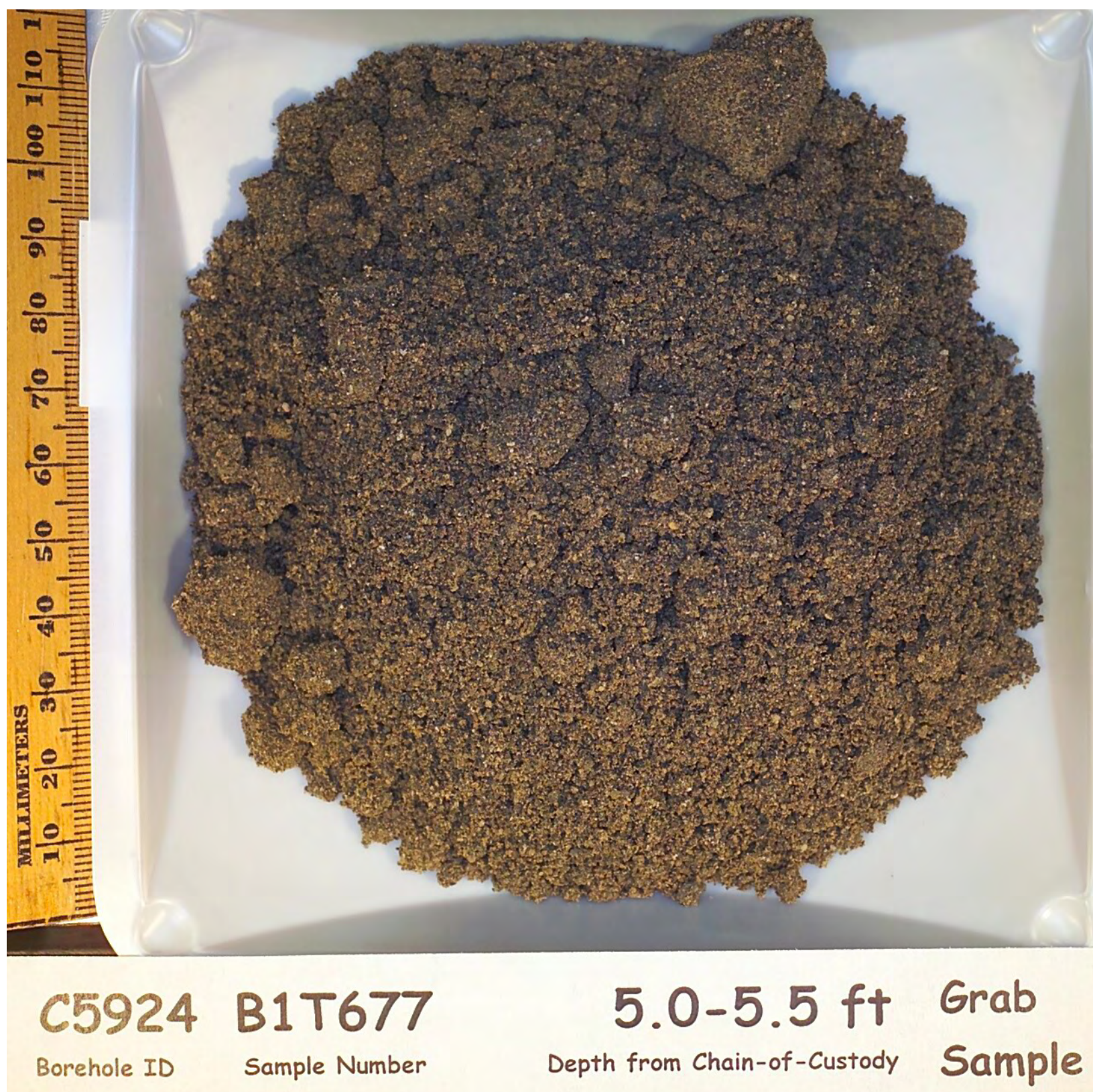


PNNL-17821

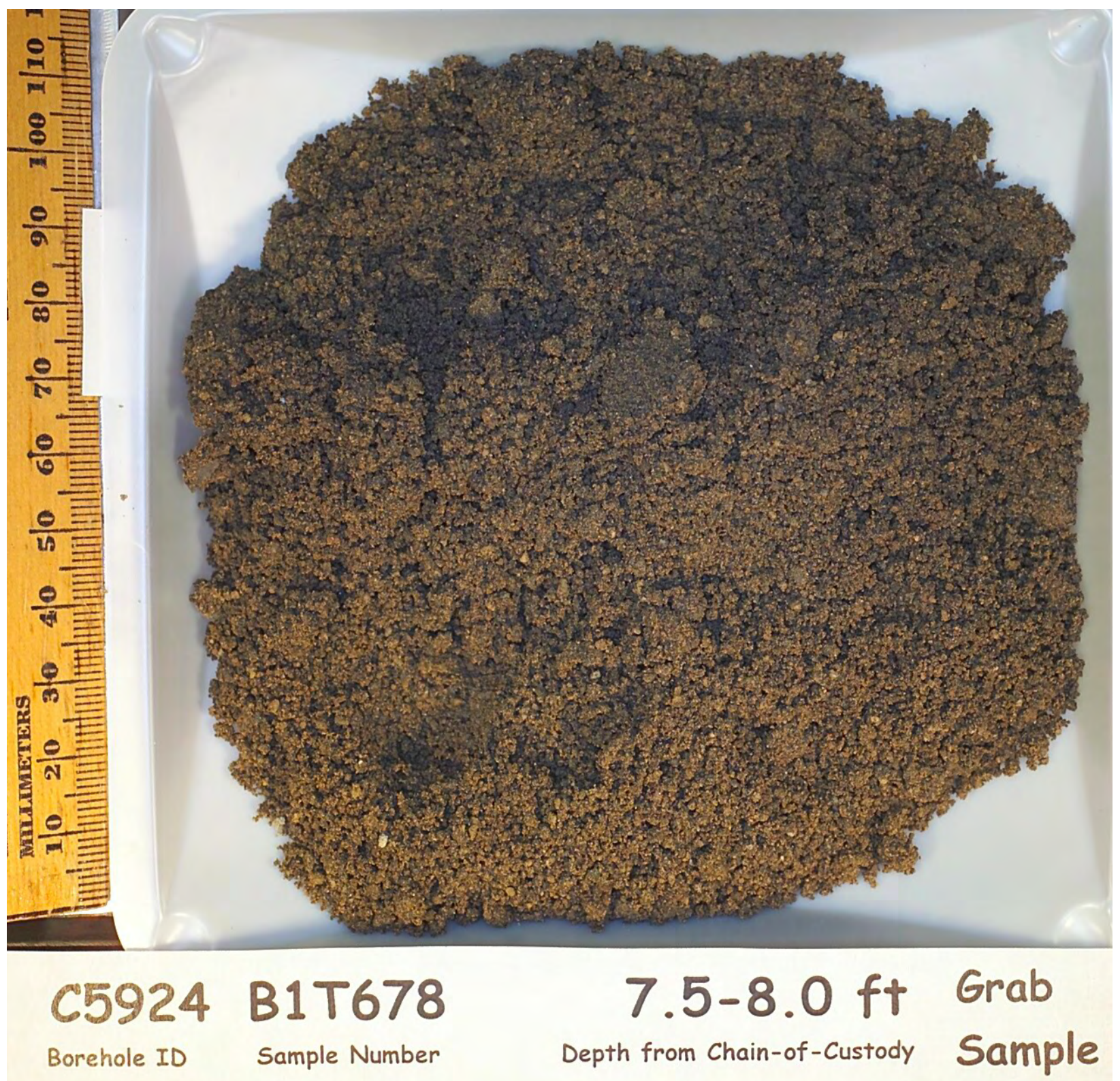


PNNL-17821

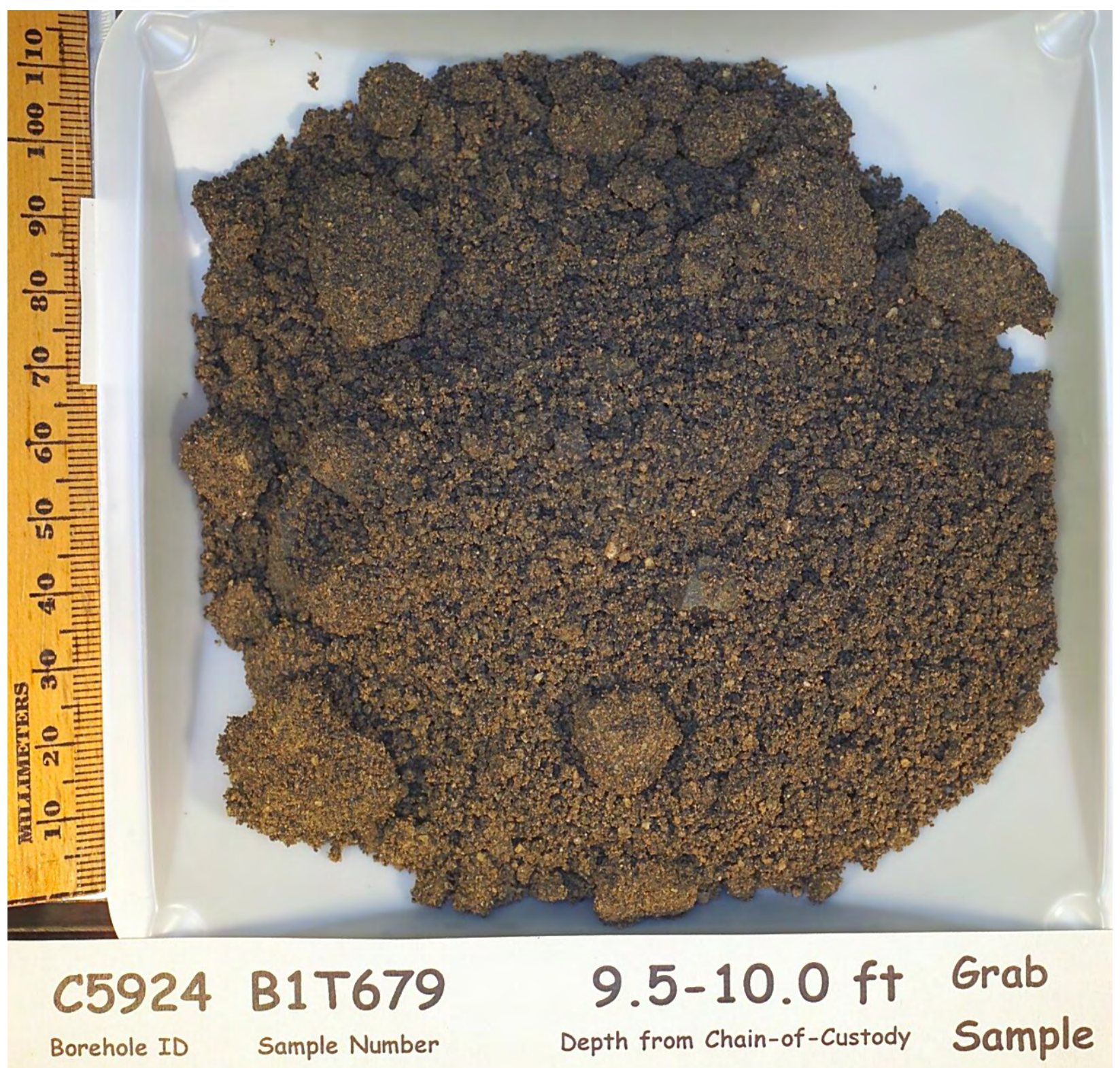


PNNL-17821

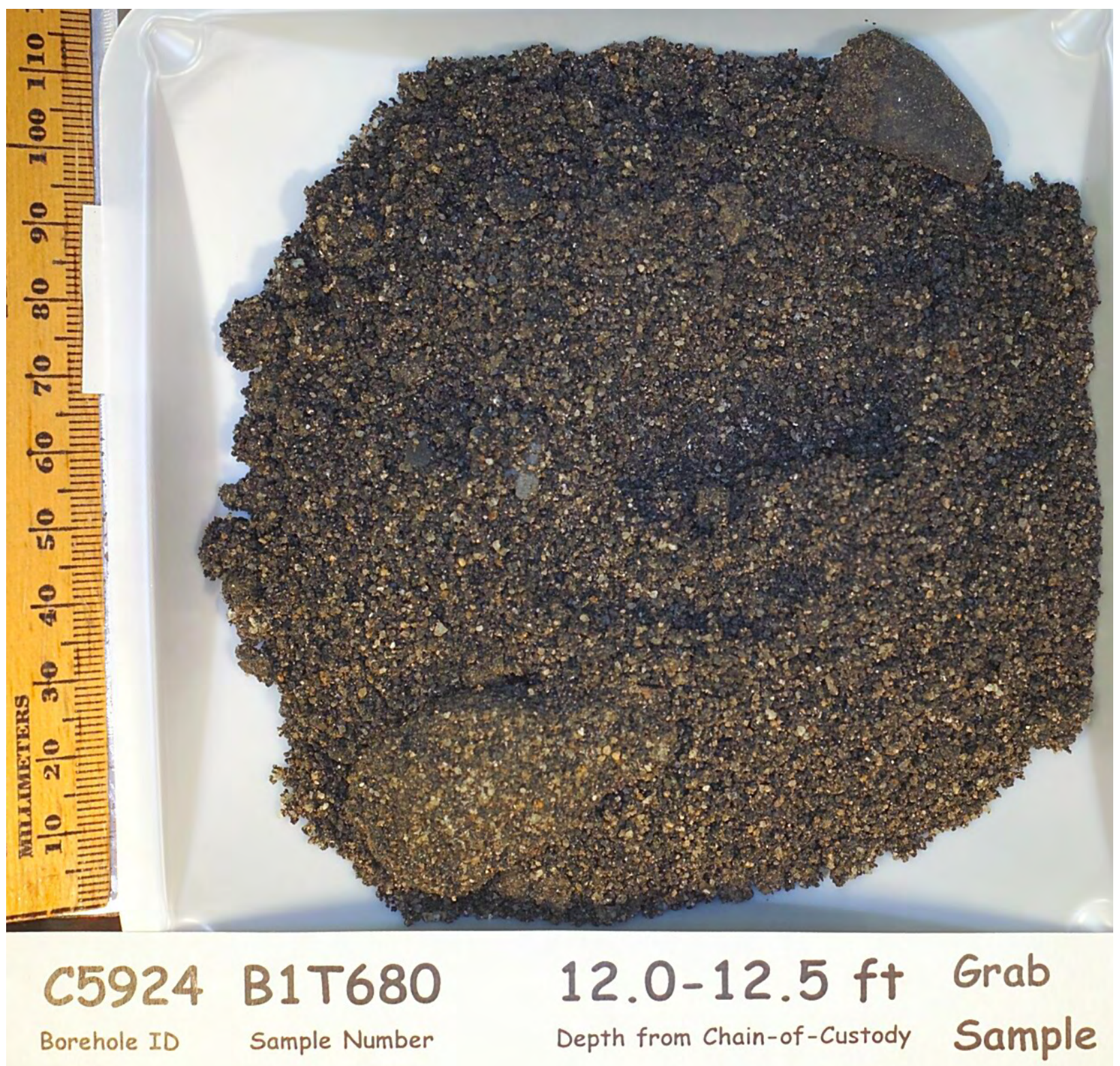




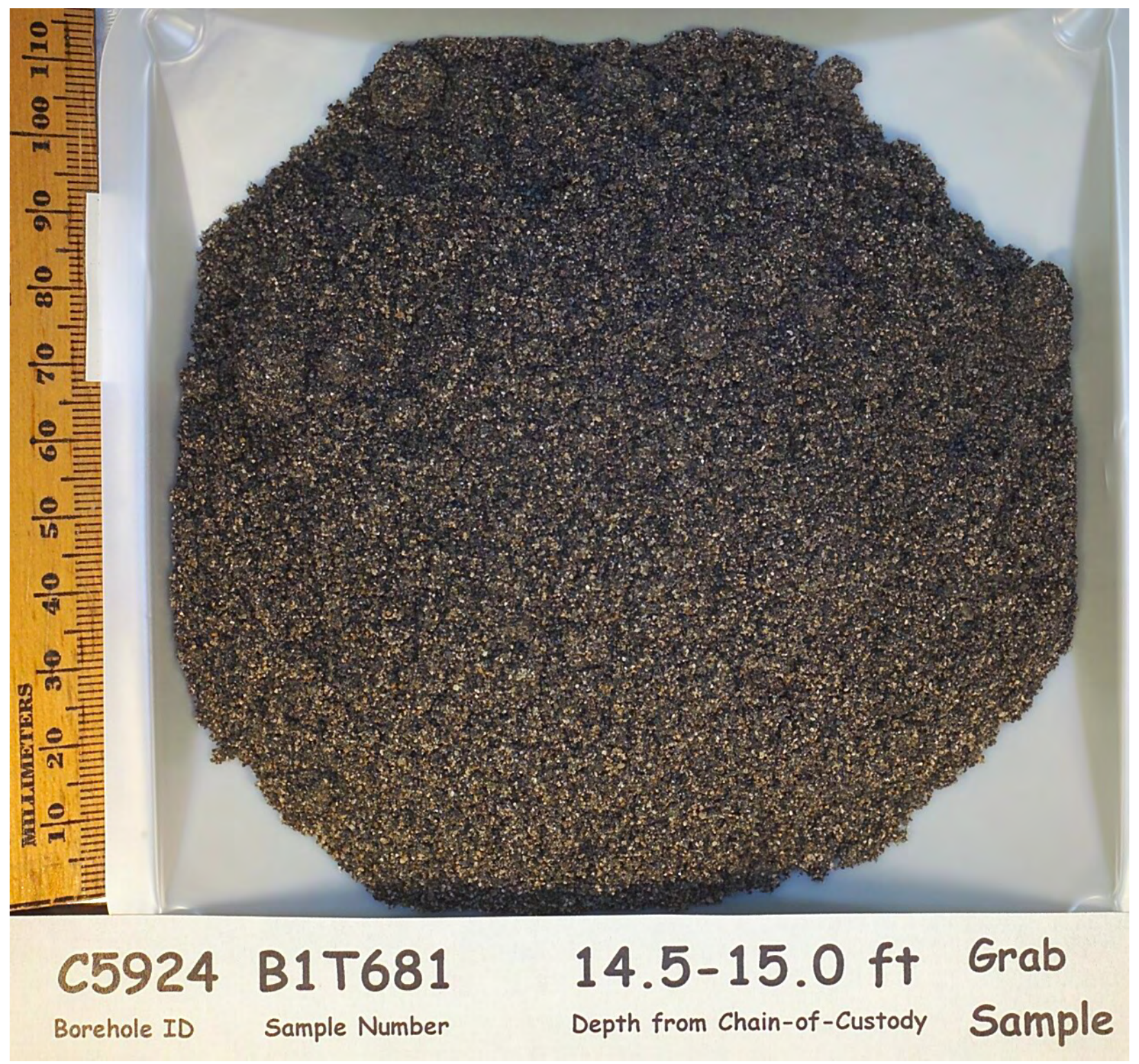


PNNL-17821

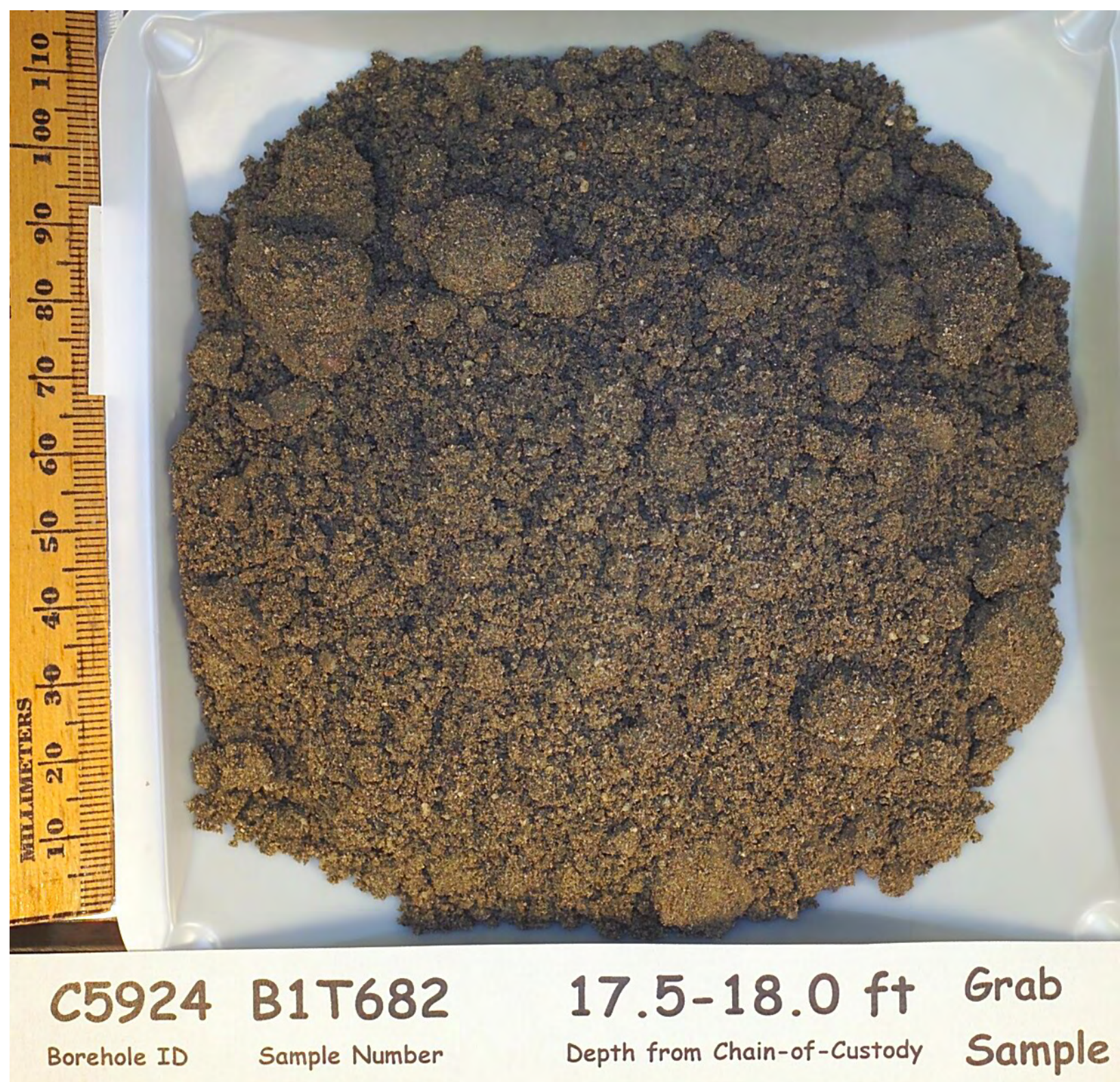


PNNL-17821

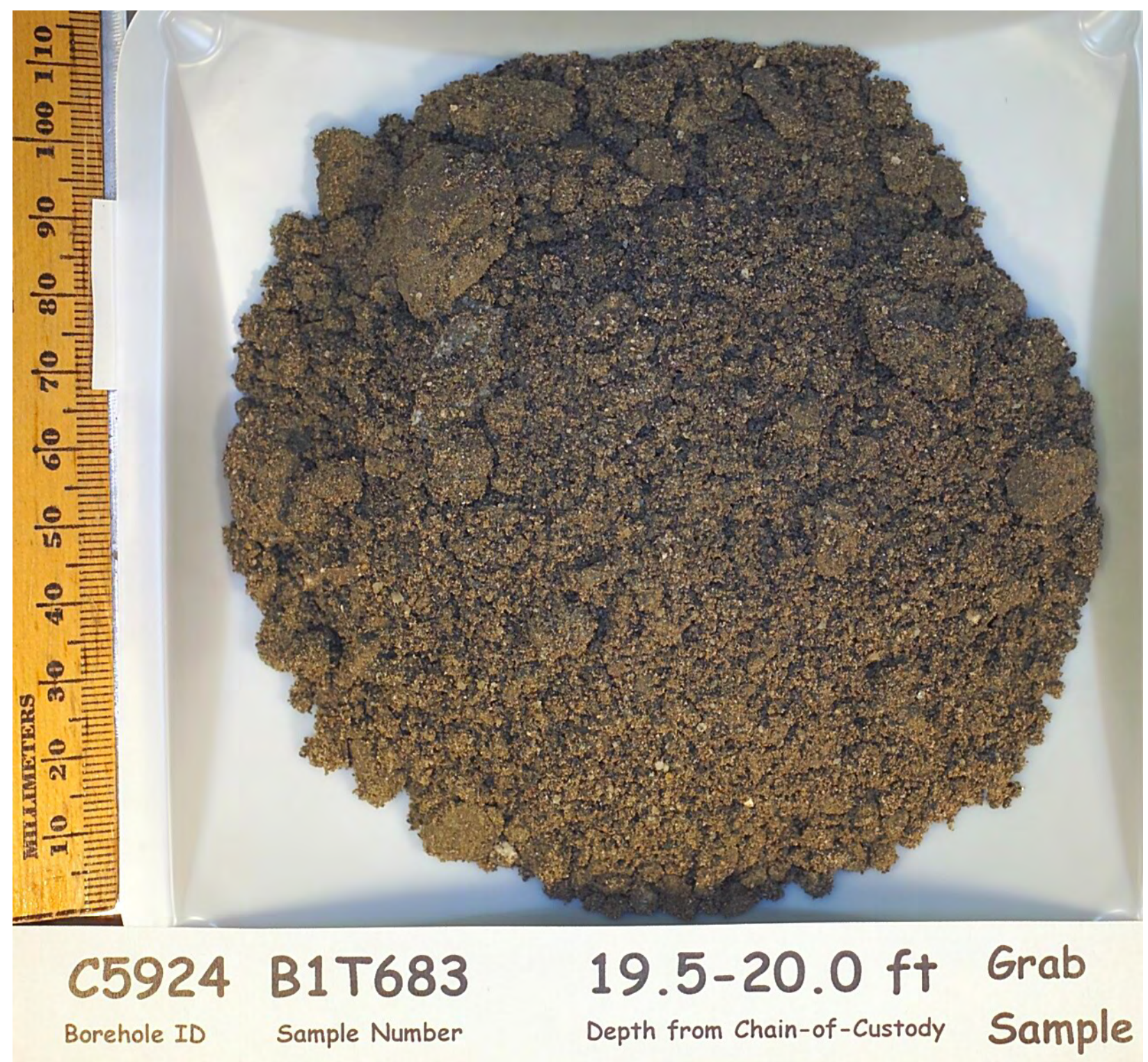


PNNL-17821

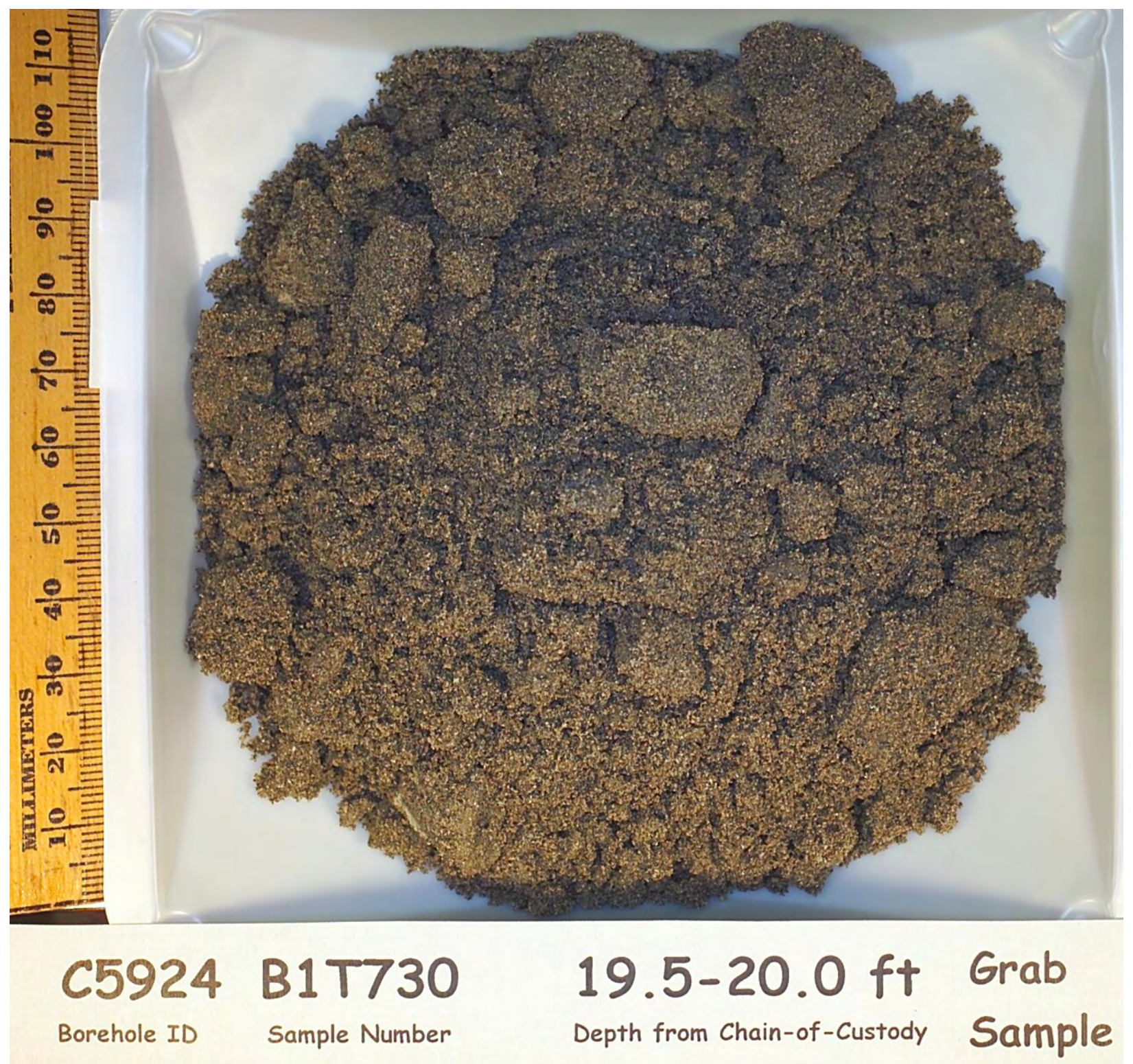


PNNL-17821

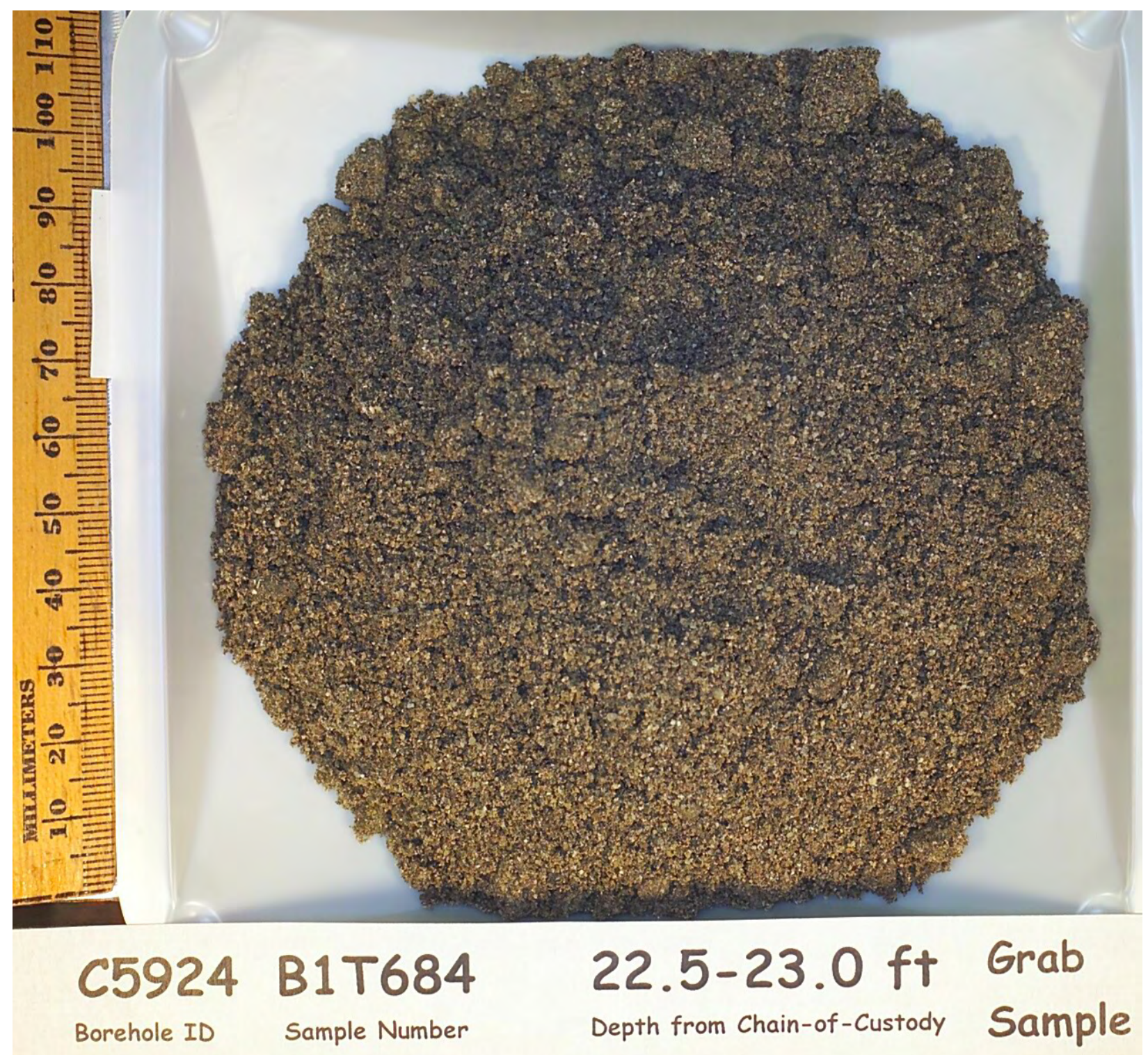




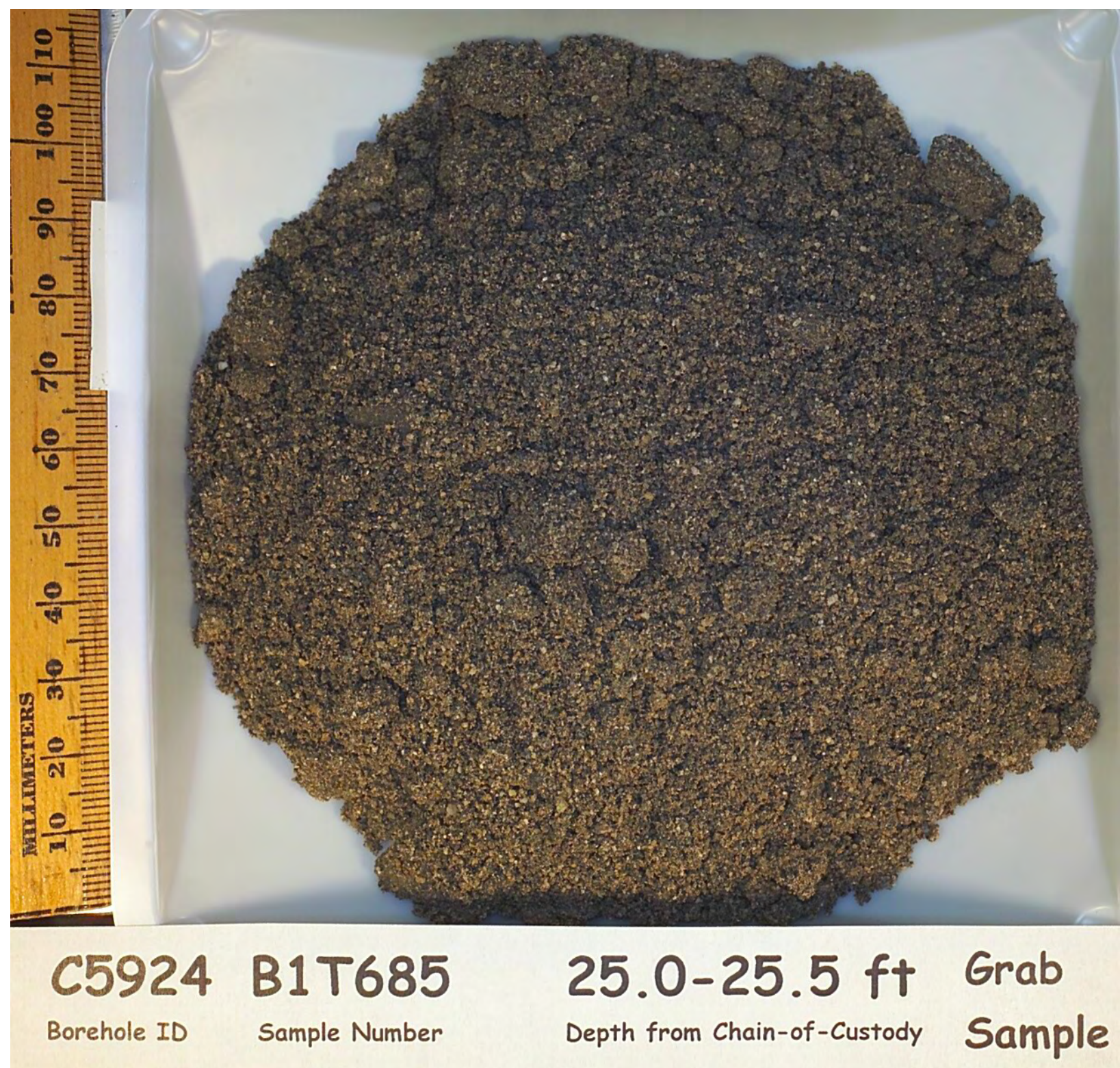


PNNL-17821

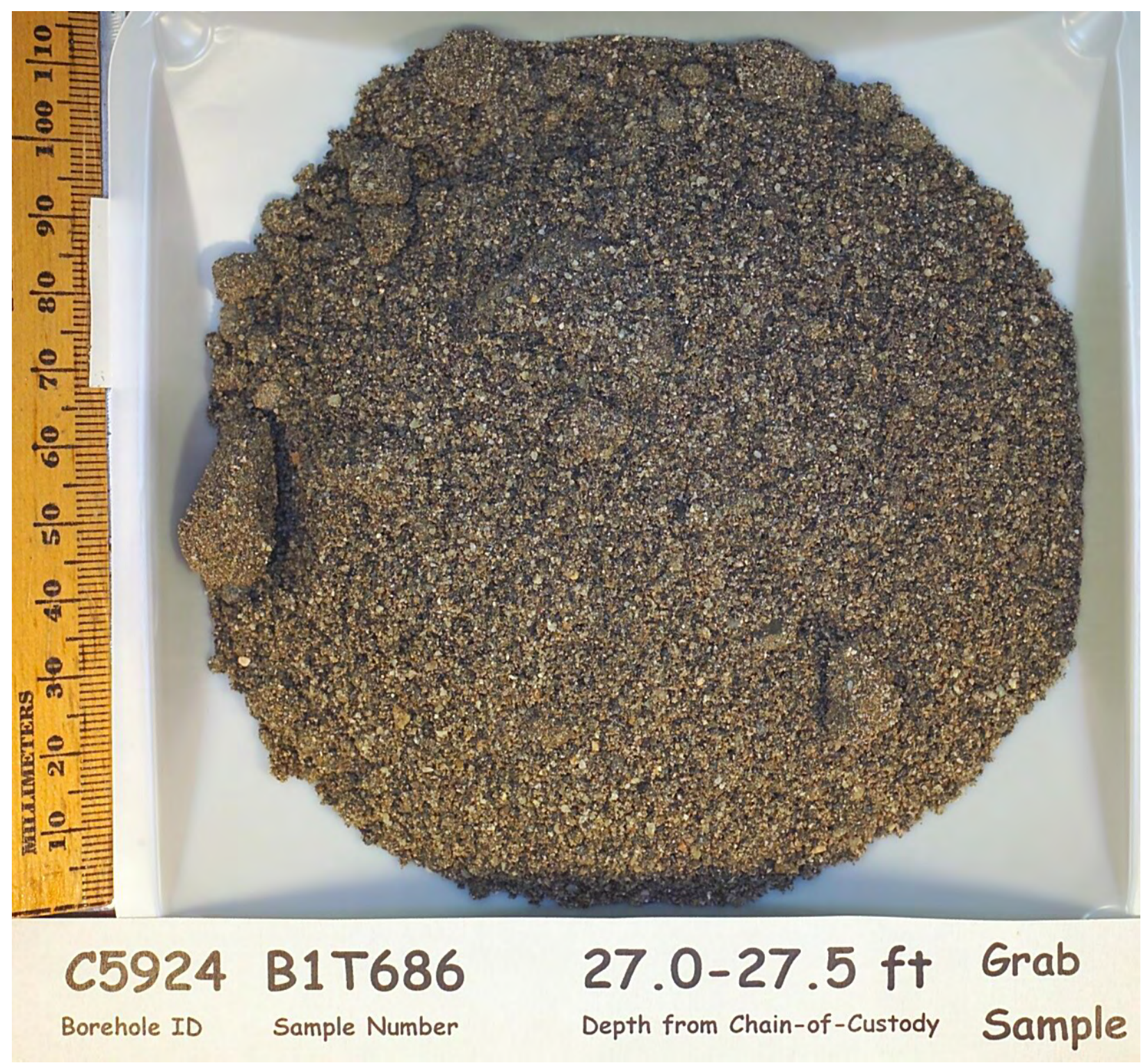




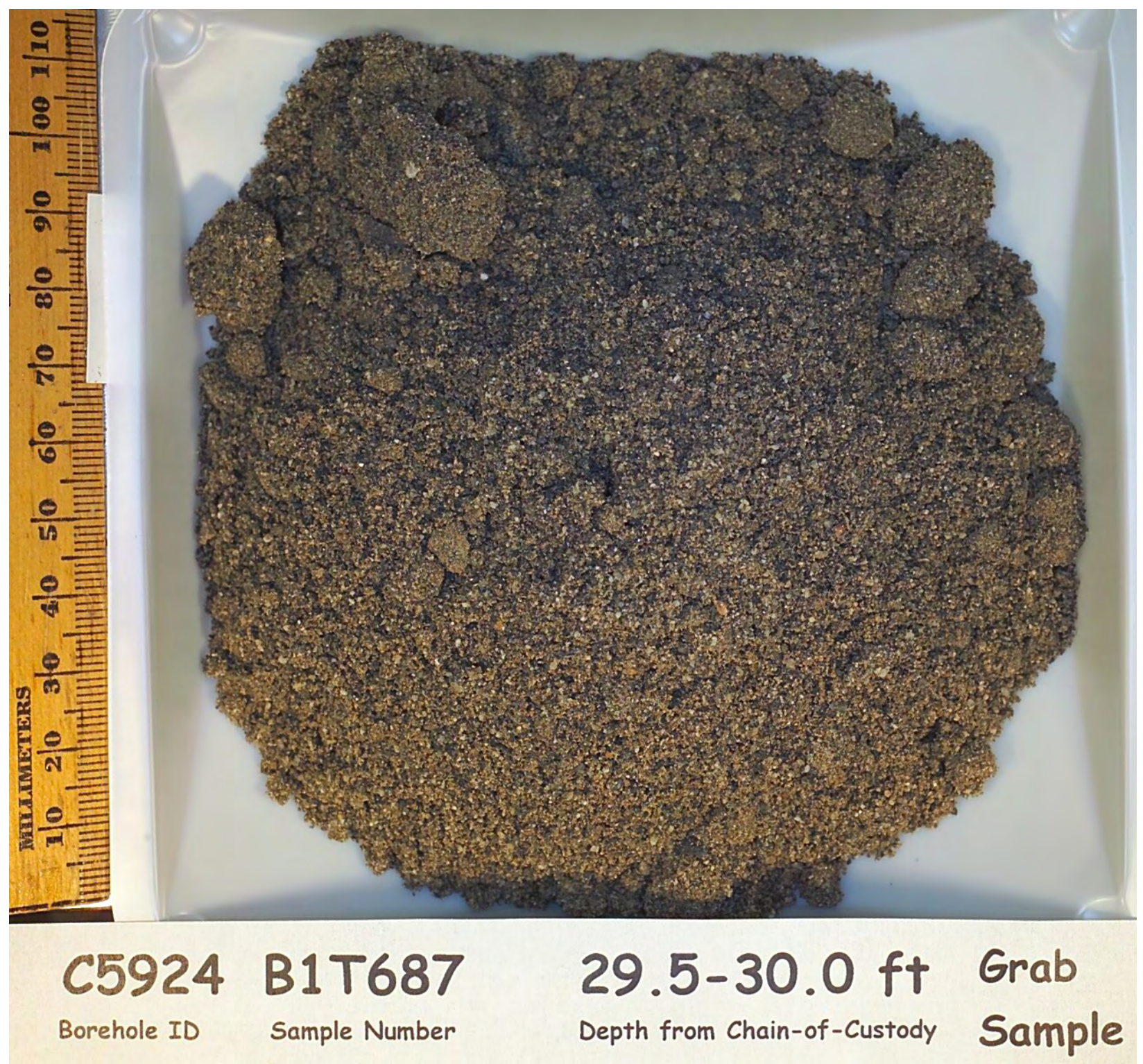


PNNL-17821

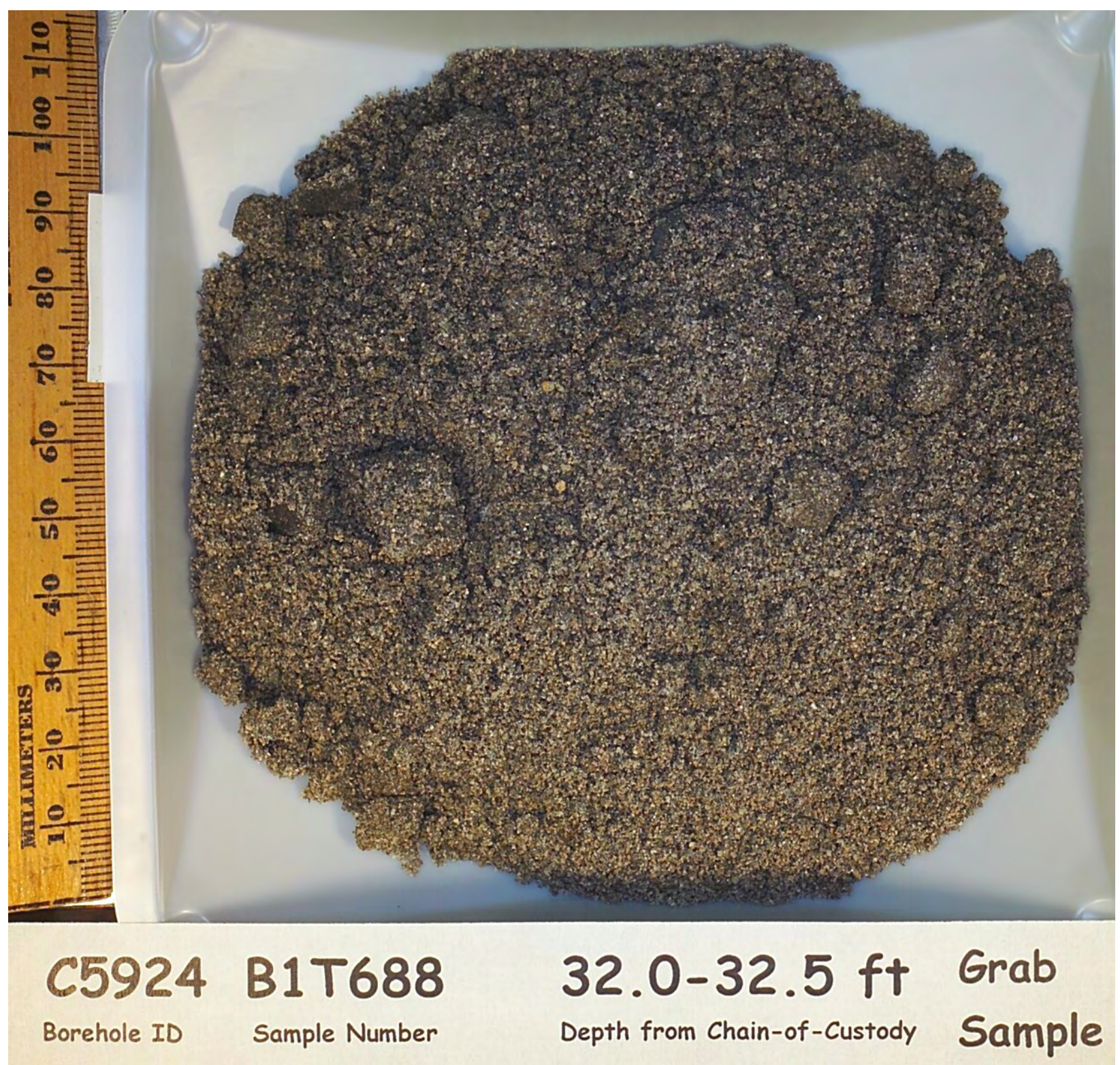


PNNL-17821

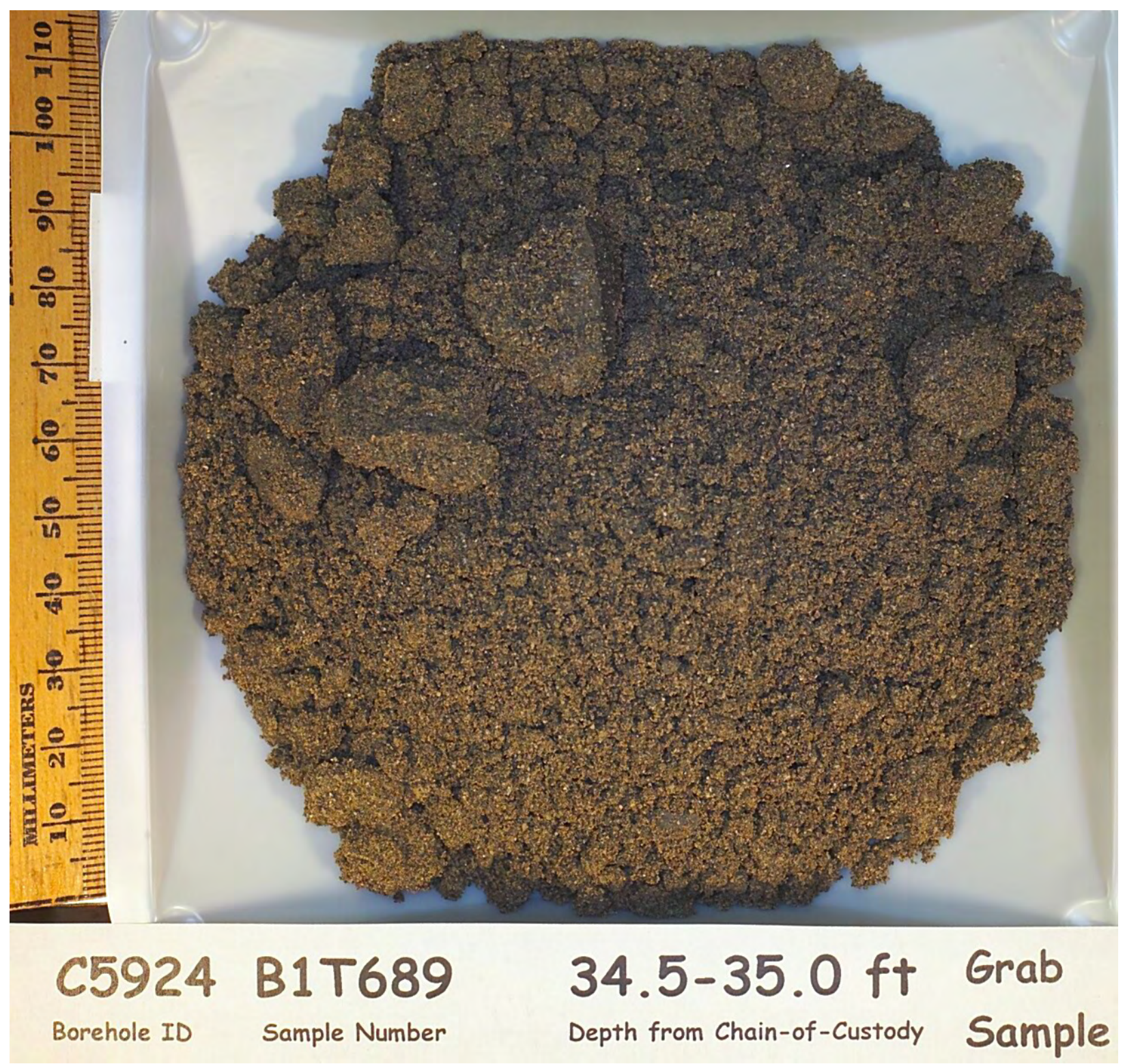


PNNL-17821

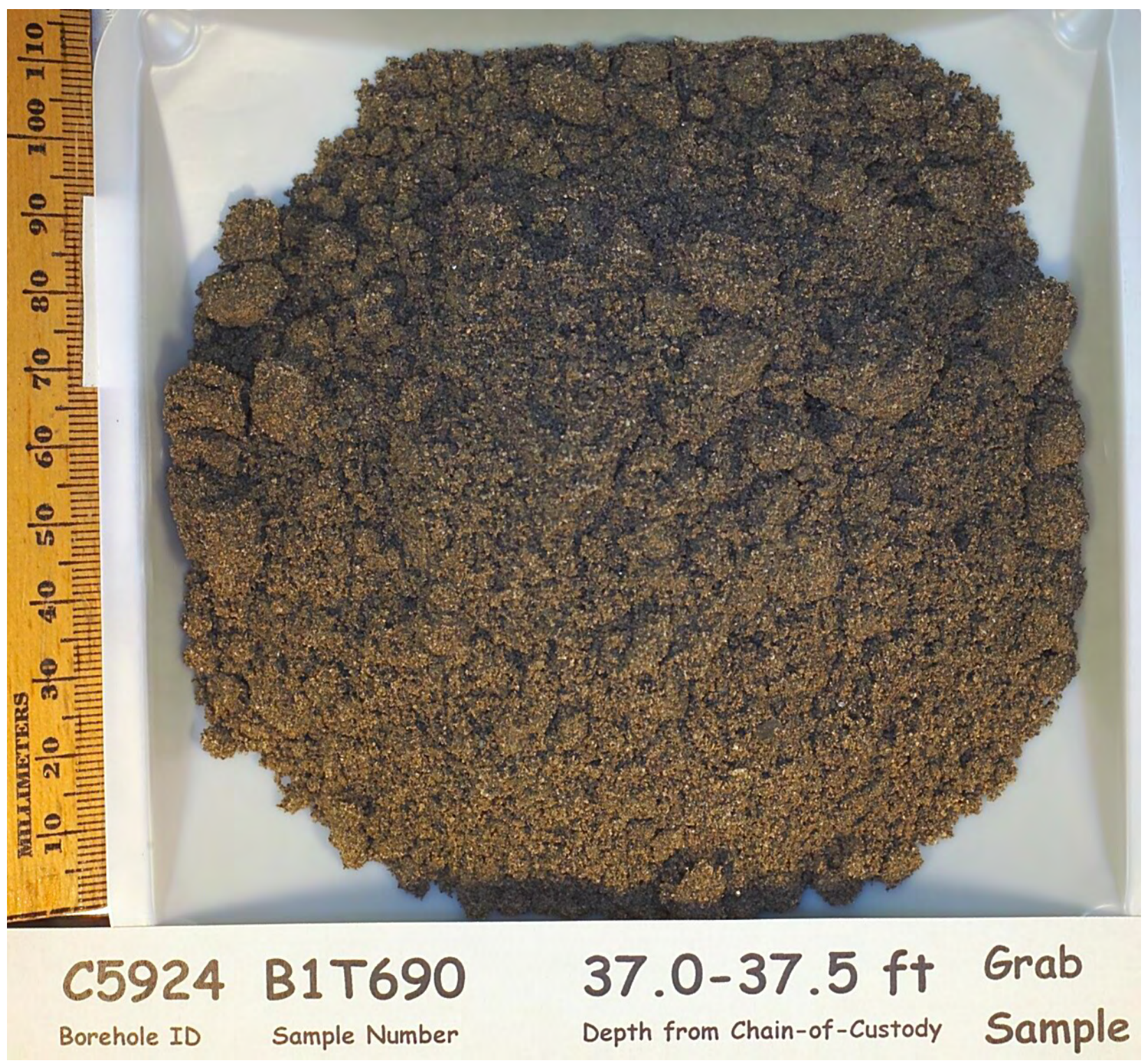




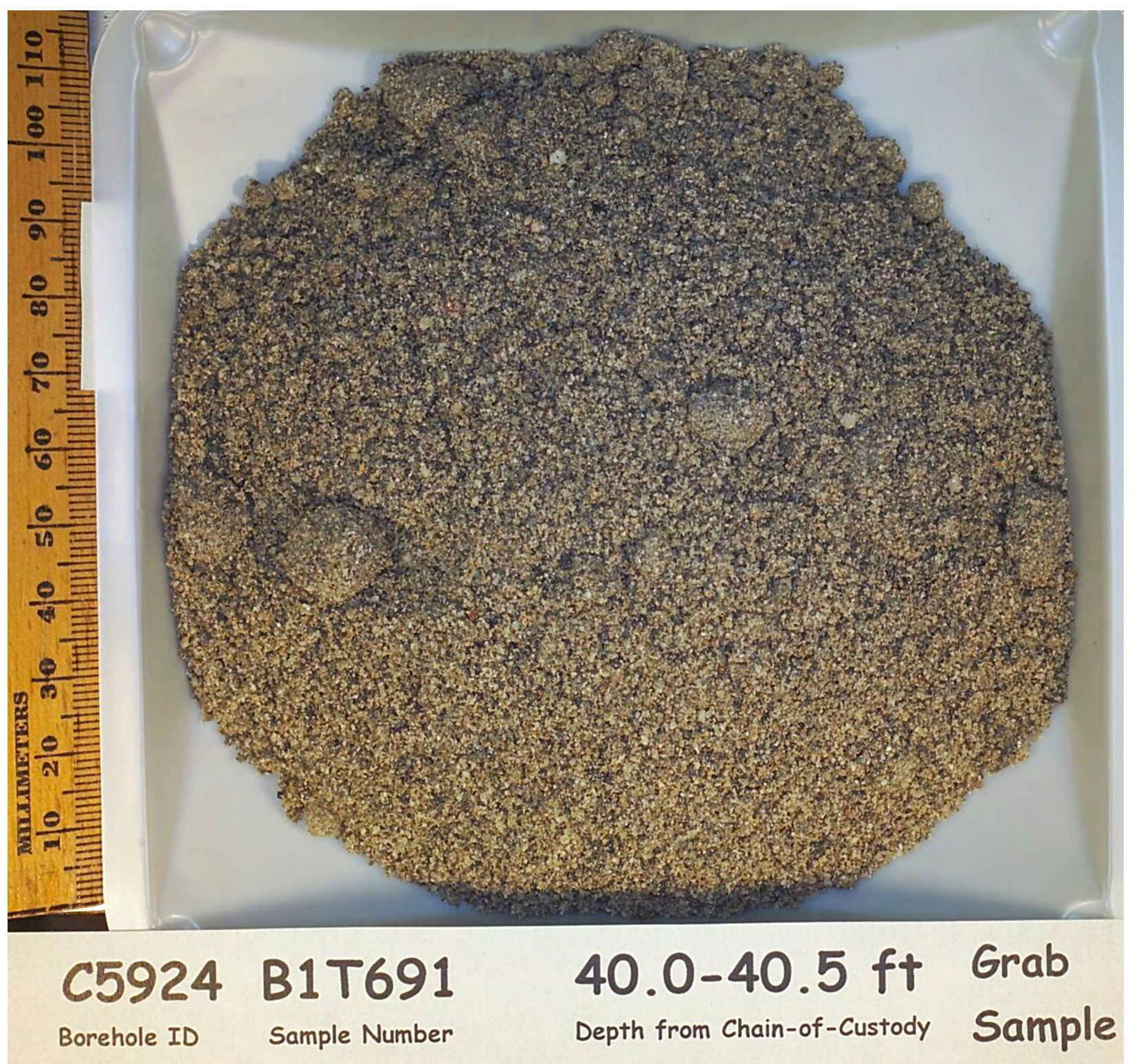


PNNL-17821

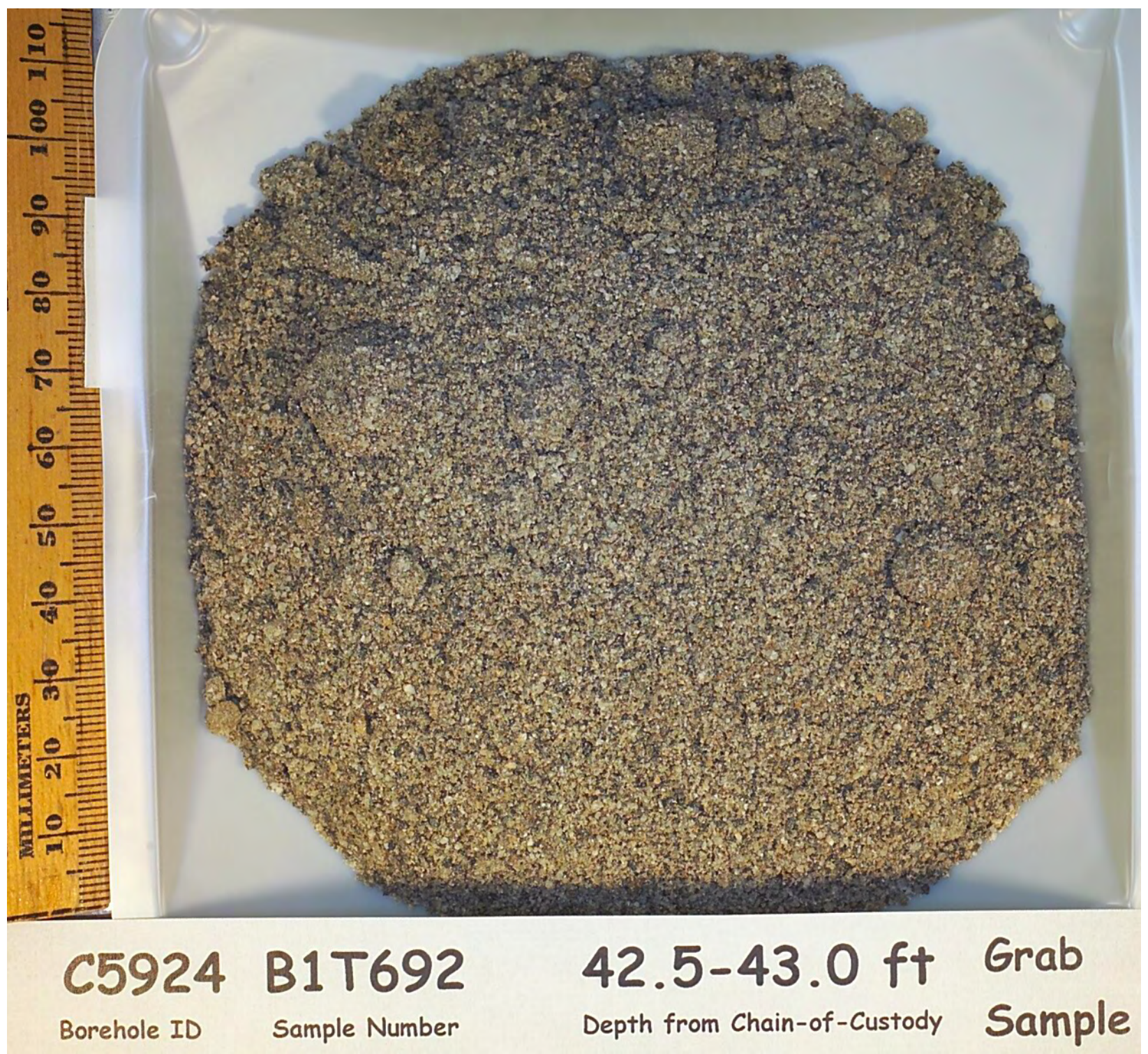




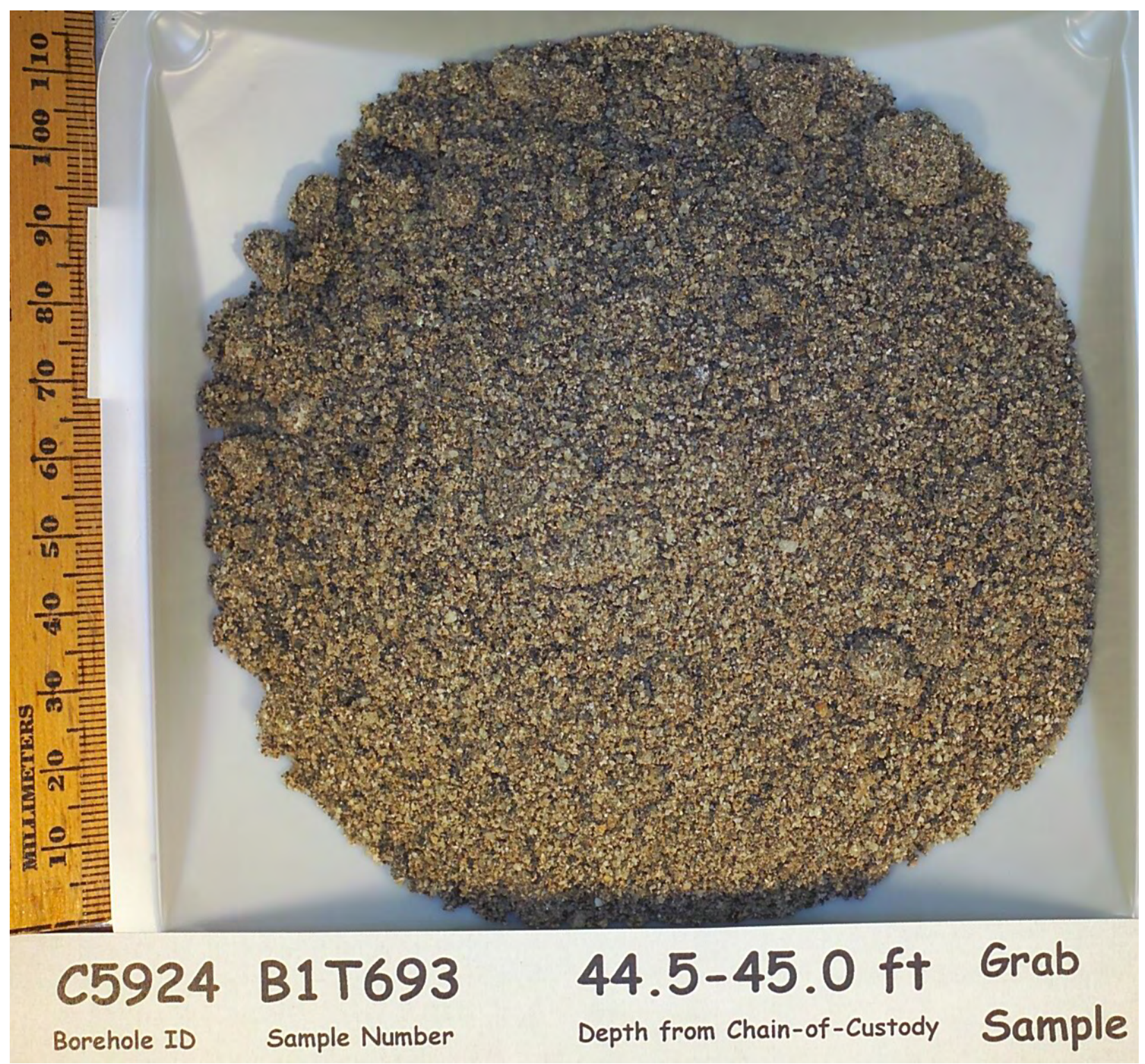




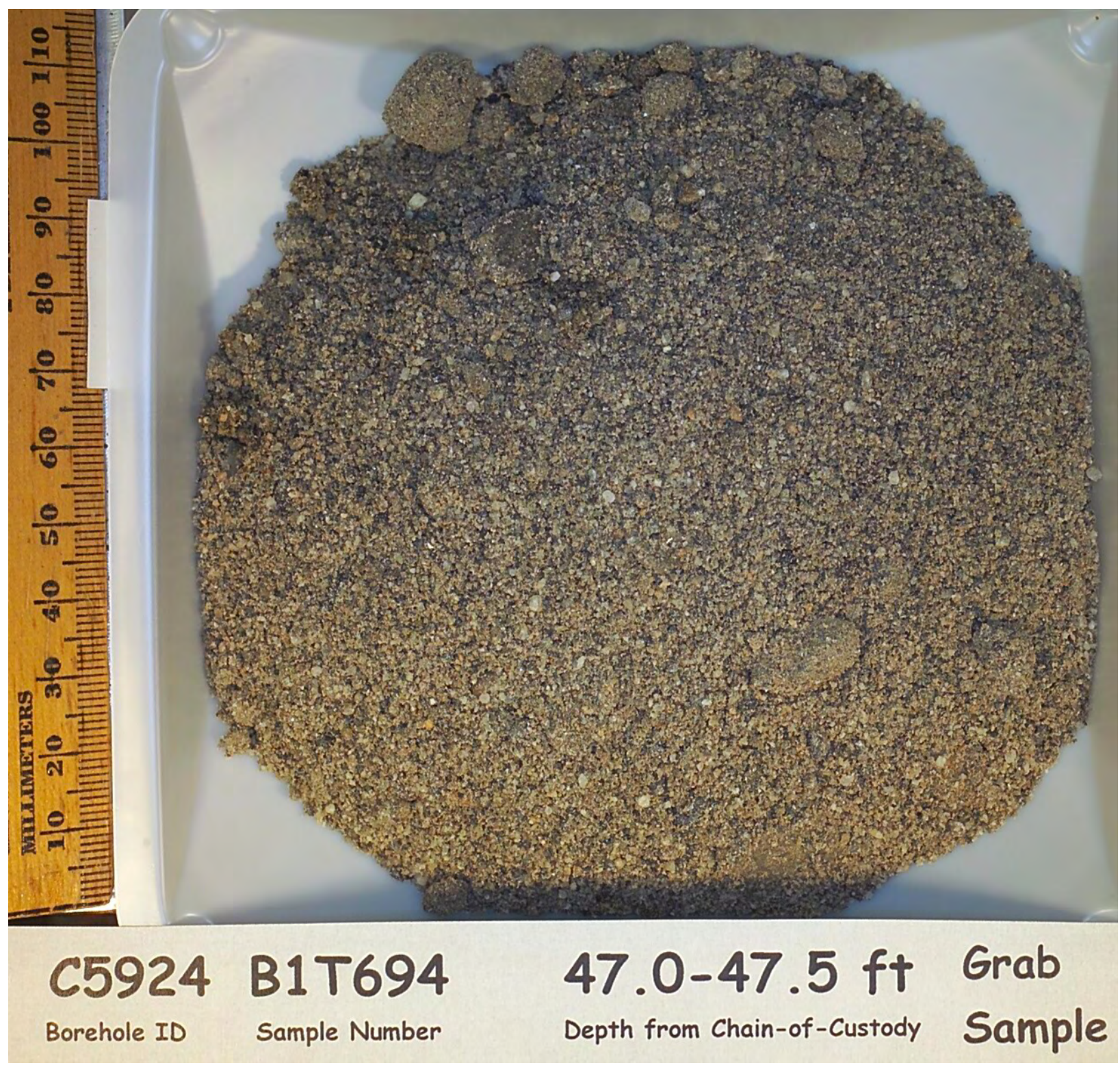




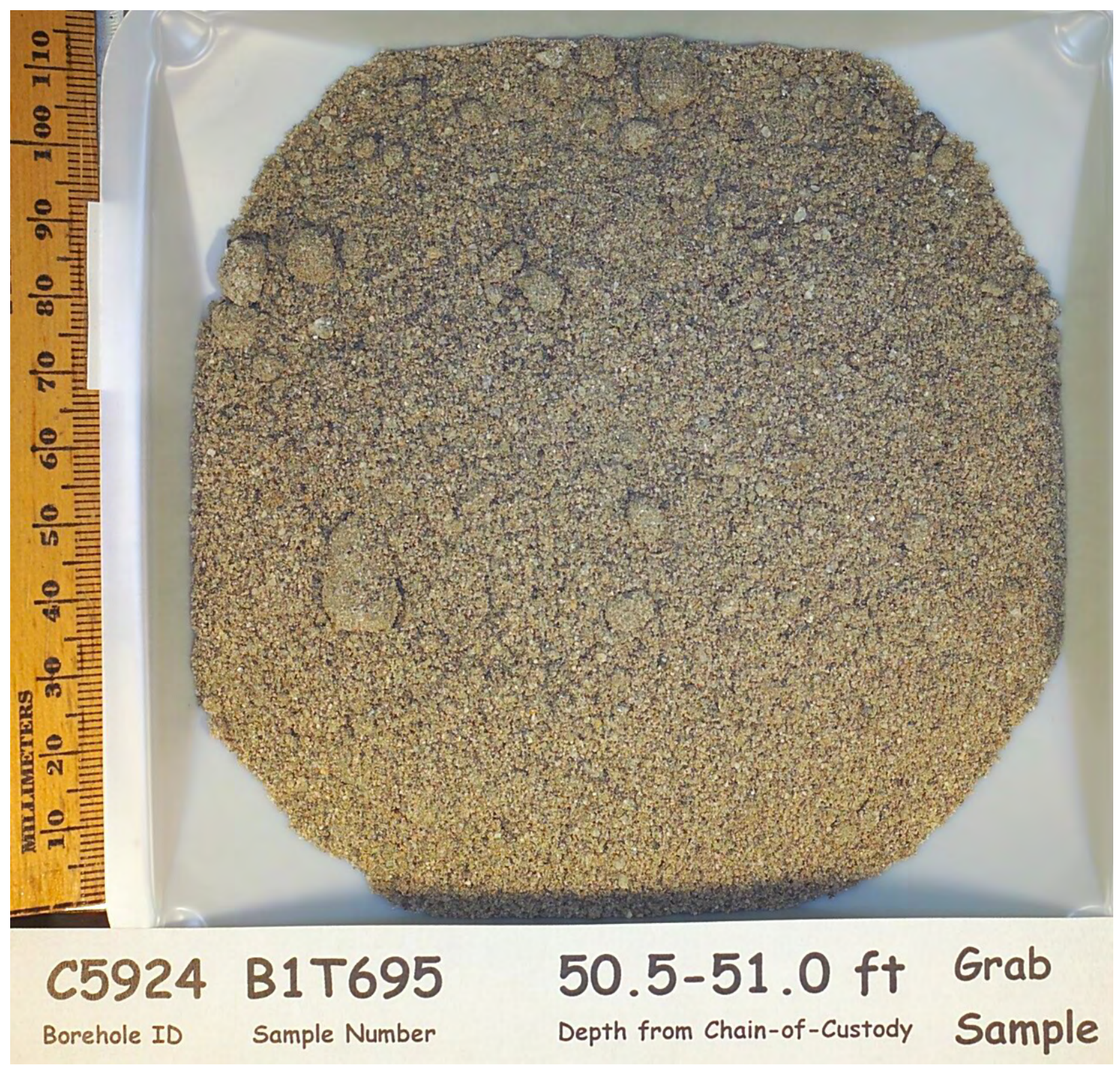




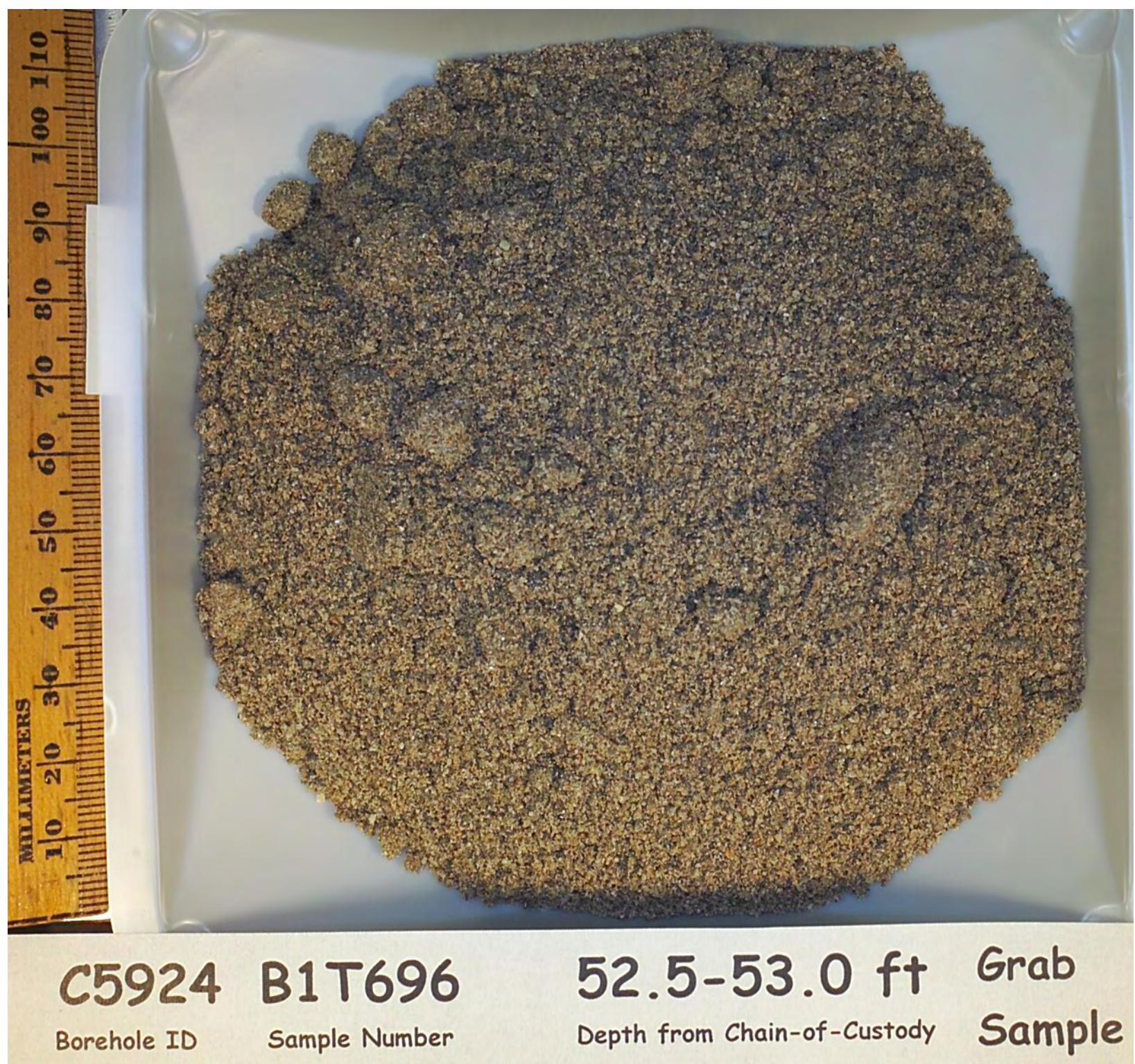




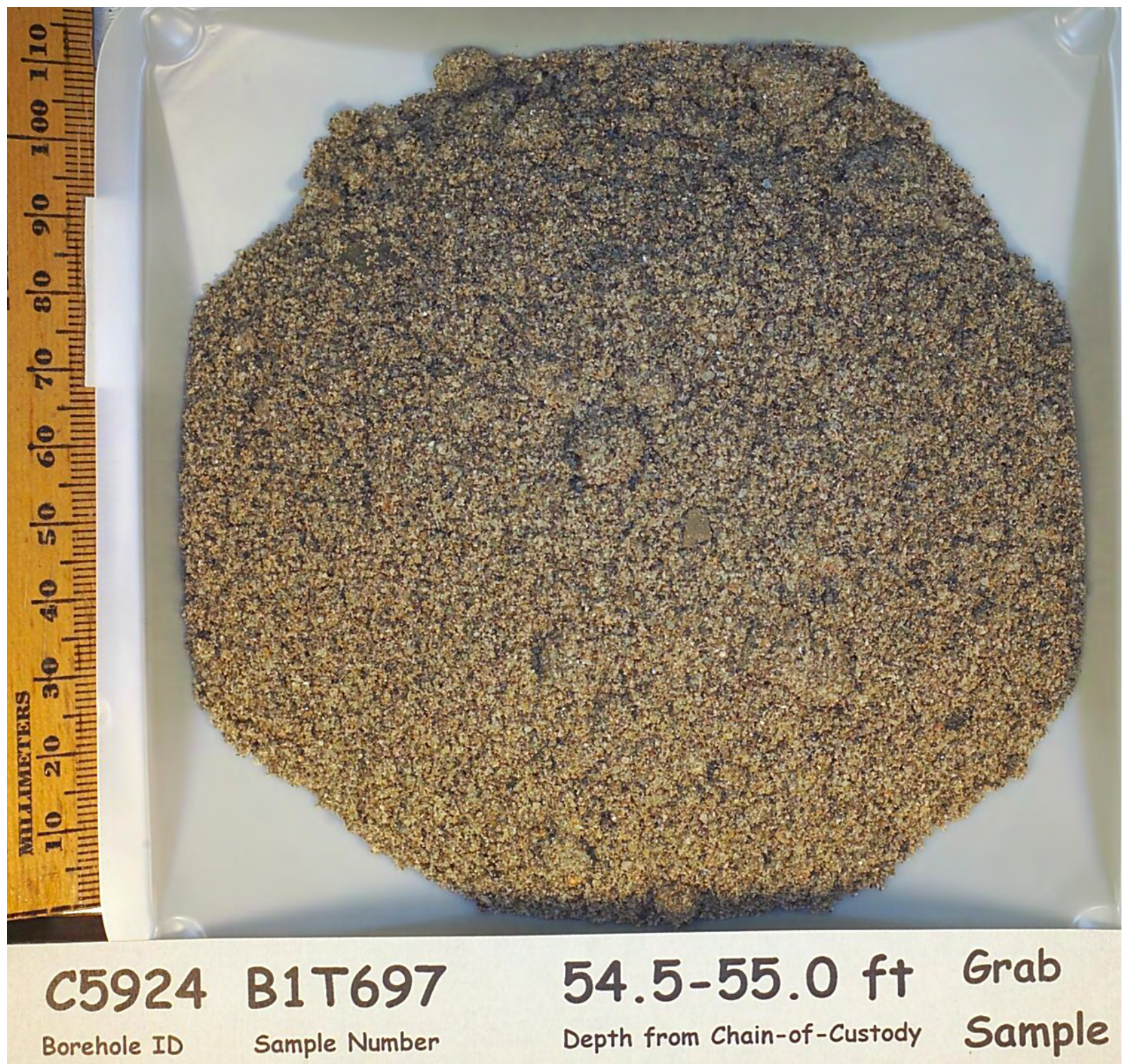




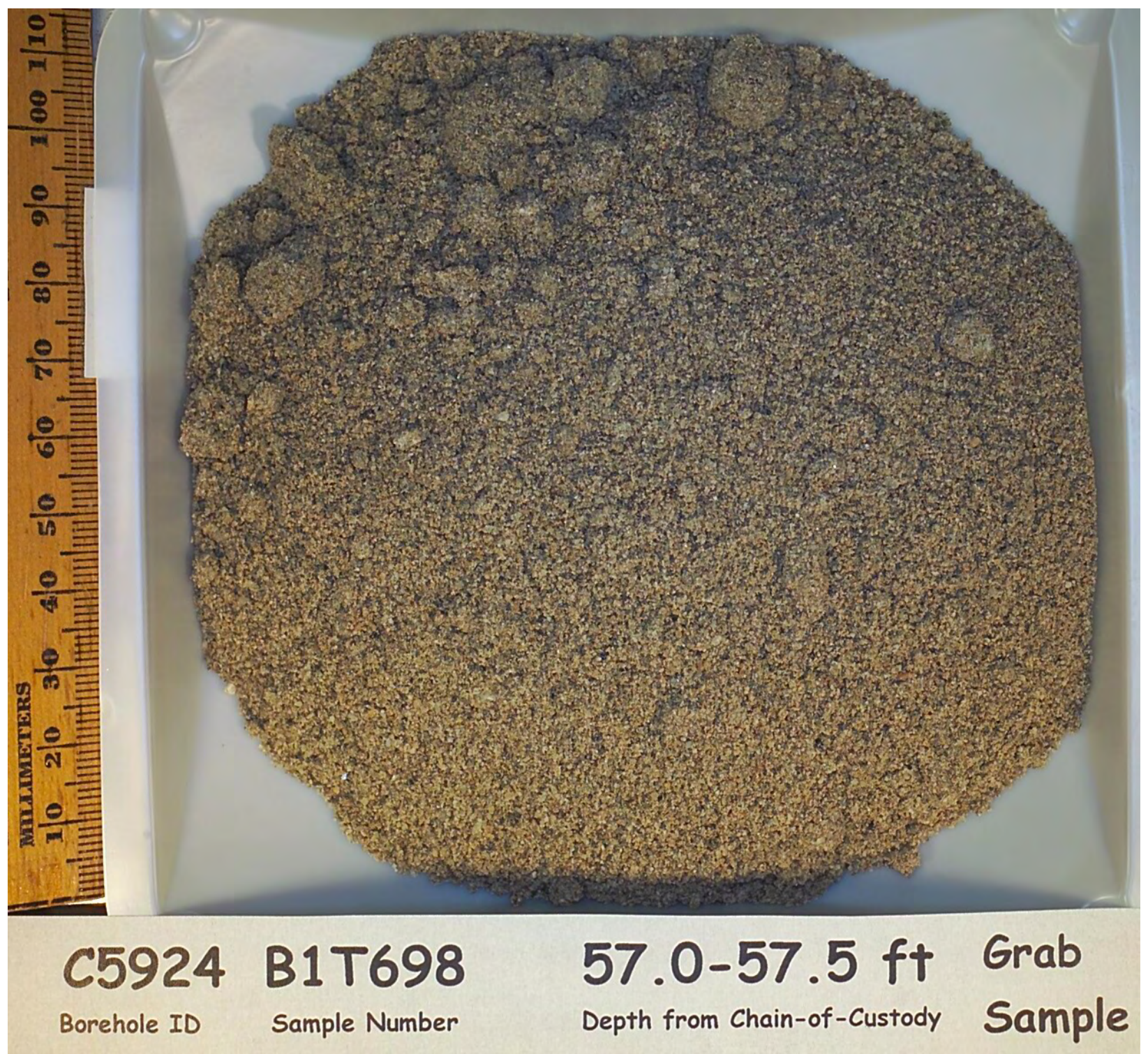


PNNL-17821

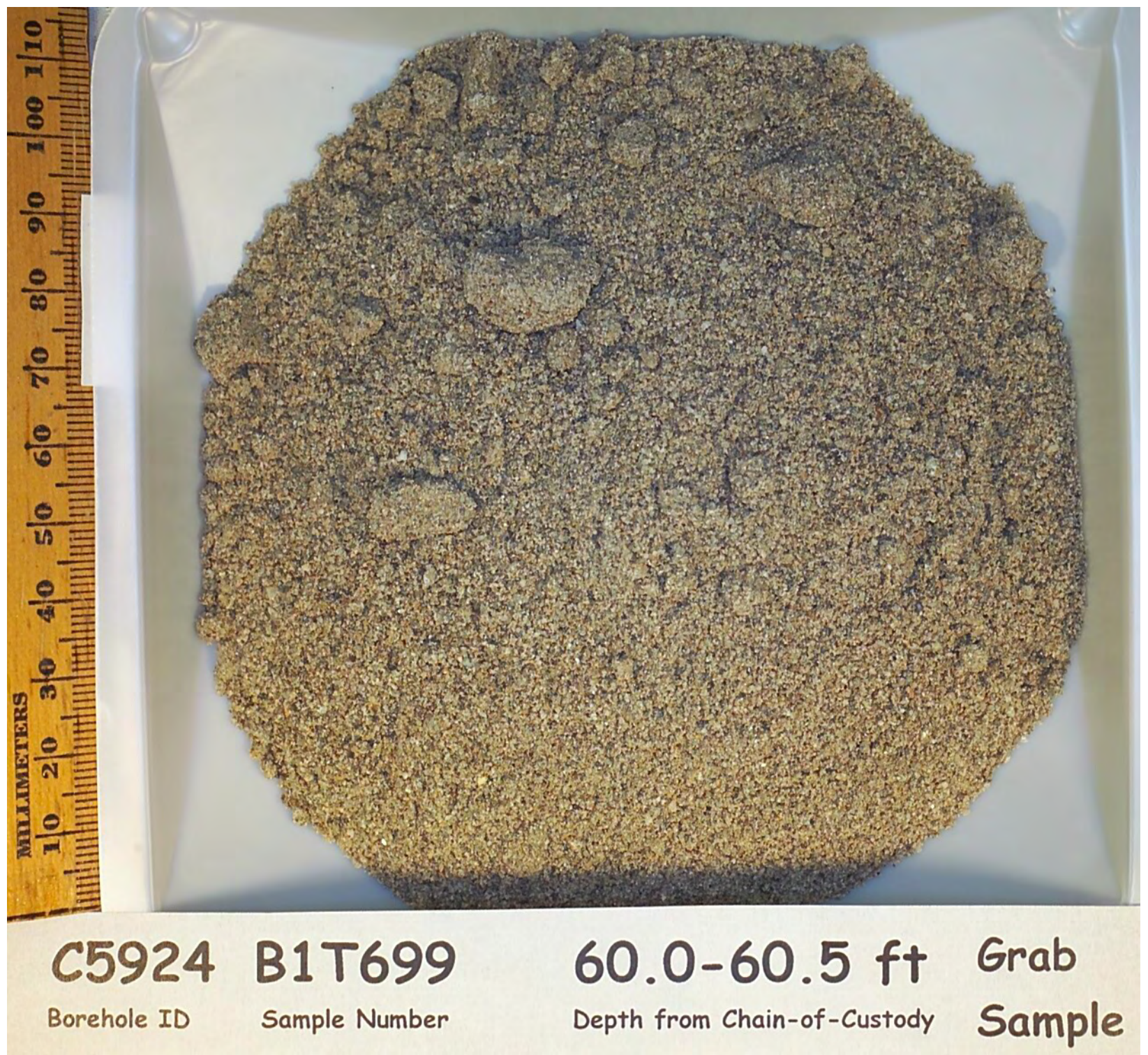




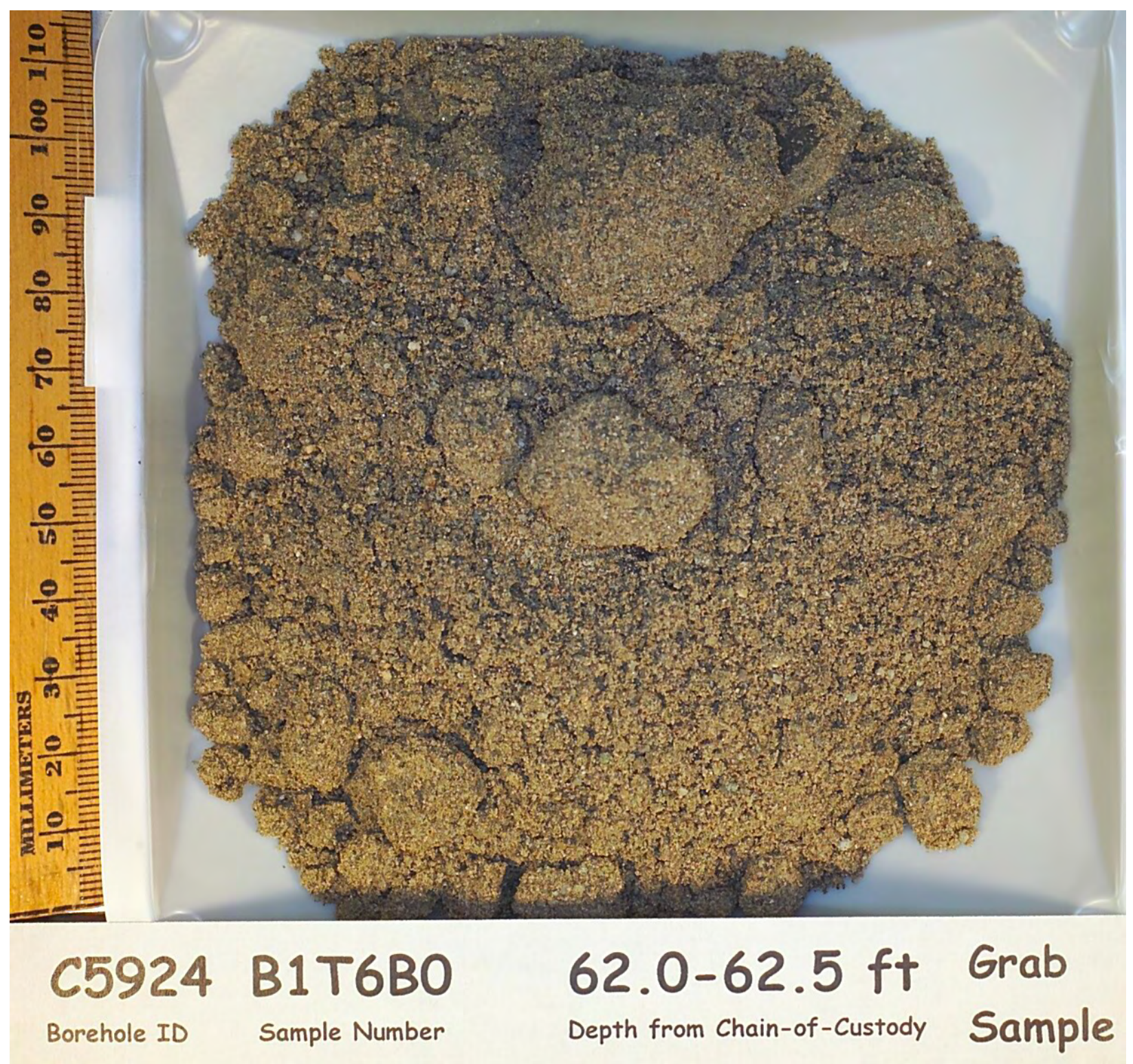




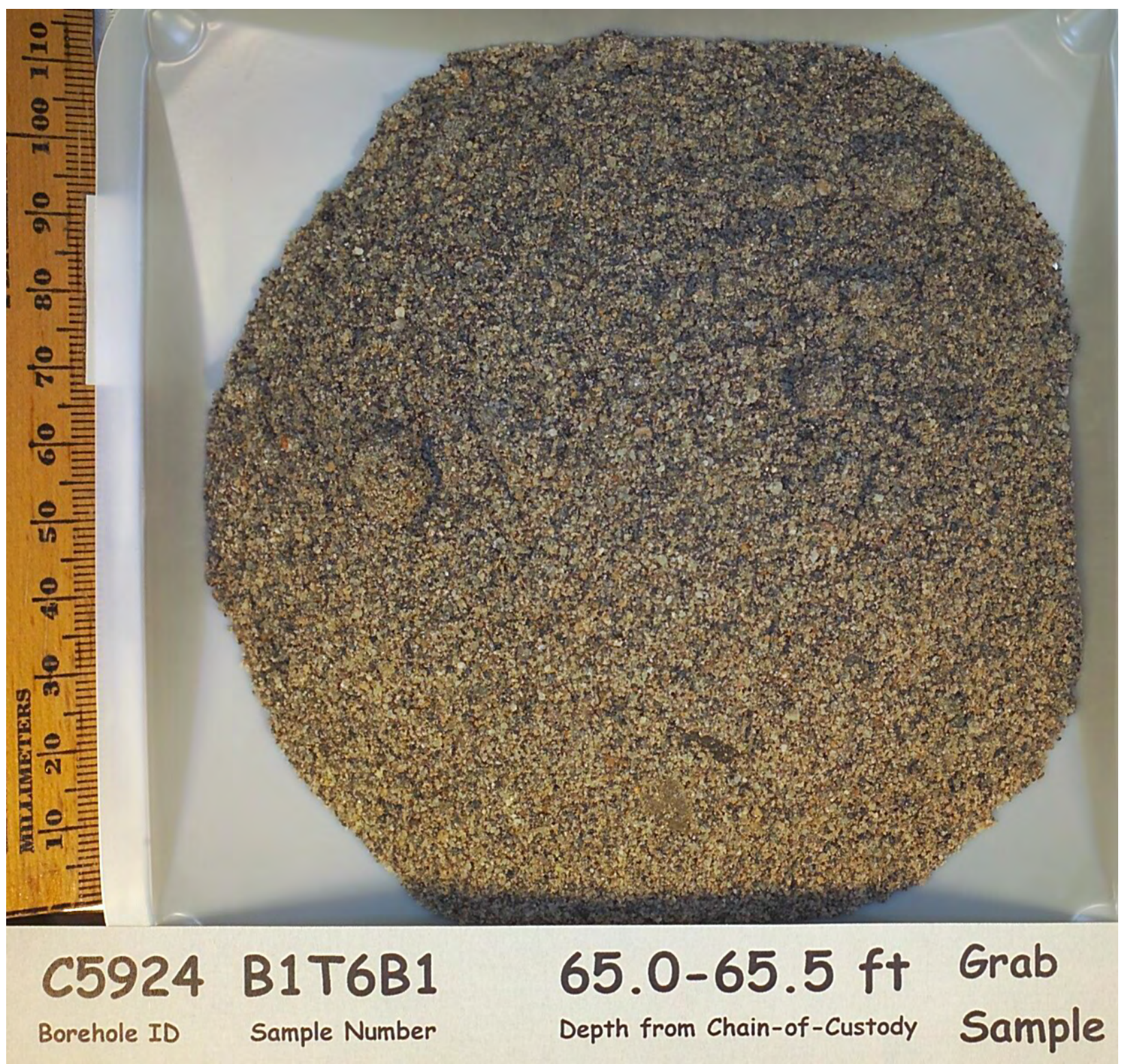




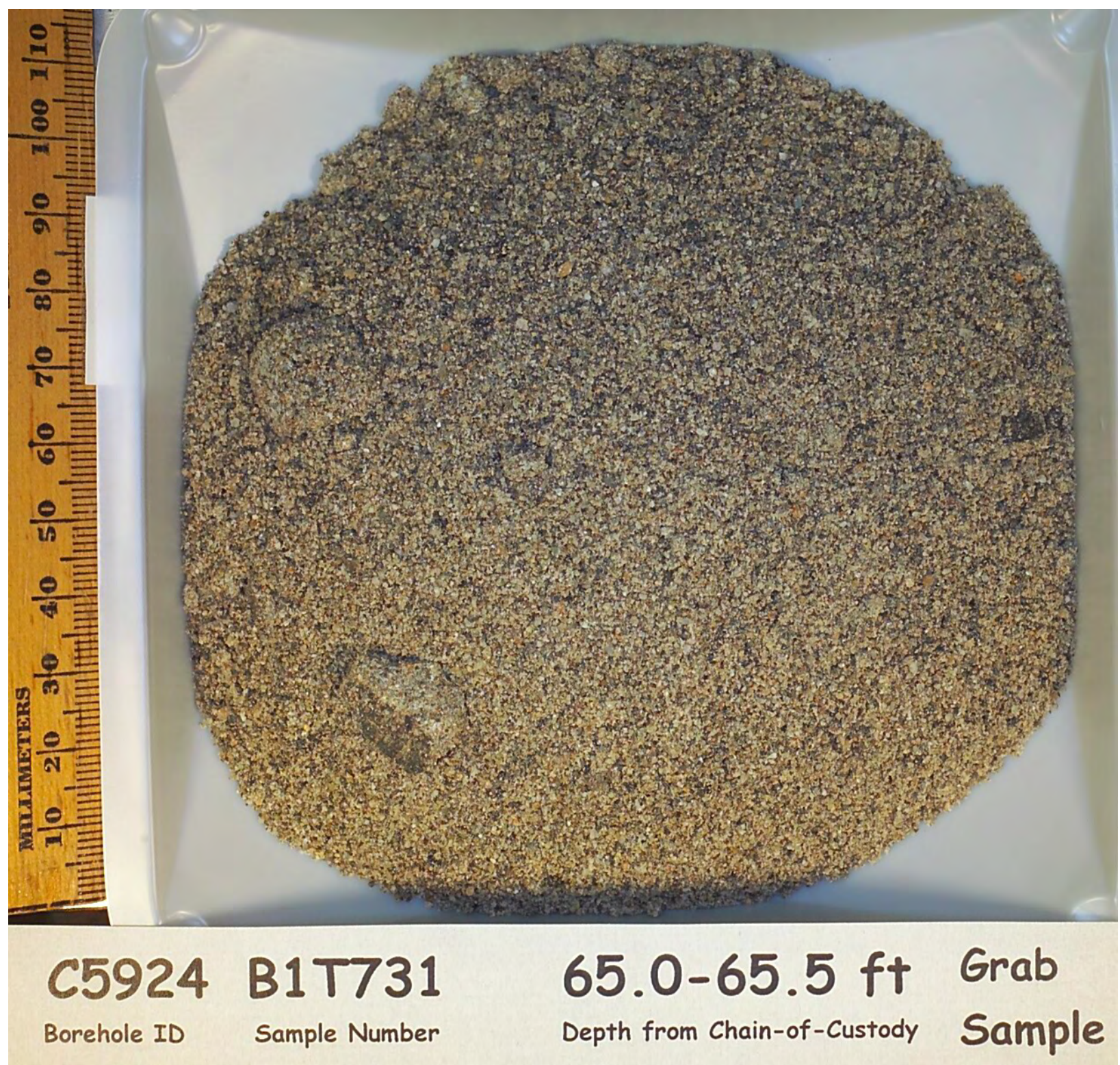




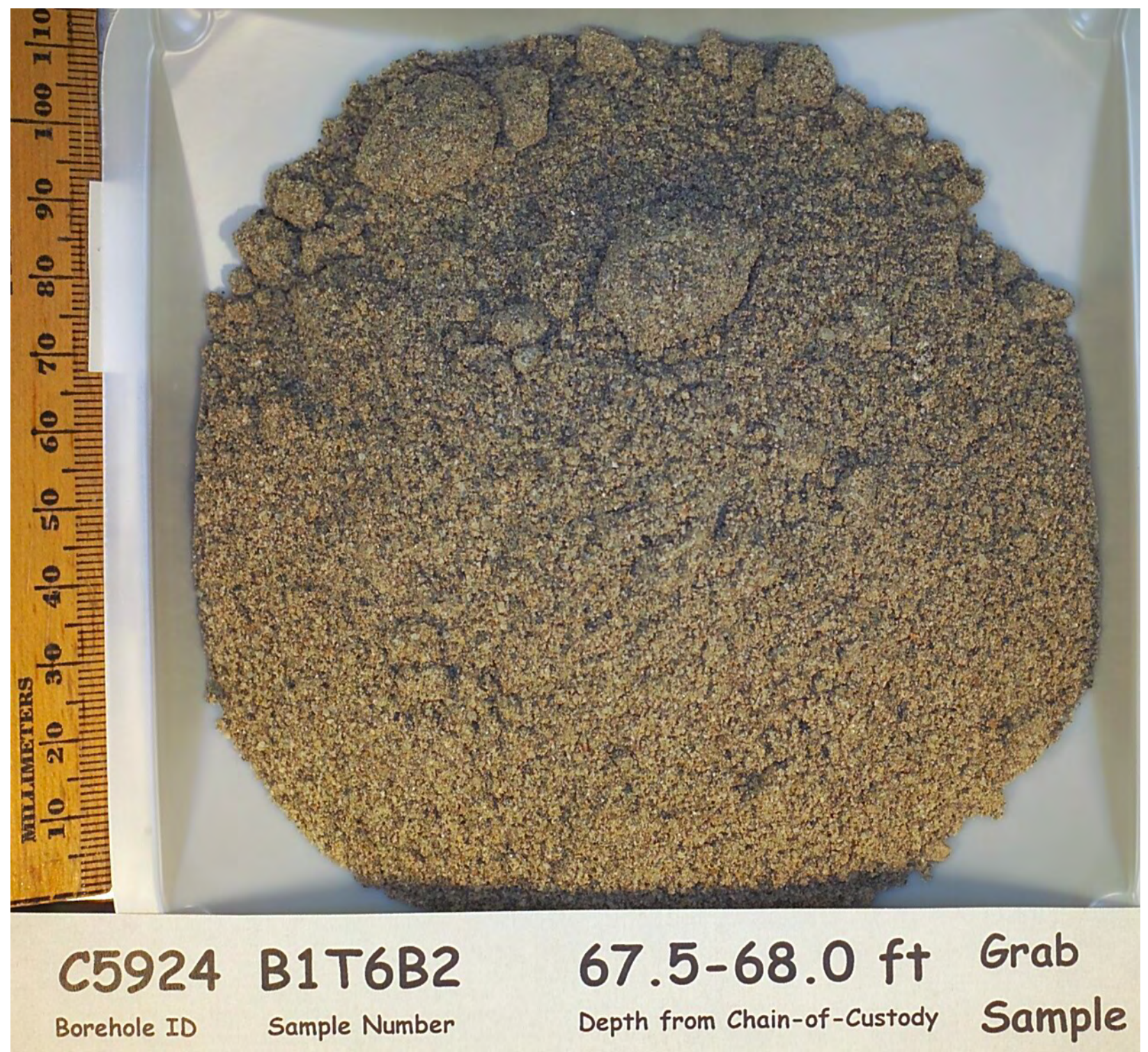


PNNL-17821

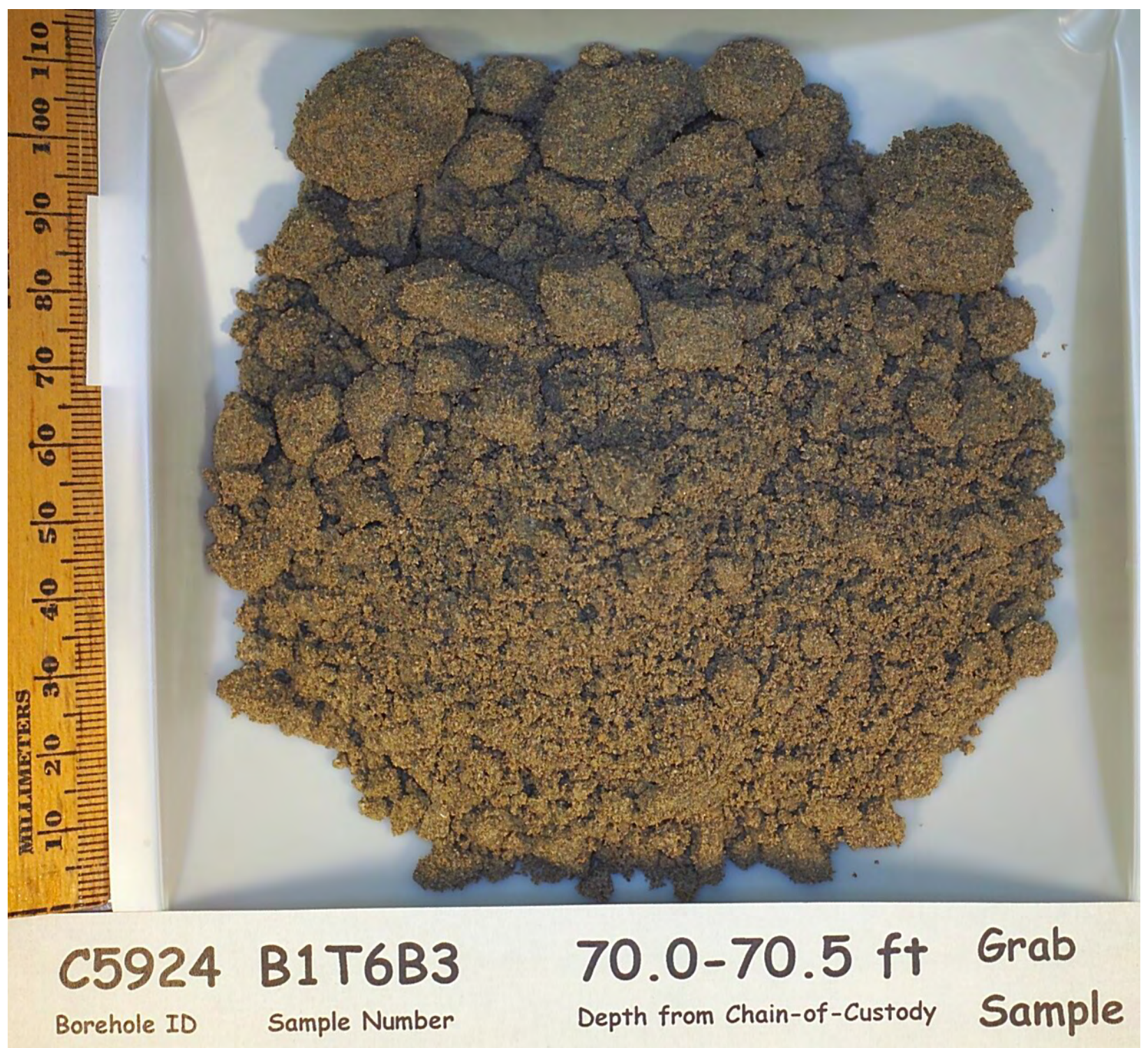




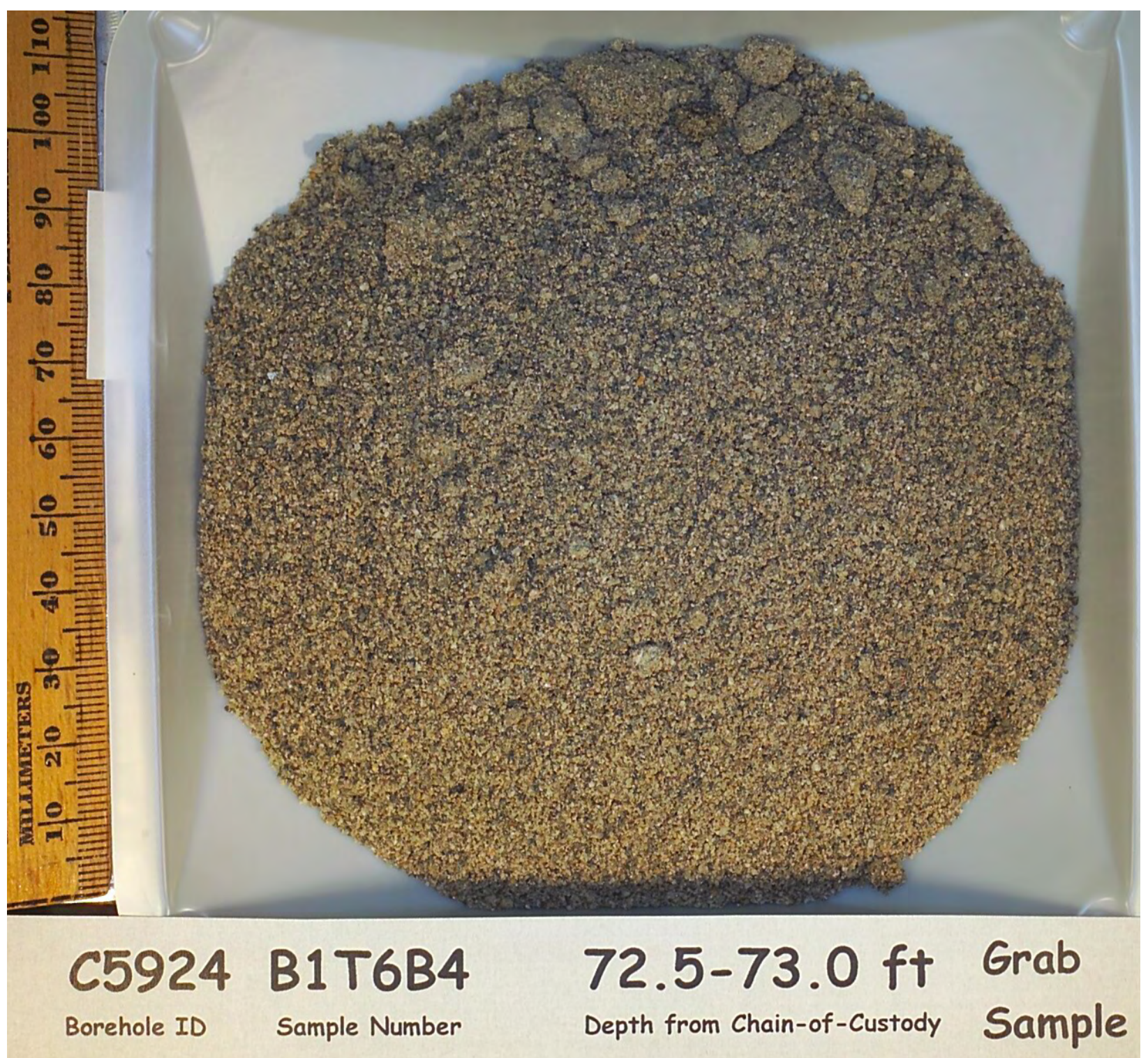




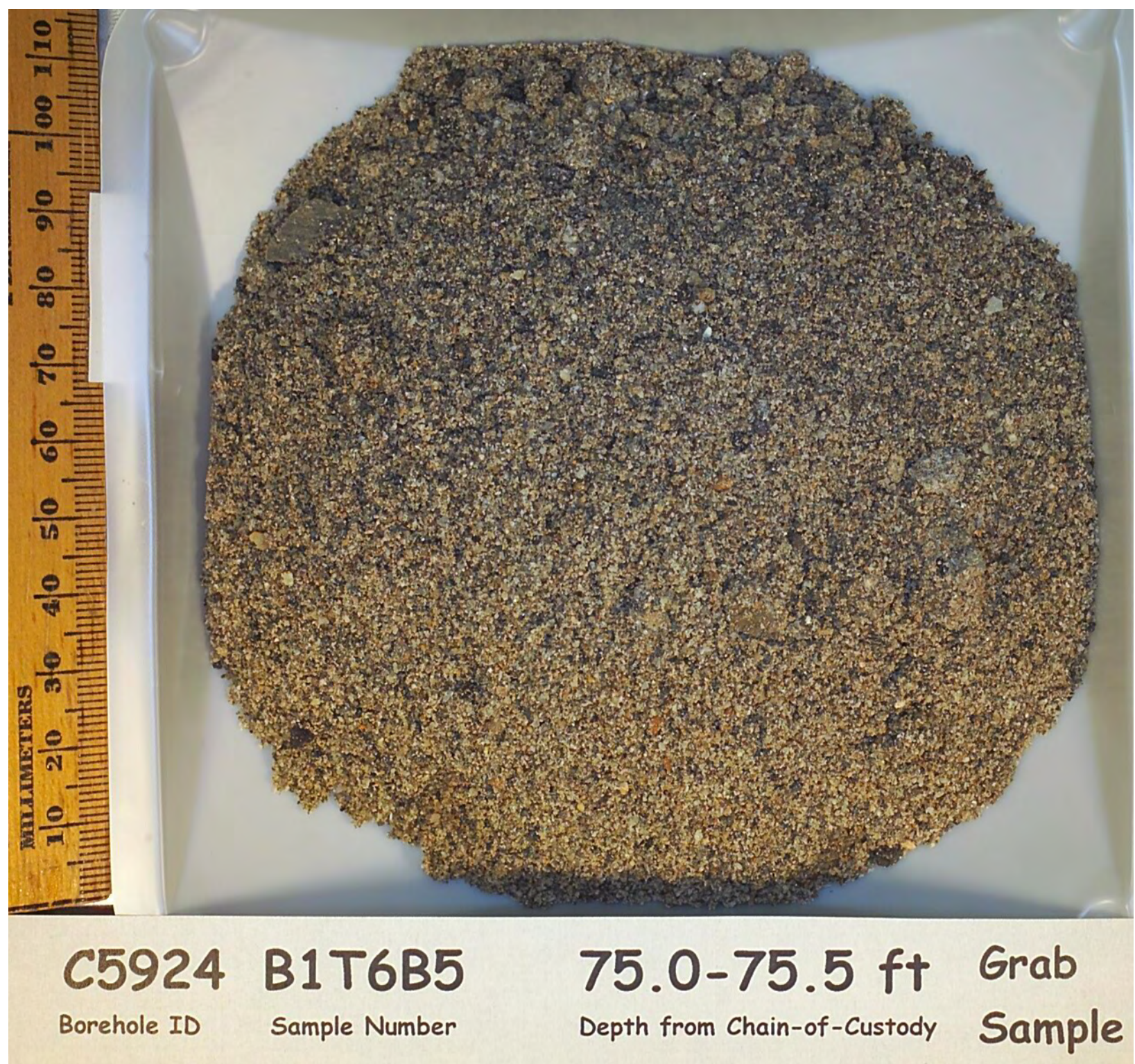




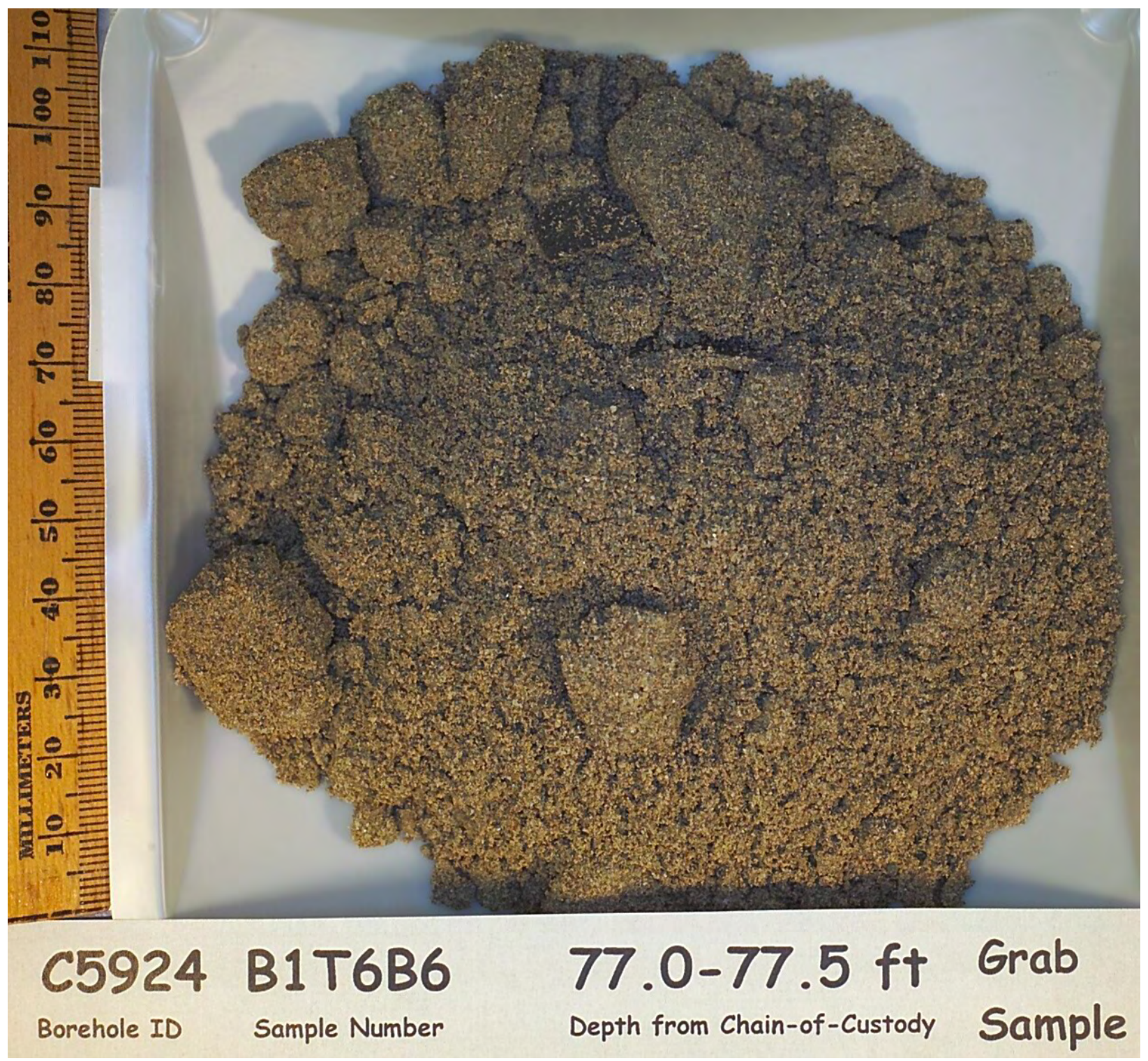




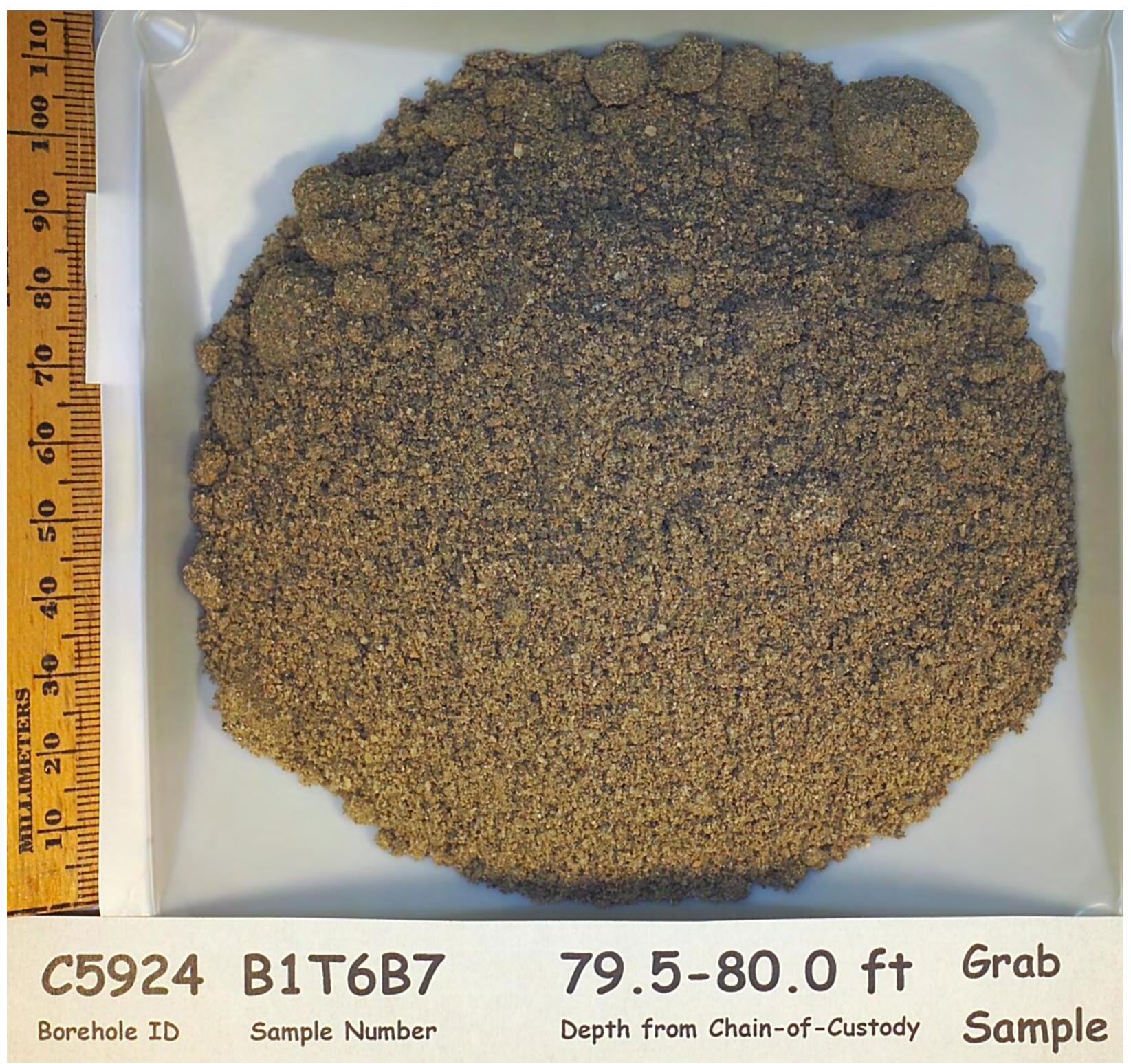




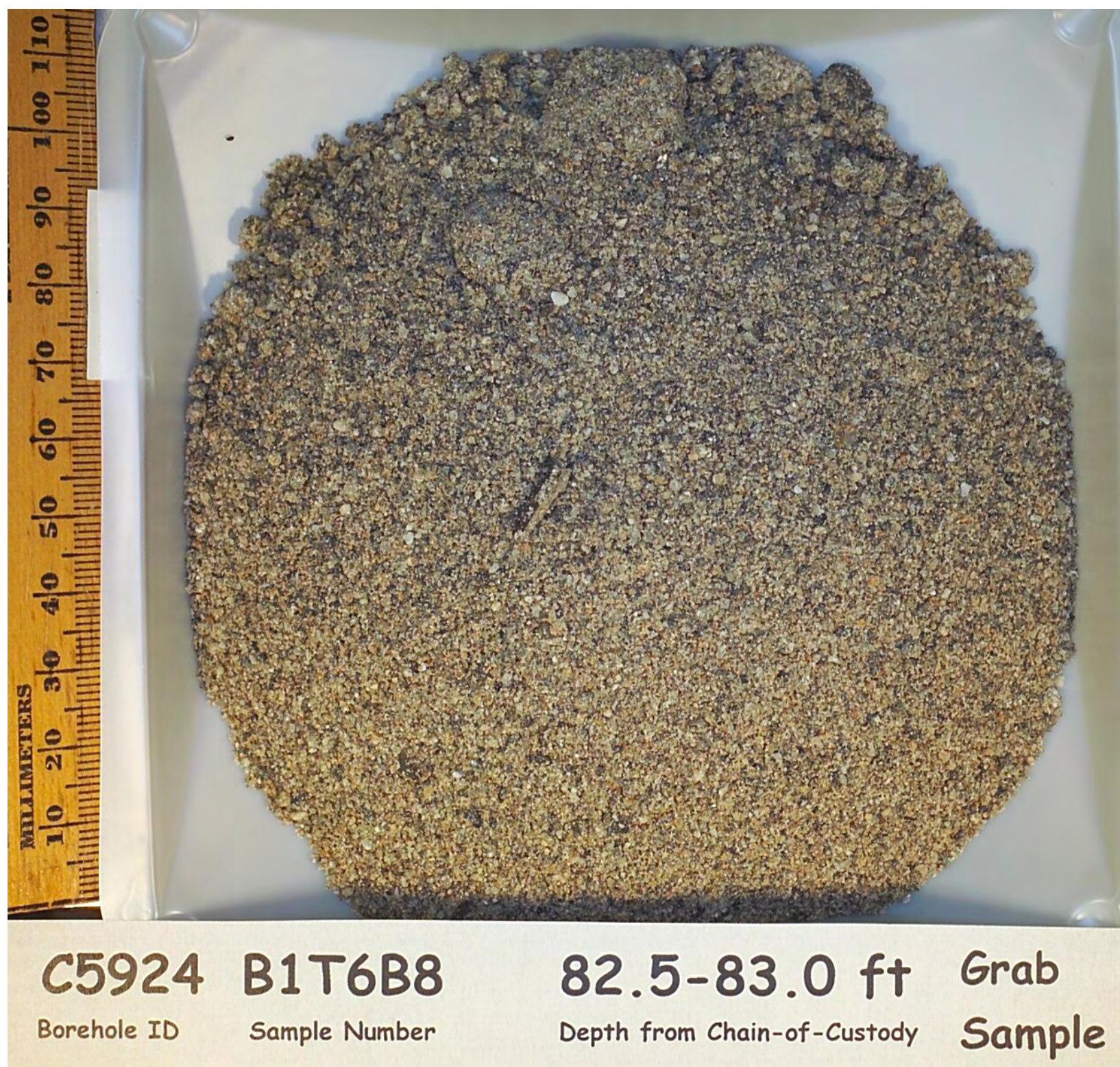


PNNL-17821

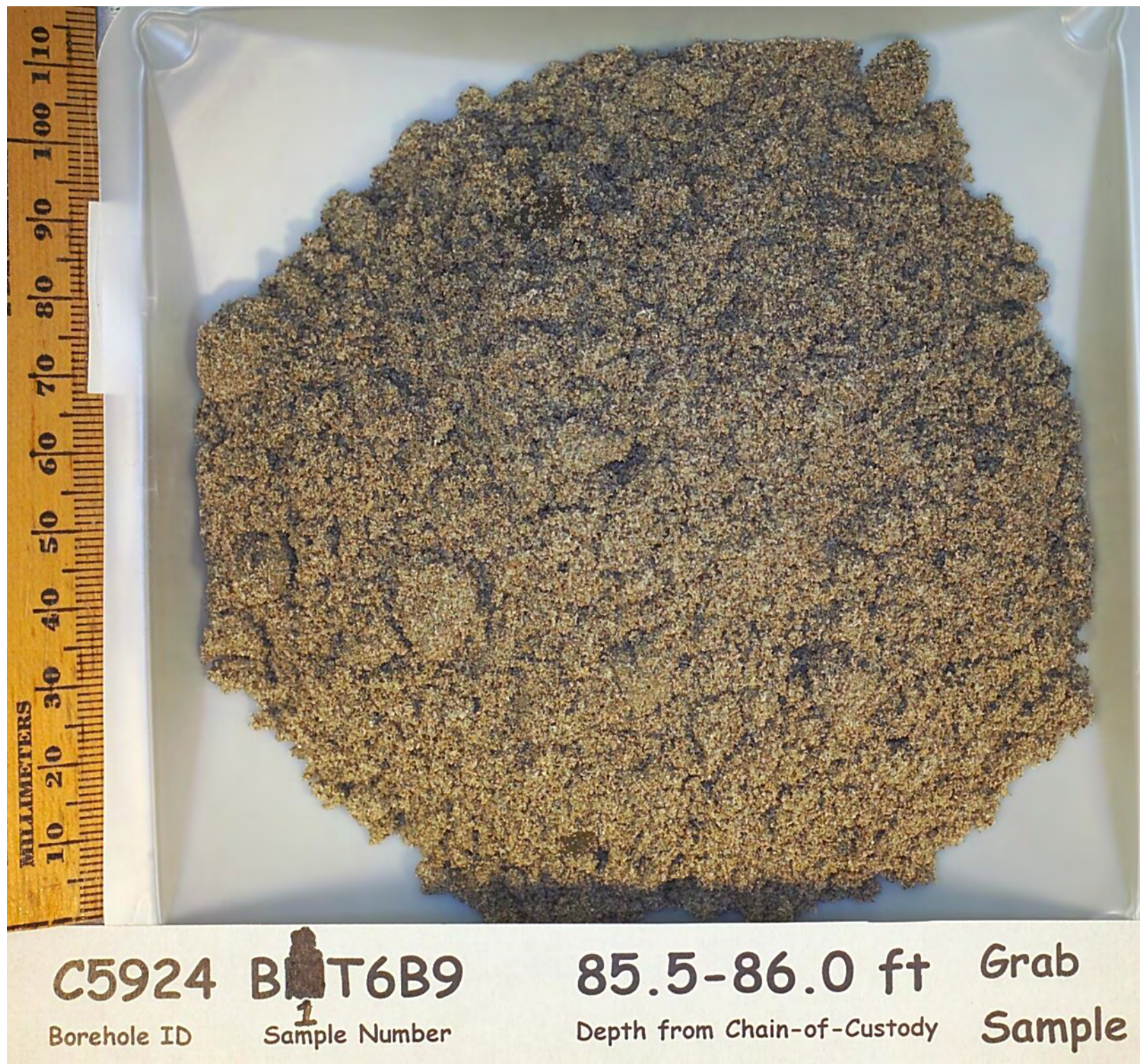




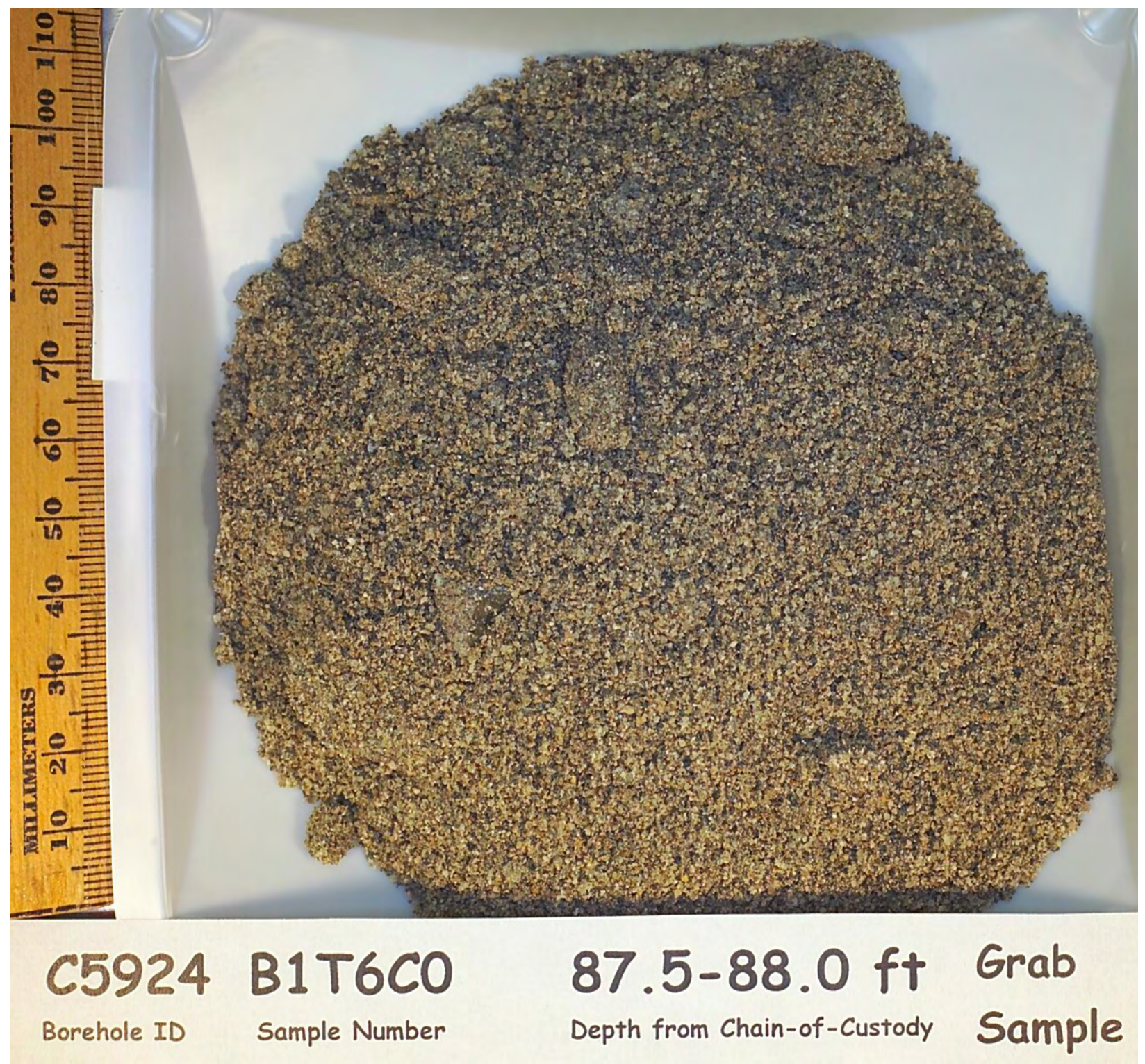




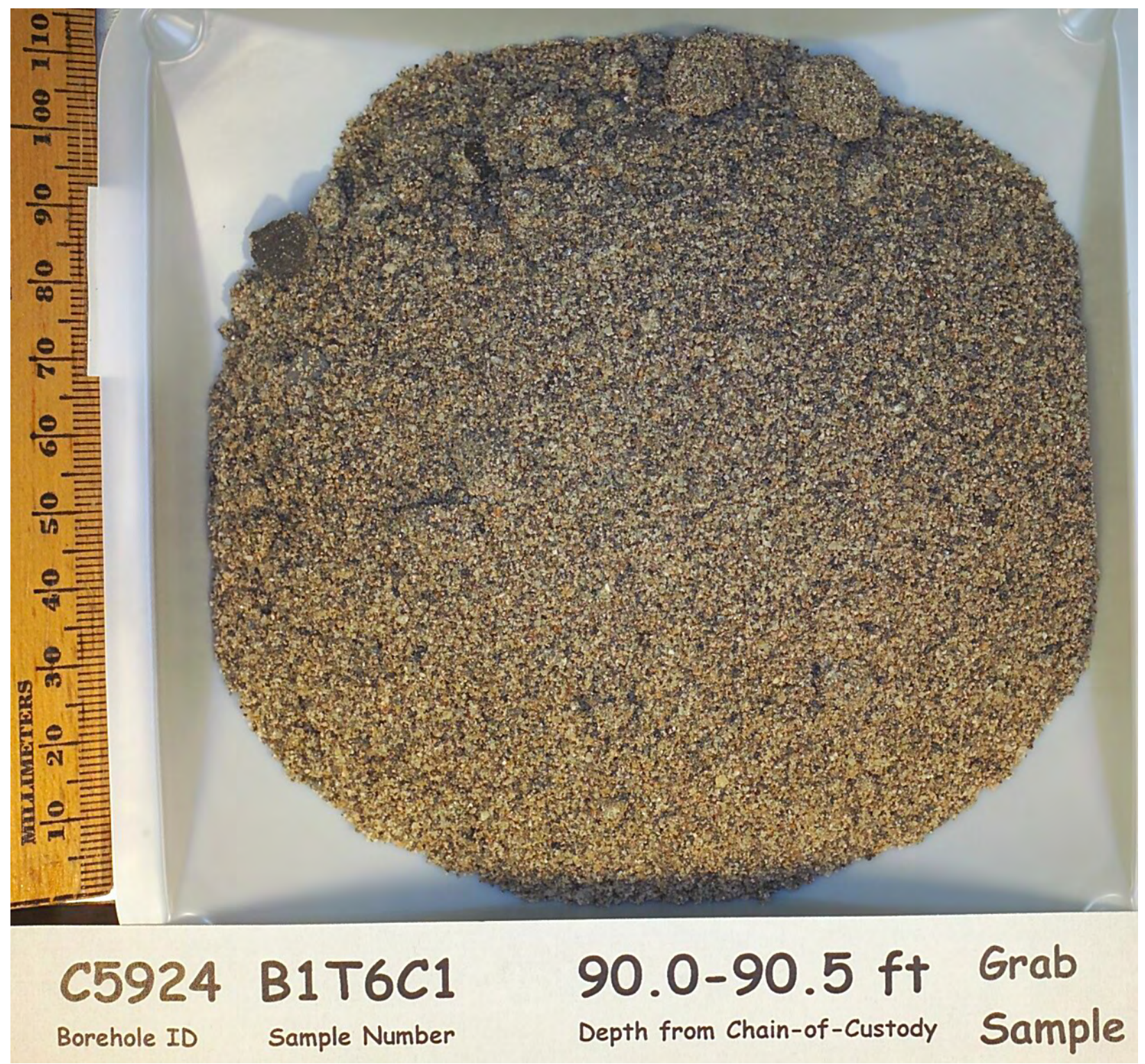




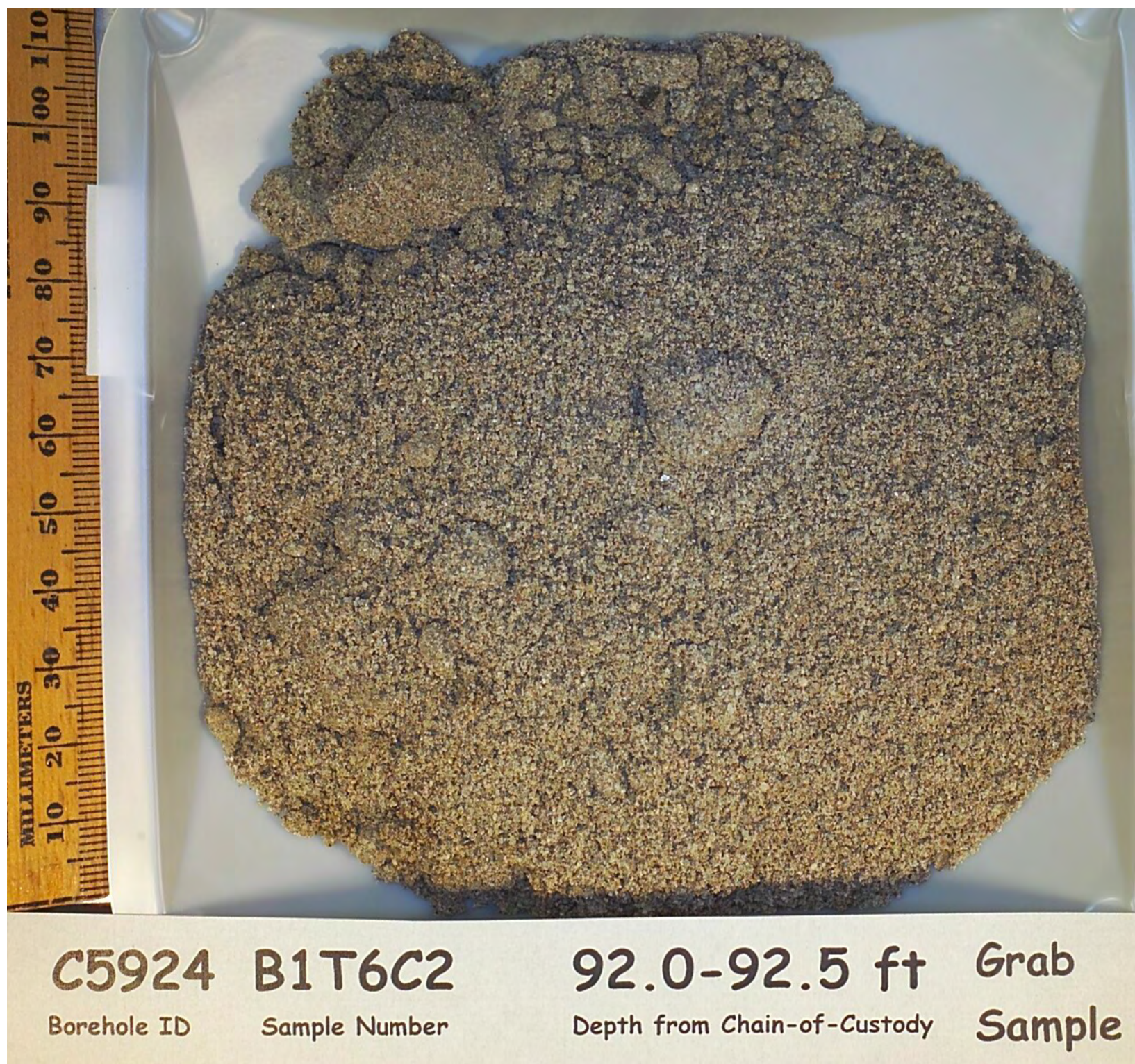


PNNL-17821

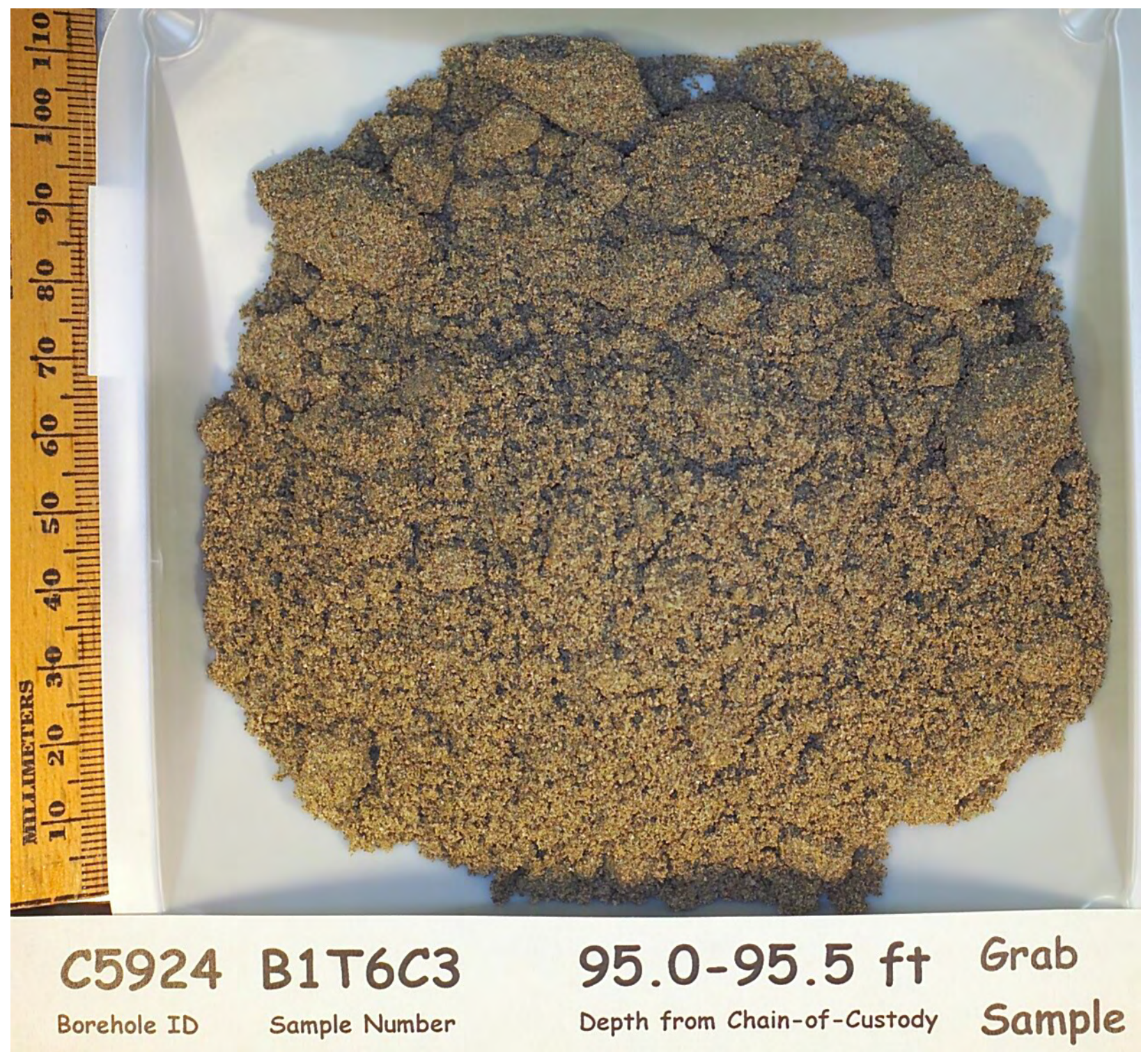




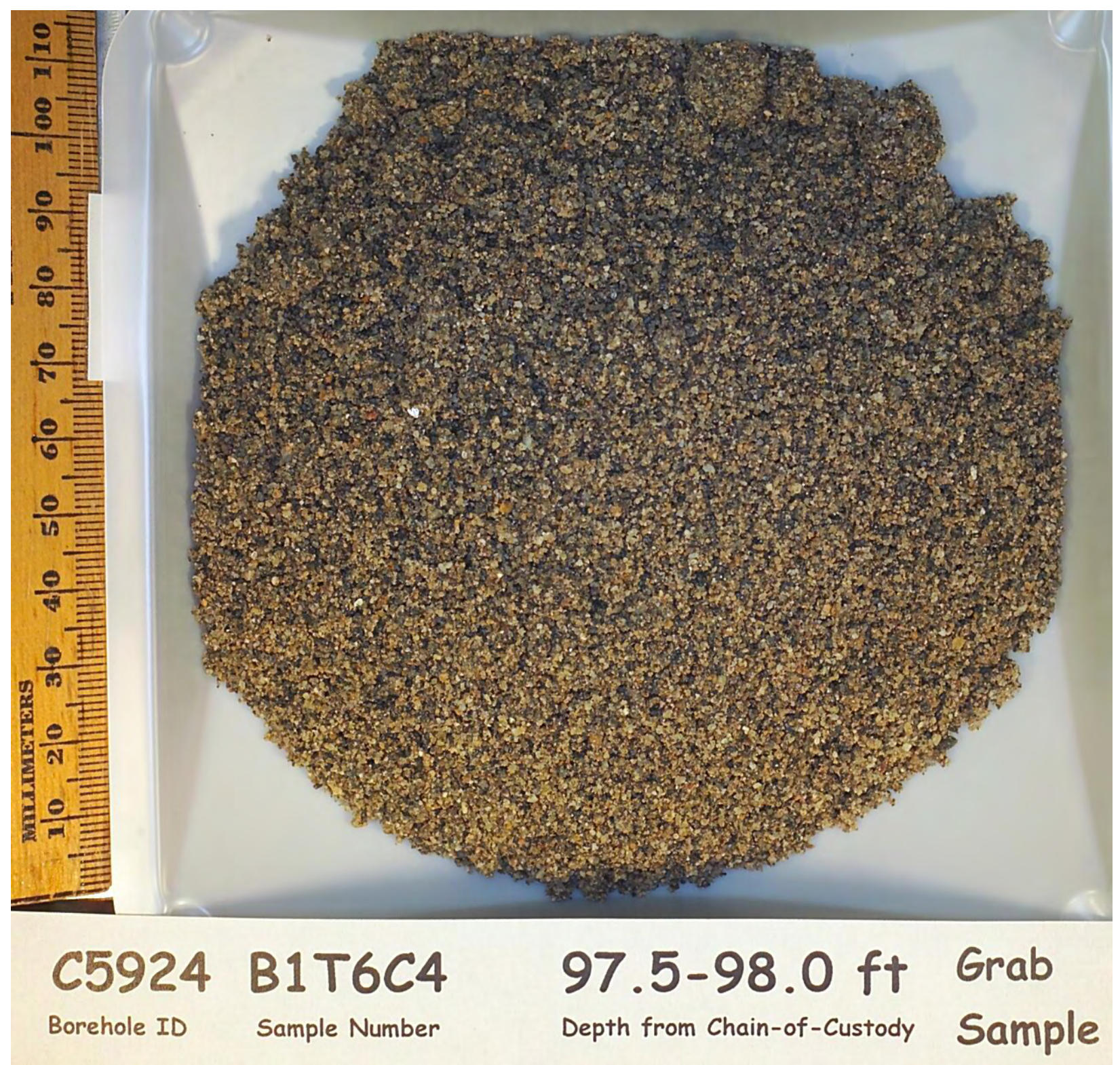




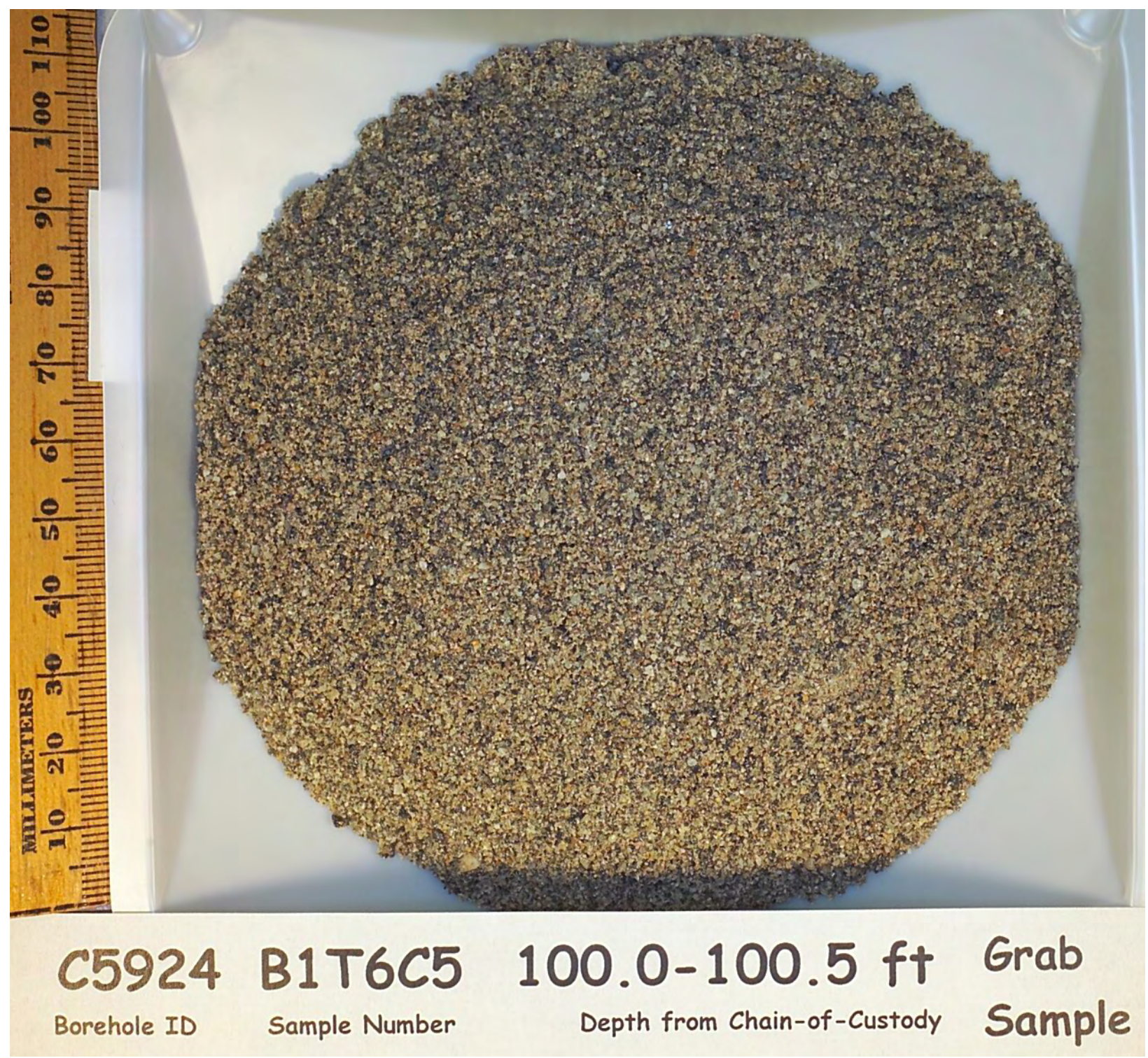




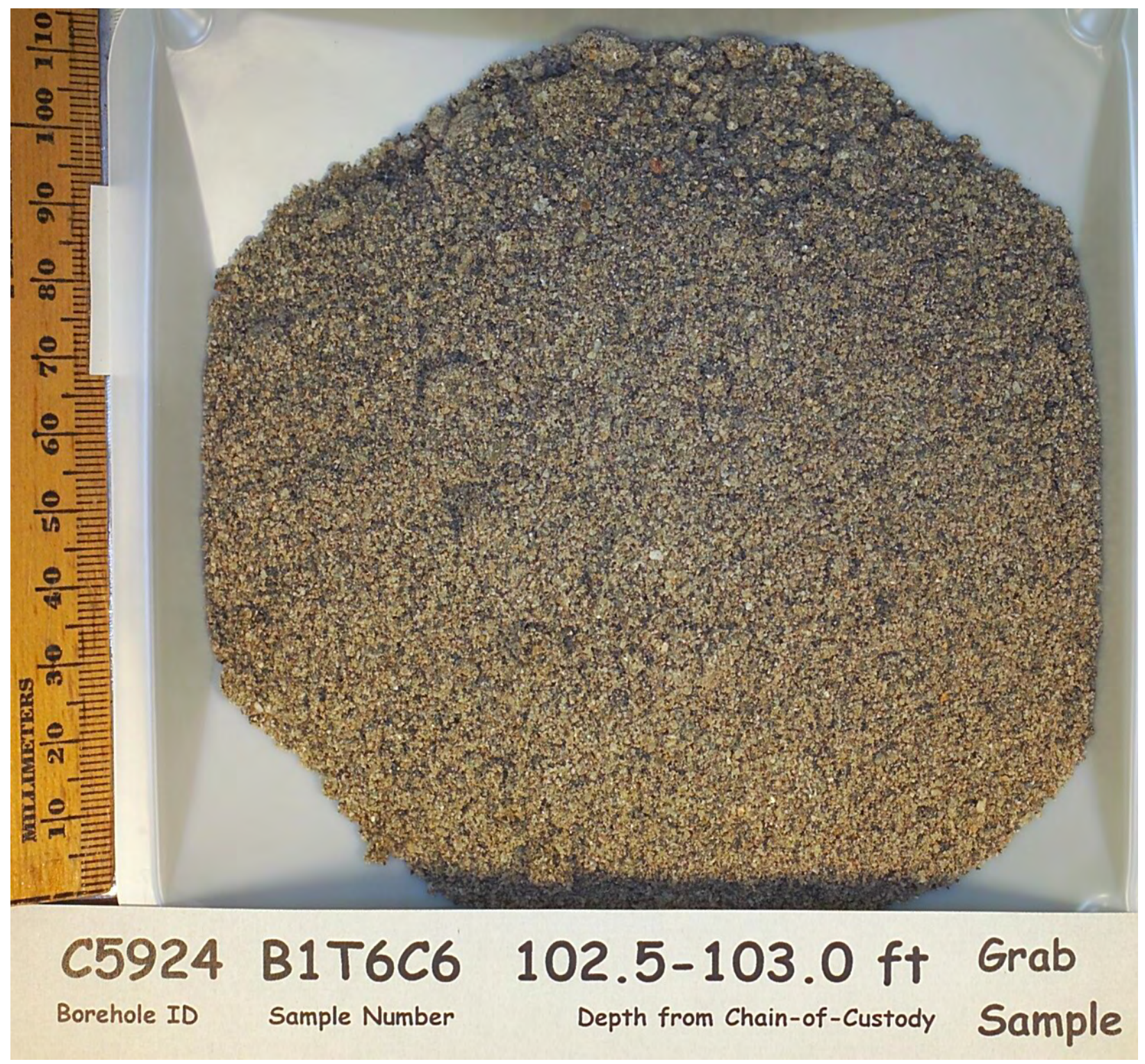




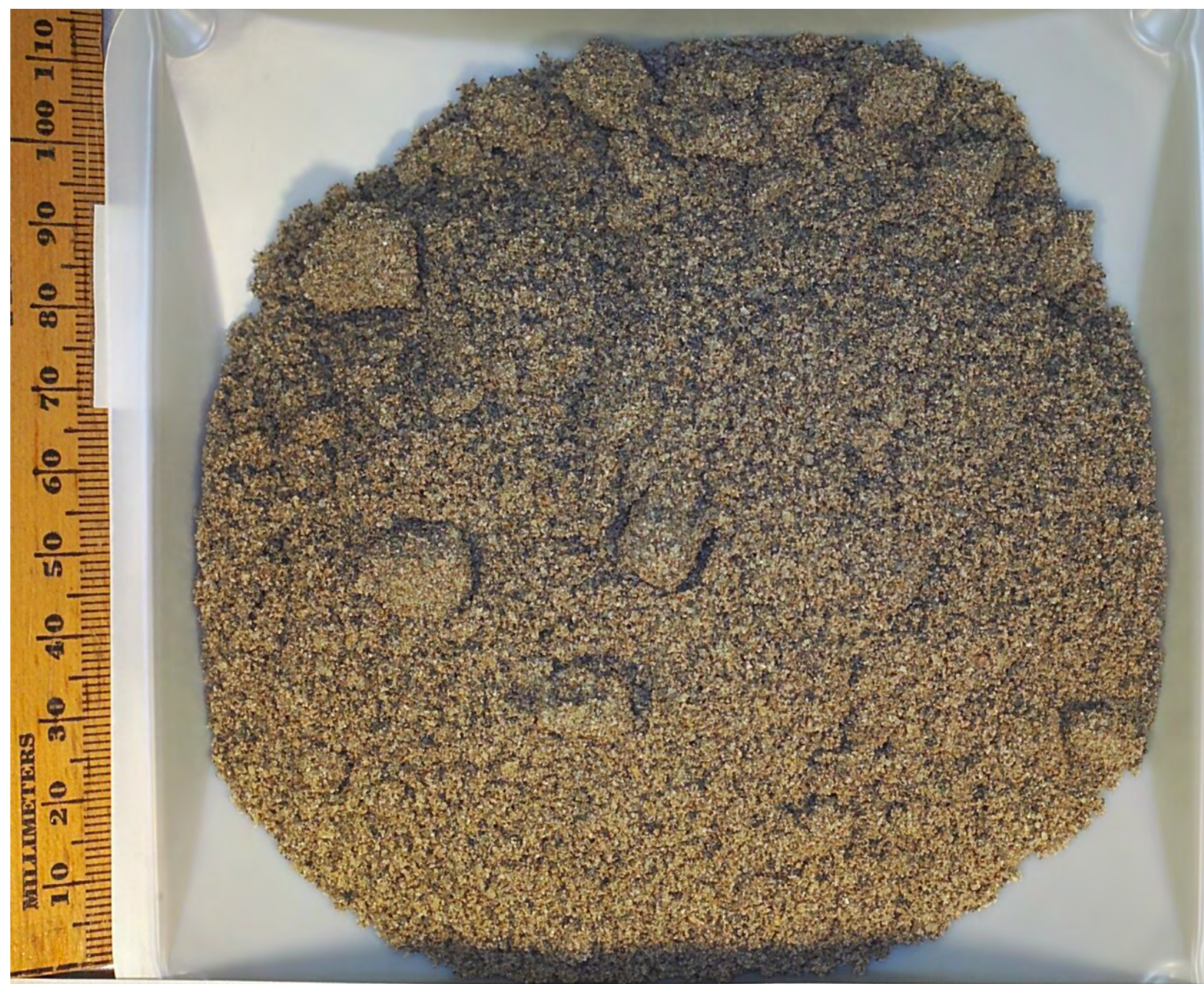

\section{C5924 B1T6C7 105.0-105.5 ft Grab \\ Borehole ID Sample Number \\ Depth from Chain-of-Custody \\ Sample}




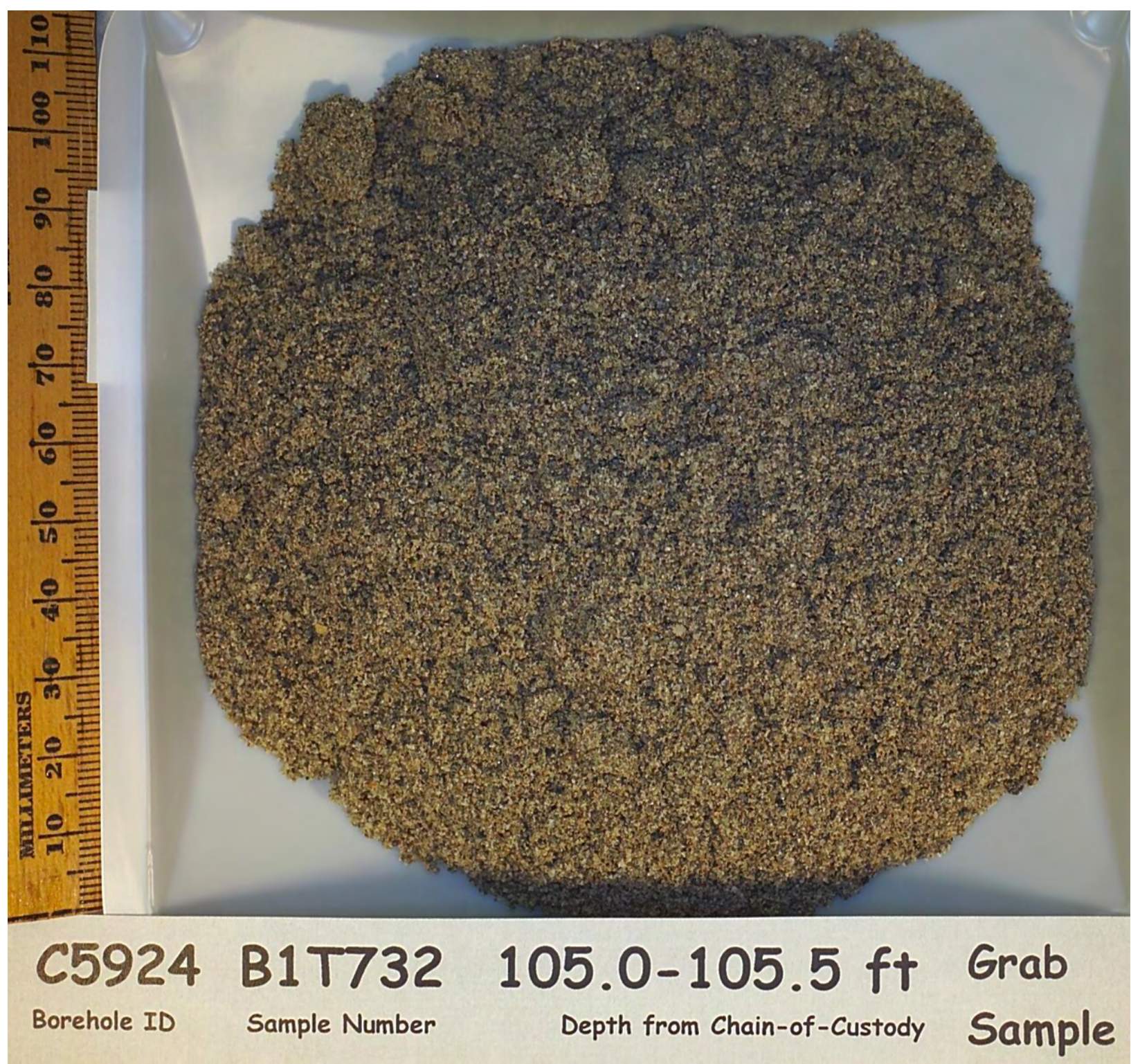




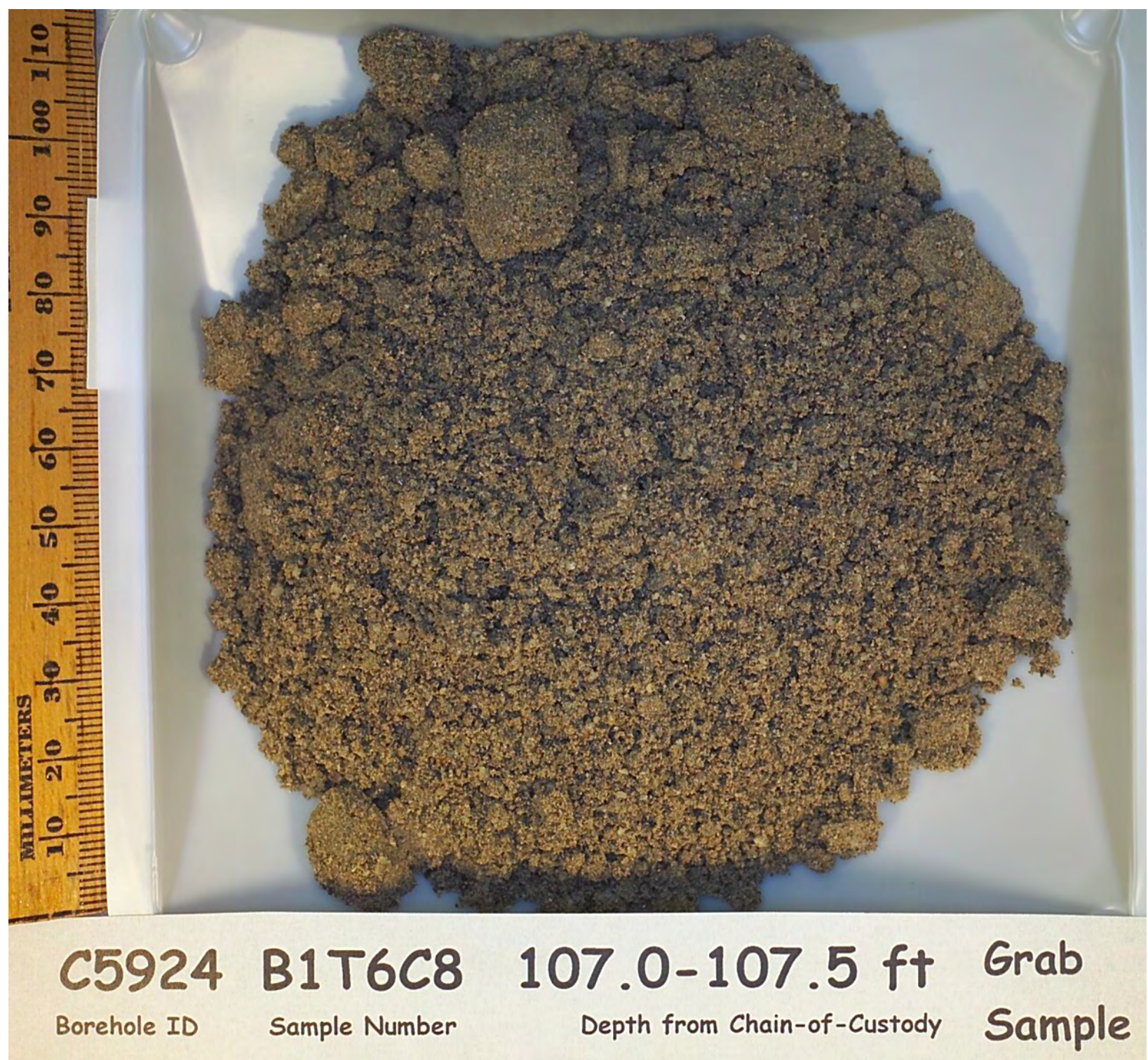




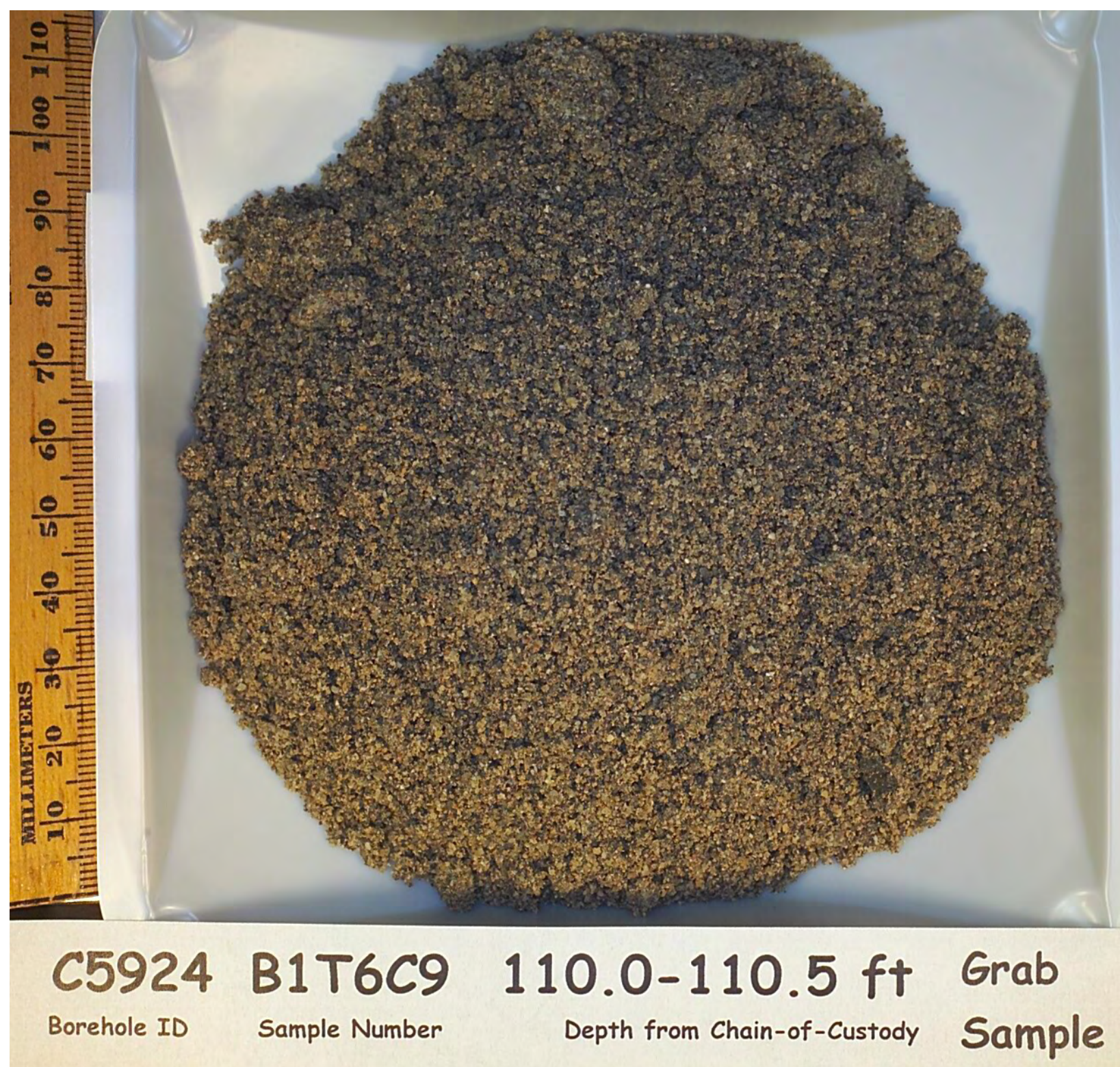




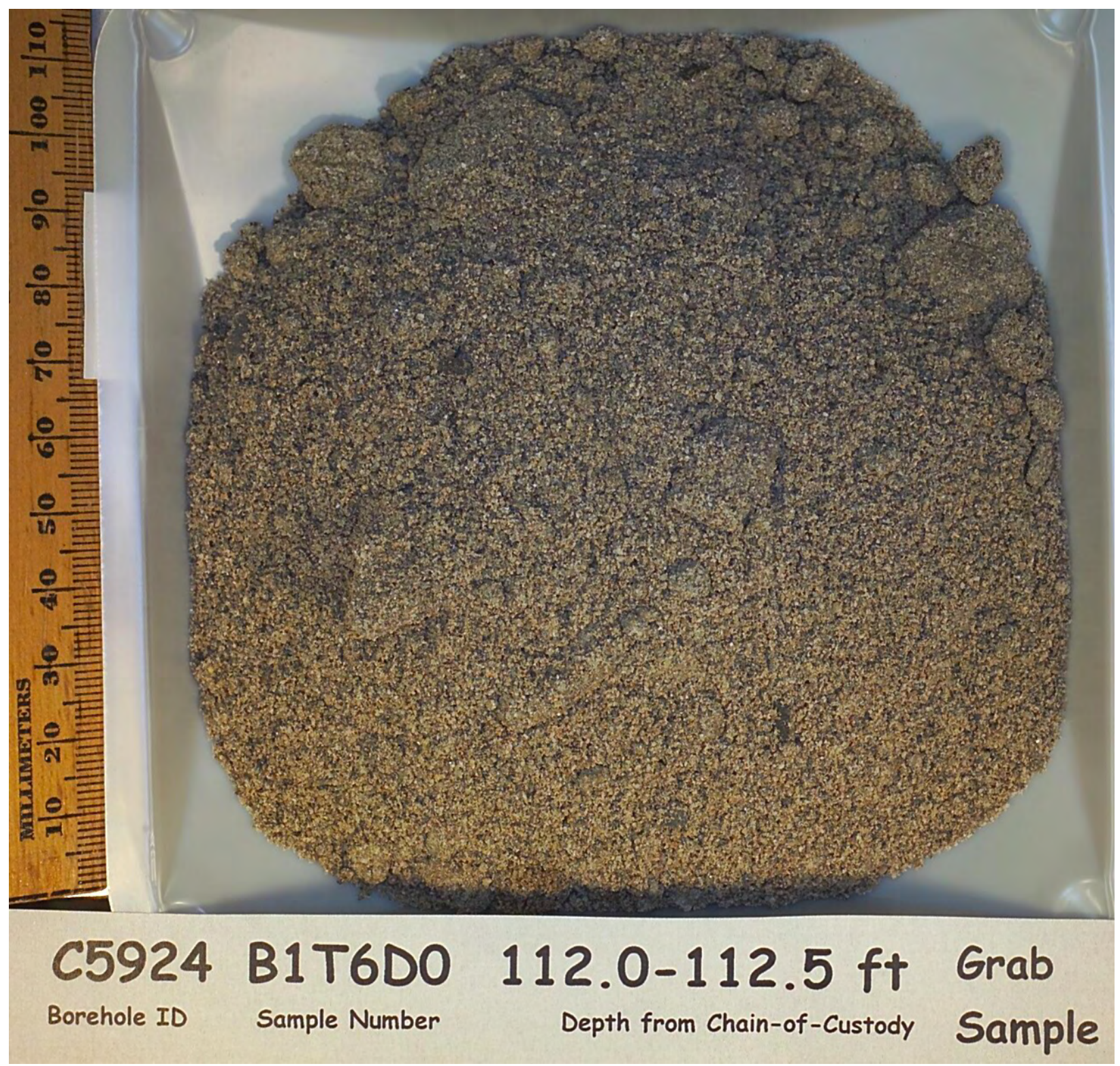




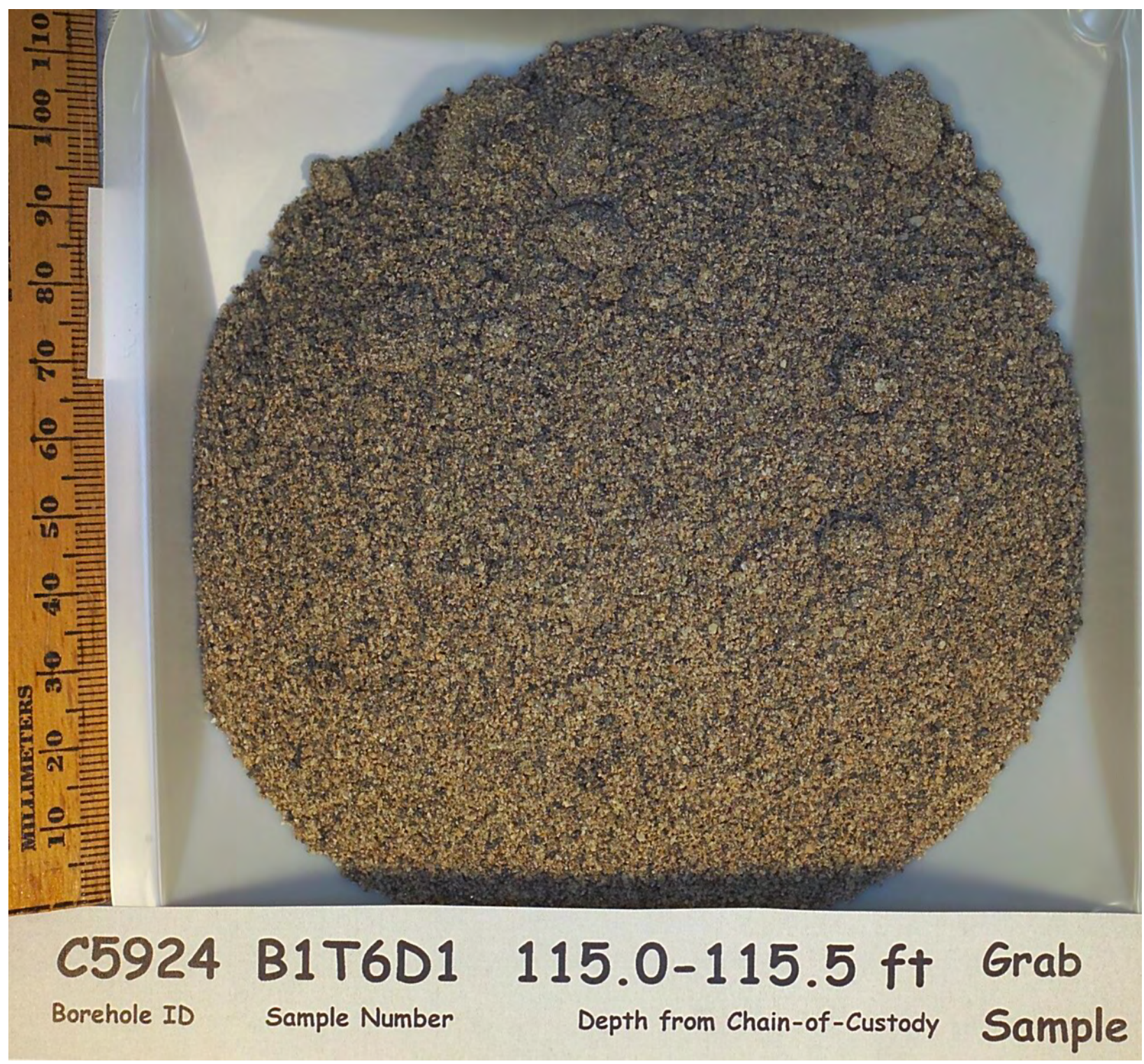




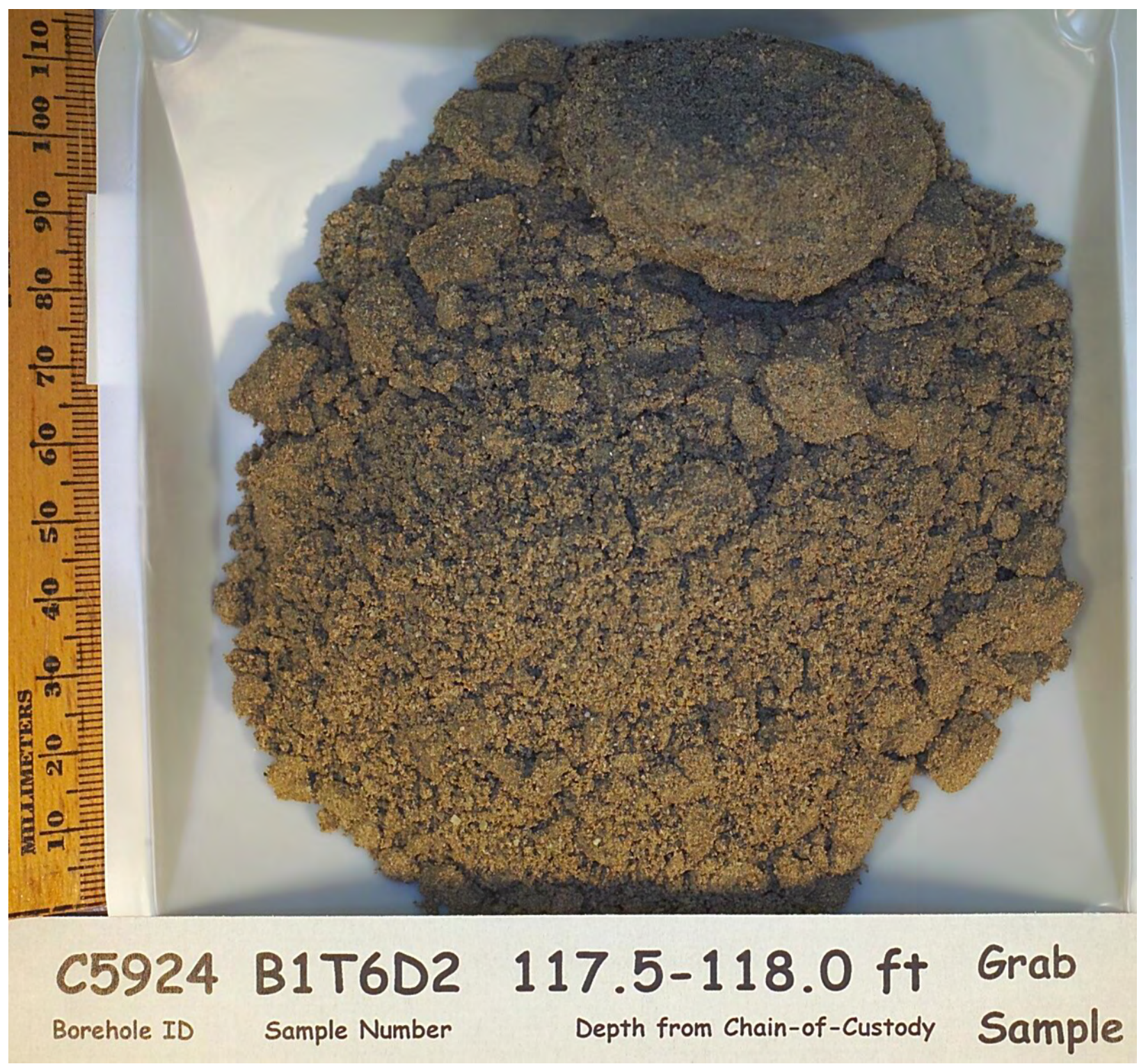


PNNL-17821

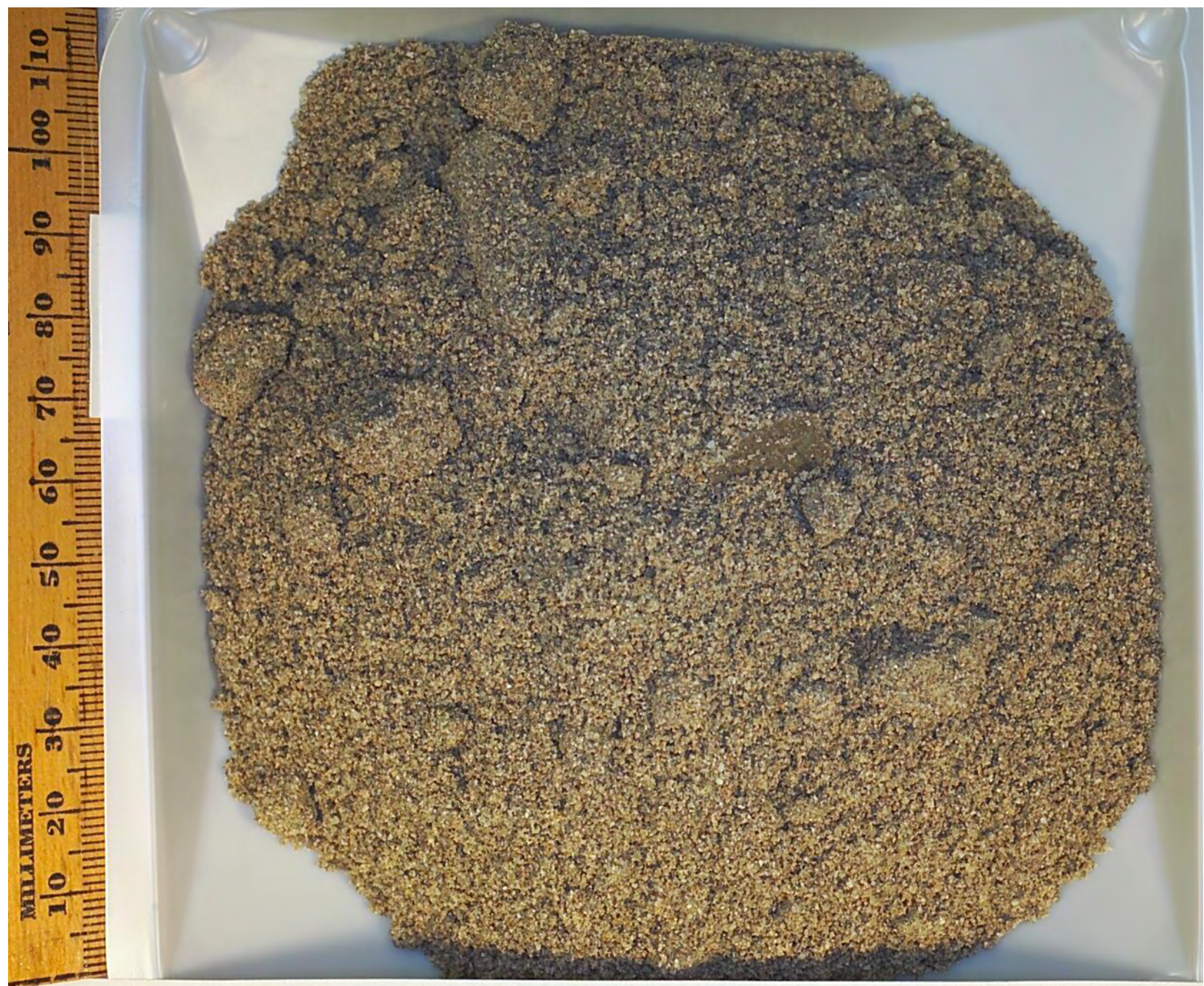

\section{C5924 B1T6D3 120.0-120.5 ft Grab}

Borehole ID Sample Number

Depth from Chain-of-Custody

Sample 


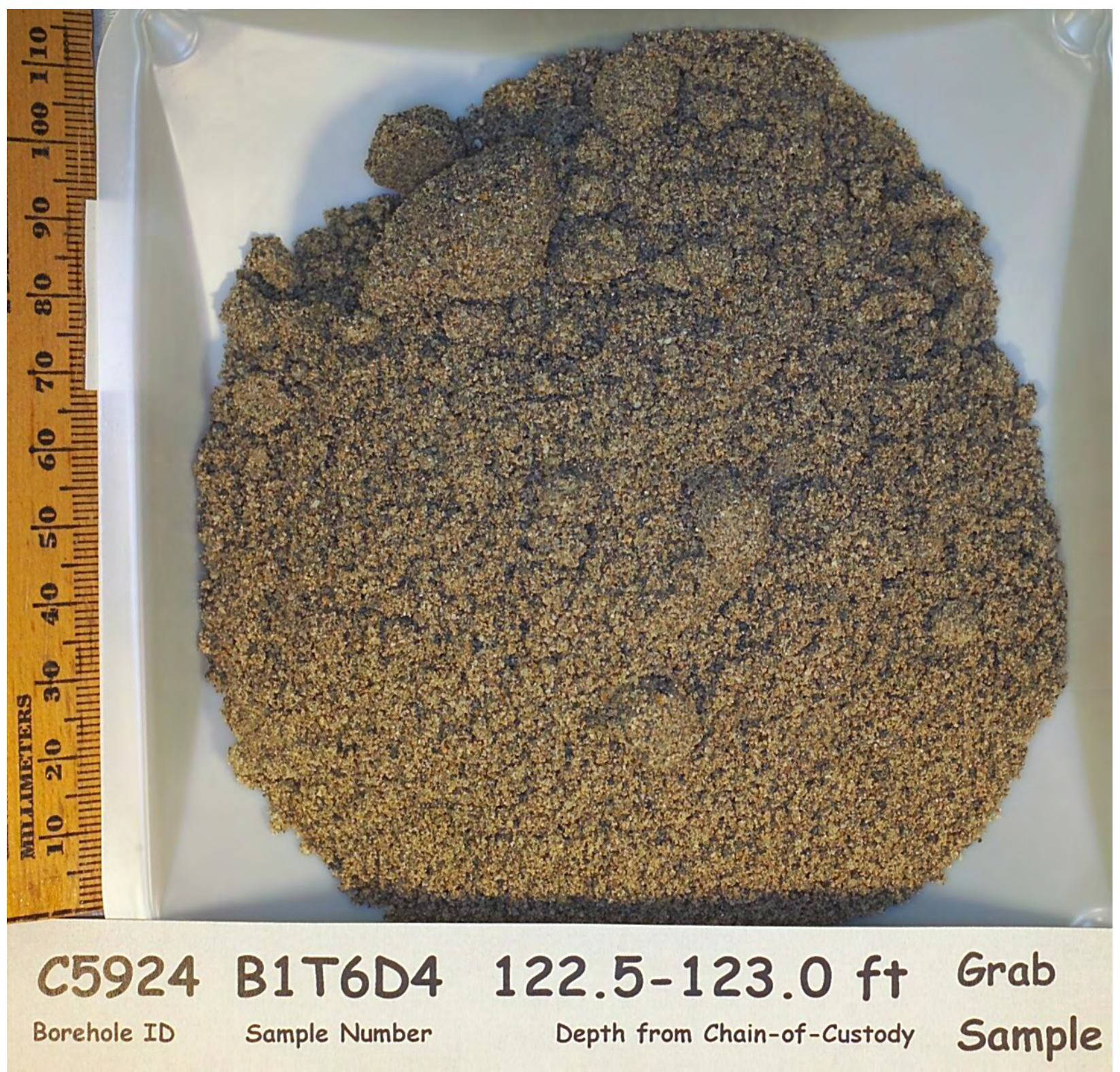




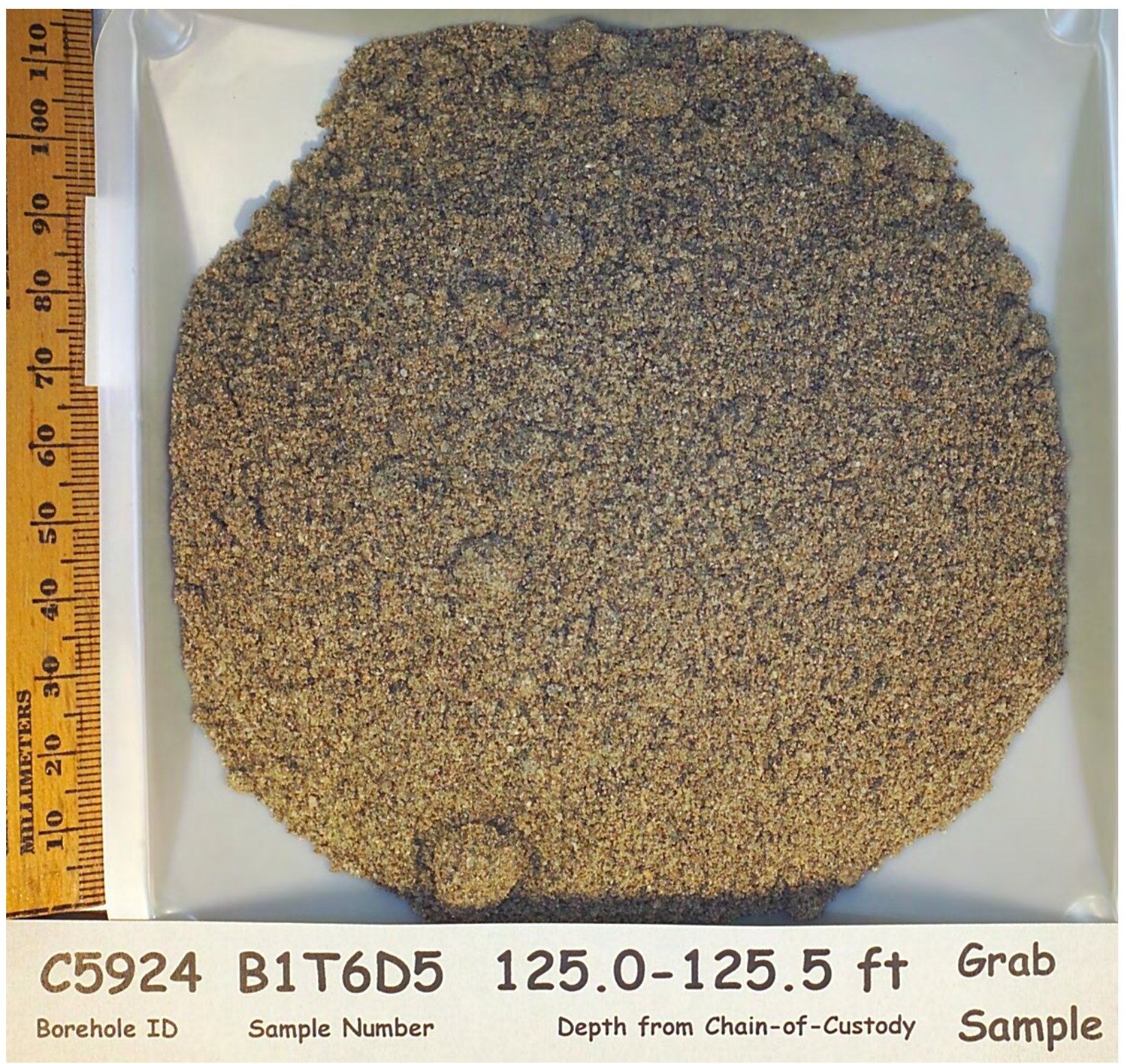




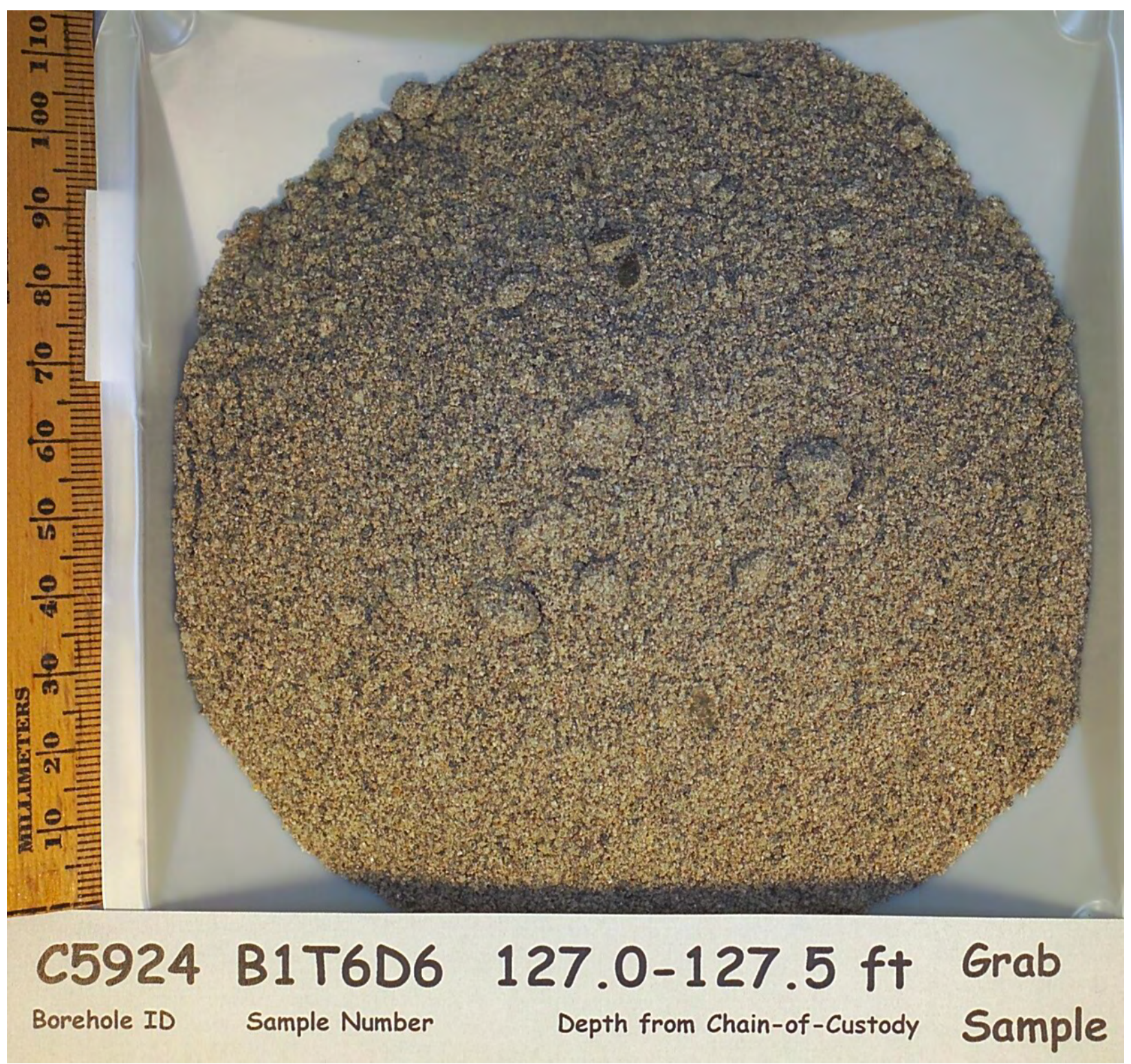




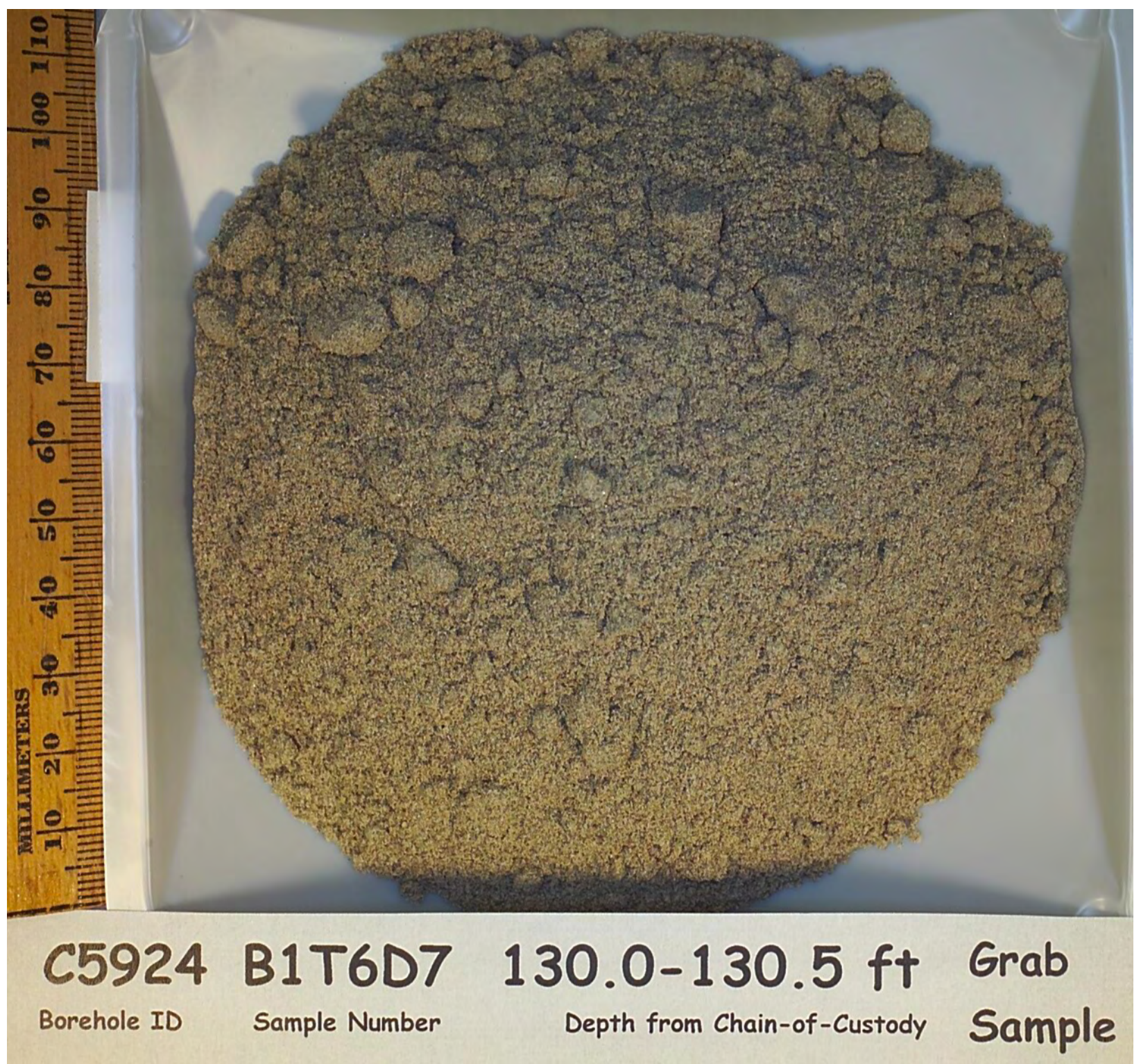




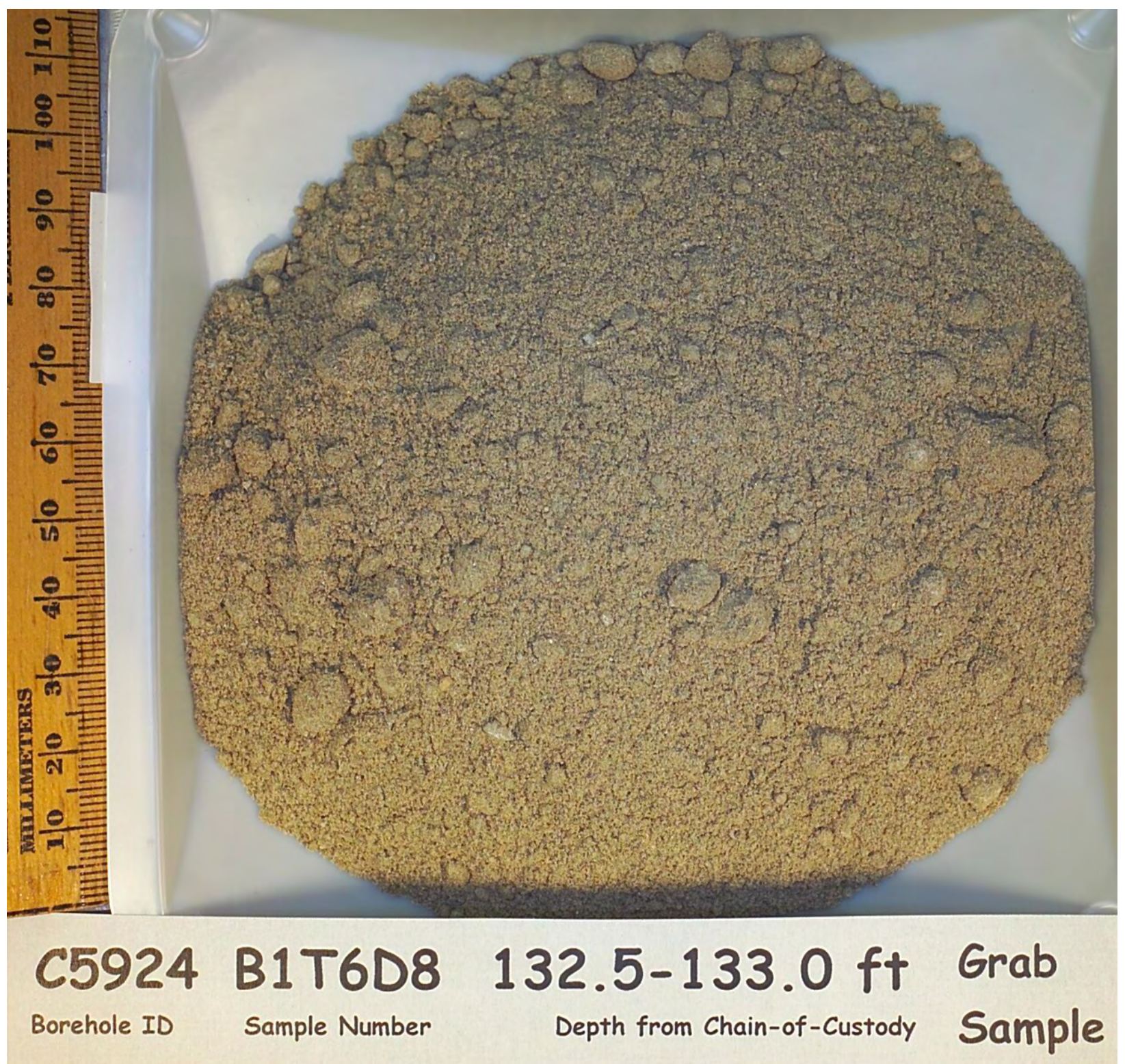




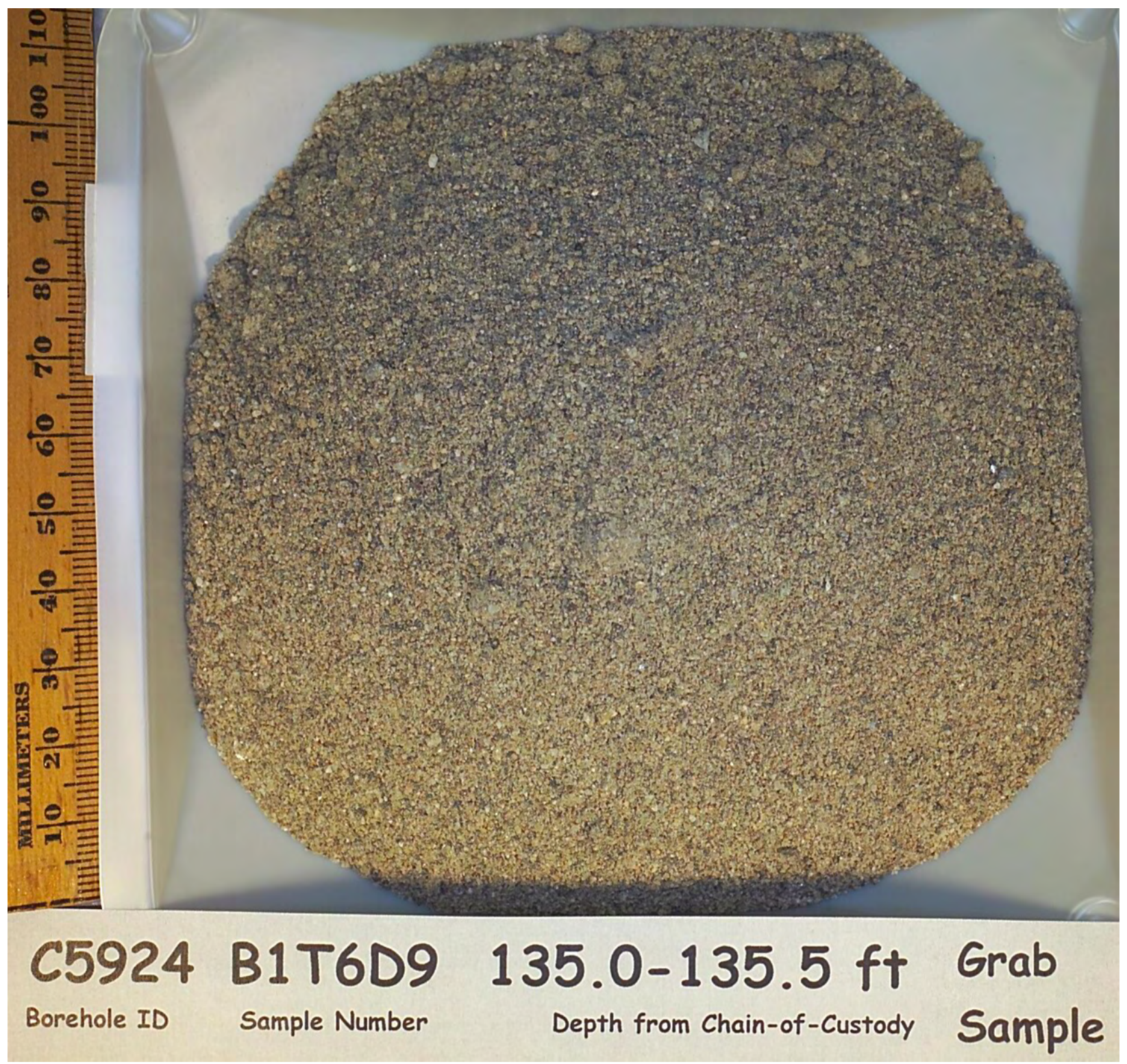




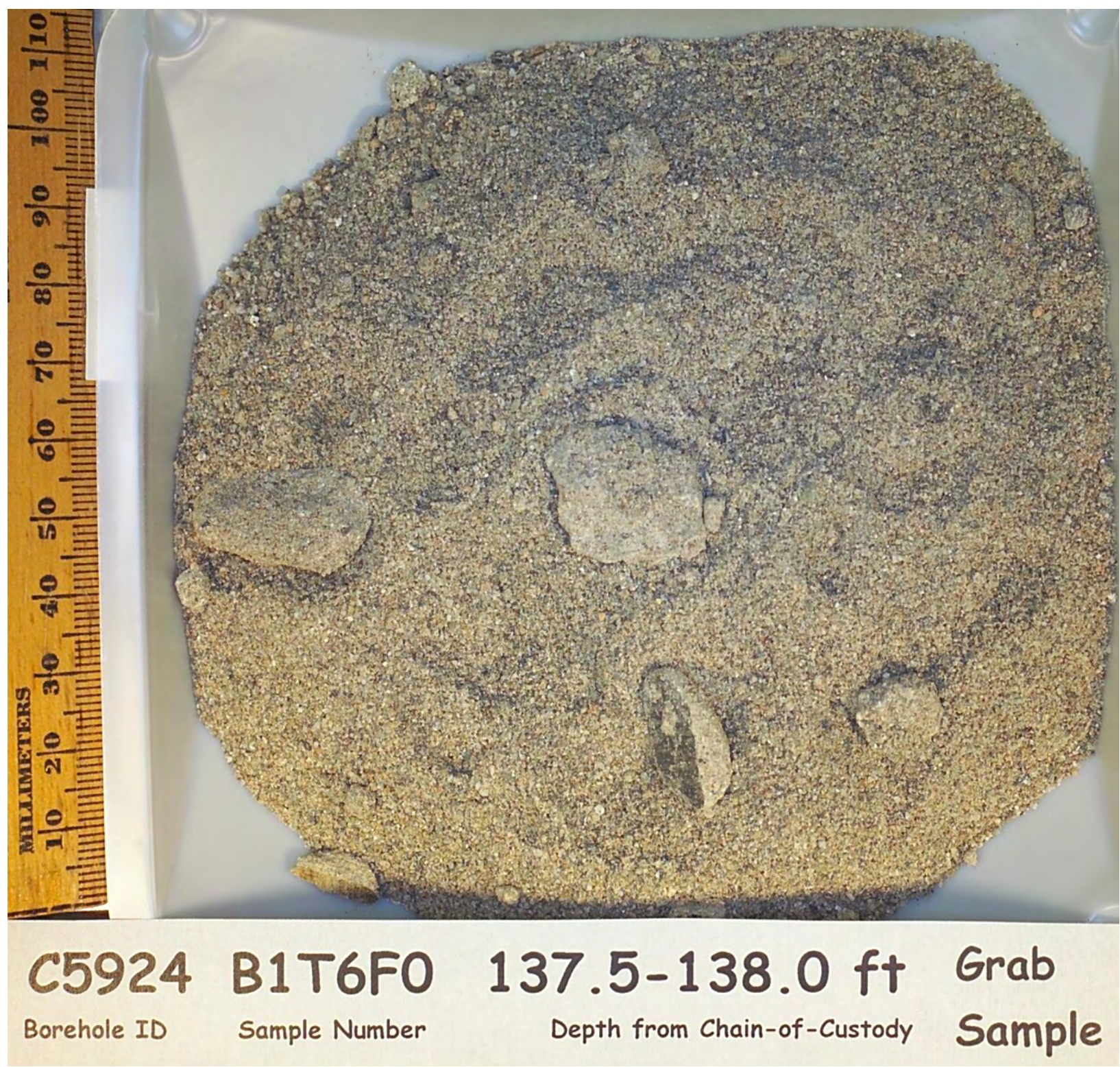




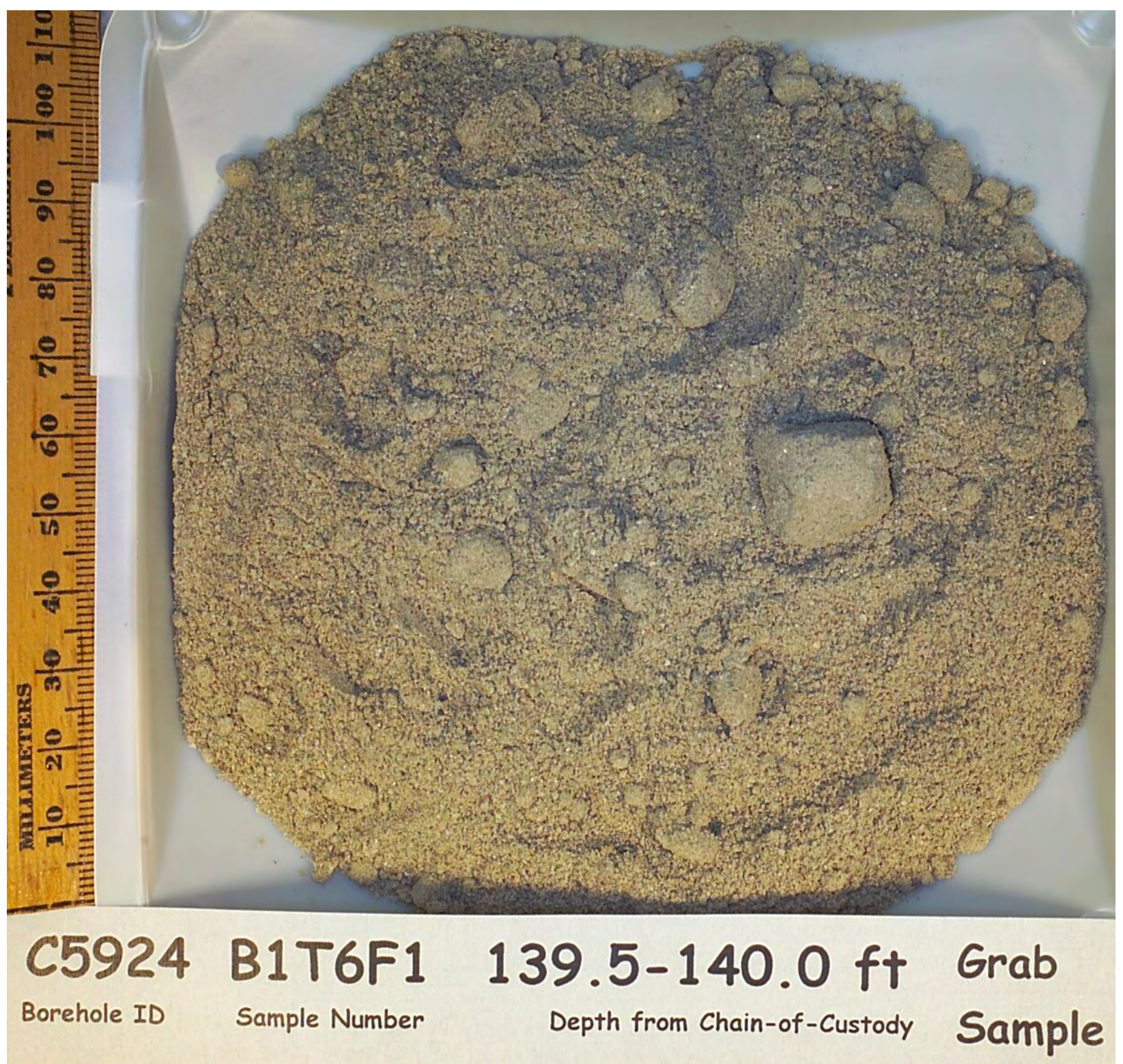




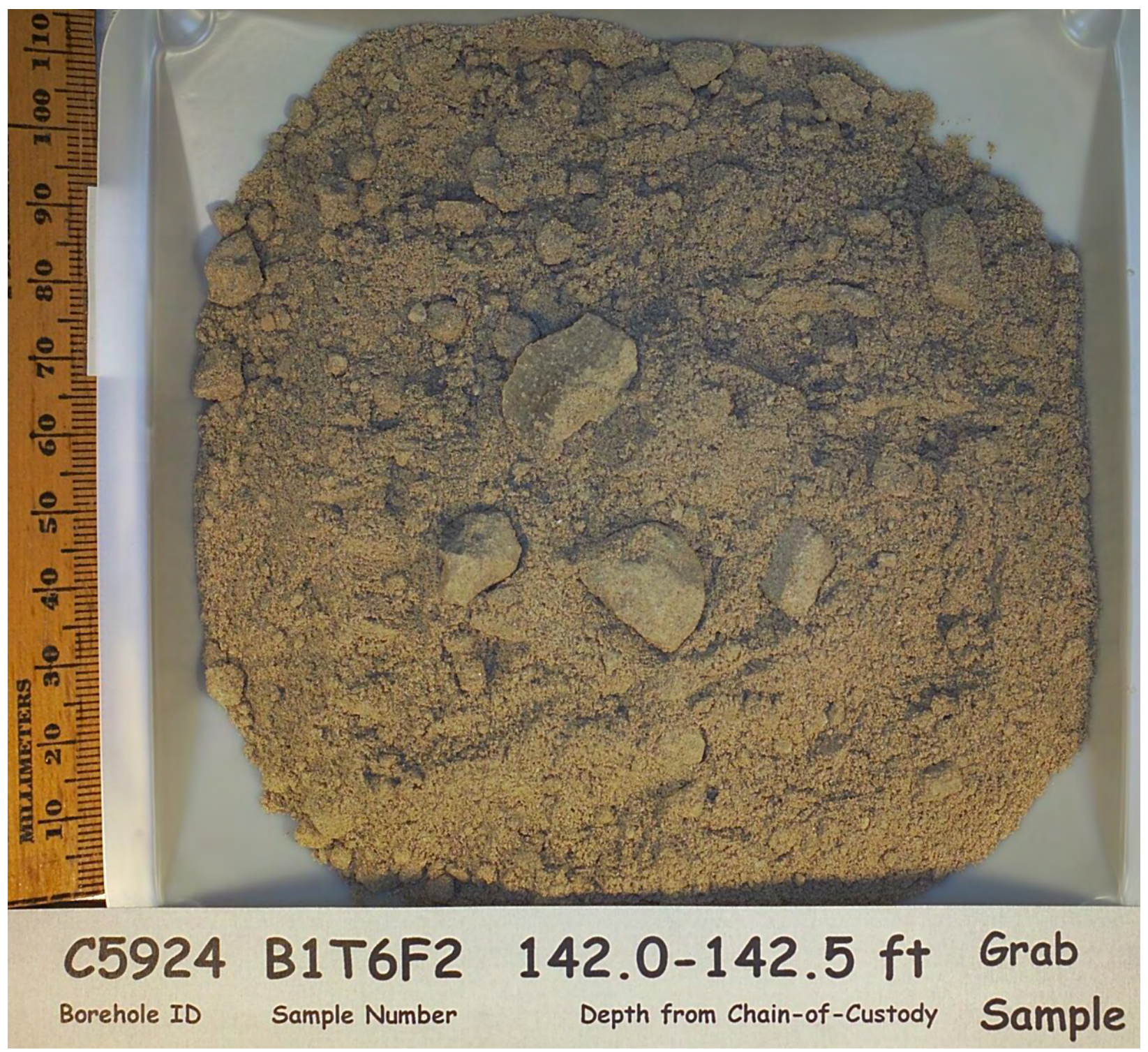




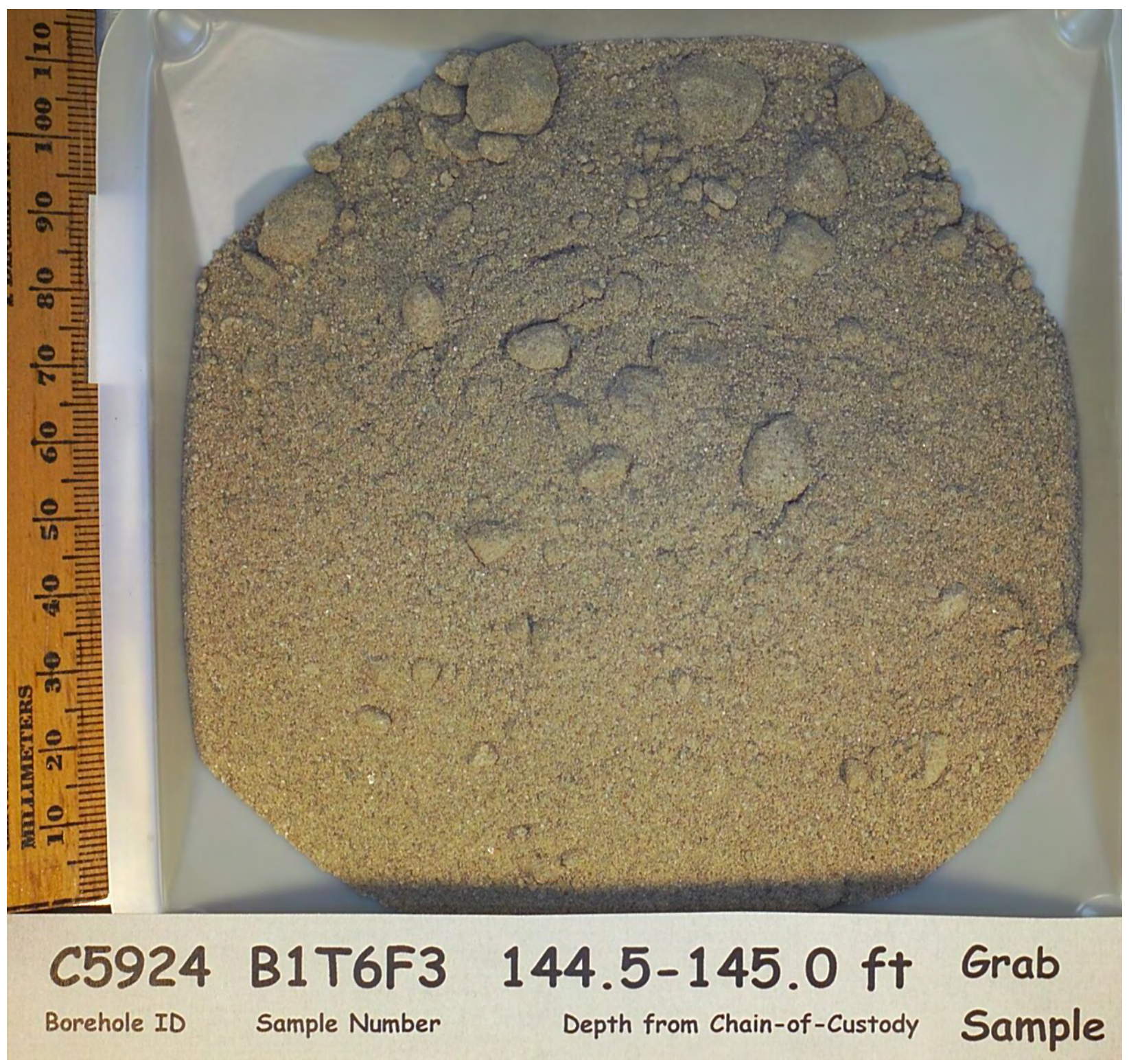




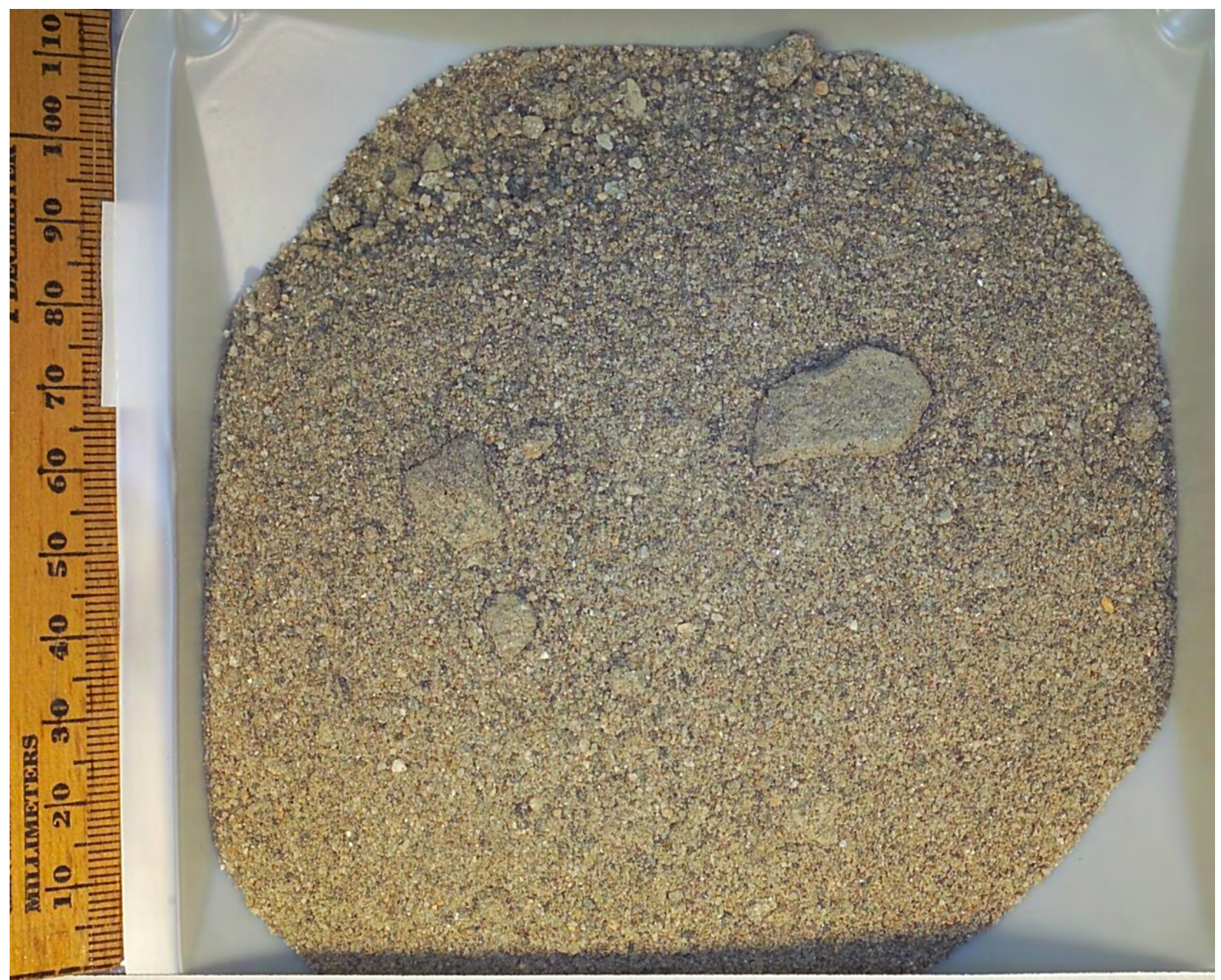

\section{C5924 B1T6F4 147.0-147.5 ft Grab \\ Borehole ID Sample Number Depth from Chain-of-Custody Sample}




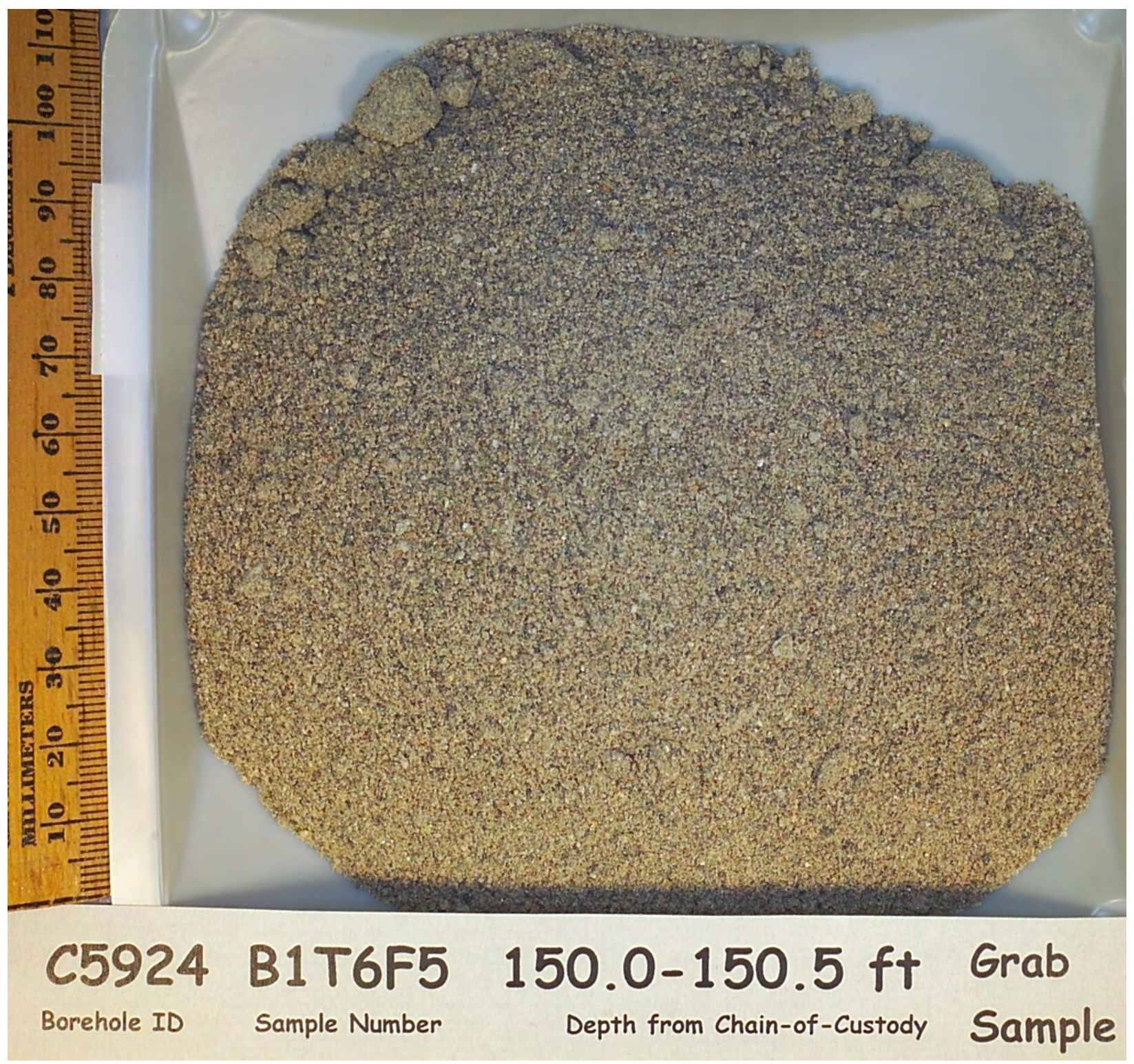




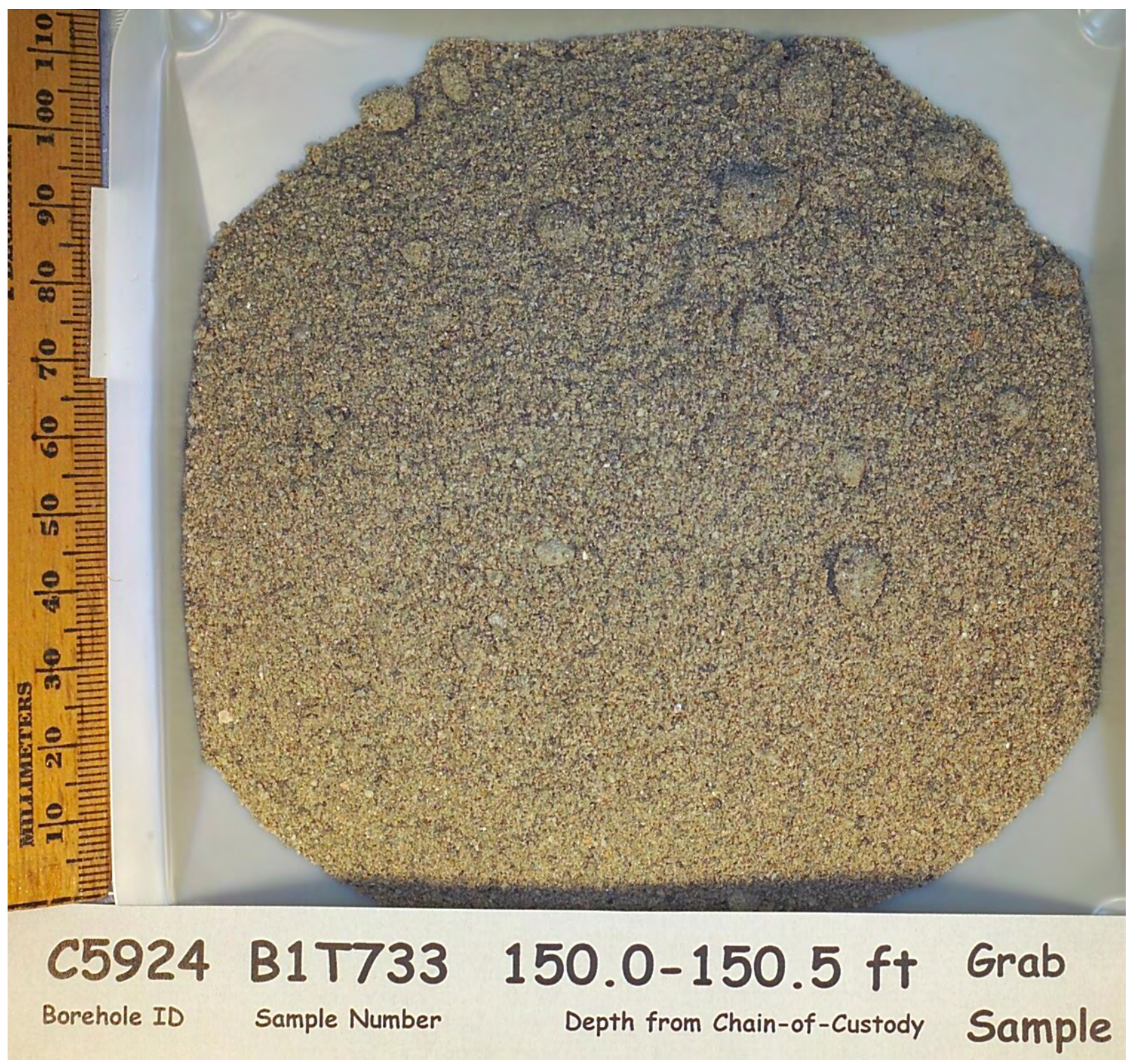




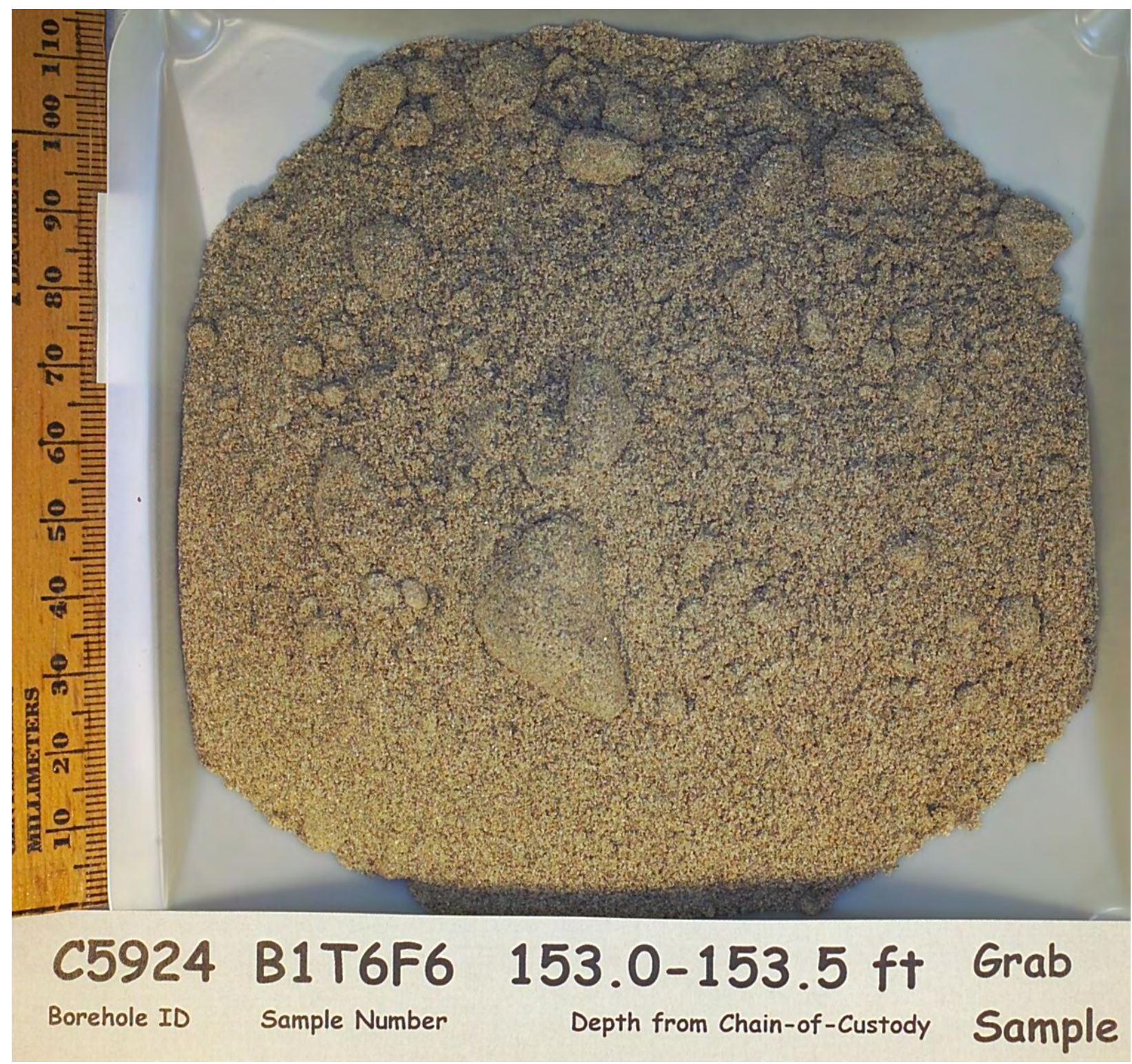




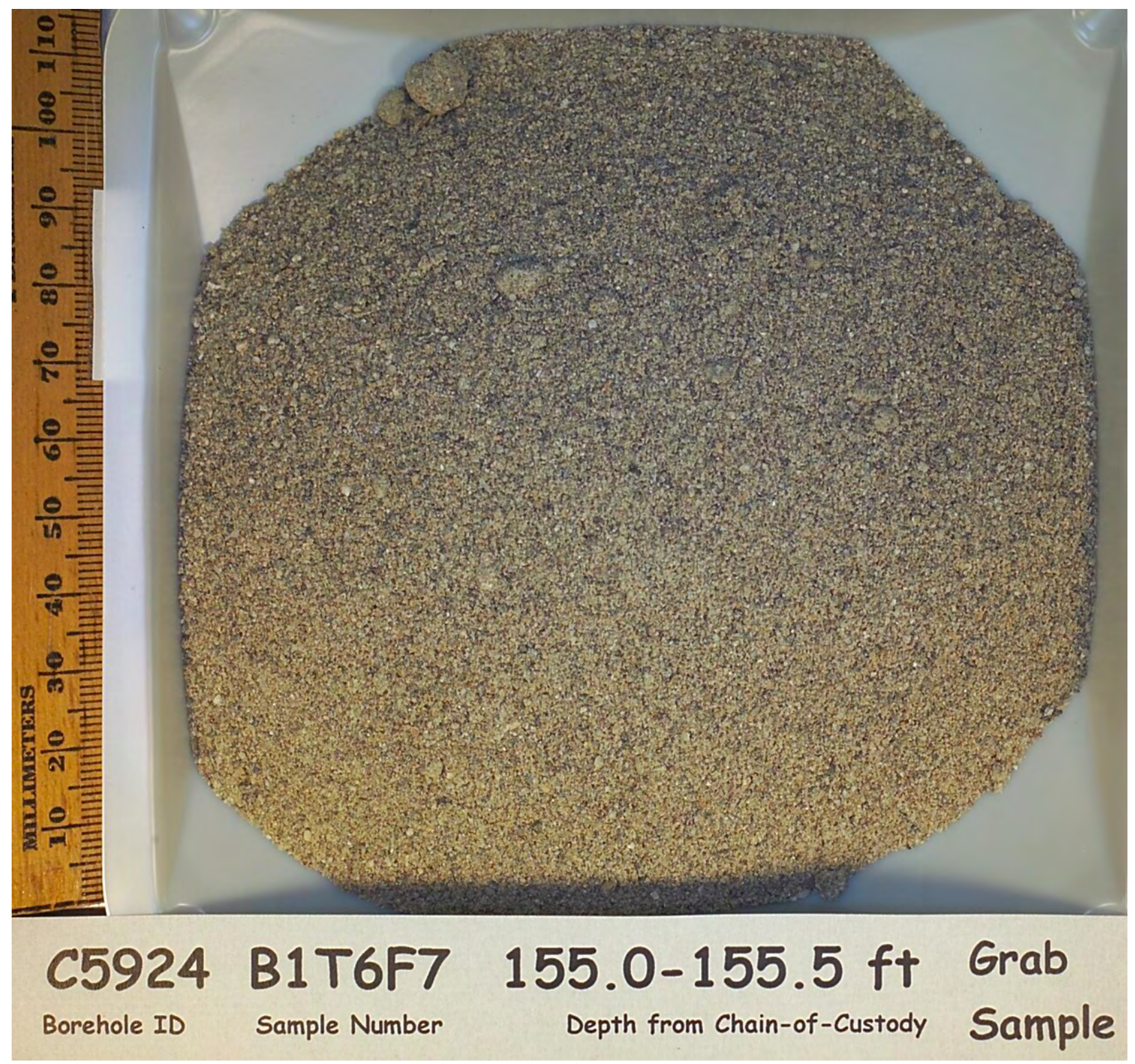




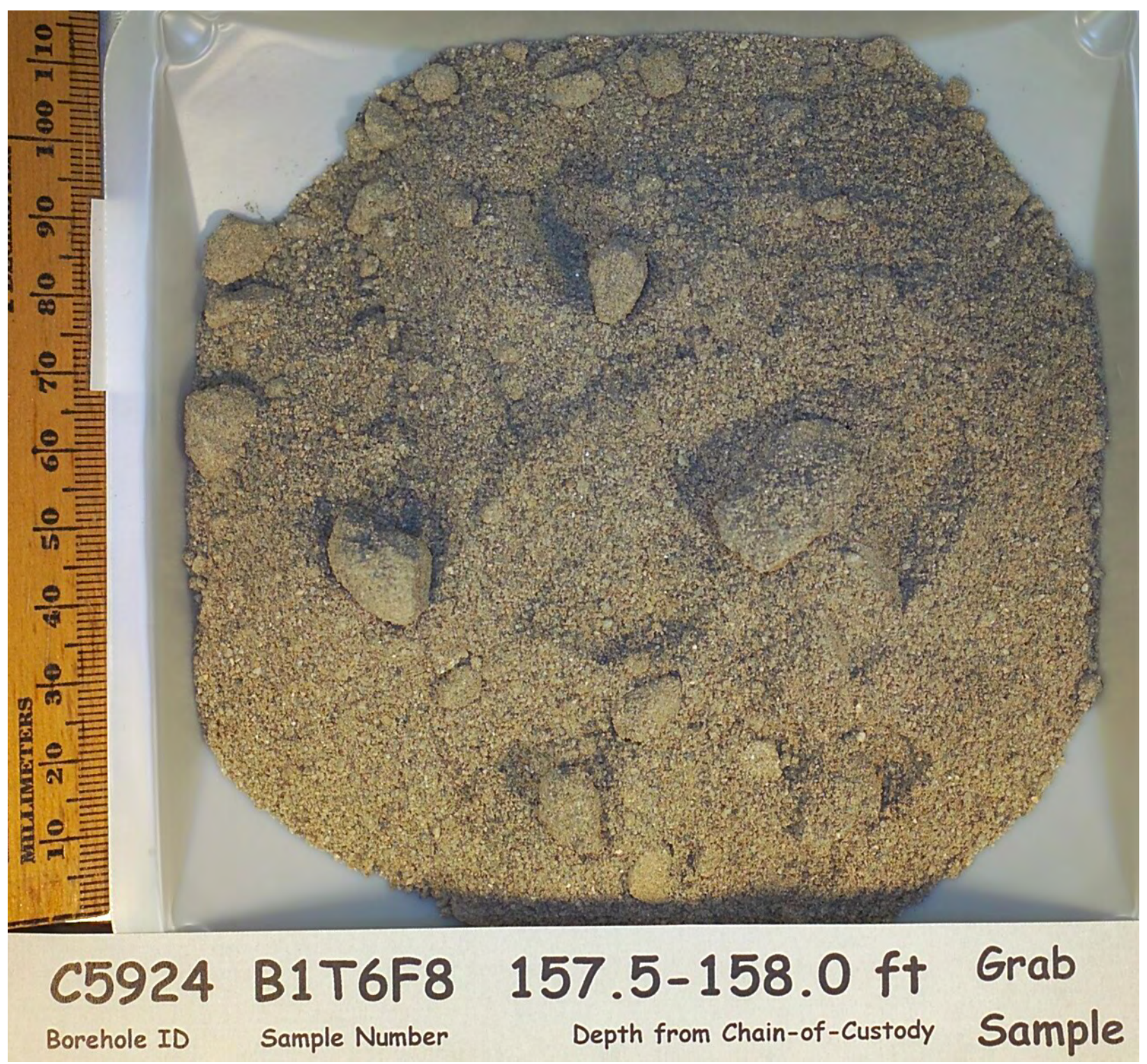




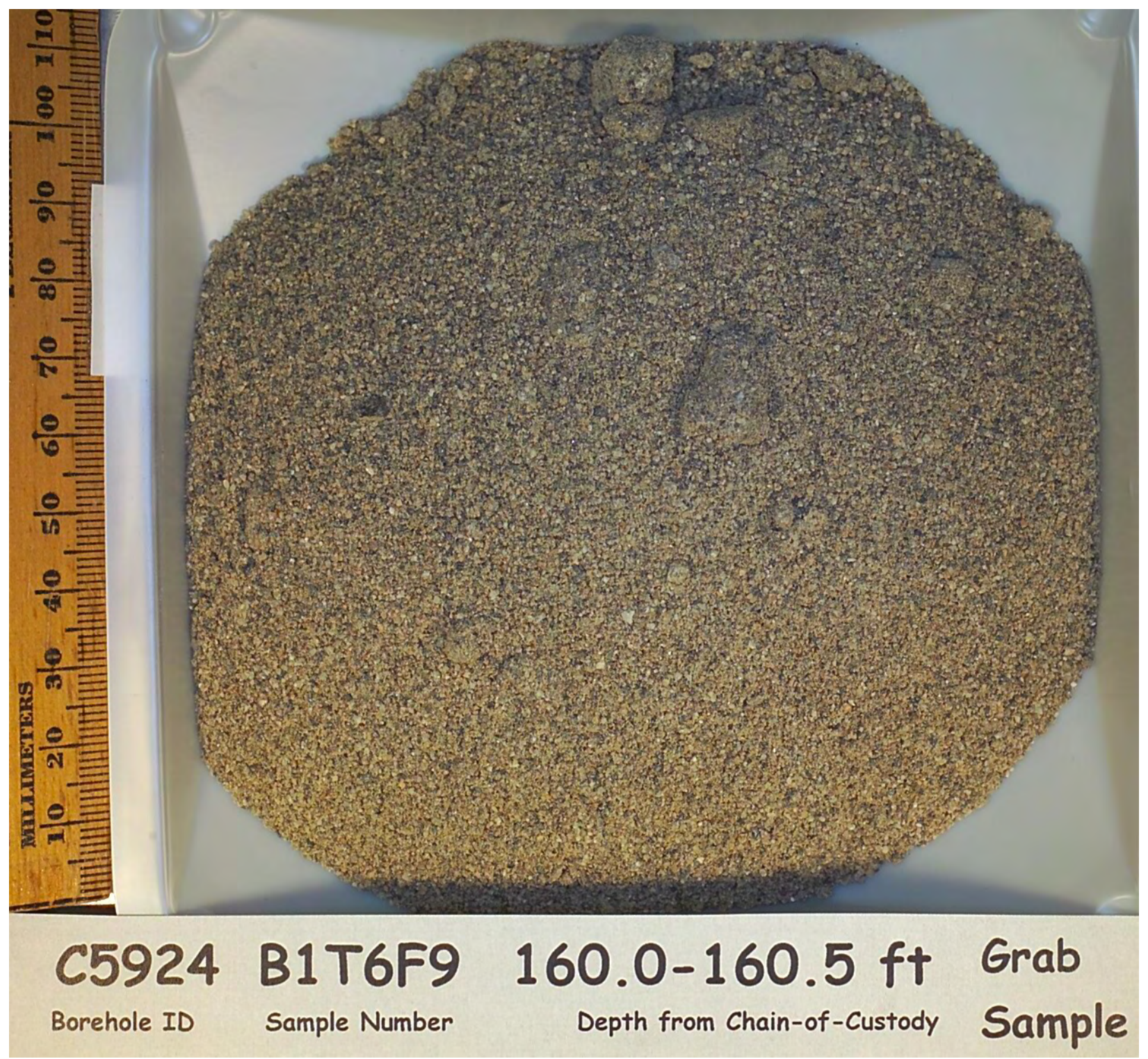




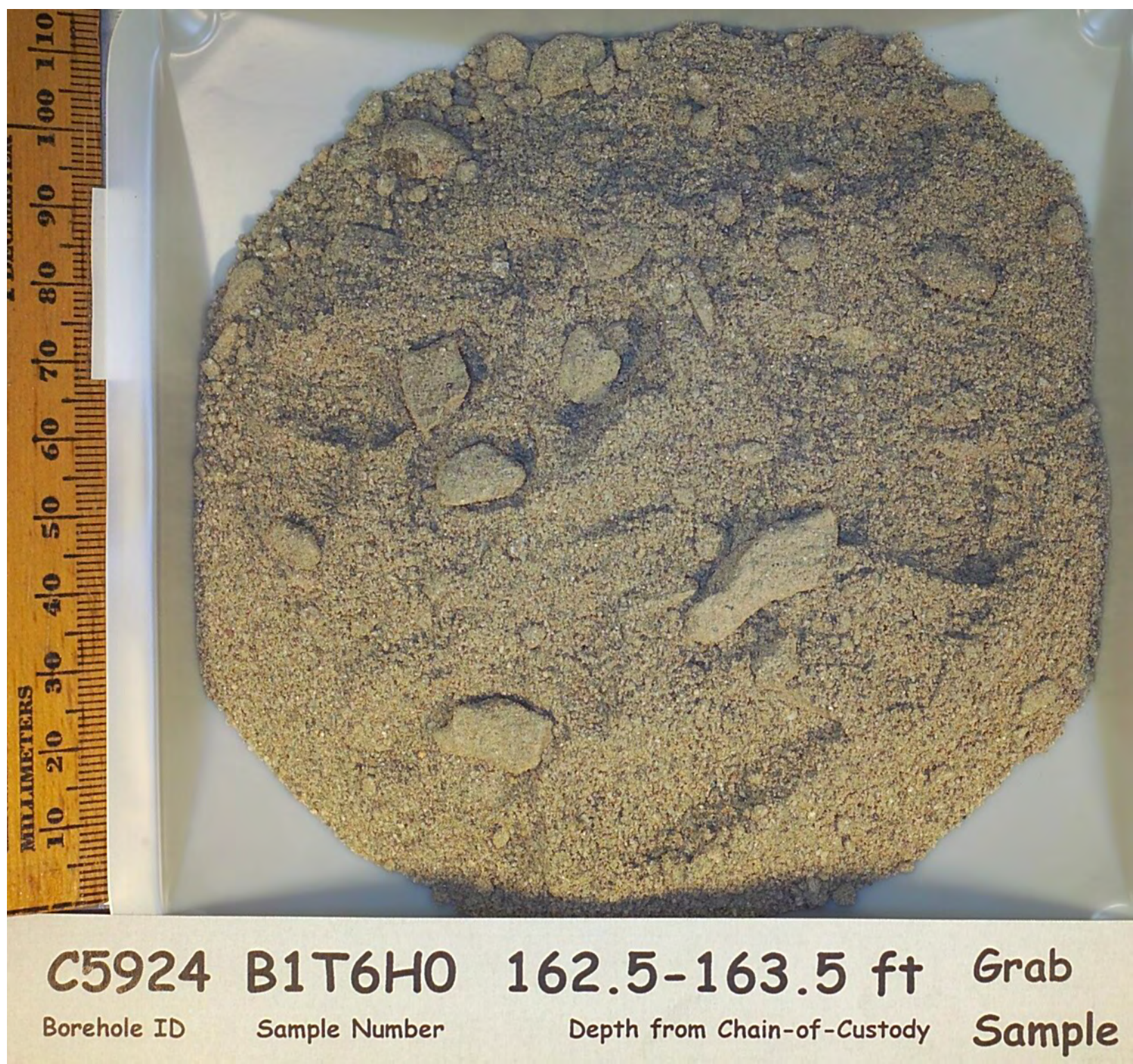




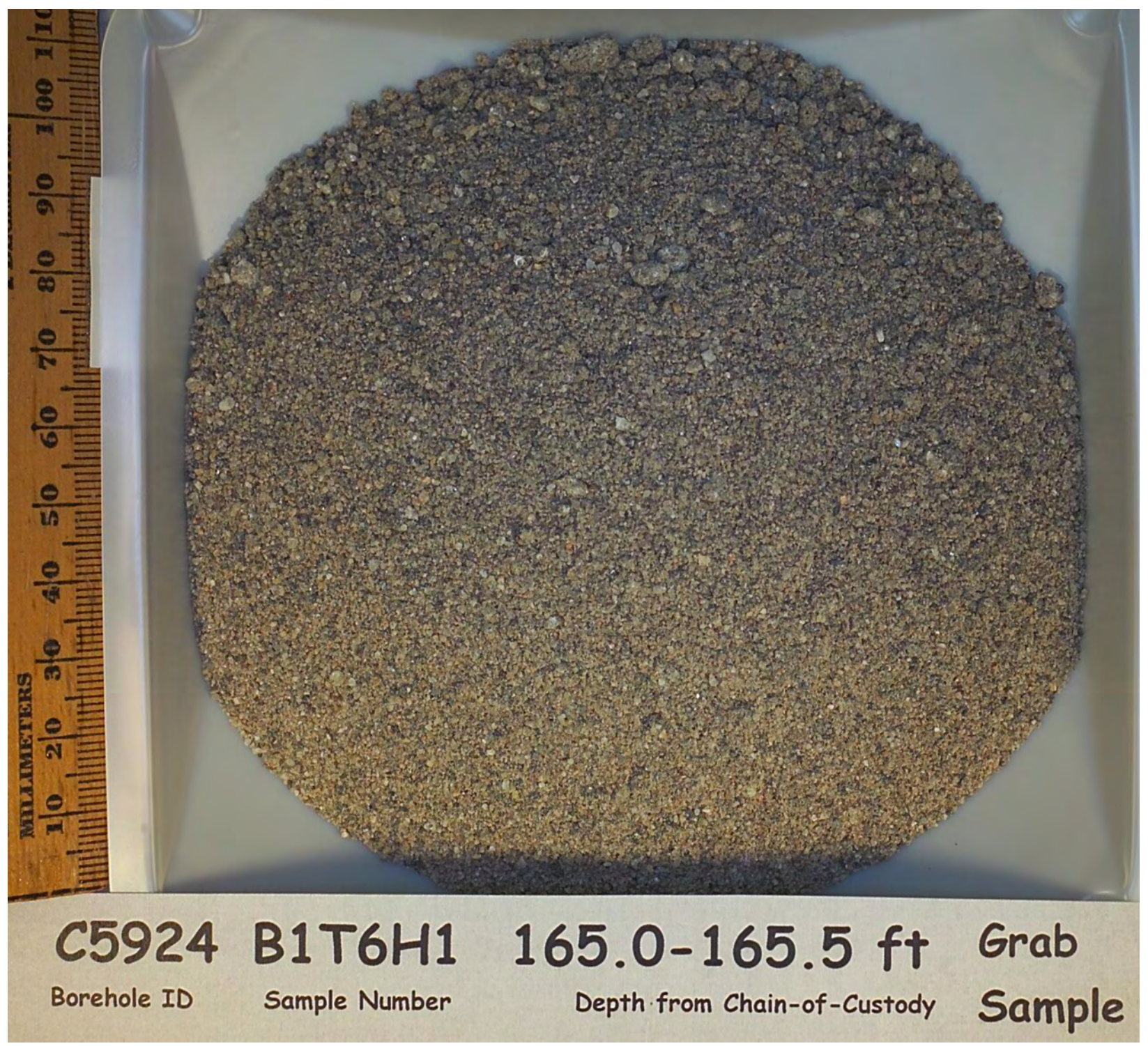




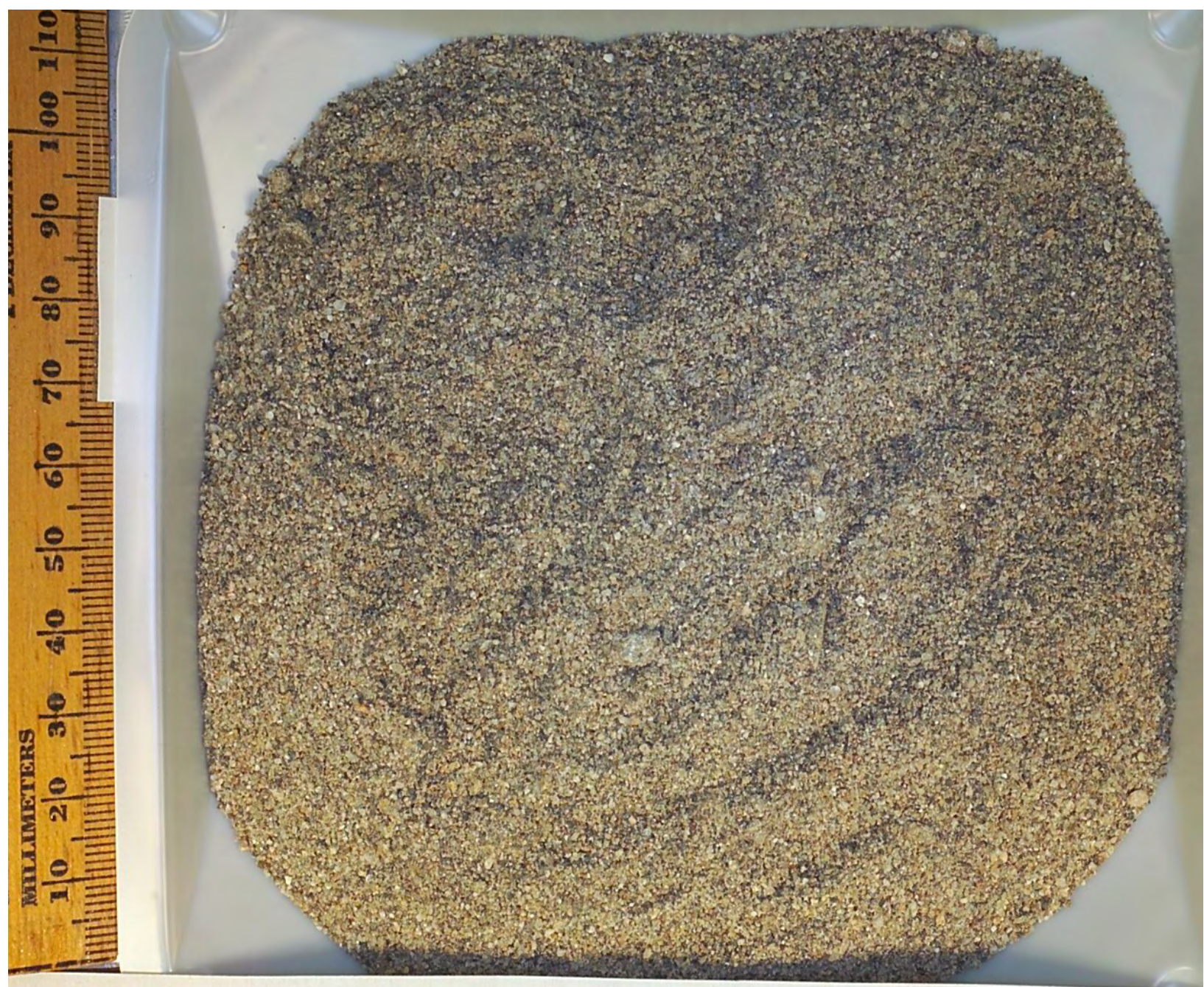

\section{C5924 B1T6H2 167.5-168.0 ft Grab Borehole ID Sample Number Depth from Chain-of-Custody Sample}




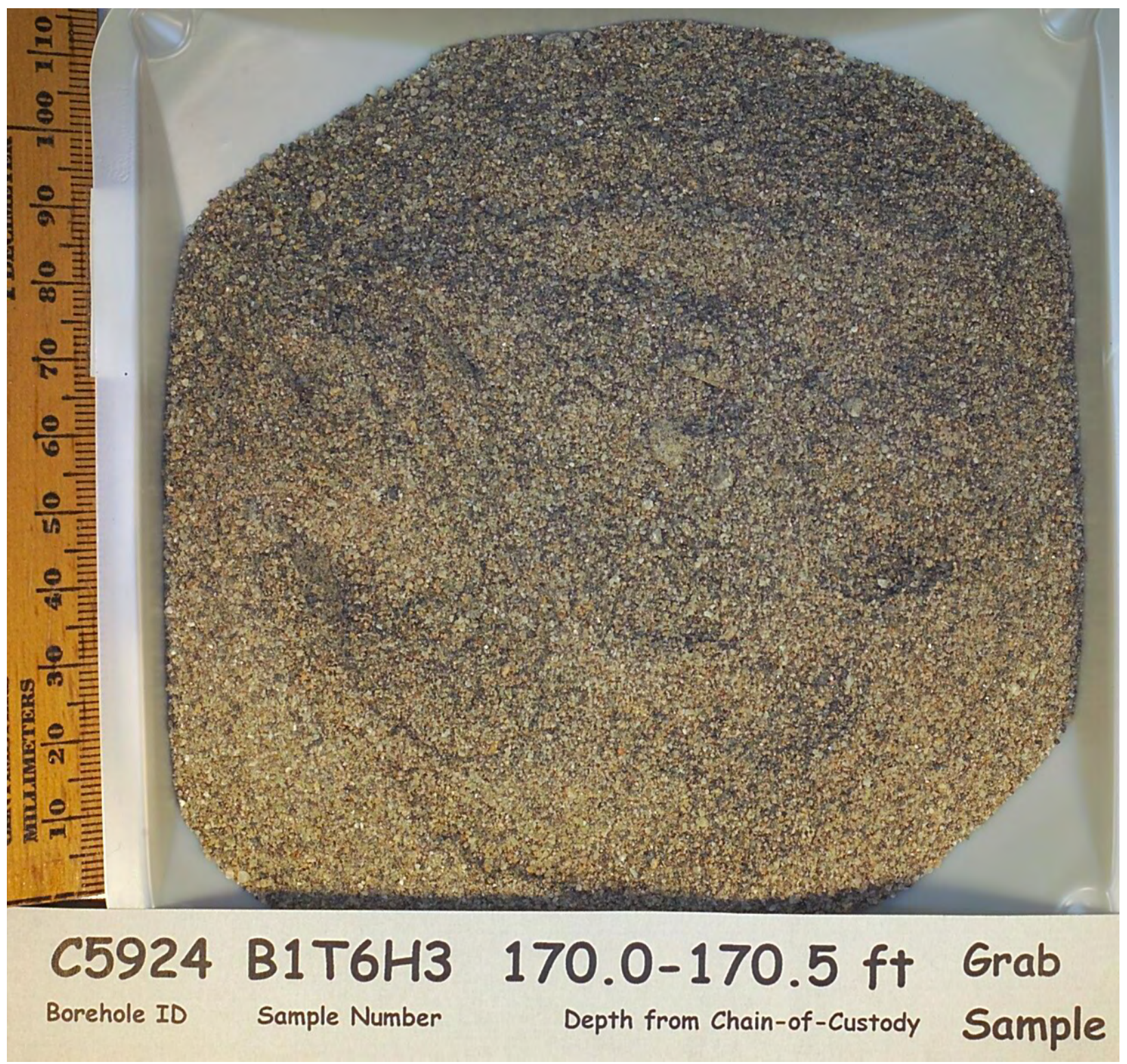




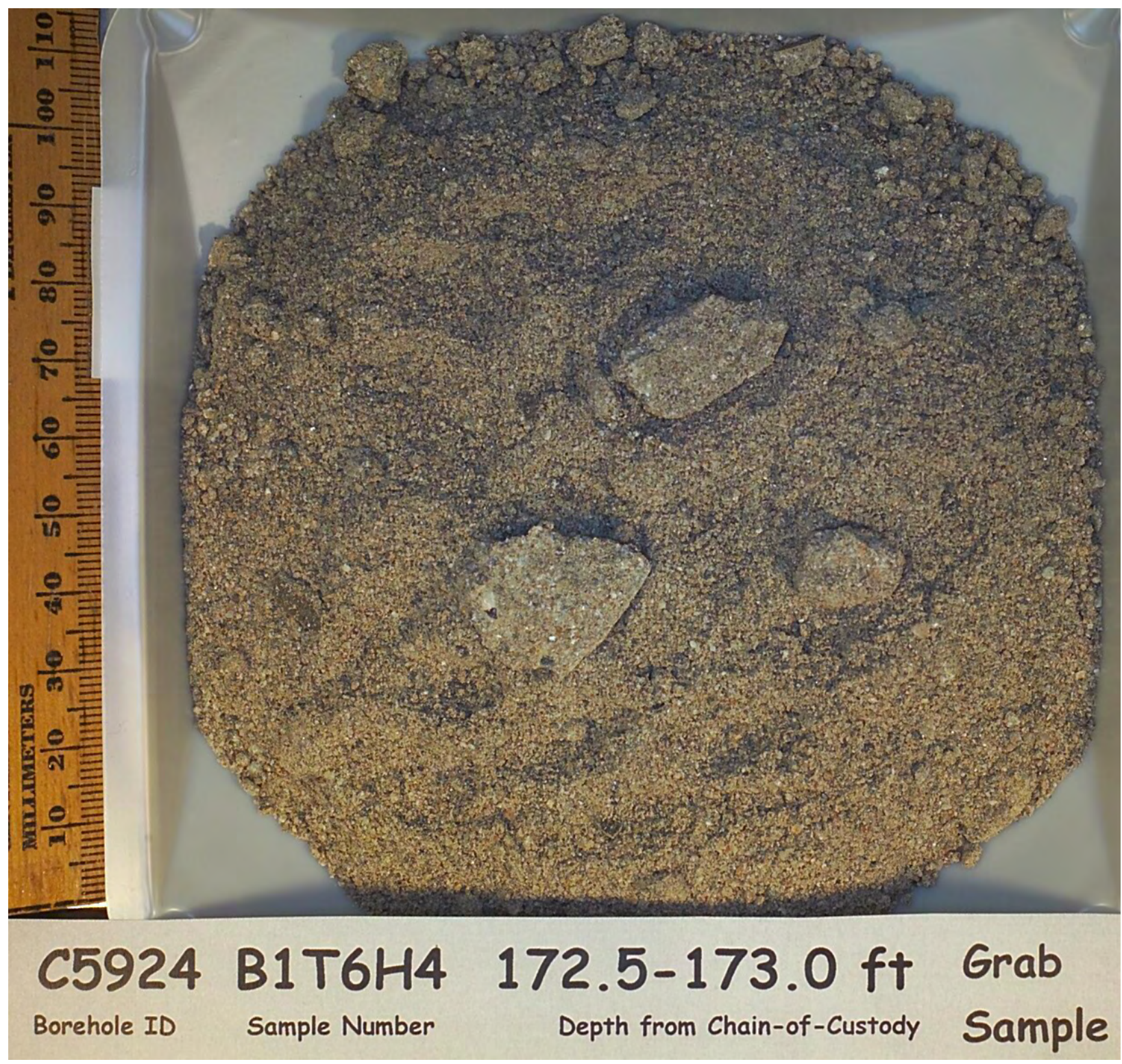




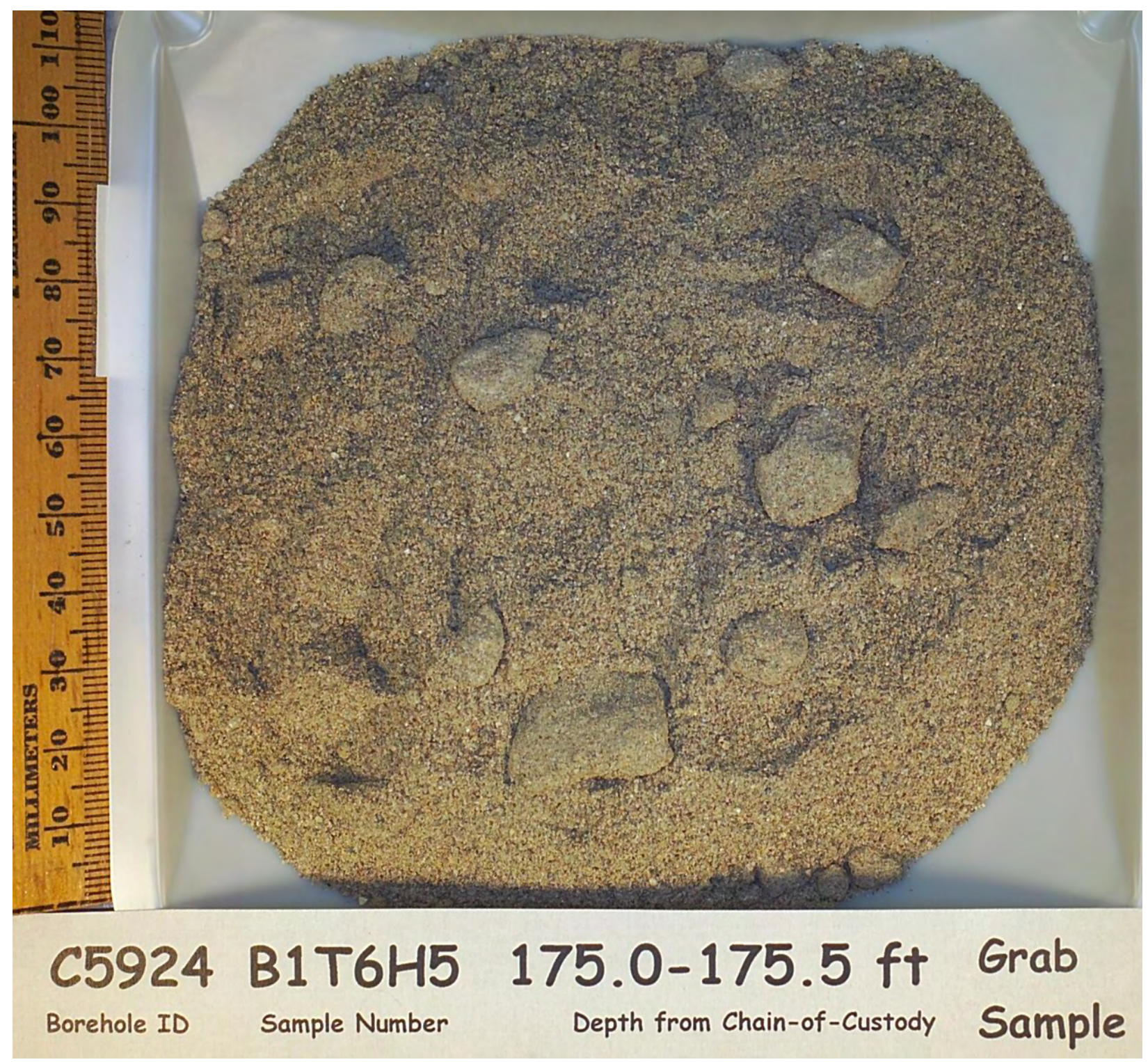




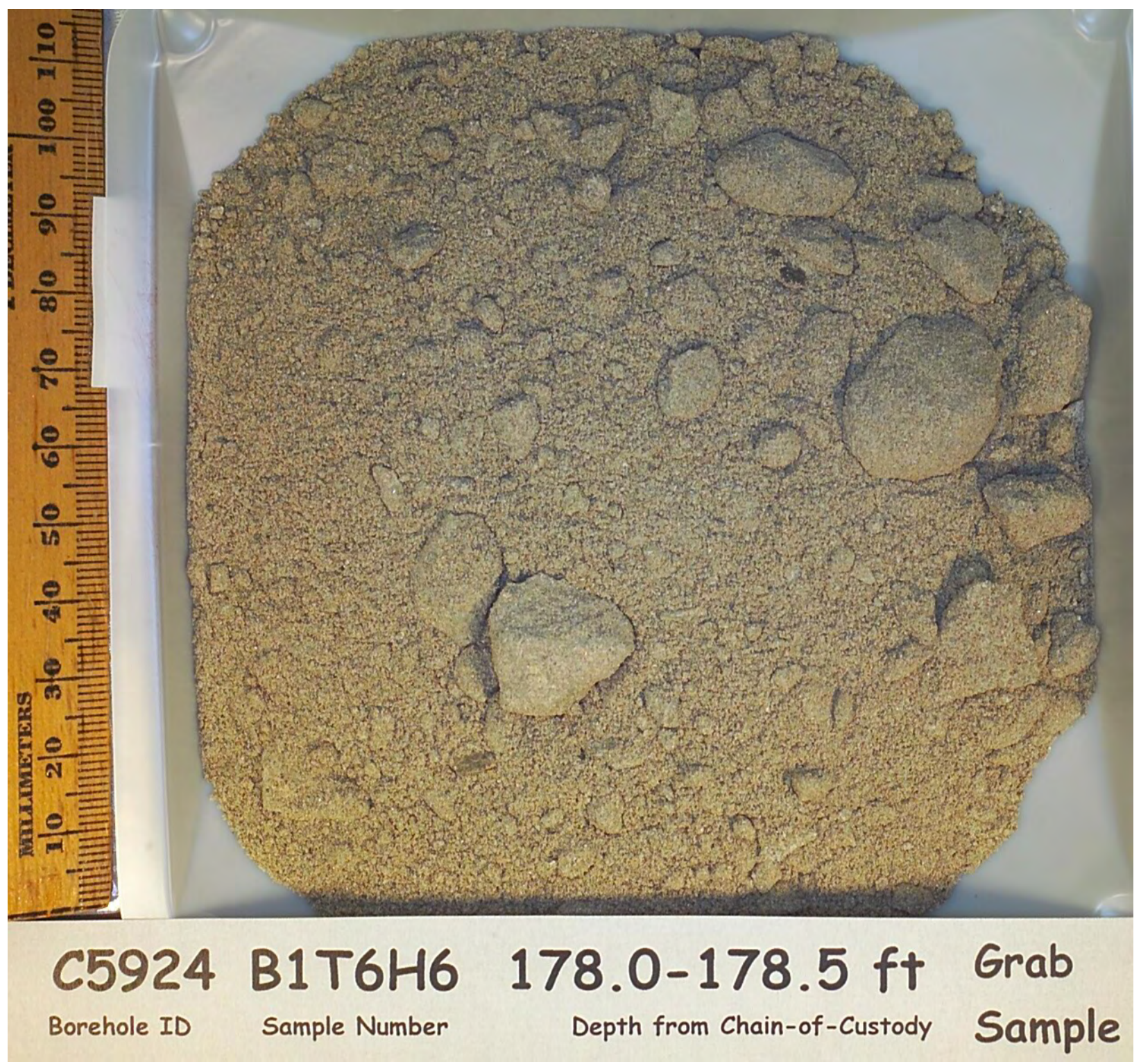


PNNL-17821

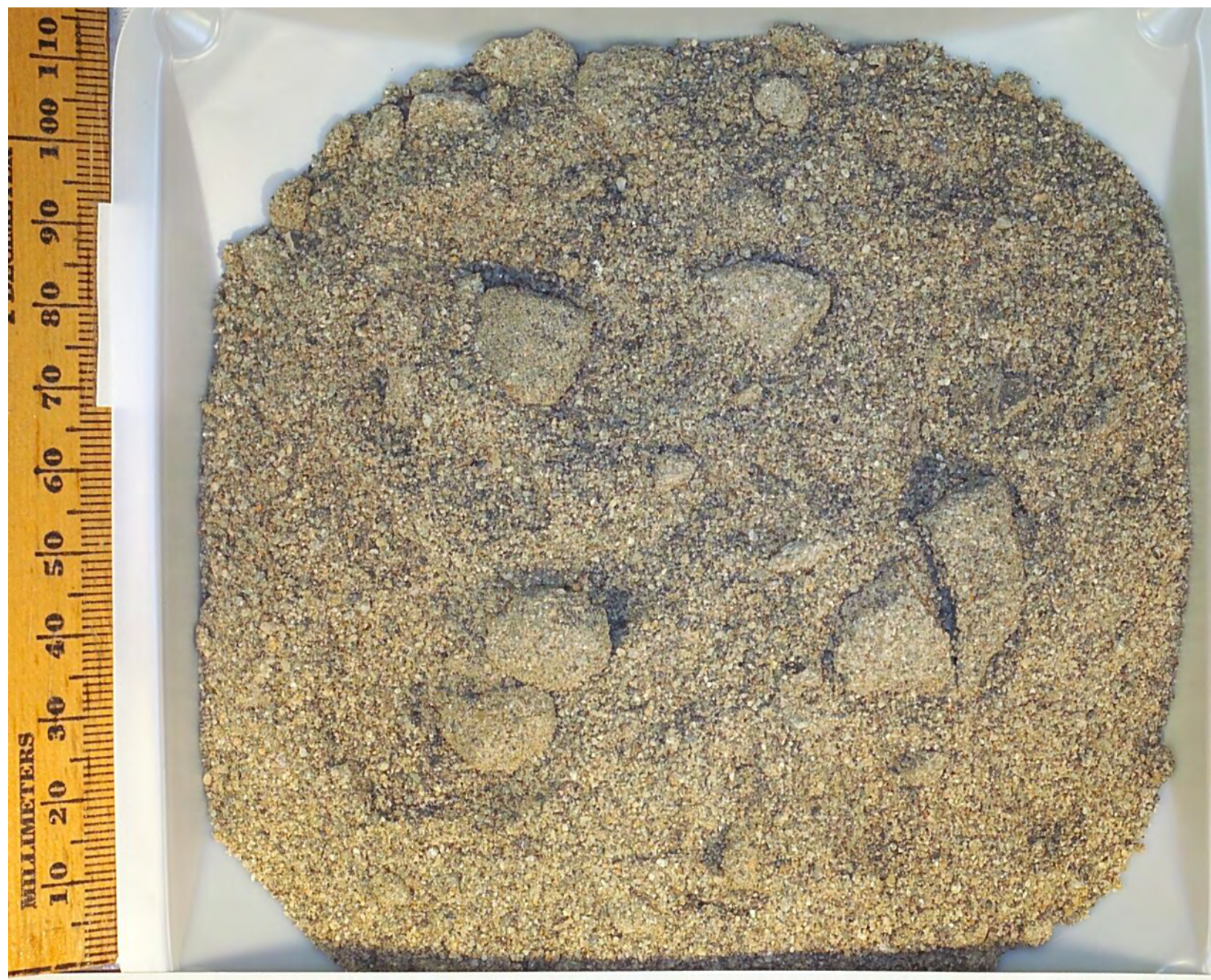

\section{C5924 B1T6H7 181.0-181.5 ft Grab}

Borehole ID Sample Number

Depth from Chain-of-Custody

Sample 
PNNL-17821

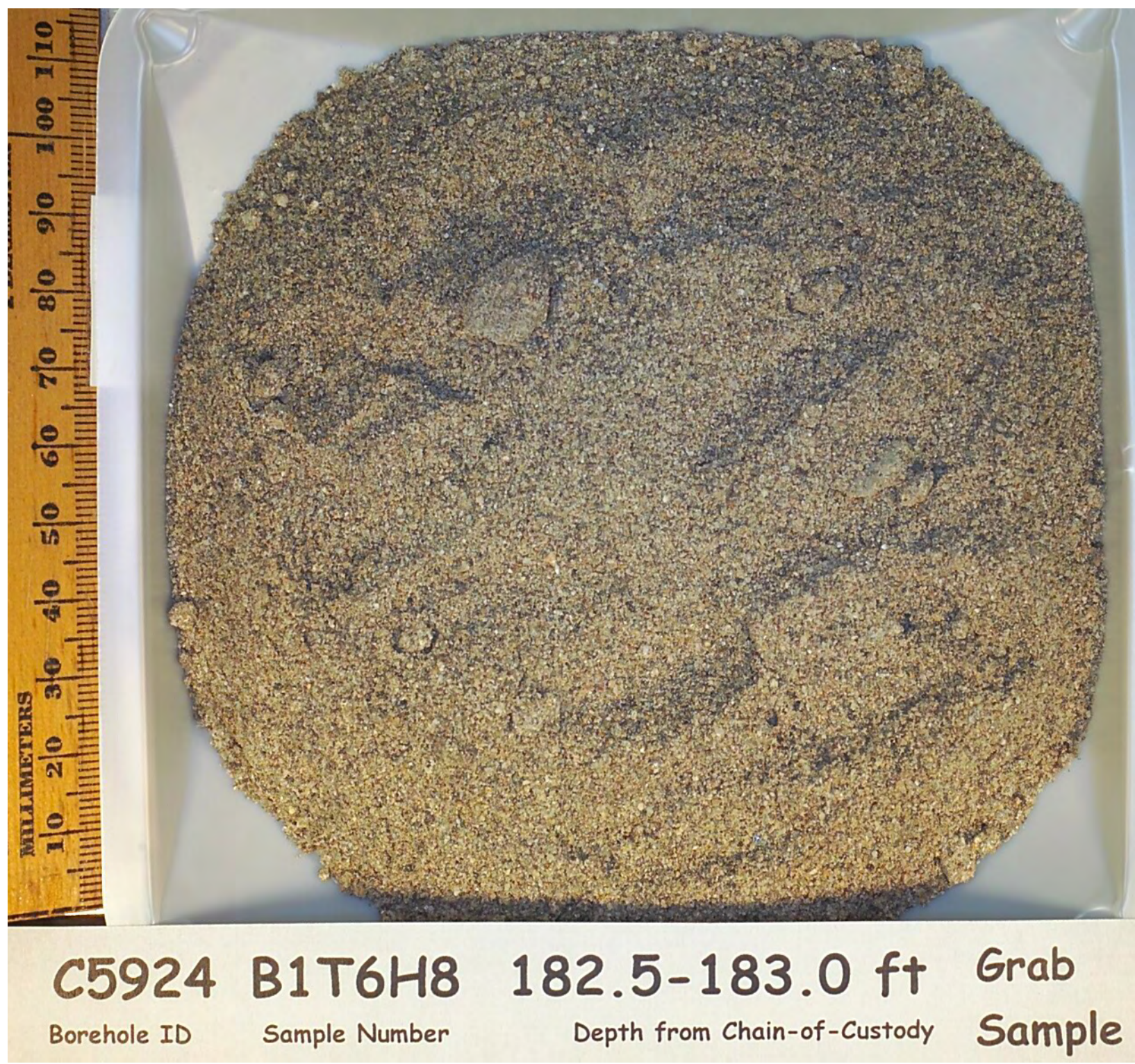




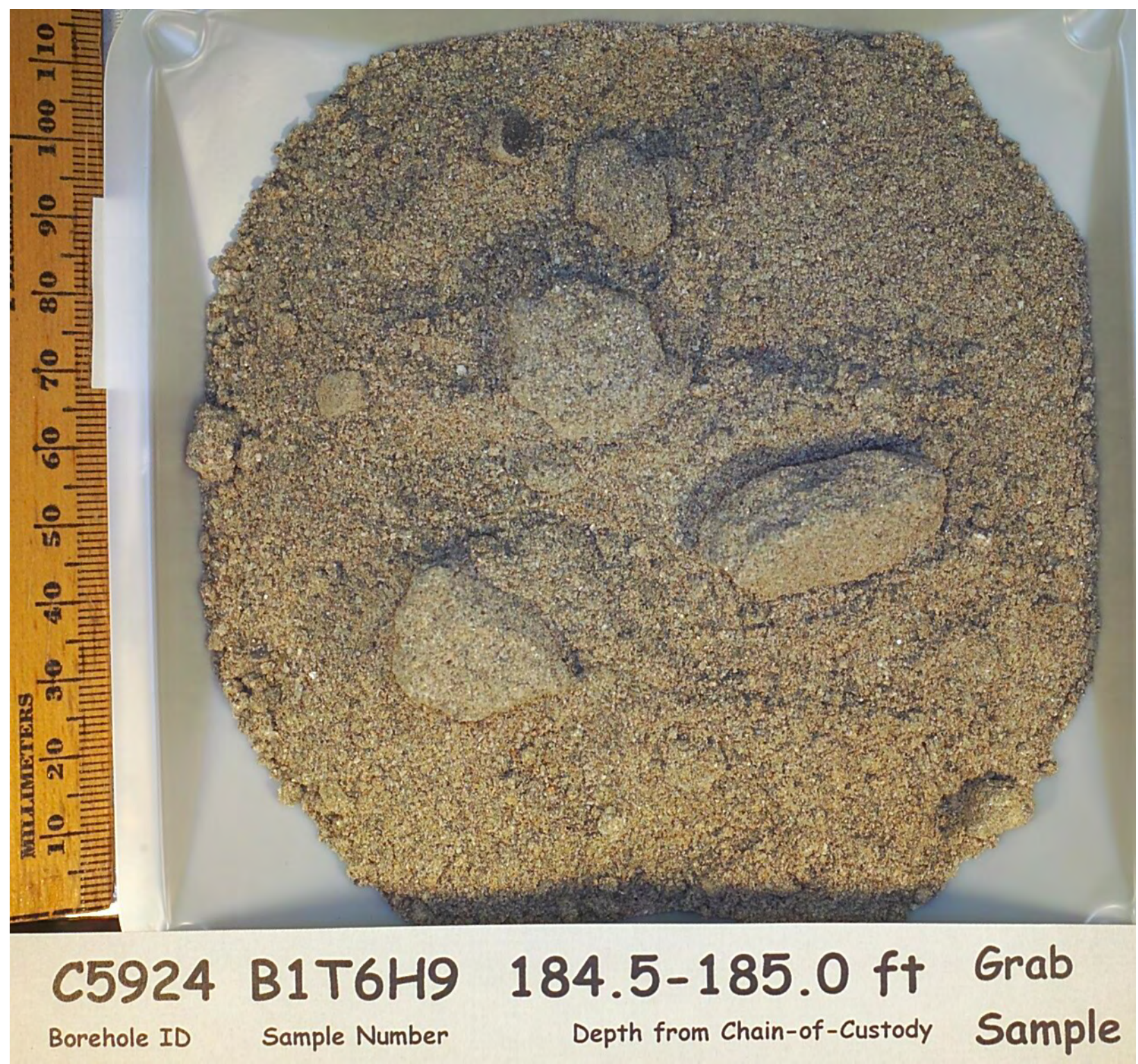




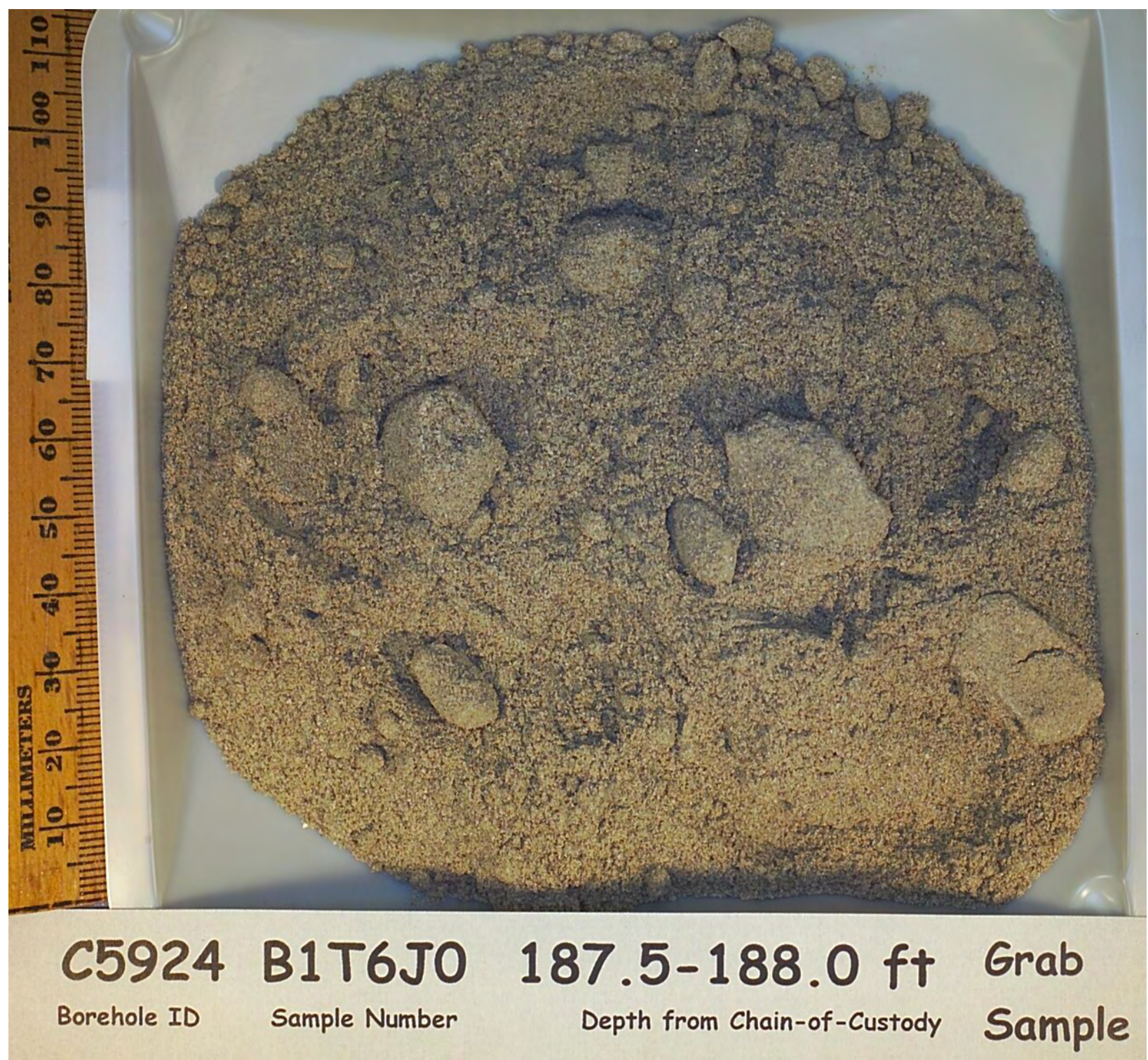


PNNL-17821

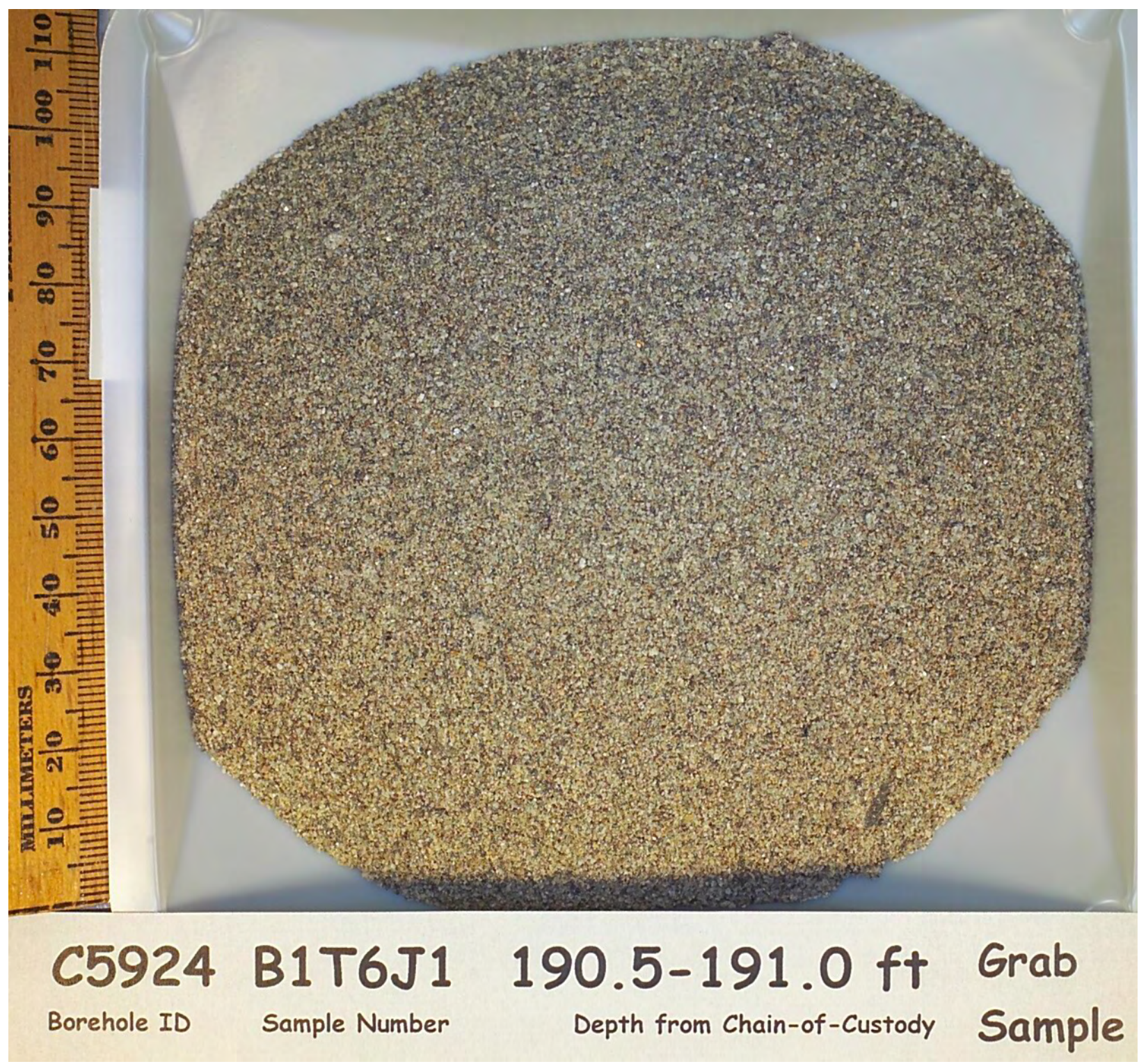




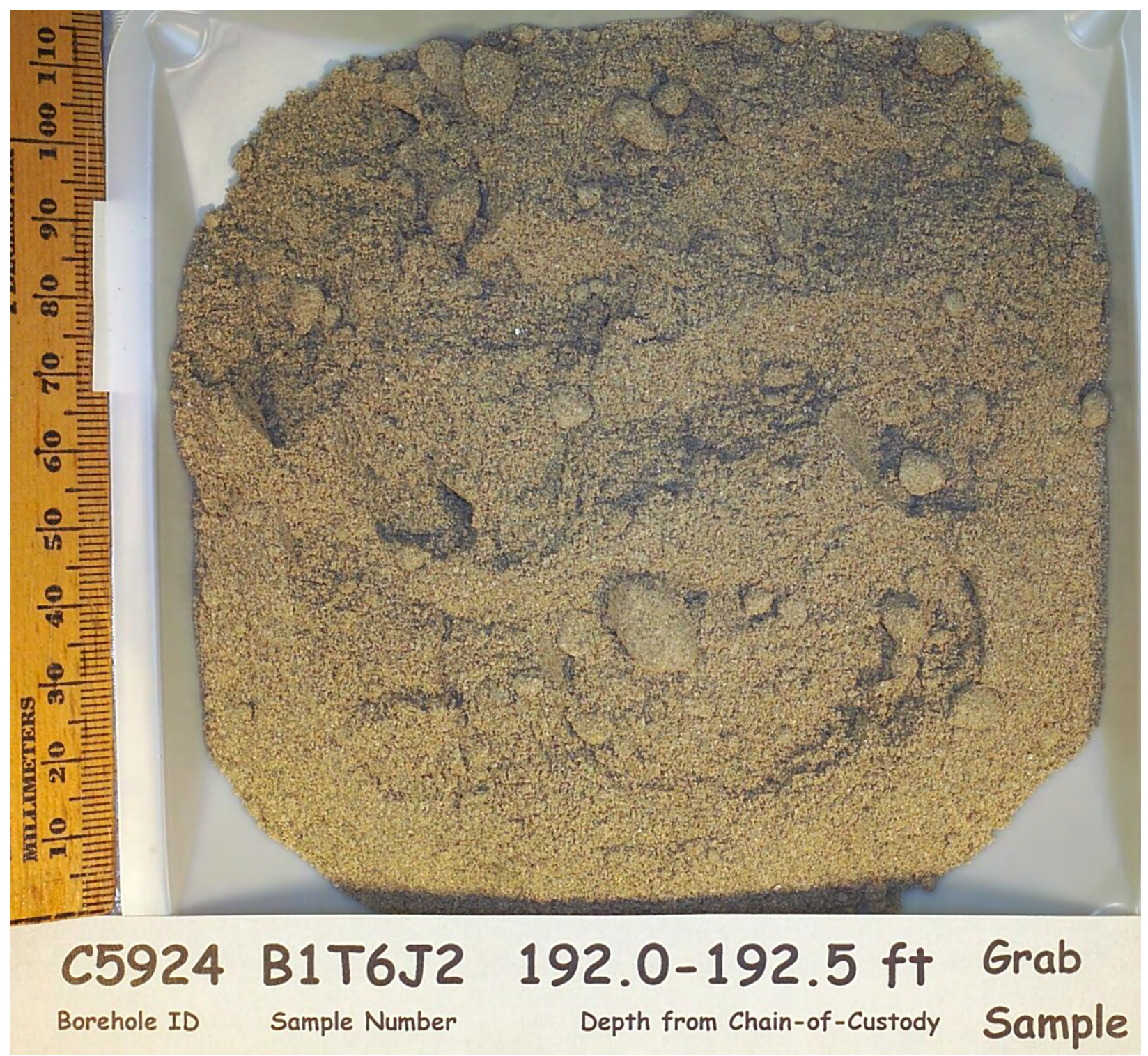




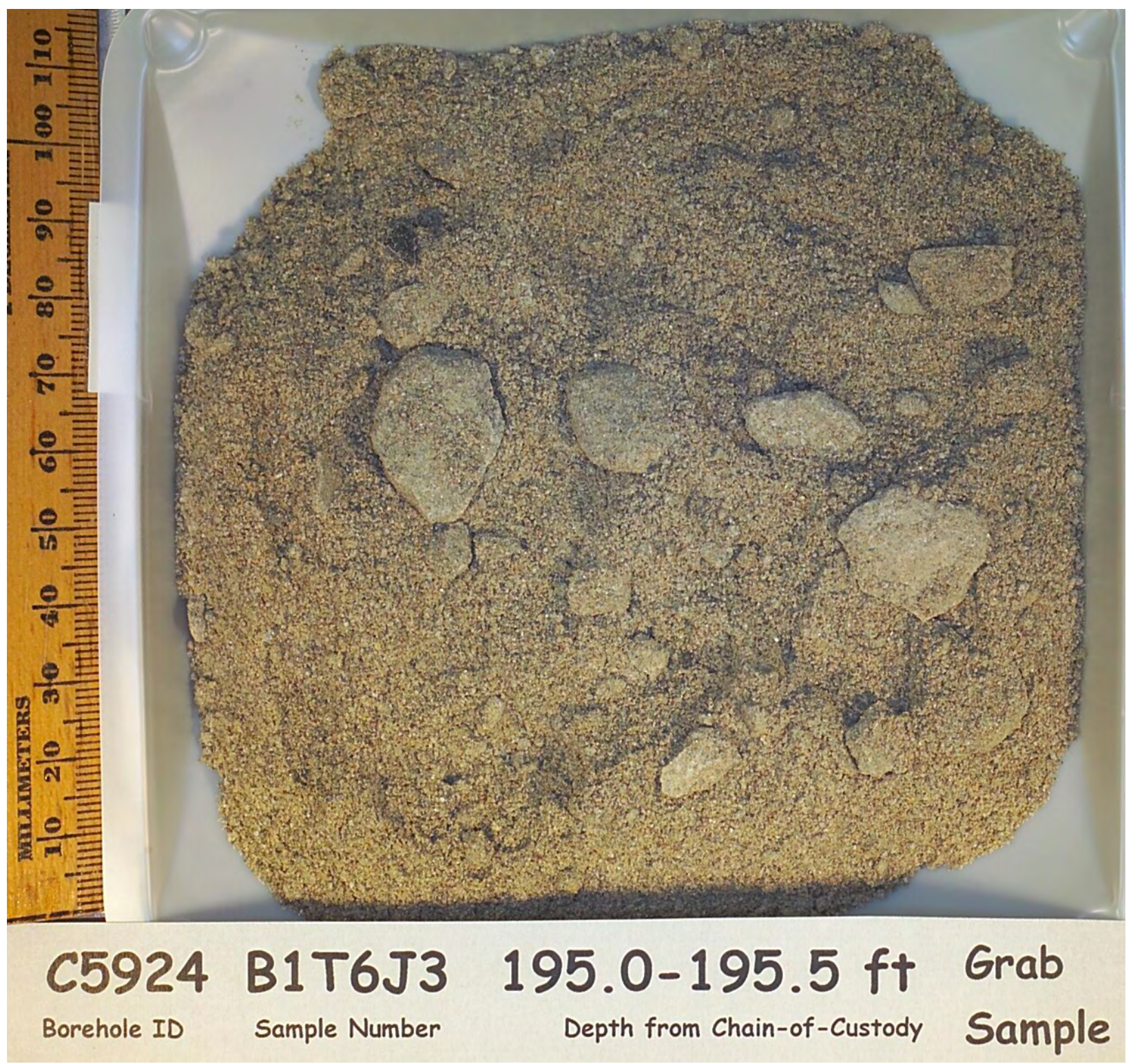




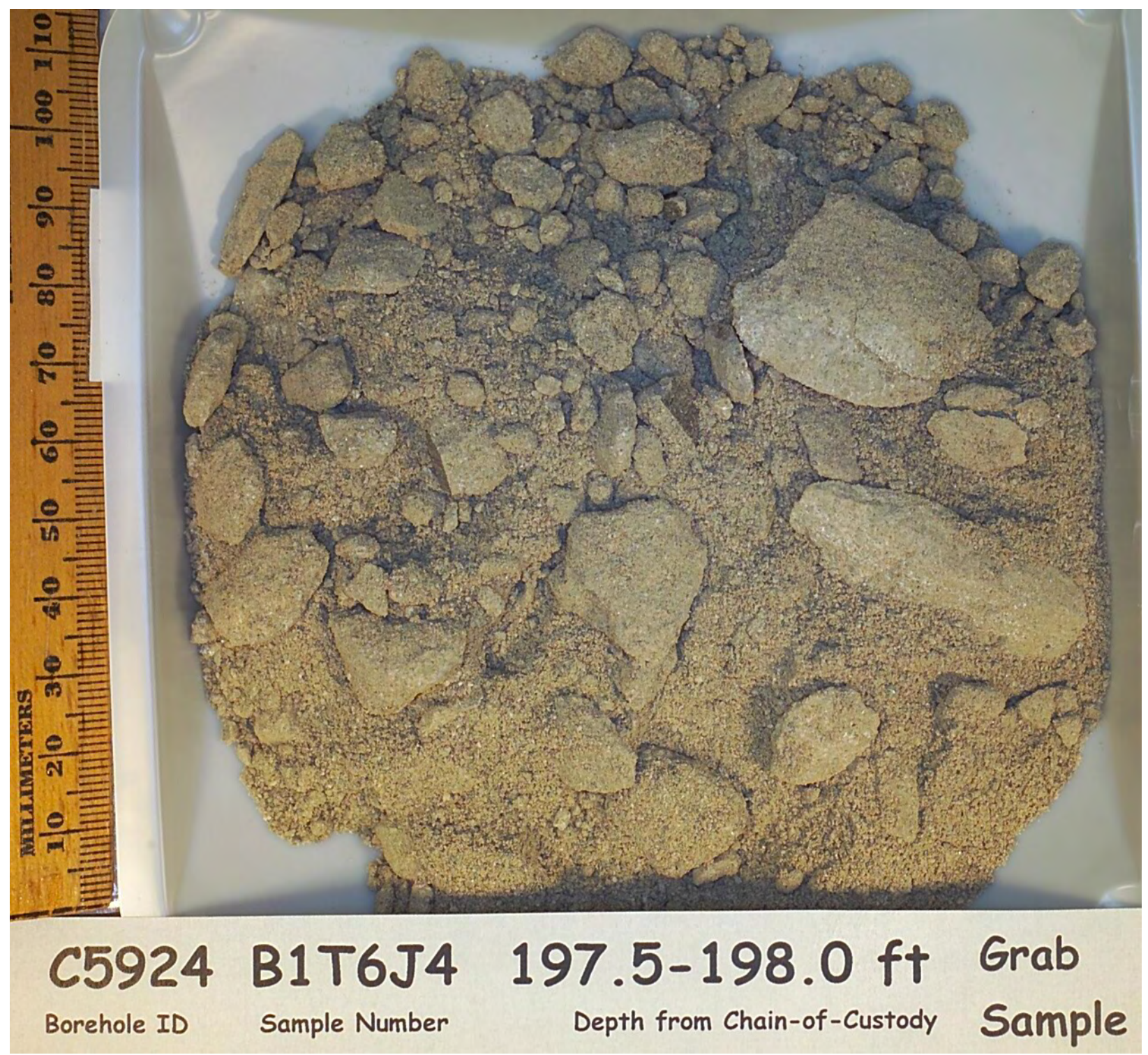


PNNL-17821

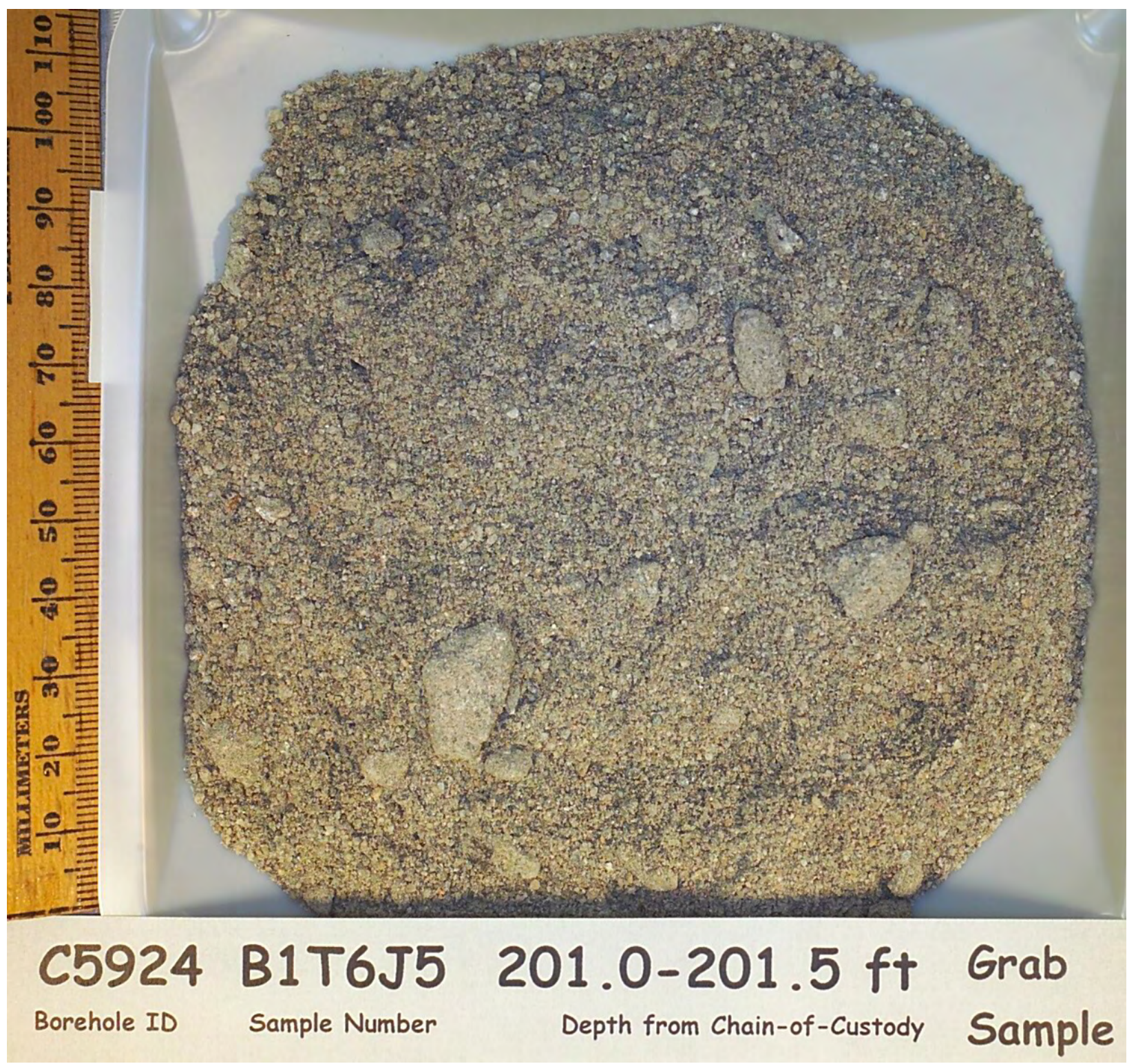


PNNL-17821

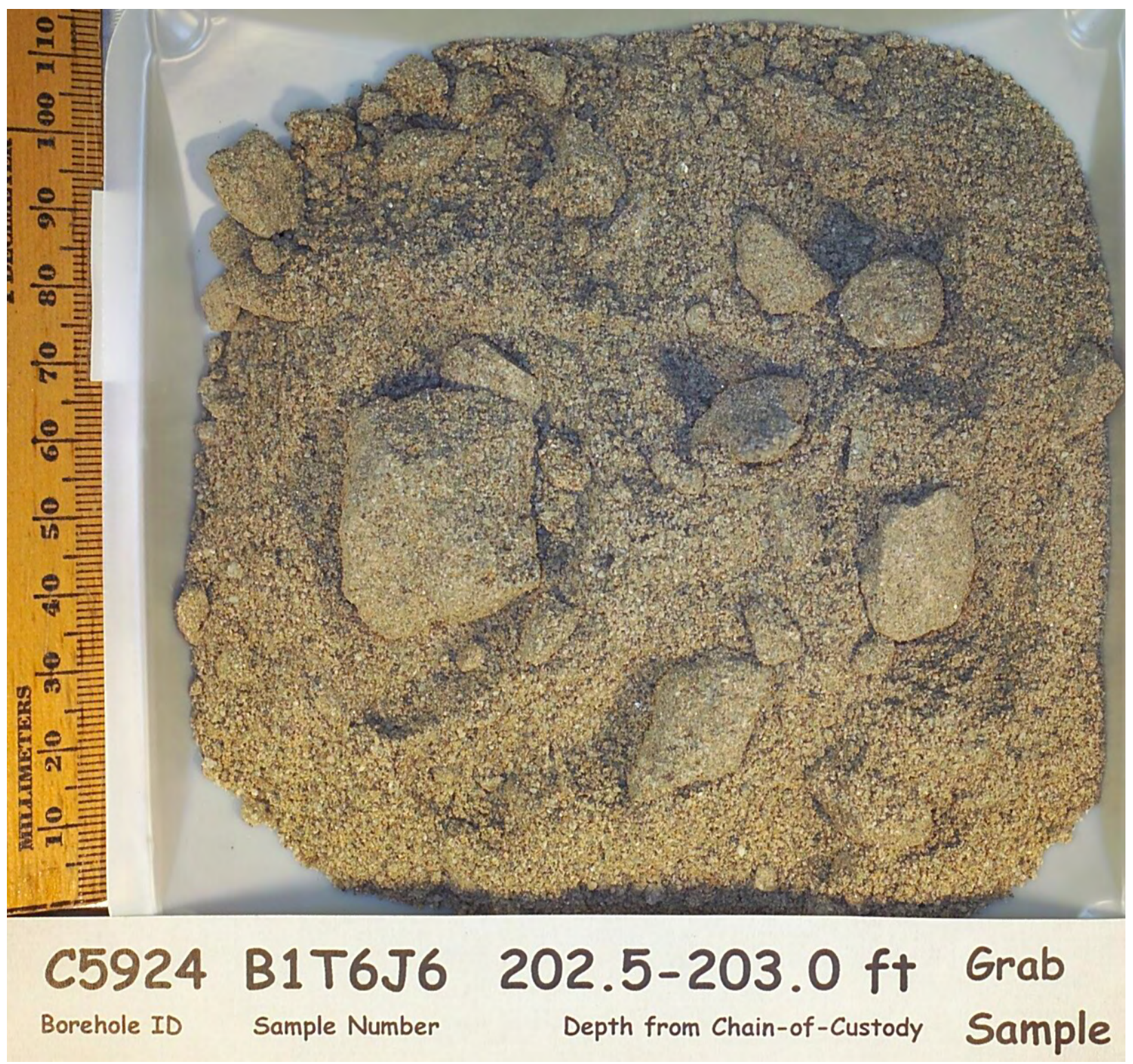




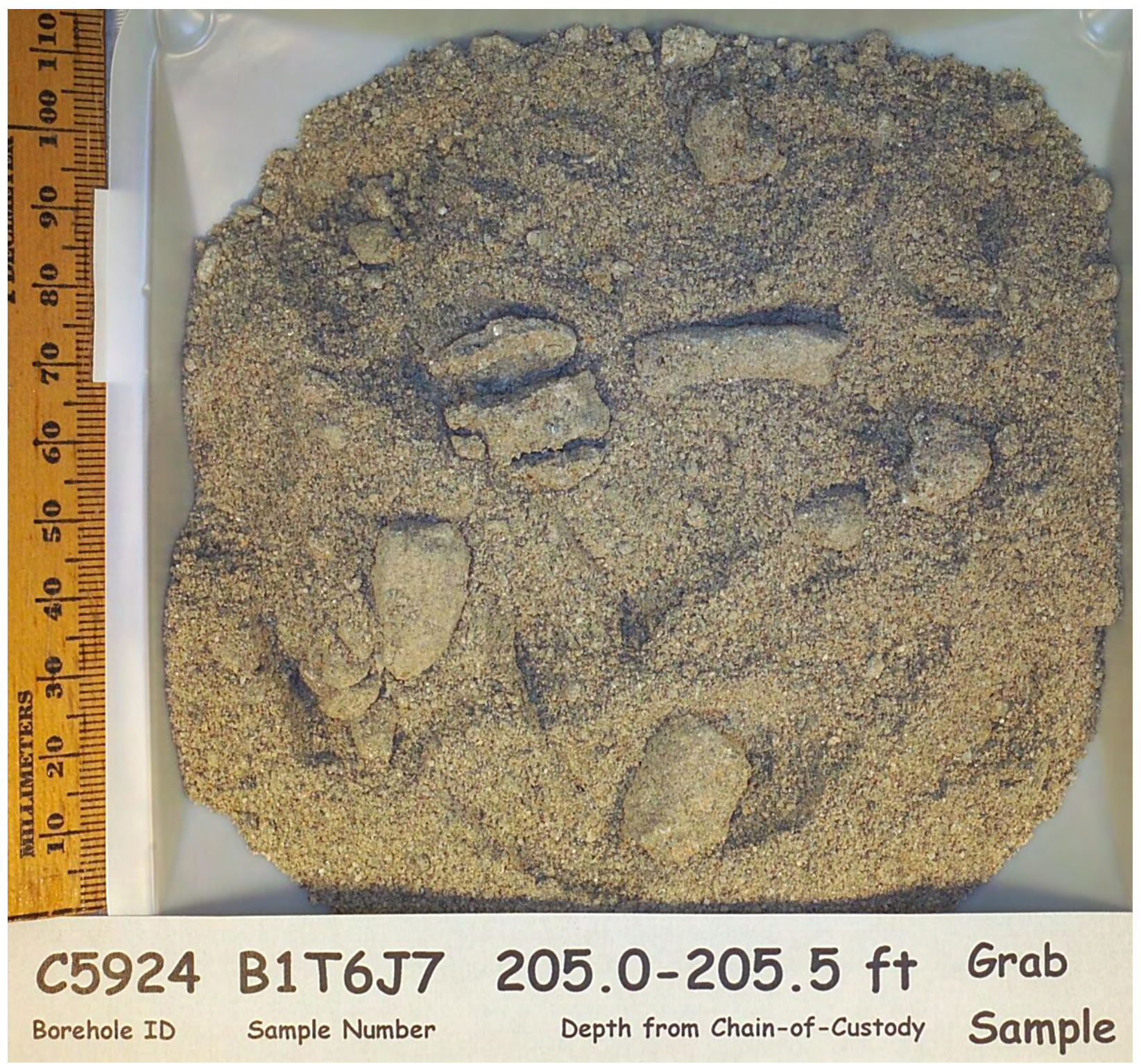




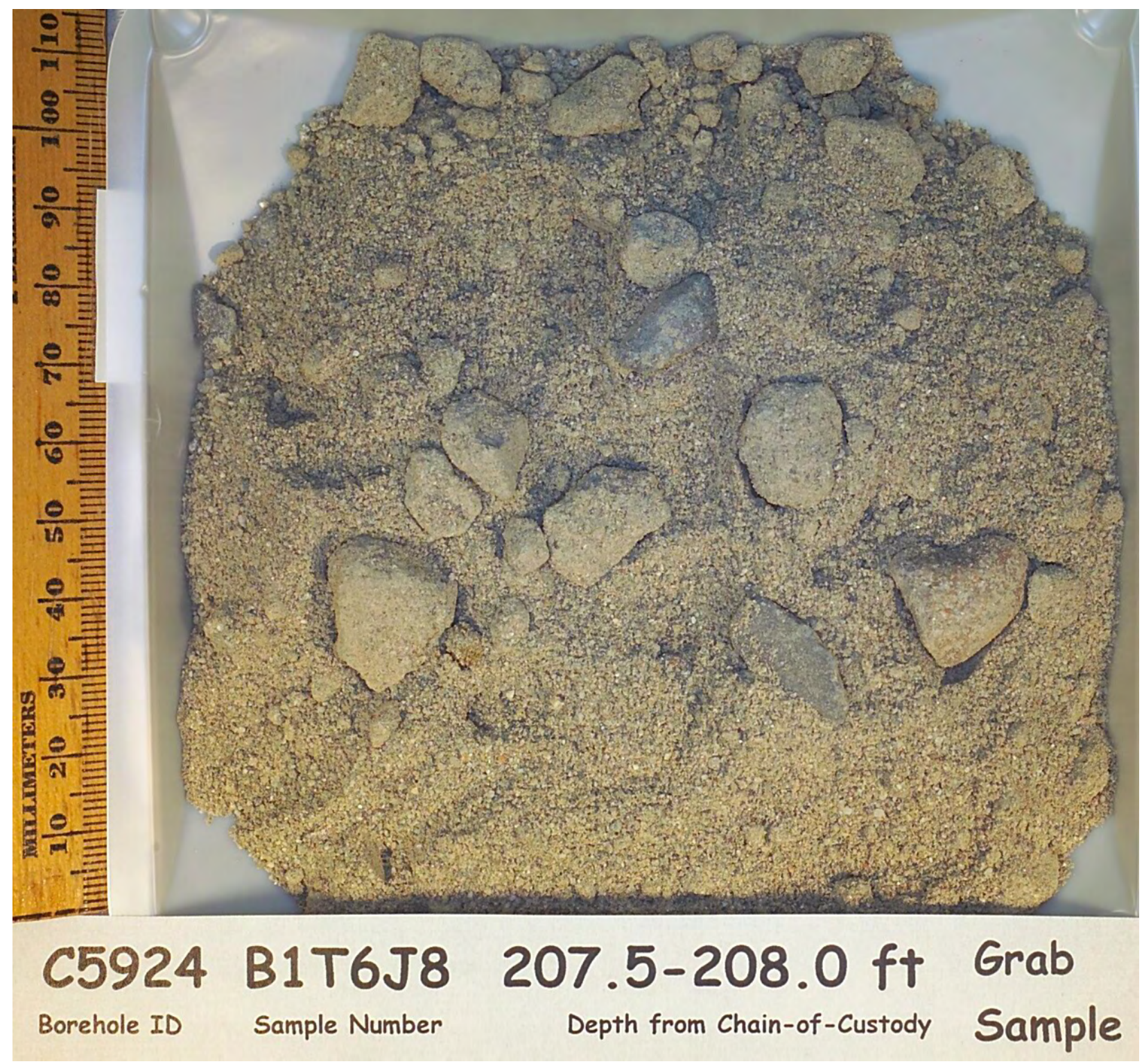




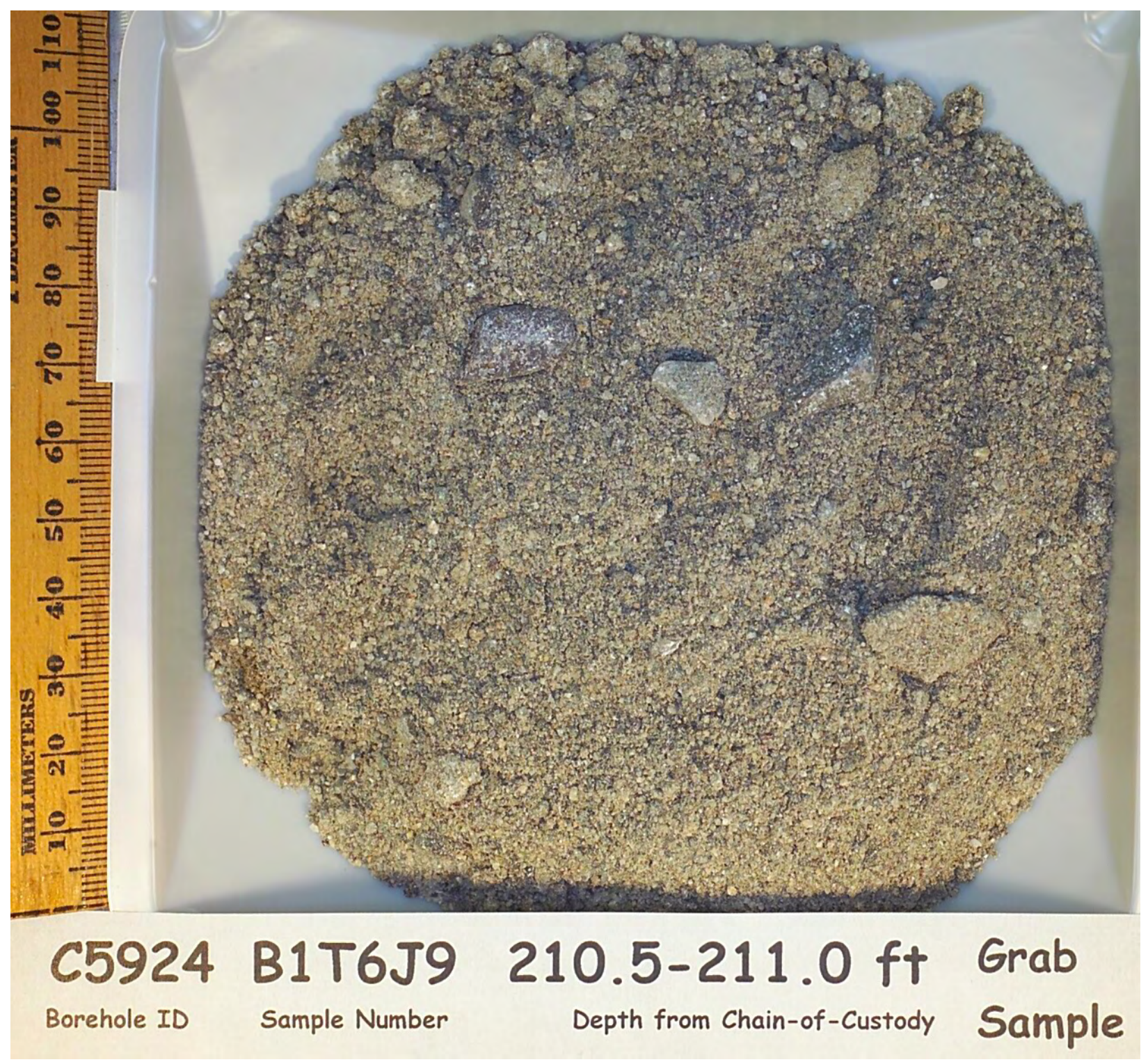


PNNL-17821

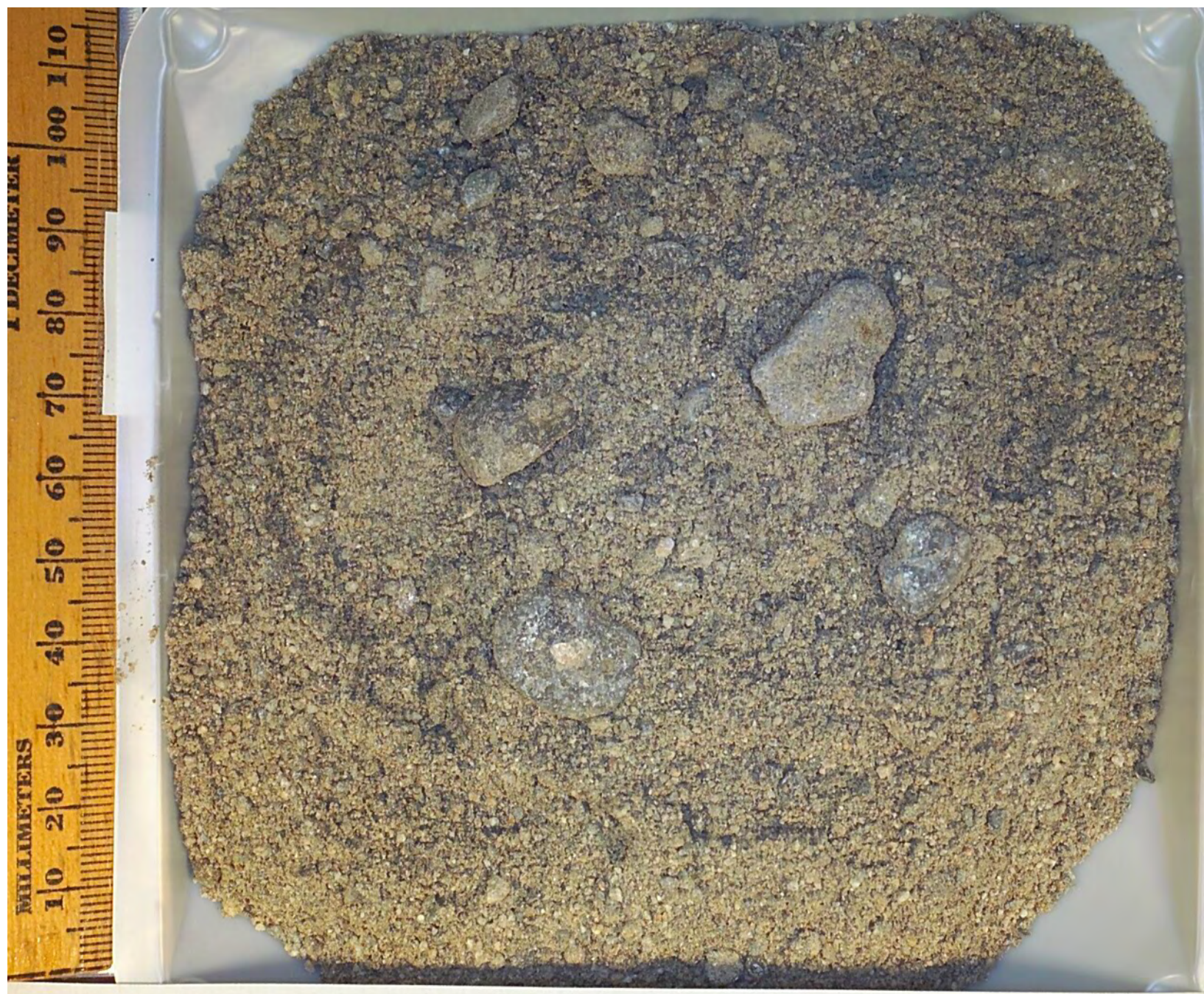

\section{C5924 B1T6KO \\ $212.0-212.5 \mathrm{ft}$ \\ Grab \\ Borehole ID \\ Sample Number \\ Depth from Chain-of-Custody \\ Sample}


PNNL-17821

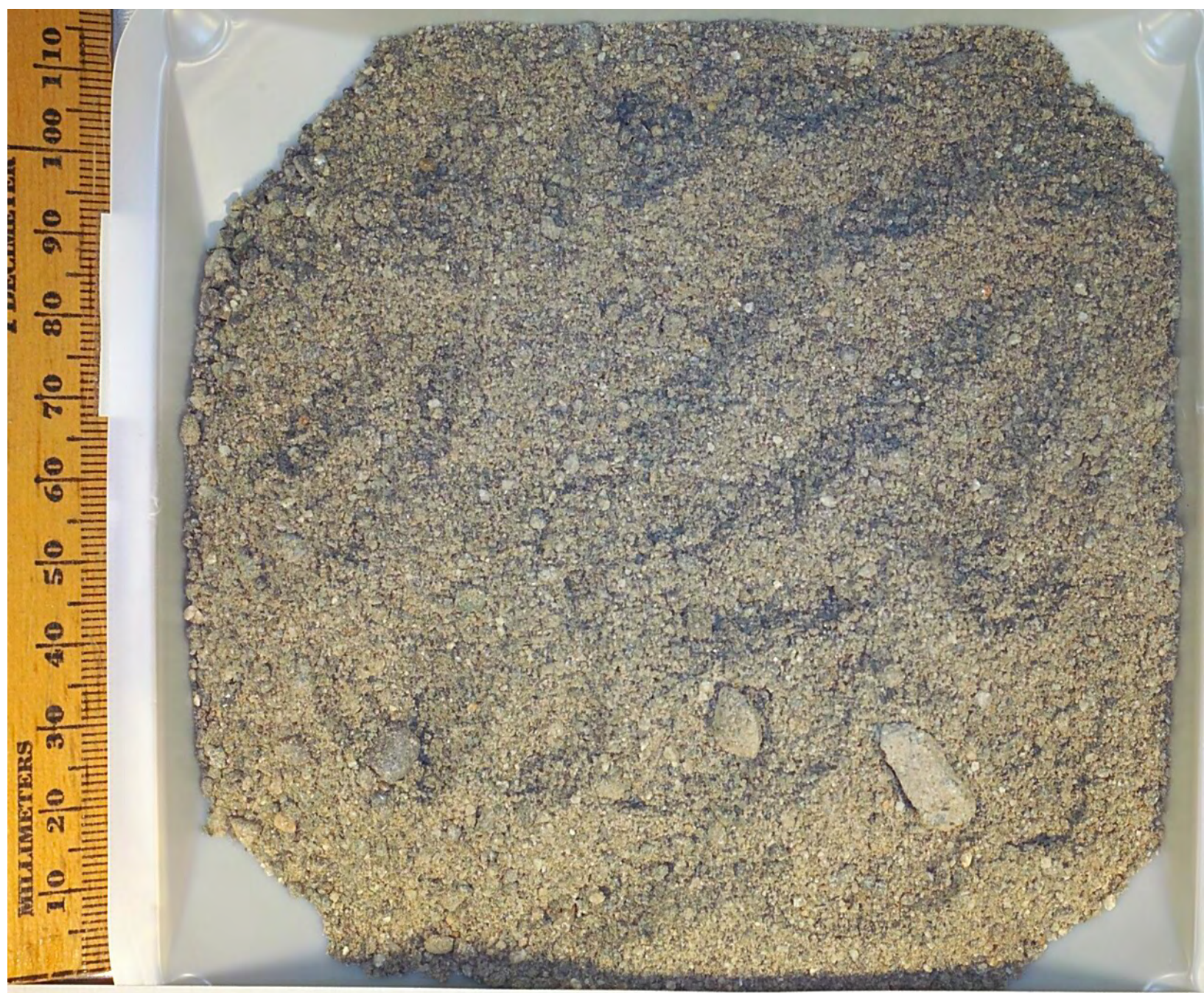

\section{C5924 B1T6K1 215.0-215.5 ft Grab Borehole ID Sample Number Depth from Chain-of-Custody Sample}


PNNL-17821

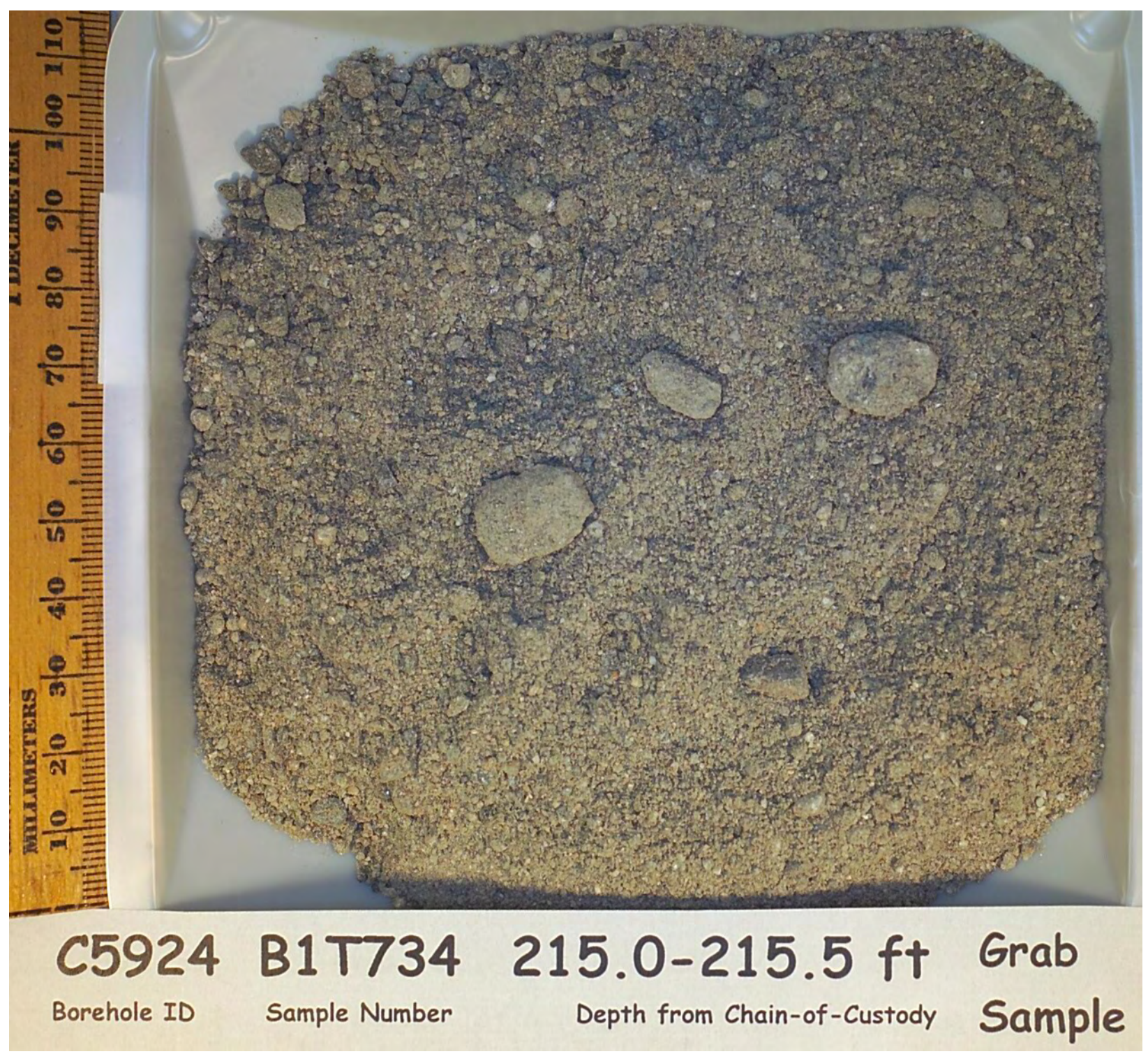




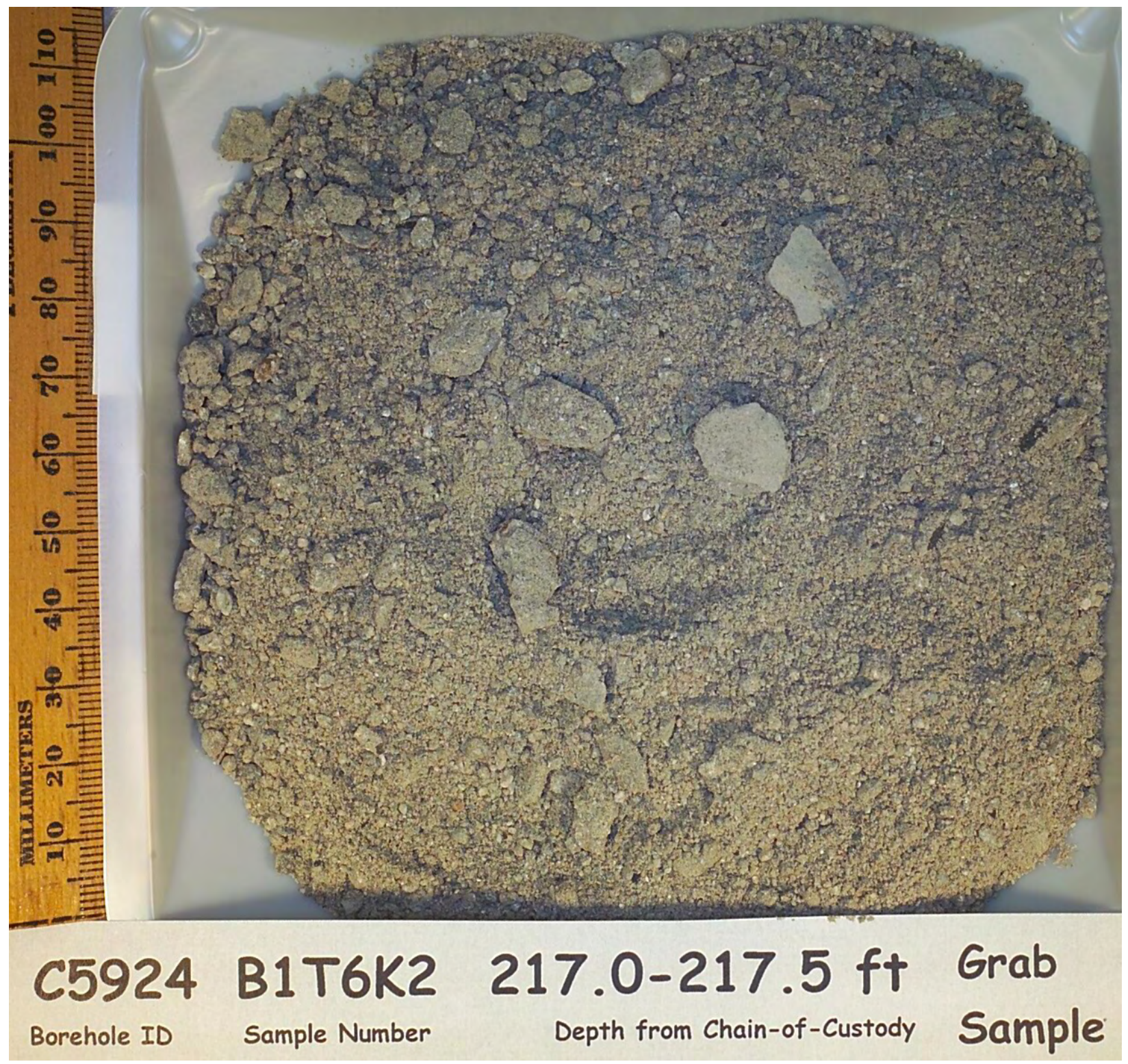




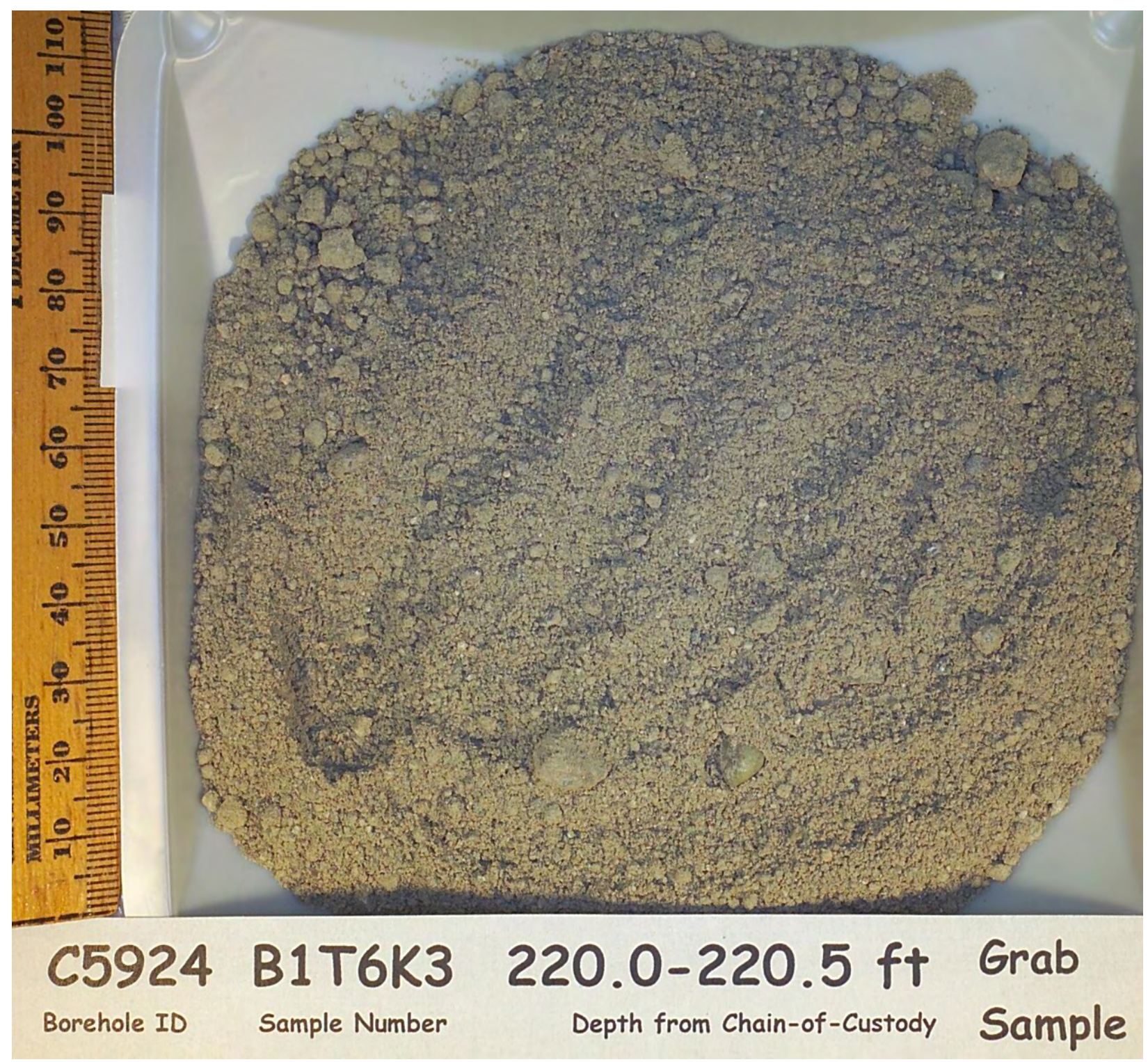




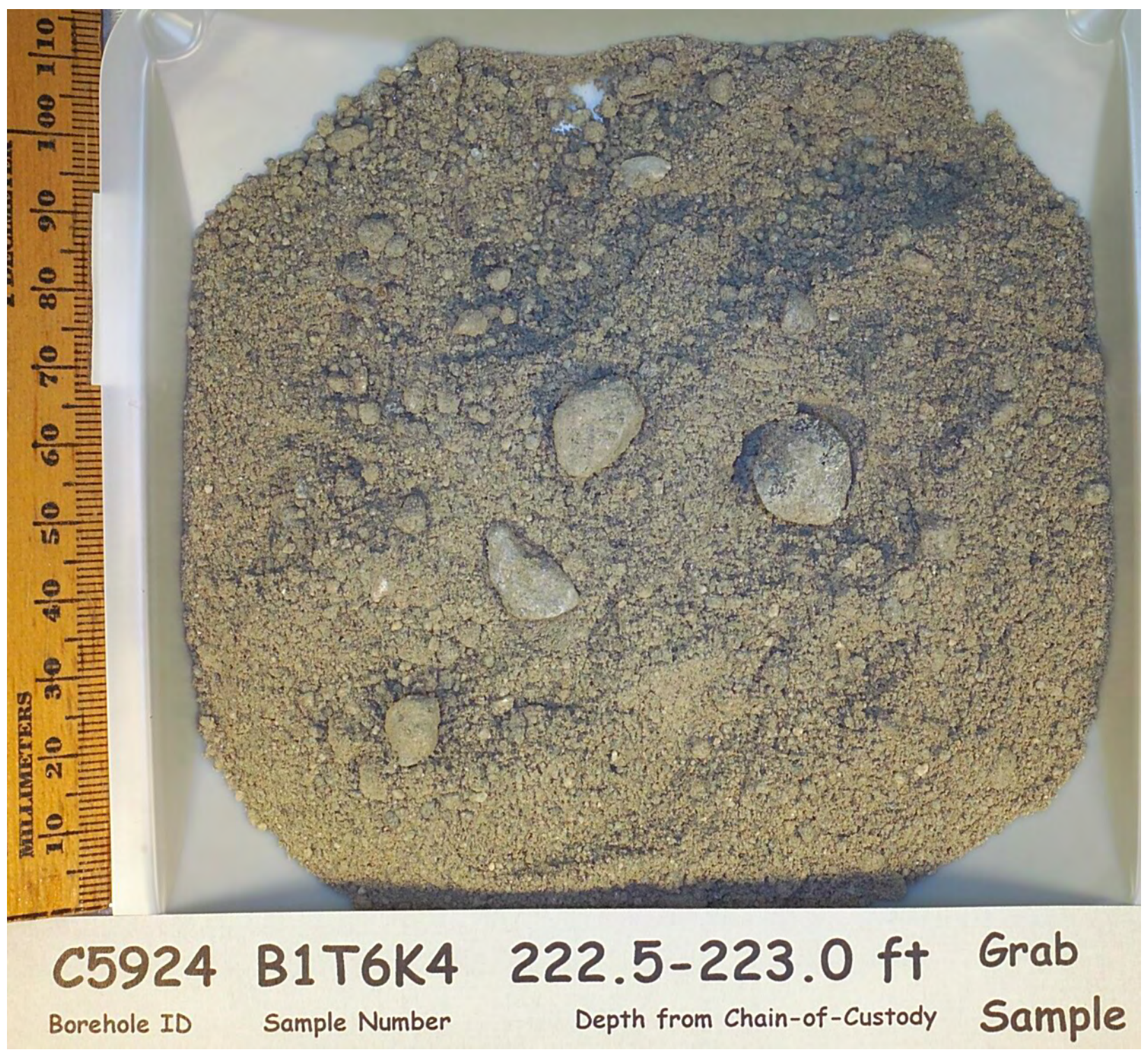




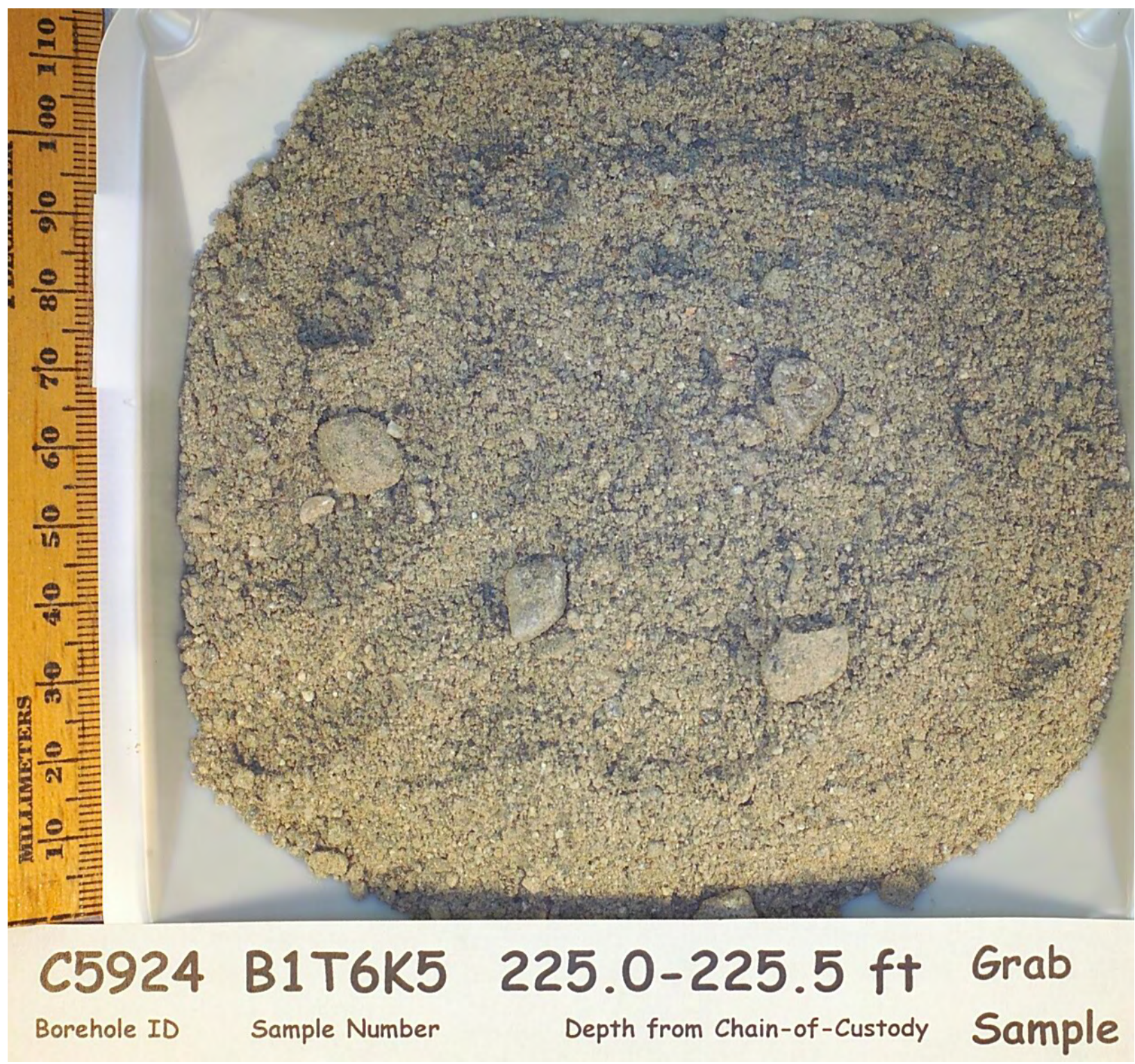




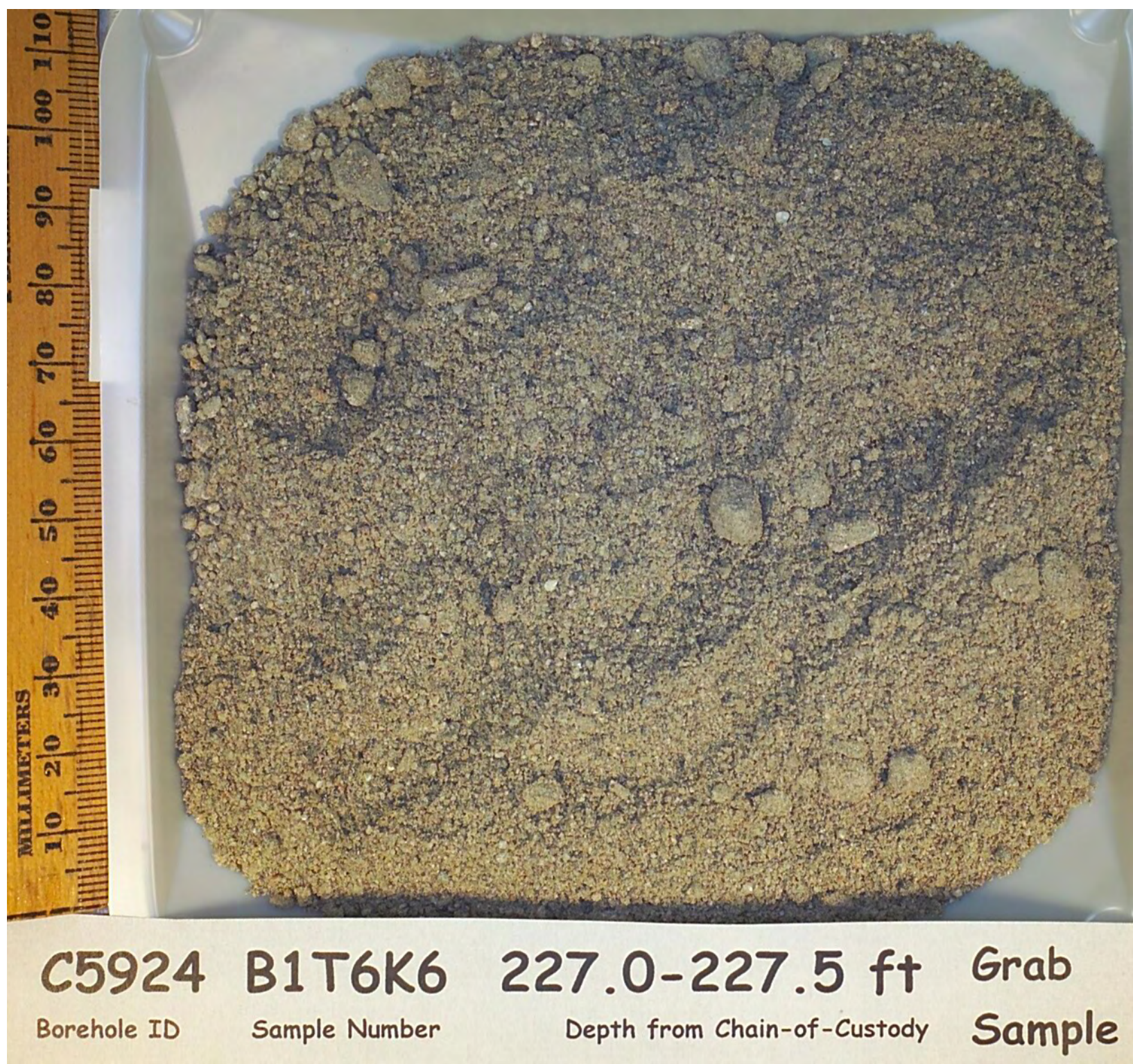


PNNL-17821

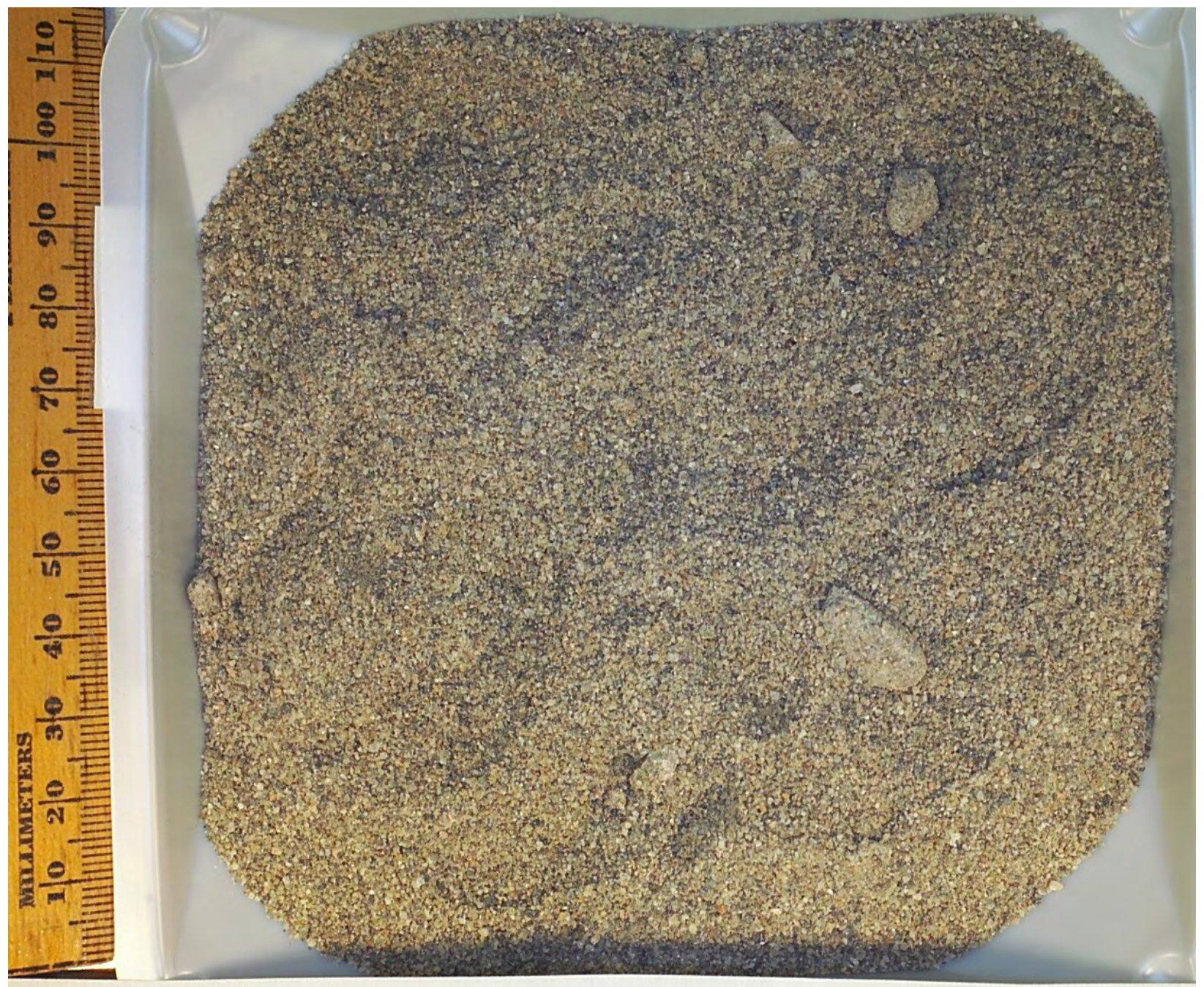

\section{C5924 B1T6K7 230.0-230.5 ft Grab Borehole ID Sample Number Depth from Chain-of-Custody Sample}




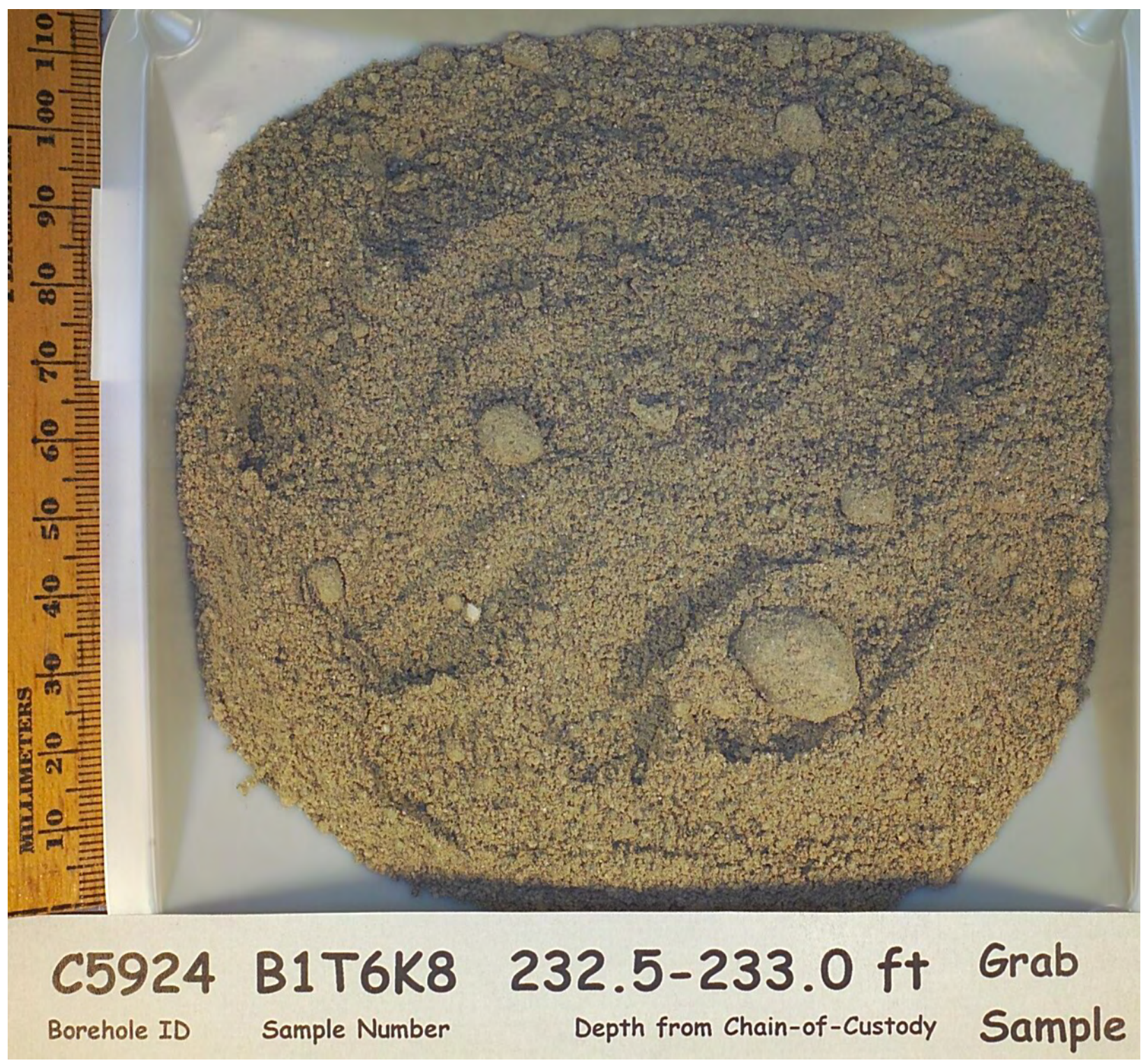


PNNL-17821

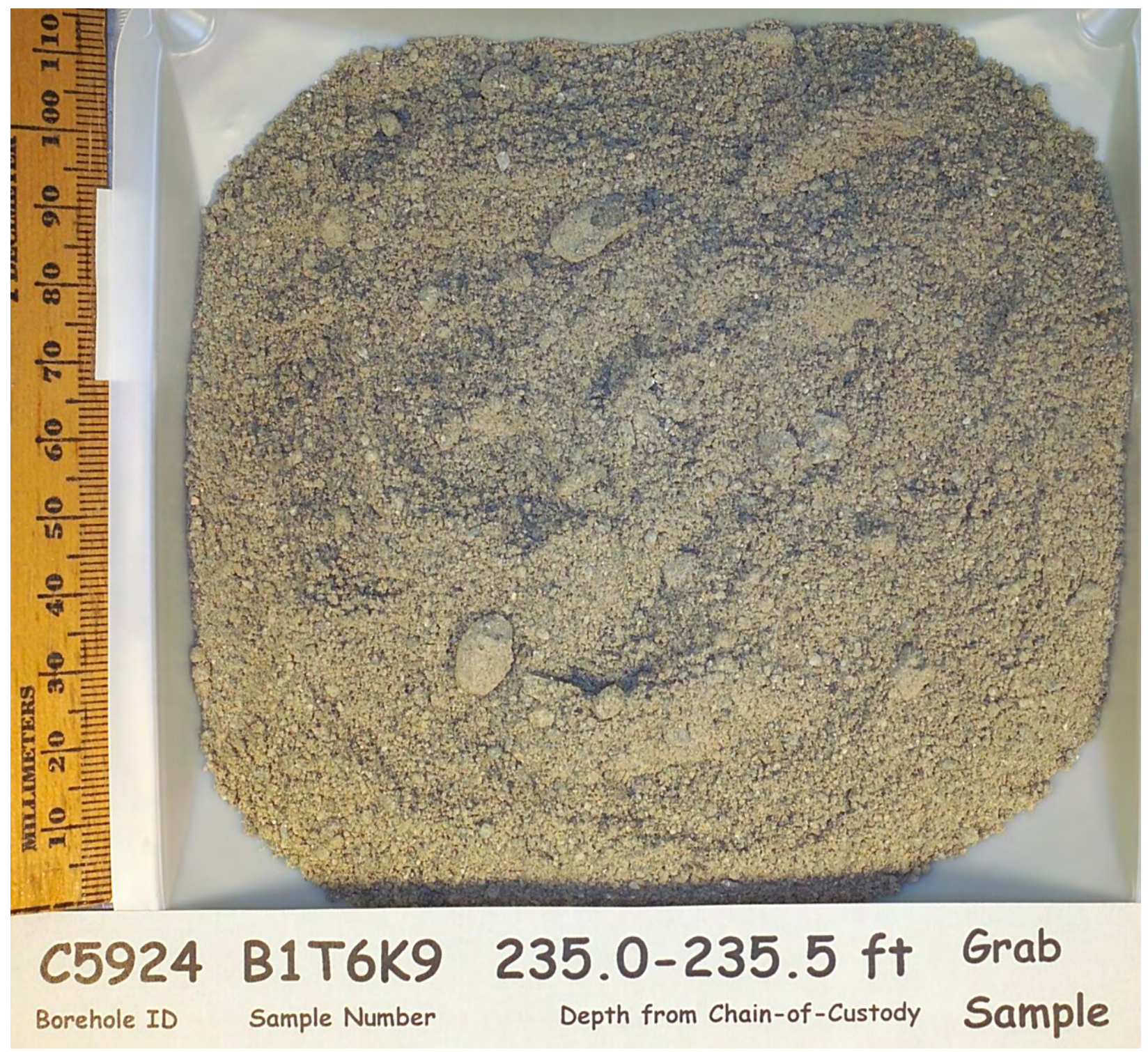


PNNL-17821

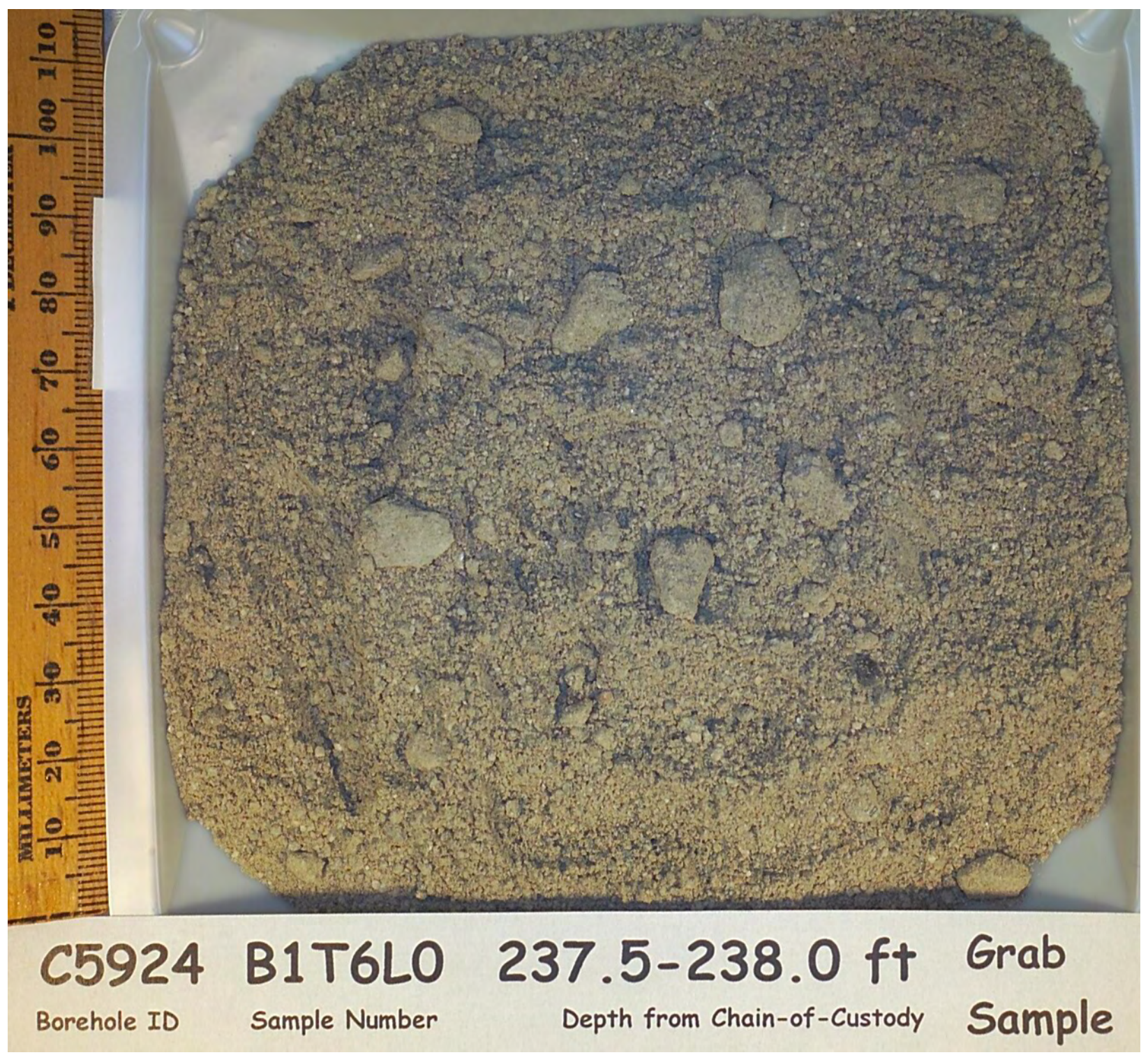




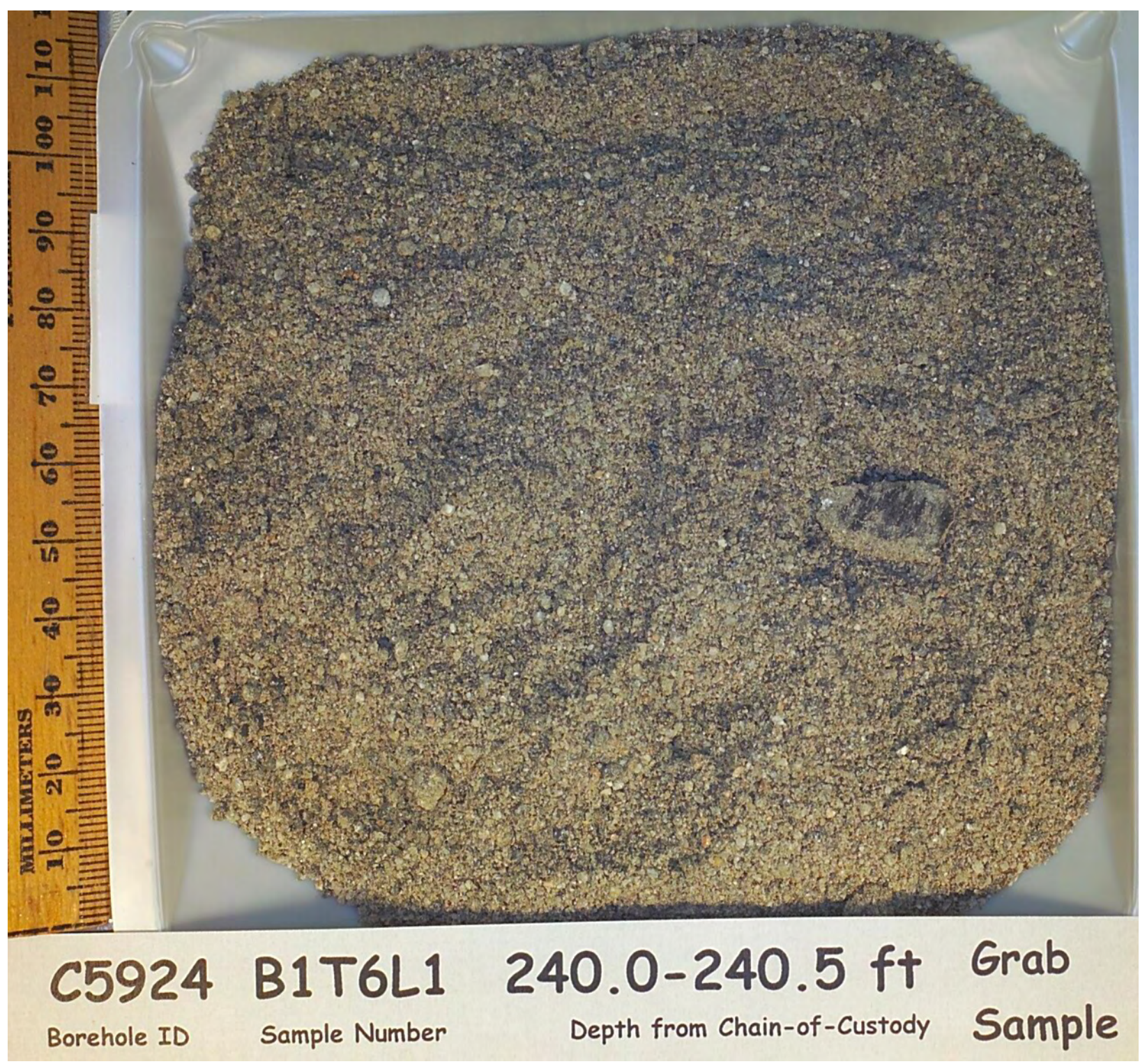




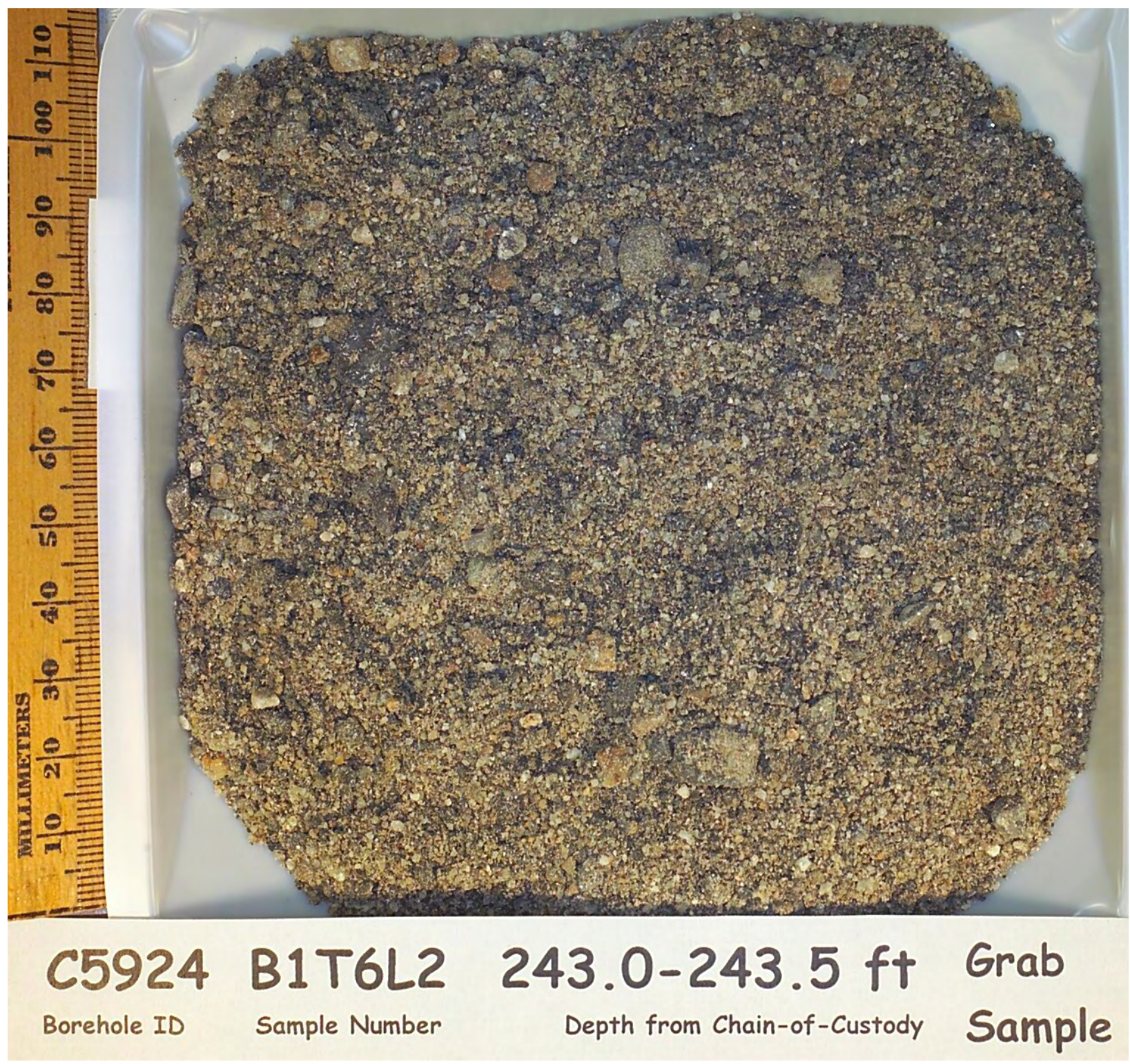




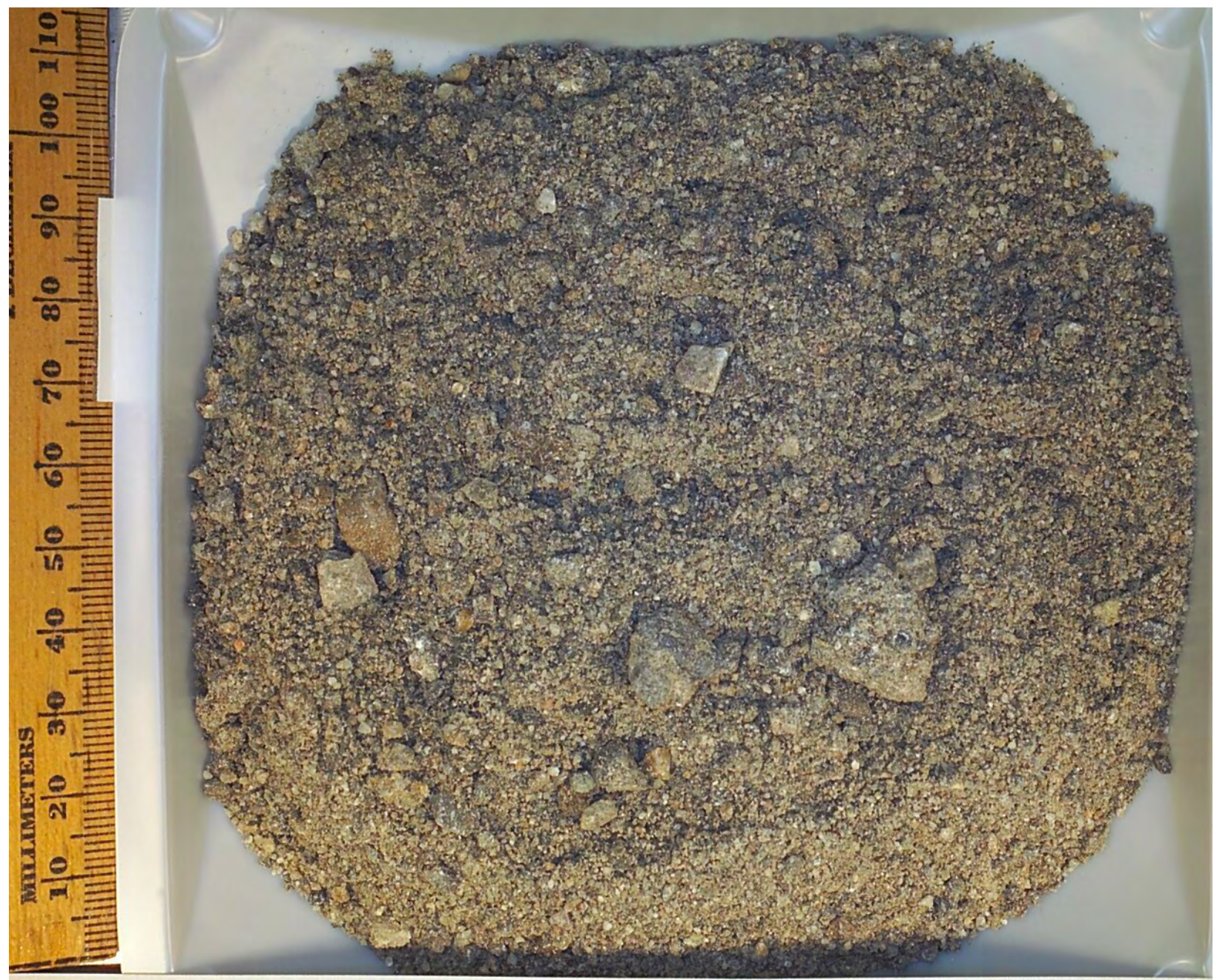

\section{C5924 B1T6L3 245.0-245.5 ft Grab \\ Borehole ID Sample Number \\ Depth from Chain-of-Custody \\ Sample}




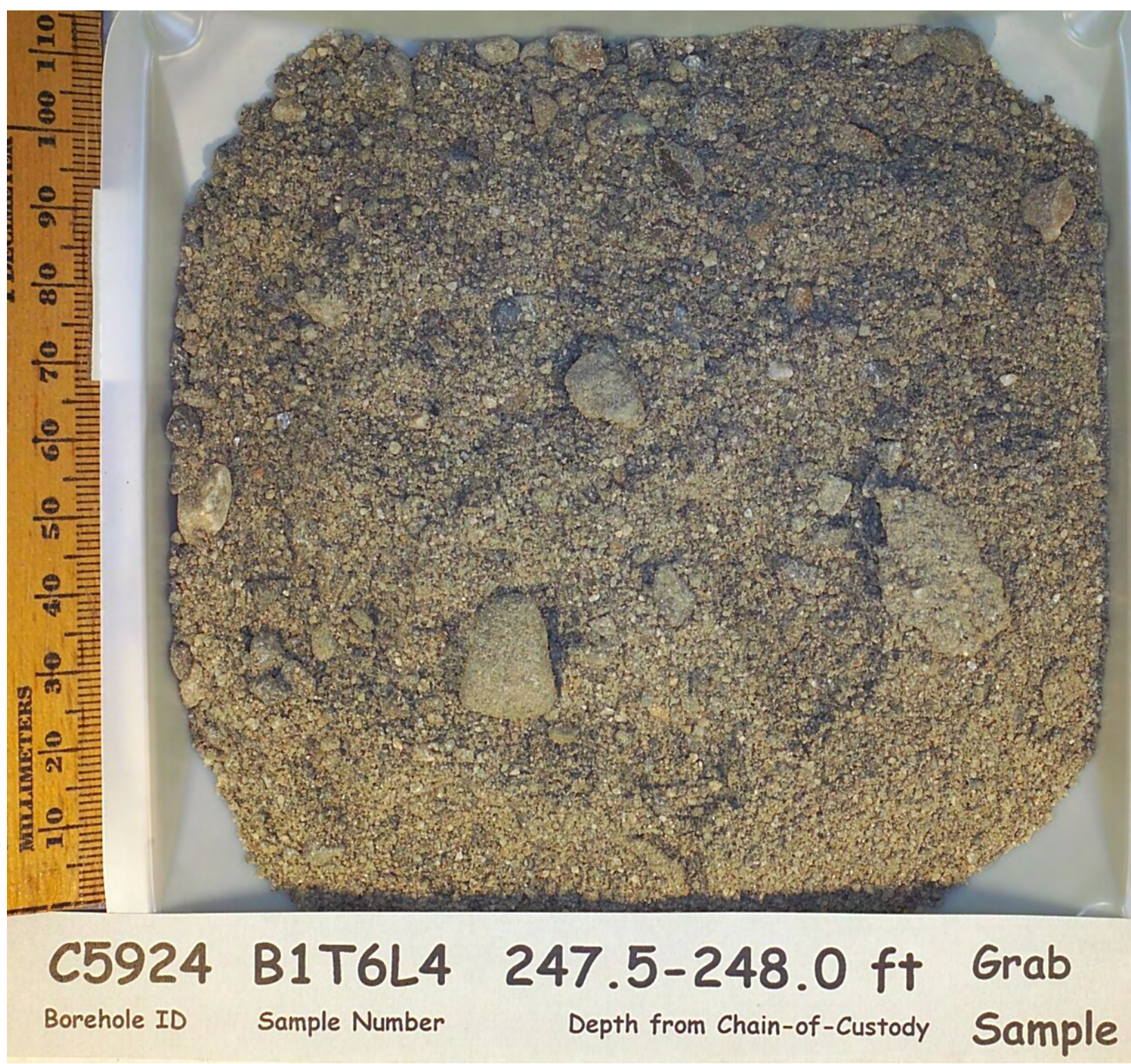


PNNL-17821

Samples from Borehole C5925 (299-E13-64)
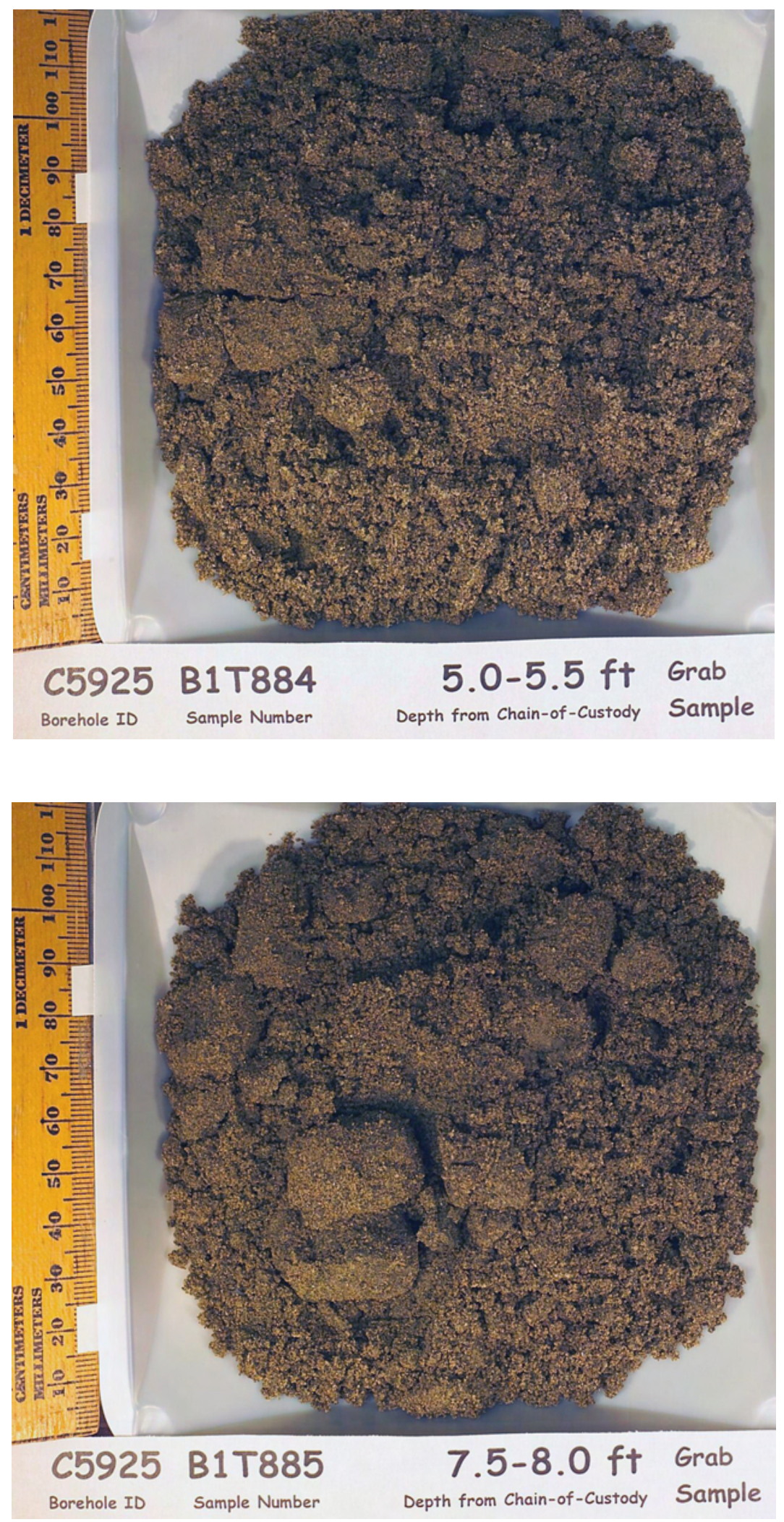
PNNL-17821
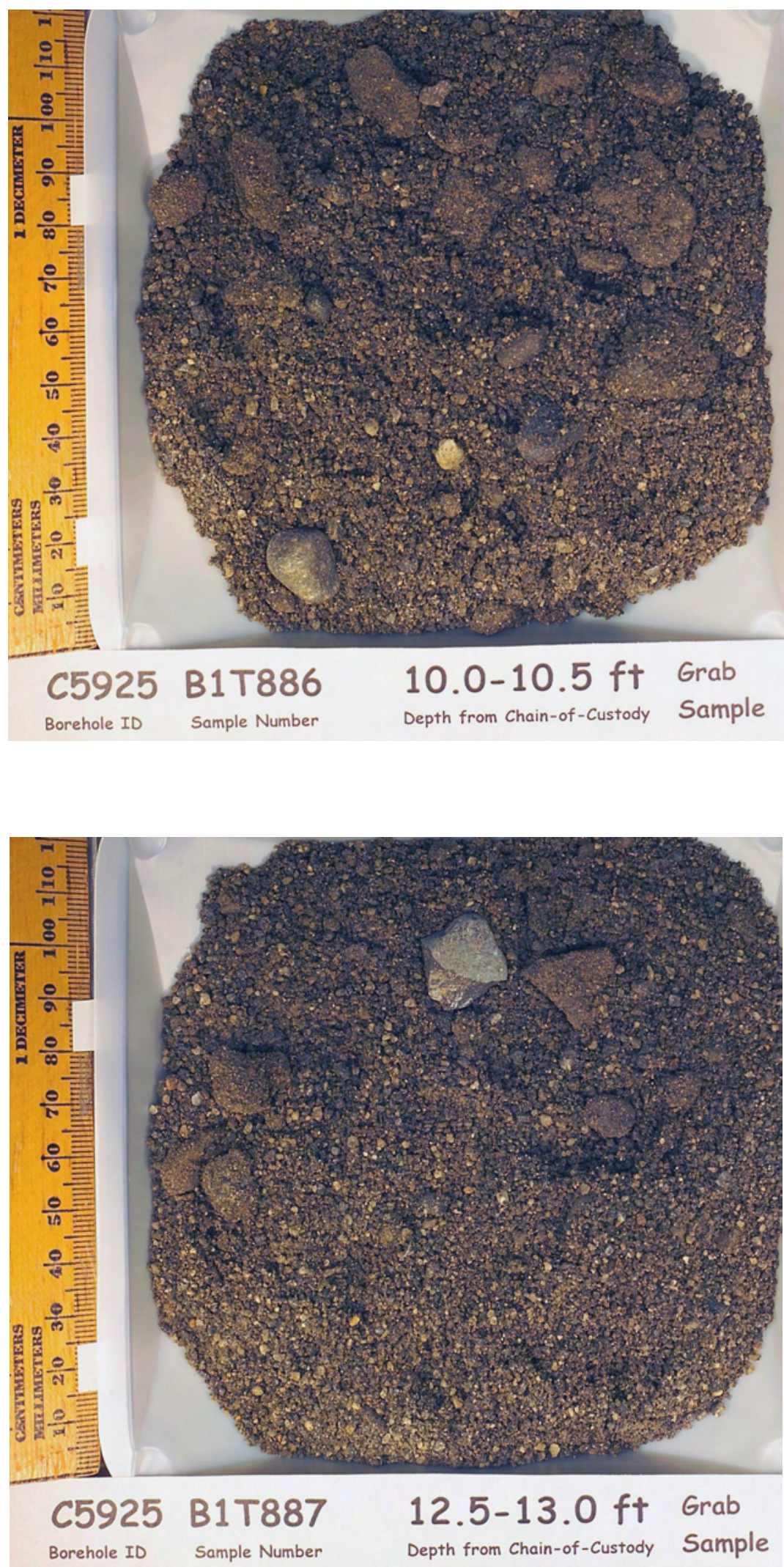
PNNL-17821
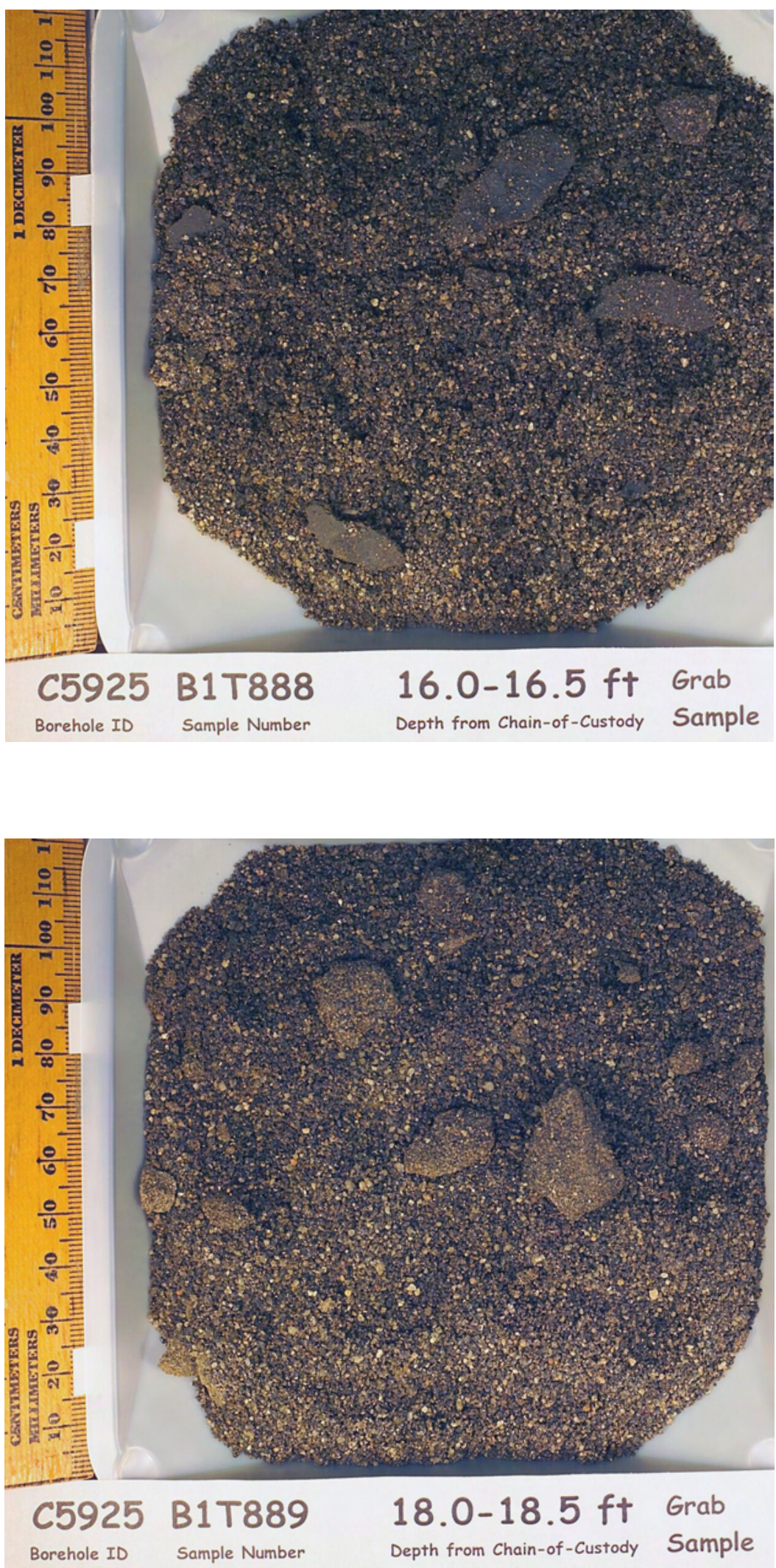
PNNL-17821
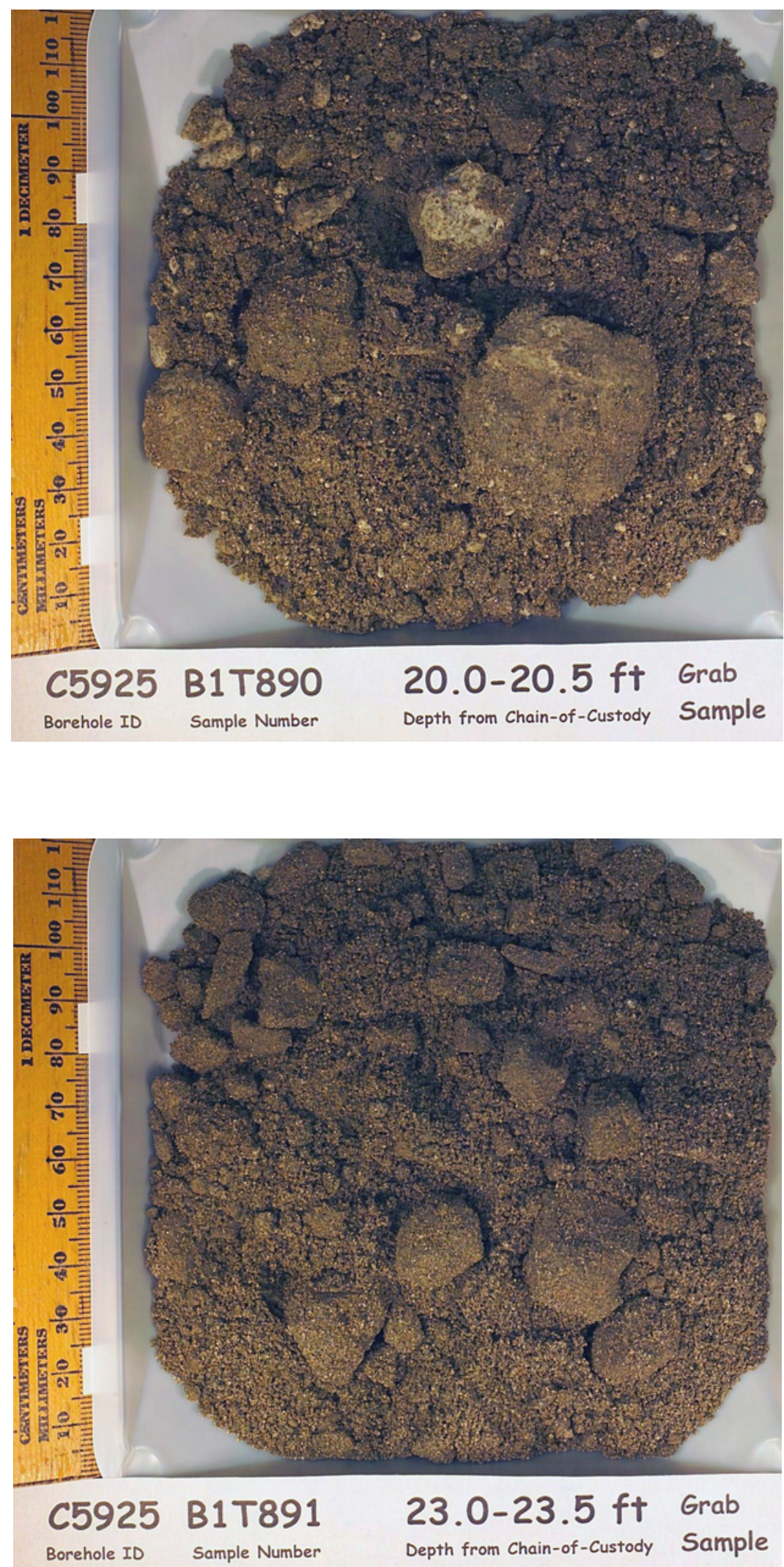
PNNL-17821
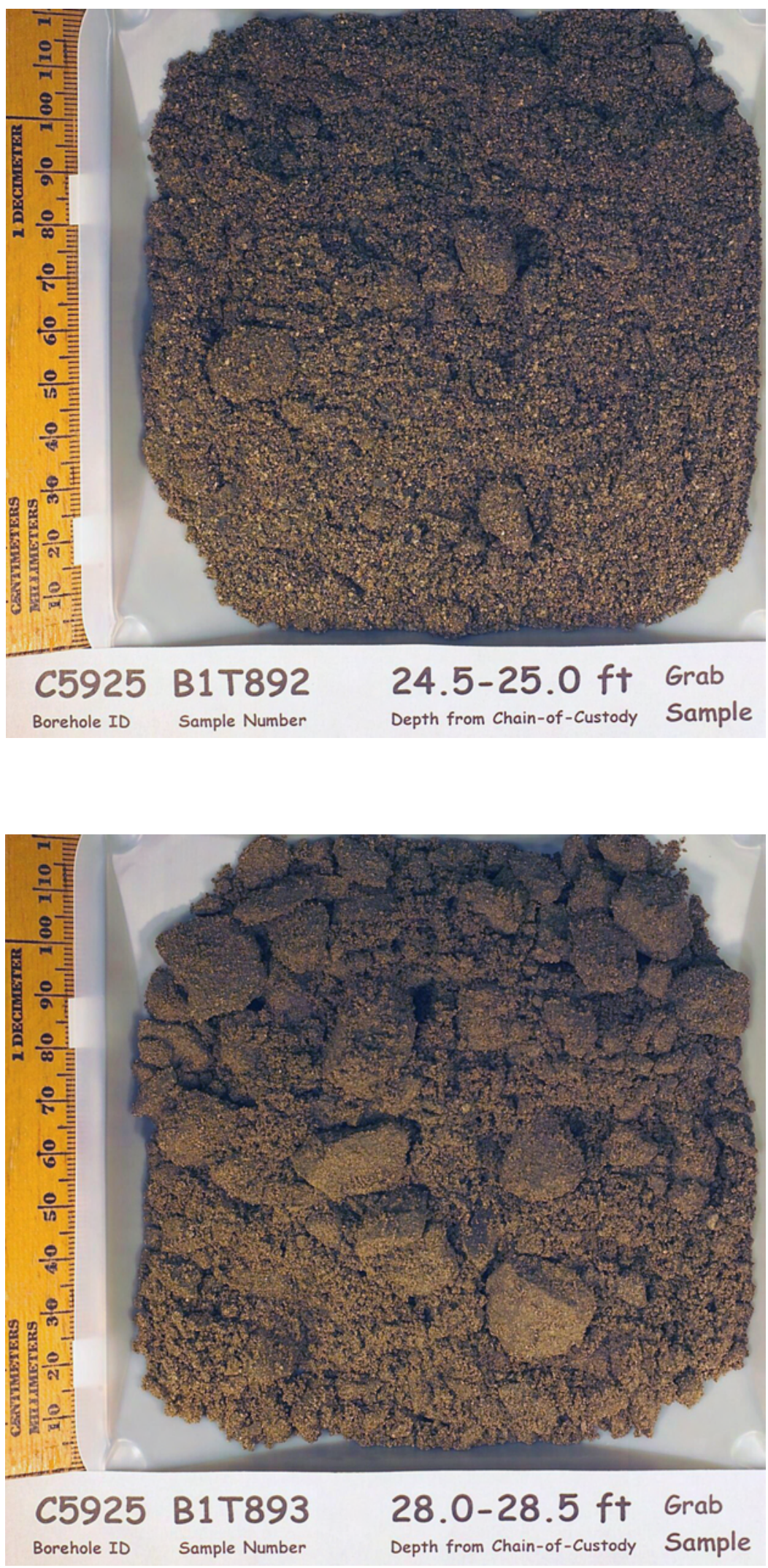
PNNL-17821
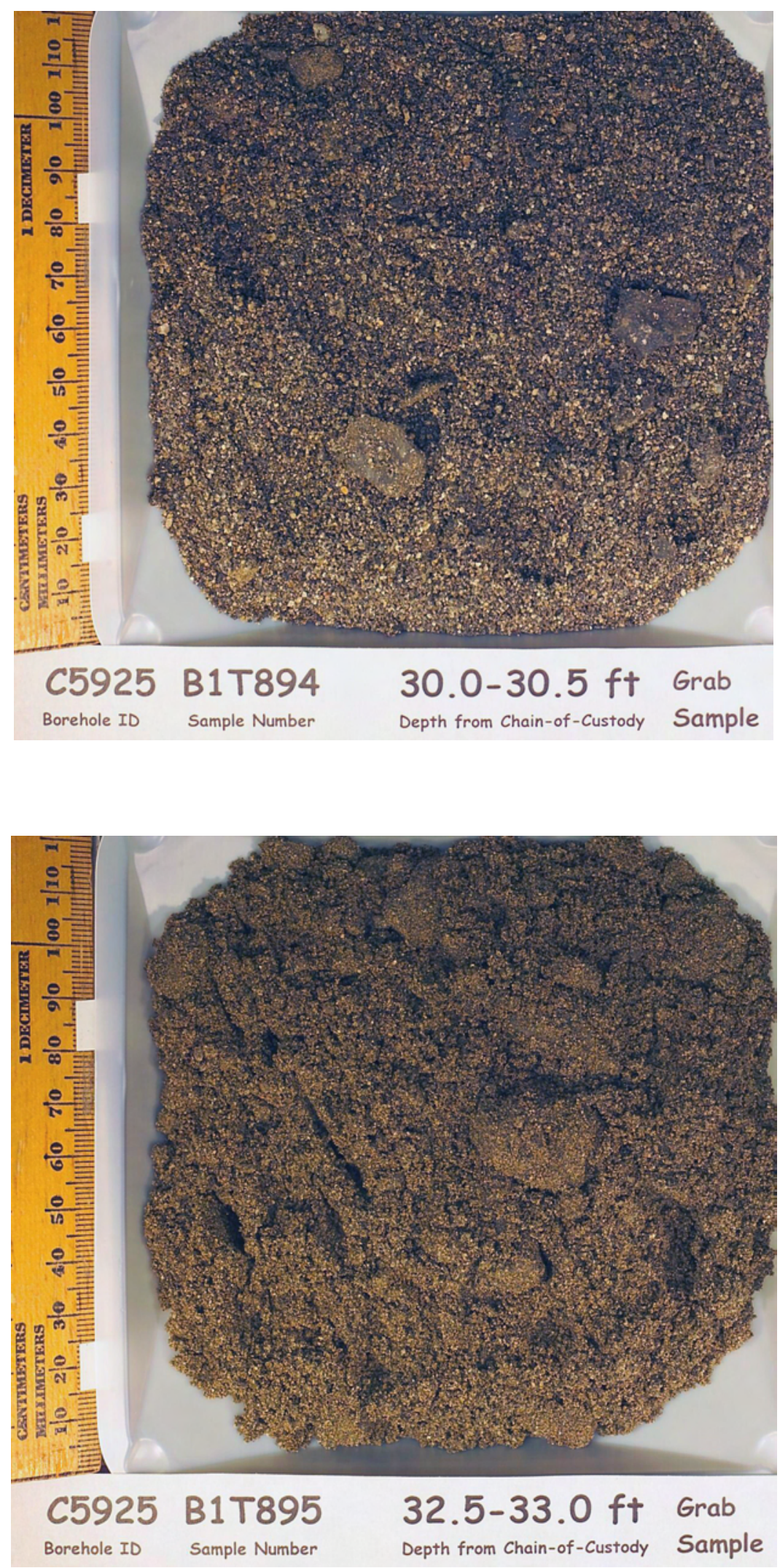
PNNL-17821
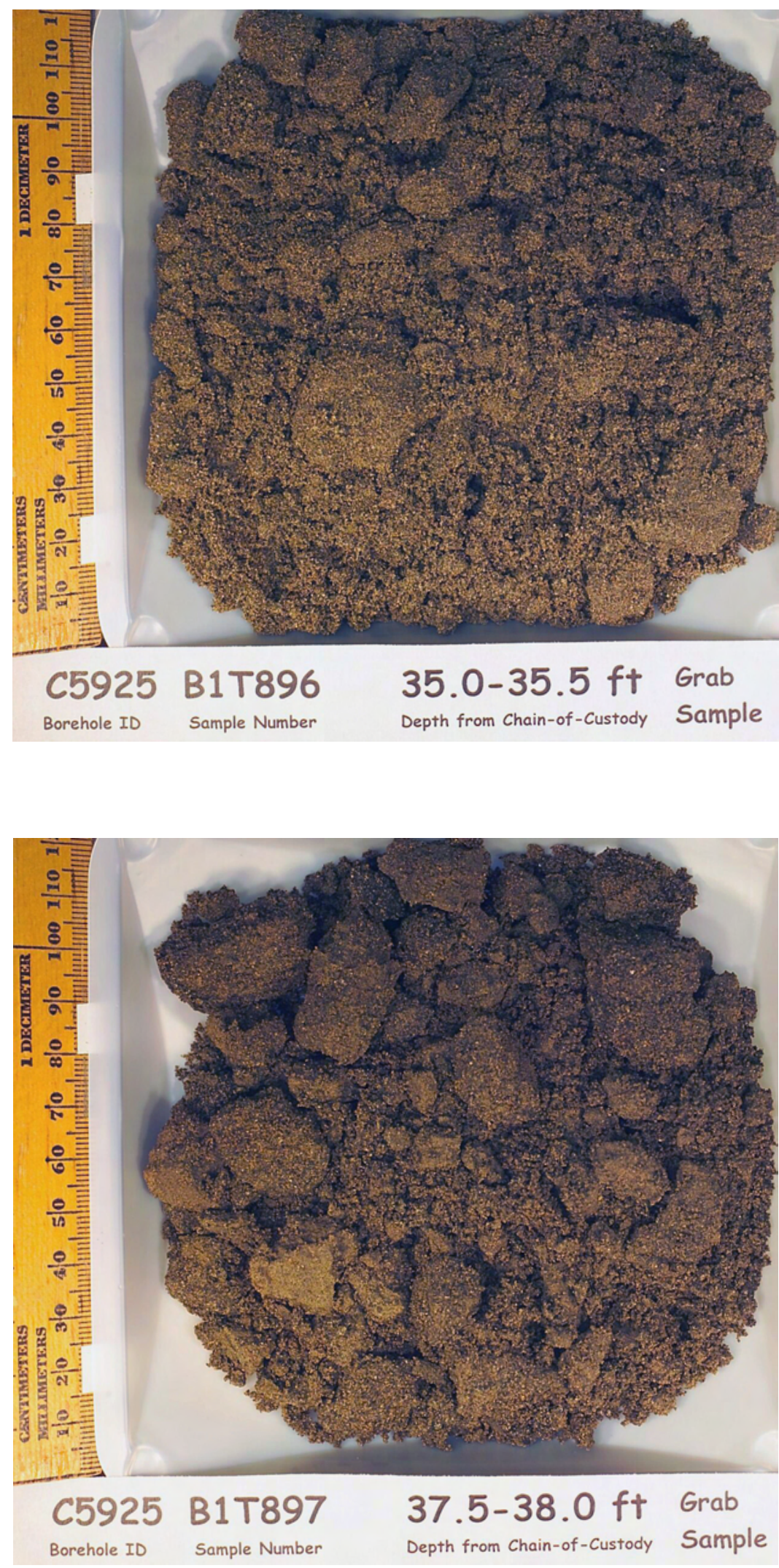
PNNL-17821
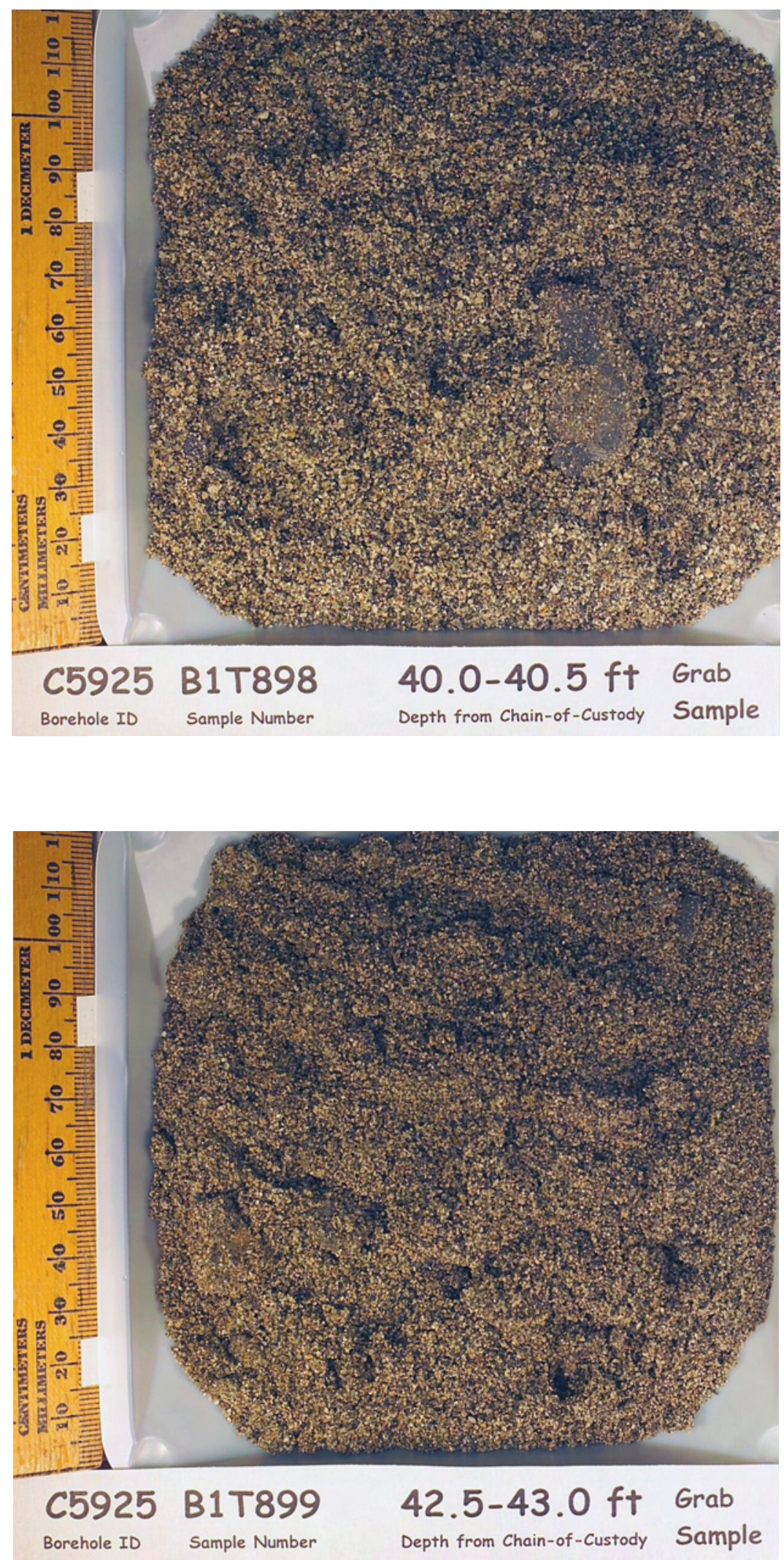
PNNL-17821
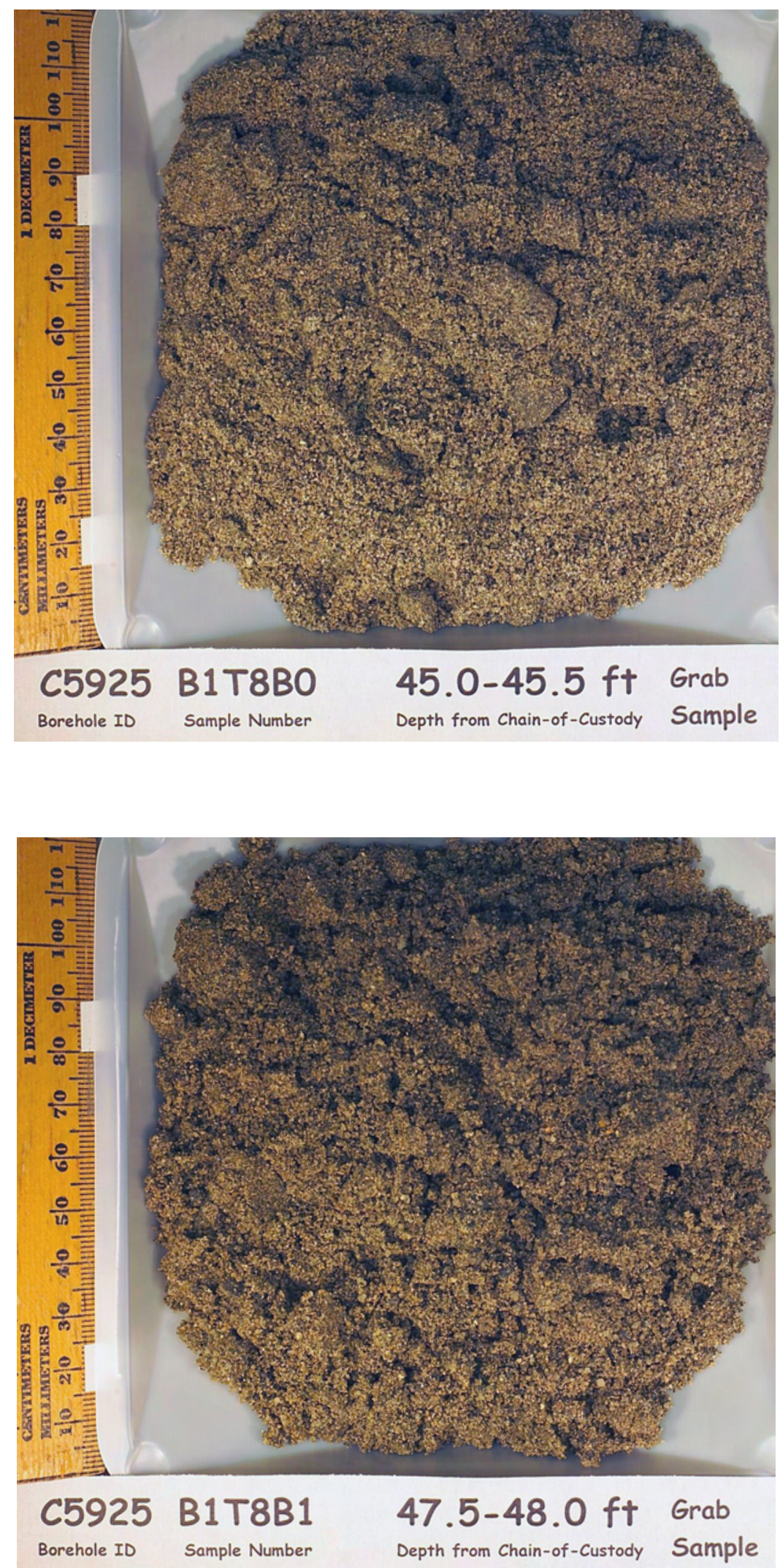
PNNL-17821
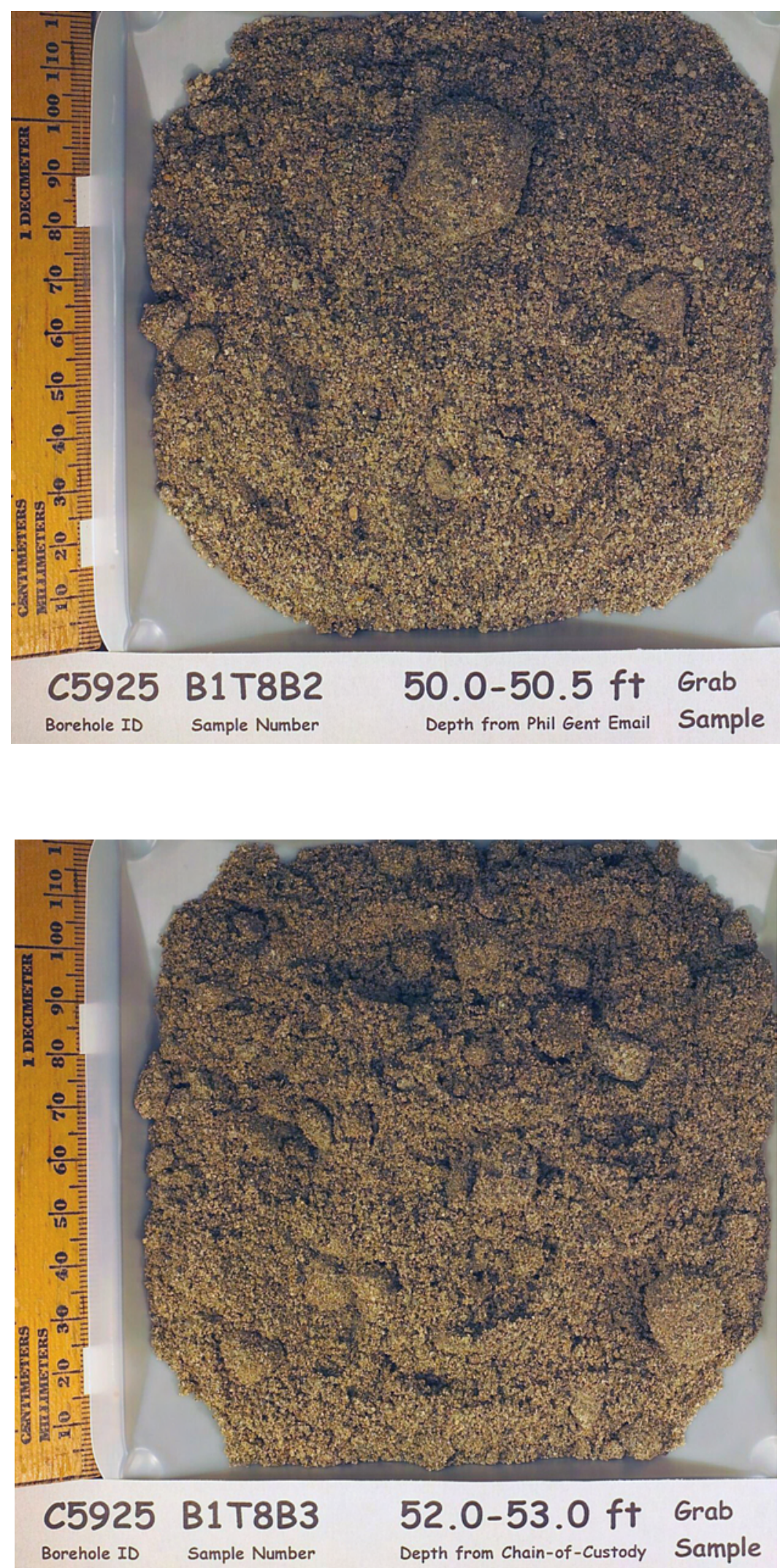
PNNL-17821
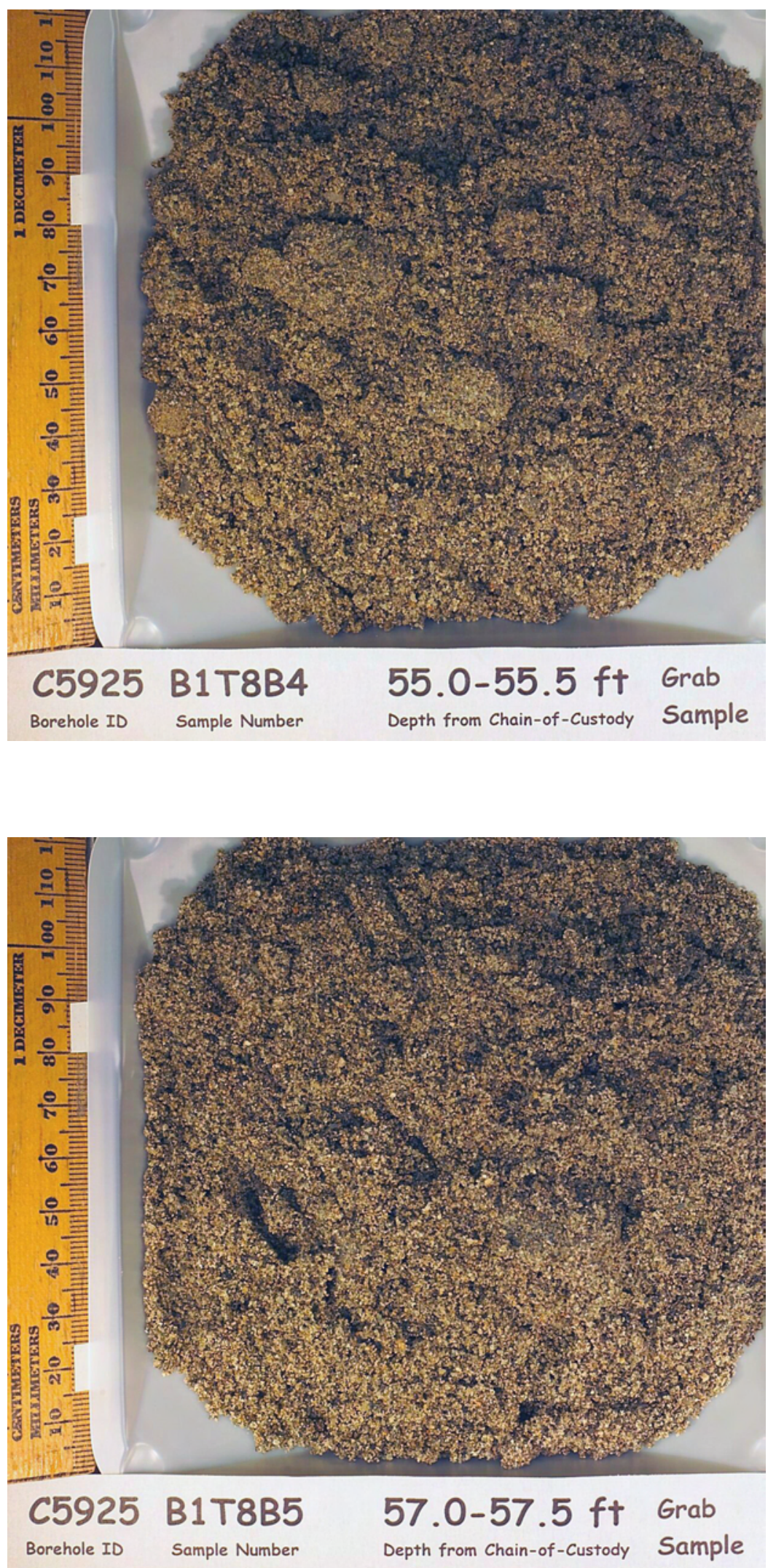
PNNL-17821
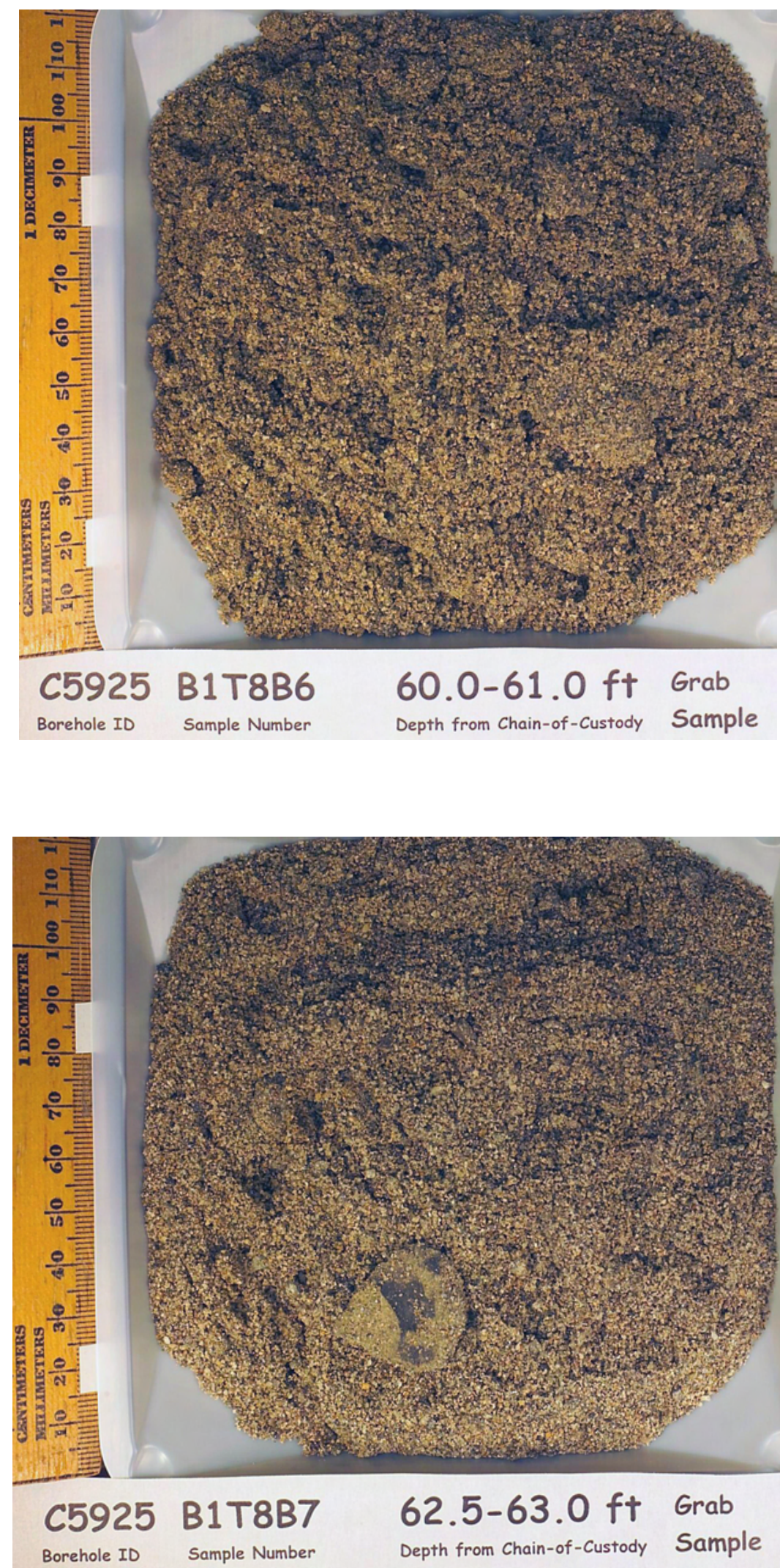
PNNL-17821
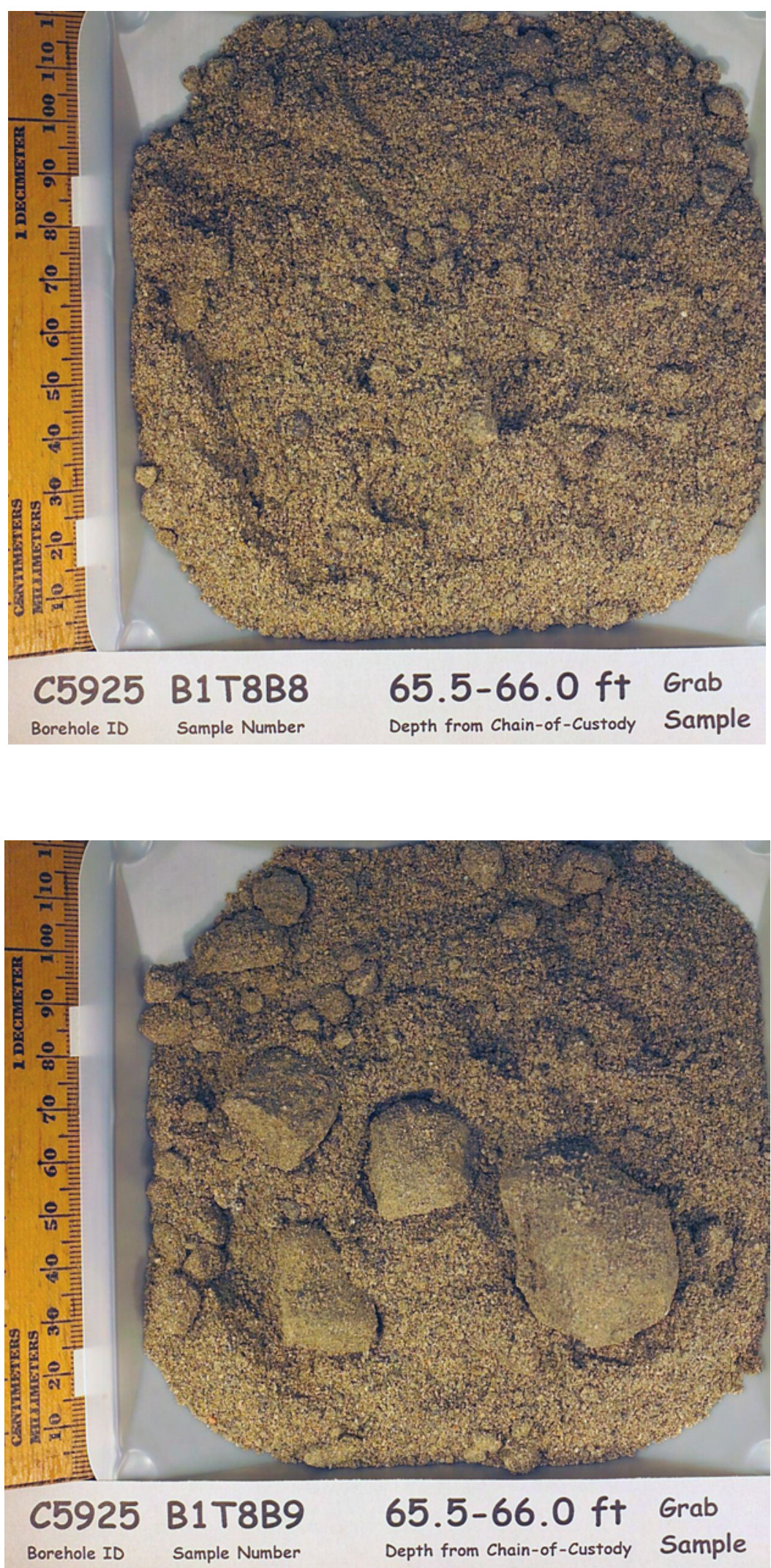
PNNL-17821
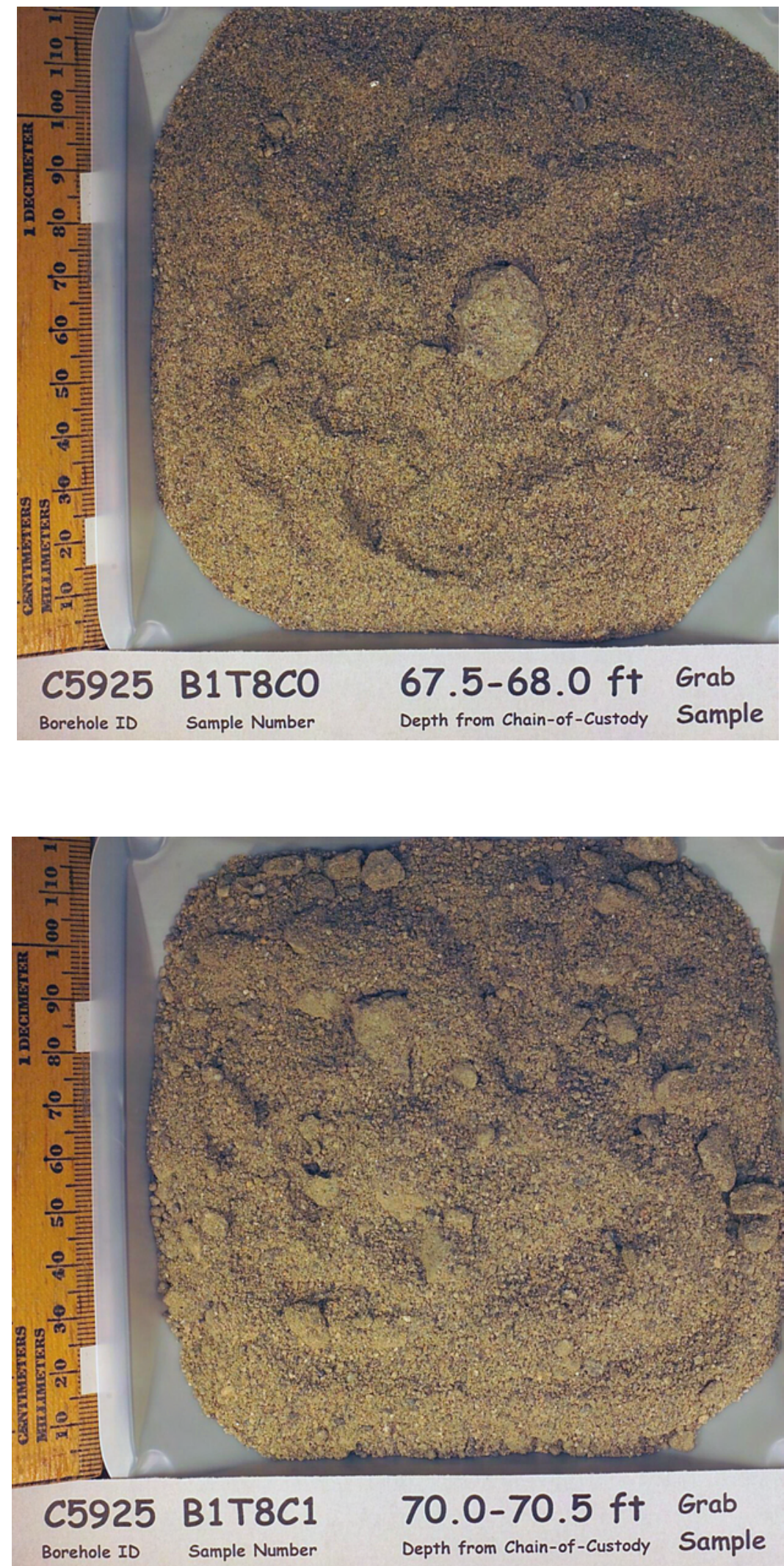
PNNL-17821
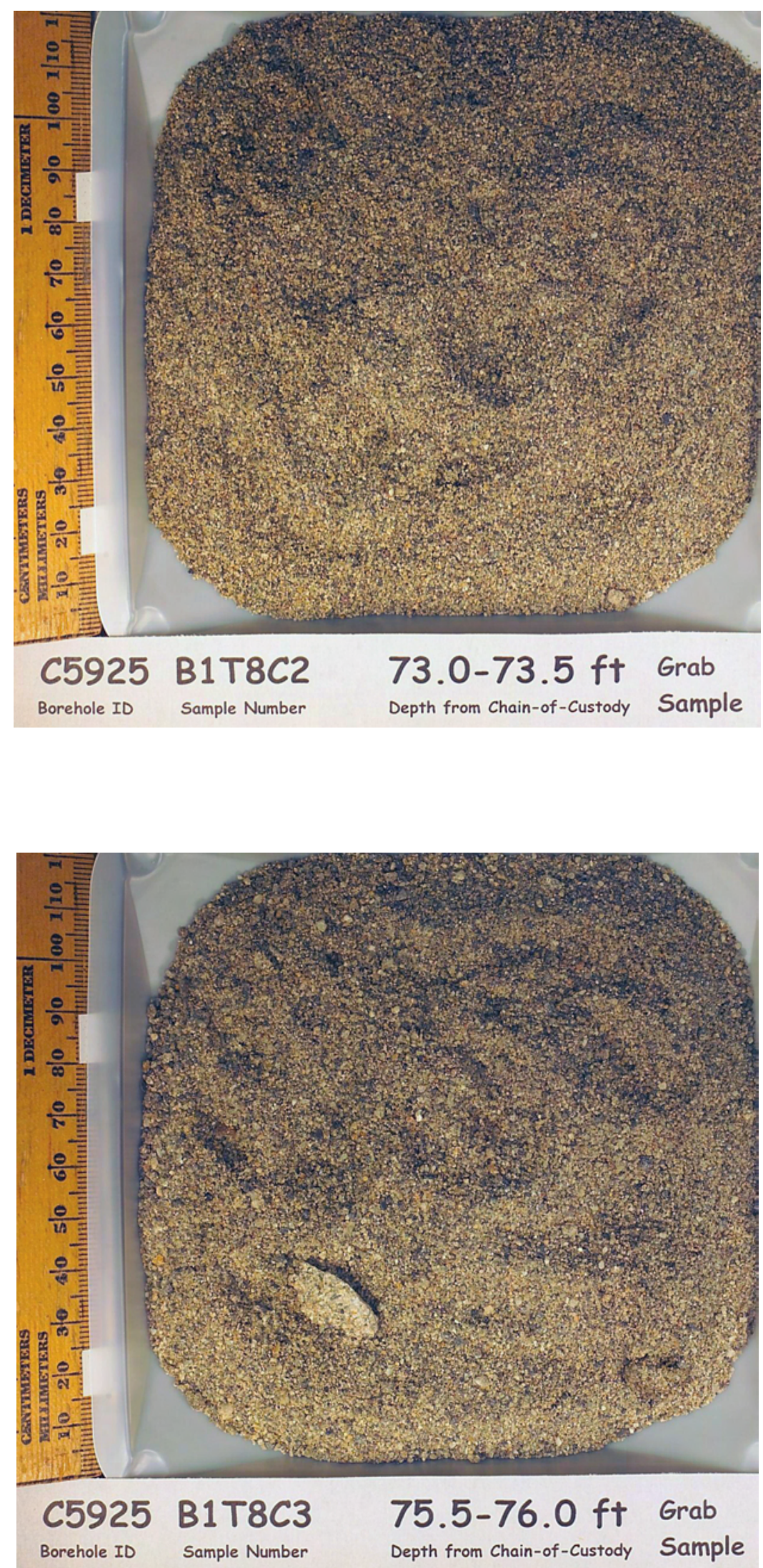
PNNL-17821
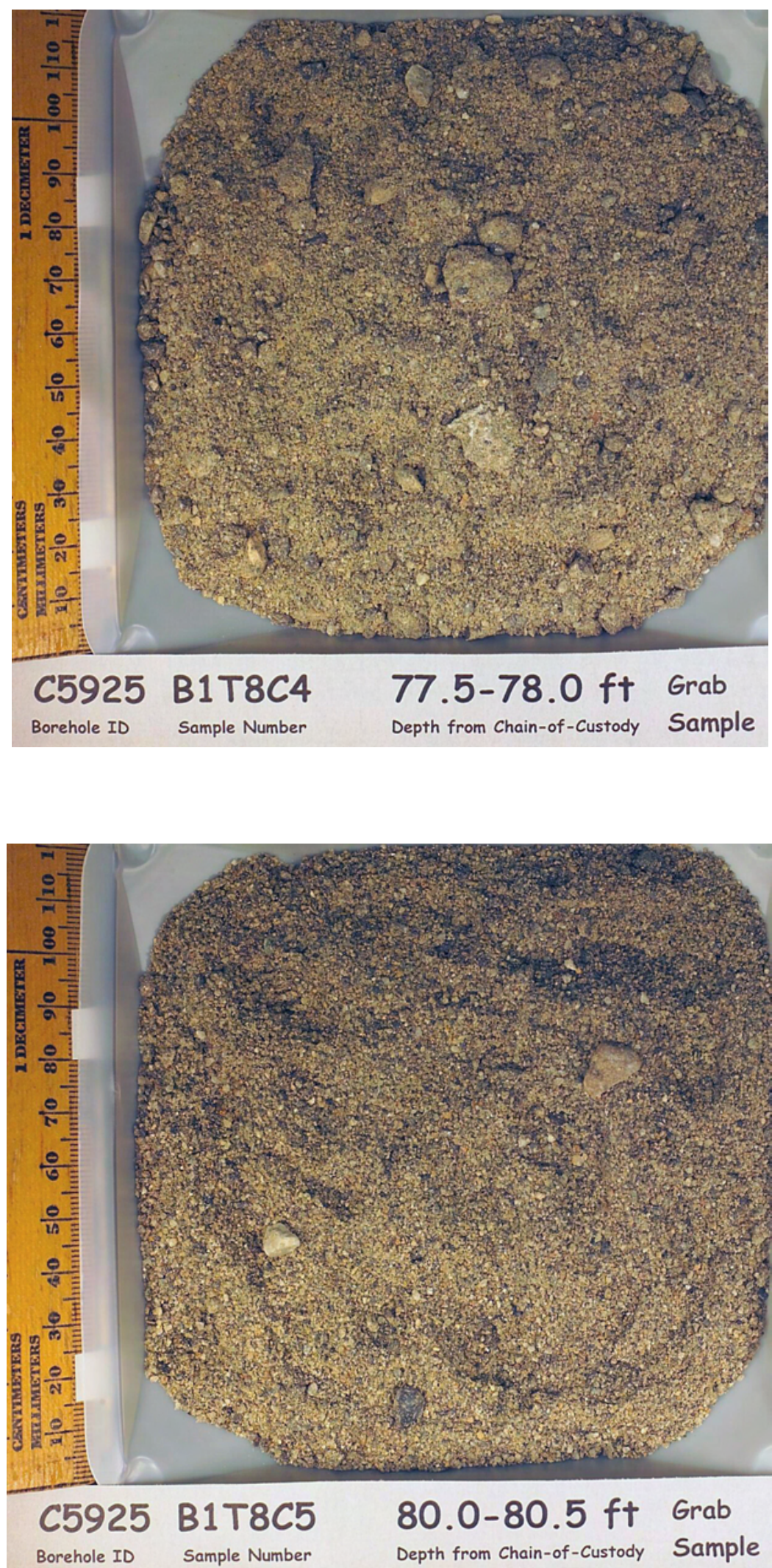
PNNL-17821
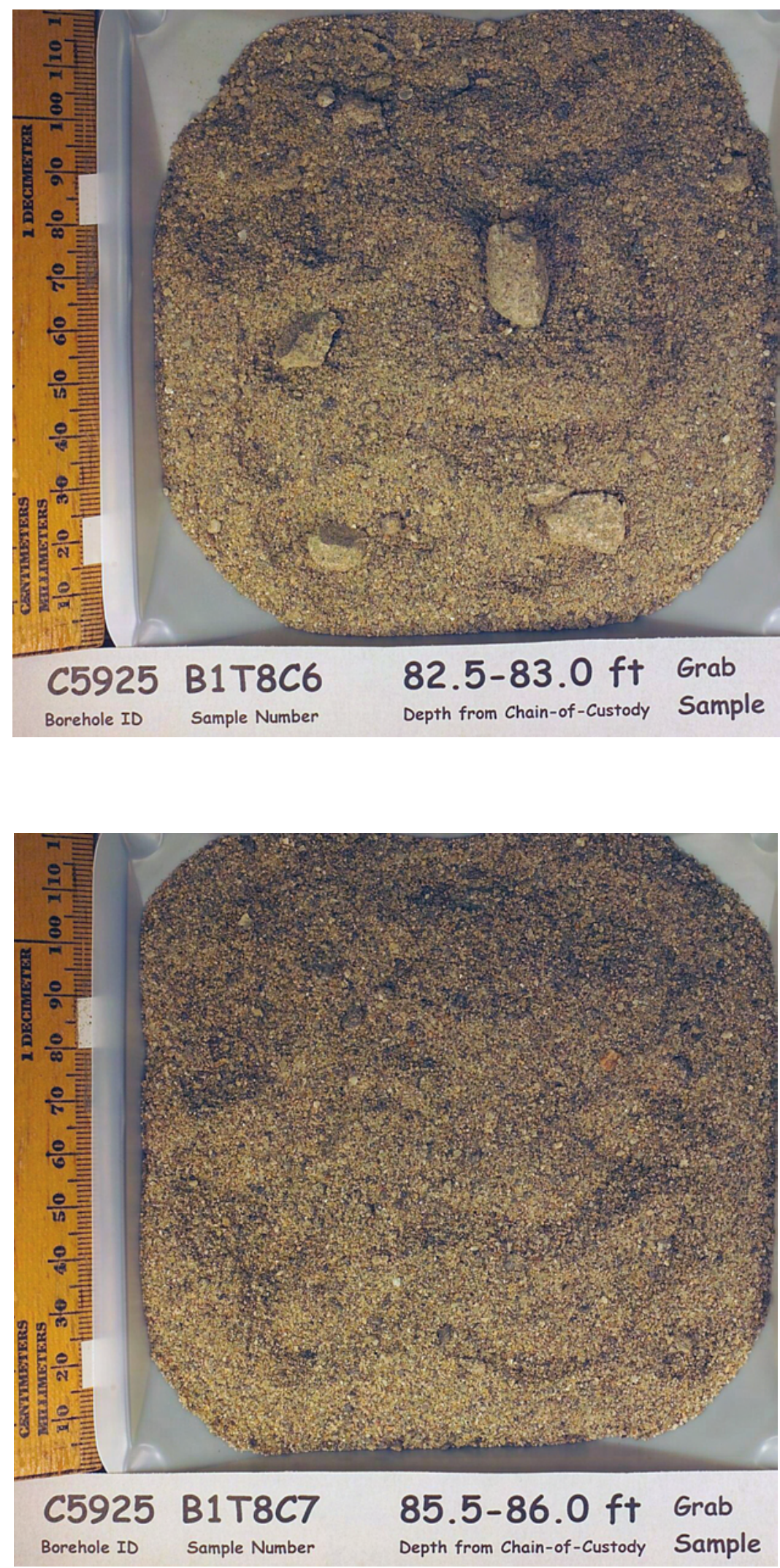
PNNL-17821
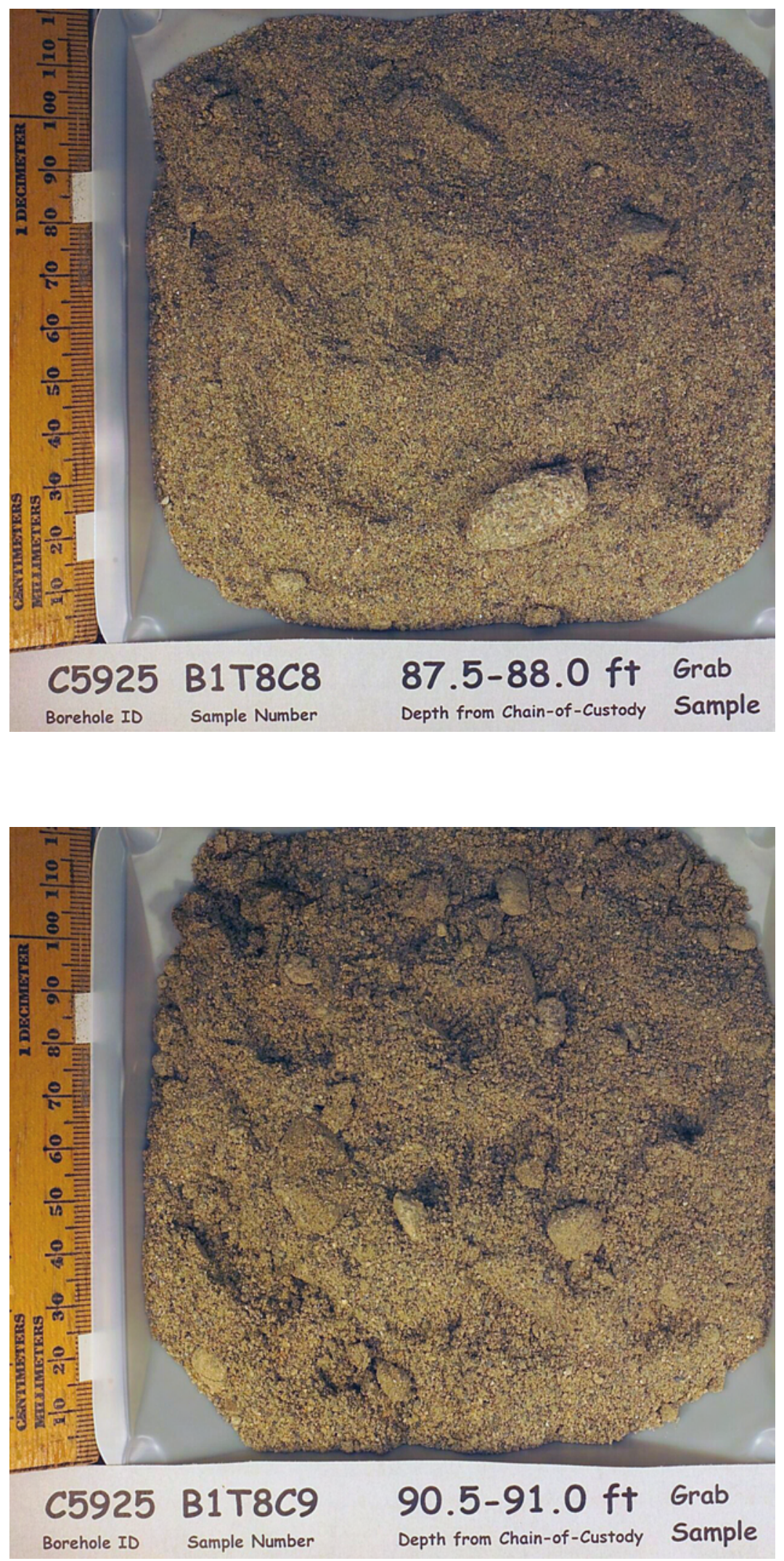
PNNL-17821
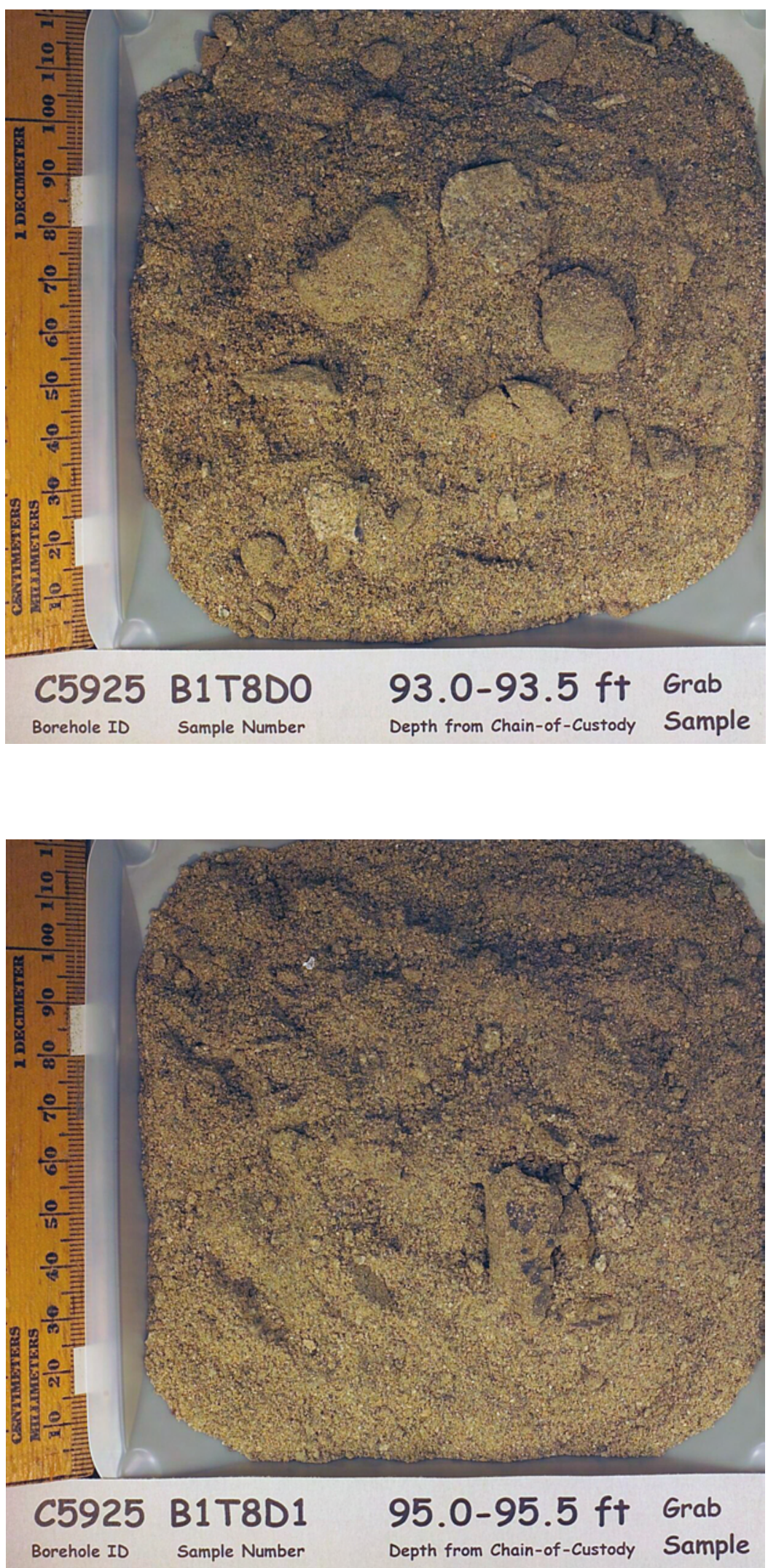
PNNL-17821
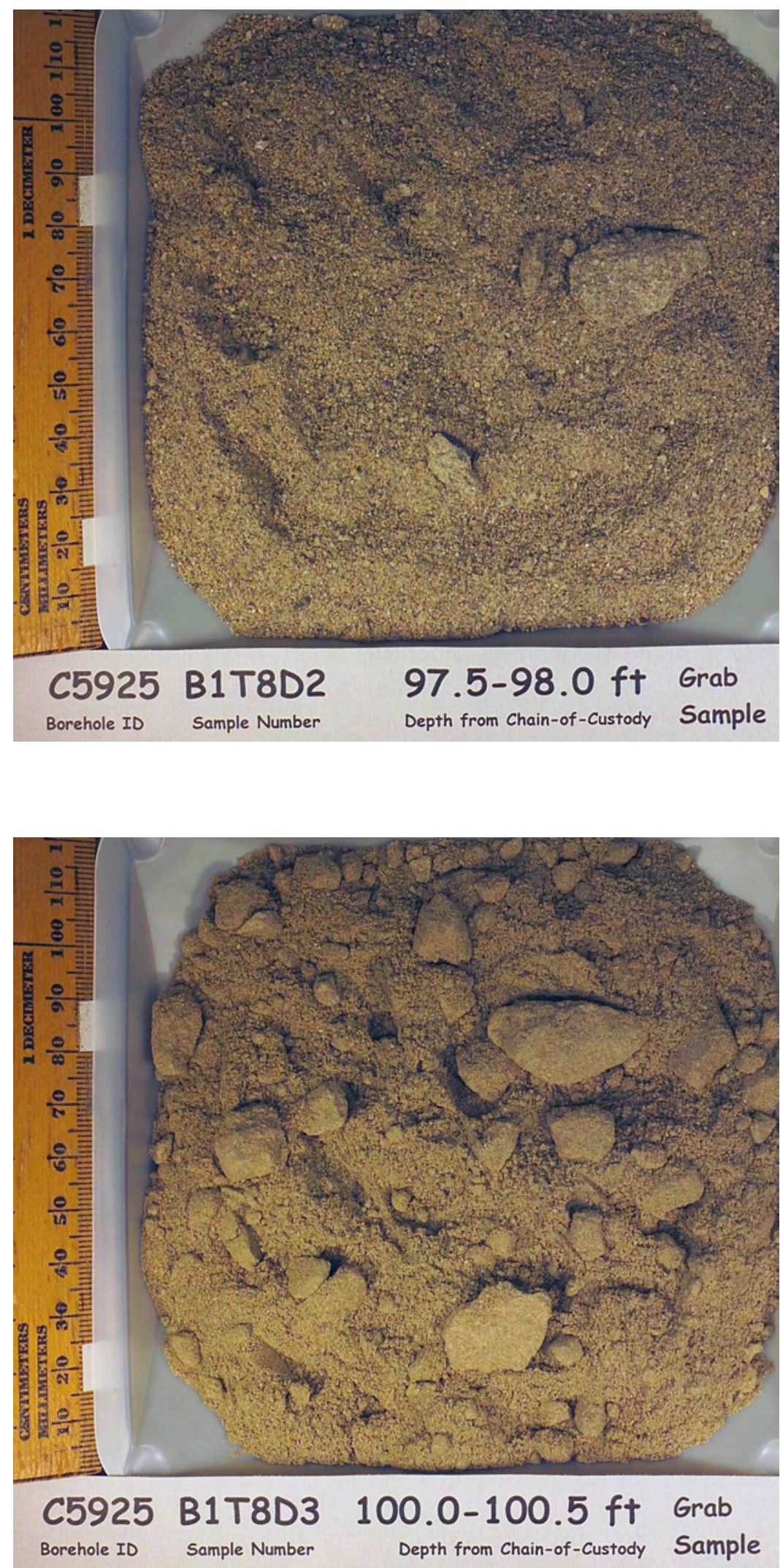
PNNL-17821

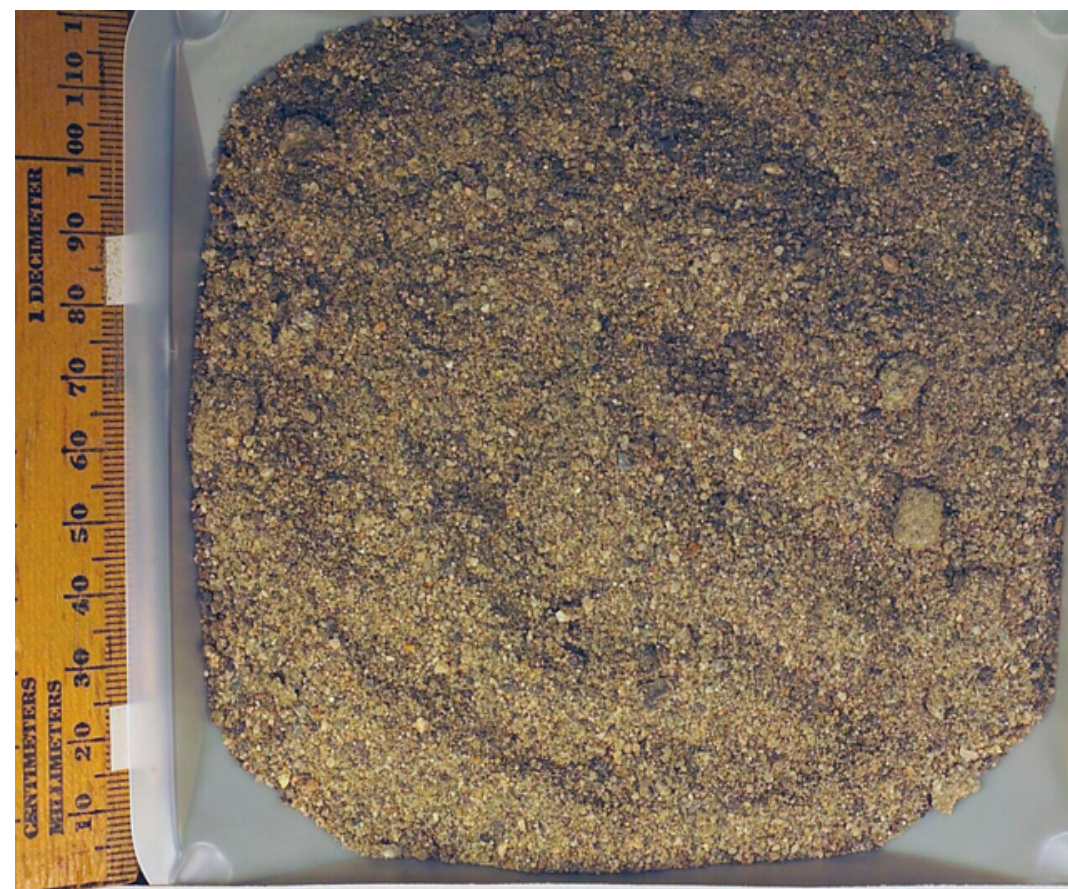

C5925
$\begin{aligned} & \text { B1T8D4 } \\ & \text { Borehole ID }\end{aligned}$ Sample Number $\begin{array}{r}102.5-103.0 \mathrm{ft} \\ \text { Depth from Chain-of-Custody Sample }\end{array}$

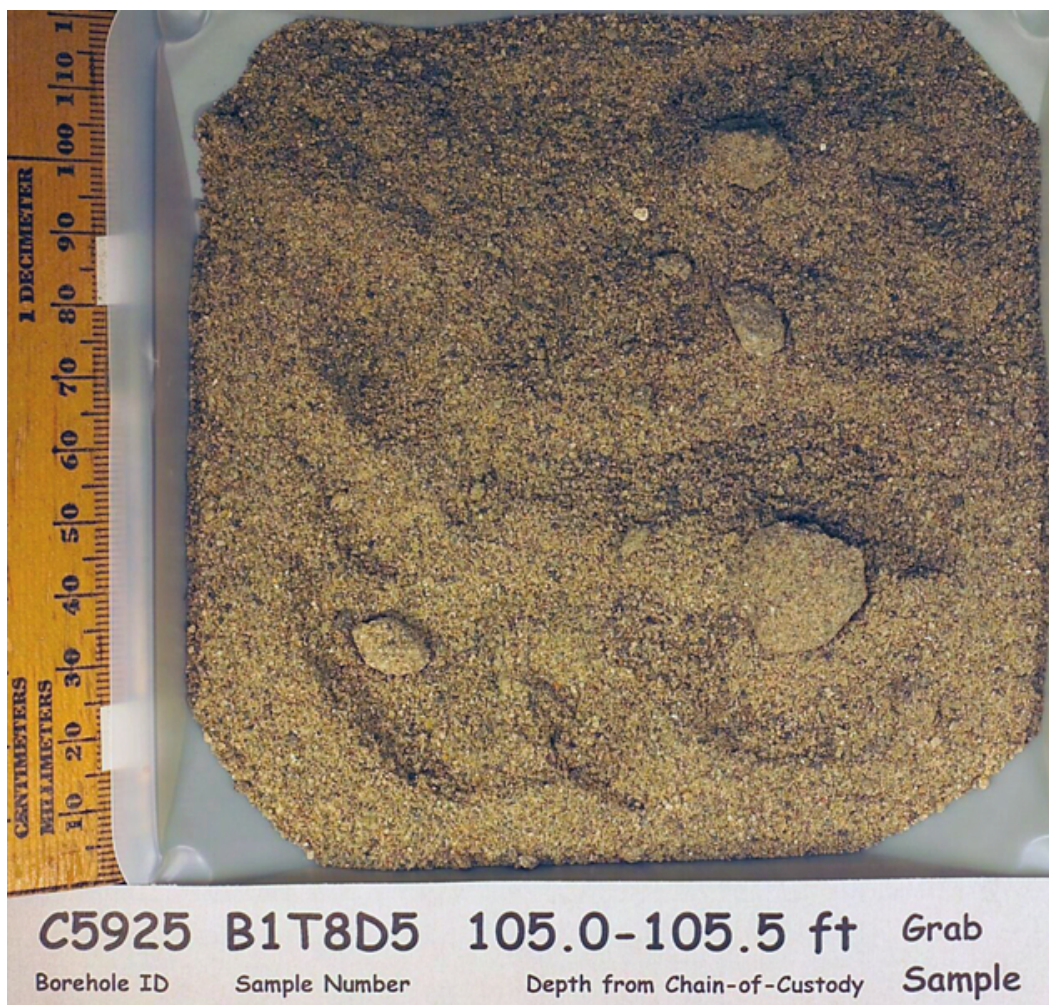


PNNL-17821

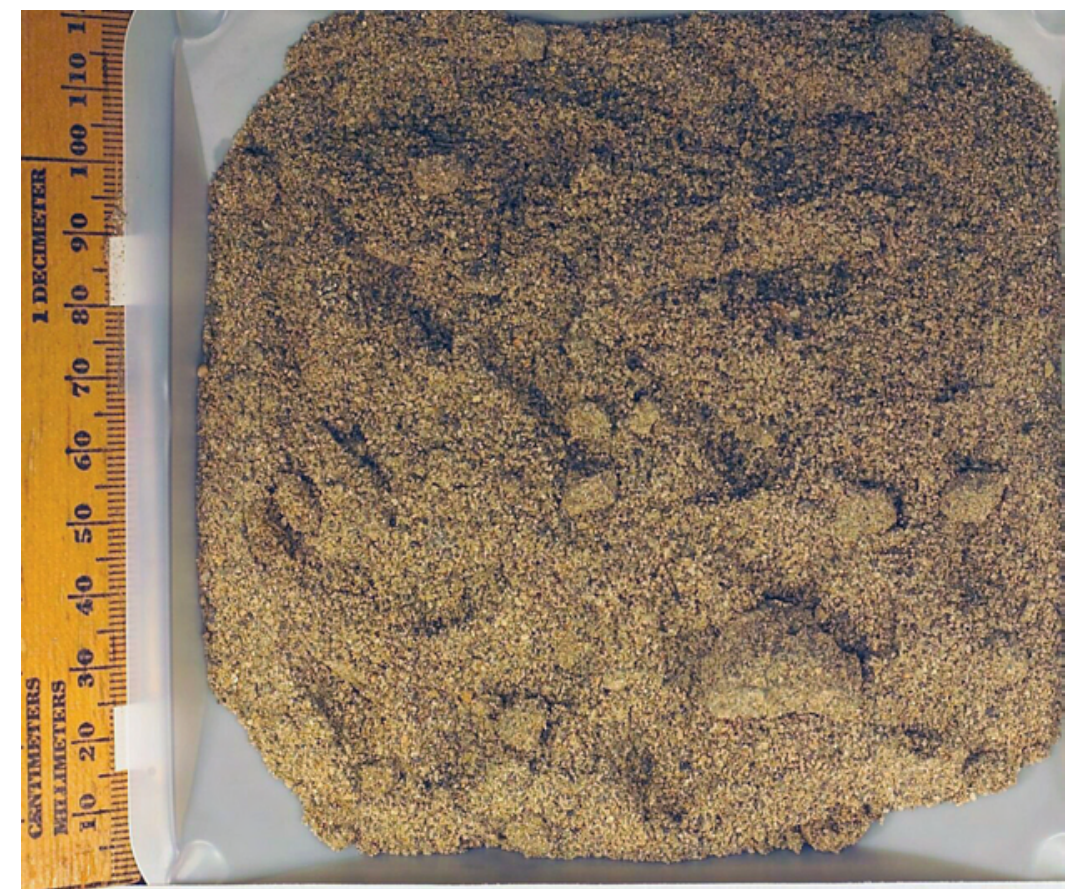

C5925 B1T8D6 108.0-108.5 ft Grab

Borehole ID

Sample Number Depth from Chain-of-Custody Sample

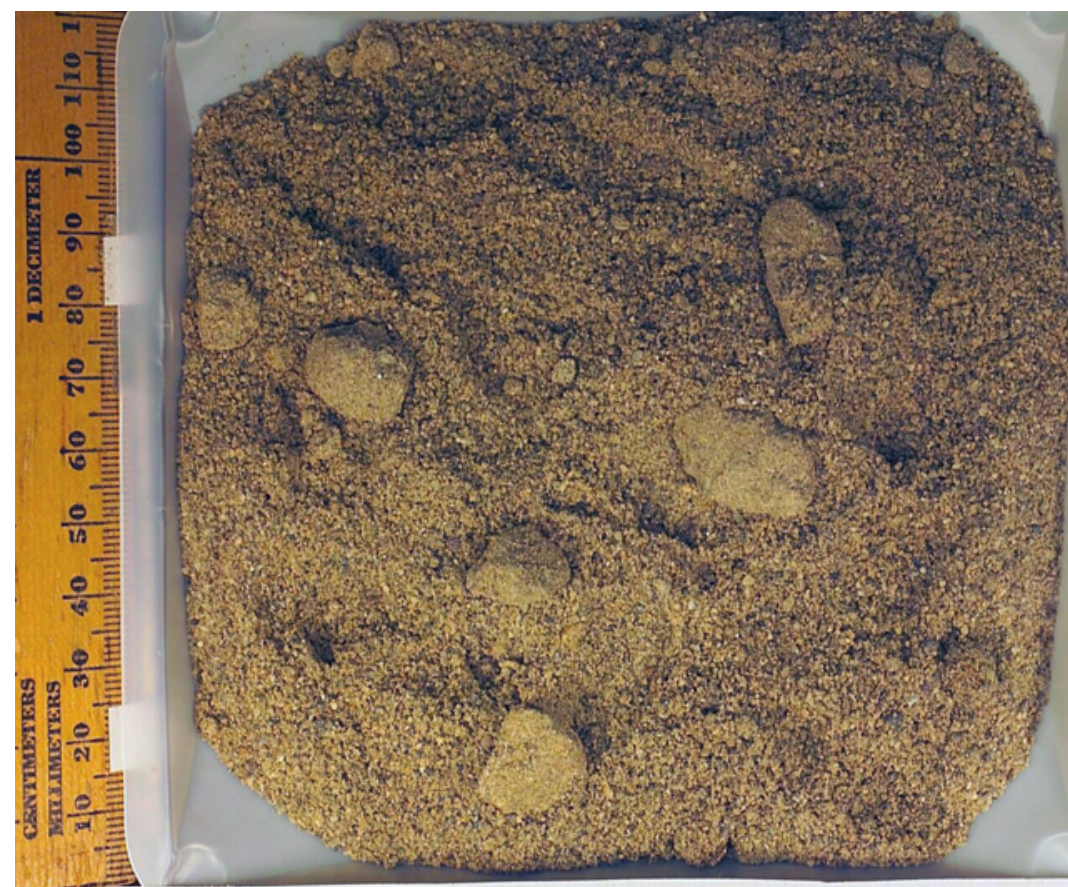

C5925 B1T8D7 110.5-111.0 ft Grab

Borehole ID

Sample Number Depth from Chain-of-Custody

Sample 
PNNL-17821
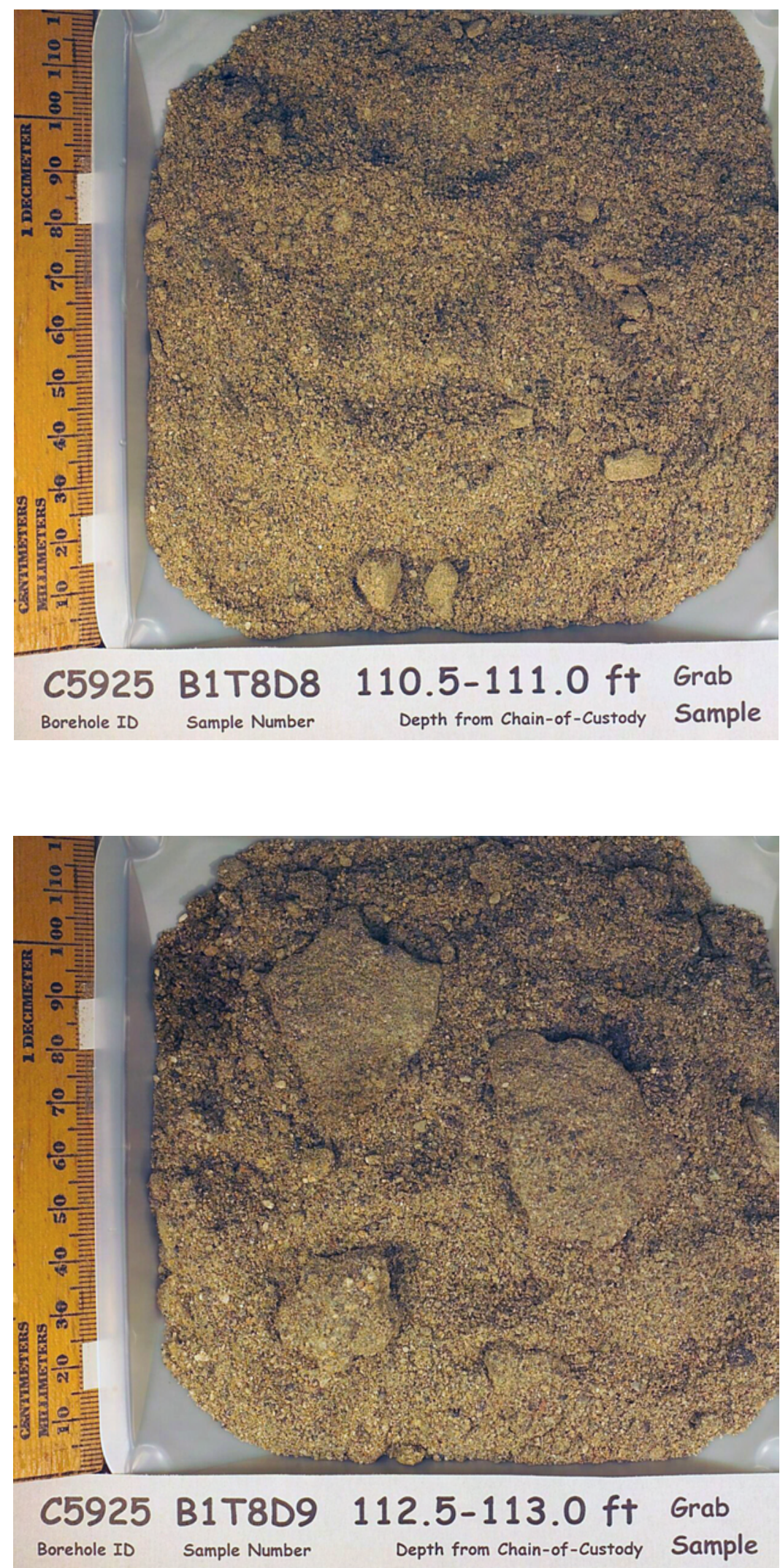
PNNL-17821
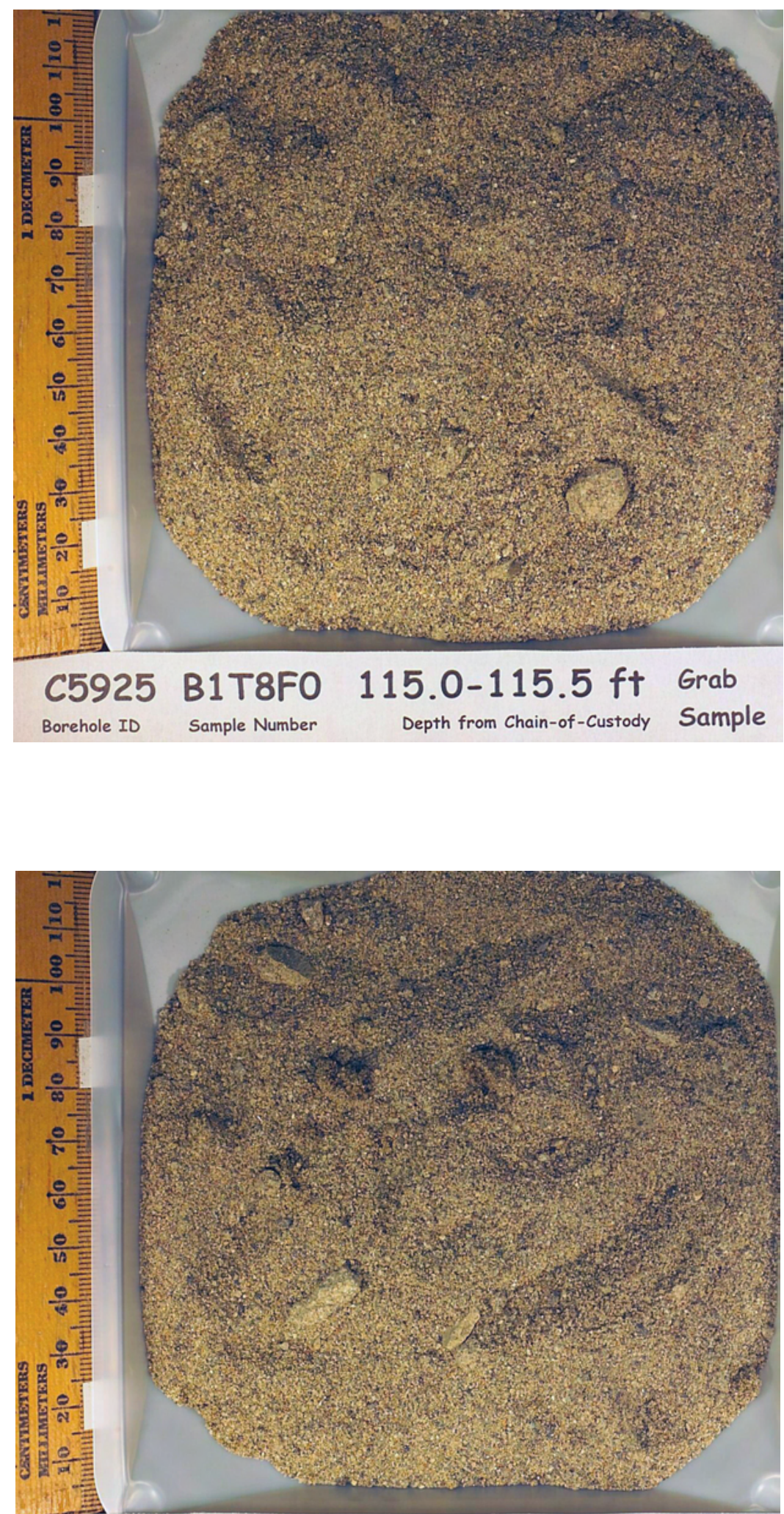
C5925
Borehole ID
B1T8F 1
Sample Number
117.5-118.0 ft
Depth from Chain-of-Custody Sample 
PNNL-17821
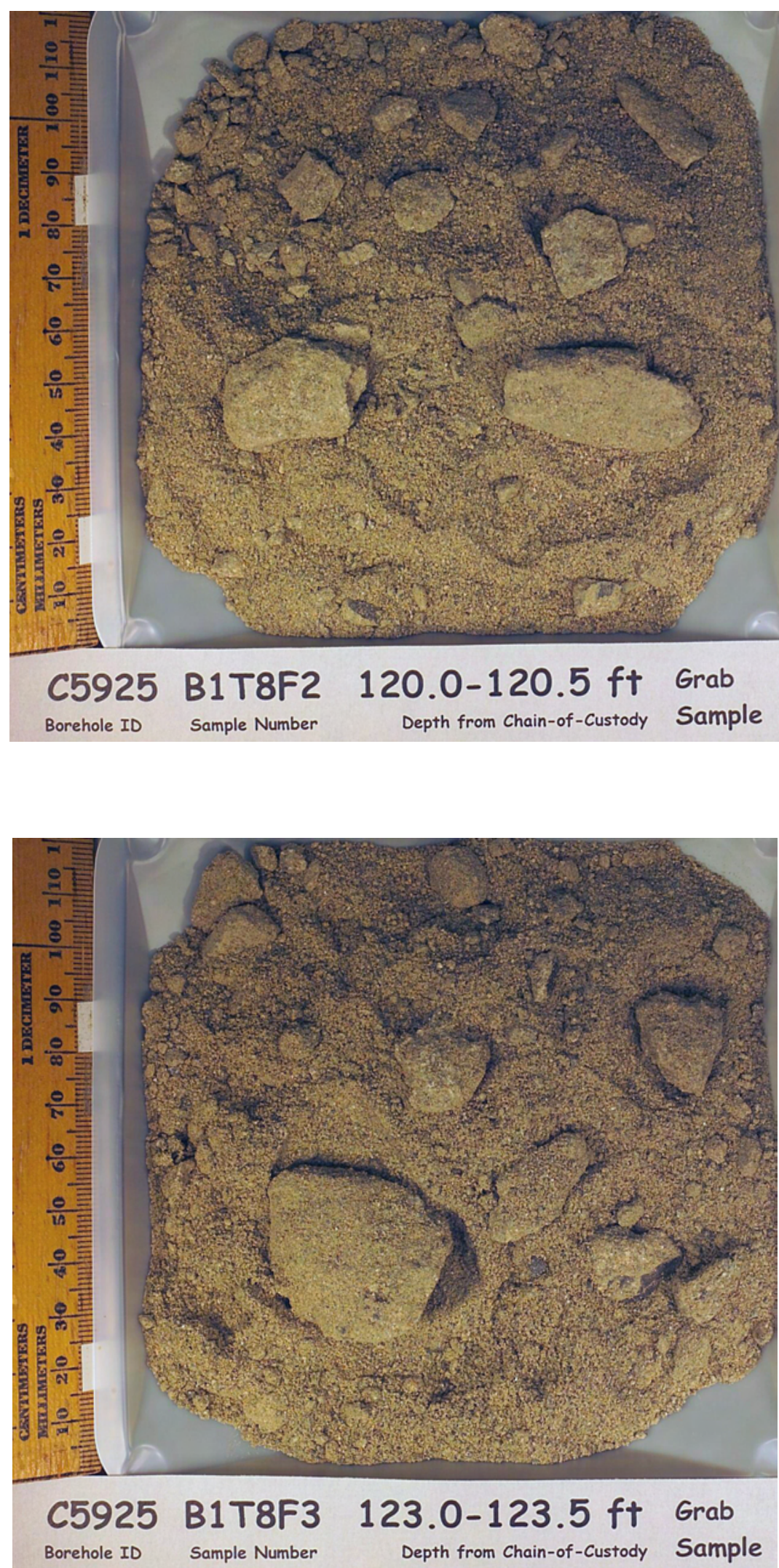
PNNL-17821
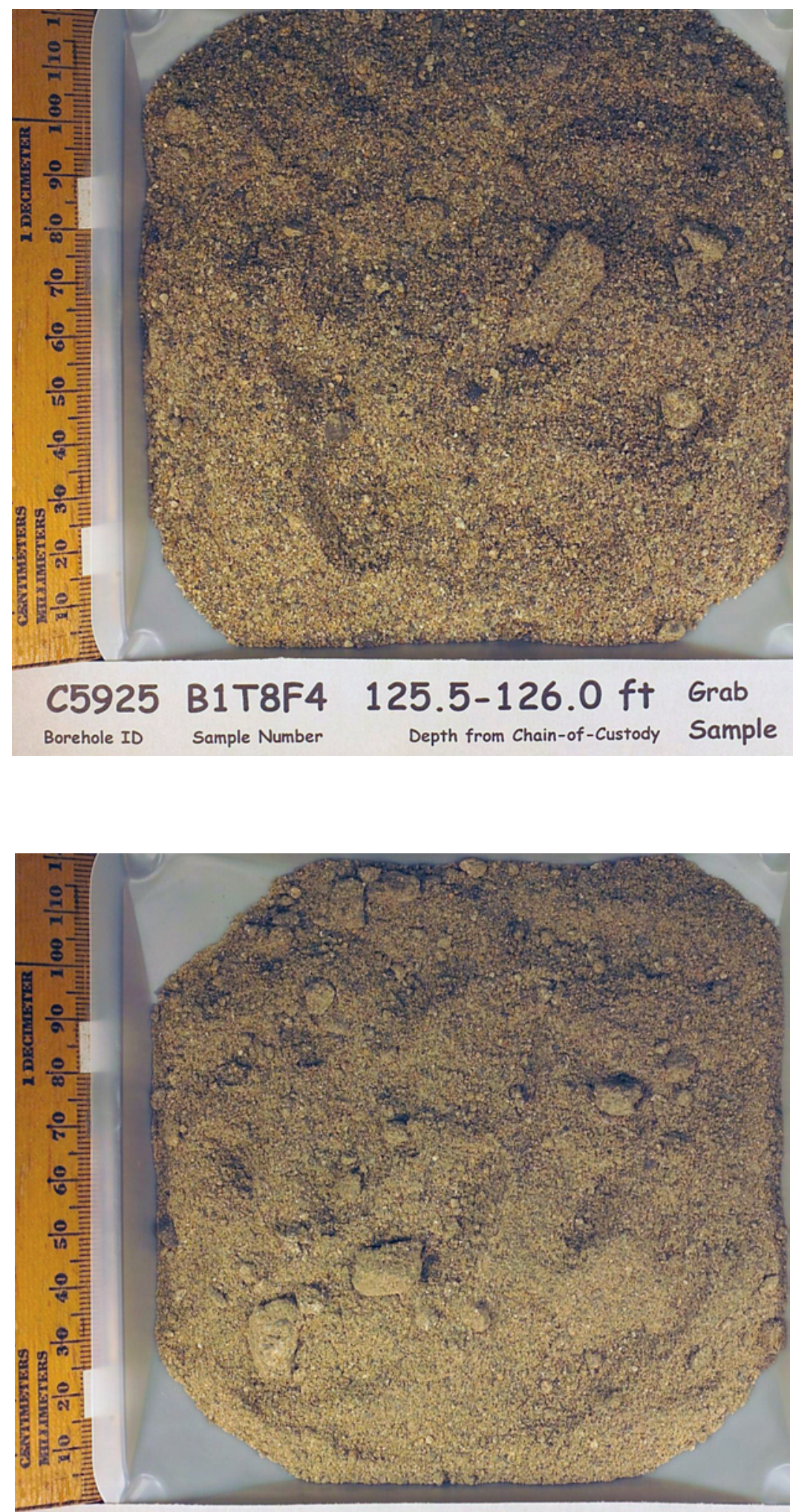

C5925 B1T8F5 127.5-128.0 ft Grab

Borehole ID

Sample Number

Depth from Chain-of-Custody Sample 
PNNL-17821
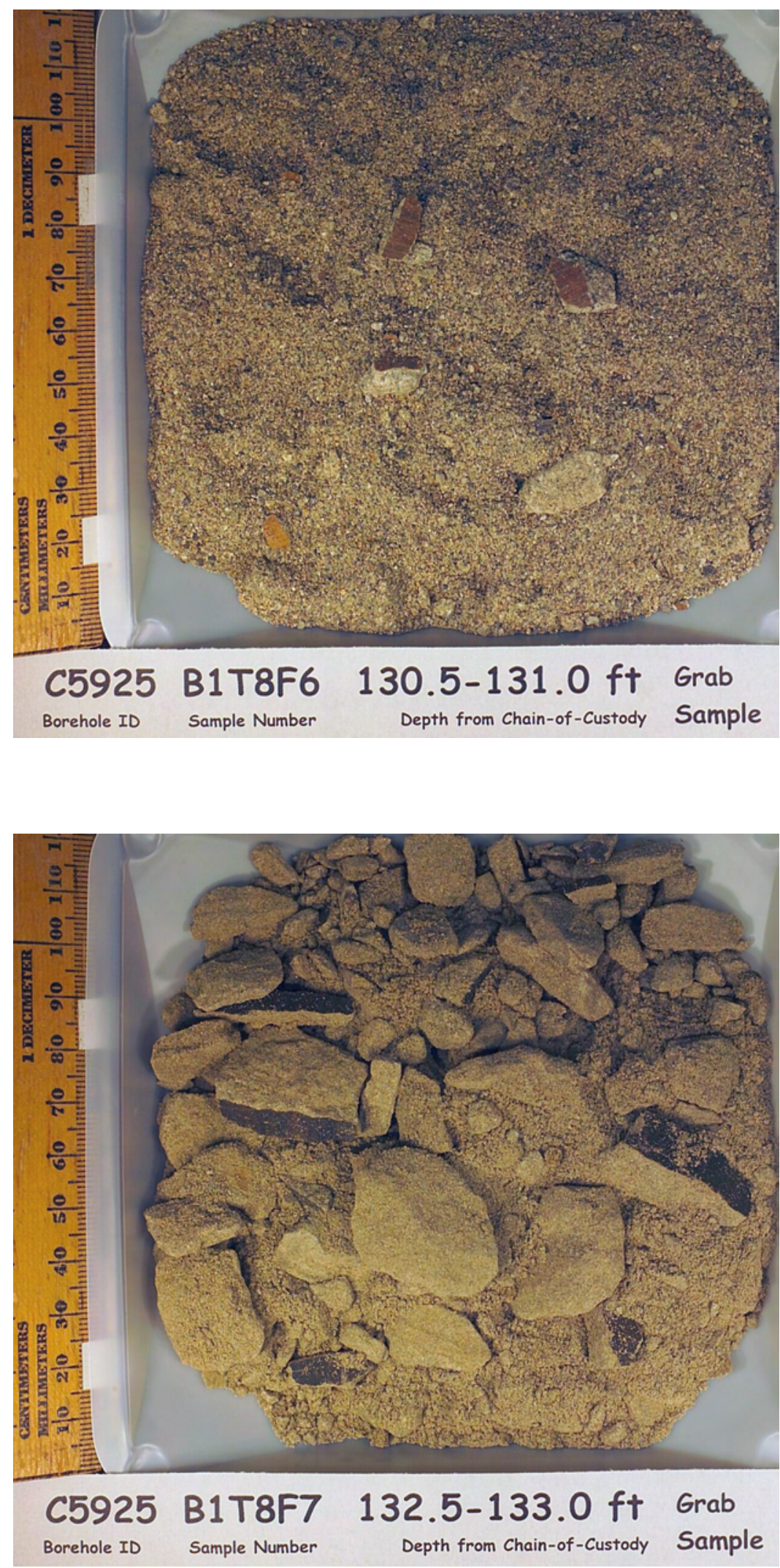
PNNL-17821
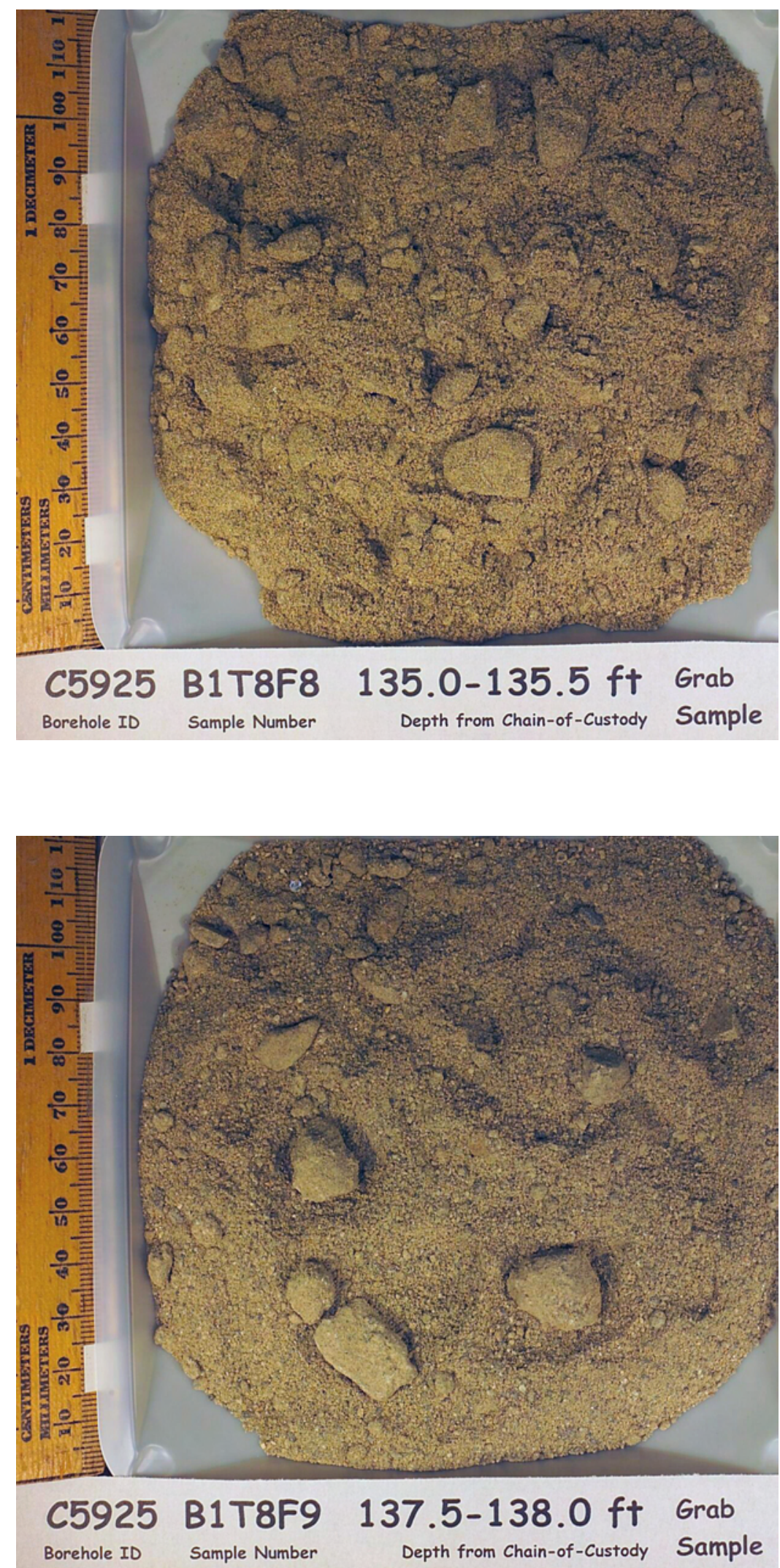
PNNL-17821
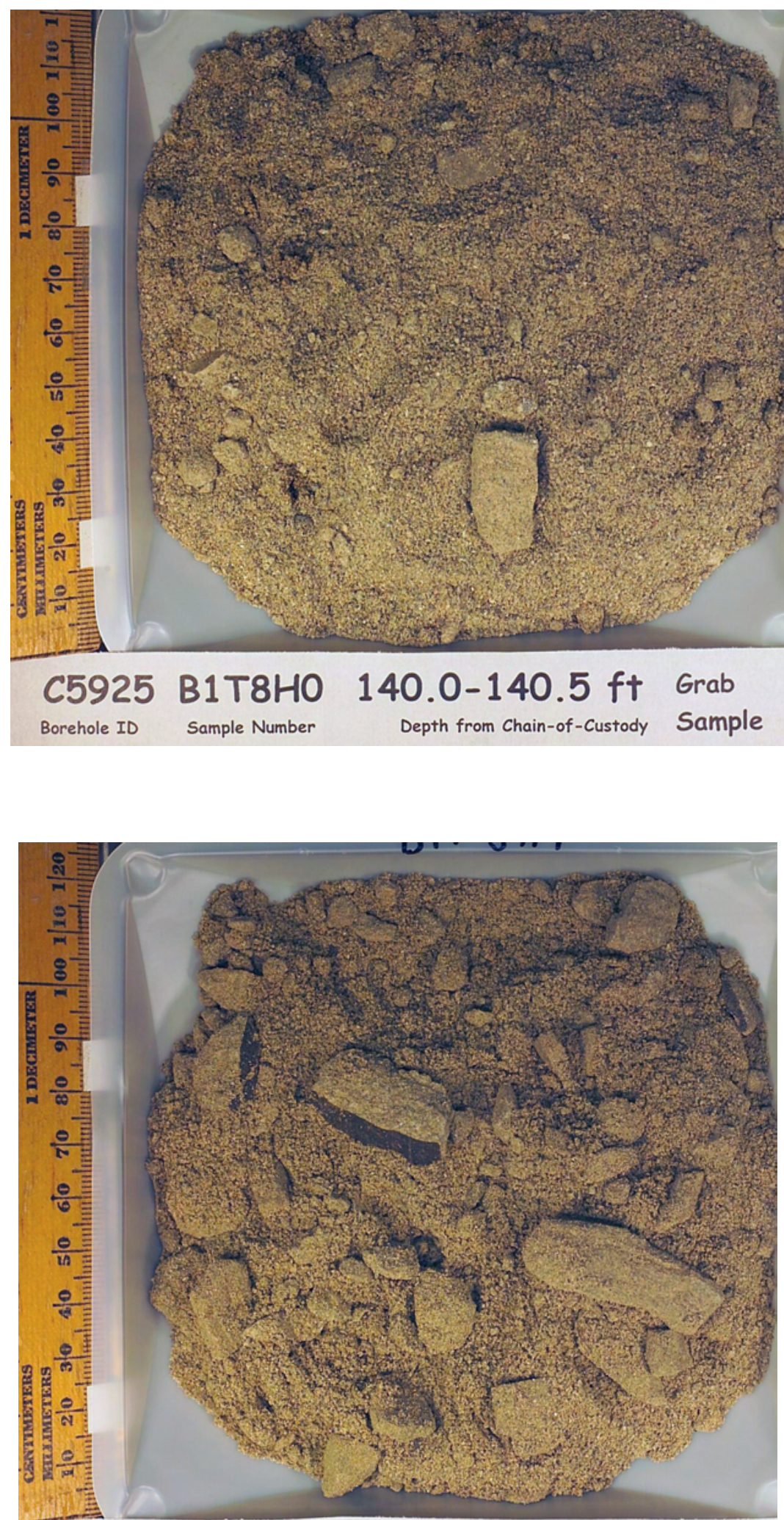

C5925 B1T8H1 142.5-143.0 ft Grab

Borehole ID

Sample Number

Depth from Chain-of-Custody Sample 
PNNL-17821
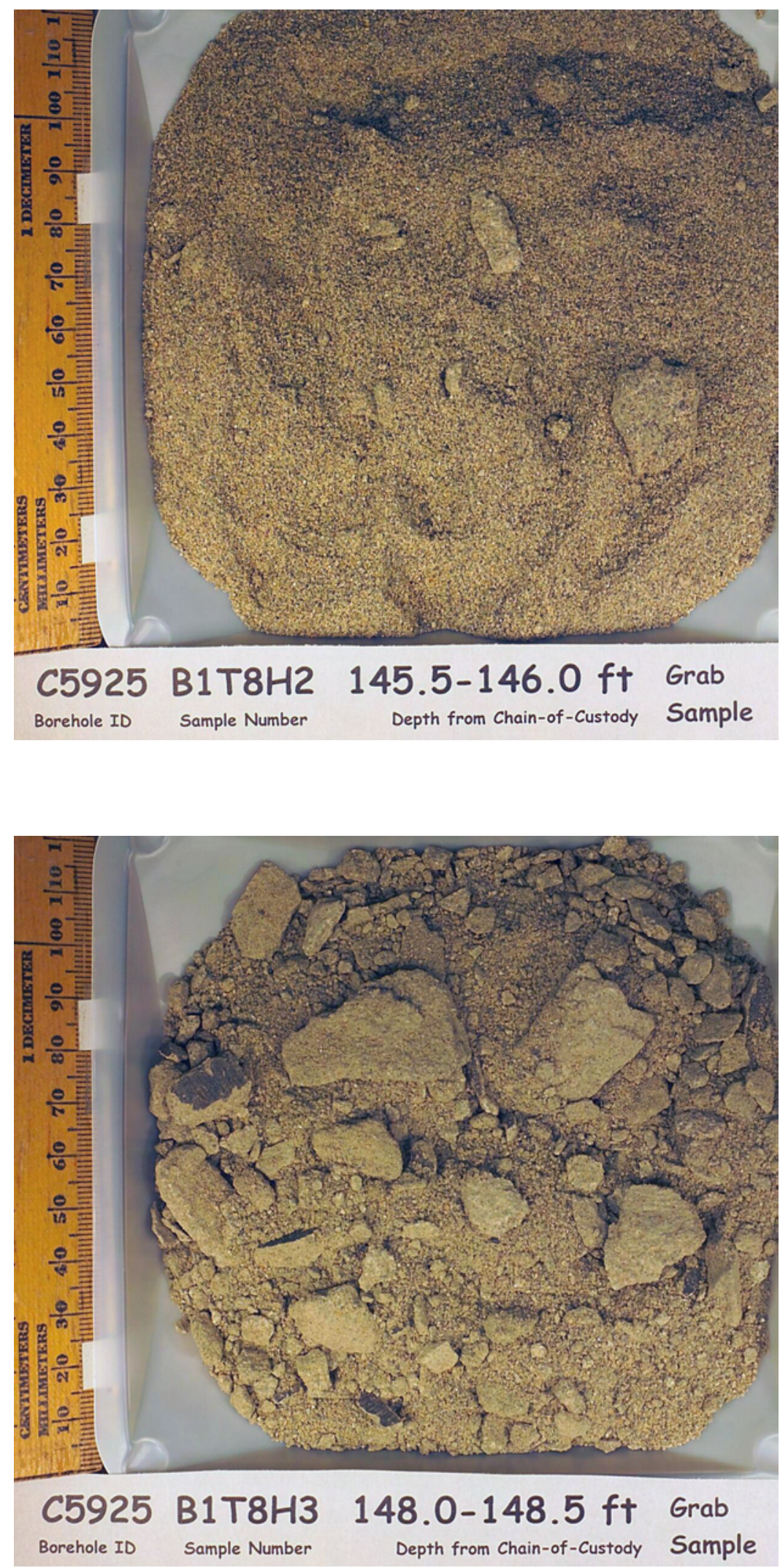
PNNL-17821
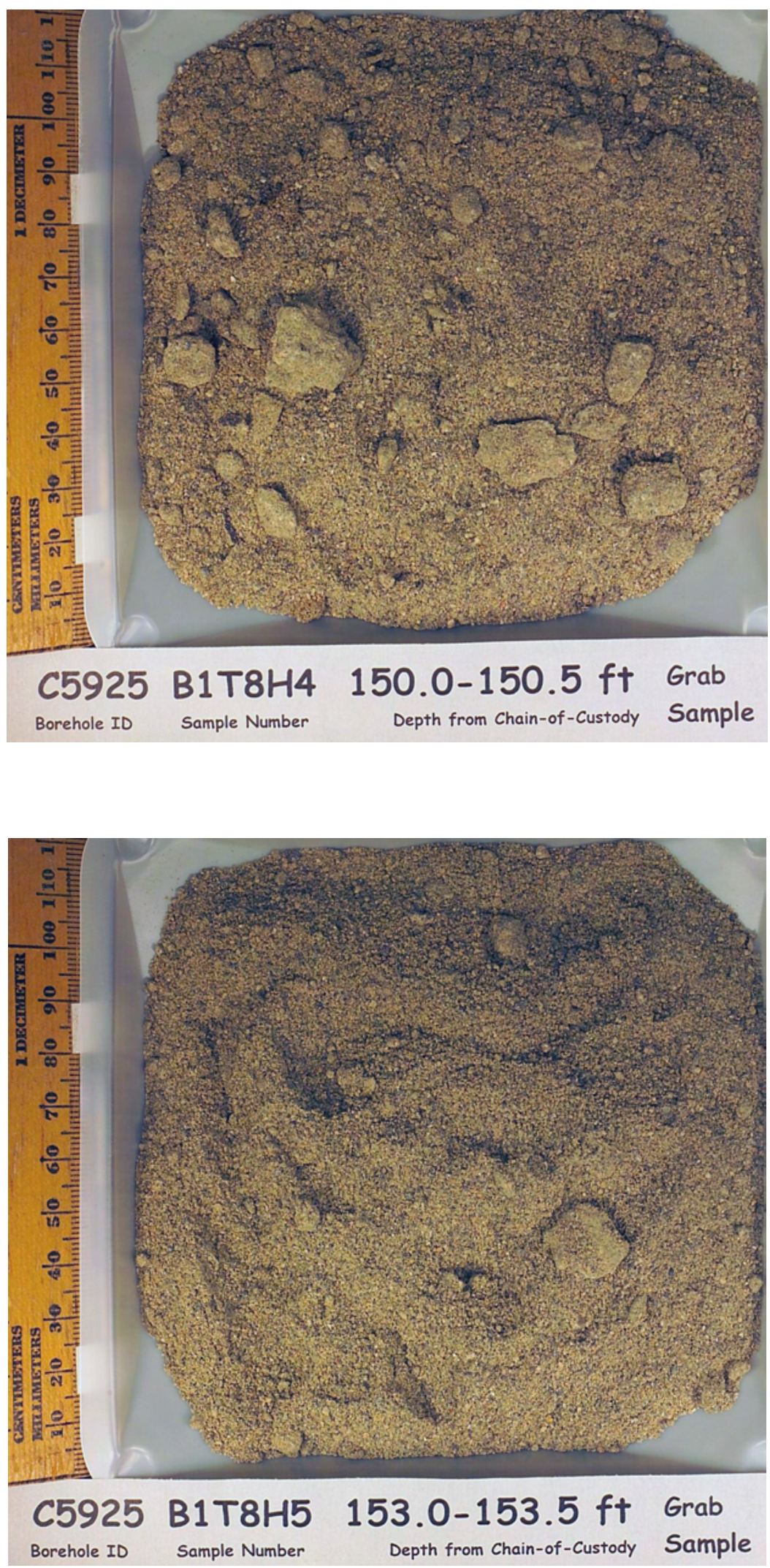
PNNL-17821

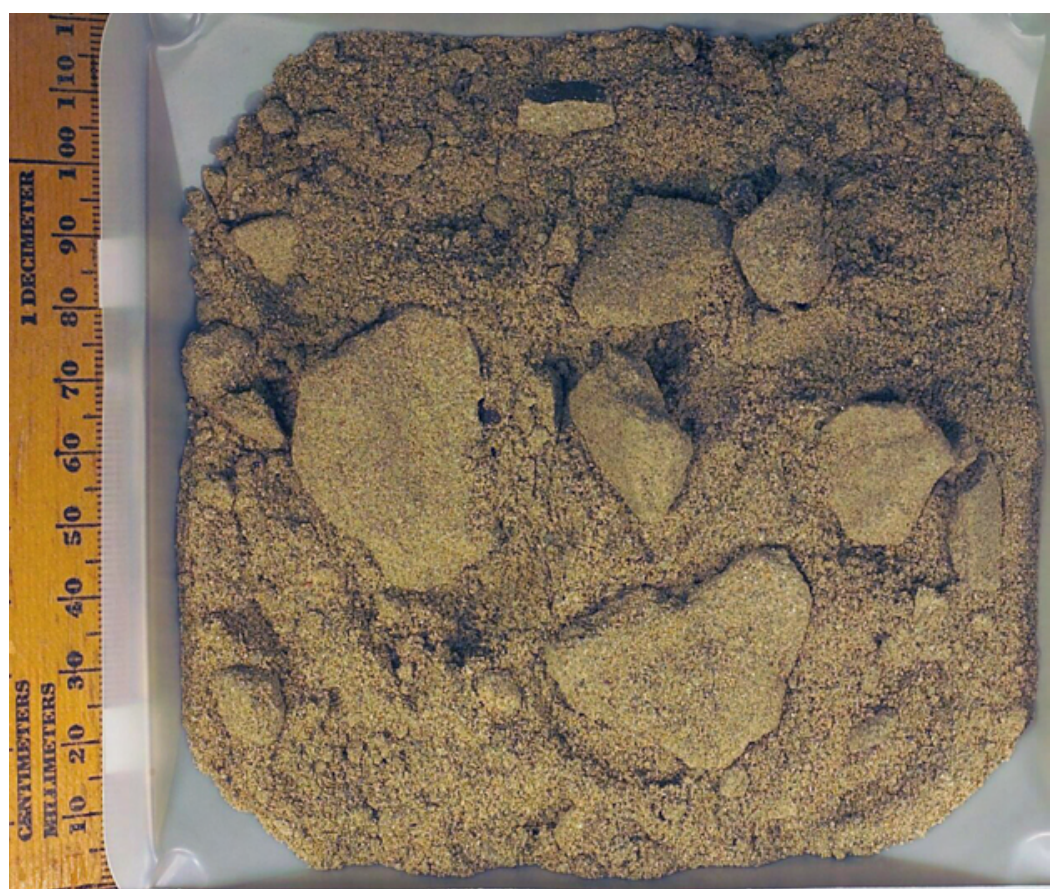

$\begin{array}{lrr}\text { C5925 B1T8H6 } & \begin{array}{l}155.0-155.5 \\ \text { Borehole ID }\end{array} \\ \text { Sample Number } & \text { Depth from Chain-of-Custody Sample }\end{array}$

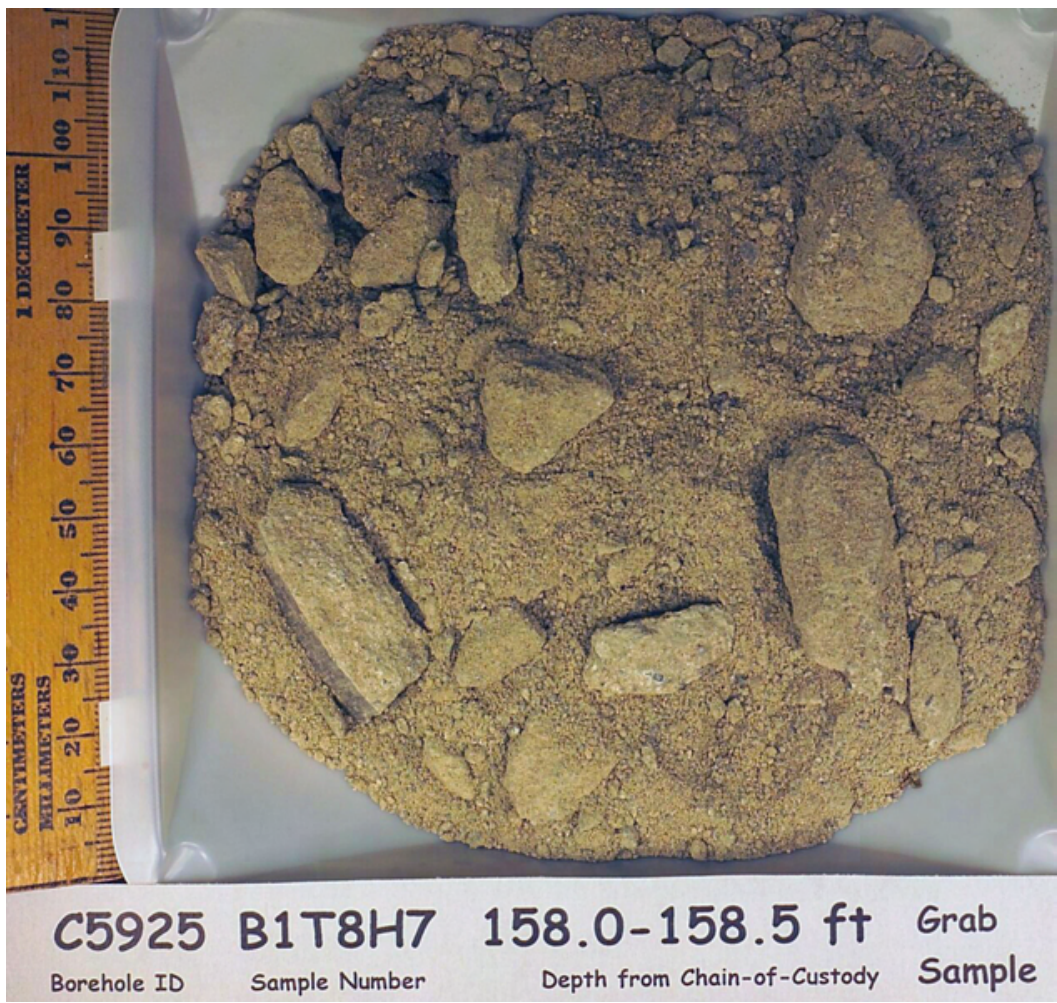


PNNL-17821
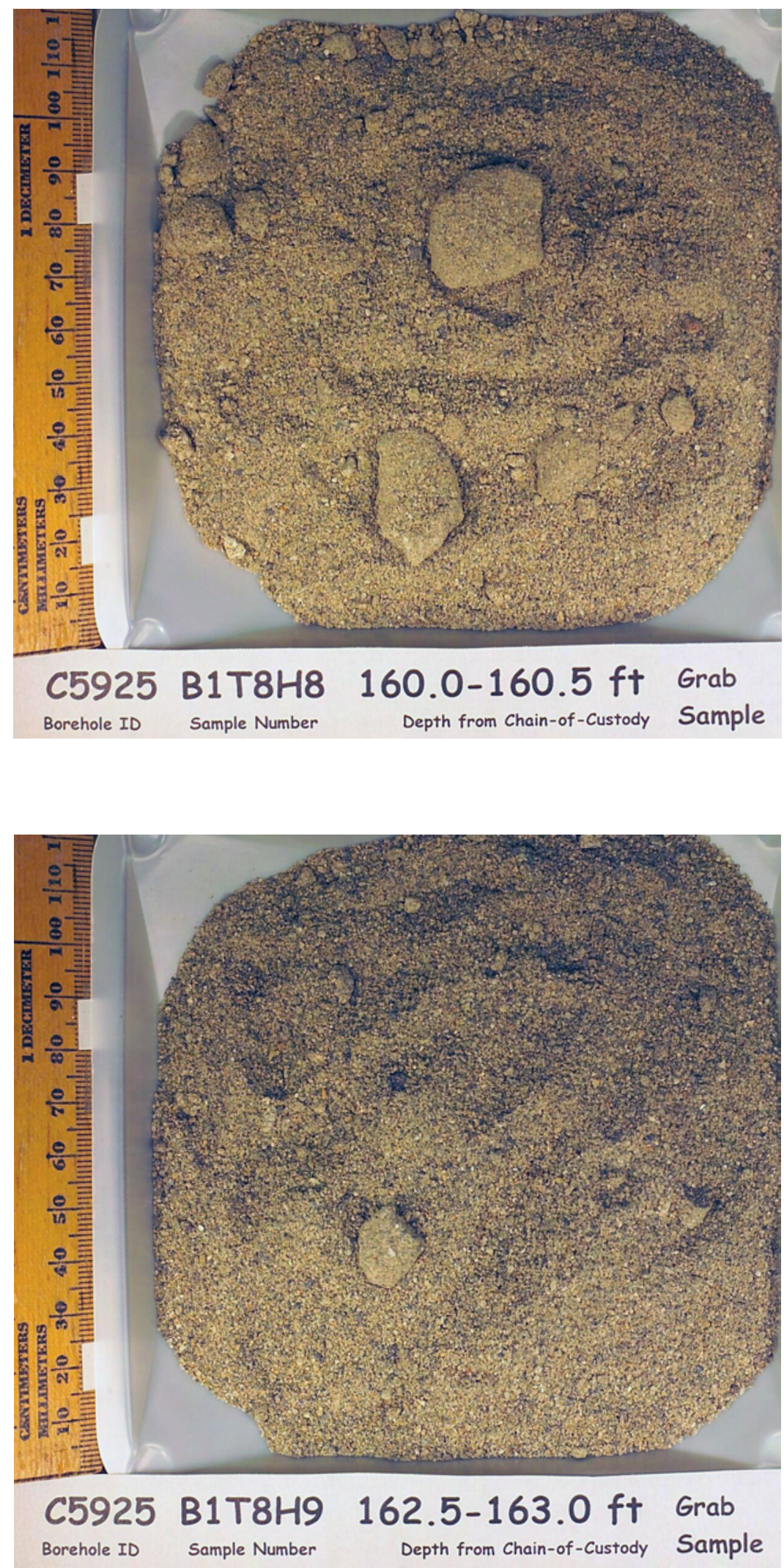
PNNL-17821

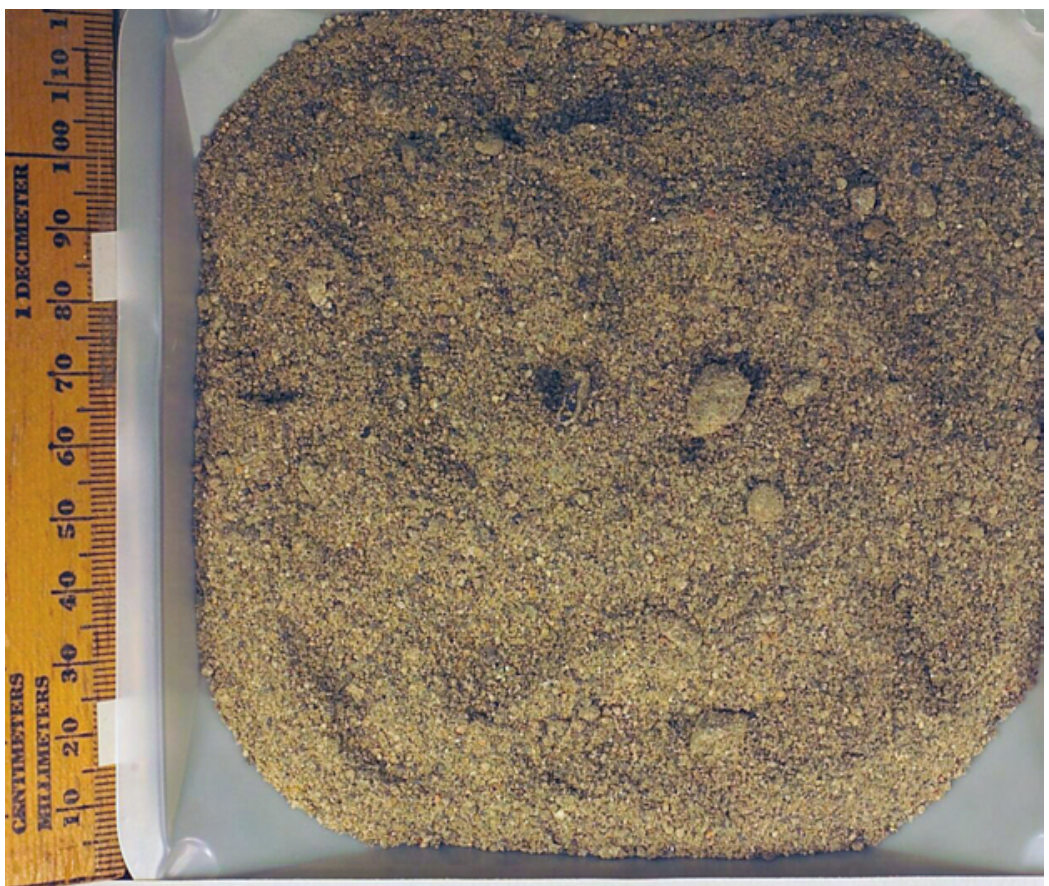

C5925 B1T8J0 162.5-163.0 ft Grab

Borehole ID Sample Number

Depth from Chain-of-Custody Sample

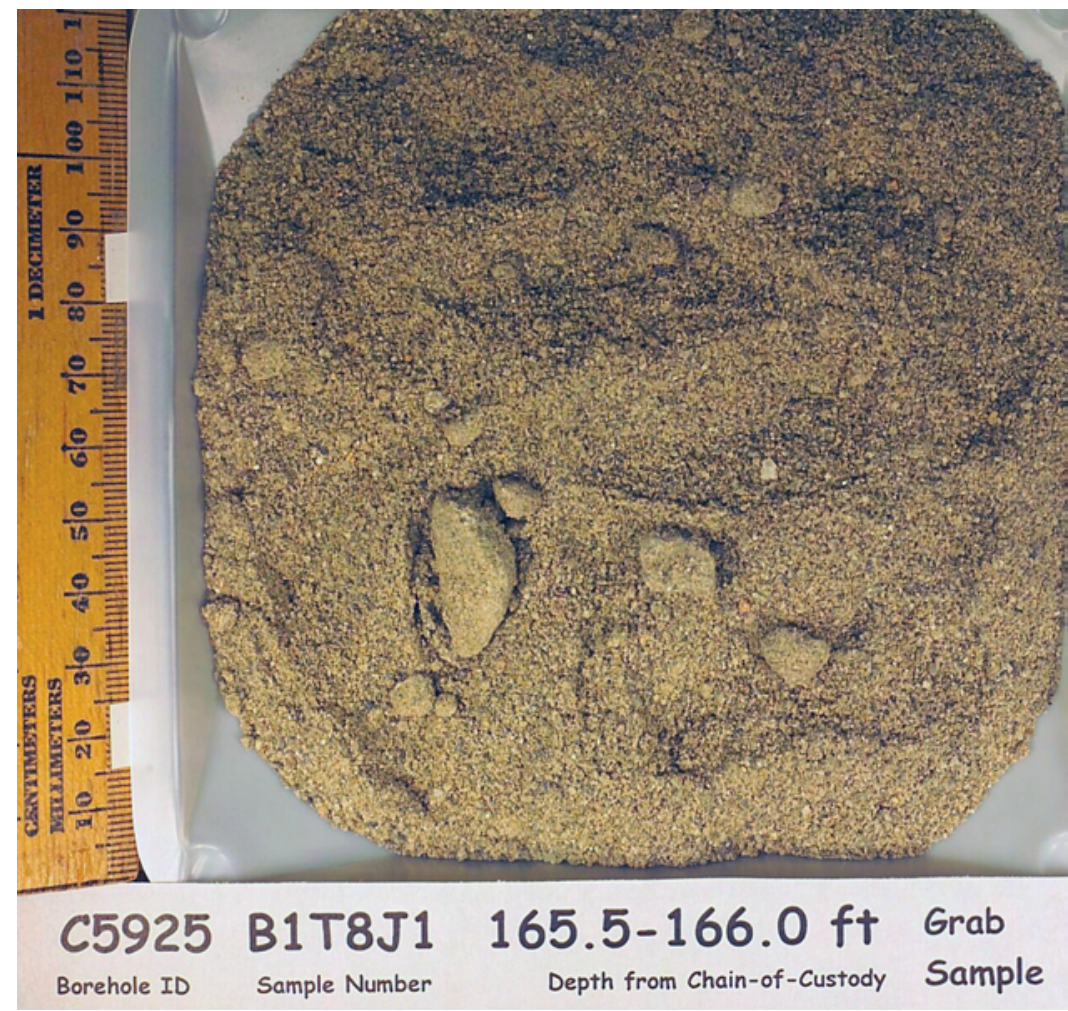


PNNL-17821

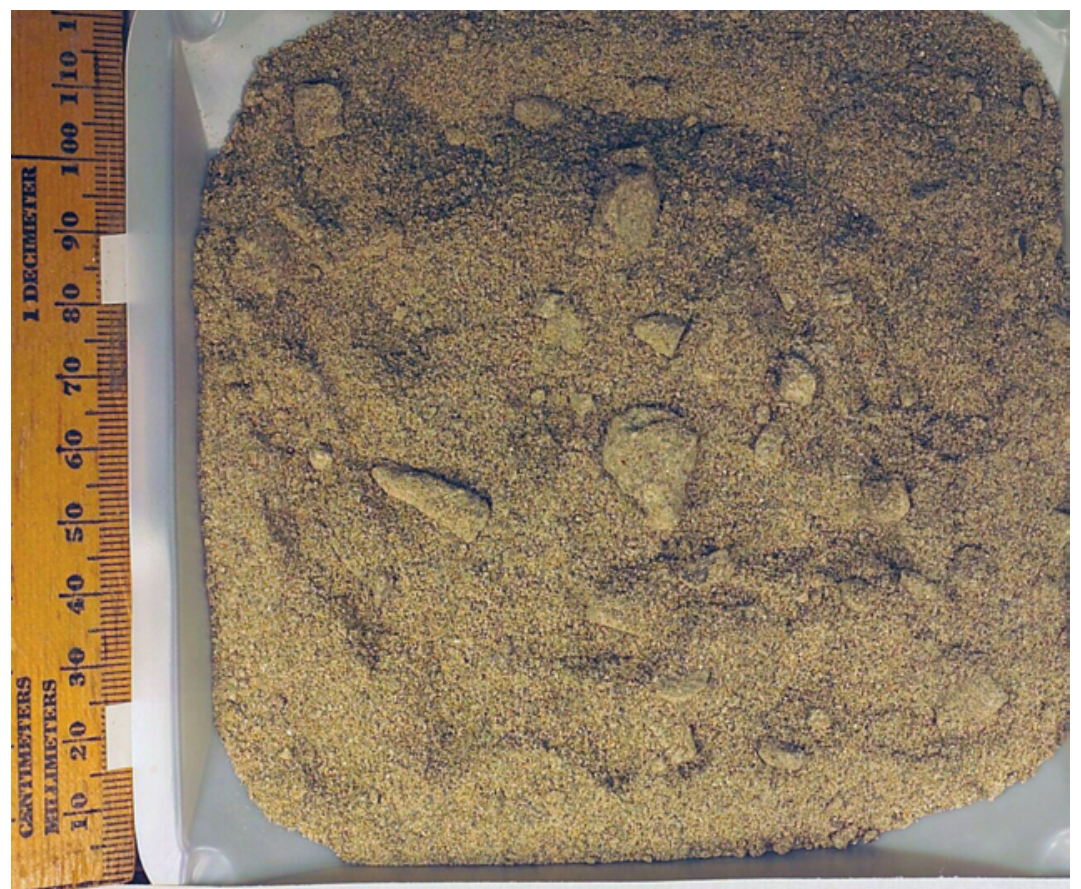

C5925 B1T8J2 167.5-168.0 ft Grab

Borehole ID

Sample Number

Depth from Chain-of-Custody Sample

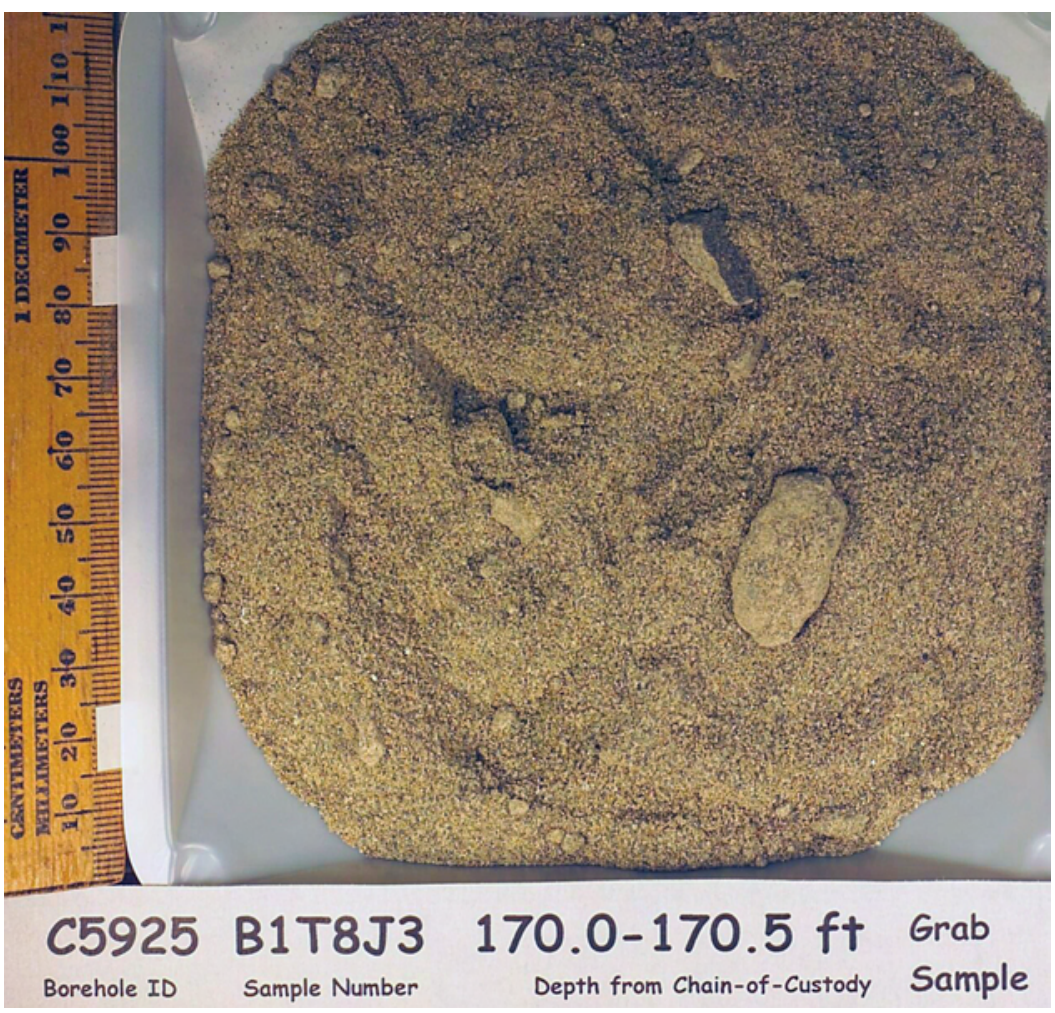


PNNL-17821
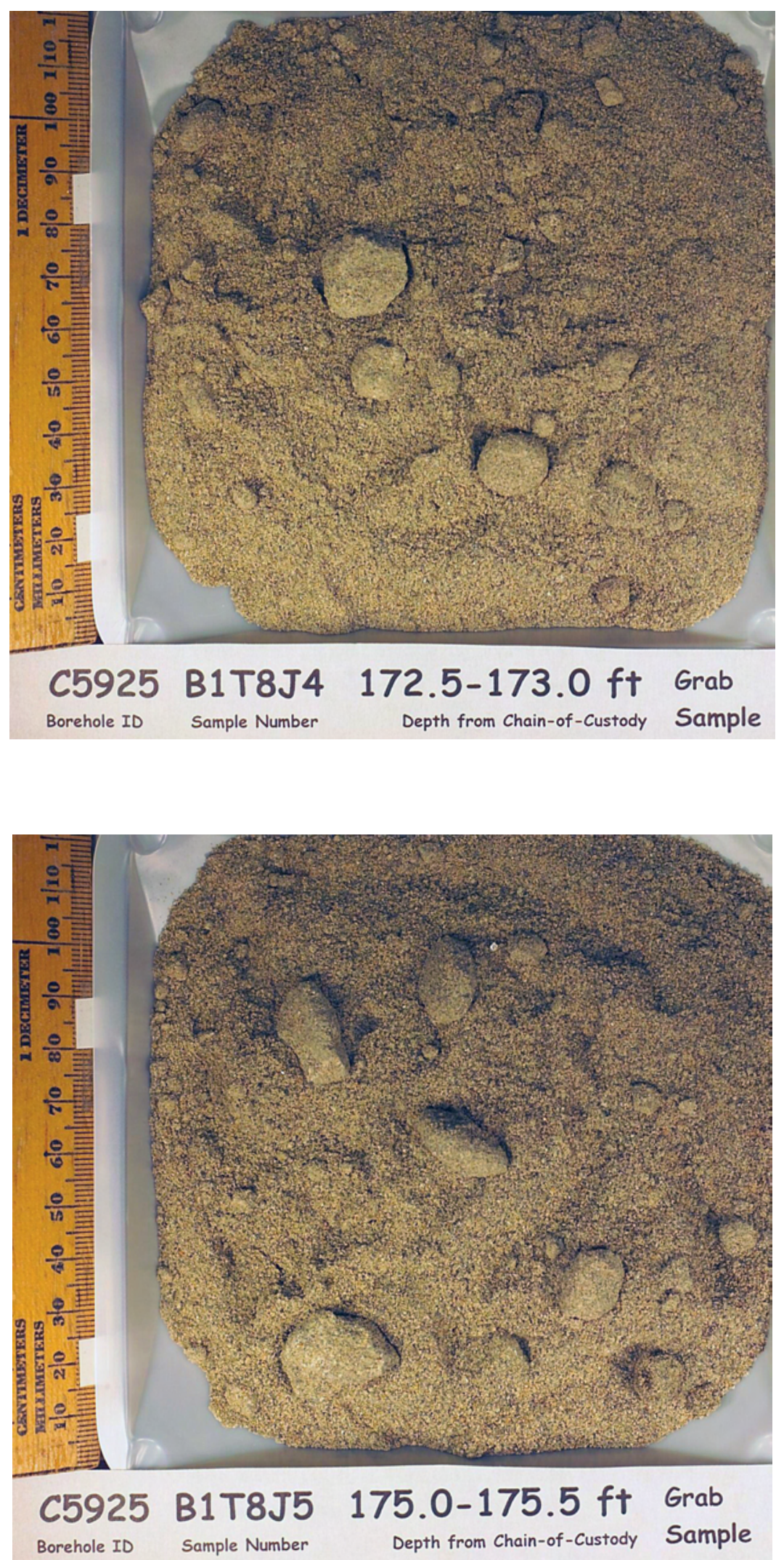
PNNL-17821

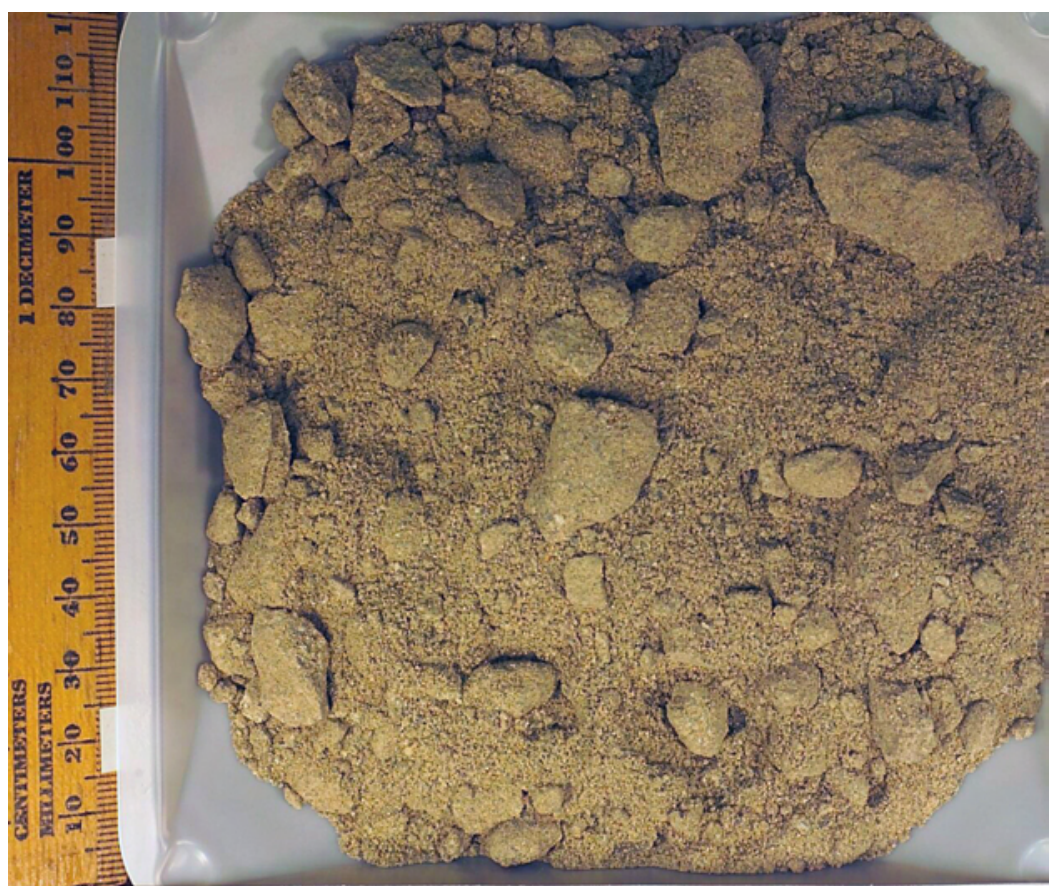

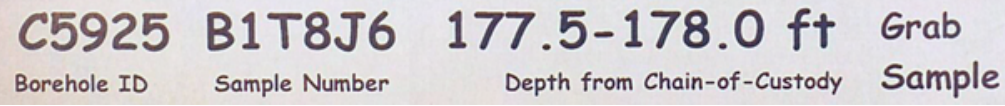

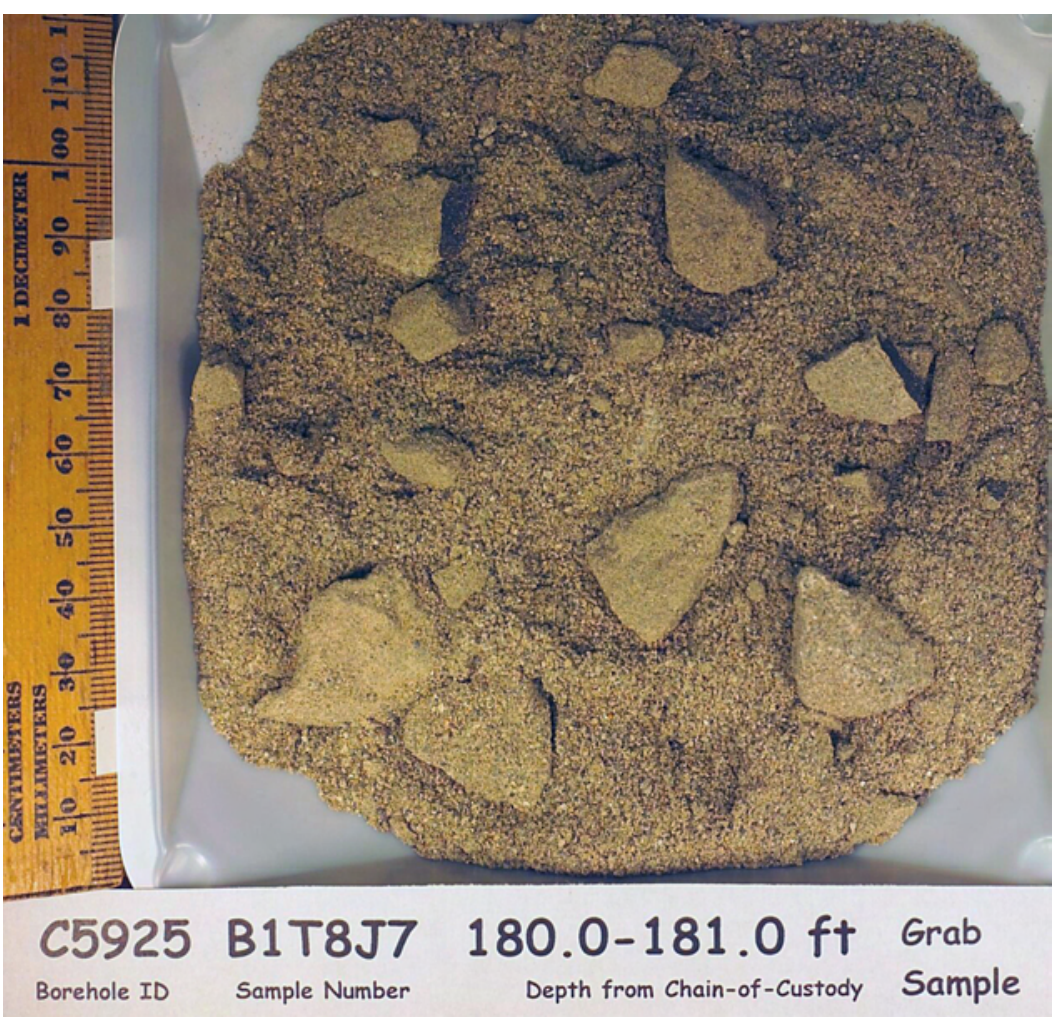


PNNL-17821
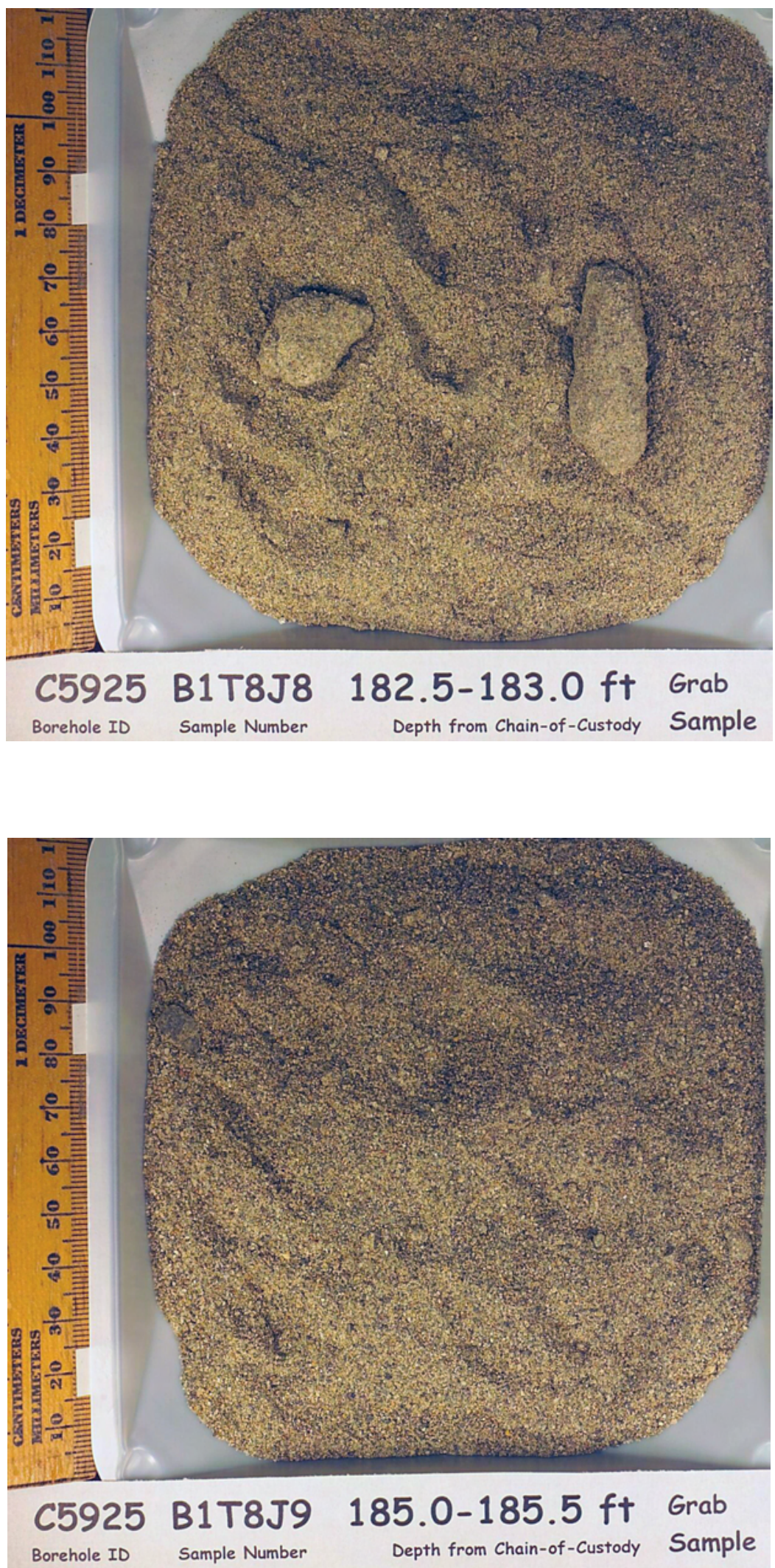
PNNL-17821
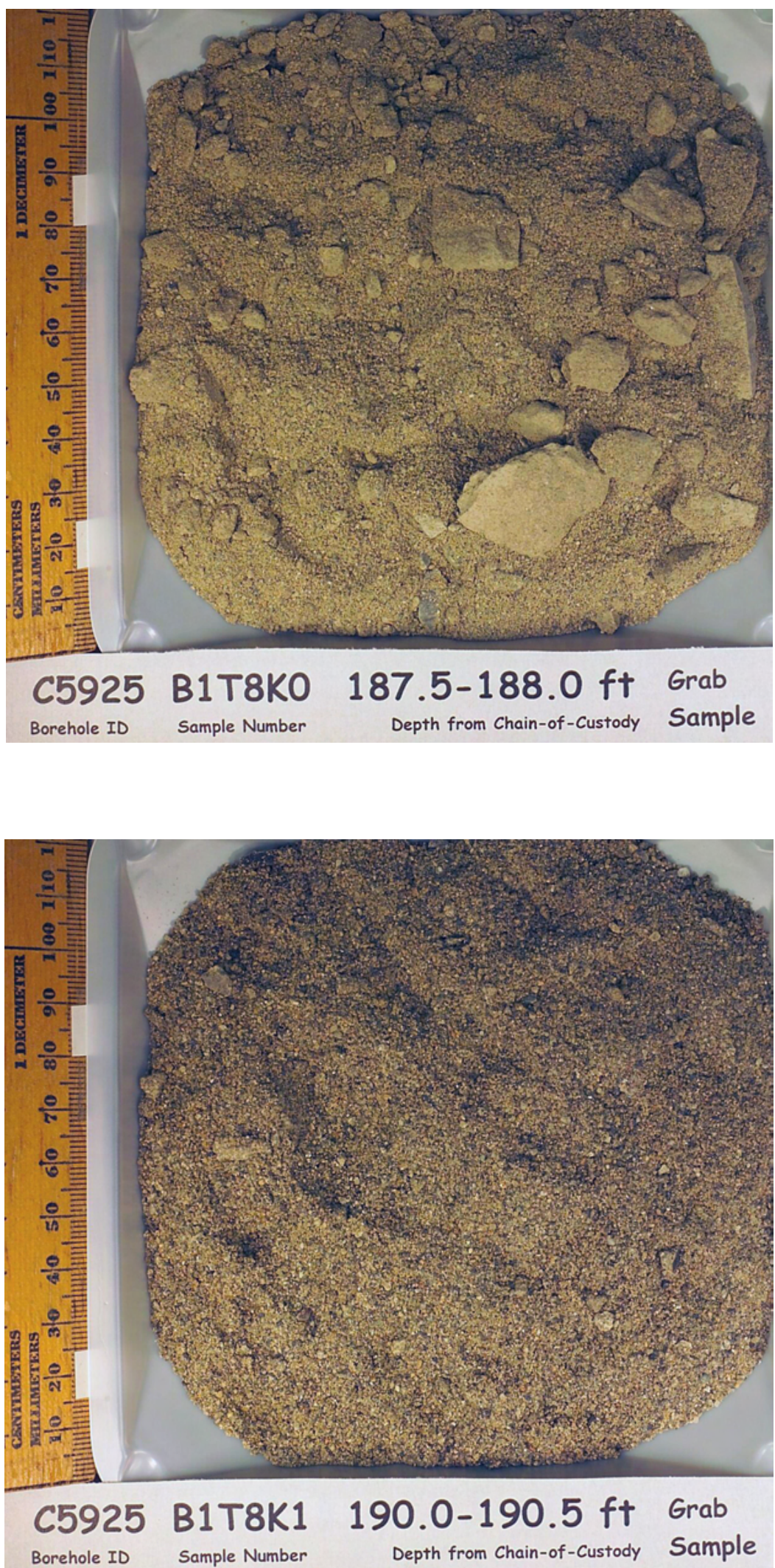
PNNL-17821

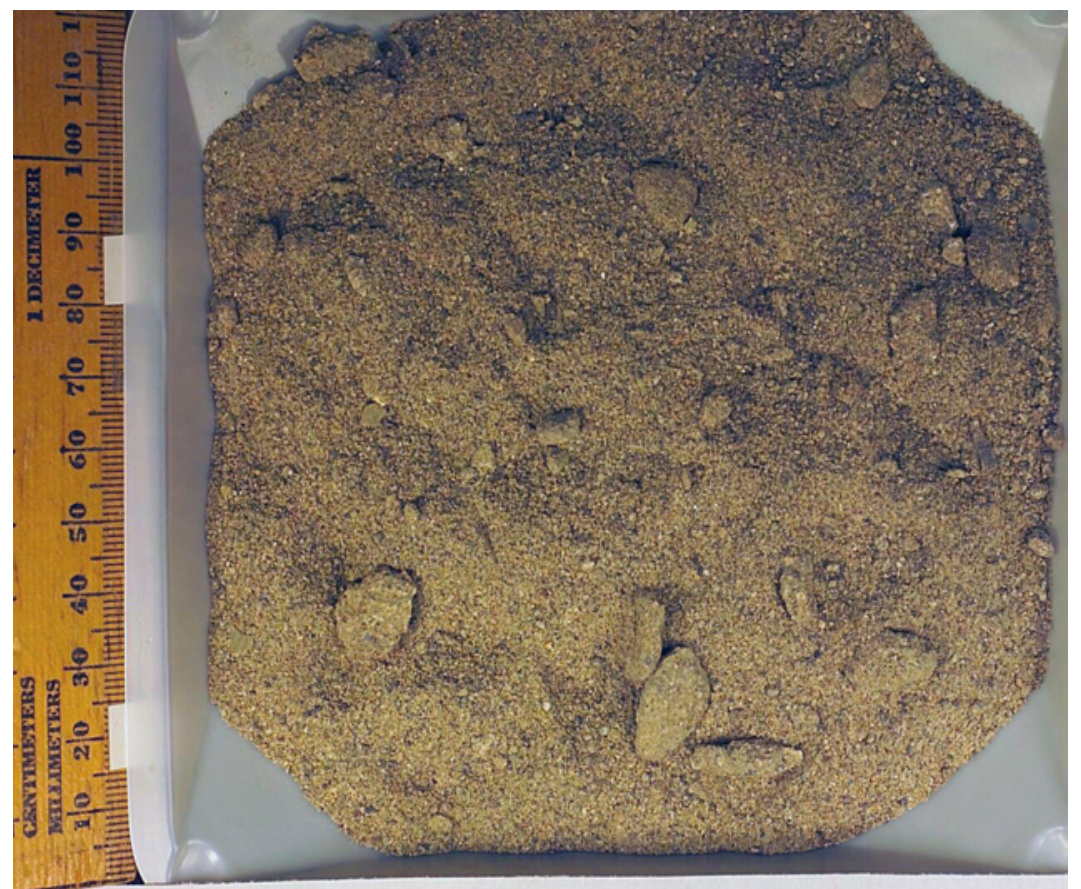

C5925 B1T8K2 192.5-193.0 ft Grab

Borehole ID

Sample Number

Depth from Chain-of-Custody Sample

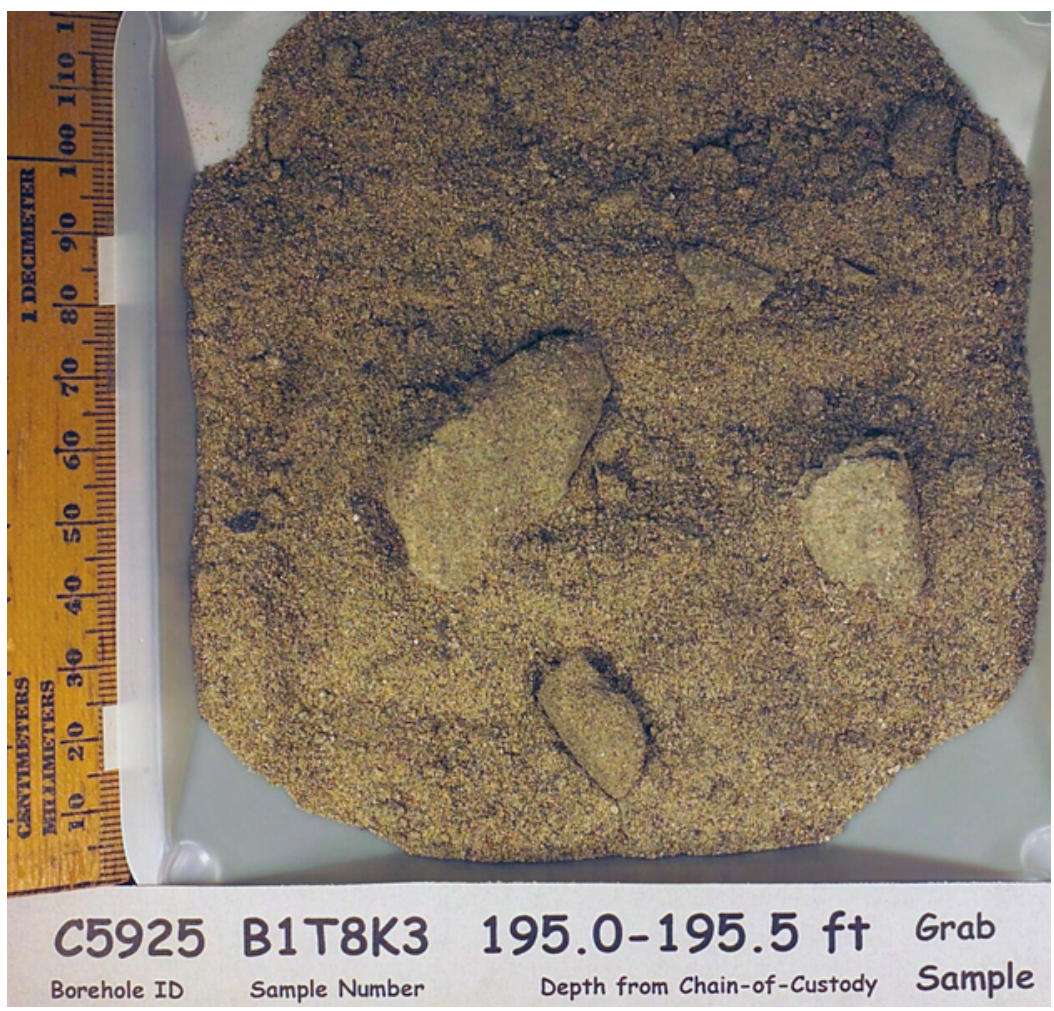


PNNL-17821

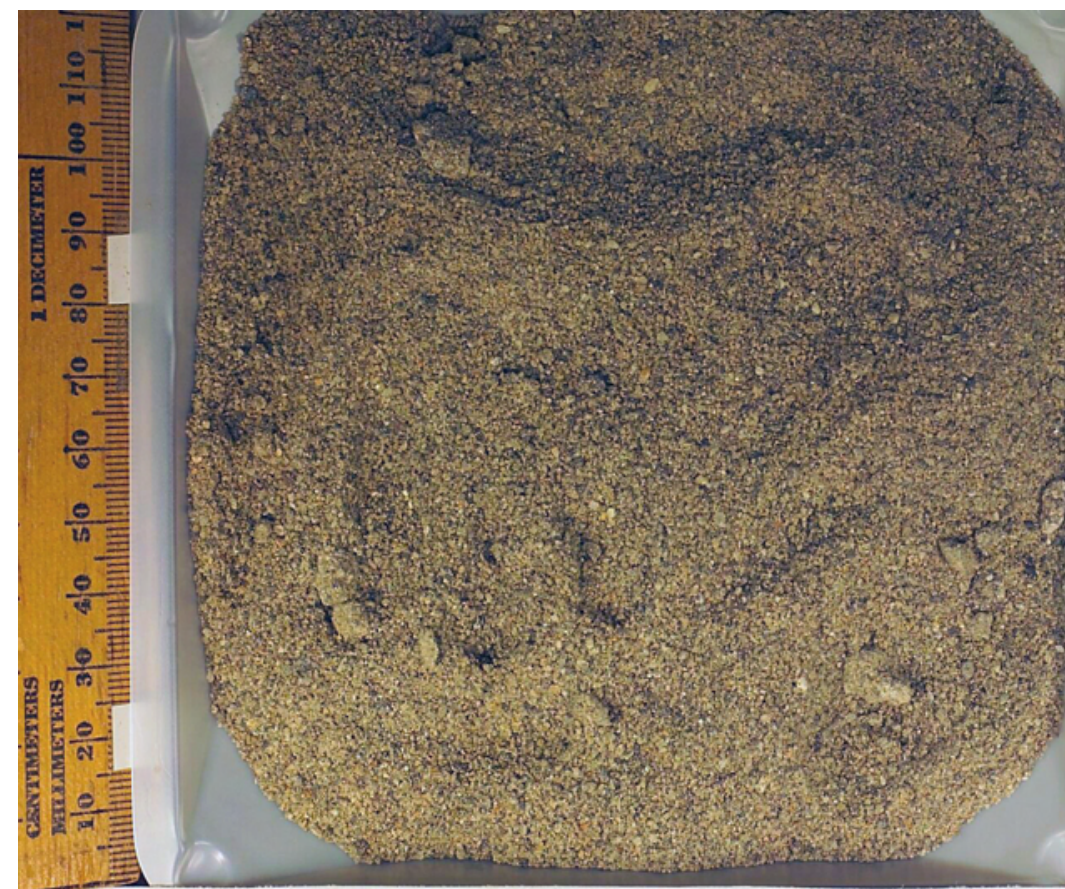

\section{C5925 B1T8K4 197.5-198.0 ft Grab \\ Borehole ID

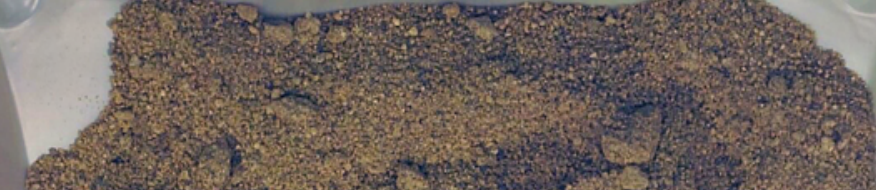

C5925

Borehole ID

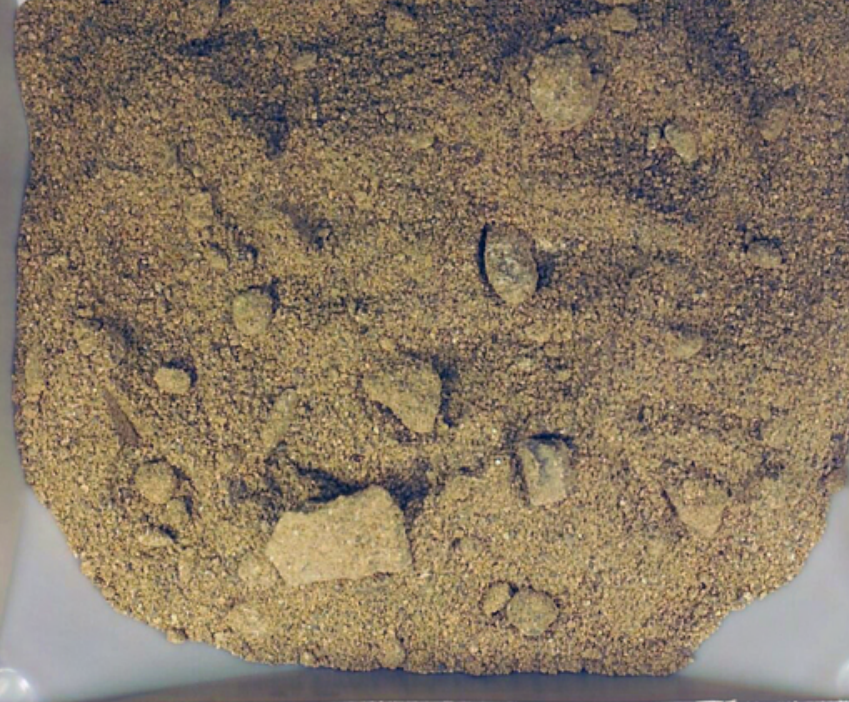
B1T8K5
200.0-200.5 ft Grab
Depth from Chain-of-Custody Sample 
PNNL-17821
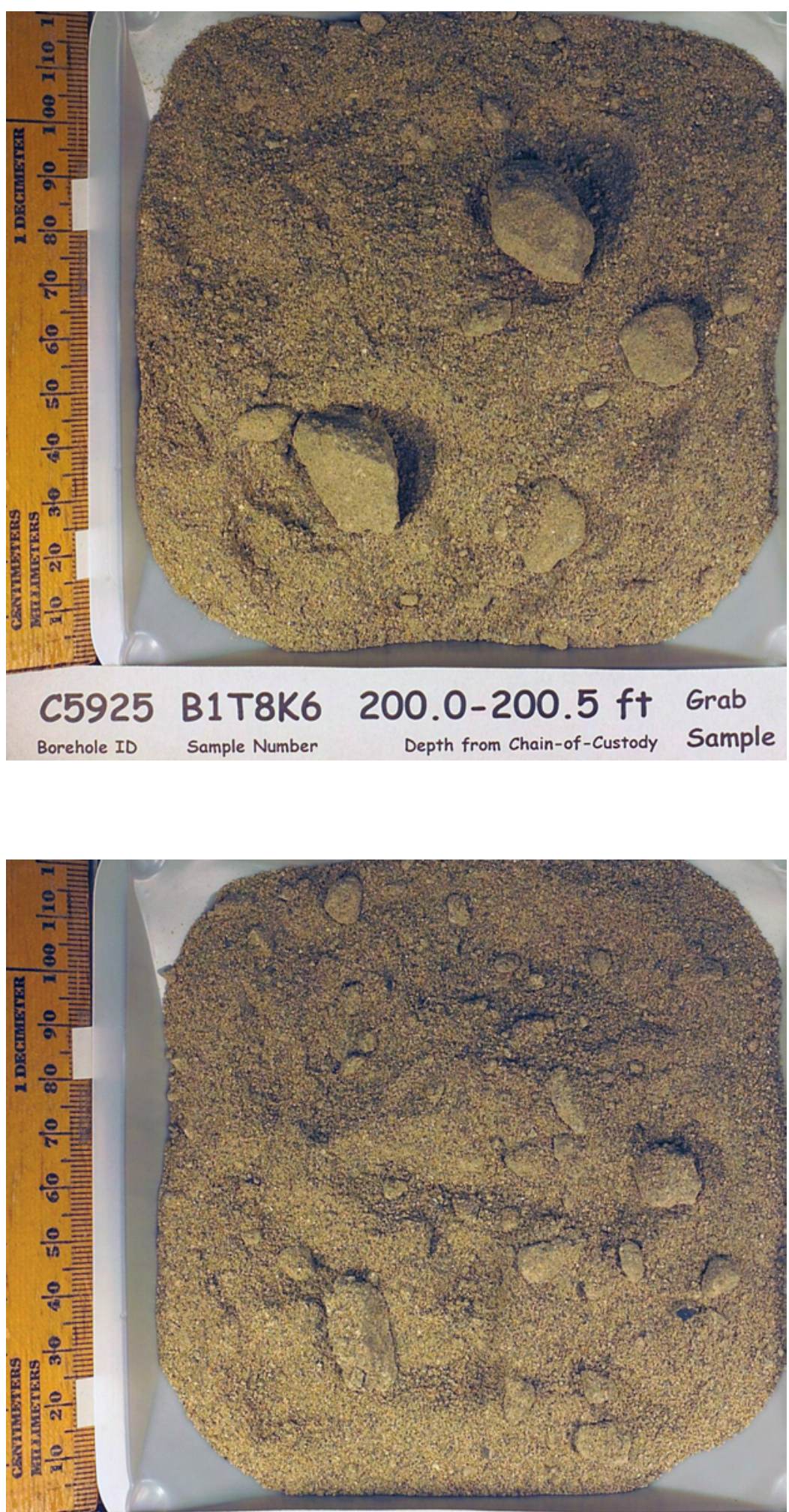

C5925 B1T8K7 203.0-203.5 ft Grab

Borehole ID

Sample Number

Depth from Chain-of-Custody Sample 
PNNL-17821

Samples from Borehole C4191
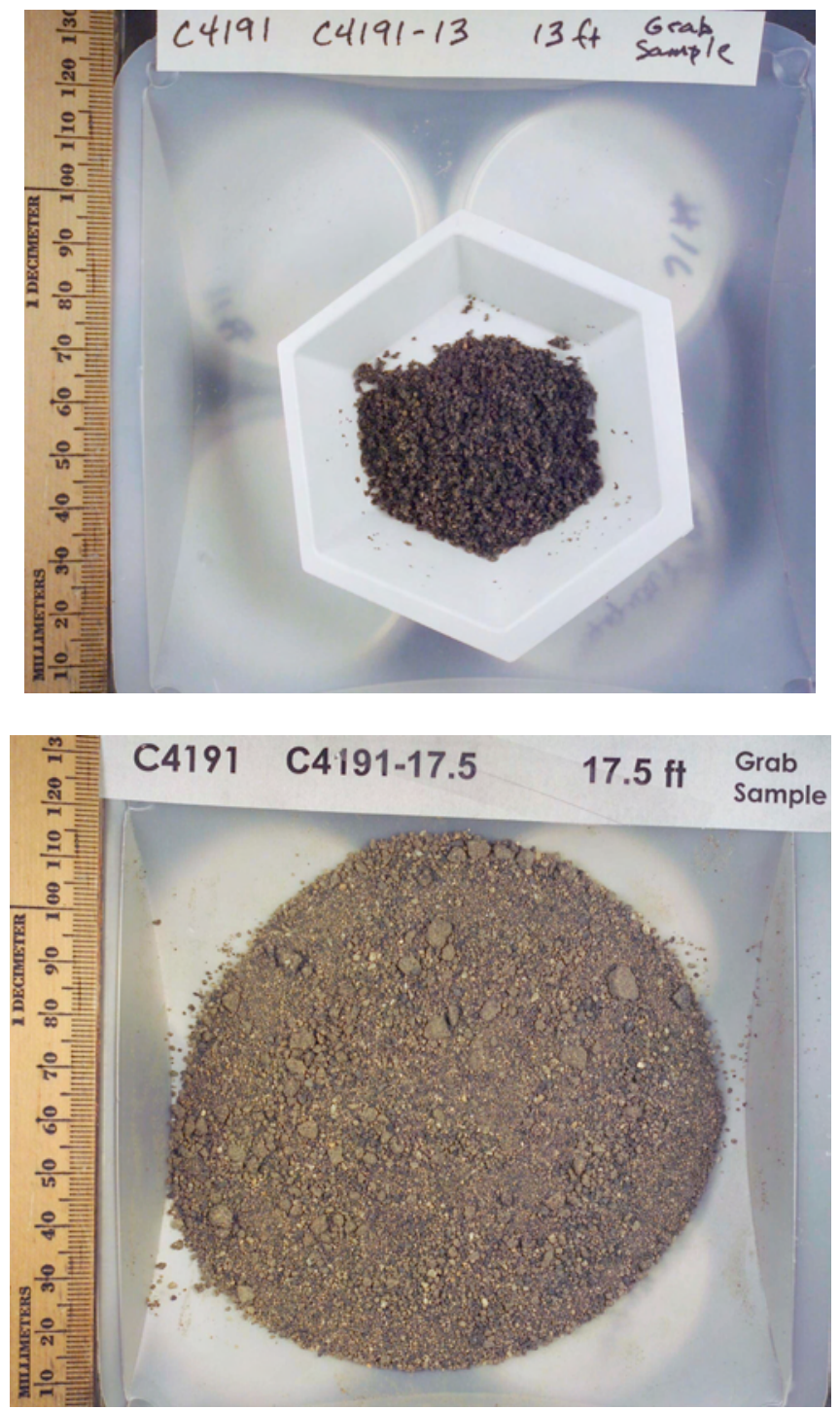

B.219 
PNNL-17821
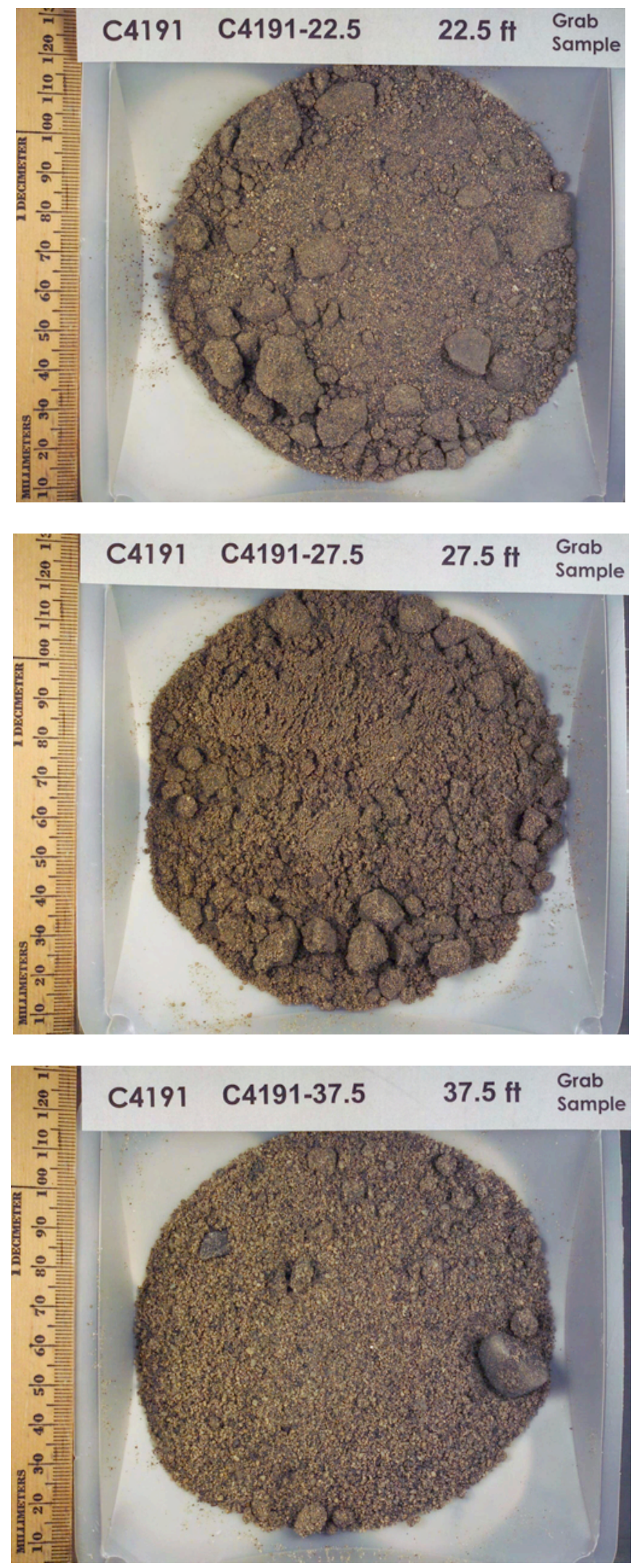

B.220 
PNNL-17821
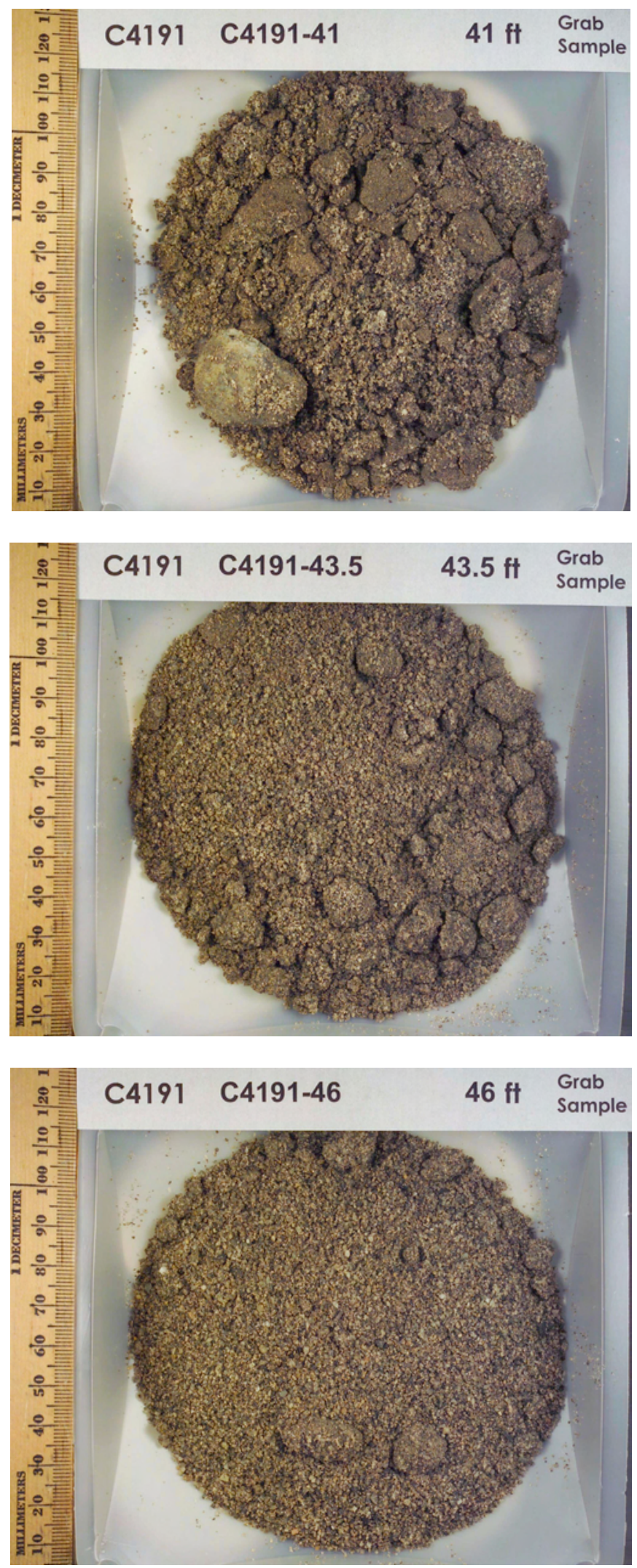

B.221 
PNNL-17821
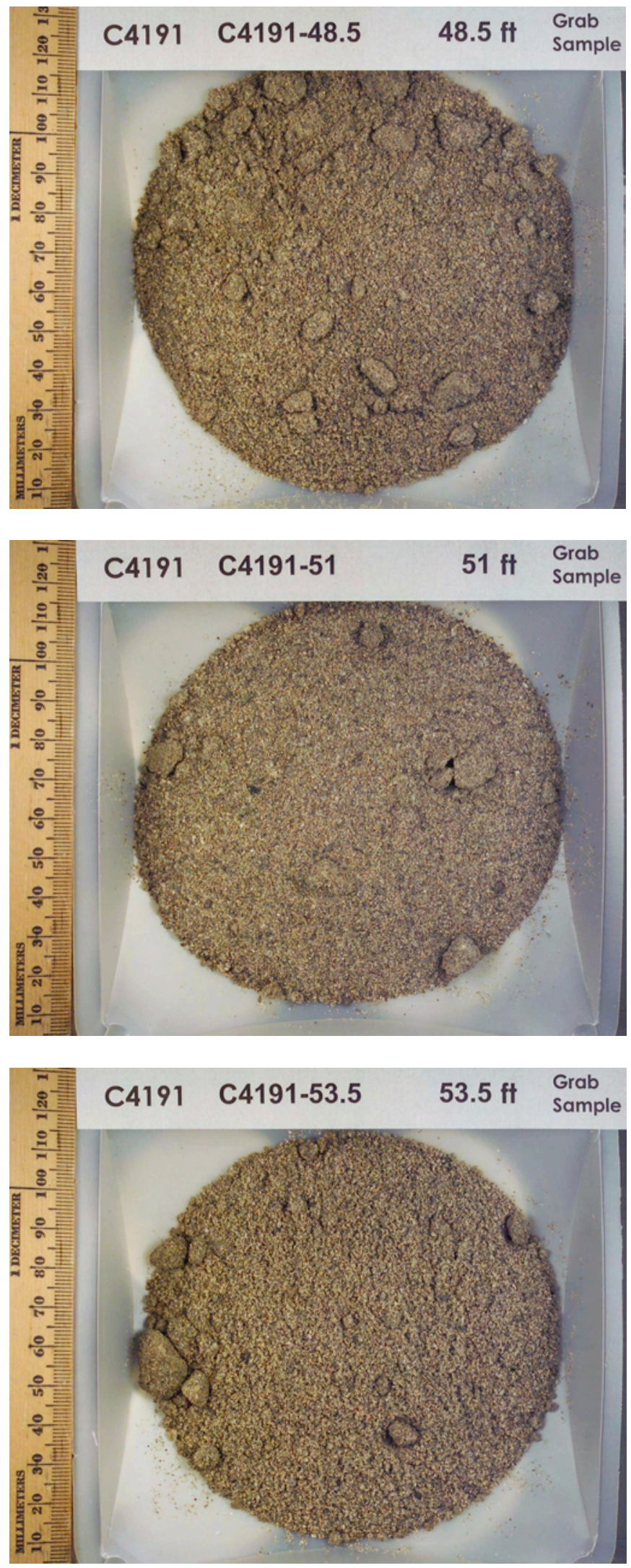

B.222 
PNNL-17821
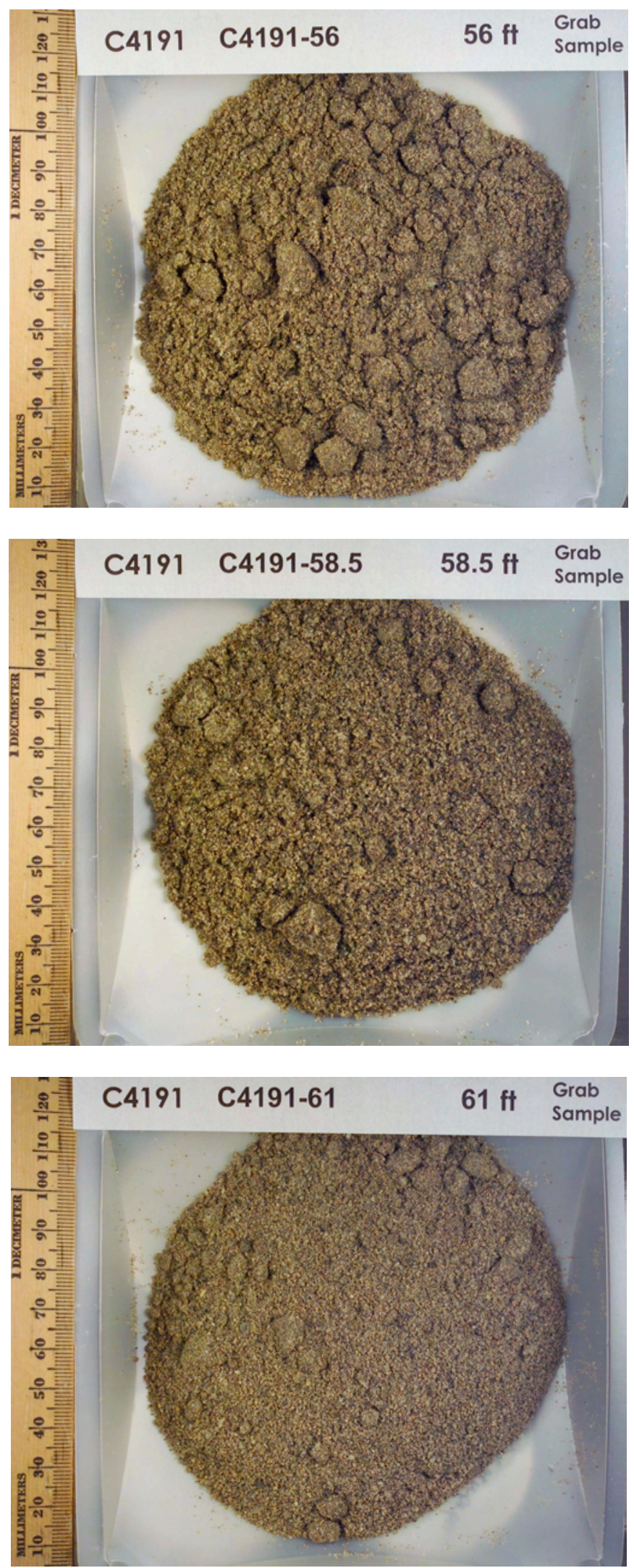

B.223 
PNNL-17821
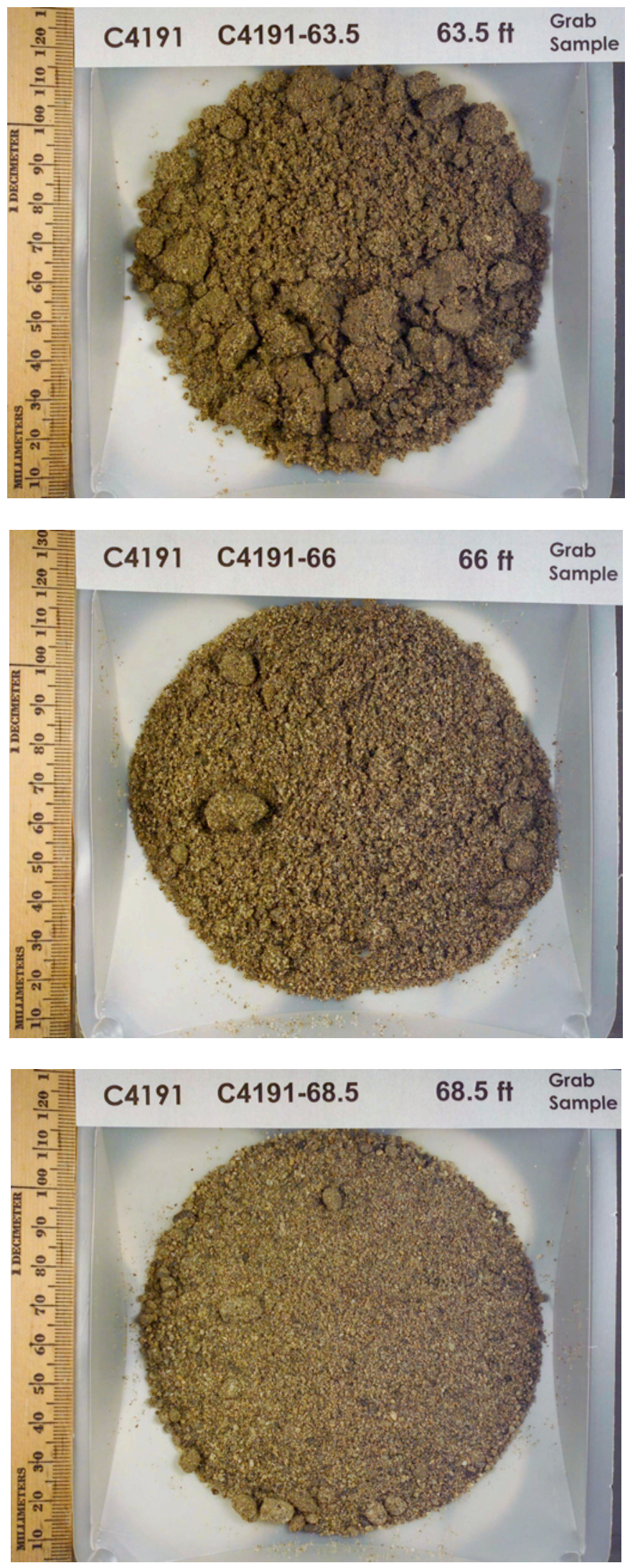
PNNL-17821
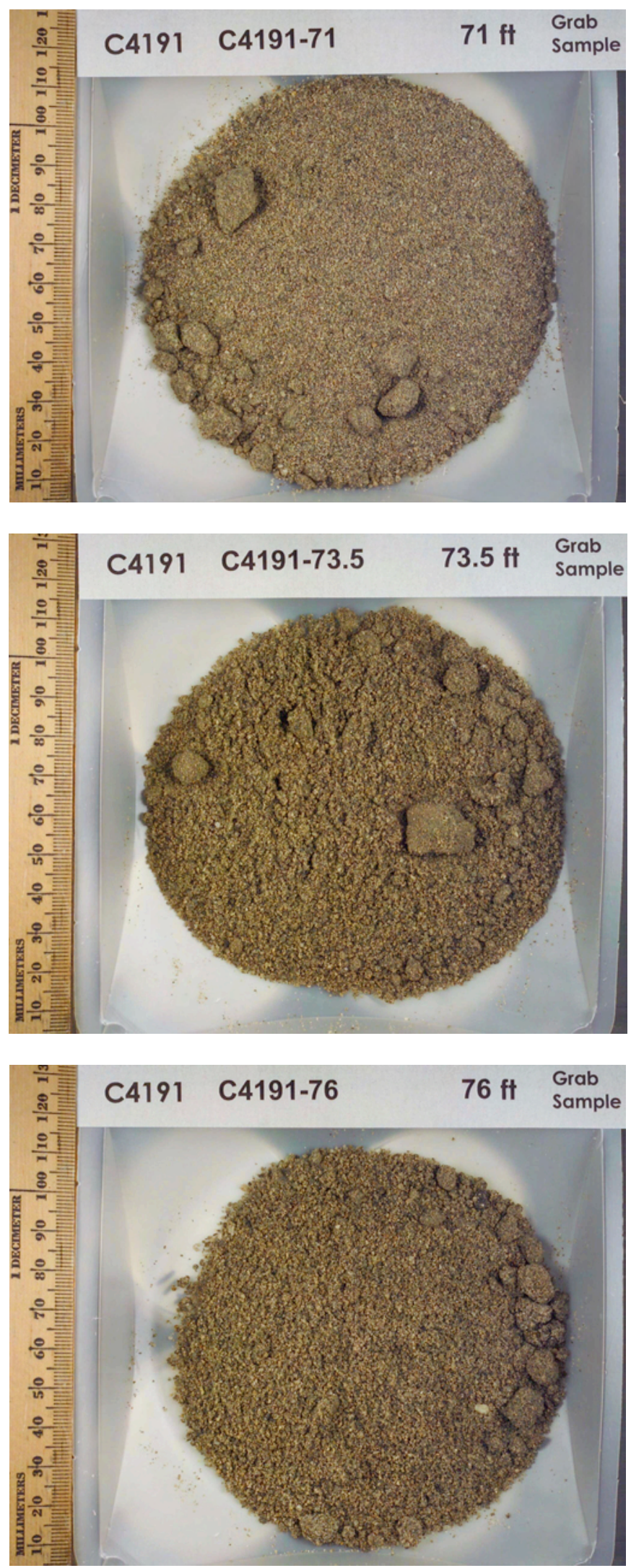

B.225 
PNNL-17821
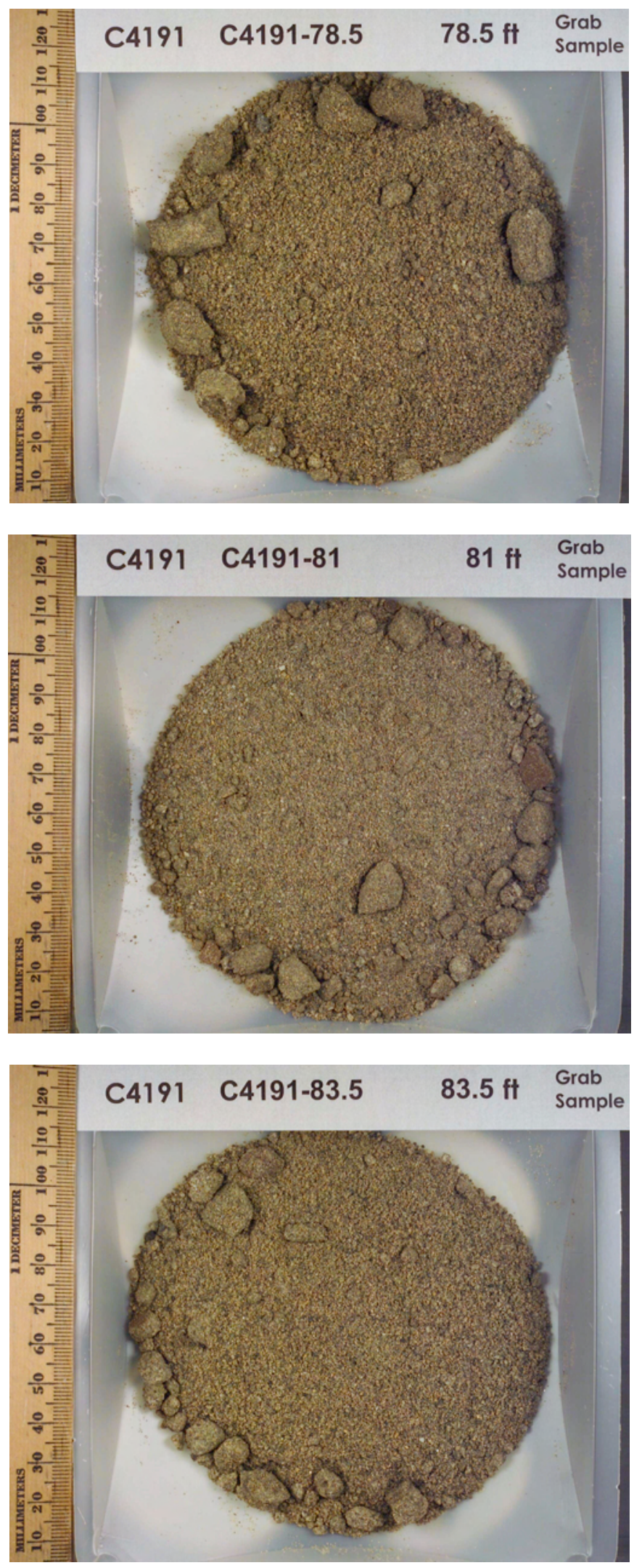

B.226 
PNNL-17821
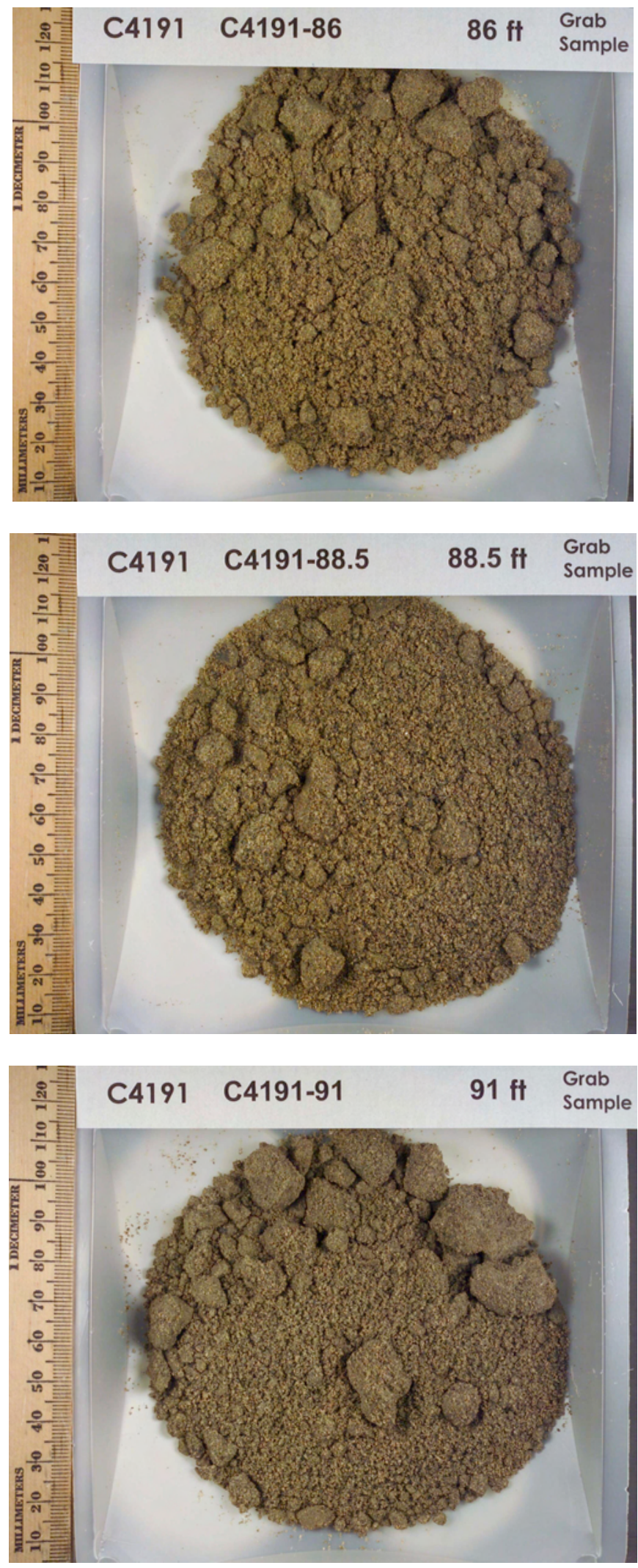

B.227 
PNNL-17821
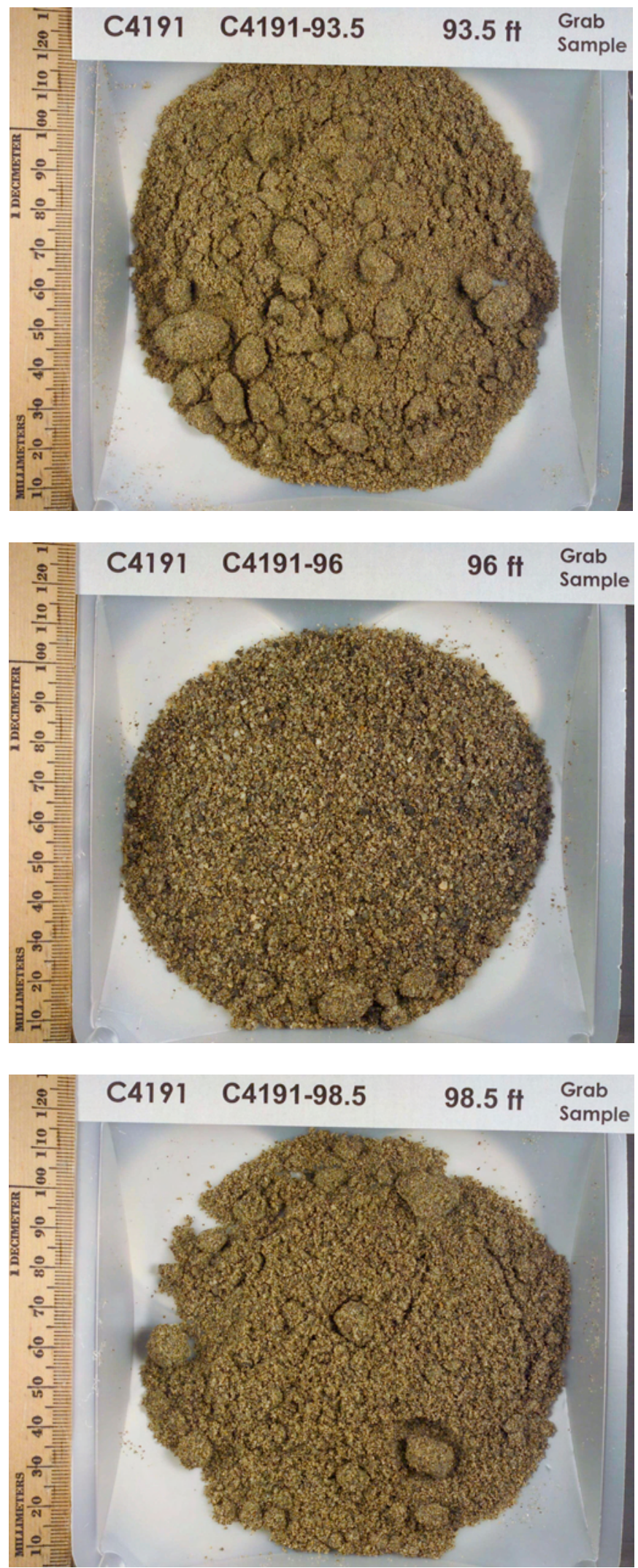
PNNL-17821
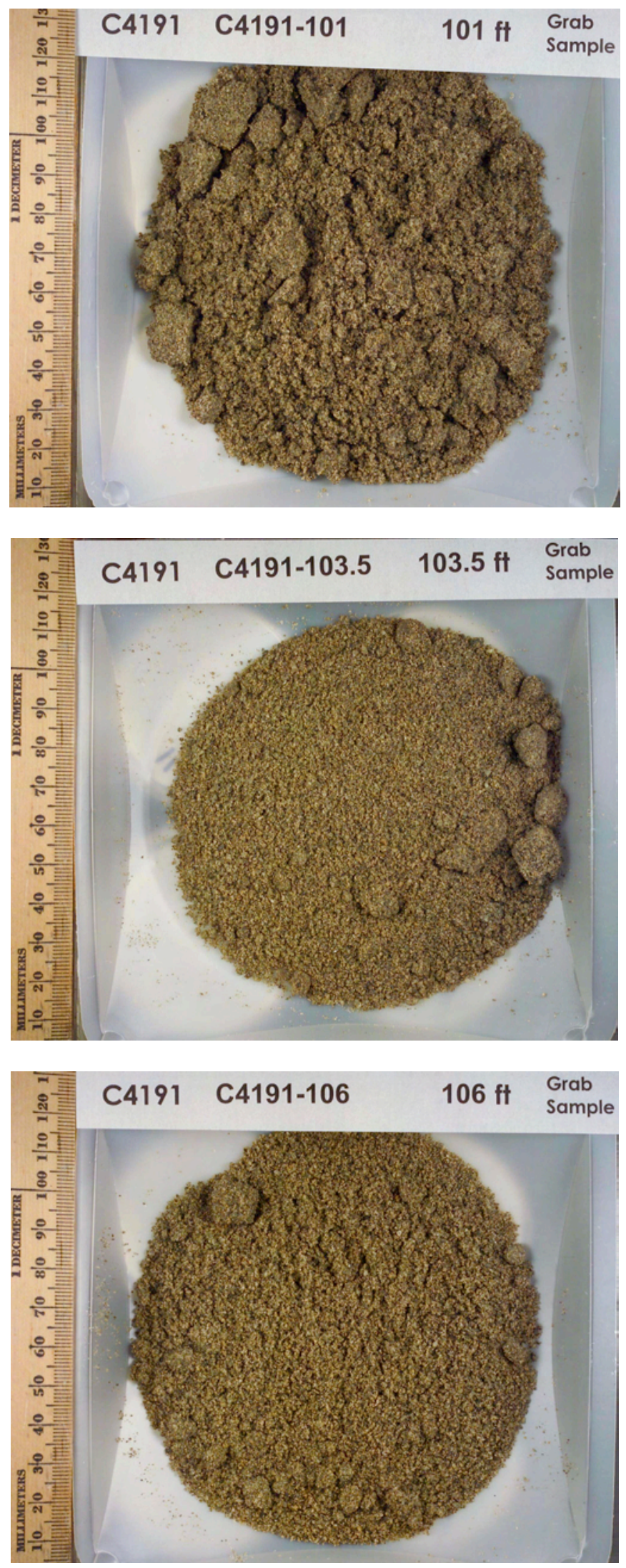

B.229 
PNNL-17821
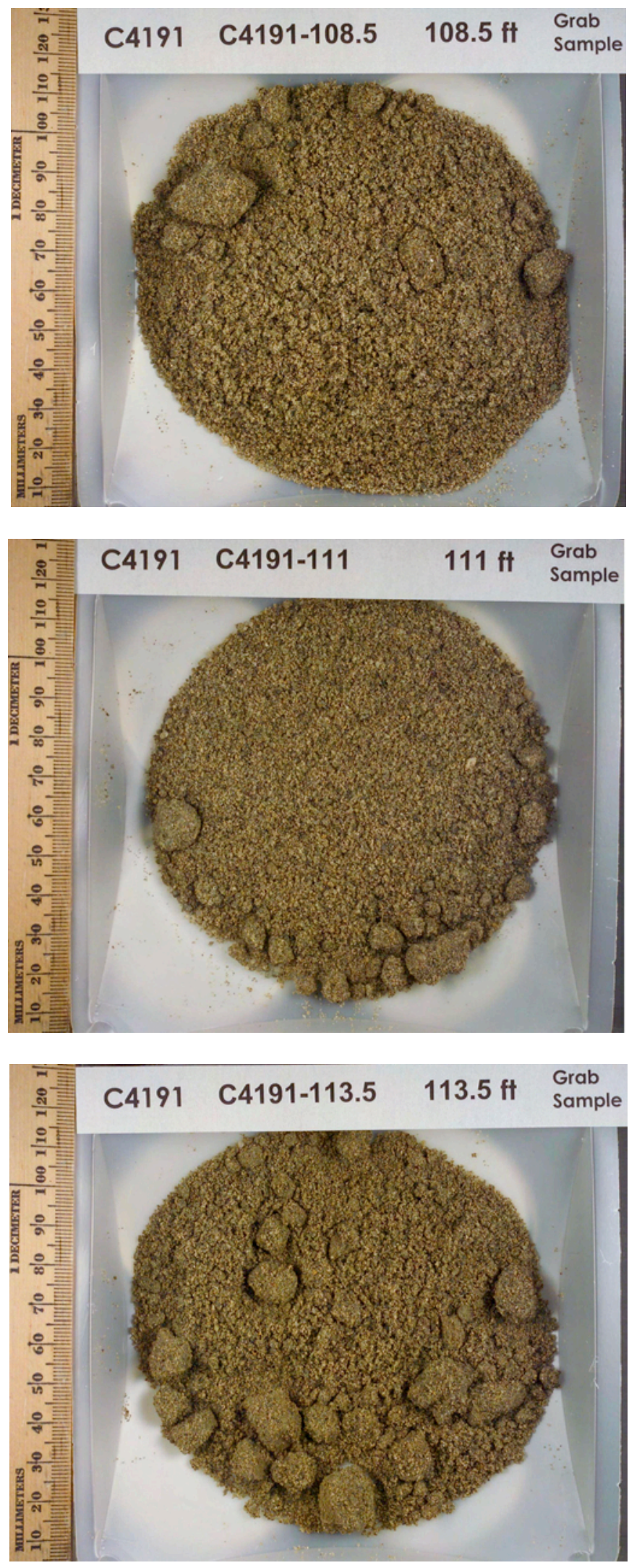

B.230 
PNNL-17821
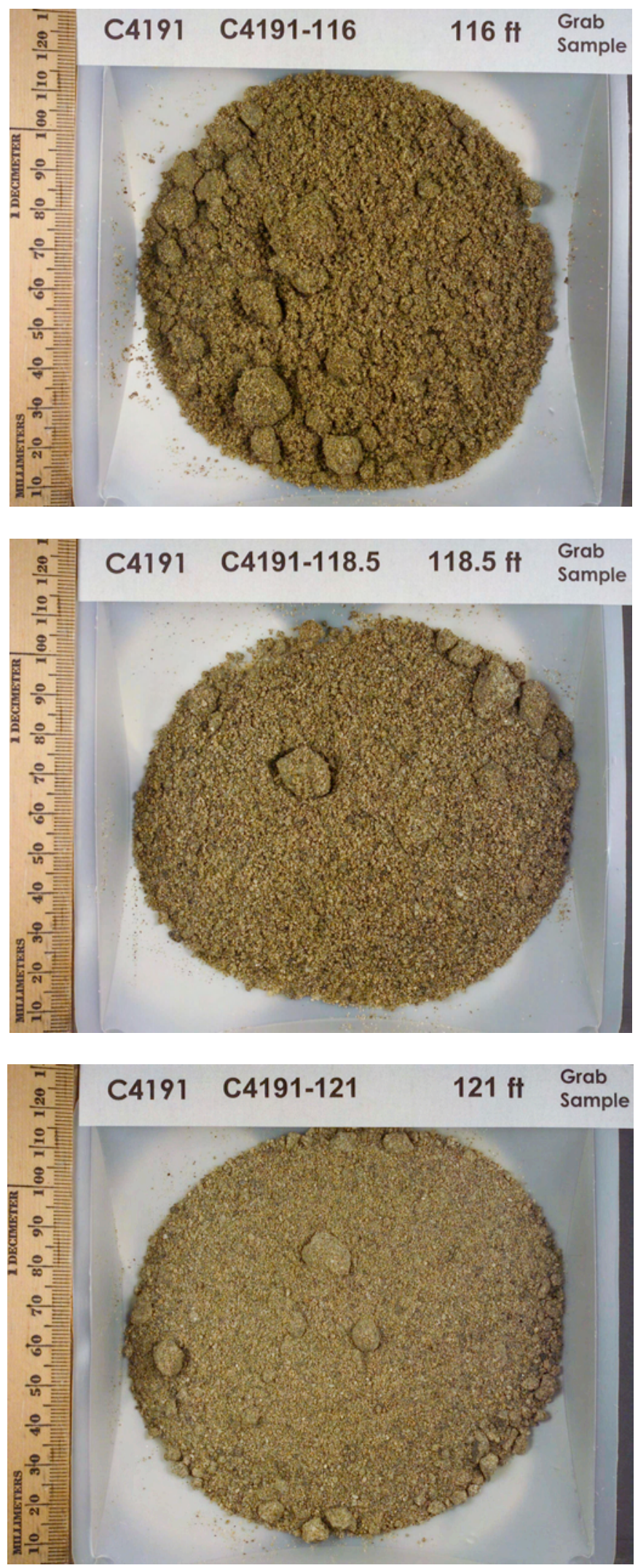

B.231 
PNNL-17821
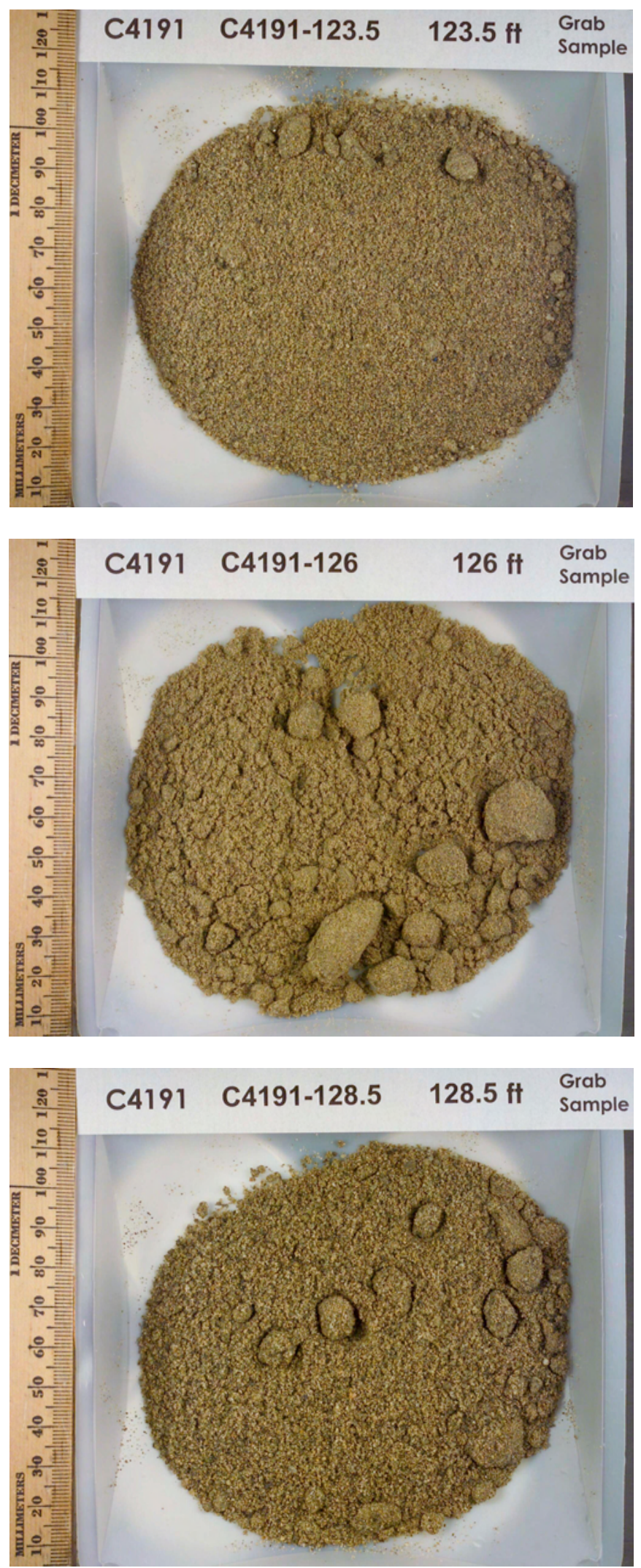

B.232 
PNNL-17821
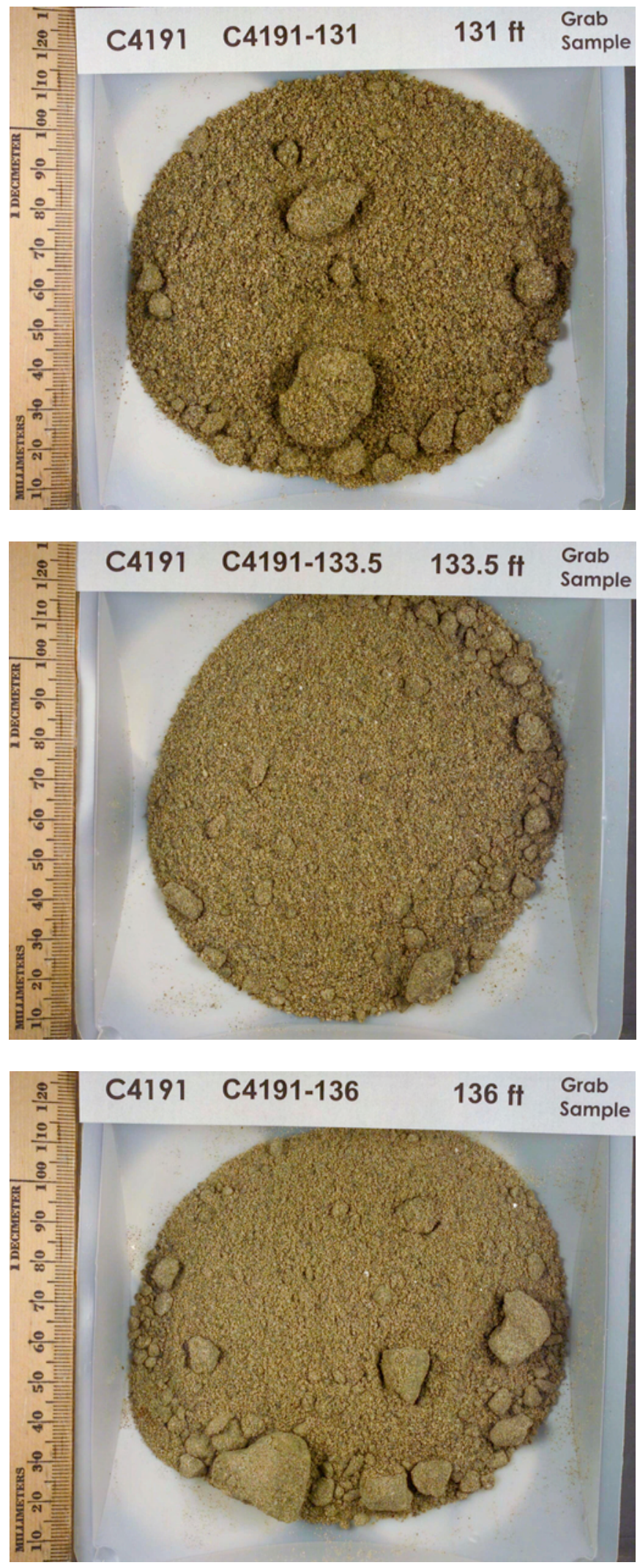

B.233 
PNNL-17821
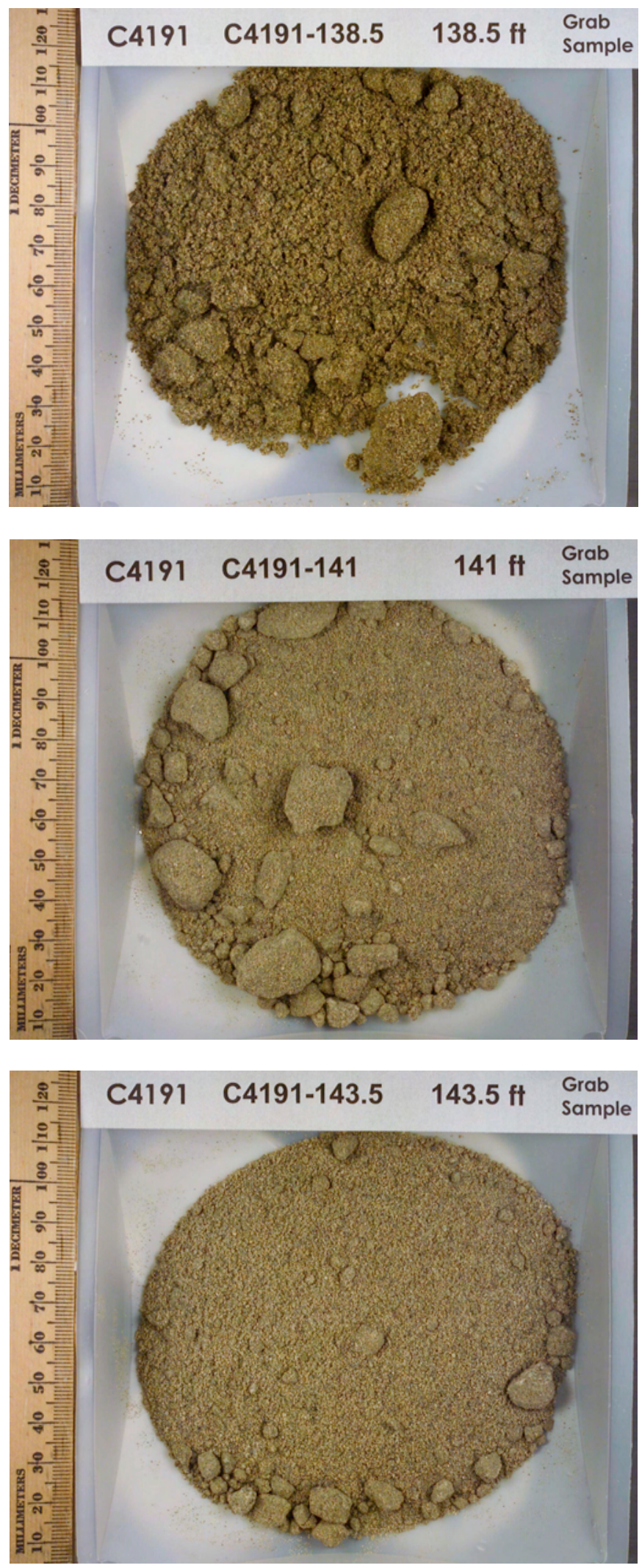

B.234 
PNNL-17821
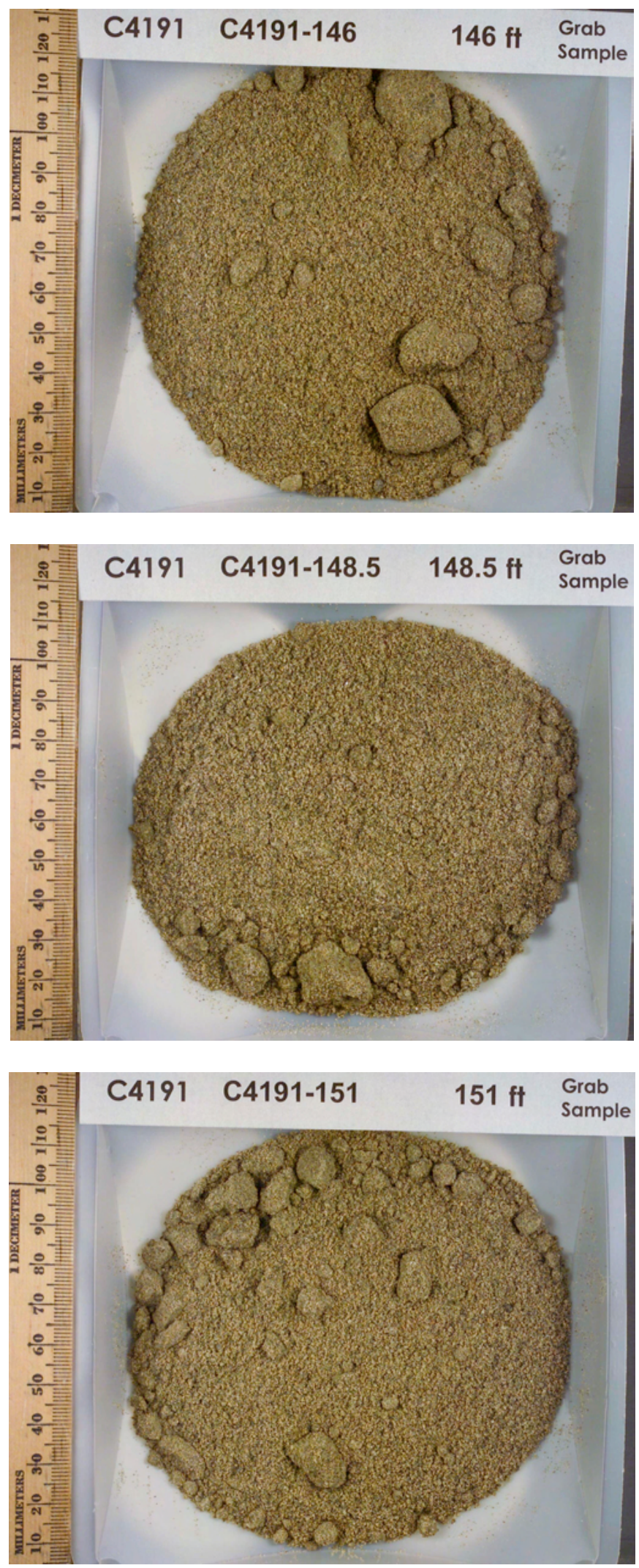

B.235 
PNNL-17821
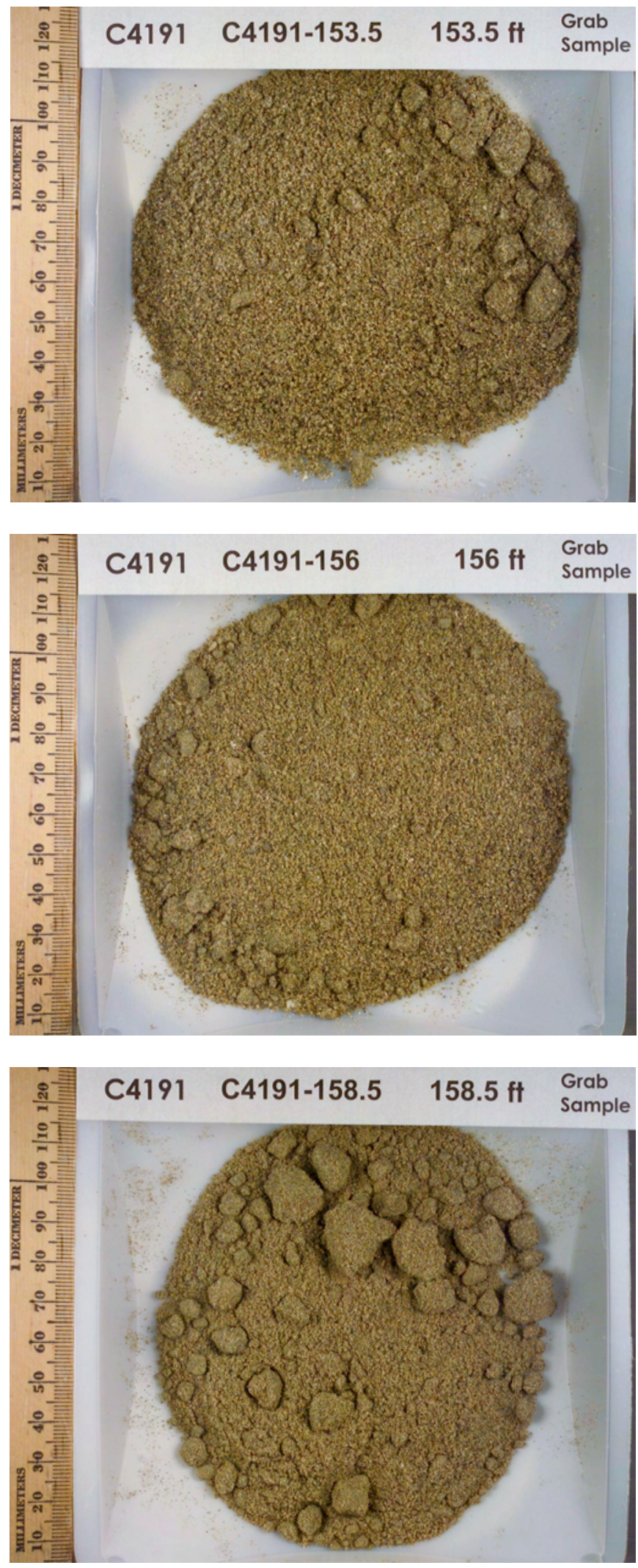

B.236 
PNNL-17821
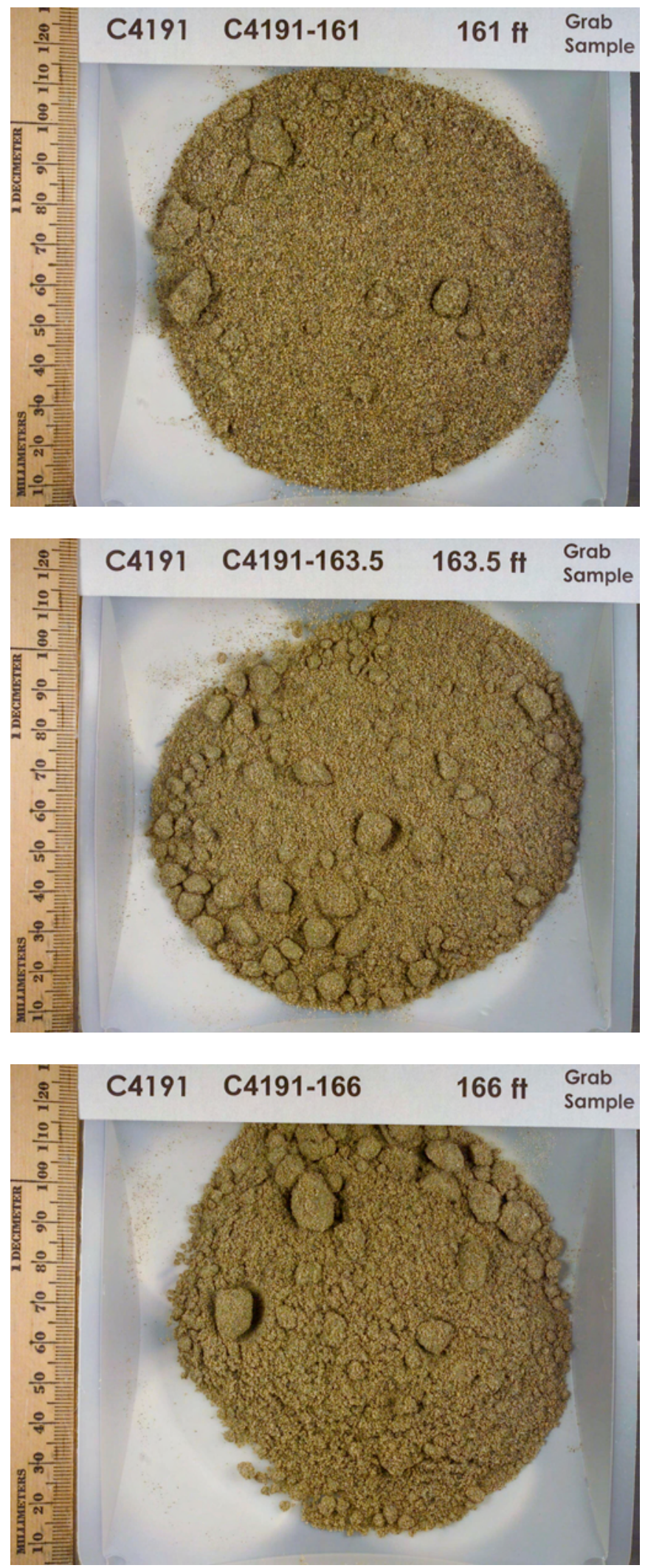

B.237 
PNNL-17821
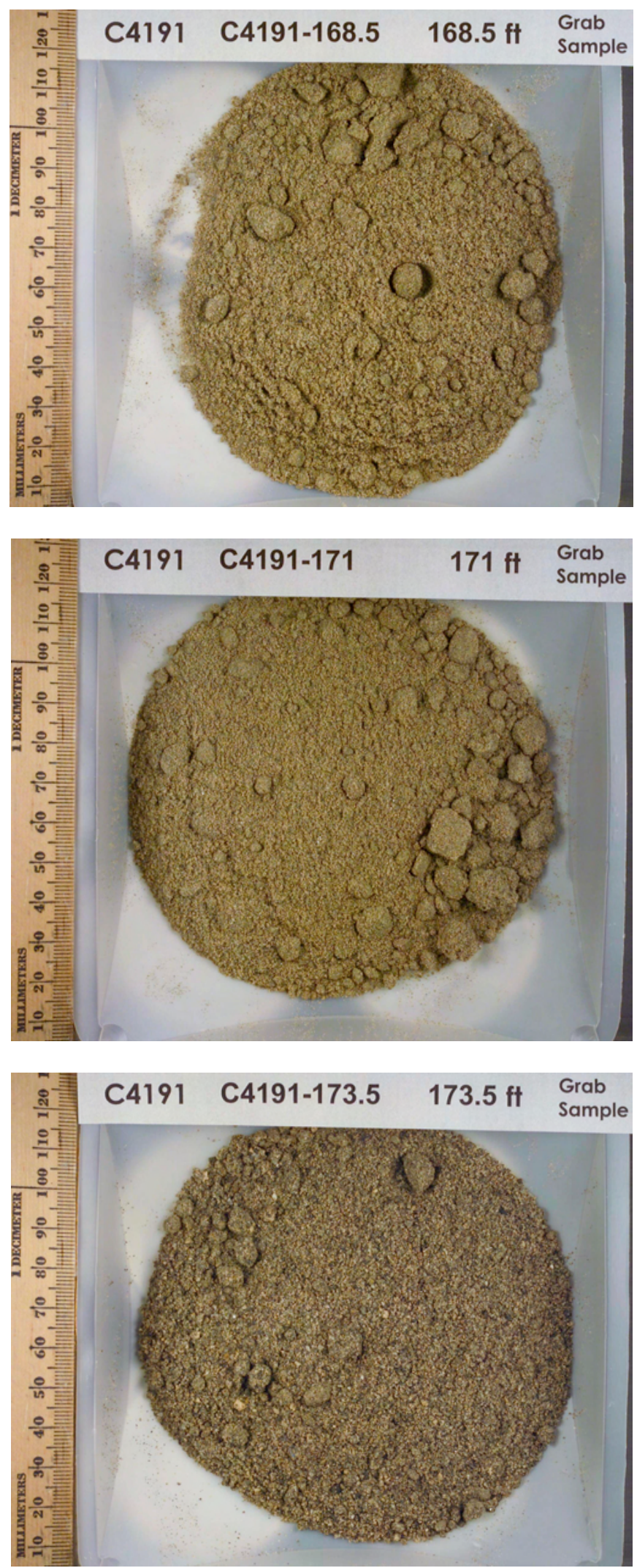

B.238 
PNNL-17821
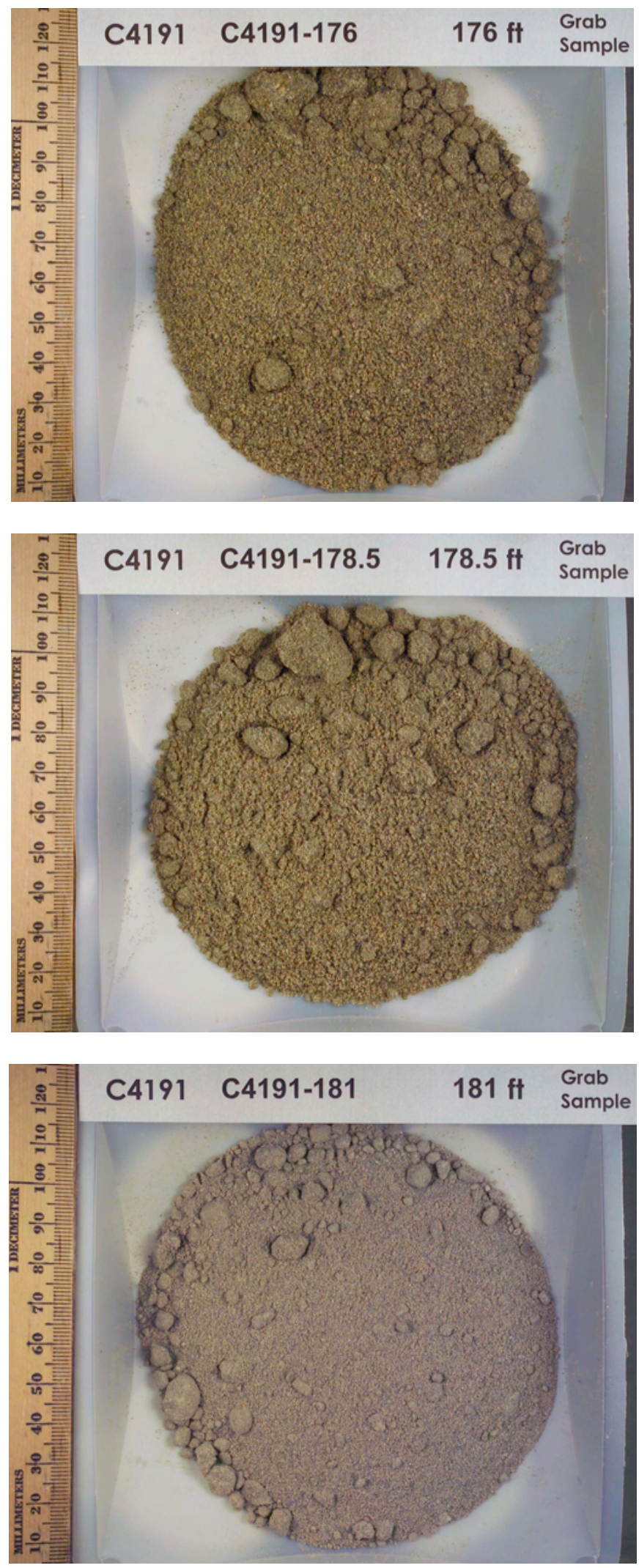

B.239 
PNNL-17821
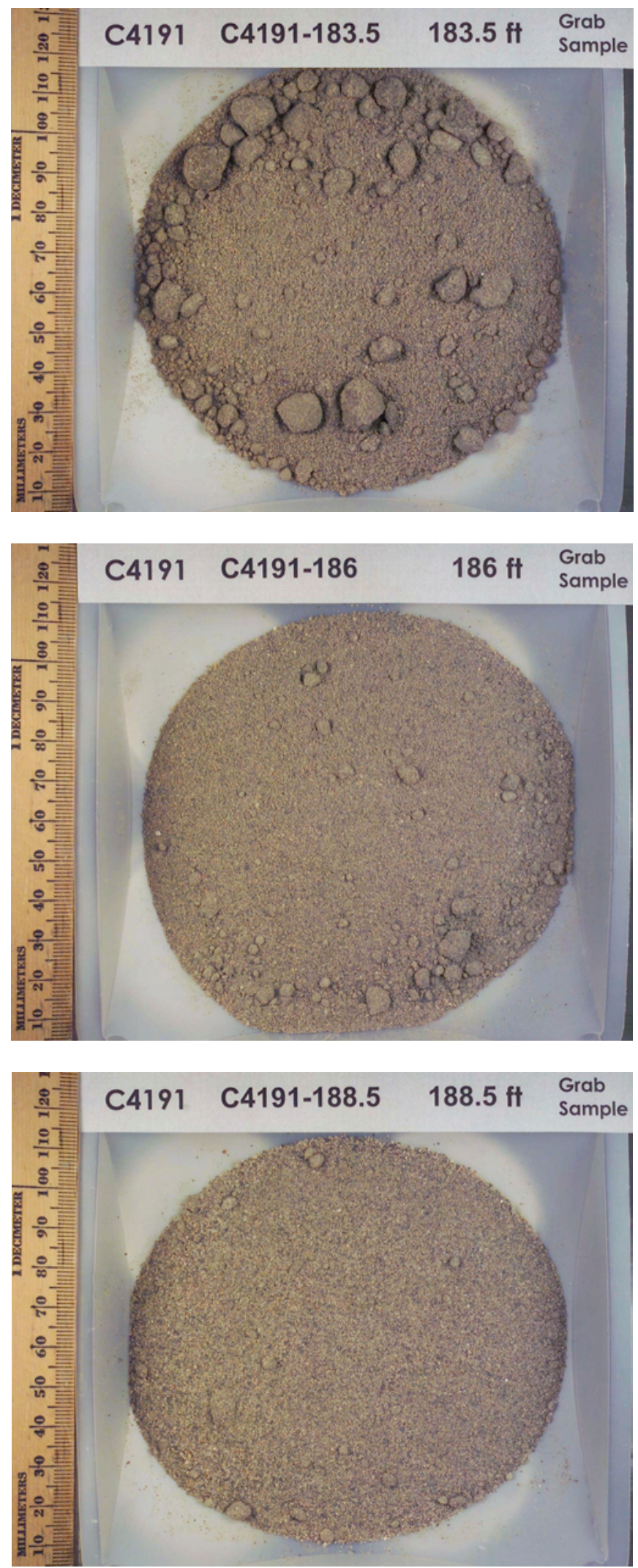

B. 240 
PNNL-17821
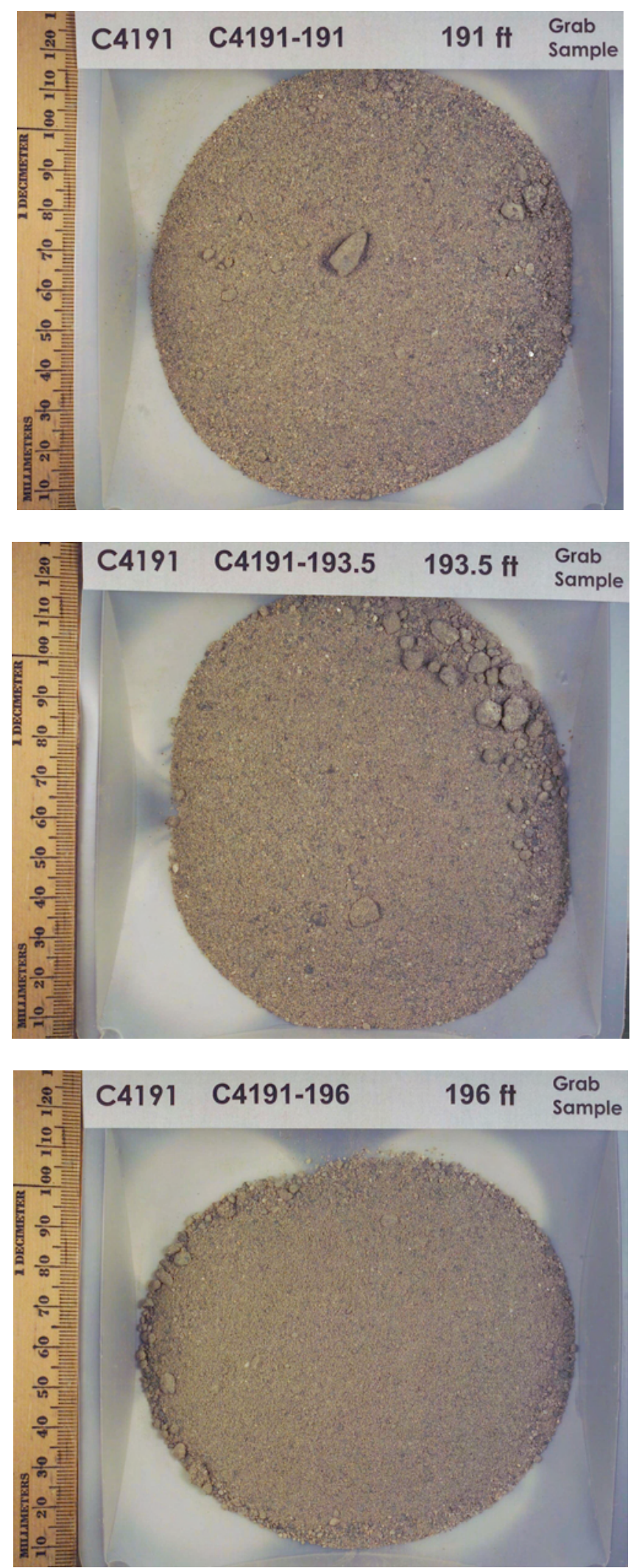

B.241 
PNNL-17821
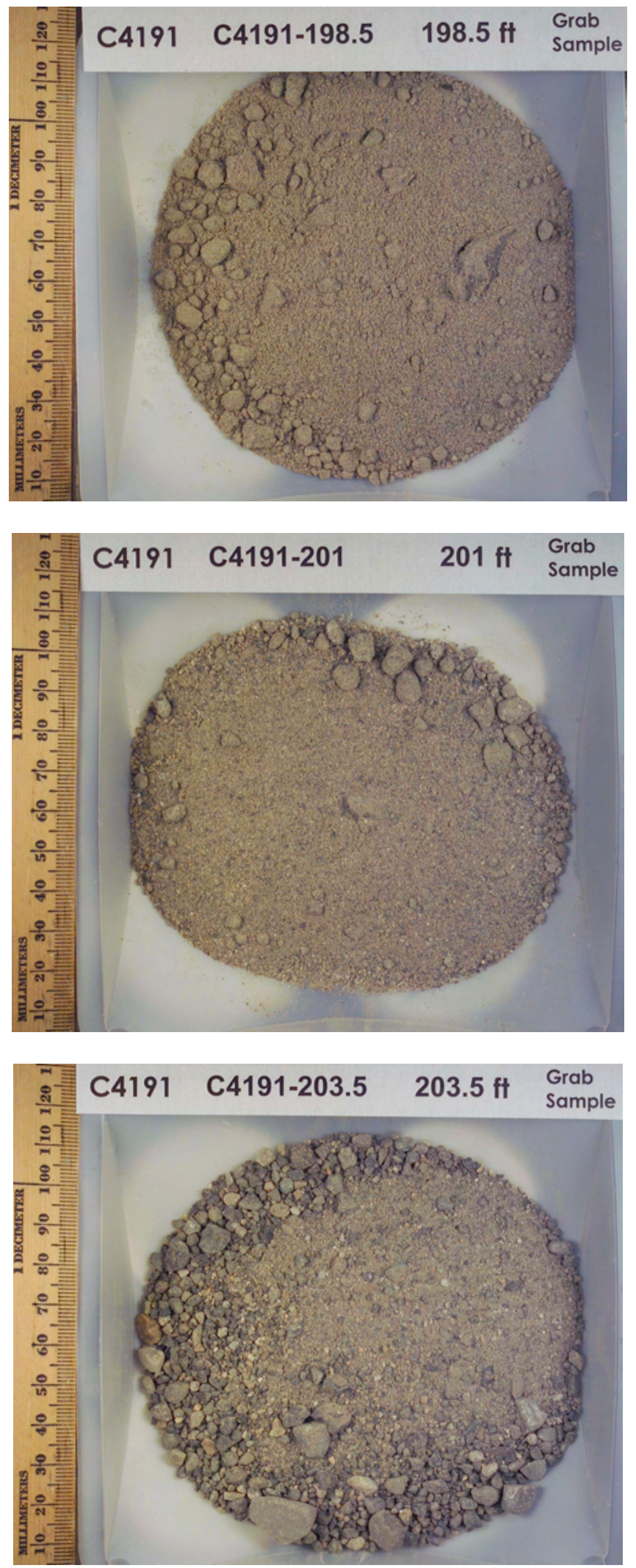

B.242 
PNNL-17821
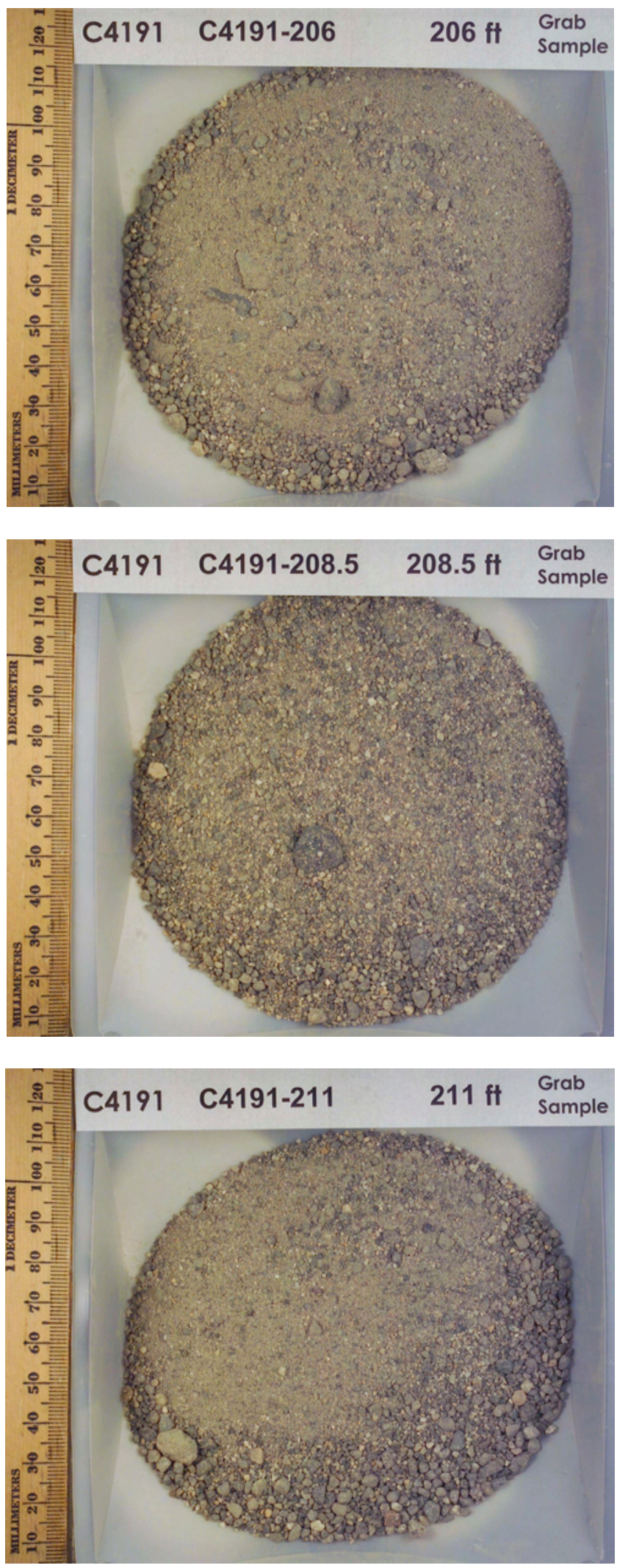

B.243 
PNNL-17821
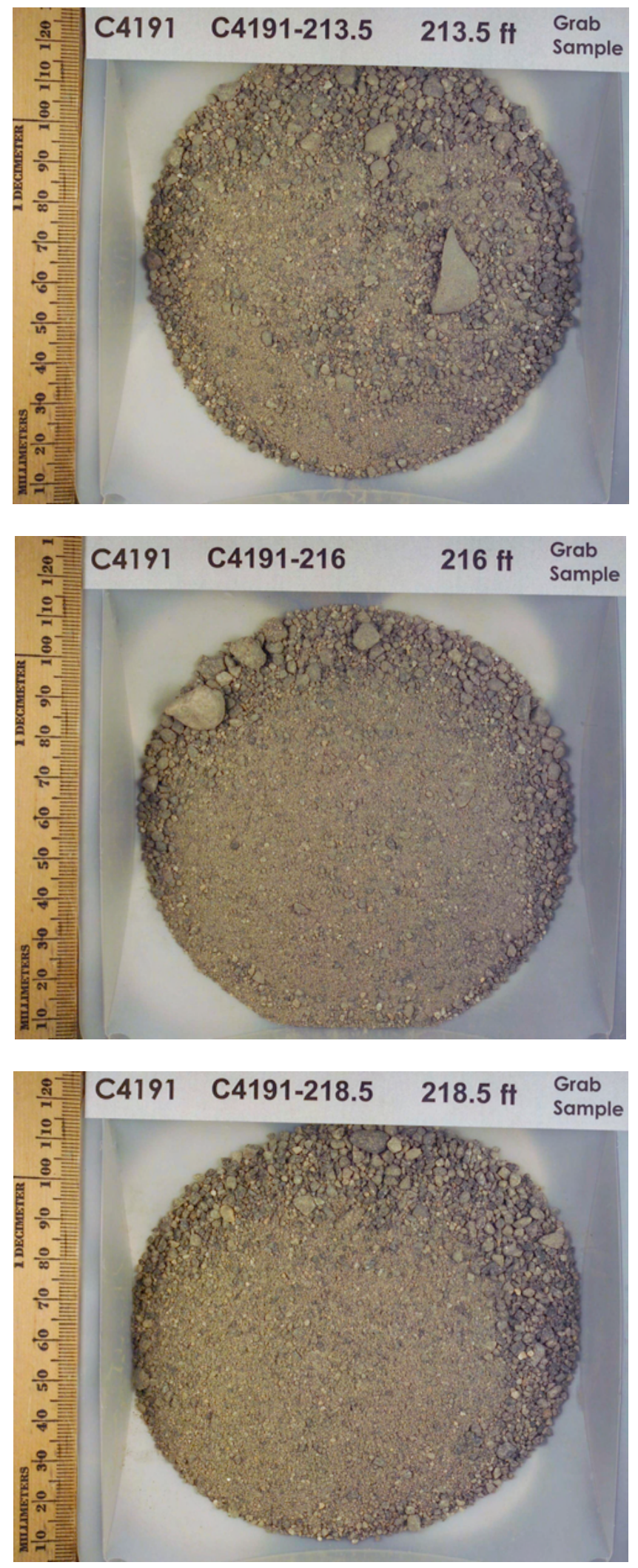
PNNL-17821
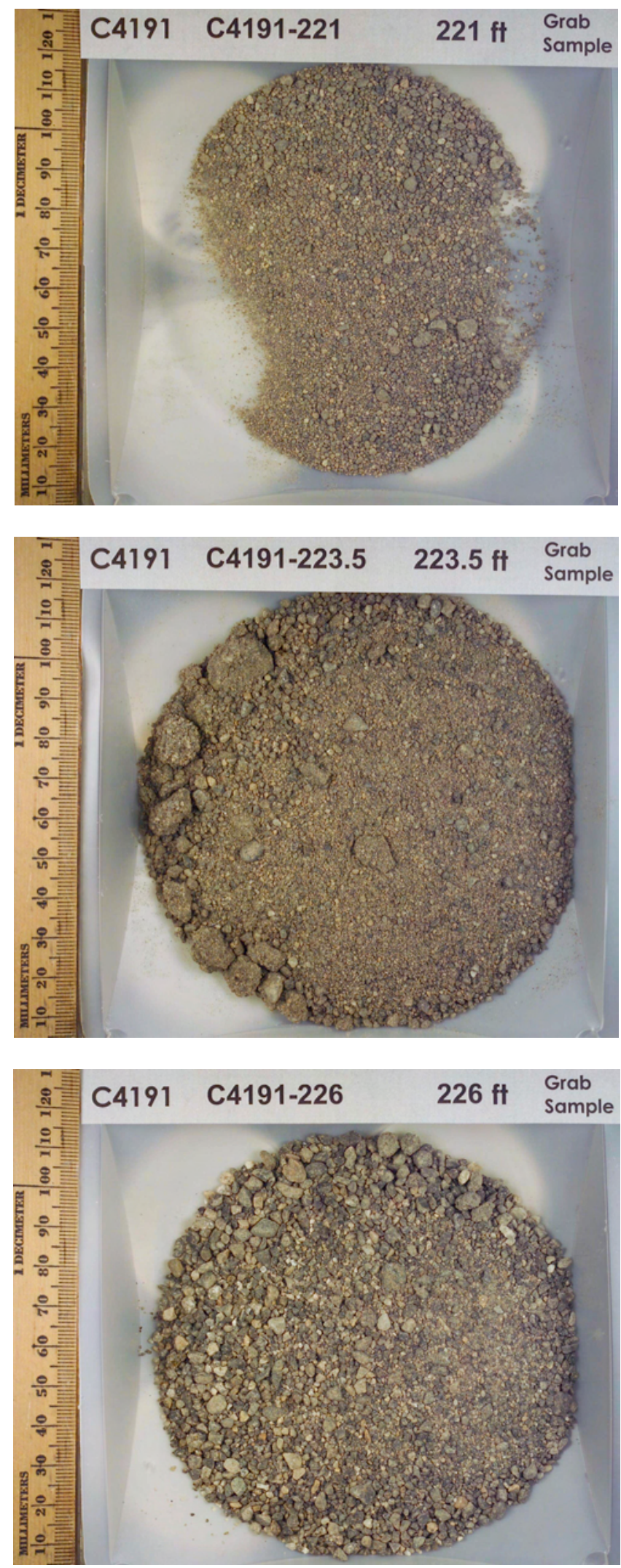

B.245 
PNNL-17821
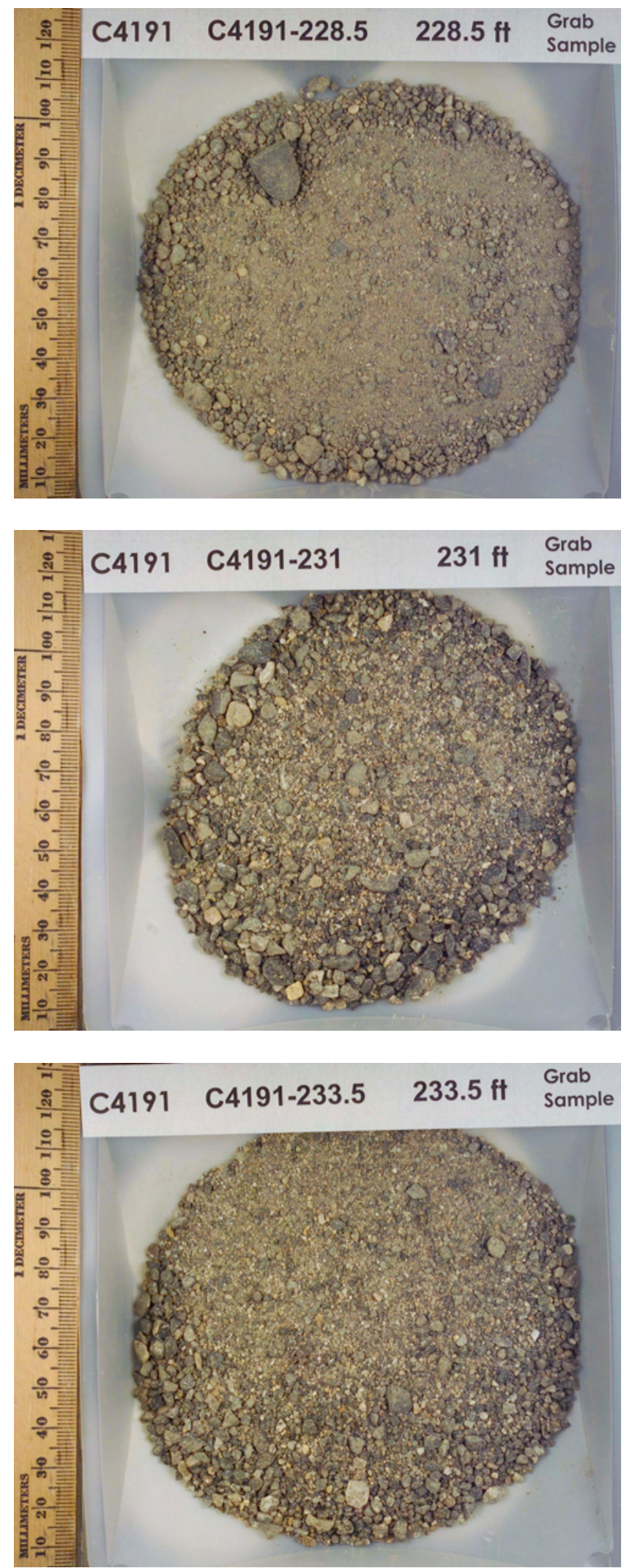
PNNL-17821
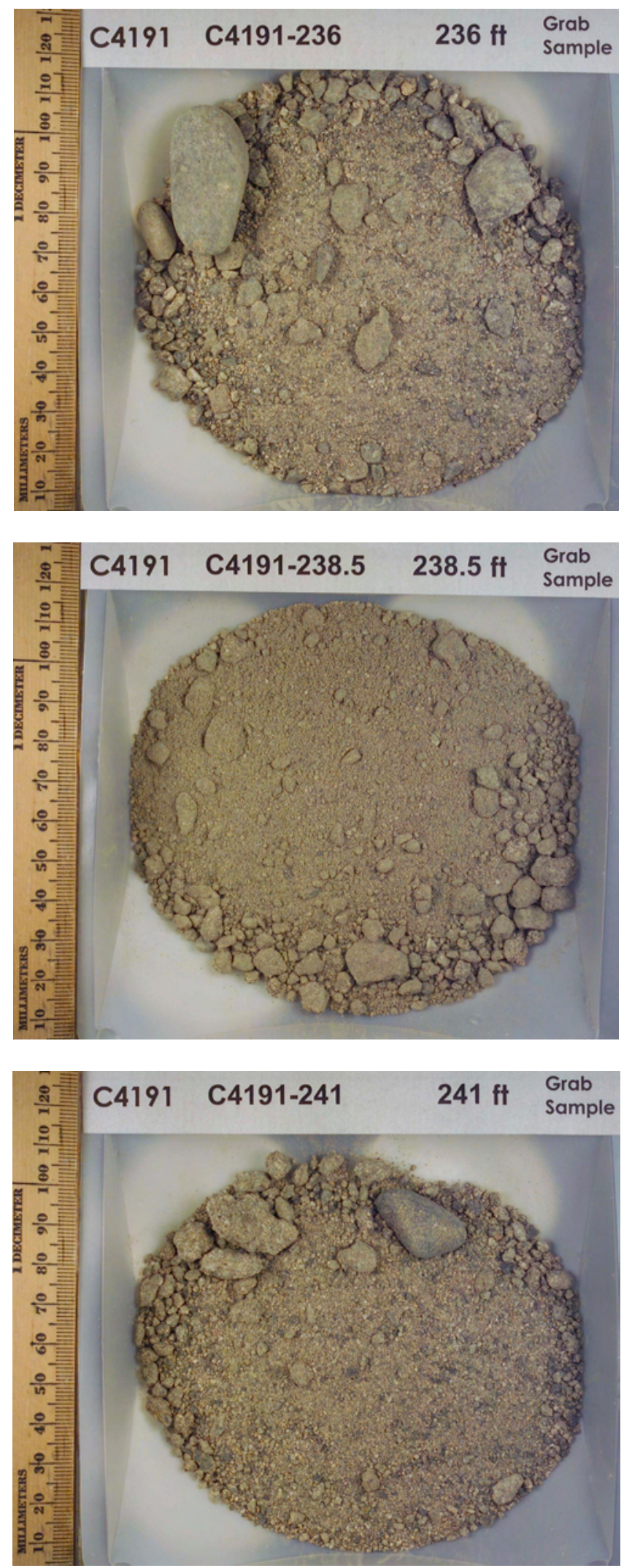
PNNL-17821
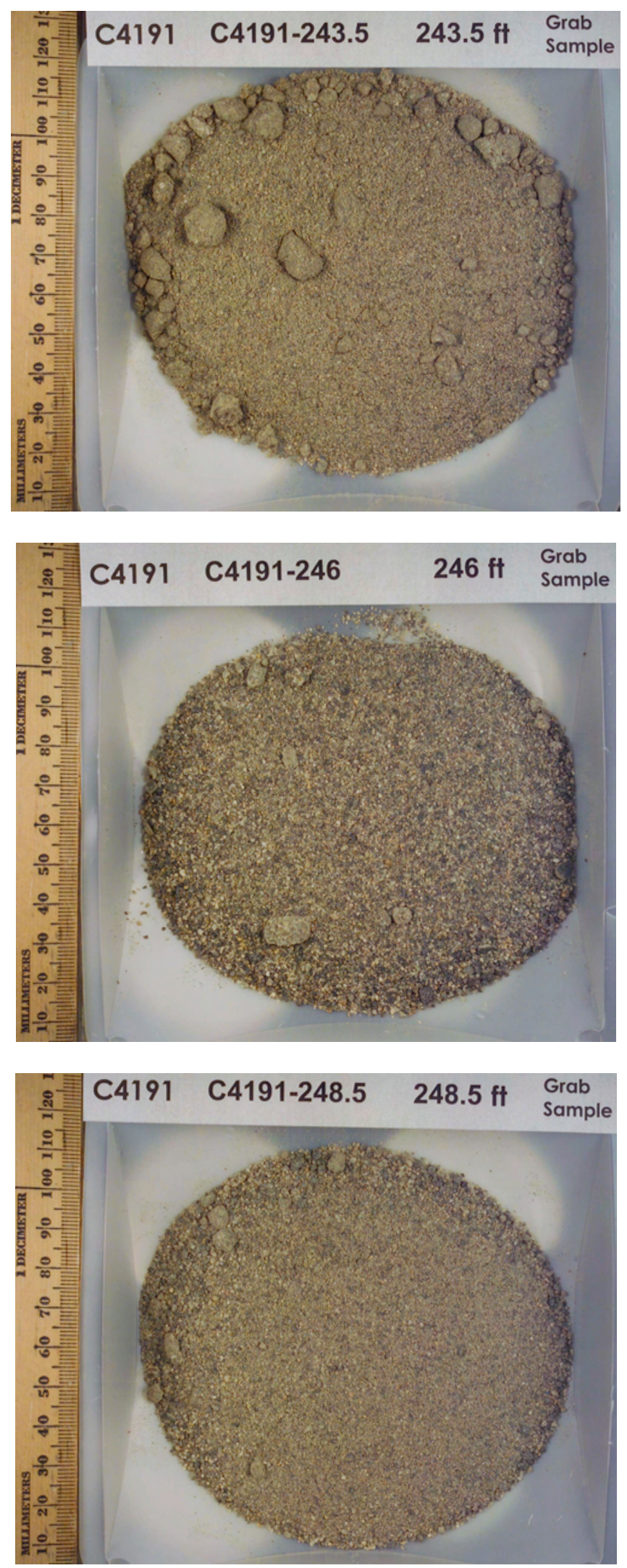

B. 248 
PNNL-17821
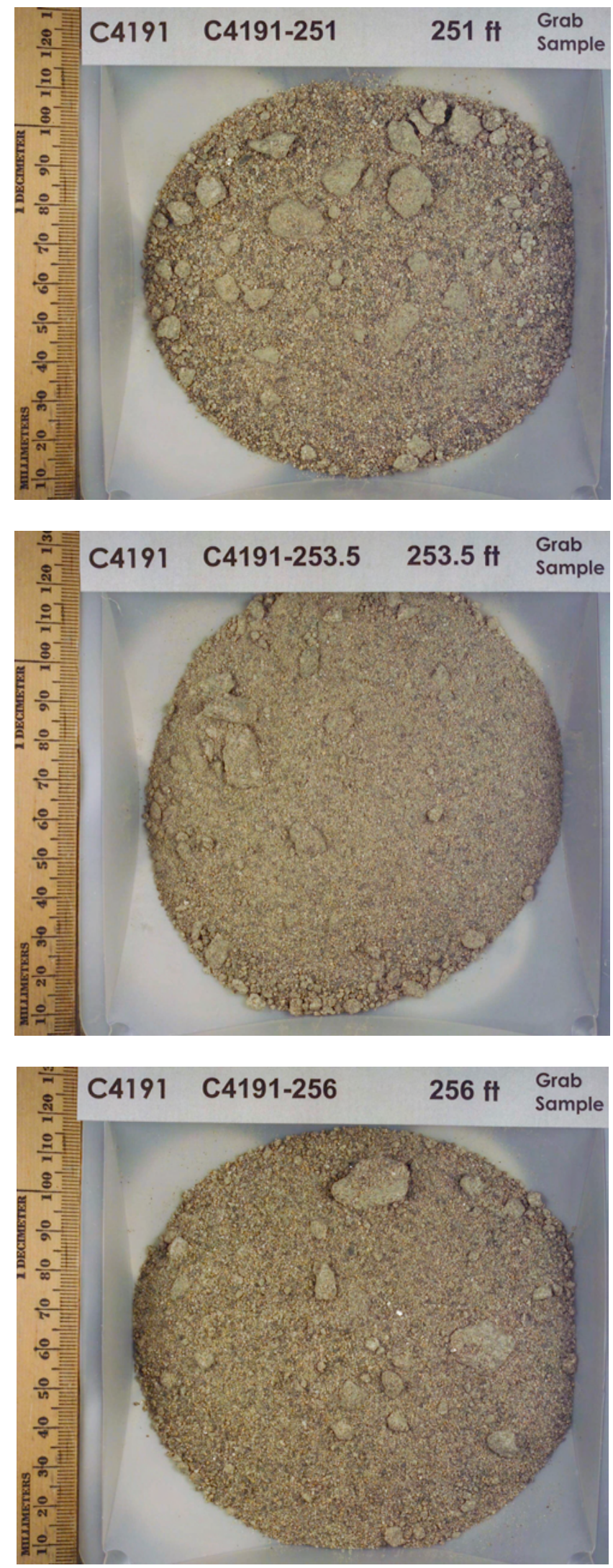

B.249 
PNNL-17821
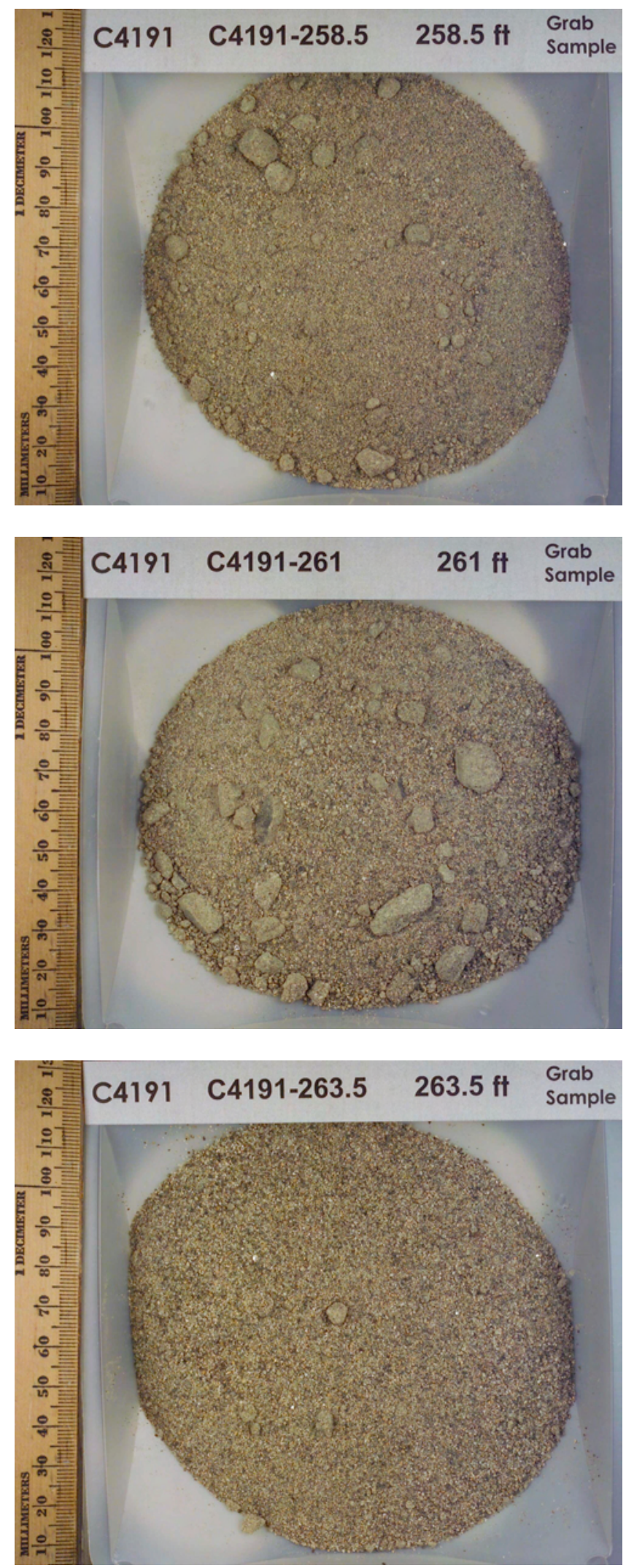

B. 250 
PNNL-17821
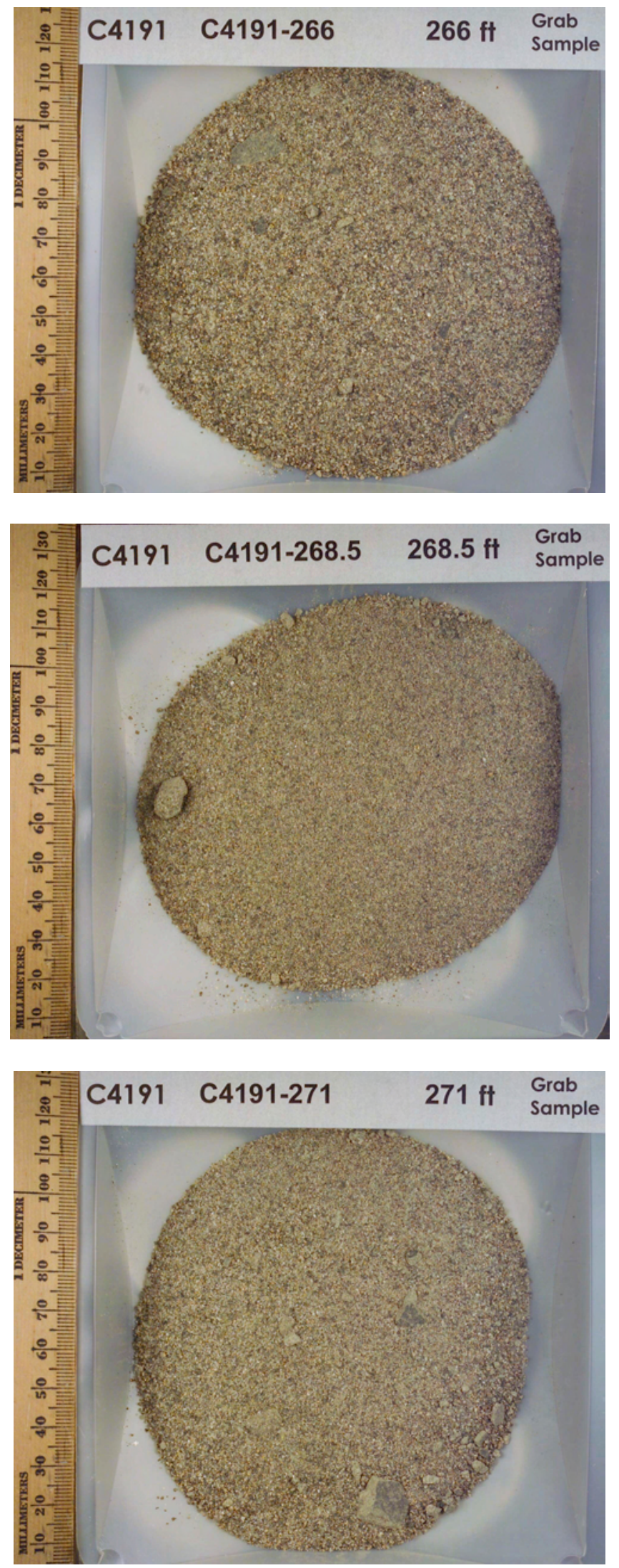

B.251 
PNNL-17821
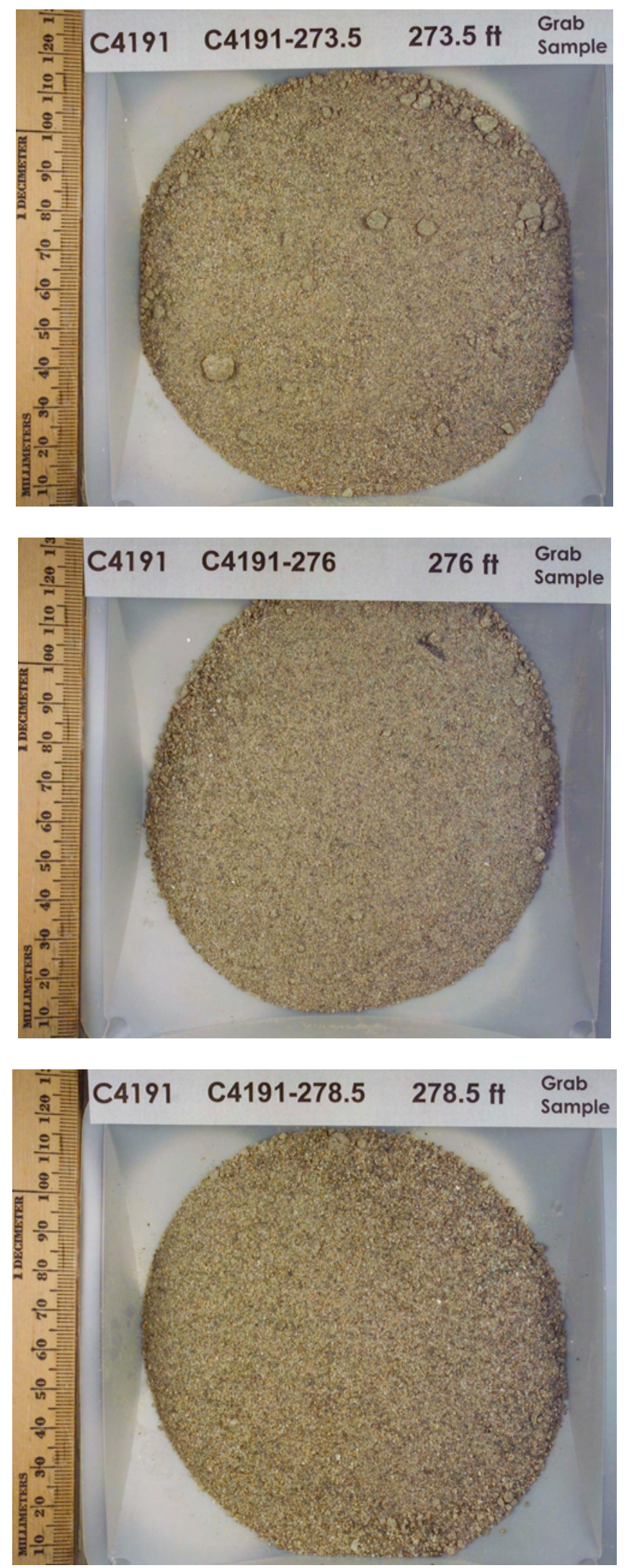

B.252 
PNNL-17821
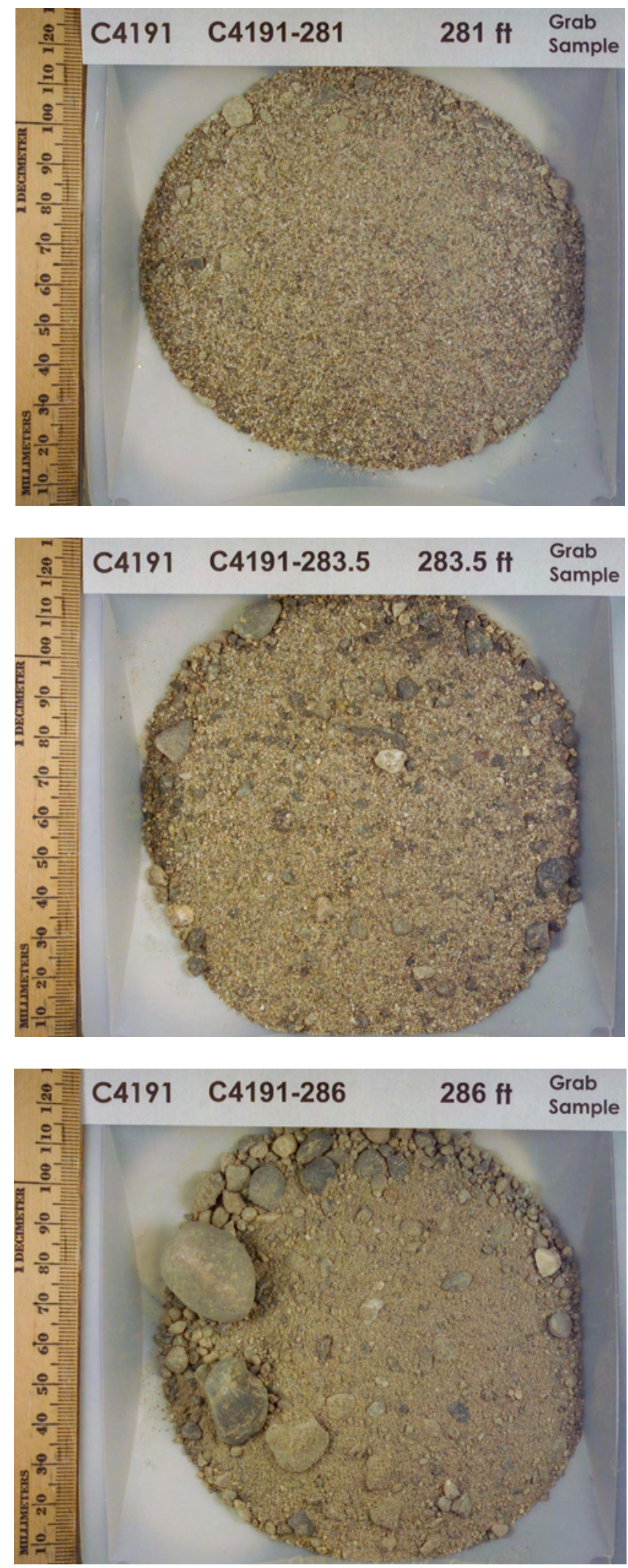

B.253 
PNNL-17821
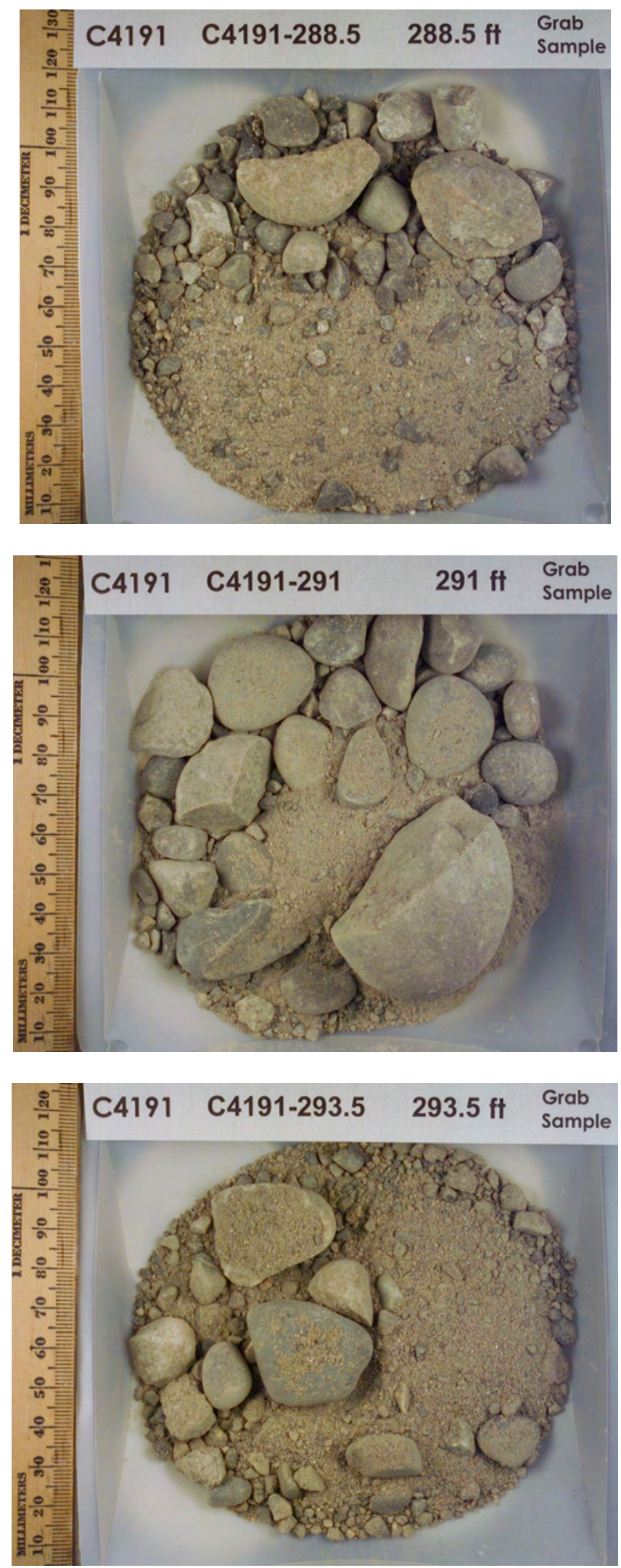
PNNL-17821
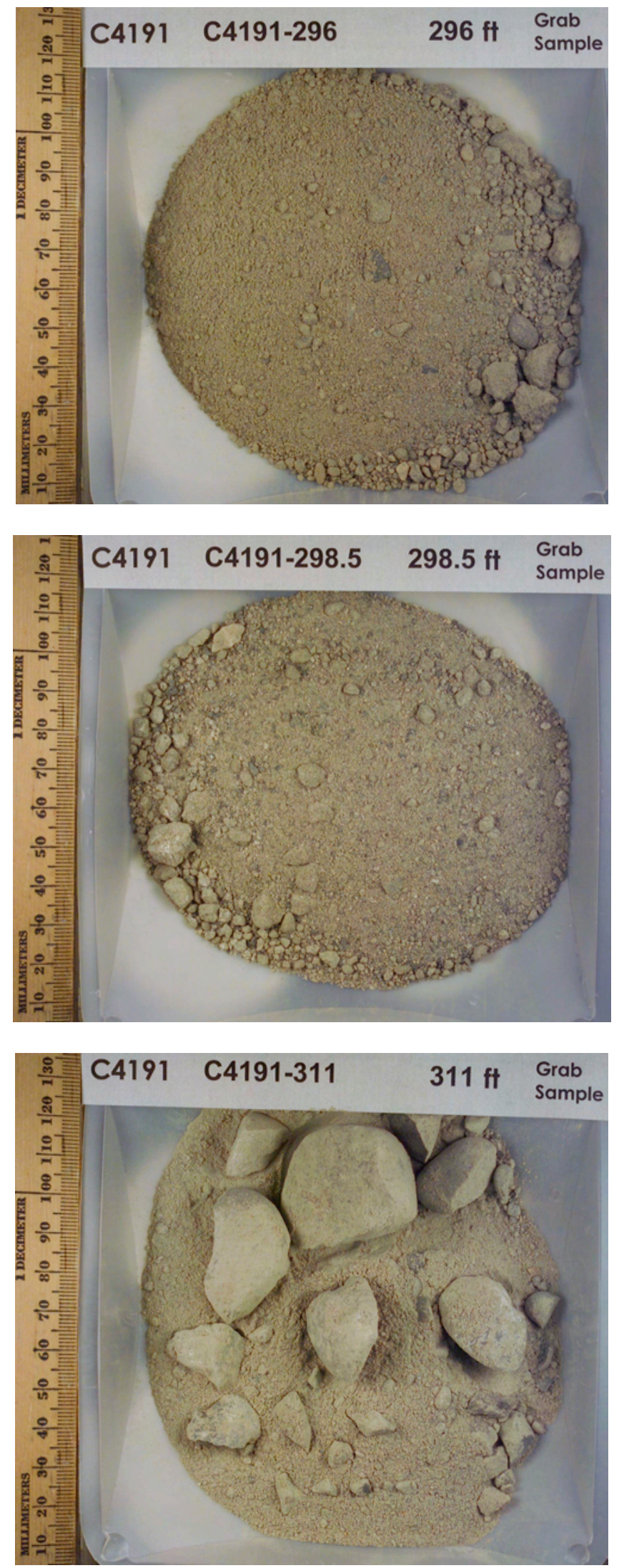

B.255 
PNNL-17821
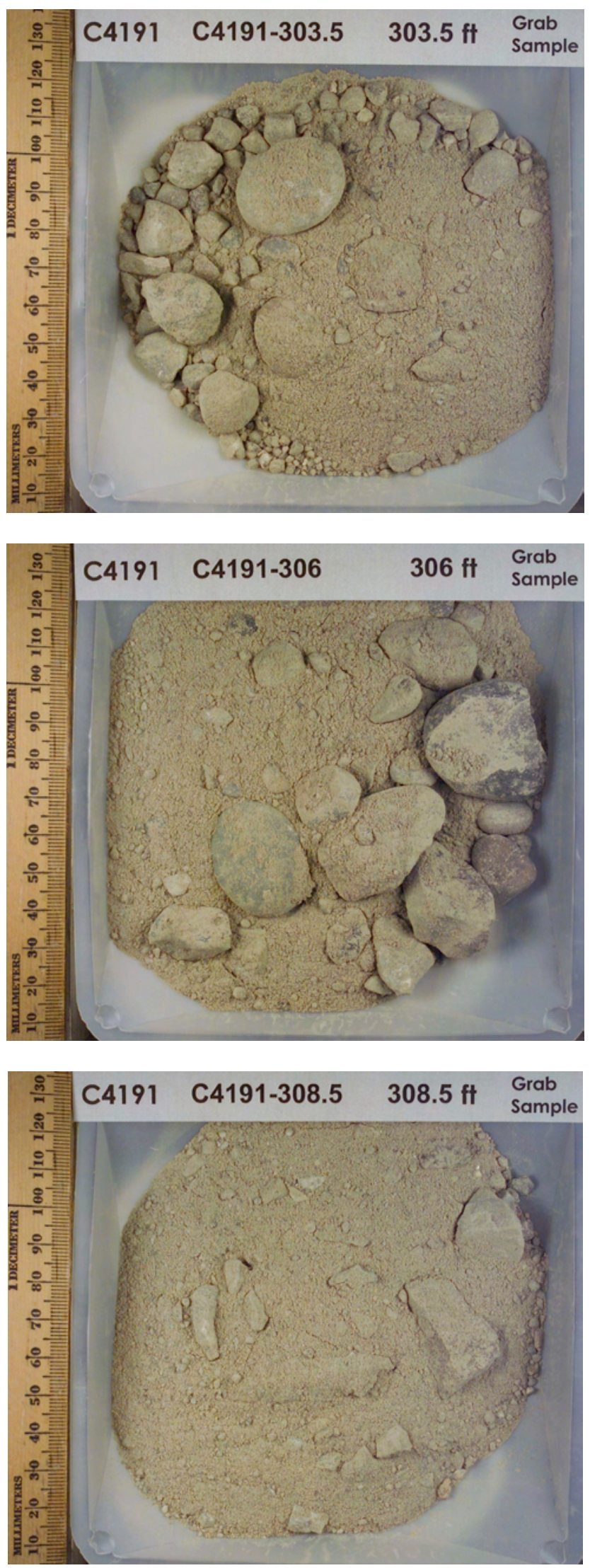

B.256 
PNNL-17821
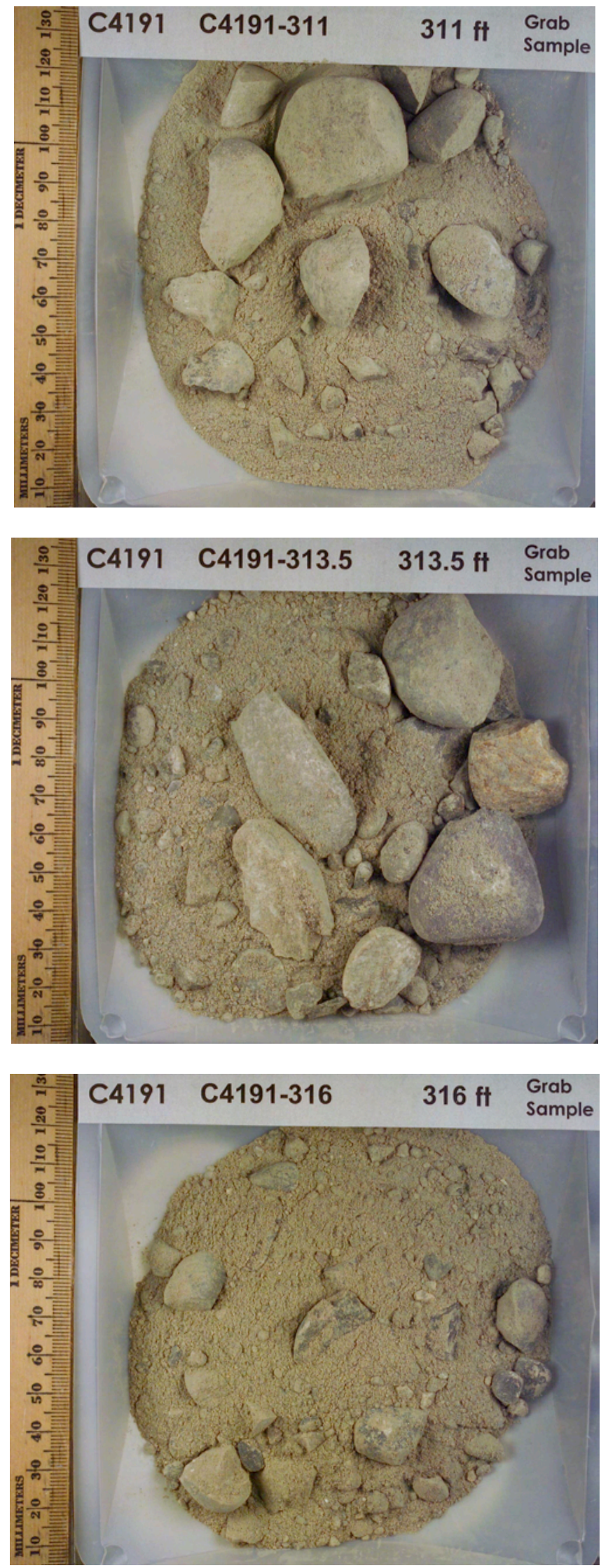

B.257 
PNNL-17821
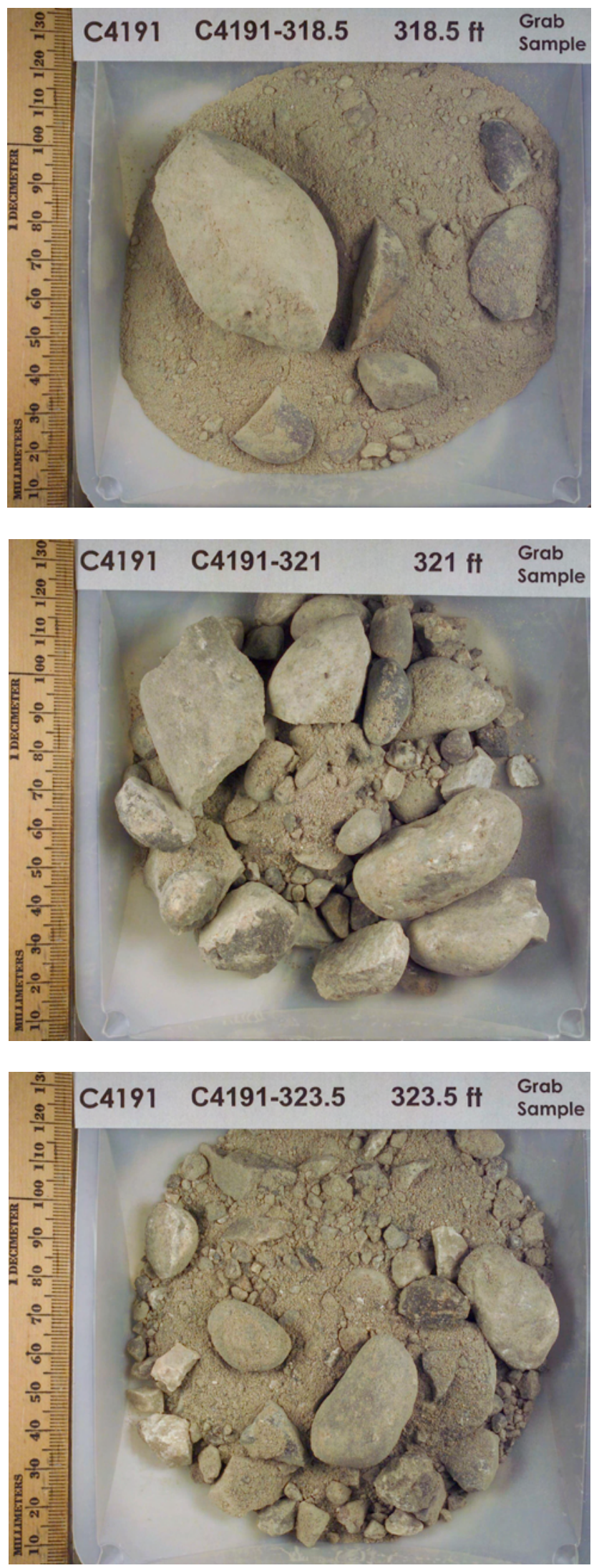

B.258 
PNNL-17821
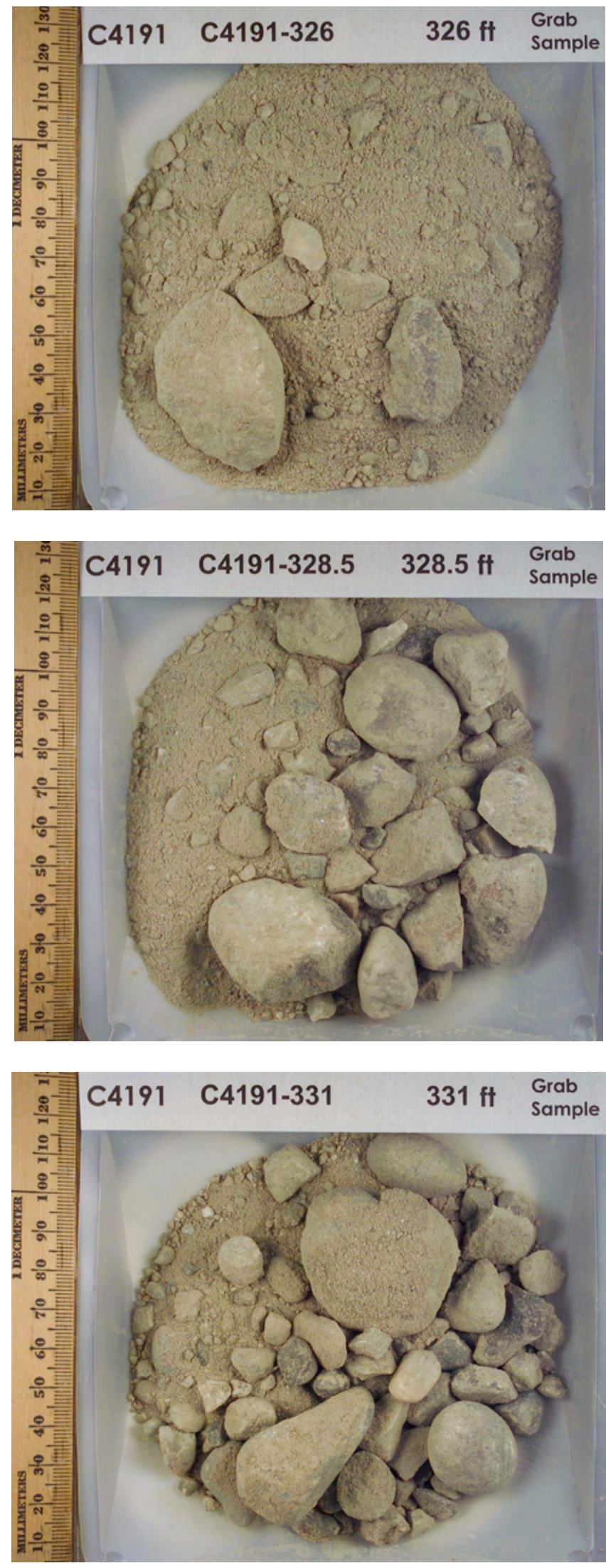

B.259 
PNNL-17821
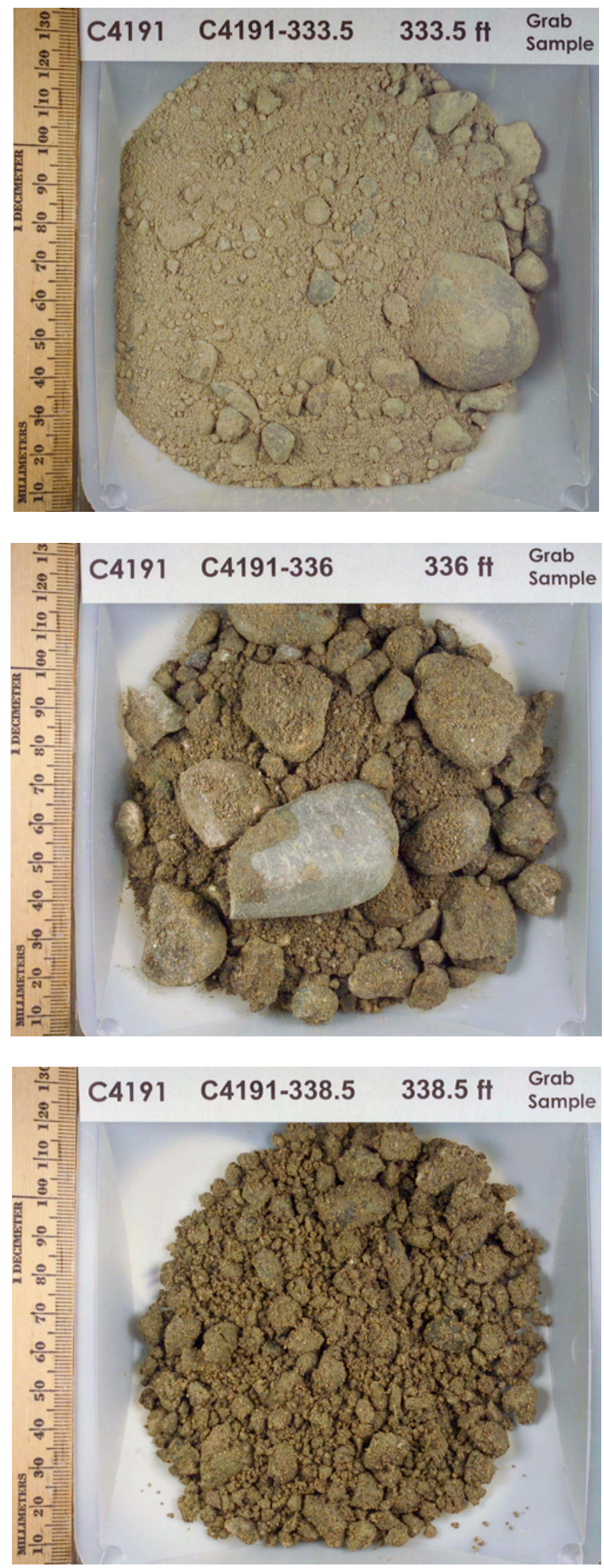

B. 260 
PNNL-17821

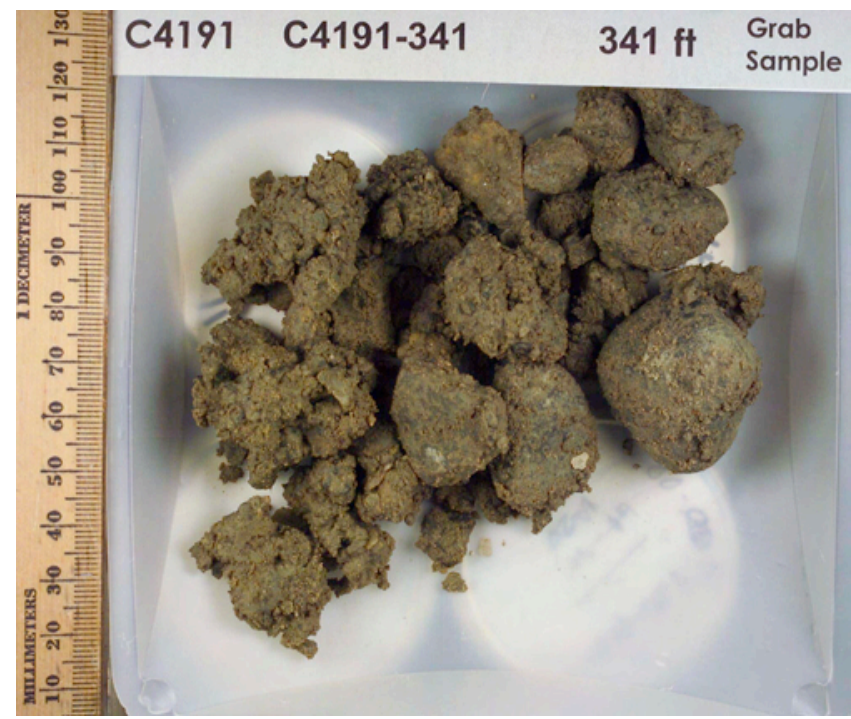

B.261 


\section{Appendix C}

Review of Historical Groundwater Monitoring Documents and Tabulation of Pertinent Groundwater Data from HEIS 


\section{Appendix C: Review of Historical Groundwater Monitoring Documents and Tabulation of Pertinent Groundwater Data from HEIS}

In this appendix, we summarize our review of historical groundwater (GW) monitoring periodic reports that were prepared over the time period covering when the BC Cribs and Trenches were first built, through the time of active liquid waste disposal, and the next 10 years post disposal. We also queried the HEIS database to find all GW and sediment data for the monitoring wells that were placed near the BC Cribs and Trenches. We created a table with the pertinent GW data for mobile constituents such as nitrate, technetium-99, sodium, and gross beta. There are no data for analyzing sediments taken during the drilling of the GW monitoring wells. However, gross gamma and more recently spectral gamma logging has been performed periodically since the mid 1950s to as recently as 2005 . The gross gamma and spectral gamma logging data were not reviewed during this assessment. Finally, the chemical compositions of the two recent GWs taken once boreholes C5923 and C4191 reached total depth are shown in Tables C.1 and C.2 for convenience.

\section{C.1 Groundwater Analysis of Sample Obtained Before Decommissioning Borehole C5923}

At the completion of drilling C5923 in July 2008, one GW sample was obtained at a depth of $359.9 \mathrm{ft}$ bgs before the lower portion of the borehole was decommissioned. The water table was $350.6 \mathrm{ft}$ bgs in July 2008 or $395.4 \mathrm{ft}$ elevation based on data found in Table 1.1 (in the main text). This elevation is in line with the decreasing water table trend shown in Figure 2.22 (in the main text) and approximately $7.5 \mathrm{ft}$ above the pre-Hanford water table. The composition of the GW was determined by the Waste Sampling and Characterization Facility (WSCF) and other commercial analytical laboratories. The results are shown in Table C.1. None of the major cations and only some of the major anions were measured, but based on the nitrate concentration, there is a hint that GW at this borehole contains a trace of the disposed scavenged bismuth phosphate waste stream. This differs from the analysis of the vadose zone pore waters from the deepest portion of the core (see main text Section 5.1.2), which shows no detectable water extractable nitrate. However, detectable water extractable nitrate and technetium-99 in the vadose zone sediments at borehole C5923 are present as deep as 290 and $260 \mathrm{ft} \mathrm{bgs,} \mathrm{respectively,} \mathrm{which} \mathrm{is} \mathrm{a} \mathrm{much}$ deeper penetration of water-extractable mobile and major contaminants than was found at borehole C4191 directly through the foot print of the 216-B-26 trench (discussed in main text Section 8). There is no detectable technetium-99 or other mobile radionuclides in the GW obtained in July 2008 from borehole C5923 (A). 
Table C.1. GW Composition at Water Table at C5923 in July 2008

\begin{tabular}{|c|c|c|c|c|c|}
\hline & Units & & & Units & \\
\hline pH Measurement & & 8.12 & Iron & $\mu g / L$ & $<54.5$ \\
\hline Specific Conductance & $\mathrm{mS} / \mathrm{cm}$ & 1.196 & Lead & $\mu g / L$ & $<45$ \\
\hline Total organic carbon & $\mu \mathrm{g} / \mathrm{L}$ & -- & Magnesium & $\mathrm{mg} / \mathrm{L}$ & -- \\
\hline Alkalinity & $\mathrm{mg} / \mathrm{L}$ & -- & Manganese & $\mu g / L$ & $406 \pm 2$ \\
\hline Chloride & $\mathrm{mg} / \mathrm{L}$ & -- & Nickel & $\mu \mathrm{g} / \mathrm{L}$ & $<4$ \\
\hline Cyanide & $\mu g / L$ & -- & Potassium & $\mathrm{mg} / \mathrm{L}$ & -- \\
\hline Fluoride & $\mathrm{mg} / \mathrm{L}$ & $0.32 \pm 0.02$ & Sodium & $\mathrm{mg} / \mathrm{L}$ & -- \\
\hline Nitrate & $\mathrm{mg} / \mathrm{L}$ & $9.34 \pm 0.18$ & Thallium & $\mu \mathrm{g} / \mathrm{L}$ & $<37$ \\
\hline Nitrite & $\mathrm{mg} / \mathrm{L}$ & $0.21 \pm 0.02$ & Vanadium & $\mu \mathrm{g} / \mathrm{L}$ & $<12$ \\
\hline Sulfate & $\mathrm{mg} / \mathrm{L}$ & -- & Zinc & $\mu \mathrm{g} / \mathrm{L}$ & $<9$ \\
\hline Phosphate & $\mathrm{mg} / \mathrm{L}$ & -- & Technetium-99 & $\mathrm{pCi} / \mathrm{L}$ & $<5.9$ \\
\hline Aluminum & $\mu g / L$ & -- & Tritium & $\mathrm{pCi} / \mathrm{L}$ & $<270$ \\
\hline Antimony & $\mu \mathrm{g} / \mathrm{L}$ & $<56$ & Uranium & $\mu \mathrm{g} / \mathrm{L}$ & $2.18 \pm 0.07$ \\
\hline Arsenic & $\mu \mathrm{g} / \mathrm{L}$ & $<78$ & Strontium-90 & $\mathrm{pCi} / \mathrm{L}$ & $<0.9$ \\
\hline Cadmium & $\mu \mathrm{g} / \mathrm{L}$ & $<4$ & Cesium-137 & $\mathrm{pCi} / \mathrm{L}$ & -- \\
\hline Calcium & $\mathrm{mg} / \mathrm{L}$ & -- & Iodine-129 & $\mathrm{pCi} / \mathrm{L}$ & $<0.828$ \\
\hline Chromium & $\mu \mathrm{g} / \mathrm{L}$ & $<13$ & Selenium-79 & $\mathrm{pCi} / \mathrm{L}$ & $<2$ \\
\hline
\end{tabular}

\section{C.2 Groundwater Analysis of Sample Obtained Before Decommissioning Borehole C4191}

At the completion of drilling C4191 in January 2004, one GW sample was obtained in late January before the borehole was decommissioned. The composition of the GW is shown in Table C.2. The GW composition suggests that the water below C4191 is not contaminated with waste fluids that were disposed of to the various BC Cribs. The GW composition is that of natural uncontaminated Hanford Site water aside from a low strontium-90 activity, which is likely not real. Natural Hanford Site GWs are calcium-magnesium-sodium-bicarbonate-sulfate dominated as is the water composition shown in Table C.2. The fact that the GW directly below the 216-B-26 trench appears to be uncontaminated corroborates the findings that the mobile salts (sodium and nitrate predominately) in the vadose zone profile at the C4191 borehole have not descended below about $158.5 \mathrm{ft}$ bgs. The salts and presumably the residual waste fluids from the mid 1950s disposal time horizon still reside well above the water table (337.8 ft bgs). 
Table C.2. Groundwater Composition at Water Table in C4191 in Jan. 2004

\begin{tabular}{|c|c|c|c|c|c|}
\hline \multicolumn{3}{|c|}{ Units } & \multicolumn{3}{|c|}{ Units } \\
\hline pH Measurement & & 7.37 & Copper & $\mu \mathrm{g} / \mathrm{L}$ & $<2.9$ \\
\hline Specific Conductance & $\mathrm{mS} / \mathrm{cm}$ & 0.368 & Iron & $\mu \mathrm{g} / \mathrm{L}$ & $<54.5$ \\
\hline Total organic carbon & $\mu \mathrm{g} / \mathrm{L}$ & -- & Magnesium & $\mathrm{mg} / \mathrm{L}$ & 9.23 \\
\hline Alkalinity & $\mathrm{mg} / \mathrm{L}$ & 123.8 & Manganese & $\mu \mathrm{g} / \mathrm{L}$ & 208 \\
\hline Chloride & $\mathrm{mg} / \mathrm{L}$ & 9.8 & Nickel & $\mu \mathrm{g} / \mathrm{L}$ & $<14$ \\
\hline Cyanide & $\mu \mathrm{g} / \mathrm{L}$ & $<4.7$ & Potassium & $\mathrm{mg} / \mathrm{L}$ & 11.1 \\
\hline Fluoride & $\mathrm{mg} / \mathrm{L}$ & 0.87 & Sodium & $\mathrm{mg} / \mathrm{L}$ & 37 \\
\hline Nitrate & $\mathrm{mg} / \mathrm{L}$ & 0.22 & Strontium & $\mathrm{mg} / \mathrm{L}$ & 0.163 \\
\hline Nitrite & $\mathrm{mg} / \mathrm{L}$ & $<0.08$ & Silicon & $\mathrm{mg} / \mathrm{L}$ & -- \\
\hline Sulfate & $\mathrm{mg} / \mathrm{L}$ & 46.6 & Zinc & $\mu \mathrm{g} / \mathrm{L}$ & $<2.7$ \\
\hline Phosphate & $\mathrm{mg} / \mathrm{L}$ & -- & Technetium-99 & $\mathrm{pCi} / \mathrm{L}$ & $<4.68$ \\
\hline Aluminum & $\mu g / L$ & $<34.2$ & Tritium & $\mathrm{pCi} / \mathrm{L}$ & $<164$ \\
\hline Barium & $\mu \mathrm{g} / \mathrm{L}$ & 58.4 & Uranium & $\mu g / L$ & -- \\
\hline Cadmium & $\mu \mathrm{g} / \mathrm{L}$ & $<3.3$ & Strontium-90 & $\mathrm{pCi} / \mathrm{L}$ & $1.59 \pm 0.44$ \\
\hline Calcium & $\mathrm{mg} / \mathrm{L}$ & 22.4 & Cesium-137 & $\mathrm{pCi} / \mathrm{L}$ & $<0.436$ \\
\hline Chromium & $\mu \mathrm{g} / \mathrm{L}$ & $<4.4$ & Iodine-129 & $\mathrm{pCi} / \mathrm{L}$ & $<0.0821$ \\
\hline Cobalt & $\mu g / L$ & $<4.8$ & & & \\
\hline
\end{tabular}

The vadose zone profile of the easily measured major mobile constituents (nitrate and technetium-99) and slightly interacting constituents (sulfate and sodium) at the four boreholes described in this report and the two new GW analyses augment the sitewide GW monitoring efforts that delineate the major GW plumes below the Hanford waste-disposal facilities. As briefly discussed in Sections 5.1 and 8.1, the vadose zone sediment water extracts and GW analyses at boreholes C5923 (A) and C4191 suggest that the bulk of the mobile contaminants disposed of over the 1956-1957 time period still reside in the vadose zone. At C5923 (A), located between cribs 216-B-15 and 216-B-16 in the southern half of the six-crib complex, the water-extractable concentrations of the two main mobile contaminants (nitrate and technetium-99) appear to return to background or non-detectable values about 290 and $260 \mathrm{ft}$ bgs, respectively, which is considerably shallower than the current water table (359.9 ft bgs) and the water table during active disposal ( 345 ft bgs). However, the GW at borehole C5923 (A) does contain slightly above background levels of nitrate, suggesting that somewhere close to the borehole residual nitrate from the mid 1950s disposal may be entering the GW.

At borehole C4191, the vadose zone profile of mobile contaminants shows the bulk of the nitrate and technetium-99 has not descended below $\sim 160 \mathrm{ft}$ bgs, which is considerably shallower than the current water table at $337.8 \mathrm{ft}$ bgs. Further, the one GW sample taken from this borehole before its decommissioning showed no detectable nitrate or technetium-99 or other signs of waste. The volumes of waste disposed of to the trenches were less proportional to their areal foot print compared to the cribs. 


\section{C.3 Summary of Findings Gleaned from Historical Groundwater Monitoring Reports}

Old GW monitoring reports were found that covered the time span from July 1956 through June 1966. Table C.3 lists the document numbers, time period covered, and comments germane to the BC Cribs and Trenches area. Notes suggest that wells very close to the BC cribs did show intermittent signs of gross beta breakthrough to the water table within a year after active disposal stopped. However, the gross beta was confirmed to be the very short half-life ruthenium-106, and throughout the 10-year period of monitoring, there was no consistent sign of a stable and spreading plume of gross beta or any other constituent that was measured. Even less breakthrough of contaminants was found over this time period below the BC trenches. Infrequently, wells close to a few trenches, especially well 299-E13-13 (just east of 216-B-27 and B-28 trenches) showed detectable gross beta.

TableC.3. Listing of Old Groundwater Monitoring Reports with Comments

\begin{tabular}{|c|c|c|}
\hline Document \# & Time Period & Comments \\
\hline HW-49465 & July to Sept 1956 & $\begin{array}{l}\text { No GW contamination below BC Cribs and Trenches; first } \\
\text { trench operational July 28, } 1956\end{array}$ \\
\hline HW-50186 & Oct to Dec 1956 & No GW contamination below BC cribs and Trenches \\
\hline HW-51095 & Jan to Mar 1957 & $\begin{array}{l}\text { Gross beta map above background covers BC Crib area, but } \\
\text { text suggests source is BY Cribs; no specific wells identified }\end{array}$ \\
\hline HW-53225 & Apr to June 1957 & $\begin{array}{l}\text { No gross beta above background below BC Cribs and } \\
\text { Trenches; discusses putting in more monitoring wells at BC } \\
\text { Cribs in early } 1958\end{array}$ \\
\hline HW-54655 & July to Sept 1957 & $\begin{array}{l}\text { Table III shows summary of volume of waste disposed of } \\
\text { through third Qtr } 1957 \text { at the six BC cribs; no GW gross beta } \\
\text { contamination below cribs yet }\end{array}$ \\
\hline HW-54848 & Oct to Dec 1957 & $\begin{array}{l}\text { Water table below BC Cribs found at } 340 \mathrm{ft} \text { bgs and all gross } \\
\text { beta }<120 \mathrm{pCi} / \mathrm{L} \text { detection limit; seven batches of waste went } \\
\text { to BC Cribs this quarter }\end{array}$ \\
\hline HW-55841 & Jan to Mar 1958 & $\begin{array}{l}\text { Intermittent signs of gross beta found below BC facilities } \\
\text { in late Dec } \mathbf{1 9 5 7} \text { and Jan 1958; gross beta ranged from } 270 \\
\text { to } 7600 \mathrm{pCi} / \mathrm{L} \text {. High value was } 10 \mathrm{ft} \text { below water table, } \\
\text { suggesting density-driven water sinking. No specific wells } \\
\text { identified. }\end{array}$ \\
\hline $\begin{array}{c}\text { HW-57002 } \\
\text { RD }\end{array}$ & Apr to Jun 1958 & $\begin{array}{l}\text { Intermittent signs of gross beta above } 150 \mathrm{pCi} / \mathrm{L} \text { below BC } \\
\text { Cribs; borehole scintillation logging showed gross gamma } \\
\text { near cribs to } 220 \mathrm{ft} \text { bgs (water table at } 340 \mathrm{ft} \text { bgs); since last } \\
\text { logged } 5 \text { months earlier, gamma descended } 80 \text { to } 90 \mathrm{ft} \text { near } \\
\text { two cribs but only } 10 \text { to } 20 \mathrm{ft} \text { at four other cribs. Which cribs } \\
\text { not identified. }\end{array}$ \\
\hline HW-58023 & Jul to Sept 1958 & $\begin{array}{l}\text { Intermittent gross beta above } 150 \mathrm{pCi} / \mathrm{L} \text { observed below BC } \\
\text { Cribs and Trenches with max } 540 \mathrm{pCi} / \mathrm{L} \text {, but specific wells } \\
\text { not identified. }\end{array}$ \\
\hline $\begin{array}{l}\text { HW-58811 } \\
\text { RD }\end{array}$ & Oct to Dec 1958 & $\begin{array}{l}\text { Intermittent gross beta above } 150 \mathrm{pCi} / \mathrm{L} \text { observed below BC } \\
\text { Cribs and Trenches. Max gross beta } 520 \mathrm{pCi} / \mathrm{L} \text { in a new well }\end{array}$ \\
\hline
\end{tabular}


TableC.3. Listing of Old Groundwater Monitoring Reports with Comments

\begin{tabular}{|c|c|c|}
\hline Document \# & Time Period & Comments \\
\hline & & $\begin{array}{l}15 \mathrm{ft} \text { south of B-18 (likely well 299-E13-5) but specific well } \\
\text { \# not identified }\end{array}$ \\
\hline HW-60163 & Jan to Mar 1959 & $\begin{array}{l}\text { No BC Cribs and Trenches wells exceeded } 150 \text { pCi/L } \\
\text { gross beta. }\end{array}$ \\
\hline $\begin{array}{l}\text { HW-61197 } \\
\text { RD }\end{array}$ & Apr to June 1959 & $\begin{array}{l}\text { No BC Cribs and Trenches wells exceeded } 150 \mathrm{pCi} / \mathrm{L} \\
\text { gross beta. Gross beta further identified as } \\
\text { ruthenium-106-rhodium-106. }\end{array}$ \\
\hline HW-62692 & Jul to Sept 1959 & $\begin{array}{l}\text { No BC Cribs and Trenches wells consistently had gross } \\
\text { beta above detection limit for all samplings. Some } \\
\text { intermittent hits above } 150 \text { pCi/L but no pattern. One } \\
\text { borehole } 299-E 13-20 \mathrm{C} \text { at southeast corner of crib } 216-\mathrm{BC}-18 \\
\text { showed gross gamma signal from crib bottom continuous to } \\
\text { water table. Nineteen other borehole logs did not show } \\
\text { continuous gross gamma to water table. }\end{array}$ \\
\hline $\begin{array}{l}\text { HW-64094 } \\
\text { RD }\end{array}$ & Oct to Dec 1959 & $\begin{array}{l}\text { New lower gross beta detection limit available and } 13 \text { of } 20 \\
\text { BC Cribs and Trenches wells showed gross beta. Well 299- } \\
\text { E13-4 at southwest corner of crib B-17 had highest gross beta } \\
\text { at } 340 \mathrm{pCi} / \mathrm{L} \text {. }\end{array}$ \\
\hline $\begin{array}{l}\text { HW- } 65464 \\
\text { RD }\end{array}$ & Jan to Mar 1960 & $\begin{array}{l}\text { No increases observed; gross beta still intermittent in } \\
\text { wells with max this quarter found at E13-2 just east of } \\
\text { crib B-15 at } 360 \text { pCi/L. No strontium-90 or cesium-137 } \\
\text { detected; just ruthenium-106. }\end{array}$ \\
\hline $\begin{array}{l}\text { HW-66859 } \\
\text { RD }\end{array}$ & Apr to Jun 1960 & $\begin{array}{l}\text { Only detect gross beta around cribs and not trenches; } \\
\text { max } 350 \text { pCi/L well not specified. E13-4 had gross beta of } \\
340 \text { pCi/L with no long-lived isotopes (all gross beta is } \\
\text { ruthenium-106) }\end{array}$ \\
\hline $\begin{array}{l}\text { HW-67753 } \\
\text { RD }\end{array}$ & Jul to Sept 1960 & $\begin{array}{l}4 \text { of } 20 \text { wells showed gross beta above } 80 \mathrm{pCi} / \mathrm{L} \text { with } \mathrm{E} 13-4 \\
\text { (near crib B-17) having the highest at } 240 \mathrm{pCi} / \mathrm{L}\end{array}$ \\
\hline HW 68543 & Oct to Dec 1960 & $\begin{array}{l}4 \text { of } 20 \text { wells showed gross gamma } 299-\mathrm{E} 13-6 \text { near crib B- } \\
19 \text { had highest this quarter at } 160 \mathrm{pCi} / \mathrm{L} \text {. }\end{array}$ \\
\hline $\begin{array}{l}\text { HW-70806 } \\
\text { RD }\end{array}$ & Jan to Jun 1961 & $\begin{array}{l}\text { Gross beta below BC Cribs decreased this quarter. Max } \\
\text { found at } 110 \mathrm{pCi} / \mathrm{L} \text { at two wells, } 13-4 \text { and } 13-6 \text {. All wells } \\
\text { monitoring the BC Trenches below } 80 \mathrm{pCi} / \mathrm{L} \text { detection } \\
\text { limit. }\end{array}$ \\
\hline $\begin{array}{l}\text { HW-72645 } \\
\text { RD }\end{array}$ & Jul to Dec 1961 & $\begin{array}{l}\text { No gross beta above } 80 \mathrm{pCi} / \mathrm{L} \text { detection limit observed } \\
\text { around } \mathrm{BC} \text { Cribs; one well monitoring the trenches (E13- } \\
13 \text { (east of trench } 216-\mathrm{B}-29 \text { ) showed } 1500 \mathrm{pCi} / \mathrm{L} \text { gross } \\
\text { beta. All other wells monitoring trenches have }<80 \mathrm{pCi} / \mathrm{L} \\
\text { gross beta. }\end{array}$ \\
\hline $\begin{array}{l}\text { HW-74915 } \\
\text { RD }\end{array}$ & Jan to Jun 1962 & $\begin{array}{l}\text { First mention of tritium and nitrate analyses added to GW } \\
\text { monitoring program. All wells monitoring BC cribs had } \\
\text { gross beta }<\mathbf{8 0} \mathbf{p C i} / \mathbf{L} \text { detection limit. All wells monitoring } \\
\text { the BC trenches except well E13-13 also had gross beta }\end{array}$ \\
\hline
\end{tabular}


TableC.3. Listing of Old Groundwater Monitoring Reports with Comments

\begin{tabular}{|c|c|c|}
\hline Document \# & Time Period & Comments \\
\hline & & $\begin{array}{l}\text { below detection. Well E13-13 had } 130 \mathrm{pCi} / \mathrm{L} \text { gross beta that } \\
\text { appeared to include } 110 \mathrm{pCi} / \mathrm{L} \text { Sr-90. A resampling of this } \\
\text { well was to be performed. No tritium or nitrate data for wells } \\
\text { monitoring BC Cribs and Trenches were reported. }\end{array}$ \\
\hline $\begin{array}{c}\text { HW-76120 } \\
\text { RD }\end{array}$ & Jul to Dec 1962 & $\begin{array}{l}\text { No changes in the below detection gross beta status at BC } \\
\text { Cribs and Trenches. The resample of GW at E13-13 } \\
\text { showed a gross beta value of } 86 \text { pCi/L (detection limit } 80 \\
\text { pCi/L) and strontium- } 9032 \mathrm{pCi} / \mathrm{L}\end{array}$ \\
\hline HW-78951 & Jan to Jun 1963 & $\begin{array}{l}\text { All wells monitoring BC Cribs and Trenches had gross } \\
\text { beta below the } \mathbf{8 0} \text { pCi/L detection limit. There was no } \\
\text { detectable strontium- } 90 \text { in the E13-13 GW sample after the } \\
\text { sample was filtered. New scintillation logging of the } \\
20 \text { boreholes inside BC Cribs and Trenches showed no } \\
\text { detectable gamma in the bottom } 100 \mathrm{ft} \text { at } 19 \text { locations. Only } \\
\text { in borehole E13-20 southeast of crib } 216-\mathrm{B}-18 \text { was there } \\
\text { intermittent signs of gamma all the way to the water table. } \\
\text { Because the GW samples at E13-20 have been below } \\
\text { detection for several years, the scintillation data were } \\
\text { thought to represent drag down of gamma during drilling. } \\
\text { No detectable tritium or nitrate was found in GWs taken from } \\
\text { below BC Cribs and Trenches. }\end{array}$ \\
\hline HW-80909 & Jul to Dec 1963 & $\begin{array}{l}\text { No specific discussion of monitoring results, but plume maps } \\
\text { show no contamination below BC Cribs and Trenches. This } \\
\text { report mainly discussed travel-time calculations from } \\
\text { disposal sites to the Columbia River. }\end{array}$ \\
\hline HW-84549 & Jan to Dec 1964 & $\begin{array}{l}\text { Well E13-4 (near crib 216-B-17) showed an average of } \\
220 \text { pCi/L gross beta a slight increase over the } 150 \mathrm{pCi} / \mathrm{L} \text { in } \\
\text { the last half of } 1963 \text {. Two wells monitoring trenches }(\mathrm{E} 13- \\
13 \text { and E13-16) also showed } 140 \text { and } 130 \mathrm{pCi} / \mathrm{L} \text { average } \\
\text { gross beta concentrations for the year, whereas in } 1963 \text {, } \\
\text { all values were below the detection limit of } 80 \mathrm{pCi} / \mathrm{L} \text {. }\end{array}$ \\
\hline $\begin{array}{c}\text { BNWL-CC- } \\
285\end{array}$ & Jan to Jun 1965 & $\begin{array}{l}\text { Only three wells (E13-13 and E13-20 with average } 170 \mathrm{pCi} / \mathrm{L} \\
\text { gross beta and well E13-16 with average } 100 \mathrm{pCi} / \mathrm{L} \text { ) were } \\
\text { above the } 80 \mathrm{pCi} / \mathrm{L} \text { detection limit. Maximum gross beta in } \\
\text { any sampling was } 300 \mathrm{pCi} / \mathrm{L} \text {, but well and date not specified. }\end{array}$ \\
\hline $\begin{array}{c}\text { BNWL-CC- } \\
574\end{array}$ & Jul to Dec 1965 & $\begin{array}{l}\text { There were no significant changes in gross beta } \\
\text { concentrations in GW below BC Cribs and Trenches since } \\
\text { first half of } 1965 . \mathrm{GW} \text { gross beta at E13-13 averaged } \\
100 \mathrm{pCi} / \mathrm{L} \text { and at E13-20 averaged } 220 \mathrm{pCi} / \mathrm{L} \text {. No tritium } \\
\text { analyses were performed on GW below BC cribs and } \\
\text { trenches because tritium has never been detected here. } \\
\text { Southeast of BC Cribs at well 699-31-53B, tritium was } \\
4800 \mathrm{pCi} / \mathrm{L} \text { and came from } 200 \mathrm{~W} \text { plume. }\end{array}$ \\
\hline
\end{tabular}


TableC.3. Listing of Old Groundwater Monitoring Reports with Comments

\begin{tabular}{ccl}
\hline Document \# & Time Period & Comments \\
\hline BNWL-CC- & Jan to Jun 1966 & There were no significant changes in gross beta \\
& concentrations in GW below BC Cribs and Trenches since the \\
& & end of $1965 . \mathrm{GW}$ gross beta at E13-16 averaged $170 \mathrm{pCi} / \mathrm{L}$ \\
& and at E13-20 averaged $140 \mathrm{pCi} / \mathrm{L}$. Wells $699-31-53 \mathrm{~B}$ \\
& (south) and 699-32-62 and 699-33-56 showed gross beta right \\
& at or slightly above the $80 \mathrm{pCi} / \mathrm{L}$ detection limit. Maximum \\
& observed gross beta in these wells was $100 \mathrm{pCi} / \mathrm{L}$. \\
\hline
\end{tabular}

\section{C.4 Review of Groundwater Data in HEIS Data Base}

The other source of historical GW data that was queried was the Hanford Environmental Information System (HEIS). The available GW data for wells 299-E13-1 through 299-E13-20 were downloaded and sorted by constituent and sampling time. Selected HEIS data for wells close to the six cribs (299-E13-1 through E-13-6 and 29-E13-20) and a few of the wells close to trenches that were noted in one or more of the periodic GW monitoring reports listed in Table C.3 are tabulated in Table C.4. The HEIS GW data for BC Trenches that are not listed in Table C.4 show very similar trends to those wells that are provided in Table C.4. In general, the HEIS data are the same as described in the old monitoring reports and corroborate the conclusions that waste fluids from crib disposal did break through to the GW in the late 1950s, but no steady increase of concentrations are observed for constituents that were measured. The HEIS GW data from below the BC trenches show the same pattern of some intermittent breakthrough of gross beta, but no signs of breakthrough of technetium-99 (data quite sparse and only available for years 2005 and 2008 for a few of the wells). For well 299-E13-5, there are technetium-99 data for the time period 1988 to 2008 (eight data points with one value in early 1988 above detection limit that does not seem consistent with the other seven data points). The nitrate concentrations in the GW are quite low and indistinguishable from concentrations of uncontaminated GWs until 2005. Since 2005, there are indications of nitrate concentrations near 10 to $20 \mathrm{mg} / \mathrm{L}$ below some of the BC Cribs. The recent GW sample taken at C5923 (A) had 10 mg/L nitrate, in agreement with nitrate values for the other wells surrounding the BC cribs observed over the period 2005 to 2008. It thus appears that some nitrate from the vadose zone sediments below the cribs is slowly bleeding into the GW. The vadose zone sediment profile of water extractable nitrate at borehole C5923 (A) shows highly elevated nitrate as deep as 250 $\mathrm{ft}$ bgs. We suspect somewhere below the BC cribs are high concentrations of water-extractable nitrate that are found closer to the water table (currently 345 ft bgs), and natural recharge is slowly pushing minor amounts of nitrate into the GW. 
TableC.4. Selected Data from HEIS Data Base for Wells Close to BC Cribs and Trenches

\begin{tabular}{|c|c|c|}
\hline Well \# & GW Sampling Date & Comments \\
\hline \multirow[t]{4}{*}{ 299-E13-1 } & Nov 1958 to Jan 1977 & $\begin{array}{l}\text { Gross beta below } 200 \mathrm{pCi} / \mathrm{L} \text {; many } \\
\text { values } 75 \mathrm{pCi} / \mathrm{L} \text { are likely unflagged } \\
<\text { values. }\end{array}$ \\
\hline & Oct 1957 to Aug 1963 & $\begin{array}{l}\text { Nitrate values }<12 \mathrm{mg} / \mathrm{L} \text { most } \\
<3 \mathrm{mg} / \mathrm{L}\end{array}$ \\
\hline & 1959 & $\begin{array}{l}\text { Sodium not elevated (five monthly } \\
\text { samples) }\end{array}$ \\
\hline & & No measurements after 1977 \\
\hline \multirow[t]{5}{*}{ 299-E13-2 } & Nov 1957 to Sep 1966 & $\begin{array}{l}\text { Gross beta below } 240 \mathrm{pCi} / \mathrm{L} \text {; many } \\
\text { are likely unflagged < values. }\end{array}$ \\
\hline & Sept 24, 1966 & $\begin{array}{l}\text { Gross beta } 39,000 \mathrm{pCi} / \mathrm{L} \text {, but no } \\
\text { other measurements afterwards. }\end{array}$ \\
\hline & Oct 1957 to Aug 1963 & $\begin{array}{l}\text { Nitrate values }<7 \text { mg/L most }<3 \\
\mathrm{mg} / \mathrm{L}\end{array}$ \\
\hline & 1959 & $\begin{array}{l}\text { Sodium not elevated (four monthly } \\
\text { samples) }\end{array}$ \\
\hline & & $\begin{array}{l}\text { No technetium-99 measurements; no } \\
\text { measurements of anything after Sep } \\
1966 \text {. }\end{array}$ \\
\hline \multirow[t]{4}{*}{ 299-E13-3 } & Nov 1958 to Jul 1974 & $\begin{array}{l}\text { Gross beta below } 375 \text { pCi/L; most } \\
\text { below } 150 \text { pCi/L; many are likely } \\
\text { unflagged < values. }\end{array}$ \\
\hline & Oct 1957 to Aug 1963 & $\begin{array}{l}\text { Nitrate values }<17 \mathrm{mg} / \mathrm{L} \text { most } \\
<5 \mathrm{mg} / \mathrm{L}\end{array}$ \\
\hline & 1959 & $\begin{array}{l}\text { Sodium not elevated (five monthly } \\
\text { samples) }\end{array}$ \\
\hline & & $\begin{array}{l}\text { No technetium-99 measurements; no } \\
\text { measurements of anything after July } \\
1974 \text {. }\end{array}$ \\
\hline \multirow[t]{7}{*}{ 299-E13-4 } & Nov 1957 to Apr 1960 & $\begin{array}{l}\text { Gross beta below } 390 \text { pCi/L; most } \\
\text { below } 200 \text { pCi/L; many are likely } \\
\text { unflagged < values. }\end{array}$ \\
\hline & $2005 ; 2008$ & Gross beta $8 \mathrm{pCi} / \mathrm{L}$ \\
\hline & Oct 1957 to Aug 1963 & Nitrate $<2$ mg/L \\
\hline & $2005 ; 2008$ & Nitrate 5 and $9 \mathrm{mg} / \mathrm{L}$ \\
\hline & 1959 & $\begin{array}{l}\text { Sodium not elevated (five monthly } \\
\text { samples) }\end{array}$ \\
\hline & 2005; 2008 & Sodium not elevated \\
\hline & 2005; 2008 & $\begin{array}{l}\text { Technetium-99 < detection limit } \\
(10 \mathrm{pCi} / \mathrm{L}) \text { and tritium }<\text { detection } \\
(230 \mathrm{pCi} / \mathrm{L})\end{array}$ \\
\hline 299-E13-5 & Nov 1957 to Sep 1959 & Gross beta below 240 pCi/L; most \\
\hline
\end{tabular}


TableC.4. Selected Data from HEIS Data Base for Wells Close to BC Cribs and Trenches

\begin{tabular}{|c|c|c|}
\hline Well \# & GW Sampling Date & Comments \\
\hline & & $\begin{array}{l}\text { below } 120 \mathrm{pCi} / \mathrm{L} \text {; many are likely } \\
\text { unflagged < values. }\end{array}$ \\
\hline & Oct 1974 to Sep 1980 & Gross beta $<75$ pCi/L \\
\hline & Feb 1981 to Jun 2008 & $\begin{array}{l}\text { Gross beta generally less than } \\
10 \mathrm{pCi} / \mathrm{L} \text {; one value } 405 \mathrm{pCi} / \mathrm{L} \text { on } \\
\text { July } 20,1983 \text {. }\end{array}$ \\
\hline & Oct 1957 to Aug 1963 & Nitrate $<3 \mathrm{mg} / \mathrm{L}$ \\
\hline & Mar 1987 to Jun 2008 & Nitrate 10 to $18 \mathrm{mg} / \mathrm{L}$ \\
\hline & 1959 to 2008 & $\begin{array}{l}\text { Sodium range } 14 \text { to } 25 \mathrm{mg} / \mathrm{L} \text {; near } \\
\text { natural background. }\end{array}$ \\
\hline & 1988 to 2008 & $\begin{array}{l}\text { Technetium-99 below detection limit } \\
(10 \mathrm{pCi} / \mathrm{L}) \text {; one value at } 67 \mathrm{pCi} / \mathrm{L} \text { on } \\
\text { Jan } 27,1988 \text {. }\end{array}$ \\
\hline & 1974 to 1984 & Possible tritium in GW \\
\hline & 1985 to 2008 & $\begin{array}{l}\text { Tritium below detection limit } \\
(300 \mathrm{pCi} / \mathrm{L})\end{array}$ \\
\hline \multirow[t]{6}{*}{ 299-E-6 } & Nov 1957 to Sep 1959 & $\begin{array}{l}\text { Gross beta less than } 200 \mathrm{pCi} / \mathrm{L} \text {; are } \\
\text { likely unflagged < values. }\end{array}$ \\
\hline & 2005; 2008 & Gross beta $7.5 \mathrm{pCi} / \mathrm{L}$ \\
\hline & Oct 1957 to Aug 1963 & $\begin{array}{l}\text { Nitrate } 1 \mathrm{mg} / \mathrm{L} \text { likely unflagged } \\
\text { <values; excepting one Dec } 1962 \\
\text { value } 3.3 \mathrm{mg} / \mathrm{L} \text {. }\end{array}$ \\
\hline & 2005; 2008 & Nitrate 4.7 to $6.4 \mathrm{mg} / \mathrm{L}$ \\
\hline & 1959 to 2008 & $\begin{array}{l}\text { Sodium range } 14 \text { to } 24 \mathrm{mg} / \mathrm{L} \text {; near } \\
\text { natural background }\end{array}$ \\
\hline & 2005; 2008 & $\begin{array}{l}\text { Technetium-99 below detection limit } \\
(10 \mathrm{pCi} / \mathrm{L}) \text {; tritium below detection } \\
\text { limit }(230 \mathrm{pCi} / \mathrm{L}) \text {. }\end{array}$ \\
\hline \multirow[t]{4}{*}{ 299-E13-13 } & $\begin{array}{l}\text { From } 1959 \text { to early } \\
1962\end{array}$ & $\begin{array}{l}\text { Gross beta } 200 \text { pCi/L (likely } \\
\text { detection limit but HEIS “U” flag is } \\
\text { missing. }\end{array}$ \\
\hline & March 1962; 1977 & $\begin{array}{l}\text { Gross beta } 86 \text { and }<75 \text { pCi/L; } \\
\text { respectively. }\end{array}$ \\
\hline & From 1957 to 1963 & $\begin{array}{l}\text { Nitrate not elevated. Values below } 9 \\
\text { mg/L. Sodium not elevated in } 1959 .\end{array}$ \\
\hline & & $\begin{array}{l}\text { Only the one gross beta measurement } \\
\text { after Oct } 1963 \text { reported in HEIS; yet } \\
\text { old monitoring reports discuss gross } \\
\text { beta up through } 1966 \text {. }\end{array}$ \\
\hline \multirow[t]{2}{*}{ 299-E13-18 } & From 1957 to 1980 & $\begin{array}{l}\text { Gross beta } 75 \text { pCi/L (likely detection } \\
\text { limit, but HEIS “U” flag is missing. }\end{array}$ \\
\hline & From 1984 to 2008 & $\begin{array}{l}\text { Gross beta is less than } 10 \mathrm{pCi} / \mathrm{L} \text {, but } \\
\text { likely above detection limit for this }\end{array}$ \\
\hline
\end{tabular}


TableC.4. Selected Data from HEIS Data Base for Wells Close to BC Cribs and Trenches

\begin{tabular}{|c|c|c|}
\hline Well \# & GW Sampling Date & Comments \\
\hline & & $\begin{array}{l}\text { time period. Technetium-99 below } \\
\text { detection in } 2005 \text { and } 2008 \text {. Sodium } \\
\text { concentrations not elevated over time } \\
\text { period } 1959 \text { to } 2008 \text {. }\end{array}$ \\
\hline & From 1957 to 1963 & $\begin{array}{l}\text { Nitrate not elevated. Values below } 3 \\
\mathrm{mg} / \mathrm{L} \text {. }\end{array}$ \\
\hline & From 2005 to 2008 & Nitrate averages 12.5 mg/L. \\
\hline \multirow[t]{4}{*}{ 299-E13-19 } & $\begin{array}{l}\text { From } 1959 ; 1977 \text { to } \\
1980\end{array}$ & $\begin{array}{l}\text { Gross beta } 200 \text { pCi/L in } 1959 \text { and } \\
75 \text { pCi/L later (likely detection } \\
\text { limit), but HEIS “U” flag is missing. }\end{array}$ \\
\hline & From 1981 to 2008 & $\begin{array}{l}\text { Gross beta is less than } 10 \mathrm{pCi} / \mathrm{L} \text {, but } \\
\text { likely above detection limit this time } \\
\text { period). Technetium- } 99 \text { below } \\
\text { detection in } 2005 \text { and } 2008 \text {. Sodium } \\
\text { concentrations not elevated over time } \\
\text { period } 1959 \text { to } 2008 \text {. }\end{array}$ \\
\hline & From 1957 to 1963 & $\begin{array}{l}\text { Nitrate not elevated. Values below } 8 \\
\mathrm{mg} / \mathrm{L} \text {. }\end{array}$ \\
\hline & $\begin{array}{l}\text { From } 1988 \text { to } 1990 ; \\
2005 \text { to } 2008\end{array}$ & $\begin{array}{l}1^{\text {st }} \text { time period-nitrate averages } \\
11 \mathrm{mg} / \mathrm{L}-\text { and for } 2^{\text {nd }} \text { time period, it } \\
\text { averages } 8.8 \mathrm{mg} / \mathrm{L} .\end{array}$ \\
\hline \multirow[t]{4}{*}{ 299-E13-20 } & $1959 ; 1977$ to 1980 & $\begin{array}{l}\text { Gross beta } 200 \mathrm{pCi} / \mathrm{L} \text { in } 1959 ; 75 \\
\mathrm{pCi} / \mathrm{L} \text { for } 2^{\text {nd }} \text { time period (likely } \\
\text { detection limit), but HEIS “U” flag is } \\
\text { missing. }\end{array}$ \\
\hline & Oct 1980 & $\begin{array}{l}\text { Gross beta is less than } 10 \mathrm{pCi} / \mathrm{L} \text {, but } \\
\text { likely above detection limit for this } \\
\text { time period). }\end{array}$ \\
\hline & From 1957 to 1981 & $\begin{array}{l}\text { No technetium-99 measurements } \\
\text { performed. }\end{array}$ \\
\hline & From 1959 to 1963 & $\begin{array}{l}\text { Nitrate less than } 1 \mathrm{mg} / \mathrm{L} \text {; no recent } \\
\text { nitrate measurements. }\end{array}$ \\
\hline
\end{tabular}




\title{
C.5 Further Reading
}

\author{
Old Groundwater Monitoring Reports:
}

Bierschenk WH (editor). 1958. Chemical Effluents Technology Waste Disposal Investigations October, November December 1976. HW-54848, Hanford Atomic Products Operation, Richland, Washington.

Bierschenk WH (editor). 1958. Chemical Effluents Technology Waste Disposal Investigations January, February, March 1958. HW-55841 RD, Hanford Atomic Products Operation, Richland, Washington.

Bierschenk WH (editor). 1958. Chemical Effluents Technology Waste Disposal Investigations April, May, June1958. HW-57002 RD, Hanford Atomic Products Operation, Richland, Washington.

Bierschenk WH (editor). 1958. Chemical Effluents Technology Waste Disposal Investigations July, August, September 1958. HW-58023, Hanford Atomic Products Operation, Richland, Washington.

Bierschenk WH (editor). 1959. Chemical Effluents Technology Waste Disposal Investigations October, November December 1958. HW-58811 RD, Hanford Atomic Products Operation, Richland, Washington.

Bierschenk WH (editor). 1959. Chemical Effluents Technology Waste Disposal Investigations January, February, March 1959. HW-60163, Hanford Atomic Products Operation, Richland, Washington.

Bierschenk WH (editor). 1959. Chemical Effluents Technology Waste Disposal Investigations April, May, June1959. HW-61197 RD, Hanford Atomic Products Operation, Richland, Washington.

Brown DJ (editor). 1957. Chemical Effluents Technology Waste Disposal Investigations July, August, September 1956. HW-49465, Hanford Atomic Products Operation, Richland, Washington.

Brown DJ (editor). 1957. Chemical Effluents Technology Waste Disposal Investigations October, November December 1956. HW-50186, Hanford Atomic Products Operation, Richland, Washington.

Brown DJ (editor). 1957. Chemical Effluents Technology Waste Disposal Investigations January, February, March 1957. HW-51095, Hanford Atomic Products Operation, Richland, Washington.

Brown DJ (editor). 1957. Chemical Effluents Technology Waste Disposal Investigations April, May, June 1957. HW-53225, Hanford Atomic Products Operation, Richland, Washington.

Brown DJ (editor). 1957. Chemical Effluents Technology Waste Disposal Investigations July, August, September 1957. HW-54655, Hanford Atomic Products Operation, Richland, Washington.

Brown DJ (editor). 1962. Chemical Effluents Technology Waste Disposal Investigations - JulyDecember, 1961. HW-72645-RD, Hanford Atomic Products Operation, Richland, Washington. 
Brown DJ (editor). 1962. Chemical Effluents Technology Waste Disposal Investigations_January-June 1962. HW-74915-RD, Hanford Atomic Products Operation, Richland, Washington.

Brown DJ (editor). 1963. Chemical Effluents Technology Waste Disposal Investigations_-July December 1962. HW-76120-RD, Hanford Atomic Products Operation, Richland, Washington.

Brown DJ (editor). 1964. Chemical Effluents Technology Waste Disposal Investigations_-January December 1964. HW-84549, Hanford Atomic Products Operation, Richland, Washington.

Brown DJ (editor). 1965. Chemical Effluents Technology Waste Disposal Investigation, January -June 1965. BNWL-CC-285, Battelle-Northwest, Richland, Washington.

Brown DJ and WA Haney. 1964. Chemical Effluents Technology Waste Disposal Investigations—July December, 1963. HW-80909, Hanford Atomic Products Operation, Richland, Washington.

Eliason JR. 1966. Earth Sciences Waste Disposal Investigations July-December, 1965. BNWL-CC574, Battelle-Northwest, Richland, Washington.

Eliason JR. 1966. Earth Sciences Waste Disposal Investigations January - June, 1966. BNWL-CC-887, Battelle-Northwest, Richland, Washington.

Haney WA (editor). 1959. Chemical Effluents Technology Waste Disposal Investigations July, August, September 1959. HW-62692 RD, Hanford Atomic Products Operation, Richland, Washington.

Haney WA (editor). 1960. Chemical Effluents Technology Waste Disposal Investigations October, November December 1959. HW-64094-RD, Hanford Atomic Products Operation, Richland, Washington.

Haney WA (editor). 1960. Chemical Effluents Technology Waste Disposal Investigations January, February, March 1960. HW-65464-RD, Hanford Atomic Products Operation, Richland, Washington.

Haney WA (editor). 1960. Chemical Effluents Technology Waste Disposal Investigations April, May, June1960. HW-66859-RD, Hanford Atomic Products Operation, Richland, Washington.

Haney WA (editor). 1960. Chemical Effluents Technology Waste Disposal Investigations July, August, September 1960. HW-67753- RD, Hanford Atomic Products Operation, Richland, Washington.

Haney WA (editor). 1961. Chemical Effluents Technology Waste Disposal Investigations October, November December 1960. HW-68543-RD, Hanford Atomic Products Operation, Richland, Washington.

Haney WA (editor). 1961. Chemical Effluents Technology Waste Disposal Investigations_JanuaryJune, 1961. HW-70806-RD, Hanford Atomic Products Operation, Richland, Washington.

Haney WA (editor). 1963. Chemical Effluents Technology Waste Disposal Investigations_JanuaryJune, 1963. HW-78951, Hanford Atomic Products Operation, Richland, Washington. 


\section{Distribution}

\section{OFFSITE}

Steve Airhart

Freestone Environmental Services

1100 Jadwin Avenue

Suite 250

Richland, WA 99354

Harry Babad

2540 Cordoba Court

Richland, WA 99352-1609

John N. Christensen

Center for Isotope Geochemistry

Lawrence Berkeley National Laboratory

1 Cyclotron Road Bldg, Mail Stop 70A4418

Berkeley, CA 94720-8179

Mark Conrad

Department of Earth and Planetary Sciences

University of California, Berkeley

Berkeley, CA 94720

Dwayne Crumpler

Columbia Energy \& Environmental Services

1806 Terminal Road

Richland, WA 99352

Donald J. DePaolo

Geology \& Geophysics Dept. MC4767

University of California

Berkeley, CA 94720-4767

Tom DiFebbo

EQM Inc

1777 Terminal Dr.

Richland, WA 99352

Dirk A. Dunning

Oregon Office of Energy

625 Mariona Street, N.E.

Salem, OR 97301-3742

Markus Flury

Department of Crop and Soil Sciences

Washington State University

Pullman, WA 99164
Daniel I. Kaplan

Westinghouse Savannah River Company

Building 774-43A, Room 215

Aiken, SC 29808

J. M. Keller

GeoSystems Analysis, Inc.

2870 Son Rise Lp.

Hood River, OR 97031

Dr. Peter C. Lichtner

Los Alamos National Laboratory

P.O. Box 1663

Los Alamos, NM 87545

Sandra Lilligren

Nez Perce

P.O. Box 365

Lapwai, ID 83540

Kevin A. Lindsey

Kennedy/Jenks Consultants, Inc. 1020 N. Center Parkway, Suite F

Kennewick, WA 99336

John Matusek

82 McGuffey Lane

Delmar, NY 12054

Melaine A. Mayes

Environmental Sciences Division

Oak Ridge National Laboratory

P.O. Box 2008

Oak Ridge, TN 37831-6038

Mitzi Miller

EQM Inc

1777 Terminal Dr.

Richland, WA 99352

Distr. 1 
Phil Reed

U.S. Nuclear Regulatory Commission

Office of Nuclear Regulatory Research

Division of Systems Analysis and

Regulatory Effectiveness

Radiation Protection, Env. Risk and Waste Management Branch

MS T9-F31

Washington, DC 20555-0001

Dale Rucker (10)

hydroGEOPHYSICS, Inc.

2302 North Forbes Boulevard

Tucson, Arizona 85745-1410

B. R. Scanlon

Bureau of Economic Geology

University of Texas at Austin

J.J. Pickle Research Campus, Building 130

10100 Burnet Road

Austin, TX 78758-4445

Doug Sherwood

Rivers Edge Environmental

1616 Riverside Drive

West Richland, WA 99353

David K. Shuh

Lawrence Berkeley National Laboratory

1 Cyclotron Road, MS 70A-1150

Berkeley, CA 94720

Robert W. Smith, Ph.D.

Professor of Subsurface Science

Adjunct Professor of Geological Sciences

University of Idaho at Idaho Falls

1776 Science Center Drive

Idaho Falls, ID 83402

Stan Sobczyk

Nez Perce Tribal Consultant

P. O. Box 365

Lapwai, ID 83832

Carl I. Steefel

Lawrence Livermore National Laboratory

Earth \& Environmental Sciences Directorate

MS L-204

P.O. Box 808

Livermore, CA 94551-9900
T. T. Chuck Vandergraaf

P.O. Box 857

Pinawa, Manitoba

R0E 1L0 Canada

Jiamin Wan

Lawrence Berkeley National Laboratory

1 Cyclotron Road, MS 70-0127A

Berkeley, CA 94720

Ronald G. Wilhelm

U.S. Environmental Protection Agency

Office of Radiation and Indoor Air

401 M Street, S.W.

Mail Code 6603J

Washington, D.C. 20460

W. Alexander Williams

U.S. Department of Energy

Office of Environmental Restoration

EM-33

19901 Germantown Road

Germantown, MD 20874-1290

\section{ONSITE}

\section{DOE Office of River Protection}

C. J. Kemp

H6-60

R. W. Lober H6-60

B. M. Mauss H6-60

DOE Public Reading Room (2) H2-53

\section{DOE Richland Operations Office}

B. L. Foley

A6-38

J. P. Hanson

A5-13

R. D. Hildebrand

A6-38

K. A. Kapsi

A5-13

K. D. Leary

A6-38

J. G. Morse

A6-38

G. L. Sinton

A6-38

K. M. Thompson

A6-38

11 Washington River Protection Solutions

M. P. Connelly S7-66

S. J. Eberlein S7-66

J. G. Field $\quad$ S7-66

F. M. Mann $\quad$ S7-66

D. A. Myers (5) S7-66

D. L. Parker S7-83

H. A. Sydnor S7-66 


\section{EFSI}

M. G. Gardner

K. D. Reynolds

G2-02

G2-02

\section{Environmental Protection Agency}
D. A. Faulk
B5-01
R. Lobos
B1-46

\section{Fluor Federal Services}

M. J. Hickey

R. Khaleel

C. T. Narquis

R. J. Puigh

P. Rogers

B4-67

R3-50

R3-50

H8-27

R3-32

26 CH2M-Hill Plateau Remediation Company, Inc.

M. W. Benecke (10)

J. V. Borghese

M. E. Byrnes

G.D. Cummins

B. H. Ford

D. G. Horton

J. W. Lindberg

S.F. Miller

S. M. Narbutovskih

S. W. Petersen

V. J. Rohay

L. C. Swanson

G. S. Thomas

M.D. Thompson

B. A. Williams

C. D. Wittreich

M. I. Wood

R3-60

R3-60

R3-60

H8-15

H8-43

R3-50

R3-50

H8-15

R3-50

R3-50

H8-15

R3-50

R3-50

R3-50

H8-51

H8-15

H8-51

\section{Stoller}

R. G. McCain

B2-62

\section{Washington State Department of Ecology}
J. A. Caggiano
S. Dahl-Crumpler
J. V. Hedges
J. J. Lyon
J. Price

H0-57

H0-57

H0-57
E. A. Rochette

H0-57

J. Yokel

H0-57

\section{Pacific Northwest National Laboratory}

B. N. Bjornstad (5) K6-81

T.M. Brouns $\quad$ K9-69

C. F. Brown P7-22

R. W. Bryce E6-35

K. J. Cantrell K6-81

R. E. Clayton K6-75

W. C. Cosby K6-50

K. Draper K6-75

P. E. Dresel K6-96

M. J. Fayer K9-33

K9-36

$\begin{array}{ll}\text { M. D. Freshley } & \text { K9-33 } \\ \text { J. S. Fruchter } & \text { K6-96 }\end{array}$

G. W. Gee K9-33

T. J. Gilmore K6-96

J. P. Icenhower K6-81

D. C. Lanigan (3) K6-75

C. T. Kincaid E6-35

K. M. Krupka K6-81

G. V. Last K6-81

M. J. Lindberg P7-22

R. Mackley K6-96

P. D. Meyer BPO

C. J. Murray K6-81

E. M. Pierce K3-62

N. Qafoku K3-61

R. G. Riley K6-81

M. L. Rockhold K9-33

S.N. Schlahta K6-83

R. J. Serne (10) P7-22

C.E. Strickland K9-36

M. B. Triplett K6-52

W. Um (5) P7-22

A. L. Ward (10) K9-33

D.M. Wellman (15) K3-62

S. B. Yabusaki K9-36

J. M. Zachara K8-96

F. Zhang K9-33

Hanford Technical Library (2) P8-55

Information Release (2) K1-06 